\title{
Wilfried Hacker
}

Geowissenschaften und Bergbaugeschichte in der Dreiländer-Region Hessen, Thüringen, Niedersachsen

Ergänzte Neuausgabe 2009 der Bibliographie zur Landschaft zwischen Diemel und Schleuse, Borkener Senke und Rhume.

Band 2: Verzeichnis nach Sachgebieten

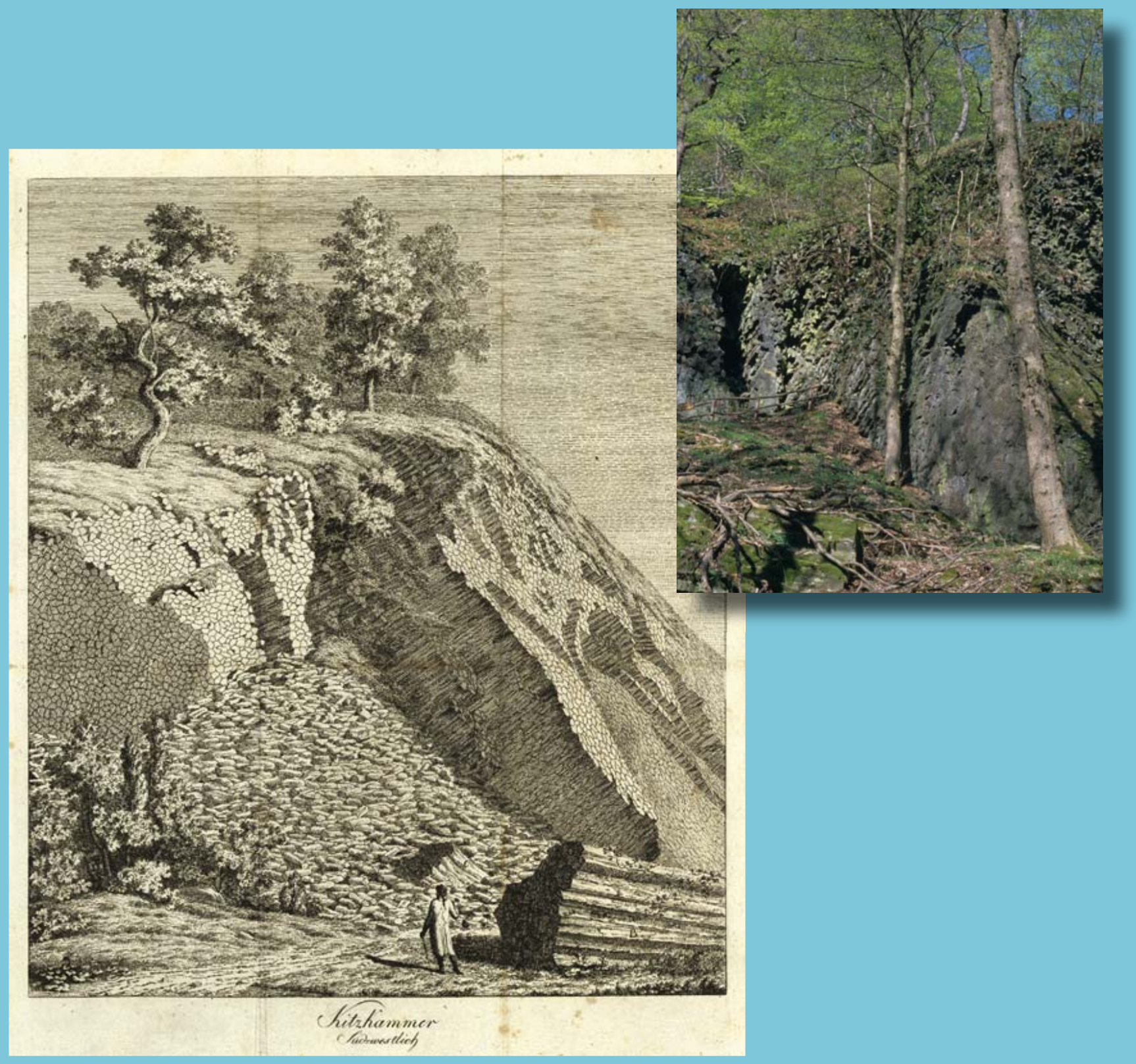

Universitätsdrucke Göttingen 

Wilfried Hacker

Geowissenschaften und Bergbaugeschichte in der Dreiländer-Region Hessen, Thüringen und Niedersachsen, Band 2

Except where otherwise noted, this work is licensed under a Creative Commons License

\section{GDTE RICHTS FEGEFUED}

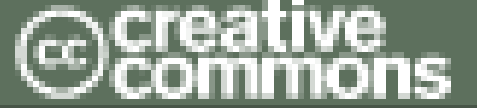


erschienen in der Reihe der Universitätsdrucke im Universitätsverlag Göttingen 2009 
Wilfried Hacker

Geowissenschaften und Bergbaugeschichte in der Dreiländer-Region Hessen, Thüringen und Niedersachsen

Ergänzte Neuausgabe 2009 der Bibliographie zur Landschaft zwischen Diemel und Schleuse, Borkener Senke und Rhume.

Band II - Verzeichnis nach Sachgebieten

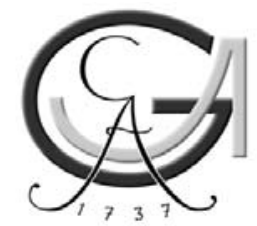

Universitätsverlag Göttingen 2009 


\title{
Bibliographische Information der Deutschen Nationalbibliothek
}

Die Deutsche Nationalbibliothek verzeichnet diese Publikation in der Deutschen Nationalbibliographie; detaillierte bibliographische Daten sind im Internet über $<$ http://dnb.ddb.de> abrufbar

Solch eine Arbeit wird eigentlich nie fertig; man muß sie für fertig erklären, wenn man nach Zeit und Umständen das Möglichste getan hat.

\author{
J. W. Goethe
}

Die Bibliographie wird laufend ergänzt und in Abständen als Neuausgabe elektronisch publiziert, um auch die älteren Ausgaben voll zitierfähig zu halten. Korrekturhinweise, Verbesserungsvorschläge und Ergänzungsmitteilungen richten Sie bitte an den Verlag.

Dieses Buch ist als freie Onlineversion über die Homepage des Verlags, das geowissenschaftliche Fachportal GEO-LEO sowie über den OPAC der Niedersächsischen Staats- und Universitätsbibliothek (http://www.sub.uni-goettingen.de) erreichbar und darf gelesen, heruntergeladen sowie als Privatkopie ausgedruckt werden. Es gelten die Lizenzbestimmungen der Onlineversion. Es ist nicht gestattet, Kopien oder gedruckte Fassungen der freien Onlineversion zu veräußern.

Satz und Layout: Wilfried Hacker Umschlaggestaltung: Margo Bargheer Titelabbildung: Naturdenkmal Kitzkammer / Hoher Meißner, Säulenbasalt; Historische Abbildung: Kupferstich um 1800, Aus: J. Schaub, Physikalischmineralogisch bergmännische Beschreibung des Meißners; Cassel 1822. Signatur 8 Min II 3028: 2, Nieders. Staats- und Universitätsbibliothek Göttingen Digitalisierung: Göttinger Digitalisierungszentrum (http://gdz.sub.uni-goettingen.de); Foto: Wilfried Hacker 2006

(C) 2009 Universitätsverlag Göttingen http:/ / univerlag.uni-goettingen.de ISBN-13: 978-3-941875-16-6 


\section{Vorwort zur 2. Auflage}

Mit dieser Neuausgabe der Bibliographie wird den Interessenten an regional relevanter Literatur eine gegenüber der Erstauflage deutlich erweitere Datensammlung an die Hand gegeben. Besonders die systematische Auswertung von Zeitschriften der ehemaligen DDR, die zum Teil nach Herstellung der deutschen Einheit weitergeführt wurden oder werden, brachte einen erheblichen Zuwachs von Literaturnachweisen, verständlicherweise mit Schwerpunkt Geowissenschaften und Bergbaugeschichte von Thüringen. Der erweiterte Umfang der Datensammlung erlaubte in der Folge eine stärkere Gliederung des Stoffe, u. a. im Kapitel Paläontologie. Deutlich erweitert wurde die Anzahl der Geotope, zu denen fachübergreifend Literatur zusammengetragen wurde. Durch eine Durchsicht schon aufgenommener Vorlagen konnten ergänzende Angaben zum Inhalt und zur regionalen Relevanz erweitert werden. Im Kapitel „Informationen zu abgekürzt zitierten Zeitschriftentiteln“ wurde bei einzelnen Titeln der Erscheinensverlauf hinzugefügt.

Die aktuelle Problematik um die Versalzung der Werra durch eine vor kurzem geplante Einleitung von Kalilauge des Kaliwerkes Neuhof-Ellers wurde zum Anlaß genommen, im Kapitel „Geologie, Bergbau und Interessenkonflikte“ hauptsächlich Zeitungsartikel zu der genannten Problematik zu berücksichtigen. Auch dem problematischen Gipsabbau im Werra-Meißner-Kreis wurden zwei neue Kapitel gewidmet.

Das Kapitel abgekürzt zitierter Zeitschriftentitel wurde überarbeitet und vielfach Informationen zum Erscheinensverlauf hinzugefügt.

Leider gab es auch Fehler zu korrigieren, hauptsächlich durch unrichtig geschriebene Autorennamen, wofür ich Autoren und Nutzer der Bibliographie nur um Nachsicht bitten kann.

Frau Bargheer vom Universitätsverlag Göttingen danke ich für die gute Zusammenarbeit bei der Erstellung dieser Neuausgabe.

Allen Interessenten wünsche ich beim Surfen in der Online-Version dieser zweiten Auflage wieder viel Klick und Erfolg bei der Suche nach Literatur über diese geologisch sehr interessante und vielfältige Region.

Wilfried Hacker

Eschwege, Juni 2009

\section{Vorwort zur 1. Auflage}

Die Geologie der bibliographisch erfassten Region ist von einer faszinierenden Vielfalt, die in Deutschland auf so kleinem Raum selten zu finden ist. Gut aufgeschlossene Formationen reichen vom Devon bis zum Tertiär, Quartär und erlauben den Rückblick auf 400 Millionen Jahre Erdgeschichte. Ablagerungen des Jura und der Kreide sind als klein dimensionierte Relikte in tektonischen Gräben erhalten. Der Thüringer Wald stellt „eine klassische Stätte der Rotliegendforschung“ dar und im Ruhlaer Kristallin des Thüringer Waldes ist ein Teil der „Mitteldeutschen Kristallinzone“ erschlossen. In der Region wurde auch Wissenschaftsgeschichte geschrieben. Die Kontaktwirkung des Basaltes auf Buntsandstein an der „Blauen Kuppe“ bei Eschwege, der Stoffelskuppe und der Pflasterkaute in Thüringen fand Anfang des 19. Jahrhunderts Eingang in die Lehrbücher der sich entfaltenden Geowissenschaften. Die „Blaue Kuppe“ und der Meißner nahmen in der ersten Hälfte des 19. Jahrhunderts im Streit um die Basaltgenese zwischen Neptunisten und Plutonisten eine Schlüsselstellung ein. Rudolf Erich Raspe entwickelte anhand der Basalte der Umgebung von Kassel seine Vorstellungen von der „feurigen“ Natur des Basaltes. Die ehemals intensive Bergwirtschaft der Region ist heute in vielen 
Bereichen nur noch Geschichte, vom Abbau auf Steine und Erden und Kalisalz abgesehen. Der historische Braunkohlen-Bergbau am Meißner und im Habichtswald zählt zu den ältesten Abbauen dieses Rohstoffes in Deutschland.

Die intensive Erforschung der Region und die bergwirtschaftliche Nutzung der Ressourcen schlug sich dabei in einer Vielzahl von Publikationen nieder. Wer sich diese Informationsfülle aus drei Bundesländern erschließen will, war und ist bisher auf drei Landes-Bibliographien angewiesen, deren thematische Zuständigkeit an den jeweiligen Landesgrenzen endet. Die vorliegende Bibliographie möchte erstmals diese Informationsfülle länderübergreifend erschließen. Die Bibliographie richtet sich an alle, die Hintergrundinformationen zur regionalen Geologie suchen: Wissenschaftler, Studierende der Geowissenschaften und Geographie, Interessenten der Heimatkunde. Wissenschaftliche Veröffentlichungen stehen dabei im Vordergrund, es wurden aber auch Beiträge aus heimatkundlichen Zeitschriften und Tageszeitungen aufgenommen, um auch interessierten Laien Informationsquellen aufzuzeigen. Ebenso wurde unveröffentlichtes Material aufgenommen.

Geowissenschaftliche Arbeiten, die das Gebiet des Werra-Meißner-Kreises betreffen und bis 1990/1991 erschienen, sind in der Bibliographie von Ulrich-Dieter Oppitz: „Bibliographie des Werra-MeissnerKreises“ - 2. Aufl., 532 S.; [Hrsg.: Historische Gesellschaft des Werralandes] Eschwege 1991 verzeichnet. Diese zweite Auflage der Bibliographie aus dem Jahre 1991 hat bis heute keine Neuauflage erfahren. Ursprünglich sollten ausschließlich die Neuerscheinungen mit Bezug auf den Werra-Meißner-Kreises ab etwa 1990/1991 erfasst werden. Verwaltungsgrenzen sind jedoch keine geologischen Grenzen. Schnell erwuchs daher bei der Arbeit der Wunsch, Interessierten die vorhandene Literatur der Region über die Grenzen des Werra-Meißner-Kreises hinweg zu erschließen. Daher wurde die Bearbeitung auf die umliegenden Landkreise, den Thüringer Wald und die Gegend am West- und Südrand des Thüringer Waldes ausgedehnt. Um eine zukünftige Aktualisierung der Werra-Meißner-Bibliographie zu erleichtern, wurde Literatur des Werra-Meißner-Kreises teilweise separat aufgeführt oder entsprechend gekennzeichnet.

Die vorhandene relevante Literatur vollständig aufzulisten, das ist der Wunschtraum des Bearbeiters einer Bibliographie - aber schwerlich zu erreichen. Die Frage der Relevanz von Publikationen ist zudem auch vom subjektiven Urteil des Bearbeiters abhängig, was sich besonders bei der Auswahl von Artikeln der Tagespresse gezeigt hat.

Die Bibliographie wurde zweibändig angelegt, um Benutzern, die ausschließlich an dem Sachverzeichnis interessiert sind, den unnötigen „Ballast“ eines allumfassenden und daher sehr umfangreichen Dokumentes zu ersparen. Während der erste Band die Literatur nach Autorennamen auflistet, ist im zweiten Band der Stoff nach Sachgebieten geordnet.

Zu großem Dank bin ich Herrn Dr. Norbert Pfurr von der Niedersächsischen Staats- und Universitätsbibliothek Göttingen verpflichtet, der die Veröffentlichung als elektronisches Dokument ermöglichte, den Kontakt zum Universitätsverlag Göttingen herstellte und mich bei der Erstellung des Manuskriptes mit Rat und Tat unterstützte. Ebenso danke ich Frau Ingeborg Becker und Herrn Dr. Andreas Quast für Rat und Hilfe.

Allen Nutzern viel Glück und - in der Online-Version auch viel Klick - bei der Literatursuche! 


\section{Inhaltsverzeichnis}

Vorwort zur 2. Auflage

Vorwort zur 1. Auflage

Inhaltsverzeichnis

Benutzerhinweise

Regionaler Bezug der Zitate

Anordnung der Zitate

Verzeichnis verwendeter Abkürzungen

VIII

Moderne und historische Schreibweisen

Informationen zu abgekürzt zitierten Zeitschriftentiteln

Literatur nach Sachgebieten geordnet

1 Allgemeines

1.1 Bibliographien

IX

$\mathrm{X}$

XII

XIV

1.1.1 Recherchemöglichkeiten..........................................................................

1.1.2 Länderübergreifende Bibliographien ...............................................................1

1.1.3 Länderbezogene Bibliographien ………………………................................2

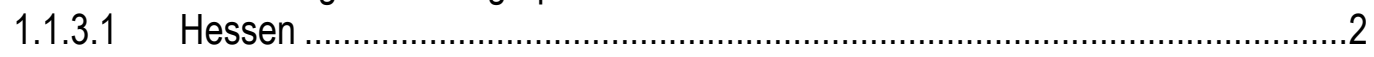

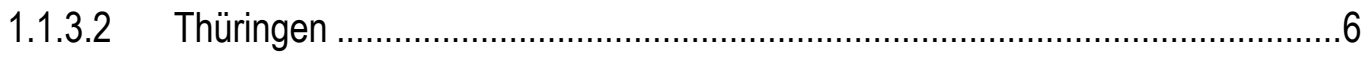

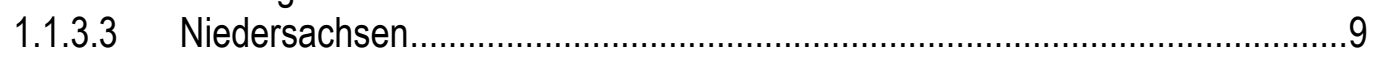

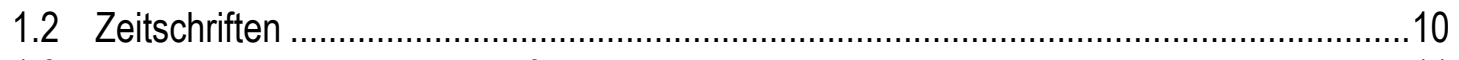

1.3 Personenehrungen - Nachrufe ...............................................................................11

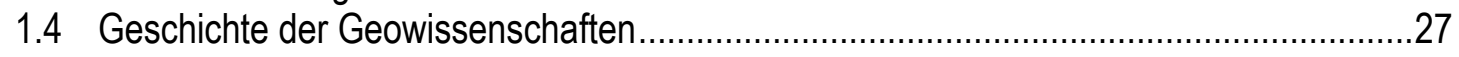

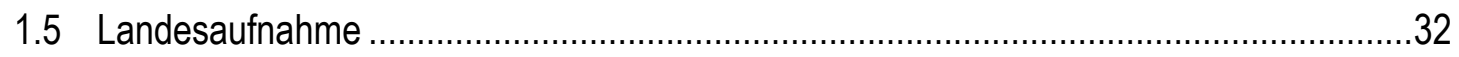

1.5.1 Institutionen .........................................................................................

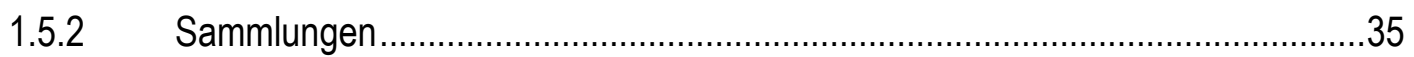

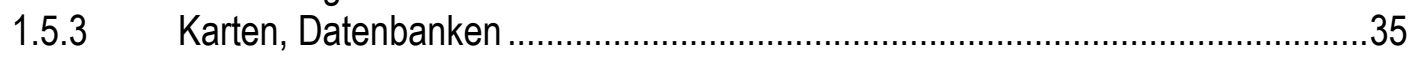

1.5.3.1 Länderübergreifende Veröffentlichungen.....................................................35

1.5.3.2 Länderbezogene Veröffentlichungen .........................................................36

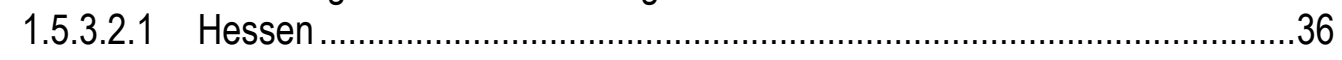

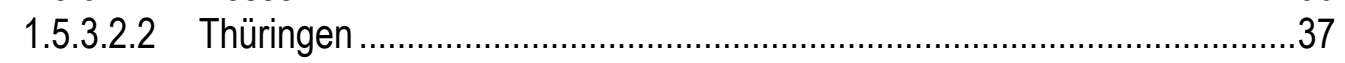

1.5.3.2.3 Niedersachsen .................................................................................37

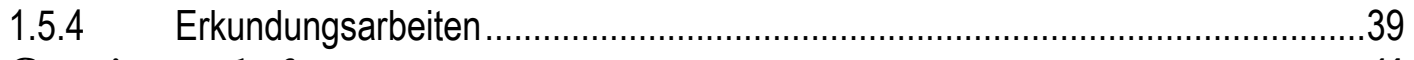

2 Geowissenschaften 41

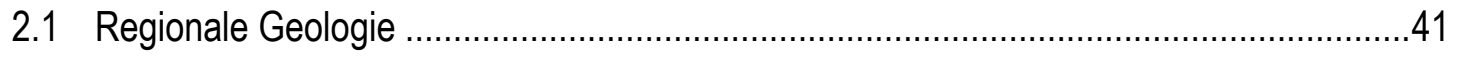

2.1.1 Regionale Geologie - Hessen (ohne Werra-Meißner-Kreis)..............................41

2.1.2 Regionale Geologie - Werra-Meißner-Kreis ...................................................51

2.1.3 Regionale Geologie - Thüringen ………………………………………….....63

2.1.4 Regionale Geologie - Niedersachsen ............................................................79

2.2 Geowissenschaftliche Literatur zu einzelnen Geotopen und Regionen .............................84

2.2.1 Hessen (ohne Werra-Meißner-Kreis) ..........................................................84

2.2.1.1 Habichtswald/Kassel ........................................................................... 84

2.2.1.1.1 Geologie, Gesamtdarstellung, Paläontologie ...........................................84

2.2.1.1.2 Mineralogie, Lagerstättenkunde, Erforschung der Basalte ........................88

2.2.1.2 „Bühl“ bei Weimar (Gemeinde Ahnatal, Lkr. Kassel) .....................................94

2.2.1.3 „Wolkenbrüche" bei Trendelburg (Lkr. Kassel) ...........................................96

2.2.1.4 Steinbruch Cornberg ............................................................................97

2.2.1.5 Richelsdorfer Gebirge (Landkreis Hersfeld-Rotenburg) ..............................100

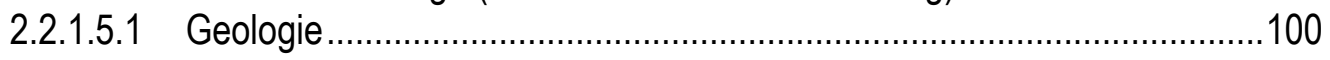

2.2.1.5.2 Paläontologie …………………………………………………….... 103 
2.2.1.5.3 Mineralogie, Geochemie, Lagerstättenkunde .....................................106

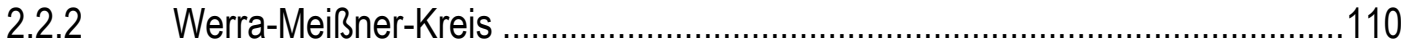

2.2.2.1 Gottesberg bei Hundelshausen ...........................................................110

2.2.2.2 Tertiärmulde Glimmerode (Werra-Meißner-Kreis) .....................................111

2.2.2.3 Hirschberg bei Großalmerode (Werra-Meißner-Kreis)................................113

2.2.2.4 „Bühlchen“ bei Epterode (Werra-Meißner-Kreis) ........................................117

2.2.2.5 Hoher Meißner (Werra-Meißner-Kreis) ...................................................118

2.2.2.5.1 Geologie, Paläontologie, Erforschungsgeschichte ...............................118

2.2.2.5.2 Geomorphologie, Glazialgeologie .....................................................124

2.2.2.5.3 Basalt (Geologie, Mineralogie, Geochemie) .........................................125

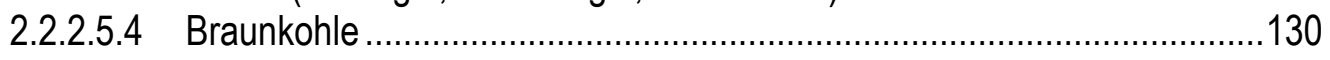

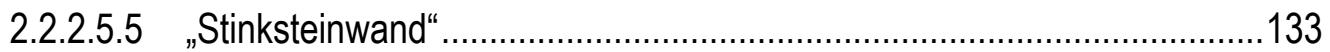

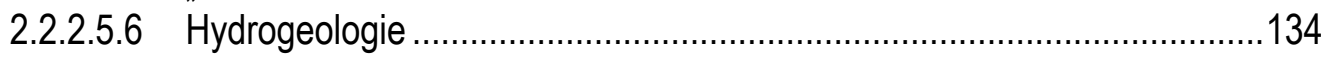

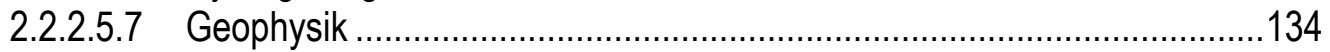

2.2.2.6 Unterwerra-Grauwackengebirge/Albunger Paläozoikum > Präzechstein .....135

2.2.2.7 Kripp- und Hielöcher, Frankershausen ....................................................139

2.2.2.8 Steinbruch am Schafhof/Frankershausen............................................140

2.2.2.9 Steinbruch Forsthaus Schmelzhütte/Frankershausen ................................141

2.2.2.10 Hohlstein bei Hilgershausen (Werra-Meißner-Kreis) ...................................142

2.2.2.11 „Blaue Kuppe“ bei Eschwege (Werra-Meißner-Kreis).................................143

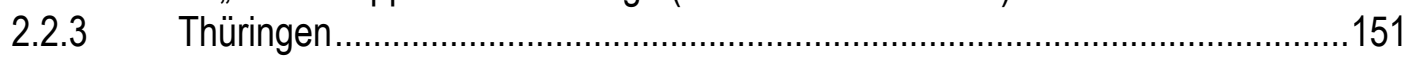

2.2.3.1 Fossilfundstätte Burgtonna (Landkreis Gotha) ........................................151

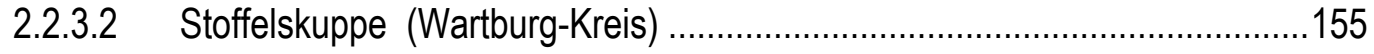

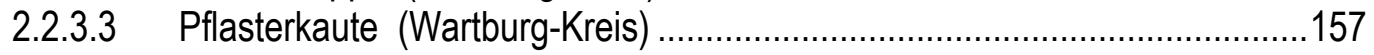

2.2.3.4 Porphyr am Heiligenstein bei Thal (WAK) .............................................. 158

2.2.3.5 Profil von Epichnellen / Bahnhof Förtha..................................................159

2.2.3.6 Basaltgang am Bahnhof Hörschel ........................................................160

2.2.3.7 Fossilfundstätte Bromacker bei Tambach-Dietharz (Landkreis Gotha).........161

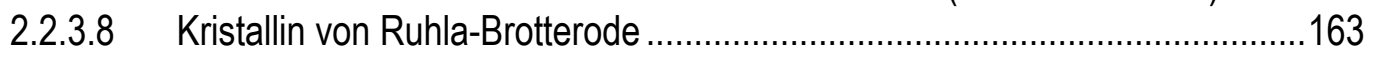

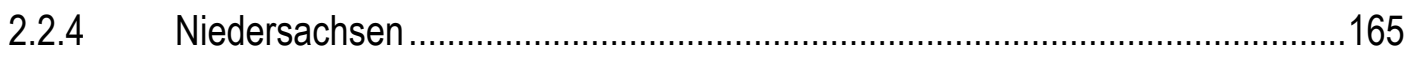

2.2.4.1 Ruhmequelle - Untereichsfeld (Lkr. Göttingen) .......................................165

2.2.4.2 Becken von Bilshausen - Untereichsfeld (Lkr. Göttingen) ..........................167

2.2.4.3 „Hoher Hagen“ bei Dransfeld .................................................................168

2.2.4.4 Tongrube Eichenberg/Hottenrode (Lkr. Göttingen)......................................169

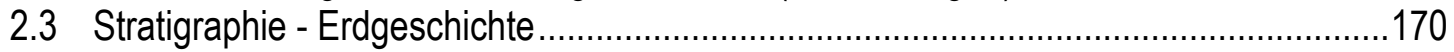

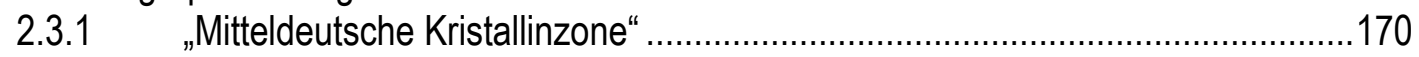

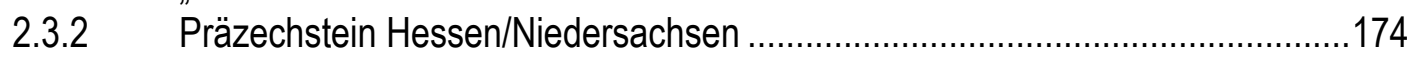

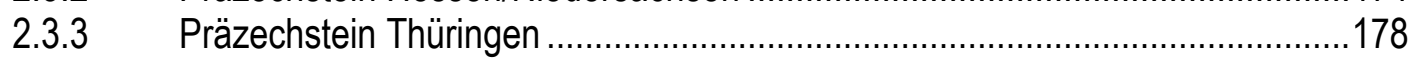

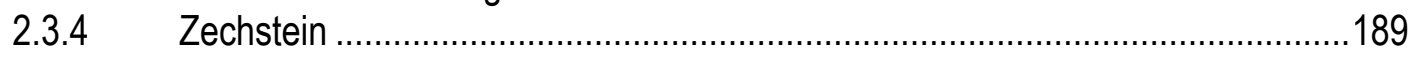

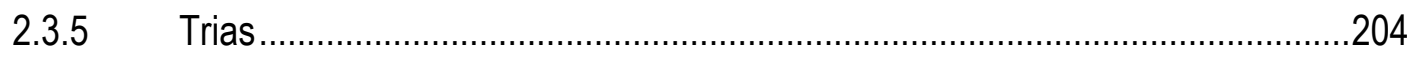

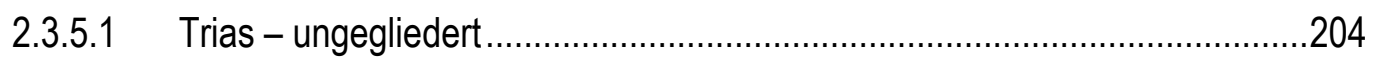

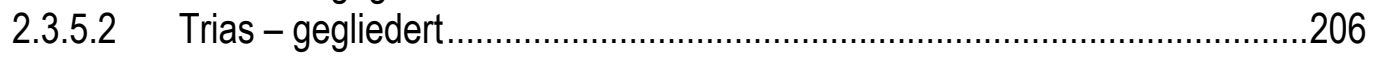

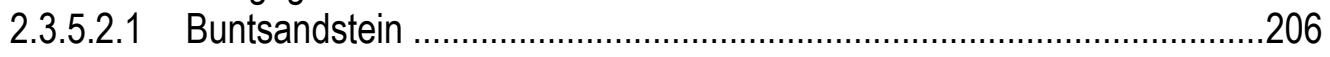

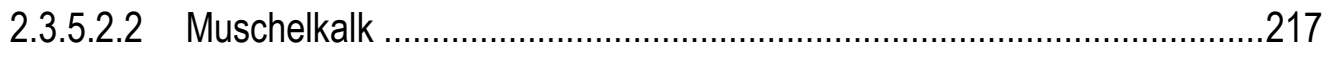

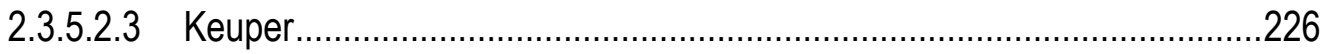

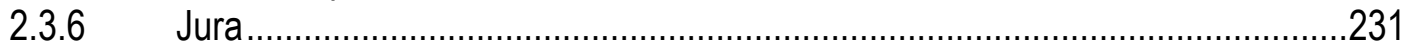

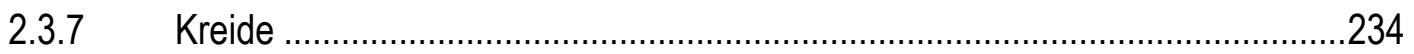

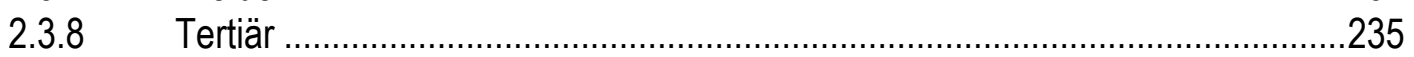

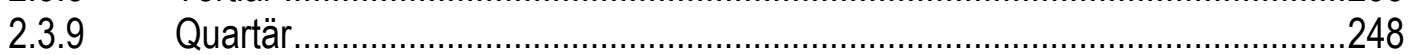

2.4 Sedimentologie - Sedimentpetrographie _.........................................................2. 259

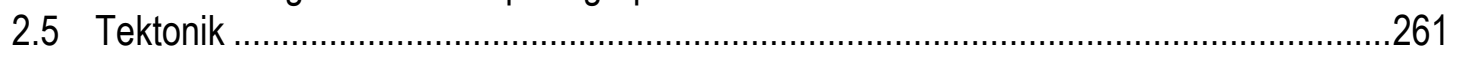




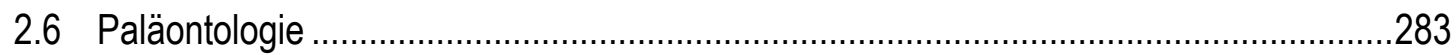

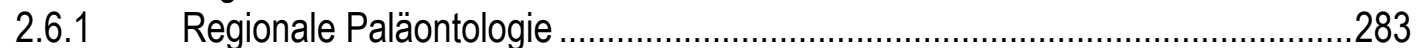

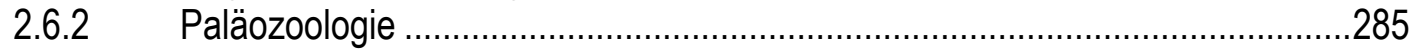

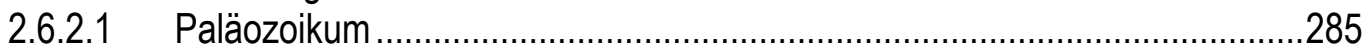

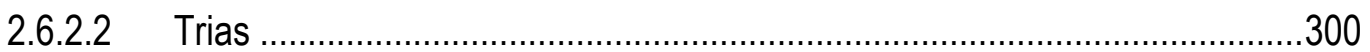

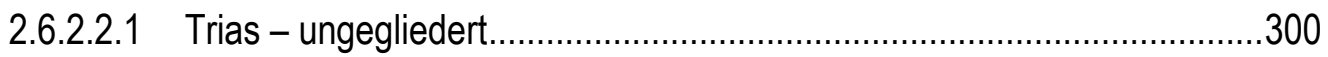

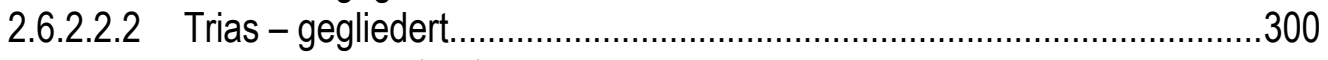

$\begin{array}{lll}2.6 .2 .2 .2 .1 & \text { Buntsandstein } & 300\end{array}$

2.6.2.2.2.2 Muschelkalk 302

2.6.2.2.2.3 Keuper 307

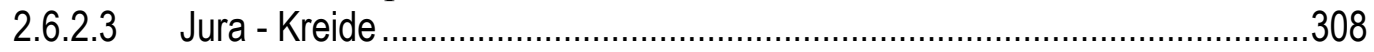

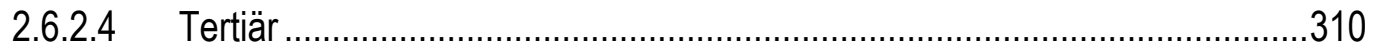

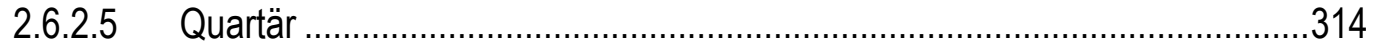

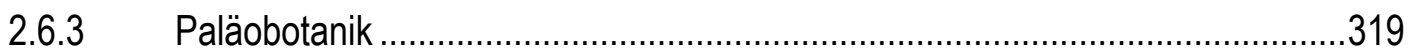

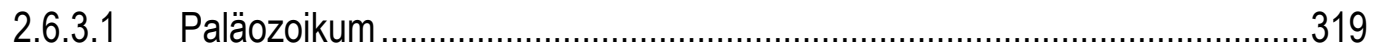

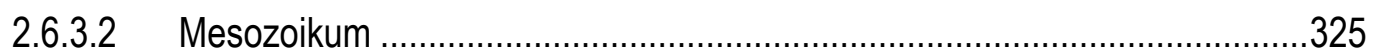

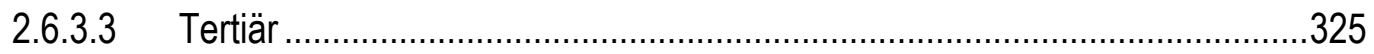

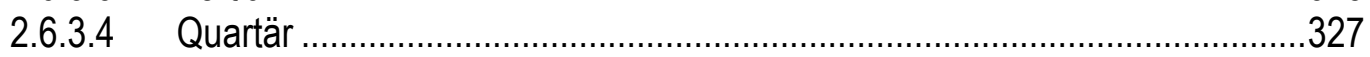

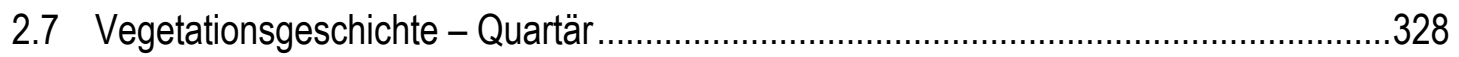

2.8 Mineralogie - Geochemie - Lagerstättenkunde .....................................................330

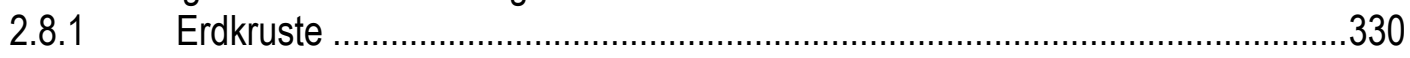

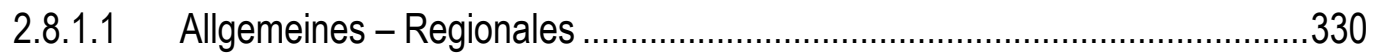

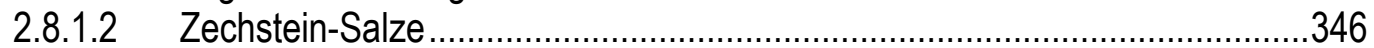

2.8.1.3 Karbonate, Sulfate (außer Zechstein-Sulfate) ….....................................356

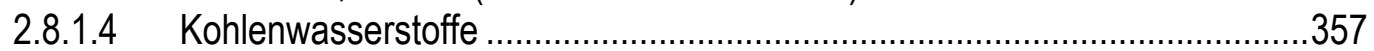

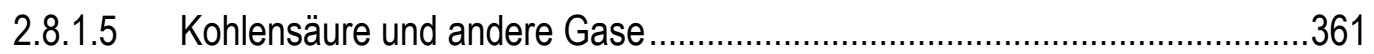

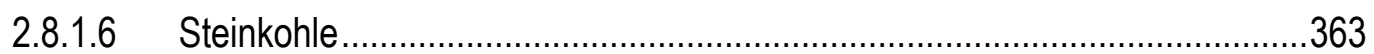

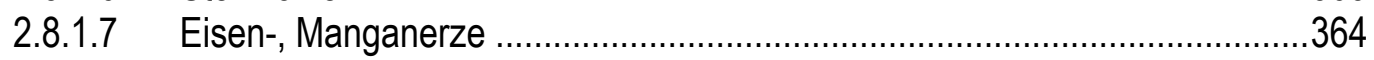

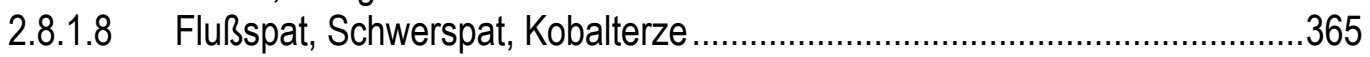

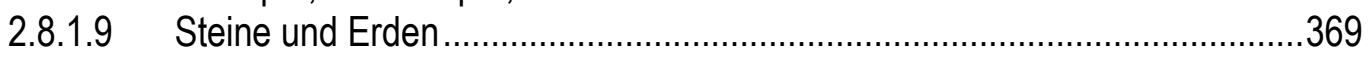

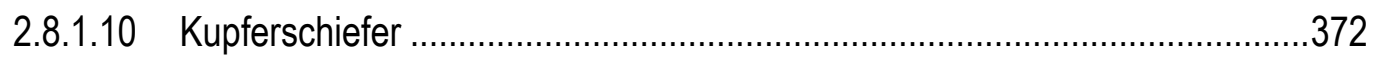

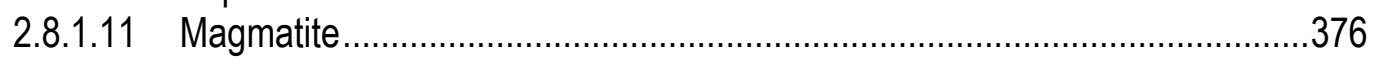

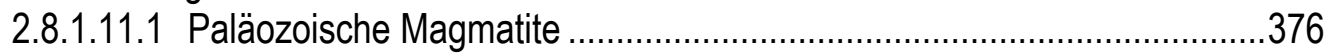

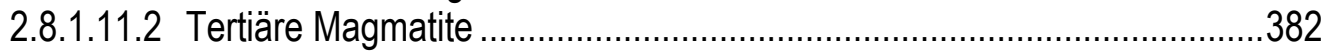

2.8.2 Extraterrestrisches Material $>$ Meteorite …................................................403

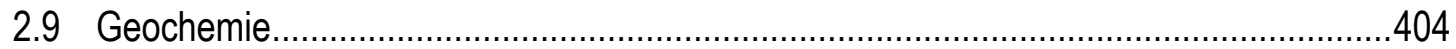

2.10 Braunkohle, Steinkohle (Stratigraphie, Petrographie, Lagerstättenkunde)....................415

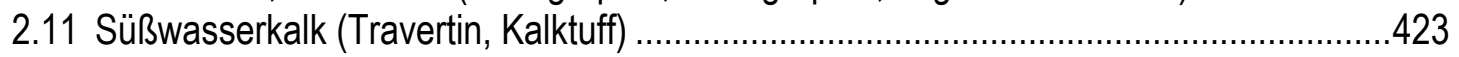

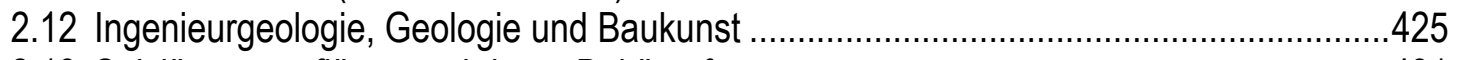

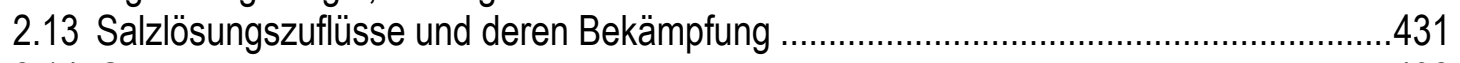

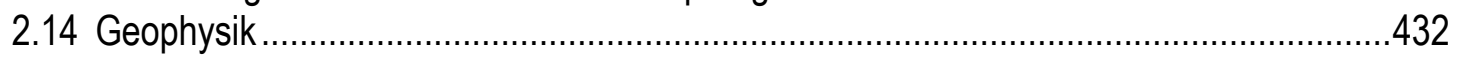

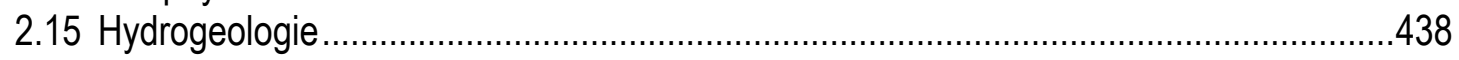

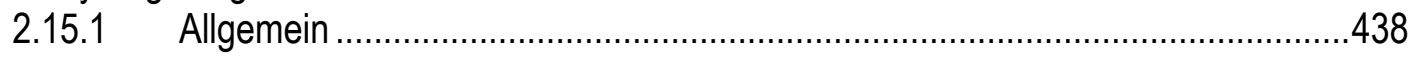

2.15.2 Karlsbrunnen bei Eichenberg, Werra-Meißner-Kreis ...................................454

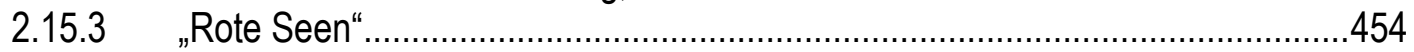

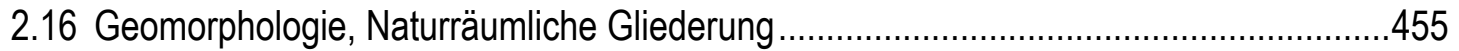

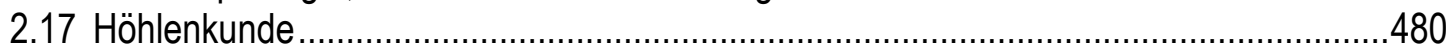

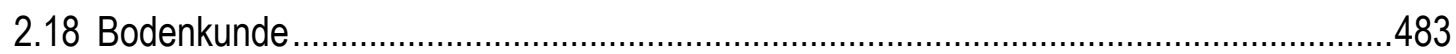

2.19 Geotourismus (Besucherbergwerke, Museen, Ausstellungen, Sammlungen, Schauhöhlen

u. a.) 493

2.20 Geologie und Archäologie, Märchen und Sagen 


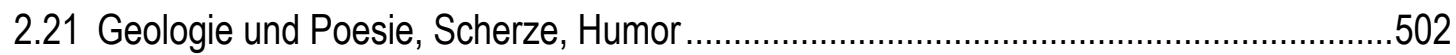

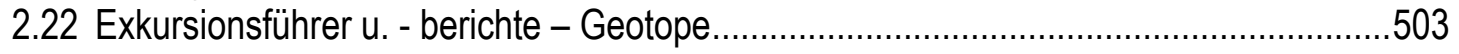

2.22.1 Exkursionsführer - Exkursionsberichte.........................................................503

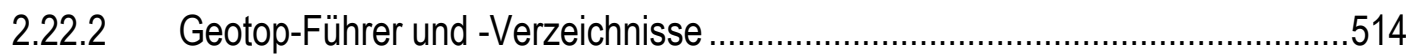

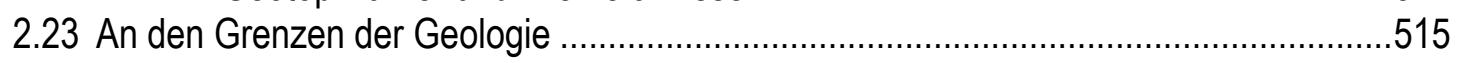

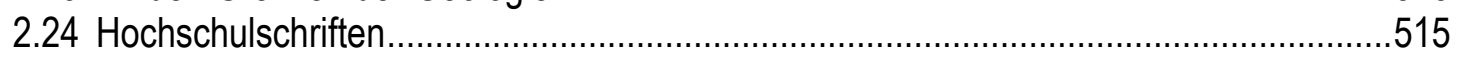

2.24.1 Diplom-Arbeiten, Diplom-Kartierungen u. a. Examensarbeiten .........................515

2.24.1.1 Hessen - ohne Werra-Meißner-Kreis ....................................................515

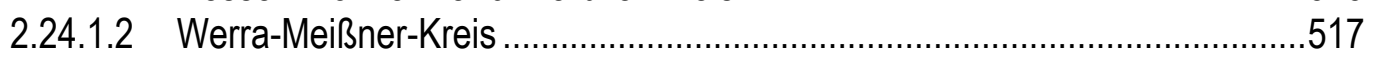

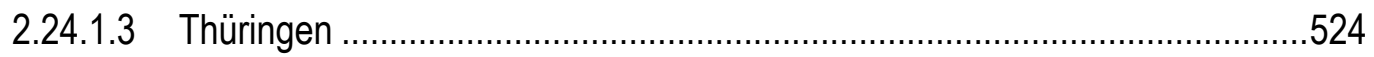

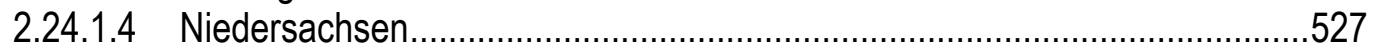

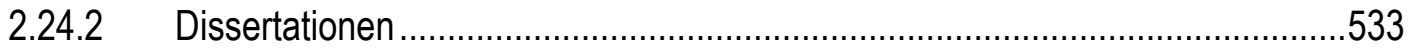

3 Bergbaugeschichte $\quad \mathbf{5 3 8}$

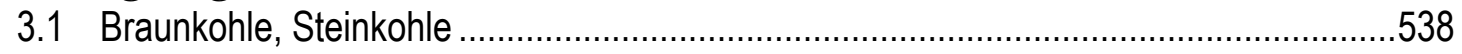

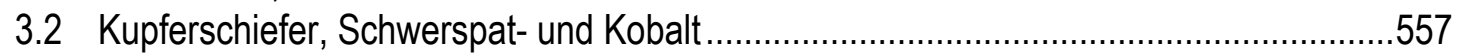

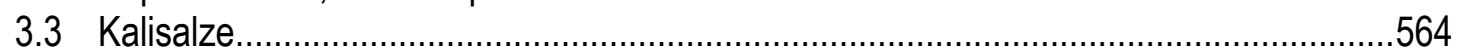

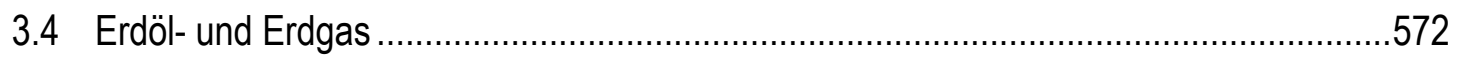

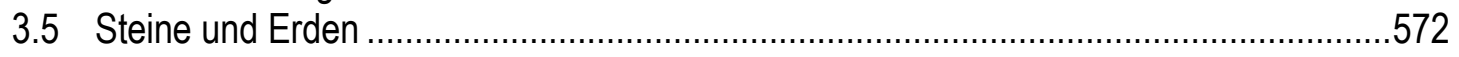

3.6 Metallische Rohstoffe (ohne Kupferschiefer) …................................................58

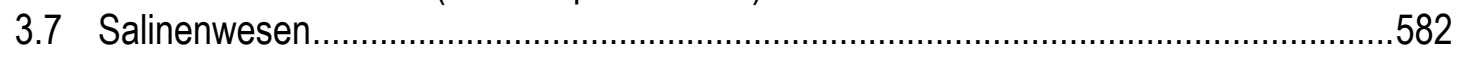

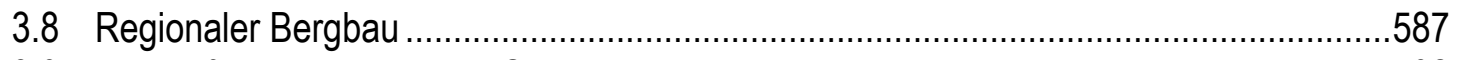

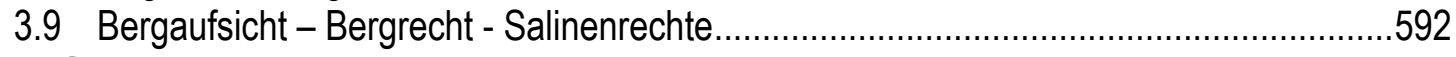

4 Geologie, Bergbau und Interessenkonflikte, Renaturierung, Naturschutz 594

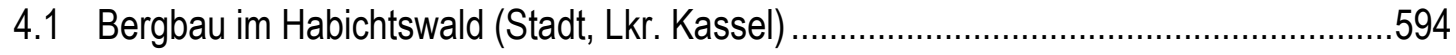

4.2 Bergbau in der Söhre (Landkreis Kassel) ..........................................................596

4.3 Bergbau im „Tiefenbach“ b. Helsa-Wickenrode (Landkreis Kassel) ...............................597

4.4 Bergbau auf dem Hohen Meißner (Werra-Meißner-Kreis) ...........................................598

4.5 Bergbau im Hessisch-Thüringischen Kali-Bergbaurevier - Werra-Versalzung ................604

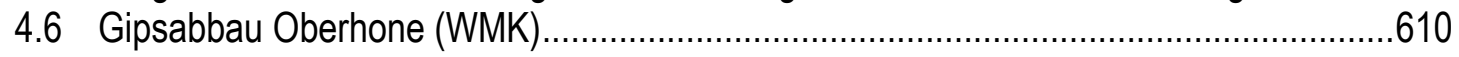

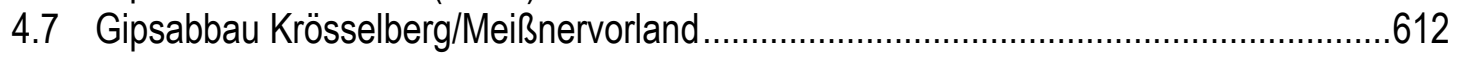

4.8 Weiterer Bergbau an anderen Lokalitäten...............................................................613

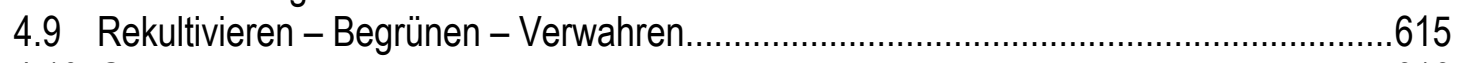

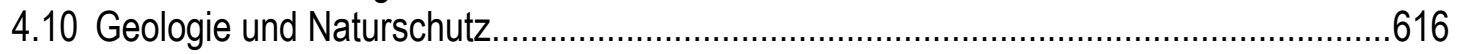

$5 \quad$ Geowissenschaftliche Karten und Kartenerläuterungen $\quad 621$

5.1 Geologische Karte $1: 25.000$ (Regelblattschnitt) ...................................................621

5.2 Geowissenschaftliche Karten - verschiedene Maßstäbe und Themen ..........................637

5.2.1 Geologische Übersichtskarten ...................................................................637

5.2.1.1 Länderübergreifende Kartenwerke .......................................................637

5.2.1.2 Länderbezogene Kartenwerke...........................................................638

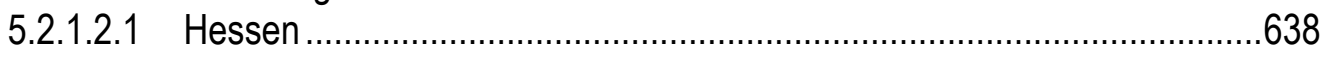

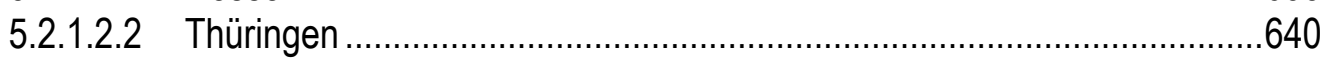

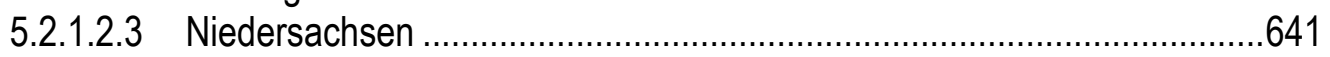

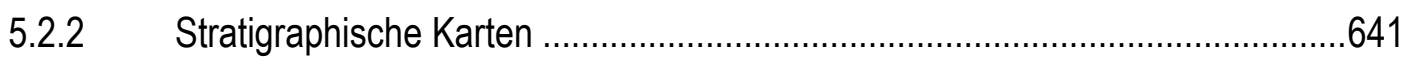

5.2.3 Rohstoff- und Lagerstättenkarten...............................................................642

5.2.3.1 Länderübergreifende Kartenwerke .....................................................642

5.2.3.2 Länderbezogene Kartenwerke.............................................................643

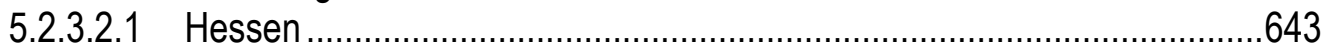

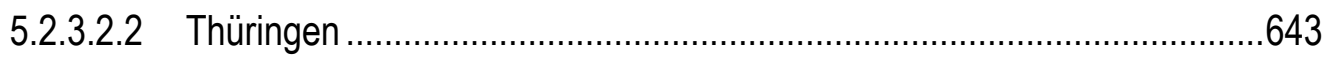

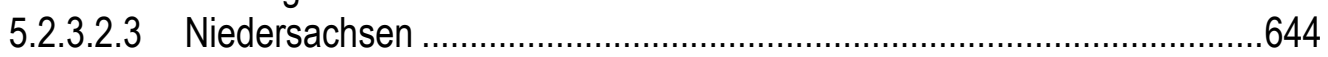

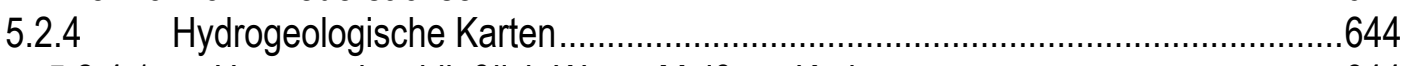

5.2.4.1 Hessen einschließlich Werra-Meißner-Kreis...........................................644 


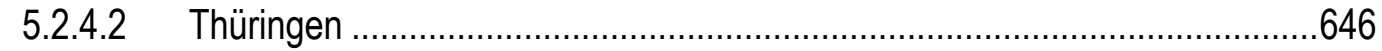

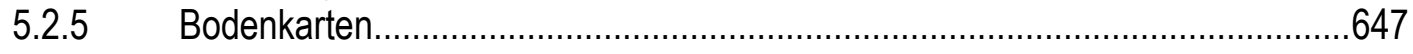

5.2.5.1 Länderübergreifende Kartenwerke .......................................................647

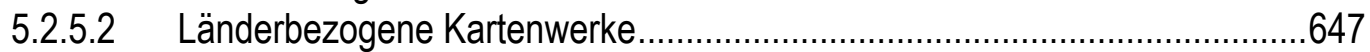

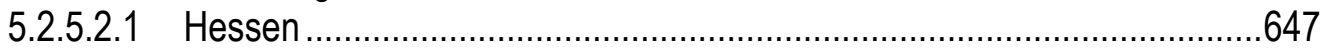

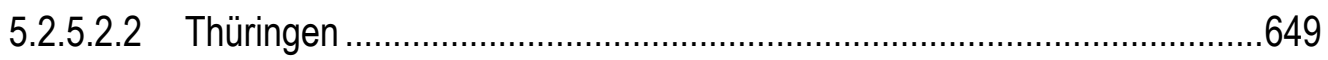

5.2.5.2.3 Niedersachsen .............................................................................649

5.2.6 Sonstige Karten (Tektonik, Geophysik, Geochemie, Ingenieurgeologie u.a.) ...652 Ende

654 


\section{Benutzerhinweise}

Ein Großteil der Literatur war zum Zeitpunkt Bearbeitung der Bibliographie in einer oder mehreren der folgenden Bibliotheken nachgewiesen:

Niedersächsischen Staats- und Universitätsbibliothek Göttingen (SUB)

Bibliotheken der Fakultät für Geowissenschaften und Geographie der Universität Göttingen (Geologie und Mineralogie; Geographie)

Bereichsbibliothek Forstwissenschaften der Universität Göttingen (BBF)

Murhard'schen und Landesbibliothek Kassel (Bereichsbibliothek 6 der Universität Kassel)

Forschungsbibliothek Gotha (besonders Schriften mit Regionalbezug zu Thüringen)

Stadtarchiv Eschwege (besonders Ortschroniken und Schriften zu Ortsjubiläen von Orten im WerraMeißner-Kreis)

Artikel der Tagespresse waren größtenteils zu finden in:

Archiv der HNA - Presse- und Druckzentrum Kassel, Frankfurter Straße (Hessische, Niedersächsische Allgemeine-HNA; Hessische Nachrichten - HN; Hessisches Allgemeine - HA)

Stadtarchiv Eschwege (Eschweger Tageblatt, Eschweger Kreisblatt, Eschweger Tage- und Kreisblatt, Werra-Rundschau)

Murhardtsche und Landesbibliothek Kassel/Bereichsbibliothek 6 der Universität Kassel (Tageszeitungen der Region Kassel)

In den Online-Katalogen der Bibliotheken sind Monographien und Zeitschriftentitel nachgewiesen, selten jedoch einzelne Zeitschriftenaufsätze. Einen bundesweiten Titel- und Bestands-Nachweis der Monographien und Zeitschriftentitel über Internet bietet der „Karlsruher Virtuelle Katalog (KVK)“, bzw. die Zeitschriftendatenbank (ZDB) der Deutschen Nationalbibliothek sowie die Virtuelle Fachbibliothek „GEO-LEO“. Die Online-Datenbanken der Landesbibliographien bieten aktuelle Neuerscheinungen, gehen jedoch im Altbestand meist nicht über das Jahr 1980 zurück.

Die Einsichtnahme in Diplom-Arbeiten/Diplom-Kartierungen der wissenschaftlichen Hochschulen ist häufig nur eingeschränkt möglich. Meist werden die Arbeiten nur in der Bibliothek des

Geologischen/Mineralogischen Institutes vorgehalten, in dem die Arbeit angefertigt wurde, gehören zum Präsenzbestand und sind nur vor Ort einsehbar. Zum Teil ist die Einsichtnahme genehmigungspflichtig, gleiches gilt für die Weitergabe und Verwertung von Inhalt, bzw. Ergebnissen. Die bibliographischen Daten dieser Hochschulschriften wurden wegen der eingeschränkten Zugriffsmöglichkeit anhand von Bibliothekskatalogen erstellt oder aus Literaturverzeichnissen ohne Einsicht in die Vorlagen übernommen. Wegen der eingeschränkten Zugänglichkeit wurden diese Arbeiten in einem eigenen Unterkapitel der Hochschulschriften aufgelistet und nur vereinzelt bei eindeutig fachlichem Bezug in Sachkapiteln aufgeführt.

Die Tageszeitungen Hessische Nachrichten (HN), Hessische Allgemeine (HA) und Hessische, Niedersächsische Allgemeine (HNA) erschienen/erscheinen in zahlreichen Regionalausgaben. Die aufgenommenen Artikel dieser Zeitungen lagen im Archiv der HNA (Presse- und Druckzentrum Kassel, Frankfurter Straße) in Form von Zeitungsausschnitten vor. Dabei wurde auf die Ermittlung der jeweiligen Regionalausgabe verzichtet, eventuell verzeichnete Kürzel für Regionalausgaben mit angegeben. 
Artikel der Tageszeitungen Eschweger Tageblatt, Eschweger Tage- und Kreisblatt, Eschweger Kreisblatt erschienen überwiegend ohne Überschrift. Die in eckige Klammern gesetzten Überschriften sind „Arbeitsüberschriften“ oder folgen den Angaben des Schlagwortkatalogs im Stadtarchiv Eschwege.

Im Sachverzeichnis wurden für einzelne Geotope und geotopträchtige Landschaften von Bedeutung eigene Kapitel erstellt, die fachübergreifend geowissenschaftliche Literatur auflisten. Auch für die Sedimentgesteine Braunkohle und Süßwasserkalk wurde dieser interdisziplinäre Ansatz realisiert.

Diese zweite Auflage enthält über 5800 Literaturnachweise im Autorenverzeichnis. 


\section{Regionaler Bezug der Zitate}

Über den regionalen Bezug der Arbeit zu einer der Bundesländer Hessen, bzw. Werra-Meißner-Kreis, Niedersachsen, Thüringen schon optisch darzustellen, informiert ein dem Zitat vorangestelltes, in der Online-Version farbiges Symbol und farbigen Autorenname über die regionale Zuordnung der aufgeführten Literatur. Die Literatur des Werra-Meißner-Kreises, ursprünglich ausschließlicher Gegenstand der Bearbeitung, wurde dabei gesondert gekennzeichnet

\section{- Hessen (ohne Werra-Meißner-Kreis)}

Stadt u. Landkreis Kassel, Schwalm-Eder-Kreis (bibliographisch erfasstes Gebiet), Kreis HersfeldRotenburg

\section{$\square \underline{\text { Werra-Meißner-Kreis }}$}

\section{o Thüringen}

Ohmgebirge, Bergbaurevier Bleicheröder Berge (Thüringen)

Eichsfeldkreis (Thüringen)

Unstrut-Hainichkreis

Wartburg-Kreis ohne Rhön-Anteile

Stadt u. Landkreis Gotha

Thüringer Wald (etwa bis zur Linie Ilm-Schleuse Südostgrenze der Rotliegend-Verbreitung)

Landkreis Schmalkalden - Meiningen (nördliche Gebiete)

\section{- Niedersachsen}

Landkreis Göttingen, ausgewählte Objekte im südlichen Landkreis Northeim

\section{- $\square$ ○・ Länderübergreifende Relevanz}

Bei geographischem Bezug auf mehrere Bundesländer werden relevante Symbole in festgelegter Reihenfolge kombiniert.

Bei der räumlichen Abgrenzung gilt generell: „Politische Grenzen sind keine geologischen Grenzen!“ 


\section{Anordnung der Zitate}

Jedes Literaturzitat, mit Ausnahme von Kartenwerken, erscheint in dieser Bibliographie im Band 1 Alphabetisches Verzeichnis nach Autorennamen

im Band 2 Verzeichnis nach Sachgebieten

Einzelne Arbeiten werden auch mehrfach im Band 2 Verzeichnis nach Sachgebieten zitiert, sofern sich aus dem Titel, bzw. Inhalt eine Zugehörigkeit zu mehrenen Sachgebieten ableiten ließ.

Im Band 1 Alphabetisches Verzeichnis werden anonyme Beiträge gesondert aufgelistet („Anonym“), ebenso die Beiträge von Autoren, die ihren Beitrag mit einem Namenskürzel gezeichnet haben („Namenskürzel“).

Informationen in eckigen Klammern im Anschluß an das Literaturzitat sind Zitate von Kapiteln der Publikation, Kommentare und Erläuterungen des Bearbeiters, um den inhaltlichen Zugang zu erleichtern. 


\section{Verzeichnis verwendeter Abkürzungen}

BÜK/GÜK 200/300

Bodenübersichtskarte/Geologische Übersichtskarte Maßstab $1: 200.000 / 300.000$

\section{DUGW/IUGS}

Deutsche Union der Geologischen Wissenschaften/International Union for Geological Sciences

Fachber. Geowiss. FU Berlin

Fachbereich Geowissenschaften - Freie Universität Berlin

Zusstlg. u. red. Vorber.

Zusammenstellung und redationelle Vorbereitung

\begin{tabular}{|c|c|}
\hline Abb. & Abbildung \\
\hline Abh. & Abhandlungen \\
\hline Abt. & Abteilung \\
\hline Anh. & Anhang \\
\hline Anl. & Anlage(n) \\
\hline Aufn. & Aufnahme \\
\hline Bd. & Band \\
\hline Bearb. & Bearbeiter/Bearbeitung \\
\hline Beih. & Beiheft \\
\hline Beil. & Beilage(n) \\
\hline Beitr. & Beitrag/Beiträge \\
\hline Ber. & Bericht \\
\hline Bez. & Bezirk (=Regierungsbezirk) \\
\hline Bhrg. & Bohrung \\
\hline Bl. & Blatt \\
\hline Briefl Mitt. & Briefliche Mitteilung \\
\hline BSA & Bad Sooden-Allendorf \\
\hline d.i. & das ist \\
\hline Diss. & Dissertation (Doktorarbeit) \\
\hline Dipl.-Arb. & Diplom-Arbeit \\
\hline $\begin{array}{l}\text { Dipl.-Kart. } \\
\text { ed. }\end{array}$ & $\begin{array}{l}\text { Diplom-Kartierung } \\
\text { editor (Herausgeber) }\end{array}$ \\
\hline $\begin{array}{l}\text { Fd./Fde. } \\
\text { fig. }\end{array}$ & $\begin{array}{l}\text { Fund, Funde } \\
\text { figures (Abbildungen) }\end{array}$ \\
\hline Fachber. & Fachbereich \\
\hline Forsch. & Forschung \\
\hline Forschber. & Forschungsbericht \\
\hline FU & Freie Universität Berlin \\
\hline Geol., geol. & Geologie, geologisch \\
\hline Geowiss. & Geowissenschaften \\
\hline Ges. Rh. & Gesamte Reihe \\
\hline Ges. & Gesellschaft \\
\hline Getr. & getrennte \\
\hline gez. Bl. & gezählte Blätter \\
\hline Ghs. & Gesamthochschule \\
\hline Gradabth. & Gradabtheilung \\
\hline Graph. Darst. & Graphische Darstellung(en) \\
\hline H. & Heft \\
\hline Hist. & Historisch/en \\
\hline Hrsg. & Herausgeber \\
\hline
\end{tabular}




$\begin{array}{ll}\text { Ill. } & \text { Illustration(en) } \\ \text { Insges. } & \text { Insgesamt/e } \\ \text { Jb. } & \text { Jahrbuch } \\ \text { Jg. } & \text { Jahrgang } \\ \text { jun. } & \text { junior } \\ \text { Kgl. } & \text { Königlich } \\ \text { Komm. } & \text { Kommission } \\ \text { korr. } & \text { korrigiert } \\ \text { Kt. } & \text { Karte(n) } \\ \text { Lfg. } & \text { Lieferung } \\ \text { Lkr. } & \text { Landkreis } \\ \text { Mitarb. } & \text { Mitarbeit(er) } \\ \text { Mber. } & \text { Monatsber. } \\ \text { N.F. } & \text { Neue Folge } \\ \text { Nr. } & \text { Nummer } \\ \text { p. } & \text { page/s (Seite/n) } \\ \text { pl. } & \text { planche/s (Bildtafel/n) } \\ \text { plt. } & \text { plate/s (Bildtafel/n) } \\ \text { Red. } & \text { Redaktion } \\ \text { Rh. } & \text { Reihe } \\ \text { S. } & \text { Seiten } \\ \text { Schriftltg. } & \text { Schriftleitung } \\ \text { Sdbd. } & \text { Sonderband } \\ \text { Seitenzählg. } & \text { Seitenzählung } \\ \text { sen. } & \text { Senior } \\ \text { sep. } & \text { separat } \\ \text { Sitzber. } & \text { Sitzungsberichte } \\ \text { Sp. } & \text { Spalte } \\ \text { Suppl.-Bd. } & \text { Supplementband } \\ \text { tab. } & \text { tables/s (Tabelle/n) } \\ \text { tabl. } & \text { tableau(x) (Tabelle/n) } \\ \text { Taf. } & \text { Tafeln (Bild-, Fototafeln) } \\ \text { TH } & \text { Technische Hochschule } \\ \text { TK 25 } & \text { Topographische Karte - Maßstab 1:25.000 } \\ \text { TLUG } & \text { Thüringer Landesanstalt für Umwelt und Geologie } \\ \text { TU } & \text { Technische Universität } \\ \text { Univ. } & \text { Universität } \\ \text { [unveröff.] } & \text { unveröffentlicht } \\ \text { Verf. } & \text { Verfasser } \\ \text { Verhdlgn. } & \text { Verhandlungen } \\ \text { WMK } & \text { Werra-Meißner-Kreis } \\ \text { Z. } & \text { Zeitschrift } \\ \text { Zahlr. } & \text { Zahlreiche } \\ \text { zgl. } & \text { zugleich } \\ \text { Zusstlg. } & \text { Zusammenstellung } \\ & \end{array}$




\section{Moderne und historische Schreibweisen der deutschen Sprache}

Mehrere Begriffe wurden in historischer Zeit abweichend von der heutigen Schreibweise geschrieben, u.a. bedingt durch die Rechtschreibreform von 1903. Das betrifft sowohl Ortsnamen als auch Sachbegriffe. Historische Schreibweisen wurden beibehalten. In der Online-Version sind daher unterschiedliche Schreibweisen bei Benutzung von Suchfunktionen zu berücksichtigen

\section{Heutige Schreibweise}

Abteilung

Baryt

Beitrag, Beiträge

Zentral

Entwicklung

Flöz

Gesamt ...

Großalmerode

i. Comm.

Kassel

Landwirtschaft...

Literatur

Meißner

Mitteilung

Pleistozän

Richelsdorf

Rotliegend...

Spezial...

Tal

Teil

Tierfährten

Ton

Über

\section{Historische Schreibweise}

Abtheilung

Baryth

Beytrag, Beyträge

Central

Entwickelung

Flötz

Gesammt..

Grossalmerode

i. Comm(ission)

Cassel

Landwirthschaft...

Litteratur

Meissner/Meisner/Weissener

Mittheilung

Pleistocän

Riegelsdorf

Rothliegend...

Special...

Thal

Theil

Thierfährten

Thon

Ueber 
Ware

Wert

Westfalen

Wirtschaf...

Zentral...
Waare

Werth

Westphalen

Wirthschaft

Central... 


\section{Informationen zu abgekürzt zitierten Zeitschriftentiteln}

Die Informationen zu den abgekürzten Titeln folgen weitestgehend den Daten der

Zeitrschriftendatenbank (ZDB) der Preußischen Staatsbibliothek Berlin. - Bei den Angaben der ZDB ist zu beachten, daß bei wechselnden Erscheinensorten und Verlagen meist nur der letzte Sachstand angegeben ist. In der Vorlage können deswegen abweichende Angaben erscheinen.

\section{$>\mathbf{A}$}

Abh. Akad. Wiss. Göttingen, math-phys. Kl.

Abhandlungen der Akademie der Wissenschaften zu Göttingen, mathematisch-physikalische Klasse; Göttingen

\section{Abh. u. Ber. Museums Natur Gotha}

Naturkundemuseum - Abhandlungen und Berichte des Naturkundemuseums Gotha -

Abhandlungen und Berichte des Museums der Natur Gotha; Gotha - Gesamttitel: Gothaer Museumshefte. - Bandzählung anfangs ohne Bandnummer [6] 1971, [7] 1973, [8] 1976

Abh. u. Ber. Vereins Naturkde. Kassel

Abhandlungen und Bericht des Vereins für Naturkunde zu Cassel [später: Kassel]; (Cassel) Kassel Erscheinensverlauf: 40.1894/95(1895) - 58.1929/36(1936), 59.1954

\section{Abh. Dt. Akad. Wiss. Berlin, Kl. Chemie, Geol., Biol.,}

Abhandlungen der Deutschen Akademie der Wissenschaften zu Berlin, Klasse Chemie, Geologie, Biologie; (Akademie-Verlag) Berlin

\section{Abh. Hess. L.-A. Bodenforsch.}

Abhandlungen des Hessischen Landesamtes für Bodenforschung; Wiesbaden

Erscheinensverlauf: $1.1950-73.1976$

Folgetitel: Geol. Abh. Hessen - Geologische Abhandlungen Hessen

\section{Abh. [Kgl.] Preuß. Geol. Landesanst. [u. Bergakad.]}

Abhandlungen der Königlich Preußischen Geologischen Landesanstalt [bis 1905: und Bergakademie]; Berlin Erscheinensverlauf: N.F. 1.1889 - 181.1938, 183.1937 - 195.1939

N.F. 182 als Abh. Reichstelle f. Bodenforschung; Berlin 1941

Vorgängertitel: Abh. geol. Specialkt. v. Preußen u.d. thür. Staaten/hrsg. V.d. Kgl. Preuß. Geol. Landesanst. - (Schropp) Berlin

Erscheinensverlauf: 1.1872/76 - 10.1889/94,7

\section{Abh. Senckenberg. Naturforsch. Ges.}

Abhandlungen der Senckenbergischen Naturforschenden Gesellschaft; (Schweizerbart) Stuttgart Erscheinensverlauf: 1.1854/55 - 43.1931/34,3 = Nr. 1-427; Nr. $428.1934-$

\section{Altenburger naturwiss. Forsch.}

Altenburger naturwissenschaftliche Forschungen; (Mauritianum, Naturkundliches Museum) Altenburg

Erscheinensverlauf: 1.1981 - 


\section{Ann. Physik u. Chemie}

Annalen der Physik und Chemie; Leipzig

\section{Der Anschnitt}

Der Anschnitt - Mitteilungsblatt der Vereinigung der Freunde von Kunst und Kultur im Bergbau (Vereinigung) Bochum

Erscheinensverlauf: 1.1949,1 (Nov.) -

\section{Archäologische Denkmäler in Hessen.}

Archäologische Denkmäler in Hessen; [Hess. Landesamt Denkmalpflege] Wiesbaden

\section{Der Aufschluss}

Der Aufschluss - Zeitschrift für die Freunde der Geologie und Mineralogie. - Hrsg.: Vereinigung der Freunde der Mineralogie und Geologie (VFMG) e.V.; Roßdorf, später Göttingen, später Heidelberg Erscheinensverlauf: 1.1950 -

\section{$>\mathbf{B}$}

\section{Beitr. Geol. Thüringen}

Beiträge zur Geologie von Thüringen. - (Thüringischer Geologischer Verein e.V.) Jena Erscheinensverlauf: 1.1925/28 - 8.1944/55; N.F. $1.1994-$

\section{Beitr. Mineral. Petrogr.}

Heidelberger Beiträge zur Mineralogie und Petrographie - Herausgegeben von O. H.

Erdmannsdörfer. - (Springer) Berlin-Göttingen-Heidelberg

Erscheinensverlauf: 1.1947/1949, Dez. (1949) - 5.1956/57(1957)

Beiträge zur Mineralogie und Petrographie - Herausgegeben von C. W. Correns. - (Springer) BerlinGöttingen-Heidelberg

Erscheinensverlauf: 6.1957/59(1959) - 11.1964/65(1965)

Fortsetzung: Contrib. Mineral. Petrol. - Contributions to Mineralogy and Petrology

Bergbau i. Hessenland (Zusatzangabe: Ausgabe Braunkohle Bde. 1.1950 - 6.1956/1.) - Revier- und Werkzeitschrift für den hessischen Bergbau. - (Verlag Unsere Arbeit) Kassel

Erscheinensverlauf: (1. Jg.) 1950 - (18. Jg.) 1968(1) [damit Erscheinen eingestellt]

\section{Berg- u. hüttenmännische Ztg.}

Berg- und hüttenmännische Zeitung mit besonderer Berücksichtigung der Mineralogie und Geologie. - (B.G.H. Schmidt) Nordhausen und Leipzig [nur 1. Jg.] - ab. Jg. 2: (Engelhardt) Freiberg; später (Felix) Leipzig

Erscheinensverlauf: $1.1842-5.1847 ;$ N.F. $1=6.1847-58=63.1904$

\section{Ber. geol. Ges. DDR}

Berichte der Geologischen Gesellschaft in der Deutschen Demokratischen Republik für das Gesamtgebiet der geologischen Wissenschaften. - (Akademie-Verlag) Berlin

Erscheinensverlauf: 1.1955/56, Nov. - 10.1965

\section{Ber. Dt. Ges. Geol. Wiss., A}

Berichte der Deutschen Gesellschaft für Geologische Wissenschaften / A - Herausgegeben vom Vorstand. - (Akademie-Verlag) Berlin

Erscheinensverlauf: $11.1966-17.1972$

\section{Ber. Dt. Ges. Geol. Wiss., B}

Berichte der Deutschen Gesellschaft für Geologische Wissenschaften / B - Herausgegeben vom Vorstand. - (Akademie-Verlag) Berlin Erscheinensverlauf: $11.1966-17.1972$ 


\section{Ber. Naturhist. Ges. Hannover}

Bericht der Naturhistorischen Gesellschaft [zu] Hannover; (Naturhistorische Gesellschaft) Hannover Erscheinensverlauf: 1.1850/51(1851) - 99/101.1947/50(1950); 102.1954 -

Ber. Oberhess. Ges. Natur- und Heilkunde., naturwiss. Abt.,

Bericht der Oberhessischen Gesellschaft für Natur- und Heilkunde, naturwissenschaftliche Abteilung; (Schmitz) Gießen

\section{Ber. Vereins Naturkde. z. Kassel}

Bericht des Vereins für Naturkunde zu Cassel; Cassel

Erscheinensverlauf: 12.1847/60(1863); 12.1860/62 - 39.1892/84(1894)

Nachfolgetitel: Abh. Ber. Vereins Naturkde. (Cassel) Kassel

\section{Berliner geowiss. Abh., Rh. A}

Berliner Geowissenschaftliche Abhandlungen, Reihe A; hrsg. V.d. Geowiss. Inst. d. Freien und der Technischen Universität Berlin; (Fachbereich Geowissenschaften - FU Berlin); Berlin

Erscheinensverlauf: 1.1977 - 215.2002; damit Erscheinen eingestellt

\section{Berliner Geogr. Abh}

Berliner Geographische Abhandlungen; (Institut für geographische Wissenschaften der Freien Universität Berlin) Berlin

Erscheinensverlauf: 1.1964 - 66.2006; damit Erscheinen eingestellt

\section{Bull. Soc. Géol. France}

Bulletin Societé géologique de France ; Paris

\section{$>\mathrm{C}$}

\section{Contrib. Mineral. Petrol.}

Contributions to mineralogy and petrology / International Mineralogical Association, IMA. - Ed. C.W. Correns [u.a.]. - (Springer) Berlin-Heidelberg

Erscheinensverlauf: $12.1966-$

Vorgängertitel: Beitr. Mineral. Petrogr. - Beiträge zur Mineralogie u. Petographie

\section{$<\mathrm{D}$}

\section{Decheniana}

Decheniana - Verhandlungen des Naturhistorischen Vereins der Rheinlande und Westfalens; Bonn Erscheinensverlauf: 91.1934(1935) - 94.1937; $103.1948-$

\section{DVWK-Mitteilungen}

Mitteilungen des Deutschen Verbandes für Wasserwirtschaft und Kulturbau; Bonn

Erscheinensverlauf: 1.1980(1981) - 29.1997; damit Erscheinen eingestellt 


\section{Eichsfeld-Jb.}

Eichsfeld/Jahrbuch; Hrsg.: Verein für Eichsfeldische Heimatkunde; (Mecke) Duderstadt

Erscheinensverlauf: $1.1993-7.1999$

Eichsfeld-Jahrbuch [Verein für Eichsfeldische Heimatkunde; Verein Goldene Mark Untereichsfeld]; (Mecke) Duderstadt

Erscheinensverlauf: 8.2000 -

\section{Exkursionsführer u. Veröff. Ges. f. Geowiss.}

Exkursionsführer und Veröffentlichungen der Gesellschaft für Geowissenschaften e.V.; Berlin

Vorgängertitel: Exkursionsführer u. Veröff. Ges. geol. Wiss. (z.T. mit Zusatz: DDR)

Nachfolgetitel: Exkursionsführer u. Veröff. Dt. Ges. geol. Wiss.

\section{$>\mathbf{F}$}

Forsch. Dt. Landes- u. Volkskde.

Forschungen zur Deutschen Landes- und Volkskunde / Zentralaussschuß für Deutsche

Landeskunde; (Engelhorn) Stuttgart, später (Hirzel) Leipzig

Erscheinensverlauf: 1.1885/86-32.1937/39

Fortsetzungstitel: Forsch. z. dt. Ldskde. - Forschungen zur deutschen Landeskunde

\section{Fortschr. Mineral.}

Fortschritte der Mineralogie, Kristallographie und Petrographe - Herausgegeben von der Deutschen Mineralogischen Gesellschaft.... - Berlin-Jena, später Stuttgart

Erscheinensverlauf: $1.1911-25.1941,26.1947(1950)-66.1988$

\section{Freiberger Forschungshefte, Rh. C}

Freiberger Forschungshefte, Reihe C: Geologie Paläontologie

Anfangs Zusatz: Beihefte der Zeitschrift „Bergakademie“. - (Akademie-Verlag) Berlin, später (Dt.

Verlag f. Grundstoffindustrie) Leipzig, später: TU Bergakademie Freiberg

Erscheinensverlauf: 1.1951; Keine Jahresbände, erscheinen in unregelmäßiger Reihenfolge

\section{$>$ G}

\section{Geologie}

Geologie - Zeitschrift für das Gesamtgebiet der Geologie und Mineralogie sowie der angewandten Geophysik / Deutsche Gesellschaft für Geologische Wissenschaften. - Mit der Herausgabe beauftragt ... - (Akademie-Verlag) Berlin

Erscheinensverlauf: $1.1952-21.1972$

\section{Geologie, Beih.}

Geologie, Beiheft - Zeitschrift für das Gesamtgebiet der Geologie und Mineralogie sowie der angewandten Geophysik - (Akademie-Verlag) Berlin Erscheinensverlauf: 1.1952 - 78/79.1973; damit Erscheinen eingestellt

\section{Geol. Abh. Hessen}

Geologische Abhandlungen Hessen. - (Hessisches Landesamt für Bodenforschung, Wiesbaden/später: Hessisches Landesamt für Umwelt und Geologie, Wiesbaden); Wiesbaden Erscheinensverlauf: $74.1976-$ Herausgeber bis 105.1999: Hessisches Landesamt für Bodenforschung 


\section{Geol. B1. NO-Bayern}

Geologisches Blätter für Nordost-Bayern und angrenzende Gebiete - Hrsg.: GeoZentrum Nordbayern der Universität Erlangen-Nürnberg, Lehrstuhl für Geologie und Lehrstuhl für Angewandte Geologie) Erlangen Erscheinensverlauf: 1.1951, Febr. -

\section{Geol. Jb.}

Geologisches Jahrbuch - Herausgegeben von der Bundesanstalt für Bodenforschung und den Geologischen Landesämtern der Bundesrepublik Deutschland. - (Bundeanstalt) Hannover Vorgängertitel: Jb. Preuß. Geol. Landesanst.

Erscheinensverlauf: 64.1943/1948(1950) - 90.1972

(Kommissionsverlag Schweizerbart;) Stuttgart

Folgetitel - Geol. Jb., Rh. A - G. - Geologisches Jahrbuch - Reihen A - G

\section{Geol. Jb., Beih.}

Geologisches Jahrbuch/Beihefte. - Herausgegeben von der Bundesanstalt für Bodenforschung und den Geologischen Landesämtern der Bundesrepublik Deutschland. - (Bundesanstalt) Hannover Erscheinensverlauf: 1.1951 - 125.1972 - damit Erscheinen eingestellt

\section{Geol. Jb. Hessen}

Geologisches Jahrbuch Hessen - (Hessisches Landesamt für Bodenforschung)/HLUG - Hessisches Landesamt für Umwelt und Geologie; (Hessisches Landesamt) Wiesbaden

Erscheinensverlauf: 104.1976 - 127.1999, 128.2000(2001) -

Vorgängertitel: Notizbl. Hess. L.-A. Bodenforsch - Notizblatt des Hessischen Landesamtes für Bodenforschung.

\section{Geol. Rundschau}

Geologische Rundschau - Herausgegeben von der Geologischen Vereinigung. - (Springer) - BerlinHeidelberg

Erscheinensverlauf: 1.1910 - 34.1944; 35.1947/48 - 87.1998.1999

Fortsetzungstitel: Int. J. earth sci. - International journal of earth science -

\section{Geol. Soc. [London] Spec. Publ.}

Geological Society [of London] Special Publications; London

\section{Geowiss. Mitt. Thüringen}

Geowissenschaftliche Mitteilungen aus Thüringen / Thüringer Landesanstalt für Umwelt und Geologie; Jena Erscheinensverlauf: 1.1993

\section{Glückauf}

Glückauf $<$ Essen $>$ Zeitschrift für Technik und Wirtschaft des Bergbaus. - Glückauf-Verlag) Essen; später: (VGE-Verlag) Essen

Erscheinensverlauf: 1.1865 - 81.1945,6; 81/84.1948,1/2 -

\section{Göttinger Arb. Geol. Paläont.}

Göttinger Arbeiten zur Geologie und Paläontologie - GAGP / Georg-August-Universität Göttingen, Institut und Museum für Geologie und Paläontologie, Institut für Geologie und Dynamik der Lithosphäre; (Geologische Institute) Göttingen Erscheinensverlauf: 1.1969 - 76.2000; damit Erscheinen eingestellt

\section{Göttinger bodenkdl. Ber.}

Göttinger bodenkundliche Berichte - GBB / Institut für Bodenkunde, Institut für Bodenkunde und Waldernährung; Göttingen

Erscheinensverlauf: 1.1968 - 


\section{Göttinger Geogr. Abh.}

Göttinger Geographische Abhandlungen; Hrsg.: Geographisches Institut der Universität Göttingen; Göttingen

Erscheinensverlauf: 1.1948 - Bände erscheinen in unregelmäßigen Abständen

\section{Göttinger Jb.}

Göttinger Jahrbuch - Unter Förderung der Stadt und des Landkreises Göttingen herausgegeben vom Geschichtsverein Göttingen und Umgebung e.V.; Genealogisch-Heraldische Gesellschaft;

Heimatkundliche Arbeitsgemeinschaft Göttingen; Göttinger Vereinigung Naturforschender Freunde; (Goltze) Göttingen

Erscheinensverlauf: [1.]1952 - [5.]1957, 6.1958 -

\section{$>\mathbf{H}$}

\section{HA}

Hessische Allgemeine; Kassel

Erschienen mit mehreren Regionalausgaben

\section{Hallesches Jb. Geowiss.}

Hallesches Jahrbuch für Geowissenschaften / Herausgegeben von der Martin-Luther-Universität Halle-Wittenberg für die Sektion Geographie. - Leipzig-Gotha, später: Gotha, später: Halle (Saale Erscheinensverlauf: 1.1977 - 15.1990, 16.1994

Hallesches Jahrbuch für Geowissenschaften, Reihe. B. - Institut für Geologische Wissenschaften und Geiseltalmuseum der Martinluther-Univ. Halle-Wittenberg. - Halle (Saale)

Erscheinensverlauf: $17.1995-27.2005$

Hallesches Jahrbuch für Geowissenschaften / Herausgeber und Schriftleitung: Institut für Geowissenschaften der Martin-Luther-Universität Halle-Wittenberg, Landesamt für Geologie und Bergwesen Sachsen-Anhalt.- Halle/S.

Erscheinensverlauf: 28.2006

\section{Hallesches Jb. mitteldt. Erdgesch.}

Hallesches Jahrbuch für mitteldeutsche Erdgeschichte / hrsg. ... - (Teubner) Leipzig

Erscheinensverlauf: 1.1949/52 - 11.1969(1972)

Folgetitel: Hallesches Jb. Geowiss. - Hallesches Jahrbuch für Geowissenschaften

\section{Hdb. d. Kreises Melsungen}

Handbuch des Kreises Melsungen; (Bernecker) Melsungen

\section{Hannoverisches Magazin}

Hannoverisches Magazin, worin kleine Abhandlungen, einzelne Gedanken, Nachrichten, Vorschläge und Erfahrungen, so die Verbesserung des Nahrungs-Standes, die Land- und Stadt-Wirthschaft, Handlung, Manufakturen und Künste, die Physik, die Sittenlehre und angenehmen Wissenschaften betreffen, gesammelt und aufbewahret sind; (Schlüter) Hannover

Hannoverisches Magazin. - Hannover 1.1763 - 28.1790

\section{Hannoverland}

Hannoverland - Monatsschrift für Geschichte, Landes- und Volkskunde, Sprache, Kunst und Literatur unserer niedersächsichen Heimat. - (Ernst Geibel) Hannover

\section{Heimatjahrbuch. f. d. Landkreis Hofgeismar}

Heimatjahrbuch für den Landkreis Hofgeismar; Hofgeismar 


\section{Hessenland}

Hessenland - Zeitschrift für hessische Geschichte und Literatur /später: Hessenland - Zeitschrift für die Kulturpflege des Bezirksverbandes Hessen - (Elwert) Marburg/L.

Erscheinensverlauf: 1886,22 (Probeheft); 1.1887 - 51.1940/41,1/2, [52.]1940/41,1-3; $1941=$ Jahresheft; 53.1942, 1943,1; damit Erscheinen eingestellt

\section{Hessische Heimat}

Hessische Heimat - Zeitschrift für Kunst, Kultur, Denkmalpflege - Organ des Hessischen

Heimatbundes e.V. und des Hessischen Museumsverbandes e.V.. - (Heimatbund) Marburg/L.

Erscheinensverlauf: 1.1937/38 - [3.]1939/49, N.F. 1.1951 - 46.1996,2/3, 49.1999

\section{Hessischer Gebirgsbote}

Zeitschrift des Hessisch-Waldeckischen Gebirgs- und Heimatvereins im Landesverband Hessen des Verbandes Deutscher Gebirgs- und Wandervereine e.V; Kassel, später: (Bernecker) Melsungen Erscheinensverlafu: 25.1917[?] - 38.1932; 40.1934 - 49.1943; 1947,1-2(Okt./Dez.); 1948,1-6(Febr.Dez.); 50.1949 -

Vorgängertitel: Tour. Mitt. a. bd. Hessen - Touristsche Mitteilungen aus beiden Hessen etc.

\section{HN}

Hessische Nachrichten; Kassel

Erschienen mit mehreren Regionalausgaben

\section{HNA}

Hessische/Niedersächsische Allgemeine; Kassel

Erscheint mit mehreren Regionalausgaben

\section{$>$ I}

Int. J. earth sci.

International journal of earth science - Geologische Rundschau, journal of Geologische Vereinigung. - (Springer) Berlin-Heidelberg

Vorgängertitel: Geol. Rundschau - Geologische Rundschau

Erscheinensverlauf: 88.1999/2000 -

\section{Jber. HLUG}

Jahresbericht des Hessisches Landesamt für Umwelt und Geologie. - (Landesamt) Wiesbaden (Unterreihe der Dachreihe Umwelt und Geologie)

Erscheinensverlauf: 2000(2001) -

\section{Jber. Mitt. Oberrhein. Geol. Verein, N.F.}

Jahresbericht und Mitteilungen des Oberrheinischen Geologischen Vereins, Neue Folge;

(Schweizerbart) Stuttgart

Erscheinensverlauf: N.F. 1.1911 -

\section{Jb. Geologie}

Jahrbuch für Geologie - Herausgegeben vom Zentralen Geologischen Institut, Staatssekretariat für

Geologie, Ministerrat der Deutschen Demokratischen Republik. - (Akademie-Verlag) Berlin

Erscheinensverlauf: 1.1965(1967) - 9/10.1973/74(1978); damit Erscheinen eingestellt 
Jb. Halleschen Verbandes etc.

Jahrbuch des Halleschen Verbandes für die Erforschung der mitteldeutschen Bodenschätze und ihrer Verwertung. - Halle (Saale)

Erscheinensverlauf: 1.1919 - 4.1923/24; N.F. 5.1926 - 18.1940

\section{Jb. Landkreis Kassel}

Heimatjahrbuch / Herausgeg. v. Kreisausschuß d. Landkreises Kassel; Kassel

Erscheinensverlauf: 1973(1972)

Jahrbuch / Kreisausschuß Landkreis Kassel; Kassel

Erscheinensverlauf: 1974(1973) -

\section{Jb. Naturschutz Hessen}

Jahrbuch Naturschutz Hessen

\section{Jb. Preuß. Geol. Landesanst.}

Jahrbuch der Königlich Preußischen Geologischen Landesanstalt und Bergakademie, Berlin

Erscheinensverlauf: 1880(1881) - 27.1906(1909), 3

Jb. der (Kgl.) Preußischen Geologischen Landesanstalt

Erscheinensverlauf: 27.1906(1909),4-59.1938(1939)

\section{Jb. Reichsamt f. Bodenforschung}

Jahrbuch des Reichsamts für Bodenforschung. - (Reichsamt) Berin

Erscheinensverlauf: 62.1941(44); 63.1942(1944)

Vorgängertitel: Jb. Reichsstelle f. Bodenforschung - Jahrbuch der Reichsstelle für Bodenforschung Folgetitel: Geol. Jb.; Hannover - Geologisches Jahrbuch. - Hannover

\section{Jb. Reichsstelle f. Bodenforschung}

Jahrbuch des Reichsamts für Bodenforschung. - (Reichsstelle) Berlin

Erscheinensverlauf: 60.1939(1941); 61.1940(1941)

Vorgängertitel: Jb. Preuß. Geol. Landesanst. - Jahrbuch der Preußichen Geologischen Landesanstalt Nachfolgetitel: Jb. Reichsamts f. Bodenforschung - Jahrbuch des Reichsamts für Bodenborschung

\section{Jber. Niedersächsischen Geol. Vereins}

Jahresbericht des Niedersächsischen Geologischen Vereins; Hannover

\section{Jenaische Z. Naturwiss.}

Jenaische Zeitschrift für Naturwissenschaften / Herausgegeben von der MedizinischNaturwissenschaftlichen Gesellschaft zu Jena. - (Fischer) Jena

\section{$>\mathbf{K}$}

\section{Kali etc.}

Kali - Zeitschrift für Gewinnung, Verarbeitung und Verwertung der Kalisalze / Deutscher

Kaliverein. - (Knapp) Halle/S.

Erscheinensverlauf: $1.1907-21.1927$

Kali und verwandte Salze - Zeitschrift für die Kali- und Steinsalzindustrie sowie das Salinenwesen / Deutscher Kaliverein. - (Knapp) Halle/S.

Erscheinensverlauf: $22.1928-25.1931,20$

Kali, verwandte Salze und Erdöl - Zeitschrift für Kali-, Steinsalz- und Erdölindustrie sowie

Salinenwesen /Deutscher Kaliverein. - (Knapp) Halle/S.

Erscheinensverlauf: 25.1931,21 - 39.1945,2 


\section{Kali und Steinsalz}

Kali und Steinsalz / Herausgeben vom Kaliverein e.V., Hannover (später: Kassel)

Erscheinensverlauf:

1.1952/1955;

2.1956/1959;

$3.1960 / 1963$

4.1964/1967;

5.1968/1971;

6.1972/1975;

7.1976/1979;

8.1980/1983;

9.1984/1987;

10.1988/1991;

11.1992/1995;

12.1996/1997,6;

1997 - 2001 aufgegangen in Glückauf; (Glückauf-Verlag) Essen

13.2000;

14.2001; (Glückauf-Verlag) Essen

2002 - ; (Kaliverein e.V.) Kassel

\section{Knüllgebirgsbote}

Knüllgebirgsbote - Zeitschrift für Wandern, Heimat u. Volkskunde, Naturschutz ; Mitteilungsblatt d. Knüllgebirgsvereins e.V. 1884; (Olten \& Wiegand) Homberg/Efze, später: (Knüllgebirgsverein)

Niederaula

Erscheinensverlauf: 1.1925 - 14.1938, 1969 -

\section{$>\mathbf{L}$}

\section{Lapis}

Lapis - die aktuelle Monatsschr. für Liebhaber \& Sammler von Mineralien \& Edelsteinen; (Weise) München

Erscheinensverlauf: 1.1976

\section{$>\mathbf{M}$}

Mitt. Grhzgl. Bad. Geol. Landesanst.

Mitteilungen der [Großherzoglichen] Badischen Geologischen Landesanstalt. - Heidelberg Erscheinensverlauf: 1.1890 - 12.1938, N.F. 1.1948[?] - Bände umfassen Heftausgaben mehrerer Jahre!

Mitt. Dt. Bodenkdl. Ges.

Mittteilungen der Deutschen Bodenkundlichen Gesellschaft; Göttingen, später: Oldenburg Erscheinensverlauf: 1.1963 -

\section{Mitt. Geol. Staatsinstitut Hamburg}

Mitteilungen aus dem Geologischen Staatsinstitut Hamburg; Hamburg

Erscheinensverlauf: $15.1935-37.1968$ 


\section{Mittbl. Thür. Geol. Vereins}

Mittteilungsblatt des Thüringischen Geologischen Vereins e.V.; Jena

Erscheinensverlauf: 1.1992 - Erscheint unregelmäßig ein- bis zweimal pro Jahr

\section{Monatsber. Dt. Akad. Wiss. Berlin}

Monatsberichte der Deutschen Akademie der Wissenschaften zu Berlin - Mitteilungen aus

Mathematik, Naturwissenschaft, Medizin u. Technik; (Akademie-Verlag) Berlin

Erscheinensverlauf: 1.1959 - 13.1971; damit Erscheinen eingestellt

\section{$>\mathbf{N}$}

Nachr. Dt. Geol. Ges.

Nachrichten der Deutschen Geologischen Gesellschaft; Hannover

Nachfolgetitel: GMIT - Geowissenschaftliche Mitteilungen, Bonn

Nachr. Ges. Wiss. Göttingen, Math.-phys. Kl, Fachgr. IV,

Nachrichten der Gesellschaft der Wissenschaften zu Göttingen, Mathematisch-physikalische Klasse, Fachgruppe IV; Göttingen

\section{N. Jb. Mineral. etc.}

Neues Jahrbuch für Mineralogie, Geognosie, Geologie und Petrefaktenkunde; 1833-1862;

Neues Jahrbuch für Mineralogie, Geologie und Paläontologie; 1863-1925.1

Neues Jahrbuch für Mineralogie, Geologie und Paläontologie, Referate, Abt. A [Mineralogie];1925.21927

Neues Jahrbuch für Mineralogie, Geologie und Paläontologie, Referate, Abt. B [Geologie, Paläontologie]; 1925.2 - 1927

Neues Jahrbuch für Mineralogie, Geologie und Paläontologie, Referate (I, II, III); 1928-1942

Bd. I( Kristallographie, Mineralogie)

Bd. II (Allgemeine Geologie, Petrographie, Lagerstättenkunde)

Bd. III (Historische und regionale Geologie, Paläontologie)

Vorgängertitel: Jahrbuch für Mineralogie, Geognosie, Geologie und Petrefaktenkunde

N. Jb. Mineral. Abt. A, Mh.

Neues Jahrbuch für Mineralogie, Geologie und Paläontologie, Abteilung A, Monatshefte. (Schweizerbart) Stuttgart

Erscheinensverlauf: 1943 - 1949

\section{N. Jb. Mineral. Abteilung A, Abh.}

Neues Jahrbuch für Mineralogie, Geologie und Paläontologie, Abt. A, Abhandlungen. (Schweizerbart) Stuttgart

Erscheinensverlauf: 78.1943; 79.1944/48(1948) - 80.1949/50(1950)

\section{N. Jb. Mineral. Abt. B, Mh.}

Neues Jahrbuch für Mineralogie, Geologie und Paläontologie, Abteilung B, Monatshefte. (Schweizerbart) Stuttgart

Erscheinensverlauf: 1943 - 1949

N. Jb. Mineral. Abt. B, Abh.

Neues Jahrbuch für Mineralogie, Geologie und Paläontologie, Abteilung B, Abhandlungen. (Schweizerbart) Stuttgart

Erscheinensverlauf: 88.1943/44 - 91.1949/50

\section{N. Jb. Mineral., Abh.}

Neues Jahrbuch für Mineralogie, Abhandlungen. - (Schweizerbart) Stuttgart

Erscheinensverlauf: 81.1950 - 


\section{N. Jb. Mineral., Mh.}

Neues Jahrbuch für Mineralogie, Monatshefte - (Schweizerbart) Stuttgart

Erscheinensverlauf: 1950.1950 -

Notizenbl. Göttingischen Vereins bergmänn. Freunde

Notizenblatt des Göttingischen [!] Vereins bergmännischer Freunde; (Verein) Göttingen

Erscheinensverlauf: 1.1837 - 47.1845; damit Erscheinen eingestellt

\section{Notizbl. Hess. L.-A. Bodenforsch.}

Notizblatt des Hessischen Landesamtes für Bodenforschung zu Wiesbaden. - (Landesamt)

Wiesbaden

Erscheinensverlauf: 6. F., H.1 [78].1950; 6. F., H. 2 [79].1951; 6. F., H. 3[80].1952; 81.1953 [6.F., H. 4];

82.1954 [6. F., H. 5]; 83.1955 [6. F., H. 6]; 84.1956 - 103.1975

Fortsetzung: Geol. Jb. Hessen - Geologisches Jahrbuch Hessen

\section{$>\mathbf{P}$}

\section{Palaeontographica}

Paläontographica - Beiträge zur Naturgeschichte der Vorwelt; (Fischer) Kassel, später (Schweizerbart) Stuttgart

Erscheinensverlauf: $1.1851-77.1933(1932 / 33)$

Folgetitel: Palaentographica / A

Erscheinensverlauf: 78.1933 -

Folgetitel: Paläontigraphica / B

Erscheinensverlauf: 78.1933 -

\section{Paläontologische Denkmäler in Hessen}

Paläontologische Denkmäler in Hessen / Herausgeben von der Abteilung Archäologie und Paläontol.ogische Denkmalspflege im Landesamt für Denkmalpflege und der Archäologischen Gesellschaft in Hessen e.V. - Wiesbaden

Erscheinensverlauf: 1.1994 -

\section{Petermanns geogr. Mitt.}

Mittheilungen aus Justus Perthes geographischer Anstalt über wichtige neue Erforschungen auf dem Gesammtgebiete der Geographie / Herausgegeben von A. Petermann. - (Perthes) Gotha u.a. Erscheinensverlauf: [1.]1855 - [14.]1868, $15.1869-24.1878$

Dr. A. Petermanns Mitteilungen aus Justus Perthes Geographischer Anstalt / Herausgegeben von Dr. A. Petermann. - (Perthes) Gotha u.a.

Erscheinensverlauf: $25.1879-83.1937$

Petermanns geographische Mitteilungen - PGM - Zeitschift für Geo- und Umweltwissenschaften /Begr. A. Petermann. - (Klett-Perthes) Gotha

Erscheinensverlauf: 84.1938 - 148.2004; damit Erscheinen eingestellt

\section{Philippia}

Philippia - Abhandlungen und Berichte aus dem Naturkundemuseum im Ottoneum zu Kassel; Kassel - Hrsg.: Magistrat der Stadt Kassel, Naturkundemuseum im Ottoneum.

Erscheinensverlauf: 1.1970/73 - Keine Jahresbände, Bände erscheinen unregelmäßig und umfassen Hefte aus mehreren Jahren. 
Rund um den Alheimer/...

Rund um den Alheimer - Beiträge zur Geschichte und Landeskunde des ehemaligen Kreises

Rotenburg; Hrsg.: Zweigverein Rotenburg d. Vereins f. Hessische Geschichte und Landeskunde;

Rotenburg

Erscheinensverlauf: 1.1979 -

\section{$>\mathrm{S}$}

Schriften Ges. Beförd. gesammt. Naturwiss. z. Marburg

Schriften der Gesellschaft zur Beförderung der gesammten Naturwissenschaften zu Marburg;

Marburg/L.

Schriftenrh. Dt. Geol. Ges.

Schriftenreihe der Deutschen Geologischen Gesellschaft; Hannover

\section{Schriftenreihe TLUG}

Schriftenreihe Thüringer Landesanstalt für Umwelt und Geologie; Jena

\section{Schriften Wirtschaftswiss. Ges. z. Studium Niedersachsens}

Schriften der Wirtschaftswissenschaftlichen Gesellschaft zum Studium Niedersachsens

Sitzber. Dt. Akad. Wiss. z. Berlin, Kl. Math. u. allgem. Naturwiss.

Sitzungsberichte der Deutschen Akademie der Wissenschaften zu Berlin,

Klasse Mathematik und allgemeine Naturwissenschaften; (Akademie-Verlag) Berlin

\section{Sitzber. Preuß. Geol. Landesanst}

Sitzungsberichte der Preußischen Geologischen Landesanstalt, Berlin

Erscheinensverlauf: 1.1926 - 7.1932[?]

\section{Studien Göttingischen Vereins bergmänn. Freunde}

Studien des Göttingischen [!] Vereins bergmännischer Freunde/im Namen desselben herausgegeben von. Joh. Friedr. Ludw. Hausmann; (Dieterich'sche Buchhandlung) Göttingen

Erscheinensverlauf: 1.1824 - 7.1856/58; damit Erscheinen eingestellt

\section{$>\mathbf{T}$}

\section{Tb. Mineral.}

Taschenbuch für die gesammte Mineralogie mit Hinsicht auf die neuesten Entdeckungen - für das Jahr.... Frankfurt/Main

Erscheinensverlauf $1.1807-18.1824$

Nebentitel: Leonhards Taschenbuch der Mineralogie

Fortsetzung: Z. Mineral. - Zeitschrift für Mineralogie - Taschenbuch für die ges. ...

\section{Mineral. petrogr. Mitt}

Tschermaks mineralogische und petrographische Mitteilungen - TMPM; (Hölder, später Springer) Wien

Erscheinensverlauf: N.Serie, 11.1889/90 - 37.1927, 38.1925; 3. Serie, 1.1948/50(1950) - 35.1986 
Vorgängertitel: Mineralogische und petrographische Mitteilungen. - (Hölder) Wien

Erscheinensverlauf: N.Serie $1.1878-10.1888 / 89,39.1928$

\section{Touristische Mitteilungen a. beiden Hessen}

Touristische Mittheilungen aus Hessen-Nassau und Waldeck einschließlich des Großherzoglichen Oberhessens und der angrenzenden Gebiete - Illustrierte Monatschrift für touristische Interessen und zur Hebung des Fremdenverkehrs - Organ des Niederhessischen Touristen- u.d. Werrathal-Vereins Herausgegeben vom Niederhessischen Touristenverein Erscheinensverlauf: 1.1892/93 (1893), Juli - 2.1893/94

Touristische Mittteilungen aus beiden Hessen, Nassau, Frankfurt a. M.; Waldeck und den Grenzgebieten - Illustrierte Monatsschrift; Kassel, später Melsungen

Erscheinensverlauf: 3.1894/95 - 24.1916(1917)

Fortsetzungstitel: Hessischer Gebirgsbote

\section{Die Umschau}

Die Umschau - Halbmonatsschrift über die Fortschritte im Wissenschaft und Technik - (UmschauVerlag) Frankfurt/M.

\section{Umweltbundesamt - Texte}

Umweltbundesamt - Texte; (Umweltbundesamt) Berlin

\section{Unser Eichsfeld}

Unser Eichsfeld - in Verbindung mit Eichsfelder Heimatglocken. - Illustrierte Monatsschrift für eichsfeldische Heimatkunde; (Cordier) Heiligenstadt; später (Aloys Mecke) Duderstadt Erscheinensverlauf: $1.1896-38.1943,1$

\section{$>\mathbf{V}$}

Verhdlgn. Naturhist. Vereins d. preuß. Rheinlande u. [Westfalens, anfangs: Westphalens] Verhandlungen des Naturhistorischen Vereins der preußischen Rheinlande und Westfalens; (Henry \& Cohen i. Comm) Bonn

\section{Veröff. Hist. Kommission für Hessen}

Veröffentlichungen der Historischen Kommission für Hessen

\section{Veröff./Naturhist. Museum Schleusingen}

Veröffentlichungen/Naturhistorisches Museum Schloss Bertholdsburg Schleusingen; Schleusingen Erscheinensverlauf: $1.1986-$

\section{Veröff. Naturkundemuseums Erfurt}

Veröffentlichungen des Naturkundemuseums Erfurt; Erfurt

Erscheinensverlauf: 1.1982

\section{Veröff. Niedersächsischen Inst. Landeskde. u. Landesentw. a.d. Univ. Göttigen}

Veröffentlichungen aus dem Niedersächsischen Institut für Landeskunde und Landesentwicklung an der Universität Göttingen; Göttingen 


\section{Das Werraland}

Das Werraland - Heimat, Kunst, Dichtung - Vierteljahreschrift des Werratalvereins e.V., Hauptleitung Eschwege; (Roßbach) Eschwege, später Bad Sooden-Allendorf

Bd. 1 (= Juli-H./September-H. $1949+$ Januar-H./April-H. 1950)

Bd. 2 (= Juli-H./Dezember-H. 1950)

Ab Bd. 3.1951 (Bandzählung und Kalenderjahr identisch; 4 Hefte pro Jahr, März, Juni, September, Dezember)

\section{Das Werratal}

Das Werratal - Illustrierte Monatsblätter für Heimat, Kunst, Dichtung - Nacharichtenblatt des Werratalvereins. - (Selbstverlag des Vereins) Eschwege

Erscheinensverlauf: 1.1924 - 15.1938 - damit Erscheinen eingestellt

\section{Die Weser}

Die Weser: Monatsschrift des Weserbundes e.V. - auch: Monatsschrift des Vereins zur Wahrung der Weserschiffahrtsinteressen e.V. - auch: Zeitschrift des Weserbundes e.V.; Bremen Erscheinensverlauf: 1.1922/23 - 22.1943(2); [23]1949 - [25]1951, 26.1952 - 69.1995(2); damit Erscheinen eingestellt

\section{Wiss. Z. E.-M.-Arndt-Univ. Greifswald, Math.-naturwiss. Rh.}

Wissenschaftliche Zeitschrift der Ernst-Moritz-Anrnd-Unviersität Greifswald, Mathematischnaturwissenschaftliche Reihe; Greifswald

Erscheinensverlauf: 1.1951/52 - 39.1990,1-3; damit Erscheinen eingestellt

Wiss. Z. Univ. Jena, Math.-naturwiss. Rh.

Wissenschaftliche Zeitschrift der Universität Jena, Mathematisch-naturwissenschaftliche Reihe/Friedrich-Schiller-Universität Jena; Jena

Erscheinensverlauf: 1.1951/52 - 32.1983

Folgetitel: Wiss. Z. /Naturwiss. Rh. /Friedrich-Schiller-Univ. Jena Erscheinensverlauf: 33.1984 - 39.1990; damit Erscheinen eingestellt

Wiss. Z. Humboldt-Univ. Berlin, Math.-nat. Rh.

Wissenschaftliche Zeitschrift der Humboldt-Universität zu Berlin, Mathematischnaturwissenschaftliche Reihe; (Humboldt-Univeristät) Berlin

Erscheinensverlauf: 1.1951/52-36.1987

Folgetitel: Wiss. Z. Humboldt-Univ. Berlin /Rh. Math., Naturwiss.

Erscheinensverlauf: 37.1988 - 39.1990

\section{$>\mathrm{Z}$}

Z. angew. Geol.

Zeitschrift für angewandte Geologie / hrsg. von der Bundesanstalt für Geowissenschaften und Rohstoffe und den Geologischen Landesämtern in der Bundesrepublik Deutschland. - Stuttgart : Schweizerbart 1.1955,Aug. - 37.1991,3; 38.1992 -

\section{Z. Berg-, Hütten- u. Salinenwesen}

Zeitschrift für das Berg-, Hütten- und Salinenwesen im preußischen Staate; später: <im Deutschen Reiche - Herausgegeben vom Reichswirtschaftsministerium>. - (Wilhelm Ernst \& Sohn) Berlin Erscheinensverlauf 1.1854 - 92.1944 (damit Erscheinen eingestellt) 


\section{Z. Berg-, Hütten- u. Salinenwesen/Atlas}

Zeitschrift für das Berg-, Hütten- und Salinenwesen im preussischen Staate, Atlasband; (Ernst) Berlin Erscheinensverlauf: 1.1861-52.1904; damit Erscheinen eingestellt

\section{Z. dt. geol. Ges. (A / B)}

Zeitschrift der Deutschen Geologischen Gesellschaft. - Berlin, später Hannover Erscheinensverlauf: 1.1848(1849) - 62.1910(1911) - 81.1929 - 155.2004/05 (2005)

Zeitschrift der Deutschen Geologischen Gesellschaft / A. - Berlin

Erscheinensverlauf: 63.1911(1912) - 80.1928/29(1929)

Zeitschrift der Deutschen Geologischen Gesellschaft / B. - Berlin

Erscheinensverlauf: 63.1911(1912) - 80.1928/29(1929)

\section{Z. Dt. Ges. Geol. Wiss.}

Zeitschrift der Deutschen Gesellschaft für geologische Wissenschaften; Stuttgart Erscheinensverlauf: 156.2006 -

Vorgängertitel: Z. Dt. geol. Ges. - Zeitschrift der Deutschen geologischen Gesellschaft

\section{Z. geol. Wiss.}

Zeitschrift für geologische Wissenschaften : ZGW / hrsg. von der Gesellschaft für Geowissenschaften e.V.. - (Akademie-Verlag) Berlin u.a.

Erscheinensverlauf: 1.1974 -

\section{Z. Geomorph., Suppl.-Bd.}

Zeitschrift für Geomorphologie, Supplementband; (Bornträger) Berlin-Stuttgart

Erscheinensverlauf: 1.1960 - 148.2006; erscheint in unregelmäßigen Abständen

\section{Z. gesammt. Naturwiss.}

Zeitschrift für die gesammten Naturwissenschaften; Halle (Saale), zeitweilig Berlin

Erschienen: 1.1853 - 54.1881

Fortsetzungstitel: Zeitschrift für Naturwissenschaften (Z. Naturwiss.); Halle (Saale), später Leipzig

Erschienen: 55.1882 - 95.1941

\section{Z. Krist. Mineral.}

Zeitschrift für Krystallographie und Mineralogie. - (Engelmann) Leipzig

Erscheinensverlauf: $1.1877-55.1915 / 20$

Nachfolgetitel: Z. Krist. - Zeitschrift für Kristallographie

\section{Z. Krist.}

Zeitschrift für Kristallographie - späterer Zusatz: International journal for structural, physical and chemical aspects of crystalline materials. - (Oldenbourg) München

Erscheinensverlauf: 56.1921/22 - 105.1943/1944; 106.1945/55

\section{Z. Mineral.}

Zeitschrift für Mineralogie - Taschenbuch; Frankfurt/Main

Erschienen: $19.1825-23.1829$

Nebentitel: Taschenbuch für die gesammte Mineralogie mit Hinsicht auf die neuesten Entdeckungen Vorgänger: Taschenbuch für die gesammte Mineralogie mit Hinsicht auf die neuesten Entdeckungen - (Tb. Mineral.)

Erschienen $1.1807-18.1824$

Fortsetzung: Jb. Mineral. etc. - Jahrbuch für Mineralogie, Geognosie, Geologie und Petrefaktenkunde

\section{Z. f. Naturwiss.}

Zeitschrift für Naturwissenschaften; Halle (Saale), später Leipzig

Erschienen: 55.1882 - 95.1941 
Vorgängertitel: Zeitschrift für die gesammten Naturwissenschaften (Z. gesammt. Naturwiss.), Halle (Saale), zeitweilig Berlin

Erscheinensverlauf: $1.1853-54.1881$

\section{Z. prakt. Geol.}

Zeitschrift für praktische Geologie mit besonderer Berücksichtigung der Lagerstättenkunde. - 1.1893 - 28.1920 (Julius Spinger) Berlin - ab. 28.1920 (Knapp) Halle/Saale

Erscheinensverlauf: 1.1893 - 22.1914, 23.1915(1916), 24.1916(1917), 25.1917 - 52.1944,9(Sept.) damit Erscheinen eingestellt

\section{Z. Vereins hess. Gesch. u. Landeskde}

Zeitschrift des Vereins für hessische Geschichte und Landeskunde - ZHG. - (Verein) Kassel Erscheinensverlauf: 1.1837 - 10.1865; N.F. $1=11.1867-52=62.1940 ; 63.1952$ -

\section{Zbl. Geologie}

Zentralblatt für Geologie und Paläontologie - 1; ab 1950

Zentralblatt für Geologie und Paläontologie - 2; ab 1950

Vorgängertiitel: Zbl. Mineral. etc.

(Schweizerbart) Stuttgart

\section{Zbl. Mineral.}

Zentralblatt für Mineralogie, Geologie und Paläontologie - (Schweizerbart) Stuttgart

Erscheinensverlauf: 1900.1900 - 1924.1924

\section{Zbl. Mineral., Abt. A}

Zentralblatt für Mineralogie, Geologie und Paläontologie - Abteilung A; (Schweizerbart) Stuttgart Erscheinensverlauf: 1925.1925 - 1942.1942

\section{Zbl. Mineral., Abt. B}

Zentralblatt für Mineralogie, Geologie und Paläontologie - Abteilung A; (Schweizerbart) Stuttgart Erscheinensverlauf: 1925.1925 - 1942.1942

Zentralblatt für Mineralogie, Geologie, Paläontologie, 1 (1943-1949)

Zentralblatt für Mineralogie, Geologie, Paläontologie, 2 (1943-1949)

Zentralblatt für Mineralogie, Geologie, Paläontologie, 3 (71.1943/33; 1948-1949)

Zentralblatt für Mineralogie, Geologie, Paläontologie, 4 (18.1944-18.1944)

Ab Jg. 1950 als Zentralblatt für Mineralogie 1 bzw. 2

(Schweizerbart) Stuttgart 


\section{Literatur nach Sachgebieten geordnet}

\section{Allgemeines}

\subsection{Bibliographien}

\subsubsection{Recherchemöglichkeiten}

- $\square$ ब्Czegka, Wolfgang \& Neininger, Klaus (1999): On- und Offline Recherchemöglichkeiten im Bereich Geowissenschaften. - Der Aufschluss, 50: 56-64, 5 Abb., 2 Tab.; Heidelberg

- $\square$-Czegka, Wolfgang \& Neininger, Klaus (1999): Einige Nachbemerkungen zu On- und Offline Recherchemöglichkeiten im Bereich Geowissenschaften. - Der Aufschluss, $\underline{\mathbf{5 0}}$ : 171-172, 2 Abb.;

Heidelberg

\subsubsection{Länderübergreifende Bibliographien}

- $\square$ • Hacker, Wilfried (2007): Geowissenschaften und Bergbaugeschichte in der Dreiländer-Region Hessen, Thüringen, Niedersachsen - Eine Bibliographie der Landschaft zwischen Diemel und Schleuse, Borkener Senke und Rhume. - Band 1: Verzeichnis nach Autorennamen. - Reihe: Universitätsdrucke Göttingen. - XX, 335 S.; (Universitätsverlag) Göttingen

- $\square$ Q $\bullet$ Hacker, Wilfried (2007): Geowissenschaften und Bergbaugeschichte in der Dreiländer-Region Hessen, Thüringen, Niedersachsen - Eine Bibliographie der Landschaft zwischen Diemel und Schleuse, Borkener Senke und Rhume. - Band 2: Verzeichnis nach Sachgebieten. - Reihe: Universitätsdrucke Göttingen. - XXI, 506 S.; (Universitätsverlag) Göttingen

- $\square$ •Keilhack, K. \& Zimmermann, E. (1897): Verzeichnis von auf Deutschland bezüglichen geologischen Schriften- und Kartenverzeichnissen. - Abh. Preuß. Geol. Landesanst., N.F., 266; IX, 108 S.; Berlin Referat in: N. Jb. Mineral. etc, $\underline{\mathbf{1 8 9 8}}$ (Bd. I): 463-464 (Th. Liebisch); Stuttgart

| $\square 0 \bullet$ Mader, Detlef (1992): Beiträge zur Paläoökologie und Paläoenvironments des Buntsandsteins sowie ausgewählte Bibliographie von Buntsandstein und Keuper in Thüringen, Franken und Umgebung. - 628 S., 17 Abb., 3 Tab., 34 Taf. m. 184 Fotos; (Gustav Fischer) Stuttgart-Jena-New York

- $\square$ - Mader, Detlef (1997): Paleoenvironmental evolution and bibliography of the Keuper (Upper Triassic) in Germany, Poland and other parts of Europe. - 1058 p., 19 fig., 25 tab., 34 pl. (337 photogr.); (Sven von Loga) Köln

- $\square$ ○|Kg1. Preuß. Geol. Landesanst. u. Bergakademie [Hrsg.] (1904-1906]: Verzeichnis der Veröffentlichungen der Königlich-Preußischen Geologischen Landesanstalt u. Bergakademie zu Berlin. - 1904-1906 [nachgewiesen]; Berlin 
- $\square$ Ql Preuß. Geol. Landesanst. [Hrsg.]: Verzeichnis der Veröffentlichungen der [Königlich] Preußischen Geologischen Landesanstalt zu Berlin. - [1908] - [1928], $\underline{\mathbf{3 1}} .1929$ - $\underline{\mathbf{3 8}} .1935$ [nachgewiesen]; Berlin

\subsubsection{Länderbezogene Bibliographien}

\subsubsection{Hessen}

\section{Hessische Bibliographie}

- $\square$ Hessische Bibliographie - Hrsg.: Stadt- und Universitätsbibliothek Frankfurt am Main i.

Zusammenarb. m. d. wiss. Bibliotheken des Landes. - (Saur) München

Erscheinungsverlauf: Bd. 1.1977 (erschienen 1979) - Bd. 24.2000 (erschienen 2002), ab. 7.1983 auch Nachträge ab 1965

Fortsetzung als Internet-Datenbank: „Hessische Bibliographie“ (Hebis), auch als CD-ROM-Ausgabe „Hessische Bibliographie“

Darin Nachweise zu den Sachgebieten Geowissenschaften, Wirtschaft/Bergbau

\section{$\underline{\text { Schrifttum zur Geschichte und geschichtlichen Landeskunde von Hessen. }}$}

- $\square$ Demandt, Karl E. (1965): Schrifttum zur Geschichte und geschichtlichen Landeskunde von Hessen,

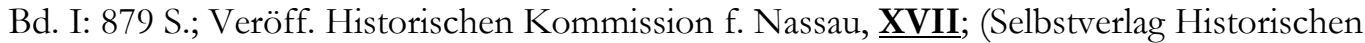
Kommission f. Nassau) Wiesbaden [darin S. 707-725: „Wirtschaft - C. Berg- und Hüttenwesen“, S. 725-737: „Bäder, Brunnen, Salinen“]

- $\square$ Leist, Winfried [Bearb.](1973): Schrifttum zur Geschichte und geschichtlichen Landeskunde von Hessen. - [Erster Band]: 1965-1967. - Veröff. Historischen Kommission für Hessen, 31,1; XX, 341 S.; (Elwert) Marburg [darin S. 97-101: „Wirtschaft: Bergbau und Hüttenwesen“]

- $\square$ Podehl, Wolfgang [Bearb.](1979): Schrifttum zur Geschichte und geschichtlichen Landeskunde von Hessen. - Zweiter Band: 1968-1970. - Veröff. Historischen Kommission für Hessen, 31,2; XXIV, 419 S.; (Elwert) Marburg [darin S. 128-132: „Wirtschaft: Bergbau und Hüttenwesen“]

- $\square$ Podehl, Wolfgang [Bearb.](1979): Schrifttum zur Geschichte und geschichtlichen Landeskunde von

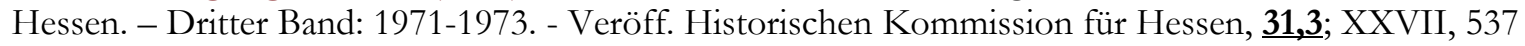
S.; (Elwert) Marburg [darin S. 153-158: „Wirtschaft: Bergbau und Hüttenwesen“]

- $\square$ Podehl, Wolfgang [Bearb.](1984): Schrifttum zur Geschichte und geschichtlichen Landeskunde von Hessen. - Vierter Band: 1974-1976. - Veröff. Historischen Kommission für Hessen, 31,4; XXIX, 746 S.; (Elwert) Marburg [darin S. 233-239: „,Wirtschaft: Bergbau und Hüttenwesen“] 


\section{... Landeskundliche Litteratur für Hessen}

- $\square$ Ackermann, Karl (1884-1895): Repertorium der landeskundlichen Litteratur für den Königlich preussischen Regierungsbezirk Kassel - Bibliotheca hassiaca. -

- (1884): Hauptband; 163 S.; (Kessler) Cassel

- (1886): Nachtrag I; 60 S.; (Kessler) Cassel

- (1889): Nachtrag II; 30 S.; (Kessler) Cassel

- (1891): Nachtrag III, 16 S.; (Kessler) Cassel

- (1892): Nachtrag IV; 14 S.; (Kessler) Cassel

- (1894): Nachtrag V; 21 S.; (Kessler) Cassel

- (1895): Nachtrag VI; 16 S.; (Kessler) Cassel

- (1895): [Autorenregister] Für den Haupttheil und die Nachtträge I - VI. - 18 S.; (Kessler) Cassel

- $\square$ Ackermann, Karl (1884): Bibliotheca Hassiaca - Repertorium der landeskundlichen Litteratur für den Königlich preussischen Regierungsbezirk Kassel. - Ber. Vereins Naturkde. z. Kassel, 31 (1882/1883), 17-175 (getr. Zählung v. Hpttl.); hier S. 17-39 [Geologisches incl. Bergbau: Hessen in seinem gesammten Gebietsumfang; Niederhessen mit Schaumburg, Schmalkalden u.a.]; Kassel

- $\square$ Ackermann, Karl (1889): Repertorium der landeskundlichen Litteratur für den Königlich preussischen Regierungsbezirk Kassel. Zweiter Nachtrag. - Ber. Vereins Naturkde. z. Kassel, 34/35: 1-30; Kassel

- $\square$ Ackermann, Karl (1891): Die landeskundliche Litteratur für Hessen - Dritter Nachtrag. - Ber. Vereins Naturkde. z. Kassel, 36/37: 81-96; Kassel

- $\square$ Ackermann, Karl (1892): Die landeskundliche Litteratur für Hessen - Vierter Nachtrag. - Ber.

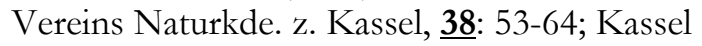

- $\square$ Ackermann, Karl (1894): Die landeskundliche Litteratur für Hessen - Fünfter Nachtrag. - Ber. Vereins Naturkde. z. Kassel, $\underline{\text { 39: }}$ 1-18; Kassel

- $\square$ Ackermann, Karl (1895): Die landeskundliche Litteratur für Hessen - Sechster Nachtrag. - Abh. u. Ber. Vereins Naturkde. z. Kassel, 40: 1-21 (sep. Zählg.); Kassel

- $\square$ Ackermann, Karl (1896): Die landeskundliche Litteratur für Hessen - Siebter Nachtrag. - Abh. u. Ber. Vereins Naturkde. z. Kassel, 41: 1-9 (sep. Zählg.); Kassel

- $\square$ Ackermann, Karl (1897): Bibliotheca Hassiaca - Repertorium der landeskundlichen Litteratur für den Königlich preussischen Regierungsbezirk Kassel, das ehemalige Kurfürstenthum Hessen. Achter Nachtrag. - Abh. u. Ber. Vereins Naturkde. z. Kassel, 42: 1-37; Kassel

- $\square$ Ackermann, Karl (1899): Bibliotheca Hassiaca - Repertorium der landeskundlichen Litteratur für den Königlich preussischen Regierungsbezirk Kassel, das ehemalige Kurfürstenthum Hessen - 9. [Neunter] Nachtrag (Schluß). - Abh. u. Ber. Vereins Naturkde. z. Kassel, 63: 1-37; Kassel

\section{Hessisches Geologisches Schrifttum}

- $\square$ Nöring, Friedrich (1950): Hessisches Geologisches Schrifttum 1938 - 1948. - Notizbl. Hess. L.-A. Bodenforsch., [78](6. F.) H. 1: 321 - 344; Wiesbaden

- $\square$ Nöring, Friedrich (1951): Hessisches Geologisches Schrifttum 1949 - 1950 - mit Nachträgen aus den Jahren 1938 - 1948. - Notizbl. Hess. L.-A. Bodenforsch., [79] (6. F.) H. 2: 243 - 255; Wiesbaden

- $\square$ Nöring, Friedrich (1952): Hessisches Geologisches Schrifttum 1951 - mit Nachträgen aus den Jahren 1938 - 1950. - Notizbl. Hess. L.-A. Bodenforsch., [80] (6. F.) H. $\underline{3}$ : 450 - 474; Wiesbaden 
- $\square$ Nöring, Friedrich (1953): Hessisches Geologisches Schrifttum 1952 - mit Nachträgen aus den Jahren 1938 - 1951. - Notizbl. Hess. L.-A. Bodenforsch., $\underline{81}$ (= 6. F., H. 4): 447 - 464; Wiesbaden

- $\square$ Nöring, Friedrich (1954): Hessisches Geologisches Schrifttum 1953 - mit Nachträgen aus den Jahren 1938 - 1952. - Notizbl. Hess. L.-A. Bodenforsch., $\underline{82}$ (= 6. F., H. 5): 401 - 410; Wiesbaden

- $\square$ Nöring, Friedrich (1955): Hessisches Geologisches Schrifttum 1954 - mit Nachträgen aus den Jahren 1938 - 1953. - Notizbl. Hess. L.-A. Bodenforsch., $\underline{\mathbf{8 3}}$ (= 6. F., H. 6): 397 - 417; Wiesbaden

- $\square$ Nöring, Friedrich (1956): Hessisches Geologisches Schrifttum 1955 - mit Nachträgen aus den Jahren 1938 - 1954. - Notizbl. Hess. L.-A. Bodenforsch., 84: 459-491; Wiesbaden

- $\square$ Nöring, Friedrich (1957): Hessisches Geologisches Schrifttum 1956 - mit Nachträgen aus den Jahren 1938 - 1955. - Notizbl. Hess. L.-A. Bodenforsch., 85: 528 - 553; Wiesbaden

- $\square$ Nöring, Friedrich (1958): Hessisches Geologisches Schrifttum 1957 - mit Nachträgen aus den Jahren 1938 - 1956. - Notizbl. Hess. L.-A. Bodenforsch., 86: 411 - 442; Wiesbaden

- $\square$ Nöring, Friedrich \& Matthess, Georg (1960): Hessisches Geologisches Schrifttum 1958 und 1959 mit Nachträgen aus den Jahren 1941 - 1957. - Notizbl. Hess. L.-A. Bodenforsch., 요: 395 - 428; Wiesbaden

- $\square$ Matthess, Georg (1961): Hessisches Geologisches Schrifttum 1960 - mit Nachträgen aus den Jahren 1938 - 1959. - Notizbl. Hess. L.-A. Bodenforsch., 89: 453 - 487; Wiesbaden

- $\square$ Kutscher, Fritz (1962): Register für die Notizblattbände der 6. Folge, (VI)1 - VI (3) und 81 - 89. Notizbl. Hess. L.-A. Bodenforsch., 90: 425 - 486, 1 Abb.; Wiesbaden

- $\square$ Matthess, Georg (1962): Hessisches Geologisches Schrifttum 1961 - mit Nachträgen aus den Jahren 1942 - 1960. - Notizbl. Hess. L.-A. Bodenforsch., 90: 525 - 547; Wiesbaden

- $\square$ Matthess, Georg (1963): Hessisches Geologisches Schrifttum 1962 - mit Nachträgen aus den Jahren 1942 - 1960. - Notizbl. Hess. L.-A. Bodenforsch., 91: 391 - 406; Wiesbaden

- $\square$ Matthess, Georg (1964): Hessisches Geologisches Schrifttum 1963 - mit Nachträgen aus den Jahren 1939 - 1962. - Notizbl. Hess. L.-A. Bodenforsch., 92: 306 - 325; Wiesbaden

- $\square$ Matthess, Georg (1965): Hessisches Geologisches Schrifttum 1964 - mit Nachträgen aus den Jahren 1948 - 1963. - Notizbl. Hess. L.-A. Bodenforsch., 93: 375 - 387; Wiesbaden

- $\square$ Matthess, Georg (1966): Hessisches Geologisches Schrifttum 1965 - mit Nachträgen aus den Jahren 1951 - 1964. - Notizbl. Hess. L.-A. Bodenforsch., 94: 420 - 441; Wiesbaden

- $\square$ Herzberg, Annelies \& Matthess, Georg (1967): Hessisches Geologisches Schrifttum 1966 - mit Nachträgen aus den Jahren 1940 - 1965. - Notizbl. Hess. L.-A. Bodenforsch., 95: 289 - 308; Wiesbaden

- $\square$ Herzberg, Annelies (1968): Hessisches Geologisches Schrifttum 1967 - mit Nachträgen aus den Jahren 1951 - 1966. - Notizbl. Hess. L.-A. Bodenforsch., 96: 385 - 408; Wiesbaden

- $\square$ Herzberg, Annelies (1969): Hessisches Geologisches Schrifttum 1968 - mit Nachträgen aus den Jahren 1957 - 1967. - Notizbl. Hess. L.-A. Bodenforsch.,97: 437 - 451; Wiesbaden

- $\square$ Herzberg, Annelies (1970): Hessisches Geologisches Schrifttum 1969 - mit Nachträgen aus den Jahren 1958 - 1968. - Notizbl. Hess. L.-A. Bodenforsch., 98: 320 - 334; Wiesbaden 
- $\square$ Herzberg, Annelies (1971): Hessisches Geologisches Schrifttum 1970 - mit Nachträgen aus den Jahren 1961 - 1969. - Notizbl. Hess. L.-A. Bodenforsch., 99: 416 - 431; Wiesbaden

- $\square$ Herzberg, Annelies (1972): Hessisches Geologisches Schrifttum 1971 - mit Nachträgen aus den Jahren 1958 - 1970. - Notizbl. Hess. L.-A. Bodenforsch., 100: 310 - 322; Wiesbaden

- $\square$ Herzberg, Annelies (1973): Hessisches Geologisches Schrifttum 1972 - mit Nachträgen aus den Jahren 1963 - 1971. - Notizbl. Hess. L.-A. Bodenforsch., 101: 403 - 414; Wiesbaden

- $\square$ Herzberg, Annelies (1974): Hessisches Geologisches Schrifttum 1973 - mit Nachträgen aus den Jahren 1963 - 1972. - Notizbl. Hess. L.-A. Bodenforsch., 102: 322 - 334; Wiesbaden

- $\square$ Herzberg, Annelies (1975): Hessisches Geologisches Schrifttum 1974 - mit Nachträgen aus den Jahren 1957 - 1973. - Notizbl. Hess. L.-A. Bodenforsch., 103: 367 - 381; Wiesbaden

- $\square$ Herzberg, Annelies (1976): Hessisches Geologisches Schrifttum 1975 - mit Nachträgen aus den Jahren 1967 - 1974. - Geol. Jb. Hessen, 104: 287 - 302; Wiesbaden

- $\square$ Herzberg, Annelies (1977): Hessisches Geologisches Schrifttum 1976 - mit Nachträgen aus den Jahren 1969 - 1975. - Geol. Jb. Hessen, 105: 263 - 273; Wiesbaden

- $\square$ Herzberg, Annelies (1979): Hessisches Geologisches Schrifttum 1977 - mit Nachträgen aus den Jahren 1967 - 1976. - Geol. Jb. Hessen, 107: 293 - 308; Wiesbaden

- $\square$ Herzberg, Annelies (1980): Hessisches Geologisches Schrifttum 1978 - mit Nachträgen aus den Jahren 1967 - 1977. - Geol. Jb. Hessen, 108: 287 - 302; Wiesbaden

- $\square$ Herzberg, Annelies (1981): Hessisches Geologisches Schrifttum 1979 - mit Nachträgen aus den Jahren 1973 - 1978. - Geol. Jb. Hessen, 109: 205 - 214; Wiesbaden

- $\square$ Herzberg, Annelies (1982): Hessisches Geologisches Schrifttum 1980 - mit Nachträgen aus den Jahren 1966- 1979. - Geol. Jb. Hessen, 110: 267 - 280; Wiesbaden

- $\square$ Herzberg, Annelies (1983): Hessisches Geologisches Schrifttum 1981 - mit Nachträgen aus den Jahren 1973- 1980. - Geol. Jb. Hessen, 111: 333 - 344; Wiesbaden

- $\square$ Herzberg, Annelies (1984): Hessisches Geologisches Schrifttum 1982 - mit Nachträgen aus den Jahren 1973 - 1981. - Geol. Jb. Hessen, 112: 313 - 324; Wiesbaden

- $\square$ Herzberg, Annelies (1985): Hessisches Geologisches Schrifttum 1983 - mit Nachträgen aus den Jahren 1976 - 1982. - Geol. Jb. Hessen, 113: 305 - 317; Wiesbaden

- $\square$ Herzberg, Annelies (1986): Hessisches Geologisches Schrifttum 1984 - mit Nachträgen aus den Jahren 1974 - 1983. - Geol. Jb. Hessen, 114: 319 - 328; Wiesbaden

- $\square$ Herzberg, Annelies (1987): Hessisches Geologisches Schrifttum 1985 - mit Nachträgen aus den Jahren 1973 - 1984. - Geol. Jb. Hessen, 115: 449 - 461; Wiesbaden

- $\square$ Poschwitz, Hartmut \& Herzberg, Annelies (1988): Hessisches Geologisches Schrifttum 1986 - mit Nachträgen aus den Jahren 1975 - 1985. - Geol. Jb. Hessen, 116: 307 - 315; Wiesbaden

- $\square$ Poschwitz, Hartmut (1989): Hessisches Geologisches Schrifttum 1987 - mit Nachträgen aus den Jahren 1973 - 1986. - Geol. Jb. Hessen, 117: 255 - 271; Wiesbaden

- $\square$ Poschwitz, Hartmut (1990): Hessisches Geologisches Schrifttum 1988 - mit Nachträgen aus den Jahren 1952/53 - 1987. - Geol. Jb. Hessen, 118: 265 - 281; Wiesbaden 
- $\square$ Poschwitz, Hartmut (1991): Hessisches Geologisches Schrifttum 1989 - mit Nachträgen aus den Jahren 1979 - 1988. - Geol. Jb. Hessen, 119: 277 - 296; Wiesbaden

\section{Selbständige Veröffentlichungen}

$\square$ Anonym (1973): Arbeiten von Prof. Dr. Hanno Beck über Eschwege. - Das Werraland, 25(3): 51-53; Eschwege

[darunter Arbeiten z. Regionalen Geologie, u.a. z. „Blauen Kuppe“ bei Eschwege]

-Kanke, Gerd [Bearb.](1996): Frielendorf und seine Ortsteile - Literatur und Dokumente zur Ortsgeschichte in Bibliotheken und Archiven - Eine Übersicht. - Reihe: Arbeitsber./Hess. Akad. Forsch. u. Planung im ländl. Raum, $\underline{\mathbf{3}}$; 429 S.; Bad Karlshafen [darin S. 25-30: „Geographie (Naturräumliche Grundlagen), Atlanten und Karten“]

- $\square$ OKeferstein, Christian (1840): Geschichte und Litteratur der Geognosie - Ein Versuch. - XIV, 281 S.; (bei Johann Friedrich Lippert) Halle darin S. 233 ff. Viertes Kapitel: Uebersicht der seit Anfang des jetztigen Jahrhunderts erschienenen geognostischen Orographien. - <Bibliographie Regionalliteratur> Thüringer Wald, „Hessen und die benachbarten Gebiete“- HE, WMK, THÜ]

-Münster, G. Graf von (1835): Bemerkungen über einige tertiäre Meerwasser-Gebilde im nordwestlichen Deutschland zwischen Osnabrück und Cassel. - N. Jb. Mineral. etc., 1835: 420-451; Stuttgart [Stratigraphie, Paläonotologie, auch Bibliographie u. Erforschungsgeschichte]

-Naumann, Peter (1998): Altkreis Hofgeismar - Bibliografia geologica Hassiae,1; 39 S.; (Selbstverlag) Hofgeismar [Bibliographie Geowissenschaften, Bergbau - Altkreis Hofgeismar]

$\square$ Oppitz, Ulrich Dieter (1965): Aufstellung - Von Eschwege - Stadt und Kreis - betreffender Literatur mit Angabe von Standorten. - [Teil 1]. - Stand: 15.1.1965; 102 gez. Bl.; (Stadtverwaltung Eschwege) Eschwege

$\square$ Oppitz, Ulrich Dieter (1969): Aufstellung - Von Eschwege - Stadt und Kreis - betreffender Literatur mit Angabe von Standorten. - [Teil 2: Nachtrag]. - Stand: September 1969; 42 ungez. Bl.; (Stadtverwaltung Eschwege) Eschwege

$\square$ Oppitz, Ulrich-Dieter (1979): Bibliographie des Werra-Meißner-Kreises. - Forschungsunternehmen d. Humboldt-Gesellschaft, $\underline{\mathbf{1 8}}$; XIV, 353 S.; (Selbstverlag) Ulm

$\square$ Oppitz, Ulrich- Dieter (1991): Bibliographie des Werra-Meissner-Kreises. - 2. Auflage, 532 S.; [Hrsg. Historische Gesellschaft d. Werralandes]; (Heinemann) Eschwege [umfassendes Verzeichnis, auch zu den Themen Geowissenschaften, Bergbau, Salinenwesen]

\subsubsection{Thüringen}

\section{Thüringen-Bibliographie}

QThüringen-Bibliographie - Hrsg.: Nationale Forschungs- und Gedenkstätten der klassischen deutschen Literatur; Universitätsbibliothek Jena; Thüringer Landes- und Universitätsbibliothek Jena Reihe: Bibliographien, Kataloge und Bestandsverzeichnisse/ Nationale Forschungs- und 
Gedenkstätten der klassischen deutschen Literatur

Nachgewiesen: Bd. 1961-1963 (erschienen 1972) - Bd. 1998 (erschienen 2000)

Fortsetzung als Internet-Datenbank: Thüringenbibliographie

Darin Nachweise zu den Sachgebieten Geowissenschaften, Wirtschaft/Bergbau

\section{Bibliographie der geologischen Wissenschaften für Thüringen/Deutsche Demokratische Republik}

@Claus, Hans \& Wiefel, Heinz [Bearb.](1974): Bibliographie der geologischen Wissenschaften für Thüringen, Deutsche Demokratische Republik - Veröffentlichungen der Jahre 1945-1966. - Abh. Zentralen Geol. Instituts, 27; 553 S.; [Hrsg. Zentrales Geol. Inst.] Berlin

@Claus, Hans \& Wiefel, Heinz [Bearb.](1976): Bibliographie der geologischen Wissenschaften für Thüringen, Deutsche Demokratische Republik - Veröffentlichungen der Jahre 1923-1944. - Abh. Zentralen Geol. Instituts, 34; 606 S.; [Hrsg. Zentrales Geol. Inst.] Berlin

oClaus, Hans \& Wiefel, Heinz [Bearb.](1981): Bibliographie der geologischen Wissenschaften für Thüringen, Deutsche Demokratische Republik - Veröffentlichungen der Jahre 1872 - 1922. - Abh. Zentralen Geol. Instituts, 42; 574 S.; [Hrsg. Zentrales Geol. Inst.] Berlin

Geowissenschaftliche Mitteilungen aus Thüringen/Schriftenreihe Thür. Landesanst. Umwelt u. $\underline{\text { Geologie }}$

OBlumenstengel, B. \& Seidel, G. (1993): Bibliographien zur Geologie von Thüringen und Thüringisches Geologisches Schrifttum 1990 und 1991. - Geowiss. Mitt. Thüringen, 1: 131-190; Weimar [Fortf. i.d. nachfolg. Bd. der Serie unter: ,Thüringisches Geologisches Schrifttum...“ und „Nachträge...." ]

OBlumenstengel, Barbara \& Hecht, Günter (1994): Thüringisches Geologisches Schrifttum 1992 und Nachträge 1990 und 1991. - Geowiss. Mitt. Thüringen, 2: 235 - 296; Weimar

@Blumenstengel, Barbara \& Hecht, Günter (1995): Thüringisches Geologisches Schrifttum 1993 und Nachträge [1990 - 1992]. - Geowiss. Mitt. Thüringen, 3: 183 - 290; Weimar

QBlumenstengel, Barbara \& Hecht, Günter (1996): Thüringisches Geologisches Schrifttum 1994 und Nachträge [1990 - 1993]. - Geowiss. Mitt. Thüringen, 4: 383 - 423; Weimar

QBlumenstengel, Barbara \& Hecht, Günter (1997): Thüringisches Geologisches Schrifttum 1995 und Nachträge [1990 - 1994]. - Geowiss. Mitt. Thüringen, ㅁ: 279 - 388; Weimar

OBlumenstengel, Barbara \& Hecht, Günter (1998): Thüringisches Geologisches Schrifttum 1996 und Nachträge [1990 - 1995]. - Geowiss. Mitt. Thüringen, ㅁ: 181 - 312; Weimar

QBlumenstengel, Barbara \& Hecht, Günter (1999): Thüringisches Geologisches Schrifttum 1997 und Nachträge [1990 - 1995]. - Geowiss. Mitt. Thüringen, 7: 143 - 296; Weimar

OBlumenstengel, Barbara \& Hecht, Günter (2000): Thüringisches Geologisches Schrifttum 1998 und Nachträge [1990 - 1997]. - Geowiss. Mitt. Thüringen, $\underline{8}$ : 95 - 167; Weimar 
OBlumenstengel, Barbara \& Hecht, Günter (2001): Thüringisches Geologisches Schrifttum 1999 und Nachträge [1990 - 1998]. - Geowiss. Mitt. Thüringen, 9: 133 - 201; Weimar

OBlumenstengel, Barbara \& Hecht, Günter (2002): Thüringisches Geologisches Schrifttum 2000 und Nachträge [1990 - 1999]. - Geowiss. Mitt. Thüringen, 10: 57 - 136; Weimar

O Blumenstengel, Barbara \& Hecht, Günter [Bearb.](2004): Thüringisches geologisches Schrifttum: 2001. - Schriftenrh. Thür. Landesanst. Umwelt u. Geologie, 66 ; 124 S.; Jena 2004

OBlumenstengel, Barbara \& Hecht, Günter [Bearb.](2005): Thüringisches geologisches Schrifttum: 2002/2003 und Nachträge 1990-2002. - Schriftenrh. Thür. Landesanst. Umwelt u. Geologie, $\underline{73} ; 175$ S.; Jena

\section{Selbständige Veröffentlichungen}

OFreyberg, Bruno von (1932): Die geologische Erforschung Thüringens in älterer Zeit - ein Beitrag zur Geschichte der Geologie bis zum Jahre 1843 - sowie einer Zusammenstellung der geologischen Literatur über Thüringen bis 1843. - VI, 160 S., 11 Abb., 8 Bildn..; (Bornträger) Berlin Referat in: N. Jb. Mineral. etc., Referate; 1932 (Bd. II): 611-612 (Erich Kaiser), 1932 (Bd. III): 963-964 (J. Weigelt); Stuttgart

- $\square$ OKeferstein, Christian (1840): Geschichte und Litteratur der Geognosie - Ein Versuch. - XIV, 281 S.; (bei Johann Friedrich Lippert) Halle darin S. 233 ff. Viertes Kapitel: Uebersicht der seit Anfang des jetztigen Jahrhunderts erschienenen geognostischen Orographien. - <Bibliographie Regionalliteratur $>$ Thüringer Wald, „Hessen und die benachbarten Gebiete“ - HE, WMK, THÜ]

OKünzel, Günter \& Schmidt, Peter (1981): Verzeichnis der von Prof. Dr. habil ARNO HERMANN MÜLLER bisher vorgelegten wissenschaftlichen Veröffentlichungen. - (Beiträge zur Paläontologie, Stratigraphie und Palökologie - Zum 65. Geburtstag von Prof. Dr. rer. nat. habil Arno Hermann Müller) Freiberger Forschungshefte, Reihe C, 363: 17-25; Leipzig

Q๑Löffler, Klemens (1915): Die heimatkundliche und geschichtliche Literatur des Eichsfeldes bis 1915. Unser Eichsfeld, 10(3/4): 81-143; (Mecke) Duderstadt

Q๑Löffler, Kl. (1915); Oberthür, Chr. (1934)[1978]: Bibliographie des Eichsfeldes, Teil I und II - Die heimatkundliche und geschichtliche Literatur des Eichsfeldes bis 1933. - Unveränderter Nachdruck der Verzeichnisse von Kl. Löffler (1915) und Chr. Oberthür (1934/1935). - (Mecke) Duderstadt Reihe: Eichsfelder Heimatstimmen, Sonderheft 2; Duderstadt 1978

D•Oberthür, Chr[istoph](1934): Die heimatkundliche und geschichtliche Literatur des Eichsfeldes bis 1915. - Unser Eichsfeld, 29; Beilage mit sep. Zählung, S. 1-73; auch als Separatdruck; (Mecke) Duderstadt Referat (Anonym) in: Unser Eichsfeld, 30: 119; (Mecke) Duderstadt 1935

ORegel, Fritz(1913): Literatur zur Vergletscherung des Thüringer Waldes. - Mitt. Geogr. Ges. (f. Thüringen), 31: 149-158; Jena [Referat]

@Rüger, L. (1940): Geologische Literatur über Thüringen seit 1936. - Beitr. Geol. Thüringen, ㅁ: 97-102; Jena 
QSeidel, Gerd [Hrsg.] (1995): Geologie von Thüringen. - 1. Aufl.; XI, 556 S., 137 Abb., 36 Tab., 1 FaltKt.-Beil.; (Schweizerbart) Stuttgart

[darin: S. 513-542: „Literaturverzeichnis (Literatur ab 1967)“]

OSeidel, Gerd [Hrsg.](2003): Geologie von Thüringen. - 2. neubearb. Aufl. ; X, 601 S., 138 Abb., 34

Tab., 5 Taf.; (Schweizerbart) Stuttgart

[darin S. 549-583, 1 Abb.[Blattübersicht GK 25]: „Literatur und geologische Karten (ab 1988)“]

OWiefel, Heinz (1997): Biobibliographische Daten über Geowissenschaftler und Sammler, die in Thüringen tätig waren. - Geowiss. Mitt. Thüringen, Beih. 뜨, 288 S.; Weimar

Q๑Wiegand, Günter (1980): Bibliographie des Eichsfeldes. - Teil 3: Heimatkundliche und geschichtliche Literatur 1933-1978. - XXXVIII, 444 S.; (Christian Albrechts-Universität) Kiel [darin Kapitel Geologie, S. 32-44; Vermischtes: Bergbau... S. 165-155]

\subsubsection{Niedersachsen}

-Wilhelm, Otto (1964): Bibliographie von Niedersachsen - [1]: 1957-1961 - Landeskunde und Landesentwicklung, Wirtschaft-Kultur-Staat. - Veröff. Niedersächsischen Inst. f. Landeskde. u. Landesentwicklung a. d. Univ. Göttingen; zgl. Schriften d. Wirtschaftswiss. Ges.. z. Studiums Niedersachsens e.V. - Reihe A: Forschungen zur Landes- und Volkskunde, I: Natur, Wirtschaft, Siedlung und Planung; Bd. 76; IX, 348 S.; (Lax i. Komm.) Hildesheim

darin: Sachgebiete (Natur des Landes):

1. Geologie, Paläontologie, Tektonik, Geophysik

2. Lagerstätten

3. Böden

4. Morphologie

-Wilhelm, Otto (1968): Bibliographie von Niedersachsen und Bremen - II: 1962-1965 - Landeskunde und Landesentwicklung, Wirtschaft-Kultur-Staat. - Veröff. Niedersächsischen Inst. f. Landeskde. u. Landesentwicklung a. d. Univ. Göttingen; zgl. Schriften d. Wirtschaftswiss. Ges. z. Studiums Niedersachsens e.V. - Reihe A: Forschungen zur Landes- und Volkskunde, I: Natur, Wirtschaft, Siedlung und Planung; Bd. 90; IXX, 471 S.; (Lax i. Komm) Hildesheim

darin: Sachgebiete (Natur des Landes):

1. Geologie, Paläontologie, Tektonik, Geophysik

2. Lagerstätten

3. Böden

4. Morphologie

-Wilhelm, Otto (1974): Bibliographie von Niedersachsen und Bremen. - Teil III: 1966-1970 Landeskunde und Landesentwicklung, Wirtschaft-Kultur-Staat. - Veröff. Niedersächsischen Inst. f. Landeskde. u. Landesentwicklung a. d. Univ. Göttingen; zgl. Schriften d. Wirtschaftswiss. Ges. z. Studiums Niedersachsens e.V. - Reihe A: Forschungen zur Landes- und Volkskunde, I: Natur, Wirtschaft, Siedlung und Planung; in zwei Teilbänden: Bd. 103.1/103.2; Bd. 103.1: Titel Nr. 1 - 9622; 523 S.; Bd. 103.2: Titel Nr. 9623-16996, Register; 1083 S.; (Göttinger Tageblatt i. Komm) Göttingen

-Oberschelp, Reinhard (1985): Niedersachsen-Bibliographie - Berichtsjahre 1908-1970 Systematisches Gesamtverzeichnis. - Bd. 1 Allgemeine Literatur. - LXIV, 451 S.; (Gaertner) MainzKastel [regional relevante Sachgebiete mit Schlüsselzahl: 0500 Geologie - 562 Pleistozän 
0600 Geophysik, allgemein - 680 Gravitmetrie

0780 Böden

0900 Morphologie, allgemein

0910 Bergland, allgemein

5900 Bergbau, allgemein; Lagerstätten, allgemein - 5920 Salze, Kali]

- Niedersächsische Bibliographie - Regionalbibliographie für die Bundesländer Niedersachsen und Bremen. - Hrsg.: Niedersächsische Landesbibliothek Hannover - (Lax i. Komm.) Hildesheim u. (Niemeyer) Hameln

Erscheinungsverlauf: Bd. 1/Berichtsjahr 1971 (erschienen 1974) - Bd. 19/ Berichtsjahr 1999 (erschienen 2004)

Fortsetzung als Internet-Datenbank: „Niedersächsische Bibliographie“

Darin Nachweise zu den Sachgebieten Geowissenschaften, Wirtschaft/Bergbau

\section{Selbständige Veröffentlichungen}

Q๑Löffler, Klemens (1915): Die heimatkundliche und geschichtliche Literatur des Eichsfeldes bis 1915. Unser Eichsfeld, 10 (3/4): 81-143; (Mecke) Duderstadt

Q•Löffler, Kl. (1915); Oberthür, Chr. (1934)(1978): Bibliographie des Eichsfeldes, Teil I und II - Die heimatkundliche und geschichtliche Literatur des Eichsfeldes bis 1933. - Unveränderter Nachdruck der Verzeichnisse von Kl. Löffler (1915) und Chr. Oberthür (1934/1935). - (Mecke) Duderstadt Reihe: Eichsfelder Heimatstimmen, Sonderheft 2; Duderstadt 1978

D•Oberthür, Chr[istoph](1934): Die heimatkundliche und geschichtliche Literatur des Eichsfeldes bis 1915. - Unser Eichsfeld, 29; Beilage mit sep. Zählung, S. 1-73; auch als Separatdruck; (Mecke) Duderstadt Referat (Anonym) in: Unser Eichsfeld: 웅 119; (Mecke) Duderstadt 1935

-Schneiderhöhn, Paula (1960): Bibliographie zur Mineralogie der Umgebung von Göttingen. Göttinger Jb., 1960: 121 - 130; Göttingen

Q•Wiegand, Günter (1980): Bibliographie des Eichsfeldes. - Teil 3: Heimatkundliche und geschichtliche Literatur 1933-1978. - XXXVIII, 444 S.; (Christian Albrechts-Universität) Kiel [darin Kapitel Geologie, S. 32-44; Vermischtes: Bergbau... S. 165-155]

\subsection{Zeitschriften}

-0•Herrmann, Albert Günter (2007): 100 Jahre „Kali und Steinsalz“ - 1907-2007. Ein Rückblick. Kali u. Steinsalz, 2007(2): 6-17, 5 Bilder; Essen

[Geschichte der Zeitschrift „Kali, etc.“, (Verlag Wilhelm Knapp) Halle; (Glückauf-Verlag) Essen]

- $\square$ O Nägele, E. (1907): Das „Neue Jahrbuch“von 1807-1907. - N. Jb. Mineral. etc., Festband zur Feier des 100jährigen Bestehens; 546 S., 2 Portr., 73 Abb. i. T., 19 Taf.; hier: S. VII-XVIII; Stuttgart 


\subsection{Personenehrungen - Nachrufe}

$>\mathbf{A}$

$\square$ Seib, Gerhard (2008): Obersteiger Johann Christian Aschermann - eine echte „Berg-Wurzel“ vom Meißner. - Das Werraland, 으(1): 16-18, 2 Abb.; Bad Sooden-Allendorf

$>\mathbf{B}$

$\square$ Perst, Otto (1966): Dr. Hanno Beck - ein heimatverbundener Eschweger. - Werra-Rundschau, 1966; Nr. 36 v. 12.2.1966, S. 5; Eschwege

$\square$ Balmer, Heinz (1973): Prof. Dr. Hanno Beck zum 13. September [50. Geburtstag]. - Das Werraland, 25(3): 44-46, 1 Portr.; Eschwege

$\square$ Balmer, Heinz (1973): Ein Besuch bei Hanno Beck. - Das Werraland, 255(3): 46; Eschwege

$\square$ Beck, Hanno (1973): Eine Lebensskizze [Autobiographisches Hanno Beck]. - Das Werraland, 25(3): 45; Eschwege

$\square$ Mench, Karl (1983): Professor Dr. Hanno Beck wurde 60. - Das Werraland, 35(3): 63-64; Eschwege

$\square$ Mench, Karl (2003): Auf dem Wege zur Geschichte der Geographie - Professor Dr. Hanno Beck zum 80. Geburtstag. - Das Werraland, 吕(3): 60-61; Eschwege

$\square$ Haberland, Detlef [Hrsg.](1993): Geographica spiritualis - Festschrift für Hanno Beck [zum 70. Geburtstag]. - 351 S., Abb.; (Peter Lang) Frankfurt/M.

[darin S. 161-162: Karl Mench: „Hanno Beck - auch der Historiker seiner Heimatstadt Eschwege“; S. 235-237: Peter Schoenwaldt: „Professor Dr. Hanno Beck - Mentor und Freund“; S. 239-240: Eva Michels-Schwarz \& Uwe Schwarz: „Mehr als ein Grußwort - Hanno Beck zum 70. Geburtstag“; S. 327-330: Krzysztof Zielnica: „Mit Professor Hanno Beck“; S. 331-350: Detlef Haberland: „Schriftenverzeichnis von Hanno Beck“ (ohne heimatkundliche Artikel)]

-Hauchecorne, W. (1900): Ernst Beyrich - seine Beziehung zur geologischen Kartierung in Preussen, zur Geologischen Landesanstalt und Bergakademie und zur Deutschen Geologischen Gesellschaft. [Nachruf] - Z. prakt. Geologie, $\underline{8}:$ 97-110; Berlin

- Koken, Ernst von (1901): Die Deutsche geologische Gesellschaft in den Jahren 1848-1898. - Mit einem Lebensabriss von Ernst Beyrich. - Mit 1 Bildnis. - 69 S., Ill.; (Stade) Berlin

- $\square$ OCarlé, Walter (1988): Werner - Beyrich - von Koenen - Stille. - Ein geistiger Stammbaum wegweisender Geologen. - Geol. Jb., Reihe A, 108: 3 - 499, 62 Abb.; Hannover [darin S. 63-90, Abb. 13-14: - 5. August Heinrich Ernst Beyrich]

D $\square$ OFliegel, Gotthard (1935): Franz Beyschlag [Nachruf]. - Forsch. u. Fortschr., 11(25): 327-328; Berlin

- $\square$ OStille, Hans (1937): Franz Beyschlag (gest. 23. Juli 1935). - Z. dt. geol. Ges., ㅇ: 573-576; Berlin [Nachruf]

- $\square$ OBerg, G. (1935): Franz Beyschlag †. - Kali, etc., 29 (17): 173-175; Halle (Saale) 
- $\square$ OBerg, G. (1935): Franz Beyschlag † - Z. prakt. Geol., 43.1935 (8): 113-114, 1 Abb.; Berlin

- $\square$ QApel, Kurt (1960): Prof. Dr. Franz Beyschlag zum Gedächtnis. - Mein Heimatland, 19 (6): 27, 1 Portr.; Bad Hersfeld

-Udluft, Hans (1953): Nachruf auf Max Blanckenhorn. - Notizbl. Hess. L.-A. Bodenforsch., $\underline{\mathbf{8 3}}$ (6. F., H. 4): 399, 1 Portr.; Wiesbaden

oBarthel, Manfred (1966): Johann Georg Bornemann - Begründer der Kutikularanalyse. - Hallesches Jb. mitteldt. Erdgeschichte, $\underline{7}$ (f. 1965): 7-10, Taf. I, III-V; Leipzig

@Hauschke, Norbert (1999): Johann Georg Bornemann (1831-1896) - Sein Beitrag zur TriasForschung. - In: Hauschke, N. \& Wilde, V. [Hrsg.]: Trias - Eine ganz andere Welt. Mitteleuropa im frühen Erdmittelalter. - S. 597-601, 4 Abb.; (Verlag Dr. Friedrich Pfeil) München 1999

QHauschke, Norbert \& Röhling, Heinz-Gerd (2006): Johann Georg Bornemann (1831-1996) - Geologe, Paläontologe und Industrieller aus Mühlhausen/Thüringen. - Mühlhäuser Beiträge, 29: 61-72, 9 Abb.; Mühlhausen

- ooWagenbreth, Otfried (1979): Leopold von Buch (1774-1853) und die Entwicklung der Geologie im 19. Jahrhundert. - Abh. d. Staatl. Museums f. Mineralogie u. Geologie z. Dresden, (Geologen der Goethezeit) 29: 41-57, 9 Bilder, 2 Tab.; Leipzig

口oWagner, W. (1933): Hugo Bücking - ein Nachruf. - Jber. Mitt. Oberrhein. Geol. Vereins., N.F., 22: XVI - XXI; darin enthalten Schriftenverz.: XVIII - XXI; Stuttgart

- Horn, Manfred \& Karschny, Alfred (1985): Erwin Busse gest. [Nachruf]. - Geol. Jb. Hessen, 113: 320 326, 1 Portr.; Wiesbaden

\section{$>\mathrm{C}$}

- $\square$ Gümbel, [Carl Wilhelm v.] (1876/1967): Cancrin - Franz Ludwig v. C[ancrin] (Cancrinus). Allgemeine Deutsche Biographie, $\underline{\mathbf{3}}$ (Bode - v. Carlowitz): 741-742; (Duncker \& Humblot) Berlin 1967 - Unveränd. Nachdruck der Erstausgabe von 1876, erschienen bei Duncker \& Humblot in Leipzig [Hrsg. Kgl. Akademie der Wissenschaften, München/Historische Kommission]

- $\square$ Namenskürzel (rff)(1984): Bergwerke in Hessen und Waldeck - Pionier Cancrinus „hob“ Silber und Kupfer aus Frankenberg. - HA, 1984; Nr. 8 v. 10.1.1984, 1 Abb.; Kassel

[Biographisches über Franz Ludwig Cancrinus]

OWagenbreth, Otfried (1959): Bernhard von Cotta und Heinrich Credner - zum 150. Geburtstag zweier Thüringer Geologen. - Ber. geol. Ges. DDR, 4(4): 355-362, 6 Abb.; Berlin

OWagenbreth, O. (1965): BERNHARD VON COTTA, sein geologisches und philosophisches Lebenswerk an Hand ausgewählter Zitate. - Ber. geol. Ges. DDR, Sh. 모 7-178, o. Abb.; Berlin

OWagenbreth, Otfried (1985): Bernhard von Cotta (1808-1879) und die Verbreitung geologischpaläontologischer Kenntnisse. - In: Prescher, Hans [Hrsg.]: Leben und Wirken deutscher Geologen im 18. und 19. Jahrhundert. - 1. Aufl.; 388 S., 108 Abb.; hier: S. 210-273, 8 Abb.; (Dt. Verlag f. Grundstoffindustrie) Leipzig 1985 [darin: Bohrversuch auf Steinkohle im Rotliegenden des Thüringer Waldes]

ㅁ Anonym (1876): Heinrich Credner [Nachruf]. - N. Jb. Mineral. etc., 1876: 895-896; Stuttgart 
OWagenbreth, Otfried (1959): Bernhard von Cotta und Heinrich Credner - zum 150. Geburtstag zweier Thüringer Geologen. - Ber. geol. Ges. DDR, 4(4): 355-362, 6 Abb.; Berlin

\section{$>$ D}

OHetzer, Hans (1963): Professor Dr. phil. FRITZ DEUBEL 65 Jahre. - Ber. Geol. Ges. DDR, $\underline{\mathbf{8}}(5 / 6)$ : 653-656, 1 Abb.; Berlin

OFalk, Fritz (1967): In memoriam FRITZ DEUBEL. - Ber. Dt. Ges. geol. Wiss., Reihe A, 12(6): 737739, 1 Portr.; Berlin

- $\square$ Koenen, A. v. (1885): Rudolf Wilhelm Dunker [Nachruf]. - N. Jb. Mineral. etc., 1885 (Bd. 2): 8 S., sep. Zählg.; Stuttgart

[Wilhelm Dunker, 1809-1885; geb. in Eschwege; Lehrer a. d. Gewerbeschule Kassel, Professor für Paläontologie a. d. Universität Marburg; Arbeiten m. Bezug auf Nordhessen]

$\square$ Beck, Hanno (1953): Wilhelm Dunker - der große Geologe aus Eschwege. - Das Werraland, $\underline{\mathbf{5}}(3)$ : 4344, 1 Abb.; Eschwege

- $\square$ Andrée, Karl (1955): Wilhelm Dunker (1809-1885) / Mineraloge, Geologe u. Konchyliologe. - In: Schnack, Ingeborg [Hrsg.]: Lebensbilder aus Kurhessen und Waldeck 1830-1930. - Bd. ㅁ; zgl. Veröff. d. Historischen Kommission f. Hessen u. Waldeck, 20; S. 50-61, 1 Portrait (Taf.); (Elwert i. K.) Marburg a. L. 1955

Referat in: Das Werraland, $\underline{\mathbf{3}}(1951): 30$ u. $\underline{\mathbf{8}}(1956): 14$ (Perst)]

$\square$ Beck, Hanno (1956): Wilhelm Dunker, Geologie und Malakozoologe. - In: Beck, Hanno: Eschwege Heimat und Welt. - 72 S.; hier S. 63-66; (Roßbach) Eschwege 1956

[Wilhelm Dunker, 1809 - 1885; geb. i. Eschwege]

- $\square$ Quenstedt, Werner (1959): Dunker, Wilhelm Bernhard Rudolph Hadrian. - In: Neue Deutsche Bibliographie, 4 (Dittel - Falk), S. 198-199; (Dunker \& Humblot) Berlin

\section{$>\mathbf{F}$}

OMey, Eberhard (2004): Der Arzt und Geologe Georg Christian Füchsel (1722 - 1773). - Gesamttitel: Kap. 9 - Von der fürstlichen Sammmlung zum Museum - Naturkundliches Sammeln und Naturwissenschaft - Geologie, Mineralogie, Paläontologie. - In: Scheumann, Konrad \& Jördis, Frank [Hrsg.]: Neu entdeckt: Thüringen $-<$ Land der Residenzen $<1485-1918><2$. Thüringer Landesausstellung Schloss Sondershausen, 15. Mai - 3. Oktober 2004>. - Katalog 2. - S. 203, 1 Abb; Mainz 2004

OSchmidt, Ralf (1998): Prof. Dr. Hermann Franke (1847-1932) - Gymnasiallehrer und Geowissenschaftler in Schleusingen/Thüringen. - Veröff./ Naturhist. Museum Schleusingen, 13: 4353, 11 Abb.; Schleusingen

QGümbel, [Carl Wilhelm v.] (1878/1968): Freiesleben - Johann Karl F. F[reiesleben]. - Allgemeine Deutsche Biographie, 7 (Ficquelmont - Friedrich Wilhelm III von Sachsen-Altenburg): 339-340; (Duncker \& Humblot) Berlin 1968 - Unveränd. Nachdruck der Erstausgabe von 1878, erschienen bei Duncker \& Humblot in Leipzig [Hrsg. Kgl. Akademie der Wissenschaften, München/Historische Kommission]

- 0 OSchellhas, Walter (1979): Johann Carl Freiesleben (1774-1846), Leben und Werk. - Abh. d. Staatl. Museums f. Mineralogie u. Geologie z. Dresden, (Geologen der Goethezeit) 29: 149-237, 22 Bilder, 1 Taf., 2 Tab.; Leipzig 
- 0 OWagenbreth, Otfried (1979): Johann Carl Freieslebens geologisches Lebenswerk. - Abh. d. Staatl. Museums f. Mineralogie u. Geologie z. Dresden, (Geologen der Goethezeit) 29: 239-312, 15 Bilder, 10 Tab.; Leipzig

OGudden, Helmut (1982): Nachruf auf Bruno von Freyberg (22. März 1894 - 3. Juni 1981). - Geologica Bavarica, 83: 263-269, 1 Portrait; München

OLüttig, Gerd (1994): Leben und Werk Bruno von Freyberg's. - Südthür. Beitr. z.d. angew. Geowiss., 1; zgl. Veröff./ Naturhist. Museum Schleusingen, Sonderheft, 1994: 1-5, 1 Portr.; Schleusingen

OSchultheiss, Timo (1994): Bruno von Freyberg (1894-1981) als Geologe in Thüringen. - Südthür. Beitr. z.d. angew. Geowiss., 1; zgl. Veröff./ Naturhist. Museum Schleusingen, Sonderheft, 1994: 7-11, 3 Abb.; Schleusingen

OLuedecke (1906): Karl Freiherr von Fritsch [Nachruf]. - Z. f. Naturwiss., $\underline{78}(3):$ 145-159, Taf. I.; Stuttgart

QGess, Joachim (1956): Ernst Fulda zum 70. Geburtstag. - Geologie, $\underline{\mathbf{5}}$ (1): 3-8, 1 Bildnis; Berlin

\section{$>\mathbf{G}$}

- OEckhardt, F. J. \& Walther, H. W. (1984): Hans-Rudolf von Gärtner 1906-1982. - Nachr. Dt. Geol. Ges., 30/1984: 6-8, 1 Portr.; Hannover

oCarlé, Walter (1988): Werner - Beyrich - von Koenen - Stille. - Ein geistiger Stammbaum wegweisender Geologen. - Geol. Jb., Reihe A, 108: 3 - 499, 62 Abb.; Hannover [darin S. 396-418, Abb. 57-58: - 8.5 - Hans Rudolf von Gärtner]

- $\square$ Fischer, Walther (1964): Zum 150. Geburtstag von Hanns Bruno Geinitz. - Der Aufschluß, 15: 281284, 1 Portr.; Göttingen

- Namenskürzel (zmb)(1991): Hellmut Gerstein: Mit 70 Jahren Doktorhut erworben. - HNA, 1991; Nr. 20 v. 24.1.1991; Kassel

[Doktorarbeit über die Wettbewerbsfähigkeit des Nordhesssichen Braunkohlebergbaus]

-Anonym (1954): Ehrendoktorat für Julius Görges - Kasseler Bankdirektor der beste Kenner der Tertiärzeit in Deutschland. - HN, 1954; Nr. 54 v. 5.3.1954; Kassel

QHorst, Ulrich (1954): Ein Leben für die Wissenschaft. Zum 75. Geburtstag von Prof. Dr. Walther Gothan. - Geologie, $\underline{\mathbf{3}}(5)$ : 492-501, 1 Portr.; Berlin

OHorst (1955): Abschied von Professor Walther Gothan. - Geologie, 4(1): 77-79, 1 Bildnis; Berlin [Nachruf]

QRoselt, Gerhard (1956): WALTHER GOTHAN und die Paläobotanik Thüringens. - Hallesches Jb. mitteldt. Erdgeschichte, 2(3): 192-193, 1 Abb.; Halle

-Anonym (1941): Oskar Grupe gestorben [Nachruf, mit Schriftenverzeichnis]. - Jb. Reichsanst. Bodenforsch.; $6 \mathbf{3}$ (f. 1940): 334 - 345, 1 Portr.; Berlin 
- $\square \bullet$ Gümbel, [Carl Wilhelm v.] (1880/1969): Hausmann - Joh. Friedr. Ludwig H[ausmann]. Allgemeine Deutsche Biographie, 11 (Hassenpflug - Hensel): 94-97; (Duncker \& Humblot) Berlin 1969 - Unveränd. Nachdruck der Erstausgabe von 1880, erschienen bei Duncker \& Humblot in Leipzig [Hrsg. Kgl. Akademie der Wissenschaften, München/Historische Kommission]

-Klein, H. v. (1940): Johann Friedrich Ludwig Hausmann [1782-1859]. - „Aus der Heimat“ Naturwiss. Monatsschr., 53.1940: 39-41, 2 Abb.; Stuttgart

- Koritnig, Sigmund (1990): Johann Friedrich Ludwig Hausmann. Ein Mann an der Wende von der alten zur neuen Mineralogie. - Der Aufschluss, 41: 27-32, 4 Abb.; Heidelberg [J.F.L. Hausmann; Professor für Mineralogie in Göttingen von 1811-1859]

- $\square$ Anonym (1996): Hausmann, (Johann) Friedrich (Ludwig). - Deutsche Biographische Enzyklopädie (DBE); 4: 452; (Saur) München u.a.

$\square$ Nesbor, Heinz Dieter (1997): Hans Henschel †. - Geol. Jb. Hessen, 125 (f. 1997): 109-111, 1 Portrait; Wiesbaden

-Stein, Volker (1995): Nachruf Prof. Dr. Axel Herrmann [2.5.1926 - 13.12.1994]. - Nachr. Dt. Geol. Ges., $\underline{\mathbf{5 3}}$ /1995: 5-7, 1 Abb.; Publikationen von Axel Hermann S. 7-10; Hannover

QZimmermann, Ernst (1933): Nachruf auf Hans Heß von Wichdorff. - Jb. Preuß. Geol. Landesanst., 53 (f. 1932): 1039-1062, 1 Bildnis; Berlin

口OKluckhohn (1880/1969): Karl Ernst Adolf von Hoff. - Allgemeine Deutsche Biographie, 12 (HenselHolste): 564-565; (Dunker \& Humblot) Berlin 1969 - Unveränd. Nachdruck der Erstausgabe von 1880, erschienen bei Dunker \& Humblot in Leipzig [Hrsg. Kgl. Akademie der Wissenschaften, München/Historische Kommission]

口OReich, O. (1905): Karl Ernst Adolf von Hoff, der Bahnbrecher moderner Geologie - eine wissenschaftliche Biographie. - VI, 144 S.; (Veit) Leipzig

@Namenskürzel (G.A.J. C.) (1905): (The Pioneers of geological thought) Karl Ernst Adolf von Hoff, der Bahnbrecher moderner Geologie. - By Dr. Otto Reich; (Veit \& Co.) Leipzig < Buchbesprechung >. Nature - A weekly illustrated Journal of Science. - LXXII [= Vol. 72] (No. 1858 - May to October 1905): 123-124; London

@Andrée, Karl (1930): Karl Ernst Adolf von Hoff als Schriftgelehrter und die Begründung der modernen Geologie. - Vortrag gehalten der Königlichen Deutschen Gesellschaft zu Königsberg i. Pr. am 28. Februar 1929. - Schriften d. Königlichen Deutschen Gesellschaft zu Königsberg i. Pr., 4; 28 S.; (Gräfe und Unzer) Königsberg Pr.

Referat in: N. Jb. Mineral. etc., Referate, 1931 (Bd. II): 293 (Erich Kaiser); Stuttgart

OKauter, Kurt (1960): Karl Ernst Adolf v. Hoff - eine weltberühmte Persönlichkeit aus Gotha. - Der Friedenstein, 1960(10): 268-275; Gotha

口OMathé, Gerhard (1985): Karl Ernst Adolf von Hoff (1771-1837) - Verdienste und Grenzen eines Gothaischen Staatsbeamten und die Förderung geologischen Denkens. - In: Prescher, Hans [Hrsg.]: Leben und Wirken deutscher Geologen im 18. und 19. Jahrhundert. - 1. Aufl.; 388 S., 108 Abb.; hier: S. 118-139, 6 Abb. Abb.; (Dt. Verlag f. Grundstoffindustrie) Leipzig 1985 [darin S. 128, Abb. 3: Hoffs Erforschung der „Blauen Kuppe“ b. Eschwege - Vorsatzblatt: Die Basaltintrusion an der „Blauen Kuppe“]

OMartens, Thomas (1987): Karl Ernst Adolf von Hoff (1771-1837) - Begründer des Aktualismus in der Geologie. - Abh. Ber. Museums d. Natur Gotha, (14) 1987: 3-18, Taf. 1-6; Gotha 
口QCarlé, Walter (1988): Werner - Beyrich - von Koenen - Stille. - Ein geistiger Stammbaum wegweisender Geologen. - Geol. Jb., Reihe A, 108: 3 - 499, 62 Abb.; Hannover [darin S. 50-53, Abb. 10: - 4.5 Karl Ernst Adolf von Hoff]

oMey, Eberhard (2004): Karl Ernst Adolf von Hoff (1771 - 1837), der Begründer der dynamischen Geologie und der Erforscher der Erdgeschichte. - Gesamttitel: Kap. 9 - Von der fürstlichen Sammmlung zum Museum - Naturkundliches Sammeln und Naturwissenschaft - Geologie, Mineralogie, Paläontologie. - In: Scheumann, Konrad \& Jördis, Frank [Hrsg.]: Neu entdeckt: Thüringen $-<$ Land der Residenzen $<1485-1918><2$. Thüringer Landesausstellung Schloss Sondershausen, 15. Mai - 3. Oktober 2004>. - Katalog 2. - S. 214-215, 3 Abb.; Mainz 2004

OMartens, Thomas (2005): Karl Ernst Adolf von Hoff - Der Begründer der modernen Geologie in Deutschland. - In: Köhler, Franz [Mitautor]: Gothaer Geowissenschaftler in 200 Jahren. - 50 S., Ill., graph. Darst., Kt.; hier S. 11-12; [Hrsg. Urania Kultur- u. Bildungsverein Gotha e.V.] Gotha

$\square$ Anonym (1837): Friedrich Hoffmann - sein Leben und Wirken. - In: Hoffmann, Friedrich (1837): Physikalische Geographie - Vorlesungen gehalten an der Universität zu Berlin in den Jahren 1834 und 1835. - Friedrich Hoffmann - Hinterlassene Werke, Bd. 1; XL, 620 S.; hier S. I - XL; (Nicolai) Berlin

$\square$ Gümbel, [Carl Wilhelm v.](1880/1969): Hoffmann - Friedrich H[offmann]. - Allgemeine Deutsche Biographie, 12 (Hensel-Holste): 588-590; (Dunker \& Humblot) Berlin 1969 - Unveränd. Nachdruck der Erstausgabe von 1880, erschienen bei Dunker \& Humblot in Leipzig [Hrsg. Kgl. Akademie der Wissenschaften, München/Historische Kommission]

$\square$ Anonym (1997): Hoffmann, Friedrich . - Deutsche Biographische Enzyklopädie (DBE); $\underline{\mathbf{5}}$ : 117; (Saur) München u.a.

OWittmann, Otto (1977): Walter Hoppe 1896 - 1976. - Jber. Mitt. Oberrhein. Geol. Vereins, 59: 91 - 92 , 1 Portr.; Stuttgart

OMichel, Gert (1996): Laudatio zum 100. Geburtstag von Prof. Dr. phil. Habil. Walter Hoppe. Geowiss. Mitt. Thüringen, (Gedenkschrift zum 100. Geburtstag von Walter Hoppe) Beih. 모 1-25, 13 Abb.; Weimar

OSteiner, Walter (1996): Erinnerungen an Walter Hoppe. - Geowiss. Mitt. Thüringen, (Gedenkschrift zum 100. Geburtstag von Walter Hoppe) Beih. ㅍ: 27-44, 12 Abb.; Weimar

-Ehrenberg, Karl-Heinz \& Stengel-Rutkowski, Witigo (1999): Manfred Horn gest. [Nachruf]. - Geol. Jb. Hessen, 127: 149 - 152, 1 Portr..; Wiesbaden [mit Verzeichnis der Veröffentlichungen]

-Ehrenberg, K. H. \& Stengel-Rutkowski, W. (1999): Manfred Horn (24.02.1934-15.03.1999). - Nachr. Dt. Geol. Ges., 69/1999: 54-55, 1 Portr.; Hannover

-Hoth, Klaus; Walter, Harald \& Freyer, Günter (2004): Manfred Horn, ein hessischer Landesgeologe aus Masuren. - Geol. Jb. Hessen, 131 (f. 2003): 225-227, 3 Abb.; Wiesbaden

$\square \bullet$ Dove, Alfred (1881/1969): Humboldt - Friedrich Wilhelm Heinrich Alexander v. H[umboldt] Allgemeine Deutsche Biographie, 13 (Holstein-Jesup): 358-383; (Duncker \& Humblot) Berlin 1969 Unveränd. Nachdruck der Erstausgabe von 1881, erschienen bei Duncker \& Humblot in Leipzig [Hrsg. Kgl. Akademie der Wissenschaften, München/Historische Kommission]

$\square$ Beck, Hanno (1954): Alexander von Humboldts Beziehungen zu Eschwege. - Das Werraland, $\underline{\mathbf{6}}(4)$ : 58-59; Eschwege 
$\square$ Beck, Hanno (1956): Alexander von Humboldt besuchte den Meißner - Wissenschaftler entdeckten neue Beziehungen des Forschers zu unserer Heimat. - Werra-Rundschau, 1956; Nr. 215 v. 14.9.1956, S. 4; Eschwege

$\square$ Beck, Hanno (1960): Ausstrahlungen Humboldts in Eschwege. - Zum Ehrentag der Alexander-vonHumboldt-Schule. - Werra-Rundschau, 1960; Nr. 214 v. 14.9.1960, S. 4; Eschwege

$\square$ Beck, Hanno (1961): Eschwege und Alexander von Humboldt. - Humboltschule gedenkt morgen ihres Patrons - Neue Sammlungen und Forschungen. - Werra-Rundschau, 1961; Nr. 212 v. 13.9.1961, [S. 4]; Eschwege

$\square$ Oppitz, Ulrich-Dieter (1962): Alexander von Humboldt und die Blaue Kuppe. - Werra-Rundschau, 1962; Nr. 110 v. 12.5.1962, [S. 4]; Eschwege

$\square$ Oppitz, Ulrich-Dieter (1962): Alexander von Humboldt und die Blaue Kuppe. - Das Werraland, 14(3): 41-43; Eschwege

$\square$ Beck, Hanno (1967): A. von Humboldt - Gerüchte und Tatsachen. Ein Beitrag zum Humboldt-Tag am 14. September. - Werra-Rundschau, 1967; Nr. 212 v. 13.9.1967, S. 4; Eschwege

A. v. H. Beziehungen zu Eschwege und Eschwegern; darin: Wilhelm Ludwig v. Eschwege]

$\square$ Beck, Hanno (1969): Alexander von Humboldt und Eschwege. - Werra-Rundschau, 1969; Nr. 212 v. 13.9.1969, S. 5; Eschwege [darin: Wilhelm Ludwig von Eschwege]

$\square$ Beck, Hanno (1969): Alexander vom Humboldt und Eschwege - Zur Feier des 200. Geburtstages des großen Geographen und Naturforschers am 14. September 1969. - Das Werraland, 21(3): 33-35; Eschwege

$\square$ Heß (1881/1969): Johann Christian Hundeshagen. - Allgemeine Deutsche Biographie, 13 (HolsteinJesup): 401-406; (Dunker \& Humblot) Berlin 1969 - Unveränd. Nachdruck der Erstausgabe von 1869, erschienen bei Dunker \& Humblot in Leipzig [Hrsg. Kgl. Akademie der Wissenschaften, München/Historische Kommission]

$\square$ Künanz, Hermann (1955): Johann Christian Hundeshagen (1788-1834), Forstmann. - In: Schnack, Ingeborg [Hrsg.]: Lebensbilder aus Kurhessen und Waldeck 1830-1930. - Bd. ㅁ; zgl. Veröff. Historischen Kommission f. Hessen u. Waldeck, 20; S. 135-149, 1 Portrait (Taf.); (Elwert i. K.) Marburg a. L. 1955

口Hasel, Karl (1985): Forstgeschichte - Ein Grundriß für Studium und Praxis. - 258 S., 6 Tab.; (Paul Parey) Hamburg - Berlin [darin S. 238-239: Die forstlichen Klassiker: Johann Christian Hundeshagen (1783-1834)]

$\square$ Hasel, Karl \& Schwartz, Ekkehard (2002): Forstgeschichte - Ein Grundriss für Studium und Praxis. -2., aktual. Aufl.; XI, 394 S., 140 Abb., 8 Tab.; (Dr. Kessel) Remagen [darin S. 348-350, 1 Abb.: Die forstlichen Klassiker in der ersten Hälfte des 19. Jahrhunderts: Johann Christian Hundeshagen (1783-1834]

\section{$>\mathbf{J}$}

$\square$ Reutter, Klaus J. (1997): Emeritierung von Volker Jacobshagen. - Nachr. Dt. Geol. Ges., 62/1997: 4950, 1 Abb.; Hannover 
- $\square$ Gümbel, [Carl Wilhelm v.] (1882/1969): Keferstein - Christian K[eferstein]. - Allgemeine Deutsche Biographie, 15 (Kähler - Kircheisen): 522-525; (Duncker \& Humblot) Berlin 1969 - Unveränd. Nachdruck der Erstausgabe von 1882, erschienen bei Duncker \& Humblot in Leipzig [Hrsg. Kgl. Akademie der Wissenschaften, München/Historische Kommission]

व $\square \bullet$ Steiner, Walter (1966): CHRISTIAN KEFERSTEIN zum 100. Todestag am 26. August 1966. Ber. Dt. Ges. geol. Wiss., Reihe A, 11(6): 747-748; Berlin

- 0 Q Steiner, Walter (1969): CHRISTIAN KEFERSTEIN - Ein Wegbereiter der regionalen Geologie Deutschlands. - Ber. Dt. Ges. geol. Wiss., Reihe A, 14(3): 269-320, 12 Abb.; Berlin

- $\square$ O०Steiner, Walter (1979): Christian Keferstein und das Erscheinen der ersten geologischen Übersichtskarte von Mitteleuropa im Jahre 1821 - Zugleich ein Beitrag zur Goetheforschung und zur Geschichte des Kartendruckes und des Verlagswesens. - Abh. d. Staatl. Museums f. Mineralogie u. Geologie z. Dresden, (Geologen der Goethezeit) 29: 99-147, 12 Bilder, 3 Farbtaf., 2 Tab.; Leipzig

- $\square$ OCSteiner, W. (1984): Christian Keferstein - zum 200. Geburtstag am 20.1.1984. - Z. angew. Geol., $\underline{30}$ (6): 314-315, 1 Abb.; Berlin

$\square$ Woldstedt, Paul (1951): KONRAD KEILHACK †. - Geol. Jb., 65: XIV - XXV, 1 Portrait; Hannover

-Namenskürzel (mdm)(1986): 83jähriger Karl Kiel arbeitete als Schmied unter Tage - Erdrutsch läßt Erinnerungen an früheren Bergbau aufleben. - HNA*, 1986; Nr. 82 v. 9.4.1986; Kassel [Bergbaugeschichte Zeche Möncheberg]

- Menzel, Hans (1907): Lebenslauf Adolf v. Koenen's. - In: Festschrift Adolf v. Koenen - Gewidmet von seinen Schuelern zum siebzigsten Geburtstage am 21. März 1907. - XXXI, 514 S., 1 Portr., 20 Abb., 13 Taf., 1 Beil.; hier: S. IX-XX; „Verzeichnis der Schriften A. v. Koenen’s“‘ XXI-XXXI; (Schweizerbart) Stuttgart

-Pompeckj, J.F. (1916): Gedenkrede auf Adolf v. Koenen. - Z. dt. geol. Ges., 67 (f. 1915): 229-268, 1 Portr. (Monatsber.); Berlin 1915

[Verz. d. wiss. Arbeiten S. 253-268]

-Haarmann, Erich (1937): Adolf v. Koenen hundert Jahre. - Geol. Rundschau, 28: 81-83, 1 Abb.; Stuttgart

- $\bullet$ Carlé, Walter (1988): Werner - Beyrich - von Koenen - Stille. - Ein geistiger Stammbaum wegweisender Geologen. - Geol. Jb., Reihe A, 108: 3 - 499, 62 Abb.; Hannover [darin S. 90-103, Abb. 15: - 6. Adolf von Koenen]

- $\square$ Schneiderhöhn, Paula (1978): Sigmund Koritnig - Siebzig Jahre. - Der Aufschluss, 34: 1-4, 1 Abb.; Heidelberg

- $\square$ Mücke, Arno (1993): Sigmund Koritnig - 80 Jahre. - Der Aufschluss, 44: 1-2, 1 Abb.; Heidelberg

- $\square$ Mücke, Arno (1994): Sigmund Koritnig gest. [Nachruf]. - Der Aufschluss, 45: 273-274, 1 Abb.; Heidelberg

- $\square$ Horn, Manfred (1997): Jens Kulick †. - Geol. Jb. Hessen, 125 (f. 1997): 113-115, 1 Portrait; Wiesbaden

$\square$ Namenskürzel [Jg.](1923): Heimatforscher Wilhelm Kunze gestorben [Nachruf]. - Eschweger Tageblatt, 1923; Nr. 217 v. 17.9.1923; Eschwege 
口Frech, F. (1917): Richard Lachmann [Nachruf]. - Zbl. Mineral. etc., 1917: 68-72; Stuttgart [Verz. d. Veröff. S. 71-72] - auch in: Die Naturwissenschaften, $\underline{\mathbf{5}}$ (16): 257-259 [mit Schriftenverzeichnis]; Berlin 1917

OLachmann, Richard (1917): Über Carnallitisierung der Südharz-Kalilager < Mit Nachruf auf Privatdozent Dr. Richard Lachmann>. - Kali, etc., 10 (12): 189-194, 3 Fig.; Halle/Saale [darin: Volkenroda]

OSteinhage, Albert (19xx): [Biographisches und Bibliographisches zu Alwin Langenhan, Geologe und Oberbeamter der Gother Lebensbank a. D.: Separatabzüge aus „Deutschlands, Oesterreich-Ungarns und der Schweiz Gelehrte, Künstler“; „Sammler und Sammlungen: Sammlung A. Langenhan, Friedrichroda“, „Geologisch-mineralogische Sammlung“" und handschriftliches Verzeichnis seiner Schriften] - [Fingierter Gesamttitel] mit Separatabdrücken und handschriftlichem Verzeichnis seiner Schriften; ohne Ort, ohne Jahr Nachgewiesen in: Forschungsbibliothek Gotha

- $\square$ Leonhard, Carl Cäsar v. (1854/1856): Aus unserer Zeit in meinem Leben [Carl Cäsar von Leonhard](Nebentitel: Leonhard's Lebensbilder). - Bd. 1, XXII, 682 S., (Schweizerbart) Stuttgart 1854; Bd. 2, VII, 216 S., (Schweizerbart) Stuttgart 1856

[Carl Cäsar Ritter von Leonhard, (1769-1862) ehemals Kurhessischer Landkassen- und Steuerassessor, später Professor der Mineralogie in Heidelberg; Begründer des „Neuen Jahrbuches der Mineralogie etc.“ und der Vorgängertitel „Taschenbuch für die gesammte Mineralogie“, „Zeitschrift für Mineralogie“ „Jahrbuch der Mineralogie“]

- $\square$ Gümbel, [Carl Wilhelm v.] (1883/1969): Leonhard - Karl Caesar v. L[eonhard] - Allgemeine Deutsche Biographie, 18 (Lassus - Litschower): 308-311; (Duncker \& Humblot) Berlin 1969 Unveränd. Nachdruck der Erstausgabe von 1883, erschienen bei Duncker \& Humblot in Leipzig [Hrsg. Kgl. Akademie der Wissenschaften, München/Historische Kommission]

- $\square$ Triller, Marlies (1991): Karl Caesar von Leonhards (1779-1862) Wirken zur Popularisierung geologisch-mineralogischer Kenntnisse. - In: Guntau, Martin [Wiss. Ltg.]: Zur Wissenschaft in der ersten Hälfte des 19. Jahrhunderts. - Rostocker Wissenschaftshistorische Manuskripte, 20; 110 S., hier S. 69-73; (Fachber. Geschichtswiss. Univ. Rostock) Rostock

- $\square$ Anonym (1997): Leonhard, Carl Cäsar von; Mineraloge, Geologe. - Deutsche Biographische Enzyklopädie (DBE); ㅁ: 328-329; (Saur) München u.a.

OEllenberg, Jürgen (1996): Laudatio [zum 65. Geburtstag von Prof. Dr. Harald Lützner]. - Beitr. Geol. Thür., N.F., $\underline{\mathbf{3}}$ (Festschrift 65. Geburtstag Prof. Dr. Harald Lützner): 7-11, 1 Bildnis; Jena

-Schneider, Otto (1930): Nachruf auf Otto von Linstow. - Jb. Preuß. Geol. Landesanst., $\underline{\mathbf{5 0}}$ (Teil II) (f. 1929): LXXXV-CII, 1 Portrait; Berlin

-Carlé, Walter (1988): Werner - Beyrich - von Koenen - Stille. - Ein geistiger Stammbaum wegweisender Geologen. - Geol. Jb., Reihe A, 108: 3 - 499, 62 Abb.; Hannover

[darin S. 345-361, Abb. 54: - 8.3 - Franz Lotze]

\section{$>\mathbf{M}$}

oBarthel, Manfred (1985): Johann Christian Mahr (1787-1869) - Goethes Fossiliensammler im Steinkohlevorkommen Manebach-Kammerberg. - In: Prescher, Hans [Hrsg.]: Leben und Wirken deutscher Geologen im 18. und 19. Jahrhundert. - 1. Aufl.; 388 S., 108 Abb.; hier: S. 162-182, 13 Abb.; (Dt. Verlag f. Grundstoffindustrie) Leipzig 1985 
-0•Schultze, Gg. R. (1970): Hans Joachim Martini (5.1.1908 - 22.10.1969). - Abh. d. Braunschweigischen wissenschaftlichen Ges., 21: 489-496, o. Abb.; Braunschweig

- $\square$ Richter-Bernburg, Gerhard (1970): Nachruf Hans Joachim Martini. - Geol. Jb., 요: XIII-XXIII, 1 Taf. (Portrait); Hannover

- $\square \bullet$ Richter-Bernburg, Gerhard (1970): Nachruf Hans Joachim Martini. - Geol. Jb., 88: XIII-XXIII, 1 Taf. (Portrait); Hannover

-oCarlé, Walter (1988): Werner - Beyrich - von Koenen - Stille. - Ein geistiger Stammbaum wegweisender Geologen. - Geol. Jb., Reihe A, 108: 3 - 499, 62 Abb.; Hannover [darin: S. 418-442, Abb. 59: - 8.6 - Hans Joachim Martini]

-Neumann-Mahlkau, Peter (1994): Nachruf Prof. Dr. Peter Meiburg (1938-1993). - Nachr. Dt. Geol. Ges., 51/1994: 9-11, 1 Portr.; Hannover

-Ludwig, Willi (1987): Der Name Artur Milde ist untrennbar mit den Cornberger Fährtenplatten verbunden. - Kreis Hersfeld-Rotenburg - Heimatkalender 1987 und Wegweiser (ㅍ․ Jg. ): 107 - 109, 2 Abb.; Bad Hersfeld

- $\square$ Strieder, Friedrich Wilhelm (1794): Mönch, Conrad. - In: Strieder, Friedrich Wilhelm: Grundlage zu einer Hessischen Gelehrten und Schriftsteller Geschichte. Seit der Reformation bis auf gegenwärtige Zeiten. - Bd. 9 (Meus - Myl), 430 S., hier S. 80-88; (Cramer) Cassel - Als Reprint: Stiftung Sippel von 1525, im Familienverband Berneburg e.V. - Veröff. a.d. Geschichte d. althess. „Landschaft an der Werra“, Bd. 28 ; Göttingen 1987

[Conrad Mönch, Apotheker u. Mineraloge, Erforscher der nordhessischen Mineralogie]

-Rose, H. (1932): Zu Otto Mügge's Gedächtnis. - Zbl. Mineral. etc., Abt. A, 1932: 401-425; Stuttgart Referat in: N. Jb. Mineral. etc., Referate, 1935 (Bd. III): 4 (Hans Himmel); Stuttgart

[Verz. d. Veröff. S. 418-425]

OWienholz, Roland (1981): ARNO HERMANN MÜLLER - Forscher und Lehrer. - (Beiträge zur Paläontologie, Stratigraphie und Palökologie - Zum 65. Geburtstag von Prof. Dr. rer. nat. habil Arno Hermann Müller) Freiberger Forschungshefte, Reihe C, 363: 9-10; Leipzig

-Winter, K. P. (1994): Nachruf Prof. Dr. Hans Murawsky. - Nachr. Dt. Geol. Ges., 52/1990: 12-13, 1 Portr.; Hannover

\section{$>\mathbf{N}$}

@Deubel, Fritz (1953): Ernst Naumann zum 80. Geburtstag. - Geologie, 2(4): 231-236, 1 Portrait; Berlin

@•Freckmann (1936): Professor Franz Neureuter gest. [Nachruf].- Unser Eichsfeld, 31: 167-168, 1

Portr.; Duderstadt

\section{$>\mathrm{O}$}

-ONamenskürzel (rff)(1980): Ein Blick zurück: Ochsenius - der Vater der Kali-Geologie. - HA, 1980; Nr. 58 v. 8.3.1980; Kassel 
OMartens, Thomas (1994): Prof. Dr. Wilhelm Pabst (1856-1908) - Mitbegründer der Fährtenkunde fossiler Wirbeltiere. - Abh. Ber. Museums d. Natur Gotha, (18) 1994: 3-14, 6 Abb.; Gotha

OSeib, Gerhard (1997/98): Dr. Gerald Patzelt in den Ruhestand verabschiedet. - Mühlhäuser Beiträge, 20/21: 140-141, 1 Abb.; Mühlhausen

-Busse, Erwin (1961): Hans Penndorf gest. [Nachruf]. - Notizbl. Hess. L.-A. Bodenforsch., $\underline{\mathbf{8 9}}$ : 451 452; Wiesbaden

- Jacobshagen, Eduard (1961): Hans Penndorf 10.1.1879 - 1.11.1960. - Hessische Heimat, N.F. 11(5): 39-40; Marburg

OAnonym (1902): Nachruf auf den Wirklichen Geheimen Oberbergrath, Berghauptmann a. D.; Johann Friedrich Hermann Pinno. - Z. Berg-, Hütten- u. Salinenwesen, $\mathbf{5 0}$ (Beil. z. Heft 3); [2] S., 1 Portrait; Berlin

\section{$>\mathbf{R}$}

- $\square$ Buschendorf, Fr. (1960): Paul Ramdohr, geboren zu Überlingen am 1. Januar 1890, zur Vollendung seines 70. Lebensjahres. - N. Jb. Mineral. , Abh., 94 (Paul Ramdohr-Festschrift zum 70. Geburtstag) (1. Teil): 1 - 29; Verzeichnis seiner Veröffentlichungen: S. 24 - 29; Stuttgart

[Mineraloge, Ezrpetrograph; Erforscher der „Blauen Kuppe“ bei Eschwege, Doktorarbeit über die „Blauen Kuppe“]

d $\square$ Strunz, Hugo (1980): Paul Ramdohr - Zum 1. Januar 1890 und 1980. - Der Aufschluss, 31: 1-3, 1 Abb.; Heidelberg

- $\square$ Stumpfl, E. F. (1985): Obitary - Professor Dr. Paul Ramdohr, Dr. hc. mult. <Nachruf $>$. Tschermaks Mineral. Petrogr. Mitt., 3. F., 34: 83-85; Wien

- $\square$ Strunz, Hugo (1985): Paul Ramdohr 1890-1985. - Der Aufschluss, 36: 141-142, 1 Portr.; Heidelberg

- $\square$ Friedrich, Günther (1990): Zum 100. Geburtstag von Paul Ramdohr (1890-1985), dem Erzvater und Lagerstättenforscher. - Erzmetall, $\underline{43}(6):$ 261-264, 6 Abb.; Clausthal-Zellerfeld

-Haarmann, Erich (1942): Ein Münchhausen als Geologe - Rudolf Erich Raspe - 1736-1794. Übertitel: Lose Blätter aus der Geschichte der Geologie - Mitteilungen des Geologenarchivs. - Geol. Rundschau, $\underline{33}(2 / 3):$ 102-120, 4 Abb.; Berlin

-Carozzi, Albert V. (1970): The geological contribution of Rudolf Erich Raspe (1737-1794). - Archives des sciences, 22(3): 625-643; Genève

[u. a. Basaltgenese]

-Nield, Edward W. (1984): The travels and campaigns of a fortunate finder [Rudolf Erich Raspe]. New scientist, 104(1435-1436): 60-62, ill.; London [Biographisches, Basalt-Genese]

-Thackeray, John C. (1987): Rudolf Erich Raspe - Scholar, scientist... - Geoloy today, $\underline{\mathbf{3}}(4)$ : 132-133; Oxford

-Waitz von Eschen, Friedrich Freiherr (2005): Vom Herkules zu den 7000 Eichen von Jospeh Beuys [Rudolf Erich] Raspe und die nordhessische Geologie. - In: Linnebach, Andrea [Hrsg.]: Der Münchhausen-Autor Rudolf Erich Raspe - Wissenschaft - Kunst - Abenteuer. - Reihe: Die Region 
trifft sich - die Region erinnert sich. - 163 S., zahlr. Abb.; hier S. 32-44, Abb. 14-21; (Euregio-Verlag) Kassel 2005

-Görlich, Paul (1995): „Berg- und Hütten-Commissarius bey dem Richelsdorfer Kupfer- und Koboldswerk" - aus dem bewegten Leben des Johann Phillip Reis. - In: Hersfeld-Rotenburg Heimatkalender des Landkreises Hersfeld-Rotenburg f. 1995 und Wegweiser ( 29. Jg.): 86-89; Bad Hersfeld

$\square$ Breuer, Johannes C. (1989): Magister Johannes Rhenanus - Aus der Geschichte der Stadt Bad SoodenAllendorf 1218-1968. Herausgegeben vom Magistrat der Stadt. - Das Werraland, 41(3): 37-39, 1 Abb.; Eschwege

$\square$ Breuer, J. C. (1955): Magister Johannes Rhenanus - Pfarrer und Salzgrebe in den Sooden zu Allendorf a. d. Werra. 1555-1589. - Das Werraland, 7(3): 41-42, (4): 56-59; Eschwege

$\square$ Namenskürzel [Lu](1963): Der Rheinlandt aus Milsungen genannt Rhenanus - Meißnerkohle für die Siedepfannen. - Bergbau im Hessenland, 13(4): 12-13, 3 Abb.; Kassel

$\square$ Walter, Hans-Henning (1989): Das deutsche Salinenwesen im 16. Jahrhundert. Reiseberichte des Allendorfer Salzgräfen Johannes Rhenanus (um 1528 - 1589). - Veröff. Wiss. Informationszentrum Bergakademie Freiberg/Sa., 116; 89 S., 3 Abb.; Freiberg/Sa.

Referat in: Das Werraland, 41: 53 (Oppitz); Eschwege [darin S. 67-72: „Leben und Wirken des Johannes Rhenanus“; S. 72-78: Die sog. „Salzbibel“...]

- $\square$-Anonym (1972): Gerhard Richter-Bernburg - 65 Jahre. - Geol. Jb., 90: IX-XIX, 1 Taf. (Portrait); Hannover

- •Kürsten, Martin (1990): Nachruf Professor Richter-Bernburg. - Nachr. Dt. Geol. Ges., 433/1990: 6-8, 1 Portr.; Hannover

- $\square 0 \bullet$ Kürsten, Martin (1991): Gerhard Richter-Bernburg zum Gedächtnis. - Kali u. Steinsalz, 10(10): 314-315, 1 Portrait; Essen

-Carlé, Walter (1991): Gerhard Richter-Bernberg, 1907 - 1990 [Nachruf]. - Jber. Mitt. Oberrhein. Geol. Vereins, N.F., 73: 19-29, 1 Portr.; Stuttgart [Publikationen über das Richelsdorfer Gebirge, Salzlagerstätten des Zechsteins]

- •Bork, Hans Rudolf (1991): Heinrich Rohdenburg in Memoriam. - Catena, Suppl., 19 (Bork, H.-R.; Ploey, J. de \& Schick, A.P. [eds.]: Erosion, transport and deposition processes - Theories and models); 7 p. (sep. Zählg.); Cremlingen-Drestedt

-Bauer, G. (1981): Harry Roth [Nachruf]. - Nachr. Dt. Geol. Ges., 24/1981: 15-16, 1 Portr.; Schriftenverzeichnis S. 16-17; Hannover

\section{$>\mathrm{S}$}

$\square$ Anonym (1974): Dr. Helmut Sauer wurde 65 Jahre alt. <Anhang: Veröffentlichungen von Dr. Helmut Sauer, zusgest. v. H. Perst u. Redaktion des WL>. - Das Werraland, 26 (3): 40-42; Eschwege

QMüller, Wolfgang (1976): Heinrich Friedrich Schäfer. - Abh. Ber. Museums d. Natur Gotha, [8] 1976: 97-100; Gotha

[Erforscher d. Rhät- u. Liasablagerungen Thüringens]

- $\square$ Anonym (1992): Kunsterzieher - Paläontologe - Maler: Günther Schaumberg zum 70. Geburtstag. Das Werraland, 44(4): 75-78, 5 Abb.; Eschwege 
- $\square$ Schultze, H.-P. (1997): Dr. h.c. G. Schaumberg als Paläontologe. - In: Kollmann, Karl [Red.](2004): Günther Schaumberg - Maler, Kunsterzieher und Paläontologe aus Eschwege. - Zum 75. Geburtstag am 28. Juni 1997. - 96 S., zahlr. Abb.; (Magistrat der Stadt Eschwege) Eschwege; hier: S. 49-57, 4 Abb.

- $\square$ Stoppel, Dieter (1997): Marburg - Ehrendoktorwürde für Günther Schaumberg. - Nachrichten Dt. Geol. Ges., 60: 95; Hannover

- $\square$ Ernst, Werner (2003): Dr. h.c. Günther Schaumberg - Künstler und Paläontologe. - Philippia - Abh. u. Ber. a. d. Naturkundemuseum i. Ottoneum z. Kassel 11(1): 41-48, 5 Abb.; Kassel

ORußwurm (1923): Geheimer Bergrat Professor Dr. <Robert> Scheibe. - Kali, etc., 17(9): 29-130, 1 Portrait; Halle/Saale

ORauff, H. (1927): Robert Scheibe †. - Jb. Preuß. Geol. Landesanst., 47 (f. 1926): LXIII-LXXI, 1 Portrait; Berlin

QZimmermann, J. E. (1927): Robert Scheibe und die Geologie des Thüringer Waldes. - Jb. Preuß. Geol. Landesanst., $\underline{47}$ (H. 2) (f. 1926): LXXI-XCIII; Berlin [Erforschungsgeschichte - Schriftenverzeichnis von R. Scheibe S. XCI-XCIII (H. Rauff)]

OGümbel, [Carl Wilhelm v.] (1890/1970): Schlotheim - Ernst Friedrich Freiherr v. S[schlotheim]. Allgemeine Deutsche Biographie, $\underline{31}$ (Scheller - Karl Schmidt): 550-551; (Duncker \& Humblot) Berlin 1970 - Unveränd. Nachdruck der Erstausgabe von 1890, erschienen bei Duncker \& Humblot in Leipzig [Hrsg. Kgl. Akademie der Wissenschaften, München/Historische Kommission]

OMartens, Thomas (1982): Ernst Friedrich von Schlothheim (1764-1832) - ein bedeutender Paläontologe der Goethezeit. - (Hefttitel: Ernst Friedrich von Schlotheim 1764-1832 - Zum 150. Todestag des Begründers der wissenschaftlichen Botanik) Abh. Ber. Museums d. Natur Gotha, (11) 1982: 5-22; Gotha

¿Carlé, Walter (1988): Werner - Beyrich - von Koenen - Stille. - Ein geistiger Stammbaum wegweisender Geologen. - Geol. Jb., Reihe A, 108: 3 - 499, 62 Abb.; Hannover [darin S. 48-50, Abb. 9: - 4.4 Ernst Friedrich Freiherr von Schlotheim]

@Mey, Eberhard (2004): Ernst Friedrich von Schlotheim (1764 - 1832), der Begründer der wissenschaftlichen Paläobotanik. - Gesamttitel: Kap. 9 - Von der fürstlichen Sammmlung zum Museum - Naturkundliches Sammeln und Naturwissenschaft - Geologie, Mineralogie, Paläontologie. In: Scheumann, Konrad \& Jördis, Frank [Hrsg.]: Neu entdeckt: Thüringen $-<$ Land der Residenzen $<1485-1918><2$. Thüringer Landesausstellung Schloss Sondershausen, 15. Mai - 3. Oktober 2004>. - Katalog 2. - S. 206-207, 2 Abb.; Mainz 2004

-Koritnig, Sigmund (1962): Prof. Dr. Hermann Schmidt [zum 70. Geburtstag] - Schrifttum von Prof. Dr. Hermann Schmidt. - Göttinger Jb., 1962: 3 - 8, 1 Portr.; Göttingen

- •Nicolaus, Hans Joachim (1978): Hermann Schmidt [Nachruf]. - Nachr. Dt. Geol. Ges., 19/1978: 5557, 1 Portr.; Schriftenverzeichnis S. 58-66; Hannover

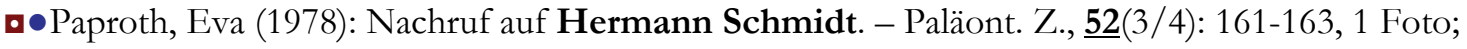
Stuttgart

- $\bullet$ Mücke, Arno (2008): Das neue Ehrenmitglied der VFMG: Günther Schnorrer. - Der Aufschluss, 59(1): 1-2, 2 Abb.; Heidelberg

OSchellhas, Walter (1985): Vom erzgebirgischen Bergjungen zum französischen Inspecteur général honoraire und Ritter der Ehrenlegion - Leben und Wirken von Johann Gottfried Schreiber (1746 
bis 1827) in Sachsen und Thüringen. - In: Prescher, Hans [Hrsg.]: Leben und Wirken deutscher Geologen im 18. und 19. Jahrhundert. - 1. Aufl.; 388 S., 108 Abb., 1 Tab.; hier S. 93-108, 7 Bilder: (Dt. Verlag f. Grundstoffindustrie) Leipzig 1985

[darin S. 105-107: „Markscheider im Kupferschieferbergbau in Ilmenau in Thüringen (August 1776 bis August 1777"]

- oLotze, Siegfried (1993): Der Weg der hessischen Montanfamilie Schreiber von Adorf bis Schmalkalden - Frühe Montanbeziehungen zwischen Waldeck und dem niederhessischen Weserraum. - Z. Vereins. Hess. Gesch. u. Landeskde., 98: 85-114, 3 Taf.; Kassel

口OGrabert, Hellmut (1970): Eckart Schröder [Nachruf]. - Decheniana - Verhdlgn. Naturhist. Vereins Rheinlande u. Westfalens, 122(2): 165-169, 1 Taf.; Bonn

-Maus, H. \& Walther, H. W. (1995): Nachruf Dr. Horst F. R. Schürenberg (8.6.1926 - 13.12. 1994). -

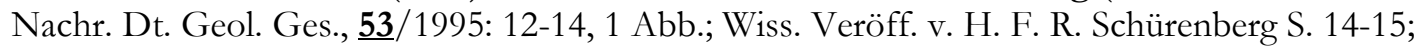
Hannover

-Anonym (1880): Karl von Seebach [Nachruf]. - N. Jb. Mineral. etc., 1880 (Bd. 1): 1 - 8; Stuttgart [Prof. für Geologie Univ. Göttingen, Kartierungen von Blättern der Geol. Spec.-Kt. v. Preussen etc., Regionalgeol. Unters.]

- Gümbel, [Carl Wilhelm v.] (1891/1971): Seebach - Karl Albert Ludwig v. S[eebach]. - Allgemeine Deutsche Biographie, $\underline{\mathbf{3}}$ (Hermann Schulze - G. Semper): 557-559; (Duncker \& Humblot) Berlin 1971 - Unveränd. Nachdruck der Erstausgabe von 1891, erschienen bei Duncker \& Humblot in Leipzig [Hrsg. Kgl. Akademie der Wissenschaften, München/Historische Kommission]

- $\square$ •Carlé, Walter (1988): Werner - Beyrich - von Koenen - Stille. - Ein geistiger Stammbaum wegweisender Geologen. - Geol. Jb., Reihe A, 108: 3 - 499, 62 Abb.; Hannover [darin S. 103-328, Abb. 16-50: 7. Hans Stille]

\section{$>\mathbf{T}$}

बFehler, Andreas (1996): Wilhelm Ernst TENTZEL (1659-1707) - Begründer der Paläozoologie in Deutschland. - Der Aufschluss, 47: 235-238, 1 Abb.; Heidelberg

OMey, Eberhard (2004): Wilhelm Ernst Tentzel (1659 - 1707). - Gesamttitel: Kap. 9 - Von der fürstlichen Sammmlung zum Museum - Naturkundliches Sammeln und Naturwissenschaft Geologie, Mineralogie, Paläontologie. - In: Scheumann, Konrad \& Jördis, Frank [Hrsg.]: Neu entdeckt: Thüringen $-<$ Land der Residenzen $<1485-1918><2$. Thüringer Landesausstellung Schloss Sondershausen, 15. Mai - 3. Oktober 2004>. - Katalog 2. - S. 204-205, 2 Abb.; Mainz 2004

口Lenz, Hans Gerhard (1981): Johann Thoelde - ein Paracelsist und „Chymicus“ und seine Beziehung zu Landgraf Moritz von Hessen-Kassel. - Diss. Univ. Marburg/Lahn 1982; 268 S.

口Humberg, Oliver (2005): Neue Erkenntnisse zur Biographie des „Haligraphen“ und Alchemisten Johann Tölde. - Jahrbuch f. Salzgeschichte - Journal Salt History, 10/11 (f. 2005/2006): 41-62; (Benekamp) [Schwaz/Tirol]

$\square$ Weber, Kristin (2006): Der vergessene Alchimist: Johann Thölde de Grevendorv. - Das Werraland, 요(1): 1-3, 4 Abb.; Bad Sooden-Allendorf

$\square$ Forbert, Stefan (2008): Der Bewahrer der Stollen - Harry Träger erhält am 19. November den Deutschen Denkmalschutzpreis 2008. - Werra-Rundschau, 2008; Nr. 243 v. 17.10.2008; 1 Abb.; Eschwege 
Der Bergbau-Ingenieur H. T. und seine Initiativen zur Erhaltung der Bergbau-Relikte am Meißner und im Höllental]

\section{$>\mathrm{U}$}

-Burre, Otto \& Nöring, Friedrich (1967): Hans Udluft gest.- Notizbl. Hess. L.-A. Bodenforsch., 95: 249 - 264, 1 Portr.; Wiesbaden [S. 259-264 Verz. d. Veröff.]

-Nöring, Friedrich (1967): Hans Udluft gest. - 1909 - 1966. [Nachruf] - Geol. Jb., 84: LV - LVI, 1 Bildnis; Hannover

-Knetsch, Karl (1903): Selbstbiographie des Johann Sigmund Urend, hessischen Berg- und Hütteninspectors und Amtmanns zu Nentershausen. - Hessenland, $\underline{17}(22): 296-298$ 17(23): 311-314; Kassel

\section{$>\mathbf{V}$}

口OGümbel, [Carl Wilhelm v.] (1896/1971): Voigt - Johann Karl Wilhelm V[oigt]. - Allgemeine Deutsche Biographie, $\underline{40}$ (Vinstingen Walram): 205; (Dunker \& Humblot) Berlin 1971 - Unveränd. Nachdruck der Erstausgabe von 1896, erschienen bei Dunker \& Humblot in Leipzig [Hrsg. Kgl. Akademie der Wissenschaften, München/Historische Kommission]

口OWagenbreth, Otfried (1979): Der Ilmenauer Bergrat Johann Carl Wilhelm Voigt und seine Bedeutung für die Geschichte der Geologie. - Abh. d. Staatl. Museums f. Mineralogie u. Geologie z. Dresden, (Geologen der Goethezeit) 29: 59-97, 7 Bilder, 7 Tab.; Leipzig

\section{$>\mathbf{W}$}

OJäger, Klaus-Dieter (2004): Erdwissenschaftliche Heimatforschung von überregionaler Bedeutung Alfred Wätzel 80 Jahre. - Mühlhäuser Beiträge, 27: 148-152; Eschwege

$\square$ Johannes, Martin O. (1959): Jakob Sigismund von Waitz, Freiherr von Eschen. - Das Werraland, 11(1): 10-11, 1 Abb. u. (2): 28-29; Eschwege

口 $\square$ Windisch, Fritz (1965): Jakob Sigismund Waitz von Eschen. - Bergbau im Hessenland, 15(5): 14-15, 1 Abb.; Kassel

oWeigelt, Johannes (1930): Der Lebensgang von Johannes Walther. - (Festschrift Johannes Walther) Leopoldina - Berichte der Kaiserlich Leopoldinischen Deutschen Akademie der Naturforscher zu Halle, 6: 3-7, 1 Bildnis, Veröffentlichungen S. 7-10; (Quelle \& Meyer) Leipzig

OBülow, Kurd v. (1962): JOHANNES WALTHER, der Begründer der Biogeologie - Gedenkwerk zu seinem 25. Todestag. - Ber. geol. Ges. DDR, $\underline{\mathbf{6}}$ (f. 1961)(4): 373-382, 1 Portr.; Berlin

OSeibold, Ilse (1993): Stationen auf dem Lebensweg Johannes Walthers. - Z. dt. geol. Ges., 144: 249254, 1 Abb.; Hannover 
QMatthes, H. W. (1962): Prof. Dr. HANS WEBER 70 Jahre. - Hallesches Jb. mitteldt. Erdgeschichte, 4: 97-102, Taf. III (1 Portrait); Berlin

QHohl, Rudolf (1966): In memoriam HANS WEBER. - Ber. Dt. Ges. geol. Wiss., Reihe A, 11(3): 413415, 1 Portr.; Berlin

QHohl, Rudolf (1966): Hans Weber zum Gedächtnis. - Hallesches Jb. Mitteldt. Erdgeschichte, $\mathbf{7}$ (f. 1965): 82-86, 1 Bildnis (Taf. II), [mit Verz. d. Veröffentlichungen]; Leipzig

QSchwab, Max \& Schultheiss, Thimo (1992): Hans Weber zum 100. Geburtstag - Leben und Werk. Geol. Bl. NO-Bayern, 42(1-2): (Gedenkschrift HANS WEBER): 1-10, 1 Portr.; Erlangen

- $\square \bullet$ Tobien, Heinz (1973): Wilhelm Weiler [Nachruf]. - Nachr. Dt. Geol. Ges., 7/1973: 14-15, 1 Abb.; Hannover

- $\square$ •Carlé, Walter (1988): Werner - Beyrich - von Koenen - Stille. - Ein geistiger Stammbaum wegweisender Geologen. - Geol. Jb., Reihe A, 108; S. 3 - 499 (499 S.); 62 Abb.; Stuttgart [u.a. Geologen Beyrich, von Koenen, Stille: Kartierer der Preußischen Geologischen Landesanstalt in der Region]

OGümbel, [Carl Wilhelm v.] (1880/1971): Weiß - Christian Ernst W[eiß]. - Allgemeine Deutsche Biographie, 41 (Walram - Werdmüller): 562-563; (Dunker \& Humblot) Berlin 1971 - Unveränd. Nachdruck der Erstausgabe von 1880, erschienen bei Dunker \& Humblot in Leipzig [Hrsg. Kgl. Akademie der Wissenschaften, München/Historische Kommission]

OSterzel (1892): Christian Ernst Weiss [Nachruf]. -N. Jb. Mineral. etc, 1892 (Bd. I): 24 S. (sep. Zählg.); Stuttgart

OSterzel (1892): Christian Ernst Weiss gest. [Nachruf]. - Jb. Preuss. Geol. Landesanst., 11 (f. 1890): CIX - CXXXIII, 1 Bildnis; Berlin

- $\square$ ○्Carlé, Walter (1988): Werner - Beyrich - von Koenen - Stille. - Ein geistiger Stammbaum wegweisender Geologen. - Geol. Jb., Reihe A, 108: 3 - 499, 62 Abb.; Stuttgart

[u.a. Beiträge über Beyrich, von Hoff, Freiesleben, von Koenen, Lotze, Stille, Voigt - Kartierer und Erforscher der Region]

口Gümbel, [Carl Wilhelm v.] (1897/1971): Werner - Abraham Gottlob W[erner] - Allgemeine Deutsche Biographie, $\underline{42}$ (Werenfels - Wilhelm d. Jüngere, Herzog zu Braunschweig und Lüneburg): 33-39; (Duncker \& Humblot) Berlin 1971 - Unveränd. Nachdruck der Erstausgabe von 18907 erschienen bei Duncker \& Humblot in Leipzig [Hrsg. Kgl. Akademie der Wissenschaften, München/Historische Kommission]

-Schröder, Wilfried (2000): Emil Wiechert (Physiker - Geophysiker - Wissenschaftsorganisator). - Mitt. Arbeitskreises Gesch. d. Geophysik, 19, H. I-2; 216 S.; o. O

[Emil Wiechert war erster Inhaber des Lehrstuhles für Geophysik an der Univ. Göttingen; ermöglichte durch seine Erfindung des „astatischen Pendels“ die korrekte Aufzeichnung und wissenschaft. Erforschung von Erdbeben. Die Errichtung der Erdbebenwarte auf dem Hainberg geht auf seine Initiative zurück. Nach Emil Wiechert und seinem Schüler Benno Gutenberg ist die Wiechert-Gutenberg-Diskontinuität benannt, die seismisch nachgewiesene Grenze zwischen Erdmantel und Erdkern in ca. $2900 \mathrm{~km}$ Tiefe]

- $\square$ Wigand (Bergrat)(1908): Meine Ausbildung als kurhessischer Bergwerksbeflissener in 1846/47. Hessenland, 22 (21): 301-303, 222(22): 319-321; Kassel

Darin: Bergreviere Richelsdorfer Gebirge u. Meißner, Hirschberg b. Großalmerode, Faulbach, Saline Sooden a.d. Werra] 
-Wachendorf, H. (1975): Hans-Georg Wunderlich [Nachruf]. - Nachr. Dt. Geol. Ges., 12/1975: 7-9, 1 Portr.; Stuttgart

\section{$>\mathrm{Z}$}

QNamenskürzel (D.) (1930): Ernst Zimmermann und seine Verdienste um die geologische Erforschung Thüringens. Zu seinem 70. Geburtstag. - Beitr. Geologie Thüringens, 2 (6): I-XVI, 1 Portrait; Jena

@Anonym (1947): (Personalnachrichten - Verstorben) <Nachruf Ernst Zimmermann>. - Z. Dt. geol. Ges., $\underline{96}$ (f. 1944): 145-146; Berlin

ODeubel, F. (1951): Ernst Zimmermann †. - Z. Dt. geol. Ges., 102 (f. 1950): 129-133, 1 Portrait; Hannover

OBerg, Georg (1951): Ernst Zimmermann gest. [Nachruf]. - Geol. Jb., 또: XXVII - XLII, 1 Bildnis, mit. Schriftenverzeichnis; Hannover

ODeubel, F. (1952): In memoriam - Ernst Zimmermann. - Geologie, 13(3): 210-214, 1 Taf.; Berlin

QDeubel, F. (1960): Ernst Zimmermann zum Gedenken an seinem 100. Geburtstag. - Ber. geol. Ges. DDR, $\underline{\mathbf{5}}(1 / 2):$ 121-123, 1 Abb.; Berlin

- $\square$ Görlich, Paul (1995): Berg- und Hütten-Commisarius bey dem Richelsdorfer Kupfer- und

Kobaldswerk. - Kreis Hersfeld-Rotenburg - Heimatkalender $\underline{1995}$ und Wegweiser (ㅍ․ Jg. ): 86 - 89;

Bad Hersfeld

\section{Personengruppen}

口OPrescher, Hans [Hrsg.](1985): Leben und Wirken deutscher Geologen im 18. und 19. Jahrhundert. 1. Aufl.; 388 S., 108 Abb.; (Dt. Verlag f. Grundstoffindustrie) Leipzig

OScheumann, Konrad \& Jördis, Frank [Hrsg.] (2004): Neu entdeckt: Thüringen $-<$ Land der Residenzen $<1485-1918><2$. Thüringer Landesausstellung Schloss Sondershausen, 15. Mai -3. Oktober 2004>. - Katalog 2. - 480 S., zahlr. Ill., 2 Beil. (Faltbl); (Philipp von Zabern) Mainz am Rhein

[Aufsatzsammlung, darin: Lebensbeschreibungen thüringischer Geologen (Sammeln und Naturwissenschaft - Geologie, Mineralogie, Paläontologie)]

- $\square$ •Wagenbreth, Otfried (1999): Geschichte der Geologie in Deutschland. - VIII, 264 S., 123 Abb.; (ENKE i. Georg Thieme Verlag) Stuttgart

[darin: Forscher, Kartieraktivitäten, ansonsten kein regionaler Bezug]

\subsection{Geschichte der Geowissenschaften}

OBarthel, M. (1982): Klassische paläobotanische Sammlungen aus dem Thüringer Wald. - Gleditschia, 9: 45-55, 1 Taf.; Berlin [darin: Sammlungen von v. Schlotheim, Goethe, v. Sternberg, Mahr, H. Cotta] 
OBarthel, Manfred (1994): Von MYLIUS bis SCHLOTHEIM - Paläobotanische Sammlungen des 18. Jahrhunderts aus Manebach, Thüringer Wald. - In: Grote, Andreas [Hrsg.]: Macrocosmos im Microcosmos - Die Welt in der Stube. Zur Geschichte des Sammelns 1450-1800. - Berliner Schr. z. Museumskde., 10; 966 S., zahlr. Abb. - S. 707-720, 2 Abb.; (Leske \& Budrich) Opladen

OBarthel, Manfred (1999): „... zur Auffrischung meiner Berg- und Gesteinslust...“ - Goethe und die Pflanzenfossilien aus dem Thüringer Wald. - Veröff. Naturkundemuseum Erfurt, Naturwiss. Rh., 18: 21-48, 2 Abb., 10 Taf.; Erfurt

[Paläobotanik Rotliegendes]

OBarthel, Manfred (2000): Manebach und die geologischen Wissenschaften. - In: Meyer, Monika [Red.]: Manebach im Thüringer Wald und seine Geschichte - Bergbau, Fossilien, Glas, Masken. - 2., verbess. Aufl.; 160 S., mehr. Abb. i. T., 12 Abb. i. Anhg.; hier S. 31-58, 1 Abb. i. T., Abb. 1-12 a. S. 101-107; (Escher) Gehren 2000

QBarthel, Manfred (2003): Otto GIMM und die Rotliegend-Pflanzen des Thüringer Waldes. - Veröff. Naturkundemuseum Erfurt, Naturwiss. Rh., 22: 5-12, 6 Abb.; Erfurt

OBarthel, Manfred \& Rößler, Ronny (1995): „Eine gannt unbekanndte Frucht...“ - 300 Jahre paläobotanisches Sammeln und Beobachten in Manebach. - Veröff./ Naturhist. Museum Schleusingen, 10: 49-56, 11 Abb.; Schleusingen

$\square$ Beck, Hanno (1952): Wie die Blaue Kuppe weltberühmt wurde. - Das Werraland, 4(1): 3-5, 1 Abb.; Eschwege

$\square$ Beck, Hanno (1952): Die Erforschung des Meißners. - Das Werraland, 4(2): 19-22, 1 Abb.; Eschwege

- $\square$ Beck, Hanno (1953): Alexander von Humboldt und das nördliche Hessen. - Hessische Heimat, N.F., $\underline{\mathbf{3}}(1): 14-15 ;$ Marburg/L.

[Geschichte der Geowissenschaften]

$\square$ Beck, Hanno (1956): Die Blaue Kuppe in der Wissenschaftsgeschichte. - In: Beck, Hanno: Eschwege - Heimat und Welt. - 72 S.; hier S. 18-21; (Roßbach) Eschwege 1956

$\square$ Beck, Hanno (1956): Die Geschichte der Meißnerforschung. - In: Beck, Hanno: Eschwege - Heimat und Welt. - 72 S.; hier S. 22-34; (Roßbach) Eschwege 1956

$\square$ Beck, Hanno (1956): Eschwege und seine Landschaft im Mund berühmter Männer. - In: Beck, Hanno: Eschwege - Heimat und Welt. - 72 S.; hier S. 8-9; (Roßbach) Eschwege 1956

[Zeungisse über „Blaue Kuppe“ und Hoher Meißner]

$\square$ Beck, Hanno (1956): Hanno Beck: „Eschwege - Heimat und Welt“ - Der Verfasser zu seinem neuen Buch über unsere Landschaft und ihre Persönlichkeiten. - Werra-Rundschau, 1956; Nr. 124 v. 30.5.1956, S. 3; Eschwege

$\square$ Beck, Hanno (1957): Hundeshagens Meißnerforschungen. - Hessische Heimat, $\underline{6}[$ f. 1956/57](1): 18-19; Marburg/L.

- $\square$ Beck, Hanno (1961): Vulkanisten und Neptunisten in Hessen. - Ber. Dt. Landeskunde, 27: 87-106; Bad Godesberg

$\square$ Beck, Hanno (1965): Natur- und Kulturgeschichte des Meißners (Serie: Eschweger Literatur, 27). Werra-Rundschau, 1965; Nr. 241 v. 16.10.1965, S. 7; Eschwege

[Erforschungsgeschichte, Bergbaugeschichte]

$\square$ Beck, Hanno (1965): <Schreiber, Carl: Medicinisch-physikalische Beschreibung des Physicatsbezirks Eschwege > Pionier in der Erforschung der Eschweger Landschaft. Dr. Carl Schreiber wurde in 
Eschwege zu Unrecht vergessen / 1849 erschien sein bahnbrechendes Werk (Serie: Eschweger Literatur, 34). - Werra-Rundschau, 1965; Nr. 288 v. 11.12.1965, S. 6; Eschwege

$\square$ Beck, Hanno (1965): Geologie der Eschweger Landschaft (Serie: Eschweger Literatur, 228). - WerraRundschau, 1965; Nr. 247 v. 23.10.1965; Eschwege

[Erforschungsgeschichte, Landesaufnahme]

$\square$ Beck, Hanno (1968): Woher kannte Humboldt die Blaue Kuppe? - Werra-Rundschau, 1968, Nr. 214 v. 14.9.1968, S. 5; Eschwege

- $\square$ Beck, Hanno (1973): Geographie. Europäische Entwicklung in Texten und Erläuterungen. - Serie: Orbis academicus. 2 $2 / 16$; 510 S.; (Albers) Freiburg i. Br. - München [darin S. 124-127: „Die Topographie des Landgrafen Hermann zu Hessen-Rotenburg“ [Werra, Meißner]; S. 146-147: „Topographische Tradition: Heinrich Hofrock“ [Beschreibung der Landschaft um Eschwege]; S. 191-192 Rudolf Erich Raspe[Habichtswald]; S. 207-208 „Vulkanismusstreit“ [Meißner, Blaue Kuppe, Habichtswald]

$\square$ Beck, Hanno (1974): Das Werden des geographischen Selbstbewußtseins der Bürger einer deutschen Stadt [Eschwege]. - Hessische Heimat, N.F., 24(2/3): 92-101; Marburg/L.

[Geschichte der geowissenschaften Erforschung der Eschweger Gegend]

口Böhme, Gottfried (2003): 200 Jahre Wissenschaftsbeziehungen auf dem Gebiet der Geologie und Paläontologie zwischen Südthüringen und Berlin. Bausteine zur Wissenschaftsgeschichte einer Region. - Veröff./ Naturhist. Museum Schleusingen, 18: 57-68, 5 Abb.; Schleusingen [darin: Paläobotanische Funde Manebach]

-Bückius, Matthias \& Schwedt, Georg (1999): Geologie - Goethe im Göttinger Reich der Steine. - In: Mittler, E.; Purpus, E. \& Schwedt, G. [Hrsg.]: „Der gute Kopf leuchtet überall hervor““. - 270 S., zahlr. Abb.; hier: S. 180-183, 1 Abb.; (Wallstein) Göttingen

-Bückius, Matthias \& Schwedt, Georg (1999): Katalog [ Fossilien, Mineralien der Goethe-Sammlung, inhaltlich an Kap. Geologie - Goethe im Göttinger Reich der Steine“" anschließend] - In: Mittler, E.; Purpus, E. \& Schwedt, G. [Hrsg.]: „Der gute Kopf leuchtet überall hervor“. - 270 S., zahlr. Abb.; hier: S. 184-187; (Wallstein) Göttingen

[Fde. I13- I19: Funde vom Hainberg/Göttingen]

ØClaus, H. (1927/28): Beiträge zur Geschichte der geologischen Forschung in Thüringen. - Beitr. Geol. Thür. , 1 (2): 34 - 35, 1 Abb.; Jena

@Claus, H. (1973): Die geologisch-paläontologische Erforschung der Burgtonnaer Travertinlagerstätten. Abh. Ber. Museums d. Natur Gotha, [7] 1973: 1-8, 1 Abb.; Gotha

QFiedler, Hans Joachim (2000): Alte und neue Beziehungen zwischen Geologie und Pedologie. - Z. geol. Wiss., 28(5): 545-557, 7 Abb.; Berlin

[Wissenschaftsgeschichte, darin: Ferdinand Senft, Forstlehranstalt Eisenach]

QFreyberg, Bruno von (1932): Die geologische Erforschung Thüringens in älterer Zeit - ein Beitrag zur Geschichte der Geologie bis zum Jahre 1843 - sowie einer Zusammenstellung der geologischen Literatur über Thüringen bis 1843. - VI, 160 S., 11 Abb., 8 Bildn..; (Bornträger) Berlin Referat in: N. Jb. Mineral. etc., Referate; 1932 (Bd. II): 611-612 (Erich Kaiser)

- Fichter, Jürgen \& Poser, Christof (2000): Die Gestein- und Mineraliensammlungen Fulda - Belege und geologische Sammlertätigkeit im 19. Jahrhundert. - Philippia, 9(4): 245-260, 4 Abb.; Kassel [Famile Fulda - Kurhessische Beamten- und Unternehmerfamilie] 
oHempel, Gerhard (2000): Die Geschichte der Fachrichtung Geologie an der Friedrich-SchillerUniversität [Jena] nach dem zweiten Weltkrieg. - Geowiss. Mitt. Thür., Beih. 9: 21-56, 9 Abb.; Weimar

$\square$ Jäger, Willy (1924): Aus dem Nachlaß des Heimatgeologen Wilhelm Kuntze (gest. 1923). - Das Werratal, $\underline{1}(8)$ : 119-122; Eschwege

[Referat über unveröffentlichte Arbeiten aus dem Nachlass]

$\square$ Kollmann, Karl (1999): Goethe und unsere Heimat - Auf den Spuren des Dichterfürsten im Werraland. - Das Werraland, 51(4): 85-87, 3 Abb.; Eschwege [Besuch des Dichterfürsten in der Saline Sooden]

- Koritnig, Sigmund (1990): Johann Friedrich Ludwig Hausmann. Ein Mann an der Wende von der alten zur neuen Mineralogie. - Der Aufschluss, 41: 27-32, 4 Abb.; Heidelberg [J.F.L. Hausmann; Professor für Mineralogie in Göttingen von 1811-1859]

- Koritnig, Sigmund (1993): Zur Frühgeschichte der Mineralogie an der Universität Göttingen. - Der Aufschluss, 44: 237-242, 1 Abb; Heidelberg

-Kraft, Fritz (1999): Basalt - am Anfang war es nur ein Wort. - Zur Wissenschaftsgeschichte des Geistwortes „basaltes“. - Der Anschnitt, $\underline{\mathbf{1 1}}$ (1): 2-15, 7 Abb.; Bochum [darin: Neptunisten-Plutonistenstreit, Bezugnahme a. Rudolf Erich Raspe]

$\square$ Lotze, Franz (1950): 100 Jahre Forschung in der saxonischen Tektonik. - Z. dt. geol. Ges., 100 (f. 1948): 321 - 337; Stuttgart [Bezugnahme auf die Kartierung der Bl. Alllendorf u. Witzenhausen von F. Moesta]

- $\square \bullet$ Lotze, Siegfried (1999): Forschen und Reisen niederhessischer Montanmänner im 19. Jahrhundert. Auslandsbeziehungen kurhessischer Berg- und Hüttenmänner. - Z. Vereins hess. Gesch. u. Landeskde., 104: 185-202, [1 Abb., 1 Stamm-Taf.]; Kassel [darin: Strippelmann, Schwarzenberg; der (Göttinger) Göttingische Verein bergmännischer Freunde]

OMartens, Thomas \& Oesterheid, Heinz (1987): Die geologische Sammlung des Gothaer Naturwissenschaftlers und Staatsbeamten KARL ERNST ADOLF von HOFF (1771-1837) und ihre wissenschaftliche Analyse - erste Ergebnisse. - Abh. Ber. Museums d. Natur Gotha, (14) 1987: 19-29, Taf. 7-11; Gotha

OMartens, Thomas (1990): Zur Geschichte und Bedeutung der paläontologischen Sammlung im Museum der Natur Gotha. - Abh. Ber. Museums d. Natur Gotha, (16) 1990: 23-28, 1 Taf.; Gotha

OMartens, Thomas (2000): Historisch und wissenschaftlich bedeutende geologische Sammlungen im Museum der Natur Gotha. - Abh. Ber. Museums d. Natur Gotha, (21) 2000: 77-98; Gotha

QMartens, Thomas (2007): Die geologische Erforschung des Thüringer Waldes von den Anfängen bis zum 1. Weltkrieg. - In: Fuchs, Thomas [Bearb.]: Die Entdeckung des Thüringer Waldes. - Katalog zur Ausstellung der Universitäts- und Forschungsbibliothek Erfurt/Gotha im Spiegelsaal auf Schloss Friedenstein in Gotha 27. Juni bis 24. August 2007 - bearbeitet von ... mit Beiträgen von Thomas Martens und Jürgen Paasch. - Veröff. Forschungsbibliothek Gotha, 43; 126 S., zahlr. Abb.; hier: S. 9 - 15, 2 Abb.; Gotha 2007

-Mayer, Gaston (1975): Rudolph Erich Raspe - Naturalienlieferant der Markgräfin Caroline Luise von Baden. - Z. Vereins hess. Gesch. u. Landeskde., 도: 185-188; Kassel [Lieferung von Exponaten aus Nordhessen]

OMeyrick, Rich \& Maul, Lutz Christian (2003): Ausgrabungen in Burgtonna seit 300 Jahren. - Natur und Museum, 133(9): 253-261, 9 Abb.; Frankfurt/M. 
$\square$ Oppitz, Ulrich-Dieter (1962): Alexander von Humboldt und die Blaue Kuppe. - Das Werraland, 14(3): 41-43; Eschwege

$\square$ Oppitz, Ulrich-Dieter (1962): Alexander von Humboldt und die Blaue Kuppe. - WR, 1962; Nr. 110 v. 12.5.1962; Eschwege

QOschmann, Martin (1969): Naturwissenschaft und Naturforscher des 18. und 19. Jahrhunderts in Gotha. - Abh. Ber. Museums d. Natur Gotha, [5] 1969: 3-18; Gotha

[Bezugn. a. Geowissenschaften und Geowissenschaftler]

OPröscholdt, Hermann (1891): Geschichte der Geologie in Thüringen. - Programm der Realschule zu Meinigen, Nr. 609; S. 1-30; Meiningen

Referat in: N. Jb. Mineral. etc., 1882 (Bd. 1): 377-378 (Referat E. W. Benecke); Stuttgart

- $\square$ •Schmeisser, Karl (1904): Die Geschichte der Geologie und des Montanwesens in den 200 Jahren des preußischen Königreichs, sowie die Entwickelung und die ferneren Ziele der Geologischen Landesanstalt und Berg-Akademie. - Festrede, gehalten von Schmeisser bei Gelegenheit der Zweihundertjahrfeier des Königreichs Preussen. - Jb. Preuß. Geol. Landesanst., $\underline{22}$ (f. 1901): XXXVI; Berlin

OSchmidt, Ralf \& Werneburg, Ralf (1994): „Würzbuger Lügensteine“ aus der Sammlung des Naturhistorischen Museums Schleusingen. - Veröff./ Naturhist. Museum Schleusingen, 9: 91-99, 5 Abb.; Schleusingen

QSchubert, Christian (1977): Zu den methodologischen und erkenntnistheoretischen Grundlagen der Geologie. - Z. geol. Wiss., $\underline{\mathbf{5}}(4)$ : 431-442; Berlin

[Kap. 4 - Die Anfänge der Wissenschaft Geologie im sächsisch-thüringischen Raum zwischen 1750$1850<$ darin: K.E.A. von Hoff>]

oSeib, Gerhard (1980): Das älteste natürliche geologische Profil Hessens - Archivalischer Fund erhellt Entstehungsgeschichte der Schichtenfolge des Richelsdorfer Gebirges. - Hessische Heimat, N.F., 30(2): 59-66, Abb. 35-40; Marburg/L.

- Seib, Gerhard (2000): Zur Geschichte der Fuldaschen Gesteins- und Mineraliensammlung und deren Urheber. - Philippia, 9 (4), 221-244, 15 Abb.; Kassel

[Famile Fulda - Kurhessische Beamten- und Unternehmerfamilie]

-Siebert, Manfred (1997): Geschichte des Instituts für Geophysik in Göttingen. - In: Neunhöfer, H.; Börngen, M.; Junge, A. \& Schweitzer, A. [Hrsg.]: Zur Geschichte der Geophysik in Deutschland. Jubiläumsschift zur 75jährigen Wiederkehr der Gründung der Deutschen Geophysikalischen Gesellschaft. - 226 S.; hier: S. 107 - 114, 6 Abb.; (Deutsche Geophysikalische Gesellschaft) Hamburg 1997

- $0 \bullet$ Stahl, Ingo (1996): 75 Jahre Kaliforschung. - Kali u. Steinsalz, 12(1): 4-17, 18 Bilder; Essen [darin: Kaliforschungs-Institut der Kali u. Salz AG, Heringen]

- $\square$ (W)Wagenbreth, Otfried (1999): Geschichte der Geologie in Deutschland. - VIII, 264 S., 123 Abb.; (ENKE i. Georg Thieme Verlag) Stuttgart

[darin: Forscher, Kartieraktivitäten, ansonsten kein regionaler Bezug]

- $\square$ Waitz von Eschen, Friedrich Frhr. (2007): Zu den Anfängen geologischer Forschung in HessenKassel im 18. Jahrhundert. - Z. Vereins hess. Gesch. u. Landeskde., 112: 203-215; Kassel

-Walliser, Otto Heinrich \& Alberti, Lieselotte (1987): Die Geschichte der Geologie und Paläontologie in Göttingen. - Georgia Augusta, 46: 73-76; Göttingen 
-Wedepohl, Karl Hans (1987): Die Geschichte der Mineralogie in Göttingen. - Georgia Augusta, 46: 6972; Göttingen

OWiefel, Heinz (1974): Geschichte der geologischen Erforschung [von Thüringen]. - In: Hoppe, Walter \& Seidel, Gerd [Hrsg.]: Geologie von Thüringen [Bezirke Erfurt, Gera, Suhl]. - S. 11-25, 2 Abb., 8 Portr.; (Haack) Gotha-Leipzig 1974

OWiefel, Heinz (1995): Geschichte der geologischen Erforschung [von Thüringen]. - In: Seidel, Gerd [Hrsg.]: Geologie von Thüringen. - 1. Aufl.; S. 1-5; Stuttgart 1995

OWiefel, Heinz (2003): Geschichte der geologischen Erforschung [von Thüringen]. - In: Seidel, Gerd [Hrsg.]: Geologie von Thüringen. - 2., neu bearb. Aufl.; S. 1-5; Stuttgart 2003

QZeissler, Hildegart (1984): Zur Geschichte der malako-zoologischen Forschung in der Umgebung von Mühlhausen in Thüringen. - Abh. Ber. Museums d. Natur Gotha, (12) 1984: 49-57; Gotha [Bezugn a. paläontologische Forschung und Forscher]

QZimmermann I, E. (1927): Robert Scheibe und die Geologie des Thüringer Waldes. - Jb. Preuß. Geol. Landesanst., $\underline{47}$ (f. 1926): LXXI-XCI; - Schriftenverzeichnis von R. Scheibe S.: S. XCI - XCIII (H. Rauff); Berlin [Erforschungsgeschichte des Thüringer Waldes]

- $\square$ Zittel, Karl Alfred v. (1899): Geschichte der Geologie und Paläontologie bis Ende des 19. Jahrhunderts. - Reihe: Geschichte der Wissenschaften in Deutschland, 23. - XI, 868 S.; (Oldenbourg) München-Leipzig

[darin S. 402-403 Kap. (Dynamische Geologie) - Erloschene Vulkane. - darin kurz erwähnt: die Vulkane der Umgebung von Cassel, im Habichtswald, Kaufunger Wald u. Meißner - weiterhin: Geschichte der geologischen Kartierung der nordhessischen Vulkangebiete]

\subsection{Landesaufnahme}

\subsubsection{Institutionen}

$\square$ Anonym (1965): Standquartier für Institute: Berliner Wissenschaftler kommen nach Eschwege. Gasthaus „Zur blauen Kuppe“ von der FU Berlin erworben. - HA (WN), 1965, Nr. 79 v. 3.4.1965; Witzenhausen

- $\square$ Bargon, Egon (1987): 40 Jahre Hessisches Landesamt für Bodenforschung. - Geol. Jb. Hessen, 115: 473 - 507, 2 Abb., 3 Tab.; Wiesbaden

- $\square$ •Beyschlag, Franz (1902): Die Aufgaben der geologischen Landesaufnahme von Preussen und den benachbarten Bundesstaaten. - Z. prakt. Geologie, 10: 177-179; Berlin [Vortragsreferat]

- $\square 0 \bullet$ Beyschlag, Franz (1914): Die preußische Geologische Landesanstalt - Entwicklung und Leistungen, Aufgaben und Ziele - Festrede am 29. November 1913. - Z. prakt. Geol., 22.1914 (1): 22-29, o. Abb.; Berlin

-Bundesanstalt f. Geowissenschaften u. Rohstoffe/Geol. Landesämter [Hrsg.](1984): 25 Jahre Bundesanstalt für Geowissenschaften und Rohstoffe und Niedersächsisches Landesamt für Bodenforschung. - Geol. Jb., Reihe A, 푸; 418 S., zahlr. Abb.; Hannover 
- $\square$ O $\bullet$ Bundesanstalt f. Geowissenschaften u. Rohstoffe, Hannover [Hrsg.] (2004): Die staatlichen geologischen Dienste - Strategien, Persönlichkeiten, Geschichte. - Geol. Jb., Reihe G, 11; 100 S., Abb., Kt.; Hannover

- $\square$ O Guntau, Martin (1998): Zur Gründung staatlicher Geological Surveys und Geologischer Dienste im 19. Jahrhundert. - Z. geol. Wiss., 26 $(1 / 2):$ 257-264, 5 Tab.; Berlin

- 0 O Hauchecorne, W. (1881): Die Gründung und Organisation der Königlichen Geologischen Landesanstalt für den Preussischen Staat. - Jb. Preuß. Geol. Landesanst., 1 (f. 1880): IX-XCVIII; Berlin

- $\square$ Hoppe, Andreas (1996): 50 Jahre Hessisches Landesamt für Bodenforschung: Standortbeschreibung und Ausblick. - Geol Jb. Hessen, 124: 5 - 13, 3 Abb.; Wiesbaden

OHoppe, Walter (1973): Zur Geschichte der Thüringischen Geologischen Landesuntersuchung. - Wiss. Z. Hochschule f. Architektur u. Bauwesen Weimar, 20(1): 91-95; Weimar

OJudersleben, Georg (2001): Zehn Jahre Geologischer Landesdienst in Weimar. - Geowiss. Mitt. Thür., 9: 5-19, 2 Abb.; Jena

- $\square$ O०Kamps, H. J. (1987): Die Bildung und Entwicklung zentraler staatlicher geologischer Institutionen in Berlin in der Periode von der Entstehung des deutschen Imperialismus bis zum Inferno des faschistischen Krieges. - Z. angew. Geol., $\underline{33}(6)$ : 148-153; Berlin [Preußische Geologische Landesanstalt]

- $\square$ Kockel, Carl Walter (1953): 100 Jahre Hessische Geologische Landesanstalt. - Oberhessische Presse, 1953; Nr. 32 v. 7.2.1953, 2 Abb.; Maburg

- $\square$ O Krusch, P. (1900): Die geologische Landesanstalt und Bergakademie zu Berlin mit besonderer Berücksichtigung ihrer Museen und Sammlungen. - Z. prakt. Geologie, $\underline{8}$ : 201-213, Abb. 30-34; Berlin

- $\square 0 \bullet$ Kürsten, Martin (1997): August Heinrich Ernst Beyrich und die Gründung der Preußischen Geologischen Landesanstalt. - Z. dt. geol. Ges., 148 (3/4): 309 - 316, 2 Abb.; Stuttgart

- $\square$ Kutscher, Fritz (1953): Zur Geschichte des staatlichen geologischen Dienstes in Hessen. - Notizbl.

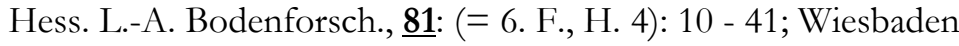

- $\square$ OlLang, Hans Dietrich [Red.](1974): 100 Jahre Preußische Geologische Landesanstalt - Festakt am 1.6.1973 in Hannover. - Grüßworte - Vorträge - wissenschaftliche Beiträge. - Geol. Jb., Reihe A, A15; 213 S., 40 Abb., 1 Tab., 1 Taf.; Hannover

- $\square$ Q $\bullet$ Lüttig, Gerd (1974): Zur 100jährigen Wiederkehr der Gründung der Preussischen Geologischen Landesanstalt. - In: Lang, Hans Dietrich [Red.](1974): 100 Jahre Preußische Geologische Landesanstalt - Festakt am 1.6.1973 in Hannover. - Grüßworte - Vorträge - wissenschaftliche Beiträge. - Geol. Jb., Reihe A, A15: 9-14, 2 Abb.; Hannover

- $\square$ OCMeinhold, Klaus-Dieter [Hrsg.] (2003): 125 Preußische Geologische Landesanstalt und ihre Nachfolger - Geschichte und Gegenwart. - Geol. Jb., Reihe G, 10 ; (zgl. Inf. Bund/LänderArbeitsgruppen staatl. Geol. Dienste); 261 S., 29 Abb., 2 Tab.; (Schweizerbart) Stuttgart

- $\square$ O Neumann-Mahlkau, Peter (1998): Die staatlichen Geologischen Dienste bis 1945. - In: Hänel, Ralph \& Homilius, J. [Koordinatoren]: Rechtsgrundlagen und Aufgaben der Staatlichen Geologischen Dienste in der Bundesrepublik Deutschland. - Geol. Jb, Reihe G, 푸 232 S., 33 Abb., 10 Tab., 54 Anl.; hier S. 7-15, 2 Abb. Hannover 1998

- $\square$ O Neumann-Mahlkau, Peter (1998): Die Entwicklung der staatlichen Geologischen Dienste nach 1945. - In: Hänel, Ralph \& Homilius, J. [Koordinatoren]: Rechtsgrundlagen und Aufgaben der 
Staatlichen Geologischen Dienste in der Bundesrepublik Deutschland. - Geol. Jb, Reihe G, $\underline{\mathbf{3}}$; 232 S., 33 Abb., 10 Tab., 54 Anl.; hier S. 17-23, 1 Abb.; Hannover 1998

- $\square 0 \bullet$ Neumann-Mahlkau, Peter (1998): Die Entwicklung der staatlichen Geologischen Dienste nach 1945. - In: Hänel, Ralph \& Homilius, J. [Koordinatoren]: Rechtsgrundlagen und Aufgaben der Staatlichen Geologischen Dienste in der Bundesrepublik Deutschland. - Geol. Jb, Reihe G, $\underline{\mathbf{3}}$; 232 S., 33 Abb., 10 Tab., 54 Anl.; hier S. 17-23, 1 Abb.; Hannover 1998

OPuff, Peter (1994): Die Thüringer Geologische Landesanstalt in Jena - ein Rückblick. - Geowiss. Mitt. Thüringen, 2: 217-234, 4 Abb.; Weimar

- $\square \bullet$ OSchmeisser (1901): Die Feier der Kgl. Geol. Landesanstalt u. Bergakademie zu Berlin am 18. Januar. - Z. prakt. Geol., 9.1901 (2): 76-79; Berlin

[Festrede des Geheimraths Schmeisser - anläßlich der 200. Wiederkehr der Krönung Friedrichs III. zum König in Preußen]

- $[0 \bullet$ Schmeisser, [Karl] (1904): Die Geschichte der Geologie und des Montanwesens in den 200 Jahren des preußischen Königreichs, sowie die Entwickelung und die ferneren Ziele der Geologischen Landesanstalt und Berg-Akademie. - Festrede, gehalten von Herrn Geheimen Bergrath Schmeisser bei Gelegenheit der Zweihundertjahrfeier des Königreichs Preussen.... - Jb. Preuß. Geol. Landesanst., $\underline{22}$ (f. 1901): I - XXXVI; Berlin

$\square$ Stäblein, Gerhard (1986): Erdwissenschaften und Feldarbeit. Das Standquartier der Freien Universität Berlin an der Blauen Kuppe bei Eschwege. - In: Stäblein, Gerhard [Hrsg.]: Geo- und biowissenschaftliche Forschungen der Freien Universität Berlin im Werra-Meißner-Kreis (Nordhessen). - Berliner Geogr. Abh., 1ㅜ; zgl. Beiträge zur Werra-Meißner-Forschung, I; S. 13 - 23, 6 Abb., 1 Tab.; (Selbstverl. Inst. Phys. Geogr. FU Berlin) Berlin 1986

- $\square$ Thews, Joe-Dietrich (1996): Geschichte des Hessischen Landesamtes für Bodenforschung 1946 1996. - Geol Jb. Hessen, 124: 15 - 37, 1 Abb.; Wiesbaden

- $\square$ Thews, Joe-Dietrich (2006): 60 Jahre Staatlicher Geologischer Dienst in Hessen - 150 Jahre geologische Dienste auf hessischem Staatsgebiet. - Reihe: Umwelt u. Geologie; 68 S., 36 Abb., 5 Tab.; [Hrsg. Hess. Landesamt f. Umwelt u. Geologie] Wiesbaden

- $\square$ Oण Udluft, Hans (1968): Die Preussische Geologische Landesanstalt 1873 - 1939. - Beihefte Geol. Jb., 푸 170 S., 2 Tab., 3 Taf.; Hannover

- $\square \bullet$ Vidal, Helmut (1985): Die Geologischen Dienste der Bundesrepublik Deutschland - Mittler zwischen Staat, Forschung, Lehre und Wirtschaft. - Z. dt. geol. Ges., 136: 23 - 68, 3 Abb., 1 Tab.; Hannover

- $\square$ •Wirth, Uwe (1983): Zur Vorgeschichte und Gründung einer staatlichen geologischen Institution in der 2. Hälfte des 19. Jahrhunderts in Preußen, dargestellt am Beispiel der Preußischen Geologischen Landesanstalt in Berlin. - Diss. Univ. Rostock 1983; II, 155, 8 S.

\section{Standquartier Erdwissenschaften - Eschwege}

$\square$ Namenskürzel (EB) (1962): Am Fuß der Blauen Kuppe entsteht ein Gasthaus. Großes Ausflugsziel mit acht Fremdenzimmern / Eröffnung im nächsten Frühjahr. - Werra-Rundschau, 1962; Nr. 200 v. 29.8.1962, [S. 4], 1 Abb.; Eschwege

[nachmaliges Standquartier Erdwissenschaften der Freien Universität Berlin]

$\square$ Namenskürzel (eb) (1963): Ausflugslokal am Fuß der Blauen Kuppe. Hotel - Restaurant - Café wird morgen eröffnet / Stätte behaglicher Gastlichkeit. - Werra-Rundschau, 1963; Nr. 279 v. 2.12.1963, S. 5, 1 Abb.; Eschwege [nachmaliges Standquartier Erdwissenschaften der Freien Universität Berlin] 
$\square$ Namenskürzel (Na) (1964): Instituts-Außenstelle auf dem Meißner? Freie Universität Berlin an wissenschaftlicher Station im Kreis Eschwege interessiert. - Werra-Rundschau, 1964; Nr. 218 v. 19.9.1964, S. 3, 1 Abb.; Eschwege

$\square$ Namenskürzel (Na) (1965): Außenstelle Eschwege der Freien Universität Berlin bezugsfertig / Nur das Laboratorium fehlt noch/ Erste Studenten ziehen im Frühjahr in das frühere Gasthaus „Blaue Kuppe“ ein. - Werra-Rundschau, 1965, Nr. 260 v. 8.11.1965, S. 3; Eschwege

$\square$ Namenskürzel (mk) (1966): < Standquartier Erdwissenschaften der Freien Universität Berlin $>$ Neues Leben in der „Blauen Kuppe“. Erste Studentengruppe bezog das Standquartier der Freien Univeristät Berlin. - Werra-Rundschau, 1966; Nr. 69 v. 23.3.1966, S. 3; Eschwege

$\square$ Sønnichsen, Katharina (2002): Biostudenten im Werratal. - Im „Haus an der Blauen Kuppe“ erforscht Hochschule die Landschaft. - Werra-Rundschau/Sontagszeit, 2002; Nr. 32 v. 11.08.2002, 1 Abb.; Eschwege [Standquartier Erdwissenschaften der FU Berlin]]

$\square$ Namenskürzel (hs) (2008): „Da steckt viel Herzblut drin“ - Ferien- und Seminarhaus an der Blauen Kuppe stehen zum Verkauf. - Werra-Rundschau, 2008; Nr. 66 v. 18.03.2008, 1 Abb.; Eschwege [Ehemaliges Standquartier Erdwissenschaften der FU Berlin]

\subsubsection{Sammlungen}

OMädler, Jonas \& Umbreit, Elke (1998): Die Sammlung der Thüringer Landesanstalt für Geologie in Weimar - 1. Die Gesteinsdünnschliff- und Erzschliffansammlung. - Geowiss. Mitt. Thüringen, ㅁ: 173180, 2 Diagr.; Weimar

OMädler, Jonas \& Umbreit, Elke (2001): Die Sammlung des Geologischen Dienstes Weimar (bsiher Thüringer Landesanstalt für Geologie) der Thüringer Landesanstalt für Umwelt und Geologie. - 2. Die geologisch-petrographisch-lagerstättenkundliche Landessammlung. - Geowiss. Mitt. Thüringen, 9: 65-69, 2 Abb.; Weimar

OSchubert, Joachim (1995): Das Bohrkern- und Probenarchiv (GEOPAT) der Thüringer Landesanstalt für Geologie in Niederpöllnitz. - Geowiss. Mitt. Thüringen, 포 329-338, 2 Abb.; Weimar

- $\square$ Strecker, Gerhard (2002): Die petrographische Sammlung im Geologischen Landesdienst Hessen. Jber. HLUG, f. 2001, S. 103-105, 3 Abb.; Wiesbaden

\subsubsection{Karten, Datenbanken}

\subsubsection{Länderübergreifende Veröffentlichungen}

d $\square$ O•Kegel, Wilhelm (1944): Die Kartenwerke des Reichsamtes für Bodenforschung. - Jb. Reichsamt f. Bodenforsch., $\underline{\mathbf{6 3}}$ (f. 1942): 599-628, 2 Abb.; Berlin

- - Lang, Hans Dietrich (1970): Geologische und bodenkundliche Kartenwerke in der Bundesrepublik Deutschland. - Geol. Jb., 요: 681-686, 1 Tab., 4 Taf.; Hannover 
- $\square$ OSchamp, Heinz (1961): Ein Jahrhundert amtliche geologische Karten - Verzeichnis der amtlichen geologischen Karten von Deutschland und Nachweis ihrer Standorte in Bibliotheken und Instituten. Ber. dt. Landeskde., Sonderh. $\underline{4}$; 536 S., 2 Kt.-Beil..; [Bundesanst. f. Landeskde. u. Raumforschung] Bad Godesberg

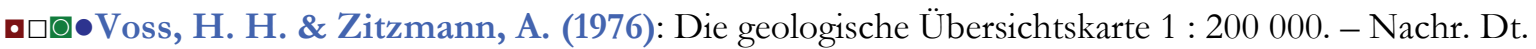
Geol. Ges., 14: 73-74; Hannover

- $\square$ OCZitzmann, Arnold (1994): Geowissenschaftliche Karten in der Bundesrepublik Deutschland. - Z. dt. geol. Ges., 145: 38-87, 9 Abb., 11 Tab.; Hannover

\subsubsection{Länderbezogene Veröffentlichungen}

\subsection{Hessen}

- $\square$ Berthold, G.; Rücker, H.; Toussaint, B.; Löns-Hanna, C. \& Bastian, D. (2002): Die Grund- und Rohwasserdatenbank Hessen (GruWaH). - Jber. HLUG, f. 2001, S. 11-17, 9 Abb., 2 Tab.; Wiesbaden

- $\square$ Friedrich, Klaus (1999): Die Bodenflächendaten 1 : 50000 Hessen - Ziele, Aufbau und Erfahrungen. - Mitt. Dt. bodenkdl. Ges., 91(2): 977-980, 2 Abb.; Oldenburg i. Old.

- $\square$ Friedrich, Klaus (2002): Die Digitale Bodenkarte von Hessen 1 : 25 000. - Jber. HLUG, f. 2001, S. 107-110, 3 Abb.; Wiesbaden

-Fuchs, Gerhard (1968): Nach 81 Jahren: Neue geologische Karte 5124 Bad Hersfeld. - Mein Heimatland, 2 3 (9): 33 - 35, 4 Abb.; Bad Hersfeld

هGöbel, Peter (1978): Vorschläge zur Aufnahme und Gestaltung geomorphologischer Karten - erläutert am Beispiel der Geomorphologischen Karte 1 : 25 000, Bl. 5125 Friedewald. - Geol. Jb. Hessen, 106: 303 - 317; Wiesbaden

- $\square$ Heggemann, Heiner; Hoselmann, Christian \& Stark, Achim (2003): Die Digitale Geologische Karte von Hessen 1:25000 (GK 25). - Jber. HLUG, f. 2002, S. 97-101, 3 Abb.; Wiesbaden

d $\square$ Jungmann, Walter Wilhelm (1980): Die Bodenkarte des Landes Hessen (1 : 25 000) mit Erläuterungen als zentraler Teil landschaftsökologischer Vorerkundung - dargestellt am Beispiel der topographischen Blätter 4921 Borken/Hessen und 4821 Fritzlar. - Diss. Univ. Marburg 1980, 168 S., graph. Darst., Kt., 10 Beil.

- $\square$ Kasel, Herbert \& Sabel, Karl-Josef (2004): Die Bodenflächendaten 1 : 50000 (BFD 50): Ein modernes Bodeninformationssystem. - Jber. HLUG, f. 2001, S. 99-103, 2 Abb.; Wiesbaden

- $\square$ Küttner-Bahr, Susanne \& Seemann, Kornelia (2004): Online-Zugriff auf Bohrdaten in Hessen eine Anwenderinformation. - Jber. HLUG, f. 2003, S. 93-98, 6 Abb.; Wiesbaden

- $\square$ Liedmann, W.; Hoffmann, M. \& Hoessle, J. v. (2002): Die neue Übersichtskarte oberflächennaher Rohstoffe in Hessen 1 : 300 000. - Jber. HLUG, f. 2001, S. 115-120, 7 Abb.; Wiesbaden

$\square$ Meier, Berndt (1989): Kartographische Herstellung der geologischen Karte des Hohen Meißner. - In: Jacobshagen, Volker \& Kuhnert, Christian [Hrsg.]: Der Hohe Meißner in Hessen - Ergebnisse geologischer und geomorphologischer Forschungen. - Berliner geowiss. Abh., Reihe A, 114; S. 5-8; (Selbstverlag Fachber. Geowiss. FU Berlin) Berlin 1989 
- $\square$ Pompejus, Roman (2004): Das Hessische Umweltportal. - Jber. HLUG, f. 2003, S. 81-85, 5 Abb.; Wiesbaden

- $\square$ Sabel, Karl Josef (1999): Gestein, Relief und Boden - Zur Philosophie der Bodenkarte von Hessen 1 : 50 000. - Frankfurter Geogr. H., 63: 119-116, 2 Tab.; Frankfurt/M.

- $\square$ Schraft, Adalbert (2005): Geotope in Hessen online - eine Datenbank für das Geotopmanagement in Hessen. - Jber. HLUG, f. 2004, S. 115-123; Wiesbaden

- $\square$ Schraft, Adalbert (2006): Eine Datenbank für das Geotopmanagement in Hessen. - Schriftenrh. Dt. Ges. f. Geowiss., 42: 68-71, 4 Abb.; Berlin-Hannover

- $\square$ Ulmer, Dominik; Friedrich, Klaus \& Ulmer, Simon [Bearb.](1999): Das Hessische Erdinformationssystem (HEISS) - Elektronische Datenverarbeitung in einem Geologischen Landesdienst. - Geologie in Hessen, $\underline{\mathbf{3}}$ /1999; 33 S., 28 Abb.; [Hrsg.: Hess. Landesamt f. Bodenforschung] Wiesbaden

\subsection{Thüringen}

QAndreas, D. (1997): Die “Geologische Karte Thüringer Wald 1 : 100.000” Herausgegeben von der Thüringer Landesanstalt für Geologie - Weimar 1996 (Posterbeitrag). - In: Büchel, Georg \& Lützner, Harald (Hrsg.): Regionale Geologie von Mitteleuropa - Geodynamische Prozesse zwischen Alpen und Nordatlantik - 149. Hauptversammlung - Deutsche Geologische Gesellschaft und Jahreshauptversammlung der Fachsektion Geoinformatik - Jena 27.09.-3.10.1997 - Kurzfassung der Vorträge und Poster. - Schriftenrh. Dt. geol. Ges., 2: 20-21; Hannover 1997

OCotta, B. (1840): Geognostische Karte von Sachsen und vom Thüringer Wald. - N. Jb. Mineral. etc., 1840: 75-76; Stuttgart

OHuckriede, H.; Heuse, Th.; Katzschmann, L.; Kümpel, P.; Peters, A. \& Schröder, A. (2005): Die digitale Geologische und Hydrogeologische Übersichtskarte von Thüringen. - Geowiss. Mitt. Thür., 12: 97-103, 4 Abb.; Jena

OMartens, Thomas (2007): Die geologische Erforschung des Thüringer Waldes von den Anfängen bis zum 1. Weltkrieg. - In: Fuchs, Thomas [Bearb.]: Die Entdeckung des Thüringer Waldes. - Katalog zur Ausstellung der Universitäts- und Forschungsbibliothek Erfurt/Gotha im Spiegelsaal auf Schloss Friedenstein in Gotha 27. Juni bis 24. August 2007 - bearbeitet von ... mit Beiträgen von Thomas Martens und Jürgen Paasch. - Veröff. Forschungsbibliothek Gotha, $\underline{43}$; 126 S., zahlr. Abb.; hier: S. 9 - 15, 2 Abb.; Gotha 2007

[darin: Geschichte der geologischen Kartierung]

\subsection{Niedersachsen}

-Becker-Platen, Jens Dieter (1983): Geowissenschaftliche Karten des Naturraumpotentials [von Niedersachsen und Bremen]. - In: Barsch, Dieter \& Richter, Gerold [Hrsg.]:

Geowissenschaftliche Kartenwerke als Grundlage einer Erfassung des Naturraumpotentials Tagungsband. - Forsch. z. Dt. Landeskde., 220: 119-163, 12 Abb.; Trier

-Benzler, Jobst Heinrich \& Müller, Werner (1983): Die Bodenkarte 1 : 25000 (BK 25) und ihre Auswertungskarten. - In: Barsch, Dieter \& Richter, Gerold [Hrsg.]: Geowissenschaftliche 
Kartenwerke als Grundlage einer Erfassung des Naturraumpotentials - Tagungsband. - Forsch. z. Dt. Landeskde., 220: 57-61; Trier - auch in: Verhdlgn. Dt. Geographentag, 43: 124-127; Wiesbaden

-Boess, Jürgen; Müller, Udo \& Sbresny, Jan (1999): Erläuterungen zur digitalen Bodenkundlichen Übersichtskarte 1: 50000 (BÜK 50) von Niedersachsen. - Arbeitshefte Boden 1999/1: 3-60, 11 Abb., 15 Tab.; Hannover

-Brüning, Kurt (1939): Bodenkundliche Kartenwerke der Provinz Hannover [Vortragstext]. - Z. dt. geol. Ges., 91: 604-611; Hannover

-Brunotte, E.; Garleff, K. \& Wahle, H. (1980): Neue morphographische und geomorphologische Karten aus dem südniedersächsischen Bergland. 6 Kartenproben im [Maßstab] 1:50 000 und 1:100 000. - Neues Archiv f. Niedersachsen, 29 (1): 85 - 96, 7 Abb.; Göttingen

-Dieler, Silvia; Elbracht, Jörg \& Schwarz, Carsten (2002): Aufbau und Nutzung des Informationssystems „Geologische Karte von Niedersachsen 1:50 000“ - Design and objectives of the information system „Geological Map of Lower Saxony $1: 50.000 “$. - Z. geol. Wiss., $\underline{\mathbf{3 0}}$ (6): 431442, 6 Abb., 2 Tab.; Berlin

-Elbracht, Jörg \& Schwarz, Carsten (2001): Die neue Geologische Karte von Niedersachsen 1:5000 Von der thematischen Karte zum modularen Informationssystem < Vortragskurzfassung >. - In: Rauche, Henry [Hrsg.]: Regionale und angewandte Geologie der Grenzregion der Süddeutschen und der Mitteldeutschen Scholle. - Programm und Kurzfassungen der Vorträge. - 10. Jahrestagung Gesellschaft f. Geowissenschaften i. Schmalkalden, 19.-22. September 2001. - Exkursionsführer u. Veröff. Ges. f. Geowiss., 214; S. 103-104; Berlin 2001

-Gehrt, Ernst \& Sbresny, Jan (1999): Erläuterungen zur Ableitung und den Inhalten der Bodenübersichtskarten $1: 200000$ (BÜK 200) und 1: 500000 (BÜK 500) von Niedersachsen. Arbeitshefte Boden, 1999/1: 61-98, 4 Abb., 12 Tab.; Hannover

-Hinze, Carsten (1983): Die Geologische Karte von Niedersachsen 1 : 25000 (GK 25) - Aktuelle Aufnahme- und Darstellungsverfahren vielschichtiger Überlagerungen. - In: Barsch, Dieter \& Richter, Gerold [Hrsg.]: Geowissenschaftliche Kartenwerke als Grundlage einer Erfassung des Naturraumpotentials - Tagungsband. - Forsch. z. Dt. Landeskde., 220: 11-26, 6 Abb.; Trier - auch: Verhdlgn. Dt. Geographentag, 노: 128-130, 1 Abb.; Wiesbaden

-Josopait, Volker (1983): Die Darstellung des Naturraumpotentials Grundwasser [Geowiss. Kt. d. Naturraumpotentials v. Niedersachsens und Bremen]. - In: Barsch, Dieter \& Richter, Gerold [Hrsg.]: Geowissenschaftliche Kartenwerke als Grundlage einer Erfassung des Naturraumpotentials - Tagungsband. - Forsch. z. Dt. Landeskde., 220: 165-179, 3 Abb.; Trier

-Krische, Paul (1941): Der „Bodenkundliche Atlas von Niedersachsen“ - ein grundlegendes Pionierwerk. - Petermanns geogr. Mitt., 87(9): 329-331; Gotha

-Lüders, Rudolf (1979): Die bodenkundlichen Kartenwerke des Niedersächsischen Landesamtes für Bodenforschung (mit einer Blattübersicht). - Neues Archiv f. Niedersachsen, 28: 237-240, 1 Falt-Kt.; Göttingen

-Meyer, Klaus-Dieter (1983): Die Geologische Übersichtskarte 1 : 200000 (GÜK 200) unter besonderer Berücksichtigung Niedersachsens - Methodik und Inhalt. - In: Barsch, Dieter \& Richter, Gerold [Hrsg.]: Geowissenschaftliche Kartenwerke als Grundlage einer Erfassung des Naturraumpotentials - Tagungsband. - Forsch. z. Dt. Landeskde., 220: 27-32, 6 Abb.; Trier - auch in: Verhdlgn. Dt. Geographentag, 43: 130-133, 1 Abb. [Blattübersicht]; Wiesbaden

-Müller, Werner (1970): Die Bodenkartierung in Niedersachsen. - Geol. Jb., Beih. 1ㅗ(1): 4-12, 4 Taf.; Hannover 
-Müller, Werner \& Lüders, Rudolf (1977): Die Bodenkundliche Standortkarte von Niedersachsen und Bremen 1 : 200 000. - Mitt. Dt. Bodenkdl. Ges., 25: 459-466, 2 Abb.; Göttingen

-Oelkers, Karl - Heinz \& Lüders, Rudolf (1983): Zur Methodik bei der Erarbeitung bodenkundlicher Kartenwerke. - In: Barsch, Dieter \& Richter, Gerold [Hrsg.]: Geowissenschaftliche Kartenwerke als Grundlage einer Erfassung des Naturraumpotentials - Tagungsband. - Forsch. z. Dt. Landeskde., 220: 43-55, 5 Abb.; Trier

- Rohde, Peter (1979): Der Stand der Geologischen Landesaufnahme in Niedersachsen (mit einer Blattübersicht). - Neues Archiv f. Niedersachsen, 28: 241-245, 1 Falt-Kt.; Göttingen

-Schwarz, Carsten; Elbracht, Jörg \& Dieter, Silvia (2001): Geologische Karte von Niedersachsen 1 : 50000 (GK 50 digital) - Darstellung der Geologie in einem neuen Rahmen. - Z. angew. Geol., 47(2): 109-113, 7 Abb.; Berlin

\subsubsection{Erkundungsarbeiten}

- $\square$ OAnonym (1885): < Stand der geologischen Landesaufnahme im Regierungsbezirk Kassel $>$. Eschweger Tageblatt, 1885; Nr. 156 v. 8.7.1885; Eschwege

[Blätter Ermschwerd, Witzenhausen, Großalmerode, Allendorf, Kella, Seifertshausen, Altmorschen, Melsungen]

-Anonym (1931): Die Geologie der Hessischen Senke. - Eschweger Tageblatt, 1934; Nr. 228 v. 29.09.1931

[Irreführender Titel; Inhalt: Geologische Karte von Preußen; Kartierung der Blätter AmöneburgHomberg a.d. Ohm, Kirchhain und Neustadt-Arnsheim durch M. Blanckenhorn]

$\square$ Anonym (1934): < Landwirtschaftliche Bodenkartierung mit Hilfe des Arbeitsdienstes> - Eschweger Tageblatt, 1934; Nr. 251 v. 26.10.1934; Eschwege

$\square$ Beck, Hanno (1965): Geologie der Eschweger Landschaft (Serie: Eschweger Literatur, 208). - WerraRundschau, 1965; Nr. 247 v. 23.10.1965; Eschwege

[Erforschungsgeschichte, Landesaufnahme]

-Becker, Roland Ernst \& Laemmlen, Manfred (1992): Die geologische Erkundung des HainrodeTunnels. - Kritische Betrachtung zur Soll-Geologie, Ist-Geologie und amtliche Blattkartierung. Geol. Jb. Hessen, 120: 171 - 193, 7 Abb., 2 Taf.; Wiesbaden [Bl. 5023 Ludwigseck]

- $\square \bullet$ Beyschlag, Fr. (1893): Geologische Specialaufnahmen - 1. Preussen und die thüringischen Staaten. - Z. prakt. Geol., [1] $\underline{1893}$ (1): 2-4; Berlin

-Beyschlag, F. (1902): < Geschichte der geologischen Erforschung der Umgebung von Kassel> - Rede zur Begrüssung der 47. Allgemeinen Versammlung der Deutschen geologischen Gesellschaft zu Cassel. - Z. dt. geol. Ges., 54: 116-117 (Verhdlgn.); Berlin

- $\square$ Blanckenhorn, M. (1932): Die geologische Landesaufnahme des Regierungsbezirks Kassel und der hessischen Provinz Oberhessen durch die Preußische und Hessische Geologische Landesanstalt. Hessenland, 43 (1/2): 10-13, 1 Index-Karte; Marburg

QEernst, Werner (1993): Vorausssetzungen und Anfänge der geologischen Spezialkartierung im Maßstab 1 : 25.000 in Mitteldeutschland. - Z. geol. Wiss., 21(5/6): 469-478, 2 Abb., 1 Tab.; Berlin [darin: Thüringen] 
OFranke, Dietrich \& Söllig, Armin (1969): 20 Jahre geologische Kartierung in der Deutschen Demokratischen Republik - Ein Überblick über die geologischen Kartenwerke der DDR. - Geologie, 18 (8): 889-910, 7 Abb.; Berlin

QGeiger, Walter (1983): Ein „Abriß der Geologie des Eichsfeldes“ ist notwendig. - Eichsfelder Heimathefte, (23. Jg.) 1983(2): 173-176; Worbis

OHetzer, Hans (1969): 20 Jahre geologische Erforschung und Erkundung in der Deutschen Demokratischen Republik. - Z. angew. Geol., 15: 447-455, 4 Abb.; Berlin

- $\square$ Keller, Thomas (1994): Paläontologische Denkmalpflege in Hessen - Eigenschaften, Aufgaben und Ziele paläontologischer Denkmalpflege. - Paläontologische Denkmäler i. Hessen, 1; 11 S., Abb., Kt.; [Hrsg. Abt. Archäologie u. Paläontologische Denkmalpflege i. Landesamt f. Denkmalpflege Hessen, Archäologische Gesellschaft in Hessen e.V.] Wiesbaden

-Koehne, W. (1915): Die Entwickelungsgeschichte der geologischen Landesaufnahmen in Deutschland. - Geol. Rundschau, ㅁ: 178 - 192; Leipzig

-Koe[h]nen, A. von (1886): Mittheilung über die geologische Aufnahme der Umgebung von Göttingen. - Nachr. Kgl. Ges. Wiss. z. Göttingen, $\underline{\mathbf{1 8 8 6}}(18)$ : 551; Göttingen [ohne regionalgeologische Beschreibung]

-Moesta, Friedrich (1872): Über die geologische Untersuchung der Provinz Hessen. - Jb. Mineral. etc., 1872: 966-973; Stuttgart

OZimmermann, E. I (1927): ROBERT SCHEIBE und die Geologie des Thüringer Waldes. - Jb. Preuß. Geol. Landesanst., $\underline{47}$ (f. 1926): LXIII-XCI; Berlin [Erforschungsgeschichte - Schriftenverzeichnis von R. Scheibe S. XCI-XCIII (H. Ranff)] 


\section{Geowissenschaften}

\subsection{Regionale Geologie}

\subsubsection{Regionale Geologie - Hessen (ohne Werra-Meißner- Kreis)}

- $\square$ Althaus (1840): Basaltdruchbrüche, Fischabdrücke, Mineralien. - N. Jb. Mineral. etc., 1840: 86 (Briefl. Mitt.); Stuttgart

[Orientierende Ersterkundung des nordosthessischen Berglandes durch einen Zugezogenen, „Blaue Kuppe“, Richelsdorfer Gebirge]

- $\square$ Anonym (1953): Erdgeschichtlicher Aufbau des Hessenlandes. - Bergbau i. Hessenland (Ausgabe Braunkohle), (3.Jg.) 1953(19): 3, 2 Abb.; Kassel

[Bezugn. a. Nordhessen]

-Anonym (1969): Geschichte und Landschaft - Vor 60 Millionen Jahren. - In: Schulze-Wegener, Günther [Red. d. Textes] : Wolfhager Land im Naturpark Habichtswald. - 60 S. u. Anzeigen-Teil, zahlr. Abb.; hier S. 11; [Hrsg. Kreisausschuß Landkreis Wolfhagen] Wolfhagen 1969

- $\square$ • Apel, Jürgen \& Rüppel, Heidi [Verfass. u. Hrsg.] (2005): Raus in die Natur - Tipps für den Sonntags-Ausflug im Dreiländereck Hessen - Niedersachsen - Thüringen. - 159 S., 111 Fotos, 34 Kt., 1 Zeit-Taf.; (LSRB-Verlag, Landschaftskundlicher-Studien-Reisebuch-Verlag) Witzenhausen [zahlreiche Ausflugsziele, auch zu nordhessischen Geotopen außerhalb des Werra-Meißner-Kreises]

-Baas, Friedrich-Karl (1973): Der Ahlberg - ein interessantes Wanderziel im Reinhardswald. Hessischer Gebirgsbote, 74(4): 85-87, 2 Abb.; Melsungen

[darin: Erdgeschichte, Braunkohle-Bergbau]

- Bender, Friedrich (1984): Zur Geologie des Raumes Spangenberg. - In: Festausschuß: Buhre, Heinz u.a. [Red. u. Gestaltg.]: Festschrift - 675 Jahre Stadt Spangenberg. - 240 S., zahlr. Abb.; hier: S. 35-37, 4 Fig, 1 geol. Profil S. 34; [Hrsg. Magistrat d. Stadt Spangenberg] Spangenberg 1984

-Berkenbusch, Christian (1854) : Beiträge zur Geographie Kurhessens. - Hessisches Jb. - für 1854: 201-218; (Bertram) Cassel

[Naturräumliche Gliederung, Erdgeschichte Hessens]

- $\square$ Beyschlag, F. (1885): Ueber Aufnahmen an der unteren Werra und Fulda (Provinz Hessen-Nassau). Jb. Preuß. Geol. Landesanst., $\underline{\mathbf{5}}$ (f. 1884): XLIX-LII; Berlin [darin: Basalt Hoher Meißner]

-0Beyschlag, Franz (1887): Ueber geologische Aufnahmen auf den Blättern Salzungen und Altmorschen (im Sommer 1886). - Jb. Preuß. Geol. Landesanstalt, $\underline{7}$ (f. 1886): XLI-XLV; Berlin

- $\square$ Beyschlag, Franz (1888): Ueber Aufnahmen in Hessen. - Jb. Preuß. Geol. Landesanst., $\underline{8}$ (f. 1887):

LXI-LXIV; Berlin

[Bibliographisch bearbeitetes Gebiet von Hessen] 
-Beyschlag, F. (1892): Ueber Aufnahmen im Gebiete des Blattes Waldeck-Kassel (1 : 80.000). - Jb. Preuß. Geol. Landesanst., 10 (f. 1889): LXX-LXXXVII; Berlin

-Blanckenhorn, Max (1903): Geologie und Topographie der näheren Umgebung von Cassel. - In: Die Residenzstadt Cassel am Anfange des zwanzigsten Jahrunderts. - Festschrift zur 75. Versammlung Deutscher Naturforscher und Ärzte, September 1903, Cassel. - Hauptbd: VIII, 445 S., zahlr. Abb.; Beih. (63 S., Abb., 2 Kt.); hier Hptbd.: S. 57-139, 17 Abb., 2 Kt. i. Beih.; (Döll) Kassel

-Blanckenhorn, Max (1919): Bericht über die wissenschaftlichen Ergebnisse der geologischen Landesaufnahmen im Jahre 1916. - Jb. Preuß. Geol. Landesanst., 37 (Teil II) (f. 1916): 483 - 518; Berlin [Regionalgeologie des Knüllgebirges; Trias, Tertiär]

- $\square$ Blume, Helmut (1951): Das Land Hessen und seine Landschaften. - Forsch. dt. Landeskde., $\underline{\mathbf{5 5}}$; 110 S., 3 Kt., 16 Taf.; (Anst. F. Landeskde.) Remagen [darin: Knüll, Bebra-Hersfelder Becken, Kasseler Becken..., Senke v. Wolfhagen..., Werra-FuldaBergland]

-Bös, Wolfgang \& Kunz, Reiner (1997): Geologische Sehenswürdigkeiten im Wolfhager Land. -1 Faltplan [ m. zahlr. Abb., Routenplänen f. geol. Exkursionen, Abriß der Erdgeschichte]. - (Landkreis Kassel/Untere Naturschutzbehörde)

-Bonnemann, Alfred (1984): Der Reinhardswald. - XI, 451 S.; 21 Abb., 90 Tab.; (Verlag d. Weserbuchhdlg) Hann.-Münden [darin S. 3 - 39: „Die geologischen Zeitalter“ (Erdgeschichte der Region), Abb. 1-7, 10 Tab.; S. 3345375: „Der Braunkohlenbergbau und seine Betriebe“]

-Brauns, Eduard (1983): Ein Streifzug durch die nordhessische Bergwelt. - Hessischer Gebirgsbote, 84(2): 63 - 66; Melsungen

-Campsheide, Sabine [1996]: Der Naturraum des Ellenbachtals - (Übertitel: Geologie und Flora in Ellenbach). - In: Klode, W.; Ludwig, H. \& Sandrock, H. [Verantwortl.]: 850 Jahre Ellenbach Eine Chronik. - 410 S., zahlr. Abb.; hier: S. 26-30; [Hrsg. Heimatverein Ellenbach 1995 eV.] AlheimEllenbach [1996]

-Classen, Traugott (1979): Niederaula - Von der karolingischen Schenkung zur Großgemeinde Untersuchende Darstellung zur 1200-Jahrfeier. - 465 S., Abb., + 8 S. Register; [Hrsg. Gemeinde Niederaula] Niederaula

[darin S. 11-30, 8 Abb., 1 strat. Tab.: „Die naturräumlichen und frühgeschichtlichen Gegebenheiten Oberflächengestalt, Nutzung des Gebietes, Wasserläufe, Geologische Übersicht, Stratigraphische Tabelle, Bodenschätze, Vor- und Frühgeschichte"]

- $\bullet$ Dauber, Adolf (1857): Das Triasgebirge an der Oberweser und seine nächsten Umgebungen - eine geologische Skizze nebst einer Karte. - Teil d. Schulprogramm d. Herzogl. Gymnasiums z. Helmstedt - Do, den 2. April 1857; 30 S., 1 Kt.; (Schmidt) Helmstedt

[Region Lkr. Göttingen, Lkr. Kassel]

- $\square$ Deisenroth, Otto (1971): Naturräumliche und geschichtliche Grundlagen des Rotenburger Landes: Die Landschaft. - In: Herzog, Friedrich [Red.]: Der Kreis Rotenburg in Nordhessen. - 243 S., zahlr. Abb.; hier: S. 27-36; [Hrsg. Landrat Otto-Ulrich Bährens u. Dr. Konrad Theiss] (Theiss) Stuttgart-Aalen 1971

-Deisenroth, Otto (1985): Das Landschaftsbild des unteren Haunetales. - In: Gemeindeverwaltung Hauneck [Red.]: Hauneck - Kreis Hersfeld-Rotenburg: Chronik der sieben Dörfer - Geschichte, Kultur, Landschaft. - 276 S., zahlr. Abb.; hier S. 7-11, 5 Abb.; [Hrsg. Gemeindevorstand Gemeinde Hauneck] Hauneck 1985 
-Deist, Adam (1938): Die Siedelungen der Bergbaulandschaften an der hessisch-thüringischen Grenze. Frankfurter Geogr. Hefte, 12(2); 157 S., 2 Abb., 6 Kt., 5 Tab.; (Triltsch) Würzburg - zgl. Diss. Univ. Frankfurt/M. 1938

[darin S. 16-24, Abb. 1: „, Gesteinsaufbau und Boden"]

-Denckmann, A. (1892): Ueber Aufnahmen im Gebiete des Blattes Waldeck-Kassel (1:80.000). - Jb. Preuß. Geol. Landesanst., 10 (f. 1889): LVIII-LXV; Berlin

-Eichborn, Rudi (1969): Biberaho - Bebra, ein Gang durch die Geschichte: Die natürlichen Grundlagen. - In: Bebra - Chronik einer Stadt. - 140 S., zahlr. Abb.; hier: S. 9-12; [Hrsg. Magistrat der Stadt Bebra] Bebra 1969

[darin Informationen zur Geologie von Bebra und Umgebung]

-Engelbrecht, Otto Karl [Beteiligt] (1997): 800 Jahre Leuderode - 1197-1997. - Buch zur Geschichte unseres Bergbauerndorfes. - 160 S., zahlr. Abb.; [Hrsg. Gemeindevorstand d. Gemeinde Frielendorf] Frielendorf

[darin S. 13-14: „Geologische Betrachtungen“]

- $\square$ Freund, Bodo (2002): Hessen. - Reihe: Perthes Länderprofile; 375 S., 142 Abb. u. Kt., 15 Übersichten, 33 Tab.; 30 Farbphotos a. 8 Taf.; Gotha-Stuttgart

[darin S. 46-49: , Reich an geologischer Differenzierung, arm an mineralischen Rohstoffen]

- $\square$ Frick, Friedrich (1981): Natürliche Voraussetzungen einer mittelalterlichen Eisengewinnung im Kaufunger Wald. - Kaufunger Wald, H. 18: 2-3; Kaufunger Wald

[Regionale Geologie, Lagerstättengenese von tertiärem Brauneisenstein]

-Frick, Friedrich (1985): Erdgeschichte des Kaufunger Waldes - erläutert an beispielhaften geologischen Aufschlüssen. - In: Wroz, Wilfried u. a. [Bearb.]: 975 Jahre Kaufungen - 1011-1986 - Beiträge zur Heimatkunde. - 383 S., zahlr. Abb.; hier: S. 209-225, 6 Abb.; [Hrsg. Gemeindevorstand d. Gemeinde Kaufungen] Kaufungen 1985

-Germeroth, Rüdiger; Koenies, Horst \& Kunz, Reiner (2005): Natürliches Kulturgut Vergangenheit und Zukunft der Naturdenkmale im Landkreis Kassel. - 1. Aufl., 192 S., zahlr. Abb., Kt., Kt.-Skizz., graph. Darst.; [Hrsg. Kreisausschuss Landkreis Kassel, Untere Naturschutzbehörde] (Cognitio) Wolfhaben [darin S. 13 - 45, Abb., Kt.-Skizz., graph. Darst.: „Geologische Naturdenkmale“ mit Abriß der regionalen Erdgeschichte]

- $\square$ OGiebel, Chr. G. A. (1851): Gaea excursoria germanica - Deutschlands Geologie, Geognosie und Paläontologie - ein unentbehrlicher Leitfaden auf Excursionen und beim Selbstunterricht - mit 24 lithograpischen Tafeln. - XII, 510 S., 24 Taf.; (Abel) Leipzig

[Stratigraphie Deutschlands und regionale Verbreitung der Formationen; darin: S. 120 (Kap. Basalt: Blaue Kuppe b. Eschwege, Meissner, Hirschberg b. Großalmerode, Stoffelskuppe b. Eisenach; S. 167: Kap. Kupferschiefergebirge: Meißnervorland, Richelsdorfer Gebirge, Thüringer Wald; S. 191 Muschelkalk: Westhüringen, Nordosthessen, Südniedersachsen; S. 206: Keuper: Hess. Lichtenau, Westthüringen]

-Habedank, Klaus-Dieter (1986): Trendelburg und Umgebung - Wissenswertes, Liebenswertes. - 84 S., 22, [1] Abb.; Trendelburg [darin S. 7-8: „Unsere Landschaft: Geologie und Flora“]

-Halfar, Wolfgang (1981): Basaltberge und Wälder - Von der Natur- zur Kulturlandschaft des Wolfhager Landes. - In: Glitsch, G.; Halfar, W.; Winter, W.G. \& Winter, W. [Red.]: 750 Jahre Stadt Wolfhagen 1231-1981. - 183 S., zahlr. Abb.; hier S. 12-31, 1 Übers.-Kt.; [Hrsg. Magistrat d. Stadt Wolfhagen] Wolfhagen 1981 [darin Bezugn. a. Erdgeschichte der Region] 
-Hartmann, Peter (2005): Gudensberg erleben - Wandern im Chattengau entlang der Gudensberger Rundwanderwege. - 48 S., zahlr. Abb.; (Wartberg-Verlag) Gudensberg-Gleichen [darin S. 15-26, 6 Abb.: „Sehenswertes und Wissenswertes am Wegesrand - Erdgeschichte“]

- $\square \bullet$ Hausmann, [J. F. L.](1824): Uebersicht der jüngeren Flöz-Gebilde im Fluß-Gebiete der Weser. Tb. Mineral., 18 (3): 678-702; Frankfurt/M. - Auszug aus Hausmann: Uebersicht der jüngeren FlözGebilde. - Studien Göttingischen Vereins bergmänn. Freunde, 1: 381 - 567, Göttingen 1824 [Regionale Stratigraphie Trias-Tertiär Hessen, WMK, Niedersachsen; darin: Tertiär Meißner, Hirschberg, Habichtswald, Wilhelmshöhe b. Kassel, Dransfeld]

- $\square$ Q $\bullet$ Hausmann, J.F.L. (1824, 1828): Übersicht der jüngeren Flötzgebilde im Flußgebiete der Weser, mit vergleichender Berücksichtigung ihrer Äquivalente in einigen anderen Gegenden von Deutschland und der Schweiz. - Studien Göttingischen Vereins bergmänn. Freunde, 1: 381 - 567, Göttingen 1824; 2: 215-482; Göttingen 1828

[Regionale Stratigraphie Trias-Tertiär Nordhessen, Südniedersachsen; Bd. 1, Stratigraphie Buntsandstein; S. 500-508 „Basaltische Massen im Sandstein“, darin: Blaue Kuppe bei Eschwege, Pflasterkaute bei Eisenach]

-Hessler, Carl [Hrsg.] (1906): Hessische Landes- und Volkskunde - Das ehemalige Kurhessen und das Hinterland. Bd. I: Hessische Landeskunde. Erste Hälfte. - 531 S., zahlr. Abb.; (Elwert) Marburg 1906

-Hessler, Carl \& Blanckenhorn, Max (1911): Geologischer Führer durch die Umgegend von Cassel nebst einem Überblick über den Bau der Erdrinde und die Entwicklung der Tier- und Pflanzenwelt. VIII, 143 S.; (Elwert) Marburg

-Hölting, Bernward \& Laemmlen, Manfred (1974): Geologische und hydrogeologische Ergebnisse von Brunnenbohrungen am Süd- und Südwesthang des Knüllgebirges (Hessen). - Notizbl. Hess. L.A. Bodenforsch., 102: 270-295, 3 Abb., 2 Tab.; Wiesbaden

-Hohmann, Hermann-Josef (2003): Steter Wandel prägt die Landschaft. - In: Hohmann, HermannJosef \& Mehnert, Dagmar: Werra, Wald und weißer Berg - Streifzüge durch Heringen in Vergangenheit und Gegenwart. - 192 S., zahlr. Abb.; hier: S. 7-20, Abb., 1 geol. Kt., 1 strat. Profil; [Hrsg. Magistrat d. Stadt Heringen] (Hoehl Druck) Bad Hersfeld 2003

- $\square$ Hoppe, A.; Mittelbach, G. [Bearb., mit Beitr. and. Autoren] (1999): Geowissenschaftlicher Atlas von Hessen. - Geologie in Hessen, 4; 61 S., 30 Abb., zahlr. Kt.; [Hrsg. Hess. Landesamt f. Bodenforschung] Wiesbaden

-Hufschmidt, Fritz (1905): Versuch einer Geschichte des oberen Warmetales, insbesondere der Stadt Zierenberg, der Dörfer Dörnberg, Ehlen, Burghasungen, des ehemaligen Klosters Hasungen, der Kolonien Friedrichsaue und Friedrichstein, der Rittergüter Bodenhausen, Oedinghausen, Laar, Hohenborn und Sieberhausen. - 275 S., 1 Falt-Kt., mehr. Abb.; (Wilhelm Bosser) Wolfhagen [darin S. 1-2: „Geographische Lage, Geologisches“ (kurz)]

- 0 -Jäger, Helmut (1963): Naturräumliche Grundlagen von Siedlung und Wirtschaft im Wesergebiet. -

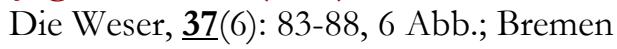

[Geographie, Regionale Geologie, Bergwirtschaft Hessen, Thüringen, Niedersachsen]

- Jäger, Helmut (1988/1951): Die Entwicklung der Kulturlandschaft im Kreise Hofgeismar. - Reihe: Arbeitskreis f. Heimatgeschichte d. Stadt Immenhausen, H. 후 201 S., 12 Taf. (Kt.) i. Anh.; (Eigenverlag d. Stadt Immenhausen) Immenhausen [Unveränderter Nachdruck d. Erstausgabe von 1951: Göttinger Geogr. H., ㅇ; (Eigenverlag d. Geogr. Inst. Univ. Göttingen) Göttingen

- $\square$ OJäschke, Max (1888): Das Meissnerland. Erster Theil: Physiographie. - Forsch. Dt. Landes- u. Volkskde., $\underline{\mathbf{3}}(2)$; 47 S.; (Engelhorn) Stuttgart - zgl. Diss. Univ. Marburg 1888

Referat in: N. Jb. Mineral. etc, $\underline{1889}$ (Bd. II): 71-72 (Franz Beyschlag); Stuttgart 
Referat in: Mitt. Geogr. Ges. (f. Thüringen), 7: 128-130 Fr. R.]; Jena

[Regionale Geologie Nordosthessen, Westthüringen]

- $\square$ OJJordan, Johann Ludwig (1803): Mineralogische, berg- und hüttenmännische Reisebemerkungen vorzüglich in Hessen, Thüringen, am Rheine und im Seyn-Altenkirchner Gebiethe. - 288 S., 1 Tab., 3 Falt-Taf.; (Dieterich) Göttingen

[Östl. Meißnervorland, „Riegelsdorfer“ [Richelsdorfer] Gebirge, Region um Schmalkalden]

-Jungmann, Olaf \& Zerr, Walter (2002): Zwischen Seulingswald und Knüllgebirge: Die Geologie der Umgebung von Friedlos. - In: 650 Jahre Friedlos - 1352-2002 - Geschichte und Geschichten eines hessischen Dorfes an der Fulda. - 528 S., zahlr. Abb.; hier: S. 28-33, 1 Abb.; [Hrsg.

Gemeindevorstand Gem. Ludwigsau, Festausschuß 650 Jahre Friedlos] Ludwigsau-Friedlos 2002

-Junker, Georg (1992): Die heimatliche Landschaft: Vom Werden der Landschaft. - In: Junker, Georg \& Mai, Gerhard: Chronik Allendorf - Texte und Bilder zur Geschichte eines Dorfes in der „Schmalzgrube“. - 216 S., zahlr. Abb.; hier S. 12-14, 1 Abb.; [Hrsg. Gemeindevorstand d. Gemeinde Frielendorf] Frielendorf-Allendorf 1992

-Kayser, E. (1906): Abriß der geologischen Verhältnisse Kurhessens. - In: Hessler, Carl [Hrsg.]: Hessische Landes- und Volkskunde - Das ehemalige Kurhessen und das Hinterland. Bd. I: Hessische Landeskunde. Erste Hälfte. - 531 S., zahlr. Abb.; hier: S. 144-169.; (Elwert) Marburg 1906

- 0 ○/Keller, H. [Hrsg.](1901): Weser und Ems, ihre Stromgebiete und ihre wichtigsten Nebenflüsse. Eine hydrographische, wasserwirtschaftliche und wasserrechtliche Darstellung. - Bd. I: Stromgebiete und Gewässer. - XVIII, 168 S., (Reimer) Berlin 1901 - Bd. II: Quell- und Nebenflüsse der Weser (ohne Aller). - [4], 603 S.; (Reimer) Berlin [darin: Werra, Fulda, Eder, Diemel, Oberweser]

[Bd. I - darin: 3. Kapitel: „Oberflächengestalt und geologische Verhältnisse“]

[Bd. II: „1. Abtheilung: Gebietsbeschreibung (Bodengestalt, Bodenbeschaffenheit, Gewässernetz, ....; 2. Abtheilung: Flußbeschreibung"]

-Kleim, Otto (1925): Geologische Wanderung [durch das Stadtgebiet von Kassel]. - Hessischer Gebirgsbote, $\underline{31}(4): 27$; Kassel

- $\square$ ○ीKlink, Hans-Jürgen (1969): Die naturräumlichen Einheiten auf Bl. 112 Kassel [TK Maßstab 1 : 200.000]. - Reihe: Geographische Landesaufnahme 1 : 200.000, Naturräumliche Gliederung Deutschlands. - 108 S., 1 Kt., 1 Beil.-Kt. 1 : 200.000 ; [Bundesforschungsanstalt f. Landeskunde u. Raumordnung] Bonn-Bad Godesberg

- $\square$ Klipstein, v. (1836): Versuch einer geographisch-geognostischen Eintheilung des westlichen Deutschlandes nebst generellen Andeutungen zur geognostischen Konstitution der verschiedenen Gebirgs-Abtheilungen desselben. - N. Jb. Mineral. etc., 1836: 255-289//; Stuttgart

[Entwurf einer regionalen Geologie von West-Deutschland; darin: „Habichtswald...“; „Meissner und Knöll“(Knüll)]

-Klugescheid, Michael (1993): Geologie des Gieselwerderer Raumes. - In: Deiß, A; Warnecke, W. \& Henne, R..: 900 Jahre Gieselwerder - 1093-1993. Beiträge zur Orts- und Heimatgeschichte und zum Dorfleben. - 504 S., zahlr. Abb.;hier S. 139-152, 3 Abb., 2 Tab.; [Hrsg. Gemeindevorstand Gemeinde Oberweser] Oberweser 1993

- Knetsch, Georg (1963): Geologie von Deutschland und einigen Randgebieten. - VII, 386 S., 63 Abb., 28 Taf., 1 geol. Kt. (Beil.); (Enke) Stuttgart

[darin: Hessische Senke]

-Krauß, Alfred (1913): Der Warburger Sattel, seine Baustörungen und die vulkanischen Durchbrüche. Jb. Preuß. Geol. Landesanst., 31 (Teil II) (f. 1910): 377-419, Taf. 12-13 (irrtüml. auch Taf. 14 angegeben); Berlin 
-Kunz, Reiner (1993): Die Geologie des Dörnberggebietes. - Jb. Lkr. Kassel, 1994: 7 - 14, 7 Abb. i. Text, 5 Abb. a. Taf.; Kassel

-Kunz, R.; Halfar, W.; Hoffmann, R. \& Schröder, A. (1992): Geologie des Wolfhagener Landes. (Führer durch Raum 10 und die Landschaft Geologie des Wolfhagener Landes). - Schr. Vereins Regionalmuseum Wolfhagen, Reihe Museumsführer, Bd. 10; 100 S., 56 Abb., 8 Taf.; (Verein Regionalmuseum) Wolfhagen

-Landau, Georg (1867): Beschreibung des Kurfürstenthums Hessen. - 2. Aufl.; X, 649 S., 2; (J. Georg Luckhardt) Kassel

[darin: Überblick über die Regionalgeologie, Bodenschätze]

-Leinhos, Waldemar (1994): Die Geologie des Baunatals. - In: [Arbeitskreis Chronik: Heinrich Pflug u.a.]: Baunatal: Chronik der Stadt Baunatal. - Teil 1 (Kneipp, Jürgen; beteiligt): Lebensraum, Vor- und Frühgeschichte.; 263 S., zahlr. Abb.; hier S. 11-26, 12 Abb.; [Hrsg. Magistrat d. Stadt Baunatal] Baunatal 1994

-Lepper, Jochen (2002): Ein Sockel aus Sandstein - die Geologie des Reinhardswaldes. - In: Rapp, Hermann-Josef [Hrsg.]): Reinhardswald - Eine Kulturgeschichte. - 240 S., 73 Abb.; hier: S. 103133, Abb. 28-40; (Euregio) Kasselm 2002

-Leppla, A. (1892): Ueber Aufnahmen im Gebiet des Blattes Waldeck-Cassel (1 : 80.000). - Jb. Preuß. Geol. Landesanst., 10 (f. 1889): LXV-LXX; Berlin

[darin: Habichtswald]

OLindemann, B. (1914): Geologie der deutschen Landschaften. - VIII, 368 S.; 317 Abb., 20 SW-Tafeln, 4 Farb-Taf.; (Franckh'sche Verlagshdlg.) Stuttgart [darin: S. 339-347, Abb. 295-304: Thüringer und Frankenwald; Abb. 303: Felsen i. Zechstein/Hauptdolomit „Der Bär“ bei Abterode/Werra-Meissner-Kreis]

-Linstow, O. v. (1924): Ergebnisse der Aufnahmen auf den Blättern Oedelsheim und Hofgeismar (Übergeordn. Titel: Berichte über die wissenschaftlichen Ergebnisse in den Jahren 1922 und 1923. Jb. Preuß. Geol. Landesanst., 44 (f. 1923): XXVII-XXIX, 1 Abb.; Berlin

-Linstow, Otto v. (1924): Die geologischen Verhältnisse von Grebenstein und Umgebung. - In: Grebenstein und seine Geschichte - Festbetrachtungen zur 600 Jahrfeier am 2.- 4. August 1924. - 56 S.; hier S. 37-45; (Schulz) Hofgeismar 1924

-Loon-Behr, van (1872): Die geognostischen Verhältnisse des Kreises Rotenburg. - Mittheilungen d. Landwirtschafthlichen Centralvereins f. d. Regierungsbezirk Cassel, (N.F 2) 1872(3/4): 25-36, 1 Tab.; Kassel [Altkreis Rotenburg d. heutigen Kreises Hersfeld-Rotenburg; Vortragsreferat]

- $\square$-Lotze, Franz (1971): Dorn-Lotze - Geologie Mitteleuropas. - 4., völlig neu bearb. Aufl., XVI, 491 S., 165 Abb. i. T. u. a. Taf., 13 Tab. a. 7 Beil., (insges. 31 Beil.); (Enke) Stuttgart [darin: „Die Paläozoikumsaufvrüche in der Hesssichen Senke“ u.a. Richelsdorfer Gebirge, Hessische Senke, Thüringer Becken, „Südhannoversches Bergland“]

-Lukas, Volker (1986): Feinstratigraphische, sedimentologisches und tektonische Untersuchungen im Hersfelder Graben. - Dipl.-Arb. [unveröff.] Univ. Giessen, 139 S., 20 Abb., Giessen

-Meiburg, Peter (1969): Die Warburger Störungszone - Ein Beitrag zur Geologie des Warme-DiemelGebietes (Nordhessen/Ost-Westfalen). - Diss. Univ. Münster 1971; 394 B., Ill., graph. Darst., Kt., Anl. 
-Mende, Bruno (1991): Wanderführer Nordhessen und angrenzende Gebiete. - 669 S., zahlr. Abb.; (Bernecker) Melsungen [Überblick Regionalgeologie]

-Milde, Artur (1958): Der geologische Aufbau des Kreises [Fritzlar-Homberg]. - In: Ide, Werner [Hrsg.]: Zwischen Kellerwald und Knüll - Heimatbuch für den Kreis Fritzlar-Homberg. - 248 S., zahlr. Ab.; hier S. 13-29, 14 Abb., 1 strat. Profil; (Spanknebel) Borken b. Kassel 1958

-Möhl, Heinrich (1863): Die Urgeschichte des Kurhessischen Landes. - 14 S., 1 Faltbl. (6 Abb.); (Freyschmidt) Kassel [Erdgeschichte, Paläogeographie]

-Möhl, Heinrich (1867): Geognostisch-topographische Beschreibung der mit dem Königl. Preußischen Regierungsbezirke Cassel (ehemaligen Kurhessen) vereinigten früher Königl. Bayerischen Landestheile Gersfeld und Orb, sowie des früher Großherzogl. Hessischen Kreises Vöhl. Landwirthschaftl. Ztg f. d. Regierungsbezirk Kassel, 13: 343-347; Kassel

-Möhl, Heinrich (1874): Die geognostischen und Boden-Verhältnsisse des Kreisses Cassel. Landwirthschaftl. Zeitschrift nebst Anzeiger f.d. Regierungsbezirk Cassel - Organ des landwirthschaftlichen Centralvereins. - $\underline{\mathbf{1 8 7 4}}(1): 2-6, \underline{\mathbf{1 8 7 4}}(4)$ : 93-98, 1874(5): 137-142, 1874(6): 174176; Kassel

-Möhl, Heinrich (1876): Neue geologische Aufschlüsse in der Stadt Cassel. - N. Jb. Mineral. etc., $\underline{\text { 1876: }}$ 724-730; Stuttgart

-Möhl, Heinrich (1895): Das Ahnetal und der Bühl im Habichtswald. - Tourist. Mitth. a. bd. Hessen, $\underline{\mathbf{3}}$ 10): 115 - 120, 2 Abb.; Kassel

- $\square$ Möhl, H[einrich] (1897): Topgraphische und geologische Verhältnisse Cassels. - In: Lange, Wilhelm Chr. [Red.]: Festschrift zur 38. Hauptversammlung d. Vereins Deutscher Ingenieure Gewidmet vom Hessischen Bezirksverein; 176 S:, Abb.; hier S. 1-14, 2 Taf.; (Weber \& Weidemeyer) Kassel 1897 [Bezugnahme a. Hirschberg b. Großalmerode und Umgebung von Kassel]

- $\square$ Moench, C. [ermittelt](1787): Beitrag zur Naturgeschichte der Landgrafschaft Hessen-Cassel. Hessische Beiträge z. Gelehrsamkeit u. Kunst, $\underline{\mathbf{I I}}(1):$ 88-105, II (2): 413-431; Frankfurt/M.

-Mötzing, Kurt (1976): Geologische Betrachungen über das hessische Wandergebiet [Nordhessen]. Hessischer Gebirgsbote, 77(2): 44 - 47, 2 Abb.; Melsungen

-Mötzing, Kurt (1976): Die natürlichen Voraussetzungen für die Entstehung der Urzelle der Stadt Kassel. - Hessischer Gebirgsbote, 77(3): 72 - 73, 1 Abb.; Melsungen

[Geologie, Hydrogeologie des Kasseler Stadtgebietes]

-Nitsche, Lothar; Nitsche, Sieglinde (2003): Naturschutzgebiete in Hessen schützen, erleben, pflegen: 2. Stadt Kassel, Landkreis Kassel und Schwalm-Eder-Kreis. - 256 S., zahlr. Abb., Kartenskizz., Tab.; (Cognitio) Niedenstein [Kurzinformationen zur Geologie der Naturschutzgebiete]

-Oebbeke, K. (1886): Mitteilungen über Aufnahme der Sektionen Niederaula und Neukirchen. - Jb. Preuß. Geol. Landesanst., $\underline{\mathbf{6}}$ (f. 1885): LII-LIV; Berlin

-Oebbeke, K. (1888): Mitteilungen über Aufnahme der Sektionen Niederaula und Neukirchen. - Jb. Preuß. Geol. Landesanst., $\underline{\mathbf{8}}$ (f. 1887): LVI-LVIII; Berlin

-Oebbeke, K. (1892): Ueber den Abschluss der Aufnahmen auf den Blättern Niederaula und Neukirchen. - Jb. Preuß. Geol. Landesanst., $\underline{10}$ (f. 1889): LVII-LVIII; Berlin 
-Penndorf, Hans (1936): Beitrag zur Stratigraphie und Tektonik des Kasseler Beckens auf Grund neuer Aufschlüsse. - Verein für Naturkunde zu Kassel - Festschrift zur Feier seines hundertjährigen Bestehens [1836 - 1936]; S. 165 - 176, 2 Abb.; Kassel

-Pfister, F. (1840): Kleines Handbuch der Landeskunde von Kurhessen. - 2. Aufl., [3 Bl.] 284 S.; [6. Bl.]; (Hotop) Kassel

[darin S. 29-71: „Die Landschaften und Gebirge“]

-Pickel, Wilhelm (1974): Die Ausgrabungen auf Burg Rodersen: Die topographisch-geologischen Gegebenheiten. - Z. Vereins hess. Gesch. u. Landeskde. - 4: 142-144, 1 Abb.; Kassel

-Pletsch, Alfred (1989): Hessen. - Reihe: Wissenschaftliche Länderkunden, 8.3; 250 S., 66 Abb., 44 Tab., 5 Kt.; (Wiss. Buchgesellschaft) Darmstadt [darin: „Grundzüge des geologischen Aufbaus“, „Oberflächenformen und naturräumliche Gliederung“, „Die Böden Hessens und ihre Eigenschaften“

darin Naturräume: Westhessisches Bergland und Westhessische Senke: u.a. „Das Kasseler Becken und seine Umrahmung“, „Fritzlarer Becken und Schwalmgebiet“; „, Osthessisches Bergland und Osthessische Senke“, u.a. „Die landschaften im Werra-Fulda-Winkel und an der Oberweser“, „Das Fulda-Werra-Bergland"]

-Rambow, D. (1984): Zur Geologie und Hydrogeologie der Gemeinde Söhrewald. - In: Heß, G.; Peter, D.; Scholz, Th. H.D. \& Werner, H.-U. [Red.-Ausschuss]: Söhrewald 1984 - ein Beitrag zur Heimatkunde. - 365 S. + Anzeitenteil (S. 366-391), Abb.; hier S. 334-339, 2 Abb.; [Hrsg. Arbeitskreis Söhrewaldbuch] Söhrewald 1984

-Rambow; Dietrich (1971): Zur Geologie des Kreises Melsungen. - Hdb. d. Kreises Melsungen, 1972 (41. Jg.): 100 - 104, 1 Abb.; Melsungen

-Rapp, Hermann-Josef [Hrsg.](2002): Reinhardswald - Eine Kulturgeschichte. - 240 S., Ill.; (Euregio) Kassel [Beiträge zur Geologie, Hydrogeologie und quartären Vegetationsgeschichte]

- Raspe, Rudolf Erich (1774): Beytrag zur allerältesten und natürlichsten Historie von Hessen oder Beschreibung des Habichtswaldes und von verschiedner andern niederhessischen Vulcane in der Nachbarschaft von Cassel. - [5 B1.] 76 S., 1 Falt-Taf.; (Cramer) Kassel [Regionale Geol. Kassel u. Umgebung; Habichtswald, Dörnberg, Kratzenberg, Frankenhausen, Katzenstein u. Hohlenstein zw. Harleshausen u. Dörnberg, Weidelsberg b. Wolfhagen, Schloßberg Felsberg, Schloßburg Aldenburg, Madenstein b. Gudensberg]

-Raspe, Rudolf Erich (1776): An account of some German volcanos, and their productions. Wiith a new hypothesis of the prismatical basaltes. Established upon facts; being an essay of physical geography for philosophers and miners. Published as supplementary to Sir William Hamilton's observations on the Italian volcanos. - XIX, 140 p., 2 pl.; (Lockyer Davis) London [Regionale Geol. Kassel u. Umgebung; Habichtswald, Dörnberg, Kratzenberg, Frankenhausen, Katzenstein u. Hohlenstein zw. Harleshausen u. Dörnberg, Weidelsberg b. Wolfhagen, Schloßberg Felsberg, Schloßburg Aldenburg, Madenstein b. Gudensberg]

-Reuter, Walter (1996): Die Entstehung der Landschaft unserer Lohfeldener Gemarkung: Eine Zeitreise. - In: Pitzschke, Angela [Bearb.]: Drei Dörfer - ein Ort: Lohfelden - Geschichte und Geschichten. -351 S., zahlr. Abb.; hier S. 3 - 6, [Hrsg. Gemeindevorstand der Gemeinde Lohfelden] Lohfelden 1996

-Rösing, Franz (1953): Die geologischen Verhältnisse des Dörnbergs westlich Kassel (Vortragskurzfassung). - Z. dt. geol. Ges., 104 (f. 1952): 189-190; Hannover

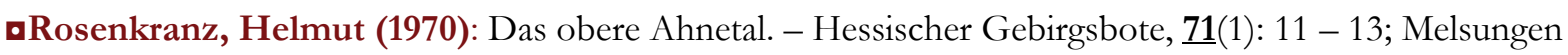


- •Rothe, Peter (2005): Die Geologie Deutschlands - 48 Landschaften im Portrait. Mit Zeichnungen von Martin Schmitteckert. - 240 S., 142 Abb.; (Wiss. Buchgesellschaft) Darmstadt

[Darin S. 163-164: „Die Große Nord-Süd-Naht: Leinetalgraben und Randgebiete"]

- $\square$ Rothe, Peter (2005): Die Geologie Deutschlands - 48 Landschaften im Portrait. Mit Zeichnungen von Martin Schmitteckert. - 240 S., 142 Abb.; (Wiss. Buchgesellschaft) Darmstadt

[Darin S. 162-163: „Die Große Nord-Süd-Naht: Hessische Senke“ < mit „Blauer Kuppe“, Hoher Meißner>]

oSchaefer, Bernhard (1926): Der Hirzstein im Habichtswald als Naturschutzgebiet. - Hessenland, $\underline{\mathbf{3 8}}(8)$ : 163-167, 8 Abb.; Kassel

[Botanik, Geologie]

- Scharlau, Kurt (1941): Siedlung und Landschaft im Knüllgebiet - Ein Beitrag zu den kulturgeographischen Problemen Hessens. - Forsch. Dt. Landeskde., 37; 335 S., 30 Abb., 28 Kt.-Beil.; (Hirzel) Leipzig

[darin Kap. „Das geographische Bild des Knüllgebietes“; Physische Geographie, Vegetationsgeschichte, Bodengeographie]

- Schlossmacher (1910): Die Entstehung des Habichtswaldes [Vortragstext]. - Tourist. Mitt. a. beid. Hessen, 18(10): 111 - 112; Kassel

- $\square$ Schmitt, Gerhard E. (1990): Naturkundliche Wanderungen in Hessen. - 158 S., 62 Abb., Kt.; (Hitzeroth) Marburg

[Darin: Werra-Meißner-Kreis; Blaue Kuppe, Erdfalltrichter bei Trendelburg]

oSchwalm, Johann H[einrich] (1919): Mit Rucksack und Hammer durch Kellerwald und Knüll Geologiesche Heimat- und Wanderbuch. - 186 S.; (Elwert) Marburg

- SSchwarz, Friedrich (1932): Geologie der Gegend zwischen Kassel und dem Reinhardswald. - Abh. Preuß. Geol. Landesanst., N.F., 132; 100S., 32 Abb., 1 Taf.; Berlin

- SSchwarzenberg (Bergkommissar) (1825): Beschreibung der im Kreise Cassel vorkommenden Gebirgs- und Erd-Arten, besonders in Beziehung auf Oekonomie und Technologie. -

Landwirthschaftliche Zeitung für Kurhessen, $\underline{\mathbf{3}}$ (1825)(Januarheft): 10 - 22; (Februarheft): 40 - 47; (Märzheft): 53 - 59; (Laupe) Kassel

- Schwarzenberg, Adolf (1827): Beschreibung der im Kreise Wolfhagen vorkommenden Gebirgs- und Erd-Arten, besonders in Beziehung auf Technologie und Oekonomie, nebst einer dazu gehörigen petrographischen Karte. - Landwirthschaftliche Zeitung f. Kurhessen, $\underline{\mathbf{5}}(20)(1827)$ : 274-295; $\underline{\mathbf{5}}(21)(1827): 306-327 ; \underline{\mathbf{5}}(21)(1827): 338-363$; Kassel

oSchwarzenberg (Bergkommissar) (1828): Beschreibung der geognostischen Verhältnisse des Ahnegrabens am Habichtswalde bei Kassel, mit besonderer Berücksichtigung der dabei vorkomenden basaltischen Ausfüllungsmassen, nebst einer petrographischen Skizze. - Studien Göttingischen Vereins Bergmänn. Freunde, 2: 195-219, 1 Falt-Bl.; Göttingen

- $S c h w a r z e n b e r g$, A. (1830): Beschreibung der im Kreise Hofgeismar vorkommenden Gebirgs- und Erdarten usw., nebst einer petrographischen Karte dieses Kreises Kurhessens. - Landwirthschaftliche Zeitung für Kurhessen, $\underline{8}(1830)$; Kassel

[Vorlage nicht eingesehen, zitiert nach Krauß 1913]

oSeib, Gerhard (1980): Das älteste natürliche geologische Profil Hessens - Archivalischer Fund erhellt Entstehungsgeschichte der Schichtenfolge des Richelsdorfer Gebirges. - Hessische Heimat, N.F., 30(2): 59 - 66, 6 Abb.; Kassel 
- Sobotha, Ernst (1981): Geologischer Aufbau und geologische Geschichte des Landes rund um den Alheimer, Rotenburg/Fulda. - Rund um den Alheimer, $\underline{3}: 45$ - 49, 3 Abb.; Rotenburg/Fulda

- $\square$ Stille, Hans (1925): < Der geologische Aufbau Niederhessens > -Eschweger Tageblatt, 1925; Nr. 272

v. 19.11.1925; Eschwege

[Bericht über Vortrag v. Hans Stille am 17.11.1925 in Eschwege]

- $\square$ Straub, August (1969): Nordhessen: Das Bergland von Niederhessen - Landschaft, Geschichte, Kultur, Kunst, Wirtschaft. - 352 S., zahlr. Abb.; (Glock u. Lutz) Nürnberg

[darin auch Informationen zur Geologie: Steinbruch Cornberg, Habichtswald, Knüll, Meißner, Reinhardswald, Richelsdorfer Gebirge, Ringgau,]

- Strippelmann (1827): Geognostische Verhältnisse des Habichtswaldes. - Z. Mineral., 1827(6): 513-518; Frankfurt/M.

-Thaetner, Ralf (1993): Geschichte der Stadt Liebenau. - 310 S., Abb.; [Hrsg. Stadt Liebenau] (Wartberg-Verlag) Gudensberg-Gleichen [darin S. 10: „Bevor der Mensch kam“ (Erdgeschichte der Region)]

-Trost, F. (1962): Landschaft und Vorgeschichte: Unsere Heimatlandschaft. - In: Hederich, Michael [Hrsg.]: Zierenberg in Geschichte und Gegenwart. - 227 S., zahlr. Abb.; hier: S. 9-23, 10 Abb., 1 strat. Profil; (Bärenreiter) Kassel 1962 [Erdgeschichte der Region um Zierenberg]

- Udluft, Hans \& Lang, Hans Dietrich (1956): Der Untergrund der Niederhessischen Senke. Notizbl. Hess. L.-A. Bodenforsch., 노: 184 - 203, 1 Abb., 1 Taf.; Wiesbaden

-Volckmar, Erwin (1877): Geologische Schilderung der Gegend von Homberg im Regierungsbezirk Cassel; 45 S., 1 Kt. u. Profile; (Freyschmidt) Cassel - zgl. Diss. Univ. Marburg 1877

-Wagner, Julius (1951): Die Landschaftsgliederung des Landes Hessen. - Geographische Rundschau, $\underline{3}$ : 85-92, 2 Abb., 1 Tab.; Braunschweig

-Wagner, Julius (1961): Hessen. - Reihe: Harms Landeskunde, Bd. I; 441 S.; 89 Abb. u. Kt.-Skizz. sowie Diagr., 16 Farb-Taf.; (List) München

[darin: „Die physisch-geographischen Verhältnisse“: S. 14-29, Abb. 1-5 „Geologie und Morphologie“; S. 37-39 „Die Böden“; S. 40-45, Abb. 6 „Gewässer und Talbildung“]

-Wahl, A. von \& Loescher, W. (1911): Geologische Mitteilungen aus der Casseler Umgebung. Festschr. Vereins f. Naturkde. z. Kassel, (341 S., 6 Taf.); hier: S. 79-85, 2 Abb.; Kassel 1911 [1. „Melanienton am Mattenberge bei Nordshausen“; 2. „Über angebohrte tertiäre Schnecken- und Muschelschalen“; 3. „Rötprofil am Reisberge bei Cassel“" (1 Abb.); 4. „Über die Eckhardtsche Kiesgrube an der Neuen Mühle“; 5. „Bericht über den Erdrutsch im Ahnetal“ (1 Abb.)]

-Waldert, E. (1927): Vom Werden der niederhessischen Gebirgswelt. - Hessischer Gebirgsbote, 33 : 57 58; Kassel

-Walter, Klaus (1961): Der geologische Aufbau des Kreises Hersfeld. - Mein Heimatland, 19(23): 89 91, 3 Abb.; Bad Hersfeld

- $\square$ OWalther, Johannes (1912): Lehrbuch der Geologie Deutschlands - Eine Einführung in die erklärende Landschaftskunde für Lehrende und Lernende. - 2., vermehrte Aufl.; XII, 429 S:, 1 Kt.Beil; (Quelle \& Meyer) Leipzig [darin: Abb. 18 Zeichnung „Basaltgang im Muschelkalk bei Hörschel“ - darin: S. 253-256, Abb. 126129 „Die hessischen Vulkane“ (Abb. 128 Profil Meissner); S. 257-261, Abb. 130-133 „Das Wesergebirge“ (Abb. 130 Heldrastein); S. 284-290, Abb. 149-152 „Der Thüringer Wald; S. 290-295, Abb. 153-158 „Die Thüringer Senke“] 
- $\square$ OWalter, Roland (2007): Geologie von Mitteleuropa. - Begründet von Paul Dorn. - 7., vollst. neu bearb. Aufl.; 511 S., 184 Abb.; (Schweizerbart) Stuttgart

[darin Kap.: Nordhessisches Bergland und Niederhessische Senke, Thüringer Wald und ThüringischFränkisches Schiefergebirge, Thüringer Becken]

-Wenk, Herbert (1985): Von den Anfängen bis zur Gegenwart - Zur Geographie und Geologie unserer Heimat. - In: Schulze, Rudolf [Red.]: Zur Geschichte des Dorfes Weißenhasel. - 144 S., zahlr. Abb.; hier S. 16-18, 1 Abb.; [Hrsg. Kirchenvorstand Ev. Kirchengemeinde Weißenhasel] Weißenhasel 1985

-Wenderoth, Georg W. F. (1839): Versuch einer Charakteristik der Vegetation von Kurhessen. Als Einleitung in die Flora dieses Landes. - Schriften Ges. Beförd. Gesammt. Naturwiss. z. Marburg; $\underline{4}$; XII, 155 S., [2]Bl., 3 Abb.; (J.C. Kriegers Verlags-Buchhdlg.) Marburg [Geologisches Profil Hoher Meißner]

-Wilke, Erich [1960]: Aus vergangenen Zeiten: Der erdgeschichtliche Werdegang des Kasseler Raumes. - In: Kreisausschuß Kassel-Land [Hrsg.]: Rund um Kassel - Heimatbuch für Schule und Haus. 309 S., 1 Falt-Kt., zahlr. Abb. i. Anh.; hier S. 6-8, 2 Abb.; Kassel 1960

-Wilke, Erich (1962): Aus der Erd- und Naturkunde: Der erdgeschichtliche Werdegang des Raumes um Oberkaufungen. - In: Meyer, Fritz: Oberkaufungen im Wandel der Zeiten. - 504 S., Abb., Tab.; hier: S. 246-251; [Hrsg. Gemeinde Kaufungen] (Bernecker) Melsungen 1962

\subsubsection{Regionale Geologie - Werra-Meißner-Kreis}

$\square$ Ackermann, Alfred (1991): Chronik der Ortschaft Berneburg. - 144 S., zahlr. Abb.; [Hrsg. Stadt Sontra] (Wartberg Verlag) Gudensberg-Gleichen [darin S. 8-9: „Die Bodenbeschaffenheit“]

$\square$ Adam, Manfred (1995): Die Geologie des Ringgaus. - In: Adam, Manfred [Zustlg.]: 800 Jahre Lüderbach - Eine Heimatgeschichte unseres Dorfes. - 600 S., Abb.; hier: S. 15-21, 4 Abb.; [Hrsg. Festausschuß] Ringgau-Lüderbach 1995

- $\square$ Althaus (1840): Basaltdruchbrüche, Fischabdrücke, Mineralien. - N. Jb. Mineral. etc., 1840: 86 (Briefl. Mitt.); Stuttgart

[Orientierende Ersterkundung des nordosthessischen Berglandes durch einen Zugezogenen, „Blaue Kuppe“, Richelsdorfer Gebirge]

$\square$ Angerhöfer, Horst (1985): Der Werra-Meißner-Kreis. Eine kurze Beschreibung nach der GrothusHeimatkarte. - 34 S., 8 Abb., 1 Tab.; [hektographiert]; Meinhard

[darin S. 4-15, Kt. 1 - 3: „Die Landesnatur"

[Nachgewiesener Standort: Stadtarchiv Eschwege]

$\square$ Angerhöfer, Horst (1987): Das Werraland - Kurze geographische Landeskunde. - Schriftenreihe Kreissparkasse Eschwege, 5; 91 S., 9 Kt., Anh. m. 4 Diagr., 4 Kt.; Eschwege

[Kap. z. Regionalgeologie, regionalen Geomorphologie]

$\square$ Angerhöfer, Horst (1993): Die Eschweger Landschaft. - In: Kollmann, Karl [Red.]: Geschichte der Stadt Eschwege. - 530 S., zahlr. Abb.; hier S. 9-16, 1 Abb., 1 strat. Tab.; (Selbstverlag Kreisstadt Eschwege) Eschwege

$\square$ Angerhöfer, Horst (2002): Geologische und sozialgeographische Verhältnisse um und in Grebendorf. In: Bachmann, H.; Menthe, H., Schönberg, D.; Schönberg, S.; Strieb, A.; Strieb, G. \& Stück, 
H. [Red.]: 740 Jahre Grebendorf - Geschichte und Geschichten eines Dorfes. - 211 S., zahlr. Abb.; hier: S. 20-32, 1 Tab.; [Hrsg.: Arbeitskreis „Geschichte Grebendorf“] Eschwege 2002

$\square$ Angerhöfer, Horst (2005): Geographische und geologische Verhältnisse in der Gemarkung Neuerode. - In: Franz, Kale \& Piègay, Hein-Enno [Erstellung d. Buches]: 1025 Jahre Neuerode Geschichte(n) eines Dorfes am Meinhard. - 1. Auflage, 211 S.; hier: S. 15-28, 3 Abb., 1 stratigr. Tab.; (Keitz \& Fischer) Eschwege 2005

$\square$ Anonym (1990): Geologie der Umgebung von Rambach. - In: Kollmann, Karl [Red., Schriftltg.]: 700 Jahre Rambach - Chronik zur 700 Jahrfeier. - 224 S., zahlr. Abb.; hier: S. 12-13; [Hrsg. Festausschuß der Gemeinde Rambach](Gajewski) Ringgau-Datterode 1990

$\square$ Anonym (1991): Geographie und Geologie [des Bilsteins im Kaufunger Wald]. - In: Rund um den Bilstein im Kaufunger Wald. - 43 S., zahlr. Abb.; hier: S. 8-13, 1 strat. Profil; [Hrsg. Werratalverein Witzenhausen e. V.] Witzenhausen 1991

$\square$ Anonym [1995]: Zur Urgeschichte des Meißnervorlandes. - In: Festausschuß: Becker, Claus u.a. [Hrsg.]: 800 Jahre Wolfterode 1195-1995. - 174 S., Abb.; hier: S. 7-8; Meißner-Wolfterode 1995

$\square$ Anonym [1995]: Bodenarten, Quellen und Flurnamen der Gemarkung [Wolfterode]. - In: Festausschuß [Hrsg.]: 800 Jahre Wolterode 1195-1995. - 174 S., Abb.; hier: S. 7-8; MeißnerWolfterode 1995

$\square$ Anonym (2000): ... Eine kleine Übersicht über die geologische Geschichte des Ulfetales. - In: Michael, Eduard [Schriftltg.]: Geschichte und Geschichten von Ulfen. - Herausgegeben anläßlich der 1225 Jahrfeier von Ulfen vom 8. bis 11. September 2000. - Beitr. Gesch. Stadt Sontra, 12; 123 S., zahlr. Abb.; hier: S. 7-8; [Hrsg. Vereinsgemeinschaft Ulfen](Gajewski) Ringgau-[Datterode] 2000

- $\square$ ○ीApel, Jürgen \& Rüppel, Heidi [Verfass. u. Hrsg.] (2005): Raus in die Natur - Tipps für den Sonntags-Ausflug im Dreiländereck Hessen - Niedersachsen - Thüringen. - 159 S., 111 Fotos, 34 Kt., 1 Zeit-Taf..; (LSRB-Verlag, Landschaftskundlicher-Studien-Reisebuch-Verlag) Witzenhausen [zahlreiche Ausflugsziele, auch zu Geotopen im Werra-Meißner-Kreis]

$\square$ Augustin, Max [Hrsg.](o.J.): Bad Sooden-Allendorf a.d. Werra und Umgebung - Reisehandbuch mit Karte. - Augustins Reisehandbücher, ; 2. Aufl., 48 S., 1 Falt-Kt.; (Max Augustin) Kassel [darin Kap.: Geologischer Bau, S. 17-19] - 1. Auflage u.d. gleichnamigen Titel herausgegeben von Max Brunnemann]

$\square$ Beck, Hanno (1956): Hanno Beck: „Eschwege - Heimat und Welt“ - Der Verfasser zu seinem neuen Buch über unsere Landschaft und ihre Persönlichkeiten. - Werra-Rundschau, 1956; Nr. 124 v. 30.5.1956, S. 3; Eschwege

$\square$ Beck, Hanno (1965): Ingeborg Tolle-Krieger: Eschwege und seine Landschaft (Serie: Eschweger Literatur, 8). - Werra-Rundschau, 1965; Nr. 134 v. 12.6.1965, S. 6; Eschwege [Buchbesprechung]

$\square$ Bachmann, H.; Menthe, H., Schönberg, D.; Schönberg, S.; Strieb, A.; Strieb, G. \& Stück, H. (2002): 740 Jahre Grebendorf - Geschichte und Geschichten eines Dorfes. - 211 S., zahlr. Abb.; hier: S. 20-32, 1 Tab.; [Hrsg.: Arbeitskreis „Geschichte Grebendorf"] Eschwege 2002 [zahlr. Beitr. einzelner Autoren, u.a. zur Regionalgeologie]

$\square$ Baier, E. \& Peppler, C. (1988): Die Pflanzenwelt des Altkreises Witzenhausen mit Meißner und Kaufunger Wald. - Eine erste Flora dieses Gebietes. - Schriften d. Werratalvereins Witzenhausen, 18; 310 S., 1 Falt-Taf. (Kt.); (Selbstverl. Werratalverein Witzenhausen e.V.) Witzenhausen [Kapitel zur Regionalgeologie] 
$\square$ Baier, E.; Peppler-Lisbach, Cord \& Sahlfrank, V. (2005): Die Pflanzenwelt des Altkreises Witzenhausen mit Meißner und Kaufunger Wald. - 2. ergänzt. u. verbess. Aufl.; Schriften d. Werratalvereins Witzenhausen, 39; 464 S., 74 Farbphotos, 1 Übers.-Kt., Ktn.; (Selbstverlag Werratalverein Witzenhausen e.V.) Witzenhausen

[Kapitel zur Regionalgeologie]

$\square$ Bauer, Günter (1989): Zur naturräumlichen Einordnung von Hessisch Lichtenau. - In: 700 Jahre Hessisch Lichtenau - 1289-1989. - 343 S:, zahlr. Abb.; hier: S. 15-17, 3 Abb.; [Hrsg. Stadt Hessisch Lichtenau] (Gutenberg) Melsungen 1989

$\square$ Beck, Hanno (1956): Wesenszüge der Eschweger Landschaft. - In: Beck, Hanno: Eschwege - Heimat und Welt. - 72 S.; hier S. 10-17; (Roßbach) Eschwege 1956

[Regionale Geologie u. Geomorphologie, Wirtschaftsgeographie]

$\square$ Beck, Hanno (1970): Von Landschaft und Menschen. - In: Höhne, Eitel O. \& Wirtz, Rudolf

[Gesamtred.]: Der Landkreis Eschwege - Tradition und Fortschritt. - 238 S., zahlr. Abb.; hier: S. 2830, 1 Abb. S. 34; (Stalling) Oldenburg i. O. 1970

[Bezugnahme a. Geologie des Landkreises]

- $\square$ Beyschlag, F. (1885): Ueber Aufnahmen an der unteren Werra und Fulda (Provinz Hessen-Nassau). Jb. Preuß. Geol. Landesanst., $\underline{\mathbf{5}}$ (f. 1884): XLIX-LII; Berlin [darin: Basalt Hoher Meißner]

$\square$ Blüse, Otto (1957): Zwischen Graburg und Schlierbachswald - Eine Heimatkunde des Dorfes Weißenborn. - 254 S., Abb.; [Hrsg. Heimatverein Weißenborn] Weißenborn [darin: S. 10-17 „Vom Werden der heimatlichen Landschaft“ (Erdgeschichte)]

$\square$ Boden, Waldemar (1959): Der Meissner. - Der Aufschluss, 10: 90 - 92, 1 Abb.; Göttingen [Geologie des Bergmassivs]

$\square$ Brachmann, Richard [Red. u. Gesamtgestaltung](1986): Zwischen Entwicklung und Bewahrung Der ländliche Raum im Jahr 2000. ASG Frühjahrstagung 1986. Herausgegeben aus Anlaß der Frühjahrstagung 1986 der Agrarsozialen Gesellschaft in Eschwege, Werra-Meißner-Kreis. 108 S:, zahlr. Abb. u. Kt.; [Hrsg. Hess. Minister f. Landwirtschaft u. Forsten] Wiesbaden

$\square$ Braunroth, Stefan (1981): Heimatkundliche Berichte eines alten Treffurters. - Das Werraland, $\underline{\mathbf{3 3}}(2)$ : 22-24, 2 Abb.; Eschwege [darin: Ortsnamensgeschichte, Gebäude u. Baudenkmale, Zur Geologie der Umgebung v. Rambach (Bohrung Mäusemühle)]

$\square$ Brehm, Helene (1992): Vom Wissener und Höllental. - In: Gier, Karl [Hrsg.]: Helene Brehm Geschichten und Gedichte. - Gesammelt und zusammengestellt von Karl Gier. - Nebentitel: Heimatklänge aus dem Meißnerland. - 250 S.; hier S. 30-35; (Eigenverlag Karl Gier) MeißnerAlberode 1992

[Geologie, Bergbau, Flora]

$\square$ Brunnemann, Max [Hrsg.](o.J.): Bad Sooden-Allendorf a.d. Werra und Umgebung - Reisehandbuch mit Karte. - Brunnemanns Reisehandbücher, $\underline{\mathbf{5}}$; 1. Aufl., 76 S., 1 Falt-Kt.; (Max Brunnemann) Kassel [darin Kap.: Geologischer Bau, S. 25-27] - 2 Aufl. u.d. gleichnamigen Titel herausgeben von Max Augustin

$\square \bullet$ Deppe, Heinrich (1912): Die Landschaften Südhannovers und der angrenzenden Gebiete dargestellt auf geologischer Grundlage. Ein Beitrag zur Einführung der Geologie in den heimatkundlichen Unterricht. - Südhannoversche Heimatbücher, 1. - X, 193 S., VIII, Abb., 1 Kt.; (Vandenhoeck \& Ruprecht) Göttingen [darin: „Der Meißner“", „Das Grauwacken- und Zechsteingebirge an der unteren Werra“] 
$\square$ Dunker [Oberbergrath](1871): Geologische Untersuchungen im Werrathale bei Allendorf und Sooden. - Z. gesammt. Naturwiss., $\underline{37}$ (N.F. 3): 171-172; Berlin

[Regionalgeologie, Untersuchungen z. Herkft. d. Soole der Saline Sooden]

- $\square$ OElsheimer, Ernst (1907): Volksdichte und Besiedelungen im Meißnerlande. - Diss. phil. Univ. Marburg 1907; 116 S., 1 Falt-Kt.; (Lüdtke \& Martens) Kiel

[WMK, Hessen, Thüringen; darin S. 6-10: Regionalgeologie, S. 10-13: Geomorphologie, S. 13-17: Hydrographie]

口Engelhardt, O. (1917/1919): Das Werratal. - Hessischer Gebirgsbote, 25(5/6): 25 - 27, 26: 42 - 44; Kassel

[Überblick Regionalgeologie]

- $\square$ Engelhardt, Oskar (1921): Führer durchs Werratal und angrenzende Gebiete. - Ein Heimatbuch. [1. Auflage] 365 S., 143 Abb., 1 Eisenbahnkarte, 1 geol. Kt., 25 Wanderkarten; S. 263-357 Anzeigenteil; (Johs. Braun) Eschwege - 2. Aufl., 253 S., Abb., Ktn.; (Johs. Braun) Eschwege [1. Auflage S. 63-69 Kapitel zur Regionalgeologie von Seminarlehrer Wilhelm Kunze]

$\square$ Fiege, Stefan \& Huck, Thomas S. (2000): Das Eschweger Becken als Naturraum. - In: Huck, Thomas S. \& Wiegand, Thomas [Konzeption u. Red.]: Eschwege - Ein kunst- und kulturgeschichtlicher Stadtführer. - 2., aktualisierte u. erweit. Aufl.; Reihe: Bild u. Geschichte; 80 S., zahlr. Abb., Kt.-Skizzen; hier S. 5-6; [Hrsg. Geschichtsverein Eschwege] Eschwege 2000

$\square$ Flörke, Wilhelm (1959): Erdgeschichtliche Skizze der Umgebung von Bad Sooden-Allendorf. Hessische Heimat, N.F., $\underline{8}$ [f. 1958/59](4): 15-18, Abb. 17; Marburg/L.

$\square$ OFrölich, Ernst (1939): Die Flora des mittleren Werratales - in pflanzengeographischen Bildern. - 144 S., Abb., Tab.; (Rossbach) Eschwege

[Werratal zwischen Hörschel und Jestädt; darin: S. 16-18 Kap. „Geologische Übersicht“; zus. Angaben zur Geologie der einzelnen Vegetationsräume]

$\square$ Gehlsdorf, Herbert (1926): Landschaft und Besiedlung im Ringgaugebiet - Eine siedlungsgeographische Untersuchung. - Reihe: Landeskundliche Arbeiten des Geographischen Seminars der Universität Göttingen, o. Zhlg.; 154 S., 5 Kt.-Beil., 12 Abb. i. Text, 36 Abb. a. Taf.; (Johs. Braun) Eschwege - zgl. Diss. Univ. Göttingen 1926

[Überblick Geologie, Geomorphologie einzelner Landschaftsteile]

$\square$ Gier, Karl (1989): Wo alle Wasser zur Netra fließen [Geologie von Röhrda und Umgebung]. - In: Kollmann, Karl [Red.]: Röhrda - Chronik des Dorfes - 1089 - 1989. - 436 S., zahlr. Abb.; hier: S. 911, 1 Abb.; [Hrsg. Festausschuß Röhrda 900 Jahr Feier] Ringgau-Röhrda 1989

$\square$ Gottschalk, Karlheinz (2003): Die Tagfalterfauna des Werra-Meissner-Kreises. - Schriften d. Werratalvereins Witzenhausen, 요; 107 S:, 116 Abb.; 1 mehrseit. Tab.; [Selbstverlag Werratalverein Witzenhausen e.V.] Witzenhausen [darin S. 13-15: „Geologie und Landschaft"]

$\square$ Graf, Manfred W. (2005): Der Ringgau. - 184 S., zahlr. Abb.; (Werra-Verlag Klute) Eschwege [Bildband; Kap."Geologie des Ringgaus"]

- $\square \bullet$ Hausmann, [J. F. L.](1824): Uebersicht der jüngeren Flöz-Gebilde im Fluß-Gebiete der Weser. Tb. Mineral., 18 (3): 678-702; Frankfurt/M. - Auszug aus Hausmann: Uebersicht der jüngeren FlözGebilde. - Studien Göttingischen Vereins bergmänn. Freunde, 1: 381 - 567, Göttingen 1824 [Regionale Stratigraphie Trias-Tertiär Hessen, WMK, Niedersachsen; darin: Tertiär Meißner, Hirschberg, Habichtswald, Wilhelmshöhe b. Kassel, Dransfeld]

- $00 \bullet$ Hausmann, J.F.L. (1824, 1828): Übersicht der jüngeren Flötzgebilde im Flußgebiete der Weser, mit vergleichender Berücksichtigung ihrer Äquivalente in einigen anderen Gegenden von Deutschland 
und der Schweiz. - Studien Göttingischen Vereins bergmänn. Freunde, 1: 381 - 567, Göttingen 1824; 2: 215-482; Göttingen 1828

[Regionale Stratigraphie Trias-Tertiär Nordhessen, Südniedersachsen; Bd. 1, Stratigraphie Buntsandstein; S. 500-508 „Basaltische Massen im Sandstein“, darin: Blaue Kuppe bei Eschwege, Pflasterkaute bei Eisenach]

$\square$ Hellmund, Wolfgang (1995): Witzenhausen im Werra-Bergland - ein Wanderführer für die Region der Kirschenstadt. - 84 S., Anzeigenteil b. S. 100, zahlr. Abb., 16 Falt-Kt.; [Hrsg. Werratalverein Witzenhausen eV.] (Selbstverlag Werratalverein Witzenhausen eV.) Witzenhausen [darin S. 9-10, 1 Abb.: „(Übertitel: Der Raum Untere Werra und Kaufunger Wald) Geologie“]

$\square$ Hildebrand, Erich [Red.] (1983/1990): Land an Werra und Meißner - Ein Heimatbuch.. - [1. Auflage]; 384 S., zahlr. Abb.; [Hrsg. Hist. Ges. Werralandes](Bing) Korbach 1983 - 2. Aufl. 1990 [zahlr. Beitr. einzelner Autoren, u.a. z. Regionalen Geologie u. Geomorphologie, Paläontologie d. Kupferschiefers]

$\square$ Hochhuth, Hermann (1952): Geologie und Pflanzenwelt der Kleinen Hasselkuppe bei Eschwege. Maschinenschriftlich, 48 S., 12 Abb., 1 Skizze. [Vorlage nicht eingesehen, zitiert nach OPPITZ 1965)

$\square$ Hochhuth, Hermann (1952): Geologie und Pflanzenwelt der Jestädter Weinberge. Maschinenschriftlich, 75 S., 20 Abb., 1 Kt. - [Vorlage nicht eingesehen - zitiert nach OPPITZ 1965]

$\square$ Horn, Klaus (1955): Geologisch-pflanzensoziologische Jahresarbeit über den Oberhoner Weinberg. Maschinenschriftlich, 23 S., 8 Kt. - [Vorlage nicht eingesehen - zitiert nach Oppitz 1965]

$\square$ Hotzler, Fritz [Bearb.] (ca. 1964): Der Meißner und seine Vorland. - Gemeinschaftsarbeit der Lehrer des Meißnervorlandes. - Maschinenschriftlich, hektographiert; 45 S.; o.O, o.J.

[Vorlage nicht eingesehen, zitiert nach Oppitz 1965]

口oHotzler, Fritz (1991): Die Ringgau-Felsenburg. - Das Werraland, 43(1): 14, 1 Abb.; Eschwege [Heimatkunde, Geologie, Botanik]

$\square$ Hotzler, Fritz (1995): Schönheit und Vielseitigkeit des Höllentales. - Das Werraland, 47(3): 62, 1 Abb.; Eschwege - [Regionalgeologie, Kupferschiefer-Bergbau]

$\square$ Hotzler, Fritz (1999): Naturdenkmäler im Meißnervorland. - Das Werraland, 51(1): 13, 1 Abb.; Eschwege

$\square$ Hübner, Gerd (2007): Ökologisch-faunistische Fließgewässerbewertung am Beispiel der salzbelasteten Unteren Werra und ausgewählter Zuflüsse. - Ökologie und Umweltsicherung, 27; XV, 303 S., 69 Abb., 77 Tab., + Tab. u. Fotos i. Anh.; (Univ. Press) Kassel - zgl. Diss. Univ. Kassel 2007 [darin Kap. „Geologie und Geomorphologie“; S. 8-11, Abb. 4, Tab. 1]

$\square$ Hundeshagen [Oberförster] [ermittelt: Johann Christian](1817): Beschreibung des Meisners. - Tb. Mineral., 11(1): 3-58 (2 Profile, 1 Kte.); Frankfurt/M.

$\square$ Jacobshagen, Volker \& Kuhnert, Christian [Hrsg.]1989): Der Hohe Meißner in Hessen Ergebnisse geologischer und geomorphologischer Forschungen. - Berliner geowiss. Abh., Reihe A, 114; 114 S., 26 Abb., 6 Tab., 3 Beil.; (Selbstverlag Fachber. Geowiss. FU Berlin) Berlin Referat in: Das Werraland, 41: 71 (Angerhöfer); Eschwege

$\square$ Jacobshagen, V.; Kuhnert, Christian \& Wycisk, Peter (1989): Geologie des Hohen Meißners in Nordhessen. - Berliner geowiss. Abh., Reihe A, 114; S. 9-76, 8 Abb., 5 Tab., 2 Beil.; (Selbstverlag Fachber. Geowiss. FU Berlin) Berlin 1989 
-Jacobshagen, V.; Möller, K. \& Jäkel, D. (1993): Hoher Meißner und Eschweger Becken Geowissenschaftliche und vegetationskundliche Charakteristik einer nordhessischen Landschaft. Berliner geogr. Abh., 56; zgl. Beiträge zur Werra-Meißner-Forschung, III.; XII, 288 S., 95 Abb., 23 Tab., 5 Kt.-Beil.; (Selbstverlag Geomorphologisches Laboratorium FU Berlin) Berlin

$\square$ Jacobshagen, V.; Brede, R.; Hampel, M. \& Kuhnert, C. (1993): Zur Geologie der Umgebung von Eschwege in Nordhessen. - In: Jacobshagen, V.; Möller, K. \& Jäkel, D. [Hrsg.]: Hoher Meißner und Eschweger Becken - Geowissenschaftliche und vegetationskundliche Charakteristik einer nordhessischen Landschaft. - Berliner geogr. Abh., 56; zgl. Beiträge zur Werra-Meißner-Forschung, III; XII, 288 S., 95 Abb., 23 Tab., 5 Kt.-Beil.; hier: S. 1-49, 11 Abb., 3 Tab., 1 geol. Kt.; (Selbstverlag Geomorphologisches Laboratorium FU Berlin) Berlin 1993

D॰OJäschke, Max (1888): Das Meissnerland. Erster Theil: Physiographie. - Forsch. Dt. Landes- u. Volkskde., $\underline{\mathbf{3}}(2) ; 47$ S.; (Engelhorn) Stuttgart - zgl. Diss. Univ. Marburg 1888

Referat in: N. Jb. Mineral. etc, $\underline{\mathbf{1 8 8 9}}$ (Bd. II): 71-72 (Franz Beyschlag); Stuttgart

Referat in: Mitt. Geogr. Ges. (f. Thüringen), 7: 128-130 (Fr. R.); Jena

[Regionale Geologie Nordosthessen, Westthüringen]

- $\square$ OCKlink, Hans-Jürgen (1969): Die naturräumlichen Einheiten auf Bl. 112 Kassel [TK Maßstab 1 : 200.000]. - Reihe: Geographische Landesaufnahme $1: 200.000$, Naturräumliche Gliederung Deutschlands. - 108 S., 1 Kt., 1 Beil.-Kt. 1 : 200.000; (Bundesforschungsanstalt f. Landeskunde u. Raumordnung) Bonn-Bad Godesberg

[HE, WMK, THÜ, NIE]

$\square$ Koch, Friedhelm (2000): Geologie und Paläontologie der Gegend von Velmeden. - In: Koch, Friedhelm [Red.]: Velmeden: Gestern - Heute - Morgen. Zur Geschichte eines 1225 Jahre alten niederhessischen Dorfes am Fusse des Hohen Meissners (775-2000). - 816 S., 243 Abb. + Abb. i. Anh.; hier: S. 668-674, Abb. 205-208; [Hessisch Lichtenau] - Velmeden 2000

$\square$ Koch, Friedhelm (2004): Geologie - Naturraum, Geologie und Paläontologie der Walburger Gemarkung. - In: Gernand, Roland (Schriftltg): 775 Jahre Walburg - 1229-2004. - 444 S., zahlr. Abb., o. J; hier: S. 7-12, 1 Abb.; [Hrsg. Festausschuss „775 Jahre Walburg“] Hessisch Lichtenau (2004)

$\square$ Koch, Friedhelm (2007): Naturraum, Geologie und Paläontologie der Gemarkung Epterode. - In: Nobel, Hermann: Chronik Epterode - Von Euerharderot zu Epterode - 825 Jahre Epterode. Mit Beiträgen von Stefan Bauer, Erich Hofsommer, Dr. Friedhelm Koch, Dr. Karl Kollmann \& Werner Sippel. - Herausgegeben vom Magistrat der Stadt Großalmerode anläßlich der 825-Jahr-Feier. - 453 S., zahlr. Abb. u. Tab.; hier S. 1-8, 6 Abb.; (Magistrat d. Stadt Großalmerode) Großalmerode 2007

$\square$ Koch, Wolfgang \& Koch, Wolfgang jr. (1981): Oberrieden und Lindewerra im schönen Werratal. 160 S., zahlr. Abb.; [Hrsg. Ev. Kirchengemeinde Oberrieden a. d. Werra] Oberrieden [darin S. 10, 1 Abb.; „Oberrieden - geologisch“]

$\square$ Kollmann, Karl (1986): Geologie. - In: Kollmann, K.; Ohland, W., Witthüser, K. \& Heinzmann, G. [Red.]: 1200 Jahre Bischhausen 786 -1986 - Ein hessisches Dorf und seine Geschichte. - 308 S., zahlr. Abb.; hier: S. 9-10; (Gajewski) Ringgau-Datterode 1986

[zahlr. Beitrage einzelner Autoren, u.a. zur Regionalgeologie]

$\square$ Kollmann, Karl (1992): Geologie [von Dudenrode und Umgebung]. - In: Kollmann, K.; Mendel, E. \& Hartmann, B. [Red.]: 725 Jahre Dudenrode - 1267-1992. - 103 S., zahlr. Abb.; hier: S. 88; (Selbstverlag d. Gemeinde Dudenrode) Bad Sooden-Allendorf - Dudenrode 1992

$\square$ Kollmann, Karl (1993): Der Hohlstein bei Hilgershausen. - In: Kollmann, K.; Faßbauer, L. \& Hennemuth, H. [Red.]: Geschichte des Dorfes Hilgershausen. - 240 S., zahlr. Abb.; hier: S. 98-119, 1 Abb.; (Selbstverlag Gemeinde Hilgershausen) Bad Soden-Allendorf - Hilgershausen 1993 
$\square$ Kollmann, Karl (1995): Landschaft, Geologie und Bergbau. - In: Kollmann, Karl [Red.]: 800 Jahre Orferode - Ein Dorf im Wandel der Zeit. - Herausgeg. V. Ortsbeirat Orferode anläßlich der 800Jahr-Feier im Jahre 1995. - 211 S., zahlr. Abb.; hier: S. 7-8, 1 Abb.; [Ortsbeirat Orferode] Bad Sooden-Allendorf - Orferode 1995

$\square$ Kollmann, Karl (o. J.): Die Geschichte des Dorfes Hitzerode im Meißnervorland. - 288 S., zahlr. Abb.; [Hrsg. Hist. Ges. d. Werralandes] Hitzerode [darin S. 9.12, 1 Abb.: ,Geologie“]

$\square$ Koritnig, Sigmund [Schriftltg.](1978): Zur Mineralogie und Geologie der Umgebung von Göttingen mit Westharz und Teilen des Nordhessischen Berglandes. - Der Aufschluss, Sdbd. 28; 285 S.; (VFMG) Heidelberg

$\square$ Kreutzer, Hans-Werner (1987): Palynologie, Stratigraphie und Tektonik im Becken von Großalmerode (Blatt 4724 Großalmerode, Niederhessen). - Gießener geol. Schriften, 41, 112 S., graph. Darst., Kt., geol. Kt.; (Lenz) Gießen; zgl. Diss Univ. Gießen 1986

口OKriege, Jörg \& Wette, Wolfgang (1992): Landschaftsführer Werratal - Abseits ausgetretener Pfade. Mit 27 ausgesuchten Wanderrouten. - 2., überarb. Aufl.; 127 S., zahlr. Abb., 21 Kt.-Skizz.; (Wartberg Verlag) Gudensberg-Gleichen

$\square$ Kühnel, Walter (1982): 1. Zur Geologie von Hessisch Lichtenau. - 2. Kurze Beschreibung der geologischen Verhältnisse der Stadtteile. - In: Hessisch Lichtenau - im Werra-Meißner-Kreis. - 96 S., 1 Falt-Bl.; hier: S. 9 - 18, 2 Abb., 1 Tab.; (Vogt) Hessisch Lichtenau 1982

$\square$ Kühnel, Walter (1989): Zur Geologie von Hessisch Lichtenau. - In: Stadt Hessisch Lichtenau [Hrsg.]: 700 Jahre Hessisch Lichtenau - 1289-1989. - 343 S:, zahlr. Abb.; hier: S. 11-14; (Gutenberg) Melsungen 1989

$\square$ Kuhnert, Christian (1986): Die geologischen Verhältnisse des Werra-Meissner-Kreises. - In.: Stäblein, Gerhard [Hrsg.]: Geo- und biowissenschaftliche Forschungen der Freien Universität Berlin im Werra-Meißner-Kreis (Nordhessen). - Berliner Geogr. Abh., 41; zgl. Beiträge zur Werra-MeißnerForschung, I; S. 25 - 39, 2 Abb., 1 Tab.; (Selbstverl. Inst. Phys. Geogr. FU Berlin) Berlin 1986

$\square$ Kunze, Wilhelm (1914): Geologische Wanderungen [Gesamttitel] - Teil I: Heimat-Geologie im Unterricht - Teil II: Geologische Streizüge in die Werralandschaften. - 119 S., Abb.; (Braun) Eschwege [Im Juli 1914 erschienen, immer noch lesenswert]

口OKunze, Wilhelm (1921): Geologische Übersicht [über das Werraland]. - In: Engelhardt, Oskar: Führer durchs Werratal und angrenzende Gebiete. - Ein Heimatbuch. - 365 S., zahlr. Abb.; S. 263357 Anzeigenteil; hier S. 63-79, 6 Abb., 1 geol. Kt.; (Johs. Braun) Eschwege 1921

$\square$ Lachmann, R. (1913): Der Bau des niederhessischen Berglandes bei Hundelshausen. - Jb. Schlesische Ges. f. vaterländ. Kultur Breslau, 90 [f. 1912](I. Bd: Sitzungen Sect. f. Geol., Geogr., Berg- u. Hüttenwesen): 13-61, 8 Abb.; Breslau Referat in: N. Jb. Mineral. etc., 1913 (Bd. I): 106-108 (O. E: Meyer); Stuttgart

$\square$ Lätsch, Götz \& Maurer, Jacob (1982): Das Naturschutzgebiet „Freudenthal bei Witzenhausen“ - eine erste Beschreibung und Bestandsaufnahme. - Schriften d. Werratalvereins Witzenhausen, $\underline{\mathbf{5}}$; 37 S.; (Selbstverl. Werratalverein) Witzenhausen [darin S. 16-19: J. Maurer: „Geologie“]

$\square$ Landefeld, Artur (2001): Zur Urgeschichte des Meißnervorlandes. - In: Ackermann, Jörg [Red., Schriftltg.]: 700 Jahre Weidenhausen - Dorfchronik. - 211 S., zahlr. Abb.; [Hrsg. Der Festausschuß Weidenhasuen] Weidenhausen 2001 
$\square$ Laspeyres (1887): Geologische Specialkarte von Preußen und den Thüringischen Staaten - 23. Lieferung (Ermschwerd, Witzenhausen, Großalmerode, Allendorf) [Referat]. - Verhdlgn. Naturhist. Vereins Preuß. Rheinlande u. Westphalens, 44: 23-37 (Sitzber.); Bonn

口OLLindemann, B. (1914): Geologie der deutschen Landschaften. - VIII, 368 S.; 317 Abb., 20 SW-

Tafeln, 4 Farb-Taf.; (Franckh'sche Verlagshdlg.) Stuttgart [darin: S. 339-347, Abb. 295-304: Thüringer und Frankenwald; Abb. 303: Felsen i. Zechstein/Hauptdolomit „Der Bär“ bei Abterode/Werra-Meissner-Kreis]

$\square$ Loewer (Generalarzt) (1896): Vom nördlichen Meissner und vom Gelsterthal. - Abh. u. Ber. Vereins Naturkde. z. Kassel, 41 (1895/1896): 32-37; Kassel [Regionalgeologie]

- $\square$ Lotz, Kurt (1995): Einführung in die Geologie des Landes Hessen. - 267 S., 148 Abb., 1 Beil.; (Hitzeroth) Marburg/L.

[Nordhessische Basalte Hoher Meißner, Blaue Kuppe; Unterwerra-Grauwackengebirge, Muschelkalk]

$\square$ Mädler, Hans Joachim (1984): Erdgeschichtliches [über Retterode und Umgebung]. - In: Festschrift 775 Jahre Retterode 1209 - 1984. - 243 S:, zahlr. Abb.; hier: S. 23-26, 6 Abb.; [Hrsg. Festausschuß 775 Jahre Retterode](Schreckhase) Spangenberg 1984

$\square$ Marzela, Clemens (1986): Zur Geologie der Umgebung von Renda. - In: Kollmann, Karl [Red.]: 1200 Jahre Gemeinde Renda. - 320 S., 2 Beil., zahlr. Abb.; hier: S. 7-9, 1 Abb., 1 Tab.; (Gajewski) Ringgau [Regionalgeologie Umgebung Renda] 1986

$\square$ Mauer, Jacob (1978): Geologische Wanderung in das Erdmittelalter - WTV Witzenhausen verfolgt erdgeschichtliche Spuren im heimatlichen Raum. - Das Werraland, $\underline{\mathbf{3 0}}(2)$ : 17-18; Eschwege [Regionalgeologie Raum Witzenhausen]

$\square$ Maurer, Jacob (1981): Neues Naturschutzgebiet Liebenberg - Hasenkanzel. - Beschreibung und Begründung für das geplante Naturschutzgebiet. - Das Werraland, $\underline{33}(1)$ : 5-6, 1 Kt., 1 Profil; $\underline{\mathbf{3 3}}(2)$ : 26-28; Eschwege

[Teil 1, darin: Geologie des Naturschutzgebietes; Teil 2, darin: Pflanzenwelt, Artenliste]

$\square$ Maurer, Jacob (1987): Geologische Wanderung im Werra-Schiefer-Gebirge bei Witzenhausen. - 47 S., 11 Abb., 2 strat. Tab.; (Selbstverlag Werrratalverein Witzenhausen e.V.) Witzenhausen [Exkursionsführer m. 17 Stationen]

$\square$ Maurer, Jacob (1993): Natur und Landschaft - Die geologischen Besonderheiten in der Umgebung von Hilgershausen. - In: Kollmann, K.; Faßbauer, L. \& Hennemuth, H. [Red.]: Geschichte des Dorfes Hilgershausen. - 240 S., zahlr. Abb.; hier: S. 93-96, 1 Abb.; (Selbstverlag Gemeinde Hilgershausen) Bad Soden-Allendorf - Hilgershausen 1993

$\square$ Maurer, Jacob (1997): Beschreibung der Geologie in der Umgebung des Dorfes Lautenbach. - In: Kollmann, Karl [Red.]: 700 Jahre Laudenbach - Ein Dorf im Wandel der Zeiten. - 279 S., zahlr. Abb.; hier: S. 267-273, 1 Abb.; [Hrsg. Stadt Großalmerode, Ortsbeirat Laudenbach u. Kulturausschuß Laudenbach] Großalmerode - Laudenbach 1997

$\square$ Möller, Klaus (1987): Geomorphologisch-Geologischer Wanderführer durch das Werra-MeißnerGebiet. Teil 1: Das östliche Meißnervorland. - 83 S., 34 Abb., 2 Tab.; (Keitz \& Fischer) Eschwege [Teil 1: Alles Erschienene!]

$\square$ Mohs, Friedrich (1806): Der Hirschberg in Hessen. - Ann. d. Berg- u. Hüttenkunde, 5 - zgl. Efemeriden d. Berg- u. Hüttenkunde, 2(5): 329-348, Taf. XII (Fig. 6); Nürnberg [Regionale Geologie] 
$\square$ Namenskürzel (mk) (1949): „Der Meißner“ - ein Heimatbuch von Prof. Ulrich. - Werra-Rundschau, $\underline{1949}$; Nr. 126 v. 1.6.1949, S. 5; Eschwege

[Buchbesprechung]

$\square$ Namenskürzel (=h)(1965): Bereits 1896 gefunden: Riesiges Steinsalzlager bei Rambach. Wertvoller Fund aus dem vorigen Jahrhundert ist wieder in Vergessenheit geraten. - HA - Werra-Nachrichten, 1965, N.r 95 v. 24.4.1965, 1 Abb.; Witzenhausen

[Bohrung a. d. Mäusemühle b. Rambach, i. Jahr 1896]

$\square$ Namenskürzel (= L.W.)(1974): Landschaftsgeschichte des Raumes Großalmerode. - In: Wollenhaupt, Gustav [Hrsg.]: Geschichte der Stadt Großalmerode und familienkundliche Nachrichten. - Teil 1; 117 S., Abb.; hier S. 3-6; (Im Selbstverlag) Großalmerode 1974

- $\square$ Nitsche, Lothar; Nitsche, Sieglinde \& Schmidt, Marcus (2005): Naturschutzgebiete in Hessen schützen, erleben, pflegen: 3. Werra-Meißner-Kreis und Kreis Hersfeld-Rotenburg. - 256 S., zahlr. Abb., Kartenskizz., Tab.; (Cognitio) Niedenstein

[Kurzinformationen zur Geologie der Naturschutzgebiete]

$\square$ Nobel, Hermann (2007): Chronik Epterode - Von Euerharderot zu Epterode - 825 Jahre Epterode. Mit Beiträgen von Stefan Bauer, Erich Hofsommer, Dr. Friedhelm Koch, Dr. Karl Kollmann \& Werner Sippel. - Herausgegeben vom Magistrat der Stadt Großalmerode anläßlich der 825-Jahr-Feier. - 453 S., zahlr. Abb. u. Tab.; (Magistrat d. Stadt Großalmerode) Großalmerode [darin: Bergwirtschaft, Geologie u. Paläontologie der Gemarkung, Geologie u. Mineralogie d. Bühlchens]

$\square$ Nöggerath, Karl Jakob (1822-186): Das Gebirge in Rheinland-Westfalen - nach mineralogischem und chemischen Bezuge. - 1. Bd., 370 S.: 7 Abb., (Eduard Weber) Bonn 1822. - 2. Bd.: 387 S., 7 Abb., (Eduard Weber) Bonn 1823. - 3. Bd.: 291 S., 6 Abb., (Eduard Weber) Bonn 1824. - 4 Bd.: 390 S., 2 Abb., (Eduard Weber) Bonn 1826

[darin Bd. III, S. 273 - 277: Kurze Nachricht von einigen wenig bekannten Basalt-Gängen in Hessen (aus einem Briefe); Kontaktmetamorphose des Basaltes auf das Rahmengestein: Habichtswald, Ahnetal, Hirschberg; Schieferberg N’ Meissner (vermutl. Heiligenberg S’Weißenbach)]

$\square$ Perst, O. (1949): Natur- und Kulturgeschichte des Meißners. - Das Werraland - Festschrift zur 700Jahrfeier der Stadtwerdung Eschweges - 1. Juli 1949. - Das Werraland [Die Null-Nummer der Zeitschrift „Das Werraland“] [= $1(1)]:$ 17-18, 3 Abb.; Eschwege

[Referat zu Wilhelm Ulrich: Der Meißner. - 116 S., 5 Abb.; (Werra-Verlagsgesellschaft) Eschwege 1949]

$\square$ Pfalzgraf, Hans (1934): Die Vegetation des Meißners und seine Waldgeschichte. - Repertorium specierum novarum regnis vegetabilis, Beih. $\underline{\mathbf{7 5}}$; 80 S., Abb., Tab., Taf., Diagr.; Dahlem b. Berlin [darin: S. 12 - 14: Kap. „Zur Morphologie und Geologie des Meißners“; S. 64 - 75: „Die Pollenanalyse und die Waldgeschichte der Meißnerlandschaft"

$\square$ Pflanzl, Günter (1953): Die Geologie des Meissners in Hessen. - Diss. Univ. Marburg 1953; 301 S., 49 Abb., 6 Anl.; Marburg

$\square$ Plein, Eberhard (1952): Der Bau des niederhessischen Berglandes im Raum von Großalmerode. - Diss. Univ. Göttingen 1952; 93 S., Abb., Taf.; Göttingen

$\square$ Q Pompeckj, J.F. (1910): Exkursion nach Eichenberg-Witzenhausen-Hanstein am 3. April.1910. Jber. Niedersächsischen Geol. Vereins, ㅁ: XVIII - XXV, 2 Abb.; Hannover Referat in: N. Jb. Mineral. etc., 1912 (Bd. I): 475-476 (Schöndorf); Stuttgart

$\square$ Ritzkowski, Siegfried (1978) : Geologie des Unterwerra-Sattels und seiner Randstrukturen zwischen Eschwege und Witzenhausen (Nordhessen). - In: Koritnig, Sigmund [Schriftltg.]: Zur Mineralogie 
und Geologie der Umgebung von Göttingen - mit Westharz und Teilen des Nordhessischen Berglandes. - Der Aufschluss, Sdbd. 28: 187 - 204, 5 Tab. 1 Faltkarte; Heidelberg 1978

$\square$ Ritzkowski, Siegfried (1986): Geologie und Hydrogeologie des Werra-Meißner-Gebietes - Geschichte, Bedeutung, Zukunftsperspektiven. - In: Brachmann, Richard [Red. u. Gesamtgestaltung]: Zwischen Entwicklung und Bewahrung - Der ländliche Raum im Jahr 2000. ASG Frühjahrstagung 1986. Herausgegeben aus Anlaß der Frühjahrstagung 1986 der Agrarsozialen Gesellschaft in Eschwege, Werra-Meißner-Kreis. 108 S:, zahlr. Abb. u. Kt.; hier S. 64-67, 2 Abb.; [Hrsg. Hess. Minister f. Landwirtschaft u. Forsten] Wiesbaden 1986

-Rösing, Gerhard (1991): Geographische-geologische Beschreibung des Wildecker Raumes. - In: Gemeindevorstand Gemeinde Wildeck [Hrsg.]: Wildeck - Geschichte einer Gemeinde Herausgegeben von der Gemeinde Wildeck anläßlich der 700-Jahrfeier Wildeck im Jahr 1991. - 462 S., zahlr. Abb.; hier S. 10.12; Wildeck

- $\square$ Rothe, Peter (2005): Die Geologie Deutschlands - 48 Landschaften im Portrait. Mit Zeichnungen von Martin Schmitteckert. - 240 S., 142 Abb.; (Wiss. Buchgesellschaft) Darmstadt [Darin S. 162-163: „Die Große Nord-Süd-Naht: Hessische Senke“ > mit „Blauer Kuppe“, Hoher Meißner>]

$\square$ Rüppel, Heidi \& Apel, Jürgen (2003): Landschaftsgeschichte. - In: Radtke, S.; Wilhelm, A., Wilhelm, R.; Süßebach, K. \& Wilhelm, B. [Red.]: Von Elgerode bis Ellingerode - Eine kleine Geschichts- und Geschichtensammlung anläßlich des 650-jährigen Bestehens. - 383 S., zahlr. Abb.; hier: S. 285-290; [Hrsg. Ortsbeirat Ellingerode] Witzenhausen-Ellingerode 2003

$\square$ Rupprecht, G. (1927): Die Tiefbohrung unweit der Mäusemühle bei Rambach. - Das Werratal, $\underline{4}(12)$ : 189-190; Eschwege

$\square$ Sauer, Helmut (1970): Naturpark Meißner. - In: Höhne, Eitel O. \& Wirtz, Rudolf [Gesamtred.]: Der Landkreis Eschwege - Tradition und Fortschritt. - 238 S., zahlr. Abb.; hier: S. 58-60; (Stalling) Oldenburg i. O. 1970

$\square$ Sauer, Helmut (1974): Die Naturlandschaft des Werralandes. - In: Fischer, Erich [Bearb.](1966): Wegweiser durch den Werra-Meissner-Kreis. - 6., erw. u. verbess. Aufl.; 407 S., zahlr. Abb.; hier: S. 175-197, 4 Abb.; [Verkehrs- u. Verschönerungsverein Eschwege][ROTARO Rossbach] Eschwege 1966 - 1-4. Aufl. u.d.T. „Eschwege - Wegweiser duch Stadt und Kreis“ [darin u.a. Überblick Regionalgeologie]

$\square$ Sauer, Helmut (1976): Die Meißnerlandschaft - Hessische Heimat, N.F., 26 (3) (Sonderheft: Braunkohlenbergbau und Landschaftspflege auf dem Hohen Meissner - Stand 1975): 82 - 84, 2 Abb.; Marburg/L.

$\square$ Sauer, Helmut (1977): Werraaue und Talhänge am Jestädter Weinberg und Fürstenstein bei Eschwege (Nordhessen). - Philippia, 3(3): 224-238, 4 Abb.; Kassel [darin Kapitel zur Geologie]

$\square$ Sauer, Helmut (1983): Die Naturlandschaft des Werralandes. - In: Hildebrand, Erich [Gesamtkonzeption, Red.]: Land an Werra und Meißner - Ein Heimatbuch. - [1. Auflage], 384 S., zahlr. Abb.; hier: S. 189-194, 2 Abb., 1 strat. Tab.; darin enthalten: „Geologisch bemerkenswerte Punkt“; [Hrsg. Hist. Ges. Werralandes](Bing) Korbach 1983

$\square$ Sauer, Helmut (1990): Die Naturlandschaft des Werralandes. - In: Hildebrand, Erich

[Gesamtkonzeption, Red.]: Land an Werra und Meißner - Ein Heimatbuch. - 3., überarb. Auflage, 384 S., zahlr. Abb.; hier: S. 191-193, 1 Abb.; (Bing) Korbach 1990 
$\square$ Schaub, Johannes (1799/1822): Physikalisch-mineralogisch-bergmännische Beschreibung des Meißners, eines merkwürdigen Basalt- und Steinkohlengebirges in Hessen. - 1. Auflage: XVI, 246 S., 2 Abb., 2 Tab.; (Selbstverl.) Kassel 1799 - 2. Aufl.; VIII, 246 S., 3 Abb.; (Luckhardt) Kassel 1822

$\square$ Schmidt, Hans Heinrich (1989): Geologische Übersicht [Umgebung Grube Gustav]. - In: Kollmann, Karl [Red.]: Die Grube Gustav im Bilsteiner Bergbaurevier. - 1. Aufl.; S. 5-9, 1 Abb.; [Hrsg. Förderverein Besucherbergwerk „Grube Gustav"] Meißner-Abterode 1989

$\square$ Schneider, Karl (1926): Die Siedlungen des Meißnergebiets. - 46 S.; (Milkereit \& Zahnwetzer) Kassel [darin: S. 5-8 „, Die natürlichen Landschaften“ (Regionalgeologie)]

$\square$ Schneider, Otto (1929): Methodische Einführung in die Grundbegriffe der Geologie. 2. Aufl., 127 S., 188 Abb.; (Enke) Stuttgart

[darin S. 146-154, Abb. 169-174: Dritter Teil: Die Formen - Ursachen für die verschiedene Verteilung der Formationen an der Erdoberfläche - III. Beispiel: „Eine mitteldeutsche Triaslandschaft, die sich auf einem Sockel von Schiefergebirge aufbaut" = östl. Meißnervorland: Hoher Meißner bis Albungen/Fürstenstein]

$\square$ Schreiber, Carl (1849): Physisch-Medicinische Topographie des Physikatsbezirks Eschwege. Preisschrift verfasst von..., Arzte zu Eschwege, Mitglied des Meisnerischen ärztlichen Vereins und es Vereins für Hessische Geschichte und Landeskunde, im Jahre 1846 gekrönt von der Gesellschaft zur Beförderung der gesammten Naturwissenschaften zu Marburg. - Schriften der Gesellschaft zur Beförderung der gesammten Naturwissenschaften zu Marburg, 7; 291 S., 1 Falt-Taf.; hier S. 7 - 26: „Erster Abschnitt: geographische Verhältnisse, $\ 2$ Geognostische Skizze“; (Elwert) Marburg/L. dazu: $\square$ Beck, Hanno (1974): Das Werden des geographischen Selbstbewußtseins der Bürger einer deutschen Stadt [Eschwege]. - Hessische Heimat, N.F., 24(2/3): 92-101; Marburg/L.

[Geschichte der geowissenschaftlichen Erforschung der Eschweger Gegend] [in der Arbeit: Petrographische Karte mit der Darstellung der Grauwacken und ZechsteinhüllGesteine; Querprofil des Unterwerra-Sattels]

$\square$ Schwarzenberg, A. (1839): Über neue Bohrversuche in den Sooden. - Notizenblatt Göttingischen Vereins bergmänn. Freunde, 24: 1-2; Göttingen [Vorlage nicht eingesehen, zitiert nach Oppitz (1991)]

$\square$ Senft, Ferdinand (1894): Wanderungen durch die Gebiete der deutschen Mittelgebirgsländer - Die Mittelgebirgszone im Allgemeinen sowie Gruppe I: die mitteldeutschen Berg- und Plateauländer mit den Basaltgebirgsgruppen. - Nebentitel: Geognostische Wanderungen in Deutschland - Ein Handbuch für Naturfreunde und Reisende. - 104 S.; (Hahn'sche Buchhdlg.) Hannover-Leipzig 1894 [darin: Meißner (Geologie des Basaltes und der Braunkohlen)]

$\square$ Siegel, G. (1897): Geschichte der Stadt Lichtenau in Hessen und ihrer Umgebung - nebst Nachrichten üer die einzelnen Amtsorte und einem Urkundenbuche. - Z. Vereins hess. Gesch. u. Landeskde., 32; 443 S., 3 Abb., 3 Kt., 1 Plan, 2 Taf.; Kassel [darin S. 2-3: Information zur Regionalgeologie]

$\square$ Simon, Helmut (2006): Hausen - Höchstgelegener Ort Kurhessens - Die Geschichte eines niederhessischen Dorfes am Meißner in der Zeit von 1364 bis 2005. - 592 S:, zahlr. Abb.; [Hrsg. Helmut Simon, Kirchenvorstand Ev. Kirchengemeinde Hausen; Ortsbeirat Hausen] Hausen [darin S. 11-18, 8 Abb.: „Zum Naturraum von Hausen“; S. 29-46, zahlr. Abb. „Die Geschichte des Bergbaues am Hohen Meißner (Braunkohle, Alaun, Wascherde)]

$\square$ Stäblein, Gerhard (1986) [Hrsg.]: Geo- und biowissenschaftliche Forschungen der Freien Universität Berlin im Werra-Meißner-Kreis (Nordhessen). - Berliner Geogr. Abh., 41; zgl. Beiträge zur WerraMeißner-Forschung, İ 265 S., 82 Abb., 45 Tab., 3 Kt.-Beil.; (Selbstverl. Inst. Phys. Geogr. FU Berlin) Berlin 
口 $\square$ Stille, Hans (1925): <Der geologische Aufbau Niederhessens> -Eschweger Tageblatt, 1925; Nr. 272 v. 19.11.1925; Eschwege

[Bericht über Vortrag v. Hans Stille am 17.11.1925 in Eschwege]

- $\square$ Straub, August (1969): Nordhessen: Das Bergland von Niederhessen - Landschaft, Geschichte, Kultur, Kunst, Wirtschaft. - 352 S., zahlr. Abb.; (Glock u. Lutz) Nürnberg [darin auch Informationen zur Geologie: Steinbruch Cornberg, Habichtswald, Knüll, Meißner, Reinhardswald, Richelsdorfer Gebirge, Ringgau,]

$\square$ Strickhausen, Gerd (1993): Die Boyneburg bei Eschwege - Untersuchungen zur Baugeschichte einer staufischen Reichsburg. - Quellen u. Forschungen z. hess. Geschichte, 6ㅜ; 99 S., 67 Abb., Anhang m. 6 Plänen (1 Fototaf., 5 Falt-Bl.; [Selbstverl. Hist. Komm. Darmstadt u. Hist. Komm. f. Hessen) Darmstadt-Marburg [darin: S. 14-15: „Lage - Geologische Situation“]

$\square$ Tolle-Krieger, Ingeborg (1941): Eschwege und seine Landschaft. - 87 S. (Braun) Eschwege - zgl. Diss. Univ. Heidelberg 1938 u. d. Titel „Das Becken von Eschwege“; 88 S.

[darin: Kap. „Die Naturlandschaft des Eschweger Beckens“ (u.a. Regionalgeologie, regionale Geomorphologie)]

$\square$ Träger, Harry \& Marzela, Clemens (2006): Der Braunkohlenbergbau am Meißner - 1558-1974. Ein historischer Rückblick und Begleitbroschüre für montanhistorische Wanderungen auf dem Meißner. 160 S., 122 Abb., 1 Kt.-Beil.; (Geiger) Horb

[darin: S. 56-59, 2 Abb.: „Geologie“ [des Meißners]]

$\square$ वUU1rich, Wilhelm (1912): Das Werratal - Kleiner Führer durch das Werratal von Münden bis Creuzburg und angrenzende Gebiete. - Mit 14 Kunstblättern, 39 Textbildern, einem Plan von Burg Hanstein und einer Übersichtskarte. - 95 S., Ill.; [Hrsg. Sektion Eschwege des Werratalvereins] ohne Ort

[Kurzinformationen zur Regionalgeologie i. d. einzeln. Kapiteln]

口Q $\bullet$ Ulrich, Wilhelm (1921): Das Werratal - Wanderbuch durch die Werralandschaft vom Thüringer Wald bis Münden - mit 25 Federzeichnungen von Ernst Metz. - 2. Auflage, 116 S., 25 Abb., 1 Kt.; (Vollprecht) Eschwege - 1. Aufl.; 132 S., 24 Abb.; (Vollprecht) Eschwege [darin S. 11-18: „Überblick über die Werralandschaft“ - Informationen zur Regionalgeologie]

口OUlrich, Wilhelm (1929): Der geologische Aufbau des Werratales. - In: Adler, Arthur [Hrsg.] Heimatkalender für das Werratal für das Jahr 1930(3. Jg.), 79 S., Abb.; hier: S. 35-39, 2 Abb.; (Johs. Braun) Eschwege 1929

[WMK, Thüringen]

$\square$ Ulrich [Wilhelm] (1949): Der Meißner. - 116 S., 5 Abb.; (Werraland-Verlag) Eschwege Referat in: Das Werraland, 1: 17-18 (Perst)

[S. 9-25, 2 Abb.: „Der Meißner landschaftlich und geologisch“; S. 25-29: „Quellen“ [auch Hydrogeologie]; S. 29-45, 1 Abb.: „Das Braunkohlenwerk“]

$\square$ Walchner, Friedrich August (1846): Handbuch der Geognosie zum Gebrauche bei seinen Vorlesungen und zum Selbststudium, mit besonderer Berücksichtigung der mineralogischen Verhältnisse des Großherzogthums Baden. - 1120 S.; (Groos) Karlsruhe - 1. Auflage u. d. T.: Handbuch der gesammten Mineralogie in technischer Beziehung - zum Gebrauche bei seinen Vorlesungen und zum Selbststudium, mit besonderer Berücksichtigung der mineralogischen Verhältnisse des Großherzogthums Baden. - Teil 2: Geognosie - mit 11 Steintafeln. - 1104 S.; (Groos) Karlsruhe 1832 [Ausgabe v. 1846 - Regionale Geologie d. Werra-Meissner-Kreises, u.a. Blaue Kuppe b. Eschwege]

- $\square$ OWWalter, Roland (2007): Geologie von Mitteleuropa. - Begründet von Paul Dorn. - 7., vollst. neu bearb. Aufl.; 511 S., 184 Abb.; (Schweizerbart) Stuttgart 
[darin Kap.: Nordhessisches Bergland und Niederhessische Senke, Thüringer Wald und ThüringischFränkisches Schiefergebirge, Thüringer Becken]

$\square$ Weichbrodt, Ernst (1981): Der Einfluß von Raumausstattung, Betriebsgrößen und Bevölkerungsgruppen auf den agrarstrukturellen Wandel in Nordhessen. Zugleich ein methodischer Beitrag zur Ermittlung sozialgeographischer Gruppen. - Berliner geogr. Studien, $\underline{\mathbf{6}}$; XI, 160 S., 27 Abb., 16 Tab., 20 Kt.; Berlin [darin S. 3-10: Die physisch-geographischen Voraussetzungen (Geologie, Naturraum)]

$\square$ Weigel, Heinrich \& Udolph, Jürgen (1998): Der Ringgau - uralter Begriff für ein hessischthüringisches Grenzland. - Das Werraland, $\underline{\mathbf{5 0}}$ (1): 1-3, 3 Abb.; Eschwege [Geologische Karte Ringgau, Netratalgraben; Schlierbachsbald, Nördl. Thüringer Wald, Gegend westl. Creuzburg]

$\square$ Weigel, Heinrich \& Ernst, Werner (1998): Die „Krone des Werratales“ - Der Heldrastein (503,4m) mit Dreiherrenstein (488,5 m) im Westen und Hüneburg (495,4 m) im Osten. - Das Werraland, $\underline{\mathbf{0 0}}$ (3): 53-57, 5 Abb., 1 Kt.; Eschwege - ebenso: Hessischer Gebirgsbote, 99(4): 135-139, 5 Abb., 1 Kt.; Melsungen

[Geol. Karte, handgez.; Region zw. Oberdünzebach - Wendehausen im Norden, Altefeld und Creuzburg im Süden]

$\square$ Weiß, Otto (1851): Ursprung der Solquelle von Soden a. d. Werra. - Archiv f. Mineralogie, Geognosie., Bergbau u. Hüttenkunde, 24 (2): 303-331; Berlin

Referat in: N. Jb. Mineral. etc., 1852: 494-495; Stuttgart

[Regionalgeologie Umgebung Bad Sooden-Allendorf]

$\square$ Weiß, Otto (1864): Ueber die geognostischen Verhältnisse sowie die nutzbaren Mineralien und Gesteine in der Umgebung der Saline Sooden bei Allendorf an der Werra. - Bericht d. Vereins f. Naturkunde zu Cassel, 14: 45 - 58; Kassel

$\square$ Wölker, Thomas (1987): Die Wüstungen des Ammicheroder Kessels - Interpretation von Geländeund Quellenbefunden. - Z. Vereins hess. Gesch. u. Landeskde., 92: 43-104, 1 Abb., 9 Kt.; Kassel [darin S. 52: „Physisch-geographische Bedingungen“]

$\square$ Wölker, Thomas (1991): Auf den Spuren der Vergangenheit - Ein historisch-geographischer Führer durch den Ammicheroder Kessel bei Bad Sooden-Allendorf. - 40 S., 8 Kt.; [Hrsg. i. Auftrag d. Vereins f. Heimatkde e.V.; Bad Sooden-Allendorf) (Selbstverlag d. Vereins) Bad Sooden-Allendorf [darin Informationen zur Geologie, Geomorphologie]

$\square$ Wollenhaupt, Gustav [Hrsg.](1974/1975): Geschichte der Stadt Großalmerode und familienkundliche Nachrichten. - Teil 1; 117 S., Abb.; ; (Im Selbstverlag) Großalmerode 1974 - Teil 2; 143 S., Abb.; (Im Selbstverlag) Großalmerode 1975

[darin Aufsätze zur Regionalgeologie, „Bühlchen“ b. Epterode, Bergbaugeschichte Hirschberg b. Großalmerode]

\subsubsection{Regionale Geologie - Thüringen}

OAmm (1902): Über die geologische Entstehung Thüringens. - In: Thüringen in Wort und Bild. - Bd. 2; 492 S., ca. 160 Abb.; hier S. 1-16, 6 Abb.; [Hrsg. Thüringer Pestalozzi-Verein] (Klinkhardt) Leipzig

DAmthor, Reinhold (1910): Geologischer Aufbau und geologische Geschichte des Wachsenburgberges. Aus den coburg-gothaischen Landen - Heimatblätter, 7: 23-32, 3 Abb.; Gotha 
QAmthor, R. (1913): Die geologische Beschaffenheit des Herzogtums S.-Gotha. - Mit einer Karte der Lagerungsverhältnisse, 3 Kartenskizzen und 3 Querprofilen. - Heimatkunde für das Herzogtum Gotha, 1. Teil.; VI, 188 S.; [Hrsg. Naturwiss. Verein z. Gotha](Selbstverlag des Vereins) Gotha

DAmthor, Reinhold (1927): Der geologische Aufbau des Stadtgebietes [von Gotha]. - In: Schmidt, K. [Hrsg.]: Gotha - Das Buch einer deutschen Stadt. - Heft 1: Die natürlichen Grundlagen der Siedelung Gotha. - 96 S., 8 Taf.; hier S. 29-46, 2 Taf. (I, IV) n. S. 96; (Engelhardt-Reyher) Gotha 1927

QAnonym (1976): Wanderungen im Kreis Worbis. - 130 Abb., zahlr. Abb.; [Hrsg. Pädagogisches Kreiskabinett Worbis i. Verb. m. Kulturbund der DDR - Worbis/Heiligenstadt] Worbis-Heiligenstadt [darin S. 5-6: „Geographische Übersicht. Geologie“]

DAnonym (1994): Östlicher Thüringer Wald - Kompass Lexikon - Wanderkarte 1022; Beiheft zur Kompass Spezial Wanderkarte 1022 Östlicher Thüringer Wald 1 : 50 000; 64 S., Abb., Kt.; (Fleischmann) Starnberg [darin S. 16-19, 1 Kt.: Geologie des Thüringer Waldes]

Dᄆ0 Apel, Jürgen \& Rüppel, Heidi [Verfass. u. Hrsg.] (2005): Raus in die Natur - Tipps für den Sonntags-Ausflug im Dreiländereck Hessen - Niedersachsen - Thüringen. - 159 S., 111 Fotos, 34 Kt., 1 Zeit-Taf.; (LSRB-Verlag, Landschaftskundlicher-Studien-Reisebuch-Verlag) Witzenhausen [zahlreiche Ausflugsziele, auch zu Geotopen in Thüringen]

OArand, Siegfried \& Kaaden, Heiko (1986): Geologische und geomorphologische Betrachtung der Landschaft um Uder (Eichsfeld). - Eichsfelder Heimathefte, (26. Jg.) 1986(1): 22-36, 3 Abb.; Worbis

OBauer, Max (1882): Die geologischen Verhältnisse der Seeberge und des Galbergs bei Gotha - Eine geologische Monographie. - 62 S., 2 Kt.; (Hartung) Königsberg

QBauer, Herbert \& Heim, Rudolf (1956): Wanderungen und Exkursionen im Hauptmassiv des Thüringer Waldes. - 135 S., Abb., Kt.; (Druckerei Thüringer Wald) Hildburghausen

OBauer, Max (1882): Die geologischen Verhältnisse der Seeberge bei Gotha und des Gralberges. - Jb. Preuß. Geol. Landesanst., $\underline{2}$ (f. 1881): 331-392, Taf. VIII, VIX; Berlin

QBeutler, G.; Franzke, H. J. \& Schüler, F. (1988): Thüringer Senke. - In: Bankwitz, Elfried [Gesamtredaktion]: Klassische Geologische Gebiete in Mitteleuropa - Fundament und Deckgebirge, Südteil DDR - Exkursionsführer. - S. 199-222, Abb. 60-70; (Akademie der Wissenschaften der DDR - Zentralinstitut f. Physik d. Erde) Potsdam 1988

OBeyrich, E. (1895): Überblick über die geologische Zusammensetzung des Thüringer Waldes, in Sonderheit des Rotliegenden desselben, unter Vorlegung einer neuen geologischen Übersichtskarte im Maßstab 1 : 100.000. - Z. dt. geol. Ges., 47: 596-607; Berlin

QBeyschlag, Franz (1882): Geognostische Skizze der Umgebung von Crock im Thüringer Walde. - Z. f. Naturwiss., 55(4. F., 1) (1882): 571-645, Anhang S. 646-647: Das Crocker Steinkohlenbergwerk; Leipzig

OBeyschlag, F. (1887): Ueber Aufnahmen auf Blatt Salzungen. - Jb. Preuß. Geol. Landesanst., $\underline{8}$ (f. 1887): LIX-LX; Berlin

OBeyschlag (1895): Geologischer Bau des Thüringer Waldes. - Z. prakt. Geologie, [3. Jg.] 1895: 498-499; Berlin [Vortragsreferat]

OBöhne, E. (1916): Das Randgebiet des Thüringer Waldes bei Schmalkalden und Steinbach-Hallenberg. Jb. Preuß. Geol. Landesanst., $\underline{\mathbf{3 6}}$ (Teil I) (f. 1915): 1 - 173, 10 Abb., 4 Taf.; Berlin 
QBornemann [sen.], J. G. (1852): Über die geognostischen Verhältnisse des Ohmgebirges bei Worbis. N. Jb. Mineral. etc., 1852: 1-34, 1 Abb., Taf. I,; Stuttgart

QBornemann [sen.], J. G. (1884): Von Eisenach nach Thal und Wutha. - Jb. Preuß. Geol. Landesanst., 4 (f. 1883): 383-409, Taf. XXII-XXVII; Berlin

Referat in N. Jb. Mineral. etc., $\underline{\mathbf{1 8 8 5}}$ (Bd. 2): 68-70 (Referat E. Dathé); Stuttgart

@Bornemann (sen.), J. G. (1886): Ueber Aufnahmen auf Section Wutha. - Jb. Preuß. Geol. Landesanst., $\underline{\mathbf{6}}$ (f. 1885): XXXVIII-XXXIX; Berlin

@Bornemann [sen.], J. G. (1888): Ueber Aufnahmen auf Blatt Wutha. - Jb. Preuß. Geol. Landesanst., $\underline{8}$ (f. 1887): XLIV-XLV; Berlin

QBornemann (jun.), G. (1887): Ueber Aufnahmen auf Section Wutha. - Jb. Preuß. Geol. Landesanst., $\mathbb{7}$ (f. 1886): XXXVII-XXXVIII; Berlin

QBornemann (jun.), G. (1886): Ueber Aufnahme der Section Fröttstedt [5029 Waltershausen N]. - Jb. Preuß. Geol. Landesanst., $\underline{\mathbf{6}}$ (f. 1885): XL; Berlin

OBornemann [jun.], L. G. (1887): [Bericht über die] Aufnahme der Section Fröttstedt [5029 Waltershausen N]. - Jb. Preuß. Geol. Landesanst., 7 (f. 1886): XXXVIII - XLI; Berlin

OBuch, Leopold von (1824): Ueber den Thüringer Wald. - Mineral. Tb., 1824: 437-471; Frankfurt/M. auch in: Ewald, J.; Roth, J. \& Dames, W. (1877): Leopold von Buch's gesammelte Schriften. - Bd. 3; VIII, 714 S., 25 Taf.; hier S. 186-203; (Reimer) Berlin

OCotta. B. (1845): Ergebnisse geognostischer Untersuchung und Chartierung in Sachsen und Thüringen. Porphyr-Arten, Hebungen usw. [Briefl. Mitth.] - N. Jb. Mineral. etc, $\underline{1845}$ : 74 - 82; Stuttgart [Bezug a. Thüringer Wald]

oCotta, B. v. (1843): Geognostische Skize von Thüringen. - In: Geinitz, H.B. [Hrsg.]: Gäa von Sachsen. Einleitung in die Flora Sachsen. - Nebentitel: Gäa von Sachsen - oder physikalischgeographische und geognostische Skizze für das Königreich Sachsen, das Großherzothum SachsenWeimar-Eisenach, die Herzogthümer Sachsen-Altenburg, Sachsen-Coburg-Gotha, SachsenMeiningen, die Fürstlich Schwarzburgischen und Reußischen Lande, die Herzogthümer AnhaltDessau, Anhalt-Bernburg und Anhalt-Köthen, die Provinz Sachsen und die Preußische Lausitz; 225 S., [6] Bl.; hier S. 165-176; (Arnoldi) Dresden-Leipzig 1843

OCredner, H. (1839): Geognostische Beschreibungen des Höhenzuges zwischen Gotha und Arnstadt. N. Jb. Mineral. etc., 1839: 379-404 (Abh.), Taf. VI, VII; Stuttgart

QCredner, H. (1840): [Géologie des] Hauteurs entre Arnstadt et Gotha. - Bull. Soc. géol. France, (1 sér.) 11: 17-20; Pairs

QCredner, Heinrich (1841): Das Flötz-Gebirge nördlich von Eisenach. - N. Jb. Mineral. etc., 1842: 1-21, Taf. I; Stuttgart

QCredner, Heinrich (1841): Übersicht der geognostischen Verhältnisse zwischen Schmalkalden und Friedrichrode. - N. Jb. Mineral. etc., 1841: 395-431, Taf. VI [Kt. u. Profil]; Stuttgart

QCredner, Heinrich (1843): Uebersicht der geognostischen Verhältnisse Thüringens und des Harzes zur Erläuterung einer orographisch-geognostischen Skizze dieser Gegend. - 1,140 S., 1, 1 Kt.; (Perthes) Gotha

QCredner, H. (1846): Geognostische Bemerkungen über die Umgegend von Ilmenau. - N. Jb. Mineral. 1846: 129-149; Stuttgart 
ODanz, C. F. \& Fuchs, C.F. (1848): Physisch-medicinische Topographie des Kreises Schmalkalden. Schriften d. Ges. z. Beförderung d. gesammt. Naturwiss. z. Marburg, 후 XII, 354 S., 2[Bl.]; (J.A. Koch) Marburg/L.

[S. 5-21 Kap. „Äußere Gestaltung (Berg- und Thalbildungen)“; S. 37-117 Kap. „Innere Beschaffenheit (Geognostische Verhältnisse)"]

QDanz, C.F. \& Fuchs, Caspar Friedrich (1848): Acht Tafeln zur phyisch-medicinischen Topographie des Kreises Schmalkalden... - Schriften d. Ges. z. Beförderung d. gesammt. Natuwiss. z. Marburg, $\underline{\mathbf{6}}$; 8 Taf.; (Elwert) Marburg

OEhrhardt, Klaus (1970): Geologische Verhältnisse im Gebiet des Kleinen Thüringer Waldes. Geologie, 19(3): 330-339, 5 Abb.; Berlin

QEllenberg, Jürgen (1968): Die geologisch-geomorphologische Entwicklung des südwest-thürinigschen Werragebietes im Pliozän und Quartär. - Diss. Univ. Jena 1969; V, 188 Bl, Anh., 3 Anl.

QEllenberg, J.; Schröder, B.; Peterek, A. \& Morgenroth, V. (2001): Exkursion A 1 - Geologie und Landschaftsgeschichte im Dreiländereck Hessen, Bayern und Thüringen. - In: Jockel, Andreas [Hrsg.]: Regionale und angewandte Geologie der Grenzregion der Süddeutschen und der Mitteldeutschen Scholle. - Exkursionsführer zur 10. Jahrestagung der Gesellschaft für Geowissenschaften e.V. in Schmalkalden - 19.-22. September 2001. - Exkursionsführer u. Veröff. Ges. f. Geowiss., 213; S. A1-1 bis A1-46, 16 Abb.; Berlin 2001

QErläuterungen zur Geologischen Karte von Preußen und benachbarten Bundesstaaten. Lfg. 112: Berlingerode, Heiligenstadt, Dingelstädt, Kella, Lengenfeld... Lfg. 128: Langensalza, Langula, Henningsleben (Großenbehringen)

Referat in: N. Jb. Mineral. etc., 1906 (Bd. II): 229-232 (Karl Walter); Stuttgart

OErnst, Werner (1991): Geologie um die Brandenburg. - Das Werraland, 43(4): 68-69, 2 Abb.; Eschwege

OEnnst, Werner (1993): Creuzburgs Umgebung - Dorado für Geologen. - Das Werraland, $\underline{45}$ (2): 60-62, 3 Abb.; Eschwege

OFiege, Aloys (1928): Eine Tiefbohrung in der Gemarkung von Heiligenstadt. - Unser Eichsfeld, 23 (8): 165-167; Duderstadt

OFranke, Hermann (1912): Geologisches Wanderbuch für den Thüringer Wald. - VIII, 196 S., 23 Abb.; (Enke) Stuttgart

Referat in: Mitt. Geogr. Ges. f. Thür., 30: 224-225 (E. Piltz); Jena 1912

QFrantzen, W. (1898): Mittheilungen über die Aufnahme des Blattes Treffurt - Jb. Preuß. Geol.

Landesanst., $\underline{18}$ (Teil I)(f. 1897): XXXIX-XLIV; Berlin

Referat in: Mitt. Geogr. Ges. (f. Thüringen), 19: 60 (E. Schütze); Jena 1900/1901

GFrantzen, W. (1900): Ueber Aufnahmen auf Blatt Treffurt 1899. - Jb. Preuß. Geol. Landesanst., 20 (f. 1899): XXI-XXIX; Berlin

OFreyberg, Bruno von (1937): Thüringen - Geologische Geschichte und Landschaftsbild. - Schriften Dt. Naturkde.-Vereins, N.F., $\underline{\mathbf{5}}$; 160 S., 252 Abb.; (Hohenlohe'sche Buchhandlung Ferdinand Rau) Öhringen

QFritsch, Karl v. (1860): Geognostische Skizze der Umgebung von Ilmenau. - Z. dt. geol. Ges., 12: 97155, Taf. III-IV; Berlin

OFritze, Eduard (2007): Der Eichsfelder Westerwald. - 1. Aufl., 240 S., zahlr. Abb., Tab.; (Rockstuhl) Bad Langensalza [darin Kap.: „Zur Geologie des Westerwaldes"] 
Q[Fritze, Franz] (1854): Der Nordwesten des Thüringer Waldes oder zehn Tage in Ruhla - Gemälde aus dem Badeort Ruhla und seiner Umgebung - Eisenach, Wilhelmsthal, Altenstein, Liebenstein, Inselsberg und Reinhardsbrunn - Ein Reisehandbuch und Wegweiser (nebst einer Reiseroute durch die übrigen Theile des Waldes). - XIV, 230 S., 1 Kt.; (Veit) Berlin

[darin S. 41-42 Alabastersteinbruch bei Kittelsthal; S. 48-51 Geologischer Überblick Thüringer Wald; S. 108-112 Die Höhle von Altenstein; S. 164-165 Marienhöhle < Marienglashöhle b. Tabarz>]

$\square$ GFrölich, Ernst (1939): Die Flora des mittleren Werratales - in pflanzengeographischen Bildern. - 144 S., Abb., Tab.; (Rossbach) Eschwege

[Werratal zwischen Hörschel und Jestädt; darin: S. 16-18 Kap. „ Geologische Übersicht“; zus. Angaben zur Geologie der einzelnen Vegetationsräume]

QFuchsel, Georgio Christiano [= Füchsel, Georg Christian] (1761): Historia terrae et maris ex historia Thuringiae per montium descriptionem erecta. - Actorum academiae electoralis moguntinae sientiarum utiliium quae erfordiae est. - Tomus II, p. 44-254; (apud Johannem Fridericum Weberum) Erfordiae

OFulda, Ludwig (1924): Über Aufnahmeergebnisse auf den Blättern Berka und Vacha im Jahre 1922. Jb. Preuß. Geol. Landesanst., 44 (f. 1923): LX-LXI; Berlin

OGeiger, Walter (1974): Ein Haifischzahnfund im Sachsental bei Kaltenohmfeld - Eine geomorphologsch-geologische Betrachtung des Ohmgebirges. - Eichsfelde Heimathefte, (14. Jg.) 1974(4): 340-354, 12 Abb.; Worbis

OGeiger, Walter (1977): Der Richteberg zwischen Leinefelde und Kallmerode. - Eichsfelder Heimathefte, (17. Jg.) 1977(4): 352-358, 3 Abb.; Worbis

QGeiger, Walter (1983): Ein „Abriß der Geologie des Eichsfeldes“ ist notwendig. - Eichsfelder Heimathefte, (23. Jg.) 1983(2): 173-176; Worbis

QGeorgi, Paul (1954): Die Suhler Steinsburg und ihre Geschichte. - Der Aufschluß, 9: 17-20; Göttingen

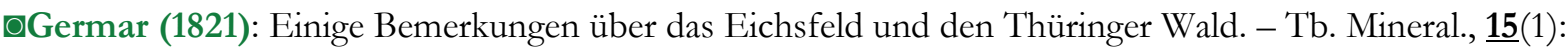
37-40; Frankfurt/M.

[Regionale Geologie]

QGertler, Erwin (1984): Treffurt und Umgebung in alter Zeit. - 377 S., zahlr. Abb. u. Skizz.; Bollendorf [darin S. 1-12: ,Zur geologischen Geschichte des mittleren Werratals“]

QGertler, Erwin: Die ältere Geschichte der Stadt Treffurt - Von der Urzeit bis in die Mitte des 19. Jahrhunderts. - 299 S., zahlr. Abb.; o.O., o. J.; (Selbstverlag) [darin S. 1-34: „Zur geologischen Geschichte des mittleren Werratals"]

- 0 OGiebel, Chr. G. A. (1851): Gaea excursoria germanica - Deutschlands Geologie, Geognosie und Paläontologie - ein unentbehrlicher Leitfaden auf Excursionen und beim Selbstunterricht - mit 24 lithograpischen Tafeln. - XII, 510 S., 24 Taf.; (Abel) Leipzig

[Stratigraphie Deutschlands und regionale Verbreitung der Formationen; darin: S. 120 (Kap. Basalt: Blaue Kuppe b. Eschwege, Meissner, Hirschberg b. Großalmerode, Stoffelskuppe b. Eisenach; S. 167: Kap. Kupferschiefergebirge: Meißnervorland, Richelsdorfer Gebirge, Thüringer Wald; S. 191 Muschelkalk: Westhüringen, Nordosthessen, Südniedersachsen; S. 206: Keuper: Hess. Lichtenau, Westthüringen]

QGläser, Friedrich Gottlob (1775): Versuch einer mineralogischen Beschreibung der gefürsteten Grafschaft Henneberg chursächsischen Anteils - nebst einer kurzen Geschichte des ehemaligen und ietzigen Bergbaues derselben. - 106 S.; (Crusius) Leipzig 
QGrieß, Werner (2005): Zur Geologie und Geographie der Iberg-Gemeinden. - In: Grieß, Werner; Häger, Ralf \& Keppler, Josef: Zur Geschichte der Iberg-Gemeinden - Thalwenden, Birkenfelde und Schönhagen - Jubiläumsschrift 2005. - 230 S., Abb.; hier: S. 13-14, 1 Abb.; [Hrsg.: IbergGemeinden Thalwenden, Birkenfelde u. Schönhagen] (Mecke) Duderstadt 2005

QGrumbt, Eberhard \& Lützner, Harald (1962): Bericht über die Neukartierung der Meßtischblätter Keula und Schlotheim (Nordwestthüringen). - Ber. Dt. Ges. geol. Wiss., Reihe A, $\underline{\mathbf{6}}$ (f. 1961)(4): 479494, 9 Abb.; Berlin

QHanle, Alfred [Hrsg.] (1992): Thüringer Wald und Schiefergebirge. - Meyers Naturführer; 123 S., zahlr. Abb.; (Meyers Lexikon-Verlag) Mannheim u.a.

[darin S. 7-14: „Landeskundlicher Überblick“ m. Inf. z. Regionalgeologie; Geowiss. Informationen auch i. d. Beschreibungen der naturkundlichen Sehenswürdigkeiten]

OHaupt, R.; Hiekel, W.; Westhus, W. \& Görner, M. (1990): Das Naturschutzgebiet „Wartburg Hohe Sonne" im nordwestlichen Thüringer Wald. - Landschaftspflege u. Naturschutz in Thüringen, Sonderheft; 27 Jg. (1990); 16 S., 16 Abb.; [Hrsg. Bezirksverwaltungsbehörden Erfurt, Gera und Suhl. , Inst. f. Landschaftsforsch. u. Naturschutz, Arbeitsgr. Jena] Jena [darin S. 1-2: „2. Landschaftlicher Überblick: 2.1 Geologie und Oberflächenformen“]

QHecht, Günter (1994): Die Mineralwasserbohrungen Bad Liebenstein 1/1979 und 2/1980 . - Geowiss. Mitt. Thüringen, 2: 149-215, 7 Abb., 8 Tab., Anl. 2 u. 3; Weimar [Hydrogeologie, Schichtenverzeichnis]

QHecht, Günter (1995): Die Solebohrungen von Bad Salzungen. - Geowiss. Mitt. Thüringen, $\mathbf{3}$ : 135-172, 2 Abb., 10 Tab., Beil. 5-9; Weimar [Hydrogeologie, Reg. Geol. - Schichtenverzeichnis)]

QHeiland, H.; Nolte, L.; Röhling, H.-G. \& Seidel, G. (2008): Geologisch-historische Stadtführung in Heilbad Heiligenstadt. - In: Wunderlich, J. [Red.]: Exkursionsführer - Geologie des Eichsfeldes zur 18. Jahreshauptversammlung (Vortrags- und Exkursionsveranstaltung) vom 16. bis 18. Mai 2008 in Heilbad Heiligenstadt. - Führung: H. Heiland, L. Nolte, H.-G. Röhling \& G. Seidel. - S. 26-32, 5 Abb., 2 Tab.; [Hrsg.: Thüringer Geologischer Verein e.V.] Jena 2008

OHeim, Johann Ludwig (1796): Geologische Beschreibung des Thüringer Waldgebürgs - Bd. 1: Von der äussern Gestalt des Thüringer Waldgebürgs. - L, 360 S.; (Joh. Gottfr. Hanisch) Meiningen [Johann Ludwig Heim, Pfarrer von Beruf, lebte von 1704-1785]

OHeim, Johann Ludwig (1798): Geologische Beschreibung des Thüringer Waldgebürgs - Bd. 2.1: Von der innern Einrichtung des Gebürgs nach seinen Gebürgslagern. - XVI, 360 S.; (Joh. Gottfr. Hanisch) Meiningen

QHeim, Johann Ludwig (1799): Geologische Beschreibung des Thüringer Waldgebürgs - Bd. 2.2: Von der innern Einrichtung des Gebürgs nach seinen Gebürgslagern. - XII, 256 S., 1 Falt-Bl.; (Joh. Gottfr. Hanisch) Meiningen

QHeim, Johann Ludwig (1803): Geologische Beschreibung des Thüringer Waldgebürgs - Bd. 2.3+4: Von der innern Einrichtung des Gebürgs nach seinen Gebürgslagern. - XIV, 312 S.; (Joh. Gottfr. Hanisch) Meiningen

OHeim, Johann Ludwig (1812): Geologische Beschreibung des Thüringer Waldgebürgs - Bd. 3: Kurze Üebersicht des Thüringerwales nach der Anordnung, Gestaltung und Gruppirung seiner Gebürgslager, nebst einigen daraus ageleiteten allgemeinen Resultaten. - XIV, 322 S.; Joh. Gottfr. Hanisch) Meiningen

OHenningsen, Dierk \& Kaatzung, Gerhard (2002): Einführung in die Geologie Deutschlands. - 6. überarb. Aufl.; 214 S, XIV Farbtaf. 95 Abb.; (Spektrum, Akademisch. Verlag) Heidelberg - Berlin 
[darin: Rotliegendlandschaften - Thüringer Wald; Landschaften des Mesozoikums - Thüringer Becken]

QHess, Christoph (1820): Übersicht der geognostischen Beschaffenheit der Umgebungen von Gotha. Tb. Mineral., 14(1): 120-185; Frankfurt/M.

QHeß von Wichdorff, [Hans] (1913): Geologischer Aufbau und Entstehung des Thüringer Waldes. In: Meyers Reisebücher - Thüringen - Große Ausgabe. - 21. Aufl., XII, 324 S., 21 Kt., 19 Pläne, 2 Panoramen; hier S. 20-24; (Bibliographisches Inst.) Leipzig-Berlin 1913

QHeuse, Thomas [1994]: Zur regionalgeologischen Stellung der näheren Umgebung Lauchrödens unter besonderer Berücksichtigung des Gebietes um die Brandenburg. - In: Bergmann, G.: Unser Dorf Lauchröden - eine Zusammenstellung heimatgeschichtlicher Beiträge - Herausgegeben aus Anlaß der 850. Wiederkehr der Ersterwähnung Lauchrödens. - 103 S., Abb.; Lauchröden [1994]

OHoff, K.E.A. von \& Jakobs, C. W. (1807-1812): Der Thüringer Wald - besonders für Reisende geschildert. - Erste oder nordwestliche Hälfte. Mit Kupfern und einer Karte - XXX, 288 S.; (Ettinger'sche Buchhdlg.) Gotha Zweite oder südöstliche Hälfte. - XXXXII, 243 S.; ; (Ettinger) Gotha [Beschreibung nach Tälern, auch Geologie]

QHoff, Karl Ernst Adolf von (1812): Gemälde der physichen Beschaffenheit von Thüringen. - 48 S.; (Beier u. Maring) Erfurt

[Orographie und Geologie von Thüringen]

QHoff, Karl Ernst Adolf von (1814): Beschreibung des Trümmergebirges und alteren Flözgebirges, welche den Thüringer Wald umgeben. - Tb. Mineral., $\underline{8}$ : 319-437; Frankfurt/M.

QHoff, Karl Ernst Adolf v. (1815): Geognostische Übersicht des Thüringer Waldes. - Tb. Mineral., 9: 485-509; Frankfurt/M

[Auszug aus: v. HOFF: Der Thüringer Wald besonders für Reisende geschildert]

QHoff, K. E. A. von (1817): Aperçu géognostique du Thüringerwald (Extrait de l’Annuaire Minéralogique de M. Léonhard, par M. de Bonnard, ingénieur en chef des mines). - Annales des mines, $\underline{1817}(3): 347-360$; Paris

QHoffmann, Karl-Heinz (2003): Kleinbartloffer Heimatschrift mit Reifenstein - 1253 - 2003. - 88 S., zahlr. Abb.; [Hrsg. Gemeinde Kleinbartloff] Kleinbartloff 2003

[darin S. 8: „Geologie, Flora und Fauna“]

QHofmann, Friedrich (1830): Uebersicht der orographsichen ung geognostischen Verhältnisse vom nordwestlichen Deutschland. - 2 Abth. i.e. Bd., XXIV, 676 S., 3 Taf. (i. sep. Quartbd.); (Barth) Leipzig

[1. Abth.: Orographische Übersicht; darin: Thüringer Wald, Hügelland zw. Harz u. Thür. Wald, Hügelland in den Umgebungen des oberen Leinethales, in Hessen .... - 2. Abth.: Geognostische Übersicht: darin: Bezugnahme auf Rotliegendes im Thüringer Wald, Richelsdorfer Gebirge]

OHoppe, Vinzenz (Verf.) \& Montag, Alfons (Bearb.)(2000): Heimat Eichsfeld - Streifzüge durch die Geschichte und Volkskunde. - 296 S.; (Mecke) Duderstadt

[darin S. 10-16: „Geologie und Geographie des Eichsfeldes“]

QHoppe (1956): Südwestrand des Thüringer Waldes zwischen Eisenach und Bad Liebenstein. Exkursion D am 18. Oktober 1955. - Bericht über die Mitgliederversammlung und Exkursionstagung der Geologischen Gesellschaft der Deutschen Demokratischen Republik vom 16. bis. 18. Oktober 1955 in Eisenach. - Ber. geol. Ges. DDR, 2 (1): 60-61; Berlin 
OHoppe, Walter [Hrsg.](1959): Exkursionsführer Thüringer Becken - Jahrestagung der Geologischen Gesellschaft in der Deutschen Demokratischen Republik vom 23. bis 26. April 1959 in Weimar. - 134 S., zahlr. Abb. auf Faltbl.; (Akademie-Verlag) Berlin

OHoppe, Walter (1974): Geologische Entwicklungsgeschichte - Mesozoikum [in Thüringen]. - In: Hoppe, Walter \& Seidel, Gerd [Hrsg.]: Geologie von Thüringen [Bezirke Erfurt, Gera, Suhl]. - S. 828-844, Abb. 164-165; (Haack) Gotha-Leipzig 1974

QHoppe, Walter \& Seidel, Gerd [Hrsg.](1974): Geologie von Thüringen - Bezirke Erfurt, Gera, Suhl 1000 S., 200 Abb., 124 Tab., 1 geol. Falt-Kt.; (VEB Hermann Haack) Gotha-Leipzig

-0•Jäger, Helmut (1963): Naturräumliche Grundlagen von Siedlung und Wirtschaft im Wesergebiet. Die Weser, 37(6): 83-88, 6 Abb.; Bremen

[Geographie, Regionale Geologie, Bergwirtschaft Hessen, Thüringen, Niedersachsen]

- $\square$ OJäschke, Max (1888): Das Meissnerland. Erster Theil: Physiographie. - Forsch. Dt. Landes- u. Volkskde., $\underline{\mathbf{3}}(2) ; 47$ S.; (Engelhorn) Stuttgart - zgl. Diss. Univ. Marburg 1888

Referat in: N. Jb. Mineral. etc, $18 \mathbf{1 8 9}$ (Bd. II): 71-72 (Franz Beyschlag); Stuttgart

Referat in: Mitt. Geogr. Ges. (f. Thüringen), 7: 128-130 Fr. R.]; Jena

[Regionale Geologie Nordosthessen, Westthüringen]

- $\square$ OJordan, Johann Ludwig (1803): Mineralogische, berg- und hüttenmännische Reisebemerkungen vorzüglich in Hessen, Thüringen, am Rheine und im Seyn-Altenkirchner Gebiethe. - 288 S., 4 FaltTaf.; (Dieterich) Göttingen

[darin: I Unterwerra-Grauwackengebirge u. Zechsteinmantel; II Bergbau i. Richelsdorfer Gebirge; IIIIII-XVI Regional-Geologie, Bergbau Umgebung Bad Liebenstein - Schmalkalden]

@Kästner, Hans; Seidel, Gerd \& Wiefel, Heinz (1995): Regionalgeologische Stellung und Gliederung [von Thüringen]. - In: Seidel, Gerd [Hrsg.]: Geologie von Thüringen. - 1. Aufl.; S. 13-21; Stuttgart 1995

OKästner, Hans; Seidel, Gerd \& Wiefel, Heinz (2003): Regionalgeologische Stellung und Gliederung [von Thüringen]. - In: Seidel, Gerd [Hrsg.]: Geologie von Thüringen. - 2., neu bearb. Aufl.; S. 1423; Stuttgart 2003

OKaiser, Ernst (1931): Thüringer Wald und Schiefergebirge - ein geographischer Führer. Mit 2 Beiträgen von Hans Weber. - Geographische Bausteine, 20; zgl. Geograph. Wanderungen d. Thüringen, $\underline{\mathbf{3}}$; 94 S., 11 Abb.; (Justus Perthes) Gotha

[Überblick Regionale Geologie, Geomorphologie]

OKaiser, Ernst (1933): Landeskunde von Thüringen. - 478 S., 48 Abb., 13 Taf., Tab., 2 Falt-Kt (1 geol. K) als Beil.; (Stenger) Erfurt [darin Erster Teil: Kap. „Entwicklungsgeschichte der thüringischen Landschaft“, „Die Bodenbeschaffenheit“; Zweiter Teil: „Die Landschaften“ mit Informationen zur Regionalgeologie]

OKaiser, Ernst (1954): Südthüringen - Das obere Werra- und Itzgebiet und das Grabfeld. - Geogr. Führer durch Thüringen, 1; 2., verb. u. ergänz. Aufl.; 147 S., 51 Abb.; (Geogr.-kartogr. Anst.) Gotha [darin: „Die geotektonischen Leitlinien der Landschaft“, Beitr. z. Regionalen Geol. der „Geographischen Wanderungen“]

OKaiser, Ernst (1954): Das Thüringer Becken - zwischen Harz und Thüringer Wald. - Geogr. Führer durch Thüringen, 2; 127 S., 20 Abb.; (Geogr.-kartogr. Anst.) Gotha [darin: „Allgemeiner Überblick“ mit Beitr. z. regionalen Geologie u. Geomorphologie; Beitr. z. Regionalen Geologie d. „Wanderungen“]

OKaiser, Ernst (1955): Thüringerwald und Schiefergebirge. - Geogr. Führer durch Thüringen, $\underline{\mathbf{3}}$; 2., verb. u. ergänz. Aufl.; 122 S., 24 Abb..; (Geogr.-kartogr. Anst.) Gotha 
[darin: „Die geologisch-tektonischen Leitlinien des Gebirges“; Beitr. zur Regionalgeologie d. „Geogr. Wanderungen"]

OKayser, Erich (1901): Mittheilungen über die Revision auf Blatt Lengenfeld im Sommer 1900. - Jb.

Preuß. Geol. Landesanst., 21 (f. 1900): XIX-XXII; Berlin

Referat in: N. Jb. Mineral. etc., 1903 (Bd. II): 93-94 (Holzapfel); Stuttgart

OKeferstein, Christian (1856): Der Ehrenberg bei Ilmenau. - In: Erinnerungen aus Ilmenau - Zweites Heft, geognostisch-geologischen Inhalts; 95 S. (davon VIII S. Vorwort); hiers. S. 11-47; (Anton) Halle

OKlett, B. (1912): Geologische Wanderungen. - Ratgeber für deutsche Lehrer und Erzieher, Reihe 1, Bd. $\underline{\mathbf{5}}, 83$ S.; Langensalza

OKober, Martin \& Voigt, Thomas (2008): Dreidimensionales Untergrundmodell der Thüringer Mulde $<$ Vortragskurzfassung >. - In: Wunderlich, J. [Red.]: Exkursionsführer - Geologie des Eichsfeldes - zur 18. Jahreshauptversammlung (Vortrags- und Exkursionsveranstaltung) vom 16. bis 18. Mai 2008 in Heilbad Heiligenstadt. - Führung: H. Heiland, L. Nolte, H.-G. Röhling \& G. Seidel. - S. 37-38, 1 Abb.; [Hrsg.: Thüringer Geologischer Verein e.V.] Jena 2008

QKrause, Torsten (2004): Geologie [des Seebergs]. - In: Tittel, R.; Bellstedt, R. \& Oppel, T. [Red.]: Zur Natur und Geschichte des Naturschutzgebietes Seeberg bei Gotha. - 194 S., Abb., Tab.; 14 Taf., 1 Falt-Bl.; hier: S. 9-28, 1 Tab.; [Hrsg. NABU (Naturschutzbund Deutschland) Kreisverband Gotha e.V.] Gotha 2004

Q $\square$ Kriege, Jörg \& Wette, Wolfgang (1992): Landschaftsführer Werratal - Abseits ausgetretener Pfade. Mit 27 ausgesuchten Wanderrouten. - 2., überarb. Aufl.; 127 S., zahlr. Abb., 21 Kt.-Skizz.; (Wartberg Verlag) Gudensberg-Gleichen

OKronfeld, C. (1879): Landeskunde des Großherzogthums Sachsen-Weimar-Eisenach - Theil 2: Topographie des Landes. - IV, 535 S.; (Böhlau) Weimar [S. 5-17: „Aufbau des Landes. Berge und Thäler. Geognostische Verhältnisse“]

OKrug v. Nidda (1838): Geognostische Bemerkungen über den Thüringer Wald und besonders über die Grafschaft Henneberg. - Archiv f. Mineral., Geogn., Bergbau u. Hüttenkde., 11(1): 3-83; Berlin Auszug in: N. Jb. Mineral. etc., 1838: 687-690; Stuttgart

OKühnlenz, Fritz (1973): Erlebnisse an der Werra - Heimatgeschichtliche Wanderungen. - 384 S., 43 Fotos; (Greifenverlag) Rudolstadt [darin S. 14-39: „Der Fluß und seine Landschaft"

口OKunze, Wilhelm (1921): Geologische Übersicht [über das Werraland]. - In: Engelhardt, Oskar: Führer durchs Werratal und angrenzende Gebiete. - Ein Heimatbuch. - 365 S., zahlr. Abb.; S. 263357 Anzeigenteil; hier S. 63-79, 6 Abb., 1 geol. Kt.; (Johs. Braun) Eschwege 1921

OLangbein, Rolf \& Seidel, Gerd (1960): Zur Geologie im Gebiet des Holunger Grabens (Ohmgebirgsgrabenzone). - Geologie, 9: 36-57, 11 Abb.; Berlin

OLangenhan, A[1win] (nach 1904): Die Wartberge bei Thal in Thüringen. - Sonderdruck aus „Thüringer Warte“, $\underline{\mathbf{6}}$; 4 S., 1 Abb.; Pößneck - Nachgewiesen in: Forschungsbibliothek Gotha

OLangenhan, A[1win] (1914): Naturkundliche Streifzüge in Friedrichroda's Umgebung (Westthüringen). - 90 S., 16 Taf.; (Schmidt) Friedrichroda

OLepsius, Richard (1910): Geologie von Deutschland und den angrenzenden Gebieten. - Zweiter Teil: Das nördliche und östliche Deutschland. - 548 S., 86 Abb., 12 Falt-Taf.; (Wilhelm Engelmann) Leipzig [darin: Der Thüringer Wald] 
口OLindemann, B. (1914): Geologie der deutschen Landschaften. - VIII, 368 S.; 317 Abb., 20 SW-

Tafeln, 4 Farb-Taf.; (Franckh'sche Verlagshdlg.) Stuttgart

[darin: S. 339-347, Abb. 295-304: Thüringer und Frankenwald; Abb. 303: Felsen i.

Zechstein/Hauptdolomit „Der Bär“ bei Abterode/Werra-Meissner-Kreis]

OLoretz, H. (1892): Ueber Aufnahmen auf den Blättern Schwarzburg, Königsee und Ilmenau. - Jb.

Preuß. Geol. Landesanst., 10 (f. 1889): XXXVII-XL; Berlin

[hauptsächlich Ilmenau]

- $\square$ OLotze, Franz (1971): Dorn-Lotze - Geologie Mitteleuropas. - 4., völlig neu bearb. Aufl., XVI, 491 S., 165 Abb. i. T. u. a. Taf., 13 Tab. a. 7 Beil., (insges. 31 Beil.); (Enke) Stuttgart

[darin: „Die Paläozoikumsaufvrüche in der Hesssichen Senke“ u.a. Richelsdorfer Gebirge, Hessische Senke, Thüringer Becken, „Südhannoversches Bergland“']

OLützner, Harald (1974): Regionalgeologische Gliederung und Stellung [von Thüringen]. - In: Hoppe, Walter \& Seidel, Gerd [Hrsg.]: Geologie von Thüringen [Bezirke Erfurt, Gera, Suhl]. - S. 47-74, 6 Abb.; (Haack) Gotha-Leipzig 1974

OLützner, Harald (2002): Tambach-Dietharz - Morphogenese und Geologie des Thüringer Waldes. In: Sedlacek, Peter [Hrsg.]: (Spuren suchen - Landschaften entdecken) Thüringen - Geographische Exkursionen. - 325 S., 105 Abb.; hier: S. 252-255, Abb. 97; (Justus Perthes) Gotha

OLusznat, M. (1950): Stratigraphie und Tektonik der Nebengesteine des Floßberggangzuges bei Ilmenau. - Dipl.-Arb. [unveröff.] Univ. Jena 1950

OLutteroth, A.. (1848): Orographisch-geognostische Skizze der Umgebung von Mühlhausen. - 39 S., 2 Taf.; Mühlhausen

OLux, K.-N. \& Tita, J. (1985): Ein Katalog geologisch-geophysikalischer Normalprofile ausgewählter stratigraphischer und regionaler Einheiten in der DDR. - Z. angew. Geol., 31(3): 68-71, 1 Abb.; Berlin [darin: Profile Westthüringen]

oMajor, Cl.; Scheibe, R. \& Zimmermann, E. (1935): Profil des Rennsteigs. - 5 Teilprofile a. 5 FaltTaf.; (Verlag d. Rennsteig-Vereins) Ruhla

OMartens, Thomas (1990): Aus dem geologischen Tagebuch des Thüringer Waldes. - In:

Zimmermann, Wolfgang [Hrsg.]: Thüringer Wald - Kleiner Naturführer. - Abh. u. Ber. Museums Natur Gotha, (9) 1990; 5., erw. Nachaufl., 94,2 S.; 35 Abb., 1 Kt.; hier: S. 4-14, Abb. 1-3; Gotha

OMehler, Ernst (1935): Chronik von Diedorf im Eichsfeld. - 399 S., 1 Beil.; (Cordier) Heiligenstadt Unveränd. reprogr. Nachdruck Dortmund 1992

[darin S. 1-3: „Ausdehnung und Oberflächengestaltung der Diedorfer Tallandschaft"; S. 3-10: „Geologisches, Wasserverhältnisse und Klima“]

Q•Namenskürzel [He](1987): Zur Geologie des Eichsfeldes. - Eichsfelder Heimatstimmen,

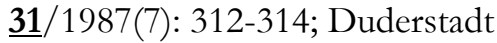

ONaturwiss. Verein z. Gotha (1901): Naturwissenschaftliches und Geschichtliches vom Seeberg. - XVI, 146 S., 3 Abb., 3 Taf., 1 Kt.-Beil.; (Thienemann) Gotha [darin auch Kapitel zur Geologie]

ONaumann, Ernst (1907): Bericht über Aufnahmen auf den Blättern Mihla und Treffurt - Mitteilugen über Ausbildung und Lagerung der Trias am Südrand des Hainichs und des Diluviums dieser Gegend: Blätter Henningsleben, Mihla, Treffurt. - Jb. Preuß. Geol. Landesanst., 25(f. 1904): 715-732, 1 Abb.; Berlin Referat in: N. Jb. Mineral. etc., 1906 (Bd. II): 229-232 (Karl Walter); Stuttgart 
ONaumann, Ernst (1908): Ueber die Ergebnisse der Aufnahme des Blattes Creuzburg im Jahre 1905. Jb. Preuß. Geol. Landesanst., $\underline{26}$ (f. 1905): 680; Berlin

ONaumann, E. (1927): Über Ergebnisse einiger Tiefbohrungen im Werragebiet. - Jb. Preuß. Geol. Landesanst., $\underline{47}$ (f. 1926): 1-18; Berlin Referat in: N. Jb. Mineral. etc., 1927 (Bd. II): 60-61 (A. Bentz); Stuttgart [Thüringer Werra-Gebiet; Rotliegendes, Zechstein, Buntsandstein]

ONeubert, Ed. (1880): Der Thüringer Wald von der Hörsel bis zum Schneekopf und Beerberg in geognostischer Beziehung. [Vortragstext]. - Z. Vereins f. Hennebergische Gesch. u. Landeskde. Z. Schmalkalden, : 31 - 58; (Feodor Wilisch) Schmalkalden - Leipzig

ONeureuther, Franz (1916): Zur eichsfeldischen Heimatkunde - 7. Die geologische Entstehungsgeschichte des Eichsfeldes. - Unser Eichsfeld, 11(1): 11-30 (Perm/Zechstein Muschelkalk); $\underline{\mathbf{1 1}}(2):$ 47-55 (Keuper - Kreide), 11(3): 84-95 (Tertiär, Diluvium oder Eiszeit); 11(4): $97-$ 100 (Alluvium oder geologische Gegenwart); Heiligenstadt

Q Neureuter, Franz (1919): Eichsfeldische Heimatkunde - Kurze naturwissenschaftliche Beschreibung der Kreise Heiligenstadt, Duderstadt, Worbis und eines Teiles des Kreises Mühlhausen. - 69 S.; (Mecke) Duderstadt - 2. Aufl. 1920; 3. Auflage 1927 u.d. erweiterten Titel: Eichfeldische Heimatkunde...; zgl. Ein Führer durch die Natur der eichsfeldischen Landschaft. - 80 S., Ill.

ONeureuter, Franz (1925): Das erste eichsfeldische Naturschutzgebiet. - Der Hasenwinkel bei Fretterode. - Unser Eichsfeld, 20: 132-135; Duderstadt [auch Regionalgeologie; Einrichtung des Naturschutzgebietes 1920]

Q Neureuter, Franz (1933): Die Landschaft des Eichsfeldes - zugleich eine Einführung in die Geologie des Gebietes für den Gebrauch im heimatkundlichen Unterricht der Schule, im Hause und auf Ausflügen - 1. Band. - Nebentitel: Das Eichsfeld - eine naturkundliche Beschreibung der Landschaft zwischen Harz und Werra, ihrer Pflanzen- und Tierwelt; 205 S., 9 Photogr., 3 Zeichng.; (Mecke) Duderstadt

ONoback, Carl August (1840): Ausführliche geographisch-statistisch-topographische Beschreibung des Regierungsbezirks Erfurt. - Vorwort, [2 S. Inhaltsverz.] 362 Spalten, [1 Tab. + 2 S. Register]; (Selbstverlag d. Verfassers) Erfurt u. (Bösenberg i. Comm.) Leipzig [darin Sp. 22-42: „Die Geognostische Beschaffenheit des Regierungsbezirks Erfurt“; Sp. 43-45: „Die Naturerzeugnissse des Regierungsbezirks - I. Aus dem Mineralreich - A. Metalle - B. Brennstoffe C. Salze - D. Steine und Erden“)

OPatzelt, Gerald (1994): Streifzüge durch die Erdgeschichte Nordwestthüringens - geologischer Abriß und Exkursionsführer. - 96 S., 53 Abb., 6 Tab.; (Perthes) Gotha

OPatzelt, Gerald (1998): Der Hainich. - 48 S., Ill., Kt. + Beil. (1 Kt.); (Cordier) Heiligenstadt/Thür.

OPatzelt, Gerald (2003): Tagung des Thüringischen Geologischen Vereins in Mühlhausen. - Mühlhäuser Beitr., 26: 141 - 144; Mühlhausen

OPlatt, H. (1916): Das Randgebiet des Thüringer Waldes bei Benshausen. - Jb. Preuß. Geol. Landesanst., $\underline{\mathbf{3 6}}$ ('Teil II) (f. 1915): 175 - 225, 10 Abb., insges. 6 Taf.; Berlin [Rotliegendes, Zechstein, Buntsandstein, Tektonik]

口Q॰Pompeckj, J.F. (1910): Exkursion nach Eichenberg-Witzenhausen-Hanstein am 3. April.1910. Jber. Niedersächsischen Geol. Vereins, $\underline{3}$ : XVIII - XXV, 2 Abb.; Hannover Referat in: N. Jb. Mineral. etc., 1912 (Bd. I): 475-476 (Schöndorf); Stuttgart 
OPröscholdt, Hermann (1891): Der Thüringer Wald und seine nächsten Umgebungen. - Forsch. z. Dt. Landes- u. Volkskde., $\underline{\mathbf{5}}(6)$ : 329-375; (Engelhorn) Stuttgart

Referat in: Z. f. Naturwiss., 64: 341-348 (Luedecke); Halle (Saale) 1892

Referat in: Globus - Ill. Z. f. Länder- u. Völkerkde., 60: 47 (Fr. Regel) Braunschweig [darin S. 329-333, 1 Abb.: „Grenzen und Orometrie des Thüringer Waldes“; S. 334-343: „, Die geologischen Verhältnisse des Thüringer Waldes“; S. 344-355 „, Die [Erd-] Geschichte des Thüringer Waldes“; S. 356-363: „Die Einwirkungen der gebirgsbildenden Kräfte“ [Tektonik]; S. 364-375: „Die hydrographischen Verhältnisse"]

OPröscholt, H. (1895): Mittheilungen über Revisionen und Aufnahmen im Eichsfeld. - Jb. Preuß. Geol. Landesanst., 15 (f. 1894): LXI-LXII; Berlin

[Bl. Lengenfeld, Heiligenstadt, Kella]

ORauche, Henry [Hrsg.](2001): Regionale und angewandte Geologie der Grenzregion der Süddeutschen und der Mitteldeutschen Scholle. - Programm und Kurzfassungen der Vorträge. - 10. Jahrestagung Gesellschaft f. Geowissenschaften i. Schmalkalden, 19.-22. September 2001. Exkursionsführer u. Veröff. Ges. f. Geowiss. e.V., Berlin, 214; 254 S., 13 Abb., 7 Tab.; Berlin

ORegel, Fritz (1892): Thüringen - Ein geographisches Handbuch. Erster Teil: Das Land. - 1. Grenzen 2. Bodengestalt und Gewässer 3. Schichtenaufbau und Entstehungsgeschichte 4. Klima. - XVI, 400 S., 40 Abb., 2 Taf. (Geol. Kt., Profile); (Gustav Fischer) Jena

[S. 88-312, „Dritter Abschnitt: Schichtenaufbau und Entwicklungsgeschichte“]

ORegel, Fritz (1906): Wie ist der Thüringer Wald entstanden? - Aus den coburg-gothaischen Landen Heimatblätter. - $\underline{4}:$ 1-11, 1 Abb.; Gotha

OReh, Herbert (1954): Die Mineralquellen des Bades Liebenstein. - Geologie, $\underline{\mathbf{3}}(6 / 7)$ : 891-916, 8 Abb.; Berlin

[Hydrogeologie, Regionale Geologie/Bohrprofil]

@Reh, Herbert (1959): Geologische Auswertung der Erkundungsergebnisse für die mineralische Rohstoffbasis der Sodafabrik Buchenau (Werra). - Z. angew. Geol., $\underline{\mathbf{5}}$ (8): 344-349, 6 Abb.; Berlin [Bohrprofil Muschelkalk, Buntsandstein]

OReling, H. (1895): Das Gebiet der drei Gleichen, Wandersleben und Umgebung. - Beschreibung der geologischen Verhältnisse und deren Einfluß auf die Bodenbeschaffenheit und Oberflächengestalt. 23 S.; (Kahle) Dessau

OReuther, R. \& Weise, R. (1996): Der Unstrut-Hainich-Kreis - mit seinen Landschaften, Naturschönheiten und Schutzgebieten. - 63 S., zahlr. Abb., 3 Tab.; (Schröter) Mühlhausen [darin Kap.: „Naturräumliche Gliederung“, „Geologie“]

ORiese, A. (1993): Naturräumliche Gliederung Thüringens. - Erfurter Geogr. Studien, 1: 3-15, Abb. 1; Erfurt [Bezugn. a. Regionale Geologie u. Geomorphologie]

QRöhling, Heinz-Gerd (2008): Au(f)s diesem Fels müßt ihr bauen! - Zur geologischen Einordnung der Burg Hanstein. - In: Hanstein, Hans-Dieter von [Hrsg.]: Burg Hanstein - Zur 700jährigen Geschichte einer eichsfeldischen Grenzfeste. - Herausgegeben im Auftrag des Familienverbandes der von Hanstein von.. - 296 S., zahlr. Abb.; hier S. 67-80, 12 Abb., 1 Tab.; (Mecke Druck u. Verlag) Duderstadt 2008

[Regionalgeologie, Erdgeschichte der Buntsandstein-Zeit, Solling-Sandstein als Baustein]

ORöhling, Heinz-Gerd \& Seidel, Gerd (2008): Geologische Übersicht über das Eichsfeld. - In:

Wunderlich, J. [Red.]: Exkursionsführer - Geologie des Eichsfeldes - zur 18.

Jahreshauptversammlung (Vortrags- und Exkursionsveranstaltung) vom 16. bis 18. Mai 2008 in 
Heilbad Heiligenstadt. - Führung: H. Heiland, L. Nolte, H.-G. Röhling \& G. Seidel. - S. 5-26, 10 Abb., 5 Tab.; Jena 2008

@Röhling, Heinz-Gerd \& Gümpel, Heinrich (2005): Geologisch-erdgeschichtlicher Überblick über das Gebiet um Worbis. - In: Müller, Thomas T. [Hrsg.]: Wurbeke - Worweze - Stadtworbis. Beiträge zur Geschichte der Stadt Worbis. - 424 S., zahlr. Abb.; hier: S. 11-28, 10 Abb., 1 Tab..; (Mecke Druck) Duderstadt 2005

QRösing, Gerhard (1991): Landschaften unserer Heimat: das Gerstunger Becken. - Das Werraland, $\underline{43}(2)$ : 28-29; Eschwege

QRösing, Gerhard (1993): Geologisch-geographische Einführung: Das Gerstunger Becken. - In: Rösing, Gerhard [Red. u. Schriftltg.]: 1250 Jahre Gerstungen - Ein Heimatbuch. - 220 S., zahlr. Abb.; hier S. 5-7; [Gajewski] Ringgau-Datterode

ORothe, Peter (2005): Die Geologie Deutschlands - 48 Landschaften im Portrait. Mit Zeichnungen von Martin Schmitteckert. - 240 S., 142 Abb.; (Wiss. Buchgesellschaft) Darmstadt [Darin S. 87-90: „Kristallingebiete in Mittel- und Süddeutschland: Thüringer Wald“]

QRothe, Peter (2005): Die Geologie Deutschlands - 48 Landschaften im Portrait. Mit Zeichnungen von Martin Schmitteckert. - 240 S., 142 Abb.; (Wiss. Buchgesellschaft) Darmstadt [Darin S. 64-67: „Harz, Harzvorland und die weitere Umgebung: Thüringer Becken“]

OSchäfer, Aloys (1926/1992): Geschichte der Stadt Dingelstädt. - 288 S.; (Josef Heinevetter) Dingelstädt/Eichsfeld - Reprint der Originalausgabe erschienen bei Mecke/Duderstadt 1992 [darin S. 1-13, 5 Abb., 1 strat. Profil: „Die Entstehung und Natur des Heimatlandes“ (Erdgeschichte, reg. Geologie]

OScheibe, R. (1888): Ueber Aufnahmen auf den Blättern Friedrichroda und Ohrdruf. - Jb. Preuß. Geol. Landesanst., $\underline{8}$ (f. 1887): XLV-XLVIII; Berlin

OScheibe, R. (1888): Ueber Aufnahmen auf Blatt Crawinkel. - Jb. Preuß. Geol. Landesanst., $\underline{8}$ (f. 1887): XLVIII-LVIII; Berlin

OScheibe, R. (1892): Ueber die wissenschaftlichen Ergebnisse der Aufnahmen auf Blatt Friedrichroda. Jb. Preuß. Geol. Landesanst., $\underline{10}$ (f. 1889): XLVII-XLVIII; Berlin

OScheibe, R. (1896): Bericht über geologische Aufnahmen im Nordosttheile des Blattes Brotterode. - Jb. Preuß. Geol. Landesanst., 16 (f. 1895): LXVII - XCIII, Taf. VII; Berlin

OScheibe, R. (1902): Geologische Spaziergänge im Thüringer Wald. - Naturwiss. Wochenschrift, N.F., 1 : (17. d. Ges.Rh.): 170-176, 433-440; auch als sep. Druck: 38 S.; (Gustav Fischer) Jena Referat in: Mitt. Geogr. Ges. i. Thür., 21: 119-120 (E. Schütze); Jena 1903

OScheibe, R. u. Zimmermann, E. (1892): Ueber die wissenschaftlichen Ergebnisse der Aufnahmen auf dem Blatte Ilmenau. - Jb. Preuß. Geol. Landesanst., 10 (f. 1889): XLI-XLVII; Berlin

OSchmid, E. E. (1884): Die Wachsenburg bei Arnstadt in Thüringen und ihre Umgebung. - Jb. Preuß. Geol. Landesanst., 4 (f. 1883): 267-309, Taf. XXI; Berlin

OSchneider, Roland (1994): Geologie und Bergbau im Gebiet um Suhl. - Würzburger geogr. Arb., $\underline{\mathbf{8 8}}$ : 205-216, 2 Abb.; Würzburg

OSchopahl, K. J. (1958): Die „bucklige Welt“ . - Eichsfelder Heimatstimmen, $\underline{\mathbf{2}}$ (18)/1958(18): 370-373; Lingen-Ems

[Regionalgeologie Thüringisches Untereichsfeld] 
OSchulze, Joachim H. (1955): Die naturbedingten Landschaften der Deutschen Demokratischen Republik - Mit einer Einleitung „Über Landschaften und ihre Gliederung“. - Petermanns geogr. Mitt., Ergänzungsheft, 257; VIII, 329 S., 10 Abb., 3 Taf.; (Geogr.-Kartograph. Anstalt) Gotha [katalogartige Gliederung der Landschaften nach Geologie, Geomorphologie, Böden: 231(Kennziffer) „N-Thüringer-Untereichsfelder Buntsandstein-Hügelland“; 232 „Ohmgebirge und Bleicheröder Berge“; 236 „NW-Randplatten des Thüringer Beckens: Hainich-Dün-Hainleite“; 237 „Thüringer Becken; 270 „Westthüringer Störungszone“; 280 „Thüringer Wald“; 300 „Salzunger Buntsandsteinland"]

OSedlacek, Peter [Hrsg.] (2002): (Spuren suchen - Landschaften entdecken) Thüringen Geographische Exkursionen. - 325 S., 105 Abb.; hier: S. 14-20, Abb. 2 u. 3; (Justus Perthes) Gotha

OSedlacek, Peter \& Ellenberg, Jürgen (2002): Die Erdgeschichte Thüringens (Thüringen-Schauplätze und Spuren der Natur- und Kulturgeschichte in der Mitte Deutschlands. - In: Sedlacek, Peter

[Hrsg.]: (Spuren suchen - Landschaften entdecken) Thüringen - Geographische Exkursionen. - 325 S., 105 Abb.; hier: S. 14-20, Abb. 2 u. 3; (Justus Perthes) Gotha 2002

OSeidel, Gerd (1965): Zur geologischen Entwicklungsgeschichte des Thüringer Beckens. - Geologie, Beih. 무, 115 S., 57 Abb., 4 Tab. z.T. als Beil.; Berlin [Mächtigkeitskarten der Sedimente bis in die Gegend Heiligenstadt, Mühlhausen]

OSeidel, Gerd (1972): Das Thüringer Becken - Geologische Exkursionen. - Reihe: Geographische Bausteine, N.F., 11. - 96 S., 13 Abb., (VEB Hermann Haack) Gotha/Leipzig

QSeidel, Gerd \& Steiner, Walter (1974): Geologische Entwicklungsgeschichte - Permosiles [in Thüringen]. - In: Hoppe, Walter \& Seidel, Gerd [Hrsg.]: Geologie von Thüringen [Bezirke Erfurt, Gera, Suhl]. - S. 811-827, Abb. 160-163; (Haack) Gotha-Leipzig 1974

OSeidel, Gerd [Hrsg.] (1995): Geologie von Thüringen. - 1. Aufl.; XI, 556 S., 137 Abb., 36 Tab., 1 FaltKt. a. Beil.; (Schweizerbart) Stuttgart

OSeidel, Gerd [Hrsg.](2003): Geologie von Thüringen. - 2. neubearb. Aufl. ; X, 601 S., 138 Abb., 34 Tab., 5 Taf.; (Schweizerbart) Stuttgart

OSellmann, Karl (1908): Heimatkunde von Mühlhausen i. Th. und Umgebung. - Erster Teil; 168 S. (Hey'sche Buchhdlg.) Mühlhausen i. Thür. [darin Kap I.: Oberflächengestalt, Bodenbildung und Mineralschätze]

OSenft, F. (1858): Geognostische Beschreibung der Umgebung Eisenachs. - 48 S., Kt.; (Bärecke) Eisenach

OSenft, F. (1858): Das nordwestliche Ende des Thüringer Waldes. - Z. dt. geol. Ges., 10: 305-355, 2 Taf.; Berlin

oSenft, F. (1892): Übersichtliche Beschreibung der Gaea, Flora und Fauna der Umgebung Eisenachs. 121 S., 1 Kt; Weimar

oSenft, Ferdinand (1894): Wanderungen durch die Gebiete der deutschen Mittelgebirgsländer - Der Thüringer Wald. - Nebentitel: Geognostische Wanderungen in Deutschland - Ein Handbuch für Naturfreunde und Reisende. - 51 S.; (Hahn’sche Buchhdlg.) Hannover - Leipzig 1894

oSeydlitz, W. von (1928): Der geologische Bau des Thüringer Waldes. - Beitr. Geol. Thür., 1(6): 30-35; Jena

OSobotha, Ernst (1933): Zwischen Rusteberg und Elisabethhöhe. Eine erdgeschichtliche und erdkundliche Wanderung und wirtschaftsgeologische Studie. - Unser Eichsfeld, 288: 3 - 14, Abb. 1 -6; 46 - 52, Abb.; 93 - 103, Abb. 8; 128 - 134, Abb. ); (Aloys Mecke) Duderstadt 
Q Sohn, Heinz (1965): Ein Vorzeithirsch geborgen. - Die paläontologische Sensation des Jahres. Eichsfelder Heimatstimmen, 9(1)/1965(Januar): 3-6, 1 Abb.; Lingen/Ems

[Paläont. Fund Tongrube Bilshausen/Untereichsfeld; des weiteren: Regionalgeologie des Eichsfeldes]

OSteinmüller, Arno (1974): Physisch-geographischer Überblick [über Thüringen]. - In: Hoppe, Walter \& Seidel, Gerd [Hrsg.]: Geologie von Thüringen [Bezirke Erfurt, Gera, Suhl]. - S. 27-45, 4 Abb.; (Haack) Gotha-Leipzig 1974

OSteinmüller, Arno (1995): Geomorphologischer Überblick [über Thüringen]. - In: Seidel, Gerd [Hrsg.]: Geologie von Thüringen. - 1. Aufl.; S. 6-12; Stuttgart 1995

OSteinmüller, Arno (2003): Geomorphologischer Überblick [über Thüringen]. - In: Seidel, Gerd [Hrsg.]: Geologie von Thüringen. - 2., neu bearb. Aufl.; S. 6-13; Stuttgart 2003

OSteinmüller, Arno \& Unger, Kurt P. (1974): Geologische Entwicklungsgeschichte - Känozoikum [in Thüringen]. - In: Hoppe, Walter \& Seidel, Gerd [Hrsg.]: Geologie von Thüringen [Bezirke Erfurt, Gera, Suhl]. - S. 845-863, Abb. 166-171; (Haack) Gotha-Leipzig 1974

ØTaeger, Frank \& Ulbricht, Antje (1992): Thüringer Wald. - Reihe: Neumanns Landschaftsführer. 176 S., zahlr. Abb., Kt.-Skizz.; (Neumann) Radebeul

[darin S. 16-22, 3 Abb.: „Erdgeschichte“; Informationen zur Erdgeschichte a. i. Unterkapitel „Erdgeschichte“ der beschriebenen Teillandsschaften]

@Thüringer Landesanstalt f. Gewasserkunde [Hrsg.](1928): Das Hörsel- und Nessegebiet in allgemein beschreibender, geologischer, hydrographischer und wasserwirtschaftlicher Beziehung. Jahresbericht Thüringer Landesanstalt f. Gewässerkunde., f. 1927?: 55-, 2 Kt., 13 Taf..; Weimar Referat in: N. Jb. Mineral. etc., Referate, 1928(II): 626-627 (J. Denner); Stuttgart [Vorlage nicht eingesehen, zitiert nach Angaben im genannten Referat]

Ø'Tornow, H. (1910): Die Geologie des Kleinen Thüringer Waldes. - Jb. Preuß. Geol. Landesanst., 28 (f. 1907): 587-638; Berlin

OUhlig, Lotar \& Langer, Helmut (1964): Exkursion B4: Der nordwestliche Thüringer Wald und sein Vorland. - In: Exkursionsführer VII. Wiss. Hauptversamlung d. Geogr. Ges. d. DDR - Leipzig 1964; S. 187-200, 1 Falt-Taf. ( 1Kt.-Skizz., 1 Langsprofil, 1 strat. Profil)

OVoigt, Johann Carl Wilhelm (1782-1785): Mineralogische Reisen durch das Herzogthum Weimar und Eisenach und einige angränzende Gegenden - in Briefen. - Erster Theil; 8, 151 S., 3, 6 graph. Darst.; (Buchhdlg. d. Gelehrten) Dessau 1782. - Zweyter Theil; 4, 134 S., 9; (C.L. Hoffmann's sel. Wwe u. Erben) Weimar

OWagenbreth, Otfried \& Steiner, Walter (1989): Geologische Streifzüge - Landschaft und Erdgeschichte zwischen Kap Arkona und Fichtelberg. - 3., durchges. Aufl., 204 S., 102 Abb., 117 Blockbilder; (Dt. Verl. f. Grundstoffindustrie) Leipzig [darin: S. 85-102: „Das Thüringer Becken“; S. 102-118 „Thüringer Wald und Südthüringen“]

OWagner, G. (1908): Die Berg- und Badestadt Friedrichroda in Thüringen und ihre Umgebung - ein Führer und Rathgeber für Kurgäste und Touristen. - 27. Aufl., 190 S., Abb., 1 Kt.-Beil.; (Schmidt) Friedrichroda [darin S. 66-67 „Geologie, Flora und Fauna“ (Kurzer Überblick)]

- $\square$ OWalter, Roland (2007): Geologie von Mitteleuropa. - Begründet von Paul Dorn. - 7., vollst. neu bearb. Aufl.; 511 S., 184 Abb.; (Schweizerbart) Stuttgart [darin Kap.: Nordhessisches Bergland und Niederhessische Senke, Thüringer Wald und ThüringischFränkisches Schiefergebirge, Thüringer Becken] 
OWalther, Johannes (1913/1927): Geologische Heimat(s)kunde von Thüringen. - 4. ergänz. Aufl., VII, 251 S., Abb., 1 geol. Übers.Kt.; (G. Fischer) Jena - 6. erw. Aufl., VIII, 272 S., Abb., Kt.; (G. Fischer) Jena 1927

- $\square$ OWalther, Johannes (1912): Lehrbuch der Geologie Deutschlands - Eine Einführung in die erklärende Landschaftskunde für Lehrende und Lernende. - 2., vermehrte Aufl.; XII, 429 S:, 1 Kt.Beil; (Quelle \& Meyer) Leipzig

[darin: Abb. 18 Zeichnung „Basaltgang im Muschelkalk bei Hörschel“ - darin: S. 253-256, Abb. 126129 „Die hessischen Vulkane“ (Abb. 128 Profil Meissner); S. 257-261, Abb. 130-133 „Das Wesergebirge“ (Abb. 130 Heldrastein); S. 284-290, Abb. 149-152 „Der Thüringer Wald; S. 290-295, Abb. 153-158 „Die Thüringer Senke“]

OWeber, Hans (1924): Beiträge zur Geologie und Morphologie des Thüringerwaldrandes zwischen Frankenhain und Georgenthal. - Z. dt. geol. Ges., $\underline{76}$ (f. 1924): 250 - 264, 1 Abb.; Berlin

口OWeber, Hans (1933): Geologische Beobachtungen auf den Blättern Berka, Creuzburg, Eisenach, Netra und Wutha. - Beitr. Geol. Thür., $\underline{3}:$ 198-211, 2 Abb.; Jena

OWeber, Hans (1938): Geologische Aufschlüsse in und bei Eisenach seit dem Jahre 1930. - Beitr. Geol. Thür., $\underline{\mathbf{5}}(2):$ 73-80, 2 Abb.; Jena Referat in: N. Jb. Mineral. etc., Referate, $\underline{1940}$ (Bd. III): 17 (Walter Fischer); Stuttgart

OWeber, Hans (1944): Die Aufschlüsse des Oststädtischen Bauvereins an der Ludwigstraße in Eisenach. - Beitr. Geol. Thür., 7: 1-6, 3 Abb.; Jena

OWeber, Hans (1955): Einführung in die Geologie Thüringens. - VIII, 201 S., 42 S. Taf. (81 Abb.), 144 Textabb., 2 Kt.-Beil; (Dt. Verlag d. Wissenschaften) Berlin Referat in: Hallesches Jb. mitteldt. Erdgeschichte, 2 (3): 207-208; Halle (Saale) 1956

OWeber, Hans (1965): Exkursionsvorschläge für die Drei Gleichen bei Arnstadt in Thüringen. Hallesches Jb. mitteldt. Erdgeschichte, $\underline{\mathbf{6}}$ (f. 1964): 67-70, Taf. XI (2 Bilder); Leipzig

OWeber, Karl August (1914): Das Störungsgebiet am Nordrande des Thüringer Waldes zwischen Friedrichroda und Georgenthal. - Jb. Preuß. Geol. Landesanst., $\underline{34}$ (Teil I)(f. 1913): 477-538, 5 Abb., 2 Taf.; Berlin - auch als Diss. Univ. Greifswald 1913

[Stratigraphie u. Tektonik Zechstein, Mesozoikum]

OWeigel, Heinrich; unter Mitarbeit von Alexander Clauén u.a. (1987): Monographie der Hörselberge - Teil 1: Zur Natur der Hörselberge. - Eisenacher Schriften zur Heimatkunde, H. 37; 79 S., zahlr. Abb. - [Hrsg.: Kreiskommission zur Erfroschung der Geschichte der örtlichen Arbeiterbewegung bei der Kreisleitung der SED, Pädagogisches Kreiskabinett und EISENACHInformation] Eisenach [darin: Geologie, Geomorphologie, Böden, Naturschutz]

QWeiss, E. (1885): Ueber Aufnahmen auf Section Brotterode und Wutha. - Jb. Preuß. Geol. Landesanst., $\underline{5}$ (f. 1884): LX-LXI; Berlin

OWeiss, E. (1886): Ueber Aufnahmen auf Blatt Wutha und Friedrichroda. - Jb. Preuß. Geol. Landesanst., 6 (f. 1885): XXXV-XXXVIII; Berlin

OWerneburg, Ralf (2003): 300 Millionen Jahre Thüringen - auf den Spuren unserer Umwelt. Führer zur gleichnamigen Ausstellung im Naturhistorischen Museum Schloss Bertholdsburg Schleusingen. - 104 S.; zahlr. Abb., Kt.; (Verlag Frankenschwelle) Hildburghausen

OZahn, G. (1908): Die geologischen Profile durch den Thüringer Wald im Seminargarten zu Gotha. Sonderabdruck a. „Aus der Natur“ - Zeitschrift für alle Naturfreunde, 1908; 4 S., 1 Abb.; (Nägele, Quelle \& Meyer) Leipzig 
OZentrales Geologisches Institut (1968): Grundriß der Geologie der Deutschen Demokratischen Republik. - Bd. 1 Geologische Entwicklung des Gesamtgebietes. - 454 S., 44 Abb., 2 Tab. i. Text; 26 Abb., 16 Anl. i. sep. Anl.-Mappe

OZimmermann, E. (1902): Geologie des Herzogthums Sachsen-Meiningen. - N. Landeskde. d. Hzgtms. Sachsen-Meiningen, 4: 319-493; Hildburghausen

Referat in: N. Jb. Mineral. etc., 11906 (Bd. II): 409-412 (Karl Walther); Stuttgart

OZimmermann, Wolfgang [Hrsg.] (1990): Thüringer Wald - Kleiner Naturführer. - Abh. u. Ber. Museums Natur Gotha, (9) 1990; 5., erw. Neuaufl., 94,2 S.; 35 Abb., 1 Kt.; Gotha [Beitr. and. Autoren z. Regionalgeologie, Bergbau, Paläontologie]

\subsubsection{Regionale Geologie - Niedersachsen}

- $\square$ OCApel, Jürgen \& Rüppel, Heidi [Verfass. u. Hrsg.] (2005): Raus in die Natur - Tipps für den Sonntags-Ausflug im Dreiländereck Hessen - Niedersachsen - Thüringen. - 159 S., 111 Fotos, 34 Kt., 1 Zeit-Taf.; (LSRB-Verlag, Landschaftskundlicher-Studien-Reisebuch-Verlag) Witzenhausen [zahlreiche Ausflugziele, auch zu Geotopen in Niedersachsen]

-Bismarck, Wolfram (1953): Das Bilshäuser Becken. Ausdehnung, Schichtenfolge und Untergrund der Ablagerung. - Die Goldene Mark, 4 (Oktober-H.): 10-14; Duderstadt [Quartär]

-Bismarck, Wolfram (1957): Das Duderstädter Becken. - Die Goldene Mark, $\underline{8}$ (Oktober-H.): 12-18; Duderstadt

- Dauber, Adolf (1857): Das Triasgebirge an der Oberweser und seine nächsten Umgebungen - eine geologische Skizze nebst einer Karte. - Teil d. Schulprogramm d. Herzogl. Gymnasiums z. Helmstedt - Do, den 2. April 1857; 30 S., 1 Kt.; (Schmidt) Helmstedt

[Region Lkr. Göttingen, Lkr. Kassel]

$\square \bullet$ Deppe, Heinrich (1912): Die Landschaften Südhannovers und der angrenzenden Gebiete dargestellt auf geologischer Grundlage. Ein Beitrag zur Einführung der Geologie in den heimatkundlichen Unterricht. - Reihe: Südhannoversche Heimatbücher, 1; X, 193 S., VIII, Abb., 1 Kt.; (Vandenhoeck \& Ruprecht) Göttingen

[darin: „Der Meißner“, „Das Grauwacken- und Zechsteingebirge an der unteren Werra“]

-Deppe, Adolf \& Troe, Heinrich (1956): Der Göttinger Wald und seine Umgebung - ein landschaftsund siedlungskundlicher Überblick mit Hinweisen für heimatkundliche Wanderungen. Beitr. Heimatkde. Südniedersachsens, $\underline{\mathbf{5}}$; 160 S., 19 Abb, 8 Sk., 3 Tab., 1 Kt.; (Reise) Göttingen Kap. I, Der Geologische Bau; Kap. II Die Oberflächengestaltung; Kap. III Täler, Wasserläufe u. Quellen]

-Ebert, Theodor (1888): Ueber Aufnahmen im Bereich der Blätter Waake und Gelliehausen. - Jb. Preuß. Geol. Landesanst., $\underline{8}$ (f. 1887): XLII-XLIV; Berlin

$\square \bullet$ Fabian, H. J. (1957): Die Bohrung „Northeim 1“. Ergebnisse eines regionalgeologisch interessanten Aufschlusses am Leinetalgraben. - N. Jb. Geol. Paläont., Abh., 105 (1): 113-122, 3 Falt-Taf.; Stuttgart

-Franke, W.; Paul, J. \& Schröder, H.-G. (1977): Stratigraphie, Fazies und Tektonik im Gebiet des Leinetalgrabens (Trias, Tertiär) - (Exkursion I). - In: Geol.-Paläont. Inst. u. Museum der Universität [Hrsg.]: Exkursionsführer - Geotagung '77 Göttingen - Band II : Nordhessen und 
Südniedersachsen (Exkursionen C - D - J - K - L). - S. 41-62, 8 Abb.; Göttingen 1977 [darin: Stbr. Marzhausen]

- Frebold, Georg (1925): Geologischer Führer durch das Hannoversche Bergland; Teil 1: Das Gebiet rheinischer Störungen (südlicher Teil). - Reihe: Sammlung geologischer Führer, Bd. 28; XVIII, 195 S.; Abb., Kt.; (Bornträger) Berlin

-Geissler, Horst (1994): Die Tunnel im Nordabschnitt der Schnellbahntrasse Hannover - Würzburg. Beih. z. Ber. Nathist. Ges. Hannover, 11: 1 - 73, 7 Abb., 3 Tab., 19 Taf., 3 Anl.; Hannover [Hannover - Göttingen - Kassel]

- Gruppe, O[skar] (1909): Die stratigraphischen und tektonischen Ergebnisse der neuen Kalibohrungen im Hannoverschen Eichsfelde und angrenzenden Gebieten des Leinetals. - Jber. Niedersächsischen Geol. Vereins, 1 [f. 1907): V-X, 1 Abb.; Hannover

-Gwinner, Manfred Peter (1956): Eine geologische Baugrundkarte der Stadt Göttingen. - Geol. u. Bauwesen, $\underline{\mathbf{2 2}}(1)$ : 49 - 53; Wien

-Hamm, Fritz (1938): Einführung in die Erdgeschichte Niedersachsens. - [III], 333 S., 141 Abb.; (Lax) Hildesheim [S. 236 Abb. u. Profil Dransfelder Basaltberge]

- $\square \bullet$ Hausmann, [J. F. L.](1824): Uebersicht der jüngeren Flöz-Gebilde im Fluß-Gebiete der Weser. Tb. Mineral., 18 (3): 678-702; Frankfurt/M. - Auszug aus Hausmann: Uebersicht der jüngeren FlözGebilde. - Studien Göttingischen Vereins bergmänn. Freunde, 1: 381 - 567, Göttingen 1824 [Regionale Stratigraphie Trias-Tertiär Hessen, WMK, Niedersachsen; darin: Tertiär Meißner, Hirschberg, Habichtswald, Wilhelmshöhe b. Kassel, Dransfeld]

- $\square$ OणHausmann, J.F.L. (1824, 1828): Übersicht der jüngeren Flötzgebilde im Flußgebiete der Weser, mit vergleichender Berücksichtigung ihrer Äquivalente in einigen anderen Gegenden von Deutschland und der Schweiz. - Studien Göttingischen Vereins bergmänn. Freunde, 1: 381 - 567, Göttingen 1824; 2: 215-482; Göttingen 1828

[Regionale Stratigraphie Trias-Tertiär Nordhessen, Südniedersachsen; Bd. 1, Stratigraphie Buntsandstein; S. 500-508 „Basaltische Massen im Sandstein“, darin: Blaue Kuppe bei Eschwege, Pflasterkaute bei Eisenach]

-Hövermann, Jürgen (1963): Die naturräumlichen Einheiten auf Bl. 99 Göttingen [TK Maßstab 1 : 200.000]. - Reihe: Geographische Landesaufnahme $1: 200.000$, Naturräumliche Gliederung Deutschlands. - 35 S., 1 Kt., 1 Beil.-Kt. 1 : 200.000; [Bundesanst. f. Ldkde. u. Raumforsch.] Bonn-Bad Godesberg

-0णJäger, Helmut (1963): Naturräumliche Grundlagen von Siedlung und Wirtschaft im Wesergebiet. -

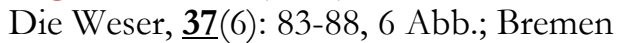
[Geographie, Regionale Geologie, Bergwirtschaft Hessen, Thüringen, Niedersachsen]

-Keindorf, Gudrun (2000): 750 Jahre Rhumspringe - Die Geschichte eines Dorfes im Untereichsfeld. 367 S:, 135 Abb., 1 Kt.-Beil.; [Hrsg. Gemeinde Rhumspringe] (Mecke) Duderstadt [darin S. 17-30, Abb. 1-6: „Eine Landschaft entwickelt sich“, S. 31-71, Abb. 7-17: „Die Rhumequelle und die Geschichte ihrer Erforschung]

-Klaer, Ute (1966): Der Flecken Bovenden im Stadtumland von Göttingen. - Vororturbanisierung bei Zentralitätsschwund eines alten Exklavenmittelpunktes. - Plesse-Archiv, 1; 169 S., 28 Abb., 46 Tab., 26 Kt., 13 Anl.; (Goltze) Göttingen; zgl. Diss. math.-nat. Univ. Göttingen 1965 [darin Kap.: Das obere Leinetal in seiner natürlichen Ausstattung [Geologie, Bodenkde., phys. Geographie] 
- $\square$ (ब Klink, Hans-Jürgen (1969): Die naturräumlichen Einheiten auf Bl. 112 Kassel [TK Maßstab 1 : 200.000]. - Reihe: Geographische Landesaufnahme 1 : 200.000, Naturräumliche Gliederung Deutschlands. - 108 S., 1 Kt., 1 Beil.-Kt. 1 : 200.000; [Bundesforschungsanst. f. Ldkde. u. Raumordn.] Bonn-Bad Godesberg

-Koenen, A. v. (1888): Ueber Aufnahmen westlich und südwestlich vom Harz. - Jb. Preuß. Geol. Landesanst., $\underline{8}$ (f. 1887): XLI-XLII; Berlin [Göttinger Wald]

-Koenen, A. v. (1892): Ueber Aufnahmen westlich und südwestlich vom Harz. - Jb. Preuß. Geol. Landesanst., 10 (f. 1889): XXXV-XXXVII; Berlin [Bl. Reinhausen, Umgebung Göttingen]

-Koenen, A. v. (1895): Mitteilungen über Aufnahmen auf den Blättern Jühnde, Freden und Alfeld. - Jb. Preuß. Geol. Landesanst., 15 (f. 1894): XXXII-XXXIII; Berlin

-Koenen, A. v. (1889): Ueber die Ergebnisse der geologischen Aufnahme der Umgebung von Göttingen. - Nachr. Kgl. Ges. Wiss. z. Göttingen, 1889(4): 57-66; Göttingen [Regionalgeologie]

-Koenen, A. v. (1912): Ueber die geologischen Verhältnisse des südlichen Reinhardswaldes und Bramwaldes, besonders auf Blatt Münden. - Nachr. Kgl. Ges. Wiss. z. Göttingen, Math.-phys. Kl., 1912(7): 898-901; Berlin

Referat in: N. Jb. Mineral. etc., 1914 (Bd. I): 103 (Schöndorf); Stuttgart

-Kriege, Jörg \& Welte, Wolfgang (1984): Landschaftsführer Leinetal - Nördliches Eichsfeld - Südharz. Abseits ausgetretener Pfade. Mit 22 ausgesuchten Wanderrouten. - 175 S:, zahlr. Abb., Kt.-Skizz.; (Wartberg) Gudensberg-Gleichen [zahlr. Informationen zur Regionalen Geologie]

-Laubach, C. \& Nerreter, W. (1985): Wandern in Göttingen. - Teil 1: Textliche Erläuterungen mit Fachbeträgen zur Geschichte und Landeskunde, Geologie und Geomorphologie, Vegetationskunde. + 7 Karten[Teil 2]; Hrsg. [Göttinger Tagebl.] Göttingen

-Lepper, Jochen (1996): Die Ballertasche bei Hann.-Münden - ein geologische Ensemble. - Ber. Naturhist. Ges. Hannover, 138: 133-139, 3 Abb.; Hannover [Buntsandstein, Quartär]

- $\square$ QӨ Lotze, Franz (1971): Dorn-Lotze - Geologie Mitteleuropas. - 4., völlig neu bearb. Aufl., XVI, 491 S., 165 Abb. i. T. u. a. Taf., 13 Tab. a. 7 Beil., (insges. 31 Beil.); (Enke) Stuttgart [darin: „Die Paläozoikumsaufbrüche in der Hessischen Senke“, Richelsdorfer Gebirge, Hessische Senke, Thüringer Becken, „Südhannoversches Bergland“]

-Menzel, Hans (1908): Hannoverlands Heimatboden - II. Das Hügel- und Bergland. - Hannoverland, [2. Jg.]1908(Juni-Heft): 123-127; Hannover

-Meyer, Lothar (1973): Einführung in die Geologie Niedersachsens. - 91 S., 29, 23, 14 Abb.; (Pieper) Clausthal-Zellerfeld [darin S. 36-64, 23 Abb.: „Das Bergland“]

-Meyer, Rolf Heinrich (1985): Die Umgebung der Burg Plesse, Gemeinde Bovenden, Kr. Göttingen aus geologischer Sicht. - Plesse-Archiv, 20 (1984): 15-27, 9 Abb.; Göttingen

-Meyer, Rolf Heinrich (1987): Streifzüge durch die Erd- und Landschaftsgeschichte des Flecken Bovenden. - Mit einem Beitrag von Th. Moritz über Zeugnisse ur- u. frühgeschichtlicher Besiedlung. - 100 S., XII, 56 + 7 Abb., 1 Kt.-Beil.; in der Vorlage enthalten: Moritz, Thomas: Zeugnisse der Urund frühgeschichtlichen Besiedlung im Flecken Bovenden, S. I-XII, 7 Abb.; [Hrsg. Flecken 
Bovenden] (Goltze) Göttingen

[Bovenden N' Göttingen]

$\square$ Moesta, Fr. A. (1867): Geologische Schilderung der Gegend zwischen dem Meissner und dem Hirschberge in Hessen - mit besonderer Berücksichtigung der daselbst auftretenden basaltischen u. tertiären Bildungen nebst einer geologischen Karte und einem Blatte mit Gebirgsprofilen. - Diss. Univ. Marburg 1867; 40 S., 1 Kt., 1 Taf. (4 Profile); (Sipmann) Marburg - Kurzfassung in: N. Jb. Mineral. etc., 1869: 241-243; Stuttgart

-Nagel, Ulrich. \& Wunderlich, Hans Georg (1968): Geologisches Blockbild der Umgebung von Göttingen. - Geol. Jb., 뜨: 5-48, 5 Abb.; Hannover

-Nagel, Ulrich \& Wunderlich, Hans Georg (1969): Geologisches Blockbild der Umgebung von Göttingen. - Veröff. Niedersächsischen Inst. Landeskde. u. Landesentw. a.d. Univ. Göttigen, $\underline{\mathbf{A 9 1}}$; zgl. Schriften Wirtschaftswiss. Ges. z. Studium Niedersachsens, N.F., 1ㅜ; auch Geol. Jb., 무,: 5-48, Hannover 1968; 48 S. + 1 Falt-Kt.

-Nagel, Ulrich \& Wunderlich, Hans Georg (1976): Geologisches Blockbild der Umgebung von Göttingen. 2. Aufl. - Veröff. Niedersächsischen Inst. Landeskde. u. Landesentwicklung a.d. Univ. Göttingen, 91; zgl. Schr. Wirschaftswiss. Ges. z. Studium Niedersachsens, N.F. 91; 50 S. + 1 FaltKt.(Göttinger Tagebl.) Göttingen

-Nagel, U1rich \& Schunke, Ekkehard (1979): Geomorphologische Erläuterungen zum Orohydrographischen Blockbild der Umgebung von Göttingen von Ulrich Nagel. - Neues Archiv f. Niedersachsen, 28 (2): 200-222; Göttingen

- Nagel, Ulrich; Ritzkowski, Siegfried \& Schunke, Ekkehard (1981): Geologisches und orohydrographisches Blockbild der Umgebung von Dransfeld (b. Göttingen). - Forsch. z. Niedersächs. Landeskde., 114; zgl. Schriften Wirtschaftswiss. Ges. z. Studium Niedersachsens, N.F, 114; zgl. Veröff. Niedersächsischen Inst. Landeskde. u. Landesentwicklung a.d. Univ. Göttingen, Forsch. Niedersächs. Ldkde., 114; 79 S., 13 Abb., 3 Beil. (Taf.); (Göttinger Tagebl.) Göttingen

-Namenskürzel (Dr. D. F.) (1963): Göttingen und das Tal der Leine. - Die Weser, $\underline{\text { 37(4/5): 48-54, } 5}$ Abb.; Bremen [darin: Geologische Entstehung des Leineberglandes/Leinetalgrabens]

○•Namenskürzel [He](1987): Zur Geologie des Eichsfeldes. - Eichsfelder Heimatstimmen, 31/1987(7): 312-314; Duderstadt

Q Neureuter, Franz (1919): Eichsfeldische Heimatkunde - Kurze naturwissenschaftliche Beschreibung der Kreise Heiligenstadt, Duderstadt, Worbis und eines Teiles des Kreises Mühlhausen. - 69 S.; (Mecke) Duderstadt - 2. Aufl. 1920; 3. Auflage 1927 u.d. erweiterten Titel: Eichfeldische Heimatkunde....; zgl. Ein Führer durch die Natur der eichsfeldischen Landschaft. - 80 S., Ill.

Q $\bullet$ Neureuter, Franz (1933): Die Landschaft des Eichsfeldes - zugleich eine Einführung in die Geologie des Gebietes für den Gebrauch im heimatkundlichen Unterricht der Schule, im Hause und auf Ausflügen - 1. Band. - Nebentitel: Das Eichsfeld - eine naturkundliche Beschreibung der Landschaft zwischen Harz und Werra, ihrer Pflanzen- und Tierwelt; 205 S., 9 Photogr., 3 Zeichng.; (Mecke) Duderstadt

口Q $\bullet$ Pompeckj, J.F. (1910): Exkursion nach Eichenberg-Witzenhausen-Hanstein am 3. April.1910. Jber. Niedersächsischen Geol. Vereins, $\underline{\mathbf{3}}$ : XVIII - XXV, 2 Abb.; Hannover Referat in: N. Jb. Mineral. etc., 1912 (Bd. I): 475-476 (Schöndorf); Stuttgart

- Rohde, Horst [Wiss. Bearb. u. Text](1985): Landschaft und Geologie in Niedersachsen. Niedersächsisches Landesmuseum Hannover - Naturkundliche Abteilung: Sonderausstellung 1985. - 
Begleitheft zur Sonderausstellung; 48 S., 17 Abb., 1 Falt-Kt.; Hannover [darin S. 26: „Der Leinetagraben und seine Randgebiete“, Abb. 24 Profil Göttinger Leinetalgraben]

- $\bullet$ Rothe, Peter (2005): Die Geologie Deutschlands - 48 Landschaften im Portrait. Mit Zeichnungen von Martin Schmitteckert. - 240 S., 142 Abb.; (Wiss. Buchgesellschaft) Darmstadt [Darin S. 163-164: „Die Große Nord-Süd-Naht: Leinetalgraben und Randgebiete"]

-Schneiderhöhn, Paula (1973): Die Gemarkung des Dorfes Mackenrode als Teil der Landschaft. (Übergeordneter Titel: Das tausendjährige Mackenrode - Beiträge zu seiner Landschaft und Geschichte) Göttinger Jb., 1973: 119 - 123; Göttingen

-Sohn, Heinz (1965): Ein Vorzeithirsch geborgen. - Die paläontologische Sensation des Jahres. Eichsfelder Heimatstimmen, 9(1)/1965(Januar): 3-6, 1 Abb.; Lingen/Ems

[Paläont. Fund Tongrube Bilshausen/Untereichsfeld; des weiteren: Regionalgeologie des Eichsfeldes]

-Wagner, B.; Lange, T. \& Sauter, M. (2008): Dreidimensionale geologische Modellierung eines innerstädtischen Industriegebietes in Göttingen. - In: Sauter, M.; Ptak, Th.; Kaufmann-Knoke, R.; Lodemann, M.; Kerckhof, A van den (Hg.): Grundwasserressourcen - Kurzfassung der Vorträge und Poster. - Tagung der Fachsektion Hydrogeologie in der DGG (FH-DGG) - Göttingen, 21 bis. 25. Mai 2008. - Schriftenrh. Dt. Ges. Geowiss., 57: 196; Berlin-Hannover 2008

- $\square$ OणWalther, Johannes (1912): Lehrbuch der Geologie Deutschlands - Eine Einführung in die erklärende Landschaftskunde für Lehrende und Lernende. - 2., vermehrte Aufl.; XII, 429 S:, 1 Kt.Beil; (Quelle \& Meyer) Leipzig

[darin: Abb. 18 Zeichnung „Basaltgang im Muschelkalk bei Hörschel“ - darin: S. 253-256, Abb. 126129 „Die hessischen Vulkane“ (Abb. 128 Profil Meissner); S. 257-261, Abb. 130-133 „Das Wesergebirge“ (Abb. 130 Heldrastein); S. 284-290, Abb. 149-152 „Der Thüringer Wald; S. 290-295, Abb. 153-158 „Die Thüringer Senke“"]

-Wilczewski, N.; Schulten, A. \& Hering, G. (1993): Geologie und Stadtentwicklungsplanung. - In: Groos-Uffenorde, Helga [Hrsg.]: O.-H.-Walliser-Festschrift; S. 155 - 159; 2 Abb.; [Selbstverl. Geol. Institute) Göttingen 1993

[Stadtgebiet Göttingen]

-Wocke, Max Ferdinand \& Mann, Hans (1953): Das niedersächsische Bergland - Kleine Heimat und Landeskunde. - Reihe: Erdkundliche Arbeitshefte; 67 S., zahlr. Abb.; (Dümmler) Bonn [einzelne Kapitel m. Bezug z. Regionalgeologie u. z. Bergbau: S. 38: „Das Leinetal - die große Fernverkehrsschleusse“; S. 42: „Das Untereichsfeld - Niedersachsens Tabakgarten“; S. 40: „Die Dransfelder Hochfläche - alte Vulkane in Niedersachsen"] 


\subsection{Geowissenschaftliche Literatur zu einzelnen Geotopen und Regionen}

\subsubsection{Hessen (ohne Werra-Meißner-Kreis)}

\subsubsection{Habichtswald/Kassel}

\subsection{Geologie, Gesamtdarstellung, Paläontologie}

- $\square$ OCApel, Jürgen \& Rüppel, Heidi [Verfass. u. Hrsg.] (2005): Raus in die Natur - Tipps für den Sonntags-Ausflug im Dreiländereck Hessen - Niedersachsen - Thüringen. - 159 S., 111 Fotos, 34 Kt., 1 Zeit-Taf.; (LSRB-Verlag, Landschaftskundlicher-Studien-Reisebuch-Verlag) Witzenhausen [zahlreiche Ausflugsziele, auch zu tertiären Vulkangebieten - Ziel 7 (Dörnbergmassiv), Ziel 10 (Habichtswald)]

- $\square$ Beck, Hanno (1973): Geographie. Europäische Entwicklung in Texten und Erläuterungen. - Reihe: Orbis academicus. 2/16; 510 S.; (Albers) Freiburg i. Br. - München

[darin S. 124-127: „Die Topographie des Landgrafen Hermann zu Hessen-Rotenburg“ [Werra, Meißner]; S. 146-147: „Topographische Tradition: Heinrich Hofrock“ [Beschreibung der Landschaft um Eschwege]; S. 191-192 Rudolf Erich Raspe[Habichtswald]; S. 207-208 „Vulkanismusstreit“ [Meißner, Blaue Kuppe, Habichtswald]

-Beyschlag, Franz (1899): Mittheilungen der Mitarbeiter der Königlichen geologischen Landesanstalt über Ergebnisse der Aufnahmen im Jahr 1898: Niederhessisches Tertiär. - Jb. Preuß. Geol. Landesanst., 19 (f. 1898): LXXXVIII - XCIV; Berlin [Habichtswald]

-Brosius, Marita \& Gramann, Franz (1957): Eine Oligozänbohrung im südlichen Habichtswald bei Kassel. - Notizbl. Hess. Landesamtes Bodenforschung, 85: 206-217, 2 Abb.; Wiesbaden

-Eigenfeld, Rolf \& Eigenfeld-Mende, Ilse (1978): Die Zuordnung kristalliner Gerölle in Devon- und Kulmkonglomeraten zu Magmatiten und Metamorphiten innerhalb der Varisziden Deutschlands. - Z. dt. geol. Ges., 129: 319-357, Abb. Kt., Tab., Taf.; Hannover [u.a. Fremdgesteinseinschlüsse in Basalten des Habichtswaldes]

-Fahlbusch, Klaus (1977): Einige Basalt-Vorkommen, baugeologisch betrachtet. - Geol. Jb. Hessen, 105: 235-243; Wiesbaden

[darin: Vorkommen im Habichtswald]

- $\square$ Freyberg, Bruno v. (1926): Die Tertiärquarzite Mitteldeutschlands und ihre Bedeutung für die feuerfeste Industrie. - 242 S., 32, Abb., 15 Taf.; (Enke) Stuttgart [Tertiär, Lagerstättenkunde; darin: Hann.-Münden, Dransfeld, Kaufunger Wald und Meißner, Habichtswald und Umgebung Kassel]

- $\square$ Gabert, C. (1922): Braunkohlenquarzite (Knollensteine) und ihre technische Verwendung. - Jb. Halleschen Verbandes etc., $\underline{\mathbf{3}}(2):$ 49-60; Leipzig [darin: Habichtswald, Hirschberg, Meißner]

- $\square$ Harder, Hermann (1993): Zur Entstehung von verkieselten Hölzern. - Der Aufschluss, 44: 23-31, 8 Abb.; Heidelberg [u.a. chem. Analysen Proben Druseltal/Habichtswald, Hoher Meißner] 
- $\square \bullet$ Hausmann, [J. F. L.](1824): Uebersicht der jüngeren Flöz-Gebilde im Fluß-Gebiete der Weser. Tb. Mineral., 18 (3): 678-702; Frankfurt/M. - Auszug aus Hausmann: Uebersicht der jüngeren FlözGebilde. - Studien Göttingischen Vereins bergmänn. Freunde, 1: 381 - 567, Göttingen 1824 [Regionale Stratigraphie Trias-Tertiär Hessen, WMK, Niedersachsen; darin: Tertiär Meißner, Hirschberg, Habichtswald, Wilhelmshöhe b. Kassel, Dransfeld]

- $\square \bullet$ Hausmann, J. F. L. (1858): Über das Vorkommen verschiedener Kieselgebilde in Begleitung des Basaltes. - Studien Göttingischen Vereins bergmänn. Freunde, $\underline{7}(2): 139$ - 192; Göttingen [darin: Blaue Kuppe, Hirschberg, Habichtswald, Meißner, Steinberg b. Hann-Münden; S. 154-156: „Absatz von Kieselsinter in dem schlackigen Anthracite des Meißners; S. 165-172: „Durch Eindringung von kieselsäurehaltigem Wasser in die Schichten des vom Basalte durchbrochenen Muschelkalkes gebildeter Kieselkalk“ (Kontkatmetamorpher Marmor vom „Schieferberg b. Bransrode“/Hoher Meißner S’ Weisenbach, heutiger Name „Heiligenberg“]

-Hessel (1825): Fische aus dem Polirschiefer des Habichtswaldes. - Z. Mineral., 1825 (Bd. II): 489; Frankfurt/M.

-Hummel, Karl (1930): Glanzkohlengänge in der Braunkohle des Habichtswaldes. - Z. dt. geol. Ges., 82: 489 - 497, 1 Abb., 1 Taf.; Berlin Referat in: N. Jb. Mineral. etc., Referate; 1932 (Bd. II): 514-515 (E. Christa); Stuttgart

- $\square$ Klipstein, v. (1836): Versuch einer geographisch-geognostischen Eintheilung des westlichen Deutschlandes nebst generellen Andeutungen zur geognostischen Konstitution der verschiedenen Gebirgs-Abtheilungen desselben. - N. Jb. Mineral. etc., 1836: 255-289 Stuttgart [Entwurf einer regionalen Geologie von West-Deutschland; darin: „Habichtswald...“; „Meissner und Knöll“(Knüll)]

-Klüpfel, Walther (1930): Die Bedeutung der Reliefgenerationen für die Vulkangebiete (Westerwald, Vogelsberg, Habichtswald, Hegau, Böhmisches Mittelgebirge). - Geol. Rundschau, 21: 151 - 162, 1 Abb.; Berlin

- $\square$ Kühnert, Ernst (1841): Ueber den Werth einiger in der Umgebung von Cassel vorkommenden Braunkohlen. - Ann. Chemie Pharmacie, 37: 94-100; Heidelberg [darin: Meißner, Habichtswald, Hirschberg, Ringenkuhl, Stellberg/Söhrewald]

- 0 OKutscher, Fritz (1953): Angewandte Erdmagnetische Messungen in Hessen: 1. Zusammenstellung der bisherigen speziellen erdmagnetischen Messungen in Hessen. - Notizbl. Hess. L.-A. Bodenforsch., [6. Folge, H. 4] 81: 350-367, 9 Abb.; Wiesbaden [darin: „Erdmagnetische Messungen auf Basalte“: a) Habichtswald b) Solling c) Umgebung Kassel, d) Stellberg/Söhrewald e) Meißner (Kitzkammer, Plateau zw. Altarstein u. Bransrod) f) Basalt i. thür. Kaligebiet]

- $\square$ Kvaček, Zlatko \& Walther, Harald (1974): Bemerkenswerte und seltene cinnamomoide Blätter aus dem Grenzbereich des Oligo-Miozäns Mitteleuropas. - Abh. Staatl. Museums f. Mineralogie u. Geologie z. Dresden, 21: 197-221, 3 Abb., 1 Taf.; Dresden [Funde Habichtswald, Meißner]

-Landgrebe (1840): Ein im Basalt-Konglomerat des Habichtswaldes aufgefundenes Sprungbein von Dorcatherium naui KAUP's. - N. Jb. Mineral. etc., 1840: 307-313; Stuttgart

-Landgrebe (1843): Ein im Polirschiefer des Habichtswaldes aufgefundener Käfer. - N. Jb. Mineral. etc., 1843: 137-142; Stuttgart

-Leppla, A. (1892): Ueber Aufnahmen im Gebiet des Blattes Waldeck-Cassel (1 : 80.000). - Jb. Preuß. Geol. Landesanst., 10 (f. 1889): LXV-LXX; Berlin [darin: Habichtswald] 
-Ließ, Siegfried (1988): Charakterisierung des bodenchemischen Zustandes von Waldböden auf Basalt und Kalk mit unterschiedlichen Lößlehmablagerungen im Habichtswald. - Dipl.-Arb. (unveröffentlicht) FB 13 Univ./Gesamthochschule Kassel; 97 S., graph. Darst., Kt.; Kassel

- $\square$ Mattig, Ulrike (2004): Naturerlebnis im Herzen Deutschlands. - In: Hessen - Land der Mitte. - 1. Aufl., 592 S., zahlr. Abb.; hier S. 130-141, 6 Abb.; (Gauweiler) Heidelberg [auch Informationen z. Regionalgeologie Naturpark Habichtswald, Naturpark Meißner-Kaufunger Wald]

-Mayer (1837): Infusorien im Polierschiefer vom Habichtswald. - N. Jb. Mineral. etc., 1837: 108; Stuttgart

- $\square$ Möhl, H[einrich] (1897): Topgraphische und geologische Verhältnisse Cassels. - In: Lange, Wilhelm Chr. [Red.]: Festschrift zur 38. Hauptversammlung d. Vereins Deutscher Ingenieure Gewidmet vom Hessischen Bezirksverein; 176 S:, Abb.; hier S. 1-14, 2 Taf.; (Weber \& Weidemeyer) Kassel 1897

[Bezugnahme a. Hirschberg b. Großalmerode und Umbgebung von Kassel]

- $\square$ Mohr (Med.-Rath)(1868): [Widerlegung der] Ansicht, dass man die stängelige Absonderung der Braunkohlen auf dem Meisner, Habichtswald und Hirschberg im Kurhessischen als einen Beweis der feurigen Einwirkung des Basaltes auf diese Brennstoffe ansehen dürfe. - Verhdlgn. Naturhist. Vereins d. Preuß. Rheinlande u. Westphalens, $\underline{\mathbf{2 5}}$ (= 3. F., $\underline{\mathbf{5}}$ ): 25 (Sitzber.); Bonn

[Ein später Schlag gegen die magmatische Natur des Basaltes im Plutonisten-, Neptunisten-Streit]

- $\square$ Oehlschlegel, H. G. (1964): Geochemische Untersuchungen an nordwestdeutschen und nordhessischen tertiären Braunkohlen. - N. Jb. Mineral. etc., Abh., 101(1): 67-96, 18 Abb., 9 Tab. i. T. u. a. Beil.; Stuttgart [u.a. Gahrenberg, Hirschberg, Hoher Meißner, Freudenthal/Oberkaufungen, Stellberg/Söhre, Marie Trost/Habichtswald]

-Penndorf, Hans (1927): Geologische Wanderungen im Habichtswald. - Hessischer Gebirgsbote, $\underline{33}(5)$ : 37; Melsungen

-Rösing, Franz (1956/1957): Das prätuffische Relief des Habichtswaldes und seiner Umgebung. - Z. dt. geol. Ges., $\underline{108}$ (f. 1956): 267-268; Hannover [Vortragstext]

- Rösing, Franz (1962): Geologische Halbtagsexkurison durch den Habichtswald un den Kasseler Graben am 24. Mai. 1961. - (Übergeordn. Titel: Bericht über die Exkursionen während der Tagung des Naturhistorischen Vereins der Rheinlande und Westfalens vom 23. - 26. Mai 1961 in Kassel). Decheniana - Verhdlgn. Naturhist. Vereins Rheinlande u. Westfalens, 114 (f. 1961): 190-194, 1 Profilberschr.; Bonn

- $\square$ Rosenthal, L. (1893): Die metamorphisierende Einwirkung der Basalte auf die Braunkohlenlager bei Cassel. - Z. prakt. Geol., 1.1893 (10): 378-381, 2 Fig.; Berlin [darin: Habichtswald, Hirschberg, Stellberg, Meißner]

- $\square$ Rosenthal, (Bergingenieur) (1895): Die tertiären Ablagerungen bei Kassel und ihre durch Basaltdurchbrüche veredelten Braunkohlenflöze. - Touristische Mitteilungen a. beiden Hessen, $\underline{\mathbf{3}}(12)$ : 149-152; Kassel [Habichtswald, Stellberg, Hirschberg, Hoher Meißner]

- $\square$ Rosenthal, (Berg-Ingenieur) (1896): Die tertiären Ablagerungen bei Kasssel und ihre durch Basaltdurchbrüche veredelten Braunkohlenflöze. - Abh. u. Ber. Vereins Naturkde. z. Kassel, $\underline{41}$ (1995/1896): 106-117, 3 Abb. (Profile); Kassel [darin: Habichtswald, Hirschberg, Stellberg, Meissner] 
- Schaefer, Bernhard (1926): Der Hirzstein im Habichtswald als Naturschutzgebiet. - Hessenland, $\underline{\mathbf{3 8}}(8)$ : 163-167, 8 Abb.; Kassel

[Botanik, Geologie]

- QSchäfer, Frank N. (2004): Eine geologische Betrachtung des spätmittelalterlichen Eisenerzabbaus im nördlichen Habichtswald bei Kassel. - Philippia, 11(3): 167-182, 2 Abb., 3 Tab.; Kassel

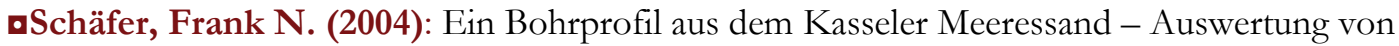
Materialproben eine Brunnenbohrung im nordöstlichen Habichtswald bei Kassel. - Philippia, 11(3): 183-194, 1 Abb.; Kassel

oSchlossmacher, K. (1910): Die Entstehung des Habichtswaldes [Vortragstext]. - Tourist. Mitt. a. beiden Hessen, 18 (10): 111 - 112; Kassel

- 0 ๑Schlotheim, [Ernst Friedrich] v. (1820): Die Petrefactenkunde auf ihrem jetztigen Standpunkte durch die Beschreibung seiner Sammlung versteinerter und fossiler Überreste des Thier- und Pflanzenreichs der Vorwelt erläutert. - 436 S., sep. Tafelbd. M. 15 Taf.; 2 Bd. Nachträge 1822, 1823 m. sep. Tafelbd., 21 Taf.; (Becker) Gotha

[Sammlungsverzeichnis, kein Lehrbuch; S. 386 Versteinertes Holz aus dem Schwalbenthaler Stollen am Meißner; S. 399ff Paläobotanische Funde aus dem Thüringer Wald; S. 389ff Blattfunde Burgtonna, Habichtswald, Kalktuff Hainberg b. Göttingen]

aSchmeisser, A. (1879): Die geognostischen Verhältnisse des Habichtswaldes bei Kassel. - Mitt. Natwiss. Vereins Maja z. Clausthal., N.F., 1: 1-11, 2 Taf.; Clausthal

aSchönhals, Ernst (1957): Eine äolische Ablagerung des Jüngeren Tundrenzeit im Habichtswald. - Geol Jb. Hessen, 모: 380 - 386, 3 Abb., 1 Tab.; Wiesbaden

-Simon, C. (1889): Entstehung von Quarziten der Braunkohlenformation. - Ber. Vereins Naturkde. z. Kassel, 34/35: 86-88; Kassel

[Trappquarzite Habichtswald]

- $\square$ Straub, August (1969): Nordhessen: Das Bergland von Niederhessen - Landschaft, Geschichte, Kultur, Kunst, Wirtschaft. - 352 S., zahlr. Abb.; (Glock u. Lutz) Nürnberg [darin auch Informationen zur Geologie: Steinbruch Cornberg, Habichtswald, Knüll, Meißner, Reinhardswald, Richelsdorfer Gebirge, Ringgau,]

oStrippelmann, F. E. (1824): [Tertiär des Habichtswaldes b. Kassel] - Z. Mineralogie, 1827(6): 513 518; Frankfurt/M.

[Basalt-Konglomerat, Polirschiefer, Trappquarz]

-Strippelmann (1827): [Nachteilige und schädliche Wirkungen von Rauchgasen brennender sog. „gemeiner“ Braunkohle auf den menschlichen Organismus]. - Z. Mineral., 1827(9): 287-293;

Frankfurt/M.

[Kohlebrände Habichtswald]

هStrippelmann (1827): Geognostische Verhältnisse des Habichtswaldes. - Z. Mineral., 1827(6): 513-518; Frankfurt/M.

-Strippelmann, F. E. (1833): Über den Brand in Braunkohlengruben mit vorzüglicher Rücksicht auf die Braunkohlenbergwerke am Habichtswald. - Studien Göttingischen Vereins bergmänn. Freunde, $\mathbf{3}$ : 99170; Göttingen

-Wilhelm, Otto (1937): Morphologische Untersuchungen am Nordrand der Niederhessischen Senke. Jb. Geogr. Ges. Hannover, 1936/1937: 77 - 165, 8 Taf. (5 Abb., 3 Falt-Kt.; Hannover [Umgebung v. Hofgeismar, Habichtswald u. a.] - zgl. Diss. Univ. Göttingen 1937 


\subsection{Mineralogie, Lagerstättenkunde, Erforschung der Basalte}

-Anonym (1898): Neue Flötzfunde im Habichtswalde bei Cassel. - Z. prakt. Geologie, [6. Jg.] 1898: 267 (Notizen); Berlin

- $\square$ Becker, Arthur (1881): Ueber die Olivinknollen im Basalt. - Z. dt. geol. Ges., 33: 21-66; Berlin [darin: Hunrodsberg/Habichtswald, Bausberg b. Cassel, Alpstein b. Sontra]

-Berns, Arthur (1915): Beiträge zur Petrographie der Basalttuffe des Habichtswaldes. - Zbl. Mineral. etc., 1915: 483-500, 517-524; Stuttgart

-Beroldingen, Franz v. (1791): Die Vulkane älterer und neuer Zeiten - physikalisch und mineralogisch betrachtet. - 1. Theil; 293 S. [9 Bl.]; 2. Theil; 406 S. [17 Bl.]; (Schwan u. Götz) Mannheim [darin 1. Theil S. 203-204, 209: Weißenstein/Habichtswald b. Kassel]

- $\square$ Blum, Reinhard (1860): Handbuch der Lithologie oder Gesteinslehre. - 356 S., 50 Abb.; (Enke) Erlangen

[darin: Meissner, Habichtswald]

-Buch, Leopold v. (1820): Über einige Berge der Trappformation in der Gegend von Grätz. Abhandlungen d. Königlichen Akademie der Wissenschaften in Berlin, 1818/1819: 111-118; (Reimer) Berlin [darin: Basalte der Umgebung v. Kassel - Ober-Vellmar („Ober-Wollmar“), Dörnberg, Weißenstein/Habichtswald]

-Buch, Leopold v. (1821): Ueber einige Berge der Trapp-Formazion bei Gräz. - Tb. Mineral., 15 (2): 457472; Frankfurt/M. - Abdruck aus: Abhandlungen d. Königlichen Akademie der Wissenschaften in Berlin, 1818/19: 111-118; Berlin [darin: Basalte der Umgebung v. Kassel - Ober-Vellmar („Ober-Wollmar"), Dörnberg, Weißenstein/Habichtswald]

verwendbarer Gesteine, Tone und Sande in Deutschland. - Die Stein-Industrie (Der Steinbruch); Berlin Deutschlandweite Darstellung m. thematischen, großmassstäiben Übersichts-Karten, darin Abbaustellen in Hessen, WMK, Thüringen, Niedersachsen]

I. -- Einführung - 26 $(10): 141-142$

II. -- 1. Tiefengesteine - 26 $(23): 318-319$, Kt. 1; -

III. -- 2. Ergußgesteine [H, WMK, TH, NIE] - 26 (24): 330-332, Kt. 2;

IV. -- 3. Vulkanische Tuffe [H (Habichtswald)]- 26 (25): 339-340, Kt. 3;

-Carpenter, R.-L.; Edgar, A. D. \& Thibault, Y. (2002): Origin of spongy textures in clinopyroxen and spinel from mantle xenoliths, Hessian Depression, Germany. - Mineralogy Petrology, 74(2/4): 149162, 6 fig.; Wien

[Druseltal, Altenburg, Stopfling, kein Vorkommen i. WMK]

- Ernst, Theodor (1941): Olivinknollen der Basalte als Bruchstücke alter Olivinfelsen. - Nachr. Ges. Wiss. Göttingen, Math.-phys. Kl, Fachgr. IV, N.F., 1 (1934-1940): 147-154, 13 Abb.; Göttingen Diagramme Kristallgitterregelung von Olivin, u.a. Hirzstein/Habichtswald b. Kassel, Hoher Hagen b. Göttingen]

-Fromm, Otto (1891): Petrographische Untersuchungen von Basalten aus der Umgebung von Kassel .Z. dt. geol. Ges., $\underline{43}$ (1891): 43-76, 9 Abb.; Stuttgart 
Referat in: N. Jb. Mineral. etc., 1892 (Bd. I): 277-278 (O. Mügge); Stuttgart

Referat in: Z. f. Naturwiss., 64: 164-167; Halle

[Habichtswald, Kaufunger Wald, Bühl. B. Weimar, Dörnberg u.a.]

-Hartmann, Gerald (1986): Chemische Zusammensetzung und Mineralbestand von Peridotit-

Xenolithen mit unterschiedlicher metasomatischer Überprägung aus Basalten der Hessischen Senke. Diss. Univ. Göttingen 1986; 99 S., 28 Abb., 10 Tab. + Anh. (Tab.)

[HE, darin: Hirzstein, Druseltal]

-Hartmann, Gerald \& Wedepohl K. Hans (1990): Metasomatically altered peridotite xenoliths from the Hessian Depressian (Northern Germany). - Geochimica Cosmochimica Acta, 54: 71-86, 7 fig., 4 tabl.;

[HE, darin: Hirzstein, Druseltal]

- $\square \bullet$ Hausmann, [J. F. L.] (1824): Uebersicht der jüngeren Flöz-Gebilde im Fluß-Gebiete der Weser. Tb. Mineral., 18(3): 678-702; Frankfurt/M. - Auszug aus Hausmann: Uebersicht der jüngeren FlözGebilde. - Studien Göttingischen Vereins bergmänn. Freunde, 1: 381 - 567, Göttingen 1824 [Regionale Stratigraphie Trias-Tertiär Hessen, WMK, Niedersachsen; darin: Meißner, Hirschberg, Habichtswald]

व $\square$ बढHausmann, J.F.L. (1824, 1828): Übersicht der jüngeren Flötzgebilde im Flußgebiete der Weser, mit vergleichender Berücksichtigung ihrer Äquivalente in einigen anderen Gegenden von Deutschland und der Schweiz. - Studien Göttingischen Vereins bergmänn. Freunde, 1: 381 - 567, Göttingen 1824; 2: 215-482; Göttingen 1828

[Regionale Stratigraphie Trias-Tertiär Nordhessen, Südniedersachsen; Bd. 1, Stratigraphie Buntsandstein; S. 500-508 „Basaltische Massen im Sandstein“, darin: Blaue Kuppe bei Eschwege, Pflasterkaute bei Eisenach]

- $\square$ Hausmann, J.F.L. (1858): Über das Vorkommen verschiedener Kieselgebilde in Begleitung des Basaltes. - Studien Göttingischen Vereins bergmänn. Freunde, 7 (1): 139 - 192; Göttingen [darin: Blaue Kuppe, Hirschberg, Habichtswald]

-Hentschel, Hans (1957): Typen tertiärer Basalttuffe im Raum des Habichtswaldes und ihre Lagebestimmungen. - Z. dt. geol. Ges., 108 (f. 1956): 268-269; Hannover [Vortragstext]

هHentschel \& Rösing (1959/60): Habichtswald und Dörnberg bei Kassel - Bericht über die Exkursionen anläßlich der 110. Hauptversammlung [der Deutschen Geologischen Gesellschaft] vom 1.-9- September 1968 [in Kassel]. - Exkursion F - Mesozoikum u. Tertiär der Hessischen Senke Montag, den 9. September 1958 - Z. dt. geol. Ges., 111 (f. 1959/60): 305-310, 1 Tab.; Hannover

- $\square$ OHoff, Karl Ernst Adolf von (1811): Beobachtungen über die Verhältnisse des Basaltes an einigen Bergen von Hessen und Thüringen. - Der Gesellschaft Naturforschender Freunde zu Berlin Magazin für die neuesten Entdeckungen in der gesammten Naturkunde, 5: 347-362 u. Taf. VIII; Berlin [darin: Blaue Kuppe b. Eschwege, Pflasterkaute b. Marksuhl, Stoffelskuppe b. Eisenach, Habichtswald/Kassel, Hirschberg b. Großalmerode, Hoher Meissner]

- $\square$ Kayser, Emanuel (1923): Lehrbuch der Allgemeinen Geologie. - (Vier Bände: I. u. II. Band Allgemeine Geologie, III u. IV. Bd. Geologische Formationskunde). - Bd. İ: Physiographische Geologie und Äussere Dynamik. - 7. u. 8. Aufl., 740 S., 549 Abb.; (Enke) Stuttgart

[darin: Abb. z. Vulkanismus Abb. 58 Basaltbruch Bühl b. Ahnatal/Weimar W’Kassel; 92a

Teufelswand, Habichtswald/Kassel; 110 Profil Meissner - 111 Profil Hirschberg b. Großalmerode Tektonik: Abb. 203 Profil Netratal b. Eschwege, 204 „Eichenberg“ b. Netra]

$\square \mathbb{Q} \bullet$ Keferstein, Christian (1820): Geognostische Bemerkungen über die basaltischen Gebilde des westlichen Deutschlands, als Fortsetzung der Beyträge zur Geschichte und Kenntniß des Basaltes. VIII, 207 S., 1 Falt-Kt.; (J. Chr. Hendel u. Sohn) Halle/Saale 
[darin S. 22 - 24: Habichtswald, Meißner, Hirschberg/Großalmerode, Erwähnung der „blauen Kuppe“, Basaltberge westl. Göttingen, Stoffelskuppe, Pflasterkaute bei Marksuhl]

- $\square$ Klipstein, v. (1836): Versuch einer geographisch-geognostischen Eintheilung des westlichen Deutschlandes nebst generellen Andeutungen zur geognostischen Konstitution der verschiedenen Gebirgs-Abtheilungen desselben. - N. Jb. Mineral. etc., 1836: 255-289 Stuttgart

[Entwurf einer regionalen Geologie von West-Deutschland; darin: „Habichtswald...“; „Meissner und Knöll“(Knüll)]

- $\square$ Krenkel, Erich (1932): Die Bodenschätze Deutschlands. - 1. Bd. - VIII, 301 S., 71 Abb.; (Bornträger) Berlin

[darin: II. Besonderer Teil - Die Bodenschätze <Kohlen> - darin S. 122-126: (Kap. 8. Braunkohlen) Der Niederhessische Bezirk (darin Habichtswald, Stellberg, Hirschberg, Meißner), Abb. 16 Druseltal, Abb. 17 Hirschberg]]

- $\square$ OLeonhard, Karl Caesar v. (1832): Die Basalt-Gebilde in ihren Beziehungen zu normalen und abnormalen Felsmassen. - Bd. 1, 498 S., sep. Taf.-Bd. 20 Taf.; Bd. 2, 536 S.; (Schweizerbart) Stuttgart [Bd. 2 beschreibt Intrusionsgefüge der Basalte und die Kontaktmetamorphose auf das Rahmengestein an verschiedenen nordhessischen Lokalitäten; Kontaktmetamorphose Basalt/Ton: Meißner; Basalt/Braunkohle: Meissner/Hirschberg/Habichtswald; Basalt/Buntsandstein: Blaue Kuppe b. Eschwege; Pflasterkaute b. Marksuhl; Basalt/Muschelkalk: Ahnetal/Kassel, Hörschel b. Eisenach]

-oLleonhard, Karl Caesar v. (1846): Lehrbuch der Geognosie und Geologie. (Übergeordn. Titel: Naturgeschichte der drei Reiche. Zur allgemeinen Belehrung bearbeitet von H.G. Bronn, K.C. v. Leonhard,F.S. Lenckart und F.S. Voigt. Dritter Band: Geologie und Geognosie). - 2. vermehrte u. verbess. Aufl.; XII, 1056 S., zahlr. Abb., 6 Falttaf.; (Schweizerbart) Stuttgart [darin: S. 185: Hörschel b. Eisenach, Basaltgang i. Unt. Muschelkalk; Habichtswald/Ziegenberg, Basaltüberdeckung der Braunkohle]

- $\square$ Lepsius, Richard (1887 - 1892): Geologie von Deutschland und den angrenzenden Gebieten. Erster Teil: Das westliche und südliche Deutschland. - Reihe: Handbücher zur Deutschen Landes- und Volkskunde, Bd. 1; XIV, 800 S., 136 Abb., 5 Falt-Taf.; in 3 Lfgn., 1.1887, 2.1889, 3.1892; (J. Engelhorn) Stuttgart [darin S. 402 Richelsdorfer Gebirge; S. 758-766 Kap.: „Basalte in nördlichen Teil des hessischen Waldgebirges (Knüll, Habichtswald, Reinhartswald, Kaufunger Wald und Meissner““‘; S. 761 - 766 Petrographie, Geologie und Erforschungsgeschichte des Meißner-Basaltes)

-Loewer, E. (1896): Ueber die Basalttuffe vom Habichtswald und von Homberg, Reg.-Bez. Kassel. Abh. u. Ber. Vereins Naturkde. z. Kassel, 41 (1895/1896): 51-68, 1 Abb.; Kassel

-Mengel, Kurt (1981): Petrographische und geochemische Untersuchungen an Tuffen des Habichtswaldes und seiner Umgebung und an deren Einschlüssen aus der tieferen Kruste und dem oberen Mantel. - Diss. Univ. Göttingen 1981; 104 S., graph. Darst.

-Mengel, Kurt (1983): Petrographie und Geochemie der Tuffe des Habichtswaldes und seiner Umgebung (Nördliche Hessische Senke). - N. Jb. Mineral., Abh., 147: 1-20, 4 Abb., 5 Tab.; Stuttgart

-Mengel, K. (1987): Petrologie und Geochemie von Unterkrusten-Xenolithen aus Tuffen des Habichtswaldes (nördliche Hessische Senke). - Fortschr. Mineral., 65, Beih. 1: 134; Stuttgart

-Mengel, K. (1990): Crustal xenoliths from Tertiary volcancis of the northern Hessian Depression Petrological and chemical evolution. - Contrib. Mineral. Petrology, 104(1): 8-26, 8 fig., 6 tabl.; BerlinHeidelberg

-Mengel, K. (1990): Chemical evolution of the lower crust beneath NW Germany, evidence from xenolithes of the Habichtswald area. - In: Crustal dynamics, pathways and records - Bochum, FRG, 21-24 February 1990. - Terra abstracts, $\underline{2}$ (1992): 46-47; (Blackwell) Oxford 
-Menzel, Herbert (2004): Betrachtungen zum tertiären Vulkanismus in der Eifel mit Beispielen weiterer Vulkan-Vorkommen im nördlichen Deutschland. - Der Aufschluss, 55(1): 25-34, 23 Abb.; Heidelberg [darin Erwähnung: Habichts- u. Reinhardswald]

-Mötzing, Kurt (1970): Die Teufelsmauer, ein oft genanntes, aber wenig bekanntes Naturdenkmal im Habichtswald. - Hessischer Gebirgsbote, 711(1): 8 - 9, 1 Abb.; Melsungen

- $\square$ Nöggerath, Karl Jakob (1822-1826): Das Gebirge in Rheinland-Westfalen - nach mineralogischem und chemischen Bezuge. - 1. Bd., 370 S.: 7 Abb., (Eduard Weber) Bonn 1822. - 2. Bd.: 387 S., 7 Abb., (Eduard Weber) Bonn 1823. - 3. Bd.: 291 S., 6 Abb., (Eduard Weber) Bonn 1824. - 4 Bd.: 390 S., 2 Abb., (Eduard Weber) Bonn 1826

[darin Bd. III, S. 273 - 277: „Kurze Nachricht von einigen wenig bekannten Basalt-Gängen in Hessen (aus einem Briefe)"; Kontaktmetamorphose des Basaltes auf das Rahmengestein: Habichtswald, Ahnetal, Hirschberg; Schieferberg N’ Meissner (vermutl. Heiligenberg S’ Weißenbach)]

- $\square$ Osann, Alfred (1901): Versuch einer chemischen Klassifikation der Eruptivgesteine: II. Die Ergußgesteine. - Tschermaks Mineral. petrogr. Mitt., 20: 399 - 558; Wien [darin: Habichtswald; S. 446 Plagioklasbasalt Typ Meissner, Analyse Dolerit Hoher Meißner]

-Penndorf, Hans (1927): Geologische Wanderungen im Habichtswald. - Hessischer Gebirgsbote, $\underline{\text { 33(5): }}$ 37; Melsungen

- $\square$ Pietzsch, Kurt (1925): Handbuch der Geologie und Bodenschätze Deutschlands / Erich Krenkel [Hrsg.]. - Abt. 3: Die Bodenschätze Deutschlands - Bd. 1: Die Braunkohlen Deutschlands. - XII, 488 S., 105 Textabb., 20 Taf.; (Bornträger) Berlin [darin S. 205-225: Der Niederhessische Bezirk [Revier Cassel] (darin; Habichtswald, Stellberg, Hirschberg, Oberkaufungen, Glimmerode, Meißner)]

-Raspe, [Rudolf Erich] (1771): Nachricht von einigen niederhessischen Basalten, besonders aber einem Säulenbasaltstein Gebürge bei Felsberg und den Spuren eines verlöschten brennenden Berges am Habichtswalde über Weissenstein nahe bei Cassel. - Deutsche Schriften von der Königlichen Societät der Wissenschaften zu Göttingen, Bd. 1: 72-83; Tab. [ula] I; (Dieterich) Göttingen u. Gotha

- Raspe, Rudolf Erich (1774): Beytrag zur allerältesten und natürlichsten Historie von Hessen oder Beschreibung des Habichtswaldes und von verschiedner andern niederhessischen Vulcane in der Nachbarschaft von Cassel. - [5 B1.] 76 S., 1 Falt-Taf.; (Cramer) Kassel [Regionale Geol. Kassel u. Umgebung; Habichtswald, Dörnberg, Kratzenberg, Frankenhausen, Katzenstein u. Hohlenstein zw. Harleshausen u. Dörnberg, Weidelsberg b. Wolfhagen, Schloßberg Felsberg, Schloßburg Aldenburg, Madenstein b. Gudensberg]

-Raspe, Rudolf Erich (1776): An account of some German volcanos, and their productions. Wiith a new hypothesis of the prismatical basaltes. Established upon facts; being an essay of physical geography for philosophers and miners. Published as supplementary to Sir William Hamilton's observations on the Italian volcanos. - XIX, 140 p., 2 pl.; (Lockyer Davis) London [Regionale Geol. Kassel u. Umgebung; Habichtswald, Dörnberg, Kratzenberg, Frankenhausen, Katzenstein u. Hohlenstein zw. Harleshausen u. Dörnberg, Weidelsberg b. Wolfhagen, Schloßberg Felsberg, Schloßburg Aldenburg, Madenstein b. Gudensberg]

- $\square \bullet$ Rinne, O. (1893): Über norddeutsche Basalte aus dem Gebiete der Weser und den angrenzenden Gebieten der Werra und Fulda - I. Untersuchungen im nördlichen, sowie einzelner Vorkommnisse im südlichen Teil des Gebietes. - Jb. Preuß. Geol. Landesanst., $\underline{13}$ (f. 1892): 1-95 (Abh. v. behördenfremden Personen) Taf. VI - IX; Berlin Referat in: N. Jb. Mineral. etc, 1894 (Bd. II): 56-59 (O. Mügge); Stuttgart [Vorkommen Lkr. Kassel, Lkr. Göttingen; Habichtswald, Meißner, S. 16-18 Blaue Kuppe b. Eschwege u. Alpstein b. Kirchhosbach] 
-Rösing, Franz (1962): Geologische Halbtagsexkurison durch den Habichtswald un den Kasseler Graben am 24. Mai. 1961. - (Übergeordn. Titel: Bericht über die Exkursionen während der Tagung des Naturhistorischen Vereins der Rheinlande und Westfalens vom 23. - 26. Mai 1961 in Kassel). Decheniana - Verhdlgn. Naturhist. Vereins Rheinlande u. Westfalens, 114 (f. 1961): 190-194, 1 Profilberschr.; Bonn

-Schlossmacher, K. (1911): Die Eruptivgesteine des Habichtswaldes und seiner Vorberge. - N. Jb. Mineral., Beil.-Bd. 31: 641 - 683, 1 Taf.; Stuttgart

aSchmidt, Kai Herbert (1996): Die Entwicklung ungewöhnlicher Isotopensignaturen im lithosphärischen Erdmantel - eine kombinierte geochemische und experimentelle Untersuchung. XXVI, 58 S., Ill., graph. Darst.; (Papierflieger) Clausthal-Zellerfeld - zgl. Diss. Univ. Göttingen 1995 [Untersuchungen an Fremdgesteins-Einschlüssen in Basalt-Tuffen des Habichtswaldes]

-Schwarzenberg , Bergkommissar (1828): Beschreibung der geognostischen Verhältnisse des Ahnegrabens am Habichtswalde bei Kassel, mit besonderer Berücksichtigung der dabei vorkomenden basaltischen Ausfüllungsmassen, nebst einer petrographischen Skizze. - Studien Göttingischen Vereins Bergmänn. Freunde, 2: 195-219, 1 Falt-Bl.; Göttingen

هStelzner, Alfred (1883): Über Melilith und Melilithbasalte. - N. Jb. Mineral. etc., Beil.-Bd. 2: 369 - 439; Stuttgart

[S. 432 Basalt des Habichtswaldes, Grebenstein b. Hofgeismar]

-Strippelmann, [F. E.] (1837): Ueber das Vorkommen von Basaltgängen auf dem Habichtswald. - Jber. Thätigkeit Vereins f. Naturkunde in Cassel. - 1 (1837): 11 - 12; Kassel

aStrippelmann, F. E. (1840): Flötz-artiger Basalt in Habichtswalder Braunkohle. - N. Jb. Mineral. etc., 1841: 369-370 (Auszug a. Bergwerks-Freund, 2: 297ff, Eisleben); Stuttgart

هStrippelmann, F. E. (1841): Über das Vorkommen einer flözartigen Einlagerung von basaltischen Massen in der Habichtsspieler Braunkohlenablagerung am Habichtswalde. - Studien Göttingischen Vereins bergmänn. Freunde, 4: 355-358; Göttingen

aStruve, [Heinrich] v. (1812): Über eine Suitensammlung [Gesteinssammlung] vom Habichtswalde. Tb. Mineral., ㅇ: 395-396; Frankf./M.

oStruve, [Heinrich] v. (1812): Über einen in der Gegend von Kassel aufgeführten Basaltgang. - Tb. Mineral., ㅁ: 361-363; Frankfurt/M.

[“Teufelsmauer” am Hirzstein b. Kassel]

-Techmer, Astrid (1989): Geochemische Untersuchungen an Xenolithen aus dem Habichtswald. Dipl.-Arb. [unveröff.] Univ. Göttingen 1989; 85 S.

-Voigt [Johann Carl Wilhelm] (1789): Beantwortung der Preisfrage. Was ist Basalt? Ist er vulkanisch oder ist er nicht vulkanisch? - Magagazin für die Naturkunde Helvetiens, 4: 213-232 + [Anonym] Anhang zu den Preisfragen über den Basalt: 233-238; Zürich

[darin: S. 221 Weißenstein/Habichtswald b. Kassel]

- $\square \bullet$ Wedepohl, K. H. \& Hoefs, J. (1968): Strontium isotope studies on young volcanic rocks from Germany and Italy. - Contrib. Mineral. Petrol., 19: 328 - 338, 2 fig., 3 tabl.; Berlin-Heidelberg [HE, NIE, WMK; Habichtswald, Meißner]

- •Wedepohl, K. H. \& Muramatsu, Y. (1979): Chlorine in Tertiary basalts from the Hessian Depression in NW Germany. - Contrib. Mineral. Petrol., 무: 357 - 366, 4fig., 3 tabl.; Berlin-Heidelberg [HE, NIE; Hirzstein]

- $\bullet$ Wedepohl, K. H.; Mengel, K. \& Ritzkowski, S. (1983): The Tertiary basalts of the northern 
Hessian Depression and their mantle xenoliths. - DMG SFMC Joint Meeting 1983 - Excursion E 4. Fortschr. Mineral. 61, Beih. 2: 117 - 134, 2 fig., 3 tab.; Stuttgart

[HE, NIE; Habichtswald]

-Wedepoh1, K. H.; Mengel, K.; Kramm, U. \& Gohn, E. (1984): Sr-isotopes in peridotite xenoliths and their basaltic host rocks from the northern Hessian Depression (NW Germany). - Contrib. Mineral. Petrol., 87: 369 - 375, 2 fig., 4 tabl.; Berlin-Heidelberg [HE, Hirzstein]

-Wedepohl, K. H.; Mengel, K. \& Oehm, J. (1984): Depleted mantle rocks and metasomatically altered peridotite inclusions in Tertiary basalts from the Hessian Depression (NW Germany). - In:

Kornprobst J. (ed.): Kimberlites II: The Mantle and Crust-Mantle Relationships. - Developments in Petrology 11 B (Proceedings of the "Third International Kimberlite Conference, Vol. II. - S. 191 201, 3 Fig., 2 Tabl.; (Elsevier) Amsterdam

[darin: Habichtswald]

- •Wedepohl, K. H.; Harmon, R.S. \& Hoefs, J. (1987): Stable isotope (O, H, S) relationships in Tertiary basalts and their mantle xenoliths from the Northern Hessian Depression, W.-Germany. Contrib. Mineral. Petrol., 95: 350-369, 8 fig., 6 tabl.; Berlin-Heidelberg [HE, NIE; Habichtswald]

-Wedepohl, Karl Hans \& Kramm, Ulrich (1990): Tertiary basalts and peridotite xenoliths form the Hessian Depression (NW Germany) reflecting mantle compositions low in radiogenic Nd and Sr. Contrib. Mineral. Petrol., 106: 1-8, 2 fig., 1 tabl.; Berlin-Heidelberg

[HE, Hirzstein]

-Wedepohl, Karl Hans \& Baumann, Albrecht (1999): Central European Cenozoic plume volcanism with OlB characteristics and indications of a lower mantle source. -Contrib. Mineral. Petrol, 136: 225239, 6 fig., 4 tabl.; Berlin-Heidelberg

[HE, Habichtswald]

- $\square$ Zinken, C. F. (1867): Die Braunkohle und ihre Verwendung. - Erster Theil: Die Physiographie der Braunkohle. - X, 818 S., Zchng., 3 Taf.; (Carl Rümpler) Hannover

[darin: umfassende Beschreibung der Vorkommen und Abbaue des nordhessischen

Braunkohlenreviers (Hessen-Cassel), ua. Hessische Senke, Reinhardswald, WMK; Lkr. Göttingen:

Steinberg b. Hann. Münden, Dransfeld]

[Ostheim/Habichtswald/Schimmberg u. Burgberg b.

Hoof/Stellberg/Möncheberg/Söhrewald/Lammsberg b.

Gudensberg/Meissner,/Hirschberg/Belgerskopf/Oberkaufungen/Steinberg N'Großalmerode,

Rommerode, Epterode, Romeberg b. Homburg, Frielendorf/Heiligenberg b.

Gensungen/Reinhardswald (Immenhausen, Hohenkirchen, Holzhausen, Ahlberg/Gottsbüren]

- $\square$ Zinken, C. F. (1871): Die Braunkohle und ihre Verwendung. - [Zweiter Theil:] Ergänzungen zu der Physiographie der Braunkohle. - 257 S., 6 Taf.; (Buchhdlg. d. Waisenhauses) Halle

[darin: Habichtswald, Meißner, Steinberg b. Großalmerode]

- $\square$ OZirkel, Ferdinand (1866): Lehrbuch der Petrographie. - [In zwei Bänden]. - Zweiter Band; 635 S:; (Adolph Marcus) Bonn.

[darin S. 273-321: Gesteine der Basalt-Familie. - Bezugn. a. Basalte i. Hessen, WMK, Thüringen; Chemischer Analysen Meißner-Basalt, Pflasterkaute; Kontaktmetamorphose Basalt/Buntsandstein:

Blaue Kuppe, Alpstein b. Sontra, Rosenbühl b. Eschwege-Niddawitzhausen; Pflasterkaute, Stoffelskuppe, Kupfergrube b. Hörschlitt; Intrusivverband m. Kalkstein: Ahnetal/Habichtswald, Basaltgang bei Hörschel(Thür.)]

- ${ }_{0}$ OZirkel, Ferdinand (1870): Untersuchungen über die mikroskopische Zusammensetzung und Structur der Basaltgesteine. - 208 S., 3 Taf.; (Marcus) Bonn 
[darin: Umgebung Kassel, Habichtswald; Dolerit Hoher Meißner, „Blaue Kuppe“ b. Eschwege; Pflasterkaute, Stoffelskuppe/Wartburgkreis; Rothweil i. Kaiserstuhl]

- $\square$ Zirkel, Ferdinand (1873): Die mikroskopische Beschaffenheit der Mineralien und Gesteine. Mit 205 Holzschnitten. - 502 S.; (Wilhelm Engelmann) Leipzig

[darin Kap. Feldspatbasalt, Anamesit, Dolerit: Nennung von Lokalitäten in Hessen, WMK, Lkr. Göttingen: Stillberg i. Habichtswald, Meissner, Dransberg u. Säsebühl b. Dransfeld]

\subsubsection{2 „Bühl“ bei Weimar (Gemeinde Ahnatal, Lkr. Kassel)}

- $\square$ • Apel, Jürgen \& Rüppel, Heidi [Verfass. u. Hrsg.] (2005): Raus in die Natur - Tipps für den Sonntags-Ausflug im Dreiländereck Hessen - Niedersachsen - Thüringen. - 159 S., 111 Fotos, 34 Kt., 1 Zeit-Taf.; (LSRB-Verlag, Landschaftskundlicher-Studien-Reisebuch-Verlag) Witzenhausen [zahlreiche Ausflugsziele, auch zu tertiären Vulkangebilden; Ziel 8 (Bühl b. Weimar/Ahnatal)]

-Eitel, W. (1920): Über das Vorkommen von Zinkblende im Basalt des Bühls bei Cassel. Mit teilweiscer Benutzung orientierender mikroskopischer Studien von W. Irmer. - Zbl. Mineral. etc.., 1920: 273 285, 6 Abb.; Stuttgart

-Eitel, Wilhelm (1920): - Studien über die Genesis der Einschlüsse des Bühlbasaltes - Über Pseudomorphosen von Magnetkies nach Pyrit im Basalt des Bühls bei Kassel. - In: Eitel, W.; Irmer, W. \& Velde, L.: Das Vorkommen tellurischen Eisens im Basalte des Bühls bei Kassel, seine Begleitmineralien und Genesis. - Abh. Senckenberg. Naturforsch. Ges., 37(2): 139-142, 5 Abb.; Frankfurt a. M. 1920

-Eitel, Wilhelm (1920): - Studien über die Genesis der Einschlüsse des Bühlbasaltes - Über die Magneteisenerzeinschlüsse des Bühlbasalts und ihre Herkunft. - In: Eitel, W.; Irmer, W. \& Velde, L.: Das Vorkommen tellurischen Eisens im Basalte des Bühls bei Kassel, seine Begleitmineralien und Genesis. - Abh. Senckenberg. Naturforsch. Ges., 37(2): 143-147, 3 Abb.; Frankfurt a. M. 1920

-Eitel, Wilhelm (1920): -Studien über die Genesis der Einschlüsse des Bühlbasaltes - Vergleichende Betrachtungen über die Natur des Ovifak- und des Bühleisens. - In: Eitel, W.; Irmer, W. \& Velde, L.: Das Vorkommen tellurischen Eisens im Basalte des Bühls bei Kassel, seine Begleitmineralien und Genesis. - Abh. Senckenberg. Naturforsch. Ges., 37(2): 148-151, 5 Abb.; Frankfurt a. M. 1920

-Eitel, Wilhelm (1920): - Studien über die Genesis der Einschlüsse des Bühlbasaltes - Über die genetischen Beziehungen des gediegenen Eisens im Bühlbasalt zu den im demselben vorkommenden Einschlüssen von Magnetkies und Magnetit. - In: Eitel, W.; Irmer, W. \& Velde, L.: Das Vorkommen tellurischen Eisens im Basalte des Bühls bei Kassel, seine Begleitmineralien und Genesis. - Abh. Senckenberg. Naturforsch. Ges., 37(2): 152-156, 5 Abb.; Frankfurt a. M. 1920

-Eitel, Wilhelm (1920): - Studien über die Genesis der Einschlüsse des Bühlbasaltes -Über die petrographische Beschaffenheit der vom Bühlbasalt durchsetzten Schichten und ihre Beziehung zu den Einschlüssen dieses Vorkommens. - In: Eitel, W.; Irmer, W. \& Velde, L.: Das Vorkommen tellurischen Eisens im Basalte des Bühls bei Kassel, seine Begleitmineralien und Genesis. - Abh.

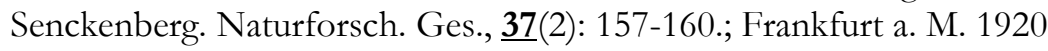

-Eitel, Wilhelm (1920): - Studien über die Genesis der Einschlüsse des Bühlbasaltes - Experimentelle Studien über die Bildung des Magnetkieses aus Pyrit bei höheren Temperaturen. - In: Eitel, W.; Irmer, W. \& Velde, L.: Das Vorkommen tellurischen Eisens im Basalte des Bühls bei Kassel, seine Begleitmineralien und Genesis. - Abh. Senckenberg. Naturforsch. Ges., 37(2): 161-165, 6 Abb.; Frankfurt a. M. 1920 [Bezugnahme a. d. Bühl-Basalt] 
-Eitel, Wilhelm (1920): - Studien über die Genesis der Einschlüsse des Bühlbasaltes - Über die experimentelle Nachbildung des Bühleisens. - In: Eitel, W.; Irmer, W. \& Velde, L.: Das Vorkommen tellurischen Eisens im Basalte des Bühls bei Kassel, seine Begleitmineralien und Genesis. - Abh. Senckenberg. Naturforsch. Ges., 37(2): 166-168, 4 Abb.; Frankfurt a. M. 1920

-Eitel, Wilhelm (1920): - Studien über die Genesis der Einschlüsse des Bühlbasaltes - Über das Vorkommen eines Sillimanitgraphitgesteins mit Umwandlungs-Pseudomorphosen von Spinell, Rutil und Enstatit nach Granat als pyrometamorphe Einschlüsse des Bühlbasalts. - In: Eitel, W.; Irmer, W. \& Velde, L.: Das Vorkommen tellurischen Eisens im Basalte des Bühls bei Kassel, seine

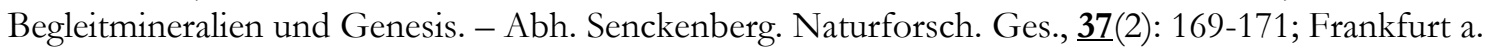
M. 1920

-Eitel, Wilhelm (1920): - Studien über die Genesis der Einschlüsse des Bühlbasaltes - Die Gasreaktionen im Bühlbasalt und ihre Rolle bei der Entstehung des gediegenen Eisens in dessen Einschlüssen. - In: Eitel, W.; Irmer, W. \& Velde, L.: Das Vorkommen tellurischen Eisens im Basalte des Bühls bei Kassel, seine Begleitmineralien und Genesis. - Abh. Senckenberg. Naturforsch. Ges., 37(2): 172-175, 1 Abb.; Frankfurt a. M. 1920

-Eitel, W.; Irmer, W. \& Velde, L. (1920): Das Vorkommen tellurischen Eisens im Basalte des Bühls bei Kassel, seine Begleitmineralien und Genesis. - Abh. Senckenberg. Naturforsch. Ges., 37(2); 175 S., 33 Abb., 12 Taf.; Frankfurt a. M.

Referat in: N. Jb. Mineral. etc., 1925 (Bd. I): 536-542 (Schlossmacher); Stuttgart

-Fromm, Otto (1891): Petrographische Untersuchungen von Basalten aus der Umgebung von Kassel . Z. dt. geol. Ges., 43 (1891): 43-76, 9 Abb.; Stuttgart

Referat in: N. Jb. Mineral. etc., 1892 (Bd. I): 277-278 (O. Mügge); Stuttgart

Referat in: Z. Naturwiss., 64: 164-167; Halle

[Habichtswald, Kaufunger Wald, Bühl. b. Ahnetal/Weimar Lkr. Kassel, Dörnberg u.a.]

-Hornstein, F. F. (1907): Kurze Mitteilung über das Basaltvorkommen vom Bühl bei Weimar, nordwestlich von Cassel, und seine Einschlüsse, insbesondere die von gediegenem Eisen. - Ber. Versamml. Niederrhein. Geol. Vereins, 1902 [1. Jg.]: 54-56; Bonn

- Irmer, Walter (1920): Der Basalt des Bühls bei Kassel und seine Einschlüsse von Magnetit, Magnetkies und gediegenem Eisen. In: Eitel, W.; Irmer, W. \& Velde, L.: Das Vorkommen tellurischen Eisens im Basalte des Bühls bei Kassel, seine Begleitmineralien und Genesis. - Abh. Senckenberg. Naturforsch. Ges., 37(2): 91-108, 4 Abb., 8 Taf. (Taf. IV-XI); Frankfurt a. M. 1920

-Möhl, Heinrich (1868): Der Bühl bei Weimar [Kassel/Ahnetal] in der Nähe von Kassel. Beitrag zur vulkanischen Entstehung basaltischer Gesteine. - Ber. Offenbacher Vereins Naturkde., 9: 61-80, 1 Abb.; Offenbach

-Möhl, Heinrich (1895): Das Ahnetal und der Bühl im Habichtswald. - Tourist. Mitth. a. bd. Hessen, $\underline{\mathbf{3}}$ (10): 115 - 120, 2 Abb.; Kassel

-Namenskürzel (h)(1969): Wertvoller Brocken mit Schnaps bezahlt - Reines Eisen nicht nur auf dem Mond, auch bei Kassel - Lockender Basalt. - HA, 1969; Nr. 270 v. 27.11.1969, 3 Abb.; Kassel [Bühl bei Weimar/Gemeinde Ahnatal b. Kassel]

-Naumann, Peter (1993): Der Bühl bei Weimar. - Mitt. Geol. Interessengemeinschaft Nordhessen (GIN), 2; 21 S., 5 Abb., 1 Tab.; (Selbstverlag Peter Naumann) Hofgeismar 1993 [Basalt-Vorkommen mit Gediegen-Eisen-Einsprenglingen]

- Ramdohr, Paul (1953): Maldonit - Neue Beobachtungen am Bühl-Eisen. - Sitzber. Dt. Akad. Wiss. z. Berlin, Kl. Math. u. allgem. Naturwiss., 1952(5); 24 S., 8 Taf.; (Akademie-Verlag) Berlin 
-Ramdohr, P. (1954): Klockmann’s Lehrbuch der Mineralogie. - 669 S., 687 Abb. u. Tab.; (Enke) Stuttgart

[Hinweis a. d. „Bühl bei Kassel“ als Fundort für tellurisches Eisen]

ه $\square$ Ritzkowski, S. \& Rösing, F. (1977): Tertiär Nordhessens - (Exkursion K) - In: Geol.-Paläont. Inst. u. Museum der Universität [Hrsg.]: Exkursionsführer - Geotagung '77 Göttingen - Band II : Nordhessen und Südniedersachsen (Exkursionen C - D - J - K - L). - S. 63-111, 16 Abb., 1 stratigr. Tab.; (Selbstverlag Geol.-paläont. Inst. Univ. Göttingen) Göttingen 1977 [darin: Borken, Verna, Obervorschütz, Knickhagen, Bühl b. Ahnatal/Weimar; Breitenbach, Hoof, Vollmarshausen, Glimmerode, Hoher Meissner]

- $\square \bullet$ Rosenbusch, Harry (1923): - Elemente der Gesteinslehre. Herausgeg. v. A. Osann. - 4., neu barb. Aufl.; 779 S., 115 Abb., zahlr. Tab.; (Schweizerbart) Stuttgart

[darin: S. 429 Hyalitbasalt d. Sababurg, Säsebühl b. Dransfeld; S. 430 Chem. Analyse Plagioklasbasalt Bühl b. [Ahnatal] Weimar; S. 434 Chem. Analyse Basalt Bramburg b. Adelebsen; S. 600 Chem.

Analyse Braunkohle Meißner]

D $\square$ Schneider, Alfred (1970): The sulfur isotope composition of basaltic rocks. - Contrib. Mineral. Petrol., 25: 95-124, 4 fig.l; Berlin-Heidelberg [darin: Bühl b. Weimar (Ahnetal b. Kassel); Hoher Meißner]

-Schwarz, M. von (1937): Gefügeausbildung der terrestrischen Eiseneinschlüsse im Basalt vom Bühl bei Kassel. - Zbl. Mineral. etc., Abt. A, 1937: 74-91, 16 Abb.; Stuttgart

-Velde, Luise (1920): Die silikatischen Einschlüsse im Basalt des Bühls bei Kassel. - In: Eitel, W.; Irmer, W. \& Velde, L.: Das Vorkommen tellurischen Eisens im Basalte des Bühls bei Kassel, seine Begleitmineralien und Genesis. - Abh. Senckenberg. Naturforsch. Ges., $\underline{\mathbf{3 7}}$ (2): 109-135, Taf. XII-XV (24 Abb.); Frankfurt a. M. 1920

\subsubsection{3 „Wolkenbrüche“ bei Trendelburg (Lkr. Kassel)}

-Bock, W. (1925): Der große Wolkenbruch bei Trendelburg. - Der Naturforscher, 2: 415-416; BerlinLichterfelde [Nicht in der Vorlage eingesehen, zitiert nach Herrmann (1972)]

-Bonnemann, Alfred (1984): Der Reinhardswald. - XI, 451 S.; 21 Abb., 90 Tab.; (Verlag d. Weserbuchhdlg) Hann.-Münden [darin S. 3 - 39: „Die geologischen Zeitalter“ (Erdgeschichte der Region), Abb. 1-7, 10 Tab.; darin S. - Die „Wolkenbrüche“ bei Trendelburg]

dDiestel, Walter (1930): Nachmittagswanderung im Diemeltal. - Die Weser, 9(7): 207-208, 1 Abb.; Bremen [darin: „Wolkenbrüche“ bei Trendelburg]

هHermann, Rudolf (1972): Über Erdfälle äußerst tiefen Ursprungs (Die „Wolkenbrüche“ bei Trendelburg und die „Meere“ bei Bad Pyrmont). - Notizbl. Hess. Landesamtes f. Bodenforsch., 100: 177-193, 5 Abb., 1 Taf.; Wiesbaden

-Herrmann, Rudolf (1972): Wie die „Wolkenbrüche“ bei Trendelburg entstanden sind. Heimatjahrbuch. f. d. Landkreis Hofgeismar, 1973: 76 - 79, 1 Abb.; Hofgeismar

-Herrmann, Rudolf (1972): Wie die „Wolkenbrüche“ bei Trendelburg entstanden sind. - Jb. Lkr. Kassel, 1973: (77 Bildseite +) 77-79, 1 Abb., Foto Bildseite 104; Wolfhagen 
-Kutscher, Fritz (1966): Angewandte Erdmagnetische Messungen in Hessen: 7. Erdmagnetische Messungen an den Wolkenbrüchen bei Trendelburg (Bl. 4422 Trendelburg, Hessen). - Notizbl. Hess. L.-A. Bodenforsch., 94: 394 - 397, 1 Abb.; Wiesbaden

-Linstow, O. v. (1929): Salzlager, Solquellen und Erdfälle in dem Gebiet zwischen Kassel und Karlshafen. - Kali, etc., $\underline{23}(4): 54-56$

$\underline{23}(5): 71-74$

23$(6): 86-88$, mehr. Fig.; Halle/Saale

Referat in: N. Jb. Mineral. etc., Referate, 1931 (Bd. III): 135 (A. Bentz); Stuttgart

[darin: Wolkenbrüche b. Trendelburg; Solquelle Kassel-Wilhelmshöhe]

oLohmann, Hans Heinrich (1962): Zur Formentwicklung von Salzauslaugungstrichtern. - Notizbl. Hess. L.-A. Bodenforsch., 90: 319-326, 2 Abb., Taf. 31; Wiesbaden

[darin: „Wolkenbrüche“ (Nördlicher Reinhardswald)]

-Namenskürzel (j) (1988): „Die Wolkenbrüche“ bei Trendelburg. Hohlräume bis in große Tiefen. HNA, 1988, v. 25.2.1988; Kassel

-Naumann, Peter (1994): Der „Große Wolkenbruch“ bei Trendelburg. - Mitt. Geol. Interessengemeinschaft Nordhessen (GIN), $\underline{5} ; 34$ S., 3 Abb., 1 Tab.; (Selbstverlag Peter Naumann) Hofgeismar

-Plaumann, Siegfried \& Lepper, Jochen (1980): Gravimetrische Untersuchungen an Erdfällen im Reinhardswald und Solling. - Geol. Jb. Hessen, 107 (f. 1979): 251-259, 6 Abb.; Wiesbaden [Untersuchungen u.a.: (Kleiner) "Trockener" und (Großer) "Nasser Wolkenbruch" E' Trendelburg]

-Redemann, Emil (1957): Der große Wolkenbruch. - Heimatjahrbuch. f. d. Landkreis Hofgeismar, 1958: 66 - 68, 1 Abb.; Hofgeismar

[Erdfälle „Großer und Kleiner Wolkenbruch“ bei Trendelburg]

- $\square$ Schmitt, Gerhard E. (1990): Naturkundliche Wanderungen in Hessen. - 158 S., 62 Abb., Kt.; (Hitzeroth) Marburg

[Darin: Werra-Meißner-Kreis; Blaue Kuppe, Erdfalltrichter „Wolkenbrüche“ bei Trendelburg]

\subsubsection{Steinbruch Cornberg}

-Anonym (1990): Saurierfährten im Cornberger Sandstein. - Hersfeld-Rotenburg - Heimatkalender u. Wegweiser, $\underline{34}$ (1990): 170-173, 3 Abb.; Bad Hersfeld

- $\square$ •Ө Apel, Jürgen \& Rüppel, Heidi [Verfass. u. Hrsg.] (2005): Raus in die Natur - Tipps für den Sonntags-Ausflug im Dreiländereck Hessen - Niedersachsen - Thüringen. - 159 S., 111 Fotos, 34 Kt., 1 Zeit-Taf.; (LSRB-Verlag, Landschaftskundlicher-Studien-Reisebuch-Verlag) Witzenhausen [zahlreiche Ausflugstipps, auch zu Geotopen, Ziel 93: Steinbruch Cornberg]

-Boy, Jürgen A. \& Fichter, Jürgen (1988): Ist die stratigraphische Verbreitung der Tetrapodenfährten im Rotliegend ökologisch beinflußt?. - Z. geol. Wiss., 16(9): 877-883, 2 Abb.; Berlin [Bezugnahme a. Cornberger Sandstein]

- $\square$ Brandes, Theodor (1912): Sandiger Zechstein am alten Gebirge an der unteren Werra und Fulda und die Kontinuität des Landwerdens in Mitteldeutschland. - Zbl. Mineral., Geol. etc., 1912: 660-671, 1 
Abb.; Stuttgart

[darin: Höllental b. Albungen, Gelsterbachtal, Cornberg]

-Credé, Heinrich (1959): Der Cornberger Sandstein. - Das Werraland, $\underline{11}(4): 58-59,1$ Abb.; Eschwege

- $\square$ Dersch-Hansmann, Michaela [Mitautorin] (1999): Geotope in Hessen. - In: Hoppe, Andreas \& Steininger, Fritz [Hrsg.]: Exkursionen zu Geopten in Hessen und Rheinland-Pfalz sowie zur naturwissenschaftlichen Beobachtungspunkten Johann Wolfgang von Goethes in Böhmen. Schriftenreihe Dt. Geol. Ges., $\underline{8}$ (Kleine Senckenberg Reihe, 31); 252 S., zahlr. Abb. S. 69-126, 43 Abb.; (Deutsche Geologische Gesellschaft) Hannover 1999 [darin: Haltepunkt 7 Blaue Kuppe, Hp. Höllental/Schmelzhütte, Hp. 9 Frankershausen/Stbr. Schafhof, Hp. 10 Hoher Meißner/Kalbe, Hp. 11 Kitzkammer, Hp. Cornberg]

-Fichter, Jürgen (1987): Zum Bearbeitungsstand der Cornberger Tetrapodenfährten-Fauna und zur Frage der Alterseinstufung des Cornberger Sandsteins. [Vortragszusammenfassung]. - In: Klare, Bernd \& Schröder, Bernd (eds.): Zechstein 1987 - International Symposium Kassel/Hannover [28. April to 9. May, 1987] - Abstracts, Posters, Program; S. 31; [Subkommission Perm/Trias der Stratigraphischen Kommission der DUGW/IUGS] Bochum 1987

-Fichter, Jürgen (1994): Permische Saurierfährten - ein Diskussionsbeitrag zu der Bearbeitungsproblematik der Tetrapodenfährten des Cornberger Sandsteins (Perm, Deutschland) und des Cocino Sandsteins (Perm, USA). - Philippia, 7(1): 61-82, 22 Abb.; Kassel

-Fichter, Jürgen (1995): Ein Versuch zur Berechnung der Laufleistungen aus jungpaläozoischen Saurierfährten - dargelegt am Beispiel der Fährten des Cornberger Sandsteins (Perm, Deutschland). Philippia, 7(3): 223-228, 4 Abb.; Kassel

-Fichter, Jürgen (1999): Interessenate Aspekte der Wirbeltierichnologie - dargestellt an permischen und triassischen Saurierfährten. - In: Hoppe, Andreas \& Apel, Heinrich [Hrsg.]: Geotope - lesbare Archive der Erdgeschichte. 151. Hauptvers. Dt. Geol. Ges. 02.10.99 - 10.10.99 Wiesbaden Kurzfassungen der Vorträge und Poster. - Schriftenreihe Dt. Geol. Ges., 7, 115 S.; hier: S. 38; (Deutsche Geologische Gesellschaft) Hannover 1999

[Vortraqszusammenfassung; Bezug auf Fährten im Cornberger Sandstein]

-Gast, Reinhard E. (1992): Cornberg outcrop revistet (Hessen, Germany) - The depositional environments of its saurian tracks and Weissliegendes sandstones - Die Cornberg-Aufschüsse neu interpretiert (Hessen): Das sedimentäre Ablagerungsmillieu der Saurierfährten und der WeissliegendSandsteine. - Meyniana, 46: 59-75, 3 Abb., 7 Taf.; Kiel

- 0 Haubold, Hartmut (1996): Ichnotaxonomie und Klassifikation von Tetrapodenfährten aus dem Perm. - Hallesches Jb. Geowiss., B 18: 23-88, 36 Abb., 8 Tab.; Halle (Saale)

[Tambach; Cornberg, Kr. Hersfeld-Rotenburg]

-Keller, Thomas (1997): Der Cornberger Sandstein - Paläontologie einer Fährtenfundstelle des Erdaltertums im Landkreis Hersfeld-Rotenburg. - Paläontologische Denkmäler i. Hessen, $\underline{\mathbf{5}}$; 14 S., Abb.; [Hsrg. Abt. Archäologie u. Paläontologische Denkmalpflege i. Landesamt f. Denkmalpflege Hessen, Archäologische Gesellschaft in Hessen e.V.] Wiesbaden

- Klingner, Fritz-Erdmann (1928): Bemerkungen zu einer Fährtenplatte aus dem Cornberger Sandstein. - Zbl. Mineral. etc., Abt. B, 1928: 641 - 646, 1 Abb.; Stuttgart

- $\square$ Kulick, Jens (1987): Zechsteinaufschlüsse in der Hessischen Senke und am westlichen Harzrand. Exkursionsführer International Zechstein Symposium Kassel/Hannover [28. April to 9.May 1987], 2 Exkursionen D, E, F, L, M; 309 S, Ill, graph. Darst., Kt.; Wiesbaden

[Stop D9: Naturkundemuseum Ottoneum/Kassel: Fährten des Cornberger Sandsteins (S. 72-79); D10 Schwerspatgrube Münden/Nentershausen, D11 Stbr. Cornberg, D18-D28 (Zechstein im Werra- 
Grauwackengebirge): Albungen, Jestädt, Reichensachsen/Weinberg, Oberhohne, Höllental/Schmelzhütte, Frankershausen/Schafhof, Hundelshausen, Witzenhausen-Papierfabrik]

-Ludwig, Willi (1987): Der Name Artur Milde ist untrennbar mit den Cornberger Fährtenplatten verbunden. - Kreis Hersfeld-Rotenburg - Heimatkalender 1987 u. Wegweiser ( $\underline{\mathbf{3 1}}$. Jg. ): 107 - 109, 2 Abb.; Bad Hersfeld

- $\bigcirc M e i n e c k e$, Franz (1913): Das Liegende des Kupferschiefers. - Jb. Preuß. Geol. Landesanst., $\underline{31}$ (Teil II) (f. 1910): 253-296, 4 Abb., 1 Taf.) Berlin [darin: Cornberger Sandstein]

- $\square$ Michel, H. (1939): Das Gesicht der niederhessischen Landschaft (Die physische Landschaft). Hessischer Gebirgsbote, 45(2): 22 - 26, 12 Abb.; Melsungen [Fotos: Todstein b. Abterode, Sandsteinbruch Cornberg, Weinberg/Kassel u.a.]

-Möller, Hans-Karl (1993): Auf den Spuren des Bergbaus in und um Cornberg. - In: HersfeldRotenburg - Heimatkalender d. Landkreises Hersfeld-Rotenburg 1993 und Wegweiser (ㅍ․ Jg.): 162166; Bad Hersfeld

-Mühlhausen, Fritz (1962): Kasseler Naturkundemuseum erwarb Cornberger Fährtenplatten. Hessischer Gebirgsbote, $\underline{\mathbf{6 3}}(3): 35$ - 36, 2 Abb.; Melsungen [Chirotherienfährten a. d. Cornberger Sandstein]

-Müller, German (1967): Sudoit („dioktaedrischer Chlorit“, „Al-Chlorit“) im Cornberger Sandstein von Cornberg/Hessen. - Contrib. Mineral. Petrol., 14: 176-189, 5 Abb., 5 Tab.; Berlin-Heidelberg

-Munk, Wolfgang; Martin, Oliver \& Trunkó, Lásló (1993): Neue Aspekte zur stratigraphischen und faziellen Bewertung des Cornberger Sandsteins (Tatarium, Oberperm) mit Beschreibung erstmaliger Pflanzenfunde. - Geol. Jb. Hessen, 121: 17-40, 14 Abb., 2 Tab.; Wiesbaden

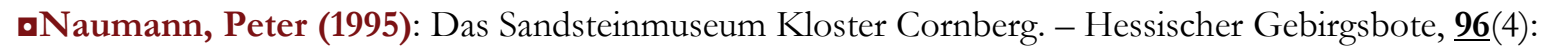
169; Melsungen

- $\square$ Pryor, Wayne A. (1971): Petrology of the Weißliegendes in the Werra-Fulda areas, Germany. - Geol. Rundschau, 60: 524-552, 13 Abb., 3 Tab.; Stuttgart [darin: Cornberg, Stbr. Forsthaus Schmelzhütte b. Frankershausen]

oProbst, Ernst (1986): Deutschland in der Urzeit - Von der Entstehung des Lebens bis zum Ende der Eiszeit. - 479 S., zahlr. Abb.; (Bertelsmann) München [darin: Fossilfunde Richelsdorfer Gebirge, Cornberger Sandstein, Cornberg/Kr. Hersfeld-Rotenburg]

-Richter-Bernburg, Gerhard (1987): Das sogenannte Zechsteinkonglomerat und die Grenze Rotliegend/Zechstein. - Geol. Jb. Hessen, 115: 117-129, 7 Abb.; Wiesbaden [darin: Cornberg]

aSchaumberg, Günther (1982): Paläozoische Reptilien in Nordhessen. - Philippia, $\underline{\mathbf{5}}$ (1): 3 - 10, 5 Abb.; Kassel [Fossilfunde Richelsdorfer Kupferschiefer, Cornberger Sandstein]

oSchmidt, Hermann (1952): Neubeschreibung und Deutung einer Fährtenplatte aus dem Cornberger Sandstsein (Perm). - Paläont. Z., 25 (3/4): 193-197, 2 Abb.; Stuttgart

oSchmidt, Hermann (1953): Reptilfährten aus dem permischen Cornberger Sandstein $<$ Vortragskurzfassung > - Paläont. Z., 27(1/2): 9; Stuttgart

aSchmidt, Hermann (1956): Versteinerte Saurierfährten im Cornberger Sandstein. - Hessische Heimat, N.F., $\underline{\mathbf{5}}$ [f. 1955/56](3): 19-21, Abb. 16-18; Marburg/L. 
aSchmidt, Hermann (1958): Cornberger Fährten melden sechs Reptil-Ordnungen $<$ Vortragskurzfassung >. - Paläont. Z., $\underline{\mathbf{3 2}}(1 / 2)$ : 4; Stuttgart

aSchmidt, Hermann (1959): Die Cornberger Fährten im Rahmen der Vierfüßler-Entwicklung. - Abh. Hess. L.-A. Bodenforsch., 28 137 S., 57 Abb., 9 Taf.; Wiesbaden Referat in: Mein Heimatland, 19(18): 72, 1 Abb. (Besch, Wulf); Bad Hersfeld

oSchmidt, Hermann (1962): Gemeinsame Ganztagsexkursion nach Rotenburg/Fulda und in das Richelsdorfer Gebirge am 26. Mai 1961 (Geologischer Bericht). - (Übergeordn. Titel: Bericht über die Exkursionen während der Tagung des Naturhistorischen Vereins der Rheinlande und Westfalens vom 23. - 26. Mai 1961 in Kassel). - Decheniana - Verhdlgn. Naturhist. Vereins Rheinlande u. Westfalens, 114 (f. 1961): 202; Bonn

- $\square$ Straub, August (1969): Nordhessen: Das Bergland von Niederhessen - Landschaft, Geschichte, Kultur, Kunst, Wirtschaft. - 352 S., zahlr. Abb.; (Glock u. Lutz) Nürnberg

[darin auch Informationen zur Geologie: Steinbruch Cornberg, Habichtswald, Knüll, Meißner, Reinhardswald, Richelsdorfer Gebirge, Ringgau,]

- $\square \bullet$ Wedepohl, Karl Hans \& Ritzkowski, S. (1980): [DMG-Tagung 1980] Exkursion E 1: Die nördliche Hessische Senke (Tertiär-Vulkanite, Kupferschiefer und variszischer Spilit). - Fortschr. Mineral., $\underline{\mathbf{5 8}}$, Beih. 2 (Einführung zu den Exkursionen anläßlich der 58. Jahrestagung der Deutschen Mineralogischen Gesellschaft in Göttingen 1980): 3-33, 2 Abb., 3 Tab.; Stuttgart [darin Hp: Werra-Meissner-Kreis: Blaue Kuppe, Bilstein, Cornberg, Forsths. Schmelzhütte, Hoher Meissner/Kalbe, Hoher Meissner/Kitzkammer; auch Hoher Hagen/Dransfeld, Westberg/Hofgeismar, Dörnberg/Zierenberg; Güntersberg b. Gudensberg, Isthaburg b. Istha, Steppling b. Homberg/Efze]

\subsubsection{Richelsdorfer Gebirge (Landkreis Hersfeld-Rotenburg)}

\subsection{Geologie}

-Beche, Henry T. de la (1830): Sections \& views illustrative of geological phaenomena. - VIII, 71 p., 40 pl.; (Treuttel \& Würtz) London, Paris \& Strasburgh [darin: Taf. XXCIII, Fig. 4 Stratigr. Profil Zechstein/Rotliegend Richelsdorfer Gebirge („Riegelsdorf'); Erläuterungen der Tafel S. 46-49]

- Bein, Georg (1932): Die Stellung des Richelsdorfer Gebirges zum Thüringer Walde und Rheinischen Schiefergebirge. - Z. dt. Geol. Ges., 4ㅗ 786 - 829, 8 Abb., Taf. 25-27; Berlin - zgl. Diss. Univ. Berlin 1932

- $\square$ Beyrich, Franz \& Moesta, Friedrich (1876): Erläuterungen zur Geologischen Specialkarte von Preussen und den Thüringischen Staaten - [Lieferung 8] - Blatt Sontra [4925 Sontra]; 25 S., 2 geol. Profile a. Taf. ; Berlin 1876

Ohne Hrsg.: d. i. Königlich Preußische Geologische Landesanstalt und Bergakademie; Berlin

-Brinkmann, Roland (1948): Die Mitteldeutsche Schwelle. - Geol. Rundschau, $\underline{\text { 36: }} 56$ - 66, 2 Abb.; Stuttgart

[Bezugnahme auf das Richelsdorfer Gebirge]

- DDachroth, Wolfgang (1988): Gesteinsmagnetischer Vergleich permischer Schichtfolgen im Mitteleuropa. - Z. geol. Wiss., 16(10): 959-968, 9 Abb.; Berlin [darin: Richelsdorfer Gebirge] 
- 00 Dietrich, Martin (1965): Fazies und Paläogeographie des Jungpaläozoikums und der unteren Glieder der Werra-Serie im Werra-Fulda-Becken und seinen Randgebieten - (Vorträge 16. Treffen des Fachverbandes Mineralogie d. Geol. Ges. i. d. DDR - 2.-4. April 1964 in Eisleben). - Freiberger Forschungshefte, Reihe C, 193: 55-81, 6 Abb.; Leipzig [Thüringen, Werra-Meißner-Kreis, Richelsdorfer Gebirge]

- $\square$ Frick, Friedrich (1969): Feinstratigraphie und mikrofazielle Untersuchungen im Plattendolomit (Ca 3 Leine-Serie) des nordosthessischen Zechsteins. - Diss. TH Aachen [unveröff.] 1969; 106 S. [Umrandung Unterwerra-Grauwackengebirge, Baumbacher Hoch W’Rotenburg/Fulda; Richelsdorfer Gebirge]

- $\square$ OGeinitz, Hanns Bruno (1861/1862): Dyas oder die Zechsteinformation und das Rothliegende. - H. I - Die animalischen Überreste der Dyas. - XVIII, S. 1-130, Taf. 1- 23; Leipzig (Engelmann) 1861; H. II - Die Pflanzen der Dyas und Geologisches. - VIII, S. 131 - 342, Taf. 24-52; (Engelmann) Leipzig [darin: Thüringer Wald, Thüringer Becken, Nordhessen, u.a. Richelsdorfer Gebirge; S. 268-270 „Zechsteinformation an der Werra bei Witzenhausen und Allendorf"]

-Geinitz, Hanns Bruno (1886): Zur Dyas in Hessen. - Festschrift Vereins Naturkde. z. Cassel- zur Feier seines fünfzigjährigen Bestehens. - S. 250 - 256, 1 Taf.; (Döll) Kassel 1886

[darin: Richelsdorfer Gebirge und Fossilieninventar des Kupferschiefers]

-Hartmann, Carl (1822): Atlas zu des Herrn von Villefosse Mineral-Reichthum, Sammlung geognostischer und technischer Beobachtungen welche den jetztigen Zustand der Bergbau- und Hüttenkunde durch von den besten Etablissements entlehnten Beyspielen darthun, und sie mit Hülfe der geometrischen Darstellung verdeutlichen. - 40 Taf.; Sondershausen [darin: Profil Zechstein/Rotliegendes Richelsdorfer Gebirge]

-Héron de Villefosse, Antoine Marie (1819): De la richesse minérale. Considérations sur les mines, usines et salines des différens états, présentées comparativement. - Avec un Atlas in-folio de 65 planches. - Tome second : Division technique (1.re et II.e parties). - XVI, 559 p.; (Impimerie royale) Paris - [Insgesamt drei Bände u. Atlas-Band in Folio-Format] [darin S. 405-406: Erläuterung Stratigraphisches Profil Zechstein/Rotliegend Richelsdorfer Gebirge]

-Héron de Villefosse, A. M. (1819): Atlas de la Richesse minérale. Recueil de faits géognostiques et de faits industriels, constatant l'état actuel de l'art des mines et usinses, par des exemples authentiques, tirés de célébres établissements, et rendus sensibles à l'oeuil, au moyen de la représentation géométrique des objects. - 63 planches; Paris [darin: Stratigraphisches Profil Zechstein/Rotliegendes Richelsdorfer Gebirge]

- 0 Hofmann, Friedrich (1830): Uebersicht der orographsichen und geognostischen Verhältnisse vom nordwestlichen Deutschland. - 2 Abth. i.e. Bd., XXIV, 676 S., 3 Taf. (i. sep. Quartbd.); (Barth) Leipzig

[1. Abth.: Orographische Übersicht; darin: Thüringer Wald, Hügelland zw. Harz u. Thür. Wald, Hügelland in den Umgebungen des oberen Leinethales, in Hessen .... - 2. Abth.: Geognostische Übersicht: darin: Bezugnahme auf Rotliegendes im Thüringer Wald, Richelsdorfer Gebirge]

- $\square$ OJordan, Johann Ludwig (1803): Mineralogische, berg- und hüttenmännische Reisebemerkungen vorzüglich in Hessen, Thüringen, am Rheine und im Seyn-Altenkirchner Gebiethe. - 288 S., 1 Tab., 3 Falt-Taf.; (Dieterich) Göttingen

[Regionalgeologie östl. Meißnervorland, „Riegelsdorfer“ [Richelsdorfer] Gebirge, Region um Schmalkalden]

- 0 Kühne, Friedrich (1923): Die palaeogeographische Entwicklung der Saar-Saale-Senke. - Jb. Preuß. Geol. Landesanst., $\underline{43}$ (f. 1922): 426-456, 1 Abb., 3 Taf. (6-8); Berlin [darin: Richelsdorfer Gebirge; Taf. 7 - Geol. Kt.Skizze] 
- $\square$ Koritnig, Sigmund (1952): Exkursion im Richelsdorfer Gebirge und zur Blauen Kuppe bei Eschwege. - Fortschr. Mineral., 29/30 (f. 1950/51): 94-100; Stuttgart

- $\square$ Kulick, Jens (1987): Exkursion M: Der über Tage anstehende Zechstein in Hessen. In: Kulick, Jens: Zechsteinaufschlüsse in der Hessischen Senke und am westlichen Harzrand. - Exkursionsführer International Zechstein Symposium Kassel/Hannover [28. April to 9.May 1987], 2 -Exkursionen D, E, F, L, M; 309 S, Ill,, graph. Darst., Kt.; Wiesbaden 1987

[Stop D9: Naturkundemuseum Ottoneum/Kassel: Fährten des Cornberger Sandsteins (S. 72-79); D10 Schwerspatgrube Münden/Nentershausen, D11 Stbr. Cornberg, D18-D28 (Zechstein im WerraGrauwackengebirge): Albungen, Jestädt, Reichensachsen/Weinberg, Oberhone, Höllental/Schmelzhütte, Frankershausen/Schafhof, Hundelshausen, Witzenhausen-Papierfabrik]

- $\square$ Lepsius, Richard (1887 - 1892): Geologie von Deutschland und den angrenzenden Gebieten. Erster Teil: Das westliche und südliche Deutschland. - Reihe: Handbücher zur Deutschen Landes- und Volkskunde, Bd. 1; XIV, 800 S., 136 Abb., 5 Falt-Taf.; in 3 Lfgn., 1.1887, 2.1889, 3.1892; (J. Engelhorn) Stuttgart [darin S. 402 Richelsdorfer Gebirge; S. 758-766 Kap.: „Basalte in nördlichen Teil des hessischen Waldgebirges (Knüll, Habichtswald, Reinhardswald, Kaufunger Wald und Meissner)“; S. 761 - 766 Petrographie, Geologie und Erforschungsgeschichte des Meißner-Basaltes)

S., 165 Abb. i. T. u. a. Taf., 13 Tab. a. 7 Beil., (insges. 31 Beil.); (Enke) Stuttgart [darin: „Die Paläozoikumsaufbrüche in der Hesssichen Senke“ u.a. Richelsdorfer Gebirge, Hessische Senke, Thüringer Becken, „Südhannoversches Bergland“, Schwarzwald, Vogesen, Oberrheingraben]

-OMoesta, Friedrich (1876): Erläuterungen zur Geologischen Specialkarte von Preussen und den Thüringischen Staaten. - [Ohne Lieferungsangabe, d.i. Lfg. 8] - Blatt Hönebach - Gradabth. 69, B1. 4; [ heute: 5025 Hönebach]. - 23 S., Anh. (Profile); (Verlag der Neumann’schen Kartenhandlung) Berlin 1876

Ohne Hrsg.: d.i. Königlich Preußische Geologische Landesanstalt und Bergakademie; Berlin Dazugehörige Karte herausgegeben 1872

- $\square$ Motzka-Nöhring, Renate (1987): Erläuterungen zur Geologischen Karte von Hessen $1: 25$ 0000, Blatt 4925 Sontra. - 2. Auflage, 296 S., 91 Abb., 14 Tab., 6 Taf., 1 Beil.; Wiesbaden 1987 Hrsg.: Hessisches Landesamt f. Bodenforschung; Wiesbaden

-Oppermann, S. A. (1970): Das Rotliegende des Richelsdorfer Gebirges. - Dipl.-Arb. [unveröff.] Univ. Mainz 1970; 63 S., 15 Abb., 1 Taf., 1 Kt.

-Oppermann, S. A. (1971): Die Zechstein-Basissedimente des Richelsdorfer Gebirges. - Abh. hess. L.A. Bodenforsch., 60: 283-287, 1 Abb.; Wiesbaden

-Paul, Josef (2006): Der Kupferschiefer: Lithologie, Stratigraphie, Fazies und Metallogenese eines Schwarzschiefers. - Z. dt. geol. Ges., 157(1): 57-76, 7 Abb., 1 Tab.; Hannover [darin: Richelsdorfer Gebirge, auch Paläontologie]

-Richter [-Bernburg], Gerhard (1941): Paläogeographie und tektonische Stellung des Richelsdorfer Gebirges im Hessischen Raume. - Jb. Reichsstelle f. Bodenforsch., 61 (f. 1940): 283 - 332, 19 Abb., Taf. 23 -25; Berlin

-Schmidt, Hermann (1962): Gemeinsame Ganztagsexkursion nach Rotenburg/Fulda und in das Richelsdorfer Gebirge am 26. Mia 1961 (Geologischer Bericht). - (Übergeordn. Titel: Bericht über die Exkursionen während der Tagung des Naturhistorischen Vereins der Rheinlande und Westfalens vom 23. - 26. Mai 1961 in Kassel). - Decheniana - Verhdlgn. Naturhist. Vereins Rheinlande u. Westfalens, $\underline{114}$ (f. 1961): 202; Bonn 
- Schumacher, Claus (1985): Die Grenze Rotliegendes/Zechstein im Werra-Fulda-Becken. - Z. dt. geol. Ges., 136: 121-128, 3 Abb.; Hannover

[Richelsdorfer Gebirge, Raum Sontra]

aStier, G, (1974): Das Perm des westlichen Richelsdorfer Gebirges und geologische Kartierung im Nordwestteil der TK 25 Hönebach. - Dipl-Arb. [unveröff.] Univ. Frankfurt; 245 S-. 26 Abb., 15 Tab., 3 Kt., 5 Profile

- $\square$ Straub, August (1969): Nordhessen: Das Bergland von Niederhessen - Landschaft, Geschichte, Kultur, Kunst, Wirtschaft. - 352 S., zahlr. Abb.; (Glock u. Lutz) Nürnberg [darin auch Informationen zur Geologie: Steinbruch Cornberg, Habichtswald, Knüll, Meißner, Reinhardswald, Richelsdorfer Gebirge, Ringgau,]

- $\square$ OVoigt, Joh. Carl. Wilh. (1797): Practische Gebirgskunde. - 2., verm. Aufl.; XVI, 286 S. [1 Bl.]; (Industrie-Comptoir) Weimar [darin: S. 128 Rotliegend-Sandstein bei Eisenach; S. 159 Profilbeschr. Zechstein/Rotliegend Richelsdorfer Gebirge, S. 173, 174, 178,179,205 Meissner; S. 193 Vulcanische Brekkzie Weißenstein/Wilhelhmshöhe b. Kassel]

\subsection{Paläontologie}

-Althaus, J. (1851): Ueber einige neue Pflanzen aus dem Kupferschiefer von Richelsdorf. Palaeontographica, 1 (1.Lfg.): 30 - 33, Taf. 4, Tab.1 (Fig. 2); Kassel

-Bendix - Almgreen, Svend \& Malzahn, Erich (1969): Über neue oder wenig bekannte Elasmobranchier aus dem deutschen Kupferschiefer. - Notizbl. Hess. L.-A. Bodenforsch., 97: 44 - 45; Wiesbaden [Richelsdorfer Gebirge]

-Hochberger, Klaus (1997): Aktueller Fossilienfund aus dem Kupferschiefer von Richelsdorf (Nordhessen) oder die Suche nach dem Flugsaurier. - Mein Heimatland, 37(22a): 145-148, 37(22b): 149-152, 37(23): 153-156; Ill.; Bad Hersfeld

-Hochberger, Klaus (1999): Fossilfunde im Richelsdorfer Kupferschiefer - Sammlung Hochberger, Bad Hersfeld, Teil 1. - Philippia, 9(2): 151-164; Ill., graph. Darst; Kassel

-Hochberger, Klaus (2002): Fossilfunde im Richelsdorfer Kupferschiefer - Sammlung Hochberger, Bad Hersfeld, Teil 2. - Philippia, 10 (2): 147-156, 9 Abb.; Kassel

-Keller, Thomas (1997): Der Richelsdorfer Kupferschiefer: Fauna und Flora eines paläozoischen Schwarzschiefers im Landkreis Rotenburg/Fulda[!]. - Paläontologische Denkmäler in Hessen, 4 ; 16 S.; [Hsrg. Abt. Archäologie u. Paläontologische Denkmalpflege i. Landesamt f. Denkmalpflege Hessen, Archäologische Gesellschaft in Hessen e.V.] Wiesbaden

-Malzahn, Erich (1972): Zur Kenntnis des Kopfskeletts von Janassa bitumonosa (SCHLOTH) aus dem hessischen Kupferschiefer. - Geol. Jb., 90: 431-440, 2 Taf. (19 u. 20); Hannover [Fundort: Brodberg b. Sontra, Fundherkunft: Richelsdorfer Gebirge]

-Paul, Josef (2006): Der Kupferschiefer: Lithologie, Stratigraphie, Fazies und Metallogenese eines Schwarzschiefers. - Z. dt. geol. Ges., 157(1): 57-76, 7 Abb., 1 Tab.; Hannover [darin: Richelsdorfer Gebirge, auch Paläontologie] 
-Probst, Ernst (1986): Deutschland in der Urzeit - Von der Entstehung des Lebens bis zum Ende der Eiszeit. - 479 S., zahlr. Abb.; (Bertelsmann) München

[darin: Fossilfunde Richelsdorfer Gebirge, Cornberger Sandstein, Cornberg/Kr. Hersfeld-Rotenburg]

-Schaumberg, Günther (1970): Auf den Spuren der „Sintflut“ im Richelsdorfer Gebirge. - Der Aufschluss, 21: 259-265, 8 Abb.; Göttingen

هSchaumberg, Günther (1976): Über ein gut erhaltenes dermales Schädeldach von Platysomus striatus AGASSIZ (Palaeonisciformes, Actynopterygii, Osteichthyes) aus dem Kupferschiefer von Richelsdorf (Perm, Hessen). - Geol. Jb. Hessen, 104: 39-42, 2 Abb.; Wiesbaden.

هSchaumberg, Günther (1976): Zwei Reptilneufunde (Weigeltisaurus KUHN (?), Lepidosauria (?), Reptilia) aus dem Kupferschiefer von Richelsdorf (Perm, Hessen). - Philippia, $\underline{\mathbf{3}}(1)$ : 3-8, 4 Abb.; Kassel.

- SSchaumberg, Günther (1977): Der Richelsdorfer Kupferschiefer und seine Fossilien - I. Bergbautätigkeit, Genese und Erforschungsgeschichte des Kupferschiefers. - Der Aufschluss, 28: 81104, 10 Abb.; Heidelberg

oSchaumberg, Günther (1977): Der Richelsdorfer Kupferschiefer und seine Fossilien - II. Die tierischen Fossilien des Kupferschiefers. 1. Invertebraten. - Der Aufschluss, 28 189-198, 8 Abb.; Heidelberg

-Schaumberg, Günther (1977): Der Richelsdorfer Kupferschiefer und seine Fossilien - III. Die tierischen Fossilien des Kupferschiefers. Vertebraten- Der Aufschluss, 28: 297-352, 42 Abb.; Heidelberg

هSchaumberg, Günther (1977): Der Richelsdorfer Kupferschiefer und seine Fossilien - IV. Die pflanzlichen Fossilien des Kupferschiefers, sonstige Lebensspuren, Aufrechnung der Fundhäufigkeit. - Der Aufschluss, 28: 427-442, 16 Abb.; Heidelberg

-Schaumberg, Günther (1977): Erster Nachweis von Elonichthus punctatus ALDINGER (Palaeonisciformes, Actinopterygii, Osteichthyes) in Mitteleuropa, im Kupferschiefer von Richelsdorf (Perm, Hessen). - Geol. Jb. Hessen, 105: 65-68, Taf. 13-14; Wiesbaden

-Schaumberg, Günther (1978): Neubeschreibung von Coelacanthus granulatus AGASSIZ (Actinistica,

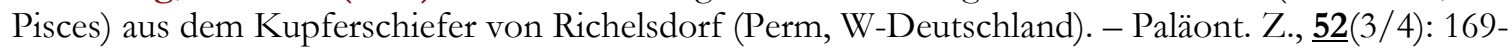
197, 21 Abb:; Stuttgart

aSchaumberg, Günther (1979): Neue Nachweise von Bryozoen und Brachiopoden als Nahrung des permischen Holocephalen Janassa bituminosa (SCHLOTHEIM). - Philippial, 4(1): 3 - 11, 4 Abb.; Kassel

[Neufunde a. d. Richelsdorfer Kupferschiefer]

-Schaumberg, Günther (1979): Neue Kenntnisse über die Anatomie von Janessa bituminosa (SCHLOTHEIM), Holocephali, Chondrichthyes aus dem permischen Kupferschiefer. - Paläont. Z., $\underline{\mathbf{5 3}}(3 / 4): 334-346,8$ Abb.; Stuttgart

[Richelsdorfer Gebirge]

-Schaumberg, Günther (1981): The vertebrate fauna of the Kupferschiefer. - In: Depowski, Stanislaw [president organizing committee]: Central European Permian - International Symposium Jabłonna, April 27-29, 1978 - Proceedings; 656 S., Abb.; hier S. 516-523; (Geological Institute) Warszawa 1981

[Bezugnahme a. Funde d. Richelsdorfer Gebirges]

oSchaumberg, Günther (1981): Coelacanthus granulatus, a Permian actinistian fish. - In: Depowski, Stanislaw [president organizing committee]: Central European Permian - International 
Symposium - Jabłonna, April 27-29, 1978 - Proceedings; 656 S., Abb.; hier S. 524-527, 3 Abb.; (Geological Institute) Warszawa 1981

[Bezugnahme a. Funde d. Richelsdorfer Gebirges]

aSchaumberg, Günther (1982): Paläozoische Reptilien in Nordhessen. - Philippia, $\underline{\mathbf{5}}(1): 3$ - 10, 5 Abb.; Kassel [Fossilfunde Richelsdorfer Kupferschiefer, Cornberger Sandstein]

-Schaumberg, Günther (1982): Hopleacanthus richelsdorfensis n.g. n. sp., ein Euselachier aus dem permischen Kupferschiefer von Hessen (W-Deutschland). - Paläont. Z., 56 (3/4): 235-257, 16 Abb.; Stuttgart [Richelsdorfer Gebirge]

- DSchaumberg, Günther (1986): Bemerkungen zu einem Neufund von „Weigeltisaurus jackell“ (WEIGELT) im nordhessischen Kupferschiefer. - Paläont. Z., 으(3/4): 319-327, 5 Abb.; Stuttgart [Richelsdorfer Gebirge]

DSchaumberg, G. (1987): 250 Mill. Jahre alte Lebenszeugnisse, gefunden in einer KupferschieferDeponie am Brodberg. - Das Werraland, 39 (2): 31, 2 Abb.m. Bildtext. [Fische Kupferschiefer]; Eschwege

aSchaumberg, G. (1987): Die tierischen Fossilien im Kupferschiefer und im Marl-Slate Bemerkenswerte Neufunde seit 1970 [Posterbeitrag]. - In: Klare, Bernd \& Schröder, Bernd [eds.]: Zechstein 1987 - International Symposium Kassel/Hannover [28. April to 9. May, 1987] - Abstracts, Posters, Program; S. 142; [Subkommission Perm/Trias der Stratigraphischen Kommission der DUGW/IUGS] Bochum 1987

-Schaumberg, Günther (1989): Muensterichthyes buergeri n.g. n.sp., ein neuer Paleoniscoide (Actinopterygii, Pisces) aus dem permischen Kupferschiefer von Richelsdorf (Hessen, West-Deutschland). - Paläont. Z., $\underline{63}(1 / 2):$ 119-131, 7 Abb.; Stuttgart

aSchaumberg, Günther (1992): Neue Informationen zu Menaspis armata EWALD. - Paläont. Z., $\underline{\mathbf{6 6}}$ : 311-329, 12 Abb., Stuttgart [Fossilien-Neufunde u.a. Richelsdorfer Kupferschiefer]

oSchaumberg, Günther (1996): Über wenig bekannte Acrolepiden aus dem oberpermischen Kupferschiefer und Marl-Slate von Deutschland und NE-England. - Philippia, $\underline{7}$ (5): 325-354, 28 Abb., Kassel [darin: Fossilien Richelsdorfer Kupferschiefer]

oSchaumberg, Günther (1999): Ergänzungen zur Revision des Euselachiers Wodnika striatula MÜNSTER 1843 aus dem oberpermischen Kupferschiefer und Marl-Slate. - Geologica et

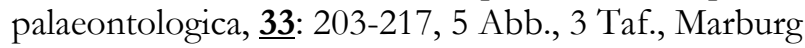
[u. a. Fossilien Richelsdorfer Kupferschiefer]

aSchaumberg, Günther (1983): Der Kupferschiefer und seine versteinerten Tier- und Pflanzenreste aus dem Erdaltertum. - In: Hildebrand, Erich [Gesamtkonzeption, Red.]: Land an Werra und Meißner - Ein Heimatbuch.. - 1. Aufl.; S. 183-188, 6 Abb.; [Hrsg. Hist. Ges. Werralandes](Bing) Korbach 1983;

aSchaumberg, Günther (1990): Der Kupferschiefer und seine versteinerten Tier- und Pflanzenreste aus dem Erdaltertum. - In: Hildebrand, Erich [Gesamtkonzeption, Red.]: Land an Werra und Meißner - Ein Heimatbuch.. - 3., überarb. Aufl.; S. 185-190, 6 Abb.; [Hrsg. Hist. Ges. Werralandes](Bing) Korbach 1990

aScheffer, Reinhard (1973): Die Mineralien und Fossilien der ehemaligen Grube „Schnepfenbusch“ im Richelsdorfer Gebirge/Nordhessen.- Der Aufschluss, 24 (7/8): 319-321, 1 Abb.; Göttingen 
-Tobien, Heinz (1953): Bemerkungen zu einem Schädelrest von Reticulolepsis WESTOLL

(Palaeonisformes, Pisces) aus dem Kupferschiefer von Sontra (Richelsdorfer Gebirge). - Notizbl.

Hess. L.-A. Bodenforsch., 81 (=6. Folge, H. 4): 59-62, 1 Taf.; Wiesbaden

-Wild, R. (1985): Ein Schädelrest von Parasaurus geinitzi H. v. MEYER (Reptilia, Cotylosauria) aus dem Kupferschiefer (Perm) von Richelsdorf (Hessen). - (Gedenkschrift Bruno v. Freyberg) Geol. Bl. NO-

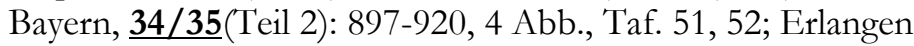

\subsection{Mineralogie, Geochemie, Lagerstättenkunde}

- $\square$ OBärtling, Richard (1911): Die Schwerspatlagerstätten Deutschlands in geologischer, lagerstättenkundlicher und bergwirtschaftlicher Hinsicht. - 188 S., 19 Abb.; (Enke) Stuttgart

[darin: Grube Chattenberg b. Bad Sooden-Allendorf; Grube Münden/Nentershausen, Richelsdorfer Gebirge und Heinebach/Rotenburg F., Grube Mannel bei Herges-Vogtei i. Thür.)

-Belendorf, K. (1986): Neufunde von Richelsdorf. - Lapis, 11(9): 32-33, 3 Abb.; München

-Cannon, Ralph (1986): Bergbau und Mineralien des Richelsdorfer Gebirges. - Rückblick, 2.1986: 6971; Hofgeismar

-Cornelius, C.-D. (1950): Kupfer-, Nickel- und Kobalterz im Richelsdorfer Gebirge. - Der Aufschluß, $\underline{1}$ : 47-48; Braunschweig

-Diedel, R. (1984): Mikrosondenuntersuchungen an Sulfiden des Kupferschiefers der Gebiete Spessart, Rhön und Richelsdorf. - Dipl.-Arb. [unveröff.] TU Aachen

-Ey d. Aelt, C. (1843): Bergmännische Bemerkungen über den Richelsdorfer Kupferschieferbergbau. Archiv. f. Mineral., Geognosie, Bergbau u. Hüttenkundde., 17(2): 750-775; Berlin

-Grassmann (1886): Das Richelsdorfer Kupfer- und Kobaltwerk in Hessen. - Hierzu die Texttafel p. Z. Berg-, Hütten- u. Salinenwesen, 34: 195-207 (Abb.); Berlin

Referat in: N. Jb. Mineral. etc, 1888 (Bd. I): 245 (G. Greim); Stuttgart

[Regionalgeologie, Lagerstättengeologie, Bergbaugeschichte, Förderstatistik]

-Großkurth, Gerhard Friedrich (1990): Einfluss der Halden des ehemaligen Kupferschiefer- und Schwerspat-Berbaues im Richelsdorfer Gebirge (Hessen) auf die Schwermetallführung des Gewässersystems. Geologische und geochemische Kartierung. - Dipl.- Arbeit [unveröff.] Univ. Göttingen; 160 S., 25 Abb., 53 Tab., 8 Anl.

-Gunzert, Gerhard (1953): Über die Bedeutung nachträglicher Erzverschiebungen in der Kupferlagerstätte des Richelsdorfer Gebirges. - Notizbl. Hess. L.-A. Bodenforsch., 81: (= 6. F. (H. 4)): 258 - 283, 6 Abb., Taf. 12-15; Wiesbaden

- $\square$ Gunzert, Gerhard (1961): Über das selektive Auftreten der saxonischen Schwerspatlagerstätten in Deutschland. - N. Jb. Mineral. Mh., 1961: 25-53, 6 Abb.; Stuttgart [darin: Richelsdorfer Gebirge, Werra-Grauwackengebirge]

- Hentschel, Gerhard (1979): Zur Kenntnis der Sekundärminerale im Richelsdorfer Gebirge (Hessen). Geol. Jb. Hessen, 107: 197-205; Wiesbaden

-Heppenheimer, Hermann (1995): Vergleichende geochemische und petrologische Untersuchungen am Kupferschiefer: ein Beitrag zur Klärung der Metallogenese. - Diss. Aachen 1995, 240 S., graph. 
Darst. Ill.

[darin: Hessische Senke (Richelsdorfer Gebirge]

-Heuser, A. (1819): Versuch einer geognostischen Beschreibung der im Richelsdorfer Gebirge auftretenden Gänge und sogenannten Veränderungen. - Taschenbuch f. Mineralogie, 1819: 311-437; Frankfurt/M.

- $\square$ Hofmann, Richard \& Schürenberg, Horst (1979): Geochemische Untersuchungen gangförmiger Barytvorkommen in Deutschland. - Übergeordneter Titel: Zur Minerogenie des hydrothermalen Baryts in Deutschland. - (Monograph Series on Mineral Deposits, 17), S. 1-80, 39 Abb.; (Bornträger) Berlin-Stuttgart [Kap. 6.3.1 Unterwerra-Grauwackengebirge, Richelsdorfer Gebirge]

- Jowett, E. C. (1987): Metal ratios in the Kupferschiefer as indicators of paleo-flow directions, Richelsdorf Hills, W. Germany [Posterbeitrag]. - In: Klare, Bernd \& Schröder, Bernd [eds.]: Zechstein 1987 - International Symposium Kassel/Hannover [28. April to 9. May, 1987] - Abstracts, Posters, Program; S. 125; [Subkommission Perm/Trias der Stratigraphischen Kommission der DUGW/IUGS] Bochum 1987

- Jowett, E. Craig (1991): Paleo-flow dircetions of basinal fluids determined from metal ratios, Richelsdorf Hills, F.R.G. - Zentralbl. Geol. Paläont. Teil1: 1991(4); S. 1017 - 1027, 10 fig., 1 tabl.; (Schweizerbart) Stuttgart

-Klauer (1855): Krystalliner Speiskobalt von Riechelsdorf in Churhessen. - N. Jb. Mineral. etc., 1855: 71 [Auszüge]; Stuttgart [chem. Analyse]

-Kleusberg, Thomas \& Tietze, Klaus-Werner (1987): Rote Zirkone in Playa-Ablagerungen des Buntsandsteins der Hessischen Senke. - Geol. et Paläont., 21: 169-172, 2 Abb.; Marburg [darin: Richelsdorfer Gebirge]

-Krusch, P. (1919): Die Verteilung der Metallgehalte (Kupfer, Silber, Molybdän und Vanadin) im Richelsdorfer Gebirge. - Z. prakt. Geologie, 27: 76-84, 1 Abb., Halle (Saale)

- $\square$ Kulick, J.; Leifeld, D.; Meisl, St.; Pöschl, W.; Stellmacher, R.; Strecker, G.; Theuerjahr, A.-K. \& Wolf, M. (1984): Petrofazielle und chemische Erkundung des Kupferschiefers der Hessischen Senke und des Harz-Westrandes. - Geol. Jb., Reihe D, 68: 3-323, 37 Abb., 15 Tab.; 34 Taf.; Hannover [darin: Richelsdorfer Gebirge, Werra-Meißner-Kreis: Ringgau u. Bohrungen]

-Kuster-Wendenburg, Elisabeth (1980): Auf der Suche nach Mineralien in Nordhessen. - Hessischer Gebirgsbote, $\underline{\mathbf{8 1}}(4)$ : 125 - 126, 3 Abb., 1 Kt.; Melsungen [darin: Richelsdorfer Gebirge]

Dall Leonhard, Karl Caesar [v.] (1805-1809): Handbuch einer allgemeinen topographischen Mineralogie. - Bd. 1, 479 S., 1805; Bd. 2, 568 S., 1808; Bd. 3, 432 S., 1809; (J. Ch. Hermann) Frankufurt/M.

[Verzeichnis von Mineralfundstätten nach Mineralen geordnet; darin: (Groß-Almerode, Hirschberg Epterode, Eschwege, Kassel, Meißner, Oberkaufungen, Richelsdorf, Göttingen, Orte i. Thüringen]

-Ludwig, Helga \& Rentzsch, Johannes (1967): Das Sanderzproblem - Ein Beitrag zur Genese des Kupferschiefers. - Ber. Dt. Ges. geol. Wiss., Reihe B, 12(1): 3-12, 7 Taf.; Berlin [darin: Richelsdorfer Gebirge]

-Messer, Ernst (1955): Kupferschiefer, Sanderz und Kobaltrücken im Richelsdorfer Gebirge. - Hess. Lagerstättenarchiv, $\underline{\mathbf{3}}$; 125 S., 39 Abb., 19 Tab., 29 Taf.; Wiesbaden - zgl. Diss. Bergakad. Clausthal 1954 
-Messer, Ernst (1997): Die Erz- und Gangartminerale der kobaltnickelhaltigen Schwerspatgänge im Richelsdorfer Gebirge. - Der Aufschluss: 48(1): 1-15; 26 Abb.; Heidelberg

-Püttmann, W.; Merz, C. \& Speczik, S. (1991): Oxidation of organic material in the Kupferschiefer and its relation to mineralization processes. - Zentralbl. Geol. Paläont - Teil1, 1991(4): 957-974, 9 fig., 3 tabl.; Stuttgart [Richelsdorfer Gebirge/Spessart-Rhön]

-Rammelsberg, C. (1897): Die Arsenverbindungen des Eisens, Nickels und Kobalts, bezogen auf eine einzige Grundmischung. - N. Jb. Mineral. etc., 1897(Bd. II): 45-66; Stuttgart [darin: Richelsdorfer Gebirge]

-oRentzsch, Johannes (1964): Der Kenntnisstand über die Metall- und Erzverteilung im Kupferschiefer. - Z. angew. Geol., 10 (6); 281-288, 1 Abb.; Berlin [darin: Richelsdorfer Gebirge]

-Rentzsch, Johannes \& Thiergärtner, Hannes (1972): Vergleichende geologisch-mathematische Untersuchung der Buntmetallverteilung in Lagerstätten vom Typ Kupferschiefer. - Z. angew. Geol., 18(12): 537-548, 14 Abb., 2 Tab.; Berlin

[Bezugnahme ausschl. a. Richelsdorfer Gebirge]

-Rentzsch, Johannes \& Franzke, Hans Joachim (1997): Regional tectonic control of the Kupferschiefer mineralization in Central Europe. - Z. geol. Wiss., 20 $2(1 / 2): 121-139,5$ fig., 3 tabl.; Berlin [darin: Richelsdorfer Gebirge]

- Rentzsch, Johannes \& Franzke, Hans Joachim (1997): Die laterale Verbreitung der Erzmineralassoziationen im deutschen Kupferschiefer. - Z. geol. Wiss., 25(1/2): 141-149, 2 Abb., 2 Tab.; Berlin [darin: Richelsdorfer Gebirge]

DoRentzsch, Johannes \& Friedrich, Günther (2003): Zur Herkunft der Metalle der Kupferschiefervererzung in Deutschland - Metallbilanz im Präzechstein und in der erzführenden Zone an der Zechsteinbasis. - Metal source of Kupferschiefer mineralization in Germany - Base metals in the Pre-Zechstein basement and in the ore bearing zone. - Hallesches Jb. Geowiss., Reihe B, 25: 1-20, 3 Abb., 4 Tab.; Halle (Saale)

[Bezugnahme a. Richelsdorfer Gebirge, Thüringer Wald]

- Scheffer, Reinhard (1973): Die Mineralien und Fossilien der ehemaligen Grube „Schnepfenbusch“ im Richelsdorfer Gebirge/Nordhessen.- Der Aufschluss, 24 (7/8): 319-321, 1 Abb.; Göttingen

-Schmetzer, Karl; Schnorrer-Köhler, Günther \& Medenbach, Olaf (1985): Wülfingite, epsilon$\mathrm{Zn}(\mathrm{OH})_{2}$ and Simonkolleite, $\mathrm{Zn}(\mathrm{OH})_{5} \mathrm{CL}_{8} 2 \mathrm{H}_{2} \mathrm{O}$, two new minerals from Richelsdorf, Hesse, F. R. G. - N. Jb. Miner. Mh., 1985: 145-154, 3 fig., 4 tabl.; Stuttgart [Mineralfundort: Richelsdorfer Hütte]

- $S$ chmidt, Franz-Peter (1985): Erzkontrolle im Kupferschiefer Osthessens, Bundesrepublik Deutschland. - Diss. Univ. Aachen 1985 [unveröff.]; 158 (48) S., Ill., graph. Darst.; Aachen [Untersuchungsgebiet Richelsdorfer Gebirge, Anteile am WMK unbekannt, da Bohrstellen anonymisiert]

aSchneiderhöhn, Hans (1949): Schwerspatgänge und pseudomorphe Quarzgänge in Westdeutschland. N. Jb. Mineral., Abt. A, 1949: 191-202, 2 Abb.; Stuttgart [darin: Richelsdorfer Gebirge (Kurzdarst.)]

- aSchnorrer-Köhler, Günter (1983): Die Mineralien des Richelsdorfer Gebirges. - Der Aufschluss, $\underline{34}$ : 534-540, 1 Abb.; Heidelberg 
aSchnorrer-Köhler, Günter (1984): Die Mineralien des Richelsdorfer Gebirges (1. Fortsetzung). - Der Aufschluss, 35: 7-20, 7 Abb.; Heidelberg

- $S$ Schnorrer-Köhler, Günter (1984): Die Mineralien des Richelsdorfer Gebirges (2. Fortsetzung). - Der

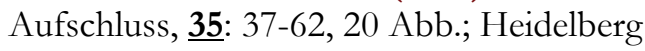

aSchnorrer-Köhler, Günter (1984): Die Mineralien des Richelsdorfer Gebirges (3. Fortsetzung). - Der Aufschluss, 35: 93-109, 24 Abb.; Heidelberg

-Schnorrer-Köhler, Günter (1984): Die Mineralien des Richelsdorfer Gebirges (Schluß). - Der Aufschluss, 35: 119-136, 17 Abb.; Heidelberg

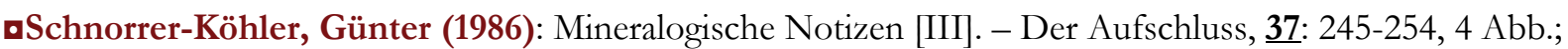
Heidelberg [Richelsdorfer Gebirge/Hessen]

-Schnorrer-Köhler, Günter (1988): Mineralogische Notizen [IV].- Der Aufschluss, 39: 153-168, 11 Abb.; Heidelberg [darin: S. 162 - 165: „Richelsdorfer Gebirge“]

- $S$ chumacher, Claus (1985): Die Kupfervererzungen des basalen Zechsteins im Rahmen der sedimentären Entwicklung des Werra-Fulda-Beckens. - Diss. Fachber. Geowiss. FU Berlin; 142 S., 57 Abb., 6 Taf.; Tabellen [darin: Richelsdorfer Gebirge, Raum Sontra]

- 0 Staub, A. Wilhelm (1929): Beiträge zur Kenntnis der Schwerspat- und Flußspatlagerstätten des Thüringer Waldes und des Richelsdorfer Gebirges. - Z. dt. geol. Ges., $\underline{\mathbf{8 0}}$ (f. 1928): 43 - 96 (Abh.), 5 Abb.; Berlin - zgl. Diss. Univ. Jena 1926

- $\square$ Stoppel, Dieter \& Gundlach, H. (1968): Die Schwerspatvorkommen im UnterwerraGrauwackengebirge und Richelsdorfer Gebirge. - Der Aufschluss, Sdh. 17 (Zur Mineralogie und Geologie der Umgebung von Göttingen): 139-147, 8 Abb.; Göttingen

- $\square$ Stoppel, Dieter \& Gundlach, Heinrich (1978): Zur Geologie und Bergbaugeschichte der Schwerspat- und Kobalterzvorkommen im Unterwerra-Grauwackengebirge und Richelsdorfer Gebirge. - In: Koritnig, Sigmund [Schriftltg.]: Zur Mineralogie und Geologie der Umgebung von Göttingen - mit Westharz und Teilen des Nordhessischen Berglandes. - Der Aufschluss, Sdbd. $\underline{\mathbf{2 8}}$ : 261-285, 23 Abb.; Heidelberg

-Stoppel, Dieter \& Gundlach, Heinrich (1983): Zur Schwerspatmineralisation und ZechsteinStratigraphie im Richelsdorfer Gebirge (NE-Hessen). - Z. dt. geol. Ges., 134: 247-268, 7 Abb., 1 Tab.; Hannover

oSüsse, Peter \& Schnorrer-Köhler, Günther (1983): Richelsdorfit, $\mathrm{Ca}_{2} \mathrm{Cu}_{5} \mathrm{Sb}\left(\mathrm{Cl} /(\mathrm{OH})_{6} /\left(\mathrm{AsO}_{4}\right)_{4} \times 6\right.$ H2O - ein neues Mineral. - N. Jb. Mineral., Mh., 1983: 145-150, 2 Abb., 4 Tab.; Stuttgart [Richelsdorfer Gebirge]

-Thienhaus, R. (1941): Die Schwerspatgänge des Richelsdorfer Gebirges. - Z. angew. Mineral., $\underline{3}$ : 21 52, 16 Abb.; Berlin

Referat in: N. Jb. Mineral. etc., Referate, 1941 (Bd. II): 149-150 (Paula Schneiderhöhn); Stuttgart

-Tobschall, H. J.; Schmidt, F. P. \& Schumacher, C. (1986): Kupferschiefer und Kupfervererzungen im Richelsdorfer Gebirge, Hessen - Ihre Entstehung im Rahmen der sedimentären Entwicklung des basalen Zechsteins. - Fortschritte Mineral., 64, Beih. 2: 143-160, 5 Abb., 2 Tab.; Stuttgart 
-Tonn, Harald (1990): A. Untersuchungen an Flüssigkeitseinschlüssen als Beitrag zur Genese der Kupferschiefermineralisation (Mikrothermometrie, Kathodenlumineszenz, REM-EDX Mikroanalytik). - B. Geologische Kartierung im Bereich Cornberg-Nentershausen (Hessen) TK 4925 Sontra .; Dipl.-Arb. + Dipl.-Kart. [unveröff.] Univ. Göttingen; 60S., 40 S., 5 Taf., 3 Anl.; Göttingen

-Tonn, H.; Schmidt, F.-P.; Porada, H. \& Horn, E.-E. (1987): Fluid inclusion studies of high grade and structure bound Kupferschiefer mineralization of Richelsdorf and Spessart/Rhön [Posterbeitrag]. - In: Klare, Bernd \& Schröder, Bernd [eds.]: Zechstein 1987 - International Symposium Kassel/Hannover [28. April to 9. May, 1987] - Abstracts, Posters, Program; S. 148; [Subkommission Perm/Trias der Stratigraphischen Kommission der DUGW/IUGS] Bochum 1987

-Wedepohl, K. H. (1987): Composition and genetic constraints of the Kupferschiefer bed [Vortragskurzfassung]. - In: Klare, Bernd \& Schröder, Bernd [eds.]: Zechstein 1987 International Symposium Kassel/Hannover - 28. April to 9. May, 1987 - Abstracts, Posters, Program; S. 116-118; [Subkommission Perm/Trias der Stratigraphischen Kommission der DUGW/IUGS] Bochum 1987 [Bezugn. a. Richelsdorfer Gebirge]

- $0 \square$ Werner, Carl - Dietrich (1958): Geochemie und Paragenese der saxonischen Schwerspat-FlußspatGänge im Schmalkaldener Revier. - Freiberger Forschungshefte, Reihe C, 47; 117 S, 24 Abb.; (Akademie-Verlag) Berlin - zgl. Diss. Univ. Halle-Wittenberg 1957

[Thüringen, Richelsdorfer Gebirge, Unterwerra-Grauwackengebirge]

- $0 \square$ Werner, C. D. (1958): Geochemie und Paragenese saxonischer Schwerspatlagerstätten in Thüringen $<$ Referat $>$. - Fortschr. Mineral., $\underline{\mathbf{3 6}}$ (1): 52-53; Stuttgart

[Thüringen, Richelsdorfer Gebirge, Albungen]

\subsubsection{Werra-Meißner-Kreis}

\subsubsection{Gottesberg bei Hundelshausen}

- $\square$ •Apel, Jürgen \& Rüppel, Heidi [Verfass. u. Hrsg.] (2005): Raus in die Natur - Tipps für den Sonntags-Ausflug im Dreiländereck Hessen - Niedersachsen - Thüringen. - 159 S., 111 Fotos, 34 Kt., 1 Zeit-Taf.; (LSRB-Verlag, Landschaftskundlicher-Studien-Reisebuch-Verlag) Witzenhausen [zahlreiche Ausflugsziele, auch zu Geotopen des Zechsteins; Ziel 45 (Gottesberg b. Hundelshausen)]

$\square$ Jacobshagen, V.; Koritnig, S.; Ritzkowski, S.; Rösing, F., Wittig, R. \& Wycisk, P. (1977): Der Unterwerra-Sattel: sein Deckgebirge (Perm - Trias) und der gefaltete paläozoische Kern - (Exkursion C). - Unter Mitarbeit von G. Schalow und H. Schulze. - In: Geol.-Paläont. Inst. u. Museum der Universität [Hrsg.]: Exkursionsführer - Geotagung '77 Göttingen - Band II : Nordhessen und Südniedersachsen (Exkursionen C - D - J - K - L). - S. 1-34; 8 Abb.; (Selbstverlag GeologischPaläontologisches Institut) Göttingen 1977 [darin: Aufschluss 14 - Der Gottesberg bei Hundelshausen]

$\square$ Faupel, Jürgen (1971): Geologische Untersuchungen im NW-Teil des Unterwerra-Sattels. - Dipl.Arb. [unveröff.] Univ. Göttingen; 110 S., 14 Abb., 3 Tab., 3 Beil.

$\square$ Faupel, Jürgen (1973): Neue Beobachtungen zu den allochthonen Triasvorkommen (“Schollen) auf dem Unterwerra-Sattel bei Hundelshausen/Nordhessen. - N. Jb. Geol. Paläont., Mh., 1973: 654-666, 5 Abb.; Stuttgart 
$\square$ Grupe, O. (1923): Zur Entstehung des Göttinger Leinetalgrabens. - Jb. Preuß. Geol. Landesanst., $\underline{42}$ (f. 1921): 595-620, 3 Abb.; Berlin

[S. 601-602 Gottesberg/Hundelshausen]

$\square$ Holzapfel, Martin (1998): Die allochthonen Triasschollen bei Hundelshausen, Nordhessen geologische Kartierung, Beschreibung und Deutung. - Diss. Univ. Würzburg [unveröff.]; XL, 79 S. (18), Ill., graph. Darst., Kt.; Würzburg

$\square$ Holzapfel, Martin (2000): Die allochthonen Triasschollen bei Hundelshausen, Nordhessen. - Ber. Naturhist. Ges. Hannover, 142: 7-77, 10 Abb., 6 Tab., 2 Kt.; Hannover

$\square$ Klingner, Fritz Erdmann (1935): Das Problem der Triasschollen auf dem Grauwackensattel der unteren Werra bei Hundelshausen. - Z. dt. geol. Ges., 87: 48-56, 3 Abb.; Berlin

$\square$ Kulick, Jens (1987): Exkursion M: Der über Tage anstehende Zechstein in Hessen. In: Kulick, Jens (1987): Zechsteinaufschlüsse in der Hessischen Senke und am westlichen Harzrand. Exkursionsführer International Zechstein Symposium Kassel/Hannover [28. April to 9.May 1987], 2 Exkursionen D, E, F, L, M; 309 S, Ill, graph. Darst., Kt.; Wiesbaden [Stop D9: Naturkundemuseum Ottoneum/Kassel: Fährten des Cornberger Sandsteins (S. 72-79); D10 Schwerspatgrube Münden/Nentershausen, D11 Stbr. Cornberg, D18-D28 (Zechstein im WerraGrauwackengebirge): Albungen, Jestädt, Reichensachsen/Weinberg, Oberhohne, Höllental/Schmelzhütte, Frankershausen/Schafhof, Hundelshausen, Witzenhausen-Papierfabrik]

$\square$ Lachmann, R. (1913): Der Bau des niederhessischen Berglandes bei Hundelshausen. - Jb. Schlesische Ges. f. vaterländ. Kultur Breslau, 90 [f. 1912](I. Bd: Sitzungen Sect. f. Geol., Geogr., Berg- u. Hüttenwesen): 13-61, 8 Abb.; Breslau Referat in: N. Jb. Mineral. etc., 1913 (Bd. I): 106-108 (O. E: Meyer); Stuttgart

$\square$ Lachmann, R. (1913): Ekzeme als geologische Chronometer - [mit Erwiderungen v. Beyschlag, Scheibe, Krusch]. - Z. dt. geol. Ges., 64 (f. 1912): 553 - 568, 5 Abb.; Berlin [darin: allochthone Triasschollen auf Zechsteingips bei Hundelshausen/Gelstertal]

$\square$ Möbus, Heinz-Martin (2004): Allochthone Triasschollen am Unterwerrasattel als Schlüssel zum Verständnis saxonischer Tektonik. - Diss. Fb. Geowiss. Univ. Marburg 2004; X, 197 S, 14 Bl. Anh., Abb., 4 Beil.

$\square \bullet$ Petraschek, Walter Emil (1931): Tektonische Studien im nördlichen Solling und am Südrand der Elfas-Achse. - Abh. Preuß. Geol. Landesanst., N.F., 128: 129-147, 9 Abb., Taf. 7 u. 8; Berlin [darin S. 141-142, Abb. 8, Kap., , Vergleichende Betrachtung im Schnittgebiet des WerraGrauwackensattels mit dem Leinetalgraben“: Der Gottesberg bei Hundelshausen]

$\square$ Rüppel, Heidi \& Apel, Jürgen (2002): Rad- und Wander-Führer - Auf Entdeckungstour im WerraBergland rund um Meißner und Kaufunger Wald. - Bd. 1 Hannoversch Münden, Witzenhausen, Bad Sooden-Allendorf. - 152 S., 33 Abb., 15 graph. Darst., 19 Kt.; (Landschaftskundlicher StudienReisebuch-Verlag) Witzenhausen 2002

$\square$ Schroeder, Eckart (1923-1925): Tektonische Studien an Niederhessischen Gräben. (Göttinger Beiträge zur saxonischen Tektonik) - Abh. Preuß. Geol. Landesanst., N.F., $9 \underline{5}$ (1923-1925), 57-82, 2 Abb., 3 Taf.; Berlin [Tektonische Gräben im Werra-Meissner-Kreis]

\subsubsection{Tertiärmulde Glimmerode (Werra-Meißner-Kreis)}


$\square$ Brosius, Marita (1957): Der Grabenknoten von Hessisch-Lichtenau und die Glimmeröder Tertiärmulde. - Diss. Univ. Marburg [unveröff.], 171 gez. Bl., Abb., Tab.

$\square$ Brosius, Marita (1959): Die Tertiärmulde von Glimmerode. - Hess. Lagerstättenarchiv, 4; 48 S., 17 Abb., 3 Tab., 5 Taf., 10 Anl.; Wiesbaden

- $\square$ Bühmann, Dieter (1974): Die Tonmineralzusammensetzung in den Sedimenten der Niederhessischen Senke als Indikator festländischer Verwitterung und brackisch-mariner Tonmineralneubildung. - Diss. math.-nat. Univ. Göttingen, 81 S., 20 Abb., Tab. i. Anhang

[Unters. v. Sedimenten d. Tertiärs. Trias; u.a. Region Kassel - Fritzlar, Beberbeck, Großalmerode, Stellberg, Glimmerode]]

- $\square$ Faupel, Myrsini (1975): Die Ostrakoden des Kasseler Meeressandes (Oberoligozün) in Nordhessen. Göttinger Arb. Geol. Paläont., 17; 77 S., 3 Abb., 1 Tab., 13 Taf.; Göttingen - zgl. Diss. Univ. Göttingen 1975

[darin: Umgebung Kassel, Kaufungen, Gudensberg, Glimmerode]

$\square$ Huckriede, Reinhold \& Janssen, Ronald (1973): Euryhaline Mollusken im älteren Chattium (,Kasseler Meeressand“) von Glimmerode in Niederhessen. - Geologica et palaeontologica, 1: 189202, 3 Taf.; Marburg

$\square$ Janssen, Ronald (1977): Die Scaphopoden und Gastropoden des Kasseler Meeressandes von Glimmerode (Niederhessen). - Geol. Jb., Reihe A, 41; 195 S., 3 Abb., 3 Tab., 7 Taf.; Hannover

- $\square$ Krutzsch, Wilfried (1970): Einige neue Pollenformen aus den Familien der Tiliaceen, Bombaceen und Sterculiaceen aus dem mitteleuropäischen Alttertiär. - Jb. Geol., $\underline{\mathbf{3}}$ (f. 1967): 275-307, 2 Abb., 2 Tab., 7 Taf.; Berlin [darin aufgelistet Tab. 1 - Wichtige Fundorte: Borken/Hessen; Flötz 5 Glimmerode (Hessen)]

$\square$ Menzel, Herbert (1983): Die Otolithen einiger oligozäner Vorkommen vorwiedend aus dem Kasseler Meeressand (Oberoligozän). - Geol. Jb. Hessen, 11: 5-45, 2 Abb., 3 Tab., 6 Taf.; Wiesbaden [darin: Glimmerode/Höllberg]

- $\square$ Mürriger, Friedrich \& Pflanzl, Günther (1955): Pollenanalytische Datierungen einiger hessischer Braunkohlen. - Notizbl. Hess. L.-A. Bodenforsch., 83: 71-89, 1 Tab., 2 Taf; Wiesbaden [Darin: Hirschberg, Glimmerode, Oberkaufungen, Stellberg/Söhrewald, Zeche Marie/Habichtswald]

- $\square$ Pflug, Hans Dieter (1966): Zur Stratigraphie des mittleren Tertärs in Hessen und in benachbarten Gebieten. - Notizbl. Hess. Landesamtes Bodenforschung., 94: 259-268, 2 Abb., 1 Tab.; Wiesbaden Palynologische Untersuchungen a. Braunkohlen; darin: Borken, Oberkaufungen, Zeche Marie i. Habichtswald/Kassel; Grube Hirschberg/Großalmerode, Grube Glimmerode/Hessisch Lichtenau]

- $\square$ Pietzsch, Kurt (1925): Handbuch der Geologie und Bodenschätze Deutschlands / Erich Krenkel [Hrsg.]. - Abt. 3: Die Bodenschätze Deutschlands - Bd. 1: Die Braunkohlen Deutschlands. - XII, 488 S., 105 Textabb., 20 Taf.; (Bornträger) Berlin [darin S. 205-225: Der Niederhessische Bezirk [Revier Cassel] (darin; Habichtswald, Stellberg, Hirschberg, Oberkaufungen, Glimmerode, Meißner)]

- $\square$ Ritzkowski, Siegfried (1965): Das marine Oligozän im nördlichen Hessen - Stratigraphie und Paläogeographie. - Diss. Univ. Marburg/L. 1965; 194 S., 28 Abb., 4 Tab. [darin S. 127: Tagebau Höllkopf / Glimmerode]

- $\square$ Ritzkowski, Siegfried (1967): Mittel-Öligozän, Ober-Oligozän und die Grenze Rupel/Chatt im nördlichen Hessen. - N. Jb. Geol. Paläont. Abh., 127: 293-336, 12 Abb., 3 Tab.; Stuttgart [Hessische Senke zw. Hofgeismar und Lauterbach, darin: Ahnetal N’Habichtswald, Glimmerode] 
- $\square$ Ritzkowski, S. (1969): Nördliches Hessen [Oligozän-Aufschlüsse]. - In: Anderson, Hans Joachim [Hrsg.]: Führer zur Oligocän-Exkursion 1969 - Köln, Münster, Hannover, Göttingen, Mainz - 20.27. April 1969. - Internationale Union f. Geologischen Wissenschaften [International Union of Geological Sciences]/Landesausschuß der Bundesrepublik Deutschland. - 112 S., 33 Abb., Tab.; hier S. 57 - 83, 17 Abb. Tab.; Marburg 1969

[Borken, Niederkaufungen, Glimmerode]

- $\square$ Ritzkowski, S. \& Rösing, F. (1977): Tertiär Nordhessens. (Exkursion K). - Exkursionsführer Geotagung '77, Bd. II, S. 63-111, 16 Abb., 1 stratigr. Tab.; (Selbstverlag Geol.-paläont. Univ. Göttingen) Göttingen [darin: Borken, Verna, Obervorschütz, Knickhagen, Bühl b. Ahnatal/Weimar; Breitenbach, Hoof, Vollmarshausen, Glimmerode, Hoher Meissner]

\subsubsection{Hirschberg bei Großalmerode (Werra-Meißner-Kreis)}

Dᄆ0•Apel, Jürgen \& Rüppel, Heidi [Verfass. u. Hrsg.] (2005): Raus in die Natur - Tipps für den Sonntags-Ausflug im Dreiländereck Hessen - Niedersachsen - Thüringen. - 159 S., 111 Fotos, 34 Kt., 1 strat. Tab.; (LSRB-Verlag, Landschaftskundlicher-Studien-Reisebuch-Verlag) Witzenhausen [zahlreiche Ausflugsziele, auch zu Geotopen des Tertiärs; Ziel 42 (Hirschberg b. Großalmerode)]

$\square \bullet$ Bender, Heike (1981): Geologische und lagerstättenkundliche Untersuchungen im Nordteil der Hessischen Senke, E. - T I: Die Geologie des Südrandes der Dransfelder Hochfläche östlich von Hann. Münden bei Wiershausen und Lippoldshausen. - Teil II: Palynologische und makropetrographische Untersuchungen der Flöze 2 und 3 der Braunkohle am Hirschberg bei Großalmerode (TK 25, Blatt Nr. 4724, Großalmerode). - Dipl.-Kart. u. Dipl.-Arb. [unveröff.] Univ. Göttingen; 173 S.

$\square \bullet$ Blanckenhorn \& Beyschlag (1902): Bericht über die in Verbindung mit der allgemeinen Versammlung in Cassel ausgeführten Exkursionen. - Z. dt. geol. Ges., 54: 149-151; Berlin [darin: „Grabenknoten“ b. Eichenberg, Meissner, Hirschberg b. Großalmerode]

- 0 Giebel, Chr. G. A. (1851): Gaea excursoria germanica - Deutschlands Geologie, Geognosie und Paläontologie - ein unentbehrlicher Leitfaden auf Excursionen und beim Selbstunterricht - mit 24 lithograpischen Tafeln. - XII, 510 S., 24 Taf.; (Abel) Leipzig

[Stratigraphie Deutschlands und regionale Verbreitung der Formationen; darin: S. 120 (Kap. Basalt: Blaue Kuppe b. Eschwege, Meissner, Hirschberg b. Großalmerode, Stoffelskuppe b. Eisenach; S. 167: Kap. Kupferschiefergebirge: Meißnervorland, Richelsdorfer Gebirge, Thüringer Wald; S. 191 Muschelkalk: Westhüringen, Nordosthessen, Südniedersachsen; S. 206: Keuper: Hess. Lichtenau, Westthüringen]

$\square$ Graeger (1847): Chemische Untersuchungen einiger Braunkohlen. - Ber. Vereins Naturkde. Kassel, 11: 15 -24; Kassel

[Meißner, Hirschberg, Faulbach]

- $\square$ Gutberlet, W. K. J. (1855): Über Sphärosiderit und Bohnerz in basaltischen Gesteinen. - N. Jb. Mineral. etc., 1855: 166-169; Stuttgart

[darin: Großalmerode/Ringenkuhl]

- $\square \bullet$ Hausmann, [J. F. L.](1824): Uebersicht der jüngeren Flöz-Gebilde im Fluß-Gebiete der Weser. Tb. Mineral., 18 (3): 678-702; Frankfurt/M. - Auszug aus Hausmann: Uebersicht der jüngeren FlözGebilde. - Studien Göttingischen Vereins bergmänn. Freunde, 1: 381 - 567, Göttingen 1824 [Regionale Stratigraphie Trias-Tertiär Hessen, WMK, Niedersachsen; darin: Tertiär Meißner, Hirschberg, Habichtswald, Wilhelmshöhe b. Kassel, Dransfeld] 
$\square$ Hausmann, Joh. Friedr. Ludw. (1847): Handbuch der Mineralogie. - Zweyter Teil: System und Geschichte der Mineralkörper - Band 2. - 2., gänzl. umgearb. Aufl.; VII, S. 897-1660, [1 Bl.]; (Vandenhoeck \& Rupprecht) Göttingen

[darin S. 1520-1529: Steinkohlen/Anthracit; Bezugnahme auf Meißner, Hirschberg]

व $\square \bullet$ Hausmann, J. F. L. (1858): Über das Vorkommen verschiedener Kieselgebilde in Begleitung des Basaltes. - Studien Göttingischen Vereins bergmänn. Freunde, $\underline{7}(2)$ : 139 - 192; Göttingen [darin: Blaue Kuppe, Hirschberg, Habichtswald, Meißner, Steinberg b. Hann-Münden; S. 154-156: „Absatz von Kieselsinter in dem schlackigen Anthracite des Meißners; S. 165-172: „Durch Eindringung von kieselsäurehaltigem Wasser in die Schichten des vom Basalte durchbrochenen Muschelkalkes gebildeter Kieselkalk“ (Kontkatmetamorpher Marmor vom „Schieferberg b. Bransrode“/Hoher Meißner S’ Weisenbach, heutiger Name „Heiligenberg“]

$\square$ Hentschel, Hans \& Pfeffer, Paul (1957): Chemisch-petrographische Untersuchungen von Gesteinsveränderungen am Kontakt Kohle-Basalt im Bereich des Braunkohlenbergwerks Zeche Hirschberg bei Großalmerode in Hessen. - Notizbl. Hess. L.-A. Bodenforsch., 85: 297-333, 4 Abb., 9 Tab., Taf. 17; Wiesbaden

- $\square$ OHoff, Karl Ernst Adolf von (1811): Beobachtungen über die Verhältnisse des Basaltes an einigen Bergen von Hessen und Thüringen. - Der Gesellschaft Naturforschender Freunde zu Berlin Magazin für die neuesten Entdeckungen in der gesammten Naturkunde, 5: 347-362 u. Taf. VIII; Berlin [darin: Blaue Kuppe b. Eschwege, Pflasterkaute b. Marksuhl, Stoffelskuppe b. Eisenach, Habichtswald/Kassel, Hirschberg b. Großalmerode, Hoher Meissner]

$\square$ Hoffmann, Friedrich (1823): Geognostische Bemerkungen über die Basalte der Gegend des Meißners und ihren vulkanischen Ursprung, (und Notiz von einigen barometrischen und electrometrischen Arbeiten). - Annalen d. Physik und der physikalischen Chemie, 15(3), zgl. Annalen der Physik, $\underline{75}$ : 323-332; Leipzig [ [darin: Blaue Kuppe, Alpstein, Hoher Meißner, Hirschberg b. Großalmerode, Heiligenberg b. Weißenbach]

- $\square$ Kayser, Emanuel (1923): Lehrbuch der Allgemeinen Geologie. - (Vier Bände: I. u. II. Band Allgemeine Geologie, III u. IV. Bd. Geologische Formationskunde). - Bd. İ: Physiographische Geologie und Äussere Dynamik. - 7. u. 8. Aufl., 740 S., 549 Abb.; (Enke) Stuttgart

[darin: Abb. z. Vulkanismus Abb. 58 Basaltbruch Bühl b. Ahnatal/Weimar W’Kassel; 92a

Teufelswand, Habichtswald/Kassel; 110 Profil Meissner - 111 Profil Hirschberg b. Großalmerode Tektonik: Abb. 203 Profil Netratal b. Eschwege, 204 „Eichenberg“ b. Netra]

$\square 0 \bullet$ Keferstein, Christian (1820): Geognostische Bemerkungen über die basaltischen Gebilde des westlichen Deutschlands, als Fortsetzung der Beyträge zur Geschichte und Kenntniß des Basaltes. VIII, 207 S., 1 Falt-Kt.; (J. Chr. Hendel u. Sohn) Halle/Saale

[darin S. 22 - 24: Habichtswald, Meißner, Hirschberg/Großalmerode, Erwähnung der „blauen Kuppe“, Basaltberge westl. Göttingen, Stoffelskuppe, Pflasterkaute bei Marksuhl]

-Klein-Reesink, Josef (1984): Stoffbestand und Genes der Niederhessischen Senke mit vergleichenden Untersuchungen an Braunkohlen der Oberpfalz und Ost-Westfalen. - Documentae naturae Forschungen aus der Naturwissenschaft, 17; 133 S., 46 Abb., 14 Tab., 5 S. Anhang (Tab.), 5 Taf. [darin: Borken, Ostheim, Hirschberg-Großalmerode]

$\square$ Klein-Reesink, J.; Riegel, W. \& Schulz, K.-H. (1982): Tertiäre Braunkohlen und Kupferschiefer in Niederhessen. - Arbeitskreis f. Paläobotanik u. Palynologie. 11. - 13.3.1982 Dassel/Solling, Exkursion A. - Courier Forschungsinstitut Senckenberg, 56: 111-132, 12 Abb., 2 Tab.; Frankfurt [Hp. 3 Tagebau Paradiesfeld/Zeche Hirschberg, HP. 4 Frankershausen/Stbr. Schafhof]

$\square$ Koch, Heinrich (1958): Im Bereich der drei Großen: Meißner - Hirschberg - Bilstein. - Hessischer Gebirgsbote, 59(3): 29 - 31; Melsungen 
- $\square$ Krenkel, Erich (1932): Die Bodenschätze Deutschlands. - 1. Bd. - VIII, 301 S., 71 Abb.; (Bornträger) Berlin

[darin: II. Besonderer Teil - Die Bodenschätze <Kohlen> - darin S. 122-126: (Kap. 8. Braunkohlen) Der Niederhessische Bezirk (darin Habichtswald, Stellberg, Hirschberg, Meißner), Abb. 16 Druseltal, Abb. 17 Hirschberg]]

- $\square$ Kühnert, Ernst (1841): Ueber den Werth einiger in der Umgebung von Cassel vorkommenden Braunkohlen. - Ann. Chemie Pharmacie, 37: 94-100; Heidelberg [darin: Meißner, Habichtswald, Hirschberg, Ringenkuhl, Stellberg/Söhrewald]

- $\square$ - Leonhard, Karl Caesar [v.] (1805-1809): Handbuch einer allgemeinen topographischen Mineralogie. - Bd. 1, 479 S., 1805; Bd. 2, 568 S., 1808; Bd. 3, 432 S., 1809; (J. Ch. Hermann) Frankufurt/M.

[Verzeichnis von Mineralfundstätten n. Mineralen geordnet; darin: (Groß-Almerode, Hirschberg, Epterode, Eschwege, , Kassel, Meißner, Oberkaufungen, Richelsdorf, Göttingen, Orte i. Thüringen]

- $\square$ OLeonhard, Karl Caesar v. (1832): Die Basalt-Gebilde in ihren Beziehungen zu normalen und abnormalen Felsmassen. - Bd. 1, 498 S., sep. Taf.-Bd. 20 Taf.; Bd. 2, 536 S.; (Schweizerbart) Stuttgart [Bd. 2 beschreibt Intrusionsgefüge der Basalte und die Kontaktmetamorphose auf das Rahmengestein an verschiedenen nordhessischen Lokalitäten; Kontaktmetamorphose Basalt/Ton: Meißner; Basalt/Braunkohle: Meissner/Hirschberg/Habichtswald; Basalt/Buntsandstein: Blaue Kuppe b. Eschwege; Pflasterkaute b. Marksuhl; Basalt/Muschelkalk: Ahnetal/Kassel, Hörschel b. Eisenach]

$\square$ Michael, Bernd (1993): Palynologische Untersuchungen am Flöz I der miozänen Braunkohle vom Hirschberg bei Großalmerode, Hessen. - Dipl.-Arb. [unveröff.] Univ. Göttingen ; 46 S.

- $\square$ Möhl, H[einrich] (1897): Topgraphische und geologische Verhältnisse Cassels. - In: Lange, Wilhelm Chr. [Red.]: Festschrift zur 38. Hauptversammlung d. Vereins Deutscher Ingenieure Gewidmet vom Hessischen Bezirksverein; 176 S:, Abb.; hier S. 1-14, 2 Taf.; (Weber \& Weidemeyer) Kassel 1897

[Bezugnahme a. Hirschberg b. Großalmerode und Umgebung von Kassel]

$\square$ Moesta, Fr. A. (1867): Geologische Schilderung der Gegend zwischen dem Meissner und dem Hirschberge in Hessen - mit besonderer Berücksichtigung der daselbst auftretenden basaltischen u. tertiären Bildungen nebst einer geologischen Karte und einem Blatte mit Gebirgsprofilen. - Diss. Univ. Marburg 1867; 40 S., 1 Kt., 1 Taf. (4 Profile); (Sipmann) Marburg Referat in: N. Jb. Mineral. etc., 1869: 241-243 (Referate); Stuttgart

- $\square$ Mohr (Med.-Rath)(1868): [Widerlegung der] Ansicht, dass man die stängelige Absonderung der Braunkohlen auf dem Meisner, Habichtswald und Hirschberg im Kurhessischen als einen Beweis der feurigen Einwirkung des Basaltes auf diese Brennstoffe ansehen dürfe. - Verhdlgn. d. Naturhistorischen Vereins d. Preuß. Rheinlande u. Westphalens, 25(= 3. F., 5): 25 (Sitzber.); Bonn [Ein später Schlag gegen die magmatische Natur des Basaltes im Plutonisten-, Neptunisten-Streit]

$\square$ Mohs, Friedrich (1806): Der Hirschberg in Hessen. - Ann. d. Berg- u. Hüttenkunde, $\underline{\mathbf{5}}$ - zgl. Efemeriden d. Berg- u. Hüttenkunde, $\underline{2}$ (5): 329-348, Taf. XII (Fig. 6); Nürnberg [Regionale Geologie]

- $\square$ Mürriger, Friedrich \& Pflanzl, Günther (1955): Pollenanalytische Datierungen einiger hessischer Braunkohlen. - Notizbl. Hess. L.-A. Bodenforsch., 3: 71-89, 1 Tab., 2 Taf; Wiesbaden [Darin: Hirschberg, Glimmerode, Oberkaufungen, Stellberg/Söhrewald, Zeche Marie/Habichtswald]

- $\square$ Nöggerath, Karl Jakob (1822-186): Das Gebirge in Rheinland-Westfalen - nach mineralogischem und chemischen Bezuge. - 1. Bd., 370 S.: 7 Abb., (Eduard Weber) Bonn 1822. - 2. Bd.: 387 S., 7 Abb., (Eduard Weber) Bonn 1823. - 3. Bd.: 291 S., 6 Abb., (Eduard Weber) Bonn 1824. - 4 Bd.: 390 S., 2 Abb., (Eduard Weber) Bonn 1826

[darin Bd. III, S. 273 - 277: „Kurze Nachricht von einigen wenig bekannten Basalt-Gängen in Hessen 
(aus einem Briefe)“; Kontaktmetamorphose des Basaltes auf das Rahmengestein: Habichtswald, Ahnetal, Hirschberg; Schieferberg N’ Meissner (vermutl. Heiligenberg S’ Weißenbach)]

a $\square$ Oehlschlegel, H. G. (1964): Geochemische Untersuchungen an nordwestdeutschen und nordhessischen tertiären Braunkohlen. - N. Jb. Mineral. etc., Abh., 101(1): 67-96, 18 Abb., 9 Tab. i. T. u. a. Beil.; Stuttgart

[u.a. Gahrenberg, Hirschberg, Hoher Meißner, Freudenthal/Oberkaufungen, Stellberg/Söhre, Marie Trost/Habichtswald]

$\square$ Pflanzl, Günter (1956): Das Alter der Braunkohlen des Meißners, der Flöze 2 und 3 des Hirschberges und eines benachbarten Kohlenlagers bei Laudenbach. - Notizbl. Hess. L.-A. Bodenforsch., 84: 232244, 1 Tab., Taf. 16-17; Wiesbaden

- $\square$ Pflug, Hans Dieter (1966): Zur Stratigraphie des mittleren Tertärs in Hessen und in benachbarten Gebieten. - Notizbl. Hess. Landesamtes Bodenforschung., 94: 259-268, 2 Abb., 1 Tab.; Wiesbaden [Palynologische Untersuchungen a. Braunkohlen; darin: Borken, Oberkaufungen, Zeche Marie i. Habichtswald/Kassel; Grube Hirschberg/Großalmerode, Grube Glimmerode/Hessisch Lichtenau]

- $\square$ Pietzsch, Kurt (1925): Handbuch der Geologie und Bodenschätze Deutschlands / Erich Krenkel [Hrsg.]. - Abt. 3: Die Bodenschätze Deutschlands - Bd. 1: Die Braunkohlen Deutschlands. - XII, 488 S., 105 Textabb., 20 Taf.; (Bornträger) Berlin [darin S. 205-225: Der Niederhessische Bezirk [Revier Cassel] (darin; Habichtswald, Stellberg, Hirschberg, Oberkaufungen, Glimmerode, Meißner)]

$\square$ Plein, Eberhard (1954): Der Basaltvulkanismus vom Hirschberg bei Großalmerode und der Bau seiner Förderzone in tertiären Sedimenten. - Notizbl. Hess. Landesamtes Bodenforschung, $\underline{\mathbf{8 2}}$ (= 6. F., H. 5): 215 - 233, 5 Abb.; Wiesbaden

$\square$ Plein, Eberhard (1954): Erdmagnetische Messungen an dem Basaltvorkommen des Hirschbergs bei Großalmerode (Niederhessen). - Notizbl. Hess. Landesamtes Bodenforschung, $\underline{\mathbf{2 2}}$ (= 6. F., H. 5): 334 - 340, 3 Abb.; Wiesbaden

$\square \bullet$ Prauss, Michael (1980): Geologische und lagerstättenkundliche Untersuchungen im Nordteil der hessischen Senke - Teil 1: Die Geologie am südöstlichen Ausläufer des Bramwaldes zwischen Schede und Werratal (Bl. Jühne). - Teil 2: Petrographische Untersuchungen der Flöze 2 und 3 der Braunkohle am Hirschberg bei Großalmerode. - Dipl.-Arb. [unveröff.] Univ. Göttingen 1980; Teil 1, 58 S.; Teil $2 ; 179 \mathrm{~S}$.

- $\square$ Prauss, Michael [Red.](1986): Die Braunkohlen der Niederhessischen Tertiärsenke. - 18 S., 5 Abb., 5 Tab.; [Stadt Kassel, Naturkundemuseum] Kassel

[Borken, Großalmerode/Hirschberg]

- $\square \bullet$ Rinne, O. (1893): Über norddeutsche Basalte aus dem Gebiete der Weser und den angrenzenden Gebieten der Werra und Fulda - I. Untersuchungen im nördlichen, sowie einzelner Vorkommnisse im südlichen Teil des Gebietes. - Jb. Preuß. Geol. Landesanst., 13 (f. 1892): 1-95 (Abh. v. behördenfremd. Pers.), Taf. VI - IX; Berlin

Referat in: N. Jb. Mineral. etc, $\underline{1894}$ (Bd. II): 56-59 (O. Mügge); Stuttgart

[Vorkommen Lkr. Kassel, Lkr. Göttingen; Habichtswald, Meißner, S. 16-18 Blaue Kuppe b.

Eschwege u. Alpstein b. Kirchhosbach]

- $\square$ Rosenthal, (Bergingenieur) (1895): Die tertiären Ablagerungen bei Kassel und ihre durch Basaltdurchbrüche veredelten Braunkohlenflöze. - Tour. Mitt. a. bd. Hessen, $\underline{\mathbf{3}}(12)$ : 149-152; Kassel [Habichtswald, Stellberg, Hirschberg, Hoher Meißner]

- $\square$ Rosenthal, (Berg-Ingenieur) (1896): Die tertiären Ablagerungen bei Kasssel und ihre durch Basaltdurchbrüche veredelten Braunkohlenflöze. - Abh. u. Ber. Vereins Naturkde. z. Kassel, $\underline{41}$ 
(1995/1896): 106-117, 3 Abb. (Profile); Kassel

[darin: Habichtswald, Hirschberg, Stellberg, Meissner]

$\square$ Schmidt, F. X. (1926): Der Hirschberg $<$ Hausberg von Großalmerode>. - Hessischer Gebirgsbote, 32(8): 57 - 58; Kassel

$\square$ Schulz, Dirk-Olaf (1994): Petrographische Untersuchungen am Flöz 1 des Braunkohlevorkommens am Hirschberg. - Dipl.-Arb. [unveröff.] Univ. Göttingen; 68 S.

- $\square$ Uthemann, A. (1892): Die Braunkohlen-Lagerstätten am Meissner, am Hirschberg und am Stellberg mit besonderer Berücksichtigung der Durchbruchs- und Contacteinwirkungen, welche die Basalte auf die Braunkohlenflöze ausgeübt haben. - Abh. Kgl. Preuß. Geol. Landesanst., N.F., 7; 54 S., 10 Abb., 3 Falt-Taf.; Berlin

Referat in: N. Jb. Mineral. etc., $\underline{1893}$ (Bd. II): 164-165 (v. Koenen); Stuttgart

- $\square$ Voigt, Johann Carl Wilhelm (1802): Mineralogische Reise nach den Braunkohlenbergwerken und Basalten Hessens, wie auch den Schieferkohlenwerken des Unterharzes. - VIII, 238 S.; Weimar [darin: Blaue Kuppe, Meißner, Hirschberg; Vorlage nicht eingesehen; zitiert nach OPPITZ 1991]

$\square$ Waitz von Eschen, R. \& Strippelmann, F. E. (1828): Geognostische Betrachtung der am Hirschberge bei Großalmerode abgelagerten, tertiären Gebilde, nebst einigen Bemerkungen über den daselbst im Betriebe stehenden Bergbau. - Studien Göttingischen Vereins bergmänn. Freunde, 2 2: 121168; (Dieterich) Göttingen

[Tertiärstratigraphie, Braunkohlenbergbau, Alaungewinnung]

$\square$ Zirkel, Ferdinand (1871): Die Umwandlungsprozesse im Mineralreich - Akademische Rede, gehalten am 19. December 1870 in der Aula zu Leipzig. - Sammlung gemeinverständlicher Vorträge, Ser. 6, H. 136; 40 S.; (Lüderitz) Berlin

[darin: Hinweis a. Kontaktmetamorphose Basalt/Kohle Meißner, Hirschberg b. Großalmerode; Brennende Kohle bei Abterode (Stinksteinwand Hoher Meißner)]

\subsubsection{4 „Bühlchen“ bei Epterode (Werra-Meißner-Kreis)}

$\square$ Anonym (1975): Das „Bühlchen“ bei Epterode. - In: Wollenhaupt, Gustav [Hrsg.]: Geschichte der Stadt Großalmerode und familienkundliche Nachrichten. - Teil 2; 143 S., Abb.; hier S. 137-139; (Im Selbstverlag) Großalmerode 1975

$\square$ Echle, Wolfram (1964): Mineralbestand und Entstehung des „Porzellanjaspis“ von Epterode (Nordhessen). - Beitr. Mineral. Petrogr., 10: 32 - 41, 2 Abb., 5 Tab.; Berlin-Göttingen-Heidelberg

$\square$ Echle, Wolfram (1968): Der Porzellanjaspis von Epterode, ein Gesteinstyp der Sanidinitfazies. - Der Aufschluss, Sdbd. 17 (Zur Mineralogie und Geologie der Umgebung von Göttingen): 128 - 150, 1 Abb.; Göttingen

$\square$ Echle, Wolfram (1978): Der Porzellanjaspis von Epterode, ein Gesteinstyp der Sanidinitfazies. - Der In: Koritnig, Sigmund [Schriftltg.]: Zur Mineralogie und Geologie der Umgebung von Göttingen mit Westharz und Teilen des Nordhessischen Berglandes. - Sdbd. 28: 205 - 207, 1 Abb.; Heidelberg 1978

$\square$ Festausschuß [Hrsg.](1982): Epterode 1182 - 1982 und Einweihung des Dorfgemeinschaftshauses vom Freitag, den 20. bis Montag, den 23. August 1982. - Ohne Seitenzählung, zahlr. Abb.; Epterode [darin Kap: Das Bühlchen bei Epterode; Der Ton, die Töpfer, die Epteroder Tiegelmacher und die Goebels] 
- $\square$ O Leonhard, Karl Caesar [v.](1805-1809): Handbuch einer allgemeinen topographischen Mineralogie. - Bd. 1, 479 S., ersch. 1805; Bd. 2, 568 S., ersch. 1808; Bd. 3, 432 S., ersch. 1809; (J. Ch. Hermann) Frankufrt/M.

[Verzeichnis von Mineralfundstätten, nach Mineralen geordnet.; darin: (Groß-) Almerode, Hirschberg, Epterode, Eschwege, , Kassel, Meißner, Oberkaufungen, Richelsdorf, Göttingen, Orte i. Thüringen]

$\square$ Mötzing, Kurt (1975): Die Alaunberghalde bei Epterode. - Hessischer Gebirgsbote, $\underline{76}(2): 44-45$; Melsungen

$\square$ Naumann, Peter (1986): Tonjaspis und Porzellanjaspis vom „Bühlchen“ bei Epterode/Meißner. Hessischer Gebirgsbote, 87(3): 105-106; Melsungen

$\square$ Naumann, Peter (1996): Der Porzellanjaspis von Epterode/Meißner. - Geol.-mineral. Mitt. Nordhessen, 10; 33 S., 9 Abb.; (Selbstverlag Naumann) Hofgeismar

$\square$ Nobel, Hermann (2007): Das Bühlchen - eine geologische Besonderheit. - In: Nobel, Hermann: Chronik Epterode - Von Euerharderot zu Epterode - 825 Jahre Epterode. Mit Beiträgen von Stefan Bauer, Erich Hofsommer, Dr. Friedhelm Koch, Dr. Karl Kollmann \& Werner Sippel. Herausgegeben vom Magistrat der Stadt Großalmerode anläßlich der 825-Jahr-Feier. - 453 S., zahlr. Abb. u. Tab.; hier S. 9-13, 7 Abb.; (Magistrat d. Stadt Großalmerode) Großalmerode 2007

口Udluft, Hans (1953): Das „Bühlchen“ bei Epterode - eine alte Alaunbergbauhalde. - Notizbl. Hess. L.A. Bodenforsch., $\underline{\mathbf{8 3}}$ (6. F., H. 4): 255 - 257; Wiesbaden

$\square$ Walchner, F. A. (1839): Allgemeine Naturgeschichte für alle Stände, von Prof. Oken - Erster Band: Mineralogie und Geognosie. - XXIII, 860 S.; (Hoffmann'sche Verlagsbuchhdlg.) Stuttgart [darin: S. 807-808 Blaue Kuppe bei Eschwege, S. 819 Bühlchen bei Epterode]

\subsubsection{Hoher Meißner (Werra-Meißner-Kreis)}

\subsection{Geologie, Paläontologie, Erforschungsgeschichte}

$\square$ Amelung, Theodor (18886): Meissner-Führer - Mit einer Specialkarte und einem kurzen Führer durch das Werrathal von Kreuzburg bis Witzenhausen nebst Karte. - 47 S., 6 S. Anh.; (Rossbach) Eschwege [darin S. 2-7: „Gebirgs- und Bodenverhältnisse“]

- $\square$ ○ीApel, Jürgen \& Rüppel, Heidi [Verfass. u. Hrsg.] (2005): Raus in die Natur - Tipps für den Sonntags-Ausflug im Dreiländereck Hessen - Niedersachsen - Thüringen. - 159 S., 111 Fotos, 34 Kt., 1 strat. Tab.; (LSRB-Verlag, Landschaftskundlicher-Studien-Reisebuch-Verlag) Witzenhausen [zahlreiche Ausflugstipps, auch zu Geotopen auf dem Meißner - Ziele 67, 68, 69, 70, 71, 72]

$\square$ Beck, Hanno (1952): Die Erforschung des Meißners. - Das Werraland, 4(2): 19-22, 1 Abb.; Eschwege

$\square$ Beck, Hanno (1956): Die Geschichte der Meißnerforschung. - In: Beck, Hanno: Eschwege - Heimat und Welt. - 72 S.; hier S. 22-34; (Roßbach) Eschwege 1956

$\square$ Beck, Hanno (1956): Eschwege und seine Landschaft im Mund berühmter Männer. - In: Beck, Hanno: Eschwege - Heimat und Welt. - 72 S.; hier S. 8-9; (Roßbach) Eschwege 1956

[Zeungisse über „Blaue Kuppe“ und Hoher Meißner]

$\square$ Beck, Hanno (1957): Hundeshagens Meißnerforschungen. - Hessische Heimat, $\underline{6}$ [f. 1956/57](1): 18-19; Marburg/L. 
- $\square$ Beck, Hanno (1961): Vulkanisten und Neptunisten in Hessen. - Ber. Dt. Landeskunde, 27: 87-106; Bad Godesberg

$\square$ Beck, Hanno (1965): Natur- und Kulturgeschichte des Meißners (Serie: Eschweger Literatur, 27). Werra-Rundschau, 1965; Nr. 241 v. 16.10.1965, S. 7; Eschwege

[Erforschungsgeschichte, Bergbaugeschichte]

- $\square$ Beck, Hanno (1973): Geographie. Europäische Entwicklung in Texten und Erläuterungen. - Serie: Orbis academicus. 2/16; 510 S.; (Albers) Freiburg i. Br. - München [darin S. 124-127: „Die Topographie des Landgrafen Hermann zu Hessen-Rotenburg“ [Werra, Meißner]; S. 146-147: „Topographische Tradition: Heinrich Hofrock“ [Beschreibung der Landschaft um Eschwege]; S. 191-192 Rudolf Erich Raspe[Habichtswald]; S. 207-208 „Vulkanismusstreit““ [Meißner, Blaue Kuppe, Habichtswald]

$\square$ OBeyschlag, Franz (1886): Erläuterungen zur Geologischen Specialkarte von Preussen und den Thüringischen Staaten. - Lieferung 23 - Blatt Allendorf - Gradabth. 55, Bl. 46; [ heute: 4725 Bad Sooden-Allendorf ]. - Geol. Aufn.: Friedrich Moesta, Verf.: ... - 66 S., 2 Taf.; (i. Comm. Simon Schropp'sche Hof-Landkartenhdlg. (J. H. Neumann)) Berlin 1886

Hrsg.: Königlich Preußische Geologische Landesanstalt und Bergakademie; Berlin Dazugehörige Karte herausgegeben 1878

$\square$ Boden, Waldemar (1959): Der Meissner. - Der Aufschluss, 10: 90 - 92, 1 Abb.; Göttingen

$\square$ Brunnemann, Max (1901): Der Meissner und angrenzende Gebietsteile - Illustrierter Führer. Brunnemanns Reisehandbücher, IV; 72 S., Abb., 1 Kt.-Beil. i. Tasche; (Brunnemann) Kassel [darin Kap. „Geologischer Bau“, „Bergbau“]

- $\square$ Busse, Hentschel, Kutscher, Laemmlen, Pflanzl, Rösing \&Udluft (1959/60): Geologie der Umgebung von Eschwege und des Hohen Meißners - Bericht über die Exkursionen anläßlich der 110. Hauptversammlung [der Deutschen Geologischen Gesellschaft] vom 1.-9- September 1958 [in Kassel] - Exkursion F - Mesozoikum u. Tertiär der Hessischen Senke - Sonntag, den 7. September 1958 - Z. dt. geol. Ges., 111 (f. 1959/60): 288-301, 1 Abb.; Hannover

[Hp. 1-4: Buntsandstein i. d. Umgebung v. Eschwege; HP 5-10: Geologie des Hohen Meißners]

$\square$ Busse, Erwin (1962): Ceratites armatus PHILIPPI im Oberen Muschelkalk des Meißners (Niederhessen). - Notizbl. Hess. L.-A. Bodenforsch., 90: 87-92, 1 Tab., Taf. 10; Wiesbaden

$\square$ Busse, E.; Hentschel, Kutscher, Laemmlen, M.; Pflanzl, G.; Rösing, F. \&Udluft, H. (1960): Geologie der Umgebung von Eschwege und des Hohen Meißners - Bericht über die Exkursionen anläßlich der 110. Haupfversammlung [der Deutschen Geologischen Gesellschaft] vom 1.-9September 1968 [in Kassel]. - Exkursion F - Mesozoikum u. Tertiär der Hessischen Senke - Sonntag, den 7. September 1958 — Z. dt. geol. Ges., 111 (f. 1959/60): 288-301, 1 Abb.; Hannover [Haltepunkt 1-4: Buntsandstein Hoheneiche, Neuerode, Straße Grebendorf-Kella; Hp 5: Buntsandstein zw. Germerode/Schwalbenthal; Hp 6/7 Seesteine und Kitzkammer/Meißner, 8 Braunkohlentagebau, Hp 9 Kalbe, Hp 10: Alte Bremsbahn unterhalb Bransrod]

$\square \bullet$ Deppe, Heinrich (1912): Die Landschaften Südhannovers und der angrenzenden Gebiete dargestellt auf geologischer Grundlage. Ein Beitrag zur Einführung der Geologie in den heimatkundlichen Unterricht. - Reihe: Südhannoversche Heimatbücher, 1; X, 193 S., VIII, Abb., 1 Kt.; (Vandenhoeck \& Ruprecht) Göttingen [darin: „Der Meißner“, „Das Grauwacken- und Zechsteingebirge an der unteren Werra“]

- $\square$ Dersch-Hansmann, Michaela [Mitautorin] (1999): Geotope in Hessen. - In: Hoppe, Andreas \& Steininger, Fritz [Hrsg.]: Exkursionen zu Geotopen in Hessen und Rheinland-Pfalz sowie zur naturwissenschaftlichen Beobachtungspunkten Johann Wolfgang von Goethes in Böhmen. Schriftenreihe Dt. Geol. Ges., $\underline{\mathbf{8}}$ (Kleine Senckenberg Reihe, 31); 252 S., zahlr. Abb. S. 69-126, 43 
Abb.; (Deutsche Geologische Gesellschaft) Hannover 1999

[darin: Haltepunkt 7 Blaue Kuppe, Hp. Höllental/Schmelzhütte, Hp. 9 Frankershausen/Stbr.

Schafhof, Hp. 10 Hoher Meißner/Kalbe, Hp. 11 Kitzkammer, Hp. Cornberg]

$\square$ Engelhardt, O. [Hrsg.](1920): Der Meissner. - 48 S.; 4 Abb.; (Johs. Braun) Eschwege

[darin: S. 13-16 „Geologisches, S. 16 „Bergbau“]

$\square$ Feiertag, Alexander \& Wilke, Sabine (1995): Der Hohe Meißner - Geologische Entwicklung und Bodenvergesellschaftung. - 37 S.; BPSII - Arbeit Fachber. 13 (Feiertag); Hausarbeit Fachber. 19 (Wilke); Ghs/Univ. Kassel

$\square$ Fey, Adolf (1894): Der Weissner [Hoher Meißner] - Natur, Sage und persönliche Erlebnisse. - Tourist. Mitth. a. beid. Hessen, $\underline{\mathbf{3}}(1): 2-3, \underline{\mathbf{3}}(2): 20-26$; Kassel

口OFirbas, Franz (1952): Spät- und nacheiszeitliche Waldgeschichte Mitteleuropas nördlich der Alpen. 2. Bd.; 256 S., 18 Abb.; (G. Fischer) Jena

[darin: Meißner, Thüringer Wald]

-Garleff, K. \& Brosche, U. (1986): Exkursion A - Kasseler Becken - Hoher Meißner - Werratal: Skulptur- und Strukturformengenese seit dem Mitteltertiär, plio-/pleistozäne Fußflächen, Morphogenese des Meissners, Talentwicklung an Werra- und Fulda. - In: Dt. Arbeitskreis f. Geomorphologie - Jahrestagung 1986, 8. - 10. Oktober 1986 in Göttingen; Exkursionsführer; 37 S.; hier: S. 1 - 12, 9 Abb.; (Geogr. Inst.) Göttingen

$\square$ Gold, Hans H. (2004): Die Vegetation des Meißners und seine Waldgeschichte. - Das Werraland, 56(3): 55 - 56, 2 Abb.; Bad Sooden-Allendorf

[Referat über die Schrift von Hans Pfalzgraf (1934): Die Vegetation des Meißners und seine Waldgeschichte]

$\square$ Hagdorn, H.; Horn, M.; Hickethier, M. \& Simon, Th. (1987): Profile durch den hessischen, unterfränkischen und baden-württembergischen Muschelkalk. - Geol. Jb. Hessen, 115: 131-160, 2 Abb., 2 Tab., 3 Taf.; Wiesbaden

[Profile Meißner und Bhrg. Röhrda, Bl. 4926 Herleshausen]

- $\square$ Harder, Hermann (1993): Zur Entstehung von verkieselten Hölzern. - Der Aufschluss, 44: 23-31, 8 Abb.; Heidelberg

[u.a. chem. Analysen Proben Druseltal/Habichtswald, Hoher Meißner]

- $\square \bullet$ Hausmann, [J. F. L.](1824): Uebersicht der jüngeren Flöz-Gebilde im Fluß-Gebiete der Weser. Tb. Mineral., 18 (3): 678-702; Frankfurt/M. - Auszug aus Hausmann: Uebersicht der jüngeren FlözGebilde. - Studien Göttingischen Vereins bergmänn. Freunde, 1: 381 - 567, Göttingen 1824 Regionale Stratigraphie Trias-Tertiär Hessen, WMK, Niedersachsen; darin: Tertiär Meißner, Hirschberg, Habichtswald, Wilhelmshöhe b. Kassel, Dransfeld]

- $\square \bullet$ Hausmann, J. F. L. (1858): Über das Vorkommen verschiedener Kieselgebilde in Begleitung des Basaltes. - Studien Göttingischen Vereins bergmänn. Freunde, $\underline{7}(2): 139$ - 192; Göttingen [darin: Blaue Kuppe, Hirschberg, Habichtswald, Meißner, Steinberg b. Hann-Münden; S. 154-156: „Absatz von Kieselsinter in dem schlackigen Anthracite des Meißners; S. 165-172: „Durch Eindringung von kieselsäurehaltigem Wasser in die Schichten des vom Basalte durchbrochenen Muschelkalkes gebildeter Kieselkalk“ (Kontkatmetamorpher Marmor vom „Schieferberg b. Bransrode“/Hoher Meißner S” Weisenbach, heutiger Name „Heiligenberg“]

$\square$ Hentschel, H.; Kortinig, S.; Kutscher, F.; Rösing, F. (1962): Ganztagsexkursion zur Blauen Kuppe, am 25. Mai 1961. Geologischer Bericht. - (Übergeordn. Titel: Bericht über die Exkursionen während der Tagung des Naturhistorischen Vereins der Rheinlande und Westfalens vom 23. - 26. Mai 1961 in Kassel). - Decheniana - Verhdlgn. Naturhist. Vereins Rheinlande u. Westfalens, 114 (f. 1961): 195201, 2 Abb.; Bonn 
[darin: Blaue Kuppe, Stbr. a. Meinhard, Wienberg/Neuerode; Hoher Meißner: Haldenhaus, Kalbe, Seesteine, Kitzkammer)

$\square$ Hotzler, Fritz (1991): Wanderführer Meißner - Naturpark Meissner-Kaufunger Wald. - 4. Aufl.; 54 S., Abb., 1 Falt-Kt.; [Hrsg. Zweckverband Naturpark-Meißner-Kaufunger Wald](Vogt) Hessisch Lichtenau [darin: S. 11-15, 2 Abb.: „Geologie des Meißners“]

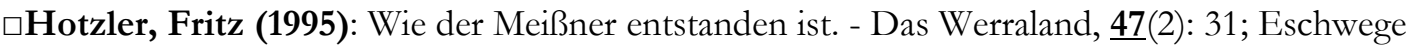

$\square$ [Humboldt, Alexander von](1790): Mineralogische Besonderheiten über einige Basalte am Rhein. Mit vorangeschickten, zerstreuten Bemerkungen über den Basalt der ältern und neuern Schriftsteller. - VIII, 126 S.; (Schulbuchhdlg.) Braunschweig

[darin: S. 16-17: Der Basalt des Meissners im Streit zwischen Neptunisten und Plutonisten]

$\square$ Hundeshagen (Oberförster) [Johann Christian](1809): Bemerkungen über den Meißner. - Tb.

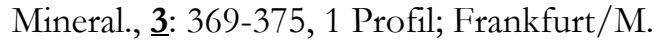

$\square$ Hundeshagen (Oberförster)[Johann Christian](1817): Beschreibung des Meisners. - Tb. Mineralogie, 11(1): 3-58 (2 Profile, 1 Kte.); Frankfurt/M.

$\square$ Jacobshagen, Volker (1997): Fossile und rezente Subrosion von Zechstein-Evaporiten der Region Eschwege - Hoher Meißner (Nordhessen). - Z. Geol. Wiss., 25(3/4): 253-261, 5 Abb.; Berlin

$\square$ Jacobshagen, Volker \& Kuhnert, Christian [Hrsg.]1989): Der Hohe Meißner in Hessen Ergebnisse geologischer und geomorphologischer Forschungen. - Berliner geowiss. Abh., Reihe A, 114; 114 S., 26 Abb., 6 Tab., 3 Beil.; (Selbstverlag Fachber. Geowiss. FU Berlin) Berlin Referat in: Das Werraland, 41 : 71 (Angerhöfer); Eschwege

$\square$ Jacobshagen, V.; Kuhnert, Christian \& Wycisk, Peter (1989): Geologie des Hohen Meißners in Nordhessen. - In: Jacobshagen, Volker \& Kuhnert, Christian [Hrsg.]: Der Hohe Meißner in Hessen - Ergebnisse geologischer und geomorphologischer Forschungen. - Berliner geowiss. Abh., Reihe A, 114; S. 9-76, 8 Abb., 5 Tab., 2 Beil.; (Selbstverlag Fachber. Geowiss. FU Berlin) Berlin 1989 [darin: „Geschichte des Bergbaus undd der geologischen Erforschung“]

$\square$ Jäger, Willy (1931): Erloschene Vulkane um Eschwege herum. - Die Weser, 10 (8): 232-233, 1 Abb.; Bremen

[Bilstein/Höllental b. Frankershausen, Hoher Meißner, Blaue Kuppe b. Eschwege]

- $\square$ Kayser, Emanuel (1923): Lehrbuch der Allgemeinen Geologie. - (Vier Bände: I. u. II. Band Allgemeine Geologie, III u. IV. Bd. Geologische Formationskunde). - Bd. I: Physiographische Geologie und Äussere Dynamik. - 7. u. 8. Aufl., 740 S., 549 Abb.; (Enke) Stuttgart [darin: Abb. z. Vulkanismus Abb. 58 Basaltbruch Bühl b. Ahnatal/Weimar W'Kassel; 92a Teufelswand, Habichtswald/Kassel; 110 Profil Meissner - 111 Profil Hirschberg b. Großalmerode Tektonik: Abb. 203 Profil Netratal b. Eschwege, 204 „Eichenberg“ b. Netra]

$\square$ Kayser, Emanuel (1924): Lehrbuch der Allgemeinen Geologie. - (Vier Bände: I. u. II. Band Allgemeine Geologie, III u. IV. Bd. Geologische Formationskunde). - Bd. IV: Geologische Formationskunde- Kreide, Tertiär- und Quartärformation. - 6. u. 7. Aufl., 147 Abb., 54 Taf.; (Enke) Stuttgart [darin S. 365 Profil Meissner]

$\square$ Kirchmeier (1940): Ferienheim Friedrichstollen am Meißner. - Hessischer Gebirgsbote, 4으(1): 5 - 6, 3 Abb.; Melsungen [darin Fotos: „Krippenlöcher“ bei Frankershausen am Meißner, Höllental am Meißner] 
$\square$ Klinge, H.; Puffe, D.; Scheffer, Fr. \& Welte, E. (1962): Die Rendsinen der mitteldeutschen Berg- und Hügellandschaften (Leine-Weser-Bergland). - 3. Mittteilung: Humus und Stickstoff in den Rendsinen unter verschiedenen Standortsbedingungen. - Z. f. Pflanzenernährung, Düngung, Bodenkde., $\underline{\mathbf{9 6}}$ (17): 46-62, 2 Abb., 10 Tab.; Weinheim

[darin: Meißner]

- $\square$ Klipstein, v. (1836): Versuch einer geographisch-geognostischen Eintheilung des westlichen Deutschlandes nebst generellen Andeutungen zur geognostischen Konstitution der verschiedenen Gebirgs-Abtheilungen desselben. - N. Jb. Mineral. etc., 1836: 255-289; Stuttgart

[Entwurf einer regionalen Geologie von West-Deutschland; darin: „Habichtswald...“; „Meissner und Knöll“(Knüll)]

$\square$ Koch, Heinrich (1958): Im Bereich der drei Großen: Meißner - Hirschberg - Bilstein. - Hessischer Gebirgsbote, 59(3): 29 - 31; Melsungen

$\square \bullet$ Koenen, A. v. (1888): Beiträge zur Kenntnis von Dislokationen. - Jb. Preuß. Geol. Landesanst., $\underline{8}$ (f. 1887): 457-471; Berlin

Referat in: N. Jb. Mineral. etc, 1891 (Bd. I): 312 (E. Koken); Stuttgart [u.a. Basaltvorkommen Hoher Meißner, Störung b. Göttingen-Weende]

$\square$ Kollmann, Karl (2002): Frau Holle und das Meißnerland - (2): Der Frauhollenteich [Teil 1]. - Das Werraland, $\underline{\mathbf{5 4}}(1):$ 1-4, 6 Abb.; Eschwege

$\square$ Kollmann, Karl (2002): Frau Holle und das Meißnerland - (3): Der Frauhollenteich [Teil 2]. - Das Werraland, $\underline{\mathbf{5 4}}(2): 33-36,3$ Abb.; Eschwege

$\square$ Kollmann, Karl (2002): Frau Holle und das Meißnerland - (4): Der Frauhollenteich [Teil 3]. - Das Werraland, 54(4): 83-84, 3 Abb.; Eschwege

$\square$ Kollmann, Karl (2004): Frau Holle und das Meißnerland - (9): Die Kitzkammer. - Das Werraland, 56(1): 10-13, 5 Abb.; Eschwege

[Geologie, Sagen um die Kitzkammer; Säulenbasaltfelsen am Westhang des Meißner]

$\square$ Kollmann, Karl (2005): Frau Holle und das Meißnerland - (12): Der Altarstein und seine Umgebung. Das Werraland, $\underline{\mathbf{5 7}}(1)$ : 5-9, 5 Abb.; Bad Sooden-Allendorf

$\square$ Kollmann, Karl (2005): Frau Holle und das Meißnerland - (14): Die Seesteine. - Das Werraland, 57(3): 52-54, 4 Abb.; Bad Sooden-Allendorf

$\square$ Kupfahl, Hans-Günther (1958): Die Abfolge des Buntsandsteins am östlichen Meißner-Gebirge. Notizbl. Hess. L.-A. Bodenforsch., 무: 202 - 214, 1 Abb., 1 Tab., 1 Taf.; Wiesbaden

- $\square$ Kvaček, Zlatko \& Walther, Harald (1974): Bemerkenswerte und seltene cinnamomoide Blätter aus dem Grenzbereich des Oligo-Miozäns Mitteleuropas. - Abh. Staatl. Museums f. Mineralogie u. Geologie z. Dresden, 21: 197-221, 3 Abb., 1 Taf.; Dresden [Funde Habichtswald, Meißner]

- $\square$ Mattig, Ulrike (2004): Naturerlebnis im Herzen Deutschlands. - In: Hessen - Land der Mitte. - 1. Aufl., 592 S., zahlr. Abb.; hier S. 130-141, 6 Abb.; (Gauweiler) Heidelberg [auch Informationen z. Regionalgeologie Naturpark Habichtswald, Naturpark Meißner-Kaufunger Wald]

- $\square$ Moench, C. [ermittelt](1787): Beitrag zur Naturgeschichte der Landgrafschaft Hessen-Cassel. -

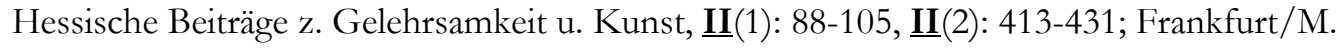
[darin: Meißner] 
$\square$ Moesta, Fr. A. (1867): Geologische Schilderung der Gegend zwischen dem Meissner und dem Hirschberge in Hessen - mit besonderer Berücksichtigung der daselbst auftretenden basaltischen u. tertiären Bildungen nebst einer geologischen Karte und einem Blatte mit Gebirgsprofilen. - Diss. Univ. Marburg 1867; 40 S., 1 Kt., 1 Taf. (4 Profile); (Sipmann) Marburg Referat in: N. Jb. Mineral. etc., 1869: 241-243; Stuttgart

$\square$ Namenskürzel (mk) (1949): „Der Meißner“ - ein Heimatbuch von Prof. Ulrich [Buchbesprechung]. Werra-Rundschau, 1949; Nr. 126 v. 1.6.1949, S. 5; Eschwege

$\square$ Penndorf, Hans (1951): Die Ceratitenschichten am Meißner in Niederhessen. - Abh. Senckenberg. Naturforsch. Ges., 484: 1-24, 3 Abb., 6 Taf.; Frankfurt/M.

$\square$ Perst, O. (1949): Natur- und Kulturgeschichte des Meißners. - Das Werraland - Festschrift zur 700Jahrfeier der Stadtwerdung Eschweges - 1. Juli 1949. - Das Werraland [Die Null-Nummer der Zeitschrift „Das Werraland“] [= 1(1)]: 17-18, 3 Abb.; Eschwege

Referat zu Wilhelm Ulrich: Der Meißner. - 116 S., 5 Abb.; (Werra-Verlagsgesellschaft) Eschwege 1949]

$\square$ Pfalzgraf, Hans (1934): Die Vegetation des Meißners und seine Waldgeschichte. - Repertorium specierum novarum regnis vegetabilis, Beih. 푸; 80 S., Abb., Tab., Taf., Diagr.; Dahlem b. Berlin [darin: S. 12 - 14: Kap. „Zur Morphologie und Geologie des Meißners“; S. 64 - 75: „Die Pollenanalyse und die Waldgeschichte der Meißnerlandschaft"]

$\square$ Pflanzl, Günter (1953): Die Geologie des Meissners in Hessen. - Diss. Univ. Marburg 1953; 301 S., 49 Abb., 6 Anl.; Marburg

$\square$ Puffe, Dieter \& Zerr, Walter (1989): Untersuchungen an Böden unter Grünland im Gebiet des Hohen Meißners. - Eichhofberichte, $\underline{\mathbf{A 1 3}} ; 32$ Bl., graph. Darst., Kt.; [Hess. Landwirtschaftl. Lehr- u. Forschungsanst.]Bad Hersfeld

-0Riess, Johann Philipp (1791): Mineralogische und bergmännische Beobachtungen über eine Hessische Gebirgsgegenden. - XIV, 102 S., 6 Taf.; (Rottmann) Berlin [darin: S. 28-54 Kupferschiefer- u. Kobalt-Bergbau Richelsdorfer Gebirge; S. 54-59 Kupferschiefer- u. Kobalt-Bergbau Glücksbrunn b. Bad Liebenstein; S. $69-84$ („,Steinkohlen“-) Braunkohlenbergbau u. Tertiär-Stratigaphie am Meissner; S. 84-89 Alaun- und (,Steinkohlen“) Braunkohlen-Bergbau Oberkaufungen]

- $\square$ Ritzkowski, S. \& Rösing, F. (1977): Tertiär Nordhessens - (Exkursion K) - Exkursionsführer Geotagung '77, Bd. II, S. 63-111, 16 Abb., 1 stratigr. Tab.; (Selbstverlag Geol.-paläont. Inst. Univ. Göttingen) Göttingen

[darin: Borken, Verna, Obervorschütz, Knickhagen, Bühl b. Ahnatal/Weimar; Breitenbach, Hoof, Vollmarshausen, Glimmerode, Hoher Meissner]

- $\square$ Rothe, Peter (2005): Die Geologie Deutschlands - 48 Landschaften im Portrait. - 240 S., 142 Abb.; (Wissenschaftliche Buchgesellschaft Darmstadt) Darmstadt [darin: Kap. „Thüringer Becken“, „Thüringer Wald“, „Hessische Senke“ (mit „Blauer Kuppe“, Hoher Meißner)]

$\square$ Sadebeck, M. (1874): Der Meissner bei Cassel. - Z. Gesell. f. Erdkunde z. Berlin, 9(3): 222-229; Berlin [darin: Geologie des Meissners, Geodäsie]

$\square$ Sauer, Helmut (1968): Der Meißner - Kernstück eines Naturparks. - Geogr. Rdschau, 20: 181-187, 1 Abb.; Braunschweig

[Geomorphologie, Geologie, Naturschutz] 
$\square$ Schaub, Johannes (1799/1822): Physikalisch-mineralogisch-bergmännische Beschreibung des Meißners, eines merkwürdigen Basalt- und Steinkohlengebirges in Hessen. - 1. Auflage: XVI, 246 S., 2 Abb., 2 Tab.; (Selbstverl.) Kassel 1799 - 2. Aufl.; VIII, 246 S., 3 Abb.; (Luckhardt) Kassel 1822

$\square$ Senft, Ferdinand (1894): Wanderungen durch die Gebiete der deutschen Mittelgebirgsländer - Die Mittelgebirgszone im Allgemeinen sowie Gruppe I: die mitteldeutschen Berg- und Plateauländer mit den Basaltgebirgsgruppen. - Nebentitel: Geognostische Wanderungen in Deutschland - Ein Handbuch für Naturfreunde und Reisende. - 104 S.; (Hahn'sche Buchhdlg.) Hannover-Leipzig 1894 [darin: Meißner (Geologie des Basaltes und der Braunkohlen)]

- $\square$ Straub, August (1969): Nordhessen: Das Bergland von Niederhessen - Landschaft, Geschichte, Kultur, Kunst, Wirtschaft. - 352 S., zahlr. Abb.; (Glock u. Lutz) Nürnberg [darin auch Informationen zur Geologie: Steinbruch Cornberg, Habichtswald, Knüll, Meißner, Reinhardswald, Richelsdorfer Gebirge, Ringgau,]

$\square$ Ulrich [Wilhelm] (1949): Der Meißner. - 116 S., 5 Abb.; (Werraland-Verlag) Eschwege Referat in: Das Werraland, 1: 17-18 (Perst)

[S. 9-25, 2 Abb.: „Der Meißner landschaftlich und geologisch“; S. 25-29: „Quellen“ [auch Hydrogeologie]; S. 29-45, 1 Abb.: „Das Braunkohlenwerk“]

$\square$ Wagner, Georg (1920): Beiträge zur Kenntnis des oberen Hauptmuschelkalkes von Mittel- und Norddeutschland. - Z. dt. geol. Ges., $\underline{71}$ (f. 1919): 80-103, 3 Abb.; Berlin [darin S. 87-91: Meißner]

$\square$ Walther, Manfred (1978): Geologie des nördlichen Hohen Meißners (GK 25 Bad Sooden-Allendorf 4725). - Dipl.-Arb. [unveröff.] Univ. Göttingen; 151 S.

- Wedepohl, Karl Hans (1961): Geochemische und petrographische Untersuchungen an einigen jungen Eruptivgesteinen Nordwestdeutschlands. - Fortschr. Mineral., 39: 142-148, 2 Abb., 3 Tab.; Stuttgart [HE, NIE; Eifel]

- $\bullet$ Wedepohl, Karl Hans \& Ritzkowski, S. (1980): [DMG-Tagung 1980] Exkursion E 1: Die nördliche Hessische Senke (Tertiär-Vulkanite, Kupferschiefer und variszischer Spilit). - Fortschr. Mineral., 58, Beih. 2 (Einführung zu den Exkursionen anläßlich der 58. Jahrestagung der Deutschen Mineralogischen Gesellschaft in Göttingen 1980): 3-33, 2 Abb., 3 Tab.; Stuttgart [darin Hp: Werra-Meissner-Kreis: Blaue Kuppe, Bilstein, Cornberg, Forsths. Schmelzhütte, Hoher Meissner/Kalbe, Hoher Meissner/Kitzkammer; auch Hoher Hagen/Dransfeld, Westberg/Hofgeismar, Dörnberg/Zierenberg; Güntersberg b. Gudensberg, Isthaburg b. Istha, Steppling b. Homberg/Efze]

$\square$ Wege (1924): Der Meißner und die Blaue Kuppe. - Das Werratal, $\underline{1}(3):$ 36-38; Eschwege

$\square$ Wenderoth, Georg W. F. (1839): Versuch einer Charakteristik der Vegetation von Kurhessen. Als Einleitung in die Flora dieses Landes. - Schriften Ges. Beförd. Gesammt. Naturwiss. z. Marburg; $\underline{4}$; XII, 155 S., [2]Bl., 3 Abb.; (J.C. Kriegers Verlags-Buchhdlg.) Marburg [Geologisches Profil Hoher Meißner]

\subsection{Geomorphologie, Glazialgeologie}

$\square$ Beck, Hanno (1956): Echte Eiszeitspuren auf dem Meißner. Überraschende Ergebnisse neuerer geographischer Forschungen. - Werra-Rundschau, 1956, Nr. 9 v. 7.12.1956, S. 4; Eschwege 
- $\square$ Ernst, Eugen \& Klingsporn, Hermann (1969): Hessen in Karte und Luftbild - Topographischer Atlas - Teil I; 182 S., zahlr. Abb. u. Kt.; [Hrsg. Hess. Landesvermessungsamt](Wachholtz) Neumünster 1969

[darin: 18. Der Meißner - 22. Der Ringgau - ein Ausläufer des Thüringer Stufenlandes - 26. Die Kragenhöfer Schleife der Fulda nördlich Kassel, jeweils 1 Karte, 1 Luftbild]

- $\square$ Garleff, K. \& Brosche, K. U. (1986): Exkusion A - Kasseler Becken - Hoher Meißner - Werratal. Skulptur- und Strukturgenese seit dem Mitteltertiär, plio-/pleistozäne Fußflächen, Morphogenese des Meißners, Talentwicklung an Werra und Fulda. - In: Hagedorn, Jürgen [Hrsg.]: Deutscher Arbeitskreis für Geomorphologie. Jahrestagung 6. - 10. Oktober 1986 in Göttingen Exkursionsführer. S. 1-12, 9 Abb.; Göttingen 1986

$\square$ Möller, Klaus (1986): Die Rutschungen im Innenkippenbereich des Tagebaus Kalbe (Hoher Meißner/Nordhessen). - In: Stäblein, Gerhard [Hrsg.]: Geo- und biowissenschaftliche Forschungen der Freien Universität Berlin im Werra-Meißner-Kreis (Nordhessen). - Berliner Geogr. Abh., 41; zgl. Beiträge zur Werra-Meißner-Forschung, İ; S. 217 - 225, 10 Abb.; (Selbstverl. Inst. Phys. Geogr. FU Berlin) Berlin 1986

$\square$ Möller, Klaus (1989): Die geomorphologischen Verhältnisse am Hohen Meissner und ihre Interpretation. - In: Jacobshagen, Volker \& Kuhnert, Christian [Hrsg.]: Der Hohe Meißner in Hessen - Ergebnisse geologischer und geomorphologischer Forschungen. - Berliner geowiss. Abh., Reihe A, 114; S. 103-114, 3 Abb., 3 Beil.; (Selbstverlag Fachber. Geowiss. FU Berlin) Berlin 1989

$\square$ Möller, Klaus \& Stäblein, Gerhard (1982): Struktur- und Prozeßbereiche der GMK 25 am Beispiel des Meißners (Nordhessen). - In: Barsch, Dietrich \& Stäblein, Gerhard [Hrsg.]: Erträge und Fortschritte der geomorphologischen Detailkartierung. - Berliner Geogr. Abh., $\underline{\mathbf{3 5}}$; 134 S., hier S. 73 85, 4 Abb., 1 Tab., 2 Beil.; (Selbstverl. Geogr. Inst. FU Berlin) Berlin 1982

$\square$ Möller, Klaus (1987): Darstellung von Subrosionsphänomenen am Beispiel Nordhessen [Vortragszusammenfassung]. - In: Hütteroth, W.-D. \& Becker, H. [Hrsg.]: Tagungsberichte und wiss. Abhandlungen 45. Dt. Geographentag Berlin - 30. September - 5. Oktober 1985; 551 S.; hier S. 521; (Steiner) Stuttgart 1987

[Zechsteinmantel Unterwerra-Grauwackengebirge]

$\square$ Poser, Hans (1933): Morphologische Studien aus dem Meißner-Gebiet. Oberflächengestaltung des Meißnergebietes. - Jb. geogr. Ges. Hannover, f. 1932/33: 121-178, 5 Abb., 3 Taf.; Hannover - in erweiterter Form als Diss. Univ. Göttingen 1930

[Hitzeröder Plateau, Wellingeröder Plateau, Gebiet um Frankershausen, Meißner]

$\square$ Poser, H. \& Brochu, M. (1954): Zur Frage des Vorkommens pleistozäner Glazialformen am Meißner. - Abh. Braunschweiger wiss. Ges., ㅁ: 113 - 115, 4 Abb.; Braunschweig

$\square$ Rother, Klaus (1971): Die eiszeitliche Vergletscherung der Mittelgebirge Mitteleuropas. Geographische Rundschau, 23: 260-266; Braunschweig [darin S. 262: Meißner, unvergletschert]

DᄆOSemmel, Arno (1996): Geomorphologie der Bundesrepublik Deutschland - Grundzüge, Forschungsstand, aktuelle Fragen, erörtert an ausgewählten Landschaften. - 5. überarb. u. reg. erweit. Aufl.; Reihe: Erdkundliches Wissen, 30; 199 S., 61 Abb.; (Franz Steiner) Stuttgart [darin: Thüringer Wald, Thüringer Becken, Hessisch-Niedersächsisches Bergland; Meißner]

\subsection{Basalt (Geologie, Mineralogie, Geochemie)}

$\square$ Aubuisson de Voisins, Jean François d' (1819) : Traité de géognosie. - Untertitel : Exposé des connaissances actuelles sur la constitution physique et minéralogie du globe terrestre. $-2 \mathrm{Bd}$. ; Bd. I, 
LXI, 496 S., 1 Taf. ; Bd. II, 2, 665 S., 1 gef. Bl., Ill.; (Levrault) Strasbourg/Paris

[darin: Meissner: S. I,230 Geomorphologie; II, 445 Braunkohle; II, 556 Dolerit - erstmals in der

Forschungsgeschichte wird die grobkörnige Varietät des Meissner-Basaltes als Dolerit bezeichnet]

- $\square$ Beyschlag, F. (1885): Ueber Aufnahmen an der unteren Werra und Fulda (Provinz Hessen-Nassau). Jb. Preuß. Geol. Landesanst., $\underline{\mathbf{5}}$ (f. 1884): XLIX-LII; Berlin

[darin: Basalt Hoher Meißner]

$\square$ Bischof, Gustav (1863/1864/1866/1871): Lehrbuch der chemischen und physikalischen Geologie. - 2., neu bearb. Aufl.; 3 Bd. + Suppl. Bd.; Bd. 1: X, 865 S., 1 Faltkt., 1863; Bd. 2: 952 S., 1864; Bd. 3: XVI, 974 S., 1866; Suppl.-Bd.: VIII, 214 S., 1871; (Adolph Marcus) Bonn

[Bischof setzt sich kritisch mit der Entstehung des Meißner-Basaltes auseinander und kommt - als vielleicht letzter - Vertreter der neptunistischen Sichtweise zu der Ansicht, daß der Basalt nicht vulkanischen Ursprungs ist - Bd. 3: S. 178, 180, 377]

- $\square$ Blum, Reinhard (1860): Handbuch der Lithologie oder Gesteinslehre. - 356 S., 50 Abb.; (Enke) Erlangen

[darin: Meißner, Habichtswald]

$\square$ Boué, Ami (1829): Geognostisches Gemälde von Deutschland. - Herausgegeben von K. C. v. Leonhard. - XVI, 623 S., 8 Taf.; (Hermann) Frankfurt/M.

[darin S. 523-547: Blaue Kuppe, Meißner; Vorlage nicht eingesehen, zitiert nach Oppitz (1991)]

$\square$ Dunker, Wilhelm (1837): Chalcedon und Quarzkrystalle im Anthrazit des Meißner - [...]. Notizenblatt Göttingischen Vereins bergmännischer Freunde, 3: 2-3; Göttingen [Vorlage nicht eingesehen, zitiert nach Oppitz (1991)]

$\square$ Faujas de Saint-Fond, Barthélemy (1805/1809) : Essai de géologie, ou mémoires pour servir à l' histoire naturelle du Globe. - Tomé 1: Animaux et végétaux fossilere, [2] Bl., 493 S., VII Bl., Ill.; (Levrault, Schoell) Paris 1805. - t. 2(p. 1): Minéraux, 400 S.; (Levrault, Schoell) Paris 1809. - T. 2(p. 2): Volcans, S. 402-731, Ill. ; (Levrault, Schoell) Paris - Taf.-Bd. XXIX pl.; (Levrault, Schoell) Paris 1809 [darin : Bd. 1, S. 450 Meißner ; Bd. 2(2), S. 417-418 Meißner]

$\square$ Faust, B. C. (1789): Nachricht von dem auf dem Meißner in Hessen über Steinkohlen und bituminösem Holze liegenden Basalte - Aus dem Augustmonate des 1784er Jahrgangs des Journals von und für Deutschland entlehnt, und mit einer Vorbemerkung, wie auch einigen erläuternden Anmerkungen versehen, von A. G. Werner. - Bergmännisches Journal, 11(1): 261-295; Freiberg/Sachsen

$\square$ Führes, Margit (1982): Die basaltische Beeinflussung des Meissner-Flözes. - Giessener Geol. Schr., $\underline{\text { 36}}$; 106 S., 29 Abb.; Giessen - zgl. Diss. Univ. Giessen 1982

$\square$ Georgi, Klaus-Henning (1971-1986): Kreislauf der Gesteine - Eine Einführung in die Geologie. Reihe: rororo-Sachbuch. - 251 S., 265 Abb. u. graph. Darst.; (Rowohlt Taschenbuch Verlag) Reinbek b. Hamburg - mehrere unveränderte Nachdrucke der Erstauflage v. 1971, letzter 1986 [darin S. 177-180, 1 Abb., Kap. 11 - Druck und Hitze verwandeln Gesteine; Kontaktmetamorphose Basalt/Buntsandstein Blaue Kuppe (Foto) u. Basalt/Braunkohle Hoher Meißner]

- $\square \bullet$ Hausmann, [J. F. L.](1824): Uebersicht der jüngeren Flöz-Gebilde im Fluß-Gebiete der Weser. Tb. Mineral., 18 (3): 678-702; Frankfurt/M. - Auszug aus Hausmann: Uebersicht der jüngeren FlözGebilde. - Studien Göttingischen Vereins bergmänn. Freunde, 1: 381 - 567, Göttingen 1824 [Regionale Stratigraphie Trias-Tertiär Hessen, WMK, Niedersachsen; darin: Meißner, Hirschberg, Habichtswald]

$\square$ Hausmann, Joh. Friedrich Ludwig (1841): Handbuch der Mineralogie. - Zweyter Teil: System und Geschichte der Mineralkörper -Bd. (2) 2; 2. Aufl.; VII, S. 897-1660, [1 B1.]; (Vandenhoeck \& Rupprecht) Göttingen 
[drinS. 1520-1529: Steinkohlen/Anthracit; Bezugnahme auf Meißner, Hirschberg]

$\square$ Haüy, René-Just (1822): Traité de minéralogie. - 2. Auflage ; 4 Textbd. + Taf.Bd. m. 86 Taf.; Bd. 1: 592 S.; Bd. 2: 613 S.; Bd. 3593 S., Bd. 4604 S.; (Louis) Paris

[Haüy bezeichnet den grobkörnigen Basalt des Meissners als „Dolerit mit symplektitischem Gefüge“; offen läßt der Autor die Kardinalfrage der Plutonisten und Neptunisten: die vulkanische oder sedimentäre Entstehung des Basaltes; der Begriff Dolerit wurde erstmals in der Petrographie von Aubuisson 1819 verwandt und für die Beschreibung des grobkörnigen Meissnerbasaltes benutzt]

$\square$ Hentschel, H. (1968): Der Basalt des Meißner. - In: In: Koritnig, Sigmund [Zusstlg. u. red. Vorber.]: Zur Mineralogie und Geologie der Umgebung von Göttingen mit Westharz und Teilen des nordhessischen Berglandes - Sonderheft zur Jahrestagung 1968 der VFMG in Göttingen. - Der Aufschluss, Sdh. 17; S. 151-165, 4 Abb., 1 Tab.; Heidelberg

$\square$ Hentschel, H. (1978): Der Basalt des Meißner. - In: Koritnig, Sigmund [Schriftltg.]: Zur Mineralogie und Geologie der Umgebung von Göttingen - mit Westharz und Teilen des Nordhessischen Berglandes. - Der Aufschluss, Sdbd. 28: 208-228, 4 Abb., 2 Tab.; Heidelberg

$\square$ Hentschel, Hans \& Pfeffer, Paul (1957): Chemisch-petrographische Untersuchungen von Gesteinsveränderungen am Kontakt Kohle-Basalt im Bereich des Braunkohlenbergwerks Zeche Hirschberg bei Großalmerode in Hessen. - Notizbl. Hess. L.-A. Bodenforsch., 포 297-333, 4 Abb., 9 Tab., Taf. 17; Wiesbaden

$\square$ Hoffmann, Friedrich (1823): Geognostische Bemerkungen über die Basalte der Gegend des Meißners und ihren vulkanischen Ursprung (und Notiz von einigen barometrischen und electrometrischen Arbeiten). - Annalen d. Physik und der physikalischen Chemie, 15(3), zgl. Annalen der Physik, $\underline{\mathbf{7 5}}$ : 323-332; Leipzig [ [darin: Blaue Kuppe, Alpstein, Hoher Meißner, Hirschberg b. Großalmerode, Heiligenberg b. Weißenbach]

$\square$ Hoffmann, Friedrich (1838): Geschichte der Geognosie und Schilderung der vulkanischen Erscheinungen - Vorlesungen gehalten an der Universität zu Berlin in den Jahren 1834 und 1835. Friedrich Hoffmann - Hinterlassene Werke, Bd. 2; VIII, 596 S.; (Nicolai) Berlin [darin S. 564: Mineralische Beschaffenheit der Laven: Dolerit vom Meissner]

$\square$ Keferstein, Christian (1819): Beiträge zur Geschichte und Kenntnis des Basaltes, und der ihm verwandten Massen, in mehreren Abhandlungen. - 252 S., (J. Ch. Hendel u. Sohn) Halle/Saale [darin: S. 214 - 216: Die „blaue Kuppe“ bei Eschwege u. Meißner]

$\square \mathbb{Q} \bullet$ Keferstein, Christian (1820): Geognostische Bemerkungen über die basaltischen Gebilde des westlichen Deutschlands, als Fortsetzung der Beyträge zur Geschichte und Kenntniß des Basaltes. VIII, 207 S., 1 Falt-Kt.; (J. Chr. Hendel u. Sohn) Halle/Saale

[darin S. 22 - 24: Habichtswald, Meißner, Hirschberg/Großalmerode, Erwähnung der „blauen Kuppe“, Basaltberge westl. Göttingen, Stoffelskuppe, Pflasterkaute bei Marksuhl]

|d $\square$-Leonhard, Karl Caesar [v.] (1805-1809): Handbuch einer allgemeinen topographischen Mineralogie. - Bd. 1, 479 S., 1805; Bd. 2, 568 S., 1808; Bd. 3, 432 S., 1809; (J. Ch. Hermann) Frankufurt/M.

[Verzeichnis von Mineralfundstätten n. Mineralen geordn.; darin: (Groß-Almerode, Epterode, Eschwege, Der Hirschberg, Kassel, Meißner, Oberkaufungen, Richelsdorf, Göttingen, Orte i. Thüringen]

- $\square$ OLeonhard, Karl Caesar v. (1832): Die Basalt-Gebilde in ihren Beziehungen zu normalen und abnormalen Felsmassen. - Bd. 1, 498 S., sep. Taf.-Bd. 20 Taf.; Bd. 2, 536 S.; (Schweizerbart) Stuttgart [Bd. 2 beschreibt Intrusionsgefüge der Basalte und die Kontaktmetamorphose auf das Rahmengestein an verschiedenen nordhessischen Lokalitäten; Kontaktmetamorphose Basalt/Ton: Meißner; Basalt/Braunkohle: Meissner/Hirschberg/Habichtswald; Basalt/Buntsandstein: Blaue Kuppe b. Eschwege; Pflasterkaute b. Marksuhl; Basalt/Muschelkalk: Ahnetal/Kassel, Hörschel b. Eisenach] 
- $\square$ Lepsius, Richard (1887 - 1892): Geologie von Deutschland und den angrenzenden Gebieten. Erster Teil: Das westliche und südliche Deutschland. - Reihe: Handbücher zur Deutschen Landes- und Volkskunde, Bd. 1; XIV, 800 S., 136 Abb., 5 Falt-Taf.; in 3 Lfgn., 1.1887, 2.1889, 3.1892; (J. Engelhorn) Stuttgart [darin S. 402 Richelsdorfer Gebirge; S. 758-766 Kap.: „Basalte in nördlichen Teil des hessischen Waldgebirges (Knüll, Habichtswald, Reinhartswald, Kaufunger Wald und Meissner“; S. 761 - 766 Petrographie, Geologie und Erforschungsgeschichte des Meißner-Basaltes)

- $\square$ Lotz, Kurt (1995): Einführung in die Geologie des Landes Hessen. - 267 S., 148 Abb., 1 Beil.; (Hitzeroth) Marburg/L.

[Nordhessische Basalte Hoher Meißner, Blaue Kuppe; Unterwerra-Grauwackengebirge, Muschelkalk]

- $\square \bullet$ Möhl, Heinrich (1871): Die Gesteine (Tachylit, Basalt und Dolerit) der Sababurg in Hessen ... nebst Vergleichung mit ähnlichen Gesteinen. - Bericht d. Vereins f. Naturkunde zu Cassel, 16/17/18; 32 S. (getr. Zählung), 2 Taf.; Kassel [darin: Dolerit Meißner, Säsebühl b. Dransfeld]

- $\square$ Möhl, Heinrich (1873): Zusammenstellung, mikroskopische Untersuchung und Beschreibung einer Sammlung typischer Basalte. - N. Jb. Mineral. etc., 1874: 897 - 942, 1 Taf.; Stuttgart [darin: Meissner, Basalte Umgeb. Kassel]

$\square$ Mötzing, Kurt (1975): Die Entstehung der basaltischen Felsenmeere unserer Heimat. - Hessischer Gebirgsbote, $\underline{\mathbf{7 6}}(4): 112$ - 113, 3 Abb.; Melsungen] [darin: Hoher Meißner]

- $\square$ Nöggerath, Karl Jakob (1822-1826): Das Gebirge in Rheinland-Westfalen - nach mineralogischem und chemischen Bezuge. - 1. Bd., 370 S.: 7 Abb., (Eduard Weber) Bonn 1822. - 2. Bd.: 387 S., 7 Abb., (Eduard Weber) Bonn 1823. - 3. Bd.: 291 S., 6 Abb., (Eduard Weber) Bonn 1824. - 4 Bd.: 390 S., 2 Abb., (Eduard Weber) Bonn 1826 [darin Bd. III, S. 273 - 277: „Kurze Nachricht von einigen wenig bekannten Basalt-Gängen in Hessen (aus einem Briefe)"; Kontaktmetamorphose des Basaltes auf das Rahmengestein: Habichtswald, Ahnetal, Hirschberg; Schieferberg N’ Meissner (heute: Heiligenberg S’ Weißenbach am Meißner)]

- $\square$ Nöggerath [Karl Jakob] (1825): Nachrichten über eine wenig bekannte Basaltgänge in Hessen. - Z. Mineral., 19 (1): 263-264; Frankfurt/M. (Auszug aus: Nöggerath: Das Gebirge in Rheinland-Westfalen, Bd. III: 273-277; Bonn)

[darin: Umgebung Kassel, Heiligenberg S’ Weißenbach am Meißner]

- $\square$ Osann, Alfred (1901): Versuch einer chemischen Klassifikation der Eruptivgesteine. II Die Ergußgesteine. - Tschermaks Mineral. petrogr. Mitt., 20: 399 - 558; Wien [darin: Habichtswald; S. 446 Plagioklasbasalt Typ Meissner, Analyse Dolerit Hoher Meißner]

$\square$ Petersen, Theodor (1868): Ueber phosphorsauren Kalk. - Verh. K. k. Geol. Reichsanstalt, 1868(14): 344-348; Wien [darin: Apatit im Dolerit des Meissners]

$\square$ Rammelsberg, C. (1855): Dolerit vom Meissner. - N. Jb. Mineral. etc., 1855: 199 (Auszüge); Stuttgart [chem. Analyse; Auszug a. Annalen Physik, 85: 298-299]

- $\square \bullet$ Rinne, O. (1893): Über norddeutsche Basalte aus dem Gebiete der Weser und den angrenzenden Gebieten der Werra und Fulda - I. Untersuchungen im nördlichen, sowie einzelner Vorkommnisse im südlichen Teil des Gebietes. - Jb. Preuß. Geol. Landesanst., $\underline{13}$ (f. 1892): 1-95 (Abh. v. behördenfremden Personen), Taf. VI - IX; Berlin Referat in: N. Jb. Mineral. etc, $\underline{1894}$ (Bd. II): 56-59 (O. Mügge); Stuttgart [Vorkommen Lkr. Kassel, Lkr. Göttingen ; Habichtswald, Meißner, S. 16-18 Blaue Kuppe b. Eschwege u. Alpstein b. Kirchhosbach] 
- $\square \bullet$ Rosenbusch, Harry (1923): - Elemente der Gesteinslehre. Herausgeg. v. A. Osann. - 4., neu barb. Aufl.; 779 S., 115 Abb., zahlr. Tab.; (Schweizerbart) Stuttgart

[darin: S. 429 Hyalitbasalt d. Sababurg, Säsebühl b. Dransfeld; S. 430 Chem. Analyse Plagioklasbasalt Bühl b. [Ahnatal] Weimar; S. 434 Chem. Analyse Basalt Bramburg b. Adelebsen; S. 600 Chem.

Analyse Braunkohle Meißner]

$\square$ Sandberger, F. (1873): Ueber Dolerit - 1. Die constituierenden Mineralien. - Sitzber. Kgl. Bayr. Akad. Wiss. München, Math.-phys. Kl., $\underline{\mathbf{3}}$ (1873): 140-154; München [darin: Ilmenit u. Apatit im Dolerit des Meissners]

$\square$ Sandberger, F. (1874): Über Dolerit. - N. Jb. Mineral. etc., 1874: 88-93; Stuttgart [darin: Hoher Meissner]

$\square$ Schaub, J [ohannes] (1799): Nachrichten an Mineralogen und Geognosten besonders auch an die Besitzer meiner Beschreibung des Meissners. - Kaiserlich privilegirter Reichsanzeiger, 1799, Nr. 120 , Sp. 1397-1402;

[Argumente für die vulkanische Natur des (Meißner-) Basaltes im Neptunisten-Plutonisten-Streit]

- $\square$ Schneider, Alfred (1970): The sulfur isotope composition of basaltic rocks. - Contrib. Mineral. Petrol., 25: 95-124, 4 fig.l; Berlin-Heidelberg

[darin: Bühl b. Weimar (Ahnetal b. Kassel); Hoher Meißner]

口OSenft, Ferdinand (1857): Classification und Beschreibung der Felsarten. - XXXII, 442 S., 12 Tab.; (Korn) Breslau

[darin: S. 273-277 („Eigentliche Basaltite, Lagerformen und Felsabsonderungen der basaltischen Gesteine") kurze Erwähnung Ahnatal b. Kassel, Blaue Kuppe b. Eschwege; detaililierter: Pflasterkaute b. Marksuhl, Stoffelskuppe b. Eisenach, Kupfergrube b. Hörschlitt/Eisenach; Chemische Analyse Dolerit vom Meissner, Steinsburg b. Suhl]

- $\square$ OVoigt, Joh. Carl. Wilh. (1797): Practische Gebirgskunde. - 2., verm. Aufl.; XVI, 286 S. [1 Bl.]; (Industrie-Comptoir) Weimar [darin: S. 128 Rotliegend-Sandstein bei Eisenach; S. 159 Profilbeschr. Zechstein/Rotliegend Richelsdorfer Gebirge; S. 173, 174, 178,179,205 Meissner; S. 193 Vulcanische Brekkzie Weißenstein/Wilhelhmshöhe b. Kassel]

- $\square$ OVoigt, Johann Carl Wilhelm (1802): Mineralogische Reise nach den Braunkohlenbergwerken und Basalten Hessens, wie auch den Schieferkohlenwerken des Unterharzes. - VIII, 238 S.; Weimar [darin: Blaue Kuppe, Meißner, Hirschberg, Habichtswald]

[Erster Brief: Reise von Ilmenau über Gotha, Eisenach und Creutzburg nach der Blauen Kuppe bei Eschwege, in Hessen / Dritter Brief: Reise vom Meißner über Laudenbach, Aebteroda, die Ringkuhle, Wickenroda und Helse nach Cassel / - Fünfter Brief: Reise von Cassel über Helse, Witzenhausen, Heiligenstadt, Duderstadt bis Kloster Walkenried - Vorlage unvollständig: Titel des zweiten und vierten Briefes nicht ermittelbar]

- $\square \bullet$ Wedepohl, Karl Hans (1968): Die tertiären basaltischen Gesteine im nördlichen Hessen und südlichen Niedersachsen. - In: Koritnig, Sigmund [Zusstellg. u. red. Vorbereitung]: Zur Mineralogie und Geologie der Umgebung von Göttingen mit Westharz und Teilen des nordhessischen Berglandes - Sonderheft zur Jahrestagung 1968 der VFMG in Göttingen. - Der Aufschluss, Sdh. 17; S. 112-120, 2 Tab., 1 Taf.; Heidelberg 1968 [darin: Hoher Meißner, Blaue Kuppe]

- $\square$ Wedepohl, Karl Hans (1978): Der tertiäre basaltische Vulkanismus der Hessischen Senke nördlich des Vogelsberges. - In: Koritnig, Sigmund [Schriftltg.]: Zur Mineralogie und Geologie der Umgebung von Göttingen - mit Westharz und Teilen des Nordhessischen Berglandes. - Sdbd. $\underline{\mathbf{2 8}}$ : 156-167; 4 Abb., 2 Tab.; Heidelberg 
[darin: Mikrosondenanalysen Basalte Hoher Meißner, Blaue Kuppe; auch radiometrische Alter der Basalte]

- $\square$ Wedepohl, Karl Hans (1982): K/Ar-Altersbestimmungen an basaltischen Vulkaniten der nördlichen Hessischen Senke und ihr Beitrag zur Diskussion der Magmengenese. - N. Jb. Mineral., Abh., 144: 172-196, 3 Abb., 2 Tab.; Stuttgart

- $\square$ Wedepohl, Karl Hans (1983): Die chemische Zusammensetzung der basaltischen Gesteine der nördlichen Hessischen Senke und ihrer Umgebung. - Geol. Jb. Hessen, 111: 261-302, 3 Abb., 16 Tab.; Wiesbaden [Untersuchungen u.a. an Proben: Hoher Meißner, Blaue Kuppe, Steinbergskopf/Kaufunger Wald]

$\square$ Wentzel, Karl Friedrich (1976): Holz, Kohle, Basalt, Naturschutz und Erholung - Der Meißner im Konflikt. - Hessische Heimat, N.F., 26 (3) (Sonderheft: Braunkohlenbergbau und Landschaftspflege auf dem Hohen Meissner - Stand 1975): 79 - 82, 2 Abb.; Marburg/L.

$\square$ Werner, A. G. (1789): Anmerkung zu Herrn Fausts Nachricht von dem auf dem Meißner in Hessen über Steinkohlen und bituminösen Holz liegenden Basalt. - Bergmännisches Journal, 2(1): 261-295; Freyberg

$\square$ Zick, Jürgen (1982): „Nein“ des Ministers zum Kohleabbau auf dem Meißner!: nicht mit den Belangen der Landesplanung vereinbar. - Das Werraland, 34(3): 33; Eschwege

- $\square$ OZirkel, Ferdinand (1866): Lehrbuch der Petrographie. - [In zwei Bänden]. - Zweiter Band; 635 S:; (Adolph Marcus) Bonn.

[darin S. 273-321: Gesteine der Basalt-Familie. - Bezugn. a. Basalte i. Hessen, WMK, Thüringen; Chemischer Analysen Meißner-Basalt, Pflasterkaute; Kontaktmetamorphose Basalt/Buntsandstein: Blaue Kuppe, Alpstein b. Sontra, Rosenbühl b. Eschwege-Niddawitzhausen; Pflasterkaute, Stoffelskuppe, Kupfergrube b. Hörschlitt; Intrusivverband m. Kalkstein: Ahnetal/Habichtswald, Basaltgang bei Hörschel(Thür.)]

- $\square$ OZirkel, Ferdinand (1870): Untersuchungen über die mikroskopische Zusammensetzung und Structur der Basaltgesteine. - 208 S., 3 Taf.; (Marcus) Bonn

[darin: Umgebung Kassel, Habichtswald; Dolerit Hoher Meißner, „Blaue Kuppe“ b. Eschwege; Pflasterkaute, Stoffelskuppe/Wartburgkreis]

$\square$ Zirkel, Ferdinand (1871): Die Umwandlungsprozesse im Mineralreich - Akademische Rede, gehalten am 19. December 1870 in der Aula zu Leipzig. - Sammlung gemeinverständlicher Vorträge, Ser. 6, H. 136; 40 S.; (Lüderitz) Berlin [darin: Hinweis a. Kontaktmetamorphose Basalt/Kohle Meißner, Hirschberg b. Großalmerode; Brennende Kohle bei Abterode (Stinksteinwand Hoher Meißner)]

- $\square$ Zirkel, Ferdinand (1873): Die mikroskopische Beschaffenheit der Mineralien und Gesteine. Mit 205 Holzschnitten. - 502 S.; (Wilhelm Engelmann) Leipzig

[darin Kap. Feldspatbasalt, Anamesit, Dolerit: Nennung von Lokalitäten in Hessen, WMK, Lkr. Göttingen: Stillberg i. Habichtswald, Meissner, Dransberg u. Säsebühl b. Dransfeld]

d $\square$ Zirkel, Ferdinand (1894): Lehrbuch der Petrographie. - [In drei Bänden]. - Zweite, gänzlich neu verfasste Auflage - Zweiter Band; 941 S.; (Wilhelm Engelmann) Leipzig [darin S. 872-941: „Dolerit, Anamesit, Feldspathbasalt“ - Bezugnahme a. Basalte in Hessen, WMK, Niedersachsen; Chemische Analyse Grobkörniger Dolerit Meißner; Lagerungsformen Meißner-Basalt]

\subsection{Braunkohle}


$\square$ Anonym (1986):- Die Braunkohlenlagerstätte des Meißner. (Übertitel: Germerode und der Bergbau am Meißner) - In: Franz, D.; Großkurth, H.; Kovács, H. \& Schulze, E. [Hrsg.]: 800 Jahre Germerode - Eine Festschrift zur 800sten Wiederkehr der ersten urkundlichen Erwähnung von Germerode. - 202 S., zahlr. Abb. + Anzeigenteil; hier S. 127-129; Meißner-Germerode 1986

$\square$ Aubuisson de Voisins, Jean François d' (1819) : Traité de géognosie. - Untertitel : Exposé des connaissances actuelles sur la constitution physique et minéralogie du globe terrestre. $-2 \mathrm{Bd}$. ; Bd. I, LXI, 496 S., 1 Taf. ; Bd. II, 2, 665 S., 1 gef. Bl., Ill.; (Levrault) Strasbourg/Paris

[darin: Meissner: S. I,230 Geomorphologie; II, 445 Braunkohle; II, 556 Dolerit - erstmals in der Forschungsgeschichte wird die grobkörnige Varietät des Meissner-Basaltes als Dolerit bezeichnet]

$\square$ Braun, Erwin (1976): Die Braunkohlenlagerstätte des Meißner und die wirtschaftlichen Aspekte des Bergbaues. - Hessische Heimat, N.F., 26(3) (Sonderheft: Braunkohlenbergbau und Landschaftspflege auf dem Hohen Meissner - Stand 1975): 85 - 88, 3 Abb.; Marburg/L.

$\square$ Braun, Erwin (1986): Die Braunkohlenlagerstätte des Meißner und die wirtschaftlichen Aspekte des Bergbaues. (Übertitel: Germerode und der Bergbau am Meißner). - In: Franz, D.; Großkurth, H.; Kovács, H. \& Schulze, E. [Hrsg.]: 800 Jahre Germerode - Eine Festschrift zur 800sten Wiederkehr der ersten urkundlichen Erwähnung von Germerode. - 202 S., zahlr. Abb. + Anzeigenteil; hier S. 129-133, 2 Abb.; Germerode 1986

- $\square$ • Bruhns, W. (1906): Die nutzbaren Mineralien und Gebirgsarten im Deutschen Reiche. - Neu bearb. u. Mitwirk. v. H. Bücking a. Grundlage d. gleichnam. Werkes v. Heinrich v. Dechen (1873); XIX, 859 S., 1 geol. Falt-Kt.; (Reimer) Berlin

[darin: Braunkohlen - S. 279-281 „Ablagerungen am Knüll und Habichtswald“, S. 281-282 „Ablagerungen im Reinhardswalde“, „Ablagerungen auf der rechten Seite der Fulda und der Weser“ (Kaufungen, Meißner, Großalmerode, Kaufunger Wald, Lkr. Göttingen)

- $\square$ ○ीDechen, Heinrich v. (1873): Die nutzbaren Mineralien und Gebirgsarten im Deutschen Reiche nebst einer physiographischen und geognostischen Übersicht des Gebietes. - XXIV, 806 S.; (Reimer) Berlin

[darin: S. 447-453: Braunkohlen: „Ablagerungen am Knüll und Habichtswalde“, „Ablagerungen im Reinhardswalde“, „Ablagerungen auf der rechten Seite der Fulda und der Weser" (Kaufungen, Meißner, Großalmerode, Kaufunger Wald, Lkr. Göttingen)]

Referat in: Z. Berg-, Hütten- u. Salinenwesen, 21: 40-41 (Litteratur); Berlin 1873

$\square$ Finkenwirth, A. (1978): Die Braunkohle am Meißner. - In: Koritnig, Sigmund [Schriftltg.]: Zur Mineralogie und Geologie der Umgebung von Göttingen - mit Westharz und Teilen des Nordhessischen Berglandes. - Sdbd. 28: 229-236, 3 Abb.; Heidelberg 1978

$\square$ Hausmann, Joh. Friedr. Ludw. (1847): Handbuch der Mineralogie. - Zweyter Teil: System und Geschichte der Mineralkörper - Band 2. - 2., gänzl. umgearb. Aufl.; VII, S. 897-1660, [1 Bl.]; (Vandenhoeck \& Rupprecht) Göttingen [darin S. 1520-1529: Steinkohlen/Anthracit; Bezugnahme auf Meißner, Hirschberg]

- $\square$ Jurasky, Karl A. (1936): Deutschlands Braunkohlen und ihre Entstehung. - Deutscher Boden, 2; VI, 165 S., 1 Titelbild, 67 Abb., .; (Bornträger) Berlin

Referat in: N. Jb. Mineral. etc., Referate, 1936 (Bd. II): 755-756 (E. Hennig); 1937 (Bd. III): 403-404 (Kräusel); Stuttgart

[darin: Niederhessen, Revier Kassel; Grube Faulbach/Steinberg b. Großalmerode, Meißner]

- $\square$ Krenkel, Erich (1932): Die Bodenschätze Deutschlands. - 1. Bd. - VIII, 301 S., 71 Abb.; (Bornträger) Berlin

[darin: II. Besonderer Teil - Die Bodenschätze <Kohlen> - darin S. 122-126: (Kap. 8. Braunkohlen) Der Niederhessische Bezirk (darin Habichtswald, Stellberg, Hirschberg, Meißner), Abb. 16 Druseltal, Abb. 17 Hirschberg]] 
- $\square$ Kühnert, Ernst (1841): Ueber den Werth einiger in der Umgebung von Cassel vorkommenden Braunkohlen. - Annalen d. Chemie u. Pharmacie, 37: 94-100; Heidelberg [darin: Meißner, Habichtswald, Hirschberg, Ringenkuhl, Stellberg/Söhrewald]

$\square[$ Lasaulx, A. von] (1871): [Untersuchungen] über die umgewandelten Kohlen des Meissners. Verhdlgn. Naturhist. Vereins d. Preuß. Rheinlande u. Westphalens, 228: 152 (Sitzber.) Bonn

- $\square$ Mohr (Med.-Rath)(1868): [Widerlegung der] Ansicht, dass man die stängelige Absonderung der Braunkohlen auf dem Meisner, Habichtswald und Hirschberg im Kurhessischen als einen Beweis der feurigen Einwirkung des Basaltes auf diese Brennstoffe ansehen dürfe. - Verhdlgn. Naturhist. Vereins Preuß. Rheinlande u. Westphalens, $\underline{\mathbf{2 5}}$ (= 3. F., $\underline{\mathbf{5}}$ ): 25 (Sitzber.); Bonn [Ein später Schlag gegen die magmatische Natur des Basaltes im Plutonisten-, Neptunisten-Streit]

- $\square$ Oehlschlegel, H. G. (1964): Geochemische Untersuchungen an nordwestdeutschen und nordhessischen tertiären Braunkohlen. - N. Jb. Mineral. etc., Abh., 101(1): 67-96, 18 Abb., 9 Tab. i. T. u. a. Beil.; Stuttgart [u.a. Gahrenberg, Hirschberg, Hoher Meißner, Freudenthal/Oberkaufungen, Stellberg/Söhre, Marie Trost/Habichtswald]

$\square$ Pflanzl, Günter (1956): Das Alter der Braunkohlen des Meißners, der Flöze 2 und 3 des Hirschberges und eines benachbarten Kohlenlagers bei Laudenbach. - Notizbl. Hess. L.-A. Bodenforsch., 84: 232244, 1 Tab., Taf. 16-17; Wiesbaden

- $\square$ Pflug, Hans Dieter (1966): Stratigraphische Einordnung weiterer hessischer und außerhessischer Tertiär-Vorkommen. - N. Jb. Geol. Paläont., Mh., 1966: 736-744, 2 Abb.; Stuttgart [darin: Hessische Senke: Hoher Meißner, Stellberg, Oberkaufungen, , Baunatal, Ostheim, Felsberg]

- $\square$ Pietzsch, Kurt (1925): Handbuch der Geologie und Bodenschätze Deutschlands / Erich Krenkel [Hrsg.]. - Abt. 3: Die Bodenschätze Deutschlands - Bd. 1: Die Braunkohlen Deutschlands. - XII, 488 S., 105 Textabb., 20 Taf.; (Bornträger) Berlin [darin S. 205-225: Der Niederhessische Bezirk [Revier Cassel] (darin; Habichtswald, Stellberg, Hirschberg, Oberkaufungen, Glimmerode, Meißner)]

$\square$ Regnault, V. (1837): Recherches sur les combustibles minéraux. - Annales des mines, (3ième sér.), $\underline{12}$ : 161-240; Paris

[darin S. 220-221: «Lignite du mont Meisner ; Braunkohle Meißner]

- $\square$ Uthemann, A. (1892): Die Braunkohlen-Lagerstätten am Meissner, am Hirschberg und am Stellberg mit besonderer Berücksichtigung der Durchbruchs- und Contacteinwirkungen, welche die Basalte auf die Braunkohlenflöze ausgeübt haben. - Abh. Kgl. Preuß. Geol. Landesanst., N.F., 7; 54 S., 10 Abb., 3 Falt-Taf.; Berlin

Referat in: N. Jb. Mineral. etc., 1893 (Bd. II): 164-165 (v. Koenen); Stuttgart

OVoigt, Johann Carl Wilhelm (1800): Ueber Stein- und Braunkohle < Abhandlung II des Bandes>. - In: Voigt, Johann Carl Wilhelm: Kleine mineralogische Schriften - Theil 2. - S. 54 - 106; (bey den Gebrüdern Gaedicke) Weimar 1800

[darin: Kohlen aus Thüringen, Meißner]

QVoigt, Johann Carl Wilhelm (1800): Einige Versuche mit Stein- und Braunkohlenarten, im Feuer $<$ Abhandlung XIII des Bandes>. - In: Voigt, Johann Carl Wilhelm: Kleine mineralogische Schriften - Theil 2. - S. 155 - 171; (bey den Gebrüdern Gaedicke) Weimar 1800 [Brennverhalten von Kohlen, darin: Kohlen aus Thüringen, Meißner]

口OVoigt, Johann Carl Wilhelm (1802/1805): Versuch einer Geschichte der Steinkohlen, der Braunkohlen und des Torfes, nebst Anleitung, diese Fossilien kennen und unterscheiden zu lernen, sie aufzusuchen und nützlich anzuwenden. - 1. Bd., XXIII, 307, [5] S.; [Hoffmann'sche Hofbuchhdlg.] Weimar 1802 - 2. Bd., [IV], 197 S. [3], 2 Taf.; [Hoffmann’sche Hofbuchhdlg.] Weimar 1805 
[darin Bd. 1: Torfabbau bei Creuzburg; Bd. 2: S. 61-90: „Der Manebacher Grund im Thüringer Wald“; S. 123-132 „Nachtrag zu des Verfassers mineralogischen Reise nach den Braunkohlenwerken und Basalten in Hessen etc.“ (Braunkohle und Basalt am/auf dem Hohen Meißner)]

\subsubsection{5 „Stinksteinwand“}

- $\square$ Zeiller, Martin (1655): Martin Zeillers Topographia Hassiae, Et Regionum Vicinarum - Das ist, Beschreibung und eygentliche Abbildung der vornehmsten Stätte und Plätze in Hessen und denen benachbarten Landschafften, als Buchen, Wetterau, Westerwald, Löhngau, Nassau, Solms/ Hanau, Wigenstein und andern. - In dieser andern Edition mit sondern Fleiß durchgesehen/ von vorigen Fehlern corrigirt, gebessert und vermehret. - [1] Bl., 151, [9] S. mit 62 Kupferstichen und einem Titelkupfer [des Kupferstechers Matthaeus Merian < des Älteren>]; (Zum Truck verlegt von denen Merianischen Erben) Franckfurt am Mayn

[Es existiert eine weiter Auflage von 1655, die im Karlsruher Virtuellen Katalog als 2. Auflage des Jahres bezeichnet wird] [darin in beiden Ausgaben: Braunkohlenschwelbrand an der „Stinksteinwand“ a. d. Meißner]

$\square$ Zirkel, Ferdinand (1871): Die Umwandlungsprozesse im Mineralreich - Akademische Rede, gehalten am 19. December 1870 in der Aula zu Leipzig. - Sammlung gemeinverständlicher Vorträge, Ser. 6, H. 136; 40 S.; (Lüderitz) Berlin [darin: Hinweis a. Kontaktmetamorphose Basalt/Kohle Meißner, Hirschberg b. Großalmerode; Brennende Kohle bei Abterode (Stinksteinwand Hoher Meißner)]

$\square$ Anonym (1922): < Felsbewegungen am „Stinkloch“ (Stinksteinwand) Meißner>. - Eschweger Tageblatt, 1922; Nr. 249 v. 24.10.1922; Eschwege

- $\square$ OPerst, Otto [Hrsg.] (1960): Das Werraland in der Beschreibung Niederhessens von Landgraf Hermann zu Hessen-Rotenburg. - Eingeleitet und herausgegeben von... - Reihe: Aus dem Werraland, 7; Separatdruck aus der Zeitschrift „Das Werraland, 12. Jahrgang. 1960, Vierteljahresschrift des Werratalverins e.V., Eschwege. - 35 S.; (Rossbach) Eschwege - auch in: Das Werraland, 12(3): 38-43, 12(4): 57-61; Eschwege

[darin erwähnt: Erdfälle b. Frauensee, Erdfälle im Amt Sontra, besonders bei Berneburg; der Rote See in Dens; das Kohlenbergwerk auf dem Meissner; die Stinksteinwand; das Salzwerk in Allendorf in den Soden]

$\square$ Hegerfeld, L. (1978): Geologische Aufnahme des Lettenberges (Meißner) mit Untersuchung der unterirdischen Kohlenbrände. - Dipl.-Arb. [unveröff.] Univ. Gießen, 45 S.

$\square$ Möller, Dieter (2001): Hoher Meissner: Rauchschwaden über der Kalbe - Kohle hat sich entzündet. Werra-Rundschau, 2001; Nr. 93 v. 21.4.2001; S. 15, 4 Abb.; Eschwege

$\square$ Möller, Dieter (2001): Hoher Meissner: Schwelbrand im Bereich der Stinksteinwand - Schlamm als Abdeckung. - Werra-Rundschau, 2001; Nr. 97 v. 26.4.2001, S. 15, 1 Abb.; Eschwege

$\square$ Namenskürzel (mö) (2001): Hoher Meissner: Schwelbrand - Löschaktion wird vorerst eingestellt. Werra-Rundschau, 2001; Nr. 99 v. 28.4.2001, S. 15; Eschwege

$\square$ Namenskürzel (ot) (2001): Hoher Meißner steht immer noch unter „Dampf“ - Keine Waldbrandgefahr. - <Schwelbrand im Bereich der Stinksteinwand $>$. - Werra-Rundschau, 2001; Nr. 197 v. 25.8.2001, S. 14, 1 Abb.; Eschwege

$\square$ Möller, Dieter (2003): < Schwelbrand im Bereich der Stinksteinwand $>$ Gemeingefahr auf dem Meißner - Flächenbrand ruft Gemeinde auf den Plan - Forderungen nach Abhilfe gestellt. - WerraRundschau, 2003; Nr. 97 v. 26.4.2003, 2 Abb.; Eschwege 
$\square$ Möller, Dieter (2006): <Schwelbrand im Bereich der Stinksteinwand> Phänomen ist stinkendes Ärgernis - Vockerode: Schwelbrand auf dem Meißner bekommt Kommune ohne Hilfe nicht in Griff. - Werra-Rundschau, 2006; Nr. 66 v. 18./19.3.2006, 1 Abb.; Eschwege

\subsection{Hydrogeologie}

$\square$ Brühl, Hanskarl \& Heger, Bernd (1989): Zur Hydrogeologie des Hohen Meissners. - In: Jacobshagen, Volker \& Kuhnert, Christian [Hrsg.]: Der Hohe Meißner in Hessen - Ergebnisse geologischer und geomorphologischer Forschungen. - Berliner geowiss. Abh., Reihe A, 114; S. 77-90, 8 Abb.; (Selbstverlag Fachber. Geowiss. FU Berlin) Berlin 1989

$\square$ Brühl, Hanskarl; Schlösser, Inga \& Wurl, Jobst (1989): Die hydrogeologischen Verhältnisse im östlichen Meißnervorland des Hohen Meißners. - In: Jacobshagen, Volker \& Kuhnert, Christian [Hrsg.]: Der Hohe Meißner in Hessen - Ergebnisse geologischer und geomorphologischer Forschungen. - Berliner geowiss. Abh., Reihe A, 114; S. 91-102, 7 Abb., 1 Tab.; (Selbstverlag Fachber. Geowiss. FU Berlin) Berlin 1989

$\square$ Keilhack, Konrad (1912/1917/1935): Lehrbuch der Grundwasser- und Quellenkunde - Für Geologen, Hydrologen, Bohrunternehmer, Brunnenbauer, Bergleute, Bauingenieure und Hygieniker. - [1. Auflage]; XI, 545 S.; (Bornträger) Berlin 1912 - Zweite, neu bearb. u. vermehrte Aufl.; XII, 640 S., 267 Abb., 1 Taf.; (Bornträger) Berlin 1917 - 3., völlig neu bearb. u. vermehrte Aufl.; XI, 575 S., 308 Abb., 1 Taf.; (Bornträger) Berlin 1935 [darin: Quellen des Meißners]

$\square$ Namenskürzel (Werra-Rundschau) (1956): Meißnerquelle mit 0 Grad Wassertemperatur. - WerraRundschau, 1956; Nr. 167 v. 20.7.1956, S. 3; Eschwege

$\square$ Namenskürzel (Werra-Rundschau) (1960): < Friedrichsstollen, Hoher Meißner >Erdrutsch geräumt $100 \mathrm{cbm}$ Wasser. Friedrichstollen-Quelle wiedergefunden - Sorgen um die Wasserversorgung. Werra-Rundschau, 1960; Nr. 173 v. 28.7.1960, S. 3, 2 Abb.; Eschwege

$\square$ Schwarzenberg (Bergrath) (1838): Ueber den unterirdischen Lauf der Grubenwasser vom Meisner. Jber. Thätigkeit Vereins f. Naturkunde in Cassel. - 2: 12 - 13; Kassel

$\square$ U1rich [Wilhelm] (1949): Der Meißner. - 116 S., 5 Abb.; (Werraland-Verlag) Eschwege Referat in: Das Werraland, 1: 17-18 (Perst); Eschwege [S. 9-25, 2 Abb.: „Der Meißner landschaftlich und geologisch“; S. 25-29: „Quellen“ [auch Hydrogeologie]; S. 29-45, 1 Abb.: „Das Braunkohlenwerk“]

$\square$ Wycisk, P.; Meissner, B. \& Eisinger, M. (1993): Geowissenschaftliche Naturraumpotentialkarten als Arbeitsmittel der Umweltplanung - Grundwassernutzung Hoher Meißner. - In: Jacobshagen, V.; Möller, K. \& Jäkel, D. [Hrsg.]: Hoher Meißner und Eschweger Becken - Geowissenschaftliche und vegetationskundliche Charakteristik einer nordhessischen Landschaft. - Berliner geogr. Abh., $\underline{\mathbf{5 6}}$; zgl. Beiträge zur Werra-Meißner-Forschung, III; XII, 288 S., 95 Abb., 23 Tab., 5 Kt.-Beil.; hier: S. 51 - 58, 1 Abb., 1 Kt.; (Selbstverlag Geomorphologisches Laboratorium FU Berlin) Berlin 1993

\subsection{Geophysik}

$\square$ Blum, Rainer (1993): Die magnetische Totalintensität am Meißner. - Geol. Jb. Hessen, 121: 191-205, 8 Abb.; Wiesbaden 
$\square \bullet$ Hinz, E.; Kaminski, W. \& Stein, A. (1976): Results of Seismic Refraction Profils from the Hoher Meißner to the North German Plain. - In: Giese, P.; Prodehl, C. \& Stein, A. [eds.]: Explosion seismology in Central Europe - data and results. - Crustal and upper mantle structure in Europe, 1; XV, 429 S., 284 fig., 3 maps; hier: S. 257-267, 7 fig; (Springer) Berlin-Heidelberg-New York 1976 [Hoher Meißner, Lkr. Göttingen, Solling - Region Nienburg]

- $\square$ OKutscher, Fritz (1953): Angewandte Erdmagnetische Messungen in Hessen: 1. Zusammenstellung der bisherigen speziellen erdmagnetischen Messungen in Hessen. - Notizbl. Hess. L.-A.

Bodenforsch., $\underline{81}$ [6. F., H. 4]: 350-367, 9 Abb.; Wiesbaden [darin: „Erdmagnetische Messungen auf Basalte“: a) Habichtswald b) Solling c) Umgebung Kassel, d) Stellberg/Söhrewald e) Meißner (Kitzkammer, Plateau zw. Altarstein u. Bransrod) f) Basalt i. thür. Kaligebiet]

\subsubsection{Unterwerra-Grauwackengebirge/Albunger Paläozoikum > Präzechstein}

- $\square$ • Apel, Jürgen \& Rüppel, Heidi [Verfass. u. Hrsg.] (2005): Raus in die Natur - Tipps für den Sonntags-Ausflug im Dreiländereck Hessen - Niedersachsen - Thüringen. - 159 S., 111 Fotos, 34 Kt., 1 Zeit-Taf.; (LSRB-Verlag, Landschaftskundlicher-Studien-Reisebuch-Verlag) Witzenhausen [zahlreiche Ausflugstipps, auch zu Geotopen des Devons - Ziele 49, 62, 65 (UnterwerraGrauwackengebirge)]

$\square$ OBeyschlag, Franz (1886): Erläuterungen zur Geologischen Specialkarte von Preussen und den Thüringischen Staaten. - Lieferung 23 - Blatt Allendorf - Gradabth. 55, Bl. 46; [ heute: 4725 Bad Sooden-Allendorf ]. - Geol. Aufn.: Friedrich Moesta, Verf.: ... - 66 S., 2 Taf.; (i. Comm. Simon Schropp'sche Hof-Landkartenhdlg. (J. H. Neumann)) Berlin 1886

Hrsg.: Königlich Preußische Geologische Landesanstalt und Bergakademie; Berlin Dazugehörige Karte herausgegeben 1878

[darin S. 6-13 Kap. „Grauwackengebirge“]

$\square 0 \bullet$ Beyschlag, Franz (1886): Erläuterungen zur Geologischen Specialkarte von Preussen und den Thüringischen Staaten. - XXIII. [23.] Lieferung - Blatt Witzenhausen - Gradabth. 55, Bl. 40; [heute: 4625 Witzenhausen]. - Geol. Aufn.; Friedrich Moesta; Verf.: ... - 37 S.; (i. Comm. Simon Schropp'sche Hof-Landkartenhdlg. (J. H. Neumann)) Berlin 1886

Ohne Hrsg.: d.i. Königlich Preußische Geologische Landesanstalt und Bergakademie; Berlin Dazugehörige Karte herausgegeben 1878

[darin S. 5-8 Kap. „Grauwackengebirge“]

$\square$ Buchholz, Peter; Schmid, Martin \& Wachendorf, Horst (2008): Unterwerra-Grauwackengebirge. In: Weddige, Karsten [Koord. / Red.]: Deutsche Stratigraphische Kommission [Hrsg.] Stratigraphie von Deutschland VIII - Devon. - Schriftenrh. Dt. Ges. f. Geowiss., ㅍ: 490-494, 3 Abb.; Berlin-Hannover 2008

$\square$ Chaudhari, Sudhakar Motiram (1963): Stratigraphische und tektonische Untersuchungen unter Berücksichtigung der Klufttektonik im Gebiet zwischen Witzenhausen und Eschwege/Hessen. Diss. [unveröff.] Fachber. Geowiss. FU Berlin; 148 S., Abb., 5 Beil.

$\square \bullet$ Deppe, Heinrich (1912): Die Landschaften Südhannovers und der angrenzenden Gebiete dargestellt auf geologischer Grundlage. Ein Beitrag zur Einführung der Geologie in den heimatkundlichen Unterricht. - Reihe: Südhannoversche Heimatbücher, 1. - X, 193 S., VIII, Abb., 1 Kt.; (Vandenhoeck \& Ruprecht) Göttingen [darin: „Der Meißner“, „Das Grauwacken- und Zechsteingebirge an der unteren Werra“] 
- $\square$ Dersch-Hansmann, Michaela [Mitautorin] (1999): Geotope in Hessen. - In: Hoppe, Andreas \& Steininger, Fritz (Hrsg.): Exkursionen zu Geopten in Hessen und Rheinland-Pfalz sowie zur naturwissenschaftlichen Beobachtungspunkten Johann Wolfgang von Goethes in Böhmen. Schriftenreihe Dt. Geol. Ges., $\underline{8}$ (Kleine Senckenberg Reihe, 31); 252 S., zahlr. Abb. S. 69-126, 43 Abb.; (Deutsche Geologische Gesellschaft) Hannover 1999 [darin: Haltepunkt 7 Blaue Kuppe, Hp. Höllental/Schmelzhütte, Hp. 9 Frankershausen/Stbr. Schafhof, Hp. 10 Hoher Meißner/Kalbe, Hp. 11 Kitzkammer, Hp. Cornberg]

$\square$ Faupel, Jürgen (1971): Geologische Untersuchungen im NW-Teil des Unterwerra-Sattels. - Dipl.-Arb. [unveröff.] Univ. Göttingen; 100, VI S.

$\square$ Hagedorn, B. (1987): Geochemie und Petrographie der Diabase des Albunger Paläozoikums. - Dipl.Arb. [unveröff.] TU Braunschweig, $157 \mathrm{~S}$.

$\square$ Heldmaier, Wolfram (1992): Zur Geologie am Nordende des Werra-Grauwacken-Sattels, S’Witzenhausen/Nordhessen. - Diplom-Arbeit Teil A (Diplom-Kartierung) [unveröff.] Fachber. Geowiss. Univ. Marburg 1992; 31 S.

-Henningsen, Dierk (1966): Die paläozoischen Grauwacken bei Gießen und ihre Fortsetzung unter der südlichen Hessischen Senke. - Ber. Oberhess. Ges. f. Natur- und Heilkunde, N.F., naturwiss. Abt., 34: 19-31, 1 Abb.; Gießen

[Unterwerra-Grauwackengebirge; Erwähnung der Devon-Aufbruches Baumbach-OberellenbachSterkelshausen; B1. 4923 Altmorschen; Bohrung „Werra-Aue“ (Bl. 5125 Friedewald), Bhg. Weißenborn 2 (Bl. 5125 Friedewald)]

$\square$ Jacobshagen, V.; Koritnig, S.; Ritzkowski, S.; Rösing, F., Wittig, R. \& Wycisk, P. (1977): Der Unterwerra-Sattel: sein Deckgebirge (Perm - Trias) und der gefaltete paläozoische Kern - (Exkursion C). - Unter Mitarbeit von G. Schalow und H. Schulze. - In: Geol.-Paläont. Inst. u. Museum der Universität [Hrsg.]: Exkursionsführer - Geotagung '77 Göttingen - Band II : Nordhessen und Südniedersachsen (Exkursionen C - D - J - K - L). - S. 1-34; 8 Abb.; (Selbstverlag GeologischPaläontologisches Institut) Göttingen 1977 [darin: Aufschluß 1, 2, 10, 12, 16 - Albunger Paläozoikum und Grauwackengebirge]

口Jacobshagen, V.; Möller, K. \& Jäkel, D. [Hrsg.](1993): Hoher Meißner und Eschweger Becken Geowissenschaftliche und vegetationskundliche Charakteristik einer nordhessischen Landschaft. Berliner geogr. Abh., 56; zgl. Beiträge zur Werra-Meißner-Forschung, III; XII, 288 S., 95 Abb., 23 Tab., 5 Kt.-Beil.; (Selbstverlag Geomorphologisches Laboratorium FU Berlin) Berlin

口Jäger, Willy (1923): Geologische Träumereien im Höllental. - Eschweger Tageblatt, 1923; Nr. 190 v. 16.8.1923; Eschwege

[Poetische Erdgeschichte des Albunger Paläozoikums]

पJäger, Willy (1924): An den Ruinen der „mitteldeutschen Alpen“ bei Albungen. - Eschweger Tageblatt, 1924; Nr. 43 v. 20.2.1924; Eschwege

[Poetische Erdgeschichte des Unterwerra-Grauwackengebirges bei Albungen]

口Jäger, Willy (1931): Erloschene Vulkane um Eschwege herum. - Die Weser, $\underline{\mathbf{1 0}}(8)$ : 232-233, 1 Abb.; Bremen [Bilstein/Höllental b. Frankershausen, Hoher Meißner, Blaue Kuppe b. Eschwege]

- $\square$ OJordan, Johann Ludwig (1803): Mineralogische, berg- und hüttenmännische Reisebemerkungen vorzüglich in Hessen, Thüringen, am Rheine und im Seyn-Altenkirchner Gebiethe. - 288 S., 4 FaltTaf.; (Dieterich) Göttingen [darin: I Unterwerra-Grauwackengebirge u. Zechsteinmantel; II Bergbau i. Richelsdorfer Gebirge; IIIIII-XVI Regional-Geologie, Mineralogie, Bergbau Region Bad Liebenstein - Schmalkalden] [S. 3-5: I Grauwackenkogeln in der Grauwacke, und bituminöser Mergelschiefer auf derselben (Unterwerra-Grauwackengebirge)] 
$\square$ Koll, Jürgen (1984): Strukturanalyse allochthoner Serien des Südharzpaläozoikums. - Braunschweiger Geol. - Paläont. Diss., 1; 124 S., 55 Abb., 6 Taf., 6 Falt-Taf.; Braunschweig [darin S. 111-117 Kap.: Geodynamische Entwicklung und regionaler Vergleich. - S. 115, Abb. 55: Vergleich mit Albunger Paläzoikum]

$\square$ Koltze, Eberhard (1975): Geologische Untersuchungen am Unterwerra-Sattel zwischen Bad SoodenAllendorf, Hilgershausen und Oberrieden (Topographische Karten, $1: 25$ 000, Witzenhausen, Nr. 4625 und Bad Sooden-Allendorf, Nr. 4725). - Dipl.-Arb. [unveröff.] Univ. Göttingen, 163 S.

$\square$ Kossmat, Franz (1927): Gliederung des variskischen Gebirgsbaues.- Abh. Sächs. Geol. L.-A., 11: 39 S., 2 Textfig., 2 Taf.; Leipzig

[Der - auch heute noch oft zitierte - Klassiker! Darin S. 14: Unterwerra-Grauwackengebirge]

$\square$ Kunze, Wilhelm (1914): Geologische Wanderungen [Gesamttitel] - Teil I: Heimat-Geologie im Unterricht - Teil II: Geologische Streizüge in die Werralandschaften. - 119 S., Abb.; (Braun) Eschwege

[Im Juli 1914 erschienen, immer noch lesenswert - darin: „Das paläozoische Werragebirge“ - „Ein Gang in das vorpermische Grundgebirge (Kulm)]]

- $\square$ Lotz, Kurt (1995): Einführung in die Geologie des Landes Hessen. - 267 S., 148 Abb., 1 Beil.; (Hitzeroth) Marburg/L.

[Nordhessische Basalte Hoher Meißner, Blaue Kuppe; Unterwerra-Grauwackengebirge, Muschelkalk]

$\square$ Maurer, Jacob (1977): Geologische Wanderung durch das Werra-Schiefer-Gebirge - WTV Witzenhausen verfolgte erdgeschichtliche Spuren im heimatlichen Raum. - Das Werraland, 292(2): 1719, 1 Abb.; Eschwege

$\square$ Maurer, Jacob (1987): Geologische Wanderung im Werra-Schiefer-Gebirge bei Witzenhausen. - 47 S., 11 Abb., 2 strat. Tab.; (Selbstverlag Werrratalverein Witzenhausen e.V.) Witzenhausen [Exkursionsführer m. 17 Stationen]

- $\square$ Moesta, Friedrich (1875): Cidaris grandaeva im oberen Muschelkalk unfern des Meissners, Inseln alten Gebirges im hessischen Lande. - N. Jb. Mineral. etc., 1875: 294-295(Briefl. Mitt.); Stuttgart [,Inseln alten Gebirges im hessischen Lande“: Unterwerra-Grauwackengebirge b. Bad SoodenAllendorf, „Baumbacher Hoch“ bei Rotenburg/Fulda]

$\square$ Mügge, O. (1921): Zur Kenntnis der Petrographie des älteren Palaeozoicums zwischen Albungen und Witzenhausen, besonders des Variolits. - Jb. Preuß. geol. Landesanst., 40 (f. 1919): 201-217; Berlin

$\square$ Neuroth, Heike (1997): K/Ar-Datierungen an detritischen Muskoviten - „Sicherungskopien“ orogener Prozesse am Beispiel der Varisziden. - Göttinger Arbeiten z. Geologie u. Paläontologie, 72; V, 143 S., 29 Ab.., 7 Tab.; Göttingen

[Darin: Devon Steinbruch Schafhof Höllental/Unterwerra-Grauwackengebirge]

$\square$ Reitz, Erhard (1989): Devonische Sporen aus Phylliten vom Südrand des Rheinischen Schiefergebirges. - Geol. Jb. Hessen, 117: 23-35, 4 Taf.; Wiesbaden [darin Kap.: Die phyllitischen Tonschiefer des Albunger Paläozoikums (Werra-Graunwackengebirge), S. 33-34, Taf. 4]

$\square$ Schmid, M. (1989): Der Stockwerksbau des Unterwerra-Sattels. - Zbl. Geol. Paläont. - Teil 1, 1989(1/2): 396-397; Stuttgart

$\square$ Schmid, Martin (1991): Der variszische Stockwerkbau des Unterwerra-Grundgebirges: das tektonische Bindeglied zwischen Harz und Rheinischem Schiefergebirge. - Braunschweiger geologischpaläontologische Dissertationen, $\underline{\mathbf{1 2}}$, 82 S., 38 Abb., 5 Tab., 3 Taf., 3 Kt.; zgl. Diss. Naturwiss. F. TU Braunschweig; Braunschweig 
$\square$ Schmidt, Hermann (1931): Die ursprünglichen Zusammenhänge zwischen Harz und Rheinischem Schiefergebirge. - Die Naturwissenschaften, 19(45): 911-916, 3 Abb.; Berlin [darin: „Das Grauwackengebirge an der Werra“, 1 Kt.-Skizze)

$\square$ Schneider, Otto (1929): Methodische Einführung in die Grundbegriffe der Geologie. 2. Aufl., 127 S., 188 Abb.; (Enke) Stuttgart

[darin S. 146-154, Abb. 169-174: Dritter Teil: Die Formen - Ursachen für die verschiedene Verteilung der Formationen an der Erdoberfläche - III. Beispiel: „Eine mitteldeutsche Triaslandschaft, die sich auf einem Sockel von Schiefergebirge aufbaut" = östl. Meißnervorland: Hoher Meißner bis Albungen/Fürstenstein]

$\square$ Schreiber, Carl (1849): Physisch-Medicinische Topographie des Physikatsbezirks Eschwege. Preisschrift verfasst von..., Arzte zu Eschwege, Mitglied des Meisnerischen ärztlichen Vereins und es Vereins für Hessische Geschichte und Landeskunde, im Jahre 1846 gekrönt von der Gesellschaft zur Beförderung der gesammten Naturwissenschaften zu Marburg. - Schriften der Gesellschaft zur Beförderung der gesammten Naturwissenschaften zu Marburg, 1; 291 S., 1 Falt-Taf.; hier S. 7 - 26: „Erster Abschnitt: geographische Verhältnisse, \$2 Geognostische Skizze“; (Elwert) Marburg/L. dazu: $\square$ Beck, Hanno (1974): Das Werden des geographischen Selbstbewußtseins der Bürger einer deutschen Stadt [Eschwege]. - Hessische Heimat, N.F., 24(2/3): 92-101; Marburg/L.

[Geschichte der geowissenschaftlichen Erforschung der Eschweger Gegend] [in der Arbeit: Petrographische Karte mit der Darstellung der Grauwacken und ZechsteinhüllGesteine; Querprofil des Unterwerra-Sattels]

$\square$ Schubart, Werner (1955): Zur Stratigraphie, Tektonik und den Lagerstätten der Witzenhäuser Grauwacke. - Abh. Hess. L.-A. Bodenforsch., 10; 67 S., 8 Abb., 3 Faltbl., 4 Taf.; Wiesbaden - zgl. Diss. Univ. Göttingen 1954

$\square$ Schulz, Klaus-Hasse (1981): Die Geologie des südöstlichen Teils des Blattes (Nr. 4725) Bad SoodenAllendorf (nördliches Hessen, Unterwerra-Sattel) und eine mikrofazielle Analyse des Zechsteinkalks (Ca1). - Dipl.-Arb. [unveröff.] Univ. Göttingen, 156 S.

$\square$ Schulze, Hartmut (1977): Geologische Untersuchungen im Zentrum des Unterwerra-Sattels unter besonderer Berücksichtigung der Tektonik und der Petrographie der Werra-Grauwacke. - Dipl.-Arb. [unveröff.] Univ. Göttingen, 116 S.

$\square$ Siuts, U. (1951) : Gesteinskundliche Lehrwanderung am 6. Juli 1951 nach der „Blauen Kuppe“ bei Eschwege und durch das „Höllental“ bei Albungen. 20 Blätter, zusammengeheftet [unveröff.], Hannoversch Münden [Standort: Bereichsbibl. Forstwissenschaften Uni. Göttingen Sign. Z 100/20]

$\square$ Stark, Hans (1950): Altersstellung und Tektonik des Paläozoikums bei Albungen. - Diss. Univ. Göttingen 1950; 56 S., 11 Abb., 6 Kt.; Göttingen

$\square$ Stark, Hans (1952): Altersstellung und Tektonik des Paläozoikums bei Albungen. - Geol. Jb., 66: 203 226, 9 Abb.; Hannover

- $\square$ Thews, Joe-Dietrich (1996): Erläuterungen zur Geologischen Übersichtskarte von Hessen 1 : 300.000 - Teil 1: Kristallin, Ordovizium, Silur, Devon, Karbon.- Geol. Abh. Hessen, 96; 237 S., 39 Abb., 17 Tab., 7 Taf.; [Hrsg.: Hess. Landesamt f. Bodenforschung] Wiesbaden [darin: auch Unterwerra-Grauwackengebirge zw. Witzenhausen und Albungen; jeweils Unterkapitel „Unterwerra-Sattel“ in den Kapiteln Unter-, Mittel-, Oberdevon, Unterkarbon]

- $\square \bullet$ Wedepohl, Karl Hans \& Ritzkowski, S. (1980): [DMG-Tagung 1980] Exkursion E 1: Die nördliche Hessische Senke (Tertiär-Vulkanite, Kupferschiefer und variszischer Spilit). - Fortschr. Mineral., $\underline{\mathbf{5 8}}$, Beih. 2 (Einführung zu den Exkursionen anläßlich der 58. Jahrestagung der Deutschen Mineralogischen Gesellschaft in Göttingen 1980): 3-33, 2 Abb., 3 Tab.; Stuttgart [darin Hp: Werra-Meissner-Kreis: Blaue Kuppe, Bilstein, Cornberg, Forsths. Schmelzhütte, Hoher 
Meissner/Kalbe, Hoher Meissner/Kitzkammer; auch Hoher Hagen/Dransfeld,

Westberg/Hofgeismar, Dörnberg/Zierenberg; Güntersberg b. Gudensberg, Isthaburg b. Istha, Steppling b. Homberg/Efze]

$\square$ Wittig, Reinhold (1965): Zur Stratigraphie des Unterwerra-Sattels. - Kurznachrichten Akad. Wiss. Göttingen, 1965(1), Mitt. Nr. 3; 7 S., 1 Abb., 1 Tab.; Göttingen

[Conodonten-Stratigraphie des „Albunger Paläozoikums"]

$\square$ Wittig, Reinhold (1967): Stratigraphie und Tektonik des gefalteten Paläozoikums im Unterwerra-Sattel. - Diss. Univ. Göttingen 1967; 82 S., 14 Abb., 3 Tab.

$\square$ Wittig, Reinhold (1968): Stratigraphie und Tektonik des gefalteten Paläozoikums im Unterwerra-Sattel. - Notizbl. Hess. L.-A. Bodenforsch. , 96: 31 - 67, 6 Abb., 2 Tab., 1 Taf.; unter gleichnamigen Titel Diss. Univ. Göttingen 1967

$\square$ Wittig, Reinhold (1970): Rotliegend im Unterwerra-Sattel (Nordhessen). - Göttinger Arb. Geol. Paläont, $\underline{\mathbf{5}}$ : 135 - 144, 5 Abb.; Göttingen

$\square$ Wittig, Reinhold (1974): Tiefoberdevonische Grauwacken unter der Hessischen Senke. - Notizbl. Hess. L.-A. Bodenforsch., 102: 46 - 57, 3 Abb.; Wiesbaden

\subsubsection{Kripp- und Hielöcher, Frankershausen}

$\square$ Anonym (1894): < Neuer Erdfall in den „Krippen“ (Kripplöchern) bei Frankershausen>. - Eschweger Tageblatt u. Kreisblatt, 1894; Nr. 74 v. 30.3.1894; Eschwege

口Jacobshagen, V.; Koritnig, S.; Ritzkowski, S.; Rösing, F., Wittig, R. \& Wycisk, P. (1977): Der Unterwerra-Sattel: sein Deckgebirge (Perm - Trias) und der gefaltete paläozoische Kern - (Exkursion C). - Unter Mitarbeit von G. Schalow und H. Schulze. - In: Geol.-Paläont. Inst. u. Museum der Universität [Hrsg.]: Exkursionsführer - Geotagung '77 Göttingen - Band II : Nordhessen und Südniedersachsen (Exkursionen C - D - J - K - L). - S. 1-34; 8 Abb.; (Selbstverlag GeologischPaläontologisches Institut) Göttingen 1977

[darin: Aufschluß 13: Hielöcher]

$\square$ Kirchmeier (1940): Ferienheim Friedrichstollen am Meißner. - Hessischer Gebirgsbote, $\underline{46}(1): 5$ - 6, 3 Abb.; Melsungen [darin Fotos: „Krippenlöcher“ bei Frankershausen am Meißner, Höllental am Meißner]

$\square$ Namenskürzel (U) (1942): < Kripplöcher und Hielöcher unter Naturschutz - Sonderbare Naturerscheinungen im Meißner-Vorland>. - Eschweger Tageblatt, 1942; Nr. 24 v. 29.01.1942; Eschwege

$\square$ Namenskürzel (HG) (1958): < Kühe in unterirdischen Hohlraum an den Kripplöchern eingebrochen> Plötzlich stürzten die Kühe in eine Erdspalte ab. - Werra-Rundschau, 1958, Nr. 149 v. 2.7.1958, S. 3; Eschwege

[Das Aufsehen erregende Ereignis im Karstgebiet NSG „Kripplöcher“ bei Frankershausen ist bis heute unvergessen]

$\square$ Namenskürzel (lh) (1958): <Einbruch im Karstgebiet Kripplöcher b. Frankershausen> Landesgeologe wird Kripplöcher untersuchen. - Werra-Rundschau, 1958; Nr. 153 v. 7.7.1958, S. 3; Eschwege [Bei dem Ereignis waren zwei Kühe in einen unterirdischen Hohlraum eingebrochen] 
$\square$ Namenskürzel (FH) (1958): Einbruchstellen an den Kripplöchern untersucht - Kommission des Geologischen Landesamtes weilte in Frankershausen. - Werra-Rundschau, 1958; Nr. 154 v. 8.7.1958, S. 3; Eschwege

$\square$ Namenskürzel (Werra-Rundschau) (1958): < Untersuchung der Erdfälle im NSG Kripplöcher> Bergrat Eckert: „Wir werden das Geheimnis der Höhle erforschen!“. In einiger Zeit: Per Strickleiter in die Kripplöcher bei Frankershausen/Vorläufig keine Sprengung. - Werra-Rundschau, 1958; Nr. 173 v. 30.7.1958, S. 3, 1 Abb.; Eschwege

[Karsthohlräume im NSG „Kripplöcher“ als mögliche Objekte für Höhlentourismus?]

$\square$ Namenskürzel (Werra-Rundschau) (1959): Kripplöcher-Geheimnis bleibt ungelöst. Kein Weg in die Frankershäuser Unglückshöhle/Fremdenverkehrs-Hoffnung war vergebens. Werra-Rundschau, 1959; Nr. 296 v. 22.12.1959, S. 4; Eschwege

$\square$ Hotzler, Fritz (1994): Über die Entstehung der Hie- und Kripplöcher. - Das Werraland, $\underline{46}(2): 42-43,5$ Abb.; Eschwege

$\square$ Namenskürzel [S.F.](1998): Neuer Weg durch das Naturschutzgebiet „Hielöcher“. - Das Werraland, 50(4): 90, 1 Abb.; Eschwege [Geotourismus]

\subsubsection{Steinbruch am Schafhof/Frankershausen}

D $\square$ Dersch-Hansmann, Michaela [Mitautorin] (1999): Geotope in Hessen. - In: Hoppe, Andreas \& Steininger, Fritz [Hrsg.]: Exkursionen zu Geopten in Hessen und Rheinland-Pfalz sowie zur naturwissenschaftlichen Beobachtungspunkten Johann Wolfgang von Goethes in Böhmen. Schriftenreihe Dt. Geol. Ges., $\underline{8}$ (Kleine Senckenberg Reihe, 31); 252 S., zahlr. Abb. S. 69-126, 43 Abb.; (Deutsche Geologische Gesellschaft) Hannover 1999

[darin: Hp7 Blaue Kuppe, , H8 Höllental/Schmelzhütte, H9 Frankershausen/Stbr. Schafhof, H10 Hoher Meißner/Kalbe, H11 Kitzkammer, HP Cornberg]

पJacobshagen, V.; Koritnig, S.; Ritzkowski, S.; Rösing, F., Wittig, R. \& Wycisk, P. (1977): Der Unterwerra-Sattel: sein Deckgebirge (Perm - Trias) und der gefaltete paläozoische Kern - (Exkursion C). - Unter Mitarbeit von G. Schalow und H. Schulze. - In: Geol.-Paläont. Inst. u. Museum der Universität [Hrsg.]: Exkursionsführer - Geotagung '77 Göttingen - Band II : Nordhessen und Südniedersachsen (Exkursionen C - D - J - K - L). - S. 1-34; 8 Abb.; (Selbstverlag GeologischPaläontologisches Institut) Göttingen 1977

$\square$ Klein-Reesink, J.; Riegel, W. \& Schulz, K.-H. (1982): Tertiäre Braunkohlen und Kupferschiefer in Niederhessen. - Arbeitskreis f. Paläobotanik u. Palynologie. 11. - 13.3.1982 Dassel/Solling, Exkursion A. - Courier Forschungsinstitut Senckenberg, 56: 111-132, 12 Abb., 2 Tab.; Frankfurt [Hp. 3 Tagebau Paradiesfeld/Zeche Hirschberg, HP. 4 Frankershausen/Stbr. Schafhof]

- $\square$ Kulick, J. \& Richter-Bernburg, G. (1987): Der über Tage anstehende Zechstein in Hessen [Exkursionen D, M] - 2. Tag: Zechstein im Richelsdorfer Gebirge und an der Fulda [Stopp D10-D17, S. 83-113, Abb. 39-60] - 3. Tag: Zechstein im Werra-Grauwackengebirge [Stopp D18-D28] S. 115140, Abb. 61-81. - In: Kulick, J. \& Paul, J. [Hrsg.]: Internationales Symposium Zechstein 1987 Kassel/Hannover. Exkursionsführer, Bd. II - Exkursionen D, E, F, L, M; S. 19-140, 81 Abb., 1 Tab.; [Hess. Landesamt f. Bodenforschung] Wiesbaden 1987

[darin: Stop D9: Naturkundemuseum Ottoneum/Kassel: Fährten des Cornberger Sandsteins (S. 7279); D10 Schwerspatgrube Münden/Nentershausen, D11 Stbr. Cornberg, D18-D28 (Zechstein im Werra-Grauwackengebirge): Albungen, Jestädt, Reichensachsen/Weinberg, Oberhone, Höllental/Schmelzhütte, Frankershausen/Schafhof, Hundelshausen, Witzenhausen-Papierfabrik] 
$\square$ Neuroth, Heike (1997): K/Ar-Datierungen an detritischen Muskoviten - „Sicherungskopien“ orogener Prozesse am Beispiel der Varisziden. - Göttinger Arb. z. Geol. u. Paläont., 2; V, 143 S., 29 Ab., 7 Tab.; Göttingen

[Darin: Kyffhäuser Kristallin; Devon Steinbruch Schafhof Höllental/Unterwerra-Grauwackengebirge]

$\square$ Schmid, Martin (1991): Der variszische Stockwerkbau des Unterwerra-Grundgebirges: das tektonische Bindeglied zwischen Harz und Rheinischem Schiefergebirge. - Braunschweiger geologischpaläontologische Dissertationen, $\underline{12}$, 82 S., 38 Abb., 5 Tab., 3 Taf., 3 Kt.; Braunschweig

$\square$ Schubart, Werner (1955): Zur Stratigraphie, Tektonik und den Lagerstätten der Witzenhäuser Grauwacke. - Abh. Hess. L.-A. Bodenforsch., 10; 67 S., 8 Abb., 3 Faltbl., 4 Taf.; Wiesbaden - zgl. Diss. Univ. Göttingen 1954

[darin: Abb. 1: Profile der Steinbrüche am Schafhof]

$\square$ Wittig, Reinhold (1968): Stratigraphie und Tektonik des gefalteten Paläozoikums im Unterwerra-Sattel. - Notizbl. Hess. L.-A. Bodenforsch. , 96: 31 - 67, 6 Abb., 2 Tab., 1 Taf.; unter gleichnamigen Titel auch als Diss. Univ. Göttingen 1967

\subsubsection{Steinbruch Forsthaus Schmelzhütte/Frankershausen}

d $\square$ Dersch-Hansmann, Michaela [Mitautorin] (1999): Geotope in Hessen. - In: Hoppe, Andreas \& Steininger, Fritz [Hrsg.]: Exkursionen zu Geopten in Hessen und Rheinland-Pfalz sowie zur naturwissenschaftlichen Beobachtungspunkten Johann Wolfgang von Goethes in Böhmen. Schriftenreihe Dt. Geol. Ges., $\underline{8}$ (Kleine Senckenberg Reihe, 31); 252 S., zahlr. Abb. S. 69-126, 43 Abb.; (Deutsche Geologische Gesellschaft) Hannover [darin: Haltepunkt 7 Blaue Kuppe, Hp. Höllental/Schmelzhütte, Hp. 9 Frankershausen/Stbr. Schafhof, Hp. 10 Hoher Meißner/Kalbe, Hp. 11 Kitzkammer, Hp. Cornberg]

$\square$ Jacobshagen, V.; Koritnig, S.; Ritzkowski, S.; Rösing, F., Wittig, R. \& Wycisk, P. (1977): Der Unterwerra-Sattel: sein Deckgebirge (Perm - Trias) und der gefaltete paläozoische Kern - (Exkursion C). - Unter Mitarbeit von G. Schalow und H. Schulze. - In: Geol.-Paläont. Inst. u. Museum der Universität [Hrsg.]: Exkursionsführer - Geotagung '77 Göttingen - Band II : Nordhessen und Südniedersachsen (Exkursionen C - D - J - K - L). - S. 1-34; 8 Abb.; (Selbstverlag GeologischPaläontologisches Institut) Göttingen 1977 [darin: Aufschluß 11: Alter Steinbruch am Forsthaus Schmelzhütte]

口Jacobshagen, V.; Möller, K. \& Jäkel, D. (1993): Hoher Meißner und Eschweger Becken Geowissenschaftliche und vegetationskundliche Charakteristik einer nordhessischen Landschaft. Berliner geogr. Abh., 뚜; zgl. Beiträge zur Werra-Meißner-Forschung, III; XII, 288 S., 95 Abb., 23 Tab., 5 Kt.-Beil.; (Selbstverlag Geomorphologisches Laboratorium FU Berlin) Berlin

- $\square$ Kulick, J. \& Richter-Bernburg, G. (1987): Der über Tage anstehende Zechstein in Hessen [Exkursionen D, M] - 2. Tag: Zechstein im Richelsdorfer Gebirge und an der Fulda [Stopp D10-D17, S. 83-113, Abb. 39-60] - 3. Tag: Zechstein im Werra-Grauwackengebirge [Stopp D18-D28] S. 115140, Abb. 61-81; In: Kulick, J. \& Paul, J. [Hrsg.]: Internationales Symposium Zechstein 1987 Kassel/Hannover. Exkursionsführer, Bd. II - Exkursionen D, E, F, L, M; S. 19-140, 81 Abb., 1 Tab.; [Hess. Landesamt f. Bodenforschung] Wiesbaden 1987

[darin: Stop D9: Naturkundemuseum Ottoneum/Kassel: Fährten des Cornberger Sandsteins (S. 7279); D10 Schwerspatgrube Münden/Nentershausen, D11 Stbr. Cornberg, D18-D28 (Zechstein im Werra-Grauwackengebirge): Albungen, Jestädt, Reichensachsen/Weinberg, Oberhone, Höllental/Schmelzhütte, Frankershausen/Schafhof, Hundelshausen, Witzenhausen-Papierfabrik] 
- $\square$ Pryor, Wayne A. (1971): Petrology of the Weißliegendes in the Werra-Fulda areas, Germany. - Geol. Rundschau, 60: 524-552, 13 Abb., 3 Tab.; Stuttgart

[darin: Cornberg, Stbr. Forsthaus Schmelzhütte b. Frankershausen]

- $\square$ Richter-Bernburg, Gerhard (1955): Der Zechstein zwischen Harz und Rheinischem Schiefergebirge - Bericht über eine Exkursion zu den Zechsteinaufschlüssen dieses Gebietes anläßlich der Frühjahrstagung der Deutschen Geologischen Gesellschaft in Goslar 1953. - Z. dt. geol. Ges., 105 (f. 1953): 876 - 899, 8 Abb.; Hannover

[Harzsüdrand - Werra-Meissner-Kreis, Umgebung Rotenburg/Fulda, Rand d. Rhein. Schiefergebirge b. Waldeck-Korbach-Marsberg]

- $\square$ Wedepohl, K arl Hans (1964): Untersuchungen am Kupferschiefer Nordwestdeutschlands: Ein Beitrag zur Deutung der Genese bituminöser Sedimente. - Geochimica et Cosmochimica Acta, 28: 305-364, 18 Abb., 8 Tab.; Oxford-London-New York-Paris

[Untersuchung an Proben: Forsthaus Schmelzhütte, 4725 Bad Sooden-Allendorf; Schacht Schnepfenbusch/Nentershausen Bl. 4925 Nentershausen]

- $\square \bullet$ Wedepohl, Karl Hans \& Ritzkowski, S. (1980): [DMG-Tagung 1980] Exkursion E 1: Die nördliche Hessische Senke (Tertiär-Vulkanite, Kupferschiefer und variszischer Spilit). - Fortschr. Mineral., $\underline{\mathbf{5 8}}$, Beih. 2 (Einführung zu den Exkursionen anläßlich der 58. Jahrestagung der Deutschen Mineralogischen Gesellschaft in Göttingen 1980): 3-33, 2 Abb., 3 Tab.; Stuttgart [darin Hp: Werra-Meissner-Kreis: Blaue Kuppe, Bilstein, Cornberg, Stbr. Forsthaus Schmelzhütte, Hoher Meissner/Kalbe, Hoher Meissner/Kitzkammer; auch Hoher Hagen/Dransfeld, Westberg/Hofgeismar, Dörnberg/Zierenberg; Güntersberg b. Gudensberg, Isthaburg b. Istha, Steppling b. Homberg/Efze]

\subsubsection{Hohlstein bei Hilgershausen (Werra-Meißner-Kreis)}

- $\square$ ○ीApel, Jürgen \& Rüppel, Heidi [Verfass. u. Hrsg.] (2005): Raus in die Natur - Tipps für den Sonntags-Ausflug im Dreiländereck Hessen - Niedersachsen - Thüringen. - 159 S., 111 Fotos, 34 Kt., 1 strat. Tab.; (LSRB-Verlag, Landschaftskundlicher-Studien-Reisebuch-Verlag) Witzenhausen [zahlreiche Ausflugstipps, auch zu Höhlen - Ziel 63 (Hohlstein b. Hilgershausen]

$\square$ Deichmann, L. (1892): Der Hohlstein bei Hilgershausen. - Tourist. Mitth. Hessen-Nassau u. Waldeck, $\underline{1}(2): 15$ - 19; Kassel

[„Hilgershäuser Höhle“]

$\square$ Kollmann, Karl (1993): Der Hohlstein bei Hilgershausen. - In: Kollmann, K.; Faßbauer, L. \& Hennemuth, H. [Red.]: Geschichte des Dorfes Hilgershausen. - 240 S., zahlr. Abb.; hier: S. 98-119, 1 Abb.; (Selbstverlag Gemeinde Hilgershausen) Bad Soden-Allendorf - Hilgershausen 1993

$\square$ Kollmann, Karl (2006): Frau Holle und das Meißnerland - (17): Der Hohlstein. - Das Werraland, $\underline{\mathbf{5 8}}(2)$ : 39-42, 6 Abb.; Bad Sooden-Allendorf

$\square$ Kollmann, Karl (2006): Frau Holle und das Meißnerland - (18): Der Hohlstein. - Das Werraland, $\underline{\mathbf{5 8}}(2)$ : 57-60, 5 Abb.; Bad Sooden-Allendorf

$\square$ Landau, G. (1833): Der Hohlstein in Niederhessen. - Archiv für die Geschichte und Alterthumskunde Westphalens, $\underline{\mathbf{6}}(2 / 3)$ : 315-318; Lemgo

[Höhlenkunde, Geologie u. Sagenwelt]

$\square \bullet$ Namenskürzel (=ns)(1957): Höhlen in Hessen und Waldeck - Wer kennt den Hohlstein, das Klingelloch, den Klugstein, die Hollenkammer. - Kasseler Post - 1957, Nr. 15 v. 18.1.1957, Beilage 
„Deutsches Vaterland“; Kassel

[Klingelloch bei Hann.-Münden/Laubach, Hohlstein b. Hilgershausen/Werra-Meißner-Kreis]

$\square$ Reinboth, Friedrich (1985): Aus der Geschichte der Kammerbacher Höhle. - In: Verband der Deutschen Höhlen- und Karstforscher e.V. [Hrsg.]: Karst und Höhle 1984/1985. Beiträge zur Karst- und Höhlenforschung in Hessen. - S. 171-175, 2 Abb.; (Selbstverlag d. Verbandes) München $1985-$

$\square$ Reinboth, Friedrich (1988): Aus der Geschichte der Kammerbacher Höhle. Die Kammerbacher Höhle - die älteste urkundlich genannte Höhle Deutschlands. - Das Werraland, 40 (2): 19-21, 4 Abb.; Eschwege - Nachdruck aus: Karst und Höhle, 1984/85: 171-175, München 1985)

$\square$ Sippel, Klaus (1997): Der Hohlstein bei Hilgershausen, Stadt Bad Sooden-Allendorf. Führungsblatt zu der Höhle zwischen Hilgershausen und Kammerbach. - Archäologische Denkmäler in Hessen, 138; 11 S.; (Landesamt für Denkmalpflege) Wiesbaden

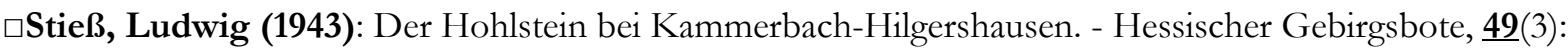
30 - 31, 2 Abb.; Melsungen

[darin Foto: Kripplöcher bei Frankershausen am Meißner]

$\square$ Weber, Alfred (1925): Der Hohlstein oder die Kammerbacher bzw. Hilgershäuser Höhle. - Das Werratal, 2 2 (1): 10-12, 3 Abb.; Eschwege [auch Geologie u. Sagen, Märchen, Mystik]

\subsubsection{1 „Blaue Kuppe“ bei Eschwege (Werra-Meißner-Kreis)}

$\square$ Anonym (1920): < Blaue Kuppe - Schutzmaßnahmen zum Erhalt des geologischen Naturdenkmals bei Eschwege - Aus einem Brief des Regierungspräsidenten zu Cassel an den Werratalverein>. Eschweger Tageblatt, 1920; Nr. 42 v. 19.02.1920; Eschwege

$\square$ Anonym (1931): < Drohender Felssturz und neu entdeckte Thermalquelle an der „Blauen Kuppe“][Aprilscherz> -Eschweger Tageblatt, 1931; Nr. 76 v. 31.3.1931; Eschwege

$\square$ Anonym (1932): <Die Blaue Kuppe als geowissenschaftliches Forschungsobjekt $>$ - Eschweger Tageblatt, 1932; Nr. 279 v. 28.11.1932; Eschwege

[Prof. Ramdohr; vermeintlich: Alexander Humboldt]

$\square$ Anonym (1932): Die "blaue Kuppe” im Werratal - eine berühmte Vulkanruine. - Die Weser, 11(10): 138-139; Bremen

$\square$ Anonym (1939): Die Blaue Kuppe, ein seltenes Naturdenkmal. - Eschweger Tageblatt, 1939; Nr. 236 v. 10.10.1939; Eschwege

- $\square$ •Apel, Jürgen \& Rüppel, Heidi [Verfass. u. Hrsg.] (2005): Raus in die Natur - Tipps für den Sonntags-Ausflug im Dreiländereck Hessen - Niedersachsen - Thüringen. - 159 S., 111 Fotos, 34 Kt., 1 Zeit-Taf.; (LSRB-Verlag, Landschaftskundlicher-Studien-Reisebuch-Verlag) Witzenhausen [zahlreiche Ausflugstipps, auch zu tertiären Vulkangebilden; Ziel 76 - „Blaue Kuppe“]

$\square$ Beck, Hanno (1952): Wie die Blaue Kuppe weltberühmt wurde. - Das Werraland, 4(1): 3-5, 1 Abb.; Eschwege 
$\square$ Beck, Hanno (1954): Alexander von Humboldts Beziehungen zu Eschwege. - Das Werraland, $\underline{\mathbf{6}}$ (4): 5859; Eschwege [Blaue Kuppe]

$\square$ Beck, Hanno (1956): Die Blaue Kuppe in der Wissenschaftsgeschichte. - In: Beck, Hanno: Eschwege - Heimat und Welt. - 72 S.; hier S. 18-21; (Roßbach) Eschwege 1956

$\square$ Beck, Hanno (1956): Eschwege und seine Landschaft im Mund berühmter Männer. - In: Beck, Hanno: Eschwege - Heimat und Welt. - 72 S.; hier S. 8-9; (Roßbach) Eschwege 1956 [Zeungisse über „Blaue Kuppe“ und Hoher Meißner]

- $\square$ Beck, Hanno (1961): Vulkanisten und Neptunisten in Hessen. - Ber. Dt. Landeskunde, 27: 87-106; Bad Godesberg

$\square$ Beck, Hanno (1968): Woher kannte Humboldt die Blaue Kuppe? - Werra-Rundschau, 1968, Nr. 214 v. 14.9.1968, S. 5; Eschwege

$\square$ Beck, Hanno (1969): Alexander vom Humboldt und Eschwege - Zur Feier des 200. Geburtstages des großen Geographen und Naturforschers am 14. September 1969. - Das Werraland, 21(3): 33-35; Eschwege

- $\square$ Beck, Hanno (1973): Geographie. Europäische Entwicklung in Texten und Erläuterungen. - Reihe: Orbis academicus. 2 $2 / 16 ; 510$ S.; (Albers) Freiburg i. Br. - München [darin S. 124-127: „Die Topographie des Landgrafen Hermann zu Hessen-Rotenburg“ [Werra, Meißner]; S. 146-147: „Topographische Tradition: Heinrich Hofrock“ [Beschreibung der Landschaft um Eschwege]; S. 191-192 Rudolf Erich Raspe[Habichtswald]; S. 207-208 „Vulkanismusstreit“ [Meißner, Blaue Kuppe, Habichtswald]

$\square$ Belendorf, Klaus \& Gottschalk, Karl-Heinz (2005): Die Blaue Kuppe bei Eschwege in Hessen, ein weltberühmter Fundort. - Mineralien-Welt, 16 (4): 38 - 48, 27 Abb.; Haltern

$\square$ Bierwirth, Heinrich (1927): Heimatklänge aus dem Werratale. - 2., vermehrte Aufl.; 195 S., Abb.; (A. Roßbach) Eschwege [darin Kap.: Auf der Blauen Kuppe; S. 89-95, Mineralogie, Landschaft]

- $\square \bullet$ Bode, Rainer \& Wittern, Artur (1989): Mineralien und Fundstellen - Bundesrepublik Deutschland. - 1. Aufl., 303 S., zahlr. Abb.; (Bode) Haltern

darin:

5. Kassel-Fulda-Gebiet

1. Basalt der Bramburg bei Adelebsen

2. Meenser Steinberg am Hohen Hagen

3. Bühl bei Kassel

4. Grube Chattenberg im Unterwerra-Grauwackengebirge

5. Grube Münden bei Nentershausen

6. Richelsdorfer Erzrevier

7. Kaliwerk Hattorf

12. Gipsfundstellen um Borken (Neuenhain)

14. Großalmerode

16. Blaue Kuppe bei Eschwege]

$\square$ Boué, Ami (1829): Geognostisches Gemälde von Deutschland. - Herausgegeben von K. C. v. Leonhard. - XVI, 623 S., 8 Taf.; (Hermann) Frankfurt/M.

[darin S. 523-547: Blaue Kuppe, Meißner; Vorlage nicht eingesehen, zitiert nach Oppitz (1991)]

$\square$ Brauns, Eduard (1962): Die Blaue Kuppe bei Eschwege - Aussicht und geologische Struktur machen sie gleichermaßen bemerkenswert. - HA, 1962; Nr. 120 v. 24.5.1962, 1 Abb.; Kassel 
$\square$ Chuang, Chung-Wie (2006): Thermische Prozesse am Kontakt Basalt-Sandstein am Beispiel der Blauen Kuppe. - Bachelor-Arbeit (unveröff.) Univ. Göttingen 2006; 39 S.

口0Cotta, B [ernhard] v. (1848): Bruchstücke [Nichtsagender Sammeltitel für petrographische Beschreibung thüringischer (hessischer) Gesteinsvorkommen]. - N. Jb. Mineral. etc., 1848: 129-135; Stuttgart

[S. 131-132 II) Granit b. Bad Liebenstein; S. 132-133 III) Basalt der Stoffelskuppe bei Eisenach (und Blaue Kuppe b. Eschwege); S. 133-134 IV) Rotliegendes bei Friedrichroda mit Thierfährten; S. 134135 V) Dolomit-Breccie bei Neustedt/Werra; S. 135 VI) Thon-Gallen im Buntsandstein der WerraGegend

$\square$ ๑Delesse, M. A. (1857): Etudes sur le métamorphisme [1] - Metamorphose des Roches [Suite]. Annales des mines, memoires, (5ième sèr.) 12: 89-828 [], 417-516 (Suite); Paris

[darin:

S. 278-279 Blaue Kuppe

S. 279-282 Stoffelskuppe

S. 476Warburg/Diemel, Säsebühl b. Dransfeld;

S. 477-478 - Pflasterkaute

S. 478 Stoffelskuppe

S. 478 - 480 Blaue Kuppe]

- $\square$ Dersch-Hansmann, Michaela [Mitautorin] (1999): Geotope in Hessen. - In: Hoppe, Andreas \& Steininger, Fritz [Hrsg.]: Exkursionen zu Geopten in Hessen und Rheinland-Pfalz sowie zur naturwissenschaftlichen Beobachtungspunkten Johann Wolfgang von Goethes in Böhmen. Schriftenreihe Dt. Geol. Ges., $\underline{8}$ (Kleine Senckenberg Reihe, 31); 252 S., zahlr. Abb. S. 69-126, 43 Abb.; (Deutsche Geologische Gesellschaft) Hannover 1999 [darin: Haltepunkt 7 Blaue Kuppe, Hp. Höllental/Schmelzhütte, Hp. 9 Frankershausen/Stbr. Schafhof, Hp. 10 Hoher Meißner/Kalbe, Hp. 11 Kitzkammer, Hp. Cornberg]

$\square$ Freyberg, Bruno v. (1920): Die Blaue Kuppe bei Eschwege. - Thüringer Monatsblätter, 1920: 78-79; Eisenach [Vorlage nicht eingesehen, zitiert nach Oppitz (1991)]

$\square$ Georgi, Klaus-Henning (1971-1986): Kreislauf der Gesteine - Eine Einführung in die Geologie. Reihe: rororo-Sachbuch. - 251 S., 265 Abb. u. graph. Darst.; (Rowohlt Taschenbuch Verlag) Reinbek b. Hamburg - mehrere unveränderte Nachdrucke der Erstauflage v. 1971, letzter 1986 [darin S. 177-180, 1 Abb., Kap. 11 - Druck und Hitze verwandeln Gesteine; Kontaktmetamorphose Basalt/Buntsandstein Blaue Kuppe (Foto) u. Basalt/Braunkohle Hoher Meißner]

- $\square 0 \bullet$ Hausmann, J.F.L. (1824, 1828): Übersicht der jüngeren Flötzgebilde im Flußgebiete der Weser, mit vergleichender Berücksichtigung ihrer Äquivalente in einigen anderen Gegenden von Deutschland und der Schweiz. - Studien Göttingischen Vereins bergmänn. Freunde, 1: 381 - 567, Göttingen 1824; 2: 215-482; Göttingen 1828

[Regionale Stratigraphie Trias-Tertiär Nordhessen, Südniedersachsen; Bd. 1, Stratigraphie Buntsandstein; S. 500-508 „Basaltische Massen im Sandstein“, darin: Blaue Kuppe bei Eschwege, Pflasterkaute bei Eisenach]

$\square$ Hausmann, J.F.L. (1849): Apophyllit von der blauen Kuppe bei Eschwege. - Studien Göttingischen Vereins bergmänn. Freunde, $\underline{\mathbf{5}}$ : 346-347; Göttingen

- $\square \bullet$ Hausmann, J. F. L. (1858): Über das Vorkommen verschiedener Kieselgebilde in Begleitung des Basaltes. - Studien Göttingischen Vereins bergmänn. Freunde, $\underline{7}(2): 139$ - 192; Göttingen [darin: Blaue Kuppe, Hirschberg, Habichtswald, Meißner, Steinberg b. Hann-Münden; S. 154-156: „Absatz von Kieselsinter in dem schlackigen Anthracite des Meißners; S. 165-172: „Durch Eindringung von kieselsäurehaltigem Wasser in die Schichten des vom Basalte durchbrochenen 
Muschelkalkes gebildeter Kieselkalk“ (Kontkatmetamorpher Marmor vom „Schieferberg b. Bransrode“/Hoher Meißner S” Weisenbach, heutiger Name „Heiligenberg“]

$\square$ Hentschel, H.; Kortinig, S.; Kutscher, F.; Rösing, F. (1962): Ganztagsexkursion zur Blauen Kuppe, am 25. Mai 1961. Geologischer Bericht. - (Übergeordn. Titel: Bericht über die Exkursionen während der Tagung des Naturhistorischen Vereins der Rheinlande und Westfalens vom 23. - 26. Mai 1961 in Kassel). - Decheniana - Verhdlgn. Naturhist. Vereins Rheinlande u. Westfalens, 114 (f. 1961): 195201, 2 Abb.; Bonn

[darin: Blaue Kuppe, Stbr. a. Meinhard, Wienberg/Neuerode; Hoher Meißner: Haldenhaus, Kalbe, Seesteine, Kitzkammer)

口 $\square$ Hessel, J. F. C. (1823): Einiges über Basaltberge und über die Lagerungsverhältnisse der Basaltsäulen an einem und demselben Basaltberge. - Schr. Ges. Beförd. Gesammt. Naturwiss. z. Marburg, 1: 153166; Marburg

[Hinweis a. „Blaue Kuppe“ b. Eschwege]

$\square$ OHoff, Karl Ernst Adolf von (1811): Beobachtungen über die Verhältnisse des Basaltes an einigen Bergen von Hessen und Thüringen. - Der Gesellschaft Naturforschender Freunde zu Berlin Magazin für die neuesten Entdeckungen in der gesammten Naturkunde, $\underline{\mathbf{5}}$ : 347-362 u. Taf. VIII; Berlin [darin: S. 349-357 „Die Blaue Kuppe bei Eschwege]

$\square 0$ Hoff, K. E. A. von (1817): Quelques montagnes basaltiques de Hesse et de Thuringue (Extrait par M. de Bonnard). - Annales des mines, 1817(3): 361-368; Paris

[darin S. 363-365: Blaue Kuppe b. Eschwege; auch Pflasterkaute, Stoffelskuppe, Steinsberg b. Suhl]

$\square$ Hoffmann, Friedrich (1823): Geognostische Bemerkungen über die Basalte der Gegend des Meißners und ihren vulkanischen Ursprung, (und Notiz von einigen barometrischen und electrometrischen Arbeiten). - Annalen d. Physik und der physikalischen Chemie, 15(3), zgl. Annalen der Physik, $\underline{\mathbf{7 5}}$ : 323-332; Leipzig [ [darin: Blaue Kuppe, Alpstein, Hoher Meißner, Hirschberg b. Großalmerode, Heiligenberg b. Weißenbach]

口OHumboldt, Alexander von (1845): Kosmos - Entwurf einer physischen Weltbeschreibung. - Bd. 1; XVI, 493 S.; (Cotta) Stuttgart

[darin S. 270: Die Pflasterkaute b. Marksuhl und die Blauen Kuppe b. Eschwege (sowie der Druidenstein am Hollerter Gangzug bei Siegen) als Beispiel für das Extrusionsverhalten von Basaltschmelzen]

口OHumboldt, Alexander von (1845): Kosmos - Entwurf einer physischen Weltbeschreibung. - Teil der Reihe: Alexander von Humboldt - Studienausgabe - 7 Bände. - Reihe: Forschungsunternehmen der Humboldt-Gesellschaft, 뜨. - hier: Band VII, Teilband 1, herausgegeben und kommentiert von ... in Verbindung mit Wolf-Dieter Grün..., mit 8 Tafeln im Beiheft. - 327 S.; (Wiss. Buchgesellschaft) Darmstadt 1993

[darin S. 231: Die Pflasterkaute b. Marksuhl und die Blauen Kuppe b. Eschwege (sowie der Druidenstein am Hollerter Gangzug bei Siegen) als Beispiel für Aufstiegsverhalten von Basaltschmelzen]

口OHumboldt, A. v. [Vortragender] Anonym [Hrsg.] (1934): Alexander von Humboldts Vorlesungen über physikalische Geographie nebst Prolegomenen über die Stellung der Gestirne/Berlin im Winter 1827 bis 1828; erstmalige (unveränderte) Veröffentlichung einer im Besitze des Verlages befindlichen Kollegnachschrift. - 190 S.; (Miron Golstein) Berlin

[darin die Erwähnung von Blauer Kuppe bei Eschwege und Pflasterkaute bei Marksuhl (sowie des Druidensteins am Hollerter Gangzug bei Siegen) als Beispiele für das Extrusionsverhalten der Basalte - 1845 unverändert im Kosmos wiederholt. - Vorlage nicht eingesehen, zitiert nach Hanno Beck 1968]

$\square$ Jacobshagen, V.; Koritnig, S.; Ritzkowski, S.; Rösing, F., Wittig, R. \& Wycisk, P. (1977): Der Unterwerra-Sattel: sein Deckgebirge (Perm - Trias) und der gefaltete paläozoische Kern (Exkursion 
C). - Exkursionsführer Geotagung '77, Bd. II; S. 1-34; 8 Abb.; (Selbstverlag Geologisch-

Paläontologisches Institut) Göttingen

[darin: Aufschluß 7 - Blaue Kuppe bei Eschwege]

$\square$ Jacobshagen, V.; Brede, R.; Hampel, M. \& Kuhnert, C. (1993): Zur Geologie der Umgebung von Eschwege in Nordhessen. - In: Jacobshagen, V.; Möller, K. \& Jäkel, D. [Hrsg.]: Hoher Meißner und Eschweger Becken - Geowissenschaftliche und vegetationskundliche Charakteristik einer nordhessischen Landschaft. - Berliner geogr. Abh., $\underline{\mathbf{5 6}}$; zgl. Beiträge zur Werra-Meißner-Forschung, III; XII, 288 S., 95 Abb., 23 Tab., 5 Kt.-Beil.; hier: S. 1-49, 11 Abb., 3 Tab., 1 geol. Kt.; (Selbstverlag Geomorphologisches Laboratorium FU Berlin) Berlin 1993

[darin: S. 32-33 Blaue Kuppe, Abb. 5 Karte der Basaltverkommen, u.a. der beiden Basaltgänge]

口Jäger, Willy (1927): Mit Prof. Dr. Ramdohr in der „Blauen Kuppe“. - Eschweger Tageblatt, 1927; Nr. 130 v. 7.6.1927; Eschwege [Exkursionsbericht]

口Jäger, Willy (1931): Erloschene Vulkane um Eschwege herum. - Hessenland, 42(8): 229-230; Marburg

口Jäger, Willy (1931): Erloschene Vulkane um Eschwege herum. - Die Weser, 10 (8): 232-233, 1 Abb.; Bremen

[Bilstein/Höllental b. Frankershausen, Hoher Meißner, Blaue Kuppe b. Eschwege]

$\square$ Jung, H. (1918): Die chemischen und provinzialen Verhältnisse der jungen Eruptivgesteine Deutschlands und Nord-Böhmens. - Chemie der Erde, $\underline{3}: 137$ - 340; Jena [darin: S. 245 - 257: Gesteine des Hessischen Berglandes, u. a. Blaue Kuppe]

$\square$ Keferstein, Christian (1819): Beiträge zur Geschichte und Kenntnis des Basaltes, und der ihm verwandten Massen, in mehreren Abhandlungen. - 252 S., (J. Ch. Hendel u. Sohn) Halle/Saale [darin: S. 214 - 216: Die „blaue Kuppe“ bei Eschwege u. Meißner]

$\square$ Keferstein, Christian (1820): Geognostische Bemerkungen über die basaltischen Gebilde des westlichen Deutschlands, als Fortsetzung der Beyträge zur Geschichte und Kenntniß des Basaltes. VIII, 207 S., 1 Falt-Kt.; (J. Chr. Hendel u. Sohn) Halle/Saale

[darin S. 22 - 24: Habichtswald, Meißner, Hirschberg/Großalmerode, Erwähnung der „blauen Kuppe“, Basaltberge westl. Göttingen, Stoffelskuppe, Pflasterkaute bei Marksuhl]

- $\bigcirc K e f e r s t e i n$, [Christian](1821): Die Entstehung der Basalte durch Feuer oder Wasser. - Tb. Mineral., 15(1): 153-169; Frankfurt/M. - Auszug aus: Keferstein, Christian: Beiträge zur Geschichte und Kenntnis des Basaltes; Halle 1819

[Der Neptunisten-Plutonisten-Streit und ihre Vertreter; darin: „Blaue Kuppe b. Eschwege, Pflasterkaute b. Marksuhl]

$\square$ Köth, Wilhelm (1989): Die Blaue Kuppe, ein alter Vulkan. - Das Werraland, 41: 67-68; Eschwege

$\square$ Kollmann, Karl (2007): Frau Holle und das Meißnerland (20): Die Blaue Kuppe bei Eschwege. - Das Werraland, 59(1): 13-15, 2 Abb.; Eschwege

- $\square$ Koritnig, Sigmund (1952): Exkursion im Richelsdorfer Gebirge und zur Blauen Kuppe bei Eschwege. - Fortschr. Mineral., 29/30 (f. 1950/51): 94-100; Stuttgart

$\square$ Koritnig, Sigmund (1954): Die Vorgänge bei der Kontaktbildung im Buntsandstein der Blauen Kuppe und des Alpstein, Nordhessen. - Beitr. Mineral. Petrologie, 4: 89 - 98, 1 Abb.; Berlin-GöttingenHeidelberg

$\square$ Koritnig, Sigmund (1955): Die Blaue Kuppe bei Eschwege mit ihren Kontakterscheinungen. - Beitr. Mineral. Petrologie, 4: 504 - 521, 11 Abb.; Berlin-Göttingen-Heidelberg 
$\square$ Koritnig, Sigmund (1956): Die „Blaue Kuppe“ bei Eschwege. - Der Aufschluss, 7: 127 - 137, 3 Abb., 2 Tab.; Göttingen

$\square$ Koritnig, Sigmund (1968): Die „Blaue Kuppe“ bei Eschwege. - Der Aufschluss, Sonderbd., 17: 173 182, 6 Abb.; Göttingen

$\square$ Koritnig, Sigmund (1978): Die „Blaue Kuppe“ bei Eschwege. - In: Koritnig, Sigmund [Schriftltg.]: Zur Mineralogie und Geologie der Umgebung von Göttingen - mit Westharz und Teilen des Nordhessischen Berglandes. - Der Aufschluß, Sdbd. 28: 237 - 247, 7 Abb., 2 Tab.; Heidelberg 1978

$\square$ Kunze, Wilhelm (1914): Geologische Streifzüge in die Werralandschaften. - 119 S., (Johannes Braun) Eschwege

[darin: S. 70 - 78 Kap. „Die Blaue Kuppe“, 2 Abb.][die Vorlage enthält zwei Werke [Übergeordneter Titel: Geologische Wanderungen]: Teil 1 - Heimatgeologie im Unterrichte - 40 S., 2 Abb., 1 stratigr. Tab.; Teil 2 - Geologische Streifzüge in die Werralandschaften, ein Heimatbuch,; 119 S., 24 Abb., 1 strat. Tab.]

- $\square$ Leonhard, Karl Caesar v. (1832): Die Basalt-Gebilde in ihren Beziehungen zu normalen und abnormalen Felsmassen. - Bd. 1, 498 S., sep. Taf.-Bd. 20 Taf.; Bd. 2, 536 S.; (Schweizerbart) Stuttgart [Bd. 2 beschreibt Intrusionsgefüge der Basalte und die Kontaktmetamorphose auf das Rahmengestein an verschiedenen nordhessischen Lokalitäten; Kontaktmetamorphose Basalt/Ton: Meißner; Basalt/Braunkohle: Meissner/Hirschberg/Habichtswald; Basalt/Buntsandstein: Blaue Kuppe b. Eschwege; Pflasterkaute b. Marksuhl; Basalt/Muschelkalk: Ahnetal/Kassel, Hörschel b. Eisenach]

$\square$ Lotz, Kurt (1995): Einführung in die Geologie des Landes Hessen. - 267 S., 148 Abb., 1 Beil.; (Hitzeroth) Marburg/L.

[Nordhessische Basalte Hoher Meißner, Blaue Kuppe; Unterwerra-Grauwackengebirge, Muschelkalk]

口OMathé, Gerhard (1985): Karl Ernst Adolf von Hoff (1771-1837) - Verdienste und Grenzen eines Gothaischen Staatsbeamten und die Förderung geologischen Denkens. - In: Prescher, Hans [Hrsg.]: Leben und Wirken deutscher Geologen im 18. und 19. Jahrhundert. - 1. Aufl.; 388 S., 108 Abb.; hier: S. 118-139, 6 Abb. Abb.; (Dt. Verlag f. Grundstoffindustrie) Leipzig 1985 [darin S. 128, Abb. 3: Hoffs Erforschung der „Blauen Kuppe“ b. Eschwege - Vorsatzblatt: Die Basaltintrusion an der „Blauen Kuppe“]

$\square$ Namenskürzel [ds](2006): Geologische Sehenswürdigkeit bei Eschwege (Hessen) wieder freigelegt. GMIT - Geowissenschaftliche Mitteilungen, $\underline{\mathbf{6}}$ (Dezember 2006): 18-19; Bonn [Zechsteinprofil Fürstenstein b. Albungen, Blaue Kuppe b. Eschwege]

$\square$ Naumann, Peter (1994): Die „Blaue Kuppe“ bei Eschwege. - Hessischer Gebirgsbote, 95(2): 59; Melsungen

$\square$ Nieuwenkamp, W. (1935): Zweidimensionale Cristobalitkristalle. - Z. Kristallogr., 90: 377 - 380, 7 Abb.; Leipzig [Röntgenograph. Untersuchung v. Christobalit der „Blauen Kuppe“ bei Eschwege]

$\square$ Oppitz, Ulrich-Dieter (1962): Alexander von Humboldt und die Blaue Kuppe. - Werra-Rundschau,

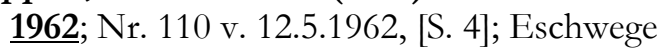

$\square$ Oppitz, Ulrich-Dieter (1962): Alexander von Humboldt und die Blaue Kuppe. - Das Werraland, 14(3): 41-43; Eschwege

$\square$ Ramdohr, Paul (1920): Über die Basalte der Blauen Kuppe bei Eschwege und benachbarter Vorkommen und ihr Cristobalit - (Vorläufige Mitteilung). - Zbl. Mineral., 1920: 33 - 36; Stuttgart [Blaue Kuppe b. Eschwege, Rosenbühl b. Niddawitzhausen, Alpstein b. Kirchhosbach] 
$\square$ Ramdohr, Paul (1921): Über die Blaue Kuppe bei Eschwege und benachbarte Basaltvorkommen. - Jb. Preuß. Geol. Landesanst. , $\underline{40}$ (Teil I) (f. 1919): 284 - 355, 3 Abb., 1 Taf.; Berlin - zgl. Diss. Univ. Göttingen 1919

[Blaue Kuppe b. Eschwege, Rosenbühl b. Niddawitzhausen, Alpstein b. Kirchhosbach]

$\square$ Ramdohr, Paul (1921): Über die Blaue Kuppe bei Eschwege und benachbarte Basaltvorkommen. (Auszüge aus den Dissertationen der mathematisch-naturwissenschaftlichen Abteilung). Jahrbuch Philosophischen Fakultät in Göttingen, 1921 (Erste Hälte: Januar-Juni) - II. Mathematisch-Naturwiss. Abteilung; S: 177-182; Göttingen

$\square$ Ramdohr, Paul (1922): Bericht über die Exkursion zur Blauen Kuppe bei Eschwege am 10.4.1921. Fortschr. Mineralogie, 1922: 36-37 (Teil Allgemeines); Jena

- $\square \bullet$ Rinne, O. (1893): Über norddeutsche Basalte aus dem Gebiete der Weser und den angrenzenden Gebieten der Werra und Fulda - I. Untersuchungen im nördlichen, sowie einzelner Vorkommnisse im südlichen Teil des Gebietes. - Jb. Preuß. Geol. Landesanst., $\underline{13}$ (f. 1892): 1-95 (Abh. v. behördenfremden Personen), Taf. VI - IX; Berlin

Referat in: N. Jb. Mineral. etc, $\underline{\mathbf{1 8 9 4}}$ (Bd. II): 56-59 (O. Mügge); Stuttgart

[Vorkommen Lkr. Kassel, Lkr. Göttingen ; Habichtswald, Meißner, S. 16-18 Blaue Kuppe b.

Eschwege u. Alpstein b. Kirchhosbach]

- $\square \bullet$ Rinne, O. (1898): Über norddeutsche Basalte aus dem Gebiete der Weser und den angrenzenden Gebieten der Werra und Fulda - II. Untersuchungen im südlichen Theile des Gebietes und Zusammenstellung von Beobachtungen im Gesamtgebiet. - Jb. Preuß. Geol. Landesanst., 18 (f. 1897): 3-102 (Abh. v. behördenfremden Personen), 29 Abb.; Berlin 1898

Referat in: N. Jb. Mineral. etc., $\underline{\mathbf{1 8 9 8}}$ (Bd. II): 433-435 (O. Mügge); Stuttgart

[Lkr. Kassel, Schwalm-Eder-Kreis, Lkr. Göttingen, WMK; „Blaue Kuppe“ b. Eschwege m. Abb]

$\square$ Rose, H. \& Mügge, O. (1921): Einschlüsse kalkiger und kieseliger Gesteine im Basalt der Blauen Kuppe bei Eschwege. - Zbl. Mineral. etc., 1921: 97 - 102; Stuttgart

$\square$ ORothe, Peter (2005): Die Geologie Deutschlands - 48 Landschaften im Portrait. - 240 S., 142 Abb.; (Wiss. Buchges. Darmstadt)

[darin: Kap. „Thüringer Becken“, „Thüringer Wald“, „Hessische Senke“ (u.a. Blaue Kuppe, Hoher Meißner)]

$\square$ Sauer, Helmut (1950): Die Blaue Kuppe und ihre Pflanzenwelt. - Das Werraland, 1950(April-Heft): 6165, 3 Abb.; Eschwege

[darin Erläuterungen zur Geologie der Blauen Kuppe]

$\square$ Schaaffs, Werner (1929): Die Blaue Kuppe bei Eschwege. - Eschweger Tageblatt, 1929; Nr. 103 v. 3.5.1929, 2 Abb. [1]; Nr. 104 v. 4.5.1929, 2 Abb. [2]; Nr. 106 v. 7.5.1929 [3]; Eschwege

$\square$ Schaumberg, Günther (1971): Die Aragonite der Blauen Kuppe bei Eschwege. - Der Aufschluss, 22: 293-297, 6 Abb.; Heidelberg

- $\square$ Schmitt, Gerhard E. (1990): Naturkundliche Wanderungen in Hessen. - 158 S., 62 Abb., Kt.; (Hitzeroth) Marburg

[Darin: Werra-Meißner-Kreis; Blaue Kuppe, Erdfalltrichter bei Trendelburg]

$\square$ Schreiber, Carl (1849): Physisch-Medicinische Topographie des Physikatsbezirks Eschwege. Preisschrift verfasst von..., Arzte zu Eschwege, Mitglied des Meisnerischen ärztlichen Vereins und es Vereins für Hessische Geschichte und Landeskunde, im Jahre 1846 gekrönt von der Gesellschaft zur Beförderung der gesammten Naturwissenschaften zu Marburg. - Schriften der Gesellschaft zur Beförderung der gesammten Naturwissenschaften zu Marburg, ; 291 S., 1 Falt-Taf.; hier S. 7 - 26: „Erster Abschnitt: geographische Verhältnisse, \$2 Geognostische Skizze“; (Elwert) Marburg/L. dazu: $\square$ Beck, Hanno (1974): Das Werden des geographischen Selbstbewußtseins der Bürger einer 
deutschen Stadt [Eschwege]. - Hessische Heimat, N.F., 244(2/3): 92-101; Marburg/L.

[Geschichte der geowissenschaftlichen Erforschung der Eschweger Gegend]

[ausführliche Beschreibung der Kontaktmetamorphose; verkürzte Wiedergabe der Nennung des

Vorkommens in Humboldts Kosmos von 1845. - Auf der Tafel: Querprofil der Blauen Kuppe mit

Basaltdurchbrüchen]

$\square$ Schreyer, W.; Blümel, P. \& Maresch, W. (1986): Cordierit und Osumilith aus den Buchiten der Blauen Kuppe bei Eschwege. - Der Aufschluss, 37: 353-367, 12 Abb.; Heidelberg

$\square$ Siuts, U. (1951) : Gesteinskundliche Lehrwanderung am 6. Juli 1951 nach der „Blauen Kuppe“ bei Eschwege und durch das „Höllental“" bei Albungen. 20 Blätter, zusammengeheftet [unveröff.], Hannoversch Münden [Standort: Bereichsbibl. Forstwissenschaften Uni. Göttingen Sign. Z 100/20]

- $\square$ Voigt, Johann Carl Wilhelm (1802): Mineralogische Reise nach den Braunkohlenbergwerken und Basalten Hessens, wie auch den Schieferkohlenwerken des Unterharzes. - VIII, 238 S.; Weimar [darin: Blaue Kuppe, Meißner, Hirschberg, Habichtswald]

[Erster Brief: Reise von Ilmenau über Gotha, Eisenach und Creutzburg nach der Blauen Kuppe bei Eschwege, in Hessen / Dritter Brief: Reise vom Meißner über Laudenbach, Aebteroda, die Ringkuhle, Wickenroda und Helse nach Cassel / - Fünfter Brief: Reise von Cassel über Helse, Witzenhausen, Heiligenstadt, Duderstadt bis Kloster Walkenried]

$\square$ Walchner, F. A. (1839): Allgemeine Naturgeschichte für alle Stände, von Prof. Oken - Erster Band: Mineralogie und Geognosie. - XXIII, 860 S.; (Hoffmann'sche Verlagsbuchhdlg.) Stuttgart [darin: S. 807-808 Blaue Kuppe bei Eschwege, S. 819 Bühlchen bei Epterode]

$\square$ Walchner, Friedrich August (1846): Handbuch der Geognosie zum Gebrauche bei seinen Vorlesungen und zum Selbststudium, mit besonderer Berücksichtigung der mineralogischen Verhältnisse des Großherzogthums Baden. - 1120 S.; (Groos) Karlsruhe - 1. Auflage u. d. T.: Handbuch der gesammten Mineralogie in technischer Beziehung - zum Gebrauche bei seinen Vorlesungen und zum Selbststudium, mit besonderer Berücksichtigung der mineralogischen Verhältnisse des Großherzogthums Baden. - Teil 2: Geognosie - mit 11 Steintafeln. - 1104 S.; (Groos) Karlsruhe 1832

[Ausgabe v. 1846 - darin: S. 955 Blaue Kuppe bei Eschwege]

- $\square$ Wedepohl, Karl Hans (1968): Die tertiären basaltischen Gesteine im nördlichen Hessen und südlichen Niedersachsen. - In: Koritnig, Sigmund [Zusstlg. u. red. Vorber.]: Zur Mineralogie und Geologie der Umgebung von Göttingen mit Westharz und Teilen des nordhessischen Berglandes Sonderheft zur Jahrestagung 1968 der VFMG in Göttingen. - Der Aufschluss, Sdh. 17; S. 112-120, 2 Tab., 1 Taf.; Heidelberg [darin: Hoher Meißner, Blaue Kuppe]

- $\square$ Wedepohl, Karl Hans (1978): Der tertiäre basaltische Vulkanismus der Hessischen Senke nördlich des Vogelsberges. - In: Koritnig, Sigmund [Schriftltg.]: Zur Mineralogie und Geologie der Umgebung von Göttingen - mit Westharz und Teilen des Nordhessischen Berglandes. - Sdbd. 28: 156-167; 4 Abb., 2 Tab.; Heidelberg 1978

[darin: Mikrosondenanalysen Basalte Hoher Meißner, Blaue Kuppe; auch radiometrische Alter der Basalte]

$\square$ Wege (1924): Der Meißner und die Blaue Kuppe. - Das Werratal, 1(3): 36-38; Eschwege

$\square$ Zeuschner, Ludwig [= Zejsznera, Ludwika] (1829): Opuwstaniu i waylednym wieku formacy bazalttowje. - Warszawa

[Bezugn. a. „Blaue Kuppe“ b. Eschwege, nach Beck (1956): Die Blaue Kuppe in der

Wissenschaftsgeschichte]

- $\square$ OZirkel, Ferdinand (1866): Lehrbuch der Petrographie. - [In zwei Bänden]. - Zweiter Band; 635 S:; (Adolph Marcus) Bonn. 
[darin S. 273-321: Gesteine der Basalt-Familie. - Bezugn. a. Basalte i. Hessen, WMK, Thüringen; Chemischer Analysen Meißner-Basalt, Pflasterkaute; Kontaktmetamorphose Basalt/Buntsandstein: Blaue Kuppe, Alpstein b. Sontra, Rosenbühl b. Eschwege-Niddawitzhausen; Pflasterkaute, Stoffelskuppe, Kupfergrube b. Hörschlitt; Intrusivverband m. Kalkstein: Ahnetal/Habichtswald, Basaltgang bei Hörschel(Thür.)]

- $\square$ OZirkel, Ferdinand (1870): Untersuchungen über die mikroskopische Zusammensetzung und Structur der Basaltgesteine. - 208 S., 3 Taf.; (Marcus) Bonn

[darin: Umgebung Kassel, Habichtswald; Dolerit Hoher Meißner, „Blaue Kuppe“ b. Eschwege; Pflasterkaute, Stoffelskuppe/Wartburgkreis; Rothweil i. Kaiserstuhl]

\subsubsection{Thüringen}

\subsubsection{Fossilfundstätte Burgtonna (Landkreis Gotha)}

\section{Publikation: Quartärgeologie und -Paläontologie des Travertins von Burgtonna/Thüringen}

OKahlke, H.-D. [Hrsg.] (1978): Das Pleistozän von Burgtonna in Thüringen - Teil. 1. Die Travertine Teil 2. Die Deckschichten der Travertine von Burgtonna in Thüringen. - Quartärpaläontologie Abh. Ber. Inst. Quartärpaläont., $\underline{\mathbf{3}}, 399$ S, 137 Abb., 56 Taf., 46 Tab.; (Akademie-Verlag) Berlin

\section{Teil 1 - Die Travertine}

○Claus, Hans (1978): Die geologisch-paläontologische Erforschung der Burgtonnaer Travertinlagerstätten. - Quartärpaläontologie, 3: 9-41, 1 Tab., Taf. 1-8; (Akademie-Verlag) Berlin

OClaus, Hans (1978): Der Gagelstrauch Myrica gale L. 1753 im Travertin von Burgtonna in Thüringen. Quartärpaläontologie, 3: 67, 1 Abb.; (Akademie-Verlag) Berlin

ODiebel, Kurt \& Pietrzeniuk, Erika (1978): Die Ostracodenfauna des eeminterglazialen Travertins von Burgtonna in Thüringen. - Quartärpaläontologie, ․ㅗ: 87-92, 3 Abb., 1 Tab., Taf. 23-26; (AkademieVerlag) Berlin

QFlerow, Constantin C. (1978): Die Bison-Reste aus den Travertinen von Burgtonna in Thüringen. Quartärpaläontologie, 3: 107- 111, 5 Abb.; (Akademie-Verlag) Berlin

OGesang, Heinrich (1978): Zur Geologie des Travertins von Burgtonna in Thüringen. Quartärpalontologie, ․․ 43-49, 9 Abb.; (Akademie-Verlag)

oGuenther, Ekke W. (1978): Die Elefantenmolaren aus den Travertinen von Burgtonna in Thüringen. Quartärpaläontologie, 조 139 - 150, 8 Tab., Taf. 38-41; (Akademie-Verlag) Berlin

OHeinrich, Wolf-Dietrich \& Jánossy, Dénes (1978): Nachweis von Anas platyrbynchos LINNEUS 1758 (Anatidae, Aves) aus dem Travertin von Burgtonna in Thüringen. - Quartärpaläontologie, $\underline{\mathbf{3}}$ : 103 105, 1 Abb., 1 Tab.; (Akademie-Verlag) Berlin

OHeinrich, Wolf-Dieter \& Jánossy, Dénes (1978): Insektivoren und Rodentier aus dem Travertin von Burgtonna in Thüringen. - Quartärpaläontologie, $\underline{3}$ : 167 - 170, 6 Tab., Taf. 46-47; (Akademie-Verlag) Berlin 
QHemmer, Helmut (1978): Die Feliden- und Canidenreste aus den jungpleistozänen Travertinen von Burgtonna in Thüringen. - Quartärpaläontologie, 3: 155 - 162, 4 Abb., 4 Tab., Taf. 44-45; (AkademieVerlag) Berlin

QHünermann, K. A. (1978): Das Wildschwein (Sus scrofa L.) aus dem Jungpleistozän von Burgtonna in Thüringen. - Quartärpaläontologie, $\underline{3}: 123$ - 127, 4 Abb.; (Akademie-Verlag) Berlin

OJäger, Klaus-Dieter \& Heinrich, Wolf-Dietrich (1978): Die stratigraphische Gliederung eines fossilführenden jungpleistozänen Deckschichten-Profils über den Interglazialtravertin von Burgtonna in Thüringen. - Quartärpaläontologie, 3: 187-202, 5 Abb., 5 Tab.; (Akademie-Verlag) Berlin

@Kahlke, Hans-Dietrich (1978): Die Cerviden-Reste aus den Travertinen von Burgtonna in Thüringen. - Quartärpaläontologie, 3: 113 - 122, 6 Abb., Taf. 32-33; (Akademie-Verlag) Berlin

QKahlke, Hans-Dietrich (1978): Die Rhinocerotiden-Reste aus den Travertinen von Burgtonna in Thüringen. - Quartärpaläontologie, 3: 129 - 135, 6 Abb., Taf. 34-37; (Akademie-Verlag) Berlin

OKahlke, Hans-Dietrich (1978): Zusammenfassender Überblick zur stratigraphischen Stellung der Travertine von Burgtonna in Thüringen. - Quartärpaläontologie, 3: 171-174, 2 Abb.; (AkademieVerlag) Berlin

○Knorre, Dietrich von (1978): Fossile Insektenreste aus letztinterglazialen Travertinen Thüringens. Quartärpaläontologie, 3: 93-95, Taf. 27-28; (Akademie-Verlag) Berlin

@Kurtén, Björn (1978): Bären- und Hyänenreste aus dem Pleistozän von Burgtonna in Thüringen. Quartärpaläontologie, $\underline{3}$ : 151 - 153, 1 Abb., Taf. 42-43; (Akademie-Verlag) Berlin

OMania, Dietrich (1978): Die Molluskenfauna aus den Travertinen von Burgtonna in Thüringen. Quartärpaläontologie, 조 69-85, 7 Abb., 2 Tab., Taf. 19-22; (Akademie-Verlag) Berlin

OMusil, Rudolf (1978): Die fossilen Equiden-Reste aus den Travertinen von Burgtonna in Thüringen. Quartärpaläontologie, $\mathbf{3}: 137$ - 138, 1 Abb.; (Akademie-Verlag) Berlin

OSchmidt, Leopold (1978): Der Biber (Castor fiber L.) aus dem Pleistozän von Burgtonna in Thüringen. Quartärpaläontologie, $\underline{3}: 163$ - 166, 1 Abb.; (Akademie-Verlag) Berlin

OSteiner, Ute (1978): Zur Problematik einiger Knochenfunde aus dem Travertin von Burgtonna in Thüringen. - Quartärpaläontologie, $\underline{3}$ : 179 - 180, Taf. 48; (Akademie-Verlag) Berlin

OSteiner, Walter (1978): Zur Genese des Travertinlagers von Burgtonna in Thüringen. Quartärpaläontologie, $\underline{3}$ : 51-58, 6 Abb.; (Akademie-Verlag) Berlin

QToepfer, Volker (1978): Die paläolithischen Funde im Travertin von Burgtonna in Thüringen. Quartärpaläontologie, 3: 175 - 178, 2 Abb. ; (Akademie-Verlag) Berlin

OUllrich, Herbert \& Mylnarski, Marian (1978): Reptilienreste aus dem jungpleistozänen Travertin von Burgtonna in Thüringen. - Quartärpaläontologie, $\underline{3}$ : 97 - 102, 1 Abb., Taf. 29-31; (Akademie-Verlag) Berlin

OVent, Walter (1978): Die Flora des Travertins von Burgtonna in Thüringen. - Quartärpaläontologie, $\underline{3}$ : 59-65, 4 Abb., Taf. 9-18; (Akademie-Verlag) Berlin

\section{Teil II - Die Deckschichten der Travertine von Burgtonna in Thüringen}


QDiebel, Kurt \& Pietrzeniuk, Erika (1978): Die Ostrakodenfauna aus den jungpleistozänen (weichselkaltzeitlichen) Deckschichten von Burgtonna in Thüringen. - Quartärpaläontologie, $\underline{3}$ : 207 221, 7 Abb., 4 Tab., Taf. 49-53; (Akademie-Verlag) Berlin

QHeinrich, Wolf-Dieter (1978): Zur Entdeckungs- und Forschungsgeschichte der Wirbeltierfundstätte in der jungpleistozänen Deckschichtenfolge über dem Travertin von Burgtonna in Thüringen. Quartärpaläontologie, $\underline{3}$ : 185 - 186, 2 Abb.; (Akademie-Verlag) Berlin

QHeinrich, Wolf-Dieter \& Jánossy, Dénes (1978): Fossile Vogelreste aus der jungpleistozänen Deckschichtenfolge über dem Travertin von Burgtonna in Thüringen. - Quartärpaläontologie, $\underline{\mathbf{3}}: 227$ - 229, 2 Abb., 1 Tab.; (Akademie-Verlag) Berlin

QHeinrich, Wolf-Dieter \& Jánossy, Dénes (1978): Fossile Säugetierreste aus einer jungpleitozänen Deckschichtenfolge über dem interglazialen Travertin von Burgtonna in Thüringen. Quartärpaläontologie, ․ㅗ: 231- 254, 13 Abb., 19 Tab., Taf. 54-56; (Akademie-Verlag) Berlin

OHeinrich, Wolf-Dieter (1978): Biometrische Untersuchungen an fossilen Kleinsäugetieren aus einer jungpleistozänen Deckschichtenfolge über dem interglazialen Travertin von Burgtonna in Thüringen. - Quartärpaläontologie, ㅈ: 255 - 268, 20 Abb.; (Akademie-Verlag) Berlin

OHeinrich, Wolf-Dieter \& Jäger, Klaus-Dieter (1978): Zusammenfassende stratigraphische und palökologische Interpretation des Fossilvorkommens in der untersuchten jungpleistozänen Deckschichtenfolge über dem Travertin von Burgtonna in Thüringen. - Quartärpaläontologie, $\underline{3}$ : 269 285, 6 Abb., 1 Tab.; (Akademie-Verlag) Berlin

J]ᅵger, Klaus-Dieter \& Heinrich, Wolf-Dieter (1978): Die stratigraphische Gliederung eines fossilführenden jungpleistozänen Deckschichtenprofils über dem Interglazialtravertin von Burgtonna in Thüringen. - Quartärpaläontologie, $\underline{3}: 187$ - 202, 5 Abb., 5 Tab.; (Akademie-Verlag) Berlin

OMania, Dieter (1978): Zur Molluskenfauna aus der jungpleistozänen Deckschichtenfolge über dem Travertin von Burgtonna in Thüringen. - Quartärpaläontologie, $\mathbf{3}$ : 203 - 205, 1 Tab.; (AkademieVerlag) Berlin

OMlynarski, M.; Böhme, G. \& Ullrich, H. (1978): Amphibien- und Reptilienreste aus der pleistozänen Deckschichtenfolge über dem Travertin von Burgtonna. - Quartärpaläontologie, 3: 223-226, 7 Abb.; (Akademie-Verlag) Berlin

\section{Weitere Publikationen zur Fossilfundstätte Burgtonna}

口Claus, H. (1973): Die geologisch-paläontologische Erforschung der Burgtonnaer Travertinlagerstätten. Abh. Ber. Museums d. Natur Gotha, [7] 1973: 1-8, 1 Abb.; Gotha

QDiebel, Kurt \& Pietrzeniuk, Erika (1975): Neue Ostracoden aus dem Pleistozän von Burgtonna (Bezirk Erfurt): Tonnaecypris gen. N. und Amplocypris tonnensis sp. n. - Z. geol. Wiss., $\underline{\mathbf{3}}(1):$ 87-97, 4 Abb., 2 Taf.; Berlin

OHeinrich, Wolf Dieter (1979): Paläökologische und biotstratigraphische Untersuchungan an Mikromammalierfaunen aus dem Pleistozän von Ehringsdorf, Taubach und Burgtonna in Thüringen. - Diss. Humboldt-Universität Berlin; Berlin

OHeinrich, Wolf Dieter (1981): Systematische Zusammenstellung der in thüringischen Interglazialtravertinen von Burgtonna, Taubach und Weimar-Ehringsdorf nachgewiesenen Kleinsäugerarten. - Quartärpaläontologie, 4: 127-130; Berlin

OHeinrich, Wolf Dieter (1986): Zur Geschichte der Erforschung von fossilen Kleinsäugerfaunen aus Interglazialtravertinen in Thüringen. - Quartärpaläontologie, $\underline{\mathbf{6}}$ : 67-74; Berlin 
OHeinrich, Wolf-Dietrich \& Jánossy, Dénes (1973): Lagurus lagurus (PALLAS, 1773) (Rodentia, Mammalia) aus dem Jungpleistozän von Burgtonna (Bezirk Erfurt). - Z. geol. Wiss., 1 (5): 587-592, 2 Abb.; Berlin

OKamradt, Ivonne (2002): Beitrag zur kleinmaßstäblichen Fazies- und Architekturelement-Analyse der Süßwasserkalke von Burgtonna in Thüringen. - Beitr. Geol. Thüringen, 9: 247-271; Jena

OKeiler, John-Albrecht (1995): Libellenlarvenreste (Odonata: Anisoptera) aus dem letztinterglazialen Travertin von Burgtonna/Thüringen. - Beitr. Geol. Thür., N.F., 2: 101 - 106, 2 Taf; Jena

OKohlstock, Karl (1926): Burgtonna: Kalktuffe; Gräfentonna: Gräberfund. - Entdeckungsreisen in der Heimat, 25; 2., vermehrte Aufl.; 16 S., Abb., Kt.; (Stollberg) Gotha

OLangenhan, A. (1906): Beiträge zur Erforschung der interglazialen Kalktuffe von Burgtonna und Gräfentonna. - Monatsschrift f. Mineralien-, Gesteins- und Petrefaktensammler, $\underline{\mathbf{3}}(1)$ : 7-10; Stuttgart

OLindner, Andreas (1995): BURGTONNAER TIBURTINUM - Gedenkschrift anläßlich des 300jährigen Jubiläums von WILHELM ERNST TENZELs Streit mit dem Collegium medicum in Gotha über einen zu Tonna gefundenen Elefanten in den Jahren 1695/96. Rückblick auf die Forschungs- und Naturgeschichte einer thüringischen Travertinlagerstätte. - Beitr. Geol. Thür., N.F., 2: 107 - 134, 3 Abb., 2 Tab.; Jena

OMallick, Ronzon \& Frank, Norbert (2002): A new technique for precise uranium-series dating of travertine micro-samples. - Geochimica et Cosmochimica Acta, $\underline{\mathbf{6 6}}(24)$ : 4261 - 4272, 6 fig., 4 tab.; Amsterdam [Bad Langensalza, Bilzingsleben, Burgtonna, Weimar-Ehringsdorf]

OMeyrick, Rich \& Maul, Lutz Christian (2003): Ausgrabungen in Burgtonna seit 300 Jahren. - Natur und Museum, 133(9): 253-261, 9 Abb.; Frankfurt/M.

OMichel, Christoph (1998): Neue Aufschlußbefunde im Bereich der weichselzeitlichen Deckschichten über dem eeminterglazialen Travertin von Burgtonna. - Geowiss. Mitt. Thüringen, Beih., 7: 79-93, 2 Abb., 1 Beil.; Weimar

OSchäfer, Heinrich Friedrich (1909): Über die pleistocäne Säugetierfauna und die Spuren des paläolithischen Menschen von Burgtonna i. Thür. - Z. dt. geol. Ges., 61: 445-469; Berlin

oSteiner, W. (1970): Stratigraphie und Sedimentationsgeschwindigkeit der Travertine von Burgtonna und Ehringsdorf. - Geologie, 19(8): 931-993, 8 Abb.; Berlin

OU1lrich, Herbert (1956): Fossile Sumpfschildkröten (Emy orbicularis L.) aus dem Diluvialtravertin von Weimar-Ehringsdorf, Taubach und Tonna (Thür.). - Geologie, $\underline{\mathbf{5}}(4 / 5):$ 360-385, 6 Abb., 4 Taf.; Berlin

OWeiss, A. (1897): Über die Conchylienfauna der interglacialen Travertine (Kalktuffe) von Burgtonna und Gräfentonna in Thüringen. Eine revidierte Liste der bis jetzt dort nachgewiesenen Conchylien. Z. dt. geol. Ges., 49: 683-689 (Briefl. Mitt.); Berlin

OWerth, E. (1925): Die pflanzenführenden Diluvial-Ablagerungen der thüringisch-sächsischen Bucht und ihre pflanzengeschichtliche und klimatologische Bedeutung. - Ber. Dt. botan. Ges., 43: 391-399, 2 Abb.; Berlin-Dahlem [Bezugnahme a. Burgtonna] 


\subsubsection{Stoffelskuppe (Wartburg-Kreis)}

\section{Stoffelskuppe}

OAbratis, M.; Mädler,J.; Hautmann, S.; Leyk, H.-J.; Meyer, R.; Lippolt, H. J. \& Viereck-Götte, L. (2007): Two distinct Miocene age ranges of basaltic rocks from the Rhön and Heldburg areas (Germany) based on 40Ar / 39Ar step heating data. - Chemie der Erde / Geochemistry, 67(2): 133150, 6 fig., 5 tabl.; München [darin: Stoffelskuppe b. Eisenach, Pflasterkaute b. Marksuhl, Hörschel]

OBornemann [jun.], L. G. (1883): Bemerkungen über einige Basaltgesteine aus der Umgebung von Eisenach. - Jb. Preuß. Geol. Landesanst., $\underline{\mathbf{3}}$ (f. 1882): 149-157 (Abh. v. behördenfremden Pers.); Berlin 1883

Referat in: N. Jb. Mineral. etc., 1884 (Bd. 2): 366 (Referat H. Rosenbusch); Stuttgart [Mineralogie; darin: Stoffelskuppe b. Eisenach, Hörschel, Hütschhof; Bezugnahme a. Blaue Kuppe b. Eschwege]

OBornemann [jun.], L. G. (1888): Ueber einige neue Vorkommnisse basaltischer Gesteine auf dem Gebiet der Messtischblätter Gerstungen und Eisenach. - Jb. Preuß. Geol. Landesanst., $\underline{8}$ (f. 1887): 291-300, (Abh. v. Mitarb....) 4 Abb.; Berlin

Referat in: N. Jb. Mineral. etc., 1888 (Bd. I): 284-285 (E. Dathe); Stuttgart [darin: Stoffelskuppe]

口0Cotta, B [ernhard] v. (1848): Bruchstücke [Nichtsagender Sammeltitel für petrographische Beschreibung thüringischer (hessischer) Gesteinsvorkommen]. - N. Jb. Mineral. etc., 1848: 129-135; Stuttgart

[S. 131-132 II) Granit b. Bad Liebenstein; S. 132-133 III) Basalt der Stoffelskuppe bei Eisenach (und Blaue Kuppe b. Eschwege); S. 133-134 IV) Rotliegendes bei Friedrichroda mit Thierfährten; S. 134135 V) Dolomit-Breccie bei Neustedt/Werra; S. 135 VI) Thon-Gallen im Buntsandstein der WerraGegend

$\square \circlearrowright \bullet$ Delesse, M. A. (1857): Etudes sur le métamorphisme [] - Metamorphose des Roches [Suite]. Annales des mines, memoires, (5 $5^{\text {ième }}$ sèr.) 12: 89-828 [1], 417-516 (Suite); Paris [darin

S. 278-279 Blaue Kuppe

S. 279-282 Stoffelskuppe

S. 476Warburg/Diemel, Säsebühl b. Dransfeld;

S. 477-478 - Pflasterkaute

S. 478 Stoffelskuppe

S. 478 - 480 Blaue Kuppe]

gGeyer, Roland (o. J.): Naturschönheiten im Landkreis Eisenach - 1. Teil: Geologische Naturdenkmale. - 32 S. zahlr. Abb. (Fotos, Profile, Kt., strat. Tab.); [Hrsg.: Umweltamt des Landrates Eisenach Untere Naturschutzbehörde] Eisenach [darin: Profil von Epichnellen/Bhf. Förtha; Kristallinaufschluß Busbahnhof Ruhla; Stoffelskuppe u. Pflasterkaute; Granitporphyr von Thal/Heiligenstein; Basaltgang Bhf. Hörschel]

- $\square$ OGiebel, Chr. G. A. (1851): Gaea excursoria germanica - Deutschlands Geologie, Geognosie und Paläontologie - ein unentbehrlicher Leitfaden auf Excursionen und beim Selbstunterricht - mit 24 lithograpischen Tafeln. - XII, 510 S., 24 Taf.; (Abel) Leipzig

[Stratigraphie Deutschlands und regionale Verbreitung der Formationen; darin: S. 120 (Kap. Basalt: Blaue Kuppe b. Eschwege, Meissner, Hirschberg b. Großalmerode, Stoffelskuppe b. Eisenach; S. 167: Kap. Kupferschiefergebirge: Meißnervorland, Richelsdorfer Gebirge, Thüringer Wald; S. 191 Muschelkalk: Westhüringen, Nordosthessen, Südniedersachsen; S. 206: Keuper: Hess. Lichtenau, Westthüringen] 
- $\square$ OHoff, Karl Ernst Adolf von (1811): Beobachtungen über die Verhältnisse des Basaltes an einigen Bergen von Hessen und Thüringen. - Der Gesellschaft Naturforschender Freunde zu Berlin Magazin für die neuesten Entdeckungen in der gesammten Naturkunde, $\underline{\mathbf{5}}$ : 347-362 u. Taf. VIII; Berlin [darin: Blaue Kuppe b. Eschwege, Pflasterkaute b. Marksuhl, Stoffelskuppe b. Eisenach, Habichtswald/Kassel, Hirschberg b. Großalmerode, Hoher Meissner]

- $\square$ OHoff, Karl Ernst Adolf von (1811): Beobachtungen über die Verhältnisse des Basaltes an einigen Bergen von Hessen und Thüringen. - Der Gesellschaft Naturforschender Freunde zu Berlin Magazin für die neuesten Entdeckungen in der gesammten Naturkunde, ㅁ: 347-362 u. Taf. VIII; Berlin [darin: Blaue Kuppe b. Eschwege, Pflasterkaute b. Marksuhl, Stoffelskuppe b. Eisenach, Habichtswald/Kassel, Hirschberg b. Großalmerode, Hoher Meissner]

口oHoff, K. E. A. von (1817): Quelques montagnes basaltiques de Hesse et de Thuringue (Extrait par M. de Bonnard). - Annales des mines, 1817(3): 361-368; Paris

[darin S. 363-365: Blaue Kuppe b. Eschwege; auch Pflasterkaute, Stoffelskuppe, Steinsberg b. Suhl]

QHoff, Karl Ernst Adolf v. (1821): Merkwürdiges Vorkommen des Basaltes in der Gegend von Eisenach. - Tb. Mineral., 15: 169-174; Frankfurt/M.

[Auszug aus: Magaz. Berliner Ges. Naturforsch. Freunde, 7, 309ff; Hörsel, Stoffelskuppe, Hütschhof, Pflasterkaute]

$\square 0 \bullet$ Keferstein, Christian (1820): Geognostische Bemerkungen über die basaltischen Gebilde des westlichen Deutschlands, als Fortsetzung der Beyträge zur Geschichte und Kenntniß des Basaltes. VIII, 207 S., 1 Falt-Kt.; (J. Chr. Hendel u. Sohn) Halle/Saale

[darin S. 22 - 24: Habichtswald, Meißner, Hirschberg/Großalmerode, Erwähnung der „blauen Kuppe“, Basaltberge westl. Göttingen, Stoffelskuppe, Pflasterkaute bei Marksuhl]

OSartorius \& Görwitz (1802): Die Basalte in der Gegend von Eisenach. - 56 S.; (Wittekindt) Eisenach [darin: Stoffelskuppe, Pflasterkaute, Basaltvorkommen b. Stedtfeld]

OVoigt, Johann Carl Wilhelm (1799): Von einigen Basalten im Eisenachischen < Abh. XVI des Bandes>. - In: Voigt, Johann Carl Wilhelm: Kleine mineralogische Schriften - Theil 1. - S. 181198; (bey den Gebrüdern Gaedicke) Weimar 1799

[Hütschhof, Stoffelskuppe, Pflasterkaue, Basaltgang in Hörschel]

OWeber, Hans (1927/1928): Halbtagesexkursion in die Tambacher Schichten des Georgentals und nach dem Basaltdurchbruch der Stoffelskuppe. - (Bericht über die Exkursionen des Thüringischen Geologischen Vereins während der dritten Hauptversammlung in Eisenach am 10. und 11. Juni 1927) - Beitr. Geol. Thür., 1 (6): 73-83, 3 Abb., 2 Tab.; Jena

- $\square$ OZirkel, Ferdinand (1866): Lehrbuch der Petrographie. - [In zwei Bänden]. - Zweiter Band; 635 S:; (Adolph Marcus) Bonn.

[darin S. 273-321: Gesteine der Basalt-Familie. - Bezugn. a. Basalte i. Hessen, WMK, Thüringen; Chemischer Analysen Meißner-Basalt, Pflasterkaute; Kontaktmetamorphose Basalt/Buntsandstein: Blaue Kuppe, Alpstein b. Sontra, Rosenbühl b. Eschwege-Niddawitzhausen; Pflasterkaute, Stoffelskuppe, Kupfergrube b. Hörschlitt; Intrusivverband m. Kalkstein: Ahnetal/Habichtswald, Basaltgang bei Hörschel(Thür.)]

- $\square$ OZirkel, Ferdinand (1870): Untersuchungen über die mikroskopische Zusammensetzung und Structur der Basaltgesteine. - 208 S., 3 Taf.; (Marcus) Bonn

[darin: Umgebung Kassel, Habichtswald; Dolerit Hoher Meißner, „Blaue Kuppe“ b. Eschwege; Pflasterkaute, Stoffelskuppe/Wartburgkreis] 


\subsubsection{Pflasterkaute (Wartburg-Kreis)}

\section{$\underline{\text { Pflasterkaute }}$}

OAbratis, M.; Mädler,J.; Hautmann, S.; Leyk, H.-J.; Meyer, R.; Lippolt, H. J. \& Viereck-Götte, L. (2007): Two distinct Miocene age ranges of basaltic rocks from the Rhön and Heldburg areas (Germany) based on 40Ar / 39Ar step heating data. - Chemie der Erde / Geochemistry, 67(2): 133150, 6 fig., 5 tabl.; München [darin: Stoffelskuppe b. Eisenach, Pflasterkaute b. Marksuhl, Hörschel]

QCredner, [Heinrich] (1860): Über den Dolerit der Pflasterkaute bei Eisenach und die in demselben vorkommenden Mineralien. - N. Jb. Mineral. etc., 1860: 56-60; Stuttgart

$\square \bullet \bullet D e l e s s e$, M. A. (1857): Etudes sur le métamorphisme [] - Metamorphose des Roches [Suite]. Annales des mines, memoires, (5ième sèr.) 12: 89-828 [], 417-516 (Suite); Paris [darin

S. 278-279 Blaue Kuppe

S. 279-282 Stoffelskuppe

S. 476Warburg/Diemel, Säsebühl b. Dransfeld;

S. 477-478 - Pflasterkaute

S. 478 Stoffelskuppe

S. 478 - 480 Blaue Kuppe]

- $\square$ Q $\bullet$ Hausmann, J.F.L. (1824, 1828): Übersicht der jüngeren Flötzgebilde im Flußgebiete der Weser, mit vergleichender Berücksichtigung ihrer Äquivalente in einigen anderen Gegenden von Deutschland und der Schweiz. - Studien Göttingischen Vereins bergmänn. Freunde, 1: 381 - 567, Göttingen 1824; 2: 215-482; Göttingen 1828

[Regionale Stratigraphie Trias-Tertiär Nordhessen, Südniedersachsen; Bd. 1, Stratigraphie Buntsandstein; S. 500-508 „Basaltische Massen im Sandstein“, darin: Blaue Kuppe bei Eschwege, Pflasterkaute bei Eisenach]

- $\square$ OHoff, Karl Ernst Adolf von (1811): Beobachtungen über die Verhältnisse des Basaltes an einigen Bergen von Hessen und Thüringen. - Der Gesellschaft Naturforschender Freunde zu Berlin Magazin für die neuesten Entdeckungen in der gesammten Naturkunde, $\underline{\mathbf{5}}$ : 347-362 u. Taf. VIII; Berlin [darin: Blaue Kuppe b. Eschwege, Pflasterkaute b. Marksuhl, Stoffelskuppe b. Eisenach, Habichtswald/Kassel, Hirschberg b. Großalmerode, Hoher Meissner]

$\square$ OHoff, K. E. A. von (1817): Quelques montagnes basaltiques de Hesse et de Thuringue (Extrait par M. de Bonnard). - Annales des mines, 1817(3): 361-368; Paris [darin S. 363-365: Blaue Kuppe b. Eschwege; auch Pflasterkaute, Stoffelskuppe, Steinsberg b. Suhl]

OHoff, Karl Ernst Adolf v. (1821): Merkwürdiges Vorkommen des Basaltes in der Gegend von Eisenach. - Tb. Mineral., 15: 169-174; Frankfurt/M.

[Auszug aus: Magaz. Berliner Ges. Naturforsch. Freunde, 7, 309ff; Hörsel, Stoffelskuppe, Hütschhof, Pflasterkaute]

- $\square$-Keferstein, Christian (1820): Geognostische Bemerkungen über die basaltischen Gebilde des westlichen Deutschlands, als Fortsetzung der Beyträge zur Geschichte und Kenntniß des Basaltes. VIII, 207 S., 1 Falt-Kt.; (J. Chr. Hendel u. Sohn) Halle/Saale [darin S. 22 - 24: Habichtswald, Meißner, Hirschberg/Großalmerode, Erwähnung der „blauen Kuppe“, Basaltberge westl. Göttingen, Stoffelskuppe, Pflasterkaute bei Marksuhl]

$\square$ OKeferstein, [Christian](1821): Die Entstehung der Basalte durch Feuer oder Wasser. - Tb. Mineral., 15(1): 153-169; Frankfurt/M. - Auszug aus: Keferstein, Christian: Beiträge zur Geschichte und Kenntnis des Basaltes; Halle 1819 
Der Neptunisten-Plutonisten-Streit und ihre Vertreter; darin: „Blaue Kuppe b. Eschwege, Pflasterkaute b. Marksuhl]

- $\square$ OLeonhard, Karl Caesar v. (1832): Die Basalt-Gebilde in ihren Beziehungen zu normalen und abnormalen Felsmassen. - Bd. 1, 498 S., sep. Taf.-Bd. 20 Taf.; Bd. 2, 536 S.; (Schweizerbart) Stuttgart [Bd. 2 beschreibt Intrusionsgefüge der Basalte und die Kontaktmetamorphose auf das Rahmengestein an verschiedenen nordhessischen Lokalitäten; Kontaktmetamorphose Basalt/Ton: Meißner; Basalt/Braunkohle: Meissner/Hirschberg/Habichtswald; Basalt/Buntsandstein: Blaue Kuppe b. Eschwege; Pflasterkaute b. Marksuhl; Basalt/Muschelkalk: Ahnetal/Kassel, Hörschel b. Eisenach]

OLüdecke (1877): Die Mineralien im Dolerit der Pflasterkaute bei Eisenach (Sitzber.). - Z. gesammt. Naturwiss., 49 (= 3. F., Bd. 1): 160-161; Berlin

OSartorius \& Görwitz (1802): Die Basalte in der Gegend von Eisenach. - 56 S.; (Wittekindt) Eisenach [darin: Stoffelskuppe, Pflasterkaute, Basaltvorkommen b. Stedtfeld]

OSoret (1825): Sur les Basaltes de Pflasterkaute. Extrait d'un lettre... - Nouveau bulletin des sciences/Soc. philomatique de Paris, $\underline{\mathbf{1 8 2 5}}$ (Août): 124-125; Paris

OSoret (1826): Basalte der Pflasterkaute bei Marksuhl. - Z. Mineral., 1826(5): 458-459; Frankf./M. Auszug aus: Bull. Soc. Phil., $\underline{\mathbf{1 8 2 5}}$ (Août): 124

[Flüssigkeitseinschlüsse in Drusenhohlräumen]

OVoigt, Johann Carl Wilhelm (1799): Von einigen Basalten im Eisenachischen <Abh. XVI des Bandes>. - In: Voigt, Johann Carl Wilhelm: Kleine mineralogische Schriften - Theil 1. - S. 181198; (bey den Gebrüdern Gaedicke) Weimar 1799

[Hütschhof, Stoffelskuppe, Pflasterkaue, Basaltgang in Hörschel]

- 0 OZirkel, Ferdinand (1866): Lehrbuch der Petrographie. - [In zwei Bänden]. - Zweiter Band; 635 S:; (Adolph Marcus) Bonn.

[darin S. 273-321: Gesteine der Basalt-Familie. - Bezugn. a. Basalte i. Hessen, WMK, Thüringen; Chemischer Analysen Meißner-Basalt, Pflasterkaute; Kontaktmetamorphose Basalt/Buntsandstein: Blaue Kuppe, Alpstein b. Sontra, Rosenbühl b. Eschwege-Niddawitzhausen; Pflasterkaute, Stoffelskuppe, Kupfergrube b. Hörschlitt; Intrusivverband m. Kalkstein: Ahnetal/Habichtswald, Basaltgang bei Hörschel(Thür.)]

- $\square$ OZZirkel, Ferdinand (1870): Untersuchungen über die mikroskopische Zusammensetzung und Structur der Basaltgesteine. - 208 S., 3 Taf.; (Marcus) Bonn [darin: Umgebung Kassel, Habichtswald; Dolerit Hoher Meißner, „Blaue Kuppe“ b. Eschwege; Pflasterkaute, Stoffelskuppe/Wartburgkreis; Rothweil i. Kaiserstuhl]

\subsubsection{Porphyr am Heiligenstein bei Thal (WAK)}

OBornemann [sen.], J. G. (1884): Von Eisenach nach Thal und Wutha. - Jb. Preuß. Geol. Landesanst., $\underline{4}$ (f. 1883): 383-409, Taf. XXII-XXVII; Berlin

Referat in N. Jb. Mineral. etc., $\underline{1885}$ (Bd. 2): 68-70 (Referat E. Dathé); Stuttgart

[darin: Porphyr Thal-Heiligenstein]

QBornemann [sen.], J. G. (1887): Der Quarzporphyr vom Heiligenstein und seine Fluidalstructur. - Z. dt. geol. Ges., 39: 793-797, 1 Taf.; Berlin

Referat in: N. Jb. Mineral. etc, $\underline{1888}$ (Bd. I): 91-92 (O. Mügge) Stuttgart 
QFutterer, K. (1890): Die „Ganggranite“ von Grosssachsen und die Quarzporphyre von Thal im Thüringer Wald. - Mitt. Grhzgl. Bad. Geol. Landesanst., 2 2: 21-64, 1 Abb, 4 Taf.; Heidelberg - zgl. Diss. Univ. Heidelberg 1890

Referat in: N. Jb. Mineral. etc, $\underline{1891}$ (Bd. II): 280-281 (Chelius); Stuttgart

OJohs, Max (1933): Der Granitporphyr von Thal-Heiligenstein im Thüringer Wald. Eine gefügeanalytische Untersuchung. - Mineral. u. petrogr. Mitt., 43: 283-318, 5 Abb., 22 Diagr.; Referat in: N. Jb. Mineral. etc., Referate; 1932 (Bd. II): 377-378 (Chudoba); Stuttgart [Tektonik, Gefügekunde]

OKlemm, E. (1899): Über die Entstehung der Parallelstructur im Quarzporphyr von Thal im Thüringer Wald. - Notizbl. Vereins f. Erdkunde etc. z. Darmstadt, (4. Reihe), 20: 4-13, Taf. I-III; Darmstadt Referat in: N. Jb. Mineral. etc, 1901 (Bd. II): 224 (O. Mügge); Stuttgart [Vorlage nicht eingesehen, zitiert nach Angaben im genannten Referat]

OLossen, K. A. (1887): Porphyr mit geschwänzten Quarzeinsprenglingen von Thal im Thüringer Wald. Z. dt. geol. Ges., 39: 836-841; Berlin

Referat in: N. Jb. Mineral. etc, $\underline{\mathbf{1 8 8 8}}$ (Bd. I): 91-92 (O. Mügge) Stuttgart

[Tektonik, Gefügekunde; Porphyr Thal-Heiligenstein]

OMädler, Jonas (1964): Petrographie, petrochemische Stellung und Metamorphose der Granitporphyrgänge von Thal-Heiligenstein im nordwestlichen Thüringer Wald. - Ber. Dt. Ges. geol. Wiss., Reihe B, 14(4): 327-337, 2 Abb., 5 Taf.; Berlin

OWeiss, E. (1884): Über den Porphyr mit sogenannter Fluidalstructur von Thal im Thüringer Wald. - Z. dt. geol. Ges., 36: 858-868, 1 Abb.; Berlin

Referat in: N. Jb. Mineral. etc., $\underline{1878}$ (2. Bd.): 54-55 (Referat O. Mügge); Stuttgart

[Thal-Heiligenstein]

QZimmermann, J. E. (1914): Der Granitporphyr von Thal oder Heiligenstein im Thüringer Wald („Porphyr mit geschwänzten Quarzen“). - Jb. Preuß. Geol. Landesanst., $\underline{34}$ (Teil I) (f. 1913): 634-647; Berlin [Tektonik, Gefügekunde]

\subsubsection{Profil von Epichnellen / Bahnhof Förtha}

OCloos, Hans (1947): Gespräch mit der Erde - Geologische Welt- und Lebensfahrt. - 407 S., 71 Taf.; (Piper) München

[Der Klassiker der poetischen Geologie! - darin S. 236-247 das Kap.: „Steine unter dem Kopfkissen“

- behandelt Thüringer Wald, Profil von Epichnellen [Bahnhof Förtha]]

QGeyer, Roland (1994): Die Geologischen Naturdenkmale im Kreis Eisenach [Wartburgkreis]: 1. Das Zechsteinprofil am Bahnhof Förtha. - Knüllgebirgsbote, 1994(2): 6, 1 Abb.; Bad Hersfeld

QGeyer, Roland (o. J.): Naturschönheiten im Landkreis Eisenach - 1. Teil: Geologische Naturdenkmale. - 32 S. zahlr. Abb. (Fotos, Profile, Kt., strat. Tab.); [Hrsg.: Umweltamt des Landrates Eisenach Untere Naturschutzbehörde] Eisenach [darin: Profil von Epichnellen/Bhf. Förtha; Kristallinaufschluß Busbahnhof Ruhla; Stoffelskuppe u. Pflasterkaute; Granitporphyr von Thal/Heiligenstein; Basaltgang Bhf. Hörschel]

QGeyer, R.; Jahne, H. \& Storch, S. (1999): Geologische Sehenswürdigkeiten des Wartburgkreises und der kreisfreien Stadt Eisenach - Schriftenreihe: Naturschutz im Wartburgkreis, H. ㅁ; 188 S., 162 Abb., 
1 Übersichtskarte 1: 100.000; [Hrsg. Thür. Landesamt f. Geologie, Wartburgkreis, Stadt Eisenach]; Eisenach

OHuckriede, Hermann (2003): Aufschluss am Bahnhof Förtha: Basisschichten (Zechsteinkonglomerat bis Zechsteinkalk) der Werra-Folge des Zechsteins / Exkursionspunkt 3

- In: Exkursionsführer - Die Geologie rund um die Wartburg. - S. 21-23; [Thür. Geol. Verein] Jena 2003

QKozur, Heinz H. (1977): Erster Nachweis von Mikrofaunen unterhalb des Kupferschiefers im Süden der DDR. - Z. geol. Wiss., $\underline{\mathbf{5}}(5)$ : 657-661; Berlin

[darin: Förtha]

ONaumann, Ernst (1913): Erläuterungen zur Geologischen Karte von Preußen und benachbarten Bundessstaaten. - Lieferung 113 - Blatt Eisenach - Gradabth. 69, Bl. 6; [heute: 5027 Eisenach]. - 74 S., 5 Abb., 3 (Foto) Taf.; Berlin 1913

Hrsg.: Königlich Preußische Geologische Landesanstalt; Berlin

Dazugehörige Karte herausgegeben 1912

[Erläuterungen: darin Profil v. Epichnellen - In: VI Der Zechstein. - Taf III: Fotographie mit

Deckblatt, Fig. 4: Stratigraphisches Profil]

OPaul, Josef (2005): Permo-carboniferous palaeosols in Central Germany (Permokarbone Paläoböden in Mitteldeutschland). - Feschrift für Gerhard H. Bachmann, Teil II. - Hallesches Jb. Geowiss., Reihe B, Beihefte, 19, 214 S., zahlr. Abb.; hier S. 25-35, 11 Abb.; Halle

[darin Profil Epichnellen/Bahnhof Förtha]

\subsubsection{Basaltgang am Bahnhof Hörschel}

QAbratis, M.; Mädler,J.; Hautmann, S.; Leyk, H.-J.; Meyer, R.; Lippolt, H. J. \& Viereck-Götte, L. (2007): Two distinct Miocene age ranges of basaltic rocks from the Rhön and Heldburg areas (Germany) based on 40Ar / 39Ar step heating data. - Chemie der Erde / Geochemistry, 67(2): 133150, 6 fig., 5 tabl.; München [darin: Stoffelskuppe b. Eisenach, Pflasterkaute b. Marksuhl, Hörschel]

QAnonym (1993): Naturdenkmal bleibt sichtbar: Ein Stück Heimatkunde. - Hessischer Gebirgsbote, 94(2): 64; Melsungen

[Bahnhof Hörschel/Werra; Basaltgang im Unteren Muschelkalk]

Ø■Bornemann [jun.], L. G. (1883): Bemerkungen über einige Basaltgesteine aus der Umgebung von Eisenach. - Jb. Preuß. Geol. Landesanst., $\underline{\mathbf{3}}$ (f. 1882): 149-157 (Abh. v. behördenfremden Pers.); Berlin 1883

Referat in: N. Jb. Mineral. etc., 1884 (Bd. 2): 366 (Referat H. Rosenbusch); Stuttgart

[Mineralogie; darin: Stoffelskuppe b. Eisenach, Hörschel, Hütschhof; Bezugnahme a. Blaue Kuppe b. Eschwege]

OGeyer, Roland (1994): Die Geologischen Naturdenkmale im Kreis Eisenach (Wartburgkreis): 3. Der Basaltgang am Bahnhof Hörschel. - Knüllgebirgsbote, 1994(4): 9-10, 1 Abb.; Bad Hersfeld

øGeyer, Roland (о. J.): Naturschönheiten im Landkreis Eisenach - 1. Teil: Geologische Naturdenkmale. - 32 S. zahlr. Abb. (Fotos, Profile, Kt., strat. Tab.); [Hrsg.: Umweltamt des Landrates Eisenach Untere Naturschutzbehörde] Eisenach [darin: Profil von Epichnellen/Bhf. Förtha; Kristallinaufschluß Busbahnhof Ruhla; Stoffelskuppe u. Pflasterkaute; Granitporphyr von Thal/Heiligenstein; Basaltgang Bhf. Hörschel] 
- $\square$ OLeonhard, Karl Caesar v. (1832): Die Basalt-Gebilde in ihren Beziehungen zu normalen und abnormalen Felsmassen. - Bd. 1, 498 S., sep. Taf.-Bd. 20 Taf.; Bd. 2, 536 S.; (Schweizerbart) Stuttgart [Bd. 2 beschreibt Intrusionsgefüge der Basalte und die Kontaktmetamorphose auf das Rahmengestein an verschiedenen nordhessischen Lokalitäten; Kontaktmetamorphose Basalt/Ton: Meißner; Basalt/Braunkohle: Meissner/Hirschberg/Habichtswald; Basalt/Buntsandstein: Blaue Kuppe b. Eschwege; Pflasterkaute b. Marksuhl; Basalt/Muschelkalk: Ahnetal/Kassel, Hörschel b. Eisenach]

- olleonhard, Karl Caesar v. (1846): Lehrbuch der Geognosie und Geologie. (Übergeordn. Titel: Naturgeschichte der drei Reiche. Zur allgemeinen Belehrung bearbeitet von H.G. Bronn, K.C. v. Leonhard, F.S. Lenckart und F.S. Voigt. Dritter Band: Geologie und Geognosie). - 2. vermehrte u. verbesserte Aufl.; XII, 1056 S., zahlr. Abb., 6 Falttaf.; (Schweizerbart) Stuttgart [darin: S. 185: Hörschel b. Eisenach, Basaltgang i. Unt. Muschelkalk; Habichtswald/Ziegenberg, Basaltüberdeckung der Braunkohle]

OVoigt, Johann Carl Wilhelm (1799): Von einigen Basalten im Eisenachischen < Abh. XVI des Bandes >. - In: Voigt, Johann Carl Wilhelm: Kleine mineralogische Schriften - Theil 1. - S. 181198; (bey den Gebrüdern Gaedicke) Weimar 1799

[Hütschhof, Stoffelskuppe, Pflasterkaue, Basaltgang in Hörschel]

- $\square$ OWalther, Johannes (1912): Lehrbuch der Geologie Deutschlands - Eine Einführung in die erklärende Landschaftskunde für Lehrende und Lernende. - 2., vermehrte Aufl.; XII, 429 S:, 1 Kt.Beil; (Quelle \& Meyer) Leipzig [darin: Abb. 18 Zeichnung „Basaltgang im Muschelkalk bei Hörschel“ - darin: S. 253-256, Abb. 126129 „Die hessischen Vulkane“ (Abb. 128 Profil Meissner); S. 257-261, Abb. 130-133 „Das Wesergebirge“ (Abb. 130 Heldrastein); S. 284-290, Abb. 149-152 „Der Thüringer Wald; S. 290-295, Abb. 153-158 „Die Thüringer Senke“]

- $\square$ OZirkel, Ferdinand (1866): Lehrbuch der Petrographie. - [In zwei Bänden]. - Zweiter Band; 635 S:; (Adolph Marcus) Bonn.

[darin S. 273-321: Gesteine der Basalt-Familie. - Bezugn. a. Basalte i. Hessen, WMK, Thüringen; Chemischer Analysen Meißner-Basalt, Pflasterkaute; Kontaktmetamorphose Basalt/Buntsandstein: Blaue Kuppe, Alpstein b. Sontra, Rosenbühl b. Eschwege-Niddawitzhausen; Pflasterkaute, Stoffelskuppe, Kupfergrube b. Hörschlitt; Intrusivverband m. Kalkstein: Ahnetal/Habichtswald, Basaltgang bei Hörschel(Thür.)]

\subsubsection{Fossilfundstätte Bromacker bei Tambach-Dietharz (Landkreis Gotha)}

OBerman, D.S.; Henrici, A.C.; Sumida, S.S: \& Martens, Th. (2000): Redescription of Swymouria sanjuanensis (Seymouriamorpha) from the Lower Permian of Germany based on complete mature specimens with a discussion of paleocology of the Bromacker locality assemblage. - J. vertebrate paleontology, 20 (2): 253-268, 7 fig., 1 tabl.; Chikago/Ill.

[Thüringer Wald, Fossilfundstätte Bromacker]

@Berman, D.S.; Reisz, R.R.; Scott, D.; Henrici, A.C.; Sumida, S.S. \& Martens, Th. (2000): Early Permian bipedal reptile. - Science, 290: 969-972, 4 fig., 1 tabl.; Washinton/DC

[Tambach-Dietharz]

OBerman, D.S.; Reisz, R.R., Martens, Th. \& Henrici, A.C. (2001): A new species of Dimetrodon (Synapsida: Sphenacodontidae) from the Lower Permian of Germany records first occurrence of genus outside of North America. - Can. J. Earth Sci., 38: 803-812, 2 fig., 3 tabl.; Ottowa [Thüringer Wald, Fossilfundstätte Bromacker] 
OEberth, D. A.; Berman, D. S.; Sumida, S. S. \& Hopf, H. (2000): Lower Permain terrestrial paleoenvironments and vertebrate paleoecology of the Tambach Basin (Thuringia, central Germany): The upland holy grail. - Palaios, 15: 293-313, 13 fig., 5 tabl.; Tulsa/Oklahoma. [Fossilfundstätte Bromacker]

OFichter, Jürgen (1998): Bericht über die Bergung einer 20 t schweren Fährtenplatte aus dem Tambacher Sandstein (Unter-Perm) des Thüringer Waldes und erste Ergebnisse ichnologischer Studien. Philippia, $\underline{\mathbf{8}}(3)$ : 147 - 208, 8 Abb., 3 Tab., 17 Taf.; Kassel

-OHaubold, Hartmut (1996): Ichnotaxonomie und Klassifikation von Tetrapodenfährten aus dem Perm. - Hallesches Jb. Geowiss., Reihe B, 18: 23-88, 36 Abb., 8 Tab.; Halle (Saale) [Tambach; Cornberg, Kr. Hersfeld-Rotenburg]

OHaubold, Hartmut (1998): The Early Permian tetrapod ichnofauna of Tambach, the changing concepts in ichnotaxonomy. - Hallesches Jb. Geowiss., B 20: 1-16, 8 fig., 1 tabl.; Halle (Saale)

OKorn, Hermann (1933): Eine für die Kenntnis der Cotyloaurier des deutschen Perms bedeutsame Schwimmfährte von Tambach. - Palaeobiologica, ㅁ: 169-200, 4 Abb., Taf. XV; Wien u. Leipzig

OKrause, T.; Martens, Th. \& Gores, J. (2006): Die Forschungsbohrung 1/2004., Bromacker 2/2004 und Altenbergen 1/2005 im Gebiet zwischen Bromacker und Kandelaber bei Tambach-Dietharz. Zielstellung, technische Arbeiten und erste Ergebnisse. - Abh. u. Ber. Museums d. Natur Gotha, 24: 199-202, 4 Abb.; Gotha

OMartens, Thomas (1988): Die Bedeutung der Rotsedimente für die Analyse der Lebewelt des Rotliegenden. - Z. geol. Wiss., 16 (9): 933-938, 2 Abb.; Berlin [Bezugnahme a. Fundstätte „Bromacker“ b. Tambach-Dietharz/Thüringer Wald]

OMartens, Thomas (1994): 20 Jahre Sauriergrabung im Oberrotliegend (Unteres Perm) am Bromacker bei Tambach-Dietharz/Thüringer Wald. - Abh. Ber. Museums d. Natur Gotha, (18) 1994: 15-26, 9 Abb.; Gotha

OMartens, Th. ; Schneider, J. \& Walter, H. (1981): Zur Paläontologie und Genese fossilführender Rotsedimente - der Tambacher Sandstein, Oberrotliegendes, Thüringer Wald (DDR). - Freiberger Forschungshefte, Reihe C, $\underline{\mathbf{3 6 3}}$ : 75-100, 5 Taf.; Leipzig

OMüller, Arno Hermann(1954): Zur Ichnologie und Stratonomie des Oberrotliegenden von Tambach (Thüringen). - Paläont. Z., 28 (1/4): 189-204, 2 Abb., 2 Tab., Taf. 16, 17; Stuttgart

OMüller, Arno Hermann (1955): Eine kombinierte Lauf- und Schwimmfährte von Korynichnium aus dem Oberrotliegenden von Tambach Thüringen): - Geologie, 4(4): 490-496, 1 Abb., 1 Taf.; Berlin

OPabst, Wilhelm (1896): Über Thierfährten aus dem Rothliegenden von Tambach in Thüringen. - Z. dt. geol. Ges., 48: 638-643, 1 Taf.; Berlin

OPabst, Wilhelm (1896): Über Thierfährten aus dem Rothliegenden von Tambach in Thüringen. - Z. dt. geol. Ges., 48: 808-829, 10 Abb., 1 Tab., Taf. XVII-XX; Berlin

Referat in: N. Jb. Mineral. etc, 1897 (Bd. I): 542-543 (Dames); Stuttgart

OPabst, Wilhelm (1896): Thierfährten in dem Oberrothliegenden von Tambach in Thüringen. Naturwiss. Wochenschrift, 11(48): 573-578, 6 Abb.; Berlin

OPabst, Wilhelm (1897): Über Thierfährten aus dem Rothliegenden von Tambach in Thüringen. - Z. dt. geol. Ges., 49(1897): 701-712, 3 Abb., 4 Taf.; Berlin 
OPabst, Wilhelm (1898): Weiterer Beitrag zur Kenntnis der Thierfährten in dem Rotliegnden Thüringens. II.: Ichnium acrodactylum „Typus“ und Ichnium acrodactylum „Varietas 1“ in dem Oberrothliegenden von Tambach. - Naturwiss. Wochenschrift, 13(29): 337-341, 8 Abb.; Berlin

OPabst, Wilhelm (1903): Die Fußspuren vorweltlicher Tiere in den Gesteinen der Umgebung von Friedrichroda, Tambach und Kabarz in Thüringen. - Aus den coburg-gothaischen Landen Heimatblätter, [1]: 45-51, 2 Abb., Taf. II; Gotha Referat in: Mitt. Geogr. Ges. f. Thür., 23: 55 (E. Schütze); Jena 1905

OScheibe, R. (1890): Pflanzenreste und Thierfährten aus dem Rothliegenden von Tambach. - Z. dt. geol. Ges., 42: 364-365 (Mber.); Berlin Referat in: N. Jb. Mineral. etc, 1894 (Bd. II): 442-443 (Sterzel); Stuttgart

oSumida, S.S.; Berman, D.S. \& Martens, Th. (1994): A trematopid amphibian from a terrestrial redbed of the Lower Permian of central Germany. - J. vertebrate paleontology, 14(Suppl to 3): 48 A; [Fossilfundstätte Bromacker]

OSumida, S.S.; Berman, D.S. \& Martens, Th. (1996): Biostratigraphic correlations between the Lower Permian of North America und Central Europe using the first record of an assemblage of terrestrial tetrapods from Germany. - PaleoBios, 17(2-4):1-12, 5 fig.; Berkeley/Calif.

[Fossilfundstätte Bromacker]

OSumida, S.S.; Berman, D.S. \& Martens, Th. (1998): A new trematopid amphibian from the Lower Permian red-bed deposit of central Germany. - Palaentology, 41 (4): 605-629, 11 fig.; London [Fossilfundstätte Bromacker]

OVoigt, S. \& Haubold, Hartmut (2000): Analyse zur Variabilität der Tetrapodenfährte Ichniotherium cottae aus dem Tambacher Sandstein (Rotliegend, Unter-Perm, Thüringen). - Hallesches Jb. Geowiss., B 22: 17-58, 11 Abb., 2 Tab., 16 Taf.; Halle (Saale)

\subsubsection{Kristallin von Ruhla-Brotterode}

OGaertner, Hans Rudolf (1951): Probleme des Saxothuringikums. - Geol. Jb., $\underline{6}$ (f. 1949): 409-450, 7 Abb., Taf. 3-4; Hannover

[darin Kap.: Der tektonische Bau - Ruhlaer Sattel. - S. 420-422, Abb. 3]

øGeyer, Roland (о. J.): Naturschönheiten im Landkreis Eisenach - 1. Teil: Geologische Naturdenkmale. - 32 S. zahlr. Abb. (Fotos, Profile, Kt., strat. Tab.); [Hrsg.: Umweltamt des Landrates Eisenach Untere Naturschutzbehörde] Eisenach

[darin: Profil von Epichnellen/Bhf. Förtha; Kristallinaufschluß Busbahnhof Ruhla; Stoffelskuppe u. Pflasterkaute; Granitporphyr von Thal/Heiligenstein; Basaltgang Bhf. Hörschel]

QHansch, Ralf \& Zeh, Armin (2000): Metabasites from the Ruhlaer Crystalline Complex: Evidence für distinct Variscan plate tectonic environments within the Mid-German Crystalline Rise / Metabasite des Ruhlaer Kristallins: Hinweise auf unterschiedliche prävariszische plattentektonische Bildungsräume in der Mitteldeutschen Kristallinzone. - Chemie der Erde, $\underline{\mathbf{6 0}}(1): 1-25,9$ fig., 4 tabl.; Jena

OKrause, Reinhard (2006): Geologische Naturdenkmale und ausgewählte Geotope. - Schriftenreihe Naturschutz i. Landkreis Gotha, H. ‥ - 1. Aufl.; 114 S., Ill., graph. Darst., Kt.; [Hrsg.: Landratsamt Gotha, Fachdienst Naturschutz u. Landschaftspflege) Gotha 
OLeonhardt, D. (2006): Ruhlaer Kristallin. - In: Heuse, Thomas \& Leonhardt, D. [Koord./Red.]: Deutsche Stratigraphische Kommission [Hrsg.] - Stratigraphie von Deutschland - VII: Silur. Schriftenrh. Dt. Ges. f. Geowiss., 46: 84; Berlin-Hannover 2006

OLützner, H., van der Klauw, S., Rauche, H. \& Zeh, A. (1997): Ruhlaer Kristallin, Tambacher und Eisenacher Rotliegendbecken - Exkursion A 1. - In: Lützner, H. \& Seidel, G. (eds):

Hauptversammlung der Deutschen Geologischen Gesellschaft - Jena, 27.9 bis 3.10.1997 - Regionale Geologie von Europa, Exkursionsführer. - Schriftenrh. Dt. Geol. Ges., 3: 1-34, 9 Abb.; Hannover 1997

QNeumann, W. (1951): Kristalline Schiefer bei Ruhla. - Dipl.-Arb. [unveröff.] [Humboldt-Univ.?] Berlin 1951

oSiebel, Wolfgang (1998): Variszischer spät- bis postkollisionaler Plutonismus in Deutschland: Regionale Verbreitung, Stoffbestand und Altersstellung. - Z. geol. Wiss., 26(3/4): 329-358, 2 Abb., 1 Tab.; Berlin

[darin: Pfalz, Schwarzwald, Thüringer Wald und Ruhlaer Kristallin, Ostbayern, Granulitgebirge, Lausitz]

口Thomson, S. N. \& Zeh, A. (2000): Fission-track thermochronology of the Ruhla Crystalline Complex; new constraints of the past - Variscan thermal evolution of the NW Saxo-Bohemian Massif. Tectonophysics, $\underline{\mathbf{3 2 4}}$ : 17-35, 8 figs., 1 tabl.; Amsterdam

QVan der Klauw, S.; Rauche, H. \& Lützner, H. (1997): Mineralparagenesen und Mikrostrukturen in Gesteinsfragmenten im Detritus permosilesischer Sedimente im westlichen Thüringer Wald: Hinweise auf eine differenzierte Hebung und Abtragung des Ruhlaer Kristallins (Vortragskurzfassung). - In: Büchel, Georg \& Lützner, Harald (Hrsg.): Regionale Geologie von Mitteleuropa - Geodynamische Prozesse zwischen Alpen und Nordatlantik - 149. Hauptversammlung - Deutsche Geologische Gesellschaft und Jahreshauptversammlung der Fachsektion Geoinformatik - Jena 27.09.-3.10.1997 Kurzfassung der Vorträge und Poster. - Schriftenrh. Dt. Geol. Ges., 22: 71; Hannover 1997

OVan der Klauw, S. \& Rauche, H. (1997): Duktile und semiduktile Verformungsgeschichte von Trusetal-Brotterode (Kristallin von Ruhla-Brotterode) (Posterbeitrag). - In: Büchel, Georg \& Lützner, Harald (Hrsg.): Regionale Geologie von Mitteleuropa - Geodynamische Prozesse zwischen Alpen und Nordatlantik - 149. Hauptversammlung - Deutsche Geologische Gesellschaft und Jahreshauptversammlung der Fachsektion Geoinformatik - Jena 27.09.-3.10.1997 - Kurzfassung der Vorträge und Poster. - Schriftenrh. Dt. Geol. Ges., 2: 70-71; Hannover 1997

OWerner, C.-D. (1972): Geochemische Untersuchungen an Gesteinen der alten Baustufe des Ruhlaer Kristallins (Thüringer Wald). - Ber. dt. Ges. geol. Wiss., Reihe B, 16 (1): 41-91, 10 Abb., 31 Tab.; Berlin

OWerner, C.-D. (1972): Zur Geochemie der Ruhlaer Folge im Thüringer Wald. - Ber. dt. Ges. geol. Wiss., Reihe B, 17(2): 131-217, 18 Abb., 54 Tab.; Berlin

OWunderlich, J. \& Zeh, A. (2000): Ruhlaer Kristallin [Einheit 23] - Teil der MKZ.- In: Hoth, K. \& Leonhardt, D. [Red.]: Stratigraphische Kommission Deutschland - Stratigraphie von Deutschland II: Ordovizium, Kambrium, Vendium, Riphäikum. - Teil II: Baden-Württemberg, Bayern, Hessen, Rheinland-Pfalz, Nordthüringen, Sachsen-Anhalt, Brandenburg. - Courier Forsch.-Inst. Senckenberg, 234: 135-162, Abb. 14-15, mehr. Tab.; Frankfurt/M.

OZeh, Armin (1996): Die Druck-Temperatur-Deformations-Entwicklung des Ruhlaer Kristallins (Mitteldeutsche Kristallinzone). Geotektonische Forschungen, 후; 212 S., 92 Abb., 6 Taf. i. Text, 3 Tab. i. Anh.; Stuttgart - zgl. Diss. Univ. Würzburg 1995

QZeh, A. (1997): Zur Entwicklung des Ruhlaer Kristallins im Oberkarbon und Perm (Vortragskurzfassung). - In: Büchel, Georg \& Lützner, Harald (Hrsg.): Regionale Geologie von 
Mitteleuropa - Geodynamische Prozesse zwischen Alpen und Nordatlantik - 149.

Hauptversammlung - Deutsche Geologische Gesellschaft und Jahreshauptversammlung der

Fachsektion Geoinformatik - Jena 27.09.-3.10.1997 - Kurzfassung der Vorträge und Poster. -

Schriftenrh. Dt. Geol. Ges., 2 : 124; Hannover 1997

OZeh, Armin (1999): Zur Metamorphose-Entwicklung der Mitteldeutschen Kristallinzone im Bereich Thüringens - Kenntnisstand aus dem Ruhlaer und Kyffhäuser Kristallin. - Beitr. Geol. Thüringen, N.F., $\underline{\mathbf{6}}$ : 249-268, 5 Abb.; Weimar

OZeh, A. (2001): Reconstruction of a prograde P-T path from zoned garnet and mineral inclusions using P-T pseudosections - problems of fractionation and changing fluid compositions. - DMG-Tagung Potsdam - Ber. Dt. Mineral. Ges. (Beih. Europ. J. Mineral.), 13: 203; Stuttgart

OZeh, A. (2002): SHRIMP-U/Pb zircon data of the Ruhla Crystalline Complex, Mid-German Crystalline Rise, provenance and climax of metamorphism. - In: Niebuhr, Birgit [Hrsg.]: GEO 2002 - Planet Erde: Vergangenheit, Entwickling, Zukunft/... 1.-5. Oktober 2002 in Würzburg -Programm und Kurzfassungen. - Programme and Abstracts. - Schriftenrh. Dt. Geol. Ges., 21: 360-361; Hannover

QZeh, A., Wunderlich, J., Okrusch, M., Werner, C.D. \& Mädler, J. (1995): Distribution of Index Minerals in the Ruhla Crystalline Complex, Mid German Crystalline Rise: A First Interpretation. - Zbl. Geol. Paläont., Teil 1, 1993 (9/10): 1459-1470, 3 figl; Stuttgart

OZeh, Armin \& Brätz, Helene (2000): Radiometrische und morphologische Untersuchungen an Zirkonen aus Granitporphyren, Rhyolithen und Granitgeröllen des nordwestlichen Thüringer Waldes. - Z. dt. geol. Ges., 151(1-2): 187-206, 4 Abb., 4 Tab.; Hannover

OZeh, A., Hansch, R., Brätz, H. \& Bombach, K. (2000): Herkunft und Verwitterung von Granitgeröllen in Rotliegendsedimenten des nordwestlichen Thüringer Waldes - Petrographische, geochemische und Zirkon-Untersuchungen. - N. Jb. Geol. Paläont., Abh., 218: 173-199, 5 Abb., 8 Tab.; Stuttgart

QZeh, Armin \& Brätz, Helene (2002): Timing of Late Carboniferous/Permian Granite and Granite Porphyry Intrusions in the Ruhla Crystalline Complex (Central Germany), New Constraints from SHRIMP and 207Pb/206Pb Single Zircon Dating. - Chemie der Erde, 62 (4): 303-316, 4 fig., 2 tabl.; Jena

QZeh, Armin, Williams, Ian S.; Brätz, Helene \& Millar, Ian L. (2003): Different age response of zircon and monazite during the tectono-metamorphic evolution of a high grade paragneiss from the Ruhla Crystalline Complex, central Germany. - Contrib. Mineral. Petrol., 145: 691-706, 6 fig., 6 tabl.; Berlin-Heidelberg

QZeh, A.; Cosca, M.; Brätz, H.; Okrusch, M. \& Tichomirowa, M. (2000): Simultaneous horst-basin formation and magmatism during Late Variscan Transtension: Evidence from 40Ar/39Ar and 207Pb/206Pb geochronology in the Ruhla Crystalline Complex. - Int. J. Earth Sciences, 89: 52-71, 12 fig., 2 tab.; Berlin-Heidelberg

\subsubsection{Niedersachsen}

\subsubsection{Ruhmequelle - Untereichsfeld (Lkr. Göttingen)}

-Anonym (1899): < Ein Quellen-Sonderling: Die Rhumequelle bei dem Dorf Rhumspringe im Kreise Heiligenstadt [!]> - Eschweger Tageblatt u. Kreisblatt, 1899; Nr. 88 v. 15.04 .1899 (Erstes Blatt); Eschwege 
Sonntags-Ausflug im Dreiländereck Hessen - Niedersachsen - Thüringen. - 159 S., 111 Fotos, 34 Kt., 1 Zeit-Taf.; (LSRB-Verlag, Landschaftskundlicher-Studien-Reisebuch-Verlag) Witzenhausen [zahlreiche Ausflugsziele, auch zu Quellen - Ziel 27 (Rhumequelle)]

$\square \bullet$ Böhme, Hermann (1932): Merkwürdige Quellen im Hannoverlande. - Die Weser, 11(6): 71-72; Bremen [Mariaspring u. Gronespring b. Göttingen, Karlsbrunnen Eichenberg, Rhumespring]

-Böttcher, M.E. ; Klein, S.; Rienäcker, J. \& Schwecke, H. (2008): A hydrochemical model for subterrestrial mixing of the Rhume Spring karst waters - Results form high water events und long term investigations. - In: Sauter, M.; Ptak, Th.; Kaufmann-Knoke, R.; Lodemann, M.;

Kerckhof, A van den (Hg.): Grundwasserressourcen - Kurzfassung der Vorträge und Poster. Tagung der Fachsektion Hydrogeologie in der DGG (FH-DGG) - Göttingen, 21 bis. 25. Mai 2008. Schriftenrh. Dt. Ges. Geowiss., 57: 44; Berlin-Hannover 2008

-Diestel, Walter (1931): Von der Rhume und ihrer Quelle. - Die Weser, 10(11): 297; Bremen

- Friese, H. (1980): Geologische Naturdenkmäler von Niedersachsen - Sonderausstellung 1974/75: Niedersächsisches Landesmuseum Hannover/Naturkunde-Abteilung. - 3. Aufl., 35 S., [17] Abb.; Hannover [darin: Rhumequelle/Rhumspringe; Basalt Hoher Hagen/Dransfeld]

-Gottlieb, Joseph (2004): Eine Beschreibung der Rhumequelle vor 80 Jahren - Europas größte Quelle. Eichsfelder Heimatzeitschrift, 48 (4)/2004(April): 125-127, 1 Abb.; Duderstadt

-Hanisch, Tobias (2003): Untersuchung zur Wasser- und Stoffbilanz im Einzugsgebiet der Rhumequelle (Südwestharz). - Bachelor-Arbeit [unveröff.] Univ. Göttingen 2003; 39 S.

-Hellrung, Carl Ludwig (1844): Die goldene Mark Duderstadt - Wahrheit und Dichtung. - 288, 16 S., 1 Abb..; (Wagner) Duderstadt [darin S. 65-144: „Der Rhumesprung“ - S. 65-113, 1 Abb.: „I. Sein Dasein“; S. 113-132: „II. Die Götter der alten Sassen“; S. 132-144: „III. Die Sage vom Ruhmesprung“]

-Herrmann, Axel (1969): Die geologische und hydrogeologische Situation der Rhumequelle am Südharz. - Abh. z. Karst- und Höhlenkunde, Reihe B - Hydrologie - Heft B1; 8 S., 2 Abb.; [Hrsg. Verbd. Dt. Höhlen- u. Karstforscher e.V., München] München - auch : Jh. f. Karst- und Höhlenkunde, $\underline{9}$ (f. 1968/69) (Der Südharz - seine Geologie, seine Höhlen- und Karsterscheinungen): 107 - 112, 2 Abb.; München

-Keindorf, Gudrun (1998): Wo die Rhumequelle rauscht... Altes und Neues von der Rhumequelle. Eichsfeld - Monatszeitschrift des Eichsfeldes, 41(1)[1998(Jan.)]: 415-417; Duderstadt

-Keindorf, Gudrun (2000): 750 Jahre Rhumspringe - Die Geschichte eines Dorfes im Untereichsfeld. 367 S:, 135 Abb., 1 Kt.-Beil.; [Hrsg. Gemeinde Rhumspringe] (Mecke) Duderstadt [darin S. 17-30, Abb. 1-6: „Eine Landschaft entwickelt sich“, S. 31-71, Abb. 7-17: „Die Rhumequelle und die Geschichte ihrer Erforschung]

-Nielbock, Ralf \& Röhling, Heinz-Gerd (2005): Einhornhöhle und Rhumequelle - herausragende Geotope im südniedersächsischen Zechstein-Karst. - Eichsfelder Heimatzeitschrift, 49(5)/2005(Mai): 161-164, 2 Abb.; Duderstadt

-Nielbock, R. \& Röhling, H.-G. (2006): Geotop-Ensemble Zechsteinkarstlandschaft Südharz: Einhorn-Höhle und Rhumequelle - Geotope von nationaler Bedeutung. - Schriftenrh. Dt. Geol. Ges., 42: 33-40, 12 Abb.; Berlin-Hannover 
-Otto, Bernhard (1966): Altes und Neues von der Rhumequelle. - Die Goldene Mark, 17 (3): 42-47, 1 Abb.; Duderstadt

[Bezugnahme a. Hydrogeologie; Geschichte, Mystik]

-Röhling, Heinz-Gerd (2003): Die Rhumequelle im Eichsfeld - eine der größten Karstquellen in Mitteleuropa. - Eichsfeld-Jahrbuch, 11 (2003): 329-357, 9 Abb., 4 Tab.; Duderstadt

-Thürnau, Karl (1913): Der Zusammenhang der Rhumequelle mit der Oder und Sieber. - Jb. f. d. Gewässerkunde Norddeutschlands - Besondere Mitteilungen, 2,6; VI, 25 S., 9 Taf.; (Mittler) Berlin zgl. Diss. Techn. Hochschule Hannover 1912

\subsubsection{Becken von Bilshausen - Untereichsfeld (Lkr. Göttingen)}

-Averdieck, Fritz-Rudolf \& Brelie, Günther von der (1963): Neue Beiträge zur pollenanalytischen Untersuchung des Interglazials von Bilshausen (Unter-Eichsfeld). - Geol. Jb., 무: 437 - 446, 2 Abb., 1 Taf.; Hannover

-Benda, L; Gaertner, H. R. v.; Herrmann, R.; Lüttig, G.; Streif, H.; Vinken, R. \& Wunderlich, H. G. (1968): Känozoische Sedimente in tektogenetischen Fallen und Subrosionssenken in SüdNiedersachsen. - Z. dt. geol. Ges., $\underline{117}$ (f. 1965): 713 - 726, 1 Abb., 1 Tab.; Hannover [darin: Bramburg, Hoher Hagen, Bilshausen, Seeburger See]

-Bismarck, Wolfram (1953): Das Bilshäuser Becken. Ausdehnung, Schichtenfolge und Untergrund der Ablagerung. - Die Goldene Mark, 4 (Oktober-H.): 10-14; Duderstadt [Quartär]

-Bismarck, Wolfram (1954): Faunistische Funde im Bilshäuser Becken. - Die Goldene Mark, $\underline{\mathbf{5}}$ (JanuarH.): 12-18; Duderstadt

[Quartär-Paläontologie]

-Bringmann, Hermann (1973): Die Bedeutung Bilshausens für die internationale geologische und paläontologische Forschung. - Eichsfelder Heimatstimmen, 17(7)/1973(Juli): 218-220; Duderstadt [Tongrube i. „Bilshäuser Becken“; Bilshausen/Untereichsfeld]

-Chanda, Sunirmal (1960): Über spättertiäre und interglaziale, pollenführende Ablagerungen im Leinetal nahe Göttingen und im südwestlichen Harzvorland (Unter-Eichsfeld). - Die Naturwissenschaften, 47(1): 19-20; Berlin

[Bilshausen (Unter-Eichsfeld), Northeim, Tongrube Eichenberg/Lkr. Göttingen]

-Chanda, Sunirmal (1960): Über spättertiäre und interglaziale, pollenführende Ablagerungen im Leinetal nahe Göttingen und im südwestlichen Harzvorland (Unter-Eichsfeld). - Die Naturwissenschaften, 47(1): 19-20; Berlin

[Bilshausen (Unter-Eichsfeld), Northeim, Tongrube Eichenberg/Lkr. Göttingen]

-Lüttig, Gerd \& Rein, Ulrich (1954): Das Cromer - (Günz/Mindel-) Interglazail von Bilshausen (Unter-Eichsfeld). - Geol. Jahrbuch, 70: 159-166, 2 Abb.; Hannover

[Vegetationsgeschichte]

-Meischner, Dieter \& Schneider, Jürgen (1967): 500000 Jahre alter Steppenhirsch geborgen $<$ Fundort Becken v. Bilshausen, Lkr. Göttingen $>$. - Sonderdrurck aus: Deutsche Jägerzeitung, 22/1967, [7 S.], 2 Abb.; (Neudamm-Neudeck) Melsungen 
-Müller, Helmut (1965): Eine pollenanalytische Neubearbeitung des Interglazial-Profils von Bilshausen (Unter-Eichsfeld). - Geol. Jb., 83: 327-352, 5 Tab.; 2 Taf. (43, 44); Hannover

[Vegetationsgeschichte]

-Sohn, Heinz (1965): Ein Vorzeithirsch geborgen. - Die paläontologische Sensation des Jahres. Eichsfelder Heimatstimmen, 9(1)/1965(Januar): 3-6, 1 Abb.; Lingen/Ems

[Paläont. Fund Tongrube Bilshausen/Untereichsfeld; des weiteren: Regionalgeologie des Eichsfeldes]

-Weiler, W[ilhelm](1965): Die Fischfauna des interglazialen Beckentones von Bilshausen bei Göttingen. - N. Jb. Geol. Paläont., Abh., 123(2): 202-219, 19 Abb., 2 Taf. (21,22); Stuttgart

\subsubsection{3 „Hoher Hagen“ bei Dransfeld}

-Anonym (1962): Der Gaußturm am Rande des Abgrundes - Ein heftiger Streit im Süden

Niedersachsens. - Die Weser, $\underline{\mathbf{3 6}}(7)$ : 117-120, 2 Abb.; Bremen

[Basaltabbau am Hohen Hagen b. Göttingen und entstehende Beeinträchtigungen]

-Bartholomä, Manuela (1987): Der Sand vom Hohen Hagen - Ingenieurgeologische Untersuchung eines Baustoffes. - Dipl.-Arb. [unveröff.] Univ. Göttingen 1987; 62 S.

-Benda, L; Gaertner, H. R. v.; Herrmann, R.; Lüttig, G.; Streif, H.; Vinken, R. \& Wunderlich, H. G. (1968): Känozoische Sedimente in tektogenetischen Fallen und Subrosionssenken in SüdNiedersachsen. - Z. dt. geol. Ges., 117 (f. 1965): 713 - 726, 1 Abb., 1 Tab.; Hannover [darin: Bramburg, Hoher Hagen, Bilshausen, Seeburger See]

-Beuermann (1962): Die Tragödie vom Gaußturm auf dem Hohen Hagen. - Das Werraland, 14(2): 2223, 1 Abb.; Eschwege

[Bergbau contra Erhalt des alten Gaußturmes]

-Bolter, Ernst (1961): Über Zersetzungsprodukte von Olivin-Feldspatbasalten. - Beitr. Mineral. Petrogr., $\underline{8}(2): 111$ - 140, 7 Abb., 14 Tab.; Berlin-Göttingen-Heidelberg

[darin: Basalte d.Umgebung v. Göttingen; Steinberg/Meensen, Hoher Hagen, Backenberg, Bramburg]

- Ernst, Theodor (1941): Olivinknollen der Basalte als Bruchstücke alter Olivinfelsen. - Nachr. Ges. Wiss. Göttingen, Math.-phys. Kl, Fachgr. IV, N.F., 11 (1934-1940): 147-154, 13 Abb.; Göttingen [Diagramme Kristallgitterregelung von Olivin, u.a. Hirzstein/Habichtswald b. Kassel, Hoher Hagen b. Göttingen]

- Friese, H. (1980): Geologische Naturdenkmäler von Niedersachsen - Sonderausstellung 1974/75: Niedersächsisches Landesmuseum Hannover/Naturkunde-Abteilung; 3. Aufl., 35 S., [17] Abb.; Hannover [darin: Rhumequelle/Rhumspringe; Basalt Hoher Hagen/Dransfeld]

-Kremp, Gerhard (1950): Pollenanalytische Braunkohlenuntersuchungen im südlichen Niedersachsen, insbesondere im Solling. - Geol. Jb., 64 (f. 1943-1948): 489-517, 4 Abb.; Hannover-Celle [darin: Lkr. Göttingen: Brunsberg, Hoher Hagen b. Dransfeld - Kl. Steinberg b. Hann. Münden]

-Linstow, Otto v. (1915): Die Braunkohlenformation in Hannover, Braunschweig, Anhalt und im Reg.Bez. Magdeburg der Provinz Sachsen. - In: Klein, Georg [Hrsg.]: Die deutsche Braunkohlenindustrie - Handbuch für den deutschen Braunkohlenbergbau. - 2. vollst. neubearb. Aufl., Textbd.: 880 S., 606 Abb. , Taf.Bd. Taf. 1-29 + 1 Kt.-Beil.; hier S. 129-146, Abb. 33+34; Halle/Saale 1915 [darin: Hoher Hagen b. Dransfeld, Steinberg/Meensen, Teichberg b. Bühren, Steinberg b. Münden] 
-Murawski, Hans (1952): Die Auswertung der Innenstrukturen von Basaltvorkommen für die Praxis. Z. Dt. geol. Ges. , 103: 414-416, 3 Abb.; Hannover

[Basaltvorkommen Umgebung Göttingen: Hoher Hagen b. Dransfeld, Bramburg b. Adelebsen]

-Namenskürzel (mic) (2005): Geologiepfad am Hohen Hagen eröffnet - Investitionsvolumen von 60.000 Euro / Konzept stammt von Geographin. - Göttinger Tageblatt, 2005; Nr. 91 v. 20.04.2005; S. 13, 1 Abb.; Göttingen

- ••Oehm J.; Schneider, A. \& Wedepohl, K. H. ( 1983): Upper mantle rocks from basalts of the northern Hessian depression (NW Germany). - TMPM - Tschermaks Mineral. u. petrogr. Mitt., 32(1): 25-48, 6 fig.; Wien-New York

[Niedersachsen: Hoher Hagen; Hessische Senke, keine Vorkommen im WMK]

$\square \bullet$ Pockels, F. (1897): Ueber den Gesteinsmagnetismus und seine wahrscheinlichen Ursachen. - N. Jb. Mineral. etc., 1897(Bd. I): 66-73 (Briefl. Mitt.); Stuttgart

[Bezugnahme a. Meissner, Bielstein i. Kaufunger Wald; Brackenberg b. Göttingen, Hoher Hagen b. Dransfeld, Hengelsberg]

- •Schwarzmann, Sigrid (1957): Über die Feldspat- und Feldspatgesteinsfremdlinge in den Tertiärvulkaniten des Oberweser-Fulda-Gebietes. - Abh. Akad. Wiss. z. Göttingen, Math-phys. Kl., 3. F., 25; 165 S., 6 Abb., 62 Tab., 4 Taf. (7 Abb.) Göttingen

[darin: Basalte d. Umgeb. v. Kassel; Lkr. Göttingen: Hoher Hagen/Dransfeld, Meensener Steinberg, Brunsberg]

- $\bullet$ Wedepohl, Karl Hans (1963): Die Nickel- und Chrom-Gehalte von basaltischen Gesteinen und deren Olivin-führenden Einschlüssen. - N. Jb. Mineral., Mh., 1963: 237 - 242, 2 Abb.; Stuttgart [Proben u.a. vom Westberg/Hofgeismar, Hirzstein, Baunsberg; Hoher Hagen/Dransfeld]

- $\square \bullet$ Wedepohl, Karl Hans \& Ritzkowski, S. (1980): [DMG-Tagung 1980] Exkursion E 1: Die nördliche Hessische Senke (Tertiär-Vulkanite, Kupferschiefer und variszischer Spilit). - Fortschr. Mineral., $\underline{\mathbf{5 8}}$, Beih. 2 (Einführung zu den Exkursionen anläßlich der 58. Jahrestagung der Deutschen Mineralogischen Gesellschaft in Göttingen 1980); S. 3-33, 2 Abb., 3 Tab.; Stuttgart [darin Hp: Werra-Meissner-Kreis: Blaue Kuppe, Bilstein, Cornberg, Forsths. Schmelzhütte, Hoher Meissner/Kalbe, Hoher Meissner/Kitzkammer; auch Hoher Hagen/Dransfeld, Westberg/Hofgeismar, Dörnberg/Zierenberg; Güntersberg b. Gudensberg, Isthaburg b. Istha, Steppling b. Homberg/Efze]

-Wollemann, Ewa Janina (2002): Der Geologie- und Bergbau-Pfad am Hohen Hagen (Südniedersachsen) - Konzeption, Rahmenbedingungen und Realisierung. - Dipl.-Arb. [unveröff.] Geogr. Inst. Univ. Göttingen; IV, 89 S., Ill., graph. Darst., Anh.Geologie und Archäologie, Märchen und Sagen

\subsubsection{Tongrube Eichenberg/Hottenrode (Lkr. Göttingen)}

-Arp, G.; Persoh, D.; Reimer, A.; Reitner, J. \& Sosnitza, M. (2000): Lias-Fossilien aus der Tongrube Eichenberg, Nordhessen. - Fossilien - Z. f. Hobbypaläontologen, 17(2): 108-113; Wiebelsheim [die Tongruben von Eichenberg/Hessen liegen jenseits der Landesgrenze in Niedersachsen]

-Arp, G.; Hoffmann, V.-E.; Seppelt, S. \& Riegel, W. (2004): Exkursion 6: Trias und Jura von Göttingen und Umgebung. - In: Reitner, Joachim; Reich, Mike \& Schmidt, G. [Hrsg.]: Geobiologie - Exkursionen und Workshops : excursions and workshops. [ 74. Jahrestagung der 
Paläontologischen Gesellschaft; Göttingen, 2.-8. Oktober 2004]. - Reihe: Universitätsdrucke Göttingen. - 256 S., zahlr. Abb., Tab.; hier: S. 147 -192, 18 Abb.; (Universitätsverlag) Göttingen 2004

-Arp, G.; Bielert, F.; Hoffmann, V.-E. \& Löffler, Th. (2005): Palaeoenvironmental significance of lacustrine stromatolithes of the Arnstadt Formation (,Steinmergelkeuper“, Upper Triassic, NGermany). - Facies, 51: 433-455, 13 fig., 2 tab. + tab. A; Berlin-Heidelberg

-Chanda, Sunirmal (1960): Über spättertiäre und interglaziale, pollenführende Ablagerungen im Leinetal nahe Göttingen und im südwestlichen Harzvorland (Unter-Eichsfeld). - Die Naturwissenschaften, 47(1): 19-20; Berlin

[Bilshausen (Unter-Eichsfeld), Northeim, Tongrube Eichenberg/Lkr. Göttingen]

-Chanda, Sunirmal (1962): Untersuchungen zur pliozänen und pleistozänen Floren- und Vegetationsgeschichte im Leinetal und im südwestlichen Harzvorland (Untereichsfeld). - Geol. Jb., 79: 783-844, 5 Abb, 4 Tab., 5 Taf.; Hannover

[Bilshausen (Unter-Eichsfeld), Northeim, Tongrube Eichenberg/Lkr. Göttingen]

Q•Ernst, Werner (1994): Zur Bedeutung reliktischer Gesteinsvorkommen für die paläogeographische Rekonstruktion - dargestellt an Beispielen aus dem deutschen Lias. - Beitr. Geol. Thür., N.F., 1: 6584, 3 Abb.; Jena

[Bezug a. Vorkommen i. Westhüringen, Eichenberg, Schwarzwald]

- $\square$ Heck, Herbert Lothar (1929): Beiträge zur Talgeschichte der oberen Leine. - Jb. Preuß. Geol. Landesanst., $\underline{49}$ (Teil I) (f. 1928)): 427 - 453, 5 Abb., 6 Taf. (28-33); Berlin [darin: Profil von Berge zw. Eichenberg u. Hebenshausen, Tongrube Eichenberg]

-Heck, Herbert Lothar (1929): Pollenanalytische Untersuchungen altdiluvialer Tone und Torfe von Northeim und Eichenberg im Flußgebiet der Leine. - Jb. Preuß. Geol. Landesanst., $\underline{49}$ (Teil II) (f. 1928): 1255-1264, 3 Abb.; 3 Tab., Taf. 80 u. 81; Berlin

-Hoffmann, Veit-Enno (2004): Sedimentologie und Paläontologie des Rhätkeupers der Tongrube Hottenrode (Ober-Trias, Landkreis Göttingen) an der Grenze zu Nordhessen. - Bachelorarbeit Geowiss. Zentrum Univ. Göttingen [unveröff.], 42 S., Anh., zahlr. Abb. u. Taf..

प0•Moesta, Friedrich (1884): Das Liasvorkommen von Eichenberg in Hessen in Beziehung auf allgemeine Verhältnisse des Gebirgsbaues in Nordwesten des Thüringer Waldes. - Jb. Preuß. Geol. Landesanst., 4 (f. 1883): 57-80, 4 Taf.; Berlin

Referat (Kurzfassung) in: N. Jb. Mineral. etc., 1886 (Bd. 2): 63-65 (E. Dathe); Stuttgart

[Saxonische Tektonik, Eichenberg-Gothaer-Graben]

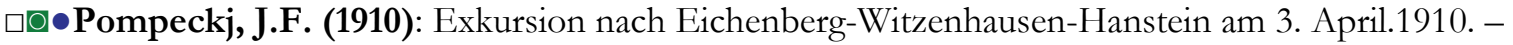
Jber. Niedersächsischen Geol. Vereins, $\underline{3}$ : XVIII - XXV, 2 Abb.; Hannover

Referat in: N. Jb. Mineral. etc., 1912 (Bd. I): 475-476 (Schöndorf); Stuttgart

[Regionalgeologie]

\subsection{Stratigraphie - Erdgeschichte}

\subsection{1 „Mitteldeutsche Kristallinzone“}

OBankwitz, Peter \& Kaemmel, Thomas (1957): Das Thüringer Hauptgranitmassiv (Ilmtal-SuhlerGranit) und sein südwestlicher Rahmen. - Abh. Dt. Akad. Wiss. z. Berlin, Kl. Chem., Geol., Biol., Jg. 1956, H. 3; 57 S., 22 Abb., 37 Diagr., 3 Beil.; (Akademie-Verlag) Berlin 
QBankwitz, Peter \& Kaemmel, Thomas (1958): Beitrag zur Geologie des Grundgebirges zwischen Ruhlaer und Schwarzburger Sattel. - Geologie, $\underline{7}$ (3-6): 597-609, 6 Abb.; Berlin Referat in: Geologie, $\underline{7}(1):$ 110-111 (G. Möbus); Berlin

口QBehr, Hans Jürgen (1966): Das metamorphe Grundgebirge im Thüringer Becken. - Ber. dt. Ges. geol. Wiss., Reihe A, 11(1/2): 39-56, 10 Abb.; Berlin

[Bezug a. Brhgn. Eschwege 1,3,4; Hainich. Langensalza, Mühlhausen]

OBenek, Reinhard \& Schust, Friedrich (1988): Bemerkungen zur partiellen Gefügedeformation in Magmatitgängen des Ruhlaer Kristallins (Thüringer Wald). - Z. geol. Wiss., 16 (8): 801-816, 16 Abb.Berlin

-OBrinkmann, Roland (1948): Die Mitteldeutsche Schwelle. - Geol. Rundschau, 36: 56 - 66, 2 Abb.; Stuttgart [Bezugnahme auf Richelsdorfer Gebirge, Thüringer Wald]

OEstrada, S.; Grunewald, V. \& Wunderlich, J. (1992): Zur Eduktcharakteristik und Lithostratigraphie von Truse- und Hohleborn-Serie (Ruhlaer Kristallin). - N. Jb. Geol. Paläont., Abh., 184: 389-419, 10 Abb., 2 Tab.; Stuttgart

OHansch, Ralf \& Zeh, Armin (2000): Metabasites from the Ruhlaer Crystalline Complex: Evidence für distinct Variscan plate tectonic environments within the Mid-German Crystalline Rise / Metabasite des Ruhlaer Kristallins: Hinweise auf unterschiedliche prävariszische plattentektonische Bildungsräume in der Mitteldeutschen Kristallinzone. - Chemie der Erde, $\underline{\mathbf{6 0}}$ (1): 1-25, 9 fig., 4 tabl.; Jena

OHesemann, J. (1928): Über kristalline Gesteine von Ruhla. - Sitzber. Preuß. Geol. Landesanst., $\underline{\mathbf{3}}$ : 169 176, 1 Abb.; Berlin

OHirschmann, Gottlieb \& Okrusch, Martin (1988): Spessart-Kristallin und Ruhlaer Kristallin als Bestandteilde der Mitteldeutschen Kristallinzone - ein Vergleich. - N. Jb. Geol. Paläont., Abh., 177: 1 - 39, 12 Abb., 1 Tab.; Stuttgart

OHuckriede, Hermann (2001): Lithologie, Stratigraphie und Struktur des nordwestlichen Ruhlaer Kristallins. - Geowiss. Mitt. Thür., 9: 95-105, 3 Abb.; Jena

OHuckriede, Hermann (2003): Lithologie, Stratigraphie und Struktur des nordwestlichen Ruhlaer Kristallins. - Geowiss. Mitt. Thüringen, 9: 95-105; Jena

OHuckriede, Hermann (2003): Lithologie, Stratigraphie und Tektonik im Nordwestteil des Ruhlaer Kristallins - Ergebnisse der geologischen Neukartierung. - In: Exkursionsführer - Die Geologie rund um die Wartburg. - S. 6-8; [Thür. Geol. Verein] Jena 2003

QHuckriede, Hermann (2003): Ringberg bei Ruhla: Gesteinsverband der Gömigenstein-Formation des nordwestlichen Ruhlaer Kristallins / Exkursionspunkt 5. - In: Exkursionsführer - Die Geologie rund um die Wartburg. - S. 25-27; [Thür. Geol. Verein] Jena 2003

OKaemmel, Thomas (1955): Untersuchungen im Thüringer Hauptgranitmassiv, besonders bei Suhl. Geologie, 4(2): 2-194; Autorreferat Diplom-Arbeit Univ. Berlin 1954; Berlin

QKoch, Werner (1940): Metatexis und Metablastesis in Migmatiten des nordwestlichen Thüringer Waldes. - Z. Kristallogr., Mineral., Petrogr.., Abt. B. - Tschermaks Mineral. Petrogr. Mitt.; N.F., $\underline{\mathbf{5 1}}$ (1/2): 1 101, 32 Abb., 1 Kt.; Leipzig

Referat in: N. Jb. Mineral. etc., Referate, 1940 (Bd. II): 309-312 (Chudoba), 1941 (Bd. III): $921-926$

(Walther Fischer); Stuttgart 
OKopp, J.; Bankwitz, P. \& Tichomirowa, M. (2001): Untersuchungen zur Alterseinstufung und Petrologie der Metamorphite der Bohrung Schleusingen 3/63 <Vortragskurzfassung >. - In: Rauche, Henry [Hrsg.]: Regionale und angewandte Geologie der Grenzregion der Süddeutschen und der Mitteldeutschen Scholle. - Programm und Kurzfassungen der Vorträge. - 10. Jahrestagung Gesellschaft f. Geowissenschaften i. Schmalkalden, 19.-22. September 2001. - Exkursionsführer u. Veröff. Ges. f. Geowiss., 214; S. 151-155 2, Abb., 2 Tab.; Berlin 2001

OLange, T. (1913): Ueber die Amphibolite des nordwestlichen Thüringer Waldes. - Jb. Preuß. Geol. Landesanst., $\underline{\mathbf{3 1}}$ (Teil I) (f. 1911): 1-52, 2 Abb., Taf. 1-3; Berlin [Ruhlaer Kristallin]

OLeonhardt, D. (2006): Ruhlaer Kristallin. - In: Heuse, Thomas \& Leonhardt, D. [Koord./Red.]: Deutsche Stratigraphische Kommission [Hrsg.] - Stratigraphie von Deutschland - VII: Silur. Schriftenrh. Dt. Ges. f. Geowiss., 46: 84; Berlin-Hannover 2006

OLützner, H., van der Klauw, S., Rauche, H. \& Zeh, A. (1997): Ruhlaer Kristallin, Tambacher und Eisenacher Rotliegendbecken - Exkursion A 1. - In: Lützner, H. \& Seidel, G. (eds):

Hauptversammlung der Deutschen Geologischen Gesellschaft - Jena, 27.9 bis 3.10.1997 - Regionale Geologie von Europa, Exkursionsführer. - Schriftenrh. Dt. Geol. Ges., ㅁ: 1-34, 9 Abb.; Hannover 1997

OMeinel, Günter (1995): Magmatismus und Metamorphose [in Thüringen]. - In: Seidel, Gerd [Hrsg.]: Geologie von Thüringen. - 1. Aufl.; S. 180-187; Stuttgart 1995

OMeinel, Günter (2003): Magmatismus und Metamorphose [in Thüringen]. - In: Seidel, Gerd [Hrsg.]: Geologie von Thüringen. - 2., neu bearb. Aufl.; S. 207-214; Stuttgart 2003

ONeumann, W. (1951): Kristalline Schiefer bei Ruhla. - Dipl.-Arb. [unveröff.] Univ. Berlin 1951, 44 S. Referat in: Geologie, 1: 400; Berlin

ONeumann, Werner (1955): Gefügeuntersuchungen im Ruhlaer Kristallin. - Diss. Univ. Berlin 1955 Geologie, 4(2): 194-195 (Autorenreferat); Berlin

ONeumann, Werner (1964): Zum Stand der Erforschung des kristallinen Grundgebirges von RuhlaBrotterode. - Abh. Akad. Wiss. z. Berlin; Kl. Bergb., Hüttenw., Montangeol., 1964(2): 327-348, 10 Abb.; Berlin

ONeumann, Werner (1966): Versuch eines lithostratigraphischen Vergleiches von Grundgebirgsanschnitten im Bereich der Mitteldeutschen Schwelle. - Geologie, 15(8): 942 - 962, 6 abb., 1 Tab.; Berlin [Ruhlaer Kristallin; Spessart und Odenwald]

ONeumann, Werner (1971): Zum Stockwerkbau im Bereich der Mitteldeutschen Kristallinzone (Speziell im Ruhlaer Kristallin) (Übergeordneter Titel: 25 Jahre Geotektonik an der Deutschen Akademie der Wissenschaften zu Berlin - Festkolloquium Potsdam, 21. und 22. Oktober 1971 -Kurzfassung der Vorträge). - o. Seitenzählung, 3 S.; (Zentralinstitut f. Physik d. Erde) Potsdam

ONeumann, Werner (1972): Die Entwicklung von variszischer und saxonischer Tektonik im Ruhlaer Kristallin. - Ber. Dt. Ges. geol. Wiss., Reihe A, 17(6): 797 - 810, 5 Abb.; Berlin

ONeumann, Werner (1973): Zum Stockwerkbau im Bereich der „Mitteldeutschen Kristallinzone“ (speziell im Ruhlaer Kristallin“). - (Übergeordnetert Titel: Stockwerksbau und Felderteilung Symposium 25 Jahre geotektonsiche Forschung an der Akademie der Wissenschaften der DDR) Veröff. Zentralinstitut f. Physik d. Erde, 14(2): 391 - 409, 5 Abb.; Potsdam 
oNeumann, Werner (1974): Baueinheiten [in Thüringen] - Mitteldeutsche Kristallinzone. - In: Hoppe, Walter \& Seidel, Gerd [Hrsg.]: Geologie von Thüringen [Bezirke Erfurt, Gera, Suhl]. - S. 75-118, 16 Abb., 1 Tab.; (Haack) Gotha-Leipzig 1974

ONeumann, Werner (1988): Mitteldeutsche Kristallinzone - Ruhlaer und Kyffhäuser Kristallin. - In: Bankwitz, Elfried [Gesamtredaktion]: Klassische Geologische Gebiete in Mitteleuropa Fundament und Deckgebirge. Südteil DDR - Exkursionsführer. - S. 180-197, Abb. 55-58; (Akademie der Wissenschaften der DDR - Zentralinstitut f. Physik d. Erde) Potsdam 1988

OSchust, F.; Büsch, W. \& Gotte, W. (2000): Über die Metamorphite der Bohrung Schleusingen 3/63 (Südthüringen) und ihre geologische Position. - Z. geol. Wiss., 28 (3/4): 381-396, 9 Abb.; Berlin

$\square$ Stark, Hans (1950): Altersstellung und Tektonik des Paläozoikums bei Albungen. - Diss. Univ. Göttingen 1950; 56 S., 11 Abb., 6 Kt.; Göttingen

$\square$ Stark, Hans (1952): Altersstellung und Tektonik des Paläozoikums bei Albungen. - Geol. Jb., $\underline{\mathbf{6 6}}$ : 203 226, 9 Abb.; Hannover

OWerner, Carl - Dietrich (1974): Metamorphose und Migmatisation im Ruhlaer Kristallin (Thüringer Wald). - Freiberger Forschungshefte, Reihe C, 284; 134 S., 24 Abb., 46 Tab.; (Dt. Verlag Grundstoffindustrie) Leipzig - Teildruck der Habilschrift Bergakad. Freiburg 1974 u.d. T. „Zum Stoffwechsel im Ruhlaer Kristallin“

OWunderlich, Jürgen (1985): Lithologie, struktureller Bau und metamorphe Entwicklung des südöstlichen Grundgebirges von Ruhla-Brotterode (westlicher Thüringer Wald). - Diss. A Bergakademie Freiberg/Sa.; Hauptbd., 99 S., graph. Darst.; sep. Tafelbd., 10 Tafel-Beil.

OWunderlich, Jürgen (1991): Exkursionsführer - Der Kristallinkomplex von Ruhla-Brotterode. - 89 S., 25 Abb.; (Thür. Geol. Verein) Jena

OWunderlich, Jürgen (1992): Petrogenese, Lagerungsverhältnisse und Gliederung der Steinbacher Augengneisfolge und ihre Position im strukturellen Bau des zentralen Ruhlaer Kristallins. - Geol Jb. Hessen, 120: 11 - 35, 12 Abb.; Wiesbaden

OWunderlich, Jörg (1995): Baueinheiten - Mitteldeutsche Kristallinzone (MKZ) [in Thüringen]. - In: Seidel, Gerd [Hrsg.]: Geologie von Thüringen. - 1. Aufl.; S. 22-46, 9 Abb., 3 Tab.; Stuttgart 1995

OWunderlich, J. \& Zeh, A. (2000): Ruhlaer Kristallin - Teil der MKZ.- In: Hoth, K. \& Leonhardt, D. [Red.]: Stratigraphische Kommission Deutschland - Stratigraphie von Deutschland II, Ordovizium, Kambrium, Vendium, Riphäikum. - Teil II: Baden-Württemberg, Bayern, Hessen, Rheinland-Pfalz, Nordthüringen, Sachsen-Anhalt, Brandenburg. - Courier Forsch.-Inst. Senckenberg, 234: 135-162, Abb. 14-15, mehr. Tab.; Frankfurt/M.

OWunderlich, Jörg \& Zeh, Armin (2003): Baueinheiten - Mitteldeutsche Kristallinzone (MKZ) [in Thüringen]. - In: Seidel, Gerd [Hrsg.]: Geologie von Thüringen. - 2., neu bearb. Aufl.; S. 24-52, 9 Abb.; Stuttgart 2003

OZeh, Armin (1996): Die Druck-Temperatur-Deformations-Entwicklung des Ruhlaer Kristallins (Mitteldeutsche Kristallinzone). - Geotektonische Forschungen, 후; 214 S., 92 Abb., 6 Tab., Anh. (3 Tab.); Stuttgart

OZeh, A. (1997): Zur Entwicklung des Ruhlaer Kristallins im Oberkarbon und Perm (Vortragskurzfassung).- In: Büchel, Georg \& Lützner, Harald (Hrsg.): Regionale Geologie von Mitteleuropa - Geodynamische Prozesse zwischen Alpen und Nordatlantik - 149.

Hauptversammlung - Deutsche Geologische Gesellschaft und Jahrestagung der Fachsektion Geoinformatik - Jena 27.09.-3.10.1997 - Kurzfassung der Vorträge und Poster. - Schriftenrh. Dt. Geol. Ges., 2: 124; Hannover 1997 
OZeh, A. ; Cosca, M.; Okrusch, M. \& Brätz, H. (1998): Differential Exhumation History of the Ruhla Crystalline Complex, Mid-German Crystalline Rise. - Acta Universitatis Carolinae, Geologica, $\underline{42}(2)$ :

361-362, 1 Fig.; Praha

\subsubsection{Präzechstein Hessen/Niedersachsen}

- $\square$ OCApel, Jürgen \& Rüppel, Heidi [Verfass. u. Hrsg.] (2005): Raus in die Natur - Tipps für den Sonntags-Ausflug im Dreiländereck Hessen - Niedersachsen - Thüringen. - 159 S., 111 Fotos, 34 Kt., 1 Zeit-Taf.; (LSRB-Verlag, Landschaftskundlicher-Studien-Reisebuch-Verlag) Witzenhausen [zahlreiche Ausflugstipps, auch zu Geotopen des Devons - Ziele 49, 62, 65 (UnterwerraGrauwackengebirge)]

-Ashry, M. (1964): Petrographie des Praezechsteins in der Bohrung „Dransfeld 1“ - Beitr. Miner. Petrogr., 11: 49 - 90, 8 Abb.; Berlin

-Bein, Georg (1932): Die Stellung des Richelsdorfer Gebirges zum Thüringer Walde und Rheinischen Schiefergebirge. - Z. dt. Geol. Ges., 84: 786 - 829, 8 Abb., Taf. 25-27; Berlin - zgl. Diss. Univ. Berlin 1932

-Besch, Wulf (1960): Das Dolomitgestein in der Gemarkung Mühlbach Reste eines Korallenriffs und einer Insel in den Meeren des Erd-Altertums. - Mein Heimatland, 19(9): 35 - 36, 1 Abb.; Bad Hersfeld Ursprüngliche stratigraphische Einordnung: Zechstein-Dolomit, später devonischer Massenkalk, s. Gunzert (1955)]

$\square$ Buchholz, Peter; Schmid, Martin \& Wachendorf, Horst (2008): Unterwerra-Grauwackengebirge. In: Weddige, Karsten [Koord. /Red.]: Deutsche Stratigraphische Kommission [Hrsg.] Stratigraphie von Deutschland VIII - Devon. - Schriftenrh. Dt. Ges. f. Geowiss., 52: 490-494, 3 Abb.; Berlin-Hannover 2008

$\square$ Chaudhari, Sudhakar Motiram (1963): Stratigraphische und tektonische Untersuchungen unter Berücksichtigung der Klufttektonik im Gebiet zwischen Witzenhausen und Eschwege/Hessen. Diss. [unveröff.] Fachber. Geowiss. FU Berlin; 148 S., Abb., 5 Beil.

$\square \bullet$ Deppe, Heinrich (1912): Die Landschaften Südhannovers und der angrenzenden Gebiete dargestellt auf geologischer Grundlage. Ein Beitrag zur Einführung der Geologie in den heimatkundlichen Unterricht. - Südhannoversche Heimatbücher, 1. - X, 193 S., VIII, Abb., 1 Kt.; (Vandenhoeck \& Ruprecht) Göttingen [darin: „Der Meißner“, „Das Grauwacken- und Zechsteingebirge an der unteren Werra“]

$\square$ Faupel, Jürgen (1971): Geologische Untersuchungen im NW-Teil des Unterwerra-Sattels. - Dipl.-Arb. [unveröff.] Univ. Göttingen; 100, VI S.

-Gunzert, Gerhard (1955): Der Grundgebirgsaufbruch von Mühlbach (Nordhessen). - Notizbl. Hess. L.A. Bodenforsch., 83: 106-125, 3 Abb., 3 Tab., 2 Taf.; Wiesbaden

[Revision der stratigraphischen Einordung eines Dolomitgesteins. Alte Interpretation:

Zechstein/Plattenkalk; neue Einstufung devonischer Massenkalk]

-Hartmann, Carl (1822): Atlas zu des Herrn von Villefosse Mineral-Reichthum, Sammlung geognostischer und technischer Beobachtungen welche den jetztigen Zustand der Bergbau- und Hüttenkunde durch von den besten Etablissements entlehnten Beyspielen darthun, und sie mit Hülfe der geometrischen Darstellung verdeutlichen. - 40 Taf.; Sondershausen [darin: Profil Zechstein/Rotliegendes Richelsdorfer Gebirge] 
-Henningsen, D. (1966): Die paläozoischen Grauwacken bei Gießen und ihre Fortsetzung unter der südlichen Hessischen Senke. - Ber. Oberhess. Ges. Natur- und Heilkunde., N.F., naturwiss. Abt., $\underline{34}$ : 19-31, 1 Abb.; Gießen

[Erwähnung der Devon-Aufbruches Baumbach-Oberellenbach-Sterkelshausen; B1. 4923

Altmorschen; Bohrung „Werra-Aue“ (Bl. 5125 Friedewald), Bhg. Weißenborn 2 (B1. 5125

Friedewald)]

-Héron de Villefosse, A. M. (1819): Atlas de la Richesse minérale. Recueil de faits géognostiques et de faits industriels, constatant l'état actuel de l'art des mines et usinses, par des exemples authentiques, tirés de célébres établissements, et rendus sensibles à l'oeuil, au moyen de la représentation géométrique des objects. - 63 planches; Paris

[darin: Stratigraphisches Profil Zechstein/Rotliegendes Richelsdorfer Gebirge]

-Héron de Villefosse, Antoine Marie (1819): De la richesse minérale. Considérations sur les mines, usines et salines des différens états, présentées comparativement. - Avec un Atlas in-folio de 65 planches. - Tome second : Division technique (1.re et II.e parties). - XVI, 559 p.; (Impimerie royale) Paris - [Insgesamt drei Bände u. Atlas-Band in Folio-Format] [darin S. 405-406: Erläuterung Stratigraphisches Profil Zechstein/Rotliegend Richelsdorfer Gebirge]

$\square$ Jacobshagen, V.; Koritnig, S.; Ritzkowski, S.; Rösing, F., Wittig, R. \& Wycisk, P. (1977): Der Unterwerra-Sattel: sein Deckgebirge (Perm - Trias) und der gefaltete paläozoische Kern - (Exkursion C). - Unter Mitarbeit von G. Schalow und H. Schulze. - In: Geol.-Paläont. Inst. u. Museum der Universität [Hrsg.]: Exkursionsführer - Geotagung '77 Göttingen - Band II : Nordhessen und Südniedersachsen (Exkursionen C - D - J - K - L). - S. 1-34; 8 Abb.; (Selbstverlag GeologischPaläontologisches Institut) Göttingen 1977 [darin: Aufschluß 1, 2, 10, 12,16 - Albunger Paläozoikum und Grauwackengebirge]

$\square$ Jacobshagen, V.; Koritnig, S.; Ritzkowski, S.; Rösing, F., Wittig, R. \& Wycisk, P. (1977): Der Unterwerra-Sattel: sein Deckgebirge (Perm - Trias) und der gefaltete paläozoische Kern - (Exkursion C). - Unter Mitarbeit von G. Schalow und H. Schulze. - In: Geol.-Paläont. Inst. u. Museum der Universität [Hrsg.]: Exkursionsführer - Geotagung '77 Göttingen - Band II : Nordhessen und Südniedersachsen (Exkursionen C - D - J - K - L). - S. 1-34; 8 Abb.; (Selbstverlag GeologischPaläontologisches Institut) Göttingen 1977

[darin: Aufschluß im Rabental, an der Saufbuche - Rotliegend-Graben im Grauwackengebirge]

$\square$ Jäger, Willy (1931): Erloschene Vulkane um Eschwege herum. - Die Weser, 10(8): 232-233, 1 Abb.; Bremen

[Bilstein/Höllental b. Frankershausen, Hoher Meißner, Blaue Kuppe b. Eschwege]

- $\square$ OJordan, Johann Ludwig (1803): Mineralogische, berg- und hüttenmännische Reisebemerkungen vorzüglich in Hessen, Thüringen, am Rheine und im Seyn-Altenkirchner Gebiethe. - 288 S., 4 FaltTaf.; (Dieterich) Göttingen [darin: I Unterwerra-Grauwackengebirge u. Zechsteinmantel; II Bergbau i. Richelsdorfer Gebirge; IIIIII-XVI Regional-Geologie, Bergbau Umgebung Bad Liebenstein - Schmalkalden]

$\square$ Koltze, Eberhard (1975): Geologische Untersuchungen am Unterwerra-Sattel zwischen Bad SoodenAllendorf, Hilgershausen und Oberrieden (Topographische Karten, 1 : 25 000, Witzenhausen, Nr. 4625 und Bad Sooden-Allendorf, Nr. 4725). - Dipl.-Arb. [unveröff.] Univ. Göttingen, 163 S.

$\square$ Kossmat, Franz (1927): Gliederung des variskischen Gebirgsbaues.- Abh. Sächs. Geol. L.-A., 1: 39 S., 2 Textfig., 2 Taf.; Leipzig

[Der - auch heute noch oft zitierte - Klassiker! Darin S. 14: Unterwerra-Grauwackengebirge]

-OKühne, Friedrich (1923): Die palaeogeographische Entwicklung der Saar-Saale-Senke. - Jb. Preuß. Geol. Landesanst., $\underline{43}$ (f. 1922): 426-456, 1 Abb., 3 Taf. (6-8); Berlin [darin: Richelsdorfer Gebirge; Taf. 7 - Geol. Kt.Skizze] 
- $\square$ ODietrich, Martin (1959): Zur Paläogeographie des Oberkarbons und Rotliegenden im Thüringer Becken. - Ber. Geol. Ges. DDR, 4(4): 326-345, 6 Abb., 2 Taf; Berlin

[Großregionale Betrachtung unter Einbeziehung von Bohrergebnissen aus Hessen, WMK und Westthüringen)

$\square$ Maurer, Jacob (1977): Geologische Wanderung durch das Werra-Schiefer-Gebirge - WTV Witzenhausen verfolgte erdgeschichtliche Spuren im heimatlichen Raum. - Das Werraland, 29(2): 1719, 1 Abb.; Eschwege

$\square$ Maurer, Jacob (1987): Geologische Wanderung im Werra-Schiefer-Gebirge bei Witzenhausen. - 47 S., 11 Abb., 2 strat. Tab.; (Selbstverlag Werrratalverein Witzenhausen e.V.) Witzenhausen [Exkursionsführer m. 17 Stationen]

-OMeinecke, Franz (1913): Das Liegende des Kupferschiefers. - Jb. Preuß. Geol. Landesanst., $\underline{31}$ (Teil II) (f. 1910): 253-296, 4 Abb., 1 Taf.) Berlin

[darin: Cornberger Sandstein]

- $\square$ Moesta, Friedrich (1875): Cidaris grandaeva im oberen Muschelkalk unfern des Meissners, Inseln alten Gebirges im hessischen Lande. - N. Jb. Mineral. etc., 1875: 294-295(Briefl. Mitt.); Stuttgart [„Inseln alten Gebirges im hessischen Lande“: Unterwerra-Grauwackengebirge b. Bad SoodenAllendorf, „Baumbacher Hoch“ bei Rotenburg/Fulda]

-Motzka-Nöhring, R. \& Weber, K. (1981): Das Paläozoikum und die phyllitischen Gesteine von Welda (Bl. 4925 Sontra). - Geol. Jb. Hessen, 109: 19 - 22, 1 Taf.; Wiesbaden

[3 Bohrprofile]

$\square$ Neuroth, Heike (1997): K/Ar-Datierungen an detritischen Muskoviten - „Sicherungskopien“ orogener Prozesse am Beispiel der Varisziden. - Göttinger Arbeiten z. Geologie u. Paläontologie, 72; V, 143 S., 29 Ab.., 7 Tab.; Göttingen

[Darin: Devon Steinbruch Schafhof Höllental/Unterwerra-Grauwackengebirge]

- $\square$ Nöring, Friedrich (1951): Die Fortsetzung der Saar-Senke in Hessen. - Notizbl. Hess. Landesamtes f. Bodenforsch., (6 F., H. 2) 풀 22-40, 1 Taf.; Wiesbaden [darin: „Verlauf der Nordgrenze in Hessen, Hessen, WMK]

-Oppermann, S. A. (1970): Das Rotliegende des Richelsdorfer Gebirges. - Dipl.-Arb. [unveröff.] Univ. Mainz 1970; 63 S., 15 Abb., 1 Taf., 1 Kt.

$\square$ Reitz, Erhard (1989): Devonische Sporen aus Phylliten vom Südrand des Rheinischen Schiefergebirges. - Geol. Jb. Hessen, 117: 23-35, 4 Taf.; Wiesbaden

[darin Kap.: Die phyllitischen Tonschiefer des Albunger Paläozoikums (Werra-Graunwackengebirge), S. 33-34, Taf. 4]

-Richter [-Bernburg], Gerhard (1941): Paläogeographie und tektonische Stellung des Richelsdorfer Gebirges im Hessischen Raume. - Jb. Reichsstelle f. Bodenforsch., $\underline{61}$ (f. 1940): 283 - 332, 19 Abb., Taf. 23 -25; Berlin

-Richter-Bernburg, Gerhard (1987): Das sogenannte Zechsteinkonglomerat und die Grenze Rotliegend/Zechstein. - Geol. Jb. Hessen, 115: 117-129, 7 Abb.; Wiesbaden [darin: Cornberg]

$\square$ Ritzkowski, Siegfried (1978) : Geologie des Unterwerra-Sattels und seiner Randstrukturen zwischen Eschwege und Witzenhausen (Nordhessen). - In: Koritnig, Sigmund [Schriftltg.]: Zur Mineralogie und Geologie der Umgebung von Göttingen - mit Westharz und Teilen des Nordhessischen Berglandes. - Der Aufschluss, Sdbd. 28: 187 - 204, 5 Tab. 1 Faltkarte; Heidelberg 1978 
$\square$ Schmidt, Hermann (1931): Die ursprünglichen Zusammenhänge zwischen Harz und Rheinischem Schiefergebirge. - Die Naturwissenschaften, 19(45): 911-916, 3 Abb.; Berlin [darin: „Das Grauwackengebirge an der Werra“, 1 Kt.-Skizz.)

$\square$ Schubart, Werner (1955): Zur Stratigraphie, Tektonik und den Lagerstätten der Witzenhäuser Grauwacke. - Abh. Hess. Landesamt Bodenforsch., 10; 67 S., 8 Abb., 3 Faltbl., 4 Taf.; Wiesbaden zgl. Diss. Univ. Göttingen 1954

$\square$ Schulz, Klaus-Hasse (1981): Die Geologie des südöstlichen Teils des Blattes (Nr. 4725) Bad SoodenAllendorf (nördliches Hessen, Unterwerra-Sattel) und eine mikrofazielle Analyse des Zechsteinkalks (Ca1). - Dipl.-Arb. [unveröff.] Univ. Göttingen, 156 S.

$\square$ Schulze, Hartmut (1977): Geologische Untersuchungen im Zentrum des Unterwerra-Sattels unter besonderer Berücksichtigung der Tektonik und der Petrographie der Werra-Grauwacke. - Dipl.-Arb. [unveröff.] Univ. Göttingen, 116 S.

- $S$ chumacher, Claus (1985): Die Grenze Rotliegendes/Zechstein im Werra-Fulda-Becken. - Z. dt. geol. Ges., 136: 121-128, 3 Abb.; Hannover

$\square$ Siuts, U. (1951) : Gesteinskundliche Lehrwanderung am 6. Juli 1951 nach der „Blauen Kuppe“ bei Eschwege und durch das „Höllental“ bei Albungen. 20 Blätter, zusammengeheftet [unveröff.], Hannoversch Münden [Standort: Bereichsbibl. Forstwissenschaften Uni. Göttingen Sign. Z 100/20]

$\square$ Stark, Hans (1950): Altersstellung und Tektonik des Paläozoikums bei Albungen. - Diss. Univ. Göttingen 1950; 56 S., 11 Abb., 6 Kt.; Göttingen

$\square$ Stark, Hans (1952): Altersstellung und Tektonik des Paläozoikums bei Albungen. - Geol. Jb., 66: 203 226, 9 Abb.; Hannover

-Stier, G, (1974): Das Perm des westlichen Richelsdorfer Gebirges und geologische Kartierung im Nordwestteil der TK 25 Hönebach. - Dipl-Arb. [unveröff.] Univ. Frankfurt; 245 S-. 26 Abb., 15 Tab., 3 Kt., 5 Profile

- $\square$ Thews, Joe-Dietrich (1996): Erläuterungen zur Geologischen Übersichtskarte von Hessen 1 : 300.000. - Teil 1: Kristallin, Ordovizium, Silur, Devon, Karbon.- Geol. Abh. Hessen, 96 ; 237 S., 39 Abb., 17 Tab., 7 Taf.; (Hess. Landesamt Bodenforschung) Wiesbaden [darin: auch Unterwerra-Grauwackengebirge zw. Witzenhausen und Albungen; jeweils Unterkapitel „Unterwerra-Sattel“ in den Kapiteln Unter-, Mittel-, Oberdevon, Unterkarbon]

$\square$ Wittig, Reinhold (1965): Zur Stratigraphie des Unterwerra-Sattels. - Kurznachrichten Akad. Wiss. Göttingen, $\underline{\mathbf{1 9 6 5}}(1)$, Mitt. Nr. 3; 7 S., 1 Abb., 1 Tab.; Göttingen

[Conodonten-Stratigraphie des „Albunger Paläozoikums"]

$\square$ Wittig, Reinhold (1967): Stratigraphie und Tektonik des gefalteten Paläozoikums im Unterwerra-Sattel. - Diss. Univ. Göttingen 1967; 82 S., 14 Abb., 3 Tab.

$\square$ Wittig, Reinhold (1968): Stratigraphie und Tektonik des gefalteten Paläozoikums im Unterwerra-Sattel. - Notizbl. Hess. L.-A. Bodenforsch. , 96: 31 - 67, 6 Abb., 2 Tab., 1 Taf.; unter gleichnamigen Titel Diss. Univ. Göttingen 1967

$\square$ Wittig, Reinhold (1970): Rotliegend im Unterwerra-Sattel (Nordhessen). - Göttinger Arb. Geol. Paläont, $\underline{\mathbf{5}}$ : 135 - 144, 5 Abb.; Göttingen

$\square$ Wittig, Reinhold (1974): Tiefoberdevonische Grauwacken unter der Hessischen Senke. - Notizbl. Hess. L.-A. Bodenforsch., 102: 46 - 57, 3 Abb.; Wiesbaden 
口OWunderlich, Jürgen (2001): - Ordovizium der Nördlichen Phyllitzone im Abschnitt Eschwege Breitungen. In: Hoth, Klaus [Red.]: Stratigraphie von Deutschland, II - Ordovizium, Kambrium, Vendium, Riphäikum. - Teil III: Nordthüringen, ... - Courier Forschungsinstitut Senckenberg, 235; 186 S., graph. Darst., Kt.; hier S. 62-63; [Hrsg.: Strat. Komm. Deutschland](Schweizerbart) Stuttgart 2001

[Großregionale Betrachtung; Eigenrieden-Gruppe (Phyllite); Bezug auf Bohrung Eschwege 4/39; ansonsten Bhgn. in der Region Eigenrieden, Heyerode, Hainich]

\subsubsection{Präzechstein Thüringen}

OAndreas, Dieter; Enderlein, Frieder \& Michael, Johannes (1966): Zur Entwicklung des Rotliegenden im Thüringer Wald auf Grund neuer Kartierungsergebnisse. - Ber. Dt. Ges. geol. Wiss., Reihe A, 11(1/2): 119-130, 3 Abb.; Berlin

OAndreas, Dieter; Lützner, Harald \& Schneider, Jörg W. (2005): Karbon des Thüringer Waldes, der Kraichgau-Main-Senke, der Thüringisch-Fränkischen Graben- bzw. Riftzone und ThüringischNordostbayerisches Scherzonensystem. - In: Wrede, Volker [Red.]: Deutsche Stratigraphische Kommission [Hrsg.]: Stratigraphie von Deutschland - V: Das Oberkarbon (Pennsylvanium) in Deutschland. - Courier Forsch.-Inst. Senckenberg, 254: 403-418, 3 Abb., 2 Tab.; Frankfurt/M. 2005

OAnonym (1932): Profile und Schichtfolgen zu den Geologischen Exkursionen in Thüringen. - Der Deutschen Geologischen Gesellschaft zu ihrer Hauptversammlung in Jena 3. - 8. August 1932 überreicht vom Thüringischen Geologischen Verein. - 28 S., 49 Profile u. Schichtfolgenverzeichn.; (Thüringischer Geologischer Verein) Jena

OAndreas, Dieter (1988): The structural dual character of the Rotliegendes in the Thurinian Forest and its surroundings. Late Hercynian morphogenic development and ist relationship to taphrogene kinematics - (Die strukturelle Entwicklung des Thüringischen Rotliegenden im Rahmen eines Mitteleuropäischen Makroblocks)-Z. geol. Wiss., 16 (10): 959-968, 5 fig.; Berlin

OAndreas, D.; Enderlein, F. \& Michael, J. (1966): Zur Entwicklung des Rotliegenden im Thüringer Wald auf Grund neuer Kartierungsergebnisse. - Ber. Dt. Ges. geol. Wiss., A $\underline{\mathbf{1 1}}$ (1/2): 119-130, 3 Abb.; Berlin

OAndreas, Dieter \& Michael, Johannes (1966): Zur geologischen Situation am Ostrand des Saaletroges im Thüringer Wald. - Hallesches Jb. mitteldt. Erdgeschichte, $\mathbf{7}$ (f. 1965): 15-38, 13 Abb.; Leipzig [Möhrenbach-Gehren]

OAndreas, D. \& Haubold, Hartmut (1973): Erste Information über die Richtgrenze Unteres/Oberes Autun (Unteres Perm, Unterrotliegend) im Niveau der Goldlauterer Schichten des Thüringer Waldes. - Z. geol. Wiss., 1 1 (6): 509-514, 1 Abb.; Berlin

OAndreas, Dieter; Enderlein, Frieder \& Michael, Johannes (1974): Siles und Rotliegendes im Thüringer Wald und seinem südlichen Vorland. - In: Hoppe, Walter \& Seidel, Gerd [Hrsg.]: Geologie von Thüringen [Bezirke Erfurt, Gera, Suhl]. - S. 356-449, Abb. 52-71, Tab. 32-38; (Haack) Gotha-Leipzig 1974

OAndreas, D.; Haubold, H. \& Katzung, G. (1975): Zur Grenze Stefan/Autun (Karbon/Perm). - Z. Geol. Wiss., $\underline{\mathbf{3}}(6)$ : 689-716, 1 Abb., 4 Tab.; Berlin

[darin: Thüringer Wald] 
OAndreas, Dieter \& Haubold, Hartmut (1975): Die biostratigraphische Untergliederung des Autun (Unteres Perm) im mittleren Thüringer Wald. - Schriftenrh. Geol. Wiss., ㅁ: 5-86, 8 Abb., 2 Tab., 18 Taf.; Berlin

OAndreas, Dieter \& Lützner, Harald (2001): Profilentwicklung und Tektonik der Oberhof-Formation und der Rotterode-Formation im mittleren Thüringer Wald (GK 25 Waltershausen und Tambach) $<$ Vortragskurzfassung>. - In: Rauche, Henry [Hrsg.]: Regionale und angewandte Geologie der Grenzregion der Süddeutschen und der Mitteldeutschen Scholle. - Programm und Kurzfassungen der Vorträge. - 10. Jahrestagung Gesellschaft f. Geowissenschaften i. Schmalkalden, 19.-22. September 2001. - Exkursionsführer u. Veröff. Ges. f. Geowiss., 214; S. 59-60; Berlin 2001

OAndreas, D.; Jungwirth, J. \& Wunderlich, J. (2001): Die Permokarbon-Entwicklung der ThüringischFränkischen Grabenzone im Licht der Ergebnisse von Tiefbohrungen im Thüringer Wald und seinen Vorländern <Vortragskurzfassung >. - In: Rauche, Henry [Hrsg.]: Regionale und angewandte Geologie der Grenzregion der Süddeutschen und der Mitteldeutschen Scholle. - Programm und Kurzfassungen der Vorträge. - 10. Jahrestagung Gesellschaft f. Geowissenschaften i. Schmalkalden, 19.-22. September 2001. - Exkursionsführer u. Veröff. Ges. f. Geowiss., 214; S. 61-63; Berlin 2001

OAnonym (1932): Profile und Schichtfolgen zu den Geologischen Exkursionen in Thüringen. - Der Deutschen Geologischen Gesellschaft zu ihrer Hauptversammlung in Jena 3. - 8. August 1932 überreicht vom Thüringischen Geologischen Verein. - 28 S., 49 Profile u. Schichtfolgenverzeichn.; (Thüringischer Geologischer Verein) Jena [darin: Exk. C 1: Rotliegendes des Thüringer Waldes bei Oberhof und Ilmenau]

- $\square$ OApel, Jürgen \& Rüppel, Heidi [Verfass. u. Hrsg.] (2005): Raus in die Natur - Tipps für den Sonntags-Ausflug im Dreiländereck Hessen - Niedersachsen - Thüringen. - 159 S., 111 Fotos, 34 Kt., 1 Zeit-Taf..; (LSRB-Verlag, Landschaftskundlicher-Studien-Reisebuch-Verlag) Witzenhausen [zahlreiche Ausflugstipps, auch zu Geotopen des Rotliegenden - Ziel 52 (Flachsbachtal/UnterwerraGrauwackengebirge), Ziel 90 (Drachenschlucht/Eisenach)]

OArnhardt, Alfred (1972): Tektonik, Stratigraphie und Flora des Stefan und Rotliegenden im Thüringer Wald. - Ber. Dt. Ges. geol. Wiss., Reihe A, 17(1): 81 - 100; Berlin

OBarthel, Manfred \& Rößler, Ronny (1993): Seismite aus dem Rotliegend des Thüringer Waldes Sedimentation und Fossilführung der Tonsteine der Oberen Gehren-Formation. - Veröff./ Naturhist. Museum Schleusingen, 7/8: 53-64, 7 Abb., 4 Taf.; Schleusingen [Lindenberg b. Ilmenau]

OBaunack, Carol \& Lippmann, Robert (2001): Kartierung der Goldlauter- und Oberhöfer Schichten parallel der BAB-Trasse (A71) nördlich Zella-Mehlis <Vortragskurzfassung>. - In: Rauche, Henry [Hrsg.]: Regionale und angewandte Geologie der Grenzregion der Süddeutschen und der Mitteldeutschen Scholle. - Programm und Kurzfassungen der Vorträge. - 10. Jahrestagung Gesellschaft f. Geowissenschaften i. Schmalkalden, 19.-22. September 2001. - Exkursionsführer u. Veröff. Ges. f. Geowiss., Berlin, 214; S. 73-74; Berlin 2001

OBaunack, Carol \& Lippmann, Robert (2002): Kartierung der Goldlauter und Oberhof-Formation parallel der BAB (A 71) nördlich Zella-Mehlis. - Mapping of the Goldlauter- and Oberhof-Formation (Rotliegend, Permian) parallel to the A 71 - highway in the north of Zella-Mehlis (Thuringia). - Z. geol. Wiss., $\underline{\mathbf{3 0}}(4 / 5)$ : 337-350, 3 Abb.; Berlin

OBehrendt, Lothar (1968): Ein Beitrag zur Rotliegendkartierung auf Blatt Tambach-Dietharz (Thüringer Wald). - Geologie, 17(3): 255-272, 9 Abb.; Berlin

-Bein, Georg (1932): Die Stellung des Richelsdorfer Gebirges zum Thüringer Walde und Rheinischen Schiefergebirge. - Z. dt. Geol. Ges., 84: 786 - 829, 8 Abb., Taf. 25-27; Berlin - zgl. Diss. Univ. Berlin 1932 
QBeyrich, E. (1886): Gliederung des Rotliegenden. -Z. dt. geol. Ges., 38: 699-701; Berlin [Bezugnahme a. Rotliegendes Eisenacher Mulde]

QBeyrich, E. (1895): Überblick über die geologische Zusammensetzung des Thüringer Waldes, in Sonderheit des Rotliegenden desselben, unter Vorlegung einer neuen geologischen Übersichtskarte im Maßstab 1 : 100.000. - Z. dt. geol. Ges., 47: 596-607; Berlin

OBornemann [sen.], J. G. (1878): Ueber mehrere Kohlenvorkommen in Thüringen. - Z. dt. geol. Ges., 30: 553-554; Berlin

[Oehrenkammer b. Ruhla, Moselberg b. Ruhla, Crock (Rotliegendkohlen); Eisenach (Keuperkohle)]

QBoy, Jürgen A. \& Martens, Thomas (1991): Zur Problematik chronostratigraphischer Korrelation im mitteleuropäischen Rotliegend (?oberstes Karbon-Perm). - Newsletter Stratigr., 25(3): 163-192, 9

Abb.; Berlin-Stuttgart

[Bezugnahme a. Thüringer Wald]

- 0 Brinkmann, Roland (1948): Die Mitteldeutsche Schwelle. - Geol. Rundschau, $\underline{\text { 36: }} 56$ - 66, 2 Abb.; Stuttgart

[Bezugnahme auf das Richelsdorfer Gebirge, Thüringer Wald]

QCotta, B. (1849): Granit-Geschiebe im Roth-Liegenden bei Eisenach. - N. Jb. Mineral. etc, 1849: 448 (Briefl. Mitt.); Stuttgart

QChrobok, Siegfried M. (1964): Über ein prätambacher Relief in Bereich der nördlichen Tambacher Mulde (Thüringer Wald). - Geologie, $\underline{\mathbf{1 3}}(8)$ : 1013-1016, 2 Abb.; Berlin

@Chrobok, Siegfried M. (1967): Zur Zeitproblematik stark reliefabhängiger Sedimentation am Beispiel der Tambacher Mulde (Thüringer Wald). - Geologie, 16(8): 907-908, 6 Abb.; Berlin

ØChrobok, Siegfried M. (1967): Verschüttung und Exhumierung eines Reliefs in einer variszischen Innensenke. - Geol. Rundschau, $\underline{\mathbf{5 6}}$ : 520-528, 4 Abb., 1 Tab.; Stuttgart

[Tambacher Mulde, Rotliegendes Thüringer Wald]

OChrobok, Siegfried M. (1967): Zur Zeitproblematik stark reliefabhängiger Sedimentation am Beispiel der Tambacher Mulde. - Geologie, $\underline{\mathbf{1 6}}(8)$ : 901-908, 6 Abb.; Berlin

- 0 Dachroth, Wolfgang (1988): Gesteinsmagnetischer Vergleich permischer Schichtfolgen im Mitteleuropa. - Z. geol. Wiss., 16(10): 959-968, 9 Abb.; Berlin

[darin: Richelsdorfer Gebirge]

QDeubel, F. (1960): Das Untere Perm in Thüringen und angrenzenden Gebieten. - Wiss. Z. Univ. Jena, Math.-Naturwiss. Rh., 9(3) (f. 1959/1969): 409-448, 12 Abb.; Jena

QDietrich, Martin (1959): Zur Paläogeographie des Oberkarbons und Rotliegenden im Thüringer Becken. - Ber. Geol. Ges. DDR, 4(4): 326-345, 6 Abb., 2 Taf; Berlin

[Großregionale Betrachtung unter Einbeziehung von Bohrergebnissen aus Nordosthessen und Westthüringen)

- $\square 0$ Dietrich, Martin (1965): Fazies und Paläogeographie des Jungpaläozoikums und der unteren Glieder der Werra-Serie im Werra-Fulda-Becken und seinen Randgebieten - (Vorträge 16. Treffen des Fachverbandes Mineralogie d. Geol. Ges. i. d. DDR - 2.-4. April 1964 in Eisleben). - Freiberger Forschungshefte, Reihe C, 193: 55-81, 6 Abb.; Leipzig [Thüringen, Werra-Meißner-Kreis, Richelsdorfer Gebirge]

OEigenfeld, Frank \& Schwab, Max (1974): Zur geotektonischen Stellung des permosilesischen subsequenten Vulkanismus in Mitteleuropa. - Z. geol. Wiss., 2(2): 115-137, 6 Abb., 2 Tab.; Berlin [Bezugn. a. Thür. Wald, „Hessischer Trog“, Schwarzwald] 
OEnderlein, F. (1974): Zur Stratigraphie der Quarzporphyre der Oberhöfer Porphyrplatte. - Diss. Hochschule f. Architektur, Bauwesen Weimar 1974; 150 S.

OEngels, Christian (1963): Beiträge zur geologischen Stellung des Dolerites der Höhenberge im Rotliegenden der Tambacher Mulde. - Diss. Univ. Jena 1963; Teil 1: 140 Bl., Teil 2: 51 Bl. (Abb. 1 98); Jena

QErnst, Werner (2004): Der Inselsberg - Geschichte und Geschichten. Der Porphyrhärtling Inselsberg ein Subvulkan der Rotliegend-Zeit. - Hörselberg-Bote, 57: 46-49; Hörselberg

OFreiesleben, Johann Carl (1807/1809/1815): Geognostischer Beytrag zur Kenntnis des Kupferschiefergebirges mit besonderer Berücksichtigung auf einen Teil der Grafschaft Mannsfeld und Thüringens. - insgesamt 4 Teile $(1807 / 1809 / 1815 / 1815$

4. Teil; VIII, 459 S., 2 Falt-Taf.; Freyberg 1815

[S. 164-169 „Kohlenschiefer am Thüringer Walde“; S. 179-191 „Steinkohlen im Thüringer Walde“; S. 200-206 Rotliegend im Thüringer Wald]

Die Beschreibung des Geologie in Hessen beruht auf Wiedergabe von Beobachtungen von Jordan, G. (1803): Mineralogische Berg- und Hüttenmännische Reisebemerkungen vorzüglich in Hessen, Thüringen, am Rhein und in Seyn-Altenkirchner Gebiete gesammelt; XVIII, 288 S.; (Diederich) Göttingen

OFriedrich, Alexander (1878): Das Rotliegende und die basischen Eruptivgesteine der Umgebung des großen Inselsberges. - Z. f. gesammt. Naturwiss., $\underline{\mathbf{5 1}}$ [= 3. F., $\underline{\mathbf{3}}$ (1878): 719-770; Taf. 21, 22; Berlin zgl. Diss. Univ. Halle 1878

Referat in: N. Jb. Mineral. etc., $1 \mathbf{1 8 8 0}$ (Bd. 2): 202-206 (Referat H. Bücking); Stuttgart

QGärtner, Hans Rudolf v. (1937): Bemerkungen zum Vulkanismus des Rotliegenden im südöstlichen Thüringer Walde. - Z. dt. geol. Ges., 89: 193-206, 8 Abb.; Berlin [Umgebung Unterneubrunn]

- 0 OGeinitz, Hanns Bruno (1861/1862): Dyas oder die Zechsteinformation und das Rothliegende. - H. I - Die animalischen Überreste der Dyas. - XVIII, S. 1-130, Taf. 1- 23; Leipzig (Engelmann) 1861; H. II - Die Pflanzen der Dyas und Geologisches. - VIII, S. 131 - 342, Taf. 24-52; (Engelmann) Leipzig [darin: Thüringer Wald, Thüringer Becken, Nordhessen; S. 268-270 „Zechsteinformation an der Werra bei Witzenhausen und Allendorf]]

-Geinitz, Hanns Bruno (1886): Zur Dyas in Hessen. - Festschrift Vereins Naturkde. z. Cassel- zur Feier seines fünfzigjährigen Bestehens. - S. 250 - 256, 1 Taf.; (Döll) Kassel 1886 [darin: Richelsdorfer Gebirge und Fossilieninventar des Kupferschiefers]

QGeinitz, H. B.; Fleck, H. \& Hartig, E. (1865): Die Steinkohlen Deutschlands und anderer Länder Europas. Ihre Natur, Lagerungs-Verhältnisse, Verbreitung, Geschichte, Statistik und technische Verwendung. - In 2 Bd. u. 1. Atlasbd. (28 Taf.); I. Bd.: Geologie; VIII, 420 S., 38 Abb.; II Bd. Geschichte, Statistik und Technik; VIII, 423 S., 4; (Oldenbourg) München [Bd. 1, S. 105 - 108: „Die Schwarzkohlen des Thüringer Waldes“]

OGerlach, Max (1909): Wie der rote Felsboden entstand, in dem Eisenachs Wälder wurzeln - Vortrag..., gehalten am 25. Mai 1909 (Das Rotliegende in Eisenachs Umgebung) [Vortragsreferat]. - 29 S.; (Kahle) Eisenach

oGeyer, Roland (1995): Die Geologischen Naturdenkmale im Kreis Eisenach (Wartburgkreis): 4. Geolog. Naturdenkmale bei Neuenhof. - Knüllgebirgsbote, 1995(1): 12, 1 Abb.; Bad Hersfeld [Rotliegendes, Zechstein] 
QGeyer, Roland (1994): Die Geologischen Naturdenkmale im Wartburgkreis: 5. Felsformationen südlich von Eisenach. - Knüllgebirgsbote, 1995(4): 6; Bad Hersfeld

[Rotliegendes]

QHalfar, A. (1883): Die Drachenschlucht bei Eisenach. - Z. dt. geol. Ges., 35: 630-632 (Monatsber.); Berlin

[Rotliegendes]

OHaubold, Hartmut (1977): Fossilienfazies und Biostratigraphie des Permosiles im Thüringer Wald. Diss. B [Habilschrift d. DDR-Universitätten] Univ. Halle-Wittenberg, 171 S., graph. Darst., Tab.; Halle

QHaubold, Hartmut (1980): Die biostratigraphische Gliederung des Rotliegenden (Permosiles) im mittleren Thüringer Wald. - Schriftenrh. Geol. Wiss., 16: 331-356, 4 Abb., 1 Tab.; Berlin

OHaubold, Hartmut (1981): Probleme der Rotliegendstratigraphie. - Z. geol. Wiss., 9 (4): 361-366, 2 Abb.; Berlin [darin: Mittlerer Thüringer Wald]

QHaubold, Hartmut [Hrsg.](1983): Exkursionsführer und Kurzreferate - Fortschritt der Paläontologie und Stratigraphie des Rotliegenden - Tagung der Ges. Geol. Wiss. DDR (GGW) vom 13.-15. April 1983 Erfurt. - Exkursionsf. u Veröff. Ges. Geolog. Wiss. DDR, 115; 36 S., Abb., 2 Beil.; (AkademieVerlag) Berlin

QHaubold, Hartmut (1985): Stratigraphische Grundlagen des Stefan C und Rotliegenden im Thüringer Wald. - Schriftenrh. Geol. Wiss., 23: 1-110, 15 Abb., 7 Tab.; Berlin [Ausführliches Literaturverzeichnis]

OHaubold, Hartmut \& Katzung, Gerhard (1972): Das Typus-Gebiet der Auton/Saxon-Grenze im Thüringer Wald. - Ber. Dt. Ges. geol. Wiss., Reihe A, $\underline{\mathbf{1 7}(6):} 849$ - 863, 2 Abb., 7 Taf.; Berlin

OHaubold, Hartmut \& Katzung, Gerhard (1972): Die Abgrenzung des Saxon. - Geologie, 21 (8): 883910, 7 Abb., 3 Tab.; Berlin [darin: Thüringer Wald, Tetrapodenfährten]

Q๑Haubold, Hartmut \& Katzung, Gerhard (1975): Die Position der Autun/Saxon-Grenze (Unteres Perm) in Europa und Südamerika. - Schriftenrh. Geol. Wiss., 3: 87-138, 4 Abb., 14 Tab.; Berlin [darin: Thüringer Wald, Richelsdorfer Gebirge]

QHaubold, H. \& Katzung, G. (1978): Zur Anwendung stratigraphischer Richtlinien im Rotliegenden. Z. angew. Geol., 24(10): 439-441; Berlin [darin: Rotliegendes Thüringer Wald]

OHaubold, Hartmut \& Katzung, Gerhard (1980): Lithostratigraphischer Standard für das Permosiles im mittleren und südöstlichen Thüringer Wald. - Z. angew. Geol., 26 (1): 10-19, 2 Abb., 2 Tab.; Berlin

QHoff, K. E. A. von (1820): Verhältnisse des bituminösen Mergelschiefer und des Todtliegenden bei Ilmenau. - Tb. Mineral., 14(2): 568-573 (Briefl. Mitt.); Frankfurt/M.

QHolub, Vlastimil \& Kozur, Heinz (1981): Die Korrelation des Rotliegenden Europas. -Geol. Paläont. Mitt. Innsbruck, 11(5): 195-242, 4 Abb.; Innsbruck [darin: Thüringer Wald]

QJuderselben, Georg (1969): Zur Petrologie des sedimentären Rotliegenden im Thüringer Wald und seinem Vorland. - Diss. Hochsch. Architektur u. Bauw. Weimar; 163 Bl., Abb., Anl.

OKatzung, Gerhard (1965): Die Stellung des Konglomerats von Fehrenbach im Unteren Perm Thüringes. - Diss. A Univ. Jena; 350, IX S.; Ill., graph. Darst., 1 Kt. 
OKatzung, G. (1965): Zur Stratigraphie, Paläogeographie und Sedimentologie des tieferen Unterrotliegenden am SE-Rand des Thüringer Waldes. - Mber. Dt. Akad. Wiss. z. Berlin, $\underline{7}(1)$ : 63-68; Berlin [Kurzauszug Diss.]

QKatzung, Gerhard (1966): Sedimentation und Paläogeographie des tieferen Unterrotliegenden im SETeil des Thüringer Waldes. - Ber. Dt. Ges. geol. Wiss., A 11(1/2): 131-136, 2 Abb.; Berlin

oKatzung, Gerhard (1971): Zyklizität und Rhythmizität sedimentärer Abfolgen - Flysch und Molassen des jungen Variszikums. - Ber. Dt. Ges. geol. Wiss., Reihe A, 16 (3-5): 265-295, 12 Abb.; Berlin [darin: Saxon, u.a. Thüringer Wald; Sedimentologie, Rotliegend-Stratigraphie]

OKatzung, Gerhard (1972): Stratigraphie und Paläogeographie des Unterperms in Mitteleuropa. Geologie, 21(5): 570-584, 3 Abb.; Berlin

[Bezugn. a. Thüringer Wald]

OKatzung, Gerhard \& Döring, Harry (1973): Die Lage der Karbon/Perm-Grenze im Permosiles-Profil des Thüringer Waldes. - Z. geol. Wiss., 1(5): 493-507, 1 Abb., 1 Tab., 1 Taf.; Berlin

OKnoth, Wolfram (1969): Beiträge zur Kenntnis des Stefan und Rotliegenden des nordwestlichen Thüringer Waldes. - Diss. Univ. Halle-Wittenberg; VI, 165 S., Abb., Taf.; Halle

QKnoth, Wolfram (1969): Zur Lithologie und Paläogeographie des höheren Rotliegenden im Thüringer Wald. - Ber. Dt. Ges. geol. Wiss., A $\underline{\mathbf{1 5}}(1)$ : 47-65, 4 Abb., 2 Tab.; Berlin

oKozur, Heinz, H. (1977): Beiträge zur Stratigraphie des Perm - Teil I: Probleme der Abgrenzung und Gliederung des Perm. - Freiberger Forschungshefte, Reihe C, $\underline{\mathbf{3 1 9}}$ : 79-221, 7 Tab.; Leipzig [Bezugn. a. Thüringer Wald]

QKozur, Heinz, H. (1980): Beiträge zur Stratigraphie des Perm - Teil III(2): Zur Korrelation der überwiegend kontinentalen Ablagerungen des obersten Karbon und Perms von Mittel- und Westeuropa. - Freiberger Forschungshefte, Reihe C, 48: 69-172, 13 Abb.; Leipzig [darin: Thüringer Wald]

OKozur, Heinz (1988): The age of the Central Europe Rotliegendes. - Z. geol. Wiss., 16 (9): 907-915, 4 tabl.; Berlin

[Bezugnahme a. Eisenacher Rotliegendbecken]

OKrause, T.; Martens, Th. \& Gores, J. (2006): Die Forschungsbohrung 1/2004., Bromacker 2/2004 und Altenbergen 1/2005 im Gebiet zwischen Bromacker und Kandelaber bei Tambach-Dietharz. Zielstellung, technische Arbeiten und erste Ergebnisse. - Abh. u. Ber. Museums d. Natur Gotha, 24: 199-202, 4 Abb.; Gotha

-OKühne, Friedrich (1923): Die palaeogeographische Entwicklung der Saar-Saale-Senke. - Jb. Preuß. Geol. Landesanst., $\underline{43}$ (f. 1922): 426-456, 1 Abb., Taf. 6-8; Berlin [darin: Richelsdorfer Gebirge]

OKunert, Reinhard (1978): Lithostratigraphische Ergebnisse der Dünnschliffintegration an Sandsteinen des Thüringer Permosiles. -Hallesches Jb. Geowiss., ㅁ: 95-104, 4 Abb., 1 Tab.; Halle [Thüringer Wald, Asbach-Rotteroder Senke]

OLoretz, H. (1893): Bemerkungen über die Lagerung des Rothliegenden südlich von Ilmenau in Thüringen. - Jb. Preuß. Geol. Landesanst., 13 (f. 1892): 115-128; Berlin Referat in: N. Jb. Mineral. etc., 1895 (Bd. II): 120-121 (Holzapfel); Stuttgart 
OLudwig, Alfred O. (1988): Climate - Tectonics - Sedimentation during the transitional period from the Early to the Late Permian. - Z. geol. Wiss., 16 (11/12): 1073-1080, 4 fig.; Berlin

[Großregionale Betrachtung Mitteleuropas]

OLützner, Harald (1966): Strömungsmarken aus dem Rotliegenden des Thüringer Waldes. - Geologie, 15: 1135 - 1160, 26 Abb.; Berlin

OLützner, Harald (1966): Fazies und Transportrichtung im Oberrotliegenden von Elgersburg (Thüringer

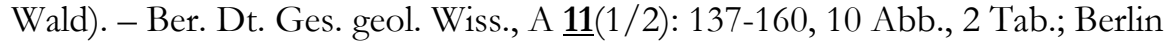

OLützner, Harald (1969): Über die Verbreitung der Manebacher Schichten im Rotliegenden des Thüringer Waldes. - Geologie, 18(7): 815-827, 5 Abb., 1 Tab.; Berlin

QLützner, H. (1970): Sedimentation und Tektonik im Rotliegenden des Thüringer Waldes. $<$ Autorreferat - Tagungsbeitrag anläßlich der> - Tagung des Fachverbandes Geologei der Deutschen Gesellschaft für Geologische Wissenschaften am 6. und 7. Dezember 1968 in Halle - „Das sedimentäre Permosiles in der Deutschen Demokratischen Republik südlich der Mitteldeutschen Hauptlinie“. - Ber. Dt. Ges. geol. Wiss., Reihe $\underline{\mathbf{A}}, 15(1):$ 102-103; Berlin

QLützner, Harald (1972): Lithostratigraphie und Paläotektonik des Rotliegenden in der Schleusinger Randzone (Thüringer Wald). - Ber. Dt. Ges. geol. Wiss., A 17(6): 811-834, 10 Abb., 1 Tab.; Berlin

OLützner, Harald (1974): Sedimentation des Rotliegenden im Thüringer Wald. - B-Dissertation [= Habilschrift der DDR-Universitäten] [unveröff.] Univ. Greifswald 1974; Teil 1: S. 1 - 161, Abb., Kt.; Teil 2: S. 161 - 384, Abb., Kt.; Teil 3: S. 385-533, Abb., Kt., 5 Beil.; Greifswald

OLützner, Harald (1978): Konglomerattypen des Rotliegenden von Thüringen und deren Vergleich mit rezenten Schwemmfächersedimenten. - Z. geol. Wiss., $\mathbf{6}(10)$ : 1187-1210, 12 Abb., 1 Tab.; Berlin

OLützner, Harald (1979): Transportanalysen der unterpermischen Sedimente im Thüringer Wald. Veröff. Zentralinstitut f. Physik d. Erde, $\underline{43}$; 132 S., 44 Abb., 3 Tab., Anh. m. Tab. A-C; Potsdam

OLützner, Harald (1981): Sedimentation der variszischen Molasse im Thüringer Wald. - Schriftenrh. Geol. Wiss., 17; 217 S., 46 Abb., 8 Tab., 21 Taf.; Berlin

OLützner, Harald (1981): Ein Aufschluß im Unterrotliegenden westlich Zella-Mehlis (Thüringer Wald). Z. geol. Wiss., 9(5): 587-590, 1 Abb.; Berlin

OLützner, Harald (1986): Exkursionsführer und Kurzreferate - Lithologie und Vulkanotektonik im Rotliegenden des Thüringer Waldes - Vortrags- und Exkrursionstagung für Junge Geologen vom 2. bis. 4. Oktober in Eisenach - Gesellschaft f. geol Wiss. d. DDR (GGW); 40 S., 9 Abb.; Berlin

OLützner, H. (compilation) (1987): Sedimentary and volcanic Rotliegendes of the Saale Depression. Excursion guide book- Symposium on Rotliegendes in Central Europe, Erfurt, May 24-30, 1987; 197 S.; (Zentralinstitut f. Physik d. Erde) Potsdam [darin: Rotliegendes of the Thuringian Forest (Thüringer Wald); Upper Carboniferous and Rotliegendes of the Mansfeld-Halle district]

OLützner, Harald (1988): Sedimentology and basin development of intramontane Rotliegend basins in Central Europe. - Z. geol. Wiss., $\underline{\mathbf{1 6}}(9):$ 845-863, 15 fig.; Berlin [Bezugnahme a. Thüringer Wald]

OLützner, Harald (1994): Clastic dykes in the distal segment of a Rotliegend alluvial fan (Eisenach Formation, Permian, Thüringer Wald). - Zentralbl. Geol. Paläont., Teil 1, 1992(11/12): 1305-1316, 5 Abb.; Stuttgart 
OLützner, Harald (2000): Das Rotliegende in Thüringen (Deubel 1948 - SPT 1998). - Geowiss. Mitt. Thüringen, Beih. 9: 83-102, 5 Abb.; Jena

OLützer, Harald (2003): Die Eisenach-Formation (Rotliegendes) - Verbreitung und Faziesinterpretation. - In: Exkursionsführer Die Geologie rund um die Wartburg. S. 8-10; [Hrsg. Thür. Geol. Verein] Jena 2003

OLützner, Harald \& Rentzsch, Johannes (1975): Sedimentation und Metallogenie in einem intramontanen Becken der variszischen Molasse. - Z. geol. Wiss., $\underline{\mathbf{3}}(11)$ : 1473-1490, 5 Abb., 2 Tab.;

Berlin [Goldlauterer Becken/Thüringer Wald]

OLützner, Harald; Ellenberg, Jürgen \& Falk, Fritz (1981): Sedimentology and basin development of Rotliegend deposits in the Saale through. - In: Depowski, Stanislaw [president organizing committee]: Central European Permian - International Symposium - Jabłonna, April 27-29, 1978 Proceedings; 656 S., Abb.; hier S. 239-252, 4 Abb.; (Geological Institute) Warszawa [darin: Thüringer Wald]

OLützner, H. \& Benek, R. (1988): Rotliegendes Thüringer Wald. (Unter Mitarbeit von P. Bankwitz und E. Bankwitz). - In: Bankwitz, Elfried [Gesamtredaktion]: Klassische Geologische Gebiete in Mitteleuropa. - Fundament und Deckgebirge, Südteil DDR - Exkursionsführer. - S. 154-179, Abb. 47-54; (Akademie der Wissenschaften der DDR - Zentralinstitut f. Physik d. Erde) Potsdam 1988

OLützner, Harald \& Mädler, Jonas (1994): Rotliegendes im Thüringer Wald. (Exkurision F am 7. und 8. April 1994 [115. Jahresversammlung d. Oberrhein. Geol. Vereins 1994 in Bad Kissingen]. - Jber. Mitt. Oberrhein. Geol. Vereins, N.F., 76: 171 - 190, 6 Abb.; Stuttgart

OLützner, H.; Andreas, D.; Mädler, J.; Michael, J.; Voigt, H.; Werneburg, R.; Judersleben, G. \& Jungwirth, J. (1995): Permosiles: Siles und Rotliegend [in Thüringen]. - In: Seidel, Gerd [Hrsg.]: Geologie von Thüringen. - 1. Aufl.; S. 188-302, 11 Abb., 2 Tab.; Stuttgart 1995

OLützner, H., van der Klauw, S., Rauche, H. \& Zeh, A. (1997): Ruhlaer Kristallin, Tambacher und Eisenacher Rotliegendbecken - Exkursion A 1. - In: Lützner, H. \& Seidel, G. (eds):

Hauptversammlung der Deutschen Geologischen Gesellschaft - Jena, 27.9 bis 3.10.1997 - Regionale Geologie von Europa, Exkursionsführer. - Schriftenrh. Dt. Geol. Ges., ㅁ: 1-34, 9 Abb.; Hannover 1997

OLützner, Harald \& Andreas, Dieter (2001): Ergebnisse tephrostratigraphischer Untersuchungen in der Goldlauter- und Oberhof-Formation (Rotleigendes) des Mittleren Thüringer Waldes

$<$ Vortragskurzfassung>. - In: Rauche, Henry [Hrsg.]: Regionale und angewandte Geologie der Grenzregion der Süddeutschen und der Mitteldeutschen Scholle. - Programm und Kurzfassungen der Vorträge. - 10. Jahrestagung Gesellschaft f. Geowissenschaften i. Schmalkalden, 19.-22. September 2001. - Exkursionsführer u. Veröff. Ges. f. Geowiss., 214; S. 165-166; Berlin 2001

OLützner, H.; Andreas, D.; Mädler, J.; Michael, J.; Voigt, H.; Werneburg, R.; Judersleben, G.; Jungwirth, J. \& Katzschmann, L. (2003): Permosiles: Siles und Rotliegend [in Thüringen]. - In: Seidel, Gerd [Hrsg.]: Geologie von Thüringen. - 2., neu bearb. Aufl.; S. 215-326, 11 Abb., 2 Tab.; Stuttgart 2003

OMägdefrau, Karl (1942): Die Thüringer Rotliegend-Kohlen und ihre Entstehung. - Natur u. Volk, $\underline{72} 8$ (9/10): 178-191, 12 Abb.; Frankfurt/M.

OMartens, Thomas (1980): Beitrag zur Taxonomie und Ökologie des Oberrotliegenden im Elgersburger Becken in Thüringen. - Abh. Ber. Museums d. Natur Gotha, (10) 1980: 21-32, 4 Abb., Taf. 5; Gotha 
QMartens, Thomas (1982): Zur Stratigraphie, Taxonomie, Ökologie und Klimaentwicklung des Oberrotliegenden (Unteres Perm) im Thüringer Wald (DDR). - Abh. Ber. Museums d. Natur Gotha, (11) 1982: 33-57, 14 Taf.; Gotha

QMeinhold, R. (1951): Die Neuaufschlüssse im Steinkohlenvorkommen der Öhrenkammer bei Ruhla. Hallesches Jb. Mitteldt. Erdgeschichte, $\underline{1}(\mathrm{Lfg}$. 2): 76-82, 8 Abb.; Halle/Saale

OMeister, Jochen (1988): Geologische und paläovulkanitische Untersuchungen an den Rhyolithen der Oberhöfer Schichten im Thüringer Wald zwischen Tambach und Gehlberg. - Diss. A Univ. HalleWittenberg; 195, [29] S., Ill., graph. Darst.

OMenning, M.; Katzung, G. \& Lützner, H. (1988): Magetostratigraphic investigations in the Rotliegendes (300-252 Ma) of Centrale Europe. - Z. geol. Wiss., 16(11/12): 1045-1063, 7 fig. Berlin [Bezugnahme a. Thüringer Wald]

QMichael, Johannes (1972): Zur Paläogeographie der Gehrener Schichten im südöstlichen Thüringer Wald. - Ber. dt. Ges. geol. Wiss., Reihe A, 17(6): 835-847, 5 Abb.; Berlin

@Möhl, Heinrich (1877): Über die Ausbreitung des Steinkohlengebirges im Centralgebiete des Thüringer Waldes. - [Vortrags-Text]. - N. Jb. Mineral. etc., 1877: 414 - 415; Stuttgart

ONaumann, E. (1932): Rotliegendes des mittleren Thüringer Waldes (Exkursionsbericht - Lehrausflüge vor u. nach d. Hauptversamml. d. Dt. Geol. Ges. in Jena vom 3.-8. August 1932). - Z. dt. geol. Ges., 84: 753-755, 1 Abb.; Berlin

DObst, K. \& Katzung, G. (1996): Der Höhenberg-Dolerit (Thüringer Wald) intrudierte zu Beginn der Rotteroder Zeit (Autun). - Beitr. Geol. Thür., N.F., 22: 37-48, 6 Abb., 1 Tab.; Jena

QObst, K.; Katzung, G. \& Hammer, J. (1999): Dating of the Late Autunian bascic magmatism in the Thuringian Forest. - N. Jb. Geol. Paläont. Mh., 1999: 1-10, 3 Abb., 1 Taf.; Stuttgart [Geochronologie des basischen Rotliegend-Magmatismus]

OPatzelt, Gerald (1966): Bau und Schichtenfolge der Asbach-Rotteröder Mulde (Thüringer Wald) nach neuen Kartierungsergebnissen. - Hallesches Jb. mitteldt. Erdgeschichte, $\underline{7}$ (f. 1965): 39-60, 8 Abb.; Leipzig

OPatzelt, Gerald (1970): Zu einigen Fragen der Gliederung und Lagerungsverhältnisse im Rotliegenden des mittleren Thüringer Waldes. - Geologie, 19(7): 789-802, 5 Abb.; Berlin

OPatzelt, Gerald (1977): Nochmals zur Frage der Einstufung der Porphyrkonglomerate im

Rennsteiggebiet des Meßtischblattes Tambach-Dietharz (Thüringer Wald). - Hallesches Jb. Geowiss., 1: 115-120, 2 Abb.; Gotha/Leipzig

OPlatt, H. (1916): Das Randgebiet des Thüringer Waldes bei Benshausen. - Jb. Preuß. Geol. Landesanst., $\underline{\mathbf{3 6}}$ (Teil II) (f. 1915): 175 - 225, 10 Abb., insges. 6 Taf.; Berlin

[Rotliegendes, Zechstein, Buntsandstein, Tektonik]

QPorstmann, E. (1961): Die Manebacher Schichten im Gebiet nordöstlich Goldlauter-Heinebach (Blatt Suhl). - Dipl.-Arb. [unveröff.] Univ. Jena, 76 S.

OPringsheim, Gustav (1880): Über einige Eruptivgesteine aus der Umgebung von Liebenstein in Thüringen. - Z. dt. geol. Ges., 32: 111-182, 7 Abb., Taf. X-XI; Berlin 1880

Referat in: N. Jb. Mineral. etc., $\underline{1881}$ (Bd. 2): 229- 231 (H. Rosenbusch); Stuttgart

QReichardt, Wolfgang (1932): Zur Stratigraphie des Rotliegenden in Thüringen. - Jb. Halleschen Verbandes etc., N.F., 11: 121-184, 6 Abb., 3 Tab.; Halle (Saale) 
Referat in: N. Jb. Mineral. etc., Referate; 1933 (Bd. III): 676 (Kräusel); Stuttgart

[S. 154-157 auch Paläobotanik]

OReichardt, Wolfgang (1933): Ueber die basale Gehrener Tuff-Sedimentfolge im östlichen Thüringer Wald. - Beitr. Geol. Thür., $\underline{3}:$ 302-316, 3 Abb.; Jena

QSamuel, M.D. (1978): Note on the origin and paleoclimatic conditions of the Tambach Sandstone. - Z. geol. Wiss., $\underline{\mathbf{6}}(10):$ 1273-1275, 3 fig.; Berlin

QScheibe, R. (1902): Geologische Spaziergänge im Thüringer Wald. I: Das Kickelhahngebiet und die Umgebung von Manebach-Kammerberg. - Naturwiss. Wochenschrift, N.F., 11: (1․ d. GesamtRh.)(15): 170-176, Abb. 1-6; (37): 433-440, Abb. 7-10; auch als sep. Druck: 38 S.; (Gustav Fischer) Jena [Rotliegend der Umgebung von Manebach]] Referat in: Mitt. Geogr. Ges. i. Thür., 21: 119-120 (E. Schütze); Jena 1903

OScheibe, R. (1907): (Bericht über wissenschaftliche Ergebnisse 1903-1904) Bericht über Kontaktgesteine im Kleinen Thüringer Wald auf Blatt Schleusingen und über Granit, Rothliegendes und Zechstein südwestlich Mehlis auf Blatt Schwarza (Mehlis) auf Grund der Aufnahmen in den Jahren 1903 und 1904. - Jb. Preuß. Geol. Landesanst., $\underline{25}$ (f. 1904): 697-715, Taf. 22; Berlin

OSchirmer, Bodo (1967): Erarbeitung und Anwendung von Methoden zur Klärung einiger Probleme der Sedimentation und des Vulkanismus an einem Einzelobjekt im Bereich der Westflanke der Tambacher Mulde, Thüringer Wald. - Diss. math.-nat. Humbold-Univ. Berlin 1967; 105 S., [12 S. Literaturverz.]; 29 Taf. (85 Abb.), 1 geol. Kt. u. weit. Anl.; Berlin [Petrographie Rotliegend]

OSchneider, Jörg (1996): Biostratigraphie des kontinentalen Oberkarbon und Perm im Thüringer Wald, SW-Saale-Senke - Stand und Probleme. - Beitr. Geol. Thür., N.F., 푸 121 - 151, 4 Abb.; Jena

OSchneider, J.; Walther, H. \& Wunderlich, R. (1982): Zur Biostratinomie, Biofazies und Stratigraphie des Unterrotliegenden der Breitenbacher Mulde (Thüringer Wald). - Freiberger Forschungshefte, Reihe C, 366: 65-84, 8 Abb., 4 Tab., 2 Taf.; Leipzig

OSchneider, J. \& Wienholz, R. (1987): Die stratigraphische und paläo[geo]graphische Entwicklung des molassoiden Permosiles im Südteil der DDR. - Freiberger Forschungshefte, Reihe C, 425: 43-52, 3 Abb., 2 Tab.; Berlin [Großregionale Betrachtung, darin: Thüringer Wald]

OSchneider, Jörg \& Gebhardt, Ute (1993): Litho- und Biofaziesmuster in intra- und extramontanen Senken des Rotliegend (Perm, Nord- und Ostdeutschland). - Geol. Jb., Reihe A, 131: 57-98, 13 Abb.; Stuttgart [darin: Tambach-Formation...., S. 72-76; Eisenach-Formation..., S. 76-78]

OSchreiber, Alfred (1952): Stratigraphie und Tektonik des Unterrotliegenden im südwestlichen Randgebiet des Thüringer Waldes bei Schleusingen und Hirschbach (Kr. Suhl). - Geologica, 11: 87106, 5 Abb.; Berlin

OSeebach, K. v. (1876): Gliederung des Rotliegenden im Thüringer Wald. - Z. dt. geol. Ges., 28: 633 (Mber.); Berlin

OSeidel, Gerd \& Steiner, Walter (1974): Geologische Entwicklungsgeschichte - Permosiles [in Thüringen]. - In: Hoppe, Walter \& Seidel, Gerd [Hrsg.]: Geologie von Thüringen [Bezirke Erfurt, Gera, Suhl]. - S. 811-827, Abb. 160-163; (Haack) Gotha-Leipzig 1974

aSeyfarth, H.-H. (1962): Beobachtungen an pyroklastischen Gesteinen der Gehrener Schichten zwischen Ilmenau und Suhl/Thüringer Wald. - Dipl.-Arb. [unveröff.] Univ. Jena 1962 
OSteiner, Walter (1991): Tambacher und Elgesburger Becken (Thüringer Wald/Rotliegendes) und ihre Entstehung über leergeförderten Magmakammern. - Z. Geol. Wiss., 19 (5): 593-596, 1 Abb.; Berlin

Ø'Tantscher (1836): Über das Steinkohlengebirge zu Manebach und Kammerberg bei Ilmenau. - Archiv f. Mineral., Bergbau u. Hüttenwesen, 9 (2): 566-577; Berlin

口Thalheimer, H. (1965): Die Tambacher Schichten. - Dipl.-Arb. [unveröff.] [Humboldt-Univ.?] Berlin 1965

OWeber, Hans (1962): Übersicht der Rotliegend-Stufen im Thüringer Wald. - N. Jb. Geol. Paläont., Mh., 1962: 150-155, 1 Tab.; Stuttgart

OWeber, Hans (1963): Zur Paläovulkanologie des Thüringer Waldes. - Hallesches Jb. mitteldt. Erdgeschichte, 5: 65-68, 2 Abb.; Leipzig

OWeiss, E. (1877): Porphyrvorkommen des nördlichen Thüringer Waldes. - Z. Dt. geol. Ges., 29: 418423 (Verhdlgn.); Berlin

Referat in: N. Jb. Mineral. etc., 1878: 83-86 (Anonym); Stuttgart

OWeiss, E. (1878): < Über die Steinkohlen-führenden Schichten der Öhrenkammer/Ehernen Kammer bei Ruhla]. - Z. dt. geol. Ges., $\underline{\text { 30: }} 542$-545, 1 Abb.; Berlin

OWerneburg, Ralf (1997): Ein See-Profil aus dem Unter-Rotliegend (Unter-Perm) von Manebach (Thüringer Wald). - Veröff./ Naturhist. Museum Schleusingen, 12: 63-67, 5 Abb.; Schleusingen

QWolf, Hans Joachim (1951): Beitrag zur Geologie und Hydrogeologie der Oberrotliegendmulde von Tambach in Thüringen. - Dipl.-Arb. Univ. Berlin 1951, 31 S.

Referat in: Geologie, 1: 400; Berlin 1952

OWunderlich, Jürgen (2001): Die Kammquerungsstrecke der Bundesautobahn A 71 - Ein geologische Querprofil durch den mittleren Thüringer Wald <Vortragskurzfassung >. - In: Rauche, Henry [Hrsg.]: Regionale und angewandte Geologie der Grenzregion der Süddeutschen und der Mitteldeutschen Scholle. - Programm und Kurzfassungen der Vorträge. - 10. Jahrestagung Gesellschaft f. Geowissenschaften i. Schmalkalden, 19.-22. September 2001. - Exkursionsführer u. Veröff. Ges. f. Geowiss., 214; S. 241-245; Berlin 2001

OZeh, A.; Cosca, M.A.; Brätz, H.; Okrusch, M \& Tichomirowa, M. (2000): Simultaneous horst-basin formation and magmatism during Late Variscan transtension: evidence from $40 \mathrm{Ar} / 39 \mathrm{Ar}$ and $207 \mathrm{~Pb} / 206 \mathrm{~Pb}$ geochronology in the Ruhla Crystalline Complex. - Int. J. Earth Sciences, 무: 52-71, 12 Abb., 3 Tab.; Berlin-Heidelberg

QZeh, A.; Hansch, R.; Brätz, H. \& Brombach, K. (2000): Herkunft und Verwitterung von Granitgeröllen im Rotliegendsedimenten des nordwestlichen Thüringer Waldes. - Provenance and alteration of granite gravels in Rotliegned beds from the northwestern Thuringian Forest. Results of petrography, geochemistry and zircon investigations. - N. Jb. Geol. Paläont. Abh., 218: 173-199, 5 Abb., 8 Tab.; Stuttgart [Petrographische, geochemische und Zirkon-Untersuchungen, u.a. Ruhlaer Kristallin, EisenachFormation (Rotliegend)]

QZeh, Armin \& Brätz, Helene (2004): Timing of upper Carboniferous-Permian horst-basin formation and magmatism in the NW Thuringian Forest, central Germany - a review. - In: Wilson, M.;

Neumann, E.-R.; Davies, G. R.; Timmermann, M.J.; Heeremans, M. \& Larsen, B.T.: PermoCarboniferous Magmatism and Rifting in Europe. - Geol. Soc. [London] Spec. Publ., 223; 448 p.; London 2004

OZimmerle, W. (1997): Petrography and Taphonomy of the Tetrapod-bearing Rotliegend Siltstones of Bromacher / Thuringian Forest, central Germany (Vortragskurzfassung). - In: Büchel, Georg \& Lützner, Harald (Hrsg.): Regionale Geologie von Mitteleuropa - Geodynamische Prozesse 
zwischen Alpen und Nordatlantik - 149. Hauptversammlung - Deutsche Geologische Gesellschaft und Jahreshauptversammlung der Fachsektion Geoinformatik - Jena 27.09.-3.10.1997 - Kurzfassung der Vorträge und Poster. - Schriftenrh. Dt. Geol. Ges., 2 2: 125; Hannover 1997

OZimmerle, Winfried \& Zinkernagel, Ulf (1988): Cathodoluminescence of Rotliegendes Sandstones from intermontane basins of Central Europe (Kathodenlumineszenz von Rotliegend-Sandsteinen aus intramontanen Becken Mitteleuropas). - Z. geol. Wiss., 16(10): 1029-1040, 3 fig., 2 pl.; Berlin [darin: Stratigraphie Rotliegendes Thüringer Wald]

\subsubsection{Zechstein}

OAlbrecht, Helmuth (1934): Neugliederung des Zechsteins im Südharzgebiete. - Kali, etc., 208(13): 157 159; Halle/Saale [Bohrprofilbeschreibungen Volkenroda]

- $\square$ • Apel, Jürgen \& Rüppel, Heidi [Verfass. u. Hrsg.] (2005): Raus in die Natur - Tipps für den Sonntags-Ausflug im Dreiländereck Hessen - Niedersachsen - Thüringen. - 159 S., 111 Fotos, 34 Kt., 1 Zeit-Taf.; (LSRB-Verlag, Landschaftskundlicher-Studien-Reisebuch-Verlag) Witzenhausen [zahlreiche Ausflugstipps, auch zu Geotopen des Zechsteins - Ziele 45, 46, 47, 53 (Zechstein-Hülle Unterwerra-Grauwackengebirge)]

QBaar, A. (1944/45): Entstehung und Gesetzmäßigkeiten der Fazieswechsel im älteren Kalilager am westlichen Südharz unter besonderer Berücksichtigung des Kaliwerkes Bischofshall. - Kali, etc., $\underline{\mathbf{3 8}}(10): 175-181$

$\underline{\text { 38}}(11): 189-197$

38(12): 207-211; Halle/Saale 1944

39(1): 3-6; zahlr. Fig.; Halle/Saale 1945

[Bischofshall zw. Kleinbodungen u. Großbodungen]

-Beche, Henry T. de la (1830): Sections \& views illustrative of geological phaenomena. - VIII, 71 p., 40 pl.; (Treuttel \& Würtz) London, Paris \& Strasburgh [darin : Taf. XXCIII, Fig. 4 Stratigr. Profil Zechstein/Rotliegend Richelsdorfer Gebirge („Riegelsdorf“"); Erläuterungen der Tafel S. 46-49]

- $\square$ Becker, Frank (2002): Zechsteinkalk und Unterer Werra-Anhydrit (Zechstein 1) in Hessen - Fazies, Sequenzstratigraphie und Diagnese. - Geol. Abh. Hessen, 109; 231 S., 42 Abb., 5 Tab., 10 Taf.; Wiesbaden - zgl. Diss. Univ. Heidelberg

[Zechstein-Mantel Unterwerra-Grauwackengebirge, Sontraer Bergland, „Baumbacher Hoch“ b. Rotenburg/Fulda]

- $\square$ Becker, Frank \& Bechstädt, Thilo (2005): Sequence stratigraphy of a carbonate-evaporite succession - Zechstein 1, Hessian Basin. - Sedimentology, $\underline{\mathbf{3}}$ (5): 1083-1120, 13 fig.; Amsterdam [Hessen, Werra-Meißner-Kreis]

OBernhardi, R. (1847): Über die Ergebnisse zweier Bohr-Versuche auf Steinsalz bei Salzungen (Bericht über die 4. Versamml. D. naturwiss. Vereins f. Thüringen im Mai 1845, S. 8). - N. Jb. Mineral. etc., 1847: 364-365; Stuttgart

[Zechsteinstratigraphie, Hydrogeologie, Salinenwesen]

DOBessert, Friedrich (1933): Geologisch-petrographische Untersuchungend der Kalilager des WerraGebietes. - Archiv Lagerstättenforsch., 57; 45 S., 6 Abb., 8 Taf.; [Preuß. Geol. Landesanst.] Berlin Referat in: N. Jb. Mineral. etc., Referate, 1935 (Bd. II): 194-196 (J. Leonhardt); Stuttgart 
- $\square$ Q Beyschlag, Franz (1900): Beitrag zur Genesis des Kupferschiefers. - Z. prakt. Geologie, ㅁ: 115117; Berlin

Referat in: N. Jb. Mineral. etc., 1903 (Bd. I): 90 (E. Sommerfeldt); Stuttgart

[Großregionale Betrachtung]

-Braitsch, Otto (1960): Mineralparagenesis und Petrologie der Staßfurtsalze in Reyershausen. - Kali u. Steinsalz, $\underline{\mathbf{3}}(1): 1$ - 14, 6 Abb., 4 Tab.; Essen

[Kali-Bergwerk Reyershausen N’ Göttingen]

- $\square$ Brandes, Theodor (1912): Sandiger Zechstein am alten Gebirge an der unteren Werra und Fulda und die Kontinuität des Landwerdens in Mitteldeutschland. - Zbl. Mineral., Geol. etc., 1912: 660-671, 1 Abb.; Stuttgart

[darin: Höllental b. Albungen, Gelsterbachtal, Cornberg]

- $\square$ OBrauch, W. (1923): Verbreitung und Bau der deutschen Zechstein-Riffbildungen. - Geol. Archiv, 2(3/4): 100-187, 30 Zeichn., 4 Photos; Königsberg i. Pr.

[darin S. 142-149: 3. Die Riffbildungen der Ruhlaer Sattelachse; S. 149-151: 4. Die Riffbildungen bei Schmalkalden und Benshausen.; S. 157-161: 6. Das Riffgebiet Rotenburg a. F. - Sontra - darin S. 157158, Fig. 27: Grauwackenaufbruch bei Sooden, Fig 27 irrtümlich als Fig. 24 bezeichnet]

-OBrinkmann, Roland (1948): Die Mitteldeutsche Schwelle. - Geol. Rundschau, 36: 56 - 66, 2 Abb.; Stuttgart

[Bezugnahme auf das Richelsdorfer Gebirge, Thüringer Wald]

QBrosin, Paul (1978): Zur Faziesdifferenzierung des Hauptkarbonats (Ca1r/Ca2) in Thüringen. - Jb. Geol., 9/10 (f. 1973/74): 261-269, 2 Abb.; Berlin

[Thüringer Becken, Bezugnahme a. Westthüringen: Kaliwerk Volkenroda, ForstbergAntiklinale/Mühlhausen, Bad Langensalza]

- $\square$ Brüning, Ulrich (1988): Die Zechstein/Buntsandstein-Grenze in Niedersachsen und Hessen. Schwermineraluntersuchungen als Beitrag zur Geologie des Bröckelschiefers. - Geol. Jb. Hessen., 116: 23-44 : 3 Abb., 6 Tab.; Wiesbaden

[Bhg. Küchen, Bl. 4825 Waldkappel; Aufschlüsse Schwarzenhasel, Baumbach/Heinebach, Bl. 4924 Seifertshsn.]

QBücking, H. (1883): Die Zechsteinformation bei Schmalkalden. - Jb. Preuß. Geol. Landesanst., $\underline{\mathbf{3}}$ (f. 1882): 29-32 (Abh. v. Mitarbeitern); Berlin

Referat in: N. Jb. Mineral. etc., 1884 (Bd. 1): 95-96 (Referat E. W. Benecke); Stuttgart Referat in: Mitt. Geogr. Ges. f. Thür., 3: 210-211 (Fr. R.); Jena

-Credé, Heinrich (1959): Der Cornberger Sandstein. - Das Werraland, 11(4): 58-59, 1 Abb.; Eschwege

OCredner, Heinrich (1846): Vorkommen und Krystallisation des Gypses zu Friedrichrode [Friedrichroda]. - N. Jb. Mineral. etc., 1846: 62-65 (Briefl. Mitt.); Stuttgart

ODeubel, F. (1954): Betrachtungen über das Auftreten von Erdöl und Erdgas im Zechstein des Thüringer Beckens. - Geologie, $\underline{\mathbf{3}}(6 / 7)$ : 804-831; Berlin [u.a. Aufschlüsse Kaliwerk Volkenroda, Bohrungen Forstberg, Mühlhausen, Mexleben-Nagelstädt, Stadtwaldd 1(Hainich), Zimmern 1]

-0•Diederich, Gisbert (1970): Die Grenze Zechstein/Buntsandstein in der südlichen Randfazies. Notizbl. Hess. L.-A. Bodenforsch., 98: 81-92, 2 Abb., 1 Tab.; Wiesbaden [Hessisch-Thüringisches Werra-Kalirevier, Südniedersachsen, Südwestthüringen - Profilkette]

ODittrich, Erhard (1962): Zur Gliederung der Werra-Serie (Zechstein 1) im Werra-Kaligebiet. - Ber. Ges. geol. Wiss. DDR, $\underline{6}$ (f. 1961)(2/3): 297-301, 3 Abb.; Berlin

[Stratigraphie, Geochemie] 
ODittrich, Erhard (1962): Zur Gliederung der Werra-Serie (Zechstein 1) im Werra-Kaligebiet. - Ber. Ges. geol. Wiss. DDR, $\underline{\mathbf{6}}$ (f. 1961)(2/3): 297-301, 3 Abb.; Berlin

[Stratigraphie, Geochemie]

- $\square$ ODietrich, Martin (1965): Fazies und Paläogeographie des Jungpaläozoikums und der unteren Glieder der Werra-Serie im Werra-Fulda-Becken und seinen Randgebieten - (Vorträge 16. Treffen des Fachverbandes Mineralogie d. Geol. Ges. i. d. DDR - 2.-4. April 1964 in Eisleben). - Freiberger Forschungshefte, Reihe C, 193: 55-81, 6 Abb.; Leipzig [Thüringen, Werra-Meißner-Kreis, Richelsdorfer Gebirge]

- $\square$ ODietrich, Martin (1965): Fazies und Paläogeographie des Unterperms und der unteren Glieder der Werra-Serie im Werra-Fulda-Becken. - Geologie, 14(4): 472-480, 4 Abb.; Berlin [HE, WMK, THÜ]

ODietz, C. (1926): Einflüsse der Tektonik auf die Auslaugung im Gebiet des Werra-Kalireviers. - Sitzber. Preuß. Geol. Landesanst., 1: 41 - 47, 1 Abb.; Berlin Referat in: N. Jb. Mineral. etc., Abt. B, 1927 (Bd. II): 62-63 (A. Bentz); Stuttgart

ODietz, C. (1929): Überblick über die Salzlagerstätte des Werra-Kalireviers und die Beschreibung der Schächte „Sachsen-Weimar“ und „Hattorf“. - Z. dt. geol. Ges., $\underline{\mathbf{8 0}}$ (f. 1928): 68 - 93, 4 Abb.; BerlinStuttgart

ODietz, C. (1930): Die Abwasserversenkung in tiefere Erdschichten. - Sitzber. Preuß. Geol. Landesanst., 5: 94-103, 2 Abb.; Berlin [darin: Werra-Kalirevier]

ODietz, C. (1928): Die Salzlagerstätten des Werra-Kaligebietes. - Archiv Lagerstätten-Forschung, $\underline{40}$; 129 S., 21 Abb., 3 Taf; (Preuß. Geol. Landesanst.) Berlin Referat in: N. Jb. Mineral. etc., Referate; 1929 (Bd. III): 33-34 (A. Bentz); Stuttgart

ODittrich, Erhard (1962): Zur Gliederung der Werra-Serie (Zechstein 1) im Werra-Kaligebiet Vorläufige Miteilung. - Ber. Ges. geol. Wiss. DDR, ㄸ (f. 1961)(2/3): 297-301, 3 Abb.; Berlin [Stratigraphie, Geochemie]

ODittrich, Eberhard (1964): Beiträge zur Kenntnis des Zechsteins im nordöstlichen Werra-Fulda-Becken und seinen Randgebieten. - Diss. Univ. Jena 1964; Teil 1 - Textband, 242, 12 Bl., Anhang; Teil 2 Anlagenband.: 60 Anl.

ODittrich, Eberhard (1966): Einige Bemerkungen über Rand- und Schwellenausbildungen im Zechstein Südwest-Thüringens. - Ber. dt. Ges. geol. Wiss., Reihe A, 11 (1/2): 185-198, 10 Abb., 1 Tab.; Berlin [Schmalkalden-Ruhlaer Insel]

QDöhner, Christian (1970): Die Feinstratigraphie des Staßfurtflözes im Südharz und ihre Parallelisierung mit dem Unstrutgebiet. - Z. angew. Geol., 16(1): 16-24, 4 Abb.; Berlin [darin: Volkenroda, Pöthen, Bischofferode, Bleicherode, Sollstedt]

ODöhner, Christian (1970): Stratigraphie des Staßfurt-Salinars und Probleme der Liegend- und Hangendabgrenzung. - Ber. Dt. Ges. geol. Wiss., Reihe A, 1ㅍ⑷: 505-515, 7 Abb.; Berlin [darin Südharz-Kalirevier - ohne konkrete Lokalitäten]

OElert, Karl-Heinz \& Henning, Ilona (1988): Bitumen A in Gesteinen des Zechsteins. - Z. angew. Geol., 34(3): 71-76, 4 Abb., 6 Tab.; Berlin [darin: Werra-Kaligebiet]

O Everding, H. (1907): Zur Geologie der deutschen Zechsteinsalze. - (Festschr. z. 10. allgem. Dt. Bergmannstage in Eisenach) Abh. Preuß. Geol. Landesanst., N.F., 52; S. 1-183, 11 Taf., 5 Beil.; Berlin 
Referat in: N. Jb. Mineral. etc., 1909 (Bd. II): 304-308 (Stelle); Stuttgart

[darin: Werra-Kalirevier, Südharz-Revier]

QFrantzen, W. (1895): Der Zechstein in seiner ursprünglichen Zusammensetzung und der Untere Buntsandstein in den Bohrlöchern bei Kaiseroda. - Jb. Kgl. Preuß. Geol. Landesanst. u.

Bergakademie, $1 \mathbf{5}$ (f. 1894): 65-121; Berlin

QFrantzen, W. (1895): Ueber neue Erfahrungen beim Kalibergbau in der Salzunger Gegend. - Jb. Preuß. Geol. Landesanst., 15 (f. 1894): LX-LXI; Berlin

Referat in: Mitt. Geogr. Ges. (f. Thüringen), 17: 99 (Alfred Berg); Jena 1898

[Kohlensäuregas-Lagerstätte]

QFreiesleben, Johann Carl (1807/1809/1815): Geognostischer Beytrag zur Kenntnis des

Kupferschiefergebirges mit besonderer Berücksichtigung auf einen Teil der Grafschaft Mannsfeld und Thüringens.

1 Teil; XIV, 202 S.; (Graz u. Gerlach) Freyberg 1807 - Teil 1 u. 2 i. e. Bd.

[darin: S. 49-50 Richelsdorfer Gebirge; S. 50-52 Thüringer Wald]

2. Teil; X, 242, 2 S., 1 Falt-Taf.; Freyberg 1809 - Teil 1 u. 2 i. e. Bd.

[darin: S. 22 Thüringer Wald, S. 103 Richelsdorfer Gebirge]

3. Teil; XXIV, 338 S., 1 Falt-Taf.; Freyberg 1815

[S. 229-234 Thüringer Wald; S. 235 Richelsdorfer Gebirge; Meißner-Vorland]

Die Beschreibung des Geologie in Hessen beruht auf Wiedergabe von Beobachtungen von Jordan, G. (1803): Mineralogische Berg- und Hüttenmännische Reisebemerkungen vorzüglich in Hessen, Thüringen, am Rhein und in Seyn-Altenkirchner Gebiete gesammelt; XVIII, 288 S.; (Diederich) Göttingen

- 0 Freyberg, Bruno von (1924): Paläogeographische Karte des Kupferschieferbeckens. - Jb. Halleschen Verbandes etc., N.F., 4(12): 266-278, 1 Abb., 1 Falt-Taf.; Halle (Saale)

[Großregionale Betrachtung, Bezug a. Hessen u. Thüringen]

- $\square$ Frick, Friedrich (1969): Feinstratigraphie und mikrofazielle Untersuchungen im Plattendolomit (Ca 3 Leine-Serie) des nordosthessischen Zechsteins. - Diss. TH Aachen 1969; 106 S.

[Umrandung Unterwerra-Grauwackengebirge, Baumbacher Hoch W’Rotenburg/Fulda; Richelsdorfer Gebirge]

- $\square$ (0)Füchtbauer, Hans (1964): Fazies, Porosität und Gasinhalt der Karbonatgesteine des norddeutschen Zechsteins. - Z. dt. geol. Ges., 114: 484-531, 10 Abb., 3 Tab., 3 Taf., ; Hannover [z2 + z3; HE, WMK, THÜ, NIE]

- 0 Fulda, Ernst (1923): Salzspiegel und Salzhang. - Z. dt. geol. Ges., 75 (f. 1922): B. 10-14, 1 Abb.; Berlin $\{$ Werra-Kalirevier]

-0Fulda, Ernst (1925): Zur stratigraphischen Einteilung des Zechsteins. - Z. dt. geol. Ges., 85: 299-301, 1 Tab.; Berlin

QFulda, Ernst (1927): Die Stratigraphie des thüringischen Zechsteins nach Tiefbohrergebnissen. - Jb. Preuß. Geol. Landesanst., 47 (f. 1926): 208-220, 1 Abb.; Berlin Referat in. N. Jb. Mineral. etc., Abt B, 1927 (Bd. I): 252-253 (A. Bentz); Stuttgart [darin: Werra-Kaligebiet]

口OFulda, Ernst (1927/1928): Die Salzlagerstätte des Werra-Kaligebietes. - Beitr. Geol. Thür., 1 (6): 3542, 4 Abb.; Jena 
- $\square$ ○ Fulda, Ernst (1935): Zechstein - Handbuch der vergleichenden Stratigraphie Deutschlands. - 409 S., 100 Abb., 1 Kt.; [Hrsg.] Preuß. Geol. Landesanst.] (Bornträger) Berlin [darin: Oberes Leinetal, Untereichsfeld; Ränder des Thüringer Waldes, Südharz-Kalirevier, WerraKalirevier, Richelsdorfer Gebirge, Unterwerra-Grauwackengebirge]

-Gast, Reinhard E. (1992): Cornberg outcrop revistet (Hessen, Germany) - The depositional environments of its saurian tracks and Weissliegendes sandstones - Die Cornberg-Aufschüsse neu interpretiert (Hessen): Das sedimentäre Ablagerungsmillieu der Saurierfährten und der WeissliegendSandsteine. - Meyniana, 46: 59-75, 3 Abb., 7 Taf.; Kiel

- $\square$ OGeinitz, Hanns Bruno (1861/1862): Dyas oder die Zechsteinformation und das Rothliegende. - H. I - Die animalischen Überreste der Dyas. - XVIII, S. 1-130, Taf. 1- 23; Leipzig (Engelmann) 1861; H. II - Die Pflanzen der Dyas und Geologisches. - VIII, S. 131 - 342, Taf. 24-52; (Engelmann) Leipzig [darin: Thüringer Wald, Thüringer Becken, Nordhessen; S. 268-270 „Zechsteinformation an der Werra bei Witzenhausen und Allendorf]]

-Geinitz, Hanns Bruno (1886): Zur Dyas in Hessen. - Festschrift Vereins Naturkde. z. Cassel- zur Feier seines fünfzigjährigen Bestehens. - S. 250 - 256, 1 Taf.; (Döll) Kassel 1886 [darin: Richelsdorfer Gebirge und Fossilieninventar des Kupferschiefers]

OGeyer, Roland (1994): Die Geologischen Naturdenkmale im Kreis Eisenach [Wartburgkreis]: 1. Das Zechsteinprofil am Bahnhof Förtha. - Knüllgebirgsbote, 1994(2): 6, 1 Abb.; Bad Hersfeld

OGeyer, Roland (1995): Die Geologischen Naturdenkmale im Kreis Eisenach (Wartburgkreis): 4. Geolog. Naturdenkmale bei Neuenhof. - Knüllgebirgsbote, 1995(1): 12, 1 Abb.; Bad Hersfeld [Rotliedendes, Zechstein]

QGrumbt, Eberhard \& Lützner, Harald (1960): Zur Leitbankgliederung des Staßfurtsteinsalzes und kalilagers der Schachtanlagen Volkenroda-Pöthen (Thüringen). - Z. angew. Geol., $\underline{\mathbf{6}}$ (5): 197-203, 3 Abb.; Berlin [Feinstratigraphie]

Q•Grupe, O. (1909): Über die Zechsteinformation und ihre Salzlager im Untergrunde des Hannoverschen Eichsfeldes und angrenzenden Leinegebietes nach den neueren Bohrergebnissen. Z. prakt. Geologie, 17: 185 -205, 4 Abb.; Jber. Niedersächsischen Geol. Vereins, 2: V-X, 1 Abb. (Vortragstext); Hannover 1909

Referat in: N. Jb. Mineral. etc., 1909 (Bd. II): 424-427 (Stille); Stuttgart [Eichsfeld, Ohmgebirge]

Q•Grupe, O. (1928): Die Harzschwelle zur jüngeren Zechsteinzeit und ihr Einfluß auf die Ausbildung des in ihrem Bereich liegenden Salzlagers. - Kali, etc., $\underline{22}(1): 1-5$

$\underline{22}(2): 20-23$

22(3): 38-41, mehr. Fig.; Halle/Saale

[THÜ, NIE]

Referat in: N. Jb. Mineral. etc., Referate, 1929 (Bd. II): 331 (Kunitz); Stuttgart

[Eichsfeld: Lkr. Göttingen, Thüringen]

Q•Grupe, O. (1929): Zur Frage der Harzschwelle im Oberen Zechstein. - Z. dt. geol. Ges., $\underline{80}$ (f. 1928): 159-161 (Mber.); Berlin

Referat in: N. Jb. Mineral. etc., Referate, 1929 (Bd. III): 84-85; Stuttgart

[Großregionale Betrachtung, Hannoversches Eichsfeld]

-Gunzert, Gerhard (1955): Der Grundgebirgsaufbruch von Mühlbach (Nordhessen). - Notizbl. Hess. L.A. Bodenforsch., 83: 106-125, 3 Abb., 3 Tab., 2 Taf.; Wiesbaden 
[Revision der stratigraphischen Einordung eines Dolomitgesteins. Alte Interpretation:

Zechstein/Plattenkalk; neue Einstufung devonischer Massenkalk]

-Gutberlet, [W. K. J.] (1847): Mergel zwischen Kupferschiefer und Sandstein an der Fulda. - N. Jb. Mineral. etc., 1847: 453-454 (Briefl. Mitt.); Stuttgart

[Rotenburg/Fulda]

QHaase, G. \& Oettel, S. (1963): Beitrag zur Kenntnis der Auslaugungserscheinungen im WerraKaligebiet. - Bergakademie, $\underline{\mathbf{1 5}}$ (5): 370 - 375; Berlin

-Hartmann, Carl (1822): Atlas zu des Herrn von Villefosse Mineral-Reichthum, Sammlung geognostischer und technischer Beobachtungen welche den jetztigen Zustand der Bergbau- und Hüttenkunde durch von den besten Etablissements entlehnten Beyspielen darthun, und sie mit Hülfe der geometrischen Darstellung verdeutlichen. - 40 Taf.; Sondershausen [darin: Profil Zechstein/Rotliegendes Richelsdorfer Gebirge]

OHartwig, Georg (1958): Zur Feinstratigraphie des Staßfurtlagers in der Thüringer Mulde. - Kali u. Steinsalz, $\underline{\mathbf{2}}(6):$ 206-210, 3 Bilder; Hessen [darin: Volkenroda, Pöthen]

OHautmann, S.; Lippolt, H. J. \& Pilot, J. (1993): Zur Altersverteilung flözumbildender Prozesse im deutschen Zechsteinsalinar. - Ber. Dt. Mineral. Ges., 1993(1) [= Beih. z. Europ. J. Mineral., 2]]: 126; Stuttgart

- $\square$-Heidorn, F. \& Schlüter, H. (1931): Zur Frage der Ölhöffigkeit und Paläogeographie des Mittleren Zechsteins. - Kali, etc., 25; Halle (Saale)

25(20): 295-298, Fig. 249, 250

[darin: Paläogeographische Karte unter Einbezug der Dreiländer-Region]

25(21): 307-312, Fig. 256, 257

[darin Kap. IV. - Einfluß nachfolgender Gebirgsbildung auf die räumliche Verteilung des Erdöls, gedeutet an dem Vorkommen von Volkenroda in Thüringen]

$\underline{\mathbf{2 5}}(22): 321-325$

[darin: Verzeichnis von Bohrprofilen und Aufschlüssen: Bezugn. a. Erdöl-Lagerstätte Volkenroda, Bhg. Rambach (Bl. Treffurt); Wiedergabe Stratigraphie Mittlerer Zechstein nach Erläuterungen Bl. Allendorf, Berka, Eisenach, Höhnebach, Kella, Netra, Sontra, Witzenhausen, Wutha]

$\square$ Heldmaier, Wolfram (1992): Mikrofazies des Zechsteinkalkes (Ca1) auf der Nordhessischen Zechsteinplattform (Buchenauer Schwelle). - Diplom-Arbeit Teil B (Diplom-Arbeit) [unveröff.] Fachber. Geowiss. Univ. Marburg 1992; 94 S.

-Hentschel, J. (1961): Die Faciesunterschiede im Kaliflöz des Kalisalzbergwerks „KönigshallHindenburg“. - Kali u. Steinsalz, 1961(5): 137 - 159, 17 Abb., 1 Tab., 2 Taf. (5 Abb.) - Auszug der Diss. „Die Faciesunterschiede im Kaliflöz Staßfurt im Kalisalzbergwerk „Königshall - Hindenburg“ bei Nörten-Hardenberg, Univ. Mainz 1958

-Héron de Villefosse, Antoine Marie (1819): De la richesse minérale. Considérations sur les mines, usines et salines des différens états, présentées comparativement. - Avec un Atlas in-folio de 65 planches. - Tome second : Division technique (1.re et II.e parties). - XVI, 559 p.; (Impimerie royale) Paris - [Insgesamt drei Bände u. Atlas-Band in Folio-Format] [darin S. 405-406: Erläuterung Stratigraphisches Profil Zechstein/Rotliegend Richelsdorfer Gebirge]

-Héron de Villefosse, A. M. (1819): Atlas de la Richesse minérale. Recueil de faits géognostiques et de faits industriels, constatant l'état actuel de l'art des mines et usinses, par des exemples authentiques, tirés de célébres établissements, et rendus sensibles à l'oeuil, au moyen de la représentation 
géométrique des objects. - 63 planches; Paris

[darin: Stratigraphisches Profil Zechstein/Rotliegendes Richelsdorfer Gebirge]

-Herrmann, A.-G.; Käding, K. Ch. \& Struensee, G. v. (1980): [DMG-Tagung 1980] Exkursionen E2 und E5 - Kalisalzlagerstätten des Sulfat-Typs - Hatttorf (Werra-Fulda-Bezirk) und Salzdetfurth (Bezirk Südhannover). Entstehung, Umbildung, Bergbau. Von wirtschaftlicher Nutzung von Salzlagerstätten. - Fortschr. Mineral., 58, Beih. 2 (Einführung zu den Exkursionen anläßlich der 58. Jahrestagung der Deutschen Mineralogischen Gesellschaft in Göttingen 1980): 33-53, 4 Abb., 6 Tab.; Stuttgart

QHeynke, Armin \& Zänker, Günter (1970): Zur Ausbildung und Leitbankgliederung des Staßfurtsteinsalzes im Südharzkalirevier. - Z. angew. Geol., 16(7/8): 344-356, 9 Abb.; Berlin [Raum Bleicherode; Volkenroda, Pöthen]

-Hilgenberg, Walter (1983): Zur Alheimer Zechstein-Landschaft. - Hessischer Gebirgsbote, 84(2): 67 68; Melsungen

-Hodenberg, R. von; Fischbeck, R. \& Kühn, R. (1987): Beitrag zur Kenntnis der Salzminerale, Salzgesteine und Salzlagerstätten, insbesondere im deutschen Zechstein. - Der Aufschluss, $\underline{\mathbf{3 8}}$ : 45-57, Abb. 1-7, Tab. 1-2; 38: 77-92, Abb. 8-10, Tab. 3; $\underline{\mathbf{3 8}}$ : 109-125, Abb. 21-32; Heidelberg

QHoff, K. E. A. von (1820): Verhältnisse des bituminösen Mergelschiefer und des Todtliegenden bei Ilmenau. - Tb. Mineral., 14(2): 568-573 (Briefl. Mitt.); Frankfurt/M.

OHoff, v. [Geheimer Konferenzrath!](1828): Auffindung des Steinsalzes bei Gotha. - Z. Mineral., $\underline{\mathbf{1 8 2 8}}$ (11/12): 829-835, Taf. VIII; Frankfurt/M.

[Buffleben N'Gotha]

QHoppe, Walter (1962): Grundlagen, Auswirkungen und Aussichten der Kaliabwasserversenkung im Werra-Kaligebiet. - Geologie, 11(9): 1059 - 1086, 8 Abb., 8 Tab.; Berlin

OHuckriede, Hermann (2003): Ehemaliger Gipssteinbruch Kittelsthal: Zechstein-Abfolge WerraAnhydrit bis Leine-Karbonat/Exkursionspunkt 6 - In: Exkursionsführer - Die Geologie rund um die Wartburg. - S. 27-29; [Thür. Geol. Verein] Jena 2003

oHuckriede, Hermann (2003): Aufschluss am Bahnhof Förtha: Basisschichten (Zechsteinkonglomerat bis Zechsteinkalk) der Werra-Folge des Zechsteins / Exkursionspunkt 3

- In: Exkursionsführer - Die Geologie rund um die Wartburg. - S. 21-23; [Thür. Geol. Verein] Jena 2003

-Hug, Nicola (2004): Sedimentgenese und Paläogeographie des höheren Zechstein bis zur Basis des Buntsandstein in der Hessischen Senke. - Geol. Abh. Hessen, 113; 238 S., 37 Abb., 8 Tab., 14 Taf., 3 Beil.; Wiesbaden

QHundt, Rudolf (1935): Wie sind die Mitteldeutschen Zechsteinriffe entstanden?. - Steinbruch u. Sandgrube, 34(12): 149-150;

Referat in: N. Jb. Mineral. etc., Referate, 1936 (Bd. II): 307-308 (Stützel)

[Bezugnahme a. Orla-Senke, Bad Liebenstein]

OJahne, Heinz (1966): Der Aufschluss des Zechsteins im Schacht „Marx-Engels“ II (Werrakaligebiet). Ber. dt. Ges. geol. Wiss., Reihe A, 11: 439-460, 6 Abb., 3 Tab.; Berlin.

[Schachtanlage S’Unterbreizbach]

OJahne, Heinz \& Zeibig, Silvio (2001): Zur Entwicklung, Ausbildung und Verbreitung der Kaliflöze im Werra-Becken <Vortragskurzfassung>. - In: Rauche, Henry [Hrsg.]: Regionale und angewandte Geologie der Grenzregion der Süddeutschen und der Mitteldeutschen Scholle. - Programm und 
Kurzfassungen der Vorträge. - 10. Jahrestagung Gesellschaft f. Geowissenschaften i. Schmalkalden, 19.-22. September 2001. - Exkursionsführer u. Veröff. Ges. f. Geowiss., 214: S. 131-312; Berlin 2001

OJahne, Heinz; Oettel, Siegfried \& Voitel, Roland (1970): Die feinstratigraphische Gliederung des Salinars im Zechstein 1 des Werra-Kaligebietes. - Ber. Dt. Ges. geol. Wiss., Reihe A, 15(4): 505-515, 7 Abb.; Berlin

-Jordan, Heinz (1979): Der Zechstein zwischen Osterode und Duderstadt (südliches Harzvorland). - Z. dt. geol. Ges., 130: 145-163, 5 Abb., 8 Tab.; Hannover

- $\square$ OJordan, Johann Ludwig (1803): Mineralogische, berg- und hüttenmännische Reisebemerkungen vorzüglich in Hessen, Thüringen, am Rheine und im Seyn-Altenkirchner Gebiethe. - 288 S., 4 FaltTaf.; (Dieterich) Göttingen

[darin: I Unterwerra-Grauwackengebirge u. Zechsteinmantel; II Bergbau i. Richelsdorfer Gebirge; IIIIII-XVI Regional-Geologie, Bergbau Umgebung Bad Liebenstein - Schmalkalden]

OJungwirth, Johannes \& Seidel, Gerhard (1969): Die faziellen Änderungen der Zechsteintone in Thüringen. - Jb. Geol. $\underline{2}$ [f. 1966]: 271-280, 5 Abb.; Berlin (Ost)

[Bezugn. a. westl. Thüringer Becken, Bohrung Küllstedt]

-Käding, Karl - Christian (1978): Stratigraphische Gliederung des Zechsteins im Werra-Fulda-Becken. - Geol. Jb. Hessen., 106: 123 - 130, 1 Tab.; Wiesbaden

-Käding, Karl-Christian (2000): Die Aller-, Ohre-, Friesland- und Fulda-Folge (vormals Bröckelschiefer-Folge) - Stratigraphie und Verbreitung des Z4 bis Z7 im Zechstein-Becken. Glückauf, 136(12), zgl. Kali u. Steinsalz, 13 (14): 760-770, 7 Abb.; Essen

- $\square$ O $\bullet$ Käding, Karl-Christian (2001): Die Aller-, Ohre-, Friesland- und Fulda-Folge (vormals Bröckelschiefer-Folge) - Stratigraphie und Verbreitung des Z4 bis Z7 im Zechstein-Becken $<$ Vortragskurzfassung $>$. - In: Rauche, Henry [Hrsg.]: Regionale und angewandte Geologie der Grenzregion der Süddeutschen und der Mitteldeutschen Scholle. - Programm und Kurzfassungen der Vorträge. - 10. Jahrestagung Gesellschaft f. Geowissenschaften i. Schmalkalden, 19.-22. September 2001. - Exkursionsführer u. Veröff. Ges. f. Geowiss., 214; S. 143-144 (Vortragskurzfassung); Berlin

OKästner, Hans (1969): Über schwankende Sedimentationsbedingungen im subsalinaren Zechstein 1 des Werra-Kaligebietes. - Geologie, 18 (7): 828-835, 3 Abb.; Berlin

OKästner, Hans (1969): Zur Geologie der Kalisalz- und Kohlensäurelagerstätten im südlichen WerraKaligebiet. - Abh. Zentralen Geol. Institutes, 11: I-VII, 1-96, 23 Abb., 2 Tab. Berlin

OKästner, Hans (1972): Der Zechstein in Süd- und Südwestthüringen. - Zusammenfassung und Diskussion des Kenntnisstandes. - Ber. Dt. Ges. geol. Wiss., Reihe A, $\underline{\mathbf{A} 17}$ (6): 897-910, 3 Abb.; Berlin

-Karch, U. \& Meiburg, P. (1987): Der Zechstein der Baumbachschwelle in Hessen [Vortragskurzfassung]. - In: Klare, Bernd \& Schröder, Bernd [eds.]: Zechstein 1987 - International Symposium Kassel/Hannover - 28. April to 9. May, 1987 - Abstracts, Posters, Program; S. 48-49; [Subkommission Perm/Trias der Stratigraphischen Kommission der DUGW/IUGS] Bochum 1987

-Keller, Rudolf (1938): Vom Ursprung der Solquellen des Kreises Hofgeismar. - Heimatkalender Landkreis Hofgeismar, 1939: 36 - 39; Hofgeismar

-Kleusberg, T. \& Tietze, K.-W. (1987): Faziesentwicklung im Grenzbereich Zechstein/Buntsandstein in der zentralen Hessischen Senke [Vortragskurzfassung]. - In: Klare, Bernd \& Schröder, Bernd [eds.]: Zechstein 1987 - International Symposium Kassel/Hannover - 28. April to 9. May, 1987 Abstracts, Posters, Program; S. 52-53; [Subkommission Perm/Trias der Stratigraphischen Kommission der DUGW/IUGS] Bochum 1987 
-Kleusberg, T. \& Tietze, K.-W. (1987): Faziesentwicklung im Grenzbereich Zechstein/Buntsandstein in der zentralen Hessischen Senke [Vortragskurzfassung]. - In: Klare, Bernd \& Schröder, Bernd [eds.]: Zechstein 1987 - International Symposium Kassel/Hannover - 28. April to 9. May, 1987 Abstracts, Posters, Program; S. 52-53; [Subkommission Perm/Trias der Stratigraphischen Kommission der DUGW/IUGS] Bochum 1987

$\square$ Klein-Reesink, Josef; Riegel, Walter \& Schulz, Karl-Heinz (1982): Tertiäre Braunkohlen und Kupferschiefer in Niederhessen. - Arbeitskreis f. Paläobotanik u. Palynologie. 11. - 13.3.1982 Dassel/Solling, Exkursion A. - Courier Forschungsinstitut Senckenberg, 56: 111-132, 12 Abb., 2 Tab.; Frankfurt/M.

[Hp. 3 Tagebau Paradiesfeld/Zeche Hirschberg, HP. 4 Frankershausen/Stbr. Schafhof]

-Kleusberg, T. \& Tietze, K.-W. (1987): Faziesentwicklung im Grenzbereich Zechstein/Buntsandstein in der zentralen Hessischen Senke [Vortragszusammenfassung] - In: Klare, Bernd \& Schröder, Bernd [eds.]: Zechstein 1987 - International Symposium Kassel/Hannover [28. April to 9. May, 1987] - Abstracts, Posters, Program; S. 52; [Subkommission Perm/Trias der Stratigraphischen Kommission der DUGW/IUGS] Bochum 1987

OKoch, Klaus \& Vogel, Jochen (1980): Zu den Beziehungen von Tektonik, Sylvinitbildung und Basaltintrusion im Werra-Kaligebiet (DDR). - Freiberger Forschungshefte, Reihe C, 347; 104 S., 53 Abb.; 2 Tab.; Leipzig

OKonitz, Otfried (1966): Zur Feinstratigraphie des Kalisalzflözes „Thüringen“. - Ber. Dt. Ges. geol. Wiss., Reihe A, 11(4): 475-487, 8 Abb., 2 Tab.; Berlin

[Thür. Werra-Kalirevier]

OKonitz, O.; Oettel, S.; Jahne, H. \& Pielert, P. (1968): Zur Feinstratigraphie und Genese des Kaliflözes „Thüringen“ im thüringischen Werra-Kalirevier. - Ber. Dt. Ges. Geol. Wiss., Reihe B, 13(5): 621-622; Berlin

OKonitz, O.; Oettel, S. \& Jahne, H. (1968): Zur Feinstratigraphie des Werra-Salinars im thüringischen Werra-Kaligebiet unter besondere Berücksichtigung des Kaliflözes „Thüringen“ und seiner Genese. Z. angew. Geol., 14(11): 578-586, 11 Abb.; Berlin

- $\square$ Kulick, Jens (1984): Petrofazielle und chemische Erkundung des Kupferschiefers der Hessischen Senke und des Harz-Westrandes. - Geol. Jb., Reihe D, 68: 3 - 323, 37 Abb., 15 Tab., 34 Taf. (davon 25 Kt.-Beil.); (Schweizerbart) Stuttgart [darin: Richelsdorfer Gebirge, Bhrgn. Werra-Meißner-Kreis]

- $\square$ Kulick, J. \& Richter-Bernburg, G. (1987): Der über Tage anstehende Zechstein in Hessen [Exkursionen D, M] - 2. Tag: Zechstein im Richelsdorfer Gebirge und an der Fulda [Stopp D10-D17, S. 83-113, Abb. 39-60] - 3. Tag: Zechstein im Werra-Grauwackengebirge [Stopp D18-D28] S. 115140, Abb. 61-81; In: Kulick, J. \& Paul, J. [Hrsg.]: Internationales Symposium Zechstein 1987 Kassel/Hannover. Exkursionsführer, Bd. II - Exkursionen D, E, F, L, M; S. 19-140, 81 Abb., 1 Tab.; [Hess. Landesamt f. Bodenforschung] Wiesbaden 1987

[Stop D9: Naturkundemuseum Ottoneum/Kassel: Fährten des Cornberger Sandsteins (S. 72-79); D10 Schwerspatgrube Münden/Nentershausen, D11 Stbr. Cornberg, D18-D28 (Zechstein im WerraGrauwackengebirge): Albungen, Jestädt, Reichensachsen/Weinberg, Oberhohne, Höllental/Schmelzhütte, Frankershausen/Schafhof, Hundelshausen, Witzenhausen-Papierfabrik]

OLangbein, Rolf (1971): Zur Petrographie und Lithostratigraphie des Thüringer Plattendolomits. Geologie, 20(1): 22-37, 9 Abb.; Berlin

[darin: Profil Raum Ohrdruf]

OLangbein, Rolf \& Seidel, Gerd (1995): Permosiles: Zechstein [in Thüringen]. - In: Seidel, Gerd

[Hrsg.]: Geologie von Thüringen. - 1. Aufl.; S. 277-302, 11 Abb., 2 Tab.; Stuttgart 1995 
OLangbein, Rolf \& Seidel, Gerd (2003): Permosiles: Zechstein [in Thüringen]. - In: Seidel, Gerd

[Hrsg.]: Geologie von Thüringen. - 2., neu bearb. Aufl.; S. 301-326, 11 Abb., 2 Tab.; Stuttgart 1995

-Linstow, O.v. (1929): Salzlager, Solquellen und Erdfälle in dem Gebiet zwischen Kassel und

Karlshafen. - Kali, etc.,

$\underline{23}(4): 54-56$

$\underline{23}(5): 71-74$

$\underline{23}(6): 86-88$, mehr. Fig.; Halle/Saale

Referat in: N. Jb. Mineral. etc., Referate, 1931 (Bd. III): 135 (A. Bentz); Stuttgart

[darin: Wolkenbrüche b. Trendelburg; Solquelle Kassel-Wilhelmshöhe]

-Ludwig, Alfred O. (1988): Climate - Tectonics - Sedimentation during the transitional period from the Early to the Late Permian. - Z. geol. Wiss., 16 (11/12): 1073-1080, 4 fig.; Berlin

[Großregionale Betrachtung Mitteleuropas]

$\square$ Maurer, Jacob (1987): Geologische Wanderung im Werra-Schiefer-Gebirge bei Witzenhausen. - 47 S., 11 Abb., 2 strat. Tab.; (Selbstverlag Werrratalverein Witzenhausen e.V.) Witzenhausen [Exkursionsführer m. 17 Stationen]

-Meinecke, Franz (1913): Das Liegende des Kupferschiefers. - Jb. Preuß. Geol. Landesanst., $\underline{31}$ (Teil II) (f. 1910): 253-296, 4 Abb., Taf. 10; Berlin

[darin: Cornberg, „Baumbacher Hoch“]

OMeinhold, Rudolf (1959): Probeme der Erdölerkundung im Zechstein. - Ber. Geol. Ges. DDR, 4(4): 269-280, 6 Abb.; Berlin

[Thüringer Becken, u.a. Bohrungen. Langensalza, Altengottern, Mühlhausen-Kirchheiligen]

OMerz, Georg (1966): Vergleich eines Zechsteinprofils von Südthüringen mit Zechsteinprofilen des Thüringer Beckens. - Ber. dt. Ges. geol. Wiss., Reihe A, 11 (1/2): 175-183, 3 Abb.; Berlin

[Bezugnahme a. Bhgn. Hainich-Berka, H.-Nazza, H-Mihla, Langensalza]

OMerz, Georg (1993): Zur Grenz Zechstein/Buntsandstein im Thüringer Becken. - Geowiss. Mitt.

Thüringen, 1: 41-48, 2 Abb.; Weimar

[Großregionale Betrachtung]

-Messer, Ernst (1955): Kupferschiefer, Sanderz und Kobaltrücken im Richelsdorfer Gebirge. - Hess. Lagerstättenarchiv , $\underline{\mathbf{3}}$; 125 S., 39 Abb., 19 Tab., 29 Taf.; Wiesbaden; zgl. Diss. Bergakad. Clausthal 1954

-Messer, Ernst (1978): Die nordhessischen Kaligruben. - Kali u. Steinsalz, $\underline{7}$ (7): 306-318, 11 Abb., 6 Tab.; Essen

[Zechstein-Stratigraphie, Lagerstättengeologie, Bergbau; Hattorf, Wintershall, Neuhof-Ellers]

- $\square$ Möller, Heiko (1985): Petrographie und Fazies des Plattendolomits (Leine-Karbonat, Ca3) im hessischen Zechsteinbecken. - Bochumer geologische und geotechnische Arbeiten, 20; 255 S., 92 Abb., 13 Tab., 14 Taf.; Bochum

[Hessen, WMK]

- $\square$ Möller, H. (1987): Fazies of the Zechstein 3-Carbonate in the Hessian Basin, Germany. - In: Klare,

Bernd \& Schröder, Bernd [eds.]: Zechstein 1987 - International Symposium Kassel/Hannover 28. April to 9. May, 1987 - Abstracts, Posters, Program; S. 67-68; [Subkommission Perm/Trias der Stratigraphischen Kommission der DUGW/IUGS] Bochum 1987

OMünzberger, Erich; Rost, Ursula \& Wirth, Joachim (1966): Vergleichende Darstellung der Sedimentationsverhältnisse des Zechsteins von Thüringen mit denen des Nordostdeutschen Flachlandes. - Ber. Dt. Ges. geol. Wiss., Reihe A, $\underline{\mathbf{1 1}}(1 / 2)$ : 161-174, 14 Abb., 4 Taf.; Berlin 
-Munk, Wolfgang; Martin, Oliver \& Trunkó, Lásló (1993): Neue Aspekte zur stratigraphischen und faziellen Bewertung des Cornberger Sandsteins (Tatarium, Oberperm) mit Beschreibung erstmaliger Pflanzenfunde. - In: Geol. Jb. Hessen, 121: 17-40, 14 Abb., 2 Tab.; Wiesbaden

ONaumann, Ernst (1934): Zur stratigraphischen Stellung des Eisenacher Dolomits. - Z. dt. geol. Ges., 86: 210-212, 1 Abb.; Berlin

ONaumann, Ernst (1952): Über einige vulkanische Schlotbrekkzien, ander vulkanische Erscheinungen und Auslaugungsbrekkzien im Werragebiet und in der Rhön. - Geologie, 11(1/2): 59 - 63, 3 Abb.; Berlin

OOettel, Siegfried \& Voitel, Roland (1966): Erste Untersuchungsergebnisse einer feinstratigraphsichen und petrographischen Gliederung im Kalisalzflöz „Thüringen“ der Gruben „Springen“ und „Alexandershall“. - Ber. Dt. Ges. geol. Wiss., Reihe A, 11(4): 489-499, 5 Abb., 4 Tab.; Berlin

-Oppermann, S. A. (1971): Die Zechstein-Basissedimente des Richelsdorfer Gebirges. - Abh. hess. L.A. Bodenforsch., (Tobien-Festschrift) 60: 283-287, 1 Abb.; Wiesbaden

Q•Paul, Josef (1982): Zur Rand- und Schwellenfazies des Kupferschiefers. - Z. dt. geol. Ges., 133: 571 605, 11 Abb., 1 Tab.; Hannover [darin: Südniedersachsen (Harzsüd- und Westrand), Thüringen]

-Paul, Josef (1991): Zechstein carbonates - marine episodes of a hyperhaline sea. - Zbl. Geol. Paläont., Teil 1, 1991(4): 1029-1045, 10 Abb., 1 Tab.; Stuttgart

Dᄆ⿴囗Paul, Josef (1993): Anatomie und Entwicklung eines permo-triassischen Hochgebietes - die Eichsfeld-Altmark-Schwelle. - Geol. Jb., Reihe A, 131: 197-218, 11 Abb.; Stuttgart

OPaul, Josef (2005): Permo-carboniferous palaeosols in Central Germany (Permokarbone Paläoböden in Mitteldeutschland). - Festchrift für Gerhard H. Bachmann, Teil II. - Hallesches Jb. Geowiss., Reihe B, Beihefte, 19, 214 S., zahlr. Abb.; hier S. 25-35, 11 Abb.; Halle [darin Profil Epichnellen/Bahnhof Förtha]

-Paul, Josef (2006): Der Kupferschiefer: Lithologie, Stratigraphie, Fazies und Metallogenese eines Schwarzschiefers. - Z. dt. geol. Ges., 157(1): 57-76, 7 Abb., 1 Tab.; Hannover [darin: Richelsdorfer Gebirge, auch Paläontologie]

OPaul, Josef (2008): Das Eichsfeld in Perm und Trias <Vortragskurzfassung >. - In: Wunderlich, J. [Red.]: Exkursionsführer - Geologie des Eichsfeldes - zur 18. Jahreshauptversammlung (Vortragsund Exkursionsveranstaltung) vom 16. bis 18. Mai 2008 in Heilbad Heiligenstadt. - Führung: H. Heiland, L. Nolte, H.-G. Röhling \& G. Seidel. - S. 33-35; [Hrsg.: Thüringer Geologischer Verein e.V.] Jena 2008

-Pflug, Hans Dieter (1962 ): Untersuchungen an Kalisalz-Profilen des Werra-Gebietes. - Hess. Lagerstättenarchiv, $\underline{\mathbf{5}}$; 50 S., 1 Abb., 1 Tab., 6 Diagr., 4 Taf.; Wiesbaden

OPippig, Matthias \& Beer, Wolfgang (2001): Exkursion B 1 - Stratigraphie, Petrologie und Tektonik der Grube Merkers. - In: Jockel, Andreas [Hrsg.]: Regionale und angewandte Geologie der Grenzregion der Süddeutschen und der Mitteldeutschen Scholle. - Exkursionsführer zur 10. Jahrestagung der Gesellschaft für Geowissenschaften e.V. in Schmalkalden - 19.-22. September 2001. - Exkursionsführer u. Veröff. Ges. f. Geowiss., 213; S. B1-1 bis B1-8, 6 Abb.; Berlin 2001

OPlatt, H. (1916): Das Randgebiet des Thüringer Waldes bei Benshausen. - Jb. Preuß. Geol. Landesanst., $\underline{\mathbf{3 6}}$ (Teil II) (f. 1915): 175 - 225, 10 Abb., insges. 6 Taf.; Berlin [Rotliegendes, Zechstein, Buntsandstein, Tektonik] 
OProescholdt, H. (1887): Die Zechsteinformation am Kleinen Thüringer Wald bei Bischofsrod. - Jb. Preuß. Geol. Landesanst., $\underline{7}$ (f. 1886): 165-169; Berlin

- $\square$ Pryor, Wayne A. (1971): Petrology of the Weißliegendes in the Werra-Fulda areas, Germany. - Geol. Rundschau, 60: 524-552, 13 Abb., 3 Tab.; Stuttgart

[darin: Cornberg, Stbr. Forsthaus Schmelzhütte b. Frankershausen]

QRegel, Fr. (1896): Einiges über Kalibohrungen in Thüringen. - Mitt. Geogr. Ges. (f. Thür.), 14: 68-70; Jena

[Kaiseroda b. Bad Salzungen]

व $\square$ OReh, H. (1959): Zur Entwicklung des Kupferschiefers im Thüringer Becken. - Ber. Geol. Ges.

DDR, $\underline{4}(4)$,: 288-298, 7 Abb.; Berlin

[Großregionale Betrachtung u. Einbeziehung von Nordosthessen]

-Richter [-Bernburg], Gerhard (1941): Paläogeographie und tektonische Stellung des Richelsdorfer Gebirges im Hessischen Raume. - Jb. Reichsstelle f. Bodenforsch., $\underline{\mathbf{6 1}}$ (f. 1940): 283 - 332, 19 Abb., Taf. 23-25; Berlin

- $\square$ OQRichter-[Bernburg], Gerhard (1941/42): Zur vergleichenden Stratigraphie des Zechsteins in Mitteldeutschland. - Kali, etc.,

35(12): 193-197; Halle/Saale 1941

36(1): 4-12, mehr. Fig.; Halle/Saale 1942

[HE, WMK, THÜ, NIE]

- $\square$ Richter-Bernburg, Gerhard (1955): Der Zechstein zwischen Harz und Rheinischem Schiefergebirge - Bericht über eine Exkursion zu den Zechsteinaufschlüssen dieses Gebietes anläßlich der Frühjahrstagung der Deutschen Geologischen Gesellschaft in Goslar 1953. - Z. dt. geol. Ges., 105 (f. 1953): 876 - 899, 8 Abb.; Hannover

[Harzsüdrand - Werra-Meissner-Kreis, Umgebung Rotenburg/Fulda, Rand d. Rhein. Schiefergeb. b. Waldeck-Korbach-Marsberg]

ORichter-Bernburg, Gerhard (1981): Some particularities in the sedimentation of the German Permian. - In: Depowski, Stanislaw [president organizing committee]: Central European Permian International Symposium - Jabłonna, April 27-29, 1978 - Proceedings; 656 S., Abb.; hier S. 48-55, 6 Abb.; (Geological Institute) Warszawa

[darin: Nordwestrand Thüringer Wald, zw. Mosbach u. Schmerbach]

-Richter-Bernburg, Gerhard (1987): Das sogenannte Zechsteinkonglomerat und die Grenze Rotliegend/Zechstein. - Geol. Jb. Hessen, 115: 117-129, 7 Abb.; Wiesbaden [darin: Cornberg]

$\square$ Ritzkowski (1987): Die Bildungstiefe des Kupferschiefers im Unterwerra-Grauwackengebirge (Nördliches Hessen) [Vortragskurzfassung]. - In: Klare, Bernd \& Schröder, Bernd [eds.]: Zechstein 1987 - International Symposium Kassel/Hannover - 28. April to 9. May, 1987 - Abstracts, Posters, Program; S. 140-141, 2 Abb.; [Subkommission Perm/Trias der Stratigraphischen Kommission der DUGW/IUGS] Bochum 1987

ORost, Ursula (1975): Beziehungen zwischen den tektonischen und den paläogeographischen Bedingungen und den lithofaziellen Verhältnissen von Werra- und Straßfurtkarbonat Thüringens. - Z. angew. Geol., 21: 462-467, 5 Abb.; Berlin

-Roth, Harry (1962): Die Werra-Kalisalzlagerstätte (Exkursionsbericht). -- (Übergeordn. Titel: Bericht über die Exkursionen während der Tagung des Naturhistorischen Vereins der Rheinlande und Westfalens vom 23. - 26. Mai 1961 in Kassel). - Decheniana - Verhdlgn. Naturhist. Vereins Rheinlande u. Westfalens, 114 (f. 1961): 203-205, 1 Profilberschr.; Bonn 
-Roth, Harry (1978): Das Stassfurt-Salinar im Werra-Gebiet. - Geol. Jb. Hessen, 106: 117-122, 1 Tab; Wiesbaden [Bezug: Bohrung Friedewald 2, B1. 5125 Friedewald]

OSchäfer, Aloys (1925): Der Kalischacht Hübstedt. - Unser Eichsfeld, 20: 33-38, 2 Abb.; Duderstadt [Zechsteinstratigraphie, Lagerstättenkunde, Bergbaugeschichte]

OScharbrodt, Thomas; Baumann, Ludwig \& Koch, Klaus (1986): Untersuchungen im Zusammenhang zwischen der Beckenentwicklung und der Halititsedimentation im Werra-Kaligebiet. - Z. geol. Wiss., 14(4): 427-435, 3 Abb.; Berlin

OScheibe, R. (1907): (Bericht über wissenschaftliche Ergebnisse 1903-1904) Bericht über Kontaktgesteine im Kleinen Thüringer Wald auf Blatt Schleusingen und über Granit, Rothliegendes und Zechstein südwestlich Mehlis auf Blatt Schwarza (Mehlis) auf Grund der Aufnahmen in den Jahren 1903 und 1904. - Jb. Preuß. Geol. Landesanst., 25 (f. 1904): 697-715, Taf. 22; Berlin

OSchirmer, Bodo \& Schwarz, Rüdiger (1991): Zum geologisch-tektonischen Bau des Deckgebirges und Subsalinars im thürinigischen Werra-Kaligebiet. - Geol. Jb. Hessen, 119: 91 - 101, 4 Abb.; Wiesbaden

-OSchlüter, H. (1932): Die Eingliederung der Werra-Serie in das deutsche Zechsteinprofil. - Kali, etc., $\underline{26}(14): 171-174$

$\underline{26}(15):$ 190-193, 1 Fig.; Halle/Saale

Referat in: N. Jb. Mineral. etc., Referate; 1933 (Bd. II): 752 (A. Geller); Stuttgart [HE, THÜ]

-Schlüter, Heinrich (1932): Die Altersstellung des Hauptsalzlagers des Werragebietes. - Nachricht. Ges. Wiss. Göttinger, Math.-Phys. Kl., 1932(2): 145 - 149, 1 Abb., 1 Tab.; Berlin

-chmidt, Hermann (1962): Gemeinsame Ganztagsexkursion nach Rotenburg/Fulda und in das Richelsdorfer Gebirge am 26. Mia 1961 (Geologischer Bericht). - (Übergeordn. Titel: Bericht über die Exkursionen während der Tagung des Naturhistorischen Vereins der Rheinlande und Westfalens vom 23. - 26. Mai 1961 in Kassel). - Decheniana - Verhdlgn. Naturhist. Vereins Rheinlande u. Westfalens, $\underline{114}$ (f. 1961): 202; Bonn

OSchott, Erhard (1989): Zum Aufschluß des Hauptdolomits durch Streckenauffahrungen in der Grube Volkenroda. - Z. geol. Wiss., 17(4): 401-406, 4 Abb., 1 Tab.; Berlin

oSchröder, B.; Käding, K.-Chr.; Kulick, J. \& Paul, J. [Hrsg.] (1991): Zechstein 1987 - International Symposium Kassel/Hannover [28. April to 9. May, 1987]. - Zentralbl. Geol. Paläont. - Teil 1: 1991(4); 1273 S., 216 Abb., 17 Tab. z.T. als Beil., 19 Taf. [Hrsg.: Subkommision Perm/Trias der Stratigraph. Kommision DUGW/IUGS], (Schweizerbart) Stuttgart [zahlr. Aufsätze, i. d. Bibliographie unter Autoren erfasst]

$\square$ Schulz, Klaus-Hasse (1981): Die Geologie des südöstlichen Teils des Blattes (Nr. 4725) Bad SoodenAllendorf (nördliches Hessen, Unterwerra-Sattel) und eine mikrofazielle Analyse des Zechsteinkalks (Ca1). - Dipl.-Arb. [unveröff.] Univ. Göttingen, 156 S.

-Schumacher, Claus (1985): Die Grenze Rotliegendes/Zechstein im Werra-Fulda-Becken. - Z. dt. geol. Ges., 136: 121-128, 3 Abb.; Hannover

-Schumacher, C. (1987): Stratigraphy and mineralizations of the basal Zechstein in the Werra-Fulda Basin of West-Germany [Vortragskurzfassung]. - In: Klare, Bernd \& Schröder, Bernd [eds.]: Zechstein 1987 - International Symposium Kassel/Hannover - 28. April to 9. May, 1987 - Abstracts, Posters, Program; S. 99-100; [Subkommission Perm/Trias der Stratigraphischen Kommission der DUGW/IUGS] Bochum 1987 
هSchwarz, Rüdiger (1992): Mächtigkeitsanstauungen von Carnallit im Kaliflöz „Thüringen“ des thüringischen Werra-Kali-Gebietes als Ausdruck halotektonischer Prozesse. - Geol. Jb. Hessen, 120: 161 - 170, 2 Abb.; Wiesbaden

oSeidel, Gerd (1964): Aufbau und Eignung der Steinsalzlagerstätten des Thüringer Beckens. - Z. angew. Geol., 10 (4): 182 - 189, 6 Abb.; Berlin

OSeidel, Gerd (1964): Zur Endlaugenversenkung im Südharzkalirevier. - Z. angew. Geol., 10 (6): 290 295, 3 Abb., 1 Tab.; Berlin

[Hydrogeolgoie, auch Zechstein-Stratigraphie]

OSeidel, Gerd (1964): Zur Endlaugenversenkung im Südharzkalirevier. - Z. angew. Geol., 10 (6): 290 295, 3 Abb., 1 Tab.; Berlin

[Hydrogeolgoie, auch Zechstein-Stratigraphie]

OSeidel, Gerd (1964): Zur Ausbildung und Genese des Kalilagers Staßfurt im Thüringer Becken. - Z. angew. Geol., 10(7): 348 - 353, 3 Abb.; Berlin

OSeidel, Gerd (1964): Geologischer Aufbau, chemische Zusammensetzung und Eignung der Kalziumsulfathorizonte von Thüringen. - Z. angew. Geol., 10 (10): 514 - 523, 13 Abb., 8 Tab.; Berlin

OSeidel, Gerd (1967): Zur Ausbildung des höheren Zechsteins in der westlichen Mühlhausener Mulde. Geologie, 16 (4): 425-432, 2 Abb., 1 Tab.; Berlin

[Profile Bohrungen Wachstedt 1, Küllstedt $1+2$, Horsmar 1, Eigenrode 1, Holzthalleben 1]

OSeidel, Gerd (1974): Zechstein [in Thüringen]. - In: Hoppe, Walter \& Seidel, Gerd [Hrsg.]:

Geologie von Thüringen [Bezirke Erfurt, Gera, Suhl]. - S. 516-553, Abb. 82-91, Tab. 53-60; (Haack) Gotha-Leipzig 1974

OSeidel, Gerd (2004): Zur Lage und Entwicklung der Zechsteinbasis in Thüringen. - Geowiss. Mitt. Thüringen, 11: 63-69, 1 Falt-Kt., 4 Tab.; Jena

-Sobotha, Ernst (1932): Salzauslaugung auf dem Untereichsfeld. - Unser Eichsfeld, 27: 79 - 82, 6 Abb.; (Aloys Mecke) Duderstadt

D-Sobotha, Ernst (1934): Zur Tektonik und Beckenbildung im nordwestlichen Eichsfeld. - Z. dt. geol. Ges., $\underline{\mathbf{8 5}}$ (f. 1933): 788 - 791, 1 Abb.; Berlin

[Östl. Lkr. Göttingen, Umgebung Heiligenstadt]

- $\square$-Sobotha, Ernst (1935): Eine Karte der Verbreitung der Zechsteinsalze zwischen Westharz und Vogelsberg/Rhön. - Kali,

29(8): 86-90,

29(9): 97-99, 1 Kt.; Halle (Saale)

Referat in: N. Jb. Mineral. etc., Referate, 1935 (Bd. II): 639 (J. Leonhardt); Stuttgart

oStange, J. (1927/28): Der Zechstein in der Umgebung von Bad Elgersburg am Thüringerwald. - Beitr. Geol. Thür., 1(4): 1-35, 3 Abb., 1 Profil; Jena

-Stier, G, (1974): Das Perm des westlichen Richelsdorfer Gebirges und geologische Kartierung im Nordwestteil der TK 25 Hönebach. - Dipl-Arb. [unveröff.] Univ. Frankfurt; 245 S-. 26 Abb., 15 Tab., 3 Kt., 5 Profile

Q๑Stille, Hans (1928): Zur Frage der Harzinsel der jüngsten Zechsteinzeit. - Z. dt. geol. Ges., 으: 146148 (Mber.); Berlin

Referat in: N. Jb. Mineral. etc., Referate, 1929 (Bd. III): 85; Stuttgart 
aStoppel, Dieter \& Gundlach, Heinrich (1983): Zur Schwerspatmineralisation und ZechsteinStratigraphie im Richelsdorfer Gebirge (NE-Hessen). - Z. dt. geol. Ges., 134: 247-268, 7 Abb., 1 Tab.; Hannover

-Storck, Ulrich (1954): Die Entstehung der Vertaubungen und des Hartsalzes im Flöz Staßfurt im Zusammenhang mit regelmäßigen Begleiterscheinungen auf dem Kaliwerk Königshall - Hindenburg. - Kali u. Steinsalz, 1(6): 21 - 3117 Abb., 2 Tab.; Essen

- $\square$ Theuerjahr, Albert-Karl (1987): Der Kupferschiefer (T1) im Bereich der Hessischen Senke [Einführung zu den Exkursionen]. - In: Kulick, J. \& Paul, J. [Hrsg.]: Internationales Symposium Zechstein 1987 - Kassel/Hannover. Exkursionsführer, Bd. II - Exkursionen D, E, F, L, M; S. 37-38; [Hess. Landesamt f. Bodenforschung] Wiesbaden 1987

-Tobschall, H. J.; Schmidt, F. P. \& Schumacher, C. (1986): Kupferschiefer und Kupfervererzungen im Richelsdorfer Gebirge, Hessen - Ihre Entstehung im Rahmen der sedimentären Entwicklung des basalen Zechsteins. - Fortschritte Mineral., 64, Beih. 2: 143-160, 5 Abb., 2 Tab.; Stuttgart

- $\square$ OVoigt, Joh. Carl. Wilh. (1797): Practische Gebirgskunde. - 2., verm. Aufl.; XVI, 286 S. [1 Bl.]; (Industrie-Comptoir) Weimar [darin: S. 128 Rotliegend-Sandstein bei Eisenach; S. 159 Profilbeschr. Zechstein/Rotliegend Richelsdorfer Gebirge; S. 173, 174, 178,179,205 Meissner; S. 193 Vulcanische Brekkzie Weißenstein/Wilhelhmshöhe b. Kassel]

OWächter, Grit \& Dietrich, Helmut (1992): Kompaktionsmodellierung und Rekonstruktion des Paläoreliefs am Beispiel des Werra-Anhydrites im Gebiet zwischen Thüringer Wald und Harz. - Zbl. Geol. Paläont., Teil 1; 1991(2): 2847-2858, 6 Abb.; Stuttgart

OWagenbreth, Otfried (1971): Die Marienhöhle bei Friedrichroda, ein wiedergewonnener Aufschluß in der Nordrand-Störungszone des Thüringer Waldes. - Geologie, 20(3): 251-262, 7 Abb., 1 Tab.; Berlin

OWeber, Hans (1933): Zur Systematik der Auslaugung. - Z. dt. geol. Ges., $\underline{82}$ (f. 1930): 179 - 186, 5 Abb.; Berlin [darin: Werra-Gebiet Vacha-Salzungen-Frauensee, Gebiet zwischen Mühlhausen und Langensalza]

OWunderlich, Jürgen (1995): Die terrestrischen Basissedimente des Zechsteins und der terrestrischmarine Faziesübergang am SE-Rand der Ruhla-Schmalkalder Insel (Raum Seligenthal-Hohleborn, Nordwestlicher Thüringer Wald). - Geowiss. Mitt. Thüringen, 3: 83-122, 8 Abb., 4 Tab.; Weimar

-00Ziegler, M. A. (1989): North German Zechstein facies patterns in relation to their substrate. - Geol. Rundschau, 78 (1): 105-127, 16 fig.; Heidelberg [darin: Werra-, Fulda-Becken]

QZimmermann, E. (1888): Über quarzitischen Zechstein mit Productus horridus von der Höhe des Thüringer Waldes. - Z. dt. geol. Ges., 40: 198-199; Berlin Referat in: N. Jb. Mineral. etc., 1889 (Bd. II): 124-124 (Franz Beyschlag); Stuttgart [b.Oberhof]

QZimmermann, Ernst (1888): Zechstein auf dem Kamm des Thüringer Waldes und seine Bedeutung für die Frage nach dem Alter des Gebirges. - Naturwiss. Wochenschrift, 2(9): 65-66, 2 Abb.; Berlin 


\subsubsection{Trias}

\subsubsection{Trias - ungegliedert}

- obBachmann, Gerhard H. \& Beutler, Gerhard (1998): Excursion G - The Classic Germanic Triassic in the Southeastern Part of the Germanic Basin: Stratigraphy, Sedimentary Environments, Cyclic and Sequence Stratigraphy. - In: Bachmann, G. H.; Beutler, G. \& Lerche, J. [eds.] (1998): Excursions on the International Symposium on the Epicontental Triassic - Halle (Saale) - September 1998. Institut f. Geologische Wissenschaften und Geiseltalmuseum Martin-Luther-Universität HalleWittenberg. - Hallesches Jb. Geowiss., Reihe B, Beih., ㅁ: 153-194, 30 Fig.; Halle (Saale) [darin Exkursionsziele: Burg Gleichen, Wartha-Hörschel, Gerstungen, Friedewald]

-Beyschlag, F. (1887): Ueber geologische Aufnahmen auf den Blättern Salzungen und Altmorschen (im Sommer 18886). - Jb. Preuß. Geol. Landesanst.., 7 (f. 1886): XLI-XLV; Berlin

-Blanckenhorn, Max (1919): Bericht über die wissenschaftlichen Ergebnisse der geologischen Landesaufnahmen im Jahre 1916. - Jb. Preuß. Geol. Landesanst., $\underline{37}$ (Teil II) (f. 1916): 483 - 518; Berlin [Regionalgeologie des Knüllgebirges; Trias, Tertiär]

QBornemann [jun.], G. L. (1887): [Bericht über die] Aufnahme der Section Fröttstedt [5029 Waltershausen N]. - Jb. Preuß. Geol. Landesanst., 7 (f. 1886): XXXVIII - XLI; Berlin

Brinkmann, R. (1927): Tekonik und Sedimentation im deutschen Triasbecken. - Z. dt. geol. Ges., $\underline{78}$ (f. 1926): 52-74, Abb. 9; Berlin

- Dauber, Adolf (1857): Das Triasgebirge an der Oberweser und seine nächsten Umgebungen - eine geologische Skizze nebst einer Karte. - Teil d. Schulprogramm d. Herzogl. Gymnasiums z. Helmstedt - Do, den 2. April 1857; 30 S., 1 Kt.; (Schmidt) Helmstedt

[Region Lkr. Göttingen, Lkr. Kassel]

OFarshad, Farhad (1995): Geologische Kartierung der Trias im Osten des Eichenberger Grabenknotens zwischen Arenshausen und Gerbershausen in Thüringen (TK 25 Blatt 4625 Witzenhausen). - Dipl.Kart. [unveröff.] Univ. Göttingen; 50 S., 2 Beil.; Göttingen

$\square$ Faupel, Jürgen (1973): Neue Beobachtungen zu den allochthonen Triasvorkommen (“Schollen) auf dem Unterwerra-Sattel bei Hundelshausen/Nordhessen. - N. Jb. Geol. Paläont., Mh., 1973: 654-666, 5 Abb.; Stuttgart

-Grupe, O. (1911): Zur Stratigraphie der Trias im Gebiete des oberen Wesertals. - Jber. Niedersächs. Geol. Vereins, 4: 1 - 102, 4 Tab.; Hannover

-Hauschke, N. \& Wilde, V. [Hrsg.] (1995): Trias - Eine ganz andere Welt. Mitteleuropa im frühen Erdmittelalter. - 647 S.; (Verlag Dr. Friedrich Pfeil) München

- $\square$ Q $\bullet$ Hausmann, J.F.L. (1824, 1828): Übersicht der jüngeren Flötzgebilde im Flußgebiete der Weser, mit vergleichender Berücksichtigung ihrer Äquivalente in einigen anderen Gegenden von Deutschland und der Schweiz. - Studien Göttingischen Vereins bergmänn. Freunde, 1: 381 - 567, Göttingen 1824; 2: 215-482; Göttingen 1828

[Regionale Stratigraphie Trias-Tertiär Nordhessen, Südniedersachsen; Bd. 1, Stratigraphie Buntsandstein; S. 500-508 „Basaltische Massen im Sandstein“, darin: Blaue Kuppe bei Eschwege, Pflasterkaute bei Eisenach]

- Hieke, Werner (1966): Stratigraphie (Trias, Tertiär) und Tektonik am Remsfelder Grabenknoten. Notizbl. Hess. L.-A. Bodenforsch., 94: 201 - 234, 7 Abb.; Wiesbaden [Bl. 4922 Homberg/Efze, 4923 Altmorschen] 
QHoppe, Walter (1966): Die regionalgeologische Stellung der Thüringer Trias. - Ber. dt. Ges. geol. Wiss, Reihe A, $\underline{\mathbf{1 1}}$ (1/2): 7-38, 6 Abb., 9 Tab., Berlin

[Bezug a. Bhrgn. i. Westthüringen]

@Kray, Markus (1994): [II.] Geologische Kartierung der Trias am Südwestrand des Eichenberg-GothaerGrabens bei Fretterode in Thüringen ( TK 25; Blatt 4625 Witzenhausen, 4626 Heiligenstadt, 4725 Bad Sooden-Allendorf, 4726 Grebendorf). - Dipl.- Kart. [unveröff.] Univ. Göttingen. - 44 S., 4, 2 Beil.; Göttingen

$\square$ Möbus, Heinz-Martin (2004): Allochthone Triasschollen am Unterwerrasattel als Schlüssel zum Verständnis saxonischer Tektonik. - Diss. Fb. Geowiss. Univ. Marburg 2004; X, 197 S, 14 Bl. Anh., Abb., 4 Beil.

OMorgenroth, V. (1989): Exkursionsführer - Trias und Tertiär in der Vorderrhön - vom 3. - bis 6. Oktober in Bad Salzungen - Gesellschaft f. geologische Wissenschaften d. DDR (GGW). Exkursionsführer u. Veröff. Ges. f. geol. Wiss., 170; 30 S., 5 Abb.; Berlin

QNaumann, E. (1907): Mitteilungen über Ausbildung und Lagerung der Trias am Südrande des Hainichs und des Diluviums dieser Gegend - (Nebentitel: Lagerungsverhältnisse, Diluvium am Hainich Blätter Henningsleben, Mihla, Treffurt). - Jb. Preuß. Geol. Landesanst., $\underline{25}$ (f. 1904): 715-732; Berlin Referat in: N. Jb. Mineral. etc., 1906 (Bd. II): 229-232 (Karl Walter); Stuttgart

QNaumann, Ernst (1940): Bemerkungen über die Trias und Tektonik im Raum zwischen Gotha, Ohrdruf, Friedrichroda und Eisenach. - Beitr. Geol. Thür., 5: 219-228; Jena

OPatzelt, Gerd (1988): Die Trias von Nordwestthüringen - Kurzreferate und Exkursionsführer, Tagung vom 12. - 14. Okt. 1988 in Mühlhausen. - 32 S., 2 Beil.

- 0 - Paul, Josef (1993): Anatomie und Entwicklung eines permo-triassischen Hochgebietes - die Eichsfeld-Altmark-Schwelle. - Geol. Jb., Reihe A, 131: 197-218, 11 Abb.; Stuttgart

OPaul, Josef (2008): Das Eichsfeld in Perm und Trias <Vortragskurzfassung > . - In: Wunderlich, J.

[Red.]: Exkursionsführer - Geologie des Eichsfeldes - zur 18. Jahreshauptversammlung (Vortragsund Exkursionsveranstaltung) vom 16. bis 18. Mai 2008 in Heilbad Heiligenstadt. - Führung: H. Heiland, L. Nolte, H.-G. Röhling \& G. Seidel. - S. 33-35; [Hrsg.: Thüringer Geologischer Verein e.V.] Jena 2008

QRhode, Dr. (1934): Die Eichsfelder Trias, besonders um Heiligenstadt. - Unser Eichsfeld, 29(5): 91-99; Duderstadt

ORöhling, Heinz-Gerd \& Heiland, Helmut (2008): Trias im Eichsfeld - Exkursion 18. Mai 2008. - In: Wunderlich, J. [Red.]: Exkursionsführer - Geologie des Eichsfeldes - zur 18. Jahreshauptversammlung (Vortrags- und Exkursionsveranstaltung) vom 16. bis 18. Mai 2008 in Heilbad Heiligenstadt. - Führung: H. Heiland, L. Nolte, H.-G. Röhling \& G. Seidel. - S. 51-70, 14 Abb.; [Hrsg.: Thüringer Geologischer Verein e.V.] Jena 2008

aSchröder, Bernd (1982): Entwicklung der Sedimentbecken und Stratigraphie der klassischen Germanischen Trias. - Geol. Rundschau, 71: 783 - 794, 5 Abb.; Stuttgart

OSeidel, Gerd (1965): Zur geologischen Entwicklungsgeschichte des Thüringer Beckens. - Geologie, Beih. 무, 115 S., 57 Abb., 4 Tab., z.T. als Beil.; Berlin

[Mächtigkeitskarten bis in die Gegend Heiligenstadt, Mühlhausen]

OWeber, Hans \& Kubald, P. (1951): Geologie der Autobahn auf den Meßtsichblättern Eisenach-Ost und Eisenach-West. - Hallesches Jb. Mitteldt. Erdgeschichte, 1(3): 109 - 123, 12 Abb., 2 Taf.; Halle 
-Weber, Jutta \& Ricken, Werner (2005): Quartz cementation and related sedimentary archictecture of the Triassic Solling Formation, Reinhardswald Basin, Germany. - Sedimentary geology, 175(1-4): 459477, 12 fig.; Amsterdam

- $\square \bullet$ Wedepohl, Karl Hans \& Ritzkowski, S. (1980): [DMG-Tagung 1980] Exkursion E 1: Die nördliche Hessische Senke (Tertiär-Vulkanite, Kupferschiefer und variszischer Spilit). - Fortschr. Mineral., 58, Beih. 2 (Einführung zu den Exkursionen anläßlich der 58. Jahrestagung der Deutschen Mineralogischen Gesellschaft in Göttingen 1980): 3-33, 2 Abb., 3 Tab.; Stuttgart [darin Hp: Werra-Meissner-Kreis: Blaue Kuppe, Bilstein, Cornberg, Forsths. Schmelzhütte, Hoher Meissner/Kalbe, Hoher Meissner/Kitzkammer; auch Hoher Hagen/Dransfeld, Westberg/Hofgeismar, Dörnberg/Zierenberg; Güntersberg b. Gudensberg, Isthaburg b. Istha, Steppling b. Homberg/Efze]

\subsubsection{Trias - gegliedert}

\subsection{Buntsandstein}

- $\square$ Altenburger, Uwe (1987): Zur Sedimentologie des Unteren und Mittleren Buntsandsteins Nordosthessens (BRD). - Diss. Univ. Mainz [unveröff.] 1987; 276 S. (92); Ill., graph. Darst.; Mainz

- $\square$ ○ीApel, Jürgen \& Rüppel, Heidi [Verfass. u. Hrsg.] (2005): Raus in die Natur - Tipps für den Sonntags-Ausflug im Dreiländereck Hessen - Niedersachsen - Thüringen. - 159 S., 111 Fotos, 34 Kt., 1 Zeit-Taf..; (LSRB-Verlag, Landschaftskundlicher-Studien-Reisebuch-Verlag) Witzenhausen [zahlreiche Ausflugstipps, auch zu Geotopen des Buntsandsteins: Ziele 12, 23, 37, 51, 58, 78]

- $\bigcirc$ Backhaus, Egon (1960): Zur Neugliederung des Odenwälder Buntsandsteins und ein Vergleich mit Nordhessen und Thüringen. - N. Jb. Geol. Paläont., Mh., 1960: 292 - 313, 2 Abb., 2 Tab.; Stuttgart

- $0 \bullet B a c k h a u s$, Egon (1994): Der Einfluß der Tektonik und des skytisch-anisischen Meeresspiegelanstiegs auf die Faziesgliederung des Oberen Buntsandsteins im Germanischen Triasbecken. - Z. dt. geol. Ges., 145: 325-342, 6 Abb.; Hannover

-Backhaus, E.; Lohmann, H. \& Regenhardt, H. (1958): Der Mittlere Buntsandstein im Reinhardswald (Nordhessen). - Notizbl. Hess. L.-A. Bodenforsch., 무: 196-201, 2 Abb.; Wiesbaden

-Backhaus, Egon \& Bindig, Michael (1990): Faziesanalytische Definition der lithostratigraphischen Einheiten der Solling-Formation (Buntsandstein, Hessische Senke). - Zentralbl. Geol. Paläont., Teil 1; 1990(11): 1587-1602; (Schweizerbart) Stuttgart

[Großregionale Betrachtung, u.a Osthessisches Bergland/Raum Bad Hersfeld]

-Becker, R.E. \& Lämmlen, H. (1988): Geologische Verhältnisse im Altmorschen-Beisheimer Grabenknie bei Wichte in Nordhessen. - Mit Detailprofilen aus Muschelkalk und Keuper. - Geol. Jb. Hessen, 116: 45-104, 4 Abb., 3 Tab., 3 Taf.; Wiesbaden

- $\square$ Bindig, Michael (1991): Räumliche und zeitliche Entwicklung der fluviatilen Environments der Solling-Formation (Buntsandstein, Germanische Trias). - Diss. TH Darmstadt 1991; 218 (162) S.; Darmstadt

-Blanckenhorn, Max (1898): Zwei isolirte Tertiär-Vorkommen im Röth auf Blatt Wilhelmshöhe bei Kassel. - Jb. Preuß. Geol. Landesanst., 18 (f. 1897): 103-108, 5 Abb.; Berlin

-Blanckenhorn, Max (1927): Über den Hessischen Chirotherien-Sandstein. - Zbl. Mineral. etc, 1927: 94 - 96; Stuttgart 
$\square \bullet$ Boigk, Heinz (1956): Vorläufige Mitteilung über eine neue Gliederung des Mittleren Buntsandsteins im Raum Südhannover. - Geol. Jb., 72: 325 - 340, 3 Abb., 1 Tab.; Hannover [Profil m. Bezug. a. Bramwald, Kaufunger Wald, Witzenhausen]

-Boigk, Heinz (1957): Vorläufige Mitteilung über eine neue Gliederung des Mittleren Buntsandssteins im Raum Südhannover. - Geol. Jb., 72: 325 - 340, 3 Abb., 1 Tab.; Hannover

-Brüggemann, Karl (1959): Stratigraphie und Tektonik des Mittleren Buntsandsteins im Raume Hannoversch-Münden. - Dipl.-Arb. [unveröff.] Univ. Göttingen 1959; 42 S.

- •Brüning, Ulrich (1986): Stratigraphie und Lithofazies des Unteren Buntsandsteins in Südniedersachsen und Nordhessen. - Geol. Jb., Reihe A, 90; 125 S., 18 Abb., 9 Tab., 8 Taf.; Hannover - auch Diss. Univ. Würzburg 1984

- $\square \bullet$ Brüning, Ulrich (1988): Die Zechstein/Buntsandstein-Grenze in Niedersachsen und Hessen. Schwermineraluntersuchungen als Beitrag zur Geologie des Bröckelschiefers. - Geol. Jb. Hessen., 116: 23-44 : 3 Abb., 6 Tab.; Wiesbaden

[Bhg. Küchen, Bl. 4825 Waldkappel; Aufschlüsse Schwarzenhasel, Baumbach/Heinebach, Bl. 4924 Seifertshsn.]

$\square$ Buchstein, Hella (1984): Zur Lithostratigraphie der Salmünster-Folge bei Eschwege (Nordhessen). Dipl.-Arb. [unveröff.] Fachber. Geowiss. FU Berlin, 130 S.

-Bühmann, Dieter \& Rambow, Dietrich (1979): Der Obere Buntsandstein (Röt) bei Borken/Hessen, Stratigraphie und Tonmineralogie. - Geol. Jb. Hessen, 107: 125-138, 1 Abb., 1 Taf.; Wiesbaden [Bohrungen Borken, Gudensberg, Ehrsten, Trendelburg]

- $\square$ Busse, Hentschel, Kutscher, Laemmlen, Pflanzl, Rösing \&Udluft (1959/60): Geologie der Umgebung von Eschwege und des Hohen Meißners - Bericht über die Exkursionen anläßlich der 110. Hauptversammlung [der Deutschen Geologischen Gesellschaft] vom 1.-9- September 1958 [in Kassel] - Exkursion F - Mesozoikum u. Tertiär der Hessischen Senke - Sonntag, den 7. September 1958 - Z. dt. geol. Ges., 111 (f. 1959/60): 288-301, 1 Abb.; Hannover

[Hp. 1-4: Buntsandstein i. d. Umgebung v. Eschwege; HP 5-10: Geologie des Hohen Meißners]

QCotta, B [ernhard] v. (1848): Bruchstücke [Nichtsagender Sammeltitel]. - N. Jb. Mineral. etc., 1848: 131-135; Stuttgart [S. 131-132 2) Granit b. Bad Liebenstein; S. 132-133 3) Basalt der Stoffelskuppe bei Eisenach; S. 133134 4) Rotliegendes bei Friedirchroda mit Thierfährten; S. 134-135 5) Dolomit-Breccie bei Neustedt/Werra; S. 135 6) Thon-Gallen im Buntsandstein der Werra-Gegend

-Demathieu, Georges \& Haubold, Hartmut (1972): Stratigraphische Aussagen der Tetrapodenfährten aus der terrestrischen Trias Europas. - Geologie, 21(7): 802-836, 8 Abb., 7 Tab.; Berlin [Bezugn. a. Karlshafen/Nordhessen; Thüringen außerhalb bibliogr. erfaßten Geb.]

-0 $\bullet$ Diederich, Gisbert (1970): Die Grenze Zechstein/Buntsandstein in der südlichen Randfazies. Notizbl. Hess. L.-A. Bodenforsch., 98: 81-92, 2 Abb., 1 Tab.; Wiesbaden

[Hessisch-Thüringisches Werra-Kalirevier, Südniedersachsen, Südwestthüringen - Profilkette]

QFalk, F.; Grumbt, E. \& Lützner, H. (1964): Stratigraphie und Fazies des Unteren und Mittleren Buntsandsteins im thürinigischen Werra-Kaligebiet. - Geologie, 13(3): 288-302, 3 Abb., 2 Tab.; Berlin

QFrantzen, W. (1895): Der Zechstein in seiner ursprünglichen Zusammensetzung und der Untere Buntsandstein in den Bohrlöchern bei Kaiseroda. - Jb. Kgl. Preuß. Geol. Landesanst. u. Bergakademie, 15 (f. 1894): 65-121; Berlin 
-Friese, Bernd (1980): Unterer Muschelkalk und Buntsandstein am Südostrand des Göttinger Waldes und am Hengstberg (TK 25: 4426 Ebergötzen). - Dipl.-Arb. [unveröff.] Univ. Göttingen 1980; 146 S.

aFritsche, H.-G.; Becker, F. \& Heggemann, H. (2001): Die Tiefbohrung HKZ 1001 - Geologie des Deckgebirges und hydrogeologische Ergebnisse. - Geol Jb. Hessen, 128: 5 - 17, 4 Abb., 1 Tab., 1 Taf.; Wiesbaden

[B1. 5024 Rotenburg/Fulda]

QGaertner, Horst (1962): Die Ausbildung de mittleren Buntsandsteins bei Brehme (Ohmgebirge) im thüringischen Eichsfeld. - Geol. Jb., 79: 173-206, 6 Abb.; Hannover

口OGaertner, Horst(1963): Zur Gliederung des Mittleren Buntsandsteins im thüringisch-nordhessischen Grenzgebiet. - Geol. Jb., 80: 741-770, 4 Abb., 1 Taf.; Hannover

[Werra-Meißner-Kreis, Thüringen]

$\square$ Gangel, L. (1970): Geologische Untersuchungen auf Bl. 4826 Eschwege (NE) und auf Bl. 4726 Grebendorf (SE) mit besonderer Berücksichtigung des mittleren und oberen Buntsandsteins und des Quartärs. - Dipl.-Arb. [unveröff.] Univ. Frankfurt/M.; 175 S., 26 Abb., 10 Diagr., 14 Profile, 1 Taf., 2 Kt.

QGeiger, Walter (1978): Ein Buntsandsteinaufschluß am Nordrand des Thüringer Beckens zwischen Wintzigerode und Ferna. - Eichsfelder Heimathefte, (18. Jg.) 1978(3): 222-233, 8 Abb., 2 Anl. (strat. Profile); Worbis

QGrumbt, Eberhard (1966): Schichtungstypen, Marken und synsedimentäre Deformationsgefüge im Buntsandstein Südthüringens. - Ber. dt. Ges. geol. Wiss., Reihe A, 11 (1/2): 217-234, 7 Abb., 2 Tab., 5 Taf.; Berlin [Bezug Bl. Vacha, Berka, Bad Salzungen, Schmalkalden]

- oGrupe, O. (1926): Voltziensandstein, Chirotheriensandsteine und Bausandstein und ihre stratigraphische Stellung innerhalb der Buntsandsteinformation. - Zbl. Mineral. etc., Abt. B, 1926: 129-145; Stuttgart [Bezugn. a. Hessen, Thüringen, Bl. Treffurt, Lengenfeld]

- •Gunzert, Gerhard (1958): Die einheitliche Gliederung des deutschen Buntsandsteins in der südlichen Beckenfazies. - Abh. Hess. L.-A. Bodenforsch., 24, 61 S., 14 Abb., 7 Tab (Beil); Wiesbaden [Bezug: Schwarzwald, Richelsdorfer Gebirge, Südhannover]

- Gutberlet, W. K. J. (1847): Über die Pseudomorphosen nach Steinsalz - [I.] zunächst in mineralogischer, petrographischer und krystallographischer Beziehung. - N. Jb. Mineral. etc., 1847: 405-438, 5 Abb.; Stuttgart

[Bezugnahme a. Lkr. Göttingen]

- Gutberlet, W. K. J. (1847): Über die Pseudomorphosen nach Steinsalz - II. in ihren geognostischen und geologischen Beziehungen. - N. Jb. Mineral. etc., 1847: 513-543.; Stuttgart [Bezugnahme a. Lkr. Göttingen]

$\square$ Haan, Karin (1985): Zur Lithostratigraphie des Unteren Buntsandsteins bei Eschwege in Niederhessen. - Dipl.-Arb. [unveröff.] FU Berlin; 137 S.; Berlin

$\square$ Haffer, Jürgen (1956): Zur Stratigraphie und Tektonik des Mittleren Buntsandsteins bei Witzenhausen/Werra. - Dipl.-Arb. [unveröff.] Univ. Göttingen 1956

- $\square$ Heim, Dieter (1966): Petrographische Beiträge zur Paläogeographie des Buntsandsteins. - Notizbl. Hess. L.-A. Bodenforsch., 94: 235-258, 1 Tab., Taf. 17; Wiesbaden 
$\square$ Hentschel, H.; Kortinig, S.; Kutscher, F.; Rösing, F. (1962): Ganztagsexkursion zur Blauen Kuppe, am 25. Mai 1961. Geologischer Bericht. - (Übergeordn. Titel: Bericht über die Exkursionen während der Tagung des Naturhistorischen Vereins der Rheinlande und Westfalens vom 23. - 26. Mai 1961 in Kassel). - Decheniana - Verhdlgn. Naturhist. Vereins Rheinlande u. Westfalens, 114 (f. 1961): 195201, 2 Abb.; Bonn

[darin: Blaue Kuppe, Stbr. a. Meinhard, Wienberg/Neuerode; Hoher Meißner: Haldenhaus, Kalbe, Seesteine, Kitzkammer)

-Herrmann, Axel (1956): Schichtausfälle im Mittleren Buntsandstein des nordwestlichen Eichsfeldes und deren mögliche Deutung. - Geol. Jb., 72: 341-345, 1 Abb; Stuttgart [Großregionale Darstellung]

-Herrmann, Axel (1961): Der Mittlere Buntsandstein im nordwestlichen Eichsfeld und im Ahlshausener Buntsandsteinsattel bei Salzderhelden. - Geol. Jb., 78: 347-386, 2 Abb., 1 Taf., 1 Tab.; Hannover [darin: Unter-Eichsfeld]

- 0 -Herrmann, Axel (1962): Zur Methodik der heutigen Buntsandsteinforschung. - Ber. Dt. Ges. geol. Wiss., Reihe A, 7(3): 337-346, 4 Abb.; Berlin [darin Abb. 4: Querprofil durch die nördliche Hessische Senke - HE, THÜ, NIE]

- $\square \bullet$ Herrmann, Axel (1964): Epirogene Bewegungen im germanischen Buntsandsteinbecken und deren Bedeutung für lithostratigraphische Parallelisierungen zwischen Nord- und Süddeutschland. - Geol. Jb., 81: 11-72, 13 Abb., 2 Tab., 3 Taf.; Hannover

[Bezugnahme a. Hessische Senke]

-Herrmann, Axel \& Hofrichter, Erich (1962): Zur Fazies der Solling-Folge (Mittlerer Buntsandstein) in der nördlichen Hessischen Senke. - Geol. Jb., 79: 551 - 554, 2 Abb., 2 Tab.; Hannover

-Herrmann, Axel \& Hofrichter, Erich (1963): Die Hardegsen-Folge (Abfolgen 1 - 4) des Mittleren Buntsandsteins in der nördlichen Hessischen Senke. - Geol. Jb., 무: 561 - 652, 8 Abb., 1 Tab., 6 Taf.; Hannover

-Herrmann, A. \& Hofrichter, E. (1963): Die Faziesgliederung der tieferen Solling-Folge des Mittleren Buntsandsteins Südniedersachsens. - Geol. Jb., 무: 653 - 740, 9 Abb., 1 Tab., 5 Taf.; Hannover

-Hinze, Carsten (1967): Der Obere Buntsandstein (Röt) im südniedersächsischen Bergland. - Geol. Jb., 84: 637 - 716, 4 Abb., 1 Tab., 2 Taf.; Hannover

[darin: Aufschl. Lkr. Göttingen]

OHoppe, W. (1959): Zyklische Gliederung des Unteren und Mittleren Buntsandsteins in Thüringen. Ber. geol. Ges. DDR, $\underline{4}(1): 3-58,1$ Abb., 2 Tab., 2 Taf.; Berlin [u.a. Bohrprofil Bohrung Langesalza 2]

QHoppe, Walter (1974): Buntsandstein [in Thüringen]. - In: Hoppe, Walter \& Seidel, Gerd [Hrsg.]: Geologie von Thüringen [Bezirke Erfurt, Gera, Suhl]. - S. 568-608, Abb. 95-106, Tab. 61-66, Photo79-81; (Haack) Gotha-Leipzig 1974

-Horn, Manfred (1958): Zur Stratigraphie und Tektonik des Mittleren Buntsandsteins zwischen Harz und Solling. - Dipl.-Arbeit [unveröff.] Univ. Göttingen 1958; 37 S.; Göttingen

-Horn, Manfred (1967): Detfurth- und Hardegsen-Folge am Naumburger Graben (Nordhessen). Notizbl. Hess. L.-A. Bodenforsch., 95: 64 - 75, 3 Abb., 1 Tab.; Wiesbaden

-Horn, Manfred (1991): Buntsandstein und Muschelkalk am Westrand der Hessischen Senke (Exkurison $\mathrm{H}$ am 6. April 1991). [112. Jahresversamml. d. Oberrhein. Geol. Vereins 1991 in Bad Wildungen]. Jber. Mitt. Oberrhein. Geol. Vereins, N.F., 73: 155 - 176, 5 Abb., 1 Tab.; Stuttgart 
-Hug, Nicola (2004): Sedimentgenese und Paläogeographie des höheren Zechstein bis zur Basis des Buntsandstein in der Hessischen Senke. - Geol. Abh. Hessen, 113; 238 S., 37 Abb., 8 Tab., 14 Taf., 3 Beil.; Wiesbaden

OJanson, Johann (1957): Die Mächtigkeit des Buntsandsteins und des Muschelkalkes im Nordwestteil des Thüringer Beckens auf Grund von Tiefbohrungen, Tagesaufschlüssen und Schachtprofilen. Dipl.-Arb. [unveröff.] Bergakademie Freiberg/Sa. 1957; 47 S.

Referat in: Geologie, $\underline{8}(2): 213$; Berlin 1959

OJülich, Eberhard (2002): Subrosionserscheinungen im Röt (Oberer Buntsandstein) im Bereich des Ohmgebirges (NW-Thüringen, Eichsfeld) - Herbstexkursion des Thüringer Geologischen Vereins am 19.10.2002. - Mittbl. Thür. Geol. Verein, 16: 34-36; Jena

○Kästner, Hans \& Seidel, Gerd (1965): Zur Ausbildung des Oberen Buntsandsteins (Röt) in Westthüringen. - Geologie, 14(2): 145-152, 1 Abb.; Berlin

[Profile Bohrungen Geisleden 1, Küllstedt 1, Zaunröden 8, Geblar 1, Hachelbich 2]

QKästner, Hans; Kühn, Wolfgang \& Langbein, Rolf (1966): Stratigraphische, petrographische und geochemische Untersuchungen im Unteren und Mittleren Buntsandstein des thüringischen WerraKaligebietes. - Geologie, 15(4/5): 461-483, 8 Abb., 1 Tab.; Berlin

$\square \bullet$ Kallies, Hans Bodo (1963): Gesteinsausbildung und Fossilführung an der Grenze Mittlerer/Oberer Buntsandstein im südlichen Niedersachsen. - Geol. Jb., 80: 367 - 436, 6 Taf.; Hannover [darin: Lkr. Göttingen; Profile Bahnhof Witzenhausen/WMK]

-Keller, Rudolf (1939): Unser Buntsandstein. - Heimatkalender Landkreis Hofgeismar, 1940: 49 - 52; Hofgeismar [Bezug auf Landkreis Hofgeismar]

OKirschstein, Mario (2001): Neubau BAB A 38 - Besonderheiten im Abschnitt des Rötausstriches am Südhang der Bleicheröder Berge und Möglichkeiten einer bautechnischen Berücksichtigung $<$ Vortragskurzfassung > . - In: Rauche, Henry [Hrsg.]: Regionale und angewandte Geologie der Grenzregion der Süddeutschen und der Mitteldeutschen Scholle. - Programm und Kurzfassungen der Vorträge. - 10. Jahrestagung Gesellschaft f. Geowissenschaften i. Schmalkalden, 19.-22. September 2001. - Exkursionsführer u. Veröff. Ges. f. Geowiss., 214; S. 145 - 146; Berlin 2001

[Stratigraphie, Geomorphologie, Ingenieurgeologie]

- Kleusberg, Thomas (1988): Playa-Entwicklungen im Buntsandstein der Hessischen Senke unter besonderer Berücksichtigung des Zechstein/Buntsandstein-Grenzbereiches. - Diss. Univ. Marburg [unveröff.]1988; XII, 126 S., Ill, graph. Darst.

[Untersuchungsgebiet auf: Bl. 4924 Seifertshausen, Aufschl. Heinebach; Bl. 5025 Hönebach, Bl. 5118 Marburg]

-Koenen, Adolf v. (1905): Über Kalksandstein-Konkretionen und fossilführende Kalke a. d. Basis des Röths. - Z. dt. geol. Ges., 57: Briefl. Mitt: 156 - 157; Berlin

Referat in: N. Jb. Mineral. etc., 1908 (Bd. II): 85 (Stille); Stuttgart

[Aufschlüsse Lkr. Göttingen]

-Koslowski, Wolfram (1986): Zur sedimentären Entwicklung des Buntsandsteins - ein Vergleich zwischen dem Ostrand d. Rheinischen Schiefergebirges und dem Raum um Bad Hersfeld. - Diss. Univ. Marburg 1986[unveröff.]; 135 S., Ill., graph. Darst.

[Untersuchungen zwischen Marburg und Niederaula; Bl. 5019 Gemünden, Bl. 5220 Kirtorf, Bl. 5224 Eiterfeld]

-Krämer, Friedrich \& Kunz, Heinrich (1968): Zur Sedimentation des höheren Buntsandsteins in Osthessen und Südniedersachsen. - Oberrhein. Geol. Abh., 17 (2): 193 - 216, 5 Abb., 1 Tab.; Karlsruhe 
- $\square$ Krämer, Friedrich; Kupfahl, Hans-Günter; Kunz, Heinrich; Rösing, Franz (1966): Leithorizonte im Mittleren und Oberen Buntsandstein zwischen Kassel und Eschwege [Vortragstext](Bericht über die 114. Hauptversamml. Frankfurt/M. 7.-15. Sept. 1962). - Z. dt. geol. Ges., 115 (f. 1963): 897-898; Hannover

-Krämer, Friedrich \& Kunz, Heinrich (1969): Leithorizonte und Schichtausfälle im Buntsandstein Hessens und Thüringens. - Oberrhein. Geol. Abh., 18: 67 - 76, 1 Abb., 1 Tab.; Karlsruhe

$\square$ Krämer, Friedrich. \& Kunz, Heinrich (1969): Sedimentations-Gesetzmäßigkeiten im Mittleren Buntsandstein am Westrand der Eichsfeld-Schwelle - Teil I: Raum Eschwege. - N. Jb. Geol. Paläont., Mh., 1969: 712-730, 5 Ab., 1 Tab.; Stuttgart

[Profil Straßenanschnitt B7/B27 bei Hoheneiche, WMK]

$\square$ Kreysing, Klaus (1956): Der Buntsandstein am abtauchenden Werra-Sattel. - Dipl.- Arb [unveröff.] Univ. Göttingen 1956

- $\square$ Kreysing, Klaus (1957): Zur Stratigraphie des mittleren Buntsandsteins in Süd-Hannover und NordHessen. - Diss. Univ. Göttingen 1957; 60 gez. Bl., 4, 10 Abb., 1 Tab.; Göttingen

D $\square$ Kreysing, Klaus (1957/1958): Zur Stratigraphie des Mittleren Buntsandsteins in Süd-Hannover und Nord-Hessen. - N. Jb. Geol. Paläont., Mh., 1957: 72 - 83, 3 Abb., 1 Tab., 1958: 101-113, 5 Abb., 5 Tab.; Stuttgart

-Kreysing, Klaus (1957): Ein Profil des Mittleren Buntsandsteins vom Kaufunger Wald zur Rheinischen Masse. - N. Jb. Geol. Paläont., Mh., 1957: 328 - 334, 1 Abb.; Stuttgart [darin: Profile Fuldatal, Rhoden, Wolfhagen]

- $\square$ Kunz, Heinrich (1964): Stratigraphisch-fazielle Untersuchungen im höheren Buntsandstein Osthessens. - Diss. Univ. Frankfurt/M. 1964; 232 S., 13 Abb., 4 Tab., 20 Taf.

$\square$ Kupfahl, Hans-Günther (1958): Die Abfolge des Buntsandsteins am östlichen Meißner-Gebirge. Notizbl. Hess. L.-A. Bodenforsch., 뚜: 202 - 214, 1 Abb., 1 Tab., 1 Taf.; Wiesbaden

-Kupfahl, Hans-Günther (1979): Der Obere Buntsandstein bei Kaufungen östlich Kassel. - Geol. Jb. Hessen, 107: 139 - 143, 1 Abb.; Wiesbaden

-Kupfahl, Hans-Günther (1982): Der Mittlere Buntsandstein auf Bl. 4822 Gudensberg (Nordhessen). Geol. Jb. Hessen, 110: 91 - 100, 1 Taf.; Wiesbaden

-Kupfahl, Hans-Günther \& Thews, Joe-Dietrich (1961): Die Gliederung der Volpriehausen Folge des Mittleren Buntsandsteins auf Blatt Oberkaufungen. - Notizbl. Hess. L.-A. Bodenforsch., 89: 235 241, 1 Abb.; Wiesbaden

- $\square$ Kutscher, Fritz (1966): Der Buntsandstein in Hessen. - Z. dt. geol. Ges., 115 (f. 1963): 692-714; Hannover

[Hessen, Werra-Meißner-Kreis]

$\square$ Laemmlen, Manfred (1958): Ein Buntsandstein-Muschelkalkprofil bei Hausen am Südwestabhang des Hohen Meißners in Nordhessen. - Notizbl. Hess. L.-A. Bodenforsch., 뚜: 215 - 240, 3 Abb.; Wiesbaden

$\square$ Laemmlen, Manfred (1961): Ein Buntsandstein-Aufschluß an der neuerbauten Bundesstraße 7/27, bei Hoheneiche in Hessen. - Notizbl. Hess. L.-A. Bodenforsch., 89: 203 - 234, 6 Abb.; Wiesbaden 
- $\square$ Laemmlen, Manfred (1961): Die Aufteilung der Hersfelder Gruppe des Mittleren Buntsandsteins. Z. dt. geol. Ges., 112 (f. 1960): 491-512, 3 Abb., 3 Tab., 1 Taf.; Hannover [darin Hoheneiche/WMK]

OLangbein, Rolf (1970): Zur Petrologie des Thüringer Buntsandsteins. - Geologie, Beih. $\underline{\mathbf{6 8}}$ : 131 S., 36 Abb., 7 Tab., 8 Taf., 22 Beil.; Berlin

[Profile Bohrungen Birkenfelde, Geisleden, Scharfenstein, Lengenfeld u. Stein, Horsmar, Forstberg, Billeberg, Bad Langensalza]

OLangbein, Rolf \& Seidel, Gerd (1961): Zur Ausbildung des Mittleren Buntsandsteins in Westthüringen. - Z. angew. Geologie, $\underline{7}(11)$ : 573-575, 2 Abb.; Berlin [ Aufschlüsse bei Lengenfeld, Treffurt]

-Lange, P.R. \& Käding, K.-C. (1961): Stratigraphie und Tektonik im Buntsandstein des hessischen Wera-Kaligebietes östlich Bad Hersfeld. - Notizbl. Hessisches Landesamt Bodenforsch., 89: 242-265, 4 Abb., 2 Taf.; Wisbaden

[Untersuchungen a. Bl. 5025 Hönebach, 5124 Bad Hersfeld, 5125 Friedewald, 5224 Eiterfeld]

OLange, Willi (1962): Zur Kenntnis der Stratigraphie und Petrographie des Mittleren Buntsandsteins in Westthüringen. - Z. angew. Geologie, $\underline{8}$ (10): 531-537, 2 Abb., 2 Tab.; Berlin

[Profile Bohrungen Forstberg N’ Mühlhausen, Bad Langensalza]

-Lepper, Jochen (1996): Die Ballertasche bei Hann.-Münden - ein geologische Ensemble. - Ber. Naturhist. Ges. Hannover, 138: 133-139, 3 Abb.; Hannover [Buntsandstein, Quartär]

-Lepper, J. \& Uchmann, A. (1994): Marine Einflüsse im Mittleren Buntsandstein der Hessischen Senke - dargestellt am Beispiel des Weserprallhanges an der Ballertasche - Marine influences in the Middle Buntsandstein of the Hessen Depression, a case study from the Weser cliff at the Ballertasche near Hann. Münden. - Zbl. Geol. Paläont. Teil 1, 1994(1/2): 175-186, 2 Abb., 2 Taf.; Stuttgart

-Lepper, Jochen; Rettig, Ben \& Röhling, Heinz-Gerd (1996): Das Buntsandsteinprofil am Weserprallhang an der Ballertasche bei Hann. Münden. - Ber. Naturhist. Ges. Hannover, 138: 141150, 5 Abb.; Hannover

- $\square$ Q $\bullet$ Lepper, J.; Röhling, H.-G.; Stollhofen, H. \& Tietze, K.-W. (1998): Excursion H - The Buntsandstein of the Hessian Depression: Contrasting Styles of Basinal and Marginal Depostition. (With contributions... ). - In: Bachmann, G. H.; Beutler, G. \& Lerche, J. [eds.] (1998):

Excursions on the International Symposium on the Epicontental Triassic - Halle (Saale) - September 1998. - Institut f. Geologische Wissenschaften und Geiseltalmuseum Martin-Luther-Universität Halle-Wittenberg. - Hallesches Jb. Geowiss., Reihe B, Beih., ㅁ: 195-227, 20 Fig.; Halle (Saale) [HE, WMK, THÜ, NIE]

- $\square$ Lohmann, H. (1960): Zur Stratigraphie und Fossilführung des Buntsandsteins in Niederhessen. Mitt. Geol. Staatsinstitut Hamburg, 29: 66-84, 4 Abb., Taf. 4; Hamburg [Hessen, Werra-Meißner-Kreis]

$\square$ Lukas, Volker; Wenzel, Bernward (1991): Pedogenese und Diagenese der Solling-Folge (Buntsandstein, Trias) in Nordosthessen. - Geol. Jb. Hessen, 119: 103 - 117, 3 Abb., 1 Taf.; Wiesbaden [darin: Werra-Meißner-Kreis]

- $\square$ Mader, Detlef (1985): Minor pedogenesis and local aeolian influences in sandy to peply braidplain deposits of the Solling-Folge (Upper Buntsandstein) in the Hessian depression (Hessen and Lower Saxony, F.R.G.). - In: Mader, Detlef (ed.): Aspects of fluvial sedimentation in the Lower Triassic Buntsandstein of Europe. - Lecture notes in earth sciendes, 4; p. 318-348, 3 fig., 1 tabl.; (Springer) Berlin-Heidelberg [darin: Stbr. Wienberg b. Neuerode/WMK] 
OMader, Detlef (1992): Beiträge zur Paläoökologie und Paläoenvironments des Buntsandsteins sowie ausgewählte Bibliographie von Buntsandstein und Keuper in Thüringen, Franken und Umgebung. 628 S., 17 Abb., 3 Tab., 34 Taf. m. 184 Fotos; (Gustav Fischer) Stuttgart-Jena-New York

oMerz, Georg (1993): Zur Grenz Zechstein/Buntsandstein im Thüringer Becken. - Geowiss. Mitt. Thüringen, 1: 41-48, 2 Abb.; Weimar

[Großregionale Betrachtung]

-Müller, Horst (1957): Stratigraphische und tektonische Untersuchungen im Mittleren Buntsandstein des Bramwaldes. - Dipl.-Arb. Univ. Göttingen 1957

ONaumann, Ernst (1959): Über einige Grenzprofile in der Trias bei Jena, Gotha und Thüringen. Geologie, $\underline{\mathbf{8}}(2)$ : 189-193, 1 Tab.; Berlin

Profil Buntsandstein Jena; Keuper-Profile Lkr. Göttingen; Keuperprofil Bornhagen/Thür. („Altes Holz"]

-Naumann, Peter (1996): Buntsandstein um Bad Karlshafen - Werkstein - Fossilien - Mineralien. Mitt. Geol. Interessengemeinschaft Nordhessen (GIN), 푸 56 S., Abb.; (Selbstverlag Peter Naumann) Hofgeismar

- Neumann-Redlin, Christian \& Lepper, Jochen (1975): Profile im Mittleren Buntsandstein am Ostrande des Bramwaldes (Südniedersachsen). - Geol. Jb., Reihe A, 29: 57 - 64, 3 Abb., 1 Tab.; Hannover

- $\square$ Ochmann, Mario (1984): Untersuchung des Geröllbestandes und von Quarzkörnern der SollingFolge (mittlerer Buntsandstein) im Gebiet der Hessischen Senke und ihre paläogeographische Ausdeutung. - Diss. Univ. Hannover 1984; 277 S., 33 Abb., 7 Tab., Taf. 1-3. Taf. 4-44 (Fototafeln) [Untersuchungsgebiet Teilgebiete A, B, C: HE, WMK]

dOlsen, Henrik (1988): The architecture of a sandy braided-meandering river system: an example from the Lower Triassic Solling Formation (Mittlerer Buntsandstein) in West-Germany. - Geol.Rdschau, 77(3): 797-814, 12 fig., 1 tabl.; Stuttgart

[darin: Wülmersen, Trendelburg]]

-PPaul, Josef (1999): Fazies und Sedimentstrukturen des Buntsandsteins. - In: Hauschke, N. \& Wilde, V. [Hrsg.]: Trias - Eine ganz andere Welt. Mitteleuropa im frühen Erdmittelalter. - 647 S., zahlr. Abb.; hier: S. 105-114, 18 Abb.; (Verlag Dr. Friedrich Pfeil) München [Photos Aufschlüsse Lkr. Göttingen/Unteres Eichsfeld, Umgebung Kassel]

- Paul, Josef (2002): Der Röt (Oberer Buntsandstein) in der nördlichen Hessischen Senke. - Geol Jb. Hessen, 129: 55 - 78, 20 Abb.; Wiesbaden [Korrelation m. Aufschlüssen im Lkr. Göttingen]

- Paul, Josef \& Franke, Wolfgang (1977): Sedimentologie einer Transgression: Die Röt/MuschelkalkGrenze bei Göttingen. - N. Jb. Geol. Paläont., Mh., 1977: 148-177, 7 Abb., 3 Tab.; Stuttgart [Stbr. Str. Sudheim-Suterode]

-Paul, Josef \& Siggelkow, Dorit (2004): Lakustrische Sedimente der Solling-Folge (Mittlerer Buntsandstein, Norddeutschland). - Geol Jb. Hessen, 131: 61 - 79, 10 Abb., 2 Tab.; Wiesbaden [darin: Aufschlüsse Landkreis Göttingen]

OPetri, Rüdiger (2004): Fluviatile Architektur der Solling-Folge bei Marth, Eichsfeld-Kreis (Thüringen). - Bachelor-Examensarbeit [unveröff.] Geowiss. Zentrum Göttingen, Univ. Göttingen, 30 Bl., Abb., Tab., 3 Beil.; Göttingen 
OPlatt, H. (1916): Das Randgebiet des Thüringer Waldes bei Benshausen. - Jb. Preuß. Geol. Landesanst., $\underline{\mathbf{3 6}}$ (Teil II) (f. 1915): 175 - 225, 10 Abb., insges. 6 Taf.; Berlin

[Rotliegendes, Zechstein, Buntsandstein, Tektonik]

-Plessmann, Wolfgang (1957): Zur Sedimentation des Bausandsteins im Raume Göttingen. - N. Jb. Geol. Paläont. Mh., 1957: 115 - 122, 6 Abb.; Stuttgart

[Profile Mittlerer Buntsandstein Hardegsen, Mariaspring b. Eddigehausen, Reinhausen]

OPröscholdt, H[ermann] (1887): Über die Gliederung des Buntsandsteins am Westrand des Thüringer Waldes. - Z. dt. geol. Ges., 39: 343-359, 1 Falt-Taf.; Berlin

Referat in: N. Jb. Mineral. etc, $\underline{1889}$ (Bd. II): 123-124 (A. Leppla); Stuttgart

OPuff, Peter (1964): Zur Paralellisierung von Becken- und Randausbildung des Buntsandsteins. Geologie, 13 (4): 395-402, 2 Abb., 1 Tab.; Berlin

[darin: Werra-Kaligebiet]

OPuff, Peter \& Radzinski, Karl-Heinrich (1976): Zur Paläogeographie und lagerstättenkundlichen Bedeutung des tieferen und mittleren Buntsandsteins im südlichen Teil der DDR. - Z. geol. Wiss., 4(11): 1483-1503, 12 Abb; Berlin

[Paläogeographische Karten, auch Weststhüringen umfassend]

OPuff, Peter; Langbein, Rolf [Beitrag](1995): Buntsandstein [in Thüringen]. - In: Seidel, Gerd [Hrsg.]: Geologie von Thüringen. - 1. Aufl.; S. 303-317, 4 Abb., 1 Tab.; Stuttgart 1995

OPuff, Peter; Langbein, Rolf [Beitrag](2003): Buntsandstein [in Thüringen]. - In: Seidel, Gerd [Hrsg.]: Geologie von Thüringen. - 2., neu bearb. Aufl.; S. 326-341, 4 Abb., 2 Tab.; Stuttgart 2003

-Rambow, Dietrich (1967): Die Hardegsen-Folge (Buntsandstein) in den Bohrungen Beberbeck und Haarhausen (Hessen). - Notizbl. Hess. L.-A. Bodenforsch., 95: 76-82, Taf. 4; Wiesbaden

- $\square$ Rambow, Dietrich (1967): Die Solling-Folge und der untere Röt (Buntsandstein) in der Niederhessischen Senke. - Notizbl. Hess. L.-A. Bodenforsch., 95: 83 - 101, 2 Abb.; Wiesbaden [Gebiete nördlich der Eder, u.a Bhrg. Elgershausen; Epterode (Werra-Meißner-Kreis)]

-Rambow, Dietrich (1973): Profile durch den Mittleren Buntsandstein am West- und Ostrand der Niederhessischen Senke. - Notizbl. Hess. Landesamtes Bodenforschung, 101: 277-283, 4 Abb., 1 Tab.; Wiesbaden [Untersuchungen randnaher Bereiche von Naumburger Graben und Altmorschener Graben, Bl. 4720 Waldeck, 4721 Naumburg, 4821 Fritzlar, 4823 Melsungen]

- $\square$ Rambow, Dietrich (1976): Profile durch den Mittleren Buntsandstein an der Ostflanke des nordhessischen Teilbeckens (Gebiet östlich Kassel). - Geol. Jb. Hessen, 104: 43 - 49, 1 Abb., 1 Tab., 1 Taf.; Wiesbaden [Bhrgn. hptsächl. zw. A7 und Hoher Meißner, auch Unteres Werratal]

- $\square$ ○•Rettig, Ben (1996): Die Solling-Folge (Mittlerer Buntsandstein) im Grenzgebiet NiedersachsenThüringen-Hessen. - Mitt. A. d. Geol. Inst. Univ. Hannover, 32 107 S., Ill, graph. Darst, Kt. + 3 Beil.; zgl. Diss. Univ. Hannover 1996; Hannover [Unterrsuchungsgebiet: Südniedersachsen, Thüringer Eichsfeld nördl. Leine, auch Gebiet des WerraMeißner-Kreises; Aufschlüsse auf Bl. 4625 Witzenhauesen, 4724 Großalmerode, 4725 Bad SoodenAllendorf, 4726 Grebendorf, 4727 Küllstedt, 4827 Treffurt]

Altmark-Schwelle und Thüringer Becken (Posterbeitrag). - In: Büchel, Georg \& Lützner, Harald (Hrsg.): Regionale Geologie von Mitteleuropa - Geodynamische Prozesse zwischen Alpen und Nordatlantik - 149. Hauptversammlung - Deutsche Geologische Gesellschaft und 
Jahreshauptversammlung der Fachsektion Geoinformatik - Jena 27.09.-3.10.1997 - Kurzfassung der Vorträge und Poster. - Schriftenrh. Dt. Geol. Ges., 2: 94-96; Hannover 1997

- $\square$ ○•Rettig, B.; Röhling, H.-G. \& Wenzel, B. (1998): Depositional History of the Solling Formation (Buntsandstein, Lower Triassic) in Southern Lower Saxony, Northern Hesse and Northwestern Thuringa. - (International Symposium on the Epicontinental Triassic/Halle (Saale) - September 1998 - Abstracts) Hallesches Jb. Geowiss., Reihe B, Beih., ㅍ: 147-148; Halle (Saale)

[HE, WKM, THÜ, NIE - ohne Lokalitäten]

$\square$ Rettig, Ben; Röhling, H.-G- \& Wenzel, B. (1999): Ein Schwellenprofil der Solling-Folge am Meinhard bei Eschwege [Posterbeitrag]. - In: Hoppe, Andreas [Hrsg.]: Geotope - lesbare Archive der Erdgeschichte. Tagung: 151. Hauptvers. Dt. Geol. Ges. 02.10.99 - 10.10.99 Wiesbaden; Schriftenreihe Dt. Geol. Ges., 7; S. 85-87; (Deutsche Geologische Gesellschaft) Hannover 1999

-Rexhäuser, H. (1958): Zur Stratigraphie und Tektonik des Mittleren Buntsandsteins zwischen Gelliehausen und Holzerode. - Dipl.-Arb. [unveröff.] Univ. Göttingen 1958; 41 S., 15 Abb., 3 Taf.

- $\square$ • Roehling, Heinz-Gerd (1993): Der Untere Buntsandstein in Nordwest- und Norddeutschland. Ein Beitrag zur Vereinheitlichung der stratigraphischen Nomenklatur. - Geol. Jb., Reihe A, 142: 149183, 12 Abb., 9 Tb.; Hannover

$\square \oslash \bullet$ Röhling, H.-G.; Stollhofen, H. \& Tietze, K.-W. (2002): Trias Exkursion I: Buntsandstein zwischen Hannover und Würzburg. - In: Niebuhr, Birgit [Hrsg.]: GEO 2002 - Planet Erde: Vergangenheit, Entwicklung, Zukunft - 1.-5. Oktober 2002 in Würzburg. - Exkursionsführer Excursion guide. - Schriftenrh. Dt. Geol. Ges., 22: 5-28, 13 Abb., 3 Tab.; Hannover 2002 [darin Aufschlüsse WMK, Thür. Eichsfeld, Niedersachsen]

-Röhling, Heinz-Gerd (2004): Als das Eichsfeld in Nordafrika lag! - Bohrungen im Buntsandstein bei

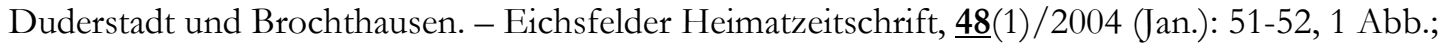
Duderstadt

QRöhling, Heinz-Gerd (2008): Au(f)s diesem Fels müßt ihr bauen! - Zur geologischen Einordnung der Burg Hanstein. - In: Hanstein, Hans-Dieter von [Hrsg.]: Burg Hanstein - Zur 700jährigen Geschichte einer eichsfeldischen Grenzfeste. - Herausgegeben im Auftrag des Familienverbandes der von Hanstein von.. - 296 S., zahlr. Abb.; hier S. 67-80, 12 Abb., 1 Tab.; (Mecke Druck u. Verlag) Duderstadt 2008

[Regionalgeologie, Erdgeschichte der Buntsandstein-Zeit, Solling-Sandstein als Baustein]

øRöhling, Heinz-Gerd (2008): Der Untere und Mittlere Buntsandstein zwischen Duderstadt und Worbis <Vortragskurzfassung>. - In: Wunderlich, J. [Red.]: Exkursionsführer - Geologie des Eichsfeldes - zur 18. Jahreshauptversammlung (Vortrags- und Exkursionsveranstaltung) vom 16. bis 18. Mai 2008 in Heilbad Heiligenstadt. - Führung: H. Heiland, L. Nolte, H.-G. Röhling \& G. Seidel. S. 47-48; [Hrsg.: Thüringer Geologischer Verein e.V.] Jena 2008

$\square$ Rösing, Franz. (1959): Bericht über die Exkursionen anläßlich der 110. Hauptversammlung in Marburg a. d. Lahn vom 1. - 9. September; Alter Steinbruch unmittelbar südlich Neuerode und Steinbruch Wienberg bei Neuerode. - Z. dt. geol. Ges., 111: 289-291; Hannover [Buntsandstein - Solling-Folge]

- Rösing, Franz (1966): Über Buntsandsteinschutt. - Z. dt. geol. Ges., 108: 990-994; Hannover [Vortragstext; Abh. ü. d. Höhenzug der Söhre E’ Kassel, Bl. 4723 Oberkaufungen, Bl. 4722 Niederzwehren]]

D0 • Schlunk, J. (1913): Salzlager und Kalisalze im Oberen Buntsandstein (Röt). - Kali, etc., $\underline{\mathbf{7}}(11): 272-276$

$\underline{\mathbf{7}}(13): 314-318$

$\underline{7}(14): 350-357$ 
7(16): 398 - 408; Halle/Saale

[darin: Werratal, Leinetal, Fuldatal, Unstruttal, Nordrand u. Südrand Thüringer Wald]

-Schmidt, Hermann (1928): Exkursion nach Diemarden und Bremke (Muschelkalk und Buntsandstein). [Tagung der Paläontologischen Gesellschaft in Göttingen - 29. September bis 4. Oktober 1926]. Paläont. Z., 9: 2-4, 2 Abb.; Berlin

-Schneider, Albert (1957): Zum Mittleren Buntsandstein im Gebiet des Bremker Waldes. - Dipl.- Arb. [unveröff.] Univ. Göttingen

OSchneider, Hans-Eckart (1968): Gipsführung und Auslaugungserscheinungen im Röt von Deuna (Eichsfeld) und ihre Bedeutung für die Zementindustrie. - Z. angew. Geol., 14(1): 18-25, 6 Abb., [1] Tab.; Berlin

-Schröder, Lothar (1960): Der Mittlere Buntsandstein im Raume Suterode, SE’ Northeim. - Dipl.-Arb. [unveröff.] Univ. Göttingen; 67 S., 2 Abb., 3 Kt.

- $\square$ Schröder, Lothar (1963): Zur Sedimentologie des Mittleren Buntsandsteins. - Diss. Univ. Göttingen 1963, 76 S.; Göttingen

[Südniedersachsen, Nordhessen]

- $\square \bullet$ Schröder, Lothar (1965): Zur Sedimentologie des Mittleren Buntsandsteins. - Geol. Jb., $\underline{82:} 655$ 704, 13 Abb., 2 Tab.; Hannover

[Gebiet a. d. Unteren Werra nördl. Witzenhausen bis Höhe Einbeck]

OSchulze, Silvia (2001): Neue Erkenntnisse zur Ausbildung und subrosiven Beeinflussung der Röt-Folge am Südhang der Bleicheröder Berge < Vortragskurzfassung>. - In: Rauche, Henry [Hrsg.]:

Regionale und angewandte Geologie der Grenzregion der Süddeutschen und der Mitteldeutschen Scholle. - Programm und Kurzfassungen der Vorträge. - 10. Jahrestagung Gesellschaft f.

Geowissenschaften i. Schmalkalden, 19.-22. September 2001. - Exkursionsführer u. Veröff. Ges. f. Geowiss., 214; S. 215-216; Berlin 2001

[Stratigraphie, Geomorphologie, Ingenieurgeologie]

OSchulze, Silvia (2002): Ausbildung und subrosive Beeinflussung des unteren Abschnitts der Röt-Folge am Südhang der Bleicheröder Berge im Land Thüringen - Character and subrosive influence of the lower intercept of Roethian-sequence on the southern slope of the Mountains of Bleicherode in

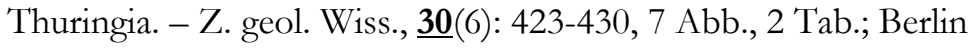

OSeidel, Gerd (1965): Zur Ausbildung des Mittleren Buntsandsteins im thüringischen Eichsfeld. Geologie, 14(4): 443-448, 3 Abb.; Berlin

[Profile Birkenfelde, Holungen 1, Scharfenstein, Billeben, Geisleden, Lengenfeld u. S.]

OSeidel, Gerd (1969): Zur Ausbildung des Unteren Buntsandsteins in Nordthüringen. - Ber. dt. Ges. geol. Wiss., Reihe A (Geol, Paläont) 14: 185-188, 2 Abb.; Berlin

[Bezug auf Bohrungen Billeben, Horsmar, Frankroda]

OSobotha, Ernst (1935): Zur Geologie des Rusteberggebietes (Beoachtungen im Bausandstein und Diluvium. - Unser Eichsfeld, $\underline{30}$ (1): 13-15; Duderstadt

QSöfner, Rudolf (1938): Zur Entstehung des Thüringer Buntsandsteins. - Chemie der Erde, 11 (3): 420 444, 8 Abb., Taf. III; Jena

Referat in: N. Jb. Mineral. etc., Referate, 1940 (Bd. III): 21-23 (Walter Fischer); Stuttgart

[Untersuch. a. Bohrkernmaterial d. Bhrg. [Bad] Langensalza 2 u. 3]

OVoss, Reimar (1928): Die paläogeographische Verbreitung des Rogensteins im deutschen Unteren Buntsandstein. - Abh. Preuß. Geol. Landesanst., N.F., 107; 66 S., 1 Beil., Ill., Kt.; Berlin - zgl. Diss. TH Berlin 1927; Berlin 
[Bezug u.a. Bhrg. Bl. Wilhelmshöhe [4622Kassel-West]; Südniedersachsen, Nordwestthüringen: Bl. 4529 Bleicherode, Groß-Keula (4629 Menteroda)]

oWeber, Hans (1951): Der Untere und Mittlere Buntsandstein an der Autobahn der Blätter Creuzburg, Herleshausen, Berka und Hönebach. - Hallesches Jb. Mitteldt. Erdgeschichte, 1 (3): 132-140; Halle

D $\square$ Weber, Jutta (2000): Kieselsäurediagenese und gekoppelte Sedimentarchitektur: eine Beckenanalyse des Reinhardswald-Troges (Norddeutsches Becken, Solling-Folge, Mittlerer Buntsandstein) - Kölner Forum Geol. Paläont., 7; 165 S., 107 Abb., 14 Tab., 11 Taf.; (Selbstverl. Geol. Inst.) Köln [Großregionale Untersuchung, u.a. Aufschlüsse Reinhausen b. Göttingen, Witzenhausen, Friedewald]

$\square$ Wenzel, Bernward (1994): Zur Lithostratigraphie und Sedimentologie des Röt und zu den Massenverlagerungen an der Röt/Muschelkalkgrenze in Nordhessen.- Gießener geol. Schriften, $\underline{\mathbf{5 3}}$; VIII, 248 S., Ill., graph. Darst., Kt.; Teil A: Zur Lithostratigraphie und Sedimentologie des Röt in Nordosthessen, S. 1-141, 23 Abb., i. Text, Taf., Tab. i. Anhang; Teil. B.: Zu den Massenverlagerungen an der Röt-/Muschelkalkgrenze in Nordosthessen. S. 141-248, 21 Abb. i. Text; Kt., Profile, Taf., Tab. i. Anhang; zgl. Diss. Univ. Gießen 1994; (Lenz) Gießen

[Untersuchungsgebiet Röt/Muschelkalkgrenze im Werra-Meißner-Kreis; Hörne, Plesse, Rabenklippe, Schiefergrundskopf, Schickeberg, Kielforst u.a.]

Dᄆ0 Wolburg, Johannes (1961): Sedimentationszyklen und Stratigraphie des Buntsandsteins im NWDeutschland. - Geotekto Forsch., 14: 7-74, 17 Abb., 5 Tab., 12 Taf.; Stuttgart $[\mathrm{N}, \mathrm{H}, \mathrm{T}, \mathrm{WMK}]$

$\square$ Wolf, Daniel (2002): Sedimentation und pedogene Bildungen der Solling-Folge bei Eschwege/NEHessen. - Dipl.-Arb. und-Kartierung [unveröff.] Univ. Göttingen; 26, 27 S., Anh., 19 Kt.-Beil.

-Worf, Hans (1959): Der Mittlere Buntsandstein im Raume Nörten-Hardenberg - Reyershausen Sudershausen. - Dipl. - Arb. [unveröff.] Geol. Paläont. Inst. Univ. Göttingen; 47 S., Abb., 1 Kt.; Göttingen

-Wunderlich, Hans Georg (1957): Liefergebiete und Schüttungsrichtungen des mitteldeutschen Buntsandsteins nach Maßgabe der Schwermineralführung. - N. Jb. Mineral. etc., 1957: 123 - 143, 6 Abb.; Stuttgart

$\square$ Wycisk, Peter (1977): Fazies und Environment der Becken- und Schwellensedimente des Mittleren Buntsandsteins (Reinhardswald - Eschwege). - Nachr. Dt. geol. Ges., 17: 64 - 65; Hannover

- $\square$ Wycisk, Peter (1984): Faziesinterpretation eines kontinentalen Sedimentationstroges (Mittlerer Buntsandstein/Hessische Senke). - Berliner geowiss. Abh., Reihe A, 54; 104 S., 39 Abb., 2 Tab., 9 Taf., 1 Falt-Taf.; Berlin - zgl. Diss. FU Berlin 1984

OZänker, Günther (1974): Beziehung zwischen stofflicher und struktureller Entwicklung im Salinargebirge des Südharz-Kalireviers. - Z. geol. Wiss., 2 (10): 1157-1175, 8 Abb.; Berlin

OZiegenhardt, W.; Rockel, W. \& Griesbach, H. (1978): Paläomorphologie und Erdöl/ErdgasLagerstättenbildung im Staßfurtkarbonat Thüringens. - Z. angew. Geol., 24: 353-363, 9 Abb.; Berlin [Geographischer Lagedaten anonymisiert]

\subsection{Muschelkalk}

$\square$ Althaus (1842): Mesothype vom Alpstein; Ausscheidungen im Muschelkalk. - N. Jb. Mineral. etc., $\underline{1842:}$ 275-276 (Briefl. Mitt.); Stuttgart

[Zeolithmineralien im Basalt; Mineralneubildung im Muschelkalk unweit d. Alpsteins] 
Q Anders, Carsten (1998): Oberer Muschelkalk und Unterer Keuper in der Bohrung 10 Deiderode (Trias, südliches Niedersachsen). - Die Geologie beiderseits der Arenshäuser Verwerfung, südlicher Leinegraben, nördlich Kirchgandern und Arenshausen, West-Thüringen, Süd-Niedersachsen (TK 25: 4625 Blatt Witzenhausen). - Dipl.-Arb. /Dipl.-Kart. [unveröff.] Univ. Göttingen, 65,33 Bl., 2 Beil.,

- $\square$ •ӨApel, Jürgen \& Rüppel, Heidi [Verfass. u. Hrsg.] (2005): Raus in die Natur - Tipps für den Sonntags-Ausflug im Dreiländereck Hessen - Niedersachsen - Thüringen. - 159 S., 111 Fotos, 34 Kt., 1 Zeit-Taf.; (LSRB-Verlag, Landschaftskundlicher-Studien-Reisebuch-Verlag) Witzenhausen [zahlreiche Ausflugstipps, auch zu Geotopen des Muschekalks: Ziele 12, 44, 55, 57, 82, 84]

$\square$ Aramesh, J. (1993): Geologie des Gebietes östlich Albungen (Nordhessen) unter besonderer Berücksichtigung der Terebratelzone (Unterer Muschelkalk). - Dipl.-Arb. [unveröff.] Fachber. Geowiss. FU Berlin, 67 S.

OAssaruri, Mustapha \& Langbein, Rolf (1987): Die Schaumkalkfazies des Unteren Muschelkalks (Trias) im Thüringer Becken. - Z. geol. Wiss., 15(4): 527-539, 4 Taf.; Berlin [darin: Abb. Gestein d. Hörselberge b. Eisenach]

$\square$ Baumgarte, Diethelm (1977): Ein Profil in der Schaumkalkzone des Unteren Muschelkalkes bei Ringgau-Renda (Hessen). - Geol. Jb. Hessen, 105: 115 - 119, o. Abb.; Wiesbaden [Stbr. Forststr. Renda-Ulfen, Bezugnahme a. Steinbruch am Köhlerskopf b. Ringgau-Röhrda]

-Baumgarte, D.; Busse, E. \& Horn, M. (1980): Muschelkalk und Lias des Homburg-Grabens (Nordhessen). - Geol. Jb. Hessen, 108: 121 - 138, 4 Abb.; Wiesbaden

-Bender, Heike (1981): Die Geologie des Südrandes der Dransfelder Muschelkalkhochfläche östlich von Hann. Münden bei Wiershausen und Lippoldshausen (TK 25, Bl. Nr. 4524 Jünhnde). -Dipl.-Kart. [unveröff.] [Dipl.-Arb. Teil 1] Univ. Göttingen, 66 S.

-Besch, Wulf (1961): Der Muschelkalk in der Umgebung von Hersfeld - Welche Ereignisse sind für die Entstehung und Erhaltung seiner Sedimente verantwortlich. - Mein Heimatland, 19 (19): 73 - 74, 2 Abb.; Bad Hersfeld

OBlum, H. (1959): Feinstratigraphische Untersuchungen des Unteren Muschelkalkes im Bereich der Hörselberge und im Raum Creuzburg-Treffurt. - Dipl.-Arb. [unveröff.] Univ. Halle; Halle

QBöttcher (1938): Die Schichtenfolge des Oberen Muschelkalkes bei Ohrdruf und ein paar seltene Versteinerungen. - Beitr. Geol. Thür., 5: 54-66, 1 Tab..; Jena

Referat in: N. Jb. Mineral. etc., Referate, 1940 (Bd. III): 18-19 (Walther Fischer); Stuttgart

QBöttcher (1938): Versteinerungen des Oberen Muschelkalks bei Ohrdruf als aufschlußreiche Dokumente für die Geschichte des deutschen Muschelkalkmeeres. - Beitr. Geol. Thür., ㅁ: 99-106, 1 Tab., 2 Taf.; Jena

Referat in: N. Jb. Mineral. etc., Referate, 1940 (Bd. III): 18-19 (Walther Fischer); Stuttgart

QBornemann [sen.], J. G. (1886): Beiträge zur Kenntnis des Muschelkalks, insbesondere der Schichtenfolge und der Gesteine des unteren Muschelkalks in Thüringen. - Jb. Preuß. Geol. Landesanst., $\underline{\mathbf{6}}$ (f. 1885): 267-321, Taf. VII-XIV; Berlin

[Steinbruch-Profile Worbis, Hainich: Craula, Mihla]

口बBornemann [sen.], J. G. (1889): Ueber den Muschelkalk. - Jb. Preuß. Geol. Landesanst., $\underline{9}$ (f. 1888): 417-439; Berlin

[Großregionale stratigraphische Korrelation; Bezugnahme a.. Bl. Sontra, Waldkappel, Netra, Eschwege, Weststhüringen] 
-Brocke, Reiner (1987): Palynologische Untersuchungen im Oberen Muschelkalk und seinem Grenzbereich westlich Göttingen. - Geologische Teilkartierung auf Blatt 4425 Dransfeld zwischen Barterode und Imbsen. - Dipl.-Arb. [unveröff.] Univ. Göttingen 1987; II, 75,83 S.

$\square$ Busse, Erwin (1954): Profil der Unteren und Mittleren Ceratitenschichten vom Eisenberg bei Hessisch Lichtenau und Walburg. - Notizbl. Hess. L.-A. Bodenforsch., 82: (= 6. F. (H. 5)): 152 - 167, 1 Taf.; Wiesbaden

-Busse, Erwin (1956): Aufschlüsse im Oberen Muschelkalk des westlichen Kasseler Grabens. - Notizbl. Hess. L.-A. Bodenforsch., 84: 170 - 175; Wiesbaden

-Busse, Erwin (1956): Ein Wellenkalkprofil vom Fürstengarten in Kassel (Blatt Kassel-West). - Notizbl. Hess. L.-A. Bodenforsch., 84: 176-183; Wiesbaden

- $\square$ Busse, Erwin (1959/60): Stratigraphische Beziehungen des Oberen Muschelkalks im Diemelgebiet und am Meißner [Vortragsreferat]. - Z. dt. geol. Ges., 111: 245 - 246; Hannover

$\square$ Busse, Erwin [1964): Stratigraphie des Unteren Muschelkalks (Wellenkalk) im westlichen MeißnerVorland. - Abh. d. Vereins f. Naturkunde z. Kassel, 2; 35 S., 1 Tab.; Kassel

-Busse, Erwin (1972): Zur Stratigraphie des Oberen Muschelkalks im Diemeltal. - Notizbl. Hess. L.-A. Bodenforsch., 100: 135 - 152, 2 Abb.; Wiesbaden

-Busse, Erwin (1973): Aufschlüsse im Oberen Muschelkalk bei Eberschütz und Manrode (Diemelgebiet, Bl. 4422 Trendelburg). - Notizbl. Hess. L.-A. Bodenforsch., 101: 176 - 187, 3 Abb.; Wiesbaden

-Busse, Erwin (1974): Der Obere Muschelkalk im nordwestlichen Niederhessen. - Notizbl. Hess. L.-A. Bodenforsch., 102: 91 - 135, 9 Abb.; Wiesbaden [Bl. 4521 Liebenau, 4522 Hofgeismar, 4520 Warburg, 4620 Arolsen]

-Busse, Erwin (1974): Die Terebratulazone des Unteren Muschelkalkes (Wellenkalk) am Eckerich westlich Fritzlar. - Philippia, 2 $2(2): 57$ - 66, 2 Abb.; Kassel

$\square$ Busse, Erwin (1980): Ein Aufschluß im tiefsten Wellenkalk bei Reichenbach (Bl. 4824 Hessisch Lichtenau). Zur Grenzziehung Röt/Wellenkalk in Niederhessen. - Geol. Jb. Hessen, 108: 111 - 119, 1 Abb., 2 Tab. Wiesbaden

-Busse, Erwin (1983): Die Muschelkalkgerölle an der Kalkreuse bei Besse südlich Kassel. - Geol. Jb. Hessen, 111: 155 - 160, 1 Tab.; Wiesbaden

-Busse, Erwin \& Rösing, Franz (1955): Über Muschelkalk-, Keuper- und Liasschollen im Stadtgebiet von Kassel. - Notizbl. Hess. L.-A. Bodenforsch., $\underline{\mathbf{3 3}}$ (= 6. F., H. 5): 198-204, 1 Abb.; Wiesbaden

-Busse, Erwin \& Rösing, Franz (1957): Aufschlüsse in der Oolithzone bei Oberelsungen und Escheberg (Blatt Wolfhagen). - Notizbl. Hess. L.-A. Bodenforsch., 85: 146 - 151; Wiesbaden

-Busse, E. \& Rösing, F. \& Vaupel, O. (1977): Der Wellenkalk (Trias) am Kalkberg bei Niederkaufungen östlich von Kassel. - Geol Jb. Hessen, 105: 121-130; Wiesbaden

-Busse, Erwin \& Horn, Manfred (1981): Fossilführung und Stratigraphie der gelben Basisschichten im Diemelgebiet. - Geol. Jb. Hessen, 109: 73 - 84, 1 Abb.; Wiesbaden

$\square$ Clasen, Frauke \& Gehrke, Bettina (1990): Isolierte Muschelkalkschollen auf Röt im Werratal (TK 25: 4624 Hedemünden u. 4625 Witzenhausen) - Kartierung 1 : 10 000. - Dipl.-Kart. [unveröff.] Univ. Göttingen, 32 S. 
-Dahmer, Dirk \& Hillbrecht, Heinz (1986): Die Faziesentwicklung des Unteren Muschelkalks bei Bad Hersfeld (Nordhessen) mit Anmerkungen zur Entstehung der Mikrite. - N. Jb. Geol. Paäont. Mh., 1986: 513-528, 3 Abb.; Stuttgart

[Untersuchungen im sog. Hersfelder Graben]

-Dünkel, Helmut (1987): Geologie der Dransfelder Hochfläche östlich Jühnde, südliches Niedersachsen - [Übergeordneter Titel]

Teil 1: Sedimentologische Untersuchungen im Bereich der Schaumkalkbände [Dipl.-Arb. ]

Teil 2: Kartierung der südlichen Dransfelder Hochfläche, östlich Jühnde (Dipl.-Kart. ]

Dipl.-Arb. u. Dipl.-Kart. [unveröff.] Univ. Göttingen, 238 S., zahlr. Abb., Taf., Tab.

-Dünkel, Helmut \& Vath, Ullrich (1990): Ein vollständiges Profil des Muschelkalks (Mitteltrias) der Dransfelder Hochfläche, SW Göttingen (Südniedersachsen). - Geol. Jb. Hessen, 118: 87-126, 6 Abb., 3 Tab., 3 Taf.; Wiesbaden

[Großregionale Untersuchungen an Kernbohrungen und Steinbrüchen zwischen Hardegsen $(\mathbb{N})$ und Jühnde) unter Einbeziehung des Blattes Sontra; TK 4324 Hardegsen, 4425 Göttingen, 4424

Dransfeld, 4525 Friedland/Reinhausen, 4524 Scheden, 4925 Sontra]

-0 •Dünkel, Helmut (1992): Stratigraphie, Petrographie und Fazies des mittleren Muschelkalks in Südostniedersachsen im Vergleich mit angrenzenden Gebieten (Nordhessen, Nordrhein-Westfalen und Thüringen). - 147 S., 22 Abb. i. Text; 13 gez. Abb. i. Anh., 11 Tab., 13 Foto-Taf.; (Cuvillier) Göttingen - zgl. Diss. Univ. Göttingen 1992

[darin: Untersuchungen. Lkr. Göttingen (Dransfelder Hochfläche); Hess. Diemelgebiet, Bhrg. Küllstedt/Thür.]

QErnst, Werner (1991): Der Muschelkalk im westlichen Thüringen. - In: Hagdorn, Hans \& Seilacher, Adolf [Hrsg.]: Muschelkalk - Schöntaler Symposium 1991. - Sdbde Ges. Naturkde. Württ., 2; 288 S., zahlr. Abb.; hier: S. 73-78, 6 Abb., 3 Tab.; (Goldschneck) Stuttgart, Korb

[Gebiet N'Thüringer Wald, W' Linie Mühlhausen-Waltershausen]

OFarshad, Farhad (1995): Geologische Kartierung der Trias im Osten des Eichenberger Grabenknotens zwischen Arenshausen und Gerbershausen in Thüringen (TK 25 Blatt 4625 Witzenhausen). - Dipl.Kart. [unveröff.] Univ. Göttingen; 50 S., 2 Beil.

-Fehr, Carl Christian (1838): Die Spangensteine und der Liebenbach zu Spangenberg. - „Aus der Vorzeit", hrsgg. v. Dr. Karl Wilhelm Justi. - [무]: 252-264, 1 Taf.; (Elwert) Marburg/L. [Herleitung des Stadtnamens von Spangenberg von den „Spangen“, das sind die Seelilien-Stielglieder imOberen Muschelkalk des Stadtberges]

- Findeisen, Hans-Kurt (1952): Ein bemerkenswerter Wellenkalkaufschluß im Stadtgebiet von Kassel. Notizbl. Hess. L.-A. Bodenforsch., (IV. F. ) H. 3: 109 - 117, 1 Abb.; Wiesbaden

QFischer, Karl (2004): Die Bonifatiuspfennige am Büttstedter Bahndamm. - Eichsfelder Heimatzeitschrift, $\underline{\text { 48}}(6) / 2004$ (Juni): 213; Duderstadt [Herkunft der lokalen Bezeichnung „Bonifatiuspfennige“ für Seelilienstielglieder]

Q■Föhlisch, Katja (2002): Synsedimentäre Defomation im unteren Muschelkalk des Germanischen Beckens. - Diss. [unveröff.] Univ. Jena 2002; V, 121, [40]Bl.

[Aufschluß/Profil Unterer Muschelkalk Hitzelrode bei Eschwege]; Jena

口OFrantzen, W. (1888): Untersuchungen über die Gliederung des unteren Muschelkalks in einem Theile von Thüringen und Hessen und über die Natur der Oolithkörner in diesen Gebirgsschichten. - J. Kgl. Preuß. Geol. Landesanst., $\underline{8}$ (f. 1887): 1-93, 3 Taf.(I-III); Berlin Referat in: N. Jb. Mineral. etc., 1890 (Bd. I): 297-299 (A. Leppla); Stuttgart [Bezugnahme auf die Geologie der „Sectionen“ [Kartenblätter] [4926 Herleshausen] Netra und [4825] Waldkappel; Treffurt, Creuzburg] 
OFrantzen, W. (1893): Bemerkungen über die Schichten des oberen Muschelkalkes und des unteren Keupers in dem Bereich der Messtischblätter Eisenach, Creuzburg und Berka. - Jb. Preuß. Geol. Landesanst., 12 (f. 1891): 179-192; Berlin

Referat in: N. Jb. Mineral. etc, 1894 (Bd. I): 480 (A. Leppla); Stuttgart

OFreyberg, Bruno von (1921): Ein Profil durch den unteren Wellenkalk bei Treffurt. - Z. dt. geol. Ges., 72, Briefl. Mitt.: 140-144; Berlin

[Muschelkalkwand unterhalb der Adolsburg]

Oreyberg, Bruno von (1922): Der Aufbau des unteren Wellenkalks im Thüringer Becken. - N. Jb. Mineral. etc.,; Beil.-Bd 45: 214-273, 5 Abb., 2 Tab., Taf. 6-10; Stuttgart

[Aufschlüsse bei Faulungen, Treffurt/Adolfsburg, Heldrastein]

-Friese, Bernd (1980): Unterer Muschelkalk und Buntsandstein am Südostrand des Göttinger Waldes und am Hengstberg (TK 25: 4426 Ebergötzen). - Dipl.-Arb. [unveröff.] Univ. Göttingen 1980; 146 S.

oGerlach, Max (1910): Im Reiche des Ceratites nodosus. Die Muschelkalkformation in Eisenachs Umgebung und ihre Beziehung zur Pflanzen-, Tier- und Menschenwelt. - 43 S., 1 Abb.; (Kahle) Eisenach

OGötz, Annette E. (1992): Feinstratigraphie und Tektonik am Südwestrand des Creuzburger Grabens. Dipl.-Arb. [unveröff.] TH Darmstadt; Darmstadt [Unterer Muschelkalk]

$\square$ OGötz, Annette E. (1994): Feinstratigraphie des Unteren Muschelkalks und Tektonik am Südwestrand des Creuzburger Grabens (Bl. 4927 Creuzburg/Westthüringen). - In: Geol. Jb. Hessen, 122: 23-38; 9 Abb., 2 Tab., 1 Tf.; Wiesbaden

[Geol. Karte Keuperverbreitung Creuzburger Graben/Netratalgraben mit hessischen Anteilen, Angaben z. Stratigraphie Oberer Muschelkalk Ringgau]

OGötz, Annette E. (1994): Feinstratigraphie und Zyklengliederung im Unteren Muschelkalk (Raum Creuzburg - Westthüringen). - Beitr. Geol. Thüringen, N.F., 1: 3-12, 3 Abb.; Jena

口OGötz, Annette: (1995): Feinstratigraphie und Mikrofazies der Oolithbänke (Unterer Muschelkalk, Trias) Mitteldeutschlands und angrenzender Gebiete. - Diss. TH Darmstadt 1995; II, 115 S., Ill., graph. Darst.; Darmstadt

OGötz, Annette E. (1996): Palynofazielle Untersuchungen zweier Geländeprofile im Unteren Muschelkalk Osthessens und Westhüringens. - Geol. Jb. Hessen, 124: 87-96; 3 Abb., 2 Taf.; Wiesbaden [Profile Hörschel/Werra, Poppenhausen/Rhön]

$\square$ Götz, Annette E. (1996): Fazies und Sequenzanalyse der Oolithbänke (Unterer Muschelkalk, Trias) Mitteldeutschlands und angrenzender Gebiete. - Geol. Jb. Hessen, 124: 67-86; 10 Abb., 2 Tab.; Wiesbaden [Untersuchungsgebiet zwischen Diemel und Saale, u.a. Blatt 4925 Sontra]

$\square$ Götz, Annette E. (2000): Palynofacieas and sequence analysis of the Lower Muschelkalk (Middle Triassic, German Basin) . - Zentralbl. Geol. Paläont. Teil 1, 1998(9/10): 877-891, 5 fig., 1 pl.; Stuttgart [Palynologische Untersuchungen am Profil der Ringgau-Bohrung]

EGötz, Annette E. (2004): Zyklen und Sequenzen im Unteren Muschelkalk des Germanischen Beckens.

- Cycles and sequences in the Lower Muschelkalk of the Germanic Bassin. - Hallesches Jb.

Geowiss., Reihe B, Beih. 18: 91 - 98; 6 Abb.; Halle/Saale

[darin: Abb. Aufschluß Hörschel] 
$\square$ Götz, A. E. \& Feist-Burkhardt, S. (2000): Palynofacies and sequence analysis of the Lower Muschelkalk (Middle Triassic, German basin). - Zbl. Geol. Paläont., Teil I, 1998 (9/10 = Vol. 2): 877891, 5 Abb., 1 Taf.; Stuttgart

[Bhg. Ringgau, Werra-Meißner-Kreis]

-Hagdorn, Hans \& Simon, Theo (1983): Ein Hartgrund im Unteren Muschelkalk von Göttingen. Der Aufschluss, 34: 255 - 263, 3 Abb.; Heidelberg

- $\square$ Hagdorn, Hans (1987): Profile durch den hessischen, unterfränkischen und badenwürttembergischen Muschelkalk. - Geol. Jb. Hessen, 115: 131-160, 2 Abb., 2 Tab., 3 Taf.; Wiesbaden [Hessen, Meißner]

$\square$ Hagdorn, H.; Horn, M.; Hickethier, M. \& Simon, Th. (1987): Profile durch den hessischen, unterfränkischen und baden-württembergischen Muschelkalk. - Geol. Jb. Hessen, 115: 131-160, 2 Abb., 2 Tab., 3 Taf.; Wiesbaden

[Profile Meißner und Bhrg. [Ringgau]-Röhrda, Bl. 4926 Herleshausen]

-Heckmann, Fritz (1916): Beiträge zur Kenntnis des hessischen Muschelkalks mit besonderer Berücksichtigung der Vorkommen Oberhessens [Niederhessens!]. - Abh. u. Ber. Vereins f. Naturkunde zu Kassel, 59: 1 - 63, 2 Taf., 2 Kt.; Kassel

[Muschelkalk in den Grabenzonen östlich von Kassel: Naumburger Graben u.a.]

هHerold, M. D. (1838): Die Spangensteine zu Spangenberg. - „Aus der Vorzeit“, hrsgeg. v. Dr. Karl Wilhelm Justi. - [10]: 418-420; (Elwert) Marburg/L.

[„Spangen“, das sind die Seelilien-Stielglieder imOberen Muschelkalk des Stadtberges, der Name der Stadt Spangenberg wird auf diese Gesteinseinsprenglinge zurückgeführt]

- $\square \bullet$ Hieke, Werner (1967): Feinstratigraphie und Paläogeographie des Trochitenkalkes zwischen Leinetal-Graben und Rhön. - Geologica et palaeontologica, 1: 57-86, 35 Abb., 4 Tab.; Marburg/L.

$\square$ Holzapfel, Martin (1998): Die allochthonen Triasschollen bei Hundelshausen, Nordhessen geologische Kartierung, Beschreibung und Deutung. - Diss. Univ. Würzburg [unveröff.]; XL, 79 S. (18), Ill., graph. Darst., Kt.; Würzburg

$\square$ Holzapfel, Martin (2000): Die allochthonen Triasschollen bei Hundelshausen, Nordhessen. - Ber. Naturhist. Ges. Hannover, 142: 7-77, 10 Abb., 6 Tab., 2 Kt.; Hannover

-Horn, Manfred (1991): Buntsandstein und Muschelkalk am Westrand der Hessischen Senke (Exkurison H am 6. April 1991). [112. Jahresversamml. d. Oberrhein. Geol. Vereins 1991 in Bad Wildungen]. Jber. Mitt. Oberrhein. Geol. Vereins, N.F., 73: 155 - 176, 5 Abb., 1 Tab.; Stuttgart

- Humboldt, Alexandre de [Humboldt, Alexander von](1823): Essai géognostique sur le gisement des roches dans les deux hémisphères. - VIII, 379 S.; (Levrault) Paris - Strasbourg [darin : S. 274-275 Muschelkalk (Calcaire coquiller, Calcaire de Goettingue) Bezug a. Verbreitung i. d. Umgebung v. Göttingen und petrograph. Besonderheiten]

-Jahnke, Hans (1966): Beobachtungen an einem Hartgrund (Oberkante Terrebratelbank mu T 2 bei Göttingen). - Der Aufschluss, 17: 2 - 5, 3 Abb.; Göttingen

OJanson, Johann (1957): Die Mächtigkeit des Buntsandsteins und des Muschelkalkes im Nordwestteil des Thüringer Beckens auf Grund von Tiefbohrungen, Tagesaufschlüssen und Schachtprofilen. Dipl.-Arb. [unveröff.] Bergakademie Freiberg/Sa. 1957; 47 S.

Referat in: Geologie, $\underline{\mathbf{8}}(2): 213$; Berlin 1959

口0•Jubitz, Karl-Bernhard (1969): Beziehungen zwischen Stoffbestand und Bauformen im Tafeldeckgebirge. Methodische Gesichtspunkte und Probleme moderner tektonischer Grundlagenforschung im germanotypen Deckgebirge junger Tafeln. - 20 Jahre Deckgebirgsforschung 
im Gebiet der DDR. - Geologie, $\underline{\mathbf{1 8}}(8)$ : 911-945, 3 Abb., 1 Taf.; Berlin

[darin Abb. 3: Mächtigkeitskarte Terebratelbänke (mu) in Thüringen unter randlicher Einbeziehung v. WMK, NIE]

QKaiser, Erich \& Naumann, Ernst (1905): Trias am Hainich. Diluvium in Nordwest-Thüringen. - Jb. Preuß. Geol. Landesanst., $\underline{23}$ (f. 1902): 641-659; Berlin

Referat in: N. Jb. Mineral. etc., 1905 (Bd. II): 447-448 (Wüst); Stuttgart

Referat in: Mitt. Geogr. Ges. i. Thür., 23: 51 (E. Schütze); Jena 1905

[Bericht über Aufnahmearbeiten zur Geologischen Karte von Preußen und benachbarten

Bundesstaaten 1901,1902 a. Bl. Langula, [Bad] Langensalza]]

-0・Kleinsorge, Hubert (1935): Paläogeographische Untersuchungen über den Oberen Muschelkalk in Nord- und Mitteldeutschland. - Mitt. Geol. Staatsinstitut Hamburg, 15: 57-107, 12 Abb., 1 Taf.; Hamburg

[Paläogeographische Kt. m. Bezug auf Südniedersachsen, Nordhessen, Westthüringen: Profile Volkenroda, Bad Langensalza-Ufhoven]

-Koenen, Adolf v. (1893): Wellenkalk aus dem Hedemündener Wald. - Z. dt. geol. Ges., 45 (1893): 554//; Berlin

[Kurze Mitteilung über Sedimentstruktur; möglicherweise subaquatische Rutschung]

$\square$ Kramm, Elmar (1997): Stratigraphie des Unteren Muschelkalks im Germanischen Becken. - Geologica et palaeontologica, 31: 215-234, 10 Abb., 2 Tab., 3 Taf.; Marburg

[Profile Hedemünden/Gertenbach; Treffurt/Heldrastein; Sontra/Mitterode]

$\square$ Laemmlen, Manfred (1958): Ein Buntsandstein-Muschelkalkprofil bei Hausen am Südwestabhang des Hohen Meißners in Nordhessen. - Notizbl. Hess. L.-A. Bodenforsch., 무: 215 - 240, 3 Abb.; Wiesbaden

-Lang, Heinrich Otto (1876): Über die Absonderung des Kalksteins von Elliehausen bei Göttingen. Z. dt. geol. Ges., 27: 842-853, Taf. XXIV; Berlin

Referat in: N. Jb. Mineral. etc., 1876: 666 (Referate); Stuttgart

OLangbein, Rolf \& Seidel, Gerd (1995): Muschelkalk [in Thüringen]. - In: Seidel, Gerd [Hrsg.]: Geologie von Thüringen. - 1. Aufl.; S. 317-331, 6 Abb., 3 Tab.; Stuttgart 1995

OLangbein, Rolf \& Seidel, Gerd (2003): Muschelkalk [in Thüringen]. - In: Seidel, Gerd [Hrsg.]: Geologie von Thüringen. - 2., neu bearb. Aufl.; S. 342-357, 6 Abb., 3 Tab.; Stuttgart 2003

OLangenhan, Oskar (1901): Der Mittlere und Obere Muschelkalk des Seebergs mit ihren Versteinerungen. - S. 52-54; [Hrsg. Naturwiss. Verein z. Gotha] (Thienemann) Gotha 1901

$\square$ Ludwig, Otto (1953): Im Muschelkalk des Ringgaus. - Werra-Rundschau, 1953; Nr. 239 v. 14.10.1953, S. 7; Eschwege

-Lukas, Volker (1986): Feinstratigraphische, sedimentologisches und tektonische Untersuchungen im Hersfelder Graben. - Dipl.-Arb. [unveröff.] Univ. Gießen, 139 S., 20 Abb.; Gießen

$\square$ Lukas, Volker (1989): Sedimentologie, Paläogeographie und Diagenese der Terebratel-Bänke (Unterer Muschelkalk, Trias) Hessens. - Diss Univ. Gießen [unveröff.] 202 S., Ill., graph. Darst., Kt.

-Lukas, Volker (1992): Zur Diagenese der Karbonate des Unteren Muschelkalk (Trias). - N. Jb. Geol. Paläont., Abh., 185(1): 85-113, 11 Abb., 1 Tab.; Stuttgart

-Lukas, Volker (1991): Die Terebratel-Bänke (Unterer Muschelkalk, Trias) in Hessen - ein Abbild kurzzeitiger Faziesänderungen im westlichen Germanischen Becken. - Geol. Jb. Hessen, 119: 119-175, 
11 Abb., 1 Tab., 3 Taf.; Wiesbaden

[Untersuchungen zwi. Göttingen und Würzburg; Bezug auf Bohrprofile im Werra-Meißner-Kreis]

-Lukas, V.; Wenzel, B. \& Rösing, F. (1988): Sedimentologisches Modell einer Rinne im Unteren Muschelkalk (Trias) Nordhessens. - Geol. Jb. Hessen, 116: 253 - 259, 3 Abb.; Wiesbaden

[Bl. 4726 Grebendorf]

QMengel, Gerhard \& Zimmermann, Erich (1937): Über den Oberen Muschelkalk bei Mühlhausen und den Unteren Keuper bei Langensalza. - Beitr. Geol. Thür., 4: 1-26, 2 Abb.; Jena

QMerz, G. (1978): Zur Petrographie, Stratigraphie, Paläogeographie und Hydrogeologie des Muschelkalkes (Trias) im Thüringer Becken. - Z. geol. Wiss., 15: 457 - 473, 9 Abb., 2 Tab.; Berlin

OMüller, A.H. (1950): Stratonomische Untersuchungen im Oberen Muschelkalk des Thüringer Beckens. - Geologica, 4; 74 S., 10 Abb., 9 Tab., 11 Taf.; Berlin

[Untersuchungen u.a. Bl. 4728 Mühlhausen, Bl. Lengenfeld (4727 Küllstedt), Bl. Ebeleben, Schönberg b. Treffurt, Kaltenohmfeld b. Worbis]

$\square$ Müller, Beate (1984): Mikrofazies des Trochitenkalkes im Bereich des Netragrabens und des Ringgaues - Nordhessen. - Dipl.-Arb. [unveröff.] Fachber. Geowiss. FU Berlin, 117 S.

-Nadjafi, Mehdi (1979): Feinstratigraphische und paläogeographische Untersuchungen im Unteren Muschelkalk zwischen Hannoversch Münden und Braunschweig. - Clausthaler geol. Abh., $\underline{33}$; 101 S., 2 Abb., 5 Tab., 14 Taf., 5 Bildtaf.; Clausthal-Zellerfeld - zgl. Diss. TU Clausthal 1979 [darin Aufschl. i. Lkr. Göttingen]

QNaumann, Ernst (1913): Drei Muschelkalkprofile und ein Grenzprofil zwischen Muschelkalk und Keuper aus Thüringen. - Mitt. Geogr. Ges. (f. Thüringen), 31: 164-171; Jena [darin: Niederdorlaer Holz, Elzenberg b. Diedorf, Bahnhof Diedorf]

$\square$ Naumann, Ernst (1924): Bemerkungen über die oberen Ceratitenschichten in den Profilen von Weimar, am Meißner und von Hameln. - Jb. Preuß. Geol. Landesanst., 44 (f. 1923): 208-216; Berlin Referat in: N. Jb. Mineral. etc., Abt B, 1926 (Bd. I): 40 (A. Bentz); Stuttgart

-Naumann, Peter (1995): Der Muschelkalksteinbruch bei Lamerden - ein besonderer Aufschluß in Nordhessen. - Geol.-mineral. Mitt. Nordhessen, 7; 18 S., Abb.; (Selbstverlag Peter Naumann) Hofgeismar

$\square$ Neuweiler, F.; Peckmann, J. \& Ziems, A. (1999): Sinusoidally deformed veins („Sigmoidalklüftung“) in the Lower Muschelkalk (Triassic, Anisian) of Central Germany: sheet injection structures defomed within the shallow subsurface. - N. Jb. Geol. Paläont., Abh., [D. Meischner-Festschrift) $\underline{214}$ (1/2): 129-148, 12 fig., 1 tabl.; Stuttgart [darin: Aufschluß a. d. „Boyneburg“ Bl. 4826 Eschwege]

QPätz, H. (1965): Zur Stratigraphie des Muschelkalks der Forstberg-Antiklinale bei Mühlhausen nach Bohrergebnissen. - Geologie, 14(7): 840-850, 5 Abb.; Berlin

OPatzelt, Gerald (1994): Der Bereich der Schaumkalkbänke (Muschelkalk) im Gebiet vom Hainich bis an den Dün. - Mühlhäuser Beitr., 17: 5 - 16, 4 Abb.; Mühlhausen

QPatzelt, Gerald (1996): Der mittlere Wellenkalk und der Bereich der Terebratelbänke in NordwestThüringen. - Mühlhäuser Beitr., 19: 9 - 18, 5 Abb.; Mühlhausen

口Patzelt, Gerald (1995): Der obere Wellenkalk in Nordwest-Thüringen. - Mühlhäuser Beitr., 18: 13-20, 3 Abb.; Mühlhausen 
OPatzelt, Gerald (1999): Eine geologische Revisionskartierung im Bereich der Eichenberg-Saalfelder Störungszone nordwestlich von Lengenfeld unterm Stein (Eichsfeldkreis). - Mühlhäuser Beitr., 22: 5 15, 4 Abb.; Mühlhausen

OPatzelt, G. (2002): Einschnitt der ehemaligen Bahntrasse zwischen Heyerode und Diedorf - Unterer Muschelkalk (Jena-Formation), Trochitenkalk und untere Ceratitenschichten (Meißner-Formation) Exkursionsführer Die Geologie von Nordwest-Thüringen - 12. Jahreshauptversamml. [Thüringer Geologischen Vereins] (Vortrags- und Exkursionstagung) vom 25. bis 26. Mai 2002 in Mühlhausen; S. 35-38; Jena

-Paul, Josef \& Franke, Wolfgang (1977): Sedimentologie einer Transgression: Die Röt/MuschelkalkGrenze bei Göttingen. - N. Jb. Geol. Paläont., Mh., 1977: 148-177, 7 Abb., 3 Tab.; Stuttgart [Stbr. Str. Sudheim-Suterode]

-Rebers, Hartmut (1987): Oberer Muschelkalk und Unterer Keuper im Einschnitt der DBNeubaustrecke Hannover-Würzburg (km 105,600 - 108,420) südlich Olenhusen bei Göttingen (Trias, südliches Niedersachsen). - Dipl.-Arb. Teil 1 [unveröff.] Univ. Göttingen 1987; 86 S.

$\square$ Röhling, Heinz-Gerd; Stollhofen, Harald \& Tietze, Klaus-Werner (2002): Trias-Exkursion I Buntsandstein zwischen Hannover und Würzburg. - In: Niebuhr, Birgit [Hrsg.]: GEO 2002 Planet Erde: Vergangenheit, Entwicklung, Zukunft. 1.-5. Oktober 2002 in Würzburg Exkursionsführer; hier: S. 5-28; Schriftenr. Dt. Geol. Ges., 22; 88 S., zahlr. Abb.; Hannover 2002 [Stop 5: Sandgrube am Wienberg, Stbr. Ortsausg. Neuerode; Sandgrube Degenhardt a.d. Str. Neuerode-Kella]

-Rösing, Franz (1953): Eine präoligozäne Doline im Unteren Muschelkalk des oberen Ahnetales bei Kassel. - Notizbl. Hess. L.-A. Bodenforsch., 81: 195-198, 2 Abb.; Wiesbaden

$\square$ Schmidt, Bernd (1991): Stratigraphie und Tektonik der Umgebung von Hessisch LichtenauHirschhagen (Nordhessen) Blatt Nr. 4724 Großalmerode. - Geol. Abh. Hessen, 94; 61 S., 6 Abb., 1 Taf., 1 Kt.; Wiesbaden

-Schmidt, Hermann (1928): Exkursion nach Diemarden und Bremke (Muschelkalk und Buntsandstein). [Tagung der Paläontologischen Gesellschaft in Göttingen - 29. September bis 4. Oktober 1926]. Paläont. Z., 9: 2-4, 2 Abb.; Berlin

$\square \bullet$ Schüller, Manfred (1967): Petrographie und Feinstratigraphie des Unteren Muschelkalkes in Südniedersachsen und Nordhessen. - Sedimentary Geol., 1: 148 - 401, 23 Abb., 7 Abb., 1 Taf. (3 Abb.); Amsterdam - auch als Diss. Univ. Kiel 1965; 145 gez. Bl., Anh., Anl. [u.a. Gertenbach, Hedemünden, Dransfeld]

-Schulz, Max Gotthard (1972): Feinstratigraphie und Zyklengliederung des unteren Muschelkalks in Nordhessen. - Mitt. Geol. Paläont. Inst. Univ. Hamburg, 41: 133-170, 2 Abb., 6 Tab., 4 Profil-Taf.; Hamburg [Umgebung Liebenau]

$\square$ Schwarz, Helmut (1952): Die Pflanzenwelt des Trimberges. - Das Werraland, 4(2): 25-26, 2 Abb.;

Eschwege

[darin kurze Erläuterung zur Geologie der Trimberg-Scholle]

OSeidel, Gerd (1965): Zur Ausbildung des Muschelkalks in NW-Thüringen. - Geologie, 14(1): 58-63, 3 Abb.; Berlin [Profile Bohrungen Billeben, Küllstedt]

oSeidel, Gerd [Autor]; Langbein, Gerd [Beitr.] (1974): Muschelkalk [in Thüringen]. - In: Hoppe, Walter \& Seidel, Gerd [Hrsg.]: Geologie von Thüringen [Bezirke Erfurt, Gera, Suhl]. - S. 609-633, Abb. 107-112, Tab. 67-72, Photo 82-84; (Haack) Gotha-Leipzig 1974 
-Seppelt, Stephan (2004): Sedimentologie und Paläontologie des Unteren Muschelkalks im Profil Forststeinbruch Herberhausen (Göttinger Wald). - Bachelorarbeit [unveröff.] Geowiss. Zentrum Univ. Göttingen; II, 27,XX S. + 1 CD-Rom.

-Stein, Volker (1968): Stratigraphische Untersuchungen im Unteren Muschelkalk Südniedersachsens. Z. dt. geol. Ges., 117: 819 - 828, 1 Abb., 1 Tab.; Hannover

[Untersuch. a. Bl. 4325 Nörten-Hardenberg, 4324 Hardegsen]

QSitte, J. (1983): Limburgitgang in der Wellenkalk-Folge - ein geologisches Naturdenkmal des Kreises

Eisenach. - Landsch.Pflege u. Natschutz. Thüringen, 20 (1): 23-25; Jena

OStammeyer, P. (1965): Feinstratigraphische Untersuchungen im Unteren Muschelkalk von NWThüringen (Eichsfeld, Hainich und westlicher Dün). - Dipl.-Arb. [unveröff.] Humboldt-Univ. Berlin; Berlin

-Stein, Volker (1966): Der Untere Muschelkalk zwischen dem Göttinger Wald und dem Elfass. - Wiss. Arbeit f. d. 2. Staatsprüfung f. Geologen - Niedersächsisches Landesamt für Bodenforschung, Hannover; 74 S., 2 Beil.

-Ulrichs, Max \& Vath, Ullrich (1990): Zur Ceratiten-Stratigraphie im Oberen Muschelkalk (Mitteltrias) bei Göttingen (Südniedersachsen). - Geol. Jb. Hessen, 118: 127-147, 1 Abb., 1 Tab., 7 Taf.; Wiesbaden [ICE-Neubaustrecke Göttingen-Kassel]

-Vath, Ullrich (1988): Geologie des Ost-Randes der Dransfelder Hochfläche zwischen Lenshausen und Deiderode, südwestlich von Göttingen. - Dipl.-Arb. [unveröff.] Univ. Göttingen, 92 S., 24 Abb, 9 Beil.

$\square$ Wagner, Georg (1920): Beiträge zur Kenntnis des oberen Hauptmuschelkalkes von Mittel- und Norddeutschland. - Z. dt. geol. Ges., 71 (f. 1919): 80-103, 3 Abb.; Berlin [darin S. 87-91: Weserland: Meißner]

OWeber, Hans \& Kubald, P. (1951): Der Obere Muschelkalk an der Autobahn bei Eisenach. Hallesches Jb. Mitteldt. Erdgeschichte, 1(3): 124 - 131; Halle

OWeber, Hans \& Kubald, P. (1955): Der Mittlere Muschelkalk an der Reichsautobahn bei Eisenach. Beitr. Geol. Thür., $\underline{8}:$ 167-189; Frankfurt/Main

-Wilfrath, M. (1934): Strömungserscheinungen im Wellenkalkmeer. - Z. dt. geol. Ges., $\underline{86}$ : 265 - 285, 3 Abb., 2 Taf.; Stuttgart

[Großregionale Betrachtung der Sedimente des Unteren Muschelkalks in Deutschland; Genese von Fossiltrümmerbänken, Konglomeratbänken, Oolithbänken]

$\square$ Woyzechowski, Sonja (1984): Biofazies des Trochitenkalkes im Bereich des Netragrabens und des Ringgaues (Nordhessen). - Dipl.- Arb. [unveröff.] Fachber. Geowiss. FU Berlin 1984

-Wunderlich, Hans Georg (1964): Die Grenzschichten Muschelkalk-Keuper bei Göttingen. - N. Jb. Geol. Paläont. Mh., 1964: 204-211; Stuttgart

\subsection{Keuper}

-Anders, Carsten (1998): Oberer Muschelkalk und Unterer Keuper in der Bohrung 10 Deiderode (Trias, südliches Niedersachsen). - Die Geologie beiderseits der Arenshäuser Verwerfung, südlicher 
Leinegraben, nördlich Kirchgandern und Arenshausen, West-Thüringen, Süd-Niedersachsen (TK 25: 4625 Blatt Witzenhausen). - Dipl.-Arb. /Dipl.-Kart. [unveröff.] Univ. Göttingen, 65,33 Bl., 2 Beil.

Sonntags-Ausflug im Dreiländereck Hessen - Niedersachsen - Thüringen. - 159 S., 111 Fotos, 34 Kt., 1 Zeit-Taf; (LSRB-Verlag, Landschaftskundlicher-Studien-Reisebuch-Verlag) Witzenhausen [zahlreiche Ausflugstipps, auch zu einem Keuper-Geotop: Ziel 34 (Eichenberg)]

-Arp, G.; Bielert, F.; Hoffmann, V.-E. \& Löffler, Th. (2005): Palaeoenvironmental significance of lacustrine stromatolithes of the Arnstadt Formation („Steinmergelkeuper“, Upper Triassic, NGermany). - Facies, 51: 433-455, 13 fig., 2 tab. + tab. A; Berlin-Heidelberg

-Becker, R.E. \& Lämmlen, H. (1988): Geologische Verhältnisse im Altmorschen-Beisheimer Grabenknie bei Wichte in Nordhessen. - Mit Detailprofilen aus Muschelkalk und Keuper. - Geol. Jb. Hessen, 116: 45-104, 4 Abb., 3 Tab., 3 Taf.; Wiesbaden

OBeutler, Gerhard (1991): Zur Frage der Eichsfeldschwelle im Keuper. - Z. geol. Wiss., 19 (1): 79-89, 5 Abb.; Berlin [darin: Ohmgebirgsgraben]

OBeutler, Gerhard (1998): Excursion F - Stratigraphy, Sedimentary Environtments and Cyclic Deposition of the Keuper in the Southeastern of the Germanic Basin (Thuringia) - (With contributions by Werner Ernst, Axel Kellner \& Joachim Schubert). - In: Bachmann, G. H.; Beutler, G. \& Lerche, J. [eds.] (1998): Excursions on the International Symposium on the Epicontental Triassic - Halle (Saale) - September 1998. - Institut f. Geologische Wissenschaften und Geiseltalmuseum Martin-Luther-Universität Halle-Wittenberg. - Hallesches Jb. Geowiss., Reihe B, Beih., ㅁ: 141-152, 8 Fig.; Halle (Saale)

[darin: Seeberg b. Gotha]

OBeutler, Gerhard \& Schubert, Joachim (1987): Fazielle Entwicklung des Mittleren Lettenkeupers im Thüringer Becken. - Z. geol. Wiss., 15(4): 475-484, 9 Abb.; Berlin [auch Westthüringen]

- $\square \bullet$ Beutler, G.; Hauschke, N.; Nitsch, E. \& Vath, U. [Red.](2005): Stratigraphie von Deutschland IV: Keuper. - Bearb. v. d. Arbeitsgruppe Keuper der Subkommission Perm-Trias der DSK [Deutschen Stratigraphischen Kommission]. - Courier Forsch.-Inst. Senckenberg, 253; 296 S., 64 Abb., 50 Tab., 2 Taf.; [Hrsg.: Deutsche Stratigraphische Kommission] Frankfurt/M.

$\square$ Brede, Rainald; Hottenrot, Martin \& Schuster, Carmen (1993): Zur Keuper-Stratigraphie im Netraer Graben Bl. 4926 Herleshausen, Nordhessen/Thüringen. - Geol. Jb. Hessen, 121: 61-81, 3 Abb., 2 Taf.; Wiesbaden

-Busse, Erwin \& Rösing, Franz (1955): Über Muschelkalk-, Keuper- und Liasschollen im Stadtgebiet von Kassel. - Notizbl. Hess. L.-A. Bodenforsch., $\underline{\mathbf{8 3}}$ (= 6. F., H. 5): 198-204, 1 Abb.; Wiesbaden

Q๑Credner, Heinrich (1860): Über die Grenz-Gebilde zwischen dem Keuper und dem Lias am Seeberg bei Gotha und in Norddeutschland überhaupt. - N. Jb. Mineral. etc., 1860: 293-319; Stuttgart [auch Lias bei Eisenach, Göttingen]

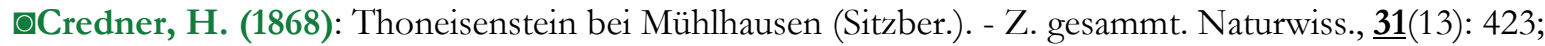
Berlin [Keuper]

ODeubel, F. (1930): Halbtagsexkursion in das Keuper- und Juragebiet nordwestlich von Eisenach. Beitr. Geol. Thür., $\underline{\mathbf{1}}(6)$ : 84-86; Jena 
QDockter, Joachim (1974): Keuper [in Thüringen]. - In: Hoppe, Walter \& Seidel, Gerd [Hrsg.]: Geologie von Thüringen [Bezirke Erfurt, Gera, Suhl]. - S. 633-682, Abb. 113-120, Tab. 73-82, Photo 85-87; (Haack) Gotha-Leipzig 1974

ODockter, J.; Langbein, R.; Seidel, G.\& Unger, K.P. (1970): Die Ausbildung des Unteren und Mittleren Keupers in Thüringen. - Jb. f. Geol., $\underline{\mathbf{3}}$ (f. 1967): 145-191, 13 Abb., 7 Tab.; Berlin [Bhrgn. Alterngottern, Eisenach-Trenkelhof]

ODokter, Joachim; Langbein, Rolf [Beitrag](1995): Keuper [in Thüringen]. - In: Seidel, Gerd [Hrsg.]: Geologie von Thüringen. - 1. Aufl.; S. 332-362, 6 Abb., 3 Taf.; Stuttgart 1995

ODokter, Joachim; Langbein, Rolf [Beitrag](2003): Keuper [in Thüringen]. - In: Seidel, Gerd [Hrsg.]: Geologie von Thüringen. - 2., neu bearb. Aufl.; S. 357-391, 7 Abb., 4 Tab.; Stuttgart 2003

QDreyer, Dieter (1962): Zur Entstehung und Paläontologie der Bonebedlagen im Unteren Rhät Thüringens. - Freiberger Forschungshefte, Reihe C, 125: 127-143, 10 Abb., 6 Taf. (I-VI); Leipzig [Gebiet der Drei Gleichen, Rhönberg/Kallenberg, Gr. Seeberg b. Gotha]

口Ernst, W. (1985): Zur Geschichte der Erforschung des Rät und Lias Thüringens. - Wissenschaftl. Z.

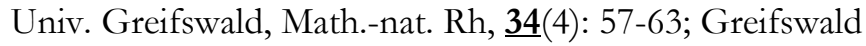

OErnst, W. (1989): Revision der stratigraphischen Einstufung rätoliassischer Sedimente im Creuzburger Graben bei Eisenach. - Wissenschaftl. Z. Univ. Greifswald, Math.-nat. Rh., $\underline{\mathbf{3 8}}(1 / 2):$ 78-84, 3 Abb., 2 Tab. Greifswald

QErnst, Werner (1992): Zur Geologie des Röhnberg-Rückens (Kreis Gotha). - Veröff. Naturkundemuseum Erfurt, Naturwiss. Rh., 11: 95-108 Abb.; Erfurt [Rhät-Lias]

OErnst, Werner (1994): Über den Rhät/Lias-Graben am Apfelstädt-Fluß zwischen Wechmar und Wandersleben (Kreis Gotha). - Veröff. Naturkundemuseum Erfurt, Naturwiss. Rh., 13: 49-59, 10 Abb.; Erfurt

OFrantzen, W. (1894): Bemerkungen über die Schichten des oberen Muschelkalkes und des unteren Keupers in dem Bereich der Messtischblätter Eisenach, Creuzburg und Berka. - Jb. Preuß. Geol. Landesanst., 12 (f. 1891): 179-192; Berlin Referat in: N. Jb. Mineral. etc, $\underline{1894}$ (Bd. I): 480 (A. Leppla); Stuttgart

OFritsch, K. v. (1870): Vorstudien über die jüngeren mesozoischen Ablagerungen bei Eisenach. - N. Jb. Mineral. etc., 1870: 385-416; Stuttgart

[Rhät, Lias]

QGeiger, Walter (1980): Zum Problem der eichsfeldischen Vorkommen an Unterem Keuper. - Ein zusammenfassender geologischer Text-Bilder-Beitrag. - Eichsfelder Heimathefte, (20. Jg.) 1980(3): 241-265, 11 Abb.; Worbis

口QGötz, Annette E. (1994): Feinstratigraphie des Unteren Muschelkalks und Tektonik am Südwestrand des Creuzburger Grabens (Bl. 4927 Creuzburg/Westthüringen). - Geol. Jb. Hessen, 122: 23-38; 9 Abb., 2 Tab., 1 Tf.; Wiesbaden

[Geol. Karte Keuperverbreitung Creuzburger Graben/Netratalgraben mit hessischen Anteilen, Angaben z. Stratigraphie Oberer Muschelkalk Ringgau]

-Grupe, O. (1907): Der untere Keuper in südlichen Hannover. - In: Festschrift für Adolf v. Koenen. Gewidmet von seinen Schülern zum 70. Geburtstage am 21. Maerz 1907. - XXXI, 515 S., 1 Portr., 20 Abb., 13 Taf., 1 Beil.; hier: S. 65-134, Taf. IV; (Schweizerbart) Stuttgart Referat in: N. Jb. Mineral. etc., 1908 (Bd. II): 83-84 (Stille); Stuttgart 
-Hoffmann, Veit Enno R. K. (2004): Sedimentologie und Paläontologie des Rhätkeupers der Tongrube Hottenrode (Ober-Trias, Landkreis Göttingen) an der Grenze zu Nordhessen. - Bachelor-Arbeit Univ. Göttingen 2004; 42 S.

- Jütte, H. (1985): Revisionskartierung des Keupers im Ostteil des Netra-Grabens. - Dipl.-Arb. [Dipl.Kart.?] [unveröff.] Ruhr-Univ. Bochum; 36 S., 7 Abb., 2 Tab.

OKellner, Axel (1998): Investigations in the Arnstadt Formation of Thuringia. - (International Symposium on the Epicontinental Triassic/Halle (Saale) - September 1998 - Abstracts). - Hallesches Jb. Geowiss., Reihe B, Beih., 5: 86-87, 1 fig.; Halle (Saale)

[Stratigraphie, Fazies Steinmergelkeuper]

$\square$ Kindermann, C. (1918): Der Keupergraben des Ringgaus. - N. Jb. Mineral., Beil.-Bd. 42: 547-609; Stuttgart [Stratigraphie, Tektonik]

OKlaua, Dieter (1969): Sedimentpetrographische Untersuchungen der Rhätsandsteine Thüringens. Geologie, $\underline{\mathbf{1 8}}$, Beih. $\underline{\mathbf{6 4}}$; 62 S. (1-62), 23 Abb, 15 Tab.; Berlin [Untersuchungen u.a. Raum Eisenach-Creuzburg]

OKlaua, Dieter (1996): Verwitterungsformen an thüringischen Rätsandsteinen. - Geowiss. Mitt. Thüringen, (Gedenkschrift zum 100. Geburtstag von Walter Hoppe) Beih. 포 217-239, 11 Abb.; Weimar [darin: Verwitterungsformen von Rät-Werktsteinen der Wartburg b. Eisenach]

-Mader, Detlief (1997): Paleoenvironmental evolution and bibliography of the Keuper (Upper Triassic) in Germany, Poland and other parts of Europe. - 1058 p., 19 fig., 25 tab., 34 pl. (337 photogr.); (Sven von Loga) Köln

OMengel, Gerhard \& Zimmermann, Erich (1937): Über den Oberen Muschelkalk bei Mühlhausen und den Unteren Keuper bei Langensalza. - Beitr. Geol. Thür., 4: 1-26, 2 Abb.; Jena

OMeinecke, Franz (1908): Neue Aufschlüsse im Keuper bei Eisenach. - Z. f. Naturwiss., $\underline{\mathbf{8 0}}$ (1/2): 135144; Leipzig

Referat in: Mitt. Geogr. Gesellschaft f. Thür., 28: 44; Jena 1910

OMöller, L. (1862): Die Lettenkohlengruppe Thüringens, im Allgemeinen und nach den Aufschlüssen bei Mühlhausen im Besonderen. - Z. gesammt. Naturwiss., 28(8/9): 189-196; Berlin Referat in: N. Jb. Mineral. etc., 1863: 494-495; Stuttgart

Q $\square$ Naumann, E. (1910): Beitrag zur Gliederung des Mittleren Keupers im nördlichen Thüringen. - Jb. Preuß. Geol. Landesanst., 28 (f. 1907): 549-579; Berlin

[Großegionale Betrachtung u.a. Bl. Netra/Herleshausen (Eichenberg b. Lüderbach); Bl. Creuzburg, Langensalza, Eisenach, Heiligenstadt]

ONaumann, Ernst (1959): Über einige Grenzprofile in der Trias bei Jena, Gotha und Thüringen. Geologie, $\underline{\mathbf{8}}(2)$ : 189-193, 1 Tab.; Berlin [Profil Buntsandstein Jena; Keuper-Profile Lkr. Göttingen; Keuperprofil Bornhagen/Thür. („Altes Holz"]

-Pflücker y Rico, Leonardo (1868): Das Rhät < die Rhätische Gruppe> in der Umgebung von Göttingen. - Diss. Univ. Göttingen; 38 S., 1 Taf.; (Starcke) Berlin; auch Z. dt. geol. Ges., 1868: 397432, Taf. VII; Stuttgart

OPicard, E. (1858): Ueber den Keuper bei Schlotheim in Thüringen und seine Versteinerungen. - Z. gesammt. Naturwiss., $\underline{11}(5):$ 425-436, Taf. IX ; Berlin 
OPutzer, Hanfrid (1938): Die Rät- und Liasablagerungen am Seeberg bei Gotha, am Rhönbergrücken und bei Eisenach. - Jen Z. Naturwiss., 71 (N.F. 64): 327 - 444, 14 Abb., 10 Taf.; Jena - zgl. Diss. Univ. Jena 1938

Referat in: N. Jb. Mineral. etc., Referate, 1938 (Bd. III): 1108-1109 (Rud. Richter)

- Rebers, Hartmut (1987): Oberer Muschelkalk und Unterer Keuper im Einschnitt der DB-

Neubaustrecke Hannover-Würzburg ( $\mathrm{km} \mathrm{105,600} \mathrm{-} \mathrm{108,420)} \mathrm{südlich} \mathrm{Olenhusen} \mathrm{bei} \mathrm{Göttingen} \mathrm{(Trias,}$ südliches Niedersachsen). - Dipl.-Arb. Teil 1 [unveröff.] Univ. Göttingen 1987; 86 S.

QReling, H. (1895): Das Gebiet der drei Gleichen, Wandersleben und Umgebung. - Beschreibung der geologischen Verhältnisse und deren Einfluß auf die Bodenbeschaffenheit und Oberflächengestalt. 23 S.; (Kahle) Dessau

-Rettberg, Herbert (1991): Kartierung des Keupers und Lias im Neubaugebiet von Weende Nord bei Göttingen (TK 25: 4425 Göttingen). - Dipl.- Kart. [unveröff.] Univ. Göttingen; 72,29 S., Abb., 3 Anl.; Göttingen

QRichter [-Bernburg], Gerhard (1936): Der Sedimentationsraum des Unteren Keupers zwischen Harz und Thüringer Wald. - Festschrift zum 60. Geburtstag von Hans Stille, 437 S., zahlr. Abb., 28 Taf; hier: S. 116 - 136, 2 Taf.; Stuttgart

Referat in: N. Jb. Mineral. etc., Referate, 1938 (Bd. III): 415 (E. Beyenburg); 1939 (Bd. II): 482-484 (Walter Fischer); Stuttgart

OSchäfer, Heinrich Friedrich (1901): Beiträge zur Kenntnis der Rhät- und Liasablagerungen des Grossen Seebergs bei Gotha. - In: Naturwissenschaftliches und Geschichtliches vom Seeberg. - S. 1935.; [Hrsg. Naturwiss. Verein z. Gotha) (Thienemann) Gotha 1901

OSchäfer, H. F. (1907): Ueber die Rhätablagerungen des Röhnberges, sowie das Liasvorkommen am Kallenberg und im Flußbett der Apfelstedt bei Wechmar i. Thür. - Z. f. Naturwiss., 78(6): 439-456; Stuttgart

-Schlüter, Petra (1992): Palynologie des Rhät-Lias-Grenzbereichs im Neubaugebiet von Weende-Nord bei Göttingen. - Dipl.-Arb. [unveröff.] Univ. Göttingen 1992; 105 S.

OSchröder, Eckart (1938): Zur Gliederung des mittleren Keupers in der Thüringer Mulde. - Beitr. Geol. Thür., $\underline{\mathbf{5}}$ (1): 34-41, 2 Abb.; Jena Referat in: N. Jb. Mineral. etc., Referate, 1940 (Bd. III): 13-14 (Walther Fischer); Stuttgart [Bezugnahme a. Langensalzaer Mulde]

ØTegetmeyer, August (1876): Beiträge zur Kenntnis des Keupers im nördlichen Thüringen. - Z. gesammt. Naturwiss., $\underline{47}$ (ges. Rh.) (N.F. 13): 405-491, Taf. 6, 7; Berlin

-Tornquist, Alexander J. H. (1892): Der Gypskeuper in der Umgebung von Göttingen. - Diss. Univ. Göttingen 1892; 38 S.; (Hofer) Göttingen

Referat in: N. Jb. Mineral. etc, $\underline{1893}$ (Bd. II): 134 (A. Leppla); Stuttgart

-Vath, Ulrich (1988): Stratigraphie und Fauna der Wasserbohrung Rosdorf bei Göttingen (Oberer Keuper, Lias). - Dipl.-Arb. Teil 1 [unveröff.] Univ. Göttingen 1988; 63 S.

-Vath, Ullrich (2005): Der Keuper im südlichen Niedersachsen bei Göttingen. - In: Beutler, G.;

Hauschke, N.; Nitsch, E. \& Vath, U. [Red.](2005): Stratigraphie von Deutschland - IV: Keuper. - Bearb. v. d. Arbeitsgruppe Keuper der Subkommission Perm-Trias der DSK [Deutschen Stratigraphischen Kommission]. - Courier Forsch.-Inst. Senckenberg, 253: 163-178, 2 Abb., 2 Tab.; Frankfurt/M.

$\square$ Vath, Ullrich (2005): Der Keuper in Nordost-Hessen. - In: Beutler, G.; Hauschke, N.; Nitsch, E. \& Vath, U. [Red.](2005): Stratigraphie von Deutschland - IV: Keuper. - Bearb. v. d. Arbeitsgruppe 
Keuper der Subkommission Perm-Trias der DSK [Deutschen Stratigraphischen Kommission]. Courier Forsch.-Inst. Senckenberg, 253: 179-191, 1 Abb., 4 Tab.; Frankfurt/M.

OVath, Ullrich (2005): Der Keuper im Thüringer Becken und im Thüringischen Grabfeld. - In: Beutler, G.; Hauschke, N.; Nitsch, E. \& Vath, U. [Red.](2005): Stratigraphie von Deutschland - IV: Keuper. - Bearb. v. d. Arbeitsgruppe Keuper der Subkommission Perm-Trias der DSK [Deutschen Stratigraphischen Kommission]. - Courier Forsch.-Inst. Senckenberg, 253: 192-202, 1 Abb., 3 Tab.; Frankfurt/M.

OWeber, Hans (1926): Der Gipskeuper der Wasserkraftanlage Spichra. - Jb. Preuß. Geol. Landesanst., $4 \underline{6}$ (f. 1925): 528-539, 1 Abb.; Berlin

OWeber, Hans (1962): Neue Aufschlüsse im Unteren und Mittleren Keuper bei Creuzburg an der Werra. - Hallesches Jb. mitteldt. Erdgeschichte, 4: 61-68, 1 Abb., 3 Profile; Berlin [Aufschlüsse S'Spichra]

OWeber, Hans \& Kubald, P. (1955): Der Kohlenkeuper an der Reichsautobahn bei Eisenach. - Beitr. Geol. Thür., $\underline{8}:$ 190-220, 2 Taf.; Frankfurt/Main

-Weber, Hellmar (1991): Herkunft und Sprachgebrauch des Wortes Lettenkeuper. - Der Aufschluss, $\underline{42}$ 231-237; Heidelberg

$\square$ Wolburg, Johannes (1969): Die epirogentischen Phasen der Muschelkalk- und Keuper-Entwicklung Nordwest-Deutschlands - mit einem Rückblick auf den Buntsandstein. - Gesamttitel: Zur epirogentischen Geschichte des Saxonikums, 2. - Geotektonische Forschungen, 32; 97 S., 32 Abb. i. Text, 7 Abb. a. Beil.; Stuttgart [u.a. Buntsandstein-Profil Wehretal-Hoheneiche (Detfurth-Folge)]

-Wunderlich, Hans Georg (1964): Die Grenzschichten Muschelkalk-Keuper bei Göttingen. - N. Jb. Geol. Paläont. Mh., 4: 204-211; Stuttgart

\subsubsection{Jura}

- $\square$ ○ीApel, Jürgen \& Rüppel, Heidi [Verfass. u. Hrsg.] (2005): Raus in die Natur - Tipps für den Sonntags-Ausflug im Dreiländereck Hessen - Niedersachsen - Thüringen. - 159 S., 111 Fotos, 34 Kt., 1 Zeit-Taf.; (LSRB-Verlag, Landschaftskundlicher-Studien-Reisebuch-Verlag) Witzenhausen [zahlreiche Ausflugstipps, auch zu einem Jura-Geotop: Ziel 35 (Jura/Eichenberg)]

OBauer, Max (1879): < Mittlerer Lias am Südabhange des grossen Seeberges bei Gotha]. - Z. dt. geol. Ges., 31: 782-785 (Briefl. Mitt.); Berlin

-Baumgarte, D.; Busse, E. \& Horn, M. (1980): Muschelkalk und Lias des Homburg-Grabens (Nordhessen). - Geol. Jb. Hessen, 108: 121 - 138, 4 Abb.; Wiesbaden

-Bornemann [sen.], J. G. (1854): Über die Liasformation in der Umgebung von Göttingen und ihre organischen Einschlüsse. Diss. Univ. [unveröff.]Göttingen 1854; 77 S., 4 Taf.; (Bornemann) Berlin

-Busse, Erwin \& Rösing, Franz (1955): Über Muschelkalk-, Keuper- und Liasschollen im Stadtgebiet von Kassel. - Notizbl. Hess. L.-A. Bodenforsch., $\mathbf{8 3}$ (= 6. F., H. 5): 198-204, 1 Abb.; Wiesbaden

QCredner, Heinrich (1843): Ablagerungen des Lias in der Umgebung von Gotha und Eisenach. - N. Jb. Mineral., 1843: 330 - 332 (Briefl. Mitt.); Stuttgart 
Q Credner, Heinrich (1860): Über die Grenz-Gebilde zwischen dem Keuper und dem Lias am Seeberg bei Gotha und in Norddeutschland überhaupt. - N. Jb. Mineral. etc., 1860: 293-319; Stuttgart [auch Lias bei Eisenach, Göttingen]

QDeubel, F. (1930): Halbtagsexkursion in das Keuper- und Juragebiet nordwestlich von Eisenach. Beitr. Geol. Thür., 1 (6): 84-86; Jena

QErnst, Werner (1970): Der Lias am NE-Abhang des Röhnbergrückens (südöstlich von Gotha). Geologie, 19 (4): 405-411, o. Abb.; Berlin [Stratigraphie, Tektonik, Paläogeographie]

OErnst, W. (1985): Zur Geschichte der Erforschung des Rät und Lias Thüringens. - Wissenschaftl. Z. Univ. Greifswald, Math.-nat. Rh, 34(4): 57-63; Greifswald

OErnst, W. (1987): Neue Ergebnisse zur Fazies, Ammoniten-Fauna, Biostratigraphie und Paläogeographie des thüringischen Lias. - Hallesches Jb. Geowiss., 12: 15-28; Gotha [Untersuchte Lokalitäten: Eisenach u.a.O.]

QErnst, W. (1989): Revision der stratigraphischen Einstufung rätoliassischer Sedimente im Creuzburger Graben bei Eisenach. - Wissenschaft. Z. Univ. Greifswald, Math.-nat. Rh., $\underline{\mathbf{3 8}}(1 / 2)$ : 78-84, 3 Abb., 2 Tab.; Greifswald

QErnst, Werner (1992): Zur Geologie des Röhnberg-Rückens (Kreis Gotha). - Veröff. Naturkundemuseum Erfurt, Naturwiss. Rh., 11: 95-108 Abb.; Erfurt [Rhät-Lias]

OErnst, Werner (1993): Fazies und paläogeographische Stellung des thüringischen Lias. - Veröff. Naturkundemuseum Erfurt, Naturwiss. Rh., 12: 4-13, 3 Abb.; Erfurt

OErnst, Werner (1994): Über den Rhät/Lias-Graben am Apfelstädt-Fluß zwischen Wechmar und Wandersleben (Kreis Gotha). - Veröff. Naturkundemuseum Erfurt, Naturwiss. Rh., 13: 49-59, 10 Abb.; Erfurt

OErnst, Werner (1994): Zur Bedeutung reliktischer Gesteinsvorkommen für die paläogeographische Rekonstruktion - dargestellt an Beispielen aus dem deutschen Lias. - Beitr. Geol. Thür., N.F., 1: 6584, 3 Abb.; Jena [Bezug a. Vorkommen i. Westhüringen, Eichenberg, Schwarzwald]

QErnst, Werner (1995): Jura [in Thüringen]. - In: Seidel, Gerd [Hrsg.]: Geologie von Thüringen. - 1. Aufl.; S. 362-369, 3 Abb., 1 Tab., 1 Taf.; Stuttgart 1995

QErnst, Werner (2003): Jura [in Thüringen]. - In: Seidel, Gerd [Hrsg.]: Geologie von Thüringen. - 2., neu bearb. Aufl.; S. 392-399, 3 Abb., 1 Tab., 1 Taf.; Stuttgart 2003

QFritsch, K. v. (1870): Vorstudien über die jüngeren mesozoischen Ablagerungen bei Eisenach. - N. Jb. Mineral. etc., 1870: 385-416; Stuttgart [Rhät, Lias]

-Glaessner, Reinhard (1913): Beiträge zur Kenntnis der Hessischen Jura-Relikte. - Abh. u. Ber. Vereins f. Naturkunde zu Kassel, 53: 51 - 144; Kassel

EGumprecht, F. E. (1842): Geognostisches über die Formationen der Gothaer Gegend im Vergleich mit anderen. - N. Jb. Mineral., 1842: 710-719; Stuttgart [darin: Lias bei Eisenach] 
-Hoffmann, Karl \& Horn, Manfred; Bloos, Gert [Beitrag](1983): Zur Stratigraphie des Lias (Hettangium-Unteres Pliensbachium) im Volkmarser Graben... mit einem Beitrag von Gert Bloos. Geol Jb. Hessen, 111: 165-202, 3 Abb., 1 Tab.; Wiesbaden

OKlaua, Dieter (1974): Jura [in Thüringen]. - In: Hoppe, Walter \& Seidel, Gerd [Hrsg.]: Geologie von Thüringen [Bezirke Erfurt, Gera, Suhl]. - S. 682-691, Abb. 71, Tab. 83 u. 84, Photo 88; (Haack) Gotha-Leipzig 1974

Q Kölbel, Heinrich (1967): Die Paläogeographie des Jura im Nordteil der DDR in Beziehung zu den Nachbargebieten. - Ber. Dt. Ges. geol. Wiss., Reihe A, 12(3/4): 259-288, 14 Abb.; Berlin [Paläogeographische Karten unter Einbeziehung von Westthüringen und Südniedersachsen]

-Koenen, Adolf v. (1910): Exkursion nach dem Hainberg bei Göttingen am 2. April 1910. - Jber. Niedersächs. Geol. Vereins Hannover, $\underline{3}$ : XVIII; enthalten in: Jber Naturhistorischen Ges. z. Hannover, $\underline{\mathbf{3}}$; Hannover

Referat in: N. Jb. Mineral. etc., 1912 (Bd. I): 475 (Schöndorf); Stuttgart [Lias]

OKrause, Torsten (1992): Bericht über eine Grabung im Oberen Lias am Nordost-Abhang des Röhnberges bei Wandersleben (Thüringen). - Abh. Ber. Museums d. Natur Gotha, (17) 1992: 15-18, 3 Abb., 3 Taf.; Gotha

OKrause, Thorsten (1994): Vorläufige Mitteilung über das Ausstreichen von Mittleren Lias am Großen Seeberg bei Gotha. - Veröff. Naturkundemuseum Erfurt, Naturwiss. Rh., 13: 60-71, 1 Kt., 4 Taf.; Erfurt

-Kuchenbuch, Franz (1892): Das Liasvorkommen von Volkmarsen. - Jb. Preuß. Geol. Landesanst., $\underline{11}$ (f. 1890): 74-101 [Abh. behördenfremder Personen],Taf. IV.; Berlin

OKühn, Wolfgang; Langbein, Rolf \& Seidel, Gerd (1967): Zur Ausbildung des Lias und Räts bei Eisenach. - Jb. Geol., 1 (f. 1965): 249-262, 6 Abb., 2 Tab.; Berlin

-Langheinrich, Gunter (1966): Syndiagenetische Fossildeformation im unteren Lias (Hettangium) von Göttingen. - N. Jb. Geol. Paläont., Mh., 1966: 666-680, 5 Abb.; Stuttgart

$\square$ 일oesta, Friedrich (1884): Das Liasvorkommen von Eichenberg in Hessen in Beziehung auf allgemeine Verhältnisse des Gebirgsbaues in Nordwesten des Thüringer Waldes. - Jb. Preuß. Geol. Landesanst., 4 (f. 1883): 57-80, 4 Taf.; Berlin

Referat (Kurzfassung) in: N. Jb. Mineral. etc., 1886 2. Bd.): 63-65 (Ref. E. Dathé); Stuttgart [Saxonische Tektonik, Eichenberg-Gothaer-Graben]

OMüller, Wolfgang (1965): Lias $\varepsilon$ im Flußbett der Apfelstädt bei Wechmar (Meßtischblatt Gotha). Hallesches Jb. mitteldt. Erdgeschichte, $\underline{\mathbf{6}}$ (f. 1964): 18-20, Taf. II-IV (insges. 6 Bilder); Leipzig

OMüller, Wolfgang (1969): Neue Untersuchungsergebnisse über die Liassedimente am Röhnberg (Meßtischblatt Ohrdruf). - Abh. Ber. Museums d. Natur Gotha, [5] 1969: 23-26, 1 Taf.; Gotha

-Murawski, Hans (1952): Exkursion in die Ziegeleigrube der Fa. Levin in Göttingen und in die Basaltsteinbrüche der Bramburg bei Adelebsen. - Z. dt. geol. Ges., 103: 423-426, 2 Abb.; Hannover

-Naumann, Peter (1993): Ein neues Liasvorkommen bei Hofgeismar. - Hessischer Gebirgsbote, 94(1): 18; Melsungen

-Naumann, Peter (1999): Das Liasvorkommen bei Breuna-Niederlistingen. - Hessischer Gebirgsbote, $\underline{100}(3): 114 ;$ Melsungen 
-Peine, Karin (1992): Mikrofazielle Analyse der Grenzbank $\gamma-\partial$ (Jura/Lias) in Göttingen. - Dipl.-Arb. Teil 1 [unveröff.] Univ. Göttingen 1992; 137 S.

OPutzer, Hanfrid (1938): Die Rät- und Liasablagerungen am Seeberg bei Gotha, am Rhönbergrücken und bei Eisenach. - Jen Z. Naturwiss., 71 (N.F. 64): 327 - 444, 14 Abb., 10 Taf.; Jena - zgl. Diss. Univ. Jena 1938

Referat in: N. Jb. Mineral. etc., Referate, 1938 (Bd. III): 1108-1109 (Rud. Richter)

-Rachimow, Nadine (2007): Lithofazies und Foraminiferen-Assoziationen der Unterjura-Sedimente der Tongrube Hottenrode, Hessen. - Bachelor-Arbeit (unveröff.) Univ. Göttingen 2007, 49, IV Bl. [Hottenrode > Landkreis Göttingen, Niedersachsen]

OReling, H. (1895): Das Gebiet der drei Gleichen, Wandersleben und Umgebung. - Beschreibung der geologischen Verhältnisse und deren Einfluß auf die Bodenbeschaffenheit und Oberflächengestalt. 23 S.; (Kahle) Dessau

-Rettberg, Herbert (1991): Kartierung des Keupers und Lias im Neubaugebiet von Weende Nord bei Göttingen (TK 25: 4425 Göttingen). - Dipl.- Kart. [unveröff.] Univ. Göttingen; 72,29 S., Abb., 3 Anl.; Göttingen

OSchäfer, Heinrich Friedrich (1901): Beiträge zur Kenntnis der Rhät- und Liasablagerungen des Grossen Seebergs bei Gotha. - In: Naturwissenschaftliches und Geschichtliches vom Seeberg. - S. 1935.; [Hrsg. Naturwiss. Verein z. Gotha) (Thienemann) Gotha 1901

OSchäfer, H. F. (1907): Ueber die Rhätablagerungen des Röhnberges, sowie das Liasvorkommen am Kallenberg und im Flußbett der Apfelstedt bei Wechmar i. Thür. - Z. f. Naturwiss., 78(6): 439-456; Stuttgart

-Schlüter, Petra (1992): Palynologie des Rhät-Lias-Grenzbereichs im Neubaugebiet von Weende-Nord bei Göttingen. - Dipl.-Arb. [unveröff.] Univ. Göttingen 1992; 105 S.

OSeifert, Hermann (1940): Beobachtungen über Stratigraphie und Lagerungsverhältnisse des Lias bei Eisenach. - Beitr. Geol. Thür., ㅍ: 229-236, 1 Abb.; Jena

-Vath, Ulrich (1988): Stratigraphie und Fauna der Wasserbohrung Rosdorf bei Göttingen (Oberer Keuper, Lias). - Dipl.-Arb. Teil 1 [unveröff.] Univ. Göttingen 1988; 63 S.

OWagenbreth, Otfried (1961): Thüringer Jura und subherzyne Kreide ( Versuch eines paläogeographisch-tektonischen Vergleichs). - Geologie, 10 (1): 3-8, 4 Abb.; Berlin [darin: Lias-Vorkommen Eisenach, SE Gotha]

\subsubsection{Kreide}

QBornemann [sen.], J. G. (1852): Über die geognostischen Verhältnisse des Ohmgebirges bei Worbis. N. Jb. Mineral. etc., 1852: 1-34, 1 Abb., Taf. I,; Stuttgart

OGiebel, K. (1856): Das Kreidegebirge in Thüringen. - Z. gesammt. Naturwiss., ㅁ: 169-174; Berlin

QGiebel (1857): Herrn Bornemann’s Entdeckung der Kreideformation in Thüringen - Z. gesammt. Naturwiss., 9: 455-456; Berlin 
-Huckriede, Reinhold (1954): Über umgelagerte marine Kreide in Hessen. - N. Jb. Geol.Paläont., Mh., 1954: 351-361, 1 Abb.; Stuttgart

[Hessische Senke nördlich Schwalmstadt]

QKästner, Hans (1997): Neuere Beobachtungen zur Tektonik der Ohmgebirgsgrabenzone. - Geowiss. Mitt. Thüringen, $\underline{5}$ : 133-148, 3 Abb.; Weimar

OKlaua, Dieter (1974): Kreide [in Thüringen]. - In: Hoppe, Walter \& Seidel, Gerd [Hrsg.]: Geologie von Thüringen [Bezirke Erfurt, Gera, Suhl]. - S. 692-698, Abb. 122 u. 123, Tab. 85 u. 86, Photo 89; (Haack) Gotha-Leipzig 1974

OKlaua, Dieter (1995): Kreide [in Thüringen]. - In: Seidel, Gerd [Hrsg.]: Geologie von Thüringen. - 1. Aufl.; S. 370-373, 2 Abb.; Stuttgart 1995

OKlaua, Dieter (2003): Kreide [in Thüringen]. - In: Seidel, Gerd [Hrsg.]: Geologie von Thüringen. - 2., neu bearb. Aufl.; S. 399-403, 2 Abb.; Stuttgart 2003

OKunth (1865): Kreidegesteine im Ohmgebirge bei Worbis. - Z. dt. geol. Ges., 17: 255-256 (Sitzber.); Berlin

OMund, K. (1906): Ueber das Vorkommen von Kreide in Thüringen. - Monatsschr. f. Mineralien-, Gesteins- und Petrefaktensammler, $\underline{\mathbf{3}}(2): 20-21$; Rochlitz - [Vorlage nicht eingesehen]

QRöhling, H.-G. (2006): Ausbildung und Gliederung der Oberkreide-Vorkommen im Ohmgebirge (Eichsfeld). - Eichsfeld-Jahrbuch, 13: 193-223, 10 Abb., 7 Tab.; Duderstadt [Vorlage nicht eingesehen]

OSeebach, K. v. (1868): Über die Entwicklung der Kreideformation im Ohmgebirge. - Nachr. Kgl. Ges. Wiss. z. Göttingen, 1868: 128-138; Göttingen

○Tröger, Karl-Armin \& Schubert, Joachim (1993): Bemerkungen zur Ausbildung und Biostratigraphie des Oberkreideprofils im nördlichen Teil des Holunger Grabens (Thüringer Becken). - Z. geol. Wiss., 21 (3/4): 403-415, 4 Abb., 1 Tab., 2 Taf.; Berlin

ø'Tröger, K. A. (2000): < Kreidegebiete in Deutschland > Thüringen (Eichsfeld). - In: Hiss. M. [Red.]: Stratigraphische Kommission Deutschlands [Hrsg.]: Stratigraphie von Deutschland III - Die Kreide der Bundesrepublik Deutschland. - Courier Forsch.-Inst. Senckenberg, 226: 132, 1 Abb. (Abb. 54); Frankfurt/M. 2000

\subsubsection{Tertiär}

-Ackermann, Ernst (1954): Ein Tertiärvorkommen auf dem Göttinger Muschelkalk und seine Bedeutung für die Datierung der Oberfläche. - N. Jb. Geol. Paläont, 98: 70-79; Stuttgart

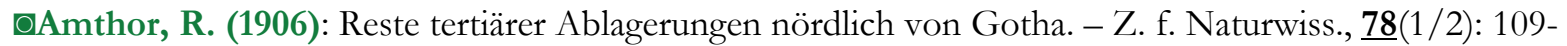
112; Leipzig

[Marine, oberoligozähe Conchylien als Aufarbeitungsmaterial in Schmelzwasserablagerungen von Westhausen]

-Angersbach, A. L. (1891): Tertiärerscheinungen auf sekundärer Lagerstätte bei Rothenditmold. - Ber. Vereins Naturkde. z. Kassel, 36/37: 115-119; Kassel 
- $\square$ Anonym (1956): Wie die hessischen Basaltkegel entstanden. - Bergbau i. Hessenland (Ausgabe Braunkohle), (6. Jg.) $\underline{\mathbf{1 9 5 6}}$ (16): 3-4, 5 Abb.; Kassel

[Erdgeschichte Tertiär]

Sonntags-Ausflug im Dreiländereck Hessen - Niedersachsen - Thüringen. - 159 S., 111 Fotos, 34 Kt., 1 Zeit-Taf.; (LSRB-Verlag, Landschaftskundlicher-Studien-Reisebuch-Verlag) Witzenhausen [zahlreiche Ausflugstipps, auch zu Geotopen des Tertiärs]

-Baatz, H. (1959): Das Kaufunger Tertiär östlich von Kassel. - Dipl.-Arb. [unveröff.] Univ. Marburg/L.

-Baatz, H. (1959/60): Gelber Berg Niederkaufungen [Tertiär von Niederkaufungen] - Bericht über die Exkursionen anläßlich der 110. Haupfversammlung [der Deutschen Geologischen Gesellschaft] vom 1.-9- September 1968 [in Kassel]. - Exkursion F - Mesozoikum u. Tertiär der Hessischen Senke Montag, den 8. September 1958, nachmittags - Fortsetzung des Kasseler Grabens und Tertiär von Ober- und Niederkaufungen - Z. dt. geol. Ges., 111 (f. 1959/60): 303-305; Hannover

-Baatz, Henning (1960): Stratigraphische und paläogeographische Untersuchungen im Kasseler Tertiär. - Diss. Univ. Marburg 1960; 90 Bl., Taf., Anh.; Marburg/L.

-Baatz, Henning \& Ritzkowski, Siegfried (1962): Wieviel Melanientone (Tertiär) gibt es in Hessen? Notizbl. Hess. L.-A. Bodenforsch., 90: 233-239, 2 Abb.; Wiesbaden

[HE]

-Bartenstein, H. (1959): Neue mikropaläontologische Beobachtungen zu den Tertiärvorkommen des Reinhardswalds und benachbarten Bramwaldes. - Notizbl. Hess. L.-A. Bodenforsch., 87: 367-375, 1 Abb., 1 Taf.; Wiesbaden

-Baumeister, Rudolf \& Schorer, Christoph (1977): Zur Stratigraphie, Fazies und Paläogeographie des Tertiärs im Reinhardswald (Nordhessen). - Münster. Forsch. Geol. Paläont., 3: 143 - 169, 3 Abb., 3 Tab., 2 Kt.; Münster

-Benda, L; Gaertner, H. R. v.; Herrmann, R.; Lüttig, G.; Streif, H.; Vinken, R. \& Wunderlich, H. G. (1968): Känozoische Sedimente in tektogenetischen Fallen und Subrosionssenken in SüdNiedersachsen. - Z. dt. geol. Ges., $\underline{117}$ (f. 1965): 713 - 726, 1 Abb., 1 Tab.; Hannover [darin: Bramburg, Hoher Hagen, Bilshausen, Seeburger See]

-Beyrich, Franz (1854): Über die Stellung der hessischen Tertiärbildungen. - Monatsber. Kgl. Preuß. Akad. Wiss. Berlin, 1854: 640-666; Berlin [Hess. Senke, Lkr. Kassel; stratigr. Korrelation m. and. europ. Vorkommen]

-Beyschlag, F. (1892): Ueber Aufnahmen im Gebiete des Blattes Waldeck-Kassel (1 : 80.000). - Jb. Preuß. Geol. Landesanst., 10 (f. 1889): LXX-LXXXVII; Berlin [darin: Stratigraphie Tertiär]

-Beyschlag, Franz (1899): Mittheilungen der Mitarbeiter der Königlichen geologischen Landesanstalt über Ergebnisse der Aufnahmen im Jahr 1898: Niederhessisches Tertiär. - Jb. Preuß. Geol. Landesanst., 19 (f. 1898): LXXXVIII - XCIV; Berlin [Habichtswald]

-Blanckenhorn, Max (1898): Zwei isolirte Tertiär-Vorkommen im Röth auf Blatt Wilhelmshöhe bei Kassel. - Jb. Preuß. Geol. Landesanst.., 18 (f. 1897): 103-108, 5 Abb.; Berlin

-Blanckenhorn, Max (1916): Die Gliederung der Tertiärbildungen in Niederhessen (besonders auf den Blättern Gudensberg und Ziegenhain). - Sitzber. Ges. z. Beförderung d. ges. Naturwiss. z. Marburg, Febr. 1916, 2: 9-43; Marburg 
Referat in: N. Jb. Mineral. etc., 1922 (Bd. II): 9-20 (Oppenheim); Stuttgart

[Vorlage nicht eingesehen, zitiert nach Angaben im genannten Referat]

-Blanckenhorn, Max (1919): Bericht über die wissenschaftlichen Ergebnisse der geologischen Landesaufnahmen im Jahre 1916. - Jb. Preuß. Geol. Landesanst., 37 (Teil II) (f. 1916): 483-518; Berlin [Regionalgeologie des Knüllgebirges; Trias, Tertiär]

- Blanckenhorn, Max (1923): Das Unteroligcän und die Melanientone des mittleren Kurhessens. - Jb. Preuß. Geol. Landesanst., $\underline{43}$ (f. 1922): 113-121; Berlin

Referat in: N. Jb. Mineral. etc., 1924 (Bd. I): 90-91 (Oppenheim); Stuttgart [Bezugn. a. Bl. Borken]

-Blanckenhorn, M. (1928): Allgemeine Ergebnisse der neueren geologischen Aufnahmen im westlichen Kurhessen - Zur Paläogeographie der Hessischen Senke während der Tertiärperiode. - Jb. Preuß. Geol. Landesanst., $\underline{48}$ (f. 1927): 158-174; Berlin

- $\square$ Blanckenhorn, Max (1933): Kritischer Überblick über die Tertiärablagerungen im nördlichen Hessen Ihr Alter, ihre Gliederung, ihr Gegensatz zu denen Südhessens und ihre Abgrenzung nach Süden. (Eine Entgegnung an W. KLÜPFEL und FR. SCHWARZ). - Jb. Preuß. Geol. Landesanst., $\underline{\mathbf{5}}$ (f. 1932): 263-303, 1 Abb.; Berlin

Referat in: N. Jb. Mineral. etc., Referate; 1933 (Bd. III): 247-250 (Oppenheim); Stuttgart [darin: Großalmerode, Oberkaufungen, Bl. Kassel-West]

-Blanckenhorn, Max (1944): Nachträge zum Aufsatz von O. Grupe „Über das Jungtertiär undd die Altersstellung der Basalte in der Hessischen Senke“. - Jb. Reichsamt Bodenforsch, $\underline{62}$ (f. 1941): 175184; Berlin

- Blanckenhorn, Max (1950): Das Tertiär Niederhessens. Ergebnisse der geologischen Aufnahmen in Niederhessen von 1911 - 1946. - Notizbl. Hess. L.-A. Bodenforsch., (6. F.) H. 1: 7 - 82, 9 Abb.; Wiesbaden

QBornemann [jun.], J. L. (1888): Ueber einige neue Vorkommnisse basaltischer Gesteine auf dem Gebiet der Messtischblätter Gerstungen und Eisenach. - Jb. Preuß. Geol. Landesanst., $\underline{8}$ (f. 1887): 291-300, 4 Abb.; Berlin

$\square$ Brosius, Marita (1957): Der Grabenknoten von Hessisch-Lichtenau und die Glimmeröder Tertiärmulde. - Diss. Univ. Marburg [unveröff.], 171 gez. Bl., Abb., Tab.

$\square$ Brosius, Marita (1959): Die Tertiärmulde von Glimmerode. - Hess. Lagerstättenarchiv, 4; 48 S., 17 Abb., 3 Tab., 5 Taf., 10 Anl.; Wiesbaden [Tertiär-Stratigraphie, Tektonik, Pollenanalytische Untersuchungen]

-Brosius, Marita \& Gramann, Franz (1957): Eine Oligozänbohrung im südlichen Habichtswald bei Kassel. - Notizbl. Hess. Landesamtes Bodenforschung, 85: 206-217, 2 Abb.; Wiesbaden

-Brosius, Marita \& Gramann, Franz (1959): Die stratigraphische Reichweite des Heskemer Pollenbildes in Borken (Tertiär, Niederhessen). - Z. dt. geol. Ges., 111: 182-197, 7 Abb., 3 Taf.; Hannover

$\square$ Brosius, Marita \& Gramann, Franz (1959): Das ältere Tertiär von Großalmerode (Hessische Senke). - Z. dt. geol. Ges., 111: 543-558, 4 Abb., 2 Tab.; Hannover

- $\square$ Busse, Hentschel, Kutscher, Laemmlen, Pflanzl, Rösing \&Udluft (1959/60): Geologie der Umgebung von Eschwege und des Hohen Meißners - Bericht über die Exkursionen anläßlich der 110. Hauptversammlung [der Deutschen Geologischen Gesellschaft] vom 1.-9- September 1958 [in Kassel] - Exkursion F - Mesozoikum u. Tertiär der Hessischen Senke - Sonntag, den 7. September 1958 - Z. 
dt. geol. Ges., 111 (f. 1959/60): 288-301, 1 Abb.; Hannover

[Hp. 1-4: Buntsandstein i. d. Umgebung v. Eschwege; HP 5-10: Geologie des Hohen Meißners]

-Carez, L. (1883): Observations sur la classification des couches tertiaires des environs de Cassel (Nord). - Bull. Soc. géol. France, (3ième sér.) 11: 162-164; Paris

-Deppe, H.; Gieseke, G. \& Ambronn : Der Hohe Hagen bei Dransfeld in Südhannover. - 96,3 S., zahlr. Abb., 1 Kt.; (Göttinger Tagebl.) Göttingen o.J. (1913/1915?)

-Dohme, H. (1952): Erdgeschichte aus dem „Kasseler Meeresand“. - HN, 1952; Nr. 175 v. 2.8.1952; Kassel

- $\square$ Ebert, Theodor (1881): Die tertiären Ablagerungen der Umgebung von Cassel. - Z. dt. geol. Ges., $\underline{33}$ : 654-679; Berlin [darin: Rommerode, Wickenrode]

- $\square$ Ebert, Theodor (1882): Die tertiären Ablagerungen der Umgebung von Cassel. - Diss. Univ. Göttingen 1881; 28 S.; Göttingen

-Ehrenberg, K.-H.; Kulick, H. \& Hottenrott, M. (1991): Basalt, Pliozän und Pleistozän bei Fritzlar (Exkursion B am 2. April 1991) [112. Jahresversamml. d. Oberrhein. geol. Vereins, 2. - 6. April 1991 in Bad Wildungen/Nordhessen]. - Jber. Mitt. Oberrhein. geol. Vereins, N.F., 73: 49 - 56, 1 Tab.; Stuttgart

-Findeisen, Hans-Kurt (1952): Pleistozäne und tertiäre Flußablagerungen in der Umgebung von Kassel. - Diss. Univ. Heidelberg 1952, 144 S., 16 Taf., 1 Tab.

- $\square$ Freyberg, Bruno v. (1926): Die Tertiärquarzite Mitteldeutschlands und ihre Bedeutung für die feuerfeste Industrie. - 242 S., 32, Abb., 15 Taf.; (Enke) Stuttgart [Tertiär, Lagerstättenkunde; darin: Hann.-Münden, Dransfeld, Kaufunger Wald und Meißner, Habichtswald und Umgebung Kassel]

QFutterer, K. (1890): Die Tertiärschichten von Grosssachsen. - Mitt. Grhzgl. Bad. Geol. Landesanst., ㄹ: 1-20, 6 Abb.; Heidelberg

-Gaertner, H. R. v. (1953): Über die Tertiärvorkommen vom Kleinen Steinberg bei Hann.-Münden. Geol. Jb., 67: 173-206, 3 Abb.; Hannover

$\square$ Goerges, Julius (1954): Marines Unterstamp von Epterode südlich Großalmerode. - Notizbl. Hess. L.A. Bodenforsch., 82: 190-195 [Vortragszusammenfassung]; Wiesbaden

-Görges, Julius \& Penndorf, Hans (1952): Das niederhessische Tertiär und seine marinen Ablagerungen. - Notizbl. Hess. L.-A. Bodenforsch., (6. F.) H. $\underline{3}: 138$ - 146; Wiesbaden

-Graul, J. (1885): Die tertiären Ablagerungen des Sollings. - N. Jb. Mineral., 1885(Teil 1): 187 - 221, 1 Taf.; Stuttgart

- •Grupe, O. (1909): Die transgredierende Lagerung des marinen Oberoligocäns im Solling und Reinhardswalde. - Jber. Niedersächsischen Geol. Verein, 2: IV-V (Vortragstext); Hannover 1909

$\square$ Grupe, O. (1937): Über das hessische Pliozän und die Altersfrage der Basalte. - Z. dt. geol. Ges., 88(1936): 634-661, 6 Abb.; Berlin

[darin: Hess. Lichtenau]

-Grupe, Otto(1944): Über das Jungtertiär und die Altersstellung der Basalte in der hessischen Senke. Jb. Reichsamt Bodenforsch., 62 (f. 1941): 163-174, 1 Abb.; Berlin 
- $\square \bullet$ Hausmann, [J. F. L.](1824): Uebersicht der jüngeren Flöz-Gebilde im Fluß-Gebiete der Weser. Tb. Mineral., 18 (3): 678-702; Frankfurt/M. - Auszug aus Hausmann: Uebersicht der jüngeren FlözGebilde. - Studien Göttingischen Vereins bergmänn. Freunde, 1: 381 - 567, Göttingen 1824 [Regionale Stratigraphie Trias-Tertiär Hessen, WMK, Niedersachsen; darin: Tertiär Meißner, Hirschberg, Habichtswald, Wilhelmshöhe b. Kassel, Dransfeld]

- $\square$ Q $\bullet$ Hausmann, J.F.L. (1824, 1828): Übersicht der jüngeren Flötzgebilde im Flußgebiete der Weser, mit vergleichender Berücksichtigung ihrer Äquivalente in einigen anderen Gegenden von Deutschland und der Schweiz. - Studien Göttingischen Vereins bergmänn. Freunde, 1: 381 - 567, Göttingen 1824; 2: 215-482; Göttingen 1828

[Regionale Stratigraphie Trias-Tertiär Nordhessen, Südniedersachsen; Bd. 1, Stratigraphie Buntsandstein; S. 500-508 „Basaltische Massen im Sandstein“, darin: Blaue Kuppe bei Eschwege, Pflasterkaute bei Eisenach]

-Hausmann, J.F.L. (1833): Über das Vorkommen von Grobkalkformation in Niedersachsen und einigen angrenzenden Gegenden Westphalens. - Studien Göttingischen Vereins bergmänn. Freunde, ․: 253 - 318; Göttingen

[Tertiär-Kalke]

-Hausmann, J.F.L. (1833): Über das Vorkommen von Grobkalkformation in Niedersachsen und einigen angrenzenden Gegenden Westphalens. - N. Jb. Mineral. etc., 1833: 586-590 (Auszüge). Auszug aus: Studien Göttingischen Vereins bergmänn. Freunde, $\underline{3}$ : 253-318; Göttingen [Tertiär-Kalke, Umgebung Göttingen u. Hann.-Münden]

-Hausmann, J.F.L: (1841): Über eine lagerähnliche basaltische Ausfüllung am Ochsenberge unweit Dransfeld. - Studien Göttingischen Vereins bergmänn. Freunde, 4: 245 - 268, Taf. I; Göttingen

-Hecker, Wilhelm (1976): Die Firnskuppe. - Hessischer Gebirgsbote, 77(2): 47, 1 Abb.; Melsungen [Basaltkuppe NW' Kassel-Harleshausen]

-Hempel, Ludwig (1954): Ein Tertiärvorkommen auf dem Göttinger Muschelkalk und seine Bedeutung für die Datierung der Oberfläche. - N. Jb. Geol. Paläont. Mh., 1954: 70-79, 2 Abb.; Stuttgart [Plesseforst zw. Plesse und Hünstollen]

-Hentschel \& Rösing (1959/60): Habichtswald und Dörnberg bei Kassel - Bericht über die Exkursionen anläßlich der 110. Hauptversammlung [der Deutschen Geologischen Gesellschaft] vom 1.-9- September 1968 [in Kassel]. - Exkursion F - Mesozoikum u. Tertiär der Hessischen Senke Montag, den 9. September 1958 - Z. dt. geol. Ges., 111 (f. 1959/60): 305-310, 1 Tab.; Hannover

-Hentschel, Hans \& Rösing, Franz (1962): Geologische Halbtagsexkursion in das Dörnberggebiet, am 23. Mai 1961. Geologischer Bericht. - (Übergeordn. Titel: Bericht über die Exkursionen während der Tagung des Naturhistorischen Vereins der Rheinlande und Westfalens vom 23. - 26. Mai 1961 in Kassel). - Decheniana - Verhdlgn. Naturhist. Vereins Rheinlande u. Westfalens, 114 (f. 1961): 187190; Bonn

- $\square$ Hessel, J. F. C. (1823): Einiges über Basaltberge und über die Lagerungsverhältnisse der Basaltsäulen an einem und demselben Basaltberge. - Schr. Ges. Beförd. Gesammt. Naturwiss. z. Marburg, 1: 153166; Marburg

[Hinweis a. „Blaue Kuppe“ b. Eschwege]

-Hieke, Werner (1966): Stratigraphie (Trias, Tertiär) und Tektonik am Remsfelder Grabenknoten. Notizbl. Hess. L.-A. Bodenforsch., 94: 201 - 234, 7 Abb.; Wiesbaden [Bl. 4922 Homberg/Efze, 4923 Altmorschen]

- $\square$ OHoff, Karl Ernst Adolf von (1811): Beobachtungen über die Verhältnisse des Basaltes an einigen Bergen von Hessen und Thüringen. - Der Gesellschaft Naturforschender Freunde zu Berlin Magazin für die neuesten Entdeckungen in der gesammten Naturkunde, ㅁ: 347-362 u. Taf. VIII; Berlin 
[darin: Blaue Kuppe b. Eschwege, Pflasterkaute b. Marksuhl, Stoffelskuppe b. Eisenach, Habichtswald/Kassel, Hirschberg b. Großalmerode, Hoher Meissner]

-Hornstein, F. (1889): Ueber eisenschüssige thonigsandige Knollen mit Petrefakten aus den oligozänen Sanden vom Gelben Berge bei Niederkaufungen. - Ber. Vereins Naturkde. Kassel, 34/35: LVIII LIX; Kassel

- Hornstein, Ferdinand Friedrich (1906): Neues vom Kasseler Tertiär. - Z. dt. geol. Ges., 1906: 114118, 2 Abb. (Monatsberichte); Berlin Referat in: N. Jb. Mineral. etc., 1907 (Bd. II): 13-14 (Max Bauer); Stuttgart [Temporäre Aufschlüsse Nähe Königstor]

-Huckriede, Reinhold (1954): Zwei Bohrungen mit marinem Chatt südlich Borken (Hessen). - Notizbl. Hess. L.-A. Bodenforsch., 82: 196-201; Wiesbaden [Stolzenbach/Borkener Senke]

-Huckriede, Reinhold \& Urban, Brigitte (1998): Ein landschafts- und flußgeschichtlich wichtiges Pannon- bis Altquartär-Profil bei Fritzlar/Hessen. - Z. dt. geol. Ges., 149: 105 - 126, 3 Abb., 6 Taf.; Stuttgart

$\square$ Hundeshagen [Oberförster] [ermittelt: Johann Christian](1817): Beschreibung des Meisners. - Tb. Mineral., 11(1): 3-58 (2 Profile, 1 Kte.); Frankfurt/M.

-Käding, Karl-Christian (1962): Geologische, magnetische und petrographische Untersuchungen tertärer Vulkanite und ihrer Begleiterscheinungen im Bereich des hessischen Werra-Kaligebietes. Diss. Freie Unversität Berlin 1962; 112 S., Abb., Anl.; Berlin

-Kaever, Matthias \& Meiburg, Peter (1970): Die Tertiär-Relikte am Nordrand der Niederhessischen Senke. - Notizbl. Hess. L.-A. Bodenforsch., ㅇ: 151 - 166, 5 Abb.; Wiesbaden [Gebiet zw. Warburg-Hofgeismar-Grebenstein-Breuna]

OKahlke, H.-D.; Eismann, L. \& Wiegank, F. (1984): Die Neogen/Quartär-Grenze Territorium der Deutschen Demokratischen Republik. - Z. angew. Geol., $\underline{30}$ (1): 44-48, 2 Abb., 1 Tab.; Berlin [Bezugnahme a. West-, bzw. Südwestthüringen]

- $\square$ Kayser, Emanuel (1923): Lehrbuch der Allgemeinen Geologie. - (Vier Bände: I. u. II. Band Allgemeine Geologie, III u. IV. Bd. Geologische Formationskunde). - Bd. I: Physiographische Geologie und Äussere Dynamik. - 7. u. 8. Aufl., 740 S., 549 Abb.; (Enke) Stuttgart [darin: Abb. z. Vulkanismus Abb. 58 Basaltbruch Bühl b. Ahnatal/Weimar W'Kassel; 92a Teufelswand, Habichtswald/Kassel; 110 Profil Meissner - 111 Profil Hirschberg b. Großalmerode Tektonik: Abb. 203 Profil Netratal b. Eschwege, 204 „Eichenberg“ b. Netra]

-Kayser, Emanuel (1923): Lehrbuch der Allgemeinen Geologie. - (Vier Bände: I. u. II. Band Allgemeine Geologie, III u. IV. Bd. Geologische Formationskunde). - Bd. II: Innere Dynamik. - 7. u. 8. Aufl., 436 S., 223 Abb.; (Enke) Stuttgart [darin Abb. 86: „Doleritstrom“ Eichelskopf b. Homberg]

$\square$ Kayser, Emanuel (1924): Lehrbuch der Allgemeinen Geologie. - (Vier Bände: I. u. II. Band Allgemeine Geologie, III u. IV. Bd. Geologische Formationskunde). - Bd. IV: Geologische Formationskunde- Kreide, Tertiär- und Quartärformation. - 6. u. 7. Aufl., 147 Abb., 54 Taf.; (Enke) Stuttgart [darin S. 365 Profil Meissner]

-Keller, Rudolf (1941): Die Braunkohlenzeit. - Heimatjahrbuch Landkreis Hofgeismar, 1942: 25 - 30; Hofgeismar [Erdgeschichte des Teriärs in der Region] 
-Klüpfel, Walther (1928): Über die natürliche Gliederung des hessischen Tertiärs und den Bewegungsmechanismus in tektonischen Senkungsfeldern. - Geol. Rundschau, 19: 263-283, 3 Tab.; Berlin [Bezug u. a. auf Bl. Kassel, Kassel-West, sonst südl. Kassel]

-Klüpfel, Walter (1937): Zur Tertiärgeologie Niederhessens, Begehungsbericht und Erörterungen. I: Bericht über die Begehung in das Tertiär der Hessischen Senke zwischen Wabern und Ziegenhain, am Samstag, dem 30. August 1936, und Erörterungen über die Entwicklung dieser Landschaft im Pliozän und Diluvium. - II. Erörterung über das Pliozän in Niederhessen und Versuch einer Neugliederung der pliozänen Ablagerungen. - III. Die Deutung der Basalte im Druseltal bei Kassel, am Lamsberg bei Gudensberg und am Kottenberg bei Ziegenhain. - Z. dt. geol. Ges., 88(f. 1936): 620-634, 4 Abb.; Berlin

$\square$ Koch, Heinrich (1958): Im Bereich der drei Großen: Meißner - Hirschberg - Bilstein. - Hessischer Gebirgsbote, $\underline{\mathbf{5 9}}(3)$ : 29 - 31; Melsungen

OKoch, Klaus \& Vogel, Jochen (1980): Zu den Beziehungen von Tektonik, Sylvinitbildung und Basaltintrusion im Werra-Kaligebiet (DDR). - Freiberger Forschungshefte, Reihe C, 347; 104 S., 53 Abb.; 2 Tab.; Leipzig

-Koenen, Adolf v. (1887): Über die ältesten und jüngsten Tertiärbildungen bei Kassel. - Nachr. Kgl. Ges. Wiss. u. d. Georg-Augusts-Universität z. Göttingen, 1887(7): 123 - 128; Göttingen

-Koenen, A. v. (1892): Über die Casseler Tertiärbildungen. - N. Jb. Mineral. etc., 1892(2. Bd.): 161-162; Stuttgart

- KKoenen, Adolf v. (1909): Das Tertiärgebirge des nordwestlichen Deutschlands. - Jber. Niedersächs. Geol. Vereins, 2: 80-96; Hannover [Hinweis a. Umgebung v. Kassel]

$\square$ Kollmann, Karl (2004): Frau Holle und das Meißnerland (9): Die Kitzkammer. - Das Werraland, 56(1): 10-13, 5 Abb.; Eschwege

[Geologie, Sagen um die Kitzkammer; Säulenbasaltfelsen am Westhang des Meißner]

-Kray, Markus (1994): [I.] Die paläogenen und neogenen Sedimente am Stellberg bei Kassel. - Dipl.Arb. [unveröff.] Univ. Göttingen. - 52 S., 40 ungez. Bl. [die Vorlage enthält zwei Arbeiten: Dipl.-Arb. u. Dipl.-Kart.]

-Kropp, Jürgen (1988): Geologie des Westteils der Dransfelder Hochfläche, westlich Göttingen. - Teil I: Geologische Kartierung des Westteils der Dransfelder Hochlfäche zwischen Varlosen, Scheden und Dransfeld. - Teil II: Stratigraphischer Vergleich tertiärzeitlicher Sande und ihre fazielle Interpretation - Bühren/Dransfelder Stadtwald. - Dipl.-Arb. Teil I u. Teil II [unveröff.] Univ. Göttingen 1988; Teil I: 58 S.; Teil II: $50 \mathrm{~S}$.

-Lang, H. D. (1959/60): Die Abhängigkeit der Braunkohlenbildung von der Gestalt und dem Untergrund der Niederhessischen Senke. - Z. dt. geol. Ges., 111: 247; Hannover

- 0 Leonhard, Karl Caesar v. (1846): Lehrbuch der Geognosie und Geologie. (Übergeordn. Titel: Naturgeschichte der drei Reiche. Zur allgemeinen Belehrung bearbeitet von H.G. Bronn, K.C. v. Leonhard, F.S. Lenckart und F.S. Voigt. Dritter Band: Geologie und Geognosie). - 2. vermehrte u. verbess. Aufl.; XII, 1056 S., zahlr. Abb., 6 Falttaf.; (Schweizerbart) Stuttgart [darin: S. 185: Hörschel b. Eisenach, Basaltgang i. Unt. Muschelkalk; Habichtswald/Ziegenberg, Basaltüberdeckung der Braunkohle]

-Linstow, Otto v. (1899): Die Tertiärablagerungen im Reinhardswalde bei Cassel. - Jb. Preuß Geol. Landesanst., 19 (f. 1898): 1-23, 1 Taf.; Berlin Referat in: N. Jb. Mineral. etc., 1905 (Bd. II): 286-287 (Karl Walther); Stuttgart 
-Meiburg, Peter \& Kaever, Matthias (1975): Quarz-Montmorillonit-Oodite als Leitmarken im OberOligozän des Reinhardswaldes/Nordhessen - (Das Nordwestdeutsche Tertiärbecken). - N. Jb. Geol. Paläont., Monatsh., 1975: 212-227, 4 Abb., 1 Tab.; Stuttgart

- $\square$ Linstow, Otto v. (1922): Die Verbreitung der tertiären und diluvialen Meere in Deutschland. - Abh. Preuß. Geol. Landesanst., N.F., 87; 243 S., 12 Abb., 14 Taf.; Berlin

[Bezug u.a. auf: Großalmerode, Oberkaufungen, Kassel]

- •Lotze, Franz (1932): Wie entstehen Schrumpfungsrisse? - Natur u. Volk, 62(4): 123-130, 11 Abb.; Frankfurt/M.

[Genese der Säulenstruktur von Basalten; auch tertiäre Toneisenstein-Geode Fdpkt. Uslar/Solling]

-Lungershausen, Karl (1961): Die Bielsteinkirche [und „Roßgang“ in Oberkaufungen]. - Hessischer Gebirgsbote, 62(3): 27 - 28, 1 Abb.; Melsungen

[Bilsteinkirche: Basaltsäulen-Felsgruppe Im Söhrewald b. Kassel; Rößgang: Pferdegöpelwerk des Braunkohlen- Bergbaus in Oberkaufungen b. Kassel]

-Matzke, Stefani (1988): Geologie der südlichen Dransfelder Hochfläche. - Teil 1: Die tertiären Sande des Steinberges bei Meensen. - Teil 2: Geologie des Steinberges bei Meensen. - Dipl.-Arb. [Teil $1 \mathrm{u}$. Teil 2] [unveröff.] Univ. Göttingen 1988; 179 S.

$\square$ Moesta, Fr. A. (1867): Geologische Schilderung der Gegend zwischen dem Meissner und dem Hirschberge in Hessen - mit besonderer Berücksichtigung der daselbst auftretenden basaltischen $u$. tertiären Bildungen nebst einer geologischen Karte und einem Blatte mit Gebirgsprofilen. - Diss. Univ. Marburg 1867; 40 S., 1 Kt., 1 Taf. (4 Profile); (Sipmann) Marburg - Kurzfassung in: N. Jb. Mineral. etc., 1869: 241-243; Stuttgart

-Mötzing, Kurt (1970): Die Teufelsmauer, ein oft genanntes, aber wenig bekanntes Naturdenkmal im Habichtswald. - Hessischer Gebirgsbote, 71(1): 8 - 9, 1 Abb.; Melsungen

OMorgenroth, V. (1989): Exkursionsführer - Trias und Tertiär in der Vorderrhön - vom 3. - bis 6. Oktober in Bad Salzungen - Gesellschaft f. geologische Wissenschaften d. DDR (GGW). Exkursionsführer u. Veröff. Ges. f. geol. Wiss., 170; 30 S., 5 Abb.; Berlin

-Münster, G. Graf von (1835): Bemerkungen über einige tertiäre Meerwasser-Gebilde im nordwestlichen Deutschland zwischen Osnabrück und Cassel. - N. Jb. Mineral. etc., 1835: 420-451; Stuttgart [Stratigraphie, Paläonotologie, auch Bibliographie u. Erforschungsgeschichte]

- $\square$ Mürriger, Friedrich \& Pflanzl, Günther (1955): Pollenanalytische Datierungen einiger hessischer Braunkohlen. - Notizbl. Hess. L.-A. Bodenforsch., 83: 71-89, 1 Tab., 2 Taf; Wiesbaden [Darin: Hirschberg, Glimmerode, Oberkaufungen, Stellberg/Söhrewald, Zeche Marie/Habichtswald]

-Murawski, Hans (1951): Zusammenhänge zwischen Basaltvulkanismus und Tektonik in Niedersachsen. - Geol. Rundschau, 39: 114-119, 3 Abb.; Stuttgart [Basalte W' Göttingen]

-Murawski, Hans (1956): Die tertiären Basaltvorkommen der Umgebung von Göttingen. Wert und Ausmaß ihrer geologischen Aussage. - N. Jb. Geol. Paläont.. Mh., 1956: 1-31, 7 Abb.; Stuttgart

-Murawski, Hans (1952): Exkursion in die Ziegeleigrube der Fa. Levin in Göttingen und in die Basaltsteinbrüche der Bramburg bei Adelebsen. - Z. dt. geol. Ges., 103: 423-426, 2 Abb.

-Murawski, Hans (1952): Die Auswertung der Innenstrukturen von Basaltvorkommen für die Praxis. Z. Dt. Geol. Ges. , 103: 414-416, 3 Abb.; Hannover

[Hoher Hagen/Dransfeld, Bramburg/Adelebsen] 
-Murawski, Hans (1953): Die Entwicklungsgeschichte des Jüngeren Tertiärs westlich des Leinetalgrabens. - Geol Jb., 67: 495-527, 11 Abb., 1 Tab.; Hannover [Kasseler Meeressande/Oberoligozän; Kiese u. Sande/Miozän, Pliozän]

-Murawski, Hans (1960): Einige Bemerkungen zur Frage der Regressionssedimente des oberoligozänen Meeres im Nordteil der Hessischen Senke. - N. Jb. Geol. Paläont., Mh., 1960: 220 - 227; Stuttgart

QNaumann, Ernst (1911): Basaltvorkommen im Salzlager des Schachtes der Gewerkschaft Heldburg bei Leimbach unweit Salzungen. - Z. dt. geol. Ges., $\underline{62}$ (f. 1910): 343-344 (Mber.); Berlin

Referat in: N. Jb. Mineral. etc., 1913 (Bd. II): 87 (E. Milch); Stuttgart

Referat in: Mitt. Geogr. Ges. (f. Thür.), $\underline{30}$ : 227; Jena 1912

ONaumann, Ernst (1952): Über einige vulkanische Schlotbrekkzien, ander vulkanische Erscheinungen und Auslaugungsbrekkzien im Werragebiet und in der Rhön. - Geologie, 11(1/2): 59 - 63, 3 Abb.; Berlin

-Naumann, Peter (1993): Rupelton und Kasseler Meeressand - Tertiärsande und ihre Verwendung im Reinhardswald und Solling. - Hessischer Gebirgsbote, 94(1): 17-18; Melsungen

- $\square$ Nöggerath, Karl Jakob (1822-1826): Das Gebirge in Rheinland-Westfalen - nach mineralogischem und chemischen Bezuge. - 1. Bd., 370 S.: 7 Abb., (Eduard Weber) Bonn 1822. - 2. Bd.: 387 S., 7 Abb., (Eduard Weber) Bonn 1823. - 3. Bd.: 291 S., 6 Abb., (Eduard Weber) Bonn 1824. - 4 Bd.: 390 S., 2 Abb., (Eduard Weber) Bonn 1826

[darin Bd. III, S. 273 - 277: „Kurze Nachricht von einigen wenig bekannten Basalt-Gängen in Hessen (aus einem Briefe)"; Kontaktmetamorphose des Basaltes auf das Rahmengestein: Habichtswald, Ahnetal, Hirschberg; Schieferberg N’ Meissner (heute: Heiligenberg S’ Weißenbach am Meißner)]

- $\square$ Nöggerath [Karl Jakob] (1825): Nachrichten über eine wenig bekannte Basaltgänge in Hessen. - Tb. Mineral., 19 (1): 263-264; Frankfurt/M. (Auszug aus: Nöggerath: Das Gebirge in Rheinland-Westfalen, Bd. III: 273-277; Bonn)

[darin: Umgebung Kassel, Heiligenberg S’ Weißenbach am Meißner]

-Oschkinis, Viktor \& Gregor, Hans-Joachim (2005): Die eozänen Braunkohlenschichten aus dem Untertagebau Stolzenbach bei Kassel (PreußenElektra, Niederhessen)- I. Geologie und Fundumstände - Nebentitel: Untertagebau Stolzenbach der PreussenElektra Niederhessen: Geologie - Paläophytologie - Mineralogie (Festband VIKTOR OSCHKINIS). - Documena naturae, 156: 1-25, 9 Abb., 5 Taf.; München

-Penndorf, Hans (1927): Geologische Wanderungen im Habichtswald. - Hessischer Gebirgsbote, $\underline{\text { 33(5): }}$ 37 - 41; Kassel

-Pflug, H.-D. (1958): Die kontinentalen Ablagerungen des Rheinischen Schiefergebirges im Tertiär (Paläozän bis Unteroligozän). - Ber. geol. Ges. DDR, $\underline{\mathbf{3}}(2 / 3)$ : 145-146; Berlin [Bezugnahme a. Hess. Senke]

- $\square$ Pflug, Hans Dieter (1966): Stratigraphische Einordnung weiterer hessischer und außerhessischer Tertiär-Vorkommen. - N. Jb. Geol. Paläont., Mh., 1966: 736-744, 2 Abb.; Stuttgart [darin: Hessische Senke: Stellberg, Oberkaufungen, Hoher Meißner, Baunatal, Ostheim, Felsberg]

$\square$ Pflug, Hans Dieter (1966): Zur Stratigraphie des mittleren Tertärs in Hessen und in benachbarten Gebieten. - Notizbl. Hess. Landesamtes Bodenforschung., 94: 259-268, 2 Abb., 1 Tab.; Wiesbaden [Palynologische Untersuchungen; Braunkohlen u.a. Oberkaufungen 4723 Oberkaufungen, Grube Hirschberg 4724 Großalmerode, Grube Glimmerode 4824 Hessisch Lichtenau]

$\square$ Plein, Eberhard (1954): Der Basaltvulkanismus vom Hirschberg bei Großalmerode und der Bau seiner Förderzone in tertiären Sedimenten. - Notizbl. Hess. Landesamtes Bodenforschung, $\underline{\mathbf{8 2}}$ (= 6. F., H. 5): 215 - 233, 5 Abb.; Wiesbaden 
$\square$ Prauss, Michael [Red.](1986): Die Braunkohlen der Niederhessischen Tertiärsenke. - 18 S., 5 Abb., 5 Tab.; [Stadt Kassel, Naturkundemuseum] Kassel

[Borken, Großalmerode/Hirschberg]

-Rambow, Dietrich \& Lemmer, Frank (2002): Zur Genese der Tertiärsenken südöstlich von Kassel : Tektonik oder Subrosion? - Geol. Jb. Hessen, 130: 73-89, 10 Abb., 1 Tab.; Wiesbaden

- 0 Riess, Johann Philipp (1791): Mineralogische und bergmännische Beobachtungen über eine Hessische Gebirgsgegenden. - XIV, 102 S., 6 Taf.; (Rottmann) Berlin [darin: S. 28-54 Kupferschiefer- u. Kobalt-Bergbau Richelsdorfer Gebirge; S. 54-59 Kupferschiefer- u. Kobalt-Bergbau Glücksbrunn b. Bad Liebenstein; S. $69-84$ („,Steinkohlen“-) Braunkohlenbergbau u. Tertiär-Stratigaphie am Meissner; S. 84-89 Alaun- und („Steinkohlen“) Braunkohlen-Bergbau Oberkaufungen]

- $\square$ Ritzkowski, Siegfried (1965): Das marine Oligozän im nördlichen Hessen - Stratigraphie und Paläogeographie. - Diss. Univ. Marburg/L. 1965; 194 S., 28 Abb., 4 Tab.

- $\square$ Ritzkowski, Siegfried (1967): Mittel-Öligozän, Ober-Oligozän und die Grenze Rupel/Chatt im nördlichen Hessen. - N. Jb. Geol. Paläont. Abh., 127: 293-336, 12 Abb., 3 Tab.; Stuttgart [Hessische Senke zw. Hofgeismar und Lauterbach, darin: Ahnetal N’Habichtswald, Glimmerode]

-Ritzkowski, Siegfried (1967): Die Feingliederung des Hessischen Melanientons (Unteroligozän nördliches Hessen). - Geologica et paleontologica, 1: 97-100, 2 Abb.; Marburg/L.

[Tagebau Altenburg/Borkener Senke]

- $\square$ Ritzkowski, S. (1969): Nördliches Hessen [Oligozän-Aufschlüsse]. - In: Anderson, Hans Joachim [Hrsg.]: Führer zur Oligocän-Exkursion 1969 - Köln, Münster, Hannover, Göttingen, Mainz - 20.27. April 1969. - Internationale Union f. Geologischen Wissenschaften [International Union of Geological Sciences]/Landesausschuß der Bundesrepublik Deutschland. - 112 S., 33 Abb., Tab.; hier S. 57 - 83, 17 Abb. Tab.; Marburg 1969

[Borken, Niederkaufungen, Glimmerode]

- $\square$ Ritzkowski, Siegfried (1969): Stratigraphie der Eozän/Oligozänen Sedimente im nördlichen Hessen und ihre Paralellisierung zu anderen Tertiärgebieten. - In: Colloque sur l'Eocène - Paris, mai 1968 vol. $\underline{3}$; Memoires BRGM, 69: 255-258; Paris [darin: Borken, Großalmerode]

- Ritzkowski, Siegfried (1993): Sequenzstratigraphie des Rupeltons im nördlichen Hessen (Oligozän, Hessische Senke). - In: Gross-Uffenorde, H.; Jahnke, H. \& Schindler, E. [Hrsg.]: O. H. Walliser Festschrift. - Göttinger Arb. Geol. Paläont., 58; S. 135-144, 6 Abb.; (Selbbstverlag d. Geol. Inst.) Göttingen 1993

-Ritzkowski, Siegfried (1999): Der Göttinger Leine-Graben im Paläogen (südliches Niedersachsen / The Göttingen Leine-Graben during the Paleogene (Southern Lower Saxony, F.R.G). - N. Jb. Geol. Paläont., Abh., (D. Meischner-Festschrift) 214(1/2): 237-256, 3 Abb.; Stuttgart

- $\square \bullet$ Ritzkowski, S. (2005): Das Tertiär der Hessischen Senke in der Stratigraphischen Tabelle von Deutschland 2002. - In: Menning, Manfred \& Hendrich, Andreas [Hrsg.]: Erläuterungen zur Stratigraphischen Tabelle von Deutschland 2005 (ESTD 2005). - Newsletters on stratigraphy, 41(1-3); 405 S., 21 Abb., 15 Tab.., 19 Beil.; hier S. 339-346, Taf. XIV; (Bornträger) Berlin-Stuttgart 2005

- $\square$ Ritzkowski, S. \& Rösing, F. (1977): Tertiär Nordhessens. (Exkursion K) - In: Geol.-Paläont. Inst. u. Museum der Universität [Hrsg.]: Exkursionsführer - Geotagung ' 77 Göttingen - Band II : Nordhessen und Südniedersachsen (Exkursionen C - D - J - K - L). - S. 63-111, 16 Abb., 1 stratigr. Tab.; (Selbstverlag Geol.-paläont. Inst. Univ. Göttingen) Göttingen 
[darin: Borken, Verna, Obervorschütz, Knickhagen, Bühl b. Ahnatal/Weimar; Breitenbach, Hoof, Vollmarshausen, Glimmerode, Hoher Meissner]

-Rösing, Franz (1953): Eine präoligozäne Doline im Unteren Muschelkalk des oberen Ahnetales bei Kassel. - Notizbl. Hess. L.-A. Bodenforsch., 81 (= VI. F., H. 4): 195-198, 2 Abb.; Wiesbaden

- Rösing, Franz (1962): Geologische Halbtagsexkurison durch den Habichtswald un den Kasseler Graben am 24. Mai. 1961. - (Übergeordn. Titel: Bericht über die Exkursionen während der Tagung des Naturhistorischen Vereins der Rheinlande und Westfalens vom 23. - 26. Mai 1961 in Kassel). Decheniana - Verhdlgn. Naturhist. Vereins Rheinlande u. Westfalens, 114 (f. 1961): 190-194, 1 Profilbeschr.; Bonn

-Rösing, Franz (1969): Geologisch-morphologische Erläuterung. - In: Hofmann, Walter [Hrsg.]: Landformen im Kartenbild: Topographisch-geomorphologische Kartenproben $1: 25.000$. Gruppe 4 Mittelgebirge: an Vulkanismus gebundene Formen. Kartenprobe 2: Vulkanstiele im Tertiärhügelland, Gudensberg bei Kassel. - 11 S., Abb., 7 Kt.-Beil.; hier: S. 10-11; (Westermann) Braunschweig

- Rösing, Franz (1971): Zur Geologie der Langenberge und ihrer Randgebiete südwestlich von Kassel. Notizbl. Hess. L.-A. Bodenforsch., 99: 240 - 245; Wiesbaden

- $\square$ Rosenthal, Bergingenieur (1895): Die tertiären Ablagerungen bei Kassel und ihre durch Basaltdurchbrüche veredelten Braunkohlenflöze. - Touristische Mitt. a. beiden Hessen, $\underline{\mathbf{3}}(12)$ : 149152; Kassel [Habichtswald, Stellberg, Hirschberg, Hoher Meißner]

- $\square$ Rosenthal, (Berg-Ingenieur) (1896): Die tertiären Ablagerungen bei Kasssel und ihre durch Basaltdurchbrüche veredelten Braunkohlenflöze. - Abh. u. Ber. Vereins Naturkde. z. Kassel, $\underline{41}$ (1995/1896): 106-117, 3 Abb. (Profile); Kassel [darin: Habichtswald, Hirschberg, Stellberg, Meissner]

-0Rothe, Peter (2005): Die Geologie Deutschlands - 48 Landschaften im Portrait. - 240 S., 142 Abb.; (Wiss. Buchges. Darmstadt) [darin: Thüringer Becken, Thüringer Wald, Hessische Senke (u.a. Blaue Kuppe, Hoher Meißner)]

OSartorius (1833): Pflanzen-Sandstein und Braunkohle bei Eisenach. - N. Jb. Mineral. etc., 1833: 407-408 (Briefl. Mittl); Stuttgart [Tertiär]

- Schäfer, Frank N. (2004): Der Tertiärquarzit des Weißensteins in Kassel [-Wilhelmshöhe]. - Jb. Lkr. Kassel, 2005: 108 - 110, 1 Abb.; Kassel

-Schäfer, Frank N. (2004): Ein Bohrprofil aus dem Kasseler Meeressand - Auswertung von Materialproben eine Brunnenbohrung im nordöstlichen Habichtswald bei Kassel. - Philippia, 11(3): 183-194, 1 Abb.; Kassel

$\square$ Schellmann, Theo (1956): Bemerkungen zum Thema „Marines Unterstamp von Epterode“. - Notizbl. Hess. L.-A. Bodenforsch., 84: 206-208; Wiesbaden

-Schlossmacher (1910): Die Entstehung des Habichtswaldes [Vortragstext]. - Tourist. Mitt. a. bd. Hessen, $\underline{18}$ (10): 111 - 112; Kassel

- -Schmeisser, A. (1879): Die geognostischen Verhältnisse des Habichtswaldes bei Kassel. - Mitt. Natwiss. Vereins Maja z. Clausthal., N.F., 1: 1-11, 2 Taf.; Clausthal

-Schmidt, Hermann (1936): Die stratigraphische Bedeutung der Knollensteinfloren von Dransfeld und Münden (Oberweser). - Festschrift zum 60. Geburtstag von Hans Stille, 437 S., zahlr. Abb., 28 Taf; hier: S. 136-148, 2 Abb.; Stuttgart 
Referat in: N. Jb. Mineral. etc., Referate, 1937 (Bd. III): 401 (Kräusel); Stuttgart

[Knollensteine $=$ Tertiärquarzite; Revision der stratigraph. Einordnung, von Miozän nach Oligozän]

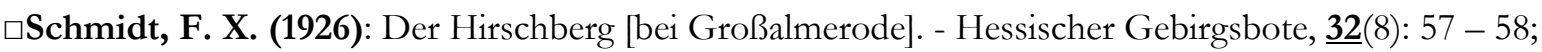
Kassel

-Schwarz, Friedrich (1932): Zur Tektonik und Morphologie Niederhessens. - Z. dt. geol. Ges., 84: 513 - 537, 3 Abb.; Berlin

[Stadtgebiet v. Kassel, Gebiet zw. Hohenkirchen, Knickhagen, Sandershausen, Rothenditmold]

$\square$ Schwarz, Friedrich (1932): Stratigraphie der Tertiärrelikte des Kaufunger Waldes. - Zbl. Mineral., Abt. B, 1932: 91 - 100, 1 Abb.; Stuttgart

-Schwarz, Friedrich (1933): Stratigraphische und tektonische Auswertungen von Tertiäraufschlüssen zwischen der Söhre und den Langenbergen in Niederhessen. - Zbl. Mineral., Abt. B., 1933: 401 - 411; Stuttgart

aSchwarzenberg, A. (1827): Vorkommen von Grobkalk-Formazion in Hessen. - Z. Mineral., 1827(2): 156 - 158; Frankfurt/M.

Kalkkonkretionen in Tertiärsanden u.a. Raum Kassel]

-Schwarzenberg , Bergkommissar (1828): Beschreibung der geognostischen Verhältnisse des Ahnegrabens am Habichtswalde bei Kassel, mit besonderer Berücksichtigung der dabei vorkomenden basaltischen Ausfüllungsmassen, nebst einer petrographischen Skizze. - Studien d. Göttingischen Vereins Bergmänn. Freunde, 2: 195-219, 1 Falt-Bl.; Göttingen

- $S$ chwarzenberg , A. (1833): Über das Vorkommen der Grobkalkformation in Niederhessen. - Studien Göttingischen Vereins Bergmänn. Freunde, $\underline{3}$ : 219-252; Göttingen

[Eisenschüssige Kalk-Konkretionen des Tertiär]

oSchwarzenberg, A. (1834): Über das Vorkommen der Grobkalkformation in Niederhessen. - N. Jb. Mineral. etc., 1834(1): 99-102; Stuttgart - Auszug a. Studien Göttingischen Vereins Bergmänn.

Freunde, $\underline{3}$ : 219-252; Göttingen

[Eisenschüssige Kalk-Konkretionen des Tertiärs]

- oSimon, C. (1889): Entstehung von Quarziten der Braunkohlenformation. - Ber. Vereins Naturkde. z. Kassel, 34/35: 86-88; Kassel

[Trappquarzite Habichtswald]

aSissingh, W. (2003): Teriary paleogeographic and tectonostratigraphic evolution of the Rhenish triple junction. - Paleogeography, Palaeoclimatology, Palaeoecology., 196(1-2): 229-263, 10 fig.; Amsterdam [Großregionale Betrachtung; darin: Oberrheingraben, Hessische Senke]

OSitte, J. (1983): Limburgitgang in der Wellenkalk-Folge - ein geologisches Naturdenkmal des Kreises Eisenach. - Landsch.Pflege u. Natschutz. Thüringen, 20(1): 23-25; Jena

- Dittler, Claude (1965): La Paléogène des Fossées Rhénan et Rhodanien, études sédimentologiques et paléoclimatologique. - Mém. Serv. Carte géol. Als. Lorr., 24; 392 p. 102 fig., 120 tabl.; Strasbourg [Chap. III - La dépression de Hesse - I. La region de Borken]

OSteinmüller, Arno (1974): Tertiär [in Thüringen]. - In: Hoppe, Walter \& Seidel, Gerd [Hrsg.]: Geologie von Thüringen [Bezirke Erfurt, Gera, Suhl]. - S. 717-742, Abb. 131-139, Tab. 87-92; (Haack) Gotha-Leipzig 1974

OSteinmüller, Arno (1995): Tertiär [in Thüringen]. - In: Seidel, Gerd [Hrsg.]: Geologie von Thüringen. - 1. Aufl.; S. 378-392, 3 Abb.; Stuttgart 1995 
QSteinmüller, Arno (2003): Tertiär [in Thüringen]. - In: Seidel, Gerd [Hrsg.]: Geologie von Thüringen. - 2., neu bearb. Aufl.; S. 409-423, 3 Abb.; Stuttgart 2003

aStremme, Eduard (1888): Beitrag zur Kenntnis der tertiären Ablagerungen zwischen Cassel und Detmold, nebst einer Besprechung der norddeutschen Pecten-Arben. - Diss. Univ. Göttingen 1888; 46 S., 1 Bl.; (Starcke) Berlin

aStremme, E. (1888): Beitrag zur Kenntnis der tertiären Ablagerungen zwischen Kassel und Detmold, nebst einer Besprechung der norddeutschen Pectenarten. - Z. dt. geol. Ges., 40: 310-354, Taf. XX, XXI; Berlin - zgl. Diss. Univ. Göttingen 1888

Referat in: N. Jb. Mineral. etc., $\underline{\mathbf{1 8 8 9}}$ (Bd. II): 146 (v. Koenen); Stuttgart [darin: Die tertiären Ablagerungen nördlich von Cassel (Reinhardswald)]

oStrippelmann, F. E. (1824): <Tertiär des Habichtswaldes b. Kassel>. - Z. Mineralogie, 1827(6): 513 518; Frankfurt/M.

[Basalt-Konglomerat, Polirschiefer, Trappquarz]

- QStrippelmann (1837): Ueber das Vorkommen von Basaltgängen auf dem Habichtswald. - Jber. Thätigkeit Vereins f. Naturkunde in Cassel. - 1 (1837): 11 - 12; Kassel

-Strippelmann, F. E. (1840): Flötz-artiger Basalt in Habichtswalder Braunkohle. - N. Jb. Mineral. etc., 1840: 369-370 (Auszug a. Bergwerks-Freund, 2: 297ff, Eisleben 1840); Stuttgart

-Strippelmann, F. E. (1841): Über das Vorkommen einer flözartigen Einlagerung von basaltischen Massen in der Habichtsspieler Braunkohlenablagerung am Habichtswalde. - Studien Göttingischen Vereins bergmänn. Freunde, 4: 355-358; Göttingen - Auszug in: N. Jb. Mineral. etc.; 1843: 809 (Auszüge); Stuttgart

$\square$ Waitz von Eschen, R. \& Strippelmann, F. E. (1828): Geognostische Betrachtung der am Hirschberge bei Großalmerode abgelagerten, tertiären Gebilde, nebst einigen Bemerkungen über den daselbst im Betriebe stehenden Bergbau. - Studien Göttingischen Vereins bergmänn. Freunde, 2: 121-168;

(Dieterich) Göttingen

[Tertiärstratigraphie, Braunkohlenbergbau, Alaungewinnung]

-Ströhmfeld, Gustav (1921): Ein Tag im Habichtswald. - Hessischer Gebirgsbote, 299(1/2): 1-2; Kassel

- Udluft, Hans (1950): Ergänzungen und kritische Bemerkungen zu der Arbeit von HANS BLANCKENHORN über das Tertiär Niederhessens. - Notizbl. Hess. L.-A. Bodenforsch., (6. F.) H. 1: 83-100; Wiesbaden

-Udluft, Hans \& Lang, Hans Dietrich (1959): Die Niederhessischen Braunkohlen in ihrer Abhängigkeit von den faziellen Verhältnissen des tertiären Sedimentationsraumes. - Notizbl. Hess. L.-A. Bodenforsch., 87: 333-366, 14 Prof. u. Tab., Taf. 20; Wiesbaden

- $\square$ Uthemann, A. (1892): Die Braunkohlen-Lagerstätten am Meisner, am Hirschberg und am Stellberg mit besonderer Berücksichtigung der Durchbruchs- und Contacteinwirkungen, welche die Basalte auf die Braunkohlenflöze ausgeübt haben. - Abh. Kgl. Preuß. Geol. Landesanst., N.F., 7; 54 S., 10 Abb., 3 Falt-Taf.; Berlin

Referat in: N. Jb. Mineral. etc., $\underline{1893}$ (Bd. II): 164-165 (v. Koenen); Stuttgart

-Vinx, Roland (1972): Vulkanische Senkungsstrukturen westlich Hofgeismar (Nordhessen). - Notizbl. Hess. L.-A. Bodenforsch., 100: 194 - 206, 4 Abb., 1 Tab.; Wiesbaden

口OVoigt, Johann Carl Wilhelm (1802/1805): Versuch einer Geschichte der Steinkohlen, der Braunkohlen und des Torfes, nebst Anleitung, diese Fossilien kennen und unterscheiden zu lernen, sie aufzusuchen und nützlich anzuwenden. - 1. Bd., XXIII, 307, [5] S.; [Hoffmann'sche Hofbuchhdlg.] Weimar 1802 - 2. Bd., [IV], 197 S. [3], 2 Taf.; [Hoffmann’sche Hofbuchhdlg.] Weimar 1805 
[darin Bd. 1: Torfabbau bei Creuzburg; Bd. 2: S. 61-90: „Der Manebacher Grund im Thüringer Wald“; S. 123-132 „Nachtrag zu des Verfassers mineralogischen Reise nach den Braunkohlenwerken und Basalten in Hessen etc.“ (Braunkohle und Basalt am/auf dem Hohen Meißner)]

$\square$ Waitz von Eschen, R. \& Strippelmann, F. E. (1828): Geognostische Betrachtung der am Hirschberge bei Großalmerode abgelagerten, tertiären Gebilde, nebst einigen Bemerkungen über den daselbst im Betriebe stehenden Bergbau. - Studien Göttingischen Vereins bergmänn. Freunde, 2: 121-168; (Dieterich) Göttingen

[Tertiärstratigraphie, Braunkohlenbergbau, Alaungewinnung]

OWeber, Hans (1952): Pliozän und Auslaugung im Gebiet der oberen Werra. - Geologica, $\underline{8}$; 136 S., 17 Abb., 4 Taf.; (Akademie-Verlag) Berlin

[Untersuchungen u.a. Blatt Berka, Creuzburg, Herleshausen u. Hönebach]

-Weber, Klaus (1999): Die Vulkangebiete Nordhessens. - Knüllgebirgsbote, 1999(3): 7-8, 2 Abb.; 1999(4): 8-11, 6 Abb.; Bad Hersfeld

- $\square \bullet$ Wedepohl, Karl Hans \& Ritzkowski, S. (1980): [DMG-Tagung 1980] Exkursion E 1: Die nördliche Hessische Senke (Tertiär-Vulkanite, Kupferschiefer und variszischer Spilit). - Fortschr. Mineral., $\underline{\mathbf{5 8}}$, Beih. 2 (Einführung zu den Exkursionen anläßlich der 58. Jahrestagung der Deutschen Mineralogischen Gesellschaft in Göttingen 1980): 3-33, 2 Abb., 3 Tab.; Stuttgart [darin Hp: Werra-Meissner-Kreis: Blaue Kuppe, Bilstein, Cornberg, Forsths. Schmelzhütte, Hoher Meissner/Kalbe, Hoher Meissner/Kitzkammer; auch Hoher Hagen/Dransfeld, Westberg/Hofgeismar, Dörnberg/Zierenberg; Güntersberg b. Gudensberg, Isthaburg b. Istha, Steppling b. Homberg/Efze]

$\square$ Weiler, Wilhelm (1989): Bemerkungen zu dem Aufsatz von J. Görges: „Marines Unterstampan von Epterode südlich von Großalmerode“. - Notizbl. Hess. L.-A. Bodenforsch., 84: 209-211; Wiesbaden

-Wunderlich, Hans Georg (1962): Umgrenzung von Basalt und Braunkohlentertiär am Brunsberg und Hohen Hagen bei Dransfeld (Südhannover). - N. Jb. Geol. Paläont., Mh., 1962: 282-293, 2 Abb.; Stuttgart

-Wunderlich, Hans Georg (1966): Bau und Bewegung der Basaltvorkommen vom Hohen Hagen (Südniedersachsen). - Z. dt. geol. Ges., 115: 758-769, 4 Abb.; Hannover

-Wunderlich, Hans Georg (1968): Der Hohe Hagen - ein Basaltschlot im südniedersächsischen Bruchschollengebirge. - Der Aufschluss, Sdbd. 17 (Zur Mineralogie und Geologie der Umgebung von Göttingen): 121-128, 3 Abb.; Göttingen

\subsubsection{Quartär}

-Ahrens, Wilhelm \& Steinberg, Kurt (1943): Jungdiluvialer Tuff im Eichsfeld. - Bericht Reichsanstalt f. Bodenforschung, 1943: 17-30, 2 Abb.; Wien

[Lutteranger b. Seeburg/Lkr. Göttingen]

-Ackermann, Erich (1954): Gliederung, Kinematik und paläoklimatische Bedeutung der würmeiszeitlichen Ablagerungen in Göttingen. - Mitt. Geol. Staatsinst. Hamburg, 23: 126 - 141, 8 Abb.; Hamburg

[Temporäre Aufschlüsse im Stadtgebiet Göttingen; Baugruben, Kanalisationsgräben] 
-Ackermann, Erich (1955): Zur Unterscheidung glazialer und postglazialer Fließerden. - Geol. Rundschau, 43: 328 - 341, 6 Abb.; Stuttgart

[Mackenröder Spitze Ostrand Göttinger Wald]

-Ahl, Christian \& Meyer, Brun (1989): Sedimentschichten aus Laacher Bims und Flugsand unter geschützten Felsdächern (Abris) im südniedersächsischen Bergland bei Göttingen. - Mitt. Dt. Bodenkdl. Ges., 59: 825-830, 8 Tab.; Oldenburg i. O.

OAmthor, R. (1906): Reste tertiärer Ablagerungen nördlich von Gotha. - Z. f. Naturwiss., $\underline{78}(1 / 2)$ : 109112; Leipzig

[Marine, oberoligozähe Conchylien als Aufarbeitungsmaterial in Schmelzwasserablagerungen von Westhausen]

- $\square$ ○ीApel, Jürgen \& Rüppel, Heidi [Verfass. u. Hrsg.] (2005): Raus in die Natur - Tipps für den Sonntags-Ausflug im Dreiländereck Hessen - Niedersachsen - Thüringen. - 159 S., 111 Fotos, 34 Kt., 1 Zeit-Taf.; (LSRB-Verlag, Landschaftskundlicher-Studien-Reisebuch-Verlag) Witzenhausen [zahlreiche Ausflugstipps, auch zu Geotopen d. Quartärs: Ziel 16 (Moorbildung Kaufunger Wald), Ziel 23 (Schwemmschuttfächer Unterwerra), Ziel 52 (Travertinbildung), Ziel 73 (Kiesablagerung), Ziel 80 (Travertinbildung), Ziel 87 (Gletscherbildungen, Travertinbildungen i. Thüringen)]

-Bartels, G. \& Meyer, B. (1972): Spät- und postglaziale Erosion und Akkumulation im Luttertal bei Göttingen. - (Übergeordneter Titel: Ergebnisse neuerer Auenforschung im Leinegraben-Gebiet) Göttinger bodenkdl. Ber., 21: 159-188, 6 Abb.; Göttingen

$\square$ Beck, Hanno (1956): Echte Eiszeitspuren auf dem Meißner. - Überraschende Ergebnisse neuerer geographischer Forschungen. - Werra-Rundschau, 1956; Nr. 286 v. 7.12.1956, S. 4; Eschwege

-Benda, L; Gaertner, H. R. v.; Herrmann, R.; Lüttig, G.; Streif, H.; Vinken, R. \& Wunderlich, H. G. (1968): Känozoische Sedimente in tektogenetischen Fallen und Subrosionssenken in SüdNiedersachsen. - Z. dt. geol. Ges., 117 (f. 1965): 713 - 726, 1 Abb., 1 Tab.; Hannover [darin: Bramburg, Hoher Hagen, Bilshausen, Seeburger See]

-Besch, Wulf (1960): Kunde von dem eiszeitlichen Klima im Kreise Hersfeld. - Mein Heimatland, 19 (6): 21 - 22; Bad Hersfeld

QBischoff, Ralf (1999): Untersuchungen an spätglazialen und holozänen Auensedimenten des Unstruttales im Bereich des zentralen Thüringer Beckens. - Geowiss. Mitt. Thüringen, ㅍ: 127-141, 5 Abb.; Jena [Unters. Lokalitäten: Altengottern, Straußfurt, Oldisleben]

QBismarck, Wolfram (1942): Diluviale Beckenablagerungen im nordwestlichen Eichsfeld. Diss.[unveröff.] Univ. Jena, 87 Bl., Abb.; Jena

-Bismarck, Wolfram (1953): Das Bilshäuser Becken. Ausdehnung, Schichtenfolge und Untergrund der Ablagerung. - Die Goldene Mark, 4 (Oktober-H.): 10-14; Duderstadt [Quartär]

-Bismarck, Wolfram (1957): Das Duderstädter Becken. - Die Goldene Mark, $\underline{8}$ (Oktober-H.): 12-18; Duderstadt [Quartärstratigraphie]

GBornemann [sen.], J. G. (1856): Über die Diluvial- und Alluvialbildungen der Umgegend von Mühlhausen im Gebiet des oberen Unstruttales. - Z. dt. geol. Ges., 8: 89-116, 1 Tab.; Berlin [u.a. Travertinbildungen] 
- $\square$ Brosche, Karl-Ulrich \& Walther, Michael (1980): Lößprofile von Vaake (Bl. 4523 Münden) und Albungen (Bl. 4725 Bad Sooden-Allendorf) in Nordhessen. - Geol. Jb. Hessen, 108: 143-150, 2 Abb.; Wiesbaden

$\square$ Brosius, Marita (1958): Tegelen-Braunkohle von Fürstenhagen bei Hessisch-Lichtenau. - Notizbl. Hess. L.-A. Bodenforsch., 86: 316 - 319, 2 Abb.; Wiesbaden

- •Brüning, Herbert (1966): Vorkommen und Entwicklungsrhythmus oberpleistozäner PeriglazialErscheinungen und ihr Wert für pleistozäne Hangformung - dargestellt an Beispielen aus dem Bereich der nördlichen Lößgrenze, aus dem Leinetal und den Leinetalrandgebieten. - Forsch. Dt. Landeskde., 156; 97 S., 52 Abb.; Bad Godesberg

[Unters. u.a. Umgebung v. Göttingen (Friedland, Krebeck, Settmarshsn.) Kassel-Niedervellmar]

-Chanda, Sunirmal (1962): Untersuchungen zur pliozänen und pleistozänen Floren- und Vegetationsgeschichte im Leinetal und im südwestlichen Harzvorland (Untereichsfeld). - Geol. Jb., 79: 783-844, 5 Abb, 4 Tab., 5 Taf.; Hannover

[darin: Untersuchungan an Material der Tongrube Eichenberg]

$\square \bullet$ Claasen, Karlheinz (1941): Die Flußterrassen des Werratals zwischen Bad Sooden-Allendorf und Hann. Münden. - Archiv f. Landes- u. Volkskunde v. Niedersachsen - Veröff., 1941(7) (= Bd. 1 $(7))$ : 125-166, 5 Abb., 10 Profile, 1 Tab., 1 Kt.; Oldenburg i. O.

$\square \bullet$ Claasen, Karlheinz (1944): Flußterrassen und Landschaft an der unteren Werra (zwischen Bad Sooden-Allendorf und Hannoversch-Münden. - Archiv f. Landes- u. Volkskunde v. Niedersachsen Veröff., 1944(20) (= Bd. $\underline{\mathbf{5}}(20))$ : 120-140, 14 Abb., 4 Profile, 2 Ktn.; Oldenburg i. O.

口Claus, H. (1973): Die geologisch-paläontologische Erforschung der Burgtonnaer Travertinlagerstätten. Abh. Ber. Museums d. Natur Gotha, [7] 1973: 1-8, 1 Abb.; Gotha

QClaus, Hans (1978): Die geologisch-paläontologische Erforschung der Burgtonnaer Travertinlagerstätten. - Quartärpaläontologie, 3: 9-41, 1 Tab., Taf. 1-8; (Akademie-Verlag) Berlin

-Diesing, Hans-Jörg \& Ledendecker, Stefan (1986): Die Niederterrasse im Subrosionsbekcen von Pöhlde. Mit einem Kataster von grundwassergefährdenden Deponien. - Dipl.-Arb. [unveröff.] Univ. Göttingen 1986; 157 S.

-Ehrenberg, K.-H.; Kulick, H. \& Hottenrott, M. (1991): Basalt, Pliozän und Pleistozän bei Fritzlar (Exkursion B am 2. April 1991) [112. Jahresversamml. d. Oberrhein. geol. Vereins, 2. - 6. April 1991 in Bad Wildungen/Nordhessen]. - Jber. Mitt. Oberrhein. geol. Vereins, N.F., 73: 49 - 56, 1 Tab.; Stuttgart

OEllenberg, Jürgen (1968): Beziehungen zwischen Auslaugung und quartärer Sedimentation im thüringischen Werra-Kaligebiet. - Z. dt. geol. Ges., 117: 670 - 679, 6 Abb., 1 Tab; Hannover

OEllenberg, Jürgen (1972): Auslaugung und Sedimentation im Gebiet von Gerstungen. - Geologie, 21(3): 295-304, 3 Abb.; Berlin

OEllenberg, Jürgen (1975): Schwermineralverteilung, Sedimentation und Stratigraphie im Quartär der mittleren Werra. - Z. geol. Wiss., $\underline{\mathbf{3}}(11): 1389-1404,13$ Abb., 1 Tab.; Berlin

[Werratal zw. Niederschmalkalden und Gerstungen]

GEllenberg, Jürgen (1976): Zur rezenten Sedimentation der Werra in Südthüringen. - Z. geol. Wiss., 4(5): 781-795, 3 Abb., 1 Tab., 4 Taf.; Berlin

QEllenberg, Jürgen (1982): Die Subrosion im Werra-Kaligebiet der DDR, quartärgeologische, geomorphologische und tektonische Aspekte. - Z. geol. Wiss., 10(1): 61-71, 6 Abb.; Berlin 
OEllenberg, Jürgen (2002): Lützensommern - Spuren der Eiszeit. - In: Sedlacek, Peter [Hrsg.]: (Spuren suchen - Landschaften entdecken) Thüringen - Geographische Exkursionen. - 325 S., 105 Abb.; hier: S. 175-176, 1 Abb., 1 Tab.; (Justus Perthes) Gotha

OEllenberg, J. \& Kuhn, G. (1969): Das Quartär und seine nutzbaren Gesteine im Werragebiet (Exkursion A). - In: Steinmüller, Arno [Hrsg.]: Exkusrionsführer zum Treffen der Sektion Quartärgeologie vom 19. - bis 21. Septemberg 1969 in Erfurt - „Ergebnisse quartärgeologischer Untersuchungen in Thüringen. - [Exkursionsführer und Veröffentlichungen - Gesellschaft für Geologische Wissenschaften der DDR, 33]; 82 S., zahlr. Abb.; hier S. 5-23, 7 Abb.; [Herausgeg. i. Auftrag d. Dt. Ges. f. geol. Wiss.] Berlin [Oberes Werratal zw. Frauensee u. Breitungen, Niederschmalkalden]

OEllenberg, J.; Kahlke, R.-D. \& Maul, L. (1997): Litho- und Biostratigraphie der thüringischen Quartär-Abfolge. Exkursion A 2. - In: Lützner, H. \& Seidel, G. (eds): Regionale Geologie von Europa - Exkursionsführer. - 149. Hauptversammlung - Deutsche Geologische Gesellschaft - Jena, 27.9 bis 3.10.1997 - Schriftenrh. Dt. Geol. Ges., ㅍ: 35-37, 8 Abb.; Hannover 1997 [darin: Travertinbruch Burgtonna, Kiesgrube Oberzella/Werra; Werra bei Breitungen, Untermaßfeld]

OErnst, Werner (1992): „Panta rhei* - auch bei der Werra“ (*“alles fließt“ - Zitat von Heraklit (540 bis 480 v. Chr.)). - Das Werraland, 44(2): 35-37, 2 Abb., 1 strat. Tab.; Eschwege [Fluviatile Geomorphologie, Quartärgeologie]]

OFehler, Andreas (1998): Die Travertine von Bad Langensalza (Thüringen) - Landschafts- und Naturgeschichte zu Beginn einer neuen erdgeschichtlichen Epoche. - 170 S., 60 Abb.; (Rockstuhl) Bad Langensalza

-Findeisen, Hans-Kurt (1952): Pleistozäne und tertiäre Flußablagerungen in der Umgebung von Kassel. - Diss. Univ. Heidelberg 1952, 144 S., 16 Taf., 1 Tab.

-Frechen, Josef (1952): Die Herkunft der spätglazialen Bimstuffe in mittel- und süddeutschen Mooren. Geol. Jb., 67: 209 - 230, 9 Tab.; Hannover [Luttersee b. Seeburg i. Untereichsfeld; Erlenbruckmoor b. Hinterzarten/Schwarzwald]

- Fromm, Kurt (1989): Paläomagnetische Datierung hochgelegener Sand-Kies-Terrassen der Weser. Eiszeitalter u. Gegenwart, 39: 57-61, 4 Abb.; Stuttgart [Gewissenruh, Fürstenberg, Warmbeck]

$\square$ Gangel, L. (1970): Geologische Untersuchungen auf Bl. 4826 Eschwege (NE) und auf Bl. 4726 Grebendorf (SE) mit besonderer Berücksichtigung des mittleren und oberen Buntsandsteins und des Quartärs. - Dipl.-Arb. [unveröff.] Univ. Frankfurt/M.; 175 S., 26 Abb., 10 Diagr., 14 Profile, 1 Taf., 2 Kt.

QGeiger, Walter (1976): Das Kalktuff-Vorkommen bei Großbartloff. - Eichsfelder Heimathefte, (16. Jg.) 1976(3): 230-238, 3 Abb.; Worbis

oGesang, Heinrich (1978): Zur Geologie des Travertins von Burgtonna in Thüringen. Quartärpalontologie, ․ㅗ: 43-49, 9 Abb.; (Akademie-Verlag)

$\square$ Ghamadan, Mohammad Naser (1992): Korngrößenverteilung, Petrographie und Kornformbestimmung von Niederterrassenschottern der Werra (Eschwege, Deutschland). - Dipl.Arb. [unveröff.] Fachber. Geowiss. FU Berlin;

- Grüger, E.; Jordan, H.; Meischner, D. \& Schlie, P. (1994): Mittelpleistozäne Warmzeiten in Göttingen, Bohrungen Ottostraße und Akazienweg (mit einem paläomalakozoologischen Beitrag von Jiri Kovanda). - (Übergeordneter Titel: Neuere Untersuchungen an Interglazialen in Niedersachsen) Geol. Jb., Reihe A, 134: 167 - 210, 6 Abb., 4 Tab., 1 Taf.; Hannover 
-Grupe, Heinrich (1950): Das Landschaftsbild des Kreises Hofgeismar während der Eiszeit. Heimatjahrbuch. f. d. Landkreis Hofgeismar, 1951: 24 - 35: 24 - 35, 4 Abb.; Hofgeismar

-Grupe, Heinrich (1951): Das Landschaftsbild des Kreises Hofgeismar in der Nacheiszeit. Heimatjahrbuch. f. d. Landkreis Hofgeismar, 1952: 36 - 46, 2 Abb.; Hofgeismar [Holozäne Vegetationsgeschichte]

OHabenicht, H. (1913): Die eiszeitliche Vergletscherung des Thüringer Waldes. - 12 S., 1 Kt.; [Selbstverlag d. Autors) Gotha Referat in: N. Jb. Mineral. etc., 1911 (Bd. I): 325 (E. Geinitz); Stuttgart

-Hempel, Ludwig (1955): Frostbodenbildung und Lößanwehung in der Würmeiszeit auf Muschelkalk und Buntsandstein bei Göttingen. - Akad. Wiss. u. Literatur z. Mainz - Abh. Math.-Naturwiss. Kl., $\underline{1955}$, H. 2; 42 S., 8 Abb.; Wiesbaden

- Hempel, Ludwig (1956): Über Alter und Herkunftsgebiet von Auelehmen im Leinetal. - Eiszeitalter u. Gegenwart, 7: 35-42, 3 Abb.; Öhringen/Württ.

OHeinrich, Wolf-Dieter \& Jäger, Klaus-Dieter (1978): Zusammenfassende stratigraphische und palökologische Interpretation des Fossilvorkommens in der untersuchten jungpleistozänen Deckschichtenfolge über dem Travertin von Burgtonna in Thüringen. - Quartärpaläontologie, $\underline{3}$ : 269 285, 6 Abb., 1 Tab.; (Akademie-Verlag) Berlin

-Henningsen, Dierk (1988): Durchsichtige Schwerminerale in quartären Flußablagerungen der oberen Weser. - N. Jb. Geol. Paläont., Mh., 1988: 537-543, 2 Abb., 1 Tab.; Stuttgart [Untersuchungen zwischen Hann.-Münden und Verden]

$\square 0 \bullet$ Hirschberg, Christian Götz (1997): Die Gerölle von Werra und Weser - Ihre strukturelle und kompositionelle Reifung in der Natur und im Experiment. - Berliner geowiss. Abh. Reihe A, 191; VIII, 114 S., Abb., Kt.; zgl. Diss. TU Berlin 1996; Berlin

[Thüringen, Hessen, Niedersachsen]

-Huckriede, Reinhold \& Urban, Brigitte (1998): Ein landschafts- und flußgeschichtlich wichtiges Pannon- bis Altquartär-Profil bei Fritzlar/Hessen. - Z. dt. geol. Ges., 149: 105 - 126, 3 Abb., 6 Taf.; Stuttgart

$\square$ Ibbeken, Hillert \& Hirschberg, Christian (1999): Die Porphyr-Gerölle von Werra und Weser, ein sedimentologisches Rätsel. / The porphyry gravels of theWerra and Weser rivers, a sedimentological enigma. - (Dieter-Meischner-Geburtstagsband) N. Jb. Geol. Paläont. Abh., 214(1/2): 25-43, 8 Abb.; Stuttgart

-Jacobshagen, Eduard (1951): Das Eiszeit-Geschehen in der Heimatkunde und Heimatpflege. Hessische Heimat, N.F., $\underline{\mathbf{1}}(1): 8$ - 9, 1 Abb.; Marburg

-Jacobshagen, E. (1958): Der Habichtswald in der eiszeitlichen Tundra. - Hessische Heimat, N.F., 7 [f. 1957/58](6): 25-30, Abb. 24-29; Marburg/L.

$\square$ Jacobshagen, Eduard \& Penndorf, Hans (1952): Die Sandgrube von Unterrieden im Werratale. Hessische Heimat, N.F., 2 $2(3): 59-62,1$ Abb.; Marburg/L.

OJäger, Klaus-Dieter \& Heinrich, Wolf-Dieter (1978): Die stratigraphische Gliederung eines fossilführenden jungpleistozänen Deckschichtenprofils über dem Interglazialtravertin von Burgtonna in Thüringen. - Quartärpaläontologie, $\underline{3}: 187$ - 202, 5 Abb., 5 Tab.; (Akademie-Verlag) Berlin

口Jäger, Willy (1923): Die Haarlache als geologischer Aufschluss. - Eschweger Tageblatt, 1923; 4.12.1923; Eschwege 
[Temporärer Quartäraufschluß; „Haarlache“: Name eines Seitenarms der Werra in Eschweger Gerberviertel; dort wurden die Häute vor dem Gerben enthaart und die Haare im Fluß entsorgt]

QKahlke, H.-D. [Hrsg.] (1978): Das Pleistozän von Burgtonna in Thüringen - Teil. 1. Die Travertine, Teil 2. Die Deckschichten der Travertine von Burgtonna in Thüringen. - Quartärpaläontologie Abh. Ber. Inst. Quartärpaläont., $\underline{\mathbf{3}}$, 399 S, 137 Abb., 56 Taf., 46 Tab.; (Akademie-Verlag) Berlin

OKahlke, Hans-Dietrich (1978): Zusammenfassender Überblick zur stratigraphischen Stellung der Travertine von Burgtonna in Thüringen. - Quartärpaläontologie, 조 171-174, 2 Abb.; (AkademieVerlag) Berlin

OKahlke, H.-D.; Eismann, L. \& Wiegank, F. (1984): Die Neogen/Quartär-Grenze Territorium der Deutschen Demokratischen Republik. - Z. angew. Geol., $\underline{\mathbf{3 0}}$ (1): 44-48, 2 Abb., 1 Tab.; Berlin [Bezugnahme a. West-, bzw. Südwestthüringen]

OKahlke, Hans-Dietrich \& Maul, Lutz Chr. (2002): Pleistozäne Fossillagerstätten in Thüringen (Exkursionen H am 5. April 2002). - Jber. Mitt. Oberrhein. geol. Vereins, N.F., 84: 225 - 239, 6 Abb.; Stuttgart

[Weimar-Ehringsdorf, Burgtonna]

OKaiser, Erich \& Naumann, Ernst (1905): Trias am Hainich. Diluvium in Nordwest-Thüringen. - Jb. Preuß. Geol. Landesanst., 23 (f. 1902): 641-659; Berlin

Referat in: N. Jb. Mineral. etc., 1905 (Bd. II): 447-448 (Wüst); Stuttgart

Referat in: Mitt. Geogr. Ges. i. Thür., 23: 51 (E. Schütze); Jena 1905

[Bericht über Aufnahmearbeiten zur Geologischen Karte von Preußen und benachbarten Bundesstaaten 1901,1902 a. Bl. Langula, [Bad] Langensalza]

OKlitzing, Antje \& Thiemeyer, Heinrich (2000): Verbreitung und Ausprägung der periglazialen Deckschichten in den Hochlagen des Thüringer Waldes im Gebiet um den Schmücker Graben. Geowiss. Mitt. Thür., ㅁ: 81-93, 2 Abb., 11 Tab.; Jena

-Koenen, A. v. (1888): Ueber neuere Aufschlüsse im Diluvium von Göttingen. - Nachr. Kgl. Ges. Wiss. z. Göttingen, 1888(9): 253-257; Göttingen

Referat in: N. Jb. Mineral. etc., 1891 (Bd. I): 309-310 (E. Koken); Stuttgart

OKamradt, Ivonne (2002): Beitrag zur kleinmaßstäblichen Fazies- und Architekturelement-Analyse der Süßwasserkalke von Burgtonna in Thüringen. - Beitr. Geol. Thüringen, 9: 247-271; Jena

OKohlstock, Karl (1926): Burgtonna: Kalktuffe; Gräfentonna: Gräberfund. - Entdeckungsreisen in der Heimat, 25; 2., vermehrte Aufl.; 16 S., Abb., Kt.; (Stollberg) Gotha

OKrause, Reinhard (1981): Der Wasserfall der Lutter bei Großbartloff. - Eichsfelder Heimathefte, [21] 1981(3): 213-216, 1 Abb.; Worbis

OKugler, H. (1961): Bemerkungen zur Gliederung und Altersstellung der pleistozänen Flußterrassen der Unstrut. - Geogr. Beitr., 20/21: 183-196; Berlin

-Lang, Hans Dietrich (1956): Jungpleistozäne Torfe im nördlichen Hessen. - Notizbl. Hess. Landesamtes f. Bodenforsch., 4ㅜ 245-252, 3 Abb., 1 Tab.; Wiesbaden [darin: Niederaula b. Bad Hersfeld, Borken]

OLangenhan, Alwin (o. J.): Beiträge zur Erforschung der interglacialen Kalktuffe des Pleistocaens (Antiquusstufe) von Burgtonna und Gräfentonna in Thüringen.

[Langenhan, Alwin 1850-1916]

-Lemmer, Frank \& Rambow, Dietrich (1996): Abgedeckte geologische Karte, Höhenlage der Quartärbasis und Mächtigkeitsverteilung von pleistozänen Terrassenkiesen im Raum Kassel 
(Nordhessen), insbesondere im Gebiet östlich der Fulda (Bettenhausen und Waldau). - Geol. Jb. Hessen, 124 : 137 - 148; 4 Abb., 1 Tab.; Wiesbaden

-Lepper, Jochen (1996): Die Ballertasche bei Hann.-Münden - ein geologische Ensemble. - Ber. Naturhist. Ges. Hannover, 138: 133-139, 3 Abb.; Hannover [Buntsandstein, Quartär]

OLindner, Andreas (1999): Diskussion der stratigraphischen Alter der Travertingerölle und der anstehenden Travertine im Gebiet der oberen Unstrut. - Geowiss. Mitt. Thüringen, 7: 99-126, 4 Abb., 1 Tab.; Jena

[Oberlauf bis Tonna]

- $\square$ Linstow, Otto v. (1922): Die Verbreitung der tertiären und diluvialen Meere in Deutschland. - Abh. Preuß. Geol. Landesanst., N.F., 87; 243 S., 12 Abb., 14 Taf.; Berlin

[Bezug u.a. auf: Großalmerode, Oberkaufungen, Kassel]

OMania, Dieter [Mitautor] (2003): Die Travertine in Thüringen und im Harzvorland - Travertines in Thuringia and the foothhills of the Harz. - Hallesches Jb. Geowiss., Reihe B, 17, 83 S., 53 Abb., Kt.; Halle/Saale

-Mensching, Horst (1949): Talauen und Schotterfluren im Niedersächsischen Bergland. - Göttinger geogr. Abh., 4 ; 60 S., 8 Abb. (2 Taf.), 3 Prof., 5 Kt.; Göttingen [darin: Leinetal]

-Mensching, H. (1951): Akkumulation und Erosion niedersächsischer Flüssse seit der Rißeiszeit [Vortragstext]. - Erdkunde, $\underline{\mathbf{5}}(1): 60$ - 70, 5 Abb.; Bonn [darin: Göttinger Leinetal]

$\square$ Mensching, H. (1953): Die periglaziale Formung der Landschaft des unteren Werratales. - Göttinger geogr. Abh., 14: 80 - 126, 16 Abb., 1 Taf; Göttingen

- Meyer, B.; Raddatz, K. \& Rohdenburg, H. (1963): Eine eisenzeitliche Siedlung in Rosdorf bei Göttingen - ihre stratigraphische Stellung zum Kalksinter - Auelehm -Komplex und ihr keramischer Fundinhalt. - Göttinger Jb., 1963: 33 - 42; 3+2 Abb. ; Göttingen

OMichel, Christoph (1998): Neue Aufschlußbefunde im Bereich der weichselzeitlichen Deckschichten über dem eeminterglazialen Travertein von Burgtonna. - Geowiss. Mitt. Thüringen, Beih. ㅍ: 79-93, 2 Abb., 1 Beil.; Weimar

OMöller, L. (1870): Die diluvialen Geschiebe bei Mühlhausen im nordwestl. Thüringen. - Z. gesammt. Naturwiss., $\underline{\mathbf{3 6}}$ (N.F. 2): 272-274; Berlin

ONaumann, E. (1907): Mitteilungen über Ausbildung und Lagerung der Trias am Südrande des Hainichs und des Diluviums dieser Gegend - (Nebentitel: Lagerungsverhältnisse, Diluvium am Hainich Blätter Henningsleben, Mihla, Treffurt). - Jb. Preuß. Geol. Landesanst., 25 (f. 1904): 715-732; Berlin Referat in: N. Jb. Mineral. etc., 1906 (Bd. II): 229-232 (Karl Walter); Stuttgart

口ONaumann, Ernst (1913): Beiträge zur Kenntnis des Thüringer Diluviums. - Z. dt. geol. Ges., $\underline{64}$ (f. 1912): 299-332, [6] Tab., Taf. V.; Berlin

[darin: „Das Diluvium des oberen Unstruttals“ - „Das Werratal zwischen Hörschel und Wanfried“]

-Nehring, A. (1880): Ein Lösslager bei Mariaspring unweit Göttingen. - N. Jb. Mineral. etc., $\underline{1880}$ (Bd. 2): 299 - 300; Stuttgart

OPatzelt, Gerald (1985): Ein interglaziales (,zwischenzeitliches“) Torfvorkommen bei Mühlhausen. Mühlhäuser Beitr., $\underline{8}:$ 79-85, 1 Abb.; Mühlhausen 
-Penndorf, Hans (1919): Die Lagerungsverhältnisse in der Ziegeleigrube in Wolfsanger bei Cassel. Abh. u. Ber. Vereins f. Naturkunde zu Kassel, 55: 219 - 223, 2 Abb.; Kassel [Quartärgeologie]

-Penndorf, Hans \& Jacobshagen, Eduard (1952): Die Sandgrube Unterrieden im Werratal. Hessische Heimat, N.F., 2 (3): 59 - 62, 1 Abb.; Marburg

$\square Q \bullet$ Rausch, Martin (1996): Mengenbestimmung der jungen Abtragungsprodukte des Thüringer Waldes am Beispiel des Weser-Fluß-Systems. - Eiszeitalter u. Gegenwart, 46: 91 - 98, 3 Abb., 1 Tab; Hannover [WMK, T, N]

ORegel, Fritz(1913): Literatur zur Vergletscherung des Thüringer Waldes. - Mitt. Geogr. Ges. (f. Thüringen), 31: 149-158; Jena

[Literaturreferat]

OReichelt, Günter (1964): Zur Frage pleistozäner Vergletscherung im Harz und Thüringer Wald. Erdkunde, 18(1): 62-65, 3 Abb.; Bonn

-Ricken, W. \& Meyer, B. (1982): Lößbürtige Böden des Jung-Quartärs zwischen Harz und Leine Beziehungen zur Quartär-Chronostratigraphie; Relief-Geschichte der Landschaft, fluviatilen Sedimentation, Paläoklimakunde und Variation der holozänen Prozesse der Bodenbildung. - Bericht über die Exkursion des Arbeitskreises „Paläoböden“ der Deutschen Bodenkundlichen Gesellschaft

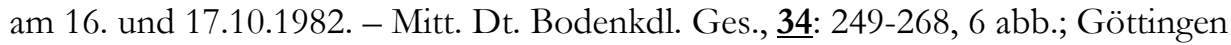
[darin: Tongrube zw. Göttingen u. Rosdorf; Kiesgrube b. Reinshof S’ Göttingen]

- •Rohde, Peter (1988): Elf pleistozäne Sand-Kies-Terrassen der Weser. Erläuterungen eines Gliederungsschemas für das obere Weser-Tal. - Eiszeitalter und Gegenwart, 모: 42-56, 4 Abb., 2 Tab.; Hannover

-Rohde, Peter (1996): Das Wesertal an der „Ballertasche“ bei Münden - Erläuterung eines quartärgeologischen Schnittes. - Ber. Naturhist. Ges. Hannover, 138: 151-161, 2 Abb., 3 Tab.; Hannover

- $\square$ Rohdenburg, Heinrich (1966): Eiskeilhorizonte in südniedersächsischen und nordhessischen Lössprofilen. - Götinger Bodenkdl. Ber., 2 2: 137-170, 20 Abb.; Göttingen; auch Land Landschaftsgenese und Landschaftsökologie, $\underline{3}$ : 91-114, 20 Abb.; Braunschweig 1979 Bodenprofile aus der Region um Kassel bis Wolfhagen (W), Vollmarshausen (E), Hofgeismar (N) und Borken (S); auch Bodenprofile von den Ziegeleigruben Albungen, Ziegeleigrube Oetmannshausen und Witzenhausen]

$\square$ Rohdenburg, H. (1968): Jungpleistozäne Hangformung in Mitteleuropa. - Beiträge zur Kenntnis, Deutung und Bedeutung ihrer räumlichen und zeitlichen Differenzierung. - Göttinger Bodenkdl. Ber., ㅁ: 3-107, 39 Abb.; Göttingen [Einzelprofile u.a. Umgebung Witzenhausen, Bischhausen i. Werra-Meissner-Kreis]

- $\square$ Rohdenburg, Heinrich (1979): Eiskeilhorizonte in südniedersächsischen und nordhessischen Lössprofilen. - Landschaftsgenese und Landschaftsökologie, 3: 91-114, 20 Abb.; Braunschweig auch Göttinger Bodenkdl. Ber., 2: 137-170; Göttingen 1966

[Bodenprofile aus der Region um Kassel bis Wolfhagen (W), Vollmarshausen (E), Hofgeismar (N) und Borken (S); auch Bodenprofile von den Ziegeleigruben Albungen, Ziegeleigrube Oetmannshausen und Witzenhausen]

- •Rohdenburg, Heinrich \& Meyer, Brunk (1968): Zur Feinstratigraphie und Paläopedologie des Jungpleistozäns nach Untersuchungen an südniedersächsischen und nordhessischen Lößprofilen. (Löß-Forschungen in Südniedersachsen und Nordhessen). - Göttinger bodenkdl. Ber., 2: 1-135, 25 Abb., 12 Tab.; Göttingen - auch: Landschaftsgenese und Landschaftsökologie, $\underline{\mathbf{3}}$ : 1-89; Braunschweig 
1979

[Südniedersachsen, Raum Kassel]

QRothe, H. W. (1954): Die Travertin-Fundstellen in Mühlhausen/Thür. - Der Aufschluss, $\underline{5}$ : 244-248, 3 Abb.; Rosdorf b. Darmstadt

OSchilling, Werner \& Wiefel, Heinz (1962): Jungpleistozäne Periglazialbildungen und ihre regionale Differenzierung in einigen Teilen Thüringens und des Harzes. - Geologie, 11(4): 428-460, 5 Abb., 2 Tab.; Berlin [darin: Profil 1 - Großer Beerberg/Thüringer Wald, Profil 2 - Röhnberg/Drei-Gleichen-Gebiet]

-Schönhals, Ernst (1945): Über verschiedenaltrige Lösse und ihre fossilen Verwitterungsdecken bei Homberg a. d. Efze (Bez. Kassel). - Bericht d. Reichsamts f. Bodenforschung, 1944 (5-8): 111-119, 2 Abb.; Wien

هSchönhals, Ernst (1957): Eine äolische Ablagerung des Jüngeren Tundrenzeit im Habichtswald. Notizbl. Hess. L.-A. f. Bodenforsch., 모: 380 - 386, 3 Abb., 1 Tab.; Wiesbaden

$\square$ Schönhals, E.; Rohdenburg, H. \& Semmel, A. (1964): Ergebnisse neuerer Untersuchungen zur Würmlößgliederung in Hessen. - Eiszeitalter u. Gegenwart, 15: 199 - 206, 1 Abb.; Öhringen [Sammelprofil Nordhessen, Bezugnahme auf Bodenprofil Ziegeleigrube Witzenhausen]

aSchröder, Ilse (1938): Die Terrassen der Fulda zwischen Hersfeld und Guntershausen. - Ber. Oberhess. Ges. Natur- u. Heilkde. Gießen, N.F., Naturwiss. Abt., 18 (f. 1937/38): 35 - 71, 2 Taf.; Gießen - zgl. Diss. phil. Univ. Gießen 1938

Referat in: N. Jb. Mineral. etc., Referate, 1940 (Bd. III): 420 (Hesemann); Stuttgart

OSchüller, A. (1954): Pleistozäne Tillite im Thüringer Wald. - Geologie, $\underline{\mathbf{3}}(8):$ 1057-1069, 12 Abb.; Berlin

$\square$ Schütt, Horst (1960): Wie wirkten sich die Eiszeiten im Werratal aus? Über einige periglaziale Spuren bei Bad Sooden-Allendorf. - Das Werraland, 12(4): 51-53, 3 Abb.; Eschwege

-Schweisfurth, W. (1955): Was der Lutteranger erzählt. - Die Goldene Mark, $\underline{6}$ (August-H.): 38-43; Duderstadt [Vegetationsgeschichte/Pollenanalyse, Stratigraphie Lacher Seetuff]

-Selzer, Georg (1936): Diluviale Lößkeile und Lößkeilnetze aus der Umgebung Göttingens. - Geol. Rundschau, 27: 2375 - 293, 10 Abb.; Stuttgart

-Selzer, Georg (1936): Die Gliederung des Lösses im westlichen Eichsfeld und im Talgebiet der oberen Leine. - Festschrift zum 60. Geburtstag von Hans Stille, 437 S., zahlr. Abb., 28 Taf; hier: S. 212 - 222, 5 Abb.; Stuttgart

Referat in: N. Jb. Mineral. etc., Referate, 1927 (Bd. II): 117-118 (Edith Ebers); 1939 (Bd. II): 104-106 (Walther Fischer); Stuttgart

-Siegert, L. (1921): Beiträge zur Kenntnis des Pliozäns und der diluvialen Terrassen im Flußgebiet der Weser. - Abh. Preuß. Geol. Landesanst., N.F., 90; 132 S., 17 Taf.; Berlin

- Sobotha, Ernst (1932): Diluviale und pliozäne (?) Bildungen im und am Fuldatal zwischen Fulda und Rotenburg a/ Fulda. - Z. dt. geol. Ges., 83 (f. 1931): 612 - 618, 7 Abb.; Berlin Referat in: N. Jb. Mineral etc., Referate, 1934 (Bd. II): 615 (E. Christa); Stuttgart

$\square$ Sobotha, Ernst (1932): Gefaltete diluviale Bildungen bei Eichenberg. Bemerkungen zu dem Vortrage des Herrn Brinkmann-Göttingen. - Z. dt. geol. Ges., 4: 724, 1 Abb.; Berlin

OSobotha, Ernst (1935): Zur Geologie des Rusteberggebietes (Beoachtungen im Bausandstein und Diluvium. - Unser Eichsfeld, $\underline{30}$ (1): 13-15; Duderstadt 
OSobotha, E. (1952): Örtliche Faltungen an Schollengrenzen südlich Leningrads und im Eichsfeld. Geol. Rundschau, 40: 285, 1 Abb.; Stuttgart [Ziegeleigrube Ferna/Eichsfeld, Quartärgeologie]

oSteiner, W. (1970): Stratigraphie und Sedimentationsgeschwindigkeit der Travertine von Burgtonna und Ehringsdorf. - Geologie, 19(8): 931-993, 8 Abb.; Berlin

OSteiner, Waltner (1978): Zur Genese des Travertinlagers von Burgtonna in Thüringen. Quartärpaläontologie, 3: 51-58,6 Abb.; (Akademie-Verlag) Berlin

OStengel, Erich (1932): Spuren der Eiszeit im Werratal. - Das Werratal, 9(11): 165-167; Eschwege [Thüringisches Werratal]

-Strautz, Willfried (1963): Auelehmbildung und -gliederung im Weser- und Leinebergland mit vergleichenden Zeitbestimmungen aus dem Flußgebiet der Elbe - Ein Beitrag zur Landschaftsgeschichte der nordwestdeutschen Flußauen. - (Festschrift f. Heinrich Friedrich Wiepking, Hrsg. Buschwald, K.; Lendholt, W. \& Meyer, K.) Beitr. z. Landespflege, 1: 273-314, 14 Abb., 1 Tab.; (Ulmer) Stuttgart

○Thiemeyer, Heinrich (2002): Körner - Eiszeitlicher Löß - Spuren längst vergangenen Klimawandels. In: Sedlacek, Peter [Hrsg.]: (Spuren suchen - Landschaften entdecken) Thüringen - Geographische Exkursionen. - 325 S., 105 Abb.; hier: S. 154-157, Abb. 59 u. 60; (Justus Perthes) Gotha

-Udluft, Hans \& Jacobshagen, Volker (1957): Zur Gliederung des Pleistozäns in Niederhessen. Notizbl. Hess. Landesamtes für Bodenforsch., 포: 255-281, 5 Abb., 1 Tab., Taf. 13-15; Wiesbaden

OUnger, Kurt P. (1971): Genese und Stratigraphie des Gothaer Schotterkomplexes. - Geologie, 20 1074-1086, 7 Abb., 2 Tab.; Berlin

oUnger, Kurt P. (1974): Die Elstervereisung des zentralen Thüringer Keuperbeckens. - Z. geol. Wiss., $\underline{2}(7): 791-800,3$ Abb.; Berlin

OUnger, Kurt P. (1974): Quartär [in Thüringen]. - In: Hoppe, Walter \& Seidel, Gerd [Hrsg.]: Geologie von Thüringen [Bezirke Erfurt, Gera, Suhl]. - S. 742-781, Abb. 140-156, Tab. 93-106; (Haack) Gotha-Leipzig 1974

OUnger, Kurt P. (1995): Quartär [in Thüringen]. - In: Seidel, Gerd [Hrsg.]: Geologie von Thüringen. 1. Aufl.; S. 392-412, 5 Abb., 2 Tab.; Stuttgart 1995

QUnger, Kurt P. (2003): Quartär [in Thüringen]. - In: Seidel, Gerd [Hrsg.]: Geologie von Thüringen. 2., neu bearb. Aufl.; S. 424-443, 5 Abb., 3 Tab.; Stuttgart 2003

oUnger, K. P. \& Schramm, H. (1962): Altpleistozäne Schichtenfolgen und deren Gliederung im nördlichen Vorland des Thüringer Waldes (Exkursion C 1). - In: Viete, Günter [Hrsg.]: „Das Pleistozän im sächsisch-thüringischen Raum“ - Exkursionsführer zur Herbsttagung 1962 vom 19. bis 21. Oktober 1962 in Leipzig und Erfurt - und Kurzreferate der Vorträge anläßlich des 2. Treffens der Sektion Quartärgeologie am 18. Oktober 1962 in Leipzig. - [Exkursionsführer und Veröffentlichungen - Gesellschaft für Geologische Wissenschaften der DDR, 12]; S. 171-180, 5 Abb.; Berlin

[Darin Aufschlüsse: Gräfentonna, Westhausen, Gotha; Alsberg W’Gotha]

OWätzel, Alfred (1995): Ein Geotop des Jungquartärs im Unstrut-Hainich-Kreis - die ehemalige Ziegeleigrube Körner. - Beitr. Geol. Thüringen, N.F., 2: 141-151, 3 Abb., 1 Tab., 2 Taf.; Weimar [Referenzprofil Löß- und Bodenstratigraphie von Thüringen] 
-Walter, Michael \& Brosche, Karl-Ulrich (1982): Zur Bedeutung der Lößstratigraphie für die Rekonstruktion des jungpleistozänen Klimas im nördlichen Mitteleuropa am Beispiel norddeutscher Lößprofile. - Ber. Naturhist. Ges. Hannover, 125: 97-159, 15 Abb., 8 Tab.; Hannover [Bezug u.a. 2 Profile im Werra-Meißner-Kreis: Eschwege, Frauenborn]

- $\square$ OWeber, Hans (1952): Pliozän und Auslaugung im Gebiet der oberen Werra. - Geologica, $\underline{8}$; 136 S., 17 Abb., 4 Taf.; (Akademie-Verlag) Berlin

Referat in: Geologie, $\underline{\mathbf{3}}(1)$ : 86-87 (F. Stock); Berlin

[darin: Untersuchungen Blätter Berka, Creuzburg, Herleshausen u. Hönebach; die Auslaugungssenke a. d. Werra zwischen Berka und Gerstungen; der Zechstein von Wommen; Tekt. Karte m. Anteilen Werra-Meissner-Kreis]

OWeber, Hans (1954/55): Die Flußschotter oberhalb der Talauen im Thüringerwalde. - Wiss. Z. E. M. Arndt - Universität Greifswald, 4 (1954/55), math.-naturwiss. R., 3/4; zgl. Mitt. Geol. Paläont. Inst. Univ. Greifswald, N.F., 19: 339 - 355, 3 Abb., 6 Taf. (12 Fotos); Greifswald

口OWiegers, Fritz (1951): Nordische Feuersteine im diluvialen Terrassenschotter der Werra. - Z. dt. geol. Ges., 103: 78-82, 1 Abb.; Stuttgart

[Region Heldra-Treffurt, Kleintöpfer]

-Wildhagen, Holger (1972): Holozäne Bodenentwicklung, Sedimentbildung und Geomorphogenese im Flussauen-Bereich des Göttinger Leinetalgrabens. - Diss. Univ. Göttingen 1972, 158 S.; s.a. Wildhagen, Holger \& Meyer, Brunk (1972): Holozäne Boden-Entwicklung, Sedimentbildung und Geomorphogenese im Flussauen-Bereich des Göttinger Leinetalgrabens - 1. Spätglazial und Holozän bis zum Beginn der eisenzeitlichen Auenlehm-Ablagerung. - (Übergeordn. Titel: Ergebnisse neuerer Auenforschungen im Leinegraben-Gebiet). - Göttinger bodenkdl. Ber., 21: 1-75, 9 Abb., 5 Tab., 1 Falt-Taf. (3 Kt. 1-3); Göttingen s.a. Wildhagen, Holger \& Meyer, Brunk (1972): Holozäne Boden-Entwicklung, Sedimentbildung und Geomorphogenese im Flussauen-Bereich des Göttinger Leinetalgrabens - 2. Die Auenlehmdecken des Subatlantikums. - (Übergeordn. Titel: Ergebnisse neuerer Auenforschungen im Leinegraben-Gebiet).- Göttinger bodenkdl. Ber., 21: 77-158, 6 Abb., 3 Tab., 2 Falt-Taf. (Kt. 4-9 Kt.); Göttingen -

-Wildhagen, H. (1974): Holozän-Chronostratigraphie der Auensedimente der Leine im Bereich des Leinetalgrabens. - Mitt. Dt. Bodenkdl. Ges., 18: 328-337, 6 Kt., 1 strat. Tab.; Göttingen [Göttinger Leinetal]

-Wildhagen, Holger \& Meyer, Brunk (1972): Holozäne Boden-Entwicklung, Sedimentbildung und Geomorphogenese im Flussauen-Bereich des Göttinger Leinetalgrabens - 1. Spätglazial und Holozän bis zum Beginn der eisenzeitlichen Auenlehm-Ablagerung. - (Übergeordn. Titel: Ergebnisse neuerer Auenforschungen im Leinegraben-Gebiet). - Göttinger bodenkdl. Ber., 21: 1-75, 9 Abb., 5 Tab., 1 Falt-Taf. (3 Kt. 1-3); Göttingen - s. a.: Wildhagen, Holger (1972): Holozäne Bodenentwicklung, Sedimentbildung und Geomorphogenese im Flussauen-Bereich des Göttinger Leinetalgrabens. Diss. Univ. Göttingen 1972

-Wildhagen, Holger \& Meyer, Brunk (1972): Holozäne Boden-Entwicklung, Sedimentbildung und Geomorphogenese im Flussauen-Bereich des Göttinger Leinetalgrabens - 2. Die Auenlehmdecken des Subatlantikums. - (Übergeordn. Titel: Ergebnisse neuerer Auenforschungen im LeinegrabenGebiet).- Göttinger bodenkdl. Ber., 21: 77-158, 6 Abb., 3 Tab., 2 Falt-Taf. (Kt. 4-9 Kt.); Göttingen s. a.: Wildhagen, Holger (1972): Holozäne Bodenentwicklung, Sedimentbildung und Geomorphogenese im Flussauen-Bereich des Göttinger Leinetalgrabens. - Diss. Univ. Göttingen 1972

OWolf, Karl (1912): Die eiszeitliche Vergletscherung des Thüringer Waldes. - Petermanns Mitteilungen, 58(1): 201-202, 2. Abb. a. Taf. 39; Gotha 
OWuest, Ewald (1901): Untersuchungen über das Pliozän und das älteste Pleistozän Thüringens. - 352 S., 4 Abb., 9 Taf; (Schweizerbart) Stuttgart; auch als Veröff. i.d. Abh. Naturforsch. Ges. z. Halle, 23 Auszug als Diss. Univ. Jena 1900

- $\square$ Wunderlich, Hans Georg (1955): Jüngste Tektonik im Gebiet des Leinetalgrabens. - Geol. Rundschau, 43: 78-93, 4 Abb., 1 Falt-Kt.; Stuttgart

[Umgebung von Göttingen; darin: Terrassen der Werra bei Witzenhausen]

-Wunderlich, Hans Georg (1959): Zur Abfolge und Altersstellung quartärer Bildungen im Stadtgebiet von Göttingen. - Eiszeitalter u. Gegenwart, 10: 41 - 55, 5 Abb., 1 Tab.; Öhringen

-Wunderlich, Hans Georg (1963): Das Quartär der Grone-Niederung westlich Göttingen. - Eiszeitalter u. Gegenwart, 14: 53 - 67, 8 Abb.; Öhringen

OZahn, G. von (1917/18): Die Moräne im Schneetiegel im Thüringerwald. - Mitt. Geogr. Ges. (f. Thür.), 35/36: 1-32, 4 Abb.; Jena

[W’ Guhlberg; Untergrund: Rotliegend der Oberhöfer Schichten]

\subsection{Sedimentologie - Sedimentpetrographie}

-Gast, Reinhard E. (1992): Cornberg outcrop revistet (Hessen, Germany) - The depositional environments of its saurian tracks and Weissliegendes sandstones - Die Cornberg-Aufschüsse neu interpretiert (Hessen): Das sedimentäre Ablagerungsmillieu der Saurierfährten und der WeissliegendSandsteine. - Meyniana, 46: 59-75, 3 Abb., 7 Taf.; Kiel

QGrumbt, Eberhard (1969): Beziehungen zwischen Korngröße, Schichtung, Materialbestand und anderen sedimentologischen Merkmalen in feinklastischen Sedimenten. - Geologie, 18 (2): 151-167, 7 Abb., 4 Tab.; Berlin

[Unterer Buntsandstein, Umrahmung nordwestlicher Thüringer Wald]

OGrumbt, Eberhard (1971): Beziehungen zwischen Sedimentationsprozeß und Gefüge in klastischen Sedimenten. - Ber. Dt. Ges. geol. Wiss., Reihe A, 16 (3-5): 297-314, 13 Abb., 2 Tab.; Berlin [darin Beispiele aus dem Buntsandsteinrahmen des Thüringer Waldes]

QGrumbt, Eberhard (1974): Sedimentgefüge im Buntsandstein Südwest- und Südthüringens. - Ein Beitrag zur Untersuchung von Rotsedimenten. - Schriftenrh. f. geol. Wiss., 1: 1-205, 80 Abb., 18 Tab., XV Taf.; Berlin

OHeubeck, Christoph (2009): Geröllführende sedimentäre Gänge der Eisenach-Formation (Oberrotliegend): modifizierte artesische Injektionen am Fuß alluvialer Fächer? - Z. Dt. Ges. Geowiss., 160(1): 41-56, 17 Abb.; Stuttgart

$\square \mathrm{D}$ Hirschberg, Chr. G.; Ibbeken, H. \& Ellenberg, J. (1993): Die strukturelle Reifung von Geröllen des Thüringer Waldes entlang der Werra und Weser. - Zbl. Geol. Paläont. - Teil I; 1992: 629-643, 5 Abb., 2 Tab.; Stuttgart

$\square$ ㅂ Hirschberg, Christian Götz (1997): Die Gerölle von Werra und Weser - Ihre strukturelle und kompositionelle Reifung in der Natur und im Experiment. - Berliner geowiss. Abh. Reihe A, 191; VIII, 114 S., Abb., Kt.; zgl. Diss. TU Berlin 1996; Berlin

[Thüringen, WMK, Niedersachsen]

$\square$ Q Ibbeken, Hillert \& Hirschberg, Christian (1999): Die Porphyr-Gerölle von Werra und Weser, ein sedimentologisches Rätsel. / The porphyry gravels of the Werra and Weser rivers, a sedimentological 
enigma. - N. Jb. Geol. Paläont. Abh., (Dieter-Meischner-Geburtstagsband) 214(1/2): 25-43, 8 Abb.; Stuttgart

[Ohne konkreten Bezug zu Probenahmepunkten (dazu: Hirschberg, Ibbeken \& Ellenberg (1993)]

@Katzung, Gerhard (1967): Synsedimentäre Deformation im Rotliegenden von Masserberg (Thüringen). - Geologie, 16(4): 2 Abb., 1 Taf.; Berlin

OKlaua, Dieter (1964): Sedimentpetrographische Untersuchungen der Rhätsandsteine Thüringens. Diss. Hochschule f. Architektur, Bauwesen Weimar 1964

OKnoth, Wolfram \& Kriebel, Ulrich (1965): Zum Problem der Geröllregelung in fluviatilen Sedimenten. - Geologie, 14(8): 949-957, 3 Abb.; Berlin [darin: Einregelung v. Geröllen des Wartburgkonglomerates bei Eisenach/Tambach-Schichten]

QKunert, Reinhard (1978): Lithostratigraphische Ergebnisse der Dünnschliffintegration an Sandsteinen des Thüringer Permosiles. -Hallesches Jb. Geowiss., 3: 95-104, 4 Abb., 1 Tab.; Halle [Thüringer Wald, Asbach-Rotteroder Senke]

OLangbein, Rolf (1965): Zur Problematik der Granatführung im Buntsandstein Thüringens. - Geologie, 14(8): 958-968, 6 Abb., 1 Tab.; Berlin

[Mineralogie (sekundäre Granatbildung) - darin: Westthüringen - Bhrgn. Lengefeld u. St., Burg

Scharfenstein b. Leinefelde, Kinderode]

OLützner, Harald (1989): Sedimentation rates of Variscan molasse bassins in Central Europe. - Z. Geol. Wiss., 17(9): 859-868, 3 fig., 2 tabl.; Berlin

[darin: Saale-Senke: Thüringer Wald]

OLützner, Harald \& Rentzsch, Johannes (1975): Sedimentation und Metallogenie in einem intramontanen Becken der variszischen Molasse. - Z. geol. Wiss., $\underline{\mathbf{3}}(11)$ : 1473-1490, 5 Abb., 2 Tab.; Berlin [Goldlauterer Becken/Thüringer Wald]

OLützner, Harald; Ellenberg, Jürgen \& Falk, Fritz (1981): Sedimentology and basin development of Rotliegend deposits in the Saale through. - In: Depowski, Stanislaw [president organizing committee]: Central European Permian - International Symposium - Jabłonna, April 27-29, 1978 Proceedings; 656 S., Abb.; hier S. 239-252, 4 Abb.; (Geological Institute) Warszawa [darin: Thüringer Wald]

OMartens, Thomas; Schneider, Jörg \& Walter, Harald (1981): Zur Paläontologie und Genese fossilführender Rotsedimente - der Tambacher Sandstein, Oberrotliegendes, Thüringer Wald (DDR). - (Beiträge zur Paläontologie, Stratigraphie und Palökologie - Zum 65. Geburtstag von Prof. Dr. rer. nat. habil Arno Hermann Müller) Freiberger Forschungshefte, Reihe C, 363: 75-100, 10 Abb., 5 Taf.; Leipzig

-Paul, Josef; Wemmer, Klaus \& Ahrendt, Hans † (2008): Provenance of siliclastic sediments (Permian to Jurassic) in the Central European Basin. - Z. dt. Ges. Geowiss., 159(4): 641-650, 5 figs., 4 tab.; Stuttgart [Südniedersachsen, u.a. Lkr. Göttingen]

OVan der Klauw, Sebastian N.G.C.; Lützner, Harald \& Rauche, Henry (2002): An investigation of the composition and microstructure of rock fragments in coarse grained Rotliegend sedimentary rocks around the Ruhla crystalline complex (Thuringian Forest, Germany) - Zusammensetzung und Mikrostrukturen von Gesteinsfragmenten in Rotliegend Sedimenten im Umfeld des Ruhlaer Kristallins. - Z. geol. Wiss., 30(4/5): 315-325, 2 fig., 2 tabl.; Berlin [Abtragungsgeschichte, Hebungsgeschichte] 
QVoigt, T. \& Föhlisch, K. (2001): Beobachtungen zur Mikritgenese im Unteren Muschelkalk <Posterbeitrag>. - In: Gaupp, R. \& Klauw, S. van der [Hrsg.]: Sediment 2001, Jena, 6.6. 8.6.2001 - Programm, Kurzfassungen, Exkursionsführer - Institut für Geowissenschaften, FriedrichSchiller-Universität Jena. - Schriftenrh. Dt. Geol. Ges, 13: 95; Hannover 2001 [Genese Gefüge Wellenkalk/Unterer Muschelkalk]

OZimmerle, W. (1997): Petrography and Taphonomy of the Tetrapod-bearing Rotliegend Siltstones of Bromacher / Thuringian Forest, central Germany (Vortragskurzfassung). - In: Büchel, Georg \& Lützner, Harald (Hrsg.): Regionale Geologie von Mitteleuropa - Geodynamische Prozesse zwischen Alpen und Nordatlantik - 149. Hauptversammlung - Deutsche Geologische Gesellschaft und Jahreshauptversammlung der Fachsektion Geoinformatik - Jena 27.09.-3.10.1997 - Kurzfassung der Vorträge und Poster. - Schriftenrh. Dt. Geol. Ges., 2: 125; Hannover 1997

\subsection{Tektonik}

-Anderle, Hans Jürgen (1983): Jungkimmerisch rotierte Kluftgefüge aus hessischen Grabenzonen. Geol. Jb., 111: 251-260, 2 Abb., 3 Tab.; Wiesbaden

[Volkmarser Graben, Kasseler Graben, Fritzlar-Naumburger Störungszone, Sontraer Graben]

-Anders, Carsten (1998): Oberer Muschelkalk und Unterer Keuper in der Bohrung 10 Deiderode (Trias, südliches Niedersachsen). - Die Geologie beiderseits der Arenshäuser Verwerfung, südlicher Leinegraben, nördlich Kirchgandern und Arenshausen, West-Thüringen, Süd-Niedersachsen (TK 25: 4625 Blatt Witzenhausen). - Dipl.-Arb. /Dipl.-Kart. (unveröff.) Univ. Göttingen, 65,33 Bl., 2 Beil.; Göttingen

OAndreas, D.; Jungwirth, J. \& Wunderlich, J. (1992): Die strukturelle Entwicklung des Thüringer Waldes und seiner Vorländer. - Geol. Bl. NO-Bayern, 42 (1-2): (Gedenkschrift HANS WEBER): 109126, 6 Abb.; Erlangen

OAndreas, D. \& Wunderlich, J. (1998): Tektonische Verhältnisse am Westthüringer Quersprung (nordwestlicher Thüringer Wald). - II Spät- und postvaristische Entwicklung an der Reifstieg-Störung und die frühe Entwicklungsphase des Ringgau-Fränkischen Lineaments. - (Festschrift zum 65. Geburtstag von Prof. Dr. Harald Lützner - Hrsgeg. vom Thür. Geol. Verein e.V. und dem Institut für Geowissenschaften der Friedrich-Schiller-Universität Jena) - Beitr. Geol. Thür., N.F., 5: 39-72, 9 Abb., 2 Tab.; Jena

OAndreas, Dieter \& Lützner, Harald (2001): Profilentwicklung und Tektonik der Oberhof-Formation und der Rotterode-Formation im mittleren Thüringer Wald (GK 25 Waltershausen und Tambach) $<$ Vortragskurzfassung >. - In: Rauche, Henry [Hrsg.]: Regionale und angewandte Geologie der Grenzregion der Süddeutschen und der Mitteldeutschen Scholle. - Programm und Kurzfassungen der Vorträge. - 10. Jahrestagung Gesellschaft f. Geowissenschaften i. Schmalkalden, 19.-22. September 2001. - Exkursionsführer u. Veröff. Ges. f. Geowiss., 214; S. 59-60; Berlin 2001

口 $\square$ OApel, Jürgen \& Rüppel, Heidi [Verfass. u. Hrsg.] (2005): Raus in die Natur - Tipps für den Sonntags-Ausflug im Dreiländereck Hessen - Niedersachsen - Thüringen. - 159 S., 111 Fotos, 34 Kt., 1 Zeit-Taf.; (LSRB-Verlag, Landschaftskundlicher-Studien-Reisebuch-Verlag) Witzenhausen [zahlreiche Ausflugstipps, auch zu tektonischen Strukturen: Ziel 43 (Hess. Lichtenauer Altmorschener Graben), Ziel 59 (Tektonik/Lindewerra) ]

OBaar, A. (1953): Über Zusammenhänge zwischen Tektonik, Landschaftsform und Kalilagerstätte am Südharz. - Freiberger Forschungshefte, Reihe C, $\underline{\mathbf{5}}$ : 5-10, 1 Bild; Berlin [darin: Bezugnahme auf Südharz-Kalirevier, Werra-Kalirevier] 
OBankwitz, P. \& Bankwitz, E. (1989): Strain Analysis in Rotliegendes Series of the Thuringian Forest. Z. geol. Wiss., 17(6): 569-580, 6 fig., 2 tab.; Berlin

OBankwitz, P. \& Bankwitz, E. (1993): Krustendeformation im Bereich der Finne-Kyffhäuser-GeraJachimov-Zone. - Z. geol. Wiss., 21 (1/2): 3-20, 14 Abb., 2 Tab.; Berlin [darin: Ohmgebirge/Meßstelle Kaltenohmfeld]

-Becker, Roland Ernst \& Laemmlen, Manfred (1994): Die östlichen Fortsetzungen von Hersfelder und Großenlüderer Graben. - Geol. Jb. Hessen, 122: 39 - 48, 4 Abb.; Wiesbaden

- $\square \bullet$ Beiersdorf, Helmut (1969): Druckspannungsindizien in Karbonatgesteinen Süd-Niedersachsens, Ost-Westfalens und Nordhessens. - Geol. Mitt., 8(f. 1967)(3): 217-262, 28 Abb.; Aachen [Lkr. Göttingen, Hessen, WMK]

-Benda, L; Gaertner, H. R. v.; Herrmann, R.; Lüttig, G.; Streif, H.; Vinken, R. \& Wunderlich, H. G. (1968): Känozoische Sedimente in tektogenetischen Fallen und Subrosionssenken in SüdNiedersachsen. - Z. dt. geol. Ges., 117 (f. 1965): 713 - 726, 1 Abb., 1 Tab.; Hannover [darin: Bramburg, Hoher Hagen, Bilshausen, Seeburger See]

QBenek, Reinhard \& Schust, Friedrich (1988): Bemerkungen zur partiellen Gefügedeformation in Magmatitgängen des Ruhlaer Kristallins (Thüringer Wald). - Z. geol. Wiss., 16(8): 801-816, 16 Abb.; Berlin

QBiewald, Wolgang (2000): Zur Ausbildung der NE-Randflexur des Thüringer Waldes zwischen Ilmenau und Elgersburg. - Geowiss. Mitt. Thüringen, Beih., 9: 103-123, 13 Abb., 2 Tab.; Weimar

-Bismarck, Wolfram (1944): Neue Untersuchungen über Tektonik und Beckenbildung in der niederhessischen Senke in der Gegend von Fritzlar und Homberg Bez. Kassel. - N. Jb. Mineral. etc., Abt. B., Beil-Bd. $\underline{88}$ : 85-106, 8 Abb., 4 Falt-Taf.; Stuttgart

oBlaschke, Arnfried-Widukind (2008): Zum Bau der Eichenberg-Gotha-Saalfeld-Störungszone im Eichsfeld <Vortragskurzfassung $>$. - In: Wunderlich, J. [Red.]: Exkursionsführer - Geologie des Eichsfeldes - zur 18. Jahreshauptversammlung (Vortrags- und Exkursionsveranstaltung) vom 16. bis 18. Mai 2008 in Heilbad Heiligenstadt. - Führung: H. Heiland, L. Nolte, H.-G. Röhling \& G. Seidel. S. 36-37; [Hrsg.: Thüringer Geologischer Verein e.V.] Jena 2008

QBornemann [sen.], J. G. (1852): Über die geognostischen Verhältnisse des Ohmgebirges bei Worbis. N. Jb. Mineral. etc., 1852: 1-34, Taf. I, 1 Abb.; Stuttgart

QBornemann [sen.], J. G. (1887): Der Quarzporphyr vom Heiligenstein und seine Fluidalstructur. - Z. dt. geol. Ges., 39: 793-797, 1 Taf.; Berlin

Referat in: N. Jb. Mineral. etc, 1888 (Bd. I): $91-92$ (O. Mügge) Stuttgart

$\square$ Bosse, Herbert (1931): Tektonische Untersuchungen an Grabenzonen südlich des Unterwerrasattels. Abh. Preuß. Geol. Landesanst., N. F., 128: 1-37, 10 Abb., 1 Taf.; Berlin [NW-Teil Sontraer Graben, Suntergraben, Nordwestl. Teil Netratal-Graben]

-Brinkmann, R. (1927): Tekonik und Sedimentation im deutschen Triasbecken. - Z. dt. geol. Ges., $\underline{78}$ (f. 1926): 52-74, Abb. 9; Berlin

-Brinkmann, Roland (1932): Morphogenie und jüngste Tektonik im Leinetalgrabengebiet. - Abh. Preuß. Geol. Landesanst., N.F.: 139: 101-135, 10 Abb.; Berlin [darin: Urwerra-Zufluß zur Leine]

-Brinkmann, Roland (1933): Landschaftsformen und junge Krustenbewegungen im Leinegebiet. - Die Naturwissenschaften, 21 (1): 7-11, 5 Abb.; Berlin

[Göttinger Leinetalgraben] 
$\square$ Brosius, Marita (1959): Die Tertiärmulde von Glimmerode. - Hess. Lagerstättenarchiv, 4; 48 S., 17 Abb., 3 Tab., 5 Taf., 10 Anl.; Wiesbaden

[Tertiär-Stratigraphie, Tektonik, Pollenanalytische Untersuchungen]

OBubnoff, Serge von (1926): Die Tektonik des Granites von Suhl-Zella im Thüringer Wald. - Abh. Preuß. Geol. Landesanst., N.F. 96 (Tektonik und Magma II): 67-71, 2 Abb.; Berlin

Referat in: N. Jb. Mineral. etc., Abt. A, 1927 (Bd. II): 293-296 (G. Fischer); Abt B, 1927 (Bd. II): 178181 (G. Fischer); Stuttgart

$\square \mathrm{OB}$ Bbnoff, Serge v. (1955): Der geotektonische Charakter Thüringens. - Abh. Dt. Akad. Wiss., K1. Math. Allgem. Naturwiss., 1953, H. 3 (Beiträge zur Tektonik des Thüringer Beckens): 5-17, 2 Abb.; Berlin [darin: Eichenberg-Gotha-Saalfelder Störungszone]

OBücking, H. (1881): Gebirgsstörungen und Erosionserscheinungen südwestlich vom Thüringer Walde. - Jb. Preuß. Geol. Landesanst., 1 (f. 1880): 60-105, 2 Abb., Taf. II u. III; Berlin

@Bücking, H. (1883): Gebirgsstörungen südwestlich vom Thüringer Walde und ihre Beziehungen zu den Eisenerzlagerstätten des Stahlberges und der Mommel. - Jb. Preuß. Geol. Landesanst., $\underline{\mathbf{3}}$ (f. 1882): 3343 (Abh. v. Mitarbeitern) Taf. I; Berlin

Referat in: N. Jb. Mineral. etc., $\underline{\mathbf{1 8 8 4}}$ (Bd. 1): 96-98 (Referat A. Stelzner); Stuttgart

Referat in: Mitt. Geogr. Ges. f. Thür., $\underline{3}:$ 210-211 (Fr. R.); Jena

QBücking, H. (1885): Gebirgsstörungen südwestlich vom Thüringer Walde. - Jb. Preuß. Geol. Landesanst., $\underline{\mathbf{5}}$ (f. 1884): 546-555, Taf. XXX; Berlin

[Kleiner Dollmar; Gegend zwischen Springstille und Steinbach-Hallenberg]

@Bücking, H. (1887): Gebirgsstörungen südwestlich vom Thüringer Walde. - Jb. Preuß. Geol. Landesanst., $\mathbf{7}$ (f. 1886): 40-43, 1 Abb. (2 Profile); Berlin [Umgebung v. Seligenthal b. Schmalkalden]

-Busse, E.; Rambow, D. \& Rösing, F. (1970): Ein Profil durch den Nordteil des Kasseler Grabens bei Burghasungen, Nordhessen (Blatt 4621 Wolfhagen). - Notizbl. Hess. L.-A. Bodenforsch., 98 : 146 150, 1 Abb., 1 Taf.; Wiesbaden

$\square$ Chaudhari, Sudhakar Motiram (1963): Stratigraphische und tektonische Untersuchungen unter Berücksichtigung der Klufttektonik im Gebiet zwischen Witzenhausen und Eschwege/Hessen. Diss. [unveröff.] Fachber. Geowiss. FU Berlin 1963; 148 S., Abb., 5 Beil.

口Cloos, H. (1917): Zur Entstehung schmaler Störungszonen. - Geol. Rundschau, $\underline{7}$ (f. 1916): 41-52, 7 Abb.; Berlin [darin: Seeberg bei Gotha)

-Closs, Hans (1939): Hebung-Spaltung-Vulkanismus. - Elemente einer geometrischen Analyse irdischer Großformen. - Geol. Rundschau, $\underline{\mathbf{3 0}}$ : 405-527, 60 Abb., 6 Taf., Berlin Referat in: N. Jb. Mineral. etc., Referate; 1941 (Bd. II): 23 (Chudoba); Stuttgart [darin: „Hessische Gräben“ ohne konkreten Bezug zum WMK]

@Cotta, B. von (1840): Bemerkungen über die Erhebungslinien im Thüringer Flözgebirge. - N. Jb. Mineral., 1840: 292 - 300, Taf. VI (6 Abb.); Stuttgart

-Diersche, Volker (1969): Zur Geologie der Warburger Störungszone süd-westliche Liebenau (N.Hessen) (Messtischblatt Liebenau 4521). - Dipl.-Arb. Univ. Hamburg, Fachber. Geowiss., 1969; 340, 38 S.; Hamburg 
QDietz, C. (1923-1925): Tektonik und Salz des Unteren Eichsfeldes. - Abh. Preuß. Geol. Landesanst., N.F., 95: 83-109, 2 Abb., Taf. 9-13; Berlin Referat in: N. Jb. Mineral. etc., Abt. B, 1927 (Bd. II): 62 (A. Bentz); Stuttgart [Gebiet des Kalibergbaus bei Bleicherode, Holunger Graben, Worbiser Graben]

ODietz, C. (1926): Einflüsse der Tektonik auf die Auslaugung im Gebiet des Werra-Kalireviers. - Sitzber. Preuß. Geol. Landesanst., 1: 41 - 47, 1 Abb.; Berlin

Referat in: N. Jb. Mineral. etc., Abt. B, 1927 (Bd. II): 62-63 (A. Bentz); Stuttgart

QDietz, C. (1930): Die Abwasserversenkung in tiefere Erdschichten. - Sitzber. Preuß. Geol. Landesanst., 5: 94 - 103, 2 Abb.; Berlin

[darin: Werra-Kalirevier]

- $\bullet$ Dreyer, Wolfgang \& Borchert, Hermann (1961): Zur Druckfestigkeit von Salzgesteinen. - Kali u. Steinsalz, $\underline{\mathbf{3}}(7)$ : 234-241, 13 Bilder, 7 Zahlentaf.; Essen [darin: untersuchte Gesteinsproben Königshall-Hindenburg, Wintershall, Hattorf]

ODreyer, D. (1965): Über die Geologie der Struktur Kirchheilingen - Allmenhausen. - Z. angew. Geol., 11(8): 423-431, 8 Abb.; Berlin

OEllenberg, Jürgen (1982): Die Subrosion im Werra-Kaligebiet der DDR, quartärgeologische, geomorphologische und tektonische Aspekte. - Z. geol. Wiss., $\underline{10}(1)$ : 61-71, 6 Abb.; Berlin

QEllenberg, Jürgen (1995): Neotektonik [in Thüringen]. - In: Seidel, Gerd [Hrsg.]: Geologie von Thüringen. - 1. Aufl.; S. 418-422, 4 Abb.; Stuttgart 1995

OEllenberg, Jürgen (2003): Neotektonik [in Thüringen]. - In: Seidel, Gerd [Hrsg.]: Geologie von Thüringen. - 2., neu bearb. Aufl.; S. 449-453, 4 Abb.; Stuttgart 2003

- $\square \bullet$ Engels, Bruno (1956): Zur Deutung der Querplattung (Sigmoidalklüftung). - Mitt. Geol. Staatsinstitut, 25: 5-25, 15 Abb.; Hamburg

[Lkr. Göttingen, Nordosthessen]

- Ernst, Th. (1941): Olivinknollen der Basalte als Bruchstücke alter Olivinfelsen. - Nachr. Ges. Wiss. Göttingen, Math.-phys. Kl, Fachgr. IV, N.F., 1 (1934-1940): 147-154, 13 Abb.; Göttingen

[Diagramme Kristallgitterregelung von Olivin, u.a. Hirzstein/Habichtswald b. Kassel, Hoher Hagen b. Göttingen]

QErnst, Werner (1994): Über den Rhät/Lias-Graben am Apfelstädt-Fluß zwischen Wechmar und Wandersleben (Kreis Gotha). - Veröff. Naturkundemuseum Erfurt, Naturwiss. Rh., 13: 49-59, 10 Abb.; Erfurt

@Fahllbusch, Klaus (1953): Die Saalfeld-Gotha-Eichenberger-Störungszone im Gebiet von Arnstadt. Dipl.-Arb. [unveröff.] Univ. Berlin 1953

Referat in: Geologie, 4 (2): 200; Berlin 1955

QFarshad, Farhad (1995): Geologische Kartierung der Trias im Osten des Eichenberger Grabenknotens zwischen Arenshausen und Gerbershausen in Thüringen (TK 25 Blatt 4625 Witzenhausen). - Dipl.Kart. [unveröff.] Univ. Göttingen; 50 S., 2 Beil.

$\square$ Faupel, Jürgen (1973): Neue Beobachtungen zu den allochthonen Triasvorkommen ("Schollen) auf dem Unterwerra-Sattel bei Hundelshausen/Nordhessen. - N. Jb. Geol. Paläont., Mh., 1973: 654-666, 5 Abb.; Stuttgart

Q $\square$ Föhlisch, Katja (2002): Synsedimentäre Defomation im unteren Muschelkalk des Germanischen Beckens. - Diss. [unveröff.]Univ. Jena 2002; V, 121, [40]Bl.; Jena [darin: Hitzelrode/Werra-Meissner-Kreis] 
QFranzke, Hans Joachim (1977): Zur kinematischen Analyse hydrothermaler Gangstrukturen, erläutert an Beispielen aus dem Unterharz und dem Thüringer Wald. - Hallesches Jb. Geowiss., 2: 41-48, 10 Abb.; Halle (Saale)

[Tektonik, Umgebung Ilmenau]

QFranzke, Hans Joachim (1991): Die kinematischen Bedingungen der mesozoischen Gangmineralisationen im Thüringer Wald. - Z. geol. Wiss., 19 (4): 401- 408, 5 Abb.; Berlin

QFranzke, Hans Joachim (1992): Bruchprozesse an der Floßberg-Störung bei Ilmenau im Thüringer Wald. - (Gedenkschrift HANS WEBER) Geol. Bl. NO-Bayern, 42(1-2): 69-84, 9 Abb.; Erlangen

QFranzke, Hans Joachim (2001): Die strukturelle Einbindung der thüringischen Gangmineralisationen $<$ Vortragskurzfassung $>$. - In: Rauche, Henry [Hrsg.]: Regionale und angewandte Geologie der Grenzregion der Süddeutschen und der Mitteldeutschen Scholle. - Programm und Kurzfassungen der Vorträge. - 10. Jahrestagung Gesellschaft f. Geowissenschaften i. Schmalkalden, 19.-22. September 2001. - Exkursionsführer u. Veröff. Ges. f. Geowiss., 214; S. 107-109; Berlin 2001

QFranzke, Hans Joachim \& Schiemenz, Fritz (1977): Die Tektonik der Gangstruktur „Hoffnung 1! Im südöstlichen Thüringer Wald. - Hallesches Jb. Geowiss., 2: 49-54, 5 Abb.; Halle (Saale) [Umgebung Ilmenau]

@Franzke, Hans Joachim \& Schiemenz, Fritz (1978): Bruchkinematische Analyse der Ganggruppe „Pluto“ im südöstlichen Thüringer Wald. - Z. geol. Wiss., $\underline{\mathbf{6}}$ (3): 341-350, 7 Abb.; Berlin [Untersuchungsgebiet südlich Ilmenau]

OFranzke, H. J. \& Schiemenz, F. (1980): Die Bruchkinematik des Floßberg-Stechberg-Gangsystems bei Ilmenau im Thüringer Wald. - Z. angew. Geol., 26 (11): 547-554, 8 Abb.; Berlin

@Franzke, H.-J.; Kapelle, C. \& Röllig, G. (1982): Flächentrendanalyse der Hauptstörungsanalyse des Floßberg-Stechberg-Mineralgangssystems bei Ilmenau/Thüringer Wald. - Z. angew. Geol., 208(2): 7376; Berlin

OFranzke, Hans Joachim \& Friedel, Carl-Heinz (1983): Resultate einer tektonischen Paläospannungsanalyse im südöstlichen Thüringer Wald. - Z. geol. Wiss., 11(8): 973-989, 8 Abb.; Berlin [Ilmenauer Gangrevier]

OFranzke, Hans Joachim \& Janssen, Christoph (1984): Geologische Interpretation von Druckspannungsmessungen im Tafeldeckgebirge der DDR. - Z. geol. Wiss., 12 (2): 235-254, 12 Abb.; Berlin [darin: Westthüringen/Vorland des Thüringer Waldes]

QFranzke, H. J.; Ahrendt, H.; Kurz, S. \& Wemmer, K. (1996): K-Ar-Datierungen von Illiten aus Kataklasiten der Floßbergstörung im südöstlichen Thüringer Wald und ihre geologische Interpretation. - Z. geol. Wiss. , 24(3/4): 441-456, 7 Abb., 3 Tab.; Berlin

-Frebold, Georg (1921): Der Einfluss der Zechsteinsalze auf die Gestaltung des Göttinger Leinetales. Diss. Univ. Tübingen 1921, 35 S. (S. 46-80; Z. nicht z. ermitteln), 1 Abb., 3 Taf.; (Riemschneider) Hannover

-Friedrich, Kuniberg (1959/60): Gefüge und Tektonik im Hartsalz des Werragebietes. - Z. dt. geol. Ges., 111 (f. 1959): 502-524, 17 Abb., Tab.; Hannover - auch als Diss. Univ. Bonn [Hattorf/Hessen] 
OGaertner, Hans Rudolf v. (1951): Probleme des Saxothuringikums. - Geol. Jb., $\underline{\mathbf{6 5}}$ (f. 1949): 409-450, 7 Abb., Taf. 3-4; Hannover

[darin S. 420-422, Abb. 3 - Kap.: Der tektonische Bau - Ruhlaer Sattel]

-Graupner, Armin (1938): Der Naumburger Graben in Hessen. - Jb. Preuß. Geol. Landesanst., $\underline{\mathbf{5 8}}$ (Teil A, Wiss. Teil) (f. 1937): 847 (Sitzber.); Berlin

OGrumbt, Eberhard (1955): Zur Tektonik am Nordostrand des mittleren Thüringer Waldes. - Ber. geol. Ges. DDR, 1(1): 68-77, 4 Abb., 3 Profil-Taf.; Berlin

QGrumbt, E. (1959/60): Zum Bau des nordöstlichen Thüringerwald-Randes [Vortragstext]. - Z. dt. geol. Ges., 111: 239-240; Stuttgart

[Tektonik]

QGrumbt, Eberhardt (1960): Der Nordrand des Thüringer Waldes zwischen Ruhlaer Kristallin und Schwarzburger Sattel. - Abh. Dt. Akad. Wiss. z. Berlin; Kl. Chemie, Geol., Biol., 1959(3): 1-76, 43 Abb, 17 Beil.; Berlin

OGrumbt, Eberhard \& Lützner, Harald (1966): Störungszonen im Deckgebirge des thüringischen Werra-Kaligebietes und ihre Beziehungen zum Basaltvulkanismus und zur AuslaugungUntersuchung der petrographischen, tektonischen und mineralischen Verhältnisse des Floßberggangzuges zwischen Ilmenau und Gehren als Beitrag zur Klärung der saxonischen Lagerstätten auf den Randspalten des Thüringer Waldes. - Geologie, 15 (4/5): 531-544, 8 Abb.; Berlin

- $\square$ O $\bullet$ Grumbt, Eberhard \& Lützner, Harald (1983): Saxonische Tektonik und Basaltvulkanismus zwischen Thüringer Wald und Vorderrhön. - Z. geol. Wiss, 11 (8): 943-954, 2 Abb., 1 Tab., 1 Faltkt.; Berlin [großregionale Betrachtung unter Einbeziehung der nordhessischen Gräben; HE, WMK, THÜR, NIE]

-Grupe, O. (1911): Über das Alter der Dislokationen des hannoversch-hessischen Berglandes und ihren Einfluß auf Talbildung und Basalteruptionen. - Z. dt. geol. Ges., 63: 264 - 316, 7 Abb.; Berlin [darin: Kassel, Oberaulaer Graben(Lkr. Hersfeld-Rotenburg)]

Referat in: N. Jb. Mineral. etc., 1913 (Bd. II): 397-399 (Hans Reck), 1914 (Bd. I): 100-101 (Schöndorf); Stuttgart

- Grupe, O. (1923): Zur Entstehung des Göttinger Leinetalgrabens. - Jb. Preuß. Geol. Landesanst., $\underline{42}$ (f. 1921): 595-620, 3 Abb.; Berlin

$\square$ Grupe, O. (1923): Über das Altersverhältnis der hercynischen und rheinischen Dislokationen. - Z. dt. geol. Ges., $\underline{74}$ (f. 1922): B. 2 - 25; Berlin

[Gelstertal-Graben; Altmorschen-Lichtenauer Graben]

$\square$ Haffer, Jürgen (1956): Zur Stratigraphie und Tektonik des Mittleren Buntsandsteins bei Witzenhausen/Werra. - Dipl.-Arb. [unveröff.] Univ. Göttingen

-Hartwig, G. (1928/29): Schematismus der Salztektonik auf nordhannov. Salzaufpressungspfeilern, mechanisch-kinetisch aus dem Bilde stratigraphischer Salzkulissenfaltung abgeleitet. - Kali, etc., $\underline{22}(24): 374-380$

$\underline{23}(2)$ : 21-25, mehr. Fig.; Halle/Saale

[darin: Kaliwerk Königshall-Hintenburg/Reyershausen; Bhr. zw. Leine- und Rhumeniedererung]

Q Hartwig, Georg (1952-1955): Zur Petrographie und Transversalschieferung der tieferen Stufen der Zechstein-Großfolge Z im Untergrund von Solling-Elfas und Dün-Hainleite-Eck mit Ausblick auf die Verhältnisse unter der östlichen Randhochfläche des Göttinger Leinetales. - Kali u. Steinsalz, 1(8): 829, 21 Abb., 8 Zahlentafeln; Essen 
QHeinrich, F. (1969): Ermittlung von Bruchkriterien durch triaxiale Festigkeitsuntersuchungen an Gesteinen. - Bergakademie, 21 (11): 642-646;

Referat (Dreyer) in: Kali u. Steinsalz, $\underline{\mathbf{5}}(8):$ 285-286, 3 Bilder, 3 Zahlentaf.; Essen

[darin: untersuchte Gesteinsprobe Übergangssylvinit Grube Marx-Engel (Unterbreizbach)]

[Vorlage nicht eingesehen - Zitiert nach angegebenem Referat]

OHempel, Gerhard (1995): Variszische Tektonik [in Thüringen]. - In: Seidel, Gerd [Hrsg.]: Geologie von Thüringen. - 1. Aufl.; S. 166-180, 6 Abb.; Stuttgart 1995

QHempel, Gerhard (2003): Variszische Tektonik [in Thüringen]. - In: Seidel, Gerd [Hrsg.]: Geologie von Thüringen. - 2., neu bearb. Aufl.; S. 192-207, 6 Abb.; Stuttgart 2003

-Hempel, Ludwig (1956): Junge pleistozäne Tektonik am Rande des Eichsfelder Beckens. - Geol. Jb., 72: 235-240, 1 Abb.; Hannover

[Unter-Eichsfeld]

QHenke, Bernd (1997): Geologische Kartierung im nordöstlichen Teil des Eichenberg-Gothaer-Grabens in Thüringen (TK 25, Blatt 4625 Witzenhausen, Blatt 4626 Heiligenstadt). - Dipl.-Kart. [unveröff.] Univ. Göttingen; 99 Bl., Ill., Tab., 3 Beil.

QHessmann, Wolf (1959): Neue Ergebnisse der Strukturerkundung und Erdgas-Suche im Thüringer Becken. - Z. angew. Geologie, $\underline{\mathbf{5}}(9): 377-381,4$ Abb.; Berlin

[Profile Bohrungen Altengottern, Bad Langensalza]

QHessmann, Wolf (1982): Tektonische Beanspruchung und Verformung, strukturelle Position und Dislokationsintensität - Kriterien zur Einschätzung hydrogeologischer Verhältnisse des Gebirges. Z. geol. Wiss., 10 (1): 31-52, 5 Abb.; Berlin

[Südwestthüringen]

OHessmann, Wolf (1983): Zur strukturellen Formung und Beanspruchung des postvariszischen Gebirges im Südwesten der DDR. - Z. geol. Wiss., 11(8): 955-971, 4 Abb.; Berlin [Werra-Gebiet]

OHessmann, W. \& Richter, E. (1978): Zu den strukturgeologisch-tektonischen Verhältnissen des Werra-Kaligebiets der DDR. - Z. angew. Geol., 24(7/8): 291-296, 4 Abb.; Berlin

QHessmann, Wolf \& Schwandt, Arnold (1981): Zur Bruchtektonik im Salinar und Deckgebirge. - Z. geol. Wiss., 9 (3): 283-292, 6 Abb.; Berlin [darin: Thüringisches Werra-Kalirevier]

-Hieke, Werner (1966): Stratigraphie (Trias, Tertiär) und Tektonik am Remsfelder Grabenknoten. Notizbl. Hess. L.-A. Bodenforsch., 94: 201 - 234, 7 Abb.; Wiesbaden [B1. 4922 Homberg/Efze, 4923 Altmorschen]

$\square$ Holzapfel, Martin (2000): Die allochthonen Triasschollen bei Hundelshausen, Nordhessen. - Ber. Naturhist. Ges. Hannover, 142: 7-77, 10 Abb., 6 Tab., 2 Kt.; Hannover

OHoppe, Walter (1962): Die Bedeutung der herzynischen Störungszonen für die Grundwasserführung des Thüringer Beckens. - Geologie, 11(6): 679 - 699, 1 Abb., 10 Tab.; Berlin [darin: Eichenberg-Gotha-Saalfelder Störungszone u. a. bekannte Störungszonen]

-Horn, Manfred (1958): Zur Stratigraphie und Tektonik des Mittleren Buntsandsteins zwischen Harz und Solling. - Dipl.-Arbeit [unveröff.] Univ. Göttingen 1958; 37 S.;

-Hornstein, F. (1879): Röth und Lias in der Stadt Kassel. - Z. dt. geol. Ges., 31: 643 [Notiz Sitzungsprotokoll]; Berlin 
OHoyningen-Huene, Ewald v. (1966): Überblick über die jungvariszischen Strukturen im Westteil der Mitteldeutschen Hauptscholle. - Ber. Dt. Ges. geol. Wiss., Reihe A, 11(1/2): 57-65, 2 Abb.; Berlin [darin einbezogen: Westthüringen]

QHurtig, E.; Grosser, H.; Knoll, P. \& Neunhöfer, H. (1982): Seismologische und geomechanische Untersuchungen des seismischen Ereignisses vom 23.6.1975 im Werragebiet bei Sünna (DDR). Gerlands Beitr. Geophysik, 91(1): 45-61, 12 Abb.; Leipzig

$\square$ Huttel, Peter (1984): Der Westrand des Leinetalgrabens bei Marzhausen (GK25 Reinhausen 4525). Dipl.-Arb. [unveröff.]. Univ. Göttingen; 196 S., 12 Beil.

OJacobi, K. (1993): 1. Geologische Kartierung der Trias am Südwestrand des Eichenberg-GothaerGrabens in Thüringen (TK 25 Blatt 4625 Witzenhausen). - Dipl.-Kart. [unveröff.] Univ. Göttingen; 66, 93 S., 12 Beil. [die Vorlage enthält 2 Werke: Dipl.-Arb. , Dipl.-Kart)

口Jäger, Willy (1926): Der „Faltenbruch“ bei Neuerode. - Eschweger Tageblatt, 1926; Nr. 90 v. 19.4.1926, 4 Skizzen; Eschwege [Tektonik im Unteren Muschelkalk der „Hessischen Schweiz“]

QJahne, Heinz; Voitel, Roland \& Haase, Günter (1983): Tektonische Erscheinungsformen im Salinar des Werra-Kaligebiets auf dem Territorium der DDR. - Z. geol. Wiss., 11(9): 1085-1100, 10 Abb.; Berlin

OJohs, Max (1933): Der Granitporphyr von Thal-Heiligenstein im Thüringer Wald. Eine gefügeanalytische Untersuchung. - Mineral. u. petrogr. Mitt., 43: 283-318, 5 Abb., 22 Diagr.; Wien Referat in: N. Jb. Mineral. etc., Referate; 1932 (Bd. II): 377-378 (Chudoba); Stuttgart [Tektonik, Gefügekunde]

口ण Jubitz, Karl-Bernhard (1969): Beziehungen zwischen Stoffbestand und Bauformen im Tafeldeckgebirge. Methodische Gesichtspunkte und Probleme moderner tektonischer Grundlagenforschung im germanotypen Deckgebirge junger Tafeln. - 20 Jahre Deckgebirgsforschung im Gebiet der DDR. - Geologie, 18 (8): 911-945, 3 Abb., 1 Taf.; Berlin [darin Abb. 3: Mächtigkeitskarte Terebratelbänke (mu) in Thüringen unter randlicher Einbeziehung v. WMK, NIE]

QKästner, Hans (1997): Neuere Beobachtungen zur Tektonik der Ohmgebirgsgrabenzone. - Geowiss. Mitt. Thüringen, $\underline{5}$ : 133-148, 3 Abb.; Weimar

QKatzung, Gerhard (1969): Das Einregelungs-Gefüge im Konglomerat von Fehrenbach (Rotliegendes, Thüringen). - Jb. Geol., $\underline{2}$ (f. 1966): 85-118, 19 Abb., 3 Tab., 3 Taf.; Berlin

QKauter, Kurt (1963): Beitrag zur Klärung der Geologie des tieferen Untergrunds im nordwestlichen Thüringer Becken. - Z. angew. Geol., 9(4): 198-204, 8 Abb.; Berlin [Strukturgeologie, Geophysikalische Messungen]

- $\square$ Kayser, Emanuel (1923): Lehrbuch der Allgemeinen Geologie. - (Vier Bände: I. u. II. Band Allgemeine Geologie, III u. IV. Bd. Geologische Formationskunde). - Bd. I: Physiographische Geologie und Äussere Dynamik. - 7. u. 8. Aufl., 740 S., 549 Abb.; (Enke) Stuttgart [darin: Abb. z. Vulkanismus Abb. 58 Basaltbruch Bühl b. Ahnatal/Weimar W'Kassel; 92a Teufelswand, Habichtswald/Kassel; 110 Profil Meissner - 111 Profil Hirschberg b. Großalmerode Tektonik: Abb. 203 Profil Netratal b. Eschwege, 204 „Eichenberg“ b. Netra]

OKenngott, [Hrsg.](1882): Encyclopädie der Naturwissenschaften, II. Abth., 1 Theil: Handwörterbuch der Mineralogie, Geologie und Paläontologie - Herausgegeben von Adolf Kenngott unter Mitwirkung von Prof. Dr. von Lasaulx und Dr. F. Rolle. - Bd. 1, VI, 550 S., Ill.; (Trewendt) Breslau [darin S. 494: [„Einsturzspalten“] Subrosionstektonik im Mittleren Muschelkalk bei Creuzburg] 
$\square \bullet$ Kienow, Sigismund (1935): Leinetalgraben und Werragrauwackengebirge, ein Beitrag zur Tektonik von Hebungsgebieten. -Bericht über die wissenschaftlichen Sitzungen der Hauptversammlung der Geologischen Vereinigung zur Feier ihres 25jährigen Bestehens am 5. und 6. Januar 1935 (Vortragskurzfassung). - Geol. Rundschau, 26: 145-146; Berlin

口oKindermann, C. (1918): Der Keupergraben des Ringgaus. - N. Jb. Mineral., Beil.-Bd. 42: 547-609; Stuttgart

[Stratigraphie, Tektonik]

$\square$ Klingner, Fritz Erdmann (1935): Das Problem der Triasschollen auf dem Grauwackensattel der unteren Werra bei Hundelshausen. - Z. dt. geol. Ges., 87: 48-56, 3 Abb.; Berlin

QKley, Jonas; Arzt, Martin \& Liß, Dirk (2001): Ein ausgeglichenes Profil über den NW-Teil des Thüringer Waldes und Folgerungen für die spätkretazischen Sockelüberschiebungen im Mitteleuropa $<$ Vortragskurzfassung > . - In: Rauche, Henry [Hrsg.]: Regionale und angewandte Geologie der Grenzregion der Süddeutschen und der Mitteldeutschen Scholle. - Programm und Kurzfassungen der Vorträge. - 10. Jahrestagung Gesellschaft f. Geowissenschaften i. Schmalkalden, 19.-22. September 2001. - Exkursionsführer u. Veröff. Ges. f. Geowiss., 214; S. 147-148; Berlin [Tektonik]

$\square$ Klohn, K.-H. (1930): Der Eichenberg-Gothaer Graben unter vergleichender Betrachtung der Viernauer Dislokationszone südlich Schmalkalden. - Abh. Preuß. Geol. Landesanstalt, N.F., 116: 113-162, 18 Abb., Taf. 9 u. 10; Berlin [Fretterode - Gerberode - Rüstrungen - Eichenberg]

QKlügel, Thomas; Simon, Dietrich \& Harwardt, Hans (2001): Mechanische Kennwerte von WerraSteinsalz (Na1 $\gamma$ ) aus Merkers. Vergleiche der Ergebnisse von Laborversuchen, in situ-Messungen und Modellierungen. - Z. dt. geol. Ges., 152(1): 77-98, 12 Abb., 6 Tab.; Stuttgart

-Klüpfel, Walter (1953): „Basaltgeologie“. Ein Beitrag zur Kenntnis der tertiären Basalte. - Z. dt. geol. Ges., 104: 326- 353, 20 Abb.; Hannover

[Tektonik und Gefüge von Basaltmassen; Abbaubeeinträchtigungen durch Verwitterungserscheinungen, u.a. Sonnenbrand, Dauchbildung]

OKnape, H. (1957): Zur Tektonik der Ohmgebirgsgrabenzone im Bereich des Thomas-MüntzerSchachtes bei Holungen. - Abh. Dt. Akad. Wiss. Berlin, Kl. Chemie, Geol., Biol., Jg. 1955(10): 50-85, 23 Abb.; Berlin

QKnieg, Norbert (1958): Zur Tektonik des westlichen Schlotheimer Grabens (Thüringer Becken) unter besonderer Berücksichtigung der Untertageaufschlüsse des Kaliwerkes Volkenroda-Pöthen. - Abh. Dt. Akad. Wiss. Berlin, Kl. F. Chemie, Geologie u. Biologie, 1956, Nr. 6 (Abh. z. Geotektonik, 14). 48 S., 22 Abb., 6 Taf.; Berlin

Referat (H. Weber) in: Hallesches Jb. mitteldt. Erdgeschichte, 4: 114-115; Halle

[Vorlage nicht eingesehen - zitiert nach oben genannten Referat]

OKoch, Klaus \& Vogel, Jochen (1980): Zu den Beziehungen von Tektonik, Sylvinitbildung und Basaltintrusion im Werra-Kaligebiet (DDR). - Freiberger Forschungshefte, Reihe C, 347; 104 S., 53 Abb.; 2 Tab.; Leipzig

- $\square$ • Kölbel, Heinrich (1954): Großes Seitenverschiebungen und Horizontalflexuren im deutschen Grundgebirge und ihre lagerstättenkundliche Bedeutung. - Geologie, $\underline{\mathbf{3}}(4)$ : 445-450; Berlin [,Werra-Sigmoidale“: Unterwerra-Grauwackengebirge, Thüringer Wald; HE, WMK, THÜ, NIE]

Q•Koenen, A. v. (1885): Über Dislokationen westlich und südwestlich vom Harz. - Jb. Preuß. Geol. Landesanst., $\underline{\mathbf{5}}$ (f. 1884): 44-55; Berlin

[Großräumige Betrachtung u. Einbez. d. Eichenberg-Gotha-Saalfelder Störungszone] 
-Koe[h]nen, A. v. (1886): Ueber die Störungen, welche den Gebirgsbau im nordwestlichen und westlichen Deutschland bedingen. - Nachr. Kgl. Ges. Wiss. z. Göttingen, 1888(6): 196-198; Göttingen [Bezugnahme a. Mediterran-Mjöse Zone, Leinetalgraben]

-Koenen, A. v. (1886): Über das Verhalten von Dislokationen im nordwestlichen Deutschland. - Jb. Preuß. Geol. Landesanst, $\underline{\mathbf{6}}$ (f. 1885): 53-83; Berlin

Referat in: N. Jb. Mineral. etc., 1887( Bd. 1): 266-267 (Referat E. Dathé); Stuttgart [darin: Mackenröder Spitze am Ostrand des Göttinger Waldes]

- $\bullet$ Koenen, A. v. (1887): Über postglaziale Dislokationen. - Jb. Preuß. Geol. Landesanst., $\underline{7}$ (f. 1886): 118; Berlin [darin: Aufschlüsse Königsplatz Kassel, Göttingen, Leineaue b. Göttingen]

$\square \bullet$ Koenen, A. v. (1888): Beiträge zur Kenntnis von Dislokationen. - Jb. Preuß. Geol. Landesanst., $\underline{8}$ (f. 1887): 457-471; Berlin

Referat in: N. Jb. Mineral. etc, 1891 (Bd. I): 312 (E. Koken); Stuttgart [u.a. Basaltvorkommen Hoher Meißner, Störung b. Göttingen-Weende]

-Koenen, A. v. (1905): Über Wirkungen des Gebirgsdruckes im Untergrunde in tieferen Salzbergwerken. - Z. prakt. Geol., 13.1905 (5): 157-167, Fig. 41-47; Berlin

[Salztektonik, darin: Kaliwerk Justus I bei Volpriehausen]

$\square$ Koll, Jürgen (1984): Strukturanalyse allochthoner Serien des Südharzpaläozoikums. - Braunschweiger Geol. - Paläont. Diss., 1; 124 S., 55 Abb., 6 Taf., 6 Falt-Taf.; Braunschweig

[darin S. 111-117 Kap.: Geodynamische Entwicklung und regionaler Vergleich. - S. 115, Abb. 55:

Vergleich mit Albunger Paläzoikum]

OKorčemagin, V.A.; Emec, V.S.; Pavlov, I.O; Nezvetaev. S.G.; Seliverstov, K.V. \& Čhernnousenko, V.V. (1996): Tectonophysikalische Besonderheiten regionaler Störungen Eurasiens. - Z. geol. Wiss., 24(3/4): 335-342, 4 Abb.; Berlin

[darin: Thüringer Wald]

OKrause, Torsten (2000): Zwei strukturgeologisch bemerkenswerte Aufschlüsse im Muschelkalk Westthüringens. - Veröff. Naturkundemuseum Erfurt, Naturwiss. Rh., 19: 5-18, 4 Abb., 8 Taf.; Erfurt [Krauthausen/Wartburgkreis; Netra-Creuzburg-Eisenacher Graben]

OKrause, Torsten (2002): Kleintektonische Vielfalt und Bedeutung der Eichenberg-Saalfelder Störungszone im Strukturbild der Thüringer Mulde - vorgestellt am Beispiel des Rät-Lias-Grabens am Wanderslebener Röhnberg (Gotha) und der Zechsteinaufpressung bei Hütscheroda (Eisenach). Exkursionsführer Die Geologie von Nordwest-Thüringen - 12. Jahreshauptversamml. [Thüringer Geologischen Vereins] (Vortrags- und Exkursionstagung) vom 25. bis 26. Mai 2002 in Mühlhausen; S. 8-10; (Thür. Geol. Verein) Jena

OKrause, Torsten \& Katzung, Gerhard (1997): Die Kleintektonik im Lias am NE-Hang des Röhnberges bei Wandersleben (Hainich-Saalfelder Störungszone). - Veröff. Naturkundemuseum Erfurt, Naturwiss. Rh., 18: 21-48, 2 Abb., 10 Taf.; Erfurt

QKrause, Torsten \& Patzelt, Gerald (2008): Die Ohmgebirgs-Störungszone im Böschungsprofil der Bundesautobahn BAB 38 zwischen Leinefelde und Breitenbach <Vortragskurzfassung $>$. - In: Wunderlich, J. [Red.]: Exkursionsführer - Geologie des Eichsfeldes - zur 18. Jahreshauptversammlung (Vortrags- und Exkursionsveranstaltung) vom 16. bis 18. Mai 2008 in Heilbad Heiligenstadt. - Führung: H. Heiland, L. Nolte, H.-G. Röhling \& G. Seidel. - S. 44-45; [Hrsg.: Thüringer Geologischer Verein e.V.] Jena 2008 
-Krauß, Alfred (1913): Der Warburger Sattel, seine Baustörungen und die vulkanischen Durchbrüche. Jb. Preuß. Geol. Landesanst., $\underline{31}$ (Teil II) (f. 1910): 377-419, Taf. 12-13 (irrtüml. auch Taf. 14 angegeben); Berlin

QKray, Markus (1994): [II.] Geologische Kartierung der Trias am Südwestrand des Eichenberg-GothaerGrabens bei Fretterode in Thüringen ( TK 25; Blatt 4625 Witzenhausen, 4626 Heiligenstadt, 4725 Bad Sooden-Allendorf, 4726 Grebendorf). - Dipl.- Kart. [unveröff.] Univ. Göttingen. - 44 S., 4, 2 Beil.

- $\square$-Kronberg, Peter (1988): Saxonische Strukturen und krustale Bruchmuster im Satellitenbild Beispiele aus Südniedersachsen. - Die Geowissenschaften - Organ der Alfred-Wegener-Stifung; $\underline{\mathbf{6}}(12)[=12 /$ '86]: 347-355; Weinheim

-Kruck, Wolfgang (1974): Querplattung im Muschelkalk Nordwestdeutschlands. - Mitt. Geol. Paläont. Inst. Univ. Hamburg, 43: 127-172, 28 Abb., 3 Tab., 4 Taf.(13-16); Hamburg [u.a. Lkr. Göttingen]

OKrzywicki, E. (1938): Die saxonische Tektonik im südwestlichen Teil des mittleren Thüringer Waldes. Jb. Preuß. Geol. Landesanst., $\underline{\mathbf{5 8}}$ (Teil A) (f. 1937): 778-838, 44 Abb., Taf. 61-63; Berlin

OKurze, Manfred \& Necke, Gerd (1979): Horizontalstylolithen als regionalgeologische Druckspannungsindizien. - Z. geol. Wiss., 7(5): 633-639, 2 Abb.; Berlin [darin: Hörselberge b. Eisenach]

-OLLachmann, Richard (1910): Studien über den Bau von Salzmassen - Zweite Folge. - I. Phänomene. - Kali, etc., 4 (22): 477-483, Abb.; Halle [darin: Hess.-Thür. Werra-Kalirevier, Alexandershall/THÜ; Wintershall/HE]

-oLachmann, Richard (1910): Studien über den Bau von Salzmassen - Zweite Folge. - II. Tektonik des Bodens. - Kali, etc., 4 (24): 517-532, Abb., 1 Falt-Kt.; Halle [Faltkarte: Die tektonischen Einheiten der deutschen Kaliprovinzen mit Relevanz zu bibliogr. erfassten Regionen]

-Lachmann, Richard (1912): Studien über den Bau von Salzmassen - Dritte Folge: Physikalische Kräfte im Salz. - Kali, etc., $\underline{\mathbf{6}}$ (14): 342-353; Halle [darin: Heringen, Hess.-Werrakalirevier]

$\square$ Lachmann, R. (1913): Der Bau des niederhessischen Berglandes bei Hundelshausen. - Jb. Schlesische Ges. f. vaterländ. Kultur Breslau, 90 [f. 1912](I. Bd: Sitzungen Sect. f. Geol., Geogr., Berg- u. Hüttenwesen): 13-61, 8 Abb.; Breslau

$\square$ Lachmann, R. (1913): Ekzeme als geologische Chronometer - [mit Erwiderungen v. Beyschlag, Scheibe, Krusch]. - Z. dt. geol. Ges., 64 (f. 1912): 553 - 568, 5 Abb.; Berlin [darin: allochthone Triasschollen auf Zechsteingips bei Hundelshausen/Gelstertal]

-Lachmann, Richard (1917): Ekzeme und Tektonik. [Posthum hrsgeg. v. F. Frech]- Zbl. Mineral. etc., 1917: 414-426, 5 Abb.; Stuttgart [u.a. Nordhessische Gräben, „Baumbacher Hoch“ bei Rotenburg/Fulda]

-Lang, Heinrich Otto (1875): Über die Absonderung des Kalksteins von Elliehausen bei Göttingen. Z. dt. geol. Ges., 27: 842-853, Taf. XXIV; Berlin

Referat in: N. Jb. Mineral. etc., 1876: 666 (Referate); Stuttgart [Tektonik, Gefügekunde]

-Lang, Heinrich Otto (1880): Über den Gebirgsbau des Leinetals bei Göttingen. - Z. dt. geol. Ges., $\underline{\text { 32: }}$ 799-806, Taf. XXIX; Berlin 
-Lang, [Heinrich] Otto (1888): Über geriefte Geschiebe von Muschelkalkstein der Göttinger Gegend. Z. dt. geol. Ges., 40: 231-249, Taf. XIV, XV; Berlin

Referat in: N. Jb. Mineral. etc, $\underline{1890}$ (Bd. I): 297 (A. Leppla); Stuttgart

OLangbein, Rolf (1984): Über subrosionsbedingte Gefüge in Anhydrit- und Gipsgesteinen. - Z. geol. Wiss., 12(3): 349-362, 12 Abb.; Berlin

[Gefügekunde, darin: Zechstein Nordrand Thüringer Wald: Marienglashöhle Friedrichroda, Gipsbruch Kittelsthal - auch Kyffhäuser, Harzsüdrand]

OLange, Peter \& Steiner, Walter (1971): Eggische Strukturlinien im geologischen Bauplan der Deutschen Demokratischen Republik. - Geologie, 20(3): 213-235, 4 Abb.; Berlin [darin: Hainich-Linie]

- •Lepper, W. (1997): Vom Reinhardswald-Trog zum Solling-Gewölbe - die strukturgeologische Entwicklung eines Teilbereiches der Hessischen Senke vom ausgehenden Paläozoikum bis ins Quartär (Vortragskurzfassung). - In: Büchel, Georg \& Lützner, Harald (Hrsg.): Regionale Geologie von Mitteleuropa - Geodynamische Prozesse zwischen Alpen und Nordatlantik - 149.

Hauptversammlung Deutsche Geologische Gesellschaft ...- Jena 27.09.-3.10.1997 - Kurzfassung der Vorträge und Poster. - Schriftenrh. Dt. Geol. Ges., 2: 75; Hannover 1997

- 0 lLorenz, Th. (1907): Ueber den Gebirgsbau Mitteldeutschlands. - Ber. Niederrhein. Geol. Vereins, 1907: 24-40, 9 Abb., Taf. 2.; Bonn

Referat in: Mitt. Geogr. Ges. (f. Thüringen), 28: 43; Jena 1910

[Bezugn. a. Ohmgebirgsgraben, Hessische Gräben, Thüringer Wald]

QLoretz, H. (1893): Bemerkungen über die Lagerung des Rothliegenden südlich von Ilmenau in Thüringen. - Jb. Preuß. Geol. Landesanst., $\underline{13}$ (f. 1892): 115-128; Berlin Referat in: N. Jb. Mineral. etc., $\underline{\mathbf{1 8 9 5}}$ (Bd. II): 120-121 (Holzapfel); Stuttgart [Tektonik]

QLossen, K. A. (1887): Porphyr mit geschwänzten Quarzeinsprenglingen von Thal im Thüringer Wald. Z. dt. geol. Ges., 39: 836-841, Berlin

Referat in: N. Jb. Mineral. etc, $\underline{\mathbf{1 8 8 8}}$ (Bd. I): 91-92 (O. Mügge) Stuttgart

[Tektonik, Gefügekunde; Porphyr Thal-Heiligenstein]

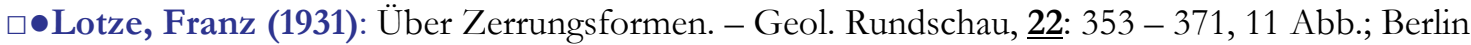
[Saxonische Tektonik, darin: Uslarer Tongrube, Mariengarten SW' Göttingen; Sontraer Graben]

- $\square 0 \bullet$ Lotze, Franz (1937): Salzabscheidung und Tektonik. - Kali, etc.,

31(3): $22-24$

$\underline{31}(4): 33-36$

31(5): $41-45$

31(6): $51-54$

31(7): 61-63

31(8): 71-72, zahlr. Fig.; Halle/Saale

[darin: Thüringer Becken; Mächtigkeitskarte Älteres Steinsalz Mitteldeutschland - HE, WMK, THÜ, NIE]

$\square \bullet$ Lotze, Franz (1957): Steinsalz und Kalisalze. - Zweite, neubearb. Aufl., I. Teil (Allgemein geologischer Teil). - XI, 465, 1 S., 226 Abb., 37 Tabl.; (Bornträger) Berlin

[darin: „Tektonik der Salzlagerstätten“; S. 265, Abb. 124: Leinetalgraben; S. 266, Abb. 126: Sontraer Graben]

•Lang, H. O. (1880): Über den Gebirgsbau des Leinetals bei Göttingen. - Z. dt. geol. Ges., 32: 799-806; Berlin 
-Langheinrich, Gunter (1966): Syndiagenetische Fossildeformation im unteren Lias (Hettangium) von Göttingen. - N. Jb. Geol. Paläont., Mh., 1966: 666-680, 5 Abb.; Stuttgart

-Langheinrich, Gunther (1978): Der Göttinger Leinetal-Graben in tektonischer Sicht. - In: Koritnig, Sigmund [Schriftltg.]: Zur Mineralogie und Geologie der Umgebung von Göttingen - mit Westharz und Teilen des Nordhessischen Berglandes. - Sdbd. 28: 146 - 155, 5 Abb.; Heidelberg 1978

-Lemmer, Frank \& Rambow, Dietrich (1994): Die Höhenlage der Rötbasis im Raum Kassel und über Zechsteinaufpressungen an nordhessischen Gräben. - Geol. Jb. Hessen, 122: 13-21, 1 Abb., 2 Taf.; Wiesbaden

-Linstow, Otto v. (1918): Ueber gegenwärtige Bodenbewegungen bei Bückeburg, Göttingen, in Thüringen und im norddeutschen Tieflande. - Z. dt. geol. Ges., $\underline{69}$ (f. 1917): 121-131, 1 Abb.; Berlin Referat in: N. Jb. Mineral. etc., 1918: 281-282 (Milch); Stuttgart

-Lohmann,, H.-H. (1959): Zum Bau des Oberweserberglandes zwischen Hannoversch-Münden und Karlshafen. - Diss. Univ. Hamburg; 233 S., 64 Abb., 4 Anl.; Hamburg

- 0 lLorenz, Th. (1907): Ueber den Gebirgsbau Mitteldeutschlands. - Ber. Niederrhein. Geol. Vereins, 1907: 24-40, 9 Abb., Taf. 2.; Bonn

Referat in: Mitt. Geogr. Ges. (f. Thüringen), 28: 43; Jena 1910

[Bezugn. a. Ohmgebirgsgraben, Hessische Gräben, Thüringer Wald]

OLoretz, H. (1893): Bemerkungen über die Lagerung des Rothliegenden südlich von Ilmenau in Thüringen. - Jb. Preuß. Geol. Landesanst., $\underline{13}$ (f. 1892): 115-128; Berlin Referat in: N. Jb. Mineral. etc., $\underline{\mathbf{1 8 9 5}}$ (Bd. II): 120-121 (Holzapfel); Stuttgart

-Lotze, Franz (1930): Der Westrand des Leinetalgrabens zwischen Hardegsen und Moringen. - Abh. Preuß. Geol. Landesanst., N.F., 116: 195 - 237, 11 Abb., Taf. 12 - 15; Berlin

-Lotze, Franz (1932): Der Südteil des Göttinger Leinetalgrabens und der Eichenberger Grabenknoten. Abh. Preuß. Geol. Landesanstalt, N.F., 139; zgl. Göttinger Beitr. z. saxon. Tektonik, IV; S. 5 - 48, 30 Abb.; Berlin

-Lotze, Franz (1932): Zur Erklärung der Querplattung (Sigmoidalklüftung) im Wellenkalk. - Zbl. Mineral. etc., Abt. B, 1932: 300 - 307, 6 Abb.; Stuttgart

[Aufschluß Göttingen-Herberhausen]

- •Lotze, Franz (1932): Wie entstehen Schrumpfungsrisse? - Natur u. Volk, 62(4): 123-130, 11 Abb.; Frankfurt/M.

[Genese der Säulenstruktur von Basalten; auch tertiäre Toneisenstein-Geode Fdpkt. Uslar/Solling]

$\square \bullet L o t z e$, Franz (1937): Zur Methodik der Forschung über saxonische Tektonik. - Geotektonische Forschungen, $\underline{1}$ (zgl. Zur germanotypen Tektonik I): 6-27; 20 Abb.; Berlin [darin: Leinetalgraben, Friedländer Spalte, Sontraer Graben]

OLützner, Harald (1961): Saalische Bewegungen im Rotliegenden des mittleren Thüringer Waldes. Geol. Rundschau, 51: 560-566, 1 Abb., Text-Taf. 20; Stuttgart

OLützner, Harald (1964): Die saalische Phase im Gebiet von Ilmenau. - Abh. Dt. Akad. Wiss. z. Berlin, Kl. Bergbau, Hüttenw., Montangeol., 1964(2)[Deubel-Festschrift]: 287-308, 5 Abb.; Berlin

OLützner, H. (1970): Sedimentation und Tektonik im Rotliegenden des Thüringer Waldes. -

$<$ Autorreferat - Tagungsbeitrag anläßlich der> - Tagung des Fachverbandes Geologei der Deutschen Gesellschaft für Geologische Wissenschaften am 6. und 7. Dezember 1968 in Halle - „Das sedimentäre Permosiles in der Deutschen Demokratischen Republik südlich der Mitteldeutschen Hauptlinie“. - Ber. Dt. Ges. geol. Wiss., Reihe $\underline{\mathbf{A}}$, 15(1): 102-103; Berlin 
OLützner, Harald (1972): Lithostratigraphie und Paläotektonik des Rotliegenden in der Schleusinger Randzone (Thüringer Wald). - Ber. Dt. Ges. geol. Wiss., A 17(6): 811-834, 10 Abb., 1 Tab.; Berlin

QLützner, Harald (1974): Variscisch-spätorogene Bewegungen [im Thüringer Wald]. - In: Hoppe, Walter \& Seidel, Gerd [Hrsg.]: Geologie von Thüringen [Bezirke Erfurt, Gera, Suhl]. - S. 554-567, Abb. 92-94; (Haack) Gotha-Leipzig 1974

OLützner, Harald (1988): Synsedimentäre Indikatoren paläotektonischer Bruchvorgänge. - Z. geol. Wiss., 16(4): 287-298, 6 Abb.; Berlin [darin: Thüringer Wald]

OLusznat, M. (1950): Stratigraphie und Tektonik der Nebengesteine des Floßberggangzuges bei Ilmenau. - Dipl.-Arb. [unveröff.] Univ. Jena 1950

-Martini, Hans Joachim (1936): Die Grabenzonen westlich Kassel als Trennungsfuge großer Schollen. - Z. dt. geol. Ges., $\underline{88:}$ 580-; Berlin

-Martini, Hans Joachim (1937): Großschollen und Gräben zwischen Habichtswald und Rheinischem Schiefergebirge. - Geotektonische Forschungen, 1: 70 - 123, 36 Abb., 3 Taf.; Berlin

OMeister, Jochen (1994): Zur Vulkanotektonik rotliegender Rhyolithe des Thüringer Waldes. Hallesches Jb. Geowiss., 16: 67-77, 6 Abb., 4 Photos; Halle (Saale)

OMartini, Hans Joachim (1940): Saxonische Zerrungs- und Pressungsformen im Thüringer Becken. Geotektonische Forschungen, ㅁ: 125-133, 5 Abb.; Berlin

-Meiburg, Peter (1969): Die Warburger Störungszone - Ein Beitrag zur Geologie des Warme-DiemelGebietes (Nordhessen/Ost-Westfalen). - Diss. Univ. Münster 1971; 394 B., Ill., graph. Darst., Kt., Anl.

-Meiburg, P. (1980): Stabile und mobile Entwicklungsstufen in der Taphrogenese der Hessischen Senke. - Berliner geowiss. Abh., Reihe A, 19: 143-147, 2 Abb.; Berlin

-Meiburg, Peter (1982): Saxonische Tektonik und Schollenkinematik am Ostrand des Rheinischen Massivs. - Geotektonische Forschungen, 62; II, 267 S., 84 Abb., 8 Beil., 1 Tab.; Stuttgart

-Michael, Joachim (1996): Tektonomechanik im nordosthessischen Buntsandsteingebirge. - Diss. Univ. Marburg [unveröff.], 215 S., Ill., graph. Darst., Kt.

-Michael, J. (1997): Tektonomechanik im nordosthessischen Buntsandsteingebirge. - Edition Wissensch., Reihe Geowissensch., 299; 217 S.; (Tectum-Verlag) Marburg

QMith, Georg; Fulda, Dieter \& Zeidler, Werner (1989): Beitrag zum Wirkmechanismus von Gastonbrüchen in den Gruben des Südharz-Kalireviers. - Z. geol. Wiss., 17(4): 407-417, 9 Abb.; Berlin [Bischofferode, Pöthen]

-Mixius, Friedrich Karl (1940): Das hessische Grabengebiet im Süden der Sollingscholle. Geotektonische Forschungen, $\underline{\mathbf{5}}$ (Zur germanotypen Tektonik III): 60 - 123, 39 Abb., 4 Taf; Berlin [Tektonische Gräbern außerhalb des Werra-Meißner-Kreises]

$\square$ Möbus, Heinz-Martin (2004): Allochthone Triasschollen am Unterwerrasattel als Schlüssel zum Verständnis saxonischer Tektonik. - Diss. Fb. Geowiss. Univ. Marburg 2004; X, 197 S, 14 Bl. Anh., Abb., 4 Beil. 
- $\square$ Möbus, Heinz Martin (2008): Die Hessischen Gräben als mehrfach duktil entkoppelte „pull apart“ Strukturen. - Geol. Jb. Hessen, 135 (f. 2007): 5-23, 12 Abb., 2 Taf.; Wiesbaden

[Altmorschener Graben (=Gelstertalgraben), Gottesberg b. Hundelshausen]

$\square 0 \bullet$ Moesta, Friedrich (1884): Das Liasvorkommen von Eichenberg in Hessen in Beziehung auf allgemeine Verhältnisse des Gebirgsbaues in Nordwesten des Thüringer Waldes. - Jb. Preuß. Geol. Landesanst., 4 (f. 1883): 57-80, 4 Taf.; Berlin

Referat (Kurzfassung) in: N. Jb. Mineral. etc., 1886 (Bd. 2): 63-65 (Ref. E. Dathé); Stuttgart

[Saxonische Tektonik, Eichenberg-Gothaer-Graben]

$\square$ Morgenroth, Kurt (1931): Zur Tektonik des Ringgaus. - Beitr. Geol. Thür., 3: 67-98, 2 Abb., 2 Taf.: Jena

$\square$ Munk, Carsten (1983): Vergleichende Gefügeuntersuchungen für den Tunnelbau im Buntsandstein. Diss. Univ. Marburg/Lahn 1983; 146 S., 48 Abb., 21 Tab., 12 Taf. (Anlage)

[Schürzeberg b. Oberrieden/Werra-Meißner-Kreis]

$\square$ Munk, C.; Prinz, H. \& Zank1, H. (1983): Vergleichende Gefügeuntersuchungen für den Tunnelbau im Buntsandstein. - In: Heitfeld, Karl-Heinrich [Hrsg.]: Ingenieurgeologische Probleme im Grenzbereich zwischen Locker- und Festgesteinen. - 695 S., 397 Abb.; hier S. 541-557, 5 Abb., 2 Tab.: (Springer) Berlin-Heidelberg u.a.

[Schürzeberg b. Oberrieden, Voruntersuchungen für den Bau des Schürzeberg-Tunnels/WerraMeißner-Kreis]

-Murawski, Hans (1951): Zusammenhänge zwischen Basaltvulkanismus und Tektonik in Niedersachsen. - Geol. Rundschau, 39: 114-119, 3 Abb.; Stuttgart [Basalte $\mathrm{W}^{\prime}$ Göttingen]

-Murawski, Hans (1955): Das Ausmaß der Vertikalleistung jungtertiärer Tektonik im Gebiet des Leinetalgrabens. - N. Jb. Geol. Paläont. Mh., 1955: 297-308, 1 Abb.; Stuttgart

- $\square \bullet$ Murawski, Hans (1960): Das Zeitproblem bei der Tektogenese eines Großgrabensystems. Ein taphrogenetischer Vergleich zwischen Hessischer Senke und Oberrheintalgraben. - Notizbl. Hess. L.A. Bodenforsch., 88: 294 - 342, 3 Abb.; Wiesbaden

-Namenskürzel (Dr. D. F.) (1963): Göttingen und das Tal der Leine. - Die Weser, $\underline{\text { 37(4/5): 48-54, } 5}$ Abb.; Bremen

[darin: Geologische Entstehung des Leineberglandes/Leinetalgrabens]

ONaumann van Padang, Maur (1924): Tektonische Studien im nordwestlichen Teil des Gothaer Grabens. - Diss. Friedrich-Wilhelms-Univ. Berlin; 80 S., Abb.

QNaumann, Ernst (1940): Bemerkungen über die Trias und Tektonik im Raum zwischen Gotha, Ohrdruf, Friedrichroda und Eisenach. - Beitr. Geol. Thür., 5: 219-228; Jena

ONeumann, Werner (1955): Gefügeuntersuchungen im Ruhlaer Kristallin. - Diss. Univ. Berlin 1955 Geologie, 4(2): 194 (Autorreferat); Berlin

QNeumann, Werner (1955): Gefügeuntersuchungen im Ruhlaer Kristallin. - Ber. geol. Ges. DDR, 1 (1): 78-86, 1 Abb.; Berlin

ONeumann, W. (1972): Die Entwicklung von variszischer und saxonischer Tektonik im Ruhlaer Kristallin. - Ber. Dt. Ges. geol. Wiss., A $\underline{17}(6)$ : 797-810, 5 Abb.; Berlin

$\square$ Neuweiler, F.; Peckmann, J. \& Ziems, A. (1999): Sinusoidally deformed veins („Sigmoidalklüftung“) in the Lower Muschelkalk (Triassic, Anisian) of Central Germany: sheet injection structures defomed within the shallow subsurface. - N. Jb. Geol. Paläont., Abh., [D. Meischner-Festschrift) $\underline{214}(1 / 2)$ : 
129-148, 12 fig., 1 tabl.; Stuttgart

[darin: Aufschluß a. d. „Boyneburg“ Bl. 4826 Eschwege]

-Neuwirth, Günther (1960): Bewegungsvorgänge im Kalibergbau des Werra-Fulda-Gebietes. - Kali u. Steinsalz, $\underline{\mathbf{3}}(2)$ : 37-54, 24 Bilder; Essen

[Untersuchungen in 3 Bergwerken; Lokalitäten anonymisiert]

$\square$ Nöll, Tilo (1973): Die Geologie im Bereich des nördlichen Teils des Altmorschener-Lichtenauer Grabens bei Trubenhausen. - Dipl.-Arb. [unveröff.] Univ. Göttingen; 76 S., 13 Abb., 7 Tab., 3 Anl.

-Ortlam, Dieter (1981): Neue Aspekte zur känozoischen Entwicklung im Nordteil der MittelmeerMjösen-Zone. - Geol. Rundschau, 70: 344-354, 5 Abb.; Stuttgart

[Großregionale Betrachtung unter Einbeziehung der Hessischen Senke, bzw. Nordhessischen Gräben]

QPatzelt, Gerald (1977): Nochmals zur Frage der Einstufung der Porphyrkonglomerate im

Rennsteiggebiet des Meßtischblattes Tambach-Dietharz (Thüringer Wald). - Hallesches Jb. mitteldt. Erdgeschichte, 1: 115-120, 2 Abb.; Gotha/Leipzig

[Tektonik]

OPatzelt, Gerald (1992): Ein tektonisch interessanter Aufschluß bei Hildebrandshausen. - Mühlhäuser Beitr., 15: 9-18, 5 Abb.; Mühlhausen

OPatzelt, Gerald (1995): Aufschlüsse im Bereich der Eichenberg-Saalfelder Störungszone zwischen Geismar und Misserode (Eichsfeldkreis). - Beitr. Geol. Thüringen, N.F., 2: 65-74, 5 Abb.; Weimar

OPatzelt, Gerald (1995): Tektonische Beobachtungen im Kalksteinbruch Schliemenköpfchen bei Nazza (Wartburgkreis) am SW-Fuß des Hainich. - Beitr. Geol. Thüringen, N.F., 2: 53-63, 5 Abb., 1 Tab.; Weimar

OPatzelt, Gerald (1998): Lagerungsverhältnisse und Oberflächenformen bei Treffurt. - Mühlhäuser Beitr., 20/21: 7-16, 7 Abb.; Mühlhausen

QPatzelt, Gerald (1999): Eine geologische Revisionskartierung im Bereich der Eichenberg-Saalfelder Störungszone nordwestlich von Lengenfeld unterm Stein (Eichsfeldkreis). - Mühlhäuser Beitr., 22: 515, 4 Abb.; Mühlhausen

OPatzelt, Gerald (2000): Ein als Naturdenkmal vorgesehener Geotop bei Misserode im Eichsfeldkreis. Mühlhauser Beitr., 23: 14-16, 2 Abb.; Mühlhausen

OPatzelt, Gerald (2002): Zum Verlauf der Küllstedter Störungszone, zur Erdfallbildung und Erdfallgefahr bei Mühlhausen und Oberdorla. - Mühlhäuser Beitr., 25: 7-14, 2 Abb.; Mühlhausen

OPeterek, Andreas (2002): Neotektonische und morphostrukturelle Entwicklung des Thüringer Waldes und Thürinigischen Schiefergebirges - Überblick und Ausblick. - Neotectonic and morphostrutural development of the Thuringian Forest und Thuringian Schiefergebirge - review and prospects. - Z. geol. Wiss., $\underline{\mathbf{3 0}}$ (4/5): 277 - 292, 8 Abb.; Berlin

$\square \bullet$ Petraschek, Walter Emil (1931): Tektonische Studien im nördlichen Solling und am Südrand der Elfas-Achse. - Abh. Preuß. Geol. Landesanst., N.F., 128: 129-147, 9 Abb., Taf. 7 u. 8; Berlin [darin S. 141-142, Abb. 8, Kap. , Vergleichende Betrachtung im Schnittgebiet des WerraGrauwackensattels mit dem Leinetalgraben“: Der Gottesberg bei Hundelshausen]

- $\square 0$ Petraschek, Walter Emil (1932): Entstehungsarten saxonischer Gräben. - Z. dt. geol. Ges., $\underline{83}$ (f. 1931): 421-431, 5 Abb.; Berlin

Referat in: N. Jb. Mineral. etc., Referate; 1933 (Bd. II): 12-13 (E. Christa); Stuttgart

[Bezugn. a. Nordhessen, Thüringen] 
OPhilippi, E. (1911): Über die präoligocäne Landoberfläche in Thüringen. - Z. dt. geol. Ges., $\underline{62}$ (f. 1910): 305-404 (Abh.), 23 Abb., Taf.. IV; Berlin

Referat in: Mitt. Geogr. Ges. (f. Thür.): 30: 228-235 (E. Piltz); Jena 1912

[Geomorphologie, Tektonik, u.a. der Thüringer Störungszonen]

OPlatt, H. (1916): Das Randgebiet des Thüringer Waldes bei Benshausen. - Jb. Preuß. Geol. Landesanst., $\underline{\mathbf{3 6}}$ (Teil II) (f. 1915): 175 - 225, 10 Abb., insges. 6 Taf.; Berlin

[Rotliegendes, Zechstein, Buntsandstein, Tektonik]

-Prechtl, Daniel (1994): I. Geologische Kartierung des Ottrauer Grabens in Hessen (TK 25: 5122 Neukirchen) - II. Geologie des Ottrauer Grabens und seine Tiefenfortsetzugn nach gravimetrischer Modellierung. - Dipl.-Kart. u. Dipl.-Arb. 1994; 73 S., ca. 20 ungez. S. Anhang

-Prinz, Helmut (1989): Ein Beitrag zur Kinematik der saxonischen Tektonik anhand der Tunnelaufschlüsse an der DB-Neubaustrecke in Ost- und Nordhessen. - Geol. Jb. Hessen, 116: 169187, 9 Abb.; Wiesbaden

$\square$ Rambow, Dietrich (1976): Der Altmorschen-Lichtenauer Graben im Gebiet Retterode. - Geol. Jb. Hessen, 104: 177 - 179, 1 Abb.; Wiesbaden

-Rambow, Dietrich (1976): Die Westfortsetzung des Grabens von Wickenrode (Nordhessen). - Geol. Jb. Hessen, 104: 181 - 182, 1 Abb.; Wiesbaden

-Rambow, Dietrich \& Lemmer, Frank (2002): Zur Genese der Tertiärsenken südöstlich von Kassel : Tektonik oder Subrosion? - Geol. Jb. Hessen, 130: 73-89, 10 Abb., 1 Tab.; Wiesbaden

QRauche, Henry (2001): Bruchmechanik der Mn-mineralisierten Gangbrekzien von Arlesberg und Oehrenstock im Thüringer Wald <Vortragskurzfassung>. - In: Rauche, Henry [Hrsg.]: Regionale und angewandte Geologie der Grenzregion der Süddeutschen und der Mitteldeutschen Scholle. Programm und Kurzfassungen der Vorträge. - 10. Jahrestagung Gesellschaft f. Geowissenschaften i. Schmalkalden, 19.-22. September 2001. - Exkursionsführer u. Veröff. Ges. f. Geowiss., 214; S. 199200; Berlin 2001

ORauche, H. \& Van der Klauw, S. (1997): Verformungsgeschichte vom Metasedimenten der Hohleborn-,,Serie“ (Kristallin-Komplex von Ruhla/Brotterode, Thüringer Wald) (Posterbeitrag). - In: Büchel, Georg \& Lützner, Harald (Hrsg.): Regionale Geologie von Mitteleuropa Geodynamische Prozesse zwischen Alpen und Nordatlantik - 149. Hauptversammlung - Deutsche Geologische Gesellschaft und Jahreshauptversammlung der Fachsektion Geoinformatik - Jena 27.09. 3.10.1997 - Kurzfassung der Vorträge und Poster. - Schriftenrh. Dt. geol. Ges., 2: 92-93; Hannover 1997

ORedlich, S.; Beer, W. \& Rauche, H. (2001): Verlauf und struktureller Bau der sallmannshäuser Störungszone <Vortragskurzfassung $>$. - In: Rauche, Henry [Hrsg.]: Regionale und angewandte Geologie der Grenzregion der Süddeutschen und der Mitteldeutschen Scholle. - Programm und Kurzfassungen der Vorträge. - 10. Jahrestagung Gesellschaft f. Geowissenschaften i. Schmalkalden, 19.-22. September 2001. - Exkursionsführer u. Veröff. Ges. f. Geowiss., 214; S. 207-208; Berlin 2001

- Rentzsch, Johannes \& Franzke, Hans Joachim (1997): Regional tectonic control of the Kupferschiefer mineralization in Central Europe. - Z. geol. Wiss., 25(1/2): 121-139, 5 fig., 3 tabl.; Berlin [darin: Richelsdorfer Gebirge]

ORichter, Gerhard (1942): Das Überleiten von variscischer zu saxonischer Tektonik am nordwestlichen

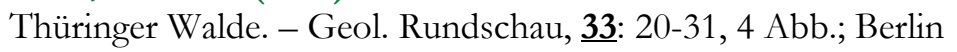
[Bereich Eisenach, Mosbach, Ruhla] 
-Richter-Bernburg, G. (1965): Saxonische Tektonik als Indikator erdtiefer Bewegungen. - Geol. Jb., 모: 997-1030, 20 Abb.; Stuttgart

Sicht. - Z. dt. geol. Ges., 128: 11-23, 10 Abb., 1 Taf.; Hannover

[Globale Betrachtung unter Einbeziehung HE, WMK, THÜ, NIE ; Profil Leinetalgraben Göttingen]

QRietschel, Manfred (1957): Der Einfluß der Tektonik auf die Ausbildung des unteren und oberen

Kalilagers im Bereich der Schachtanlage Dietlas I. - Dipl.-Arb. [unveröff.] Bergakademie

Freiberg/Sa., $48 \mathrm{~S}$.

Referat in: Geologie, $\underline{8}(2): 216-217$; Berlin 1959

-Ritzkowski, Siegfried (1968): Die Tektonik der Braunkohlenlagerstätte von Borken (Tertiär, nördliches Hessen). - Notizbl. Hess. L.-A. Bodenforsch., 96: 273-280, 3 Abb., Taf. 9; Wiesbaden

OSchäfer, Aloys (1921): Die Tektonik der Hansteinscholle. - Unser Eichsfeld., 16(1/2): 10-13, 2 Abb.; Heiligenstadt

OScharbrodt, Thomas; Baumann, Ludwig \& Alexosky, Hans (1989): Zur Rekonstruktionsmethodik von Paläobruchstrukturen im Salinar. - Z. geol. Wiss., 17(2): 89-96, 5 Abb.; Berlin [Werra-Kalirevier]

OScheffzük, Christian (1996): Neutron diffraction texture analysis of natural and experimentally deformed Halite samples of the Merkers mine. - Z. geol. Wiss., 24(3/4): 403-410, 6 fig., 1 tabl.; Berlin

OSchilder, Christian \& Schwandt, Arnold (1983): Zur Tektonik und Auslaugung in Kali- und Steinsalzabbaugebieten. - Z. geol. Wiss., 11(8): 1023-1033, 8 Abb.; Berlin

[Werra-Kalirevier; Südharz-Kalirevier]

$\square$ Schmid, M. (1989): Der Stockwerksbau des Unterwerra-Sattels. - Zbl. Geol. Paläont., Teil 1, 1989(1/2): 396-397; Stuttgart

$\square$ Schmid, Martin (1991): Der variszische Stockwerkbau des Unterwerra-Grundgebirges: das tektonische Bindeglied zwischen Harz und Rheinischem Schiefergebirge. - Braunschweiger geologischpaläontologische Dissertationen, $\underline{\mathbf{1 2}}$, 82 S., 38 Abb., 5 Tab., 3 Taf., 3 Kt.; zgl. Diss. Naturwiss. F. TU Braunschweig; Braunschweig

$\square$ Schott, W. (1930): Überschiebungserscheinungen bei Marzhausen südlich Göttingen. - Abh. Preuß. Geol. Landesanst., N.F., 116: 233-237, 3 Abb., Taf. 17; Berlin

OSchreiber, Alfred (1952): Stratigraphie und Tektonik des Unterrotliegenden im südwestlichen Randgebiet des Thüringer Waldes bei Schleusingen und Hirschbach (Kr. Suhl). - Geologica, 11: 87106, 5 Abb.; Berlin

OSchreiber, Alfred (1955): Über orogene Bewegungen im Unterrotliegenden des Thüringer Waldes. Abh. Dt. Akad. Wiss., Kl. Mathem. u. Allgem. Naturwiss.; 1954, H. 7 - (Abhandlungen zur Geotektonik, 6); 54 S., 28 Abb., Kt., 3 Kt-Beil.; (Akademie-Verlag) Berlin

$\square$ Schroeder, Eckart (1923-1925): Tektonische Studien an Niederhessischen Gräben. (Göttinger Beiträge zur saxonischen Tektonik, [1]) - Abh. Preuß. Geol. Landesanst., N.F., 95, 57-82, 6 Abb., 3 Taf.; Berlin [Tektonische Gräben im Werra-Meissner-Kreis]

- $\square$ Schuh, Fr. (1922): Die saxonische Gebirgsbildung. - I. Teil. - Kali, etc., $\underline{16}(8): 145-152$, 16(9): 167-174, 9 Fig.; [darin erwähnt: Niederhessische Gräben]

Die saxonische Gebirgsbildung. - II. Teil - Kali, etc., 16(15): 285-291 
16(16): 306-312, 9 Fig.; Halle/Saale

[recht theoretische Abhandlung]

OSchwandt, Arnold (1972): Beziehungen zwischen Salzlösungszuflüssen und Tektonik im Kalibergbau der DDR. - Ber. Dt. Ges. geol. Wiss., Reihe A, $\underline{\mathbf{A} 17}(2)$ : 177-190, 9 Abb.; Berlin [darin: Merkers/Werra-Kalirevier]

هSchwarz, Friedrich (1948): Säkulare Vertikalbewegungen tektonischer Kleinschollen der Kasseler Umgebung. - N. Jb. Mineral., Geol., Paläont., Mh., Abt. B, 1945-1948: 78-94, 2 Taf.; Stuttgart

OSeidel, Gerd (1974): Saxonische Tektogenese [in Thüringen]. - In: Hoppe, Walter \& Seidel, Gerd [Hrsg.]: Geologie von Thüringen [Bezirke Erfurt, Gera, Suhl]. - S. 699-716, Abb. 124-130; (Haack) Gotha-Leipzig 1974

oSeidel, Gerd (1989): Zur Tektonik der Störungszonen des südlichen Thüringer Beckens. - Z. geol. Wiss., 17 (3): 311-316, 10 Abb.; Berlin

OSeidel, Gerd (1995): Saxonische Tektonik [in Thüringen]. - In: Seidel, Gerd [Hrsg.]: Geologie von Thüringen. - 1. Aufl.; S. 373-377, 3 Abb.; Stuttgart 1995

OSeidel, Gerd (1998): Zum Bau des Leinefelder Sattels (Thüringischer Teil der Eichsfeldscholle). Geowiss. Mitt. Thüringen, ㅁ: 83-88, 2 Abb.; Weimar

OSeidel, Gerd (2003): Saxonische Tektonik [in Thüringen]. - In: Seidel, Gerd [Hrsg.]: Geologie von Thüringen. - 2., neu bearb. Aufl.; S. 403-409, 3 Abb.; Stuttgart 2003

aSeidel, Gerhard (1938): Die Dislokationszonen zwischen Bonenburg und Volkmarsen. Geotektonische Forschungen, 3: 1-32, 17 Abb.; 4 Taf.; Berlin - zgl. Diss. Univ. Berlin 1938

OSeidlitz, W. v. (1927/1928): Die Vergitterung tektonischer Achsen im Bauplan Thüringens. - Beitr. Geol. Thüringen, $\underline{1}$ (1): 1-15, 1 Abb.; Jena

Referat in: N. Jb. Mineral. etc., Referate, 1929 (Bd. III): 333-334 (Hans Becker); Stuttgart

aSemmel, Arno (1991): Neotectonics and geomorphology in the Rhenish Massif and the Hessian Basin. - Tectonophysics, 195: 291-297, 1 Abb.; Amsterdam [darin: Fuldatal]

OSeidlitz, W. v. (1927/1928): Die Vergitterung tektonischer Achsen im Bauplan Thüringens. - Beitr. Geol. Thüringen, 1(1): 1-15, 1 Abb.; Jena

Referat in: N. Jb. Mineral. etc., Referate, 1929 (Bd. III): 333-334 (Hans Becker); Stuttgart

OSeidlitz, W. v. (1928): Die Bedeutung nörd-südlich gerichteter Störungen für die Tektonik des westlichen Thüringer Waldes. - Zbl. Mineral. etc., Abt B., 1928: 401 - 408; Stuttgart

aSissingh, W. (2003): Teriary paleogeographic and tectonostratigraphic evolution of the Rhenish triple junction. - Paleogeography, Palaeoclimatology, Palaeoecology., 196(1-2): 229-263, 10 fig.; Amsterdam [Großregionale Betrachtung; Bezug auf Oberrheingraben, Hessische Senke]

-Sobotha, Ernst (1932): Über Salzauslaugung, Tektonik und Oberflächenformen zwischen Westharz und Vogelsberg. - Z. dt. geol. Ges., 4: 725 - 732, 3 Abb.; Berlin

Q•Sobotha, Ernst (1934): Zur Tektonik und Beckenbildung im nordwestlichen Eichsfeld. - Z. dt. geol. Ges., $\underline{\mathbf{8 5}}$ (1933): 788 - 791, 1 Abb.; Berlin

[Östl. Lkr. Göttingen, Umgebung Heiligenstadt]

$\square$ Stark, Hans (1950): Altersstellung und Tektonik des Paläozoikums bei Albungen. - Diss. Univ. Göttingen 1950; 56 S., 11 Abb., 6 Kt. 
$\square$ Stark, Hans (1952): Altersstellung und Tektonik des Paläozoikums bei Albungen. - Geol. Jb., 66: 203 226, 9 Abb.; Hannover

$\square$ Stille, Hans (1923-1925): Die saxonischen Brüche (Schlußwort zu den „Göttinger Beiträgen zur saxonischen Tektonik 1923 - 1925`). - Abh. Preuß. Geol. Landesanst., N.F., 95: 149 - 207, 1 Abb., 1 Taf.; Berlin

Referat in: N. Jb. Mineral. etc., Abt B, 1927 (Bd. II): 307 (W. Eder); Stuttgart

- $\square$ •Stille, Hans (1926): Beitrag zur Frage der saxonischen Zerrungen. - Nachr. Ges. Wiss. z. Göttingen, Math-phys. Kl., 1925: 178-183, 1 Abb.; Berlin

Referat in: N. Jb. Mineral. etc., Abt. B, 1927 (Bd. II): 307-308 (W. Eder); Stuttgart

[Bezugn. a. Hessisch-Thüringische Gräben u.a. Gelstertalgraben, Göttinger Leinetalgraben]

Q Stille, Hans (1928): Tektonische Schlußfolgerungen aus der Umgrenzung der permischen Lagerstätten. - Z. dt. geol. Ges., 으: 146-148 (Mber.); Berlin

Referat in: N. Jb. Mineral. etc., Referate, 1929 (Bd. III): 84; Stuttgart

-0 $\bullet$ Stille, Hans (1929): Tektonische Schlußfolgerungen aus der Umgrenzung der permischen Salzlagerstätten. - Z. dt. geol. Ges., $\underline{\mathbf{8 0}}$ (f. 1928): 146-148 (Mber.); Berlin

Referat in: N. Jb. Mineral. etc., Referate, 1929 (Bd. III): 84; Stuttgart

-0•Stille, Hans (1929): Zur Frage der Harzinsel der jüngsten Zechsteinzeit. - Z. dt. geol. Ges., $\underline{80}$ (f. 1928): 188-200 (Mber.); Berlin

Referat in: N. Jb. Mineral. etc., Referate, 1929 (Bd. III): 85; Stuttgart

[Großregionale Betrachtung]

-Stille, Hans \& Lotze, Franz (1931): Zur Frage der Überschiebungserscheinungen im Leinetal. Nachr. Ges. Wiss. z. Göttingen, Math.-phys. Kl., Fachgr. IV; Bd. 1 (1930/31)[1931, Nr. 14]: 227-235; Göttingen

Referat in: N. Jb. Mineral. etc., Referate, 1933 (Bd. III): 13-14 (A. Bentz); Stuttgart

[Aufschlüsse u.a. Lkr. Göttingen]

QStöcke, K. \& Borchert, H. (1936): Fließgrenzen von Salzgesteinen und Salztektonik. - Kali, etc., $\underline{\mathbf{3 0}}(21):$ 204-207, 30(22): 214-217, 2 Taf.; Halle

[darin: Anhydrit Sollstedt - Felsmechanik]

OStolle, E. (1957): Disharmonische Abscherungsbewegungen der Hangendschichten des Kalilagers Staßfurt im Südharz-Kalirevier. (Mit 32 Abb. u. 42 Anl.). - Diss. Univ. Jena 1957; Textbd. 115, V Bl.; Anl.-Bd. 15 Bl., Abb., Kt.

OStolle, Ernst (1957): Disharmonische Tektonik im Zechstein des Südharzgebietes. - Ber. geol. Ges. DDR, 4(4): 299-312, 10 Abb.; Berlin [Ohmgebirge, Bleicherode, Sondershsn.]

-Uhlenbecker, Friedrich-Wilhelm (1971): Gebirgsmechanische Untersuchungen auf dem Kaliwerk Hattorf (Werra-Revier). - Kali u. Steinsalz, $\underline{\mathbf{5}}(10):$ 345-359, 38 Bilder; Essen

QVan der Klauw, S. \& Rauche, H. (1997): Duktile und semiduktile Verformungsgeschichte von Trusetal-Brotterode (Kristallin von Ruhla-Brotterode) (Posterbeitrag). - In: Büchel, Georg \& Lützner, Harald (Hrsg.): Regionale Geologie von Mitteleuropa - Geodynamische Prozesse zwischen Alpen und Nordatlantik - 149. Hauptversammlung - Deutsche Geologische Gesellschaft und Jahreshauptversammlung der Fachsektion Geoinformatik - Jena 27.09.-3.10.1997 - Kurzfassung der Vorträge und Poster. - Schriftenrh. Dt. Geol. Ges., 2: 70-71; Hannover 1997 
QVan der Klauw, S.; Rauche, H. \& Lützner, H. (1997): Mineralparagenesen und Mikrostrukturen in Gesteinsfragmenten im Detritus permosilesischer Sedimente im westlichen Thüringer Wald: Hinweise auf eine differenzierte Hebung und Abtragung des Ruhlaer Kristallins (Vortragskurzfassung). - In: Büchel, Georg \& Lützner, Harald (Hrsg.): Regionale Geologie von Mitteleuropa Geodynamische Prozesse zwischen Alpen und Nordatlantik - 149. Hauptversammlung - Deutsche Geologische Gesellschaft und Jahreshauptversammlung der Fachsektion Geoinformatik - Jena 27.09.3.10.1997 - Kurzfassung der Vorträge und Poster. - Schriftenrh. Dt. Geol. Ges., 2: 71; Hannover 1997

QVan der Klauw, Sebastian N.G.C.; Lützner, Harald \& Rauche, Henry (2002): An investigation of the composition and microstructure of rock fragments in coarse grained Rotliegend sedimentary rocks around the Ruhla crystalline complex (Thuringian Forest, Germany) - Zusammensetzung und Mikrostrukturen von Gesteinsfragmenten in Rotliegend Sedimenten im Umfeld des Ruhlaer Kristallins. - Z. geol. Wiss., 30(4/5): 315-325, 2 fig., 2 tabl.; Berlin [Abtragungsgeschichte, Hebungsgeschichte]

OVogel, Jochen \& Schäbitzer, Rudolf (1967): Zur Tektonik der Kaliflöze „Thüringen“ und „Hessen“ auf der Schachtanlage „Ernst Thälmann“, Merkers (Rhön), des VEB Kalikombinat „Werra“ - I. Teil: Beschreibung der tektonischen Erscheinungsformen. - Z. angew. Geol., 13(1): 1-9, 11 Abb., 1 Tab.; Berlin

QWagenbreth, Otfried (1964): Über den Begiff der synthetischen und antithetischen Störungen und ihre Bedeutung für die saxonische Tektonik Mitteldeutschlands. - Geologie, 13(9): 1043-1058, 16 Abb.; Berlin [darin: Thüringer Wald, Wuthaer Störung, Kyffhäuser, Stockheimer Rotliegendbecken]

OWagenbreth, Otfried (1965): Zur Theorie der Randtröge und Randmulden. - Geologie, 14(8): 931-948, 12 Abb.; Berlin [darin: Creuzburger Graben, Finne-Störung]

QWeber, Hans (1938): Die Strukturelemente des Thüringer Waldes und ihre Entwicklungsgeschichte. Z. dt. geol. Ges., 90: 75-87, 2 strat. Tab.; Berlin

OWeber, Hans (1944): Die Kleinstörungen in den Tambacher Schichten bei Eisenach. - Beitr. Geol. Thür. 7: 15-48, 4 Abb.; Jena

OWeber, Hans (1954): Der Suhler Sattel im Thüringerwalde. - Geologie, $\underline{\mathbf{3}}(4):$ 454-461, 1 Abb.; Berlin

oWeber, Hans (1955): Der Kleine Thüringer Wald als Strukturlandschaft. - Beitr. Geol. Thür. , ㅁ: 2-30, 7 Abb., 2 Taf.; Frankfurt/M.

[Tektonik, Geomorphologie]

QWeber, Hans (1962): Nachträge zu den Kleinstörungen in den Tambacher Schichten bei Eisenach. Hallesches Jb. mitteldt. Erdgeschichte, 4: 103-107, 1 Abb.; Berlin

OWeber, Hans (1963): Halokinese der Ohmgebirgsgräben. - Hallesches Jb. Mitteldt. Erdgeschichte, $\underline{\mathbf{5}}$ : 69-70; Leipzig

OWeber, Karl August (1914): Das Störungsgebiet am Nordrande des Thüringer Waldes zwischen Friedrichroda und Georgenthal. - Jb. Preuß. Geol. Landesanst., $\underline{34}$ (Teil I)(f. 1913): 477-538, 5 Abb., 2 Taf.; Berlin - auch als Diss. Univ. Greifswald 1913

[Stratigraphie u. Tektonik Zechstein, Mesozoikum]

-Wedel, Angelika (1990): Mikrostrukturuntersuchungen an Peridotiteinschlüssen in Basalten der Hessischen Senke. - Göttinger Arb. Geol. Paläont., 45; VI, 63 S., Ill, graph. Darst, Tab.; Göttingen zgl. Diss. Univ. Göttingen 1989 
-Wedel, Angelika; Skrotzki, Werner \& Weber, Klaus (1992): Microstructure and texure in peridotite xenoliths from the Hessian depression. - In: Skrotzki, W.; Weber, K. Wedel, A. (1992): The geological significance of microstructures in crystalline rocks. - Geotektonische Forschungen, ㅍ: 89125, 16 fig., 5 tab.; Stuttgart

[Nordhessen, keine Vorkommen im WMK]

OWegener, H. (1953): (Die Störungszonen am Südwestrande des Thüringer Beckens -) Zum tektonischen Bau des Hainich-Abschnittes innerhalb des Gothaer Grabens. - Übergeordn. Titel: Beiträge zur Tektonik des Thüringischen Beckens. - (Abh. Geotektonik, $\underline{\mathbf{5}}$ ) Abh. Dt. Akad. Wiss. Berlin, Kl. Math. allgem. Natwiss., 1953(3): 95-134, 77 Abb., 2 Taf.-Beil.; Berlin [Eichenberg-Gotha-Saalfelder Störungszone, Abschnitt Diedorf - Großbehringen]

OWolf, Manfred (1964): Der Floßberggangzug bei Ilmenau und Gehren. - Freiberger Forschungshefte, Reihe C, 148: 1-157, 78 Abb., 7 Tab.; Leipzig

OWüstner, L. (1964): Salzauslaugung und Tektonik im Zechstein des Werra-Kaligebietes nach Ergebnissen seismischer Messungen. - Z. angew. Geol., 10 (4): 172 - 179, 6 Abb., Berlin

$\square \bullet$ Wunderlich, Hans Georg (1955): Jüngste Tektonik im Gebiet des Leinetalgrabens. - Geol. Rundschau, 43: 78-93, 4 Abb., 1 Falt-Kt.; Stuttgart

[Umgebung von Göttingen; darin: Terrassen der Werra bei Witzenhausen]

-Wunderlich, Hans Georg (1957): Grenzfragen der saxonischen Tektonik Südniedersachsens Fältelungserscheinungen und Bruchschollentektonik - Z. dt. geol. Ges., 109: 159-168, 4 Abb., 2 Taf.; Hannover [Aufschlüsse u.a. Reckershausen, Marzhausen S’Göttingen]

-Wunderlich, Hans Georg (1957): Tektogenese des Leinetalgrabens und seiner Randschollen. - Geol. Rundschau., 46: 372-413, 7 Abb.; Stuttgart [Aufschlüsse u.a. Marzhausen S'Göttingen]

-Wunderlich, Hans Georg (1966): Ausweitung und Einengung an saxonischen Bauformen Südniedersachsens. - Z. dt. geol. Ges., 116 (f. 1964): 683 - 695, 3 Abb.; Hannover [darin: Göttinger Leinetalgraben]

QZänker, G. (1972): Beiträge zur Tektonik des Salinargebirges im Südharz-Kalirevier. - Diss. Bergakademie Freiberg; Textbd. 189, XII Bl.; Bildbd. 65 Bl.; Anl.-Bd.

@Zänker, Günther (1974): Beziehung zwischen stofflicher und struktureller Entwicklung im Salinargebirge des Südharz-Kalireviers. - Z. geol. Wiss., 2(10): 1157-1175, 8 Abb.; Berlin

OZeh, Armin \& Brätz, Helene (2004): Timing of upper Carboniferous-Permian horst-basin formation and magmatism in the NW Thuringian Forest, central Germany - a review. - In: Wilson, M.; Neumann, E.-R.; Davies, G. R.; Timmermann, M.J.; Heeremans, M. \& Larsen, B.T. [eds.]: Permo-Carboniferous Magmatism and Rifting in Europe. - Geol. Soc. [London] Spec. Publ., 223; 448 p.; London 2004

OZeibig, Silvio \& Jahne, Heinz (1993): Struktureller und petrographischer Aufbau einer Carnallitanstauung des Kaliflözes Thüringen im Werra-Gebiet. - Kali u. Steinsalz, 11(3/4): 74-85, 33 Abb., 2 Tab.;

[Kaliwerk Unterbreizbach]

QZiegenhardt, W. (1960): Der Nordrand des Thüringer Waldes bei Eisenach. - Geologie, 9(3): 259-275, 18 Abb., Berlin

QZiegenhardt, Werner (1960): Zur saxonischen Tektonik im mittleren Thüringer Wald. - Geologie, $\underline{\mathbf{9}}(8)$ : 897-908, 6 Abb.; Berlin 
OZiegenhardt, Werner (1966): Zum Nachweis tektonischer Bewegungen an der Wende

Rotliegendes/Zechstein an N-Rand des Thüringer Waldes. - Geologie, 15 (9): 1088-1092, 1 Abb., 1

Tab; Berlin

[Elgersburg-Roda]

- $\square$ Ziegler, Peter A. (1992): European Cenozoic rift system. - Tectonophysics, 208: 91-101, 8 fig.; Amsterdam

[Großregionale Darstellung unter Einbeziehung des Leinetalgrabens und der Hessischen Senke]

OZimmermann, I. E. (1914): Der Granitporphyr von Thal oder Heiligenstein im Thüringer Wald („Porphyr mit geschwänzten Quarzen“). - Jb. Preuß. Geol. Landesanst., 34 (Teil I) (f. 1913): 634-647; Berlin

[Tektonik, Gefügekunde]

OZwerger, R. v. (1934): Tektonik, Anomalien des Erdmagnetismus und Erdölhöffigkeit in Mitteldeutschland. - Kali, etc.,

$\underline{29}(5): 62-65$

$\underline{29}(6): 72-75$

29$(7): 86-88$

$\underline{29}(8): 98-100$

29$(9):$ 112-114, 5 Fig.; Halle/Saale

[darin: Westthüringen, Isoanomalienkarte der Vertikalintensität]

\subsection{Paläontologie}

\subsubsection{Regionale Paläontologie}

$\square$ Anonym (1907): [Beim Kiesbaggern in der Werra auf Fossilien-Funde achten - Fund eines Unterkieferknochens]. - Eschweger Tageblatt, 1907; Nr. 134 v. 11.6.1907; Eschwege

- $\square$ Bergmann, Waltari; Schad, Ernst \& Tunger, Horst (1969): Hessen - unser Heimatland. - 6., durchges. Auflage, zahlr. Abb.; (Verlag Moritz Diesterweg) Frankfurt a. M. u.a. [Schulbuch für den Heimatkunde-Unterricht 4. Klasse;

darin S. 13-16 Thema: „Bodenfunde und Gesteine unserer Heimat“ (u.a. „Von Spangensteinen, Fischaugen und Bonifatiuspfenningen“ - „Mammut und Wollnashorn am Schmisssing bei Altmorschen" darin S. 101-116: „Reich ist das Land an Bodenschätzen“ (Lagerstätten, Bergbau]

○Claus, H. (1973): Die geologisch-paläontologische Erforschung der Burgtonnaer Travertinlagerstätten. Abh. Ber. Museums d. Natur Gotha, [7] 1973: 1-8, 1 Abb.; Gotha

oClaus, Hans (1978): Die geologisch-paläontologische Erforschung der Burgtonnaer Travertinlagerstätten. - Quartärpaläontologie, 모 9-41, 1 Tab., Taf. 1-8; (Akademie-Verlag) Berlin

-Hartmann, Curt (1976): Fossilfunde im Landkreis Kassel. - Jb. Lkr. Kassel, 1976: 87 - 89, 3 Abb., 2 Taf. m. 9 Abb.; Kassel

OHeinrich, Wolf-Dieter (1978): Zur Entdeckungs- und Forschungsgeschichte der Wirbeltierfundstätte in der jungpleistozänen Deckschichtenfolge über dem Travertin von Burgtonna in Thüringen. Quartärpaläontologie, $\underline{3}$ : 185 - 186, 2 Abb.; (Akademie-Verlag) Berlin 
QHeinrich, Wolf-Dieter \& Jäger, Klaus-Dieter (1978): Zusammenfassende stratigraphische und palökologische Interpretation des Fossilvorkommens in der untersuchten jungpleistozänen Deckschichtenfolge über dem Travertin von Burgtonna in Thüringen. - Quartärpaläontologie, $\underline{3}$ : 269 285, 6 Abb., 1 Tab.; (Akademie-Verlag) Berlin

-Hornstein, F. F. (1902): Belegmaterialien zur Geologie der Umgebung von Cassel. - Z. dt. geol. Ges., 54: 118-121(Verhdlgn.), 1 Abb.; Berlin [Fossilien d. Lias, (Basalte), Buntsandstein m. Thierfährten v. Karlshafen]

QKahllke, H.-D. [Hrsg.] (1978): Das Pleistozän von Burgtonna in Thüringen - Teil. 1. Die Travertine Teil 2. Die Deckschichten der Travertine von Burgtonna in Thüringen. - Quartärpaläontologie Abh. Ber. Inst. Quartärpaläont., $\mathbf{3}, 399$ S, 137 Abb., 56 Taf., 46 Tab.; (Akademie-Verlag) Berlin

-Keller, Thomas (1997): Der Richelsdorfer Kupferschiefer - Fauna und Flora eines paläozoischen Schwarzschiefers im Landkreis Hersfeld-Rotenburg. - Paläontologische Denkmäler in Hessen, 4 ; 14 S.; Hess. [Hrsg. Landesamt f. Denkmalpflege] Wiesbaden

-Ludwig, Willi (1991): Tiere in grauer Vorzeit. - Kreis Hersfeld-Rotenburg - Heimatkalender 1991 und Wegweiser (35. Jg. ): 53 - 56, 4 Abb.; Bad Hersfeld [Fossilfunde des Kreisgebietes]

口Jäger, Willy (1922): Geologische Funde für das Heimatmuseum sichern! [Leserbrief] - Eschweger Tageblatt, 1922; Nr. 50 v. 28.2.1922; Eschwege

Q•Jansen, Ulrich; Köngishoff, Peter \& Steininger, Fritz F. [Hrsg.] (2004): Zeugen der Erdgeschichte - Ein Reiseführer zu den schönsten Fossilien in deutschen Naturkundemuseen. - 2., überarb. u. erweit. Aufl., 127 S., 251 Abb.; (Schweizerbart) Stuttgart [darin: Exponate a. d. Geowissenschaftlichen Zentrum der Universität Göttingen; Museum am Lindelbühl/Mühlhausen]

QKohlstock, Karl (1926): Burgtonna: Kalktuffe; Gräfentonna: Gräberfund. - Entdeckungsreisen in der Heimat, 25; 2., vermehrte Aufl.; 16 S., Abb., Kt.; (Stollberg) Gotha

-Kunz, Reiner \& Fichter, Jürgen (2005): Saurier, Panzerfische, Seelilien - Fossilien aus der Mitte Deutschlands. - 140S., zahlr. Abb., Kt..; (Edition Goldschneck) Wiebelsheim [Bezug Lkr. Waldeck-Frankenberg, Kassel, Schwalm-Eder-Kreis, Werra-Meissner, HersfeldRotenburg]

OMeyrick, Rich \& Maul, Lutz Christian (2003): Ausgrabungen in Burgtonna seit 300 Jahren. - Natur und Museum, 133(9): 253-261, 9 Abb.; Frankfurt/M.

-Naumann, Peter (1983): Fossilien und Mineralien in Nordhessen. - Jb. Lkr. Kassel, 1983: 38 - 39; Kassel

- Reich, M.; Hagdorn, H. \& Reitner, J. [Hrsg.](2005): Stachelhäuter 2004 - 3. Arbeitstreffen deutschsprachiger Echinodermenforscher in Ingelfingen, 29.-31. Oktober 2004 - Arbeiten und Kurzfassungen der Vorträge und Poster; 78 S., zahlr. Abb.; (Unversitätsverlag) Göttingen

- Reich, Mike (2005): Wissenschaftliche Originale in den Sammlungen des Geowissenschaftlichen Zentrums der Universität Göttingen (GZG) - Schriftenverzeichnis, Teil 1: Echinodermata. - In: Reich, M.; Hagdorn, H. \& Reitner, J. [Hrsg.](2005): Stachelhäuter 2004 - 3. Arbeitstreffen deutschsprachiger Echinodermenforscher in Ingelfingen, 29.-31. Oktober 2004 - Arbeiten und Kurzfassungen der Vorträge und Poster; 78 S., zahlr. Abb; hier: S. 58-72.; (Unversitätsverlag) Göttingen 
OSchäfer, Fr. (1903): Was uns die Kalktuffe von Tonna erzählen. - Aus den coburg-gothaischen Landen - Heimatblätter, $\underline{3}$ : 58-63; Gotha

- $10 \bullet$ Schlotheim, [Ernst Friedrich] v. (1820): Die Petrefactenkunde auf ihrem jetztigen Standpunkte durch die Beschreibung seiner Sammlung versteinerter und fossiler Überreste des Thier- und Pflanzenreichs der Vorwelt erläutert. - 436 S., sep. Tafelbd. M. 15 Taf.; 2 Bd. Nachträge 1822, 1823 m. sep. Tafelbd., 21 Taf.; (Becker) Gotha

[Sammlungsverzeichnis, kein Lehrbuch; S. 386 Versteinertes Holz aus dem Schwalbenthaler Stollen am Meißner; S. 399ff Paläobotanische Funde aus dem Thüringer Wald; S. 389ff Blattfunde Burgtonna, Habichtswald, Kalktuff Hainberg b. Göttingen]

\subsubsection{Paläozoologie}

\subsubsection{Paläozoikum}

-Althaus (1845): < Neufunde im Richeldorfer Kupferschiefer] Dunker setzt Münster's Beiträge zur Petrefaktenkunde durch ein Heft mit Kupferschiefer-Versteinerungen fort. - N. Jb. Mineral. etc., 1845: 313 (Briefl. Mitt.); Stuttgart

-Anonym (1990): Saurierfährten im Cornberger Sandstein. - Hersfeld-Rotenburg - Heimatkalender u. Wegweiser, $\underline{34}$ (1990): 170-173, 3 Abb.; Bad Hersfeld

OAndreas, Dieter \& Haubold, Hartmut (1975): Die biostratigraphische Untergliederung des Autun (Unteres Perm) im mittleren Thüringer Wald. - Schriftenrh. Geol. Wiss., $\underline{3}$ : 5-86, 8 Abb., 2 Tab., 18 Taf.; Berlin

QBarthel, Manfred (2003): Otto GIMM und die Rotliegend-Pflanzen des Thüringer Waldes. - Veröff. Naturkundemuseum Erfurt, Naturwiss. Rh., 22: 5-12, 6 Abb.; Erfurt

QBarthel, Manfred \& Rößler, Ronny (1993): Seismite aus dem Rotliegend des Thüringer Waldes Sedimentation und Fossilführung der Tonsteine der Oberen Gehren-Formation. - Veröff./ Naturhist. Museum Schleusingen, 7/8: 53-64, 7 Abb., 4 Taf.; Schleusingen [Lindenberg b. Ilmenau]

-Bendix - Almgreen, Svend \& Malzahn, Erich (1969): Über neue oder wenig bekannte Elasmobranchier aus dem deutschen Kupferschiefer. - Notizbl. Hess. L.-A. Bodenforsch., 97: 44 - 45; Wiesbaden [Richelsdorfer Gebirge]

QBerman, D.S.; Henrici, A.C.; Sumida, S.S: \& Martens, Th. (2000): Redescription of Swymouria sanjuanensis (Seymouriamorpha) from the Lower Permian of Germany based on complete mature specimens with a discussion of paleocology of the Bromacker locality assemblage. $-\mathrm{J}$. vertebrate paleontology, 20 (2): 253-268, 7 fig., 1 tabl.; Chikago/Ill.

[Thüringer Wald, Fossilfundstätte Bromacker]

OBerman, D.S.; Reisz, R.R.; Scott, D.; Henrici, A.C.; Sumida, S.S. \& Martens, Th. (2000): Early Permian bipedal reptile. - Science, 290: 969-972, 4 fig., 1 tabl.; Washinton/DC

[Tambach-Dietharz]

OBerman, D.S.; Reisz, R.R., Martens, Th. \& Henrici, A.C. (2001): A new species of Dimetrodon (Synapsida: Sphenacodontidae) from the Lower Permian of Germany records first occurrence of genus outside of North America. - Can. J. Earth Sci., 38: 803-812, 2 fig., 3 tabl.; Ottowa [Thüringer Wald, Fossilfundstätte Bromacker] 
QBoy, Jürgen A. \& Fichter, Jürgen (1988): Ist die stratigraphische Verbreitung der Tetrapodenfährten im Rotliegend ökologisch beinflußt? - Z. geol. Wiss., $\underline{\mathbf{1 6}}(9)$ : 877-883, 2 Abb.; Berlin [Bezugnahme a. Cornberger Sandstein]

OBoy, Jürgen A. \& Martens, Thomas (1991): Ein neues captorhinomorphes Reptil aus dem thüringischen Rotliegend (Unter-Perm; Ost-Deutschland). - Paläont. Z., 65(3/4): 363-389, 6 Abb.; Stuttgart

EEberth, D. A.; Berman, D. S.; Sumida, S. S. \& Hopf, H. (2000): Lower Permain terrestrial paleoenvironments and vertebrate paleoecology of the Tambach Basin (Thuringia, central Germany): The upland holy grail. - Palaios, 15: 293-313, 13 fig., 5 tabl.; Tulsa/Oklah.. [Fossilfundstätte Bromacker]

-Fichter, Jürgen (1987): Zum Bearbeitungsstand der Cornberger Tetrapodenfährten-Fauna und zur Frage der Alterseinstufung des Cornberger Sandsteins. [Vortragszusammenfassung]. - In: Klare, Bernd \& Schröder, Bernd [eds.]: Zechstein 1987 - International Symposium Kassel/Hannover [28. April to 9. May, 1987] - Abstracts, Posters, Program; S. 31; [Subkommission Perm/Trias der Stratigraphischen Kommission der DUGW/IUGS] Bochum 1987

-Fichter, Jürgen (1992): Leben im Kupferschiefermeer - im Gestein überliefertes Leben. (Naturkundemuseum im Ottoneum - Begleitheft zur Ausstellung); 14 S., 11 Abb., 1 Tab.; [Kulturamt Stadt Kassel, Naturkundemuseum] Kassel

-Fichter, Jürgen (1994): Permische Saurierfährten - ein Diskussionsbeitrag zu der Bearbeitungsproblematik der Tetrapodenfährten des Cornberger Sandsteins (Perm, Deutschland) und des Cocino Sandsteins (Perm, USA). - Philippia: $\mathbf{7}(1)$ : 61-82, 22 Abb.; Kassel

-Fichter, Jürgen (1995): Ein Versuch zur Berechnung der Laufleistungen aus jungpaläozoischen Saurierfährten - dargelegt am Beispiel der Fährten des Cornberger Sandsteins (Perm, Deutschland). Philippia, 7(3): 223-228, 4 Abb.; Kassel

-Fichter, Jürgen (1995): Katalog des publizierten Materials aus der paläontologischen Sammlung des Naturkundemuseums der Stadt Kassel. Teil 1. - Philippia, 7(2): 129-157, 30 Abb.; Kassel

-Fichter, Jürgen (1997): Katalog des publizierten Materials aus der paläontologischen Sammlung des Naturkundemuseums der Stadt Kassel, Teil 2, mit einem Nachtrag zu Teil 1 - Philippia, $\underline{8}(2): 77-88$, 11 Abb.; Kassel

QFichter, Jürgen (1998): Bericht über die Bergung einer 20 t schweren Fährtenplatte aus dem Tambacher Sandstein (Unter-Perm) des Thüringer Waldes und erste Ergebnisse ichnologischer Studien. Philippia, $\underline{8}(3): 147$ - 208, 8 Abb., 3 Tab., 17 Taf.; Kassel

-Fichter, Jürgen (1999): Interessenate Aspekte der Wirbeltierichnologie - dargestellt an permischen und triassischen Saurierfährten. - In: Hoppe, Andreas \& Apel, Heinrich [Hrsg.]: Geotope - lesbare Archive der Erdgeschichte. 151. Hauptvers. Dt. Geol. Ges. 02.10.99 - 10.10.99 Wiesbaden Kurzfassungen der Vorträge und Poster. - Schriftenreihe Dt. Geol. Ges., 7, 115 S.; hier: S. 38; (Deutsche Geologische Gesellschaft) Hannover 1999

[Vortraqszusammenfassung; Bezug auf Fährten im Cornberger Sandstein]

OFischer, Karlheinz (1963): Panzerplattenabdrücke von Cotylosauriern aus dem Rotliegenden des Thüringer Waldes. - Hall. Jb. Mitteldt. Erdgeschichte, $\underline{\mathbf{5}}$ : 44-46, Taf. III, IV; Berlin

OFritsch, K. v. (1875): Kommentar zu GAUDRY: Sur les reptiles des temps primaires - Comptes rendus Acad. Sciences Paris, 1878/87 : 956ff. - N. Jb. Mineral. etc., 1879: 720; Stuttgart [darin: Labyrinthodonten von Oberhof im Thüringer Walde] 
QGand, Georges \& Haubold, Hartmut (1988): Permian tetrapod footprints in Centrale Europe, stratigraphical and paleontological aspects. - Z. geol. Wiss., 16(9): 885-994, 4 fig.; Berlin [Bezugnahme a. Thüringer Wald]

QGeorgi, Paul (1954): Auf Fährtensuche im Rotliegenden Thüringens. - Der Aufschluß, 모 15-17, 4 Abb.; Göttingen [Fundorte Umgebung Friedrichroda]

QGeorgi, Paul (1954): Von den Koprolithen im thüringischen Rotliegenden. - Der Aufschluß, ㅁ: 222225, 3 Abb.; Göttingen [Fundorte Umgebung Friedrichroda, Goldlauter]

OGocht, Hans (1955): Acanthodierstacheln und andere Fischreste im Unteren Rotliegenden bei Manebach. - Hall. Jb. Mitteldt. Erdgeschichte, 2(2): 110-111, 1 Abb. i. T., 6 Fig. a. Taf. VIII; Halle

QGuthörl, Paul (1933): Neue Insektenreste aus dem Rotliegenden von Oberfranken und Thüringen. Jber. Mitt. Oberrhein. Geol. Vereins, N.F., 22: 44-49, 3 Abb., Taf. II(Abb. 5-7); Stuttgart Referat in: N. Jb. Mineral. etc., Referate, 1938 (Bd. III): 126 (R. Keilbach); Stuttgart [Stockheim i. Oberfranken; Crock/Thür.]

OHaubold, Hartmut (1971): Die Tetrapodenfährten aus dem Permosiles (Stefan und Rotliegendes) des Thüringer Waldes. - Abh. Ber. Museums d. Natur Gotha, [6] 1971: 15-41, 12 Abb.; Gotha

QHaubold, Hartmut (1972): Panzerabdrücke von Tetrapoden aus dem Rotliegenden (Unterperm) des Thüringer Waldes. - Geologie, 21(1): 100-115, 4 Abb.; Berlin

QHaubold, Hartmut (1973): Lebewelt und Ökologie des Tambacher Sandsteins (Unteres Perm, Saxon) im Rotliegenden des Thüringer Waldes. - Z. geol. Wiss., 1 (3): 247-268, 3 Abb., 11 Taf.; Berlin

QHaubold, Hartmut (1973): Die Tetrapodenfährten aus dem Perm Europas. - Freiberger Forschungshefte, Reihe C, 285: 5-55, 46 Abb.; Leipzig [Bezugn. a. Funde Thüringer Wald]

QHaubold, Hartmut (1973): Tetrapodenfährten aus den Keele und Enville Groups (Permokarbon, Stefan und Autun) von Shropshire and South Staffordshire, Großbritannien. - Z. geol. Wiss., 1 (8): 895-933, 5 Abb., 5 Tab., 8 Taf.; Berlin [darin: Vergleich mit Spurenfossilien Thüringer Wald]

QHaubold, Hartmut (1977): Fossilienfazies und Biostratigraphie des Permosiles im Thüringer Wald. Diss. B [Habilschrift d. DDR-Universitätten] Univ. Halle-Wittenberg, 171 S., graph. Darst., Tab.; Halle

QHaubold, Hartmut (1983): Die Lebewelt des Rotliegenden. - 2. Aufl.; Reihe: Die neue BrehmBücherei, 154; 246 S., 163 Abb.; (Ziemsen) Wittenberg

- 0 Haubold, Hartmut (1996): Ichnotaxonomie und Klassifikation von Tetrapodenfährten aus dem Perm. - Hallesches Jb. Geowiss., B $\underline{18}$ : 23-88, 36 Abb., 8 Tab.; Halle (Saale) [Tambach; Cornberg, Kr. Hersfeld-Rotenburg]

OHaubold, Hartmut (1998): The Early Permian tetrapod ichnofauna of Tambach, the changing concepts in ichnotaxonomy. - Hallesches Jb. Geowiss., B 르: 1-16, 8 fig., 1 tabl.; Halle (Saale)

OHaubold, Hartmut \& Katzung, Gerhard (1972): Die Abgrenzung des Saxon. - Geologie, 21 (8): 883910, 7 Abb., 3 Tab.; Berlin [darin: Thüringer Wald, Tetrapodenfährten] 
QHaubold, Hartmut \& Katzung, Gerhard (1978): Palaecology and paleoenvironments of tetrapod footprints from the Rotliegend (Lower Permain) of Central Europe. - Paleogeography, Paleoclimatology, Palaeoecology, 23: 307-323, 6 fig.; Amsterdam [darin: Thüringer Wald]

-Haubold, H.; Lockley, M.G.; Hunt, A.P. \& Lucius, Sp. G. (1995): Lacertold footprints from Permian dune sandstones, Cornberg and DeChelly sandstones. - In: Lucius, Sp.-G. \& Hecker, A.B. (eds.): Early permian footprints and facies. - Bull. New Mexico Museum of Natural History and Science, ㅁ: 235-244; Albuquerque/NM 1995

[Vorlage nicht eingesehen]

OHaupt, Hermann (1952): Insektenfunde aus den Goldlauterer Schichten des Thüringer Waldes. - Hall. Jb. mitteldt. Erdgeschichte, 1(4): 241-258, 18 Abb., Taf. XL (Fig. 1+2); Halle

-Hochberger, Klaus (1997): Aktueller Fossilienfund aus dem Kupferschiefer von Richelsdorf (Nordhessen) oder die Suche nach dem Flugsaurier. - Mein Heimatland, 37(22a): 145-148; 37(22b): 149-152; 37(23): 153-156; Ill.; Bad Hersfeld

-Hochberger, Klaus (1999): Fossilfunde im Richelsdorfer Kupferschiefer - Sammlung Hochberger, Bad Hersfeld, Teil 1. - Philippia, 9(2): 151-164; Ill., graph. Darst; Kassel

-Hochberger, Klaus (2002): Fossilfunde im Richelsdorfer Kupferschiefer - Sammlung Hochberger, Bad Hersfeld, Teil 2. - Philippia, 10 (2): 147-156, 9 Abb.; Kassel

QHoehne, Karl (1957): Fischschuppen im Vitrit unterrotliegender Steinkohlenflöze von Stockheim in Oberfranken und Manebach in Thüringen. - Geologie, $\underline{\mathbf{6}}(5)$ : 528-540, 8 Taf. (16 Bilder); Berlin

OJacobi, Bernhard (1963): Saurierfährten in den Oberhöfer Schichten von Friedrichroda in Thüringen. Hallesches Jb. mitteldt. Erdgeschichte, $\underline{\mathbf{5}}$ : 75; Berlin

- Jäkel, Otto (1899): Ueber die Organisation der Petalodonten. - Z. dt. geol. Ges., 51: 258-298, Taf. XIV, Fig. 1; Berlin

[Fund aus Riecheldorf/Hessen; Kupferschiefer]

- Keller, Thomas (1997): Der Cornberger Sandstein - Paläontologie einer Fährtenfundstelle des Erdaltertums im Landkreis Hersfeld-Rotenburg. - Paläontologische Denkmäler i. Hessen, $\underline{\mathbf{5}}$; 14 S., Abb.; [Hsrg. Abt. Archäologie u. Paläontologische Denkmalpflege i. Landesamt f. Denkmalpflege Hessen, Archäologische Gesellschaft in Hessen e.V.] Wiesbaden

-Keller, Thomas (1997): Der Richelsdorfer Kupferschiefer: Fauna und Flora eines paläozoischen Schwarzschiefers im Landkreis Rotenburg/Fulda[!]. - Paläontologische Denkmäler in Hessen, 4 ; 16 S.; [Hsrg. Abt. Archäologie u. Paläontologische Denkmalpflege i. Landesamt f. Denkmalpflege Hessen, Archäologische Gesellschaft in Hessen e.V.] Wiesbaden

-Klingner, Fritz-Erdmann (1928): Bemerkungen zu einer Fährtenplatte aus dem Cornberger Sandstein. - Zbl. Mineral. etc., Abt. B, 1928: 641 - 646, 1 Abb.; Stuttgart

OKorn, Hermann (1933): Eine für die Kenntnis der Cotyloaurier des deutschen Perms bedeutsame Schwimmfährte von Tambach. - Palaeobiologica, $\underline{\mathbf{5}}$ : 169-200, 4 Abb., Taf. XV; Wien u. Leipzig

○Kozur, Heinz H. (1977): Erster Nachweis von Mikrofaunen unterhalb des Kupferschiefers im Süden der DDR. - Z. geol. Wiss., $\underline{\mathbf{5}}(5)$ : 657-661; Berlin [darin: Förtha]

QKozur, Heinz (1978): Bemerkungen zum Vorkommen der Gattung Callipterus BRONGN. im Karbon. - Verh. Geol. Bundesanst., 1978(2): 11-22; Wien [darin: Funde Thüringer Wald] 
OLangenhan, A. (1890): Fischabdrücke, wahrscheinlich Palaeoniscus sp. n. und einige Pflanzenreste, (Calamiten und Walchia (Lycopodes) piniformies) aus dem unteren Rothliegenden vom Westhange des Gottlob bei Friedrichroda in Thüringen. - Jber. d. Schlesischen Gesellschaft f. Vaterländische Cultur, $\underline{67}$ (f. 1889): 84-85; Breslau

OLangenhan, A[1win] (1905): Flora und Fauna des Rotliegenden in der Umgebung von Friedrichroda in Thüringen. Mit einigen Textfiguren, einer Lichtdrucktafel nach Original-Zeichnungen, mit 12 vom Autor lithographierten Bildtafeln. - 12 S. o Zählg.; 12 Taf.; (Selbstverlag des Verfassers) Friedrichroda - Nachgewiesen in: Forschungsbibliothek Gotha

OLangenhan, A[1win] (1909): Fauna und Flora des Rotliegenden in der Umgebung von Friedrichroda. II. Teil mit 3. Taf. und begleitendem Texte (Nachträge). - 2 S. Tafelerläuterung o. Zählg., Taf. I-III, Ergänzungstafel IV; (Selbstverlag d. Verfassers) Friedrichroda Nachgewiesen in: Forschungsbibliothek Gotha

OLotze, Franz (1928): Die Tambacher Sphaerodactylen-Fährten. - Paläontol. Z., 9: 170-171; Stuttgart

-Ludwig, Willi (1987): Der Name Artur Milde ist untrennbar mit den Cornberger Fährtenplatten verbunden. - Kreis Hersfeld-Rotenburg - Heimatkalender 1987 und Wegweiser (ㅍ․ Jg. ): 107 - 109, 2 Abb.; Bad Hersfeld

-Malzahn, Erich (1972): Zur Kenntnis des Kopfskeletts von Janassa bitumonosa (SCHLOTH) aus dem hessischen Kupferschiefer. - Geol. Jb., 90: 431-440, 2 Taf. (19 u. 20); Hannover [Fundort: Brodberg b. Sontra, Fundherkunft: Richelsdorfer Gebirge]

OMartens, Thomas (1975): Zur Taxonomie, Ökologie und Biostratigraphie des Oberrotliegenden (Saxon) der Tambacher Mulde in Thüringen. - Freiberger Forschungshefte, Reihe C, 309: 115-133, 4 Taf.; Leipzig

OMartens, Thomas (1979): Arthropodenfährten aus dem Rotliegenden der Eisenacher Mulde (Thrüinger Wald). - Z. geol. Wiss., $\underline{7}(12):$ 1457-1462, 2 Taf.; Berlin

OMartens, Thomas (1980): Zur Fauna des Oberrotliegenden (Unteres Perm) im Thüringer Wald Vorläufige Mitteilung. - Abh. Ber. Museums d. Natur Gotha, (10) 1980: 19-20; Gotha

OMartens, Thomas (1981): Zur Fauna der Manebacher Schichten (Unteres Rotliegendes) bei Manebach (Thüringer Wald). - Z. geol. Wiss., $\underline{\mathbf{9}}(9)$ : 1057-1063, 3 Taf.; Berlin

OMartens, Thomas (1983): Zur Taxonomie und Biostratigraphie der Conchostraca (Phyllopoda, Crustacea) des Jungpaläozoikums der DDR. - Teil I. - Freiberger Forschungshefte, Reihe C, 382: 7 105, 60 Abb., XLVI Taf.; Leipzig

[Rotliegendes]

OMartens, Thomas (1983): Zur Taxonomie und Biostratigraphie der Conchostraca (Phyllopoda, Crustacea) des Jungpaläozoikums der DDR, Teil II. - Freiberger Forschungshefte., Reihe C, 384: $24-$ 48, 3 Bilder; Leipzig

OMartens, Thomas (1988): Die Bedeutung der Rotsedimente für die Analyse der Lebewelt des Rotliegenden. - Z. geol. Wiss., 16 (9): 933-938, 2 Abb.; Berlin [Bezugnahme a. Fundstätte „Bromacker“ b. Tambach-Dietharz/Thüringer Wald]

OMartens, Thomas (1990): Fossile Lebenszeichen der Rotliegendzeit. - In: Zimmermann, Wolfgang [Hrsg.]: Thüringer Wald - Kleiner Naturführer. - Abh. u. Ber. Museums Natur Gotha, (9) 1990; 5 , erw. Nachaufl., 94,2 S.; 35 Abb., 1 Kt.; hier: S. 19-23, Abb. 5, 6; Gotha 
OMartens, Thomas (1991): Ein besonderes Fossil. - Paläont. Z., 65(3/4): 225-226, 2 Abb.; Stuttgart [Tetrapodenfährten Rotliegendes, Thüringer Wald]

OMartens, Thomas (1994): 20 Jahre Sauriergrabung im Oberrotliegend (Unteres Perm) am Bromacker bei Tambach-Dietharz/Thüringer Wald. - Abh. Ber. Museums d. Natur Gotha, (18) 1994: 15-26, 9 Abb.; Gotha

OMartens, Thomas (2001): Permokarbonische Tetrapodenfaunen auf Pangea - ein ungleicher Erforschungsgrad? - Permocarboniferous tetrapods at Pangea - a different stage of investigation? Vortrag auf dem Festkolloquium anläßlich des 60. Geburtstages von H. Haubold am 15. Januar 2001. - Hallesches Jb. Geowiss., Reihe B, 23: 45-68, 2 Abb., 2 Tab., 5 Taf.; Halle (Saale) [Bezugnahme. a. Thüringer Wald]

OMartens, Thomas; Schneider, Jörg \& Walter, Harald (1981): Zur Paläontologie und Genese fossilführender Rotsedimente - der Tambacher Sandstein, Oberrotliegendes, Thüringer Wald (DDR). - (Beiträge zur Paläontologie, Stratigraphie und Palökologie - Zum 65. Geburtstag von Prof. Dr. rer. nat. habil Arno Hermann Müller) Freiberger Forschungshefte, Reihe C, $\underline{\mathbf{3 6 3}}$ : 75-100, 10 Abb., 5 Taf.; Leipzig

-Mühlhausen, Fritz (1962): Kasseler Naturkundemuseum erwarb Cornberger Fährtenplatten. Hessischer Gebirgsbote, $\underline{\mathbf{6 3}}(3): 35$ - 36, 2 Abb.; Melsungen [Chirotherienfährten a. d. Cornberger Sandstein]

OMüller, Arno Hermann (1954): Zur Ichnologie <Fährtenkunde $>$ und Stratinomie des Oberrotliegenden von Tambach (Thüringen). - Paläont. Z., 료(3/4): 189-203, 2 Abb., 2 Tab., Taf. 1617; Stuttgart

QMüller, Arno Hermann (1955): Eine kombinierte Lauf- und Schwimmfährte von Korynichnium aus dem Oberrotliegenden von Tambach Thüringen): - Geologie, 4(4): 490-496, 1 Abb., 1 Taf.; Berlin

OMüller, Arno Hermann (1956): Über den Verbleib des Holotypus von Germanoprisca zimmermani ZEUN. (Insecta) aus den Oberhöfer Schichten (Unterrotliegendes) von Thüringen. - Ber. geol. Ges. DDR, 2(1): 57; Berlin

OMüller, Arno Hermann (1956): Über problematische Lebensspuren aus dem Rotliegenden von Thüringen. - Ber. geol. Ges. DDR, $\underline{1}(2)$ : 147-154, 2 Abb., 1 Tab., Taf. V-VIII; Berlin

OMülller, Arno Hermann (1957): Über Mylacridenreste (Insecta) aus dem Unterrotliegenden von Thüringen. - Geologie, $\underline{6}(4):$ 445-450, 1 Abb., 1 Tab., 2 Taf.; Berlin

OMüller, Arno Hermann (1957): Ein Arachnidenrest (Braylycosa? manebachensis) n. sp. aus dem Unterrotliegenden (Manebacher Schichten) von Thüringen. - Geologie, $\underline{\mathbf{6}}(1)$ : 95-98, 2 Abb.; Berlin

QMüller, Arno Hermann (1962): Körperlich erhaltene Fische (Paleoniscoidea) aus dem Zechstein (Kupferschiefer) von Ilmenau (Thüringen). - Geologie, 11(7): 845-856, 11 Abb., 1 Tab.; Berlin

QMüller, Arno Hermann (1967): Zur Ichnologie von Perm und Trias im Mitteldeutschland. - Geologie, 16(9): 1061-1071, 6 Abb., 1 Tab., 2 Taf.; Berlin

[darin: S. 1063-1067: „2. Corophioides? Minus n. sp. aus dem Unt. Muschelkalk (mu2, OrbicularisSchichten) von West-Thüringen" - Craula (Blatt Mihla)]

QMüller, A. H. (1969): Über ein neues Ichnogenus (Tambia n.g.) und andere Problematica aus dem Rotliegenden (Unterperm) von Thüringen. - Monatsber. Dt. Akad. Wiss. z. Berlin, 11(11-12): 922-931, 4 Abb., 2 Taf.; Berlin

[Lebenspuren, Fundort Bromacher b. Tambach u.a. Lokalitäten] 
OMüller, Arno Hermann (1975): Zur Entomofauna des Permokarbon: 1. Mylacrida (Blattoidea) aus dem Unterrotliegenden (Unterperm, Autun) von Thüringen. - Z. geol. Wiss., $\underline{\mathbf{3}}(5)$ : 621-641, 7 Abb., 6 Taf.; Berlin [Funde Bezirk Suhl/Thüringer Wald]

OMüller, Arno Hermann (1977): Zur Entomofauna des Permokarbon - 2. Über einige Blattinopsidae (Protothoptera) aus dem Unterrotliegenden (Unteres Autun) von Mitteleuropa. - Z. geol. Wiss., $\underline{\mathbf{5}}(8)$ : 1029-1051, 10 Abb., 1 Tab., 3 Taf.; Berlin [darin: Bezugn. a. Funde Thüringer Wald]

@Müller, Arno Hermann (1977): Über interessante Insektenreste aus dem mitteleuropäischen Unterperm (Rotliegendes) mit allgemeinen Bemerkungen zur Morphologie, Ökologie und Phylogenetik. - Biologische Rundschau, 15(1): 41-58, 12 Abb.; Jena [darin: Funde Thüringer Wald]

@Müller, Arno Hermann (1978): Zur Entomofauna des Permokarbon - 4.: Revision von Germanoprisca zimmermani („Protoperlaria“, Protothoptera) aus dem Unterrotliegenden des Thüringer Walde. - (Autorenkollektiv: Stratigraphie, Biofazies und Taxonomie des europäischen Phanerozoikums, Teil VII). - Freiberger Forschungshefte, Reihe C, 334: 41-48, 1 Abb., 3 Taf.; Leipzig

OMüller, Arno Hermann (1978): Über Hydromedusen (Coelenterata) und medusoide Problematica aus dem Rotliegenden von Mitteleuropa. - Freiberger Forschungshefte, Reihe C, 342: 29-44, 8 Abb., 7 Taf.; Leipzig [darin: Fde. Gottlob-Steinbruch b. Friedrichroda/Thüringer Wald]

-Munk, Wolfgang; Martin, Oliver \& Trunkó, Lásló (1993): Neue Aspekte zur stratigraphischen und faziellen Bewertung des Cornberger Sandsteins (Tatarium, Oberperm) mit Beschreibung erstmaliger Pflanzenfunde. - Geol. Jb. Hessen, 121: 17-40, 14 Abb., 2 Tab.; Wiesbaden

-Namenskürzel (HC) (1957): Wertvolle Chirotherien-Fährtenplatte gefunden. - Bedeutsame Entdeckung in einem Cornberger Sandsteinbruch. - Werra-Rundschau, 1957; Nr. 145 v. 27.6.1957, S. 4; Eschwege

-Naumann, Peter (1992): Parasaurus - Ein seltenes Kupferschiefer-Fossil. - Hessischer Gebirgsbote, 93 (3): 85-86 ; Melsungen

OPabst, Wilhelm (1895): Über Thierfährten aus dem Rothliegenden von Friedrichroda, Tambach und Kabarz. - Z. dt. geol. Ges., 477(1895): 570-576 (Vortrag 41. Versamml. DGG Coburg August 1895); Berlin

OPabst, Wilhelm (1896): Fossile Thierfährten aus dem „Rothliegenden“ Thüringens - nach den im Herzoglichen Museum in Gotha befindlichen Vorkommnissen. - Blätter f. Gothaische Heimathskde., 1896 (14-18): 57-76; Gotha

OPabst, Wilhelm (1896): Über Thierfährten aus dem Rothliegenden von Tambach in Thüringen. - Z. dt. geol. Ges., 48 (1896): 638-643, 1 Taf.; Berlin

OPabst, Wilhelm (1896): Über Thierfährten aus dem Rothliegenden von Tambach in Thüringen. - Z. dt. geol. Ges., 48: 808-829, 10 Abb., 1 Tab., Taf. XVII-XX; Berlin

Referat in: N. Jb. Mineral. etc, $\underline{1897}$ (Bd. I): 542-543 (Dames); Stuttgart

OPabst, Wilhelm (1896): Thierfährten in dem Oberrothliegenden von Tambach in Thüringen. Naturwiss. Wochenschrift, 11(48): 573-578, 6 Abb.; Berlin

OPabst, Wilhelm (1897): Über Thierfährten aus dem Rothliegenden von Tambach in Thüringen. - Z. dt. geol. Ges., $\underline{49}$ (1897): 701-712, 3 Abb., 4 Taf.; Berlin 
OPabst, Wilhelm (1897): Thierfährten in dem mittleren Rothliegenden von Kabarz in Thüringen. Naturwiss. Wochenschrift, 12(8): 85-87, 4 Abb.; Berlin

OPabst, Wilhelm (1897): Fährten von „Ichniotherium Cottae Pohlig“ im Herzoglichen Museum zu Gotha. - Naturwiss. Wochenschrift, 12(27): 313-317, 8 Abb.; Berlin

OPabst, Wilhelm (1898): Weiterer Beitrag zur Kenntnis der Thierfährten in dem Rotliegenden Thüringens. I.: Theoretisches - Trockenrisse der Fährtenplatten. - Naturwiss. Wochenschrift, $\underline{\mathbf{1 3}}$ (22): 249-253, 6 Abb.; Berlin

OPabst, Wilhelm (1898): Weiterer Beitrag zur Kenntnis der Thierfährten in dem Rotliegnden Thüringens. II.: Ichnium acrodactylum „Typus“ und Ichnium acrodactylum „Varietas 1“ in dem Oberrothliegenden von Tambach. - Naturwiss. Wochenschrift, 13(29): 337-341, 8 Abb.; Berlin

OPabst, Wilhelm (1899): Weiterer Beitrag zur Kenntnis der Thierfährten in dem Rotliegnden Thüringens. III.: Versuch einer Einteilung der Thierfährten in dem Rothliegenden „Deutschlands“. Die Fährten des „brachydactylen“ Typus in dem Rothliegenden „Thüringens“. - Naturwiss. Wochenschrift, 15(11): 121-127, 6 Abb.; Berlin

OPabst, Wilhelm (1904): Abbildungen und kurze Beschreibungen aus dem Rotliegenden Deutschlands. Lfg. 1; Taf. I - XII; (Perthes) Gotha

Referat in: Mitt. Geogr. Ges. f. Thür., 23: 56 (E. Schütze); Jena 1905

[Paläontologie; Friedrichroda, Tabarz, Tambach]

OPabst, Wilhelm (1900): Beiträge zur Kenntnis der Thierfährten in dem Rothliegenden „Deutschlands“ I . - Z. dt. geol. Ges., $\underline{\mathbf{5 2}}(1900):$ 48-63; Berlin

Referat in: N. Jb. Mineral. etc., 1902 (Bd. I): 308 (E. Koken); Stuttgart

OPabst, Wilhelm (1905): Beiträge zur Kenntnis der Thierfährten in dem Rothliegenden „Deutschlands“ -

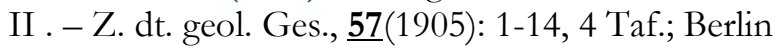

OPabst, Wilhelm (1905): Beiträge zur Kenntnis der Tierfährten in dem Rotliegenden „Deutschlands“ -

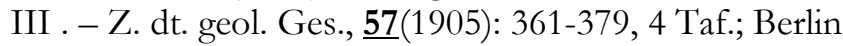

OPabst, Wilhelm (1908): Beiträge zur Kenntnis der Thierfährten in dem Rothliegenden „Deutschlands“ - IV Endgültige Abgrenzung und Charakterisierung der Fährtenarten der Tierfärten des Rotliegenden „Deutschlands“. - Z. dt. geol. Ges., $\underline{\mathbf{6 0}}$ (1908): 325-345; Berlin

OPabst, Wilhlem (1903): Die fossilen Tierfährten aus dem Rotliegenden Thüringens im Herzoglichen Schloß zu Gotha - ein Führer durch ihre Sammlung. - 23 S., 12 [Taf.] Bl., 6 Abb.; (Perthes) Gotha Referat in: Mitt. Geogr. Ges. f. Thür., 23: 56 (E. Schütze); Jena 1905

OPabst, Wilhelm (1903): Die Fußspuren vorweltlicher Tiere in den Gesteinen der Umgebung von Friedrichroda, Tambach und Kabarz in Thüringen. - Aus den coburg-gothaischen Landen Heimatblätter. - [1]: 45-51, 2 Abb., Taf. II; Gotha Referat in: Mitt. Geogr. Ges. f. Thür., 23: 55 (E. Schütze); Jena 1905

OPabst, Wilhelm (1905): Fauna und Flora des Rotliegenden in der Umgebung von Friedrichroda in Thür. - 12 S., Abb., 12 Taf.; (Selbstverl.) Friedrichroda

OPabst, Wilhelm (1908): Die Tierfährten im Rotliegenden „Deutschlands“. - Nova Acta Leopoldina Halle, 89: 315-480, 36 Abb., 35 Taf.; Halle/Saale

-Paul, Josef (2006): Der Kupferschiefer: Lithologie, Stratigraphie, Fazies und Metallogenese eines Schwarzschiefers. - Z. dt. geol. Ges., 157(1): 57-76, 7 Abb., 1 Tab.; Hannover [darin: Richelsdorfer Gebirge, auch Paläontologie] 
-Penndorf, Hans (1919): Über die im Zechsteinkalk Niederhessens entdeckte fossile Fauna. - Abh. u. Ber. Vereins f. Naturkde. z. Kassel, 포: 246 - 247; Kassel

[Fossilfunde im Zechsteinkalk der Umgebung von Cornberg Lkr. Hersfeld-Rotenburg]

OPohlig, H. (1885/1886): Fährten von „Saurichnites Cottae“ in dem unteren Rotliegenden von Friedrichroda. - Verh. Naturhist. Vereins preuß. Rheinlande, 42 (1885): 285-286 (Sitzber. Niederrh. Ges. Natur- u. Heilkunde); Bonn

OPohlig, H. (1886): Neue Ausbeute an den Fundstellen von Saurierfährten und -resten, Fischen, Ostracoden und Pflanzen bei Friedrichroda an dem Thüringer Wald. - Verh. Naturhist. Ges. preuß. Rheinlande, 43: 277-278 (Sitzber. Niederrhein. Ges. Natur- u. Heilkde.); Bonn

OPohlig, H. (1887): Steinplatten mit Saurierfußstapfen aus dem Rotliegenden und Buntsandstein. - Verh. Naturhist. Ges. preuß. Rheinlande, 444: 271-274 (Sitzber. Niederrhein. Ges. Natur- u. Heilkde.): 271274; Bonn

[Rotliegendes Friedrichroda, Buntsandstein Bad Karlshafen/Weser]

OPohlig, H. (1887): Thierfährten und Medusenabdrücke aus dem unteren Rotliegenden des Thüringer Waldes. - Z. dt. geol. Ges., 39: 644-645 (Mber.); Berlin

-Probst, Ernst (1986): Deutschland in der Urzeit - Von der Entstehung des Lebens bis zum Ende der Eiszeit. - 479 S., zahlr. Abb.; (Bertelsmann) München [darin: Fossilfunde Richelsdorfer Gebirge, Cornberger Sandstein, Cornberg/Kr. Hersfeld-Rotenburg]

QReichardt, Wolfgang (1932): Tierische Reste aus den untersten Gehrener Schichten im oberen Ilmtal. Beitr. Geol. Thür., $\underline{\mathbf{3}}(3 / 4)$ : 222-225, 2 Abb.; Jena - Kurzeferat in: N. Jb. Mineral. etc., Referate; $193 \mathbf{3}$ (Bd. III): 457 (Beurlen); Stuttgart

ORoselt, Gerhard (1962): Untersuchungen zur Gattung Callipteris. - Freiberger Forschungshefte, C $\underline{131}$ : 1-81, 15 Abb., 21 Taf.; Berlin [darin: Thüringer Wald]

OScheibe, R. (1890): Pflanzenreste und Thierfährten aus dem Rothliegenden von Tambach. - Z. dt. geol. Ges., 42: 364-365 (Mber.); Berlin Referat in: N. Jb. Mineral. etc, $\underline{1894}$ (Bd. II): 442-443 (Sterzel); Stuttgart

- SSchaumberg, Günther (1970): Auf den Spuren der „Sintflut“ im Richelsdorfer Gebirge. - Der Aufschluss, 21: 259-265, 8 Abb.; Göttingen

aSchaumberg, Günther (1976): Über ein gut erhaltenes dermales Schädeldach von Platysomus striatus AGASSIZ (Palaeonisciformes, Actynopterygii, Osteichthyes) aus dem Kupferschiefer von Richelsdorf (Perm, Hessen). - Geol. Jb. Hessen, 104: 39-42, 2 Abb.; Wiesbaden.

-SSchaumberg, Günther (1976): Zwei Reptilneufunde (Weigeltisaurus KUHN (?), Lepidosauria (?), Reptilia) aus dem Kupferschiefer von Richelsdorf (Perm, Hessen). - Philippia, $\underline{\mathbf{3}}(1)$ : 3-8, 4 Abb.; Kassel.

-Schaumberg, Günther (1977): Erster Nachweis von Elonichthus punctatus ALDINGER (Palaeonisciformes, Actinopterygii, Osteichthyes) in Mitteleuropa, im Kupferschiefer von Richelsdorf (Perm, Hessen). - Geol. Jb. Hessen, 105: 65-68, Taf. 13-14; Wiesbaden

- $S$ Schaumberg, Günther (1977): Der Richelsdorfer Kupferschiefer und seine Fossilien - I. Bergbautätigkeit, Genese und Erforschungsgeschichte des Kupferschiefers. - Der Aufschluss, 28: 81104, 10 Abb.; Heidelberg 
- DSchaumberg, Günther (1977): Der Richelsdorfer Kupferschiefer und seine Fossilien - II. Die tierischen Fossilien des Kupferschiefers. 1. Invertebraten. - Der Aufschluss, 28 189-198, 8 Abb.; Heidelberg

aSchaumberg, Günther (1977): Der Richelsdorfer Kupferschiefer und seine Fossilien - III. Die tierischen Fossilien des Kupferschiefers. Vertebraten- Der Aufschluss, 28: 297-352, 42 Abb.; Heidelberg

هSchaumberg, Günther (1977): Der Richelsdorfer Kupferschiefer und seine Fossilien - IV. Die pflanzlichen Fossilien des Kupferschiefers, sonstige Lebensspuren, Aufrechnung der Fundhäufigkeit. - Der Aufschluss, 28: 427-442, 16 Abb.; Heidelberg

- $S$ Schaumberg, Günther (1978): Neubeschreibung von Coelacanthus granulatus AGASSIZ (Actinistica,

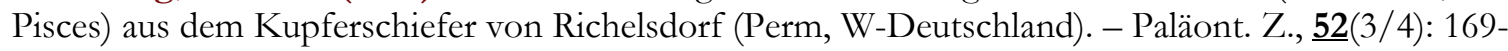
197, 21 Abb:; Stuttgart

-Schaumberg, Günther (1979): Neue Kenntnisse über die Anatomie von Janessa bituminosa (SCHLOTHEIM), Holocephali, Chondrichthyes aus dem permischen Kupferschiefer. - Paläont. Z., $\underline{\mathbf{5 3}}(3 / 4):$ 334-346, 8 Abb.; Stuttgart

[Richelsdorfer Gebirge]

-Schaumberg, Günther (1979): Neue Nachweise von Bryozoen und Brachiopoden als Nahrung des permischen Holocephalen Janassa bituminosa (SCHLOTHEIM). - Philippia, 4(1): 3 - 11, 4 Abb.; Kassel

[Neufunde a. d. Richelsdorfer Kupferschiefer]

aSchaumberg, Günther (1981): The vertebrate fauna of the Kupferschiefer. - In: Depowski, Stanislaw [president organizing committee]: Central European Permian - International Symposium Jabłonna, April 27-29, 1978 - Proceedings; 656 S., Abb.; hier S. 516-523; (Geological Institute) Warszawa

[Bezugnahme a. Funde d. Richelsdorfer Gebirges]

-Schaumberg, Günther (1981): Coelacanthus granulatus, a Permian actinistian fish. - In: Depowski, Stanislaw [president organizing committee]: Central European Permian - International Symposium - Jabłonna, April 27-29, 1978 - Proceedings; 656 S., Abb.; hier S. 524-527, 3 Abb.; (Geological Institute) Warszawa [Bezugnahme a. Funde d. Richelsdorfer Gebirges]

-Schaumberg, Günther (1982): Hopleacanthus richelsdorfensis n.g. n. sp., ein Euselachier aus dem permischen Kupferschiefer von Hessen (W-Deutschland). - Paläont. Z., $\underline{\mathbf{6}}$ (3/4): 235-257, 16 Abb.; Stuttgart [Richelsdorfer Gebirge]

- SSchaumberg, Günther (1982): Paläozoische Reptilien in Nordhessen. - Philippia, $\underline{\mathbf{5}}$ (1): 3 - 10, 5 Abb.; Kassel [Fossilfunde Richelsdorfer Kupferschiefer, Cornberger Sandstein]

aSchaumberg, Günther (1983): Der Kupferschiefer und seine versteinerten Tier- und Pflanzenreste aus dem Erdaltertum. - In: Hildebrand, Erich [Gesamtkonzeption, Red.]: Land an Werra und Meißner - Ein Heimatbuch.. - 1. Aufl.; S. 183-188, 6 Abb.; [Hrsg. Hist. Ges. Werralandes](Bing) Korbach 1983;

- oSchaumberg, Günther (1986): Bemerkungen zu einem Neufund von „Weigeltisaurus jackeli" (WEIGELT) im nordhessischen Kupferschiefer. - Paläont. Z., 60 (3/4): 319-327, 5 Abb.; Stuttgart [Richelsdorfer Gebirge] 
-Schaumberg, Günther (1987): 250 Millionen Jahre alte Lebenszeugnisse, gefunden in der Kupferschieferdeponie am Brodberg bei Sontra. - Das Werraland, 39: 31, 3 Abb.; Eschwege

- Schaumberg, G. (1987): Die tierischen Fossilien im Kupferschiefer und im Marl-Slate Bemerkenswerte Neufunde seit 1970 [Posterbeitrag]. - In: Klare, Bernd \& Schröder, Bernd [eds.]: Zechstein 1987 - International Symposium Kassel/Hannover [28. April to 9. May, 1987] - Abstracts, Posters, Program; S. 142; [Subkommission Perm/Trias der Stratigraphischen Kommission der DUGW/IUGS] Bochum 1987

aSchaumberg, Günther (1989): Muensterichtbyes buergeri n.g. n.sp., ein neuer Paleoniscoide (Actinopterygii, Pisces) aus dem permischen Kupferschiefer von Richelsdorf (Hessen, West-Deutschland). - Paläont. Z., 63(1/2): 119-131, 7 Abb.; Stuttgart

-Schaumberg, Günther (1989): Die Fossilien des Kupferschiefers. - In: Kollmann, Karl [Red.]: Die Grube Gustav im Bilsteiner Bergbaurevier. - 1. Aufl.; S. 10-14, 3 Abb.[Hrsg. Förderverein Besucherbergwerk „Grube Gustav“] Meißner-Abterode 1989

-Schaumberg, Günther (1990): Der Kupferschiefer und seine versteinerten Tier- und Pflanzenreste aus dem Erdaltertum. - In: Hildebrand, Erich [Gesamtkonzeption, Red.]: Land an Werra und Meißner - Ein Heimatbuch.. - 3., überarb. Aufl.; S. 185-190, 6 Abb.; [Hrsg. Hist. Ges. Werralandes](Bing) Korbach 1990

dSchaumberg, Günther (1992): Neue Informationen zu Menaspis armata EWALD. - Paläont. Z., 66 , 311-329, 12 Abb., Stuttgart

[Fossilien-Neufunde u.a. Richelsdorfer Kupferschiefer]

هSchaumberg, Günther (1996): Über wenig bekannte Acrolepiden aus dem oberpermischen Kupferschiefer und Marl-Slate von Deutschland und NE-England. - Philippia, 7(5): 325-354, 28 Abb., Kassel

[darin: Fossilien Richelsdorfer Kupferschiefer]

- $S c h a u m b e r g$, Günther (1999): Ergänzungen zur Revision des Euselachiers Wodnika striatula MÜNSTER 1843 aus dem oberpermischen Kupferschiefer und Marl-Slate. - Geologica et palaeontologica, 33: 203-217, 5 Abb., 3 Taf., Marburg

[u. a. Fossilien Richelsdorfer Kupferschiefer]

- $S$ Scheffer, Reinhard (1973): Die Mineralien und Fossilien der ehemaligen Grube „Schnepfenbusch“ im Richelsdorfer Gebirge/Nordhessen.- Der Aufschluss, 24 (7/8): 319-321, 1 Abb.; Göttingen

aSchaumberg, Günther (1976): Über ein gut erhaltenes dermales Schädeldach von Platysomus striatus AGASSIZ (Palaeonisciformes, Actynopterygii, Osteichthyes) aus dem Kupferschiefer von Richelsdorf (Perm, Hessen). - Geol. Jb. Hessen, 104: 39-42, 2 Abb.; Wiesbaden.

هSchaumberg, Günther (1976): Zwei Reptilneufunde (Weigeltisaurus KUHN (?), Lepidosauria (?), Reptilia) aus dem Kupferschiefer von Richelsdorf (Perm, Hessen). - Philippia, 3 (1): 3-8, 4 Abb.; Kassel.

- SSchaumberg, Günther (1977): Der Richelsdorfer Kupferschiefer und seine Fossilien - I. Bergbautätigkeit, Genese und Erforschungsgeschichte des Kupferschiefers. - Der Aufschluss, 28: 81104, 10 Abb.; Heidelberg

- $S$ Schaumberg, Günther (1977): Der Richelsdorfer Kupferschiefer und seine Fossilien - II. Die tierischen Fossilien des Kupferschiefers. 1. Invertebraten. - Der Aufschluss, 28 189-198, 8 Abb.; Heidelberg 
-Schaumberg, Günther (1977): Der Richelsdorfer Kupferschiefer und seine Fossilien - III. Die tierischen Fossilien des Kupferschiefers. Vertebraten- Der Aufschluss, 28: 297-352, 42 Abb.; Heidelberg

- SSchaumberg, Günther (1977): Der Richelsdorfer Kupferschiefer und seine Fossilien - IV. Die pflanzlichen Fossilien des Kupferschiefers, sonstige Lebensspuren, Aufrechnung der Fundhäufigkeit. - Der Aufschluss, 28: 427-442, 16 Abb.; Heidelberg

-Schaumberg, Günther (1979): Neue Nachweise von Bryozoen und Brachiopoden als Nahrung des permischen Holocephalen Janassa bituminosa (SCHLOTHEIM). - Philippia, 4(1): 3 - 11, 4 Abb.; Kassel

[Neufunde a. d. Richelsdorfer Kupferschiefer]

oSchaumberg, Günther (1982): Paläozoische Reptilien in Nordhessen. - Philippia, $\underline{\mathbf{5}}(1): 3$ - 10, 5 Abb.; Kassel [Fossilfunde Richelsdorfer Kupferschiefer, Cornberger Sandstein]

-Schaumberg, G. (1987): 250 Mill. Jahre alte Lebenszeugnisse, gefunden in einer KupferschieferDeponie am Brodberg. - Das Werraland, 39(2): 31, 2 Abb.m. Bildtext. [Fische Kupferschiefer]; Eschwege

-Schaumberg, G. (1987): Die tierischen Fossilien im Kupferschiefer und im Marl-Slate Bemerkenswerte Neufunde seit 1970 [Posterbeitrag]. - In: Klare, Bernd \& Schröder, Bernd [eds.]: Zechstein 1987 - International Symposium Kassel/Hannover [28. April to 9. May, 1987] - Abstracts, Posters, Program; S. 142; [Subkommission Perm/Trias der Stratigraphischen Kommission der DUGW/IUGS] Bochum 1987

- $S$ Schaumberg, Günther (1992): Neue Informationen zu Menaspis armata EWALD. - Paläont. Z., $\underline{\mathbf{6}}$, 311-329, 12 Abb., Stuttgart

[Fossilien-Neufunde u.a. Richelsdorfer Kupferschiefer]

aSchaumberg, Günther (1996): Über wenig bekannte Acrolepiden aus dem oberpermischen Kupferschiefer und Marl-Slate von Deutschland und NE-England. - Philippia, 7(5): 325-354, 28 Abb., Kassel [darin: Fossilien Richelsdorfer Kupferschiefer]

- $\square$ Schaumberg, Günther [1983/1990]: Der Kupferschiefer und seine versteinerten Tier- und Pflanzenreste aus dem Erdaltertum. - In: Hildebrand, Erich [Red.]: Land an Werra und Meißner Ein Heimatbuch.. - [1. Aufl.]; 384 S., zahlr. Abb.; hier: S. 183-188, 6 Abb.; 2. Aufl.: S. 185-190

[Hrsg. Hist. Ges. Werralandes](Bing) Korbach 1983;

-Schaumberg, Günther (1999): Ergänzungen zur Revision des Euselachiers Wodnika striatula MÜNSTER 1843 aus dem oberpermischen Kupferschiefer und Marl-Slate. - Geologica et palaeontologica, 33: 203-217, 5 Abb., 3 Taf., Marburg [u. a. Fossilien Richelsdorfer Kupferschiefer]

هSchaumberg, Günther (2008): Paläozoische Reptilien in Nordhessen II. - Ergänzungen zu einem gleichnamigen Artikel einer Zeitschrift in 1982. - Philippia, 13(3): 201-216, 13 Abb.; Kassel [Bezugn. a. Funde Richelsdorfer Gebirge, Cornberg]

- -Scheffer, Reinhard (1973): Die Mineralien und Fossilien der ehemaligen Grube „Schnepfenbusch“ im Richelsdorfer Gebirge/Nordhessen.- Der Aufschluss, 24 (7/8): 319-321, 1 Abb.; Göttingen

OSchlotheim, Ernst [Friedrich] v. (1820): Beiträge zur Naturgeschichte der Versteinerungen in geognostischer Hinsicht. - Denkschriften d. Kgl. Akademie d. Wissenschaften zu München, VI (f. 1816/1817): 13-36, 8 Taf.; München 
[Zechstein Glücksbrunn, (Bad) Liebenstein]

OSchlotheim, [Ernst Friedrich] v. (1821): Beiträge zur Naturgeschichte der Versteinerungen in geognostischer Hinsicht. - Tb. Mineral., 15(1): 195-215; Frankfurt/M. - Auszug aus: Denkschriften der Königlichen Akademie der Wissenschaften zu München, VI: 13-36; München [Zechstein Glücksbrunn, (Bad) Liebenstein]

-Schmidt, Hermann (1952): Neubeschreibung und Deutung einer Fährtenplatte aus dem Cornberger Sandstsein (Perm). - Paläont. Z., 25 (3/4): 193-197, 2 Abb.; Stuttgart

-Schmidt, Hermann (1953): Reptilfährten aus dem permischen Cornberger Sandstein $<$ Vortragskurzfassung >. - Paläont. Z., 27(1/2): 9; Stuttgart

-Schmidt, Hermann (1956): Versteinerte Saurierfährten im Cornberger Sandstein. - Hessische Heimat, N.F., $\underline{\mathbf{5}}$ [f. 1955/56](3): 19-21, Abb. 16-18; Marburg/L.

هSchmidt, Hermann (1958): Cornberger Fährten melden sechs Reptil-Ordnungen $<$ Vortragskurzfassung>. - Paläont. Z., $\underline{\mathbf{3 2}}(1 / 2)$ : 4; Stuttgart

-Schmidt, Hermann (1959): Die Cornberger Fährten im Rahmen der Vierfüßler-Entwicklung. - Abh. Hess. L.-A. Bodenforsch., 28; 137 S., 57 Abb., 9 Taf.; Wiesbaden

OSchneider, Jörg (1978): Zur Taxonomie und Biostratigraphie der Blattodea (Insecta) des Karbon und Perm der DDR. - Freiberger Forschungshefte, Reihe C, $\underline{\mathbf{3 4 0}}$; 152 S., 2 Abb., 2 Tab., 85 Taf.; Leipzig [Bezugn. a. Fde. Thüringer Wald]

OSchneider, Jörg (1980): Zur Taxonomie der jungpaläozoischen Neorthroblattidae. - In: (Autorenkollektiv: Stratigraphie, Biofazies und Taxonomie des europäischen Phanerozoikums - Teil IX). -Freiberger Forschungshefte., Reihe C, 348: 31-39, 1 Bild, 4 Bildtaf.; Leipzig [Bezugn. a. Funde Goldlauterer Schichten, Manebacher Schichten/Thüringer Wald]

OSchneider, Jörg (1982): Entwurf einer biostratigraphischen Zonengliederung anhand der Spiloblattinidae (Blattodea, Insecta) für das kontinentale euroamerische Permokarbon. - Freiberger Forschungshefte., Reihe C, 375: 27-47, 5 Bildtaf.; Leipzig [darin Bezugnahme a. Fde Thüringer Wald]

OSchneider, Jörg (1983): Die Blattodea (Insecta) des Paläozoikums - Teil I: Systematik, Ökologie und Biostratigraphie. - Freiberger Forschungshefte, Reihe C, 382: 106-145, 1 Abb., 1 Diagr., 3 Taf.; Leipzig [Bezugn. a. Funde Thüringer Wald]

OSchneider, J. (1985): Elsamobranchier-Zahntypen (Pisces, Chondrichthyes) und ihre stratigraphische Verbreitung im Karbon und Perm der Saale-Senke (DDR). - Freiberger Forschungshefte, Reihe C, 400: 90-100, 3 Abb., 4 Taf.; Leipzig [darin: Thüringer Wald]

OSchneider, Jörg W. (1996): Xenacanth teeth - a key for taxonomy and biostratigraphy. - Modern Geology, 20: 321-340, 10 fig., 1 tabl.; [darin Funde Rotliegedes der Saalesenke; Formationen des Thüringer Waldes]

OSchneider, J.; Walther, H. \& Wunderlich, R. (1982): Zur Biostratinomie, Biofazies und Stratigraphie des Unterrotliegenden der Breitenbacher Mulde (Thüringer Wald). - Freiberger Forschungshefte, Reihe C, 366: 65-84, 8 Abb., 4 Tab., 2 Taf.; Leipzig

OSchneider, Jörg \& Werneburg, Ralf (1993): Neue Spiloblattinidae (Insecta, Blattoidea) aus dem Oberkarbon und Unterperm von Mitteleuropa sowie die Biostratigraphie des Rotliegend. - Veröff./ Naturhist. Museum Schleusingen, 7/8: 31-52, 10 Abb., 6 Taf.; Schleusingen 
OSchneider, Jörg \& Werneburg, Ralf (1993): Neue Spiloblattinidae (Insecta, Blattoidea) aus dem Oberkarbon und Unterperm von Mitteleuropa sowie die Biostratigraphie des Rotliegend. - Veröff./ Naturhist. Museum Schleusingen, 7/8: 31-52, 10 Abb., 6 Taf.; Schleusingen

OSchneider, Jörg W. \& Zajic, Jaroslav (1994): Xenacanthiden (Pisces, Chondrichthyes) des mitteleuropäischen Oberkarbon und Perm. - Freiberger Forschungshefte, Reihe C, 452: 101-151, 31 Abb., 3 Taf.; Leipzig

OSchneider, Jörg W. \& Werneburg, Ralf (1998): Arthropleura und Diplopoda (Arthropoda) aus dem Unter-Rotliegend (Unter-Perm, Assel) des Thüringer Waldes (Südwest-Saale-Senke). - Veröff./ Naturhist. Museum Schleusingen, 13: 43-53, 1 Abb.; Schleusingen

OSumida, S.S.; Berman, D.S. \& Martens, Th. (1994): A trematopid amphibian from a terrestrial redbed of the Lower Permian of central Germany. - J. Vertebrate Paleont., 14(Suppl to 3): 48 A; [Fossilfundstätte Bromacker]

OSumida, S.S.; Berman, D.S. \& Martens, Th. (1996): Biostratigraphic correlations between the Lower Permian of North America und Central Europe using the first record of an assemblage of terrestrial

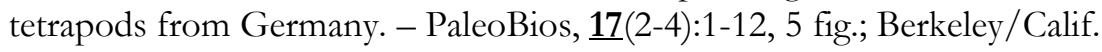

[Fossilfundstätte Bromacker]

OSumida, S.S.; Berman, D.S. \& Martens, Th. (1998): A new trematopid amphibian from the Lower Permian red-bed deposit of central Germany. - Palaentology, 41 (4): 605-629, 11 fig.; London [Fossilfundstätte Bromacker]

-Tobien, Heinz (1953): Bemerkungen zu einem Schädelrest von Reticulolepsis WESTOLL (Palaeonisformes, Pisces) aus dem Kupferschiefer von Sontra (Richelsdorfer Gebirge). - Notizbl. Hess. L.-A. Bodenforsch., $\underline{81}$ (=6. Folge, H. 4): 59-62, 1 Taf.; Wiesbaden

OVoigt, Sebastian (2005): Die Tetrapodenichnofauna des kontinentalen Oberkarbon und Perm im Thüringer Wald - Ichnotaxonomie, Paläoökologie und Biostratigraphie. Vorgelegt von ... 1. Aufl., VI, 179, [118] S., Ill., graph. Darst.; (Cuvillier) Göttingen - zgl. Diss. Univ. Halle-Wittenberg 2004

QVoigt, Sebastian \& Haubold, Hartmut (2000): Analyse zur Variabilität der Tetrapodenfährte Ichnotherium cottae aus dem Tambacher Sandstein (Rotliegend, Unter-Perm, Thüringen). - Analysis of the variability of Ichnotherium cottae from the Tambach Sandstone (Rotliegend, Lower Permian, Thuringia). - Hallesches Jb. Geowiss., Reihe B, 22: 17-58, 11 Abb., 2 Tab., 16 Taf.; Halle (Saale)

OWalter, Harald (1982): Neue Arthropodenfährten aus den Oberhöfer Schichten (Rotliegendes, Thüringer Wald) mit Bemerkungen über Ichnia limnisch-terrestrischer Tuffite innerhalb der varistischen Molasse. - Freiberger Forschungshefte, Reihe C, 375: 87-100, 7 Abb., 3 Taf.; Leipzig

QWalter, Harald (1983): Zur Taxonomie, Ökologie und Biostratigraphie der Ichnia limnischterrestrischer Arthropoden des mitteleuropäischen Jungpaläozoikums. - Freiberger Forschungshefte, Reihe C, 382: 146-193, 8 Abb., 2 Tab., Taf. I-XI; Leipzig [darin: Fde. Rotliegendes Thüringer Wald]

OWalter, Harald \& Werneburg, Ralf (1988): Über Liegespuren (Cubichnia) aquatischer Tetrapoden (?Diplocauliden, Nectridea) aus den Rotteröder Schichten (Rotliegendes, Thüringer Wald/DDR). Freiberger Forschungshefte, Reihe C, 419: 96-106, 4 Abb., 2 Taf.; Leipzig

OWeigelt, Johannes (1927): Das Posidonymenproblem im Obercarbon Westfalens. Nebst Beschreibung einer neuen Art aus dem Rotliegenden von Thüringen. - Jb. Halleschen Verbandes etc., N.F., 6: 72 82, 3 Taf. (12 Abb); Halle (Saale)

Referat in: N. Jb. Mineral. etc., Referate; 1928 (Bd. III): 308 (A. Bentz); Stuttgart [Goldlauterer Schichten] 
OWeiss, E. (1877): Ueber Protriton petrolei von Friedrichroda in Thüringen. - Z. dt. geol. Ges., 29: 202 (Mber.); Berlin

OWerneburg, Ralf (1983): Stegocephalen (Rhachitomi, Amphibia) aus den hohen Unterrotliegenden (Oberhöfer Schichten) des Thüringer Waldes. - Freiberger Forschungshefte, Reihe C, $\underline{\text { 384: 111-129, } 6}$ Tab., 8 Taf.; Leipzig

OWerneburg, Ralf (1986): Die Stegocephalen (Amphibia) der Goldlauterer Schichten (Unterrotliegendes, Perm) des Thüringer Waldes. Teil I: Apateon flagrifer (WHITTARD). - Freiberger Forschungshefte, Reihe C, 410: 88-101, 12 Abb., 2 Tab., 2 Taf.; Leipzig

OWerneburg, Ralf (1986): Erste Übersicht der permokarbonen Tetrapodenfauna des Thüringer Waldes. - Veröff./ Naturhist. Museum Schleusingen, 1: 41-46, 4 Abb., [1 Tab.]; Schleusingen

OWerneburg, Ralf (1987): Schädelrest eines sehr großwüchsigen Eryopiden (Amphibia) aus dem Unterrotliegenden (Unterperm) des Thüringer Waldes. - Veröff./ Naturhist. Museum Schleusingen, 2: 52-56, 4 Abb.; Schleusingen

OWerneburg, Ralf (1988): Die Amphibienfauna der Oberhöfer Schichten (Unterrotliegendes, Unterperm) des Thüringer Waldes. - Veröff./ Naturhist. Museum Schleusingen, ㅍ: 2-27, 15 Abb.; Schleusingen

OWerneburg, Ralf (1988): Die Stegocephalen (Amphibia) der Goldlauterer Schichten (Unterrotliegendes, Perm). Teil II: Apateon kontheri n. sp., Mealnerpeton eisfeldi n. sp. des Thüringer Waldes und andere. Freiberger Forschungshefte, Reihe C, 427: 7-29, 16 Abb., 1 Tab., 5 Taf.; Leipzig

OWerneburg, Ralf (1988): Die Stegocephalen (Amphibia) der Goldlauterer Schichten (Unterrotliegendes, Perm) des Thüringer Waldes. Teil III. - Veröff. Naturkundemuseum Erfurt, Naturwiss. Rh., 7: 80-96, 12 Abb.; Erfurt

OWerneburg, Ralf (1988): Paläobiogeographie der labyrinthodonten Amphibien im Oberkarbon und Rotliegenden Mitteleuropas. - Z. geol. Wiss., $\underline{\mathbf{1 6}}(9)$ : 929-932, 1 Abb.; Berlin [Bezugn. a. Thüringer Wald]

OWerneburg, Ralf (1989): Die Amphibienfauna der Manebacher Schichten (Unterrotliegendes, Unterperm) des Thüringer Waldes. - Veröff./ Naturhist. Museum Schleusingen, 4: 55-68, 12 Abb., 2 Tab.; Schleusingen

OWerneburg, Ralf (1989): Labyrinthodontier (Amphibia) aus dem Oberkarbon und Unterperm Mitteleuropas - Systematik, Phylogenie und Biostratigraphie. - Freiberger Forschungshefte, Reihe C, 436: 29-48; Leipzig

OWerneburg, Ralf (1992): Sclerocephalus jogischneiderei n. sp. (Eryopoidea, Amphibia) aus dem Unterrotliegende (Unterperm) des Thüringer Waldes. - Freiberger Forschungshefte, Reihe C, 445: 2948, 11 Abb., 2 Tab., 2 Taf.; Leipzig

OWerneburg, Ralf (1993): Trematosaurus (Amphibia) aus dem Mittleren Buntsandstein (Untertrias) von Thüringen. - Veröff./ Naturhist. Museum Schleusingen, 7/8: 17-29, 7 Abb., 2 Tab., 1 Taf.; Schleusingen

[Fundort: Vacha]

OWerneburg, Ralf (1996): Temnospondyle Amphibien aus dem Karbon Mitteldeutschlands. - Veröff./ Naturhist. Museum Schleusingen, 11: 23-64, 25 Abb.; Schleusingen [Thüringer Wald] 
OWerneburg, Ralf (1996): Erster Fossilnachweis vom Wartburg-Aufschluß bei Eisenach (Rotliegend). Beitr. Geol. Thür., N.F., 3: 115 - 119, 5 Abb.; Jena

OWerneburg, Ralf (2001): Apateon dracyiensis - eine frühe Pionierform der Branchiosaurier aus dem Europäischen Rotliegend Teil 1: Morphologie. - Veröff./ Naturhist. Museum Schleusingen, 16: 17-36, 16 Abb.; Schleusingen

[darin: Fde. Cabarz/Thür. Wald]

OWerneburg, Ralf (2002): Apateon dracyiensis - eine frühe Pionierform der Branchiosaurier aus dem Europäischen Rotliegend Teil 2: Paläoökologie. - Veröff./ Naturhist. Museum Schleusingen, 17: 1732, 10 Abb.; Schleusingen [darin: Fde. Cabarz/Thür. Wald]

OWeyer, Dieter (1979): Korallenfunde im europäischen Zechstein-Meer. - Z. geol. Wiss., 7 (8): 981-1021, 9 Abb., 4 Taf.; Berlin

[Ilmenau, Wartberg b. Seebach SE’ Eisenach, Thal SE’ Eisenach]

-Wild, R. (1985): Ein Schädelrest von Parasaurus geinitzi H. v. MEYER (Reptilia, Cotylosauria) aus dem Kupferschiefer (Perm) von Richelsdorf (Hessen). - (Gedenkschrift Bruno v. Freyberg) Geol. Bl. NOBayern, $\underline{\mathbf{3 4 / 3 5}}$ (Teil 2): 897-920, 4 Abb., Taf. 51, 52; Erlangen

OZessin, Wolfgang (1997): Thueringoedischia trostheidei nov. Gen. Et nov. Sp. (Insecta, Orthoptera) aus dem unteren Rotliegenden von Thüringen. - Veröff. Naturkundemuseum Erfurt, Naturwiss. Rh., 16: 172-183, 9 Abb.; Erfurt

\subsubsection{Trias}

\subsection{Trias - ungegliedert}

•Lange, W. (1923): Über neue Fossilfunde aus der Trias von Göttingen. - Z. dt. geol. Ges., $\underline{74}$ (f. 1922): 162-168, 1 Taf.; Berlin

Referat in: N. Jb. Mineral. etc., Referate, 1929 (Bd. III): 424-425 (Rud. Richter); Stuttgart

OLangenhan, Alwin (1903): Versteinerungen der deutschen Trias (des Buntsandsteins, Muschelkalks und Keupers) aufgrund vierzigjähriger Sammeltätigkeit und nach den Naturobjekten autographiert. 21 S.; (Scholz) Liegnitz

OLangenhan, Alwin (1915): Versteinerungen der deutschen Trias. - 2., erw. Auflage; 10 S., 47 Bl., 33 Taf.; (Selbstverl.) Friedrichroda

[u.a. Fossilfunde Trias nördlich des Thüringer Waldes]

-Volger (1846): Trias und ihre Versteinerungen um Göttingen... - N. Jb. Mineral. etc., 1846: 818-819 (Briefl. Mitt.); Stuttgart

\subsection{Trias - gegliedert}

\subsection{Buntsandstein}

- $\square$ • Apel, Jürgen \& Rüppel, Heidi [Verfass. u. Hrsg.] (2005): Raus in die Natur - Tipps für den Sonntags-Ausflug im Dreiländereck Hessen - Niedersachsen - Thüringen. - 159 S., 111 Fotos, 34 Kt., 
1 Zeit-Taf.; (LSRB-Verlag, Landschaftskundlicher-Studien-Reisebuch-Verlag) Witzenhausen [zahlreiche Ausflugstipps, auch zu Fossilfundstätten: Ziel 6 (Saurier-Fußspuren Wolfhagen)]

-Besch, Wulf (1960): Chirotherienspuren im Buntsandstein. - Mein Heimatland, $\underline{19}$ (10): 38, 1 Abb.; Bad Hersfeld

-Demathieu, Georges \& Haubold, Hartmut (1972): Stratigraphische Aussagen der Tetrapodenfährten aus der terrestrischen Trias Europas. - Geologie, 21(7): 802-836, 8 Abb., 7 Tab.; Berlin [Bezugn. a. Karlshafen/Nordhessen; Thüringen außerhalb bibliogr. erfaßten Geb.]

- $\square$ Demathieu, Georges \& Haubold, Hartmut (1982): Reptilienfährten aus dem Mittleren Buntsandstein von Hessen (BRD). - Hallesches Jb. Geowiss., 7: 97-110, 2 Abb., 4 Phots, 1 Tab.; Gotha [Fährten auf Buntsandsteinplatten der Museen Eschwege, Fritzlar, Lauterbach]

-Demathieu, Georges \& Fichter, Jürgen (1989): Die Karlshafener Fährten im Naturkundemuseum der Stadt Kassel. - Philippia, $\underline{\mathbf{6}}(2): 111$ - 154, 13 Abb., 3 Tab., 4 Taf.; Kassel [Spurenfossilien des Mittleren Buntsandsteins]

-Fichter, Jürgen (1997): Die Fährtenplatte vom Heuberg bei Gieselwerder - in memoriam Dr. Jens Kulick ( 1931 - 1996). - Philippia, $\underline{\mathbf{8}}(1): 35$ - 60, 17 Abb., 1 Tab.; Kassel

-Fichter, Jürgen (1995): Ein bemerkenswerter Fund von Hans Penndorf (1879-1960). - Philippia, 7(2): 91-108, 14 Abb.; Kassel [Spurenfossilien (Reptilfährten) Solling-Folge/Mittlerer Buntsandstein Kasseler Becken]

-Fichter, Jürgen \& Lepper, Jochen (1997): Die Fährtenplatte vom Heuberg bei Gieselwerder. Philippia - Abh. u. Ber. a. d. Naturkundemuseum i. Ottoneum z. Kassel, $\underline{\mathbf{8}}(1)$ : 35 - 60, 17 Abb., Tab.; Kassel [Spurenfossilien (Reptilfährten) Hardegsen-Folge (Mittlerer Buntsandstein) des Reinhardswaldes]

व•Fichter, Jürgen; Heggemann, Heiner \& Kunz, Reiner (1999): Neue bzw. bisher nicht veröffentlichte Tetrapodenfährten-Lokalitäten im Mittleren Buntsandstein Nordhessens und Südniedersachsens - In memoriam Dr. Manfred Horn (1934-1999). - Geol. Jb. Hessen, 127: 33-55, 25 Abb.; Wiesbaden [Fährten a. d. „Ballertasche“ TK 25 Bl. 4523 Hannoversch-Münden; 4620 Arolsen, 4621 Wolfhagen, 4721 Naumburg, 4725 Oberkaufungen, 5021 Schwalmstadt]

-Fichter, Jürgen \& Kunz, Reiner (2004): New genus and species of Chiroheroid tracks in the DetfurthFormation (Middle Bunter, Lower Triassic) of Central Germany. - Ichnos, 11: 183-193, 13 fig.; Philadelphia/Pennsyl. [Fundort Nähe Wolfhagen]

-Fichter, Jürgen \& Kurnz, Reiner (2006): Buntsandstein-Fossilien im Landkreis Kassel - Saurierspuren aus einer aufgelassenen Sandgrube im Stadtwald von Wolfhagen. - Paläontologische Denkmäler in Hessen, 16; 16 S., 16 Abb.; [Hrsg. Abt. Archäologische u. Paläontologische Denkmalspflege i. Landesamt f. Denkmalpflege Hessen, Archäologische Gesellschaft i. Hessen e.V.] Wiesbaden

-Hartmann, Curt (1975): Fossilfunde im Landkreis Kassel. - Jb. Lkr. Kassel, 1976: 87 - 89, 3 Abb., 2 Taf. m. 9 Abb.; Kassel

-Haubold, Hartmut (1971): Die Tetrapodenfährten des Buntsandsteins in der Deutschen Demokratischen Republik und in Westdeutschland und ihre Äquivalente in der gesammten Trias. Paläont. Abh., Reihe A, 4(3): 397-548, 34 Abb., 22 Tab., 35 Taf.; Berlin [darin: Fossilfunde Bad Karlshafen, Krebeck-Waake, Volpriehausen] 
QHeisig, Klaus (2004): Das Nothosaurier-Skelett im Eichsfelder Heimatmuseum Heiligenstadt. Eichsfeld-Jahrbuch, $\underline{\mathbf{1 1}}$ (2004): 265-288, 15 Abb., 1 Tab.; Duderstadt

OHoppe, Walter (1965): Die Fossilien im Buntsandstein Thüringens sowie ihre stratigraphsiche und ökologische Bedeutung. - Geologie, 14(3): 272-323, 1 Abb., 6 Taf., 3 Tab.; Berlin

-Hornstein, F. (1876): Entdeckung von Thierfährten im Buntsandstein bei Karlshafen. - N. Jb. Mineral. etc., 1876: 923-924 (Briefl. Mitt.); Stuttgart

-Hornstein, F. F. (1902): Belegmaterialien zur Geologie der Umgebung von Cassel. - Z. dt. geol. Ges., 54: 118-121(Verhdlgn.), 1 Abb.; Berlin

[Fossilien d. Lias, (Basalte), Buntsandstein m. Thierfährten v. Karlshafen]

口Jäger, Willy (1926): Der „Aal“ in der Parkmauer zu Völkershausen. - Eschweger Tageblatt, 1926; Nr. 190 v. 16.8.1926, 2 Abb.; Eschwege

[Fischfossil oder Spiellaune der Natur in einem Mauerstein aus dem Mittleren Buntsandstein]

- 0 Krämer, Friedrich \& Kunz, Heinrich (1966): Chirotherium, das „unbekannte“ Tier. - Natur u. Museum, 96: 12-19, 2 Abb., 2 Tab.; Frankfurt/M.

[Fundstellen u. a. Walldorf/Südthüringen, Treffurt, Bad Karlshafen]

-Krebs, Bernhard (1969): Ctenosauriscus koeneni (v. HUENE), die Pseudosuchia und die BuntsandsteinReptilien. - Eclgoae geolica Helvetiae, 62: 697-714, 2 Abb., Taf. I u. II; Basel [Fundort: Bremker Tal SE' Göttingen]

-Kunz, Rainer \& Fichter, Jürgen (2000): Saurierfährten aus dem Buntsandstein Wolfhagens. Jahrbuch Lkr. Kassel, 2001: 79 - 80, 5 Abb.; Kassel

- Kunz, Rainer; \& Fichter, Jürgen (2000): Die Wolfhager Saurierfährten. - Schr. Vereins Regionalmuseum Wolfhagen, Reihe Forschungen, Bd. 9; 17 S., Abb.; (Verein Regionalmuseum) Wolfhagen

-Lepper, Jochen \& Uhl, Dieter (2001): Farnreste aus dem Buntsandstein von Bad Karlshafen (Weserbergland) - Fundbericht. - Ber. Naturhist. Ges. Hannover, 143: 19-26, 3 Abb.; Hannover

OMüller, Arno Hermann (1956): Weitere Breiträge zur Ichnologie, Stratonomie und Ökologie der germanischen Trias - Teil I. - Geologie, $\underline{\mathbf{5}}$ (4/5): 405-423, 3 Abb., 5 Taf.; Berlin [darin: Fund Spurenfossil Unterer Buntsandstein Nähe Schmalkalden]

-Naumann, Peter (1997): Neue Saurierfunde an Weser und Diemel. - Hessischer Gebirgsbote, 98(4): 151, 1 Abb.; Melsungen [darin: Fundort Heuberg bei Gieselwerder, Mittlerer Buntsandstein]

OPohlig, H. (1887): Steinplatten mit Saurierfußstapfen aus dem Rotliegenden und Buntsandstein. - Verh. Naturhist. Ges. preuß. Rheinlande, 44: 271-274 (Sitzber. Niederrhein. Ges. Natur- u. Heilkde.): 271274; Bonn

[Rotliegendes Friedrichroda, Buntsandstein Bad Karlshafen/Weser]

-Schmidt, H[ermann] (1928): Exkursion nach Diemarden und Bremke (Muschelkalk und Buntsandstein) - Tagung der Paläontologischen Gesellschaft in Göttingen [29. September bis 4. Oktober] 1926. - Paläontologische Z., 9: 3-4, 2 Abb.; Stuttgart

\subsection{Muschelkalk}


QBarthel, Manfred (2002): Ceratites undulatus in Manebach (Thüringer Wald). - Veröff. Naturkundemuseum Erfurt, Naturwiss. Rh., 21: 7-13, 6 Abb.; Erfurt

-Bielert, Ulrich \& Bielert, Friedrich (1995): Encriniden aus dem Bereich der Basiskonglomeratbänke des Unteren Muschelkalks von Weißenborn (Südniedersachsen). - Der Aufschluss, 뜨: 23-31, 13 Abb.; Heidelberg [Lkr. Göttingen]

-Bielert, Friedrich \& Bielert, Ulrike (2004): Echinodermen-Lagerstätten der Oberen Terebratelbank des Unteren Muschelkalks von Südniedersachsen [Posterbeitrag]. - In: Reich, Mike; Hagdorn, H. \& Reitner, J. [Hrsg.]: Stachelhäuter 2004 - 3. Arbeitstreffen deutschsprachiger Echinodermenforscher - Ingelfingen, 29. bis 31. Oktober 2004 - Arbeiten \& Kurzfassungen der Vorträge und Poster. - Reihe: Universitätsdrucke Göttingen; 78 S., Abb.; hier S. 7-12, 8 Abb.; (Universitätsverlag) Göttingen [Funde Lkr. Göttingen, Lkr. Northeim]

-Brauns, D. (1875): Über einige neue Petrefaktenfunde am Hainberge bei Göttingen. - Z. gesammt. Naturwiss., 46 (N. F. 12): 449-453; Berlin

-Brocke, Rainer \& Riegel, Walter (1996): Phytoplankton responses to shoreline fluctuations in the Upper Muschelkalk (Midddle Triassic) of Lower Saxony (Germany). - N. Jb. Geol. Paläont., Abh., $\underline{200}$ (1/2): 53-73, 6 fig.; Stuttgart

[Fundpunkte LKr. Göttingen]

-Bückius, Matthias \& Schwedt, Georg (1999): Katalog [ Fossilien, Mineralien der Goethe-Sammlung, inhaltlich an Kap. Geologie - Goethe im Göttinger Reich der Steine“" anschließend] - In: Mittler, E.; Purpus, E. \& Schwedt, G. [Hrsg.]: „Der gute Kopf leuchtet überall hervor“. - 270 S., zahlr. Abb.; hier: S. 184-187; (Wallstein) Göttingen

[Fde. I13- I19: Funde vom Hainberg/Göttingen]

QBülert, Ulrich \& Bülert, Friedrich (1996): Verschüttet im Konglomerat - Encrinus robustus ASSMANN aus dem Unteren Muschelkalk aus Nord-West-Thüringen. - Der Aufschluss, 47: 301306, 6 Abb.; Heidelberg

[Fundort: Steinbruch Zementwerk Deuna]

$\square$ Busse, Erwin (1962): Ceratites armatus PHILIPPI im Oberen Muschelkalk des Meißners (Niederhessen). - Notizbl. Hess. L.-A. Bodenforsch., 90: 87-92, 1 Tab., Taf. 10; Wiesbaden

$\square$ Busse, Erwin (1964): Die Gastropoden-Gattungen Undularia KOKEN und Pustularia KOKEN im obersten Mittleren Muschelkalk des westlichen Meißner-Vorlandes. - Notizbl. Hess. L.-A. Bodenforsch., 92: 29-51, 5 Tab., Taf. 1-2; Wiesbaden

- $\square$ Busse, Erwin (1970): Ceratiten und Ceratitenstratigraphie. - Notizbl. Hess. L.-A. Bodenforsch., $\underline{98}$ : 112-145, 2 Tab.; Wiesbaden [darin: Hessen, Meißner-Gebiet (Eisenberg b. Hess. Lichtenau]

-Busse, Erwin \& Horn, Manfred (1981): Fossilführung und Stratigraphie der gelben Basisschichten im Diemelgebiet. - Geol. Jb. Hessen, 109: 73 - 84, 1 Abb.; Wiesbaden

-Cajus, Dietrich (2003): Die Wirbeltierfauna aus einer Bonebed-Prospektionsgrabung in der enodis/posseckerie-Zone des Oberen Muschelkalkes (Unter-Ladin, Mitteltrias) von Lamerden (NWDeutschland). - Philippia, 11(2): 133-150, 12 Abb.; Kassel

øClaus, H. (1969): Über einige Strömungsmarken und Spuren aus der Trias Thüringens. - Natur u. Museum - Ber. Senckenbergischen Naturforsch. Ges., 99(10): 475-480, Abb. 5; Frankfurt/M. [darin: Muschelkalk b. Schlotheim/Unstrut-Hainich-Kreis] 
QCredner, Georg Rudolf (1875): Ceratites fastigatus und Salenia texana. - Z. f. d. gesamt. Naturwiss., 46 [N.F. 12]: 105-115, Taf. 5; Berlin

-Ernst, Robert \& Löffler, Thomas (1993): Crinoiden aus dem Unteren Muschelkalk (Anis) Südniedersachsens. - In: Hagdorn, Hans \& Seilacher, Adolf [Hrsg.]: Muschelkalk - Schöntaler Symposium 1991. - Sdbde Ges. Naturkde. Württ., 2; 288 S., zahlr. Abb.; hier: 223-233, 12 Abb.; (Goldschneck) Stuttgart, Korb

[Funde Lkr. Northeim, Lkr. Göttingen]

-Fichter, Jürgen (1997): Vorläufige Mitteilungen über ein Vorkommen von Tetrapodenfährten im Mittleren Muschelkalk bei Lamerden, Nordhessen. - Philippia, $\underline{8}(1): 61$ - 72, 8 Abb.; Kassel

-Fichter, Jürgen (2000): Ein neuer Nachweis von Saurierfährten im Mittleren Muschelkalk von Lamerden. - Philippia, 9(3): 215 - 217, 3 Abb.; Kassel

QFischer, Karl (2004): Die Bonifatiuspfennige am Büttstedter Bahndamm. - Eichsfelder Heimatzeitschrift, $\underline{\text { 48}(6) / 2004(J u n i): ~ 213 ; ~ D u d e r s t a d t ~}$ [Herkunft der lokalen Bezeichnung „Bonifatiuspfennige“ für Seelilienstielglieder]

Q $\bullet$ Götz, Annette E. (1995): Neue Conodonten aus dem Unteren Muschelkalk (Trias, Anis) des Germanischen Beckens. - Geol. Paläont. Mitt. Innsbruck, 20: 51-59, 1 Abb., 1 Tab., 2 Taf.; Innsbruck [Probenahmepunkte: u. a. Creuzburg u. Deuna (Thüringen), Hardegsen (Südniedersachsen)]

QGrundel, Joachim (1973): Zur Kenntnis der Gattung Liebea (Bivalvia) im deutschen Zechstein. (Autorenkollektiv: Stratigraphie, Biofazies des europäischen Phanerozoikums, Teil I), Freiberger Forschungshefte, Reihe C, 282: 89-97, 6 Abb.; Berlin [darin: Bezugnahme a. Fde. Bl. Eisenach-West, Oberrhon b. Bad Salzungen]

$\square$ Hotzler, Fritz (1997): Die bekanntesten Fossilien unserer Heimat. - Das Werraland, $\underline{49}(2)$ : 41, 1 Abb.; Eschwege [,Ammonshörner“/Ammoniten des Oberen Muschelkalks]

$\square$ Hotzler, Fritz (1997): Schmelzschupper, Seelilie und Limamuschel. Fossilien unserer Heimat. - Das Werraland, $\underline{49}$ (3): 61; Ill.; Eschwege

[Fossilien des Muschelkalks]

$\square$ Humberg, Hermann (1974): Ein Ceratites meissnerianus vom Meißner. - Der Aufschluss, 25: 321, 1 Abb.; Göttingen

$\square$ Koch, Friedhelm (2007): Kelche von Encrinus liliiformis auf der Westseite des Meißners. Ein nicht alltäglicher Fund in der Gemarkung von Velmeden. - Das Werraland, 59(2): 31-33, 3 Abb.; Bad Sooden-Allendorf

$\square$ Koch, Friedhelm (2007): Kelche von Encrinus liliiformis (Seelilie). Selten Funde im Trochitenkalk oberhalb von Velmeden am Meißner. - Hessischer Gebirgsbote, 108(1): 7-9, 3 Abb.; Melsungen

$\square$ Koch, Friedhelm \& Volland, Herbert (2003): Auf dem Weg ins/vom Werratal - Ammonitensuche an der künftigen Autobahn A44. - Das Werraland, 55(2): 28-31, 5 Abb.; Eschwege

QKozur, Heinz (1968): Conodonten aus dem Muschelkalk des germanischen Binnenbeckens und ihr stratigraphischer Wert - Teil I: Conodonten vom Plattformtyp und stratigraphische Bedeutung von Conodonten aus dem Oberen Muschelkalk. - Geologie, 17(8): 930-946, 3 Taf.; Berlin

QKrause, Thorsten (1993): Eine Ceratitenplatte mit Schlangensteinen aus dem Oberen Muschelkalk von Eisenach (Thüringen). - Veröff. Naturkundemuseum Erfurt, Naturwiss. Rh., 12: 56-59, 3 Abb.; Erfurt 
OKrause, Torsten (1995): Die Zähne der Lungenfische Ptyboceratodus und Ceratodus aus der Trias von Thüringen - historische und neue Funde. - Veröff./ Naturhist. Museum Schleusingen, 10: 57-74, 7 Abb., 6 Taf.; Schleusingen

[darin: Fde. Steinmergelkeuper Wandersleben/Burgruine Gleichen]

OKrause, Torsten (2000): Aktuelle Zahnfunde der Lungenfische Ptychoceratodus und Ceratodus aus der Thüringer Triasmulde (Nachtrag). - Veröff./ Naturhist. Museum Schleusingen, 15: 41-45, 9 Abb.; Schleusingen

-Kunz, Reiner (1999): Muschelkalkfossilien aus der Umgebung Wolfhagens. - Jahrbuch Lkr. Kassel., 2000: 47 - 50, 2 Abb. i. Text, 7 Abb. (a. 2 Farbtaf.); Kassel

OLangenhan (1907): Ein Belemnid im Oberen Muschelkalk von Gräfentonna (Mitteilung an Herrn Joh. Bohm). - Z. dt. geol. Ges., 59: 41-43 (Mber.), 1 Abb.; Berlin

- Meischner, Klaus Dieter (1962): Neue Funde von Psammolimulus gottingensis (Merostomata, Xiphosura) aus dem Mittleren Buntsandstein von Göttingen. - Paläont. Z. - Festband Hermann Schmidt; S. 185 - 193, 1 Abb., 2 Taf.; Stuttgart

$\square$ Moesta, Friedrich (1872): Cidaris grandaeva im oberen Muschelkalk unfern des Meissners, Inseln alten Gebirges im hessischen Lande. - N. Jb. Mineral. etc., 1875: 294-295(Briefl. Mitt.); Stuttgart [„Inseln alten Gebirges im hessischen Lande“: Unterwerra-Grauwackengebirge, „Baumbacher Hoch“ bei Rotenburg/Fulda]

QMüller, Arno Hermann (1955): Beiträge zur Stratonomie und Ökologie des germanischen Muschelkalkes. - Geologie, 4 (3): 285-297, 1 Abb., 3 Taf.; Berlin [darin Funde: Thüringer Becken, Mühlgraben/Reiser b. Mühlhausen, Schloßberg Waltershausen; Kaltenohmfeld (Ohmgebirge)]

OMüller, Arno Hermann (1959): Weitere Breiträge zur Ichnologie, Stratonomie und Ökologie der germanischen Trias - Teil II. - Geologie, $\underline{8}$ (3): 239-261, 5 Abb., 7 Taf.; Berlin [darin: Fund i. Ob. Muschelkalk Groß-Vargula]

OMüller, Arno Hermann (1962): Eine Napfschnecke (Tropidosalpix triassina) aus dem Oberen Muschelkalk von Thüringen. - Geologie, 11 (8): 986-988, 2 Abb.; Berlin [Fundort: Ohrdruf, Straße n. Mühlberg]

OMüller, Arno Hermann (1963): Über Rhyncholithen aus dem Oberen Muschelkalk des germanischen Triasbeckens. - Geologie, 12(7): 842-857, 12 Abb., 1 Tab., 3 Taf.; Berlin [darin: Fund v. Reiser b. Mühlhausen; Rhyncholithen: Oberkiefer Nautiliden]

OMüller, Arno Hermann (1967): Zur Ichnologie von Perm und Trias im Mitteldeutschland. - Geologie, 16(9): 1061-1071, 6 Abb., 1 Tab., 2 Taf.; Berlin

[darin: S. 1063-1067: „2. Corophioides? Minus n. sp. aus dem Unt. Muschelkalk (mu2, OrbicularisSchichten) von West-Thüringen“ - Craula (Blatt Mihla)]

OMüller, Wolfgang (1961): Fischreste aus dem Oberen Muschelkalk. - Der Aufschluss, 12: 132-133, 7 Abb.; Göttingen [Funde: Fahnersche Höhe b. Molschleben, Ohrdruf, Sundhausen]

-Naumann, Peter (1986): Fische und Wirbeltierfunde aus dem Oberen Muschelkalk von LiebenauHaueda. - Jahrbuch Lkr. Kassel, 1986: 175 - 176, 1 Taf. (4 Abb.); Kassel

-Naumann, Peter (1990): Fossilien des Muschelkalkmeeres von Liebenau-Haueda. - Hessischer Gebirgsbote, 91(1): 20 - 24; Melsungen 


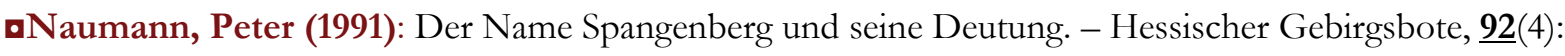
140; Melsungen [,Spangen“ = Regionalbezeichnung für Seelilien-Stielglieder]

$\square$ Neuweiler, F.; Peckmann, J. \& Ziems, A. (1999): Sinusoidally deformed veins („Sigmoidalklüftung“) in the Lower Muschelkalk (Triassic, Anisian) of Central Germany: sheet injection structures defomred within the shallow subsurface. - N. Jb. Geol. Paläont., Abh., [D. Meischner-Festschrift) 214 (1/2): 129-148, 12 fig., 1 tabl.; Stuttgart [darin: Aufschluß a. d. „Boyneburg“ Bl. 4826 Eschwege]

OPatzelt, Gerald (1995): Beobachtungen zur Fossilisation von Germonautilus (Nautiliden, Mitteltrias). Mühlhäuser Beitr., 18: 89-94, 5 Abb.; Mühlhausen

$\square$ Penndorf, Hans (1951): Die Ceratitenschichten am Meißner in Niederhessen. - Abh. Senckenberg. Naturforsch. Ges., 484: 1-24, 3 Abb., 6 Taf.; Frankfurt/M.

DOPhilippi, E. (1901): Die Ceratiten des oberen deutschen Muschelkalkes. - Paläont. Abh., $\underline{\mathbf{8}}(=$ N. F. $\underline{4})$ H. 4: 114 S. [347-458 ges. Bd.], 19 Abb. i. Text, 25 Taf. (Taf. 34-54); Jena [darin Funde: Bremsbahn am Wilhelmstollen/Hoher Meißner, Laudenbach/Hoher Meißner, Burgtonna, Göttingen u. Umgebung]

OPicard, K. (1886): Ueber Ophiuren aus dem Oberen Muschelkalk bei Schlotheim in Thüringen. - Z. dt. geol. Ges., 38: 879-893, Fig. 4-7, Taf. XXVIII; Berlin

QRein, Siegfried (1988): Die Ceratiten der pulcher/robustus-Zone Thüringens. - Veröff./ Naturhist. Museum Schleusingen, $\underline{\mathbf{3}}$ : 28-38, 4 Abb., 7 Tab.; Schleusingen [darin: Fde. Umgebung Mühlhausen]

ORein, Siegfried (1990): Über Ceratiten (Cephalopoda, Ammonoidea) mit „fehlenden“ Septa. - Veröff./ Naturhist. Museum Schleusingen, $\underline{\mathbf{5}}$ : 22-25, 4 Abb.; Schleusingen [darin: Fde. Dingelstädt]

QRein, Siegfried (1991): Über Ceratiten mit asymmetrischen Phragmokon. - Veröff./ Naturhist. Museum Schleusingen, ㅁ: 63-69, 11 Abb.; Schleusingen

ORein, Siegfried (1998): Biologie und Lebensweise von Germanonautilus MOJSISOVICS 1902 - Teil II: Ontogenie, Ernährung und Ökologie von Germanonautilus. - Veröff./ Naturhist. Museum Schleusingen, 13: 3-14, 14 Abb.; Schleusingen [darin: Fd. Kammerforst/Hainich]

-Rosenbusch, Adolf (1911): Ueber Technocheilus nodosus aus den Ceratitenschichten der Göttinger Trias. Zbl. Mineral. etc., 1911: 74-78, 2 Abb.; Stuttgart

$\square$ Schaumberg, Günther (1995): Ein umfangreicher Fund von Beneckeia buchi (v. ALBERTI) im Unteren Wellenkalk des Ringgaus (Nordhessen). - Philippia, 7(3): 169-175, 5 Abb.; Kassel

-Schlüter, Heinrich \& Schmidt, Hermann (1927): Voltzia, Yuccites und andere neue Funde aus dem südhannoverschen Buntsandstein. - N. Jb. Mineral etc. , Abt. B, Beilbd. 57: 12 - 27, 3 Taf.; Stuttgart Referat in: N. Jb. Mineral. etc., Referate; $\underline{1928}$ (Bd. II): 517-518 (Kräusel); Stuttgart [Fürstenberg a.d. Weser; Bremke b. Göttingen]

-Schmidt, H[ermann] (1928): Exkursion nach Diemarden und Bremke (Muschelkalk und Buntsandstein) - Tagung der Paläontologischen Gesellschaft in Göttingen [29. September bis 4. Oktober] 1926. - Paläont. Z., 9: 3-4, 2 Abb.; Stuttgart

-Schultze, Hans Peter \& Möller, Heiko (1986): Wirbeltierreste aus dem Mittleren Muschelkalk (Trias) von Göttingen, West-Deutschland. - Paläont. Z., 무: 109-129, 13 Abb.; Stuttgart 
-Schweizer, Rolf (1966): Ein Coelacanthide aus dem Oberen Muschelkalk Göttingens. - N. Jb. Geol. Paläont., Abh., [O. H. Schindewolf-Festband] 125: 216-226, 5 Abb., Taf. 22; Stuttgart

$\square$ Sommerfeld, Gustav (1928): Versteinerungen in der Umgebung Grandenborns auf dem Ringgau. Das Werratal, $\underline{\mathbf{5}}$ (7): 112-113, 2 Abb.; (8) 122-123, 1 Abb.; Eschwege

-U1richs, Max \& Vath, Ullrich (1990): Zur Ceratiten-Stratigraphie im Oberen Muschelkalk (Mitteltrias) bei Göttingen (Südniedersachsen). - Geol. Jb. Hessen, 118: 127-147, 1 Abb., 1 Tab., 7 Taf.; Wiesbaden [ICE-Neubaustrecke Göttingen-Kassel]

-Wiedemann, Heinz (1983): „Ulentränen“ im Oberen Muschelkalk Hessens. - Jahrbuch Kreisausschuß Landkreis Kassel, 1984: 144, 1 Abb.; Kassel [,Ulentränen“ = Seelilien-Stielglieder]

$\square$ Woyzechowski, Sonja (1984): Biofazies des Trochitenkalkes im Bereich des Netragrabens und des Ringgaues (Nordhessen). - Dipl.- Arb. Univ. Berlin

-Wunsch, Louis Paul (1958): Fährtenrest eines Vierfüßlers im oberen Muschelkalk. - Der Aufschluss, $\underline{9}$ : 155-156, 2 Abb.; Roßdorf b. Darmstadt [Fund v. Diemarden b. Göttingen; St. Barbara b. Dillingen/Saarland]

\subsection{Keuper}

OAmthor, R. (1908): Das Bonebed im Rhät des Apfelstedt-Grundes südöstlich von Gotha. - Z. f. Naturwiss., $\underline{\mathbf{8 0}}(1 / 2)$ : 91-96, Taf. II; Leipzig

OBornemann [sen.], J. G. (1856): Ueber organische Reste der Lettenkohlengruppe Thüringens - Ein Beitrag zur Fauna und Flora dieser Formation, besonders über fossile Cycadeen, nebst vergleichenden Untersuchungen über die Blattstruktur der jetztweltlichen Cydadeengattungen. - VIII, 85 S., 12 Taf.; (Engelmann) Leipzig

[Unterer Keuper i. d. Umgebung v. Mühlhausen]

○Chop, Carl (1857): Neue Mittheilungen über die Zähne und Fischreste aus dem Thüringer Keuper. - Z. gesammt. Naturwiss., 9: 127-132, Taf. IV; Berlin [Schlotheim]

QDreyer, Dieter (1962): Zur Entstehung und Paläontologie der Bonebedlagen im Unteren Rhät Thüringens. - Freiberger Forschungshefte, Reihe C, 125: 127-143, 10 Abb., 6 Taf. (I-VI); Leipzig [Gebiet der Drei Gleichen, Rhönberg/Kallenberg, Gr. Seeberg b. Gotha]

OGiebel, C. (1856): Ueber Saurier- und Fischreste aus dem Thüringer Keuper. - Z. gesammt. Naturwiss., 8: 422-429, Taf. I; Berlin

[Schlotheim]

OHopf, Hagen \& Martens, Thomas (1992): Erster Nachweis von Dinosaurierresten im Steinmergelkeuper der Drei Gleichen bei Arnstadt. - Ein Beitrag zur Fauna des Mittleren Keupers Thüringens. - Z. geol. Wiss., 20 (4): 327-335, 4 Abb., 2 Taf.; Berlin

OPicard, E. (1858): Ueber den Keuper bei Schlotheim in Thüringen und seine Versteinerungen. - Z. gesammt. Naturwiss., 11(5): 425-436, Taf. IX ; Berlin 


\subsubsection{Jura - Kreide}

-Arp, G.; Persoh, D.; Reimer, A.; Reitner, J. \& Sosnitza, M. (2000): Lias-Fossilien aus der Tongrube Eichenberg, Nordhessen. - Fossilien - Z. f. Hobbypaläontologen, 17(2): 108-113; Wiebelsheim

- Bornemann [sen.], Johann Georg (1854): Ueber die Liasformation in der Umgebung von Göttingen und ihre organischen Einschlüsse - mit einer geognostischen Skizze und drei Steindrucktafeln. - Diss. Univ. Göttingen - 77 S., 4 Taf.; (Schade) Berlin

QBurbach, O. (1884): Über einige neue Funde in dem Liasgebiet des grossen Seebergs bei Gotha. - Z. f. Naturwiss., 57(3): 348-349; Halle (Saale)

QBurbach, O. (1886): Beiträge zur Kenntnis der Foraminiferen des mittleren Lias vom grossen Seeberg bei Gotha - I. Die Gattung Frondicularia, Defr. - Z. f. Naturwiss., 59(1): 30-72, Taf. 1; Halle (Saale)

@Burbach, Otto (1886): Beiträge zur Kenntnis d. Foraminiferen des mittleren Lias vom grossen Seeberg

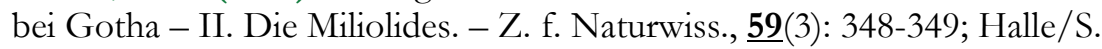

@Burbach, O. (Verfass.) \& Dreyer, Fr. (Hrsg.)(1888): Beiträge zur Kenntnis der Foraminiferen des mittleren Lias vom grossen Seeberg bei Gotha - III. Die Gattung Cristellaria, Lam. - Z. f. Naturwiss., 61(5): 493-515, Taf. X, XI; Halle (Saale)

OErnst, Werner (1986): Einige Nautiliden-Neufunde aus dem Unter- und Mittel-Jura der DDR (Vorläufige Mitteilung). - Freiberger Forschungshefte, Reihe C, 410: 59-64, 2 Taf. (I-II); Leipzig [darin: Röhnberg b. Gotha]

QHerrig, Ekkehard (1979): Die Gattung Bairdia (Ostracoda, Crustacea) im Lias von Thüringen. Teil I. Z. geol. Wiss., 7(5): 641-661, 16 Abb., 1 Taf.; Berlin

[Eisenach-Nord, Apfelstedt bei Wechmar, Röhnberg b. Wandersleben]

QHerrig, Ekkehard (1979): Ostrakoden aus dem Lias von Thüringen: Die Gattung Bairdia (Teil II), Fabalicypris und Bairdiacypris. - Z. geol. Wiss., 7(6): 763-782, 12 Abb., 1 Taf.; Berlin

[Eisenach-Nord, Apfelstedt bei Wechmar, Röhnberg b. Wandersleben]

QHerrig, Ekkehard (1979): Weitere glattschalige Ostrakoden aus dem Lias von Thüringen. - Z. geol. Wiss., $\underline{\mathbf{7}}(11):$ 1343-1361, 10 Abb., 2 Tab.; Berlin

[Eisenach-Nord, Apfelstedt bei Wechmar, Röhnberg b. Wandersleben]

OHerrig, Ekkehard (1980): Ostrakoden der Gattungen Ledalia und Pseudohealdia (Familie: Healdiidae HARLTON) aus dem Lias von Thüringen. - Z. geol. Wiss., $\underline{8}(12):$ 1539-1551, 9 Abb., 1 Taf.; Berlin [Röhnberg b. Wandersleben]

QHerrig, Ekkehard (1981): Die Gattung Ogmoconcha TRIEBEL, 1941 (Ostracoda) im Lias von Thüringen. - Z. geol. Wiss., 9 (2): 207-219, 1 Abb., 3 Taf.; Berlin

[Eisenach-Nord, Röhnberg b. Wandersleben]

QHerrig, Ekkehard (1981): Die Ogmoconchella-Arten (Ostracoda) im Lias von Thüringen. - Z. geol.

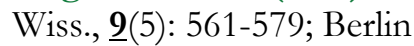

[Eisenach-Nord, Apfelstedt bei Wechmar, Röhnberg b. Wandersleben]

QHerrig, Ekkehard (1981): Die polycopen Ostrakoden aus dem thüringischen Lias. - Z. geol. Wiss., 9(6): 675-696, 4 Abb., 5 Taf.; Berlin

[Eisenach-Nord, Apfelstedt bei Wechmar, Röhnberg b. Wandersleben] 
QHerrig, Ekkehard (1981): Ostrakoden aus dem Lias von Thüringen - Die Familien Bythocyteridae, Glorianellidae und Cytheruidae (I). - Z. geol. Wiss., 9 (8): 871-887, 5 Abb., 2 Taf.; Berlin [Eisenach-Nord, Apfelstedt bei Wechmar, Röhnberg b. Wandersleben]

OHerrig, Ekkehard (1981): Ostrakoden aus dem Lias von Thüringen - Die Familie Cytheruidae (II) und die Gattungen Acrocythere, Dominocythere und Aphelocythere. - Z. geol. Wiss., $\underline{\mathbf{9}}(9)$ : 1017-1029, 1 Abb., 2 Tab.; Berlin

[Eisenach-Nord, Apfelstedt bei Wechmar, Röhnberg b. Wandersleben]

QHoffmann, Karl (1941): Revision einiger Ammoniten aus dem Lias alpha3 (Arietenstufe) vom Seeberg bei Gotha. - Zbl. Mineral. etc., Abt. B, 1941: 142-148; Stuttgart

Referat in: N. Jb. Mineral. etc., Referate, 1942 (Bd. III): 118-119 (Jaworski); Stuttgart

-Hornstein, F. F. (1902): Belegmaterialien zur Geologie der Umgebung von Cassel. - Z. dt. geol. Ges., 54: 118-121 (Verhdlgn.), 1 Abb.; Berlin

[Fossilien d. Lias, (Basalte), Buntsandstein m. Thierfährten v. Karlshafen]

OKrause, Torsten (1999): Das „Belemniten-Schlachtfeld“ aus dem Oberen Lias vom Röhnberg bei

Wandersleben (Thüringer Mulde). - Veröff. Naturkundemuseum Erfurt, Naturwiss. Rh., 18: 49-56, 3 Taf.; Erfurt

QKrause, Torsten (2001): Zwei bemerkenswerte Ammonitenfunde aus dem Unteren Jura der Thüringer Mulde. - Veröff. Naturkundemuseum Erfurt, Naturwiss. Rh., 20: 23-26, 3 Abb.; Erfurt

OLange, W. (1939): Revision der Ammoniten aus dem Lias alpha1 (Psilonotenschichten) von Coburg und Gotha, nebst Bemerkungen über den Lias beta von Gotha. - Zbl. Mineral., Abt. B., 1939: 463477; Stuttgart

Referat in: N. Jb. Mineral. etc., Referate, 1940 (Bd. III): 504-505 (Jaworski); Stuttgart

-Lange, Werner (1941): Die Ammonitenfauna der Psiloceras-Stufe Norddeutschlands. Palaeontographica, Reihe A, 93: 1-192, Taf. I-XX; Stuttgart

Fundorte u. a. Göttingen u. Rosdorf bei Göttingen]

OLangenhan, A[1win] (1883): Die Versteinerungen des Lias am großen Seeberge bei Gotha. Nach der Natur gezeichnet und autographiert, sowie mit einem Profil der Ablagerungs-Verhälntisse versehen.... - 4 S. o. Zählg., davon 2 S. Tafelerklärung, Taf. I-V; Breslau - Nachgewiesen in:

Forschungsbibliothek Gotha

OLangenhan, A[1win] (1884): Foraminiferen, Radiolarien etc. aus dem Lias Mergel des großen Seeberges bei Gotha. - Nach dem Mikroskop gezeichnet und autographiert.... - 1 Bl. handschriftl. Tafelerläut., 3 Taf.; Breslau - Nachgewiesen in: Forschungsbibliothek Gotha

OLangenhan, A[1win] (1885): Ueber Foraminiferen aus dem Lias des grossen Seeberges bei Gotha. Jber. Schles. Ges. f. vaterländ. Cultur, 2: 249-252 [Vortragstext]; Breslau

-Langheinrich, Gunter (1966): Syndiagenetische Fossildeformation im unteren Lias (Hettangium) von Göttingen. - N. Jb. Geol. Paläont., Mh., 1966: 666-680, 5 Abb.; Stuttgart

OMüller, Wolfgang (1962): Die Liasablagerungen am Seeberg bei Gotha. - Der Aufschluß, 13(10): 245247, 2 Abb.; Göttingen

OMüller, Wolfgang (1967): Die Fischfauna aus dem Lias epsilon von Wechmar (Kreis Gotha). - Abh. Ber. Museums d. Natur Gotha, [4] 1967: 3-8, 7 Abb.; Gotha

OPietrzeniuk, Erika (1961): Zur Mikrofauna einiger Liasvorkommen in der Deutschen Demokratischen Republik. - Freiberger Forschungshefte, Reihe C, $\underline{\mathbf{1 1 3}}$, S. 1-129, 21 Bilder, 5 Tab., 15 Tafeln; Leipzig [darin: Lias in Thüringen: Eisenach, Gotha] 
OPutzer, H. (1938): Die Planorbis-Zone am Großen Seeberg bei Gotha. - Zbl. Mineral. etc., Abt. B, $\underline{12}$ : 475-486, 5 Abb.; Stuttgart

[Paläontologie/Fauna Jura-Schichten]

-Rabitz, Gisela (1961): Foraminiferen des Göttinger Lias. - Paläont. Z., 37(3/4): 198-224, 2 Taf. (16,17); Stuttgart - auch als Diss. Univ. Göttingen 1961; 154 S., 5 Taf.

-Rachimow, Nadine (2007): Lithofazies und Foraminiferen-Assoziationen der Unterjura-Sedimente der Tongrube Hottenrode, Hessen. - Bachelor-Arbeit (unveröff.) Univ. Göttingen 2007, 49, IV Bl. [Hottenrode > Landkreis Göttingen, Niedersachsen]

-Rettberg, Herbert (1991): Die Foraminiferen-Fauna der Wasserbohrung Milchhof Göttingen aus dem Lias. - Dipl.-Arb. [unveröff.] Univ. Göttingen; 111 S., 9 Taf., 4 Anl.

OSteinmann, G. (1886): Das Leptaenbett bei Gotha. - N. Jb. Mineral. etc., 1886(Bd. II): $81-82$ (Briefl. Mitt.); Stuttgart

\subsubsection{Tertiär}

OAmthor, R. (1906): Reste tertiärer Ablagerungen nördlich von Gotha. - Z. f. Naturwiss., 78(1/2): 109112; Leipzig

[Marine, oberoligozähe Conchylien als Aufarbeitungsmaterial in Schmelzwasserablagerungen von Westhausen]

$\square$ Anonym (1910): < Fossile Tierknochen in einem Steinbruch bei Oberhone gefunden]. - Eschweger Tageblatt, 1910; Nr. 30 v. 5.2.1910; Eschwege

$\square$ Anonym (1910): < Deutung der fossilen Tierknochenfunde bei Oberhone]. - Eschweger Tageblatt, 1910; Nr. 36 v. 12.2.1910; Eschwege

[Deutung als Reste eines tertiärzeitlichen Pferdes]

-Baatz, Henning (1958): Ophiomorpha LUNDGRUN, ein marines Spurenfossil, im Oberen Quarzitsand Niederhessens. - Notizbl. Hess. L.-A. Bodenforsch., 87: 168 - 171; Wiesbaden

- Bartenstein, Helmut (1958): Alttertiäre Mikrofaunen aus dem Reinhardswald, ein Beitrag zur Frage der Südverbreitung marinen Prä- Mitteloligozäns. - Notizbl. Hess. L.-A. Bodenforsch., 무: 269 - 280, 1 Abb., 2 Taf. (17,18); Wiesbaden

-Bartenstein, Helmut (1959): Neue mikropaläontologische Beobachtungen zu den Tertiärvorkommen des Reinhardswalds und benachbarten Bramwaldes. - Notizbl. Hess. L.-A. Bodenforsch., 87: 367-375, 1 Abb., 1 Taf.; Wiesbaden

OBraun, v. (1869): Beschreibung antediluvialer Knochen und Zähne, die bei dem Bau der GothaLeinefelder Eisenbahn aufgefunden wurden. - Z. gesammt. Naturwiss., $\underline{\mathbf{3}}$ (5/6): 463-465; Berlin

-Brosius, Marita (1963/64): Plankton aus dem Nordhessischen Kasseler Meeressand (Oberoligozän). Z. dt. geol. Ges., 114: 32-56, 2 Abb., 8 Tab., 8 Taf.; Hannover

- $\square$ David, L; Mongerau, N.; Pouyet, S. \& Ritzkowski, S. (1968): Les Bryozoaires du Chattien de la région de Kassel. Atti della Società Italiana di Scienze Naturali e del Museo Civico di Storia Naturale in Milano, 108: 327-344, 2 Abb.; Milano

[Vorlage nicht eingesehen, zitiert nach Kupfahl (1981)] 
-Deutsch, Brigitte (1995): Die Seekuh (Sirene) von Schauenburg-Hoof. - Jahrbuch Lkr. Kassel, 1996 (24. Jg.): 93, 7 Abb.; Kassel

$\square$ Dunker, [Wilhelm] (1853): Ueber die in der Braunkohlen-Formation von Gross-Almerode in neuerer Zeit entdeckten Süsswasser-Mollusken. - N. Jb. Mineral. etc., 1853: 751 (Auszüge aus: Progr. Höhere Gewerbeschule i. Cassel, z. Michaelis, 1953, S. 2-18); Stuttgart

$\square$ Dunker, Wilhelm (1854): Über die in der Braunkohlenformation von Großalmerode in neuerer Zeit entdeckten Süßwassermollusken. - Studien Göttingischen Vereins bergmänn. Freunde, $\underline{\mathbf{6}}$ : 268-285; Göttingen

$\square$ Dunker, Wilhelm (1863/1864): Über die im plastischen Thone von Grossalmerode vorkommenden Mollusken. - Palaeontographica, $\underline{\mathbf{9}}$ (Textbd.): 86-90; Taf. XVI (Atlas-Bd.); Kassel

- $\square$ Faupel, Myrsini (1975): Die Ostrakoden des Kasseler Meeressandes (Oberoligozün) in Nordhessen. Göttinger Arb. Geol. Paläont., 17; 77 S., 3 Abb., 1 Tab., 13 Taf.; Göttingen [darin: Umgebung Kassel, Kaufungen, Gudensberg, Glimmerode]

-Fichter, Jürgen (1999): Die fossile Seekuh von Schauenburg-Hoof, Kreis Kassel - Ein bemerkenswerter Wirbeltierfund aus dem Alttertiär Nordhessens. - Paläontologische Denkmäler in Hessen, $\underline{8}$; [15] S., [9] Abb.; [1] Kt.; [Hrsg. Abt. Archäologische u. Paläontologische Denkmalspflege i. Landesamt f. Denkmalpflege Hessen, Archäologische Gesellschaft i. Hessen e.V.] Wiesbaden

-Gaudant, Jean (1995): Mise au point sur les poissons Cyprinidae miocènes du Habichtswald, près de Cassel (Hesse, Allemagne). - A restatement on the Miocene cyprinid fishes from the Habichtswald near Cassel (Hesse, Germany). -N. Jb. Geol. Paläont., Mh., 1995(6): 363-374, 6 fig.; Stuttgart [Fisch-Fossilien im miozänen „Polierschiefer“ des Habichtswaldes]

-Görges, Julius (1952): Die Lamellibranchiaten und Gastropoden des oberoligozänen Meeresandes von Kassel. - Abh. hess. L.-A. Bodenforsch., 4: 1-134, 3 Taf.; Wiesbaden

-Goerges, J. \& Gramann, F. (1957): Gastropoden und Lamellibranchiaten aus dem Melanienton von Borken (Niederhessische Senke). - Notizbl. Hess. L.-A. Bodenforsch., 포: 53-61, Taf. 4; Wiesbaden

-Gramann, F. (1956): Schildkröten aus dem Melanienton von Borken (Niederhessische Senke). Notizbl. Hess. L.-A. Bodenforsch., 84: 16-20, 1 Abb., Taf. 3; Wiesbaden

-Gramann, F. (1958): Der Crocodilide Diplocynodon hantoniensis (WOOD) aus dem unteroligozänen Melanienton Niederhessens. - Notizbl. Hess. L.-A. Bodenforsch., 86: 77-78, Taf. 8; Wiesbaden [Fundort: Borkener Senke]

-Gregor, Hans-Joachim; Micklisch, N. [Beitr.]; Oschkinis, V.[Beitr.]; Thewalt, U. [Beitr.]; Vavra, N. [Beitr.] (2005): Pflanzen und Tiere aus den eozänen Braunkohlen des Untertagebaues Stolzenbach bei Kassel. - Philippia, 12(2): 147-181, 36 Abb., 2 Tab.; Kassel

-Gürs, Karl (1992): Zwei neue Polyplacophorenarten (Mollusca) aus marinen Küstenablagerungen des Mainzer Beckens und der Kasseler Bucht. - Geol. Jb. Hessen, 120: 5-9, 1 Abb., 1 Taf.; Wiesbaden

-Hartmann, Curt (1975): Fossilfunde im Landkreis Kassel. - Jb. Lkr. Kassel, 1976: 87 - 89, 3 Abb., 2 Taf. m. 9 Abb.; Kassel

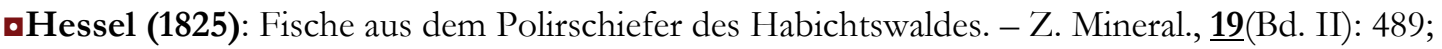
Frankfurt/M.

-Holtz, Siegfried (1961): Sporen und Pollen im marinen Mitteloligozän des Ahne-Tales (Blatt KasselWest). - Notizbl. Hess. L.-A. Bodenforsch., 모: 73 - 84, 2 Tab., 2 Taf.; Wiesbaden 
-Holtz, S. (1962): Sporenstratigraphische Untersuchungen im Oligozän von Hessen. - Abh. hess. L.-A. Bodenforsch., $\underline{40}$; 46 S., 1 Abb., 6 Taf.; Wiesbaden [darin: Umgebung Kassel]

-Hornstein, F. (1889): Ueber eisenschüssige thonigsandige Knollen mit Petrefakten aus den oligozänen Sanden vom Gelben Berge bei Niederkaufungen. - Ber. Vereins Naturkde. Kassel, 34/35: LVIII LIX; Kassel

$\square$ Huckriede, Reinhold \& Janssen, Ronald (1973): Euryhaline Mollusken im älteren Chattium („Kasseler Meeressand“) von Glimmerode in Niederhessen. - Geol. et Paläont., 7: 189-202, 3 Taf.; Marburg

$\square$ Janssen, Ronald (1977): Die Scaphopoden und Gastropoden des Kasseler Meeressandes von Glimmerode (Niederhessen). - Geol. Jb., Reihe A, 41; 195 S., 3 Abb., 3 Tab., 7 Tafl; Hannover

- $\square$ Janssen, Ronald (1979): Revision der Bivalvia des Oberoligozäns (Chattium, Kasseler Meeressand). Geol. Abh. Hessen, 푸; 181 S., 1 Abb., 4 Taf.; Wiesbaden

-Jugler (1844): Tertiäre Reste im Hannoverschen [Briefl. Mitt.]. - N. Jb. Mineral. etc., 1844: 459 - 460; Stuttgart

[Fossilien von Hann.-Münden/Lutterberg]

-Kaever, Matthias \& Meiburg, Peter (1975): Arenoparella hagni, eine neue Forminifere aus dem jüngsten Oligozän des Reinhardswaldes (Nordhessen) - (Das Nordwestdeutsche Tertiärbecken). Paläont. Z., 49: 24-34, 1 Abb., Taf. 3-4; Stuttgart [Profil am Gahrenberg]

-Kayser, E. (1893): Über die Fauna des hessischen Mitteloligocäns. - Z. dt. geol. Ges., 47: 595-596 (Mber.); Berlin

Referat in: N. Jb. Mineral. etc, 1896 (Bd. II): 334 (v. Koenen); Stuttgart

- Landgrebe (1840): Ein im Basalt-Konglomerat des Habichtswaldes aufgefundenes Sprungbein von Dorcatherium naui KAUP’s. - N. Jb. Mineral. etc., 1840: 307-313; Stuttgart

- Landgrebe (1843): Ein im Polirschiefer des Habichtswaldes aufgefundener Käfer. - N. Jb. Mineral. etc., 1843: 137-142; Stuttgart

-Ludwig, Rudolph (1865): Fossile Conchylien aus den tertiären Süsswasser- und MeerwasserAblagerungen in Kurhessen, Grossherzogthum Hessen und der Bayer`schen Rhön. Palaeontographica, 14: 40-97, 13 Taf.; Stuttgart

-Martin, Erlend (1987): Nannoplankton aus dem nordhessischen Melanienton und von Sieblos/Rhön (Unter-Oligozän). - Geol. Jb. Hessen, 115: 161-169, 1 Abb., 1 Tab., 1 Taf.; Wiesbaden [darin: Borken]

-Mayer (1837): Infusorien im Polierschiefer vom Habichtswald. - N. Jb. Mineral. etc., 1837: 108; Stuttgart

$\square$ Menzel, Herbert (1983): Die Otolithen einiger oligozäner Vorkommen vorwiedend aus dem Kasseler Meeressand (Oberoligozän). - Geol. Jb. Hessen, 11: 5-45, 2 Abb., 3 Tab., 6 Taf.; Wiesbaden [darin: Glimmerode/Höllberg]

-Mötzing, Kurt (1972): Die „Schlangenzungen“ im Ahnatal bei Kassel. - Hessischer Gebirgsbote, $\underline{73}(2)$ : 32; Melsungen

[„Schlangenzungen“ - Fossile Haifischzähne des Tertiärs] 
-Münster, G. Graf von (1835): Bemerkungen über einige tertiäre Meerwasser-Gebilde im nordwestlichen Deutschland zwischen Osnabrück und Cassel. - N. Jb. Mineral. etc., 1835: 420-451; Stuttgart [Stratigraphie, Paläonotologie, auch Bibliographie u. Erforschungsgeschichte]

-Naumann, Peter (1993): Opiomorpha ein Superfossil im „Kasseler Meeressand“. - Hessischer Gebirgsbote, 94(4): 161; Melsungen [Spurenfossilfund von Immenhausen, Lkr. Kassel]

$\square$ Pflug, H.-D. (1966): Zur Stratigraphie des mittleren Tertärs in Hessen und in benachbarten Gebieten. Notizbl. Hess. Landesamtes Bodenforschung., 94: 259-268, 2 Abb., 1 Tab.; Wiesbaden Palynologische Untersuchungen; Braunkohlen u.a. Oberkaufungen 4723 Oberkaufungen, Grube Hirschberg 4724 Großalmerode, Grube Glimmerode 4824 Hessisch Lichtenau]

-Phillipi, R. A. (1841): Über die Tertiär-Versteinerungen der Wilhelmshöhe bei Cassel. - N. Jb. Mineral. etc., 1841: 613-614 (Auszug Programm höheren Gewerbeschule i. Cassel, 1841/1842: 1-32; Cassel) Stuttgart

- $0 \square \bullet$ Schlotheim, [Ernst Friedrich] v. (1820): Die Petrefactenkunde auf ihrem jetztigen Standpunkte durch die Beschreibung seiner Sammlung versteinerter und fossiler Überreste des Thier- und Pflanzenreichs der Vorwelt erläutert. - 436 S., sep. Tafelbd. M. 15 Taf.; 2 Bd. Nachträge 1822, 1823 m. sep. Tafelbd., 21 Taf.; (Becker) Gotha

[Sammlungsverzeichnis, kein Lehrbuch; S. 386 Versteinertes Holz aus dem Schwalbenthaler Stollen am Meißner; S. 399ff Paläobotanische Funde aus dem Thüringer Wald; S. 389ff Blattfunde Burgtonna, Habichtswald, Kalktuff Hainberg b. Göttingen]

- Speyer, Oskar (1862-1870): Die Conchylien der Kasseler Tertiärbildungen. -

- - Palaeontographica, 9 (3. Lfg.): I. S. 91-141, Taf. 18-22.; Kassel 1862-1864

- - Palaeontographica, 9 (5. Lfg.): II. S. 153-198, Taf. 30-34; Kassel 1862-1864

- - Palaeontographica, $\underline{\mathbf{1 6}}$ (4./5.Lfg.): III. S. 175 - 218, Taf. 16-24; Kassel 1867

- - Palaeontographica, $\underline{\mathbf{1 6}}$ (7. Lfg.): IV. S. 297-339, Taf. 31-35; Kassel 1869

- - Palaeontographica, 19 (4. Lfg.): V. S. 47-101, Taf. 10-15; Kassel 1870

- - Palaeontographica, 19 (4. Lfg.): VI. S. 159-202, Taf. 18-21; Kassel 1870

aSpeyer, Oskar (1863): Die fossilen Ostracoden aus den Casseler Tertiärbildungen. - Ber. Vereins Naturkde. z. Kassel, $\underline{12}$ (1860/1861, 1861/1862): 1-62, 4 Taf.; Kassel

- $\square$ Speyer, Oskar (1884): Die Bivalven der Casseler Tertiärbildungen - Mit einem Vorwort und Tafelerklärungen von A. v. Koenen. - Abh. Geol. Spec.-Kt. Preuss u.d. Thüringischen Staaten, 4(4); XII, 31 Taf.; (Schropp) Berlin

Referat in: N. Jb. Mineral. etc., $\underline{1885}$ (Bd. 2): 196 (Referat A. v. Koenen); Stuttgart

[darin: Grossalmerode, Kaufungen, Ahnetal b. Kassel]

-Tobien, H. (1961): Säugetierpaläontologische Daten zur Alterstellung des Hessischen Melanientons. Z. dt. geol. Ges., 112: 590; Hannover [Bezug auf Hessische Senke, Reg. Kassel]

-Weiler, Wilhelm (1961): Die Fischfauna des unteroligozänen Melanientons und Rupeltons der hessischen Senke. - Notizbl. Hess. L.-A. Bodenforsch., 모: 44-65, 2 Taf.; Wiesbaden [darin: Beschreibungen Funde d. Borkener Senke] 


\subsubsection{Quartär}

-Althaus (1846): Trogentherium in einer Höhle bei Rothenburg [Rotenburg/Fulda]. - N. Jb. Mineral. etc., 1846: 711-712 (Briefl. Mitt.); Stuttgart

$\square$ Anonym (1913): < Diluviales Hirschgeweih in einer Sandgrube bei Unterrieden gefunden $>-$ Eschweger Tageblatt, 1913; Nr. 91 v. 19.04.1913; Eschwege

QAnonym (1921): <Mammutstoßzahn bei Bauarbeiten in der Nähe von Großburschla gefunden]. Eschweger Tageblatt, 1921; Nr. 106 v. 9.5.1921; Eschwege

$\square$ Anonym (1923): < Mammutstoßzahn bei Umbauarbeiten an der Schleuse Eschwege gefungen]. Eschweger Tageblatt, 1923; Nr. 76 v. 31.3.1923; Eschwege

- $\square$ ○ीApel, Jürgen \& Rüppel, Heidi [Verfass. u. Hrsg.] (2005): Raus in die Natur - Tipps für den Sonntags-Ausflug im Dreiländereck Hessen - Niedersachsen - Thüringen. - 159 S., 111 Fotos, 34 Kt., 1 Zeit-Taf.; (LSRB-Verlag, Landschaftskundlicher-Studien-Reisebuch-Verlag) Witzenhausen [zahlreiche Ausflugstipps, auch zu Fossilfundstätten: Ziel 77 (Quartäre Säugetierfunde - ZechsteinDolinen Oberhone]

-Bismarck, Wolfram (1954): Faunistische Funde im Bilshäuser Becken. - Die Goldene Mark, $\underline{\mathbf{5}}$ (JanuarH.): 12-18; Duderstadt

[Quartär-Paläontologie]

QBraun, v. (1869): Beschreibung antediluvialer Knochen und Zähne, die bei dem Bau der GothaLeinefelder Eisenbahn aufgefunden wurden. - Z. gesammt. Naturwiss., 33(5/6): 463-465; Berlin

-Bringmann, Hermann (1973): Die Bedeutung Bilshausens für die internationale geologische und paläontologische Forschung. - Eichsfelder Heimatstimmen, 17(7)/1973(Juli): 218-220; Duderstadt [Tongrube i. „Bilshäuser Becken“; Bilshausen/Untereichsfeld]

oClaus, H. (1958): Ein neuer Splintkäfer (Scolytus tiburtinus n. sp.) aus dem Diluvialtravertin Nordwestthüringens (Coleoptera: Scolytidae). - Beitr. z. Entomologie, $\underline{8}(5 / 6)$ : 710-716, 2 Textfig.; Berlin [Vorkommen „An der Klippe“ bei Mühlhausen] Referat (H. Weber) in: Hallesches Jb. mitteldt. Erdgeschichte, 4: 114-115; Halle

oClaus, Hans (1964): Vinca cf. major L. im Travertin von Mühlhausen in Thüringen und ihre klimatologische Bedeutung. - Geologie, $1 \mathbf{3}$ (9): 1147-1149, 2 Abb.; Berlin

QCredner (1869): Lagerstätten diluvialer Knochen bei Gotha. - Z. gesammt. Naturwiss., $\underline{33}(5 / 6)$ : 517; Berlin [Elephant, Rhinoceros]

QDiebel, K. \& Pietrzeniuk, E. (1975): Ostracoden aus dem holozänen Travertin von Bad Langensalza. - Quartärpaläontologie, 1: 27-55, 4 Abb., 6 Taf.; Weimar

QDiebel, Kurt \& Pietrzeniuk, Erika (1975): Neue Ostracoden aus dem Pleistozän von Burgtonna (Bezirk Erfurt): Tonnaecypris gen. N. und Amplocypris tonnensis sp. n. - Z. geol. Wiss., $\underline{\mathbf{3}}(1):$ 87-97, 4 Abb., 2 Taf.; Berlin 
ODiebel, Kurt \& Pietrzeniuk, Erika (1978): Die Ostracodenfauna des eeminterglazialen Travertins von Burgtonna in Thüringen. - Quartärpaläontologie, 3: 87-92, 3 Abb., 1 Tab., Taf. 23-26; (AkademieVerlag) Berlin

ODiebel, Kurt \& Pietrzeniuk, Erika (1978): Die Ostracodenfauna aus den jungpleistozänen (weichselkaltzeitlichen) Deckschichten von Burgtonna in Thüringen. - Quartärpaläontologie, $\underline{3}$ : 207 221, 7 Abb., 4 Tab., Taf. 49-53; (Akademie-Verlag) Berlin

OFehler, Andreas (1996): Ein fossiles Vogelei aus dem ober-pleistozänen Travertin von Burgtonna (Thüringen). - Abh. Ber. Museums d. Natur Gotha, (19) 1996: 99-101, 2 Abb.; Gotha

QFehler, Andreas (1999): Erster Nachweis von fossilen Schlammfliegenlarven (Mealoptera, Sialidae) aus dem altholozänen Travertin von Bad Langensalza/Thüringen. - Der Aufschluss, 50: 287-290, 3 Abb.; Heidelberg

-Fichter, J. [1985]: Das Eiszeitpferd „Equus germanicus“ von Kaufungen. - 15 S., Abb.; [Magistrat Stadt Kassel) Kassel [Separatdruck aus: Wroz, Winfried [Bearb.](1985): 975 Jahre Kaufungen - 1011 1986; Beiträge zur Heimatkunde. - 383 S., Abb.; (Gemeindevorstand) Kaufungen]

-Fichter, Jürgen (1985): Das Eiszeitpferd „Equus germanicus“ von Kaufungen. - In: Wroz, Wilfried u. a. [Bearb.]: 975 Jahre Kaufungen - 1011-1986 - Beiträge zur Heimatkunde. - 383 S., zahlr. Abb.; hier: S. 195-208, 7 Abb.; [Hrsg. Gemeindevorstand d. Gemeinde Kaufungen] Kaufungen 1985 - auch als Separatdruck

EFlerow, Constantin C. (1978): Die Bison-Reste aus den Travertinen von Burgtonna in Thüringen. Quartärpaläontologie, 3: 107- 111, 5 Abb.; (Akademie-Verlag) Berlin

QGuenther, Ekke W. (1978): Die Elefantenmolaren aus den Travertinen von Burgtonna in Thüringen. Quartärpaläontologie, ㅈ: 139 - 150, 8 Tab., Taf. 38-41; (Akademie-Verlag) Berlin

OHeinrich, Wolf-Dieter (1978): Biometrische Untersuchungen an fossilen Kleinsäugetieren aus einer jungpleistozänen Deckschichtenfolge über dem interglazialen Travertin von Burgtonna in Thüringen. - Quartärpaläontologie, ․․: 255 - 268, 20 Abb.; (Akademie-Verlag) Berlin

OHeinrich, Wolf Dieter (1979): Paläökologische und biotstratigraphische Untersuchungan an Mikromammalierfaunen aus dem Pleistozän von Ehringsdorf, Taubach und Burgtonna in Thüringen. - Diss. Humboldt-Universität Berlin; Berlin

OHeinrich, Wolf Dieter (1981): Systematische Zusammenstellung der in thüringischen Interglazialtravertinen von Burgtonna, Taubach und Weimar-Ehringsdorf nachgewiesenen Kleinsäugerarten. - Quartärpaläontologie, 4: 127-130; Berlin

QHeinrich, Wolf Dieter (1986): Zur Geschichte der Erforschung von fossilen Kleinsäugerfanen aus Interglazialtravertinen in Thüringen. - Quartärpaläontologie, ㅁ: 67-74; Berlin

oHeinrich, Wolf-Dieter (1987): Neue Ergebnisse zur Evolution und Biostratigraphie von Avicola (Rodentia, Mammalia) im Quartär Europas. - Z. geol. Wiss., 15(3): 389-406, 9 Abb.; Berlin [Avicola = Wühlmäuse; darin: Tambach, Burgtonna]

OHeinrich, Wolf D. \& Jànossy, Dénes (1973): Lagurus lagurus (PALLAS, 1773) (Rodentia, Mamalia) aus dem Jungpleistozän von Burgtonna (Bezirk Erfurt). - Z. geol. Wiss., 1 (5): 587-592, 2 Abb.; Berlin

QHeinrich, Wolf-Dietrich \& Jánossy, Dénes (1978): Nachweis von Anas platyrhynchos LINNEUS 1758 (Anatidae, Aves) aus dem Travertin von Burgtonna in Thüringen. - Quartärpaläontologie, $\underline{\mathbf{3}}$ : 103 105, 1 Abb., 1 Tab.; (Akademie-Verlag) Berlin 
QHeinrich, Wolf-Dieter \& Jánossy, Dénes (1978): Insektivoren und Rodentier aus dem Travertin von Burgtonna in Thüringen. - Quartärpaläontologie, $\underline{3}$ : 167 - 170, 6 Tab., Taf. 46-47; (Akademie-Verlag) Berlin

QHeinrich, Wolf-Dieter \& Jánossy, Dénes (1978): Fossile Vogelreste aus der jungpleistozänen Deckschichtenfolge über dem Travertin von Burgtonna in Thüringen. - Quartärpaläontologie, $\underline{3}$ : 227 - 229, 2 Abb., 1 Tab.; (Akademie-Verlag) Berlin

QHeinrich, Wolf-Dieter \& Jánossy, Dénes (1978): Fossile Vogelreste aus der jungpleistozänen Deckschichtenfolge über dem Travertin von Burgtonna in Thüringen. - Quartärpaläontologie, $\underline{3}: 227$ - 229, 2 Abb., 1 Tab.; (Akademie-Verlag) Berlin

QHeinrich, Wolf-Dieter \& Jánossy, Dénes (1978): Fossile Säugetierreste aus einer jungpleitozänen Deckschichtenfolge über dem interglazialen Travertin von Burgtonna in Thüringen. Quartärpaläontologie, ․ㅗ: 231- 254, 13 Abb., 19 Tab., Taf. 54-56; (Akademie-Verlag) Berlin

QHellmann, A. (1862): Die Petrefacten Thüringens nach dem Materiale des Herzogl. NaturalienKabinets in Gotha. - 1. Lfg.: Die Diluvialfauna von Tonna, Werningshausen und Wandersleben. Palaeontographica, Supplement, 1; 39 S., Taf. I-XXIV; (Fischer) Cassel

QHemmer, Helmut (1978): Die Feliden- und Canidenreste aus den jungpleistozänen Travertinen von Burgtonna in Thüringen. - Quartärpaläontologie, 3: 155 - 162, 4 Abb., 4 Tab., Taf. 44-45; (AkademieVerlag) Berlin

$\square$ Holtz, S. (1973): Das Quellmoor von Hausen am Meißner. - Nachr. Dt. Geol. Ges., 7: 51-52; Hannover [Palozoologie Quartär]

QHünermann, K. A. (1978): Das Wildschwein (Sus scrofa L.) aus dem Jungpleistozän von Burgtonna in Thüringen. - Quartärpaläontologie, $\underline{3}: 123$ - 127, 4 Abb.; (Akademie-Verlag) Berlin

$\square$ Jacobshagen, Eduard (1934): Fossile Reste der Mammut-Fauna aus Marburg und anderen Orten der Provinz Hessen-Nassau. - Sitzber. Ges. Beförderung d. ges. Naturwiss. z. Marburg, $\underline{\mathbf{6 8}}(1): 1$ 1-32, 26 Abb.; Marburg [darin: Wollnashorn von Grebendorf b. Eschwege, m. Zchng. Unterkiefer-Bruchstück]

-Jacobshagen, Eduard (1953): Die Gipsbrüche von Altmorschen und ihre eiszeitliche Tierwelt. - Hdb. d. Kreises Melsungen, 1954 (27. Jg.): 9 S (o. Zählg.), 4 Abb.; Melsungen

$\square$ Jacobshagen, Eduard (1956): Moschusochsenreste aus nordhessischen Pleistozän. - Notizbl. Hess. L.A. Bodenforsch., $\underline{84:} 7$ - 15, 2 Taf.; Wiesbaden [Fossilfund Werra-Aue, Bl. 4827 Treffurt]

OJordan, Hanspeter; Bernstorff, Ute \& Gründel, Joachim (1962): Die Ostracoden des älteren Travertins (Pleisozän) von Mühlhausen (Thür.). - Freiberger Forschungshefte, Reihe C, 125: 65-125, 26 Abb., 8 Tab., 9 Taf. (I-IX); Leipzig

口Kahlke, Hans-Dietrich (1978): Die Cerviden-Reste aus den Travertinen von Burgtonna in Thüringen. - Quartärpaläontologie, 3: 113 - 122, 6 Abb., Taf. 32-33; (Akademie-Verlag) Berlin

OKahlke, Hans-Dietrich (1978): Die Rhinocerotiden-Reste aus den Travertinen von Burgtonna in Thüringen. - Quartärpaläontologie, $\underline{\mathbf{3}}: 129$ - 135, 6 Abb., Taf. 34-37; (Akademie-Verlag) Berlin

QKahlke, Hans-Dietrich \& Maul, Lutz Chr. (2002): Pleistozäne Fossillagerstätten in Thüringen (Exkursionen H am 5. April 2002). - Jber. Mitt. Oberrhein. geol. Vereins, N.F., 84: 225 - 239, 6 Abb.; Stuttgart [Weimar-Ehringsdorf, Burgtonna] 
QKeiler, John-Albrecht (1995): Libellenlarvenreste (Odonata: Anisoptera) aus dem letztinterglazialen Travertin von Burgtonna/Thüringen. - Beitr. Geol. Thür., N.F., 2: 101 - 106, 2 Taf; Jena

$\square$ Keller, Th. (2000): Eschwege-Oberhone: Notbergung einer eiszeitlichen Säugetierfauna. Denkmalpflege \& Kulturgeschichte, 2000(1); S. 33/34; Wiesbaden

$\square$ Keller, Thomas (2000): Wollnashorn und Riesenhirsch in Nordhessen. - In: Archäologie in Deutschland, $\underline{16}(3)$ : 40; Ill.; Stuttgart

$\square$ Keller, Thomas \& Sander, Anne (2003): Das Rentier aus dem Gipsloch : eiszeitliche Säugetierfunde von Eschwege-Oberhone ; Paläontologie bei Eschwege, Werra-Meißner-Kreis. - Hessen-Archäologie, 2002 : 15-18; Wiesbaden

OKlett, Bernhard (1927): Die Conchylien diluvialer und alluvialer Schichten in Westthüringen - I. Die Cyrenenkiese Westthüringens. - Z. f. Naturwiss., 87: 49-64, 1 Abb. Halle/Saale

QKlett, Bernhard (1928): Die Conchylien diluvialer und alluvialer Schichten in Westthüringen - II. Die diluvialen Kalktufflager - III. Die alluvialen Kalktufflager. - Z. f. Naturwiss., 88: 58-148, 1 Tab.; Halle/Saale

QKnorre, Dietrich von (1978): Fossile Insektenreste aus letztinterglazialen Travertinen Thüringens. Quartärpaläontologie, 3: 93-95, Taf. 27-28; (Akademie-Verlag) Berlin

QKurtén, Björn (1978): Bären- und Hyänenreste aus dem Pleistozän von Burgtonna in Thüringen. Quartärpaläontologie, 조 151 - 153, 1 Abb., Taf. 42-43; (Akademie-Verlag) Berlin

- $\square$ OLandau, G. (1850): In Hessen aufgefundens urweltliche Tierreste. - Z. Vereins hess. Gesch. u. Landeskde., $\underline{\mathbf{5}}(3)$ : 307-308; Kassel

[Rhinoceros-Horn b. Treffurt, „Einhorn“ am Meißner; „Elephanten-Geriffel““ v. Dennhaussen b. Kassel]

OLangenhan, Alwin (19XX): Diluviale Süßwasserkalke bei Brüheim nordwestlich Gotha. - 3 S.; SeparatAbdruck a. Z. Mineral., Geol., Paläont., 1; Berlin [um 1900] - Nachgewiesen in: Forschungsbibliothek Gotha

OLindner, Andreas (1995): BURGTONNAER TIBURTINUM - Gedenkschrift anläßlich des 300jährigen Jubiläums von WILHELM ERNST TENZELs Streit mit dem Collegium medicum in Gotha über einen zu Tonna gefundenen Elefanten in den Jahren 1695/96. Rückblick auf die Forschungs- und Naturgeschichte einer thüringischen Travertinlagerstätte. - Beitr. Geol. Thür., N.F., 2: 107 - 134, 3 Abb., 2 Tab.; Jena

-Ludwig, Willi (1966): Knochen von Wollhaar-Nashorn. - Hessischer Gebirgsbote, 67(6): 66 - 67; Melsungen

[Fossilfund Gipssteinbruch Konnefeld Landkr. Hersfeld-Rotenburg/Schwalm-Eder-Kreis]

OMania, Dietrich (1978): Die Molluskenfauna aus den Travertinen von Burgtonna in Thüringen. Quartärpaläontologie, $\underline{3}$ : 69-85, 7 Abb., 2 Tab., Taf. 19-22; (Akademie-Verlag) Berlin

OMania, Dieter (1978): Zur Molluskenfauna aus der jungpleistozänen Deckschichtenfolge über dem Travertin von Burgtonna in Thüringen. - Quartärpaläontologie, 3: 203 - 205, 1 Tab.; (AkademieVerlag) Berlin

-Meischner, Dieter \& Schneider, Jürgen (1967): 500000 Jahre alter Steppenhirsch geborgen $<$ Fundort Becken v. Bilshausen, Lkr. Göttingen $>$. - Sonderdrurck aus: Deutsche Jägerzeitung, 22/1967, [7 S.], 2 Abb.; (Neudamm-Neudeck) Melsungen 
OMeyrick, Rich \& Maul, Lutz Christian (2003): Ausgrabungen in Burgtonna seit 300 Jahren. - Natur und Museum, $\underline{\mathbf{1 3 3}}(9)$ : 253-261, 9 Abb.; Frankfurt/M.

OMlynarski, M.; Böhme, G. \& Ullrich, H. (1978): Amphibien- und Reptilienreste aus der pleistozänen Deckschichtenfolge über dem Travertin von Burgtonna. - Quartärpaläontologie, $\underline{\mathbf{3}}$ : 223-226, 7 Abb.; (Akademie-Verlag) Berlin

OMusil, Rudolf (1978): Die fossilen Equiden-Reste aus den Travertinen von Burgtonna in Thüringen. Quartärpaläontologie, $\underline{3}: 137$ - 138, 1 Abb.; (Akademie-Verlag) Berlin

OPohlig, Hans (1885): Vorläufige Mitteilungen über das Pleistocän insbesondere Thüringens. - Z. f. Naturwiss., 58: 259-276; Berlin

[Paläontologie, Paläozoologie, u.a. Funde aus Westthüringen]

$\square$ Roatsch, Tilman (1991): Knochenfunde aus dem Werrakies bei Eschwege. - Der Aufschluss, 42 (1): 3946, 7 Abb.; Heidelberg

QSchäfer, H. F. (1909): Über die pleistocäne Säugetierfauna und die Spuren des paläolithischen Menschen von Burgtonna i. Thür. - Z. dt. geol. Ges., 61: 445-469(Abh.); Berlin

- 0 • Schlotheim, [Ernst Friedrich] v. (1820): Die Petrefactenkunde auf ihrem jetztigen Standpunkte durch die Beschreibung seiner Sammlung versteinerter und fossiler Überreste des Thier- und Pflanzenreichs der Vorwelt erläutert. - 436 S., sep. Tafelbd. M. 15 Taf.; 2 Bd. Nachträge 1822, 1823 m. sep. Tafelbd., 21 Taf.; (Becker) Gotha

[Sammlungsverzeichnis, kein Lehrbuch; S. 386 Versteinertes Holz aus dem Schwalbenthaler Stollen am Meißner; S. 399ff Paläobotanische Funde aus dem Thüringer Wald; S. 389ff Blattfunde Burgtonna, Habichtswald, Kalktuff Hainberg b. Göttingen]

OSchmidt, Leopold (1978): Der Biber (Castor fiber L.) aus dem Pleistozän von Burgtonna in Thüringen. Quartärpaläontologie, $\underline{3}: 163$ - 166, 1 Abb.; (Akademie-Verlag) Berlin

-Sohn, Heinz (1965): Ein Vorzeithirsch geborgen. - Die paläontologische Sensation des Jahres. Eichsfelder Heimatstimmen, 9(1)/1965(Januar): 3-6, 1 Abb.; Lingen/Ems [Paläont. Fund Tongrube Bilshausen/Untereichsfeld; des weiteren: Regionalgeologie des Eichsfeldes]

OSteiner, Ute (1978): Zur Problematik einiger Knochenfunde aus dem Travertin von Burgtonna in Thüringen. - Quartärpaläontologie, $\underline{3}: 179$ - 180, Taf. 48; (Akademie-Verlag) Berlin

øTentzel, Wilhelm Ernst (1696): Inhalt eines Lateinischen Schreibens an ... Herrn Antonio Magliabechi ... von dem zu Tonna ausgegrabenen Elephanten-Cörper / ausgefertigt von Wilhelm Ennst Tentzeln. - [6] Bl.; (Reyher) Gothae

[siehe Tentzel, Wilhelm Ernst (1696): Epistola de secleto elephantino tonnae nuper effoso, ad Antonium Magliabechium]

口'Tentzel, Wilhelm Ernst (1696): Epistola de secleto elephantino tonnae nuper effoso, ad Virum orbe deleberrimum Antonium Maglia-Bechium /Wilhelmi Ernestis Tentzelii. - Editio secunda correctior., [32] S.; (Bielcke) Jenae

QTentzel, Wilhelm Ernst (1696): Epistola de secleto elephantino tonnae nuper effoso, ad Antonium Magliabechium /Wilhelmus Ernestus Tentzelius. - 16 Bl.; (Reyher) Gothae

-Tobien, H. (1961): Ein Lophiodon-Fund (Tapiroidea, Mamm.) aus den niederhessischen Braunkohlen. - Notizbl. Hess. L.-A. Bodenforsch., 오: 7-16, 1 Abb., Taf. 1; Wiesbaden [Fundort: Grube Stolzenbach, Borkener Senke]

OUllrich, Herbert (1956): Fossile Sumpfschildkröten (Emy orbicularis L.) aus dem Diluvialtravertin von Weimar-Ehringsdorf, Taubach und Tonna (Thür.). - Geologie, $\underline{\mathbf{5}}$ (4/5): 360-385, 6 Abb., 4 Taf.; Berlin 
OUllrich, Herbert \& Mylnarski, Marian (1978): Reptilienreste aus dem jungpleistozänen Travertin von Burgtonna in Thüringen. - Quartärpaläontologie, $\underline{3}$ : 97 - 102, 1 Abb., Taf. 29-31; (Akademie-Verlag) Berlin

OViete, Günter [Hrsg.] (1962): „Das Pleistozän im sächsisch-thüringischen Raum“ - Exkursionsführer zur Herbsttagung 1962 vom 19. bis 21. Oktober 1962 in Leipzig und Erfurt - und Kurzreferate der Vorträge anläßlich des 2. Treffens der Sektion Quartärgeologie am 18. Oktober 1962 in Leipzig. [Exkursionsführer und Veröffentlichungen - Gesellschaft für Geologische Wissenschaften der DDR, 12]; 224 S., zahlr. Abb., Tab.; Berlin

-Weiler, W[ilhelm](1965): Die Fischfauna des interglazialen Beckentones von Bilshausen bei Göttingen. - N. Jb. Geol. Paläont., Abh., 123(2): 202-219, 19 Abb., 2 Taf. (21,22); Stuttgart

OWeiss, A. (1897): Über die Conchylienfauna der interglacialen Travertine (Kalktuffe) von Burgtonna und Gräfentonna in Thüringen. Eine revidierte Liste der bis jetzt dort nachgewiesenen Conchylien. Z. dt. geol. Ges., 49: 683-689 (Briefl. Mitt.); Berlin

\subsubsection{Paläobotanik}

\subsubsection{Paläozoikum}

-Althaus, J. (1851): Ueber einige neue Pflanzen aus dem Kupferschiefer von Richelsdorf. Palaeontographica, 1 (1.Lfg.): 30 - 33, Taf. 4, Tab.1 (Fig. 2); Kassel

OArnhardt, A. (1968): Paläobotanische Beobachtungen im Stefan und Rotliegenden des Thüringer Waldes. - Paläont. Abh., Reihe B, 2, H. 4: 751-761, 1 Abb., 3 Taf.; Berlin

OArnhardt, Alfred (1972): Tektonik, Stratigraphie und Flora des Stefan und Rotliegenden im Thüringer Wald. - Ber. Dt. Ges. geol. Wiss., Reihe A, 17(1): 81-100; Berlin

QBarthel, Manfred (1977): Die Gattung Dicranophyllum GR. Eury in den varistischen Innensenken der DDR. - Hall. Jb. f. Geowiss., 2: 73-86, 2 Abb., 20 Fotos; Gotha/Leipzig [Paläobotanik Stephan, Autun; darin: Funde Thüringer Wald]

OBarthel, Manfred (1980): Pecopteris-Arten E. F. v. SCHLOTHEIMs aus Typuslokalitäten in der DDR. - In: Rudolf Daber [Hrsg.]: Evolution/Naturgeschichte höherer Pflanzen. - Schriftenrh. geol. Wiss., 16: 275-304, 1 Abb., 8 Taf.; Berlin 1980

[darin: Funde a. d. Thüringer Wald - Manebach, Mordfleck]]

QBarthel, M. (1980): Pecopteris (Scolecopteris)-Arten aus dem Rotliegenden von Manebach in Thüringen. - Wiss. Z. Humboldt-Univ. Berlin, Math.-naturwiss. Rh., 29 (3): 351-366, 8 Taf.; Berlin

OBarthel, Manfred (1980): Calamiten aus dem Oberkarbon und Rotliegenden des Thüringer Waldes. In: Vent, Walter [Hrsg.]: 100 Jahre ARBORETUM BERLIN - Jubiläumsschrift zusammengestellt anläßlich des 100 Jährigen Bestehens des Arboretums des Museums für Naturkunde der HumboldtUniversität zu Berlin. - 364 S., 135 Abb., 12 Tab.; hier: S. 237-258, Abb. 90-97; (Akademie-Verlag) Berlin 1980

@Barthel, M. (1982): Klassische paläobotanische Sammlungen aus dem Thüringer Wald. - Gleditschia, 9: 45-55, 1 Taf.; Berlin [darin: Sammlungen von v. Schlotheim, Goethe, v. Sternberg, Mahr, H. Cotta] 
OBarthel, Manfred (1985): Johann Christian Mahr (1787-1869) - Goethes Fossiliensammler im Steinkohlevorkommen Manebach-Kammerberg. - In: Prescher, Hans [Hrsg.]: Leben und Wirken deutscher Geologen im 18. und 19. Jahrhundert. - 1. Aufl.; 388 S., 108 Abb.; hier: S. 162-182, 13 Abb.; (Dt. Verlag f. Grundstoffindustrie) Leipzig 1985

OBarthel, Manfred (1994): Von MYLIUS bis SCHLOTHEIM - Paläobotanische Sammlungen des 18. Jahrhunderts aus Manebach, Thüringer Wald. - In: Grote, Andreas [Hrsg.]: Macrocosmos im Microcosmos - Die Welt in der Stube. Zur Geschichte des Sammelns 1450-1800. - Berliner Schr. z. Museumskde., 10; 966 S., zahlr. Abb. - S. 707-720, 2 Abb.; (Leske \& Budrich) Opladen

OBarthel, Manfred (1999): „,.. zur Auffrischung meiner Berg- und Gesteinslust...“ - Goethe und die Pflanzenfossilien aus dem Thüringer Wald. - Veröff. Naturkundemuseum Erfurt, Naturwiss. Rh., 18: 21-48, 2 Abb., 10 Taf.; Erfurt

[Paläobotanik Rotliegendes]

OBarthel, Manfred (2001): Ambardtia scheibei (GOTHAN) HAUBOLD \& KERP und andere RotliegendPeltaspermaceen - Wege und Irrwege ihrer Erforschung. - Arnhardtia scheibei (GOTHAN) HAUBOLD \& KERP and other Rotliegend Peltaspermaceen. Paths and False Paths for their Investigations. Hallesches Jb. Geowiss., Reihe B, 23: 1-8, 6 Abb.; Halle [Paläobotanik - darin: Funde Thüringer Wald]

QBarthe1, Manfred (2003): Die Rotliegendflora des Thüringer Waldes. Teil 1: Einführung und Keilblattpflanzen (Sphenophyllales). - Veröff./ Naturhist. Museum Schleusingen, 18: 3-16, 15 Abb.; Schleusingen

OBarthel, Manfred (2004): Die Rotliegendflora des Thüringer Waldes. Teil 2: Calamiten und Lepidophyten. - Veröff./ Naturhist. Museum Schleusingen, 19: 19-48, Abb. 16-55 [+1 o. Zählg]; Schleusingen

QBarthel, Manfred (2005): Die Rotliegendflora des Thüringer Waldes. Teil 3: Farne. - Veröff./ Naturhist. Museum Schleusingen, 20: 27-56, Abb. 56-108; Schleusingen

QBarthel, Manfred; Mütze, Karl \& Simon, Rudolf (1975): Neue fossile Pflanzen aus dem Saale-Trog. Wiss. Z. Humboldt-Univ. Berlin, Math-Naturwiss. Rh., 24(4): 475-485, 1 Abb., 4 Taf.; Berlin [Paläbotanik Rotliegend, darin: Funde a. d. südl. Saale-Trog (Thüringer Wald)]

OBarthel, Manfred \& Haubold, Hartmut (1980): Zur Gattung Callipteris, Brgnt. - Teil I: Die Ausbildung von Callipteris enferta (STRBG.) BRONGNIART im mitteleuropäischen Rotliegenden. In: Rudolf Daber [Hrsg.]: Evolution/Naturgeschichte höherer Pflanzen. - Schriftenrh. geol. Wiss., 16: 49-105, 13 Abb., 15 Taf.; Berlin [Bezugn. a. Funde Thüringer Wald]

QBarthel, Manfred \& Kozur, Heinz (1981): Ein Callipteris-Vorkommen im Thüringer Wald. - (Beiträge zur Paläontologie, Stratigraphie und Palökologie - Zum 65. Geburtstag von Prof. Dr. rer. nat. habil Arno Hermann Müller) Freiberger Forschungshefte, Reihe C, 363: 27-41, 1 Abb., 5 Taf.; Leipzig [Paläobotanik; Fde. Goldlauter Schichten, Umgebung Zella-Mehlis]

OBarthel, Manfred \& Rößler, Ronny (1993): Calamiten im Oberrotliegend des Thüringer Waldes. Was ist „Walchia imbricata“? - Veröff./ Naturhist. Museum Schleusingen, 9: 69-80, 3 Abb., 2 Taf.;

Schleusingen

[Tambach-Formation]

QBarthel, Manfred \& Rößler, Ronny (1996): Paläontologische Fundschichten im Rotliegend von Manebach (Thür. Wald) mit Calamites gigas (Sphenophyta). - Veröff./ Naturhist. Museum Schleusingen, 11: 3-21, 15 Abb.; Schleusingen 
OBarthel, Manfred \& Rößler, Ronny (1997): Tiefschwarze Kieselstämme aus Manebach. - - Veröff./ Naturhist. Museum Schleusingen, 12: 53-61, 12 Abb.; Schleusingen

@Barthel, Manfred \& Riedel, Gerd-Rainer (2004): Die paläobotanische Rotliegend-Sammlung aus dem Thüringer Wald. - Veröff. Naturkundemuseum Erfurt, Naturwiss. Rh., 23: 5-12, 6 Abb.; Erfurt

OFulda, Ernst (1938): Ein Koniferenstamm aus dem älteren Kalilager (Oberer Zechstein) des Kaliwerks Bismarckhall bei Bischofferode. - Kali, etc., 32(1): 1 - 2, 2 Abb.; Halle/Saale

Referat in: N. Jb. Mineral. etc., Referate, 1938 (Bd. II): 200 (J. Leonhardt), 1938(Bd. III): 995

(Kräusel); Stuttgart

oGothan, Walter (1925): Neue Funde fossiler Flora aus Thüringen. - Z. dt. geol. Ges., 77: 251-252

(Monatsber.); Berlin

Referat in: N. Jb. Mineral. etc., Abt. B, 1926 (Bd. II): 265 (Kräusel); Stuttgart

[Friedrichroda, Manebach]

@Gothan, Walter (1928): Ueber Aequivalente der Wettiner Schichten im Thüringer Walde. - Z. dt. geol. Ges., $\underline{79}$ (f. 1927): 121-123 (Mber.); Berlin

Referat in: N. Jb. Mineral. etc., Referate, 1929 (Bd. III): 180-181 (Kräusel); Stuttgart

[Paläobotanik, Öhrenkammer b. Ruhla]

@Gothan, Walter (1934): Acer monspessulanum im Kalktuff von Burgtonna (Thüringen). - Sitzber. Ges. Naturforsch. Freunde z. Berlin, 1934: 285-288, 1 Abb.; Berlin

Referat in: N. Jb. Mineral. etc., Referate, 1936 (Bd. III): 200 (Kräusel); Stuttgart

QGothan, W. (1937): Zwei interessante Funde von Rotliegendpflanzen in Thüringen. - Jb. Preuß. Geol. Landesanst., $\underline{\mathbf{5 7}}$ (f. 1936): 507-513, Taf. 27-28, 29(1); Berlin Referat in: N. Jb. Mineral. etc., Referate, 1938 (Bd. III): 995 (Kräusel); Stuttgart

OGothan, Walter (1944): Das Thüringer Rotliegende und die Paläobotanik. - Beitr. Geol. Thür., $\underline{7}(4 / 5)$ : 227-233; Jena

OGothan, Walter \& Gimm, Otto (1930): Neuere Beobachtungen und Betrachtungen über die Flora des Rotliegenden in Thüringen. - Arb. a. d. Inst. f. Paläobotanik u. Petrographie d. Brennsteine, 2 (1): 3974, 2 Abb., Taf. 9; [Hrsg. Preuß. Geol. Landesanst.] Berlin

OGothan, W. \& Grimm-Elgersburg, O. (1952): Über die verkieselte Kohle des Manebacher Oberflözes. - Sitzber. Dt. Akad. Wiss. z. Berlin - Kl. f. Mathem. u. allgem. Naturwiss.; 1952(II); 13 S., 1 Taf.; Berlin

OHaubold, Hartmut (1980): Zur Gattung Callipteris Brongniart - Teil II. Indizien für nordamerikanische Callipteriden - Tinsleya, Yakia und Supaia - im Rotliegenden des Thüringer Waldes und der Innersudetischen Mulde. - Z. geol. Wiss., $\underline{\mathbf{8}}(6)$ : 747-767, 3 Abb., 4 Taf.; Berlin [Paläobotanik]

OHaubold, Hartmut (1983): Zur Gattung Callipertis BRONGNIART - Teil III. - Die sterile Befiederung von Callipteris naumanni (GUTBIER) STERZEL. - Z. geol. Wiss., 11(4): 465-481, 5 Abb., 1 Tab., 3 Taf.; Berlin

[Paläobotanik Rotliegendes Thüringer Wald]

OMartens, Thomas (1986): Ein neues Vorkommen von Callipteris scheibei GOTHAN im Rotliegenden des Thüringer Waldes - erste Ergebnisse. - Z. geol. Wiss., 14(6): 761-764, 1 Taf.; Berlin [Paläobotanik]

QHeß v. Wichdorf, Hans \& Gothan, Walter (1927): Zur weiteren Kenntnis der Steinkohlenlagerstätten im untersten Rotliegenden von Manebach in Thüringen. - Jb. Preuß. Geol. Landesanst., 47 (f. 1926): 
433-457, 2 Fig., Taf. 15-17; Berlin

Referat in: N. Jb. Mineral. etc., Abt. B, 1927 (Bd. II): 163-164 (Kräusel); Stuttgart

OHofmann, Elise (1942): Ein fossiles Holz aus dem Pliocän von Gerstungen im Werratale. - Beitr. Geol. Thür., ㅁ: 134-137, 1 Abb.; Jena

-Keller, Thomas (1997): Der Richelsdorfer Kupferschiefer: Fauna und Flora eines paläozoischen Schwarzschiefers im Landkreis Rotenburg/Fulda[!]. - Paläontologische Denkmäler in Hessen, 4; 16 S.; [Hsrg. Abt. Archäologie u. Paläontologische Denkmalpflege i. Landesamt f. Denkmalpflege Hessen, Archäologische Gesellschaft in Hessen e.V.] Wiesbaden

OLangenhan, A[1win] (1905): Flora und Fauna des Rotliegenden in der Umgebung von Friedrichroda in Thüringen. Mit einigen Textfiguren, einer Lichtdrucktafel nach Original-Zeichnungen, mit 12 vom Autor lithographierten Bildtafeln. - 12 S. o Zählg.; 12 Taf.; (Selbstverlag des Verfassers) Friedrichroda - Nachgewiesen in: Forschungsbibliothek Gotha

OLangenhan, A[1win] (1909): Fauna und Flora des Rotliegenden in der Umgebung von Friedrichroda. II. Teil mit 3. Taf. und begleitendem Texte (Nachträge). - 2 S. Tafelerläuterung o. Zählg., Taf. I-III, Ergänzungstafel IV; (Selbstverlag d. Verfassers) Friedrichroda Nachgewiesen in: Forschungsbibliothek Gotha

OLangenhan, A[1win] [um 1914]: Unteres Rotliegendes (Gehrener Schichten) aus dem Tunnel beim Bahnhof Mehlis. - 1 S. Tafelerläuterung, 2 Taf.; [ohne Ort] Nachgewiesen in: Forschungsbibliothek Gotha

OLangenhan, A[1win] (1914): Einzelfund eines Pflanzenfossils (Phycodes circinatum) bei Friedrichroda. - Monatsschr. f. Mineralien-, Gesteins- und Petrefaktensammler, $\underline{\mathbf{3}}(2)$ : 22-23; Rochlitz - [Vorlage nicht eingesehen]

-Namenskürzel (eb) (1964): Wertvoller Fund im Cornberger Sandsteinbruch. Erster Hinweis auf die Vegetation vor Jahrmillionen im Sontraer Land. - Werra-Rundschau, 1964; v. 30.1.1964, S. 5; Eschwege

$\square$ Reitz, Erhard (1989): Devonische Sporen aus Phylliten vom Südrand des Rheinischen Schiefergebirges. - Geol. Jb. Hessen, 117: 23-25, 4 Taf.; Wiesbaden [darin Kap.: Die phyllitischen Tonschiefer des Albunger Paläozoikums (Werra-Graunwackengebirge), S. 33-34, Taf. 4]

OPotonié, H. (1891): Pflanzenreste aus dem thüringer Rothliegenden. - Z. dt. geol. Ges., 43: 978-980 (Verhdlg.); Berlin

OPotonié, Henry (1893): Die Flora des Rothliegenden von Thüringen - (Übergeordneter Titel: Ueber das Rothliegende des Thüringer Waldes - Theil 2); Abh. Kgl. Preuß. Geol. Landesanst. u. Bergakad. N.F., 9; 298 S., 34 Taf.; Berlin

OPotonié, Henry (1903-1913): Abbildungen und Beschreibungen fossiler Pflanzenreste. - [Hrsg.] Kgl. Preuß. Geol. Landesanst. [u. Bergakademie]; Berlin [Funde aus dem Rotliegenden des Thüringer Waldes]

Lfg. I [1-20] 1903: (10) Pecopterois Candolleana ...; 6 S., 3 Abb. - Abb. 2A+B: Funde Manebach/Thür.

Lfg. II [21-40] 1904: (25) Odontopteris osmundaeformis (Schlotheim erweitert); 5 S., 2 Abb. - Abb. Funde Manebach u. Mordfleck

Lfg. II [21-40] 1904: (30) Linopteris Germori (Giebel)Potonié; 5 S., 4 Abb.; Abb. 1: Fd. ManebachKammerberg 
Lfg. III [41-60] 1905: (58) Sigilaria (Voltzi-Brongiart erweitert); 10 S., 19 Abb.; Abb. 1: Fd. Vogesen St. Pilt

Lfg. V [81-100] 1907: (85) Callipteris conferta; 18 S., 9 Abb.; (Walter Gothan); Abb. 3: Fd.

Ochsenwiese b. Breitenbach

Lfg. V [81-100] 1907: (86) Callipteris Jutieri; 4 S., 2 Abb.; (Walter Gothan); Abb. 1: Fd. Ochsenwiese b. Breitenbach

Lfg. V [81-100] 1907: (87) Callipteris Naumanni; 5 S., 3 Abb.; Abb. 2 (mehr. Fd. a. Thüringen)

Lfg. V [81-100] 1907: (95) Callipteris Scheibei; 2 S., 1 Abb.; (W. Gothan); Abb. Fd. Winterstein b. Brotterode

Lfg. V [81-100] 1907: (99) Aphlebia dissoluta; 6 S., 2 Abb.; Fd. Öhrenkammer b. Ruhla

Lfg. VI nicht Bestandteil der Auflistung von Artbeschreibungen

Lfg. VII (121-140) 1910: (135) Sphenophyllum Thoni; 6 S., 2 Abb.; (A. Zobel); Abb. 2: Fd. Ilmenau

Lfg. IX 8161-180) 1913): (176) Alethopteris subelegans; 3 S., 2 Abb.; (Fritz Franke); Abb. 1:

Öhrenkammer b. Ruhla

OReichardt, Wolfgang (1932): Zur Stratigraphie des Rotliegenden in Thüringen. - Jb. Halleschn Verb.

F..d. Erforsch. mitteldt. Bodenschätze u. ihre Verwert., N.F., 11: 121-184, 6 Abb., 3 Tab.; Halle (Saale)

Referat in: N. Jb. Mineral. etc., Referate; 1933 (Bd. III): 676 (Kräusel); Stuttgart

[S. 154-157 auch Paläobotanik]

- •Reitz, Erhard (1985): Palynologie der Trias in Nordhessen und Südniedersachsen. - Geol. Abh.

Hessen, $\underline{86}$; 36 S., 11 Abb., 11 Taf.; Wiesbaden

[Region Karlshafen/Northeim/Remlingen b. Braunschweig]

ORemy, Winfried (1953): Die Rotliegendflora Thüringens und ihre Stellung im Gesamtbild der PermKarbon-Flora. - Hallesches Jb. mitteldt. Erdgeschichte, $\underline{2}$ (Lfg. 1): 28-31; Halle (Saale)

ORemy, Wilfried (1954): Beiträge zur Kenntnis der Rotliegendflora Thüringens. Teil I: Zwei bisher unbekannte Pteridospermen-Fruktifikationen aus dem Thüringer Rotliegenden. - Sitzber. Dt. Akad. Wiss. z. Berlin - Kl. f. Mathem. u. allgem. Naturwiss.; 1953(I); 24 S., 4 Abb., 5 Taf.; Berlin

QRemy, Wilfried (1954): Beiträge zur Kenntnis der Rotliegendflora Thüringens. Teil II: Fruktifikationen. - Sitzber. Dt. Akad. Wiss. z. Berlin - Kl. f. Mathem. u. allgem. Naturwiss.; 1953(3); 20 S., 4 Abb., 4 Taf.; Berlin

口Remy, R. (1961): Beiträge zur Flora des Autunien III. - Monatsber. Dt. Akad. Wiss. z. Berlin, $\underline{\mathbf{3}}(9)$ : 331 336, 2 Taf.; Berlin

[Bezugn a. Funde: Crock, Thüringer Wald]

@Remy, Winfried \& Remy, Renate (1959): Pflanzenfossilien - Ein Führer durch die Flora des limnisch entwickelten Paläozoikums. - IX, 285 S., 209 Abb., 3 Taf., 2 Kt., 1 Portr.; (Akademie-Verlag) Berlin [Darin: Fossilfunde Thüringer Wald]

ORemy, W. \& Remy, R. (1960): Beiträge zur Flora des Autunien i.w.S. - Callipteris scheibei GOTHAN vor spinosa n. var. und Revision von Callipteris scheibei GOTHAN var. scheibei. - Monatsber. Dt. Akad. Wiss. z. Berlin, $\underline{\mathbf{2}}(9)$ : 567-582, 6 Taf.; Berlin [Bezugn. a. Funde: Oberhof/Thüringer Wald] 
QRemy, W. \& Remy, R. (1961): Beiträge zur Flora des Autunien II. - Monatsber. Dt. Akad. Wiss. z. Berlin, $\underline{\mathbf{3}}(3 / 4)$ : 213-225, 3 Abb., 4 Taf.; Berlin

[Fde. Crock, Gottlob-Stbr. b. Friedrichroda/Thüringer Wald]

ORemy, W. \& Remy, R. (1961): Beiträge zur Flora des Autunien IV. - Monatsber. Dt. Akad. Wiss. z. Berlin, $\underline{\mathbf{3}}(9)$ : 489-502, 1 Abb., 4 Taf.; Berlin

[Bezugn. a. Funde: Winterstein, Crock/Thüringer Wald]

ORemy, W.; Andreas, D. \& Kampe, A. (1963): Beiträge zur Kenntnis des Stephanien im Saaletrog. -Jb. Staatl. Museum Mineral., Geol., 1963: 115-146, 1 Abb., 1 Kt., 2 Tab.; 4 Taf.; Dresden [Bezugnahme a. Thüringer Wald; Floren des Stephanien, Biostratigraphie]

ORemy, Winfried. \& Remy, Renate. (1977): Die Flora des Erdaltertums - Einführung in die Morphologie, Anatomie, Geobotanik und Biostratigraphie der Pflanzen des Paläophytikums. - 468 S., zahlr. Abb.; (Glückauf) Essen

[darin: Fossilfunde Thüringer Wald]

OSamiez, Rainer (1980): Fossile Charophyten-Oogonien vom Siebleber Ried bei Gotha. - Abh. Ber. Museums d. Natur Gotha, (10) 1980: 33-39, Taf. 7; Gotha

OSchaarschmidt, F. (1960): Sporenanalytische Untersuchungen im Rotliegenden des Thüringer Waldes $<$ Vortragskurzfassung>. - Paläont. Z., 34: 11; Stuttgart [darin: Crock b. Eisfeld, „Öhrenkammer“ b. Ruhla]

OScheibe, R. (1890): Pflanzenreste und Thierfährten aus dem Rothliegenden von Tambach. - Z. dt. geol. Ges., 42: 364-365 (Mber.); Berlin Referat in: N. Jb. Mineral. etc, 1894 (Bd. II): 442-443 (Sterzel); Stuttgart

OSchirmer, Bodo (1969): Beitrag zur Kenntnis von Annularia spicata GUTBIER und Annularia galioides (L. \& H.) KIDSTON. - Geologie, 18(7): 844-861, 4 Abb., 1 Tab., 5 Taf.; Berlin

[Paläobotanik Präperm; Manebach, Pappenheim [heute: Kleinschmalkalden])

-0 $\bullet$ Schlotheim, [Ernst Friedrich] v. (1820): Die Petrefactenkunde auf ihrem jetztigen Standpunkte durch die Beschreibung seiner Sammlung versteinerter und fossiler Überreste des Thier- und Pflanzenreichs der Vorwelt erläutert. - 436 S., sep. Tafelbd. M. 15 Taf.; 2 Bd. Nachträge 1822, 1823 m. sep. Tafelbd., 21 Taf.; (Becker) Gotha

[Sammlungsverzeichnis, kein Lehrbuch; S. 386 Versteinertes Holz aus dem Schwalbenthaler Stollen am Meißner; S. $399 f f$ Paläobotanische Funde aus dem Thüringer Wald; S. 389ff Blattfunde Burgtonna, Habichtswald, Kalktuff Hainberg b. Göttingen]

OSchütze (1878): Ueber das angebliche Vorkommen der Sphenopteris distans in Manebach. - Verh. K.K. Geol. Reichsanst., 1878: 209-211; Wien [Paläobotanik]

OSolms-Laubach, H. Graf zu (1884): Die Coniferenformen des deutschen Kupferschiefers und Zechsteins. - Paläont. Abh., Bd. 2, H. 2; 38 S., 3 Taf.; (Reimer) Berlin Referat in: N. Jb. Mineral. etc., $\underline{1885}$ (Bd. 1): 348-351; Stuttgart [darin: I. Die Kornähren von Ilmenau]

OVoigt, Sebastian \& Rößler, Ronny (2004): Taeniopterid-type leaf fragments - the first record of macrophytic remains from the Eisenach Formation (Rotliegend, Permian, Thuringian Forest). Taeniopteride Blattfragmente - der Erstnachweis von Macrophytenresten aus der EisenachFormation (Rotliegend, Perm, Thüringer Wald). - Hallesches Jb. Geowiss., Reihe B, Beih., 18: 27-37, 3 fig., 2 pl.; Halle (Saale) 
QWeiss, E. (1881): Die verticale Verbreitung von Steinkohlepflanzen [im Rotliegenden]. - Z. dt. geol. Ges., 33: 176-181; Berlin

[Rotliegend von Crock/Thüringer Wald, Rotliegendbecken von Stockheim/Frankenwald]

\subsubsection{Mesozoikum}

-Brocke, Reiner (1987): Palynologische Untersuchungen im Oberen Muschelkalk und seinem Grenzbereich westlich Göttingen. - Geologische Teilkartierung auf Blatt 4425 Dransfeld zwischen Barterode und Imbsen. - Dipl.-Arb. [unveröff.] Univ. Göttingen 1987; II, 75,83 S.

○Cotta, B. (1834): Kalamiten-Reste im Keuper bei Eisenach.... - N. Jb. Mineral. etc., 1834(2): 210-(211) (Briefl. Mitt.); Stuttgart

$\square$ Götz, Annette E. (2000): Palynofacieas and sequence analysis of the Lower Muschelkalk (Middle Triassic, German Basin). - Zentralbl. Geol. Paläont. Teil 1, 1998(9/10): 877-891, 5 fig., 1 plt.; Stuttgart [Palynologische Untersuchungen am Profil der Ringgau-Bohrung]

$\square$ Götz, A. E. \& Feist-Burkhardt, S. (2000): Palynofacies and sequence analysis of the Lower Muschelkalk (Middle Triassic, German basin). - Zbl. Geol. Paläont., Teil I, 1998 (9/10,Vol. 2): 877891, 5 Abb., 1 Taf.; Stuttgart

[Bhg. Ringgau, Werra-Meißner-Kreis]

-Schlüter, Petra (1992): Palynologie des Rhät-Lias-Grenzbereichs im Neubaugebiet von Weende-Nord bei Göttingen. - Dipl.-Arb. [unveröff.] Univ. Göttingen 1992; 105 S.

OSchulz, Eberhard (1962): Sporenpaläontologische Untersuchungen zur Rhät-Lias-Grenze in Thüringen und der Altmark. - Geologie, 11(3): 308-319, 1 Abb., 1 Tab., 2 Taf.; Berlin [darin: Gr. Seeberg bei Gotha]

\subsubsection{Tertiär}

$\square$ Anonym (1920): <Verkieseltes Holz in der Braunkohle des Hirschberges bei Großalmerode]. Eschweger Tageblatt, 1920; Nr. 221 v. 22.9.1920; Eschwege

$\square$ Brosius, Marita (1959): Die Tertiärmulde von Glimmerode. - Hess. Lagerstättenarchiv, 4; 48 S., 17 Abb., 3 Tab., 5 Taf., 10 Anl.; Wiesbaden [Tertiär-Stratigraphie, Tektonik, Pollenanalytische Untersuchungen]

-Brosius, Marita \& Gramann, Franz (1959): Die stratigraphische Reichweite des Heskemer Pollenbildes in Borken (Tertiär, Niederhessen). - Z. dt. geol. Ges., 111: 182-197, 7 Abb., 3 Taf.; Hannover

-Gothan, Walter (1926): Die „Siegellackhölzer“ aus der Braunkohle von Volpriehausen bei Göttingen. Braunkohle - Z. f. Gewinnungen und Verwertung der Braunkohle, 24(46): 1002-1005, Abb. 331; Halle a.d. S.

Referat in: N. Jb. Mineral. etc., Abt. B, 1926 (Bd. II): 265 (Kräusel); Stuttgart

-Gregor, Hans-Joachim; Micklisch, N. [Beitr.]; Oschkinis, V.[Beitr.]; Thewalt, U. [Beitr.]; Vavra, N. [Beitr.] (2005): Pflanzen und Tiere aus den eozänen Braunkohlen des Untertagebaues Stolzenbach bei Kassel. - Philippia, 12(2): 147-181, 36 Abb., 2 Tab.; Kassel 
-Gregor, Hans-Joachim \& Oschkinis, Viktor (2005): Die eozänen Braunkohlenschichten aus dem Untertagebau Stolzenbach bei Kassel (PreußenElektra, Niederhessen)- II. Die Blattabdrücke. Nebentitel: Untertagebau Stolzenbach der PreussenElektra Niederhessen: Geologie - Paläophytologie - Mineralogie (Festband VIKTOR OSCHKINIS). - Documena naturae, 156: 27-65, 1 Tab.., 14 Taf.; München

-Gregor, Hans-Joachim \& Oschkinis, Viktor (2005): Die eozänen Braunkohlenschichten aus dem Untertagebau Stolzenbach bei Kassel (PreußenElektra, Niederhessen)- III. Die Frucht- und Samenflora. - Nebentitel: Untertagebau Stolzenbach der PreussenElektra Niederhessen: Geologie Paläophytologie - Mineralogie (Festband VIKTOR OSCHKINIS). - Documena naturae, 156: 67-93, 1 Tab.., 9 Taf.; München

-Holtz, Siegfried (1961): Sporen und Pollen im marinen Mitteloligozän des Ahne-Tales (Kassel-West). Notizbl. Hess. L.-A. Bodenforsch., 89: 73-84, 2 Tab., Taf. 12-13; Wiesbaden

-Holtz, Siegfried (1962): Sporenstratigraphische Untersuchungen im Oligozän von Hessen. - Abh. Hess. L.-A. Bodenforsch., $\underline{40}$; 46 S., 1 Abb., 6 Taf.; Wiesbaden [darin: Bhg. Ahnetal, Bhgn. KS-Niederzwehren W7, W9]

-Koritnig, Sigmund (1978): Ein verkieseltes Holz aus dem Tertiär des Druseltales. - Der Aufschluss, $\underline{29}$ : 426; Heidelberg [Habichtswald/Kassel]

-Kröninger, Brigitte (1991): Palynologische Untersuchungen an der miozänen Braunkohle von Ostheim (Nordhessen). - Dipl.-Arb. Teil II [unveröff.] Univ. Göttingen 1991; 123 S.

$\square$ Krutzsch, Wilfried (1962): Stratigraphisch bzw. botanisch wichtige neue Sporen- und Pollenformen aus dem deutschen Tertiär. - Geologie, 11(3): 265-307, 12 Abb., 10 Taf., 1 Tab.; Berlin [darin: Cupanieidites eucalyptoides n. fsp. - Funde aus Glimmerde/Hess. Lichtenau, WMK]

- $\square$ Krutzsch, Wilfried (1970): Einige neue Pollenformen aus den Familien der Tiliaceen, Bombaceen und Sterculiaceen aus dem mitteleuropäischen Alttertiär. - Jb. Geol., $\underline{\mathbf{3}}$ (f. 1967): 275-307, 2 Abb., 2 Tab., 7 Taf.; Berlin [darin aufgelistet Tab. 1 - Wichtige Fundorte: Borken/Hessen; Flötz 5 Glimmerode (Hessen)]

- $\square$ Kvaček, Zlatko \& Walther, Harald (1974): Bemerkenswerte und seltene cinnamomoide Blätter aus dem Grenzbereich des Oligo-Miozäns Mitteleuropas. - Abh. Staatl. Museums f. Mineralogie u. Geologie z. Dresden, 21: 197-221, 3 Abb., 1 Taf.; Dresden [Funde Habichtswald, Meißner]

-Lengtat, Karl Heinz (1989): Paläobotanische Untersuchungen eines Blattlagenhorizontes in der Ostheimer Braunkohle (Nordhessen). - Dipl.-Arb. Teil II [unveröff.] Univ. Göttingen 1989; 52 S.

@Mai, Dieter \& Walther, Harald (1988): Die pliozänen Floren von Thüringen, Deutsche Demokratische Republik. - Quartärpaläontologie, 7: 55-297, 101 Abb., 2 Tab, 41 Taf; Berlin [darin: Gerstungen]

OMai, Dieter \& Walther, Harald (1988): Die pliozänen Floren von Thüringen, Deutsche Demokratische Republik. - Quartärpaläontologie, 7: 55-297, 101 Abb., 2 Tab, 41 Taf; Berlin [darin: Gerstungen]

-Oschkinis, Viktor \& Gregor, Hans-Joachim (2005): Die eozänen Braunkohlenschichten aus dem Untertagebau Stolzenbach bei Kassel (PreußenElektra, Niederhessen)- I. Geologie und

Fundumstände - Nebentitel: Untertagebau Stolzenbach der PreussenElektra Niederhessen: Geologie - Paläophytologie - Mineralogie (Festband VIKTOR OSCHKINIS). - Documena naturae, 156: 1-25, 9 Abb., 5 Taf.; München 
- Schindehütte, G. (1907): Die Tertiärflora des Basalttuffes vom Eichelskopf bei Homberg (Bez. Kassel). - Abh. Kgl. Preuß. Geol. Landesanst., N.F., 포, 81 S., 1 Tab., 13 Taf.; Berlin Referat in: N. Jb. Mineral. etc., 1909 (Bd. II): 147-149 (H. Salfeld); Stuttgart

-Schmidt, Hermann (1936): Die stratigraphische Bedeutung der Knollensteinfloren von Dransfeld und Münden (Oberweser). - Festschrift zum 60. Geburtstag von Hans Stille, 437 S., zahlr. Abb., 28 Taf; hier: S. 136-148, 2 Abb.; Stuttgart

Referat in: N. Jb. Mineral. etc., Referate, 1937 (Bd. III): 401 (Kräusel); Stuttgart

[Knollensteine $=$ Tertiärquarzite; Revision der stratigraph. Einordnung, von Miozän nach Oligozän $]$

-Wójcicki, Jan J. \& Wilde, Volker (2001): A new species of Trapa (Trapaceae) from the Pliocene of the Zennern Depression, near Fritzlar (Hesse, Germany). - Senckenbergiana lethaea, 81(1): 17-23; Frankfurt/M.

[Paläobotanik; Trapa (Wassernuß)]

\subsubsection{Quartär}

-Anonym (1878): Fossiler Eichenwald in den Kiesen der Fulda-Aue bei Rotenburg entdeckt. Eschweger Kreisblatt, 1878; Nr. 101 v. 25.12.1878; Eschwege

@Claus, Hans (1978): Der Gagelstrauch Myrica gale L. 1753 im Travertin von Burgtonna in Thüringen. Quartärpaläontologie, 3: 67,1 Abb.; (Akademie-Verlag) Berlin

ODaut, G.; Henkel, K.; Ig1. M.; Mäusbächer, R. \& Schneider, H. (2002): Untersuchungen an Subrosionssenken des mittleren Werratales (Vortrag und Poster). - In: (Sediment 2002) Schriftenrh. Dt. Geol. Ges., 17: 48-49; Hannover

[Hptsächl. Gebiet zw. Immelborn und Schwallungen (Krs. Schmalkalden; Geomorphologie, Geochemie, Pollenanalyse]

OLange, Peter; Steiner, Walter \& Süss, Herbert (1984): Eichenholzfunde aus den jungquartären Werraschottern bei Immelborn und Breitungen, Bezirk Suhl, DDR. - Z. geol. Wiss., 12(6): 751-760, 12 Abb., 1 Tab.; Berlin

-Leuschner, Hans-Hubert; Delorme, Axel; Tuexen, Jens \& Hoefle, Hans-Christian (1985): Eichenstammlagen in Mooren und Talauen und die Klimaverschlechterung in Subboreal. - Flora Morphologie, Geobotanik, Oekophysiologie, 177: 283-295, 5 Abb., 1 Tab.; Jena [darin: Funde Fuldatal zw. Bad Hersfeld u. Kassel; Werratal zwischen Philippsthal und Eschwege (Lokalität Widdershausen]

OSchneider, H.; Ig1, M.; Mäusbacher, R. \& Ellenberg, J. (2001): Untersuchungen zur spät- und postglazialen Landschaftsgenese des mittleren Werratales. [Vortrags-Kurzfassung]. - In: Gaupp, R. \& Van der Klauw, S. [Hrsg.]: Sediment 2001, Jena, 6.6. - 8.6.2001 - Programm, Kurzfassungen, Exkursionsführer; Schriftenreihe Dt. Geol. Ges, 13: 86; Hannover 2001

[Südwestthüringen, Geomorpologie, Palynologie]

- 0 Stapf, E. M. (1879): Begrabene Eichenwälder im Fulda- und Werrathale. - N. Jb. Mineral., 1879: 370 371; Stuttgart

[Fulda zw. Bad Hersfeld und Melsungen; Werra zw. Heerda, Berka, Untersuhl, Gerstungen, Böller]

OVent, Walter (1978): Die Flora des Travertins von Burgtonna in Thüringen. - Quartärpaläontologie, $\underline{3}$ : 59-65, 4 Abb., Taf. 9-18; (Akademie-Verlag) Berlin 
OWerth, E. (1925): Die pflanzenführenden Diluvial-Ablagerungen der thüringisch-sächsischen Bucht und ihre pflanzengeschichtliche und klimatologische Bedeutung. - Ber. Dt. botan. Ges., 43: 391-399, 2 Abb.; Berlin-Dahlem

[Bezugnahme a. Burgtonna]

\subsection{Vegetationsgeschichte - Quartär}

-Averdieck, Fritz-Rudolf \& Brelie, Günther von der (1963): Neue Beiträge zur pollenanalytischen Untersuchung des Interglazials von Bilshausen (Unter-Eichsfeld). - Geol. Jb., 무: 437 - 446, 2 Abb., 1 Taf.; Hannover

-Beug, Hans-Jürgen (2002): Vegetationsgeschichte im Weserbergland. - In: Rapp, Hermann-Josef [Hrsg.]: Reinhardswald - Eine Kulturgeschichte. - 240 S., 73 Abb.; hier: S. 134-137; (Euregio) Kassel 2002

-Chanda, Sunirmal (1960): Über spättertiäre und interglaziale, pollenführende Ablagerungen im Leinetal nahe Göttingen und im südwestlichen Harzvorland (Unter-Eichsfeld). - Die Naturwissenschaften, 47(1): 19-20; Berlin

[Bilshausen (Unter-Eichsfeld), Northeim, Tongrube Eichenberg/Lkr. Göttingen]

-Chanda, Sunirmal (1960): Über spättertiäre und interglaziale, pollenführende Ablagerungen im Leinetal nahe Göttingen und im südwestlichen Harzvorland (Unter-Eichsfeld). - Die Naturwissenschaften, 47(1): 19-20; Berlin

[Bilshausen (Unter-Eichsfeld), Northeim, Tongrube Eichenberg/Lkr. Göttingen]

-Chen, Su-Hwa (1988): Neue Untersuchungen über die spät- und postglaziale Vegetationsgeschichte im Gebiet zwischen Harz und Leine (BRD). - Flora - Morphologie, Geobotanik, Ökologie; 181: 147-177, 5 Abb., 3 Tab.; (VEB Gustav Fischer Verlag) Jena

[Luttersee/Untereichsfeld; Lüderholz/Herzberg; Silberhohl/Seesen]

口QFirbas, Franz (1952): Spät- und nacheiszeitliche Waldgeschichte Mitteleuropas nördlich der Alpen. 2. Bd.; 256 S., 18 Abb.; (G. Fischer) Jena

[darin: Meißner, Thüringer Wald]

-Firbas, Franz (1954): Zur Vegetationsgeschichte des Göttinger Gebietes. - Göttinger Jb., 1954: 60 - 64; Göttingen

$\square$ Gold, Hans H. (2004): Die Vegetation des Meißners und seine Waldgeschichte. - Das Werraland, 56(3): 55 - 56, 2 Abb.; Bad Sooden-Allendorf

[Referat über die Arbeit von Hans Pfalzgraf (1934): Die Vegetation des Meißners und seine

Waldgeschichte]

-Heck, Herbert-Lothar (1929): Pollenanalytische Untersuchungen altdiluvialer Tone und Torfe von Northeim und Eichenberg im Flußgebiet der Leine. - Jb. Preuß. Geol. Landesanst., $\underline{49}$ (Teil II) (f. 1928): 1255-1264, 3 Abb.; 3 Tab., Taf. 80 u. 81; Berlin

- Jaeschke, J. (1938): Zur Waldgeschichte des Knüllgebirges. - Forstwiss. Zbl., 60: 676-683, 1 Abb., 2 Tab.; Berlin

[Vegetationsgeschichte, Pollenanalyse]

OJahn, Reinhold (1930): Pollenanalytische Untersuchungen an Hochmooren des Thüringer Waldes. Diss. Univ. Jena 1930, 25 S., 6 Abb., 5 Tab.; Jena 
[Großes Moor am Beerberg, Teufelskreis, Saukopfmoor NW' Oberhof, Schwarzwassergrund b. Schmiedefeld]

-Koch, Hanns (1956): Torf an der Fulda - Ein Beitrag zur kurhessischen Waldgeschichte. - Z. Vereins hess. Gesch. u. Landeskde., 67: 199-203, 1 Abb.; Kassel

[Pollenanalyse]

-Kremp, Gerhard (1950): Pollenanalytische Braunkohlenuntersuchungen im südlichen Niedersachsen, insbesondere im Solling. - Geol. Jb., 64 (f. 1943-1948): 489-517, 4 Abb.; Hannover-Celle [Lkr. Göttingen: Brunsberg, Hoher Hagen b. Dransfeld - Kl. Steinberg b. Hann. Münden]

OLange, Elisabeth (1967): Zur Vegetationsgeschichte des Beerberggebietes im Thüringer Wald. Feddes repertorium - Z. botan. Taxonomie Geobotanik, $7 \mathbf{6}$ (3): 205 - 219, 4 Abb., 1 Tab.; Berlin [Untersuchgn. a. Bl. 4730 Ebeleben, 4830 Großvargula, 4831 Gebesee, 4832 Sömmerda]

OLange, Elisabeth (1965): Zur Vegetationsgeschichte des zentralen Thüringer Beckens. - Drudea Mitt. Geobotan. Arb.Kreis. Sachsen-Thür., $\underline{\mathbf{5}}$ (1): 3 - 58, 14 Abb., 6 Tab.; Jena

-Lesemann, Brunhild (1968): Pollenanalytische Untersuchung eines Flachmoores im Umlauftal der Weser bei Bodenfelde. - Ber. Naturhist. Ges. Hannover, 112: 91-96, 1 Abb. (2 Pollendiagr.); Hannover

-Lüttig, Gerd \& Rein, Ulrich (1954): Das Cromer - (Günz/Mindel-) Interglazail von Bilshausen (Unter-Eichsfeld). - Geol. Jahrbuch, 무: 159-166, 2 Abb.; Hannover

[Vegetationsgeschichte]

-Müller, Helmut (1965): Eine pollenanalytische Neubearbeitung des Interglazial-Profils von Bilshausen (Unter-Eichsfeld). - Geol. Jb., 83: 327-352, 5 Tab.; 2 Taf. (43, 44); Hannover [Vegetationsgeschichte]

$\square$ Pfalzgraf, Hans (1934): Die Vegetation des Meißners und seine Waldgeschichte. - Repertorium specierum novarum regnis vegetabilis, Beih. $\underline{75}$; 80 S., Abb., Tab., Taf., Diagr.; Dahlem b. Berlin [darin: S. 12 - 14: Kap. „Zur Morphologie und Geologie des Meißners“; S. 64 - 75: „Die Pollenanalyse und die Waldgeschichte der Meißnerlandschaft"]

-Pörtge, Karl-Heinz \& Schäbitz, Frank (1992): Interglaziale Ablagerungen in einer Subrosionssenke bei Wöllmarshausen, Südniedersachsen. - In: (Grunert, Jörg \& Höllermann, Peter [Hrsg.]: Geomorphologie und Landschaftsökologie) Bonner Geogr. Abh., 85: 209-222, 4 Abb.; Bonn [Quartär, Vegatationsgeschichte/Pollenanalyse Gartetal E’ Göttingen]

-Rohdenburg, H.; Meyer, B.; Willerding, U. \& Jankuhn, H. (1962): Quartärgeomorphologische, bodenkundliche, paläobotanische und archäologische Untersuchungen an einer Löß-SchwarzwerdeInsel mit einer wahrscheinlich spätneoltihischen Siedlung im Bereich der Göttinger Leineaue. Göttinger Jb., 1962: 36 - 56, 6 Abb., 2 Tab., 1 Foto; Göttingen

-Rühl, Arthur (1973): Waldvegetationsgeographie des Weser-Leineberglandes. - Veröff. Niedersächsischen Inst. Landeskde. Landesentw. a.d. Univ. Göttingen, zgl. Schr. Wirtschaftswiss. Ges. z. Studium Niedersachsens e.V., N:F: - Reihe 5: Forschungen zur Landes- und Volkskunde, 101. - 95 S., 30 S., Kt.; (Wurm) Göttingen

[Bodenausgangsgestein, Bodentyp und Vegetation]

OSchneider, Heike (2002): Die spät- und postglaziale Vegetationsgeschichte des oberen und mittleren Werratals - paläobotanische Untersuchungen unter besonderer Berücksichtigung anthropogener Einflüsse. - Diss. Univ. Jena 2002; VI, 172 Bl, graph. Darst., Kt. [Pollenanalytische Untersuchungen u.a Säulingssee SW' Gerstungen, Gerstunger Becken]

oSchneider, Heike (2006): Die spät- und postglaziale Vegetationsgeschichte des oberen und mittleren Werratals. - Paläobotanische Untersuchungen unter besonderer Berücksichtigung anthropogener 
Einflüsse. - Dissertationes Botanicae, 403; 220 S., 32 Abb., 13 Tab., 7 Diagr.; (Bornträger) StuttgartBerlin

OSchneider, H.; Ig1, M.; Mäusbacher, R. \& Ellenberg, J. (2001): Untersuchungen zur spät- und postglazialen Landschaftsgenese des mittleren Werratales. [Vortrags-Kurzfassung]. - In: Gaupp, R. \& Van der Klauw, S. [Hrsg.]: Sediment 2001, Jena, 6.6. - 8.6.2001 - Programm, Kurzfassungen, Exkursionsführer; Schriftenreihe Dt. Geol. Ges, 13: 86; Hannover 2001

[Südwestthüringen, Geomorpologie, Palynologie]

-Schweisfurth, W. (1955): Was der Lutteranger erzählt. - Die Goldene Mark, $\underline{6}$ (August-H.): 38-43; Duderstadt

[Vegetationsgeschichte/Pollenanalyse, Stratigraphie Lacher Seetuff]

$\square$ Seifert, U. (1993): Folgen des forstwirtschaftlichen Nutzungswandels am Beispiel ehemaliger Eichenlohwälder im Meinhard. - In: Jacobshagen, V. ; Möller, K. \& Jäkel, D. [Hrsg.]: Hoher Meißner und Eschweger Becken: geowissenschaftliche und vegetationskundliche Charakteristik einer nordhessischen Landschaft. -Berliner geogr. Abh., $\underline{\mathbf{5 6}}$; zgl. Beiträge zur Werra-Meißner-Forschung, III; S. 189-198; (Selbstverlag Geomorphologisches Laboratorium FU Berlin) Berlin 1993

-Steinberg, Kurt (1944): Zur spät- und nacheiszeitlichen Vegetationsgeschichte des Untereichsfeldes. Hercynia - Abh. Bot. Vereinigung Mitteldtschlds., $\underline{\mathbf{3}}$ (7/8): 529 - 587, 11 Abb., 2 Tab.; Halle/Saale Berlin

QVölkel, J. \& Leopold, M. (2001): Zur zeitlichen Einordnung der jüngsten periglazialen Aktivitätsphase im Hangrelief zentraleuropäischer Mittelgebirge. - Z. Geomorph. N.F., $\underline{45}$ (3): 273 - 294, 5 Abb., 1 Tab.; Berlin-Stuttgart [darin: Thüringer Wald, Bezug a. Beerbergmoor, Schneekopfmoor]

-Willerding, Ulrich (1960): Beiträge zur Geschichte der Flora und Vegetation der Flußauen (Untersuchungen aus dem Leinetal bei Göttingen). - Flora, 149: 435 - 476, 7 Abb., 1 Tab., 1 Taf.; Jena

-Willerding, Ulrich (1971): Ergebnisse vegetationsgeschichtlicher und paläoethnobotanischer Untersuchungen im südlichen Niedersachsen. - Göttinger Jb., 19 (1971): 5-20, 2 Abb., 2 Tab.; Göttingen [darin: Lkr. Göttingen]

\subsection{Mineralogie - Geochemie - Lagerstättenkunde}

\subsubsection{Erdkruste}

\subsubsection{Allgemeines - Regionales}

-Abo-Rady, Mustafa D. K. (1980): Schwermetalle in den Sedimenten der oberen Leine. - Dt. Gewässerkdl. Mitt.; 24(3): 93-100, 4 Abb., 10 Tab.;

[Mineralogie, Geochemie; Stadtgebiet Göttingen]

$\square$ Althaus (1842): Mesothype vom Alpstein; Späroidische Ausscheidungen im Muschelkalk. - N. Jb. Mineral. etc., 1842: 275-276 (Briefl. Mitt.); Stuttgart 
OAndreas, Dieter (1988): Diskussionsbeitrag zu einer hydrothermal-postmagmatischen Genese der Vulkanitachate. - Z. angew. Geol., 34(3): 65-71, 14 Abb.; Berlin

[Rotliegendes westl. Thüringer Wald: Winterstein, Ohrdruf, Georgenthal]

$\square$ Anonym (1890): <Nachgrabungen nach Kupferschiefer und Silbererz am Kupferberg bei Wellingerode - Zwei Schurfstollen zur Lagerstättenerkundung geplant> - Eschweger Tageblatt u. Kreisblatt, 1890; Nr. 73 v. 27.03.1890; Eschwege

$\square$ Anonym (1910): <Mineralische Bodenschätze bei Hundelshausen]. - Eschweger Tageblatt, 1910; Nr. 171 v. 25.7.1910; Eschwege

$\square$ Anonym (1975): Das „Bühlchen“ bei Epterode. - In: Wollenhaupt, Gustav [Hrsg.]: Geschichte der Stadt Großalmerode und familienkundliche Nachrichten. - Teil 2; 143 S., Abb.; hier S. 137-139; (Im Selbstverlag) Großalmerode 1975

OAnschütz, Johann Mathäus (1788): Die Gebirgs- und Steinarten des kursächsischen Hennebergs nebst einer allgemeinen Übersicht aller bis jetzo bekannten Mineralien dieses Landes, und einem Anhange vom Schneekopf und Ruppberg. - LII, 120 S.; (Müller) Leipzig

OAnschütz, Johann Matthäus (1798): Berichtigungen und Zusätze zu der Schrift über die Gebirgs- und Steinarten des chursächsischen Hennebergs, nebst einem neuen nach Wernerischem System geordneten Verzeichniss der Mineralien dieses Landes. - 82 S:, (Müller) Leipzig

-Babcock, S. M. (1879): Ueber den Coelestin aus dem Muschelkalke von Jühnde bei Göttingen. - N. Jb. Mineral. etc., 1879: 835 - 838, 1 Abb.; Stuttgart

$\square$ Bierwirth, Heinrich (1927): Heimatklänge aus dem Werratale. - 2., vermehrte Aufl.; 195 S., Abb.; (A. Roßbach) Eschwege

[darin Kap.: Auf der Blauen Kuppe; S. 89-95, Mineralogie, Landschaft]

-Belendorf, K. (1986): Neufunde von Richelsdorf. - Lapis, 11(9): 32-33, 3 Abb.; München

- $\square$ Bode, Rainer \& Wittern, Artur (1989): Mineralien und Fundstellen - Bundesrepublik Deutschland. - 1. Aufl., 303 S., zahlr. Abb.; (Bode) Haltern

darin:

5. Kassel-Fulda-Gebiet

1. Basalt der Bramburg bei Adelebsen

2. Meenser Steinberg am Hohen Hagen

3. Bühl bei Kassel

4. Grube Chattenberg im Unterwerra-Grauwackengebirge

5. Grube Münden bei Nentershausen

6. Richelsdorfer Erzrevier

7. Kaliwerk Hattorf

12. Gipsfundstellen um Borken (Neuenhain)

14. Großalmerode

16. Blaue Kuppe bei Eschwege]

-Booth, J.-C. (1834): Über das Arseniknickel vom Riegelsdorf in Kurhessen. - Ann. Physik u. Chemie, (2. Reihe) $\underline{\mathbf{3 2}}$ (31-36) (= 108 Ges. Rh.): 395-399; Leipzig

Referat in: N. Jb. Mineral. etc., 1834(5): 561-562; Stuttgart

-Borstel, L.E. v.; Herrmann, A. G. \& Knipping, B. (1989): Basalte in Zechsteinevaporiten der WerraFolge. - Ber. Dt. Mineral. Ges., 1(1): 16; Stuttgart

d $\square$ OCBruhns, W. (1906): Die nutzbaren Mineralien und Gebirgsarten im Deutschen Reiche. - Neu bearb. u. Mitwirk. v. H. Bücking a. Grundlage d. gleichnam. Werkes v. Heinrich v. Dechen (1873); XIX, 859 S., 1 geol. Falt-Kt.; (Reimer) Berlin 
[Regionale Lagerstätten - darin: Braunkohlen - S. 279-281 „Ablagerungen am Knüll und Habichtswald“, S. 281-282 „Ablagerungen im Reinhardswalde“, „Ablagerungen auf der rechten Seite der Fulda und der Weser" (Kaufungen, Meißner, Großalmerode, Kaufunger Wald, Lkr. Göttingen); darin S. 236-238 Steinkohlen Thüringer Wald, Bohrversuch auf Steinkohlen bei Nentershausen, ebenso kurz erwähnt Tone, feuerfeste Steine a. Großalmerode; S. 444-447: Erze (Metallische Mineralien) im Thüringer Wald)

- $\square$ Bühmann, Dieter (1970): Tonmineralogische Untersuchungen an tertiären Sedimenten aus dem nördlichen Hessen. - Dipl.-Arb. [unveröff.] Univ. Göttingen, 40 S.

- $\square$ Bühmann, Dieter (1974): Die Tonmineralzusammensetzung in den Sedimenten der Niederhessischen Senke als Indikator festländischer Verwitterung und brackisch-mariner Tonmineralneubildung. - Diss. Univ. Göttingen, 81 S., 20 Abb., Tab. i. Anhang

Untersuchung v. Sedimenten d. Tertiärs. Trias; u.a. Region Kassel - Fritzlar, Beberbeck, Glimmerode, Großalmerode, Stellberg]

-Bückius, Matthias \& Schwedt, Georg (1999): Katalog [ Fossilien, Mineralien der Goethe-Sammlung, inhaltlich an Kap. Geologie - Goethe im Göttinger Reich der Steine“ anschließend] - In: Mittler, E.; Purpus, E. \& Schwedt, G. [Hrsg.]: „Der gute Kopf leuchtet überall hervor“. - 270 S., zahlr. Abb.; hier: S. 184-187; (Wallstein) Göttingen

[Fde. I13- I19: Funde vom Hainberg/Göttingen]

$\square$ Chuang, Chung-Wie (2006): Thermische Prozesse am Kontakt Basalt-Sandstein am Beispiel der Blauen Kuppe. - Bachelor-Arbeit (unveröff.) Univ. Göttingen 2006; 39 S.

-Cornelius, C.-D. (1950): Kupfer-, Nickel- und Kobalterz im Richelsdorfer Gebirge. - Der Aufschluß, 1: 47-48; Braunschweig

口OCotta, B [ernhard] v. (1848): Bruchstücke [Nichtsagender Sammeltitel für petrographische Beschreibung thüringischer (hessischer) Gesteinsvorkommen]. - N. Jb. Mineral. etc., 1848: 129-135; Stuttgart

[S. 131-132 II) Granit b. Bad Liebenstein; S. 132-133 III) Basalt der Stoffelskuppe bei Eisenach (und Blaue Kuppe b. Eschwege); S. 133-134 IV) Rotliegendes bei Friedrichroda mit Thierfährten; S. 134135 V) Dolomit-Breccie bei Neustedt/Werra; S. 135 VI) Thon-Gallen im Buntsandstein der WerraGegend

口Credner, Heinrich (1843): Die Augit und Hornblende führenden Gesteine am Thüringer Walde. - N. Jb. Mineral. etc., 1843: 264-294; Stuttgart

OCredner, Heinrich (1847): Über das Vorkommen von vanadium-saurem Kupfer-Oxyd und KupferManganerz bei Friedrichroda [Friedrichroda] im Thüringer Wald. - N. Jb. Mineral. etc., 1847: 1 - 7; Stuttgart

QCredner, Heinrich (1847): Vorkommen des vanadium-sauren Kupfers und des Mangankupfers bei Friedrichsrode [Friedrichroda] am Thüringer Wald. - N. Jb. Mineral. etc., 1847: 310-312 (Auszug a. Annalen d. Physik, 74: 546ff); Stuttgart

- $\square$ @ Dechen, Heinrich v. (1873): Die nutzbaren Mineralien und Gebirgsarten im Deutschen Reiche nebst einer physiographischen und geognostischen Übersicht des Gebietes. - XXIV, 806 S.; (Berlin) Berlin

[darin: S. 447 ff Braunkohlen: „Ablagerungen am Knüll und Habichtswalde“, „Ablagerungen im Reinhardsswalde“, „Ablagerungen auf der rechten Seite der Fulda und der Weser" (Kaufungen, Meißner, Großalmerode, Kaufunger Wald, Lkr. Göttingen)]

Referat in: Z. Berg-, Hütten- u. Salinenwesen, 21: 40-41 (Litteratur); Berlin 1873

$\square 0 \bullet$ Delesse, M. A. (1857): Etudes sur le métamorphisme [] - Metamorphose des Roches [Suite]. Annales des mines, memoires, (5ième sèr.) 12: 89-828 [1], 417-516 (Suite); Paris 
[darin

S. 278-279 Blaue Kuppe

S. 279-282 Stoffelskuppe

S. 476Warburg/Diemel, Säsebühl b. Dransfeld;

S. 477-478 - Pflasterkaute

S. 478 Stoffelskuppe

S. 478 - 480 Blaue Kuppe]

-Dürrfeld, V. (1911): Ueber Weißnickelkies von Riechelsdorf. - Z. Krist., 49: 199-200, 1 Abb.; Leipzig Referat in : N. Jb. Mineral. etc., 1912 (Bd. I): 11 (Max Bauer); Stuttgart

$\square$ Dunker, Wilhelm (1837): Chalcedon und Quarzkrystalle im Anthrazit des Meißner - [...]. Notizenblatt Göttingischen Vereins bergmänn. Freunde, $\underline{3}$ : 2-3; Göttingen

[Vorlage nicht eingesehen, zitiert nach Oppitz (1991)]

OEberhardt, Wilhelm(1855): Analysen einiger Thüringer Mineralien. - Diss. Univ. Göttingen 1855; 32 S.; (Huth) Göttingen

$\square$ Ebhardt, H.; King, M.-T. \& Meyer, B. (1969): Mineralogisch-chemische Untersuchungen zum Prozeß der Rubefizierung in Kalkstein-Rotlehm und fossilem Laterit in Nordhessen. - Göttinger Bodenkdl. Ber., 9: 65-124, 6 Abb., 7 Tab.; Göttingen

[Untersuchg. in Kammerbach b. Bad Sooden-Allendorf, B1. 4725 Bad Sooden-Allendorf]

-Echle, Wolfram (1960): Mineralogische Untersuchungen an Sedimenten des Steinmergelkeupers und der Roten Wand aus der Umgebung von Göttingen. - Diss. Univ. Göttingen 1960; 76 gez. Bl., Abb.

-Echle, Wolfram (1961): Mineralogische Untersuchungen an Sedimenten des Steinmergelkeupers und der roten Wand aus der Umgebung von Göttingen. - Beitr. Mineral. Petrogr., 8: 28 - 59, 5 Abb.; Berlin-Göttingen-Heidelberg [Untersuchgebiet S' Großschneen]

$\square$ Echle, Wolfram (1964): Mineralbestand und Entstehung des „Porzellanjaspis“ von Epterode (Nordhessen). - Beitr. Mineral. Petrogr., 10: 32 - 41, 2 Abb., 5 Tab.; Berlin-Göttingen-Heidelberg

$\square$ Echle, Wolfram (1968): Der Porzellanjaspis von Epterode, ein Gesteinstyp der Sanidinitfazies. - Der Aufschluss, Sdbd. 17 (Zur Mineralogie und Geologie der Umgebung von Göttingen): 128 - 150, 1 Abb.; Göttingen

$\square$ Echle, Wolfram (1978): Der Porzellanjaspis von Epterode, ein Gesteinstyp der Sanidinitfazies. - Der In: Koritnig, Sigmund [Schriftltg.]: Zur Mineralogie und Geologie der Umgebung von Göttingen mit Westharz und Teilen des Nordhessischen Berglandes. - Sdbd. 28: 205 - 207, 1 Abb.; Heidelberg 1978

QEllenberg, Jürgen (1975): Schwermineralverteilung, Sedimentation und Stratigraphie im Quartär der mittleren Werra. - Z. geol. Wiss., $\underline{\mathbf{3}}(11): 1389-1404,13$ Abb., 1 Tab.; Berlin

QEllenberg, Jürgen \& Kuhn, Gerd (1966): Kieselgur im Werra-Kaligebiet. - Hall. Jb. f. Mitteldt. Erdgeschichte, $\underline{8} .1966:$ 67-86, 8 Abb., Taf. XI-XII; Leipzig

OEllenberg, J. \& Kuhn, G. (1969): Das Quartär und seine nutzbaren Gesteine im Werragebiet (Exkursion A). - In: Steinmüller, Arno [Hrsg.]: Exkursionsführer zum Treffen der Sektion Quartärgeologie vom 19. - bis 21. Septemberg 1969 in Erfurt - „Ergebnisse quartärgeologischer Untersuchungen in Thüringen. - Exkursionsführer u. Veröff. Ges. geol. Wiss. DDR, $\underline{3}$; 82 S., zahlr. Abb.; hier S. 5-23, 7 Abb.; [Herausgeg. i. Auftrag d. Dt. Ges. f. geol. Wiss.] Berlin 1969

[Oberes Werratal zw. Frauensee u. Breitungen, Niederschmalkalden] 
$\square$ Erxleben, J. C. P.(1765): Nachricht von einer Reise nach dem Weißner, in Absicht auf die natürliche Geschicht dieses Berges und der um ihn liegenden Gegend. - Hannoverisches Magazin, $1765=3$. Jg.)(63): Sp. 993-1007, (64): Sp. 1009-1014; [Auszug in Tourist. Mitt. Hessen, $\underline{8}:$ 8-11; Kassel 1899] [Saline Sooden, Braunkohlenbergbau a. d. Meißner, ausführlich: Alaunherstellung in Großalmerode, Strahlkies v.on Großalmerode; Botanik]

OFranke, H. (1923): Das Vorkommen von Anatas im Thüringer Walde. - Zbl. Mineral. etc., 1923: 417418; Stuttgart

[Fund Umgebung Tambach]

QFranzke, H. J.; Ahrendt, H.; Kurz, S. \& Wemmer, K. (1996): K-Ar-Datierungen von Illiten aus Kataklasiten der Floßbergstörung im südöstlichen Thüringer Wald und ihre geologische Interpretation. - Z. geol. Wiss. , 24(3/4): 441-456, 7 Abb., 3 Tab.; Berlin [Mineralogie]

QFranzke, H. J.; Morgenroth, V. \& Rauche, Henry (2001): Exkursion C 1 - Ganglagerstätten im westlichen Thüringer Wald. - In: Jockel, Andreas [Hrsg.]: Regionale und angewandte Geologie der Grenzregion der Süddeutschen und der Mitteldeutschen Scholle. - Exkursionsführer zur 10. Jahrestagung der Gesellschaft für Geowissenschaften e.V. in Schmalkalden - 19.-22. September 2001. - Exkursionsführer u. Veröff. Ges. f. Geowiss., 213; S. C1-1 bis C1-24, 13 Abb.; Berlin 2001

- $\square$ Frick, Friedrich (1981): Natürliche Voraussetzungen einer mittelalterlichen Eisengewinnung im Kaufunger Wald. - Kaufunger Wald, H. 18: 2-3; Kaufunger Wald

[Regionale Geologie, Lagerstättengenese von tertiärem Brauneisenstein]

-Friedrich, G.; Diedel, R.; Schmidt, F.P. \& Schumacher, A. (1984): Untersuchungen an Cu-AsSulfiden und Arsendiden des basalen Zechsteins der Gebiete Spessart/Rhön und Richelsdorf. Fortschr. Mineral., 62, Beih. 1: 63-65; Stuttgart

$\square$ Führes, Margit (1979): Untersuchungen zur Mineralführung und Geochemie an einem Bohrprofil im Braunkohlengebiet des Hohen Meißners. - Dipl.-Arb. [unveröff.] Univ. Gießen

$\square$ Ganßloser, Martin (1998): Detrital relics of a highpressure metamorphism in Rhenohercynian graywackes. - Z. geol. Wiss., 26 (3/4): 271-291, 6 fig., 4 tabl.; Berlin [darin: Unterwerra-Grauwackengebirge ("Unterwerra-Decke”)]

$\square \bullet$ Gebhardt, H.; Hugenroth, P. \& Meyer, B. (1969): Pedochemische Verwitterung und MineralUmwandlung im Trachyt-Bims, Trachyt-Tuff und in den Tuff-Mischsedimenten der Laacher Eruptionsphase. - Göttinger Bodenkdl. Ber., 11: 1-83, 14 Abb., 7 Tab., 1 Übers.-Kt.; Göttingen [darin: Profile Hünstollen/Göttingen, Northeim, Bischhausen/Werra-Meißner-Kreis, Lutteranger/Untereichsfeld]

$\square$ Georgi, Klaus-Henning (1971-1986): Kreislauf der Gesteine - Eine Einführung in die Geologie. Reihe: rororo-Sachbuch. - 251 S., 265 Abb. u. graph. Darst.; (Rowohlt Taschenbuch Verlag) Reinbek b. Hamburg - mehrere unveränderte Nachdrucke der Erstauflage v. 1971, letzter 1986 [darin S. 177-180, 1 Abb., Kap. 11 - Druck und Hitze verwandeln Gesteine; Kontaktmetamorphose Basalt/Buntsandstein Blaue Kuppe (Foto) u. Basalt/Braunkohle Hoher Meißner]

-0•Gillitzer, G. (1936): Die Geologie der Erzanreicherungen im mitteldeutschen Kupferschiefer. - Jb. Hallesches Verb. f. d. Erforsch. d. mitteldt. Bodenschätze u. deren Verwertg., N.F., 15: 9-27, 14 Abb.; Halle (Saale)

Referat in: N. Jb. Mineral. etc., Referate, 1939 (Bd. II): 268-270 (D. Hoenes), 1939 (Bd. III): 584-586 (Walther Fischer); Stuttgart

[Paläogeogr. Kt. Kupferschiefer: Hessen, Thüringen, Niedersachsen]

-Grassmann (1886): Das Richelsdorfer Kupfer- und Kobaltwerk in Hessen. - Hierzu die Texttafel p. Z. Berg-, Hütten- u. Salinenwesen, 34: 195-207 (Abb.); Berlin 
Referat in: N. Jb. Mineral. etc, $\underline{1888}$ (Bd. I): 245 (G. Greim); Stuttgart

[Regionalgeologie, Lagerstättengeologie, Bergbaugeschichte, Förderstatistik]

-Gunzert, Gerhard (1953): Über die Bedeutung nachträglicher Erzverschiebungen in der Kupferlagerstätte des Richelsdorfer Gebirges. - Notizbl. Hess. L.-A. Bodenforsch., 81: (= 6. F. (H. 4)): 258 - 283, 6 Abb., Taf. 12-15; Wiesbaden

- $\square$ Gutberlet, [W. K. J.] (1846): Beiträge zur mineralogischen Topographie von Kurhessen. - N. Jb. Mineral. etc., 1846: 150-162; Stuttgart

[Mineralien und deren Fundstellen in Hessen]

-Gutberlet, W. K. J. (1847): Über die Pseudomorphosen nach Steinsalz - [I.] zunächst in mineralogischer, petrographischer und krystallographischer Beziehung. - N. Jb. Mineral. etc., 1847: 405-438, 5 Abb.; Stuttgart [Bezugnahme a. Lkr. Göttingen]

-Gutberlet, W. K. J. (1847): Über die Pseudomorphosen nach Steinsalz - II. in ihren geognostischen und geologischen Beziehungen. - N. Jb. Mineral. etc., 1847: 513-543.; Stuttgart [Bezugnahme a. Lkr. Göttingen]

-Gutberlet, W. K. J. (1853): Über Psilomelan im Bunten Sandstein. - N. Jb. Mineral. etc., 1853: 802-804; Stuttgart [Fundort Eddigehausen b. Göttingen, Bezugnahme Fuldaer Gegend]

OHaase, Günter \& Oettel, Siegfried (1962): Kieselgurvorkommen im Werra-Kaligebiet. - Geologie, 11(4): 488-494, 1 Abb.; Berlin

$\square$ Hausmann, Joh. Friedrich Ludw. (1828): Handbuch der Mineralogie. - Erster Theil: Einleitung in die Mineralogie. - XXX, 687 S., 2 Taf.; (Vandenhoeck \& Ruprecht) Göttingen [darin S. 243: Wasserkies von Großalmerode]

QHeidorn, F. (1932): Ueber ein Vorkommen von Sellait $(\mathrm{MgF} 2)$ in Paragenese mit Bitumen aus dem Hauptdolomit des mittleren Zechsteins bei Bleicherode. - Zbl. Mineral. etc., Abt. A, 1932: 356-364, 3 Abb.; Stuttgart

- $\square$ Heim, Dieter (1966): Petrographische Beiträge zur Paläogeographie des Buntsandsteins. - Notizbl. Hess. L.-A. Bodenforsch., 94: 235-258, 1 Tab., Taf. 17; Wiesbaden

QHellmers, J. H. \& Pfeiffer, P. (1937): Verwitterungsstudien an Bodenprofilen des mittleren und südöstlichen Thüringer Waldes. - Jb. Preuß. Geol. Landesanst., $\underline{\mathbf{5 7}}$ (Teil II) (f. 1936): 333-358, 32 Abb., 1 Taf.; Berlin [Schwarzburger Sattel, angrenzendes Permo-Siles]

$\square$ Henkel, Johann Friedrich (1725): Pyritologia oder: Kieß-Historie als des vornehmsten Minerals, nach dessen Nahmen, Arten, Lagerstätten, Ursprung.... - 1008 S., + Register, XII Taf.; Joahnn Christian Martini) Leipzig

[„Historie vom heßischen Kieß, Terra martis Haßiaca genannt“ - Pyrit von Großalmerode]

$\square$ Henkel, Johann Friedrich (1754): Pyritologia oder Kieshistorie als des vornehmsten Minerals... - [2.] neue verbesserte Auflage; 919 S. ; (Groß) Leipzig 1754 [darin S. 875 - 883: XVI. Capitel Nachlese, I. Historie v. heßischen Kies [Großalmerode]]

$\square$ Henningsen, Dierk (1980): Schwerminerale vulkanischer Herkunft in quartären Flußablagerungen der Weser und Leine. - Eiszeitalter u. Gegenwart, $\underline{\mathbf{3 0}}$ : 63 - 72, 1 Abb., 3 Tab.; Öhringen

口OHirschberg, Christian Götz (1997): Die Gerölle von Werra und Weser - Ihre strukturelle und kompositionelle Reifung in der Natur und im Experiment. - Berliner geowiss. Abh., Reihe A, 191; 
VIII, 114 S., Abb., Kt.; zgl. Diss. FU Berlin 1996; Berlin

[Werra-Weser bis Strom-Km 510; Unters. u.a. b. Meinhard-Grebendorf]

OHoppe, Günter (1970): Zum Problem der pigmentierten akzessorischen Apatite. - Ber. Dt. Ges. f. geol. Wiss., Reihe B, 15(1): 33-54, 2 Tab., 7 Taf.; Berlin

[darin Tab. 1: Apatite Thüringer Wald]

$\square \bullet$ Hugenroth, Peter (1969): Pedochemische Verwitterung und Mineral-Umwandlung im Trachyt-Bims, Trachyt-Tuff und in den Tuff-Mischsedimenten der Laacher Eruptionsphase. - Diss. Landwirtschaftl. Fakultät Univ. Göttingen; 83 S., 14 Abb., 7 Tab. - Auch in: Göttinger Bodenkundl. Ber., 11: 1-83; Göttingen 1969

[darin: Hünstollen (b. Göttingen), Leine (b. Northeim), Hoher Meißner (Bischhausen)/WMK, Lutteranger (Unter-Eichsfeld)]

-Hülsemann, P. [Hrsg.](1930): Die Bergwerke Deutschlands - Auf bergwirtschaftlicher und lagerstättenkundlicher Grundlage. - XI, 412 S., zahlr. Abb., Tab. 8 Kt.; (Enke) Stuttgart

-Hufmann, H. (1954): Mineralogische Untersuchungen an fünf Bodenprofilen über Basalt, Muschelkalk und Buntsandstein. - Heidelberger Beitr. Mineral. Petrogr., 4: 67-88, 3 Abb.; Berlin-GöttingenHeidelberg [Untersuchte Profile i. Lkr. Göttingen; Brunsberg, Bramburg, Steinberg, Bremke, Sauenberg]

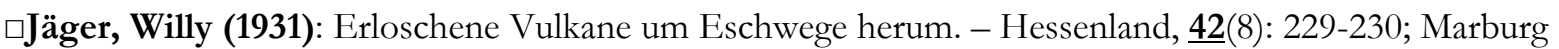

$\square$ Jordan, Johann Ludwig (1800): Mineralogische und chemische Beobachtungen und Erfahrungen. XXXVIII, 326 S., [1] Bl. Ill.; (Johann Christian Dieterich) Göttingen [darin S. 292-303, Kap. XIV: Aeußere Beschreibung und Zerlegung eines Kieselsinters aus dem Kohlenwerke des Meißners unweit Almerode $<$ Petrographie, Geochemie>]

- $\square$ Jordan, Johann Ludwig (1803): Mineralogische, berg- und hüttenmännische Reisebemerkungen vorzüglich in Hessen, Thüringen, am Rheine und im Seyn-Altenkirchner Gebiethe. - 288 S., 1 Tab., 3 Falt-Taf.; (Dieterich) Göttingen

[Regionalgeologie östl. Meißnervorland, „Riegelsdorfer“ [Richelsdorfer] Gebirge, Region um Schmalkalden]

OJudersleben, Georg (1972): Zur Petrologie des sedimentären Rotliegenden im Thüringer Wald und in seinem Vorland. - Jb. Geol., 4 (f. 1968): 181-289, 26 Abb., 4 Tab., 13 Taf.; Berlin

QKaemmel, Thomas (1968): Die Rolle der Metasomatose im Rahmen der Lagerstättengenese. - Ber. Dt. Ges. f. geol. Wiss., Reihe B, $\underline{\mathbf{3}}(2)$ : 183-191, 1 Abb., 1 Tab.; Berlin [darin erwähnt S. 185 Thüringer Wald; Abb. 1: Gestein d. Bhrg. Ohrdruf]

- $\square$ Kauter, Kurt (1962): Uran in Westdeutschland. - Z. angew. Geol., $\underline{8}(3): 129-132,1$ Übers.-Kt.; Berlin [darin: Richelsdorfer Gebirge, Umgebung Kassel, Sontra, Sulzburg i. Schwarzwald, Kaiserstuhel, Wittichen/Schwarzwald, Nordostbayerisches Grundgebirge: Weißenstadt, Tirschenreuth]

-Kharkwai, Amba Datt (1959): Über den Mineralbestand des Göttinger Lias. - Beitr. Mineral. Petrogr., 7: 45 - 62, 2 Abb., 11 Tab.; Berlin-Göttingen-Heidelberg

OKlaua, Dieter (1969): Sedimentpetrographische Untersuchungen der Rhätsandsteine Thüringes. Geologie, Bh. 64: 1-82, 23 Abb., 15 Tab.; Berlin [darin: Gesteine der Region Gotha-Arnstadt, Eisenach-Creuzburg]

-Kleusberg, Thomas \& Tietze, Klaus-Werner (1987): Rote Zirkone in Playa-Ablagerungen des Buntsandsteins der Hessischen Senke. - Geol. et Paläont., 21: 169-172, 2 Abb.; Marburg [darin: Richelsdorfer Gebirge] 
QKnoth, W. (1960): Über sedimentpetrographische Untersuchungen von Konglomerathorizonten des Eisenacher und Tambacher Oberrotliegendgebietes. - Ber. Geol. Ges. DDR, ㅍ: 62-63; Berlin

OKoch, Klaus (1978): Zur Entstehung von Tonmineralen im Kontaktbereich Basalt-Salinar. - Z. geol. Wiss., $\underline{\mathbf{6}}(6)$ : 733-747, 15 Abb.; Berlin

[Thür. Werra-Kalirevier]

$\square$ Köhler, Friedrich (1828): Ueber den Strahlkies von Großallmerode [Großalmerode] in Hessen. Annalen d. Physik u. Chemie, 14(1) (Ges. Rh.: 90): 91-97, Taf. II; Leipzig

-Koenen, Adolf v. (1905): Über Kalksandstein-Konkretionen und fossilführende Kalke a. d. Basis des Röths. - Z. dt. geol. Ges., 57: Briefl. Mitt: 156 - 157; Berlin

Referat in: N. Jb. Mineral. etc., 1908 (Bd. II): 85 (Stille); Stuttgart

[Aufschlüsse Lkr. Göttingen]

- •Kreuzer, H.; Besang, C.; Harre, W.; Mueller, Ullrich, H.-J. \& Vinken, R. (1973): K/Ar Datierungen an jungtertiäraren Basalten aus dem Vogelsberg und aus dem Raum zwischen Kassel und Göttingen. - Fortschr. Mineral., $\underline{\mathbf{5 0}}$, Beih. $\underline{\mathbf{3}}$ : 10-11; Stuttgart

[Darin: Südniedersächsische Basalte W' Göttingen]

-Krusch, P. (1919): Die Verteilung der Metallgehalte (Kupfer, Silber, Molybdän und Vanadin) im Richelsdorfer Gebirge. - Z. prakt. Geologie, 27: 76-84, 1 Abb.,; Halle (Saale)

-01Kubach, Isa (1945): Mineralogische Untersuchungen einiger Lößprofile Mitteldeutschlands. Chemie der Erde, 15(1/2): 7-25, 6 Abb., 10 Tab.; Jena [darin: 4 Lokalitäten Umgebung Hofgeismar; weiterhin Brotterode, Kattenbühl (Lkr. Göttingen?)]

-Kühn, Robert (1971): Beiträge zur Kenntnis der mitteleuropäischen Ulexit (= Boronatrocalcit)Vorkommen, insbesondere von Niederellenbach (Hessen). - Notizbl. Hess. L.-A. Bodenforsch., 99: 253 - 268, 1 Abb., 4 Tab., 3 Taf.; Wiesbaden

OKühn, Wolfgang (1991): Buntmetallführende Ton- und Sandsteine des Keupers im Thüringer Becken und in angrenzenden Gebieten. - $\mathrm{Cu}, \mathrm{Pb}, \mathrm{Zn}$-bearing pelite- and sandstone-layers of Keuper (Upper Trias) in Thuringian Basin and adjacent areas. - Chemie der Erde, 51(2/3): 131-140, 3 Abb., 1 Tab.; Jena

$\square$ Kühnel, F. W. (o. J.): Bodenschätze des Werra-Meißner-Kreises. - Schriftenreihe Kreissparkasse Eschwege, H. $\underline{\text {; }} 36$ S., Abb.; [Hrsg. Kreissparkasse Eschwege] Eschwege

- Kuster-Wendenburg, Elisabeth (1980): Auf der Suche nach Mineralien in Nordhessen. - Hessischer Gebirgsbote, $\underline{\mathbf{8 1}}(4): 125$ - 126, 3 Abb., 1 Kt.; Melsungen [darin: Richelsdorfer Gebirge]

-Lang, Heinrich Otto (1881): Über Sedimentär-Gesteine aus der Umgebung von Göttingen. - Z. dt. geol. Ges., 33: 217-281; Berlin

Referat in: N. Jb. Mineral. etc., $\underline{1882}$ (Bd. 2): 68-71 (Referat H. Bücking); Stuttgart [Petrographie]

OLangbein, Rolf (1964): Geochemische Untersuchungen an Salztonen des Zechsteins im SüdharzKalirevier. - Chemie der Erde, 23: 1-70, 28 Abb., 6 Tab.; Jena

OLange, T. (1913): Ueber die Amphibolite des nordwestlichen Thüringer Waldes. - Jb. Preuß. Geol. Landesanst., $\underline{\mathbf{3 1}}$ (Teil I) (f. 1911): 1-52, 2 Abb., Taf. 1-3; Berlin

Referat in: Mitt. Geogr. Ges. f. Thür., $\underline{\mathbf{3 0}} 226$ (E. Piltz); Jena 1912

[Ruhlaer Kristallin]

- $\square$ OlLeonhard, Karl Caesar [v.] (1805-1809): Handbuch einer allgemeinen topographischen Mineralogie. - Bd. 1, 479 S., ersch. 1805; Bd. 2, 568 S., ersch. 1808; Bd. 3, 432 S., ersch. 1809; J. Ch. 
Hermann) Frankufrt/M.

[Verzeichnis von Mineralfundstätten nach Mineralen geordnet.; darin: (Groß-) Almerode, Hirschberg, Epterode, Eschwege, Kassel, Meißner, Oberkaufungen, Richelsdorf, Göttingen, Orte i. Thüringen]

- $\square$ Lippmann, Friedrich (1952): Mineralogische Untersuchungen an einigen nordhessischen

Tertiärtonen. - Diss. Univ. Göttingen 1952; 73, IV gez. Bl.

[Großalmerode, Oberkaufungen]

$\square$ Lippmann, Friedrich (1953): Der Mineralbestand der Tone von Großalmerode. - Der Sprechsaal - f. Keramik - Glas - Email, $\underline{\mathbf{8 6}}(9):$ 218-224, 10 Abb., 6 Tab.; Coburg

-Lippmann, Friedrich (1958): Die Tonminerale des Göttinger Röt. - Fortschr. Mineral., $\underline{35}$ (1957): 28 30; Stuttgart

OLötzsch, Frieder (1968): Zur metallogenetischen Analyse des Südens der DDR. - Z. angew. Geol., 14(7): 338-355, 7 Abb., 1 Tab.; Berlin [darin: „Westthüringische metallogenetische Zone"]

-Loewer (Generalarzt I. Classe a. D.) (1893): Waffen und Geräthe der Steinzeit in Hessen in geologischer Beziehung. - Ber. Vereins Naturkde. z. Kassel, $\underline{38}$ (1892/1893): 16-28; Kassel

-Ludwig, Helga \& Rentzsch, Johannes (1967): Das Sanderzproblem - Ein Beitrag zur Genese des Kupferschiefers. - Ber. Dt. Ges. geol. Wiss., Reihe B, 12(1): 3-12, 7 Taf.; Berlin [darin: Richelsdorfer Gebirge]

OLuedecke (1878): Tridymit am Spiessberg bei Friedrichroda. - Z. gesammt. Naturwiss., $\underline{\mathbf{5 1}}$ (= 3. F., $\underline{3})$ : 147, 340; Berlin

OLuedecke, Otto (1885): Ueber Thüringer Mineralvorkommnisse. - Z. Kristallographie, 10: 187-201, 6 Abb.; Leipzig

[darin: Anatas vom Brand b. Oberhof, Orthit von Brotterode, Orthit v. Glasbachskopfe u. Straße v. Schloss Altenstein n. Ruhla]

QLützner, Harald \& Rentzsch, Johannes (1975): Sedimentation und Metallogenie in einem intramontanen Becken der variszischen Molasse. - Z. geol. Wiss., $\underline{\mathbf{3}}(11)$ : 1473-1490, 5 Abb., 2 Tab.; Berlin [Goldlauterer Becken/Thüringer Wald]

OMädler, Jonas (1993): Scheelitmineralistion im Augengneis von Steinbach bei Bad Liebenstein/Thüringer Wald - Geowiss. Mitt. Thüringen, 11: 129-130; Weimar

OMädler, Jonas \& Schröder, Norbert (1969): Zur Kenntnis der Rückenmineralisation bei Bad Liebenstein-Schweina (Thüringer Wald). - Ber. Dt. Ges. geol. Wiss., Reihe B, 14(3): 243-256, 3 Abb., 1 Tab., 6 Taf.; Berlin

[Calcit, Schwerspat, Speiskobalt]

口Mädler, Jonas \& Voigt, Heinz (1994): Aufbau, Petrographie und Genese eines Systems zusammengesetzter Gesteinsgänge am Südrand des Ruhlaer Kristallins westlich Seeligenthal/Thüringer Wald (ehemaliger Gieselsberg-Schacht) - Geowiss. Mitt. Thüringen, 2: 1-28, 12 Abb., 4 Tab.; Weimar

OMeinel, Günther (1993): Die Bildung der Gangmineralisationen Thüringens. - Geowiss. Mitt. Thür., Beih, 1: 1-111, 21 Abb.; Weimar [darin: Thüringer Wald]

QMeinel, Günter \& Mädler, Jonas (1995): Bodenschätze [in Thüringen] - Erze. - In: Seidel, Gerd [Hrsg.]: Geologie von Thüringen. - 1. Aufl.; S. 423-433; Stuttgart 1995 
OMeinel, Günter \& Mädler, Jonas (2003): Bodenschätze [in Thüringen] - Erze. - In: Seidel, Gerd [Hrsg.]: Geologie von Thüringen. - 2., neu bearb. Aufl.; S. 455-464; Stuttgart 2003

-Menschel, G. \& Usdowski, E. (1975): Experimentelle Untersuchungen über die Stabilität von CuKarbonat zur Klärng der Genese von Azurit im Cornberger Sandstein. - Contrib. Mineral. Petrol. (Beitr. Mineral. Petrogr.), 49 (2): 141-147, 1 Abb., 3 Tab.; Berlin-Heidelberg

-Messer, Ernst (1978): Die nordhessischen Kaligruben. - Kali u. Steinsalz, $\underline{7}$ (7): 306-318, 11 Abb., 6 Tab.; Essen

[Zechstein-Stratigraphie, Lagerstättengeologie, Bergbau; Hattorf, Wintershall, Neuhof-Ellers]

$\square$ Mötzing, Kurt (1975): Die Alaunberghalde bei Epterode. - Hessischer Gebirgsbote, $\underline{76}(2)$ : 44-45; Melsungen

$\square$ Mügge, O. (1921): Zur Kenntnis der Petrographie des älteren Palaeozoicums zwischen Albungen und Witzenhausen, besonders des Variolits. - Jb. Preuß. geol. Landesanst., 40 (f. 1919): 201-217; Berlin

OMühlenberg, A. (1908): Das Konglomerat des Gottlob bei Friedrichroda, ein Rhyakkumulat. Typus einer neuen Gesteinsart. - Diss. Univ. Halle 1908, 55 S.; (Karras) Halle

-Namenskürzel (lh) (1956): Uranfunde in Nordhessen - Mit dem Geigerzähler in den Sontraer Gruben - Atomminister Strauß soll einen Zuschuß geben - Seit einigen Wochen Suche auch im Zonengrenzgebiet. - Werra-Rundschau, 1956; Nr. 213 v. 12.9.1956, S. 3; Eschwege

-Namenskürzel [u](1965): Knollen wie Blumenkohl: Seltenes Mineral Ulexit erstmals in Europa gefunden - im Gipsbruch Niederellenbach (Kreis Rotenburg). - HA - Fulda-Bote, 1965, Nr. 81 v. 6.4.1965, 6 Abb.; Rotenburg/Fulda

-Namenskürzel (2007): Gold im Stadtwald - Wissenschafter entdecken begehrtes Edelmetall $<$ Wolfhagen, Lkr. Kassel>. - Werra-Rundschau, 2007; Nr. 278 v. 29.11.2007; Eschwege

$\square$ Naumann, Peter (1981): Amethyst, Achat, Chalcedon und Hornstein von Retterode bei Hessisch Lichtenau/Hessen. - Der Aufschluß, 32, Beilage Aktuell 9-81; S. 8-9; Heidelberg

-Naumann, Peter (1983): Fossilien und Mineralien in Nordhessen. - Jb. Lkr. Kassel, 1983: 38 - 39; Kassel

$\square$ Naumann, Peter (1986): Tonjaspis und Porzellanjaspis vom „Bühlchen“ bei Epterode/Meißner. Hessischer Gebirgsbote, 87(3): 105-106; Melsungen

$\square$ Naumann, Peter (1993): Farbsteine von Hessisch Lichtenau und Retterode/Meißner. - Hessischer Gebirgsbote, 94(2): 69; Melsungen

[SiO2-Modifikationen, Amethyst, Chalcedon, Jaspis, Hornstein u.a.]

- $\square$ Naumann, Peter (1994): Schwefel in Nordhessen - Funde in Hundelshausen und Konnefeld. Hessischer Gebirgsbote, 95(1): 14; Melsungen

$\square$ Naumann, Peter (1996): Der Porzellanjaspis von Epterode/Meißner. - Geol.-mineral. Mitt. Nordhessen, 10; 33 S., 9 Abb.; (Selbstverlag Naumann) Hofgeismar

$\square$ Naumann, Peter (1999): Retinit und Quarz in der Braunkohle von Großalmerode. - Hessischer Gebirgsbote, 100: 15; Melsungen

ONebel, Brigitte \& Nebel, Jürgen (1969): Mineralogische und geochemische Untersuchungen an Höhleneinlagerungen. - Geologie, 18(10): 1214-1230, 10 Abb., 3 Tab.; Berlin [Einlagerungen: Höhlenlehm, Tropfstein-Kalksinter; darin: Altensteiner Höhle] 
$\square$ Neuroth, Heike (1997): K/Ar-Datierungen an detritischen Muskoviten - „Sicherungskopien“ orogener Prozesse am Beispiel der Varisziden. - Göttinger Arbeiten z. Geologie u. Paläontologie, 2; V, 143 S., 29 Ab.., 7 Tab.; Göttingen

[Darin: Devon Steinbruch Schafhof Höllental/Unterwerra-Grauwackengebirge]

-Niemann, Hans (1960): Untersuchungen am Grauen Salzton der Grube „Königshall - Hindenburg“ Reyershausen bei Göttingen. - Beitr. Mineral. Petrogr., 7: 137 - 165, 7 Abb., 15 Tab.; BerlinGöttingen-Heidelberg - auch als Diss. Univ. Göttingen 1959, 49 gez. Bl., Abb.

$\square$ Nölke, G. (1940/41): Über rezente und fossile Verwitterung des unteren Buntsandsteins im Gebiet des Harzes, der Hain- und Windleite sowie des Kaufunger Waldes. - In: Blanck, E. \& Melville, R.: Untersuchungen über die rezente und fossile Verwitterung der Gesteine, innerhalb Deutschlands, zugleich ein Beitrag zur Kenntnis der alten Landoberflächenbildungen der deutschen Mittelgebirgsländer - Teil I. - Chemie der Erde, 13 (2): 99 - 191; hier: S. 135 - 169, 31 Tab.; Jena 1940/41

QOelsner, Oscar (1956): Zur Entstehung der saxonischen Lagerstätten, speziell auf den Randspalten des Thüringer Waldes. - Geologie, $\underline{\mathbf{5}}(8)$ : 685-694; Berlin

OPensold, G.; Theilig, F. \& Thomaser, P. (1964): Auftreten von Sellait im Hauptdolomit des Zechsteins von Thüringen. - Z. angew. Geol., 10 (2): 75-77, 2 Abb.; Berlin [darin: Funde aus den Strukturen Hainich (Eigenrieden), Keula, Gebra-Lohra]

OPhilippi (1843): Kohlensandstein wird Dolerit ähnlich durch Melaphyr. - N. Jb. Mineral. etc., 1843: 594595 (Briefl. Mittl); Stuttgart

[Vorkommen zw. Kleinschmalkalden u. Friedrichroda]

- $\square$ Pryor, Wayne A. (1971): Petrology of the Weißliegendes in the Werra-Fulda areas, Germany. - Geol. Rundschau, 60: 524-552, 13 Abb., 3 Tab.; Stuttgart [darin: Cornberg, Stbr. Forsthaus Schmelzhütte b. Frankershausen]

-Püttmann, W.; Merz, C. \& Speczik, S. (1991): Oxidation of organic material in the Kupferschiefer and its relation to mineralization processes. - Zentralbl. Geol. Paläont. Teil1: 1991(4), S. 957-974, 9 fig., 3 tabl.; Stuttgart

[Richelsdorfer Gebirge/Spessart-Rhön]

OPuff, Peter \& Radzinski, Karl-Heinrich (1976): Zur Paläogeographie und lagerstättenkundlichen Bedeutung des tieferen und mittleren Buntsandsteins im südlichen Teil der DDR. - Z. geol. Wiss., 4(11): 1483-1503, 12 Abb.; Berlin

[Paläogeographische Karten, auch Weststhüringen umfassend]

-Putzer, Hanfrid (1972): Kupferschiefer in Zambia und Mitteleuropa, ein paläogeographischer Vergleich. - Geol. Jb., 90: 415-430, 3 Abb., 3 Tab.; Hannover [darin: Richelsdorfer Gebirge]

-Rammelsberg, C. (1897): Die Arsenverbindungen des Eisens, Nickels und Kobalts, bezogen auf eine einzige Grundmischung. - N. Jb. Mineral. etc., 1897(Bd. II): 45-66; Stuttgart [darin: Richeldorfer Gebirge, Wolfach, Reinerzau, Wittichen]

ORau, Dietrich \& Heide, Klaus (1966): Über Tonmineraluntersuchungen an thüringischen LößBodentypen. - Geologie, 15 (7): 833 - 840, 4 Abb., 1 Tab.; Berlin [darin: Bodenprofil Lokalität Körner/Unstrut-Hainich-Kreis]

@Reh, Helmut \& Schröder, Norbert (1974): Bodenschätze [in Thüringen] - Erze. - In: Hoppe, Walter \& Seidel, Gerd [Hrsg.]: Geologie von Thüringen [Bezirke Erfurt, Gera, Suhl]. - S. 867-897, Abb. 172-182, Tab. 108; (Haack) Gotha-Leipzig 1974 
OReidemeister, Carl (1912): Über Salztone und Plattendolomit im Bereiche der norddeutschen Kalisalzlagerstätten. - Kali, etc., $\underline{\mathbf{6}}(10)$ : 226-234, Fig. 69-73, [4] Tab., 4 Diagr.; Halle

[Mineralogie - darin: Südharz-Kalirevier: Bleicherode, Bischofferode; Thür. Werra-Kalirevier: Dietlas, Kaiseroda]

- $\square$ Qण Remélé, Adolf (1873): Uebersicht der Hauptgesteinsarten des K Preuszischen Staatsgebietes mit Berücksichtigung angrenzender Länder. - 58 S.; (Julius Springer) Berlin

[HE, WMK, THÜ, NIE - Knappe petrographische Charakterisierung mit ausführlichen Angaben zur Verbreitung]

aORentzsch, Johannes (1964): Der Kenntnisstand über die Metall- und Erzverteilung im Kupferschiefer. - Z. angew. Geol., 10(6); 281-288, 1 Abb.; Berlin [darin: Richelsdorfer Gebirge]

- Rentzsch, Johannes \& Friedrich, Günther (2003): Zur Herkunft der Metalle der Kupferschiefervererzung in Deutschland. - Metallbilanz im Präzechstein und in der Erzführenden Zone an der Zechsteinbasis. - Hallesches Jb. Geowiss, Reihe B (Geol. Mineral.), 25: 1-20, 3 Abb., 4 Tab.; Halle (Saale)

ORichter, R. (1859): Zur Petrographie des Thüringerwaldes. - Z. gesammt. Naturwiss., 14: 352-353; Berlin [Magmatite, Fleckschiefer]

ORösler, H. J. \& Pilot, J. (1967): Die zeitliche Einstufung der sächsisch-thüringischen Ganglagerstätten mit Hilfe der K-Ar-Methode. - Freiberger Forschungshefte, Reihe C, 209: 87-98, 2 Abb., 1 Tab.; Leipzig [darin: Thüringer Wald: Ilmenau-Gehren, Schmalkaldener Revier, Schönbrunn]

ORykart, Rudolf (1995): Zur Entstehung der sternförmigen Achate in sauren Vulkaniten. - Der Aufschluss, 46: 33-36, 6 Abb.; Heidelberg [Bezugnahme a. Fde. Thüringer Wald]

- -Sandberger, F. (1875): Wapplerit bei Wittichen und Riechelsdorf, ...- N. Jb. Mineral. etc., 1875: 853854 (Briefl. Mitt.); Stuttgart

هSchade, Hartmut (1984): Bergbauliche Lagerstätten im Bereich des Blattes [4925) Sontra. - Geol. Jb. Hessen, 112: 165 - 178, 2 Abb.; Wiesbaden

-Scheffer, F.; Meyer, B. \& Kalk, E. (1958): Mineraluntersuchungen am Würm-Löß südniedersächsicher Lößfluren als Voraussetzung für die Mineralanalyse verschiedener Lößbodentypen. - Chemie der Erde, 19 (4): 338 - 360, 6 Abb.; Jena

aScheffer, Reinhard (1973): Die Mineralien und Fossilien der ehemaligen Grube „Schnepfenbusch“ im Richelsdorfer Gebirge/Nordhessen.- Der Aufschluss, 24(7/8): 319-321, 1 Abb.; Göttingen

OScheibe, R. (1907): (Bericht über wissenschaftliche Ergebnisse 1903-1904) Bericht über Kontaktgesteine im Kleinen Thüringer Wald auf Blatt Schleusingen und über Granit, Rothliegendes und Zechstein südwestlich Mehlis auf Blatt Schwarza (Mehlis) auf Grund der Aufnahmen in den Jahren 1903 und 1904. - Jb. Preuß. Geol. Landesanst., $\underline{25}$ (f. 1904): 697-715, Taf. 22; Berlin

口Schmetzer, Karl; Schnorrer-Köhler, Günther \& Medenbach, Olaf (1985): Wülfingite, epsilon$\mathrm{Zn}(\mathrm{OH})_{2}$ and Simonkolleite, $\mathrm{Zn}(\mathrm{OH})_{5} \mathrm{CL}_{8} 2 \mathrm{H}_{2} \mathrm{O}$, two new minerals from Richelsdorf, Hesse, F. R. G. - N. Jb. Miner. Mh., 1985: 145-154, 3 fig., 4 tabl.; Stuttgart

[Mineralfundort: Richelsdorfer Hütte] 
OSchmid, E. E. (1876): Der Ehrenberg bei Ilmenau. - Jenaische Z. f. Naturwiss., 10(1)[N.F. 3]: 56-124, Taf. III-V; Jena

[Mineralogie, Petrographie]

- dSchmidt, Franz-Peter (1985): Erzkontrolle im Kupferschiefer Osthessens, Bundesrepublik Deutschland. - Diss. Univ. Aachen 1985 [unveröff.]; 158 (48) S., Ill., graph. Darst.; Aachen [Richelsdorfer Gebirge]

OSchmidt, Ralf (1986): Zur Gangmineralisation im Steinbruch Nesselgrund bei Schnellbach/Thür. Veröff./ Naturhist. Museum Schleusingen, 1: 15-40, 33 Abb.; Schleusingen

oSchmidt, Ralf (1989): Sekundärminerale des Bergbaureviers Glücksbrunn bei Schweina/Thür. Veröff./ Naturhist. Museum Schleusingen, 4: 41-46, 12 Abb.; Schleusingen

OSchneider, Hans-Eckart (1974): Bodenschätze [in Thüringen] - Steine und Erden. - In: Hoppe, Walter \& Seidel, Gerd [Hrsg.]: Geologie von Thüringen [Bezirke Erfurt, Gera, Suhl]. - S. 918-939, Abb. 189-190, Tab. 111-116; (Haack) Gotha-Leipzig 1974

OSchneider, Hans-Eckart (1995): Bodenschätze [in Thüringen] - Steine und Erden. - In: Seidel, Gerd [Hrsg.]: Geologie von Thüringen. - 1. Aufl.; S. 444-452, 1 Tab.; Stuttgart 1995

OSchneider, Hans-Eckart (2003): Bodenschätze [in Thüringen] - Steine und Erden. - In: Seidel, Gerd [Hrsg.]: Geologie von Thüringen. - 2., neu bearb. Aufl.; S. 487-529, 8 Tab.; Stuttgart 2003

- DSchneiderhöhn, Hans (1949): Schwerspatgänge und pseudomorphe Quarzgänge in Westdeutschland. N. Jb. Mineral., Abt. A, 1949: 191-202, 2 Abb.; Stuttgart [darin: Richelsdorfer Gebirge (Kurzdarst.)]

-Schneiderhöhn, Paula (1965): Nontronit vom Hohen Hagen und Chloropal vom Meenser Steinberg bei Göttingen. - Tschermaks Mineral. petrogr. Mitt., (3. F.) 10: 385-399; Wien

-Schneiderhöhn, Paula (1978): Der Chloropal vom Meenser Steinberg. - In: Koritnig, Sigmund [Schriftltg.]: Zur Mineralogie und Geologie der Umgebung von Göttingen - mit Westharz und Teilen des Nordhessischen Berglandes. - Sdbd. 28: 182-183; Heidelberg 1978

-Schneiderhöhn, Paula (1978): Beitrag zur Petrographie des „Mühlsteinquarzites“vom Kattenbühl bei Hannoversch Münden. - In: Koritnig, Sigmund [Schriftltg.]: Zur Mineralogie und Geologie der Umgebung von Göttingen - mit Westharz und Teilen des Nordhessischen Berglandes. - Sdbd. 288: 184-186; Heidelberg 1978

-Schnorrer-Köhler, Günter (1983): Die Mineralien des Richelsdorfer Gebirges. - Der Aufschluss, $\underline{\mathbf{3 4}}$ : 534-540, 1 Abb.; Heidelberg

aSchnorrer-Köhler, Günter (1984): Die Mineralien des Richelsdorfer Gebirges (1. Fortsetzung). - Der Aufschluss, 35: 7-20, 7 Abb.; Heidelberg

口Schnorrer-Köhler, Günter (1984): Die Mineralien des Richelsdorfer Gebirges (2. Fortsetzung). - Der Aufschluss, 35: 37-62, 20 Abb.; Heidelberg

هSchnorrer-Köhler, Günter (1984): Die Mineralien des Richelsdorfer Gebirges (3. Fortsetzung). - Der Aufschluss, 35: 93-109, 24 Abb.; Heidelberg

口Schnorrer-Köhler, Günter (1984): Die Mineralien des Richelsdorfer Gebirges (Schluß). - Der Aufschluss, 35: 119-136, 17 Abb.; Heidelberg 


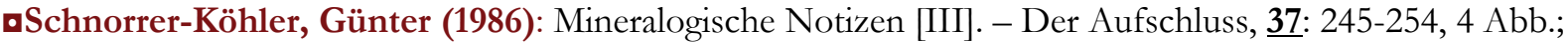
Heidelberg

[Richelsdorfer Gebirge/Hessen]

aSchnorrer-Köhler, Günter (1988): Mineralogische Notizen [IV].- Der Aufschluss, $\underline{\text { 39: }}$ 153-168, 11 Abb.; Heidelberg

[darin: S. 162 - 165: „Richelsdorfer Gebirge“]

-Schumacher, C. (1985): Die Kupfervererzungen des basalen Zechsteins im Rahmen der sedimentären Entwicklung des Werra-Fulda-Beckens. - Diss. TU Braunschweig; 142 S., 57 Abb., 6 Taf.

OSchust, F.; Büsch, W. \& Gotte, W. (2000): Über die Metamorphite der Brg. Schleusingen 3/63 (Südthüringen) und ihre geologische Position. - Z. geol. Wiss., 28(3/4): 381-396, 9 Abb.; Berlin

-Simon, C. (1889): Entstehung von Quarziten der Braunkohlenformation. - Ber. Vereins Naturkde. z. Kassel, 34/35: 86-88; Kassel

[Trappquarzite Habichtswald]

-Smith, D. B. (1971): Discussion: W.A. PRYOR „Petrology of the Weissliegendes Sandstones in the Harz and Werra-Fulda areas, Germany“. - Geol. Rundschau, 60: 1600-1602; Stuttgart

oStruve, [Heinrich] v. (1812): Über eine Suitensammlung [Gesteinssammlung] vom Habichtswalde. Tb. Mineral., 6: 395-396; Frankf./M.

- $\square$ Strouhal, Arno \& Hendriks, Frits (1988): Die Tonmineralassoziation in der Trias von Bad Hersfeld und von Eschwege unter besonderer Berücksichtigung der Avicula-Schichten. - In: Richter, Detlev K. [Hrsg.]: 3. Treffen deutschsprachiger Sedimentologen 23.-26. Mai 1988 in Bochum. - Bochumer Geologische u. Geotechnische Arbeiten, 29: 216-219, 1 Abb.; Bochum

-Süsse, Peter \& Schnorrer-Köhler, Günther (1983): Richelsdorfit, $\mathrm{Ca}_{2} \mathrm{Cu}_{5} \mathrm{Sb}\left(\mathrm{Cl} /(\mathrm{OH})_{6} /\left(\mathrm{AsO}_{4}\right)_{4} \mathrm{x} 6\right.$ H2O - ein neues Mineral. - N. Jb. Mineral., Mh., 1983: 145-150, 2 Abb., 4 Tab.; Stuttgart [Richelsdorfer Gebirge]

-Thewalt, Ulf \& Gregor, Hans-Joachim (2005): Die eozänen Braunkohlenschichten aus dem Untertagebau Stolzenbach bei Kassel (PreußenElektra, Niederhessen)- V. Die Minerale. - Nebentitel: Untertagebau Stolzenbach der PreussenElektra Niederhessen: Geologie - Paläophytologie Mineralogie (Festband VIKTOR OSCHKINIS). - Documena naturae, 156: 113-123, 5 Abb., 3 Taf.; München

ØThomas, Rainer \& Blankenburg, Hans-Joachim (1981): Erste Ergebnisse über Einschlußuntersuchungen an Quarzen aus Achatmandeln und -Kugeln basischer und saurer Vulkanite. - Z. geol. Wiss., 9(6): 625-633, 10 Abb., 1 Tab.; Berlin [darin Fde. Thüringer Wald: Oberhof, Schneekopf]

口Thomson, S. N. \& Zeh, A. (2000): Fission-track thermochronology of the Ruhla Crystalline Complex; new constraints of the past - Variscan thermal evolution of the NW Saxo-Bohemian Massif. Tectonophysics, $\underline{\mathbf{3 2 4}}$ : 17-35, 8 figs., 1 tabl.; Amsterdam

Ø'Tischendorf, Gerhard; Lächelt, Siegfried \& Rentzsch, Johannes (1989): Zu Problemen der Metallogenie in der Deutschen Demokratischen Republik - I. Die metallogenetische Rayonierung des Territoriums der DDR. - Z. angew. Geol., 15(9): 455-472, 5 Abb.; Berlin [darin: Westthüringen, Thüringer Wald]

QTischendorf, Gerhard \& Schwab, Günther (1989): Metallogenesis of the Transition Period between Hercynian Orogenesis and Subsequent Platform Stage in Central Europe. - Z. Geol. Wiss., 17(8): 815842, 3 fig., 3 tabl.; Berlin [Bezugn. a. Thüringer Wald] 
-Tonn, Harald (1990): A. Untersuchungen an Flüssigkeitseinschlüssen als Beitrag zur Genese der Kupferschiefermineralisation (Mikrothermometrie, Kathodenlumineszenz, REM-EDX Mikroanalytik). - B. Geologische Kartierung im Bereich Cornberg-Nentershausen (Hessen) TK 4925 Sontra .; Dipl.-Arb. + Dipl.-Kart. [unveröff.] Univ. Göttingen; 60S., 40 S., 5 Taf., 3 Anl.

-Tonn, H.; Schmidt, F.-P.; Porada, H. \& Horn, E.-E. (1987): Fluid inclusion studies of high grade and structure bound Kupferschiefer mineralization of Richelsdorf and Spessart/Rhön [Posterbeitrag]. - In: Klare, Bernd \& Schröder, Bernd [eds.]: Zechstein 1987 - International Symposium Kassel/Hannover [28. April to 9. May, 1987] - Abstracts, Posters, Program; S. 148; [Subkommission Perm/Trias der Stratigraphischen Kommission der DUGW/IUGS] Bochum 1987

口Udluft, Hans (1953): Das „Bühlchen“ bei Epterode - eine alte Alaunbergbauhalde. - Notizbl. Hess. L.A. Bodenforsch., 83 (6. F., H. 4): 255 - 257; Wiesbaden

$\square$ Urban, Heinz (1951): Korngrößenverteilung und Mineralinhalt des Glashafentons von Großalmerode. - In: Silikattechnik $\underline{2}(3):$ 71-73, 5 Abb.; Berlin

OVan der Klauw, S.; Rauche, H. \& Lützner, H. (1997): Mineralparagenesen und Mikrostrukturen in Gesteinsfragmenten im Detritus permosilesischer Sedimente im westlichen Thüringer Wald: Hinweise auf eine differenzierte Hebung und Abtragung des Ruhlaer Kristallins (Vortragskurzfassung). - In: Büchel, Georg \& Lützner, Harald (Hrsg.): Regionale Geologie von Mitteleuropa Geodynamische Prozesse zwischen Alpen und Nordatlantik - 149. Hauptversammlung - Deutsche Geologische Gesellschaft und Jahreshauptversammlung der Fachsektion Geoinformatik - Jena 27.09.3.10.1997 - Kurzfassung der Vorträge und Poster. - Schriftenrh. Dt. Geol. Ges., 2: 71; Hannover 1997

-Vavra, Norbert (2005): Die eozänen Braunkohlenschichten aus dem Untertagebau Stolzenbach bei Kassel (PreußenElektra, Niederhessen)- IV. Analyse des Bernsteins. - Nebentitel: Untertagebau Stolzenbach der PreussenElektra Niederhessen: Geologie - Paläophytologie - Mineralogie (Festband VIKTOR OSCHKINIS). - Documena naturae, 156: 95-111, 4 Abb., 1 Tab.., 3 Taf.; München

QVochten, R.; Doorselaer, M. van; Springel, Karel \& Fabig, M. (1993): Stahlberg in Thüringen Eine neue Fundstelle für Tirolit. - Lapis, 18(12): 18-20, 8 Abb.; München

OVoigt, Johann Carl Wilhelm (1782-1785): Mineralogische Reisen durch das Herzogthum Weimar und Eisenach und einige angränzende Gegenden - in Briefen. - Erster Theil; 8, 151 S., 3, 6 graph. Darst.; (Buchhdlg. d. Gelehrten) Dessau 1782. - Zweyter Theil; 4, 134 S., 9; (C.L. Hoffmann's sel. Wwe u. Erben) Weimar

- $\square$ OVoigt, Joh. Carl Wilh. (1797): Practische Gebirgskunde. - 2., verm. Aufl.; XVI, 286 S. [1 Bl.]; (Industrie-Comptoir) Weimar [darin: S. 128 Rotliegend-Sandstein bei Eisenach; S. 159 Profilbeschr. Zechstein/Rotliegend Richelsdorfer Gebirge, S. 173, 174, 178,179,205 Meissner; S. 193 Vulcanische Brekkzie Weißenstein/Wilhelhmshöhe b. Kassel]

OVoigt, [Johann Carl Wilhelm](1808): Über Starsteine von Manebach. - Tb. Mineral., 2: 385-386; Frankfurt/M.

[Starsteine: Versteinertes Holz]

OVollstädt, H.; Schmidt, R. \& Weiß, St. (1991): Mineralfundstellen - Thüringen und Vogtland. Beschreibung von 51 Fundstellen mit mehr als 70 Einzelfundstellen... - 128 S., 60 Abb., 4 Übers.-Kt., 32 Detail-Kt.; (Weise) München

OWagenbreth, Otfried (1971): Die Bedeutung der thüringischen Erzlagerstätten für die Entwicklung der Lagerstättenlehre. - Geologie, 20 (4/5): 609-623, 6 Abb.; Berlin 
$\square$ Waitz von Eschen (1880): Das Vorkommen von Schwefelkies in Thon von Grossalmerode [Vortragskurzfassung]. - Abh. Ber. Vereins f. Naturkunde z. Kassel; 26/27: 47-48 (Berichte); Kasssel

-Weber, Jutta \& Ricken, Werner (2005): Quartz cementation and related sedimentary archictecture of the Triassic Solling Formation, Reinhardswald Basin, Germany. - Sedimentary geology, 175(1-4): 459477, 12 fig.; Amsterdam

-Weiss, Stefan (1990): Atlas der Mineralfundstellen in Deutschland-West. Beschreibung von 1038 Fundstellen im Gebiet von Deutschland-West. - Mit 56 farbigen Kartenausschnitten im Maßstab 1 : 30000 mit Fundstellen-Eintragungen. - 319 S.; (Verlag Christian Weise) München [darin: Niedersachsen, Nordhessen]

- $\square$ Wilke, Hans-Jürgen (1981): Mineralfundstellen - Hessen. - Reihe: Mineralfundstellen, $\underline{7}$; 2 . korrig. Aufl. 1981; 240 S., 61 SW-Abb., 16 Farb-Taf., zahrl. Übers.-Kt.; (Weise) München

OWolf, Manfred (1964): Der Floßberggangzug bei Ilmenau und Gehren. - Freiberger Forschungshefte, Reihe C, 148: 1-157, 78 Abb., 7 Tab.; Leipzig

OZeh, Armin (1999): Zur Metamorphose-Entwicklung der Mitteldeutschen Kristallinzone im Bereich Thüringens: Kenntnisstand aus dem Ruhlaer und Kyffhäuser Kristallin. - Beitr. Geol. Thür., N.F., $\underline{\mathbf{6}}$ : 249-268, 5 Abb.; Jena

QZeh, A. (2001): Reconstruction of a prograde P-T path from zoned garnet and mineral inclusions using P-T pseudosections - problems of fractionation and changing fluid compositions. - DMG-Tagung Potsdam - Ber. Dt. Mineral. Ges. (Beih. Europ. J. Mineral.), 13: 203; Stuttgart

OZeh, A. (2002): SHRIMP-U/Pb zircon data of the Ruhla Crystalline Complex, Mid-German Crystalline Rise, provenance and climax of metamorphism. - In: Niebuhr, Birgit [Hrsg.]: GEO 2002 - Planet Erde: Vergangenheit, Entwickling, Zukunft/... 1.-5. Oktober 2002 in Würzburg -Programm und Kurzfassungen. - Programme and Abstracts. - Schriftenrh. Dt. Geol. Ges., 21: 360-361; Hannover 2002

@Zeh, A., Wunderlich, J., Okrusch, M., Werner, C.D. \& Mädler, J. (1995): Distribution of Index Minerals in the Ruhla Crystalline Complex, Mid German Crystalline Rise: A First Interpretation. - Zbl. Geol. Paläont. - Teil 1, 1993(9/10): 1459-1470, 3 figl; Stuttgart

OZeh, A., Hansch, R., Brätz, H. \& Bombach, K. (2000): Herkunft und Verwitterung von Granitgeröllen in Rotliegendsedimenten des nordwestlichen Thüringer Waldes - Petrographische, geochemische und Zirkon-Untersuchungen. - N. Jb. Geol. Paläont., Abh., 218: 173-199, 5 Abb., 8 Tab.; Stuttgart

QZeh, Armin \& Brätz, Helene (2002): Timing of Late Carboniferous/Permian Granite and Granite Porphyry Intrusions in the Ruhla Crystalline Complex (Central Germany) - New Constraints from SHRIMP and ${ }^{207} \mathrm{~Pb} /{ }^{206} \mathrm{~Pb}$ Single Zircon Dating. - Chemie der Erde, 62 (1-4): 303-316, 4 fig., 2 tab.; Jena

@Zeh, Armin, Williams, Ian S.; Brätz, Helene \& Millar, Ian L. (2003): Different age response of zircon and monazite during the tectono-metamorphic evolution of a high grade paragneiss from the Ruhla Crystalline Complex, central Germany. - Contrib. Mineral. Petrol., 145: 691-706, 6 fig., 6 tabl.; Berlin-Heidelberg

OZeh, A.; Cosca, M.; Brätz, H.; Okrusch, M. \& Tichomirowa, M. (2000): Simultaneous horst-basin formation and magmatism during Late Variscan Transtension: Evidence from 40Ar/39Ar and $207 \mathrm{~Pb} / 206 \mathrm{~Pb}$ geochronology in the Ruhla Crystalline Complex. - Int. J. Earth Sciences, $\underline{89}: 52-71,12$ fig., 2 tab.; Berlin-Heidelberg 
$\square$ Zirkel, Ferdinand (1871): Die Umwandlungsprozesse im Mineralreich - Akademische Rede, gehalten am 19. December 1870 in der Aula zu Leipzig. - Sammlung gemeinverständlicher Vorträge, Ser. 6, H. 136; 40 S.; (Lüderitz) Berlin

[darin: Hinweis a. Kontaktmetamorphose Basalt/Kohle Meißner, Hirschberg b. Großalmerode; Brennende Kohle bei Abterode (Stinksteinwand Hoher Meißner)]

\subsubsection{Zechstein-Salze}

- DAhlborn, Otto (1955): Die Flöze „Thüringen“ und „Hessen“ der Werraserie und ihre wechselseitigen Beziehungen. - Z. dt. geol. Ges., 105: 664-673, 7 Abb.; Hannover

[Werra-Kalirevier, Lokalitäten anonymisiert]

$\square$ Anonym (1910): < Mineralische Bodenschätze bei Hundelshausen]. - Eschweger Tageblatt, 1910; Nr. 171 v. 25.7.1910; Eschwege

$\square$ Baier, Hans-Rudolf (1966): Die Gipsvorkommen bei Hundelshausen. - (maschschr.) Witzenhausen: 1966, 10 S., 12 Abb.

[Vorlage nicht eingesehen, zitiert nach OPPITZ 1991]

-Beck, Kurt (1912): Petrographisch-geologische Untersuchung des Salzgebirges im Werra-Fulda-Gebiete der deutschen Kalisalzlagerstätten. - Z. prakt. Geologie, 20: 135-158, 12 Fig.; Berlin Referat in: N. Jb. Mineral. etc., 1913 (Bd. II): 187-188 (H. E. Boeke); Stuttgart

- $\bigcirc$ Beck, Kurt (1912): Petrographisch-geologische Untersuchung des Salzgebietes im Werra-FuldaGebiete der deutschen Kalisalzlagerstätten. - Kali, etc., $\underline{\mathbf{6}}$ (11): 262-265; Halle [darin: Hess.-Thür. Werra-Kalirevier]

OdBeer, Wolfgang (1996): Kalilagerstätten in Deutschland. - Kali und Steinsalz, 12(1): 18 - 30, 14 Abb., 5 Tab.; Essen [darin: Werra-Fulda-Revier, Südharz-Revier]

-Burghardt, Gustav-Adolf \& Kokorsch, Rudolf (1990): Der Verbund der Grubenbetriebe Hattorf und Wintershall. - Kali u. Steinsalz, 10(7/8): 233-240, 16 Bilder; Essen

[darin: die Werra-Kalilagerstätte]

OBeier, Peter-Michael (2004): Das Mineral Rinneit: Vorkommen, Eigenschaften, Analytik und Abtrennung - Vortrag anlässlich der K+S-Forschungstagung am 03. November 2003 in Kassel. Kali u. Steinsalz, 2004(1): 36-41, 6 Abb.; Essen [darin: Unterbreizbach]

OBessert, F. (1933): Eine neue Methode zur Erkennung der Strukturen von Carnallitgesteinen. - Kali, etc., 27(19): 239-240, 2 Fig.; Halle/Saale

[darin: untersuchte Gesteinsprobe Schacht „Sachsen-Weimar“ i. thüringisches Werra-Kalirevier]

- 0 Bessert, Friedrich (1933): Geologisch-petrographische Untersuchungen der Kalilager des WerraGebietes. - Archiv f. Lagerstättenforsch., 57; 45 S., 6 Abb., 8 Taf.; [Preuß. Geol. Landesanst.] Berlin Referat in: N. Jb. Mineral. etc., Referate, $\underline{1935}$ (Bd. II): 194-196 (J. Leonhardt); Stuttgart

- 0 Bessert, F. (1935): Geologisch-petrographische Untersuchungen der Kalilager des Werra-Gebietes unter besonderer Berücksichtigung der Vertaubungserscheinungen. - Kali, etc.,

29(3): $27-30$

29(4): $40-43$

29(5): $53-58$ 
$\underline{29}(6): 63-66$

$\underline{29}(7): 73-75$

$\underline{29}$ Abb., VII Profile; Halle (Saale)

Referat in: N. Jb. Mineral. etc., Referate, 1935 (Bd. II): 194-196 (J. Leonhardt); Stuttgart

OBorissenkow, W. I. (1968): Geologischer Aufbau und Mineralogie einiger Vertaubungszonen des Kaliflözes Hessen (Werra-Serie) der Schachtanlage Merkers (Rhön). - Z. angew. Geol., 14 (1): 7-10, 1 Abb., 1 Tab.; Berlin

-Borstel, Lieselotte Ernestine v. (1991): Die Charakterisierung des Stoffbestandes von fluid inclusions in Zechsteinevaporiten mittels der Lösungsgleichgewichte mariner Salzsysteme. - Kali u. Steinsalz, 10(12): 409-415, 7 Bilder, 3 Tab.; Essen

[darin: Untersuchungen an Proben Kaliwerk Wintershall]

-Braitsch, Otto (1959): Über p-Veachtit, eine neue Veachtit-Varietät aus dem Zechsteinsalz. - Beitr. Mineral. Petrogr., $\mathbf{6}: 352$ - 356, 1 Abb., 1 Tab.; Berlin-Göttingen-Heidelberg [Kalibergwerk Königshall - Hindenburg, Reyershausen b. Göttingen]

-Braitsch, Otto (1959): Über Strontioginorit, eine neue Ginorit-Varietät aus dem Steinsalz. - Beitr. Mineral. Petrogr., $\mathbf{6}: 366$ - 370, 3 Abb., 2 Tab.; Berlin-Göttingen-Heidelberg [Kalibergwerk Königshall - Hindenburg, Reyershausen b. Göttingen]

-Braitsch, Otto (1960): Mineralparagenesis und Petrologie der Staßfurtsalze in Reyershausen. - Kali u. Steinsalz: $\underline{\mathbf{3}}(1): 1$ - 14, 6 Abb., 4 Tab.; Essen [Kalibergwerk Königshall - Hindenburg, Reyershausen b. Göttingen]

-Braitsch, Otto (1961): Neue Daten für Lüneburgit und Sulfoborit. - Beitr. Mineral. Petrogr., $\underline{8}: 60$ - 66, 1 Abb., 3 Tab.; Berlin-Göttingen-Heidelberg

[Kalibergwerk Königshall - Hindenburg, Reyershausen b. Göttingen]

OBudzinski, H.; Langbein, R. \& Stolle, E. (1959): Danubrit im Zechstein des Südharzes. - Chemie der Erde, 20: 53-70, 6 Abb., 3 Tab., Taf. X/XI; Jena

Referat (Kühn) in: Kali u. Steinsalz, 3(2): 67-68, 1 Bild; Essen

[Bleicherode, Kleinbodungen, Bhrg. Ascherode SW' Sollstedt]

-Dietrich, A.; Behnke, G. \& Thönelt, T. (2004): Kristalle aus der Tiefe - Eine Auswahl von Mineralien aus Kali- und Steinsalzlagerstätten. - Kali u. Steinsalz, 2004(3): 6 - 15, 24 Abb.; Essen [Mineralfundstätte Hattorf-Wintershall]

ODietz, C. (1928): Die Salzlagerstätten des Werra-Kaligebietes. - Archiv f. Lagerstättenforschung, 40; 129 S., 21 Abb., 3 Taf; (Preuß. Geol. Landesanst.) Berlin

Referat in: N. Jb. Mineral. etc., Referate; 1929 (Bd. III): 33-34 (A. Bentz); Stuttgart

QDöhner, Christian (1962): Zur Vorratsberechung und Abbauplanung in Feldesteilen mit absetzigen Hartsalzvorkommen. - Z. angew. Geol., $\underline{8}(4)$ : 198-202, 8 Abb.; Berlin

[Bleicherode]

ODöhner, Christian \& Elert, Karl-Heinz (1975): Genetische Prozesse im Staßfurt-Salinar. - Z. geol. Wiss., $\underline{\mathbf{3}}(2):$ 121-141, 9 Abb., 2 Tab., 2 Taf.; Berlin

[Thüringisches Eichsfeld]

$\square$ Dreizler, Ingo (1962): Mineralogische Untersuchungen an zwei Gipsvorkommen der Werraserie (Zechstein). - Beitr. Mineral. Petrogr., $\underline{8}: 323$ - 338, 6 Abb., 9 Tab.; Berlin-Göttingen-Heidelberg [Hundelshausen, Osterode/Harz]

QElert, Karl Heinz (1989): Minerale im Kaliflöz „Staßfurt“ des Thüringer Beckens. - Veröff. Naturkundemuseum Erfurt, Naturwiss. Rh., ㅍ: 26-32, 2 Abb.; Erfurt 
OElert, Karl-Heinz \& Henning, Ilona (1988): Bitumen A in Gesteinen des Zechsteins. - Z. angew. Geol., 34(3): 71-76, 4 Abb., 6 Tab.; Berlin [darin: Thüringer Becken, Werra-Gebiet]

○ Everding, H. (1907): Zur Geologie der deutschen Zechsteinsalze. - (Festschrift z. 10. allgemeinen deutschen Bergmannstage in Eisenach) Abh. Preuß. Geol. Landesanst., N.F., 52; S. 1-183, 11 Taf., 5 Beil.; Berlin

Referat in: N. Jb. Mineral. etc., 1909 (Bd. II): 304-308 (Stelle); Stuttgart [darin: Werra-Kalirevier, Südharz-Revier]

OFreyburg, Ernst (1967): Bleichungshöfe im südwestthüringischen Buntsandstein. - Geologie, $\underline{16}(3)$ : 296-302, 3 Abb.; Berlin

[Untersuchungen Bl. Stadtlengsfeld; Mineralogie]

-Friedrich, G.; Diedel, R.; Schmidt, F.P. \& Schumacher, A. (1984): Untersuchungen an Cu-AsSulfiden und Arseniden des basalen Zechsteins der Gebiete Spessart/Rhön und Richelsdorf. Fortschr. Mineral., 62, Beih. 1: 63-65; Stuttgart

- $\square$ O $\bullet$ Füchtbauer, Hans (1964): Fazies, Porosität und Gasinhalt der Karbonatgesteine des norddeutschen Zechsteins. - Z. dt. geol. Ges., 114: 484-531, 10 Abb., 3 Tab., 3 Taf., ; Hannover [z2 + z3; HE, WMK, THÜ, NIE]

QFürste, Ria (1956): Untersuchungen über Zusammenhänge zwischen Basaltvorkommen und Vertaubungszonen auf dem Kaliwerk „Ernst Thälmann“ II/III. - Dipl.-Arb. [teilveröff.] Bergakademie Freiberg/Sa. 1956, 85 S. - Teilveröffentlichung in: Bergbautechnik, $\mathbf{7}$ (7/8); 1957 [Bibliographische Angaben nach: Auflistung von Diplomarbeiten BA Freiberg 1956 in: Geologie, $\underline{7}(1)$ : 102; Berlin 1958]

OFulda, Ernst (1921): Entstehung und Einteilung der deutschen Kalilagerstätten. - Z. prakt. Geol., 29.1921 (11): 161-165, 1 Abb.; Berlin

[HE, THÜ, NIE]

-OFulda, Ernst (1938): Die Salzlagerstätten Deutschlands. - Deutscher Boden, ㅁ; IV, 140 S., 52 Abb.; (Bornträger) Berlin Referat in: N. Jb. Mineral. etc., Referate, 1939 (Bd. II): 270-271 (H. Schneiderhöhn); Stuttgart [darin: Thüringer Mulde, Werra- und Fulda-Kaligebiet]

-0•Fulda, Ernst (1938): Steinsalz und Kalisalze. - Reihe: Beyschlag, F.; Krusch, P. \& Voigt, J.

[Hrsg.]: Die Lagerstätten der nutzbaren Mineralien und Gesteine, Bd. III, 2. Teil - 240 S., 94 Abb.; (Enke) Stuttgart 1938

Referat in: N. Jb. Mineral. etc., Referate, 1938 (Bd. II): 200 (J. Leonhardt), 1938 (Bd. III): 995

(Kräusel); Stuttgart

[darin S. 86-87: „Südliches Hannover“; S. 88-93, Abb. 42,43: „Thüringer Mulde“; S. 93-96, Abb. 4446: Werra- und Fulda-Kaligebiet]

-OFulda, Ernst (1929): Die Entstehung der deutschen Zechsteinsalz, heutige und frühere Anschauungen. - Z. dt. geol. Ges., $\underline{\mathbf{8 0}}$ (f. 1928): 145-146 (Mber.); Berlin [Bezugn. a. Hessisch-Thüringisches Kaligebiet]

@Gottesmann, Wolfram (1962): Zur Trümmercarnallititbildung auf Menzengraben (Rhön). - Geologie, 11(1): 51-82, 21 Abb., 5 Tab.; Berlin

OGottesmann, Wolfram (1965): Zur Frage synsedimentärer Hartsalzbildung im Kaliflöz Staßfurt. Geologie, 14(4): 420-434, 3 Abb.; Berlin

[Kaliwerk Bischofferode] 
QGottesmann, Wolfram (1965): Petrographische Argumente zur Kalisalzgenese im Staßfurtflöz. Geologie, 14(10): 1215-1223, 4 Abb.; Berlin

[Südharz-Kalirevier: Kailwerke Sollstedt, Bischofferode, Klein-Bodungen]

- doGraupner, Torsten; Reutel, Christian \& Pilot, Joachim (1996): Charakterisierung von Langbeiniten mit Hilfe einschlußanalytischer Untersuchungen. - Kali u. Steinsalz, 12 (3): 93-102, 5 Bilder, 3 Tab.; Esssen

[darin: untersuchte Proben Bischofferode, Hattorf/Philippsthal, Merkers, Volkenroda-Pöthen]

-Gutsche, A. \& Hermann, A. G. (1988): Wechselwirkungen zwischen fluiden Phasen und Evaporiten im Nahbereich von Basaltgängen. - Fortschr. Mineral., $\underline{\mathbf{6}}$, Beih. 1: 49; Stuttgart

[Werk Hattorf, Philippsthal]

QHaase, Günter (1966): Mächtigkeitsanomalien im Werrasteinsalz des Werrakaligebiets. - Z. angew. Geol., 12 (7): 355-361, 3 Abb.; Berlin

[Thüringisches Werrakaligebiet]

QHaase, Günter (1966): Die Bedeutung neuer geologischer Erkenntnisse für die Einschätzung der Entwicklungsperspektive des Kalibergbaues im thüringischen Werragebiet. - Ber. Dt. Ges. geol. Wiss., Reihe A, 11(4): 425-437, 5 Abb.; Berlin

[Lagerstättenkunde, auch Kohlensäure/Gebirgsschläge]

OHaase, Günther (1976): Beitrag zur Kenntnis der Salzlagerstätte im thüringischen Werra-Kaligebiet. Jb. Geol., $\underline{7 / 8}$ (f. 1971/72): 211-261, 9 Abb., 8 Tab., 1 Taf.; Berlin

QHartwig, Georg (1952-1955): Zur Petrographie und Transversalschieferung der tieferen Stufen der Zechstein-Großfolge $2 \mathrm{im}$ Untergrund von Solling-Elfas und Dün-Hainleite-Eck mit Ausblicken auf die Verhältnisse unter der Östlichen Randhochfläche des Göttinger Leinetales. - Kali u. Steinsalz, 1(1952-1955) (8): 8 - 29, 21 Abb..; Essen

OHartwig, Wilhelm (1954/55): Salzmagnesit von Unterbreizbach (Rhön). - Chemie der Erde, 17(4): 324-328, 1 Abb., 3 Tab.; Jena

هOHautmann, S.; Lippolt, H. J. \& Pilot, J. (1993): Zur Altersverteilung flözumbildender Prozesse im deutschen Zechsteinsalinar. - Ber. Dt. Mineral. Ges., 1993(1)/Beih. z. Europ. J. Mineral., ㅁ: 126; Stuttgart

[Isotopenchronometrie - Z1/Z2; darin: Südharz-Kalirevier, Werra-Fulda-Kalirevier (HE-THÜ)]

QHeide, F. (1954/55): Über bemerkenswerte Borazitvorkommen in den Kalilagern des Südharzbezirkes. - Chemie der Erde, 17(3): 211-216, Taf. XVIII-XIX; Jena

[darin: Bischofferode, Sollstedt, Kraja, Bleicherode, Volkenroda, Pöthen]

QHeide, F. \& Bader, E. (1964): Boracit und Lüneburgit im Werra-Kaligebiet. - Chemie der Erde, 23: 219-221, 1 Abb.; Jena

[Thüringisches Werra-Kaligebiet]

QHeide, K.; Franke, H. \& Brückner, H.-P. (1980): Vorkommen und Eigenschaften von Boracit in den Zechsteinlagerstätten der DDR - Occurences and properties of Boracite from the Zechstein salt deposits in the G.D.R. - Chemie der Erde, 39(3): 201-232, 17 Abb., 3 Tab., 2 Taf.; Jena [darin: Südharz-Kalirevier]

-Hentschel, Joachim (1961): Die Faciesunterschiede im Kaliflöz des Kalisalzbergwerks „KönigshallHindenburg“'. - Kali u. Steinsalz, $\underline{\mathbf{3}}$ (5): 137 - 159, 17 Abb., 1 Zahlentafel, 2 Taf. (5 Abb.); Essen Auszug der Diss. „Die Faciesunterschiede im Kaliflöz Staßfurt im Kalisalzbergwerk „Königshall Hindenburg“ bei Nörten-Hardenberg. - Diss. Univ. Mainz 1958 
QHerrmann, Albert Günter (1961/62): Zur Geochemie des Strontiums in den salinaren

Zechsteinablagerungen der Staßfurt-Serie des Südharzbezirkes. - Chemie der Erde, 21(2): 137-194, 3

Abb., 18 Tab.; Jena

[darin: Bischofferode, Sollstedt, Bleicherode, Volkenroda, Pöthen; Bhrgn. Urbach, Kirchheilingen,

Langensalza]

-OHerrmann, Albert Günter (1998): Die Entstehung der Salzvorkommen im Werra-Fulda-Gebiet. - In:

Eisenbach, Ulrich \& Paulinyi, Akos [Hrsg.]: Die Kaliindustrie an Werra und Fulda - Geschichte eines landschaftsprägenden Industriezweigs. - Schriften z. hessischen Wirtschafts- und Unternehmensgeschichte, $\underline{\mathbf{3}}$; S. 13-30, Abb. 1-4, Tab. 1-3; (Hessisches Wirtschaftsarchiv) Darmstadt 1998

-Hodenberg, Renate \& Kühm, Robert (1981): Vergleichende Betrachtungen an den Mineralien der Hilgarditgruppe. - Kali u. Steinsalz, $\underline{\mathbf{8}}(6):$ 206-217, 13 Bilder; Essen

[darin: Kaliwerk Königshall-Hindenburg, Reyershausen]

-Hodenberg, R. von; Fischbeck, R. \& Kühn, R. (1987): Beitrag zur Kenntnis der Salzminerale, Salzgesteine und Salzlagerstätten, insbesondere im deutschen Zechstein. - Der Aufschluss, 38: 45-57, Abb. 1-7, Tab. 1-2; $\underline{\mathbf{3 8}}$ : 77-92, Abb. 8-10, Tab. 3; 요: 109-125, Abb. 21-32; Heidelberg

OHoffbauer, Andreas (1993): Kali-Qualität: Ganz besonderer Stoff - Der Streit um Bischofferode dreht sich auch um die dort förderbare Kali-Qualität - Gutachten gibt es viele, einheitliche Meinungen nicht. - HNA, 1993; Nr. 169 v. 27.7.1993; Kassel

[Kaliwerk Bischofferode, Nordthüringen]

OHoppe, Walter (1960): Die Kali- und Steinsalzlagerstätten des Zechsteins in der DDR, Teil 1: Das Werra-Gebiet. - Freiberger Forschungshefte, Reihe C, 97/I: 1-166, 38 Abb., 23 Tab.; Berlin

OHorst, Ulrich (1989): Der Boracit von Bischofferode in Thüringen. - Der Aufschluss, 40: 115-120, 1 Tab.; Heidelberg

OJäger, Andreas (1994): Die hydrothermal-sedimentäre Entstehung der Salzablagerungen des Zechsteins am Beispiel des Werra-Kaligebietes - ein Modell. - Veröff. Naturkundemuseum Erfurt, Naturwiss. Rh., 13: 31-48, 5 Abb.; Erfurt

OJahne, Heinz \& Pielert, Peter (1964): Beitrag zur Ausbildung des hangenden Begleitflözes zum Kaliflöz „Hessen“ im Werra-Kaligebiet unter besonderer Berücksichtigung der Schachtanlage „MarxEngels“ Unterbreizbach. - Ber. Ges. geol. Wiss. DDR, 9 (6): 641-665, 8 Abb., IX Tafeln; Berlin

-OJahne, Heinz \& Zeibig, Silvio (2002): Zur Entwicklung, Ausbildung und Verbreitung der Kaliflöze im Werra-Becken - Development, lithology and distribution of the potash seams in the Werra basin. - Z. geol. Wiss., 30(4/5): 327-336, 6 Abb.; Berlin

QKästner, Hans (1966): Beitrag zur Geologie der Kalisalz- und Kohlensäurelagerstätten im südlichen Werra-Kaligebiet. - Diss. Hochschule f. Architektur u. Bauwesen Weimar 1966; VII, 129 S.; 8 Bl., 36 Beil. (Text- u. Anlagenbd.)

OKästner, Hans (1969): Zur Geologie der Kalisalz- und Kohlensäurelagerstätten im südlichen WerraKaligebiet. - Abh. Zentralen Geol. Institutes, 11: I-VII, 1-96, 23 Abb., 2 Tab. Berlin

QKästner, Hans (1995): Bodenschätze [in Thüringen] - Salze. - In: Seidel, Gerd [Hrsg.]: Geologie von Thüringen. - 1. Aufl.; S. 433-443, 5 Abb.; Stuttgart 1995

OKästner, Hans (2003): Bodenschätze [in Thüringen] - Salze. - In: Seidel, Gerd [Hrsg.]: Geologie von Thüringen. - 2., neu bearb. Aufl.; S. 464-474, 5 Abb.; Stuttgart 2003 
-Knipping, B. (1986): 34S/32S Ratios of native sulphur in Zechstein 1 evaporites. - Die Naturwissenschaften, 73: 614; Berlin-Heidelberg

[Werra-Kali-Revier, Werk Hattorf/Philippsthal]

-Knipping, Bernhard (1987): Basaltische Gesteine in Zechsteinevaporiten [Vortragszusammenfassung]. - In: Klare, Bernd \& Schröder, Bernd [eds.]: Zechstein 1987 - International Symposium Kassel/Hannover [28. April to 9. May, 1987] - Abstracts, Posters, Program; S. 54-55; [Subkommission Perm/Trias der Stratigraphischen Kommission der DUGW/IUGS] Bochum 1987 [Isotopengeochemie; Kaliwerk Hattorf/Philippsthal]

-Knipping, Bernhard (1989): Basalt intrusions in evaporites. - Lecture Notes in Earth Sicences, 24; 131 p., 8 fig., 8 tabl.; (Springer) Berlin-Heidelberg-New York

[Kaliwerk Hattorf]

-Knipping, Bernhard (1991): Basaltische Gesteine in Zechsteinevaporiten. - Zentralbl. Geol. Paläont. Teil1: 1991(4): S. 1149 - 1163, 7 Abb., 2 Tab.; (Schweizerbart) Stuttgart

[Modell Temperaturentwicklung; Isotopengeochemische Veränderungen in Zechstein 1 - Evaporiten des Werra-Fulda-Lagerstättenbezirkes, Kaliwerk Hattorf/Philippsthal]

-Knipping, Bernhard \& Herrmann, Albert Günter (1985): Mineralreaktion und Stofftranspoett an einem Kontakt Basalt-Carnallitit im Kalisalzhorizont Thüringen der Werra-Serie des Zechsteins. Kali u. Steinsalz, 9(4): 111-124, 6 Abb., 6 Tab; Essen

QKoch, Günter \& Gaitzsch, Hendrik (1989): Speicherraumausbildung in Salzlösungsvorkommen im Salinar des Werra-Kaligebietes und ihre Bedeutung für Abdichtungsinjektionen. - Z. angew. Geol., 35(6): 175-179, 10 Abb.; Berlin

[Petrographie]

ØKoch, Klaus (1961): Die Blei-Kupfer-Verhältnisse an einigen Profilen in Unterbreizbach/Rhön. - Dipl.Arb. [unveröff.] Bergakademie Freiberg (Sachsen) 1961

Referat in: Geologie, 11(6): 743-744; Berlin 1962

[Geochemie Salinar Thür. Werra-Kalirevier]

OKoch, Klaus (1978): Zur Entstehung von Tonmineralen im Kontaktbereich Basalt-Salinar. - Z. geol. Wiss., $\underline{\mathbf{6}}(6)$ : 733-747, 15 Abb.; Berlin

[Thüringisches Werra-Kalirevier; Merkers, Unterbreizbach]

OKoch, Klaus; Kockert, Werner \& Grunewald, Volker (1968): Geochemische Untersuchungen an Salzen und Salzlösungen (Laugen) von Salzlagerstättten in der Deutschen Demokratischen Republik. - Geologie, 17(6/7): 792-803, 2 Abb., 1 Tab.; Berlin

OKoch, Klaus \& Oettel, Siegfried (1969): Zur Sylvinitbildung auf der Schachtanlage AlexandershallAbteroda im Werra-Kaligebiet. - Jb. Geol., 2 (f. 1966): 223-242, 4 Abb., 2 Tab., 5 Taf.; Berlin

- 0 Kokorsch, Rudolf \& Psotta, Manfred (1984): Die Rohstoffversorgung der Kalifabriken Wintershall und Hattorf. - Kali u. Steinsalz, 9(2): 39-51, 21 Bilder; Essen

[darin: die Hess.-Thür. Werra-Kalilagerstätte]

OKonitz, Otfried \& Schäbitzer, Rudolf (1964): Neue Erkenntnisse über die Ausbildung des Kaliflözes Thüringen. - Erfahrungen in den Grubenfeldern „Ernst Thälmann II/III“ und Menzengraben und deren bergmännische Berücksichtigung. - Z. angew. Geol., 10 (3): 129-133, 7 Abb.; Berlin

QKröll, Dieter \& Nachsel, Gerhard (1967): Zur Ausbildung des Staßfurt-Steinsalzes im SüdharzKalirevier. - Geologie, 16(3): 269-279, 4 Abb.; Berlin [darin: Nordwestthüringen] 
-Kühn, Robert (1952): Nachexkursion im Kaliwerk Hattorf, Philippsthal - als Beitrag zur Kenntnis der Petrographie des Werra-Kaligebietes. - Fortschr. Mineral., 29/30 (f. 1950/51): 101-114, 9 Abb. (i. Text u. Taf. 7-10); Stuttgart [Salzpetrographie, Basaltgänge u. Kontaktmetamorphose]

-Kühn, Robert \& Ritter, Karl-Heinrich (1958): Der Kristallwassergehalt von Kainit und von Löweit. Kali u. Steinsalz, 2(7): 238-240, 5 Zahlentaf.; Essen

[Taf. 1: Kainit Werk Hattorf/Philippsthal, hess. Werra-Kalirevier]

- 0 Kunze, Dietmar \& Stahl, Ingo (1997): The Werra Production Center of the newly formed Kali and Salz GmbH - Complex Raw Ore and Diversified Product Lines. - Kali u. Steinsalz, 12(4): 135-140, 15 Fig.; Essen

[HE, THÜ, darin: Lagerstättengeologie]

OLachmann, Richard (1916): Über Carnalittisierung der Südharz-Kalisalzlagerstätten. - N. Jb. Mineral. etc., 1916 (Bd. II): 165-176, 1 Abb., Taf. VII, VIII; Stuttgart

[darin: Volkenroda]

OLachmann, Richard (1917): Über Carnallitisierung der Südharz-Kalilager < Mit Nachruf auf Privatdozent Dr. Richard Lachmann>. - Kali, etc., 10 (12): 189-194, 3 Fig.; Halle/Saale [darin: Volkenroda]

QLangbein, Rolf (1984): Über subrosionsbedingte Gefüge in Anhydrit- und Gipsgesteinen. - Z. geol. Wiss., 12(3): 349-362, 12 Abb.; Berlin

[Gefügekunde, darin: Zechstein Nordrand Thüringer Wald: Marienglashöhle Friedrichroda, Gipsbruch Kittelsthal - auch Kyffhäuser, Harzsüdrand]

OLangbein, Rolf \& Seidel, Gerd (1979): Zur Ausbildung des Leinekarbonats am Südrand des Thüringer Beckens. - Z. geol. Wiss., $\mathbf{7}(8):$ 967-980, 9 Abb.; Berlin

[darin: Profile am Rand des Thüringer Waldes]

-Linstow, O. v. (1929): Salzlager, Solquellen und Erdfälle in dem Gebiet zwischen Kassel und Karlshafen. - Kali, etc.,

$\underline{\mathbf{2 3}}(4): 54-56$

$\underline{23}(5): 71-74$

$\underline{23}(6): 86-88$, mehr. Fig.; Halle/Saale

Referat in: N. Jb. Mineral. etc., Referate, 1931 (Bd. III): 135 (A. Bentz); Stuttgart

[darin: Wolkenbrüche b. Trendelburg; Solquelle Kassel-Wilhelmshöhe]

- $\square 0 \bullet$ Lotze, Franz (1937): Salzabscheidung und Tektonik. - Kali, etc.,

31(3): $22-24$

31(4): $33-36$

31(5): $41-45$

31(6): $51-54$

31(7): 61-63

31(8): 71-72, zahlr. Fig.; Halle/Saale

[darin: Thüringer Becken; Mächtigkeitskarte Älteres Steinsalz Mitteldeutschland - HE, WMK, THÜ, NIE]

- 0 Lotze, Franz (1938): Steinsalze und Kalisalze - Geologie. - Reihe: Die wichtigsten Lagerstätten der „Nicht-Erze“, Bd. III, Teil 1; X, 936 S., 353 Abb.; (Bornträger) Berlin

[darin: Werra-Fulda-Kaligebiet, Thüringer Becken]

$\square \bullet L o t z e$, Franz (1957): Steinsalz und Kalisalze. - Zweite, neubearb. Aufl., I. Teil (Allgemein geologischer Teil). - XI, 465, 1 S., 226 Abb., 37 Tabl.; (Bornträger) Berlin [darin: „Tektonik der Salzlagerstätten“; S. 265, Abb. 124: Leinetalgraben; S. 266, Abb. 126: Sontraer Graben] 
-Messer, E. \& Roth, H. (1983): Geology of the Werra-Fulda potash deposit and application of geological research for planning and operation of the North-Hessian potashmines. - Monograph series on mineral deposits, 22: 79-107, 14 fig., 1 tabl.; (Bornträger) Berlin-Stuttgart

OMötzing, R. (1988): Görgeyit im Zechstein 2 - Goergeyite in Zechstein 2. - Chemie der Erde, 48(3): 233-244, 10 Abb.; Jena

[Volkenroda, Pöthen]

-Müller, German (1967): Sudoit („dioktaedrischer Chlorit“, „Al-Chlorit“) im Cornberger Sandstein von Cornberg/Hessen. - Contrib. Mineral. Petrol., 14: 176-189, 5 Abb., 5 Tab.; Berlin-Heidelberg

QNachsel, Gerhard (1969): Idiomorphe Quarze und Vertaubungen im Kaliflöz „Staßfurt“ des SüdharzKalireviers. - Z. angew. Geol., 15(8): 420-425, 7 Abb.; Berlin

[darin: Bleicherode]

$\square$ Namenskürzel (=h)(1965): Bereits 1896 gefunden: Riesiges Steinsalzlager bei Rambach. Wertvoller Fund aus dem vorigen Jahrhundert ist wieder in Vergessenheit geraten. - HA - Werra-Nachrichten, $\underline{\mathbf{1 9 6 5}}$, N.r 95 v. 24.4.1965, 1 Abb.; Witzenhausen

[Bohrung a. d. Mäusemühle b. Rambach, i. Jahr 1896]

- ONamenskürzel (mle)(1991): Geschichte: Wo Meer war, wird heute nach Salz gegraben. - HNA, (RA) Rotenburger Ausgabe, 1991; Nr. 180 v. 6.8.1991; Kassel

-Ochsenius, Carl (1889): Ueber Salzlager, Mineralquellen, Salzseen etc. - Ber. Vereins Naturkde. z. Kassel, 34/35: 89-106; Kassel

[Ochsenius postulierte das heute noch weitgehend akzeptierte petrogenetische Modell der ZechsteinSalzlagerstättenbildung in abgeschnürten Meereslagunen - „Barrentheorie“]

QOettel, Siegfried \& Voitel, Roland (1966): Erste Untersuchungsergebnisse einer feinstratigraphsichen und petrographischen Gliederung im Kalisalzflöz „Thüringen“ der Gruben „Springen“ und „Alexandershall“. - Ber. Dt. Ges. geol. Wiss., Reihe A, 11(4): 489-499, 5 Abb., 4 Tab.; Berlin

OPippig, Matthias (1992): Über das Vorkommen einer Kristallsalzschlotte im Kalibergwerk Merkers. Kali u. Steinsalz, 11 (1/2): 2-7, 9 Bilder; Essen

ORepetzke, Kurt (1926): Beiträge zur Frage der Metamorphose insbesondere der Thermodynamikmetamorphose der Salzgesteine der deutschen Steinsalzlager und ihrer Mineralparagenese. - Kali, etc., $\underline{20}(9): 139-142$, 20(13): 200-204, 15 Fig.; Halle/Saale [darin: Thür. Werra-Kalirevier]

QRichter, Albrecht (1962): Die Rotfärbung in den Salzen der deutschen Zechsteinlagerstätten - 1. Teil. (Fritz Heide zum 70. Geburtstag) Chemie der Erde, 22: 508-546, 20 Abb., Taf. XXV-XXVI, 6 Tab.; Jena [darin: Südharz-Kalirevier]

QRichter, Albrecht (1962): Die Rotfärbung in den Salzen der deutschen Zechsteinlagerstätten - 2. Teil. Chemie der Erde, 23: 179-203, 10 Abb., 1 Tab.; Taf. II-III; Jena [darin: Südharz-Kalirevier: Sollstedt, Kraja, Bischofferode, Kleinbodungen]

ORichter, Albrecht (1965): Zur Problematik der Kalisalzerkundung im Staßfurtflöz. - Z. angew. Geol., 11(3): 113-121, 9 Abb., 9 Tab.; Berlin [Lagerstättenerkundung; darin: Region Bleicherode, Bischofferode] 
ORichter, Albrecht (1995): Petrogenetische Studien an der Hartsalz-Carnallititgenze - Petrogenetic studies on the Transition Hartsalz - Carnallitit. - Chemie der Erde, 52 (2): 109-117, 14 Abb.; Jena [Bleicherode, Bischofferode]

QRietschel, Manfred (1957): Der Einfluß der Tektonik auf die Ausbildung des unteren und oberen Kalilagers im Bereich der Schachtanlage Dietlas I. - Dipl.-Arb. [unveröff.] Bergakademie Freiberg/Sa., $48 \mathrm{~S}$.

Referat in: Geologie, $\underline{8}(2): 216-217$; Berlin 1959

- 0 Roeber, Joachim (1938): Die Jodverteilung in den deutschen Lagerstätten. Gründe für das Auftreten und Fehlen von Jod in verschiedenen Horizonten des Zechsteins und in Erdölwässern. - Kali, etc., 32(20): 209-211

32(21): 221-223

32(22): 233-236; Halle/Saale

[darin: Volkenroda; Hess.-Thür. Werra-Kalirevier: Wintershall, Kaiseroda]

- 0 Roeber, Joachim (1938): Der Jodgehalt der deutschen Salzlagerstätten. - Jb. Halleschen Verbandes etc., N.F. 16: 129-196, 5 Abb., 23 Tab., 1 Falt-Taf. (Kt.); Leipzig

[darin: Volkenroda, Wintershall, Kaiseroda]

- Roth, Harry (1958): Befahrung des Kalisalzbergwerkes „Wintershall“ der Gewerkschaft Wintershall in Heringen/Werra..- Fortschr. Mineralogie, 포; Beih. 1: 82-88, 1 Abb.; 1 Tab.; Stuttgart [Mineralogie, Petrographie Zechstein-Salzlagerstätte]

- Roth, Harry \& Messer, Ernst (1981): Die Nutzung lagerstättenkundlicher Erkenntnisse für Planung und Betrieb nordhessischer Kaliwerke. - Kali u. Steinsalz, $\underline{8}(5): 145-157,12$ Abb.; Essen

- oRózsa, M. (1914): Über die posthumen Umwandlungen der Kali- und Magnesiumslaz in den Salzablagerungen der Werragegend. - Z. anorg. u. allgem. Chemie, $\underline{88}(3)$ : 321-332, 4 Abb.; HamburgLeipzig

Referat in: N. Jb. Mineral. etc., 1916 (Bd. II): 21 (W. Eitel); Stuttgart

OSchäfer, Aloys (1925): Der Kalischacht Hübstedt. - Unser Eichsfeld, 20: 33-38, 2 Abb.; Duderstadt [Zechsteinstratigraphie, Lagerstättenkunde, Bergbaugeschichte]

- 0 Scharbrodt, Thomas \& Baumann, Ludwig (1994): Das Zechsteinsalinar im System von Beckentypen. - Z. geol. Wiss., 22 (3/4): 469-474, 2 Abb., 1 Tab.; Berlin [Lagerstättengenese, darin: Werra-Becken, Südharz-Becken]

OSchneider, Hans-Eckart (1962): Erscheinungen der Hydrometamorphose im Oberen Kalilager der Schachtanlage Springen <SE’Vitzeroda, Thür. Werra-Kalirevier>. - Z. angew. Geol., $\underline{8}(10):$ 524-529, 5 Abb.; Berlin

OSchütze, R. (1957): Mineralogisch-petrographische Untersuchung der Kaligrube Pöthen. - Dipl.-Arb. [unveröff.] Univ. Jena 1967

OSchwandt, Arnold (1962): Zur Faziesdifferenzierung im Werra-Kaligebiet. - Ber. Ges. geol. Wiss. DDR, 6 (f. 1961)(2/3): 288-295, 9 Abb.; Berlin [auch Südharz-Kalirevier: Bischofferode, Volkenroda]

OSeidel, Gerd (1964): Geologischer Aufbau, chemische Zusammensetzung und Eignung der Kalziumsulfathorizonte von Thüringen. - Z. angew. Geol., $\underline{10}(10): 514-523,13$ Abb., 10 Tab.; Berlin [Z - A1-A3, darin Fazies- und Mächtigkeitskarten, einbezogen: Westthüringen] [Lagerstättenkunde]

OSeid1, E. (1923): Die geologischen Gesetzmäßigkeiten, welche im Hessisch-Thüringischen (WerraFulda-) Gebiet für den Zechstein-Kalisalzbergbau maßgebend sein müssen. - Kali, etc., 
$\underline{17}(2): 17-26$

$\underline{17}(5): 69-77$

17(6): 84-93, 34 Fig.; Halle/Saale

oSimon, Johannes (1929): Petrogenetische Studie der Salzlagerstätte der Gewerkschaften Volkenroda und Pöthen im Südharzbezirk. - Mitt. Lagerstätten-Inst. TH Charlottenburg, 13; 26 S.; Diss. Techn. Hochschule Berlin - auch in Kali, etc., 1929; Halle (Saale)

OSimon, Johannes (1929): Petrogenetische Studie der Salzlagerstätte der Gewerkschaften Volkenroda und Pöthen im Südharzbezirk. - auch Kali, etc.,

$\underline{23}(12): 181-187$

233(13): 203-207

$\underline{23}(14): 218-221$

$\underline{23}(15): 232-236$

233(16): 248-252; mehrere Abb., Halle (Saale)

- $\bullet$ Stascheit, Annemarie \& Knipping, Bernhard J. (1995): Die Lanthanoidenverteilung in Evaporitgesteinen. - Kali u. Steinsalz, 11(10): 355-360, 4 Bilder, 2 Tab.; Essen

[darin: Königshall-Hindenburg/Reyershausen; Hattorf/Philippsthal, Wintershall/Heringen]

OStolle, Ernst (1962): Zur Faziesdifferenzierung im Südharz-Kalirevier. - Ber. Ges. geol. Wiss. DDR, $\underline{6}$ (f. 1961)(2/3): 266-287, 10 Abb., 1 Tab.; Berlin

[Mächtigkeitskarten, Lagerstättengenese Zechstein]

OStolle, Ernst (1963): Zur Hartsalzerkundung im Kalisalzlager Staßfurt unter besonderer

Berücksichtigung des Südharzgebietes. - Z. angew. Geol., 9(1): 3-14; 2 Abb.; Berlin

[Gebiet Bleicherode-Sollstedt, Holungen-Großbodungen]

oStolle, Ernst (1974): Bodenschätze[in Thüringen] - Salze. - In: Hoppe, Walter \& Seidel, Gerd

[Hrsg.]: Geologie von Thüringen [Bezirke Erfurt, Gera, Suhl]. - S. 899-914, Abb. 183-188, Photo 98 u. 99; (Haack) Gotha-Leipzig 1974

-Storck, Ulrich (1954): Die Entstehung der Vertaubungen und des Hartsalzes im Flöz Staßfurt im Zusammenhang mit regelmäßigen Begleiterscheinungen auf dem Kaliwerk Königshall - Hindenburg. - Kali u. Steinsalz, 1(6): 21 - 3117 Abb., 2 Tab.; Essen

OStrienitz, Rolf (1962): Paragenetisches und geochemische Untersuchungen verschiedener Salzgesteine der Flöze Thüringen und Hessen. - Dipl.-Arb. [unveröff.] Bergakademie Freiberg/Sa. 1962

Referat in: Geologie, 12(9): 1113-1114; Berlin 1963

[Thür. Werra-Kalirevier]

OUrban, H. (1953): Über ein neues Vorkommen von Bittersalz in der Grube „Kaiseroda II/III“ des Werra-Kaligebietes. - Chemie der Erde, 16 (2): 194-196, 3 Abb.; Jena

OWalger, Günther (1962): Vorläufige Mitteilungen zum Vorkommen sulfatischer Kaliminerale in der Schachtanlage Pöthen im Bereich der Störungszone des Schlotheimer Grabens. - Ber. geol. Ges. DDR, $\underline{\mathbf{6}}$ (f. 1961)(2/3): 258-265, 5 Abb., 1 Tab.; Berlin

-Wirtschaftsvereinigung Bergbau e.V., Bonn [Hrsg.] (1976): Das Bergbau-Handbuch. Herausgegeben von der Wirtschaftsvereinigung Bergbau e.V. - 3., neu bearb. Aufl.; 280 S., Ill., graph. Darst., Kt.; (Glückauf) Essen

[darin S. 171-186, 12 Bilder, 3 Taf.: Kap. 5 - Kali und Steinsalz - darin S. 172-173 - Bild 2: 1

Querprofil Werra-Fulda-Lagerstätte Schnitt Neuhof - Mausbach/Hattorf-Richelsdorf]

OZeibig, S. (1983): Strukturelle und substanzmäßige Gesetzmäßigkeiten des Kaliflözes Thüringen im Werra-Kaligebiet. - Dipl.-Arb. [unveröff.] Bergakademie Freiberg/Sa. 1983 
OZeibig, Silvio \& Jahne, Heinz (1993): Struktureller und petrographischer Aufbau einer Carnallitanstauung des Kaliflözes Thüringen im Werra-Gebiet. - Kali u. Steinsalz, 11(3/4): 74-85, 33 Abb., 2 Tab.;

[Kaliwerk Unterbreizbach]

\subsubsection{Karbonate, Sulfate (außer Zechstein-Sulfate)}

@Alberti, v. (1837): Gyps des Muschelkalks bei Eisenach. - N. Jb. Mineral., 1837: 41 (Briefl. Mitt.), Taf. I(Fig. C, D]; Stuttgart

$\square$ Anonym (1897): < Kalkmergel-Lagerstätte bei Netra entdeckt].- Eschweger Tageblatt u. Kreisblatt, 1897; Nr. 277 v. 26.11.1897; ebenso Nr. 279 v. 29.11.1897; Nr. 285 v. 6.12.1897; Eschwege

$\square$ Anonym (1897): <Zum Mergellager bei Netra].- Eschweger Tageblatt u. Kreisblatt, 1897; Nr. 295 v. 17.12.1897; Eschwege

$\square$ Anonym (1899): <Zur Mergellagerstätte bei Netra] - Eschweger Tageblatt u. Kreisblatt, $\underline{\mathbf{1 8 9 9}}$; Nr. 67 v. 20.3.1899; Eschwege

oCredner, Heinrich (1846): Vorkommen und Krystallisation des Gypses zu Friedrichrode [Friedrichroda]. - N. Jb. Mineral. etc., 1846: 62-65 (Briefl. Mitt.); Stuttgart

- $\square 0 \bullet$ Fulda, Ernst (1931): Der Hauptdolomit des Mittleren Zechsteins als Erdölmuttergestein. - Kali, etc., 25(13): 193-198, 3 Fig.; Halle/Saale

[HE, WMK, THÜ, NIE]

oGesang, Heinrich (1984): Zur Genese und petrofaziellen Gliederung der Süßwasserkalke des Thüringer Beckens. - Veröff. Naturkundemuseum Erfurt, Naturwiss. Rh., 4: 55-63, 6 Abb.; Erfurt

-Hausmann, J.F.L. (1854): Über das Vorkommen des Dolomits am Hainberge bei Göttingen. - Studien Göttingischen Vereins bergmänn. Freunde, ㅁ: 295-310; Göttingen

$\square$ Holzapfel, Hans-Wilhelm (1991): Fazies und Diagenese der Zechstein 1 - Karbonate vom südlichen Küstenrand zum niedersächsischen Becken. - Diss. Univ. Marburg [unveröff.]; 189 S., Ill., graph. Darst., Kt.

$\square$ Hotzler, Fritz (1996): Kalksinter - Ein Gestein, das noch heute entsteht. - Das Werraland, $\underline{48}(1)$ : 10; Eschwege

OLangbein, Rolf (1971): Zur Petrographie und Lithostratigraphie des Thüringer Plattendolomits. Geologie, 20 (1): 22-37, 9 Abb.; Berlin

[darin: Profil Raum Ohrdruf]

-Lüdecke, Carl (1892): Untersuchungen über Gesteine und Böden der Muschelkalkformation in der Gegend von Göttingen. - Z. f. Naturwiss., $\underline{\mathbf{5}}$ [= 5. F., $\mathbf{3}]: 219-349,11$ Tab.; Leipzig - zgl. Diss. Univ. Leipzig

Referate in: N. Jb. Mineral. etc, 1894 (Bd. I): 480-483 (A. Leppla); Stuttgart - Z. prakt. Geologie, 1.1893 (5): 206-209 (Wahnschaffe)

[Mineralogie, Geochemie, Bodenkunde]

oLukas, Volker (1992): Zur Diagenese der Karbonate des Unteren Muschelkalk (Trias). - N. Jb. Geol. Paläont. Abh., 185: 85-113, 11 Abb., 1 Tab.; Stuttgart 
OMädler, Jonas \& Schröder, Norbert (1969): Zur Kenntnis der Rückenmineralisation bei Bad Liebenstein-Schweina (Thüringer Wald). - Ber. Dt. Ges. geol. Wiss., Reihe B, 14(3): 243-256, 3 Abb., 1 Tab., 6 Taf.; Berlin

[Calcit, Schwerspat, Speiskobalt]

OMallick, Ronzon (2000): Entwicklung der Mikrobeprobung zur Th-, U-Datierung und Anwendung an quartären Travertinen aus dem Thüringer Becken. - Diss. Univ. Heidelberg 2000; 162 S.

OMallick, Ronzon (2001): Präzise Th/U-Datierung archäologisch relevanter Travertinvorkommen Thüringens. - In: Wagner, G. [Hrsg.]: Frühe Menschen in Mitteleuropa - Chronologie, Kultur, Umwelt [Kolloquium 9.-11. März 2000 Heidelberg]. - Veröff. d. Vereins Homo Heidelbergensis von Mauer e.V. 1; 163 S., Abb., Kt.; hier: S. 77-89; (Shaker) Aachen 2001

OMallick, Ronzon \& Frank, Norbert (2002): A new technique for precise uranium-series dating of travertine micro-samples. - Geochimica et Cosmochimica Acta, $\underline{\mathbf{6 6}}$ (24): 4261 - 4272, 6 fig., 4 tab.; Amsterdam [Bad Langensalza, Bilzingsleben, Burgtonna, Weimar-Ehringsdorf]

$\square$ Pagenkopf (1898): Der Mergel und seine Verwendung in der Landwirtschaft $<$ Bezugnahme auf neu entdecktes Mergellager bei Netra u. Landwirtschaft der Region>. - Eschweger Tageblatt u. Kreisblatt, $\underline{\mathbf{1 8 9 8}}$; Nr. 30 v. 5.02.1898; Eschwege

$\square$ Salzwedel, Ute (1992): Kalktuffvorkommen im Eschweger Raum. - Berliner Geogr. Abh., Beih.; 1; 85 S., 14 Abb., 20 Tab., 3 Taf., 3 Kt.; (Selbstverlag d. Instituts f. physische Geographie FU Berlin) Berlin [Travertinvorkommen Wanfried/Elfengrund, Grebendorf/Badstube]

OSchmidt, R. (1914): Über die Beschaffenheit und Entstehung parallelfaseriger Aggregate von Steinsalz und Gips. - Kali, etc., $\underline{8}(10)$ : 239-245; Halle [darin: Friedrichsroda, Bhrg. Sondra II b. Eisenach; Wasenweiler a. Kaiserstuhl, Schwarzwald]

$\square$ Schramm, Michael (1996): Die Mineralparagenesen des magnesitführenden Zechsteins: eine mineralogische, petrologische und geochemische Untersuchung. - Diss. Univ. Göttingen 1995, 121 S., graph. Darst.; (Cuvillier) Göttingen

- •Smykatz-Kloss, Werner (1966): Sedimentpetrographische und geochemische Untersuchungen an Karbonatgesteinen des Zechsteins - II. Spezieller Teil. - Contrib. Mineral. Petrol., 13: 232-268, 19 Abb., 11 Tab.; Berlin

[Untersuchungen u. a. Kernmaterial Bohrungen Northeim 1, Reinhardswald 1]

ØThomaser, Peter (1969): Der Mineralbestand der Zechsteinkarbonate auf dem Gebiet der DDR. - Jb. Geol., $\underline{2}$ (f. 1966): 27-62, 4 Abb., 4 Taf.; Berlin

[darin: Bohrungen i. Westthüringen]

OWolf, Peter \& Schwahn, Hans-Jürgen (1990): Die Ressourcen an karbonatischen Rohstoffen in der

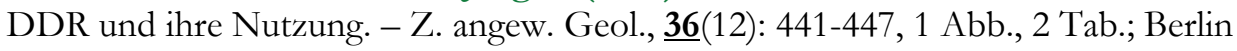
[darin erwähnt: Traverinte Thür. Becken, u. Langensalza, Kalkstein Oberdorla]

\subsubsection{Kohlenwasserstoffe}

QAlbrecht, Helmuth (1932): Das Erdölvorkommen von Volkenroda. - Kali, etc., $\underline{\mathbf{2 6}}(3): 25-33,8$ Abb., 2 Taf., $\underline{\mathbf{2 6}}$ (4): 39-43, 10 Abb.; Halle (Saale)

Referat in: N. Jb. Mineral. etc., Referate; 1932 (Bd. II): 550 (Krejci); 1933 (Bd. II): 803 (A. Geller) 
Stuttgart

[Physikal., chem. Analyse]

QAlbrecht, Helmuth (1932): Das Erdölvorkommen von Volkenroda. - Petroleum - Z. f.d. ges. Interessen d. Erdölindustrie u. d. Minerlalölhandels, 208(18): 11-16, 6 Abb.; Berlin-Wien Referat in: N. Jb. Mineral. etc., Referate; 1933 (Bd. II): 803 (Krejci); Stuttgart

QAlbrecht, Helmuth (1932): Neuere Erfahrung über das Erdlölvorkommen von Volkenroda. - Z. dt. geol. Ges., 84: 361 - 363; Berlin

OAlbrecht, Helmuth (1934): Neue Aufschlüsse im Zechstein auf Volkenroda. - Z. dt. geol. Ges., $\underline{\mathbf{8 5}}$ (f. 1933): 303; Berlin

[Bohrprofilbeschreibung]

$\square$ Anonym (1892): < Petroleumquelle bei Netra entdeckt]. - Eschweger Tageblatt u. Kreisblatt, 1892; Nr. 44 v. 22.2.1892; Eschwege

QBenz, A. (1932): Geologische Voraussetzungen für das Auftreten von Erdöllagerstätten in Deutschland. - Z. dt. geol. Ges., 84: 369 - 389, 3 Abb.; Berlin [darin: Profilskizzen Volkenroda, Pechelbronn]

QBrosin, Paul (2008): Ergebnisse der Erdöl- und Erdgaserkundung in Westthüringen $<$ Vortragskurzfassung >. - In: Wunderlich, J. [Red.]: Exkursionsführer - Geologie des Eichsfeldes - zur 18. Jahreshauptversammlung (Vortrags- und Exkursionsveranstaltung) vom 16. bis 18. Mai 2008 in Heilbad Heiligenstadt. - Führung: H. Heiland, L. Nolte, H.-G. Röhling \& G. Seidel. - S. 43; Jena 2008

[Umgebung Mühlhausen: Volkenroda-Pöthen, Langensalza]

QDeubel, F. (1932): Zur Frage der Erdölhöffigkeit Thüringens. - Z. dt. geol. Ges., 84: 389 - 395; Berlin [darin: Lagerstätten Volkenroda, Thüringer Becken]

ODeubel, F. (1954): Betrachtungen über das Auftreten von Erdöl und Erdgas im Zechstein des Thüringer Beckens. - Geologie, $\underline{\mathbf{3}}(6 / 7)$ : 804-831; Berlin [u.a. Aufschlüsse Kaliwerk Volkenroda, Bohrungen Forstberg, Mühlhausen, Mexleben-Nagelstädt, Stadtwaldd 1(Hainich), Zimmern 1]

QDeubel (1956): Besuch der erdgasführenden Strukturen im Raum Mühlhausen - Langensalza Exkursion C am 17. Oktober 1955. - Bericht über die Mitgliederversammlung und Exkursionstagung der Geologischen Gesellschaft der Deutschen Demokratischen Republik vom 16. bis. 18. Oktober 1955 in Eisenach. - Ber. geol. Ges. DDR, 2 (1): 60; Berlin

OElert, Karl-Heinz; Henning, Ilona \& Kanbe, Hans-Jürgen (1988): Untertägige Erdöl-Vorkommen und ihre bergbausicherheitliche Beurteilung. - Z. angew. Geol., 34(5): 139-144, 3 Abb., 5 Tab.; Berlin [Thüringer Becken, thüringisches Werra-Kalirevier]

OFiege, K. (1934): Übersicht über das Vorkommen der Erdöle, Erdgase und Asphalte in Deutschland (I).

- Kali, etc.,

$\underline{28}(15): 183-191$

$\underline{28}(16): 200-204$

$\underline{28}(17): 214-219$

$\underline{28}(18): 228-230$

28 (19): 242-245; 1 Abb., 1 Tab.; Halle (Saale)

[darin: Erdöllagerstätte Volkenroda/Thür.]

- $\square$ OӨ Fulda, Ernst (1931): Der Hauptdolomit des Mittleren Zechsteins als Erdölmuttergestein. - Kali, etc., 
25(13): 193-198, 3 Fig.; Halle/Saale

[HE, WMK, THÜ, NIE]

OFulda, Ernst (1931): Zur Entstehung des Erdöls in Thüringen und Hannover. - Jb. Hallesches

Verbandes etc., N.F., 10: 113 - 116, 2 Abb.; Halle/Saale

Referat in: N. Jb. Mineral. etc., Referate; 1932 (Bd. II): $91-92$ (v. Freyberg); Stuttgart

[darin: Volkenroda, Menteroda; Profile d. Zechsteins]

-Gerling, Peter; Beer, Wolfgang \& Bornemann, Otto (1991): Gasförmige Kohlenwasserstoffe in Evaporiten des deutschen Zechsteins. - Kali u. Steinsalz, 10(11): 376-383, 6 Bilder, 3 Tab.; Essen [darin: Untersuchungen an Proben aus Neuhof-Ellers, Hattorf, Wintershall]

OGrobleben, J.; Voigt, Th. \& Schöner, R. (2008): Paläothermische Rekonstruktion und Kohlenwasserstoff-Generierung permokarboner Sedimente im Untergrund der Thüringer Mulde $<$ Vortragskurzfassung > . - In: Wunderlich, J. [Red.]: Exkursionsführer - Geologie des Eichsfeldes - zur 18. Jahreshauptversammlung (Vortrags- und Exkursionsveranstaltung) vom 16. bis 18. Mai 2008 in Heilbad Heiligenstadt. - Führung: H. Heiland, L. Nolte, H.-G. Röhling \& G. Seidel. - S. 39-40; [Hrsg.: Thüringer Geologischer Verein e.V.] Jena 2008 [darin: Manebach/Thüringer Wald]

- $\square$ (ब•Heidorn, F. \& Schlüter, H. (1931): Zur Frage der Ölhöffigkeit und Paläogeographie des Mittleren Zechsteins. - Kali, etc., 25; Halle (Saale)

$\underline{25}$ (20): 295-298, Fig. 249, 250

[darin: Paläogeographische Karte unter Einbezug der Dreiländer-Region]

$\underline{25}$ (21): 307-312, Fig. 256, 257

[darin Kap. IV. - Einfluß nachfolgender Gebirgsbildung auf die räumliche Verteilung des Erdöls, gedeutet an dem Vorkommen von Volkenroda in Thüringen]

$\underline{25}$ (22): $321-325$

[darin: Verzeichnis von Bohrprofilen und Aufschlüssen: Bezugn. a. Erdöl-Lagerstätte Volkenroda, Bhg. Rambach (Bl. Treffurt); Wiedergabe Stratigraphie Mittlerer Zechstein nach Erläuterungen Bl. Allendorf, Berka, Eisenach, Höhnebach, Kella, Netra, Sontra, Witzenhausen, Wutha]

OHessmann, Wolf (1963): Erdöl- und Erdgasspeichereigenschaften des Staßfurtkarbonats im Süden der DDR. - Z. angew. Geol., $\underline{\mathbf{9}}(10):$ 513-516, 1 Abb.; Berlin [Region Mühlhausen]

QKästner, Hans (1964): Beobachtungen zum Auftreten von Kohlenwasserstoffen im Werrakaligebiet. Z. angew. Geol., $\underline{10}$ (7): 359 - 364, 2 Abb.; Berlin

QKästner, Hans (1995): Bodenschätze [in Thüringen] - Erdöl, Erdgas, Kohlendioxid. - In: Seidel, Gerd [Hrsg.]: Geologie von Thüringen. - 1. Aufl.; S. 452-455, 1 Abb., 1 Tab.; Stuttgart 1995

ØKästner, Hans (2003): Bodenschätze [in Thüringen] - Erdöl, Erdgas, Kohlendioxid. - In: Seidel, Gerd [Hrsg.]: Geologie von Thüringen. - 2., neu bearb. Aufl.; S. 483-486, 1 Abb., 1 Tab.; Stuttgart 2003

@Karinin, W.-D.; Merkel, D.; Piske, J. \& Schrekenmayr, St. (1998): Historie und gemeinsames Explorationskonzept EEG/BEB nach 1990. - In: Karinin, W.-D.; Merkel, D. \& Piske, J.: Geowissenschaftliche Ergebnisse der Kohlenwasserstoff-Exploration im Land Brandenburg und im Thüringer Becken in den Jahren 1991-1196 (Zechstein und Rotliegendes). [Beiträge von zahlreichen Autoren]- Geol. Jb., Reihe A., 149, 320 S., zahlr. Abb., Tab., Kt.; Hannover - hier: S. 7 - 23, 11 Abb., 2 Tab.; Hannover 1998 [darin: statist. Angaben über Lagerstätten in Westthüringen: Volkenroda, Mühlhausen, Langensalza] 
QKarpe, W. (1959): Ein Beitrag zur Kenntnis der Erdöllagerstätte Volkenroda. - Z. angew. Geol., $\underline{\mathbf{5}}(10)$ : 422-425; Berlin

OKauter, Kurt (1959): Erdölgeologische Probleme der thüringischen Erdgaslagerstätten. - Ber. geol. Ges. DDR, 4(4): 281-287, 4 Abb.; Berlin

[Lagerstätten bei Bad Langensalza, Mühlhausen]

OKöltzel, H. (1957): Entwicklung, Ergebnisse und Perspektiven der Erkundung auf Erdöl und Erdgas im Gebiet der Deutschen Demokratischen Republik. - Z. angew. Geol., $\underline{\mathbf{3}}(5 / 6):$ 201-209, 2 Abb., 1 Tab.; Berlin [darin: Volkenroda, Mühlhausen/Langensalza]

OMathes, F. \& Noack, A. (1932): Das Naturgasvorkommen von Volkenroda in Thüringen. - Die „Umschau“ in Wissenschaft u. Technik, 36 (35): 681-682

Referat in: N. Jb. Mineral. etc., Referate; 1932 (Bd. II): 265 (M. Henglein); Stuttgart

OMay, F.; Freund, W.; Müller, E. P. \& Dostal, K. P. (1968): Modellversuche über Isotopenfraktionierung von Erdgaskomponenten während der Migration. - Z. angew. Geol., 14(7): 377-380, 6 Abb., 3 Tab.; Berlin [darin: Strukturen Langensalza, Kirchheilingen - Allmenhausen]

QMeinhold, Rudolf (1959): Probleme der Erdölerkundung im Zechstein. - Ber. geol. Ges. DDR, 4(4): 269-280, 6 Abb.; Berlin [darin: Westthüringen]

OMeinhold, Rudolf (1960): Der geologische Bau und die Erdöl- und Erdgasführung der Deutschen Demokratischen Republik und der angrenzenden Gebiete des Norddeutschen Flachlandes. Geologie, Beih., 27; S. 1-66, 26 Abb.; Berlin [Großregionale Betrachtung, darin erwähnt: Mühlhausen, Langensalza]

OMüller, E. P. (1984): Zur Genese von Erdölen in Karbonaten am Beispiel der Lagerstätten im Oberen Perm des Terrotoriums der DDR. - Z. angew. Geol., 30(5): 214-218, 8 Abb.; Berlin [darin: Westthüringen, verzeichnet a. Abb. 1: Mühlhausen-Langensalza, Kirchheilingen, Behringen]

QPröhl, Stefan (1962): Ergebnsise von Kohlenwasserstoff-Messungen im Gebiet Schlotheim und ihre Problematik. - Z. angew. Geol., $\underline{\mathbf{8}}(12):$ 627-632, 3 Abb.; Berlin [Bodenluftmessungen, Gaschromatographie auf Kohlenwasserstoffe]

ØRische, H. (1960): Über die Möglichkeien der reflexionsseismischen Erkundung im Thüringer Becken. - Ber. geol. Ges. DDR, $\underline{\mathbf{5}}(1 / 2)$ : 78-84, 4 Abb., 1 Tab.; Berlin [Erdöl-, Erdgasgebiet Mühlhäusen-Bad Langensalza]

- $\bigcirc$ Roeber, Joachim (1938): Die Jodverteilung in den deutschen Lagerstätten. Gründe für das Auftreten und Fehlen von Jod in verschiedenen Horizonten des Zechsteins und in Erdölwässern. - Kali, etc., 32(20): 209-211

$\underline{32}(21): 221-223$

32(22): 233-236; Halle/Saale

[darin: Volkenroda; Hess.-Thür. Werra-Kalirevier: Wintershall, Kaiseroda]

ORost, Ursula (1957): Erdöl- und Erdgasvorkommen in den Kaliwerken des Werragebietes und des nordöstlichen Teiles des Thüringer Beckens. - Dipl.-Arb. [unveröff.] Bergakademie Freiberg/Sa. 1957, $60 \mathrm{~S}$.

Referat in: Geologie, $\underline{8}(2): 217$; Berlin 1959

OSchroeder, E. (1931): Das Erdölvorkommen von Volkenroda (Thüringen). - Petroleum, 27 (43): 770772; Wien 
OSchröder, Eckart (1934): Die Erschließung der Erdöllagerstätte in Thüringen. - Jb. Preuß. Geol. Landesanst., $\underline{\mathbf{5 4}}$ (f. 1933): 7 (Sitzber.); Berlin

[Unstrut-Hainich-Kreis]

oSimon, Wilhelm Georg (1935): Die erdölhöffigen Gebiete Deutschlands. - Z. prakt. Geol., $\underline{43}$ (1): 1014, 3 Abb.; Berlin

[darin: Volkenroda/Thür.]

OStutzer, O. (1933): Über die im Mikroskop sichtbare Bitumenführung des Hauptdolomits von

Volkenroda und des „Stinkschiefers“ von Mansfeld. - Kali, etc.,

$\underline{27}(4): 43-45$

27(5): $53-56$

27(6): 73-75, 6 Fig.; Halle/Saale]

OWerner (1931): Die Abhängigkeit der norddeutschen Salzstöcke und Erdöllagerstätten von der Tektonik des tieferen Untergrundes. - Kali, etc., 25 (17): 253-254; Halle (Saale)

[darin: Bezugnahme auf Erdölvorkommen i. Kaliwerk Volkenroda]

QZiegenhardt, W.; Rockel, W. \& Griesbach, H. (1978): Paläomorphologie und Erdöl/Erdgas-

Lagerstättenbildung im Staßfurtkarbonat Thüringens. - Z. angew. Geol., 24 (9): 353-362, 9 Abb.;

Berlin

[Lokalitäten anonymisiert]

QZwerger, R. v. (1934): Tektonik, Anomalien des Erdmagnetismus und Erdölhöffigkeit in

Mitteldeutschland. - Kali, etc.,

29(5): $62-65$

$\underline{\mathbf{2 9}}(6): 72-75$

$\underline{29}(7): 86-88$

$\underline{\mathbf{2 9}}(8): 98-100$

$\underline{29}$ (9): 112-114, 5 Fig.; Halle/Saale

[darin: Westthüringen, Isoanomalienkarte der Vertikalintensität]

\subsubsection{Kohlensäure und andere Gase}

@Anonym (1919): Die vermutliche Entstehung der Gasausbrüche auf dem Kaliwerk Craja. - Jb. Halleschen Verbandes etc., 11: 161-162; Leipzig

OAnonym (1919): Auftreten von Kohlenoxyd in den Urgasen von Kalisalzbergwerken. - Jb. Halleschen Verbandes etc., 1: 162-165; Leipzig

[darin: Sollstedt, Weidtmannshall, Neu-Bleicherode]

QBeck, Kurt (1912): Über Kohlensäureausbrüche im Werragebiete der deutschen Kalilagerstätten. - Kali, etc., $\underline{\mathbf{6}}$ (6): 125-128, 5 Fig.; Halle

[Thür. Werra-Kalirevier: Kaliwerk „Großherzog Sachsen“/Dietlas]

-Beer, Wolfgang W. \& Lindecke, Bernd (1997): Die mengenmäßige Erfassung gesteins- und kluftgebundener Gase im Kalibergwerk Wintershall. - Kali u. Steinsalz, 12(6): 196-200, 11 Bilder;

Essen

[Überwiegend CO2-Gase]

- $\bigcirc D^{\prime}$ Ans, Jean (1967): Das CO2 in Kalisalzlagern - Sein Zustand und die Bedingungen seines Entstehens. - Kali u. Steinsalz, 4(12): 396-401; Essen

[Hess.-Thür. Werra-Kalirevier] 
ODittrich, Erhard (1960): Kohlensäure-Erkundung in der Vorderrhön. - Z. angew. Geol., ㅁ⑹: 249-253, 5 Abb; Berlin

[Südwestthüringen]

ODuchrov, Günther (1997): Der 100-jährige „Rhönmarsch“ in die Kohlensäurefelder des südthüringischen Kalibergbaus. - Der Anschnitt, 49 (4): 123-147; [12] Abb., 2 Tab.; Bochum [Kohlensäure, Kalibergbau thüringisches Werra-Kalirevier]

OFrantzen, W. (1895): Ueber neue Erfahrungen beim Kalibergbau in der Salzunger Gegend. - Jb. Preuß. Geol. Landesanst., 15 (f. 1894): LX-LXI; Berlin

Referat in: Mitt. Geogr. Ges. (f. Thüringen), 17: 99 (Alfred Berg); Jena 1898

[Kohlensäuregas-Lagerstätte]

QFrantzen, W. (1896): Kohlensäurequellen in Thüringen. - Z. f. Naturwiss., 6 9 [= 5. F., 7]: 91-93; Leipzig [Umgebung Bad Salzungen]

OGiesel, R.-J.; Haase, G.; Marggraf, P.; Salzer, K. \& Thoma, K. (1989): Drei Jahrzehnte Ausbruchsforschung im Kalibergbau des Werrareviers der DDR. - Z. angew. Geol., 17(4): 333-346, 11 Abb.; Berlin

-OGropp (Bergassessor) (1919): Gasvorkommen im Kalisalzbergwerken in den Jahren 1907-1917 $<$ mehrseitiges Tabellenwerk>. - Kali, etc., $\underline{13}(3): 33-42$

13 (5): 70-76 (Tabelle); Halle/Saale - Tabellen

[darin: Südharz-Kalirevier: Bleicherode, Klein-Bodungen, Sollstedt, Craja, Weidtmannshall b. Bischofferode; hess. Werra-Kalirevier: Hattorf, Wintershall - Tab.: Verzeichnis von Gasvorkommen u. Ausbrüchen]

oHaase, Günter (1966): Die Bedeutung neuer geologischer Erkenntnisse für die Einschätzung der Entwicklungsperspektive des Kalibergbaues im thüringischen Werragebiet. - Ber. Dt. Ges. geol. Wiss., Reihe A, 11(4): 425-437, 5 Abb.; Berlin

[Lagerstättenkunde, auch Kohlensäure/Gebirgsschläge]

-oHartwig, Georg (1954): Zur Kohlensäureführung der Werra- und Fulda-Kalisalzlager. - Kali u. Steinsalz, 1(5): 3-26, 6 Bilder.; Essen

OHoppe, Walter (1966): Die Herkunft der Kohlensäure in den Grundwässern Thüringens. - Geologie, 15(6): 1042-1052, 1 Abb., 2 Tab.; Berlin

[darin: Bad Liebenstein]

OKästner, Hans (1966): Beitrag zur Geologie der Kalisalz- und Kohlensäurelagerstätten im südlichen Werra-Kaligebiet. - Diss. Hochschule f. Architektur u. Bauwesen Weimar 1966; VII, 129 S.; 8 Bl., 36 Beil. (Text- u. Anlagenbd.)

OKästner, Hans (1968): Zur Entstehung und Verbreitung von Kohlendioxidlagerstätten. - Z. angew. Geol., 14(6): 316-323, 2 Abb.; Berlin [darin: Thüringisches Werra-Kalirevier]

OKästner, Hans (1969): Zur Geologie der Kalisalz- und Kohlensäurelagerstätten im südlichen WerraKaligebiet. - Abh. Zentralen Geol. Institutes, 11: I-VII, 1-96, 23 Abb., 2 Tab. Berlin

OKästner, Hans (1994): Zur Kenntnis der Kohlendioxidlagerstätten in der Vorderrhön. - Geowiss. Mitt. Thür., 2: 73-96, 6 Abb., 2 Tab.; Weimar

OKästner, Hans (1995): Bodenschätze [in Thüringen] - Erdöl, Erdgas, Kohlendioxid. - In: Seidel, Gerd [Hrsg.]: Geologie von Thüringen. - 1. Aufl.; S. 452-455, 1 Abb., 1 Tab.; Stuttgart 1995 
OKästner, Hans (2003): Bodenschätze [in Thüringen] - Erdöl, Erdgas, Kohlendioxid. - In: Seidel, Gerd [Hrsg.]: Geologie von Thüringen. - 2., neu bearb. Aufl.; S. 483-486, 1 Abb., 1 Tab.; Stuttgart 2003

oKauenhoven, Walter (1932): Heliumgewinnung in den Vereinigten Staaten und ihre Aussichten in Deutschland. - Kali, etc., 26(9): 106-110, 26(10): 121-123, 2 Fig.; Halle/Saale

[Heliumführendes Erdöl- u. Erdgasgebiet von Amarillo, Texas - darin erwähnt: Volkenroda]

ORost, Wolfgang (1957): Geologische Untersuchungen zu den Kohlensäurevorkommen auf dem Kaliwerk „Marx-Engels“ in Unterbreizbach. - Dipl.-Arb. [unveröff.] Bergakademie Freiberg/Sa., 62 S. Referat in: Geologie, $\underline{\mathbf{8}}(2):$ 217; Berlin 1959

QVogel, Jochen \& Schäbitzer, Rudolf (1970): Zur geologischen Situation der Kohlensäureausbrüche im Werra-Gebiet unter besonderer Berücksichtigung des Grubenbetriebs „E. Thälmann“. - Z. angew. Geol., 16 (6): 298-301, 2 Abb.; Berlin

QWager, Rudolf (1938): Heliumlagerstätten - Zusammenfassende Besprechung der Literatur über Heliumlagerstätten und -spuren. - Kali, etc.,

32(15): 159-164

32(16): 173-175

32(17): 179-181

32(18): 189-192

32(19): 199-203, 2 Fig.; Halle/Saale

[nternationale Betrachtung; darin aufgelistet: Volkenroda]

OZiegenhardt, W. \& Werner, R. (1979): $\mathrm{CO}_{2}$ in Erdgaslagern des thüringischen Staßfurtkarbonats (Herkunft, Migration und Akkumulation). - Z. angew. Geol., 25(5): 165-169, 3 Abb.; Berlin

\subsubsection{Steinkohle}

-OBruhns, W. (1906): Die nutzbaren Mineralien und Gebirgsarten im Deutschen Reiche. - Neu bearb. u. Mitwirk. v. H. Bücking a. Grundlage d. gleichnam. Werkes v. Heinrich v. Dechen (1873); XIX, 859 S., 1 geol. Falt-Kt.; (Reimer) Berlin

[Regionale Lagerstätten - darin: darin S. 236-238 Steinkohlen Thüringer Wald, Bohrversuch auf Steinkohlen bei Nentershausen/Richelsdorfer Gebirge]

QGothan, W. \& Grimm-Elgersburg, O. (1952): Über die verkieselte Kohle des Manebacher Oberflözes. - Sitzber. Dt. Akad. Wiss. z. Berlin - Kl. f. Mathem. u. allgem. Naturwiss.; 1952(II); 13 S., 1 Taf.; Berlin

OHeß v. Wichdorf, Hans \& Gothan, Walter (1927): Zur weiteren Kenntnis der Steinkohlenlagerstätten im untersten Rotliegenden von Manebach in Thüringen. - Jb. Preuß. Geol. Landesanst., 47 (f. 1926): 433-457, 2 Fig., Taf. 15-17; Berlin

Referat in: N. Jb. Mineral. etc., Abt. B, 1927 (Bd. II): 163-164 (Kräusel); Stuttgart

OHoehne, Karl (1957): Zur Entstehungsgeschichte der Flözverkieselungen in den unterrotliegenden Steinkohlen von Stockheim in Oberfranken und Manebach in Thüringen. - Geologie, ㅁ⑻: 806-836, 10 Taf. (21 Bilder); Berlin 
QKaemmel, Thomas (1973): Regionale Grobübersicht über den Inkohlungsgrad der Kohlen und kohlenhaltigen Substanz in paläozoischen Sedimenten im Südteil der DDR. - Z. angew. Geol., 19 (11): 569-575, 4 Abb.; Berlin [darin: Lauchagrund-Kleinschmalkalden, Bhr. Ohrdruf, Öhrenkammer, Manebach, Crock]

OKästner, Hans (1974): Bodenschätze [in Thüringen] - Kohlen. - In: Hoppe, Walter \& Seidel, Gerd [Hrsg.]: Geologie von Thüringen [Bezirke Erfurt, Gera, Suhl]. - S. 915-917, tab. 109 u. 110; (Haack) Gotha-Leipzig 1974

OKästner, Hans (1995): Bodenschätze [in Thüringen] - Kohlen und Torfe. - In: Seidel, Gerd [Hrsg.]: Geologie von Thüringen. - 1. Aufl.; S. 443-444; Stuttgart 1995

QKästner, Hans (2003): Bodenschätze [in Thüringen] - Kohlen und Torfe. - In: Seidel, Gerd [Hrsg.]: Geologie von Thüringen. - 2., neu bearb. Aufl.; S. 474-475; Stuttgart 2003

OSchwab, Günter (1964): Zur petrographischen Ausbildung von Steinkohlen aus dem Permokarbon des Thüringer Waldes. - Abh. Dt. Akad. Wiss.; Kl. Bergbau, Hüttenwesen, Montangeologie, 1964(2)[Deubel-Festschrift]: 135-146, 2 Abb., 3 Tab., Taf. 5-8; Berlin.

\subsubsection{Eisen-, Manganerze}

QBankwitz, Peter (2003): Zur Geologie der Magnetitlagerstätte Schwarze Crux, nördlich von Vesser (Thüringer Wald). - Veröff./ Naturhist. Museum Schleusingen, 18: 31-44, 14 Abb., 2 Tab.; Schleusingen [Schiefergebirgsinsel von Schmiedefeld-Vesser]

-Beyschlag, F. (1919): Die Manganerzlagerstätte von Hohenkirchen bei Kassel. - Z. prakt. Geologie, 27(6): 87-89; 1 Abb.; Halle (Saale)

QBöhne, E. (1921): Die Eisenerzlagerstätten der Klinger Spalte zwischen Trusegrund und Thüringer Tal am Südwestrand des Thüringer Waldes. - Jb. Preuß. Geol. Landesanst., $\underline{40}$ (Teil II) (f. 1919): 2 Abb., Taf. 1-3; Berlin Referat in: N. Jb. Mineral. etc., 1925 (Bd. I): 558-559 (G. Fischer); Stuttgart

QBöhne, E. (1925): Die Eisenerzlagerstätte des Stahlbergs bei Schmalkalden am Südwestrand des Thüringer Waldes. - Archiv f. Lagerstättenforschung, 31; 75 S., 8 Abb., 6 Taf.; [Hrsg. Preuß. Geol. Landesanst.] Berlin

QBrander, Thomas \& Lippolt, Hans Joachim (2005): Mehrphasige Entstehung von Braunem Glaskopf an der Klinge-Störung im Schmalkalden-Revier des Thüringer Waldes. - Geowiss. Mitt. Thür., 12: 79-95, 6 Abb., 4 Tab.; Jena

GBruhns, W. (1906): Die nutzbaren Mineralien und Gebirgsarten im Deutschen Reiche. - Neu bearb. u. Mitwirk. v. H. Bücking a. Grundlage d. gleichnam. Werkes v. Heinrich v. Dechen (1873); XIX, 859 S., 1 geol. Falt-Kt.; (Reimer) Berlin

[Regionale Lagerstätten - darin S. 444-447: Eisenerze im Thüringer Wald)

QBücking, H. (1883): Gebirgsstörungen südwestlich vom Thüringer Walde und ihre Beziehungen zu den Eisenerzlagerstätten des Stahlberges und der Mommel. - Jb. Preuß. Geol. Landesanst., $\underline{\mathbf{3}}$ (f. 1882): 3343 (Abh. v. Mitarb....) Taf. I; Berlin Referat in: N. Jb. Mineral. etc., $\underline{1884}$ (Bd. 1): $96-98$ (Referat A. Stelzner); Stuttgart Referat in: Mitt. Geogr. Ges. f. Thür., $\underline{3}:$ 210-211 (Fr. R.); Jena 
-Giesecke, Bruno Th. (1858): Analysen des Bohnerzes von Mardorf in Kurhessen, und des daraus auf der Homberger Eisenhütte gewonnenen Roheisens - nebst einleitenden Bemerkungen über das Mardorfer Bohnerzlager v. J. F. L. Hausmann. - Studien Göttingischen Vereins Bergmänn. Freunde, $\underline{7}(2):$ 113-138; Göttingen

OIsert, F. (1930): Eisen- und Manganerze - Thüringisch-Sächsischer Bezirk. - In: Hülsemann, P. [Hrsg.](1930): Die Bergwerke Deutschlands - Auf bergwirtschaftlicher und lagerstättenkundlicher Grundlage. - XI, 412 S., zahlr. Abb., Tab. 8 Kt.; hier: S. 194-197; (Enke) Stuttgart

OJahns, H. (1925): „Äußere“ Gangmetasomatose und Genesis der Thüringer Manganerzgänge. - Jb. Preuß. Geol. Landesanst., $\underline{45}$ (f. 1924): 98-118, Taf. 3; Berlin

-Koenen, A. v. (1883): Ueber das Alter der Eisensteine bei Hohenkirchen. - Nachr. Kgl. Ges. Wiss. z. Göttingen u. d. Georg-Augusts-Univ. Göttingen, 1883(12): 346-349; Göttingen

OLowag, J. (1902): Mangan- und Eisenerzvorkommen im Thüringer Wald. - Österreich. Z. f. Berg- u. Hüttenwesen, 1902: 46-48; Wien

Referat in: N. Jb. Mineral. etc., 1904 (Bd. I): 239 (Katzer); Stuttgart [Vorlage nicht eingesehen, Zitat nach Angaben im genannten Referat]

oMenzel, Hans (1898): Die Lagerstätten der Stahlberger und Klinger Störung im Thüringer Wald. - Z. prakt. Geologie, [6. Jg.] 1898: 273-278, Abb. 95-98; Berlin

Referat in: N. Jb. Mineral. etc, 1900 (Bd. I): 78 (Beushausen); Stuttgart

[Klinge, Mommel, Stahlberg]

- •Lepper, Jochen; Koch, Michale, Siewers, Ulrich \& Stephan, Hans-Georg (2002): EisenerzVorkommen im Solling, Reinhardswald und Bramwald (Südniedersachsen und Nordhessen) und deren geochemische Charkterisierung im Rahmen eines Archäometallurgie-Projekts. - Nachrichten a. Niedersachsens Urgeschichte, 72: 51-63, 3 Abb., 1 Tab.; Stuttgart

QU1rich, Horst (1956): Untersuchung des Eisenmanganerz-Schwerspatvorkommens von Schmalkalden /Thür. - Dipl.-Arb. [unveröff.] Bergakademie Freiberg i. S. 1956

Referat in: Geologie, ㅁ: 456; Berlin 1957

QVoigt, [Johann Carl Wilhelm] (1821): Strahliges Graubraunsteinerz von Oehrenstock unweit Ilmenau. - Tb. Mineral., 15(2): 918-923; Frankfurt/M.

-Württenberger, G. (1867): Die diluvialen Eisensteine im Regierungsbezirke Cassel, verglichen mit den Basalteisensteinen des Vogelsberges. - N. Jb. Mineral. etc., 1867: 685-695; Stuttgart

[Umgebung v. Fritzlar, Gudensberg, Felsberg]

QZerrenner, Carl (1861): Der Braunstein- oder Manganerz-Bergbau in Deutschland, Frankreich und Spanien. - Ein mongraphischer Versuch für Geologen, Bergleute, Glashüttenbesitzer, Leiter von Chemikalien-Fabriken usw. - IX, 186 S., 2 Falt-Taf.; (J.G. Engelhardt) Freiberg [darin S. 108-169: „Die Braunstein-Bergbaue des Thüringer Waldes“ (Region Schmalkalden, Herzogthum Sachsen-Gotha, Region Gehren]

\subsubsection{Flußspat, Schwerspat, Kobalterze}

-Anonym (1928): <Baryt-Vorkommen bei Weißenhasel entdeckt]. - Eschweger Tageblatt, 1928; Nr. 247 v. 19.10.1928; Eschwege

-Bärtling, Richard (1911): Die Schwerspatlagerstätten Deutschlands in geologischer, lagerstättenkundlicher und bergwirtschaftlicher Hinsicht. - 188 S., 19 Abb.; (Enke) Stuttgart 
[darin: Grube Chattenberg b. Bad Sooden-Allendorf; Grube Münden/Nentershausen, Richelsdorfer Gebirge und Heinebach/Rotenburg F., Grube Mannel bei Herges-Vogtei i. Thür.)

QBaumann, Ludwig; Lange, Horst \& Werner, Carl-Dietrich (1968): Spurenelemente zur Lösung petrogenetischer und lagerstättengenetischer Probleme. - Ber. Dt. Ges. f. geol. Wiss., Reihe B, $\underline{\mathbf{3}}(2)$ : 135-182, 19 Abb., 16 Tab.; Berlin

[darin S. 156: Fluorite Schmalkaldener Revier]

-Becker, Roland Ernst \& Theuerjahr, Albert Karl (2004): Die Schwerspatgänge im Mittleren Buntsandstein bei Lichtenhagen, Bl. 4923 Altmorschen. - Geol Jb. Hessen, 131: 97 - 103, 3 Abb.; Wiesbaden

QBeyschlag, Franz (1898): Die Kobaltgänge von Schweina in Thüringen. - Z. prakt. Geologie, [6. Jg.] 1898: 1-4, 3 Abb.; Berlin

-Cannon, Ralph (1986): Bergbau und Mineralien des Richelsdorfer Gebirges. - Rückblick, 2: 69-71; Hofgeismar

-Cornelius, C.-D. (1950): Kupfer-, Nickel- und Kobalterz im Richelsdorfer Gebirge. - Der Aufschluß, 1 : 47-48; Braunschweig

$\square$ Gundlach, Heinrich \& Stoppel, Dieter (1966): Zur Geologie und Geochemie der Schwerspatlagerstätten im Unterwerra-Grauwackengebirge. - Notizbl. Hess. L.-A. Bodenforsch., $\underline{94}$ : 321-338, 4 Abb., 4 Tab.; Stuttgart

-Grassmann (1886): Das Richelsdorfer Kupfer- und Kobaltwerk in Hessen. - Hierzu die Texttafel p. -

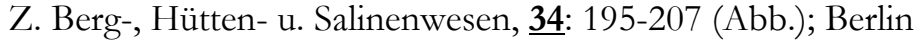

Referat in: N. Jb. Mineral. etc, $\underline{1888}$ (Bd. I): 245 (G. Greim); Stuttgart

[Regionalgeologie, Lagerstättengeologie, Bergbaugeschichte, Förderstatistik]

- $\square$ Gunzert, Gerhard (1961): Über das selektive Auftreten der saxonischen Schwerspatlagerstätten in Deutschland. - N. Jb. Mineral., Mh., 1961: 25-53, 6 Abb.; Stuttgart

[darin: Richelsdorfer Gebirge, Werra-Grauwackengebirge]

QHähnel, R.; Hähnel, C.; Mädler, J.; Meinel, G. \& Wunderlich, J. (1995): Strukturelle und stoffliche Entwicklung der anhydritführenden Karbonat-Baryt-Fluorid-Assoziation in der Lagerstätte Hühn (Nordwestlicher Thüringer Wald). - Geol Jb. Hessen, 123: 5 - 24, 11 Abb., 1 Tab., 2 Taf.; Wiesbaden

QHahn, Wilfried (1978): Schwerspat - seine Eigenschaften und technische Nutzung. - Z. geol. Wiss., 6(7): 921-924; Berlin [darin: „Metasomatische Lagerstätten im Raum Trusetal“]

OHake, Hans (1961): Schwerspat in der DDR - Lagerstättenübersicht, Betriebsverhältnisse, Produktionsübersicht. - Freiberger Forschungshefte, Reihe A, 202: 1-73, 39 Abb., 8 Tab.; Berlin

-Hausmann, J.F.L. (1857): Über den faserigen Baryth um Göttingen. - N. Jb. Mineral. etc., 1857: 414 (Briefl. Mitt.); Stuttgart

-Heuser, A. (1819): Versuch einer geognostischen Beschreibung der im Richelsdorfer Gebirge auftretenden Gänge und sogenannten Veränderungen. - Tb. Mineral., 1819: 311-437; Frankfurt/M.

-Hofmann, Richard (1979): Die Entwicklung der Abscheidungen in den gangförmigen, hydrothermalen Barytvorkommen Mitteleuropas. - Übergeordneter Titel: Zur Minerogenie des hydrothermalen Baryts in Deutschland. - Monograph Series on Mineral Deposits, 17; S. 81-214, 52 Abb., 13 Tab.; (Bornträger) Berlin-Stuttgart [u. a. Hessisches Bergland] 
OHübner, Manfred (1968): Die Fluordispersion im Nebengestein hydrothermaler Flußspatgänge in Thüringen und im Harz. - Z. angew. Geol., 14(6): 297-302, 4 Abb.; Berlin

[,Pluto“-Gänge Ilmenau; Rottleberode u. Straßberg im Harz]

OKlaus, Dieter \& Schröder, Norbert (1967): Erfahrungen beim Einsatz geophysikalischer Meßverfahren in der Flußspat- und Schwerspaterkundung. - Z. angew. Geol., 13 $111 / 12)$ : 610-618, 11 Abb.; Berlin [darin: Bohrungen bei Ruhla]

- $\square \bullet$ Koritnig, S. (1951): Ein Beitrag zur Geochemie des Fluors. - Geochimimica et Cosmochimica Acta, 1: 89-116, 1 Abb., 4 Tab.; London [Fluor i. Vulkaniten u. Sedimenten]

OKrusch, P. (1902): Neue Kobaltaufschlüsse im Thüringer Walde. - Z. dt. geol. Ges., 54: 55-58 (Verhdlgn.); Berlin Referat in: Mitt. Geogr. Ges. i. Thür., 21: 116-117 (E. Schütze); Jena 1903

$\square$ List, Karl-Albrecht (1975): Über ein Flußspatvorkommen in den Dolomiten des Mittleren Zechsteins (Ca2) westlich von Eschwege. - Der Aufschluß, 26: 487-491, 6 Abb.; Heidelberg

OLoos, G.; Saupe, M.; Mädler, U. \& Meinel, G. (1981): Beitrag zur Klärung der epithermalen FluoritGenese mit Hilfe der Spurenelementanalyse. - Z. angew. Geol., 27(12): 567-573, 2 Abb., 4 Tab.; Berlin [darin: Lagerstätten des Thüringer Waldes u.a. Ilmenau, Hühn]

OMädler, Jonas \& Schröder, Norbert (1967): Tektonik, Mineralisation und Nebengestein der Schwerspatlagerstätte Friedenstein bei Ruhla. - Ber. Dt. Ges. geol. Wiss., Reihe B, 12(3): 239 - 255, 8 Abb., 1 Tab., 3 Taf.; Berlin

OMädler, Jonas \& Schröder, Norbert (1969): Zur Kenntnis der Rückenmineralisation bei Bad Liebenstein-Schweina (Thüringer Wald). - Ber. Dt. Ges. geol. Wiss., Reihe B, 14(3): 243-256, 3 Abb., 1 Tab., 6 Taf.; Berlin [Calcit, Schwerspat, Speiskobalt]

OMeinel, Günther (1993): Die Bildung der Gangmineralisationen Thüringens. - Geowiss. Mitt. Thür., Beih, 1: 1-111, 21 Abb.; Weimar [darin: Thüringer Wald]

-Messer, Ernst (1997): Die Erz- und Gangartminerale der kobaltnickelhaltigen Schwerspatgänge im Richelsdorfer Gebirge. - Der Aufschluss: $\underline{48}(1)$ : 1- 15, 26 Abb.; Heidelberg

OMichael, Paul Johannes (1983): Höffigkeitseinschätzung des Feldes Mittlerer Thüringer Wald auf Fluorit. - Diss. Bergakademie Freiberg/Sa.; 122 Bl.

$\square$ Möller, P.; Schulz, S. \& Jacob, K. H. (1980): Formation of fluorite in sedimentary basins. - Chemical

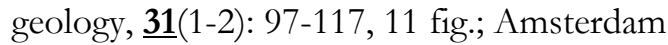
[Zechstein $\mathrm{W}^{\prime}$ Eschwege]

OMorgenroth, Volker \& Böhner, Hartwig (1992): Zur Geologie der Spatlagerstäten im Raum Trusetal. - Veröff. Naturkundemuseum Erfurt, Naturwiss. Rh., 11: 89-94, 1 Abb., [2 Tab.]; Erfurt

OPratzka, G. (1956): Lagerstättengeologische Bearbeitung der Flußspat-Schwerspatlagerstätten in der Umgebung von Trusetal/Thür. - Dipl-Arb. [unveröff.] Bergakademie Freiberg/Sa. 1956

OPratzka, Günter (1959): Zur Paragenese der Flußspat-Schwerspat-Lagerstätte Hühn/Trusetal am SWRand des Thüringer Waldes. - Z. angew. Geol., $\underline{\mathbf{5}}(1)$ : 27-34, 8 Abb., 1 Tab.; Berlin 
QReh, Herbert (1959): Einige Bemerkungen zur Entstehung der Thüringer saxonischen Lagerstätten. Z. angew. Geol., $\underline{\mathbf{5}}(7)$ : 293-296; Berlin [darin: Flußspat-, Schwerspat-Lagerstätten Schmalkaldener Revier]

QRentzsch, Johannes (1956): Untersuchungen der Flußspatvorkommen des Thüringer Waldes. - Dipl.Arb. [unveröff.] Bergakademie Freiberg i. S.

Referat in: Geologie, ㅁ: 454; Berlin 1957

[darin: Floßberggang - Steinbach, Mommel, Hühn i.d. Region Steinbach - Schmalkalden]

QRentzsch, J. (1958): Beiträge zur Geochemie der Fluoritvorkommen des Thüringer Waldes. - Geologie, 7(7): 924-934, 1 Abb., 3 Tab.; Berlin

OScheibe, R. (1889): Schwerspathzwillinge von der Grube Morgenroth-Alexe, nördöstlich von Gehlberg (Thüringer Wald). - Z. dt. geol. Ges., 411: 563 (Mber.); Berlin

Referat in: N. Jb. Mineral. etc, $\underline{1891}$ (Bd. I): 376 (Max Bauer); Stuttgart

aSchneiderhöhn, Hans (1949): Schwerspatgänge und pseudomorphe Quarzgänge in Westdeutschland. N. Jb. Mineral., Abt. A, 1949: 191-202, 2 Abb.; Stuttgart

[darin: Richelsdorfer Gebirge (Kurzdarst.)]

OSchröder, Norbert (1966): Geologisch-lagerstättenkundliche Untersuchungen an Schwerspatvorkommen im Thüringer Wald. - Ber. Dt. Ges. geol. Wiss., Reihe B, $\underline{11}(2): 173$ - 185, 8 Abb.; Berlin [Schmalkaldener Revier, Gebiet von Ruhla]

OSchröder, Norbert (1969): Zur Kenntnis der Schwerspat- und Flußspatvorkommen im Thüringer Wald, Thüringer Becken und in Südwest-Thüringen. - Diss. Bergakademie Freiberg 1969; Textbd. X, 216 S, 72 Abb., Anl.-Bd. 1, 48 Bl., Ill., graph. Darst.; Anl.-Bd 2, 64 Bl. graph. Darst.; Freiberg

- $\square$ Schulz, Siegmund (1980): Verteilung und Genese von Fluorit im Hauptdolomit Norddeutschlands. Berliner geowiss. Abh., Reihe A, 23 ; 85 S., 71 Abb, 26 Tab., 1 Taf.; (Reimer) Berlin - zgl. Diss. FU Berlin 1980

- 0 Staub, A. Wilhelm (1929): Beiträge zur Kenntnis der Schwerspat- und Flußspatlagerstätten des Thüringer Waldes und des Richelsdorfer Gebirges. - Z. dt. geol. Ges., $\underline{\mathbf{8 0}}$ (f. 1928): 43 - 96 (Abh.), 5 Abb.; Berlin - zgl. Diss. Univ. Jena 1926

OStaub, A. Wilhelm (1929): Die Flußspatlagerstätten des Thüringer Waldes. - Z. prakt. Geologie, 37: 4955, 68-72, insges. 2 Abb.; Berlin

- $\square$ Stoppel, Dieter \& Gundlach, Heinrich (1968): Die Schwerspatvorkommen im UnterwerraGrauwackengebirge und Richelsdorfer Gebirge. - In: Koritnig, Sigmund [Zusstellg. u. red. Vorbereitung]: Zur Mineralogie und Geologie der Umgebung von Göttingen mit Westharz und Teilen des nordhessischen Berglandes - Sonderheft zur Jahrestagung 1968 der VFMG in Göttingen. Der Aufschluss, Sdh. 17; S. 139 - 147, 8 Abb.; Göttingen

- $\square$ Stoppel, Dieter \& Gundlach, Heinrich (1978): Zur Geologie und Bergbaugeschichte der Schwerspat- und Kobalterzvorkommen im Unterwerra-Grauwackengebirge und Richelsdorfer Gebirge. - In: Koritnig, Sigmund [Schriftltg.]: Zur Mineralogie und Geologie der Umgebung von Göttingen - mit Westharz und Teilen des Nordhessischen Berglandes. - Der Aufschluss, Sdbd. 28: 261-285, 23 Abb.; Heidelberg 1978

oStoppel, Dieter \& Gundlach, Heinrich (1983): Zur Schwerspatmineralisation und ZechsteinStratigraphie im Richelsdorfer Gebirge (NE-Hessen). - Z. dt. geol. Ges., 134: 247-268, 7 Abb., 1 Tab.; Hannover 
- $\square$ Stoppel, Dieter \& Gundlach, Heinrich (1984): Junge Mineralisationen im Südwestharz und in Nordhessen. - In: Postvaristische Gangmineralisation in Mitteleuropa. Alter, Genese und Wirtschaftliche Bedeutung. - Jahrestagung der Fachsektion Lagerstättenforschung in der GDMB vom 12. bis 16. April 1983 in Warstein (Sauerland). - Schriftenrh. GDMB Gesellschaft Deutscher Metallhütten- und Bergleute e.V.; $\underline{41}, 425$ S., Abb., Kt.; hier: S. 79-90; (Verlag Chemie) Weinheim 1984

[Unterwerra-Grauwackengebirge, Richelsdorfer Gebirge]

-Thienhaus, R. (1940): Die Schwerspatgänge des Richelsdorfer Gebirges. - Z. angew. Mineral., $\underline{3}$ : 21 52, 16 Abb.; Berlin

OUlrich, Horst (1956): Untersuchung des Eisenmanganerz-Schwerspatvorkommens von Schmalkalden /Thür. - Dipl.-Arb. [unveröff.] Bergakademie Freiberg i. S. 1956

Referat in: Geologie, $\underline{\mathbf{6}}$ : 456; Berlin 1957

-0口Werner, Carl - Dietrich (1958): Geochemie und Paragenese der saxonischen Schwerspat-FlußspatGänge im Schmalkaldener Revier. - Freiberger Forschungshefte, Reihe C, 47; 117 S, 24 Abb.;

(Akademie-Verlag) Berlin - zgl. Diss. Univ. Halle-Wittenberg 1957

[Thüringen, Richelsdorfer Gebirge, Unterwerra-Grauwackengebirge]

-0口WWerner, C. D. (1958): Geochemie und Paragenese saxonischer Schwerspatlagerstätten in Thüringen $<$ Referat $>$. - Fortschr. Mineral., $\underline{\mathbf{3 6}}$ (1): 52-53; Stuttgart

[Thüringen, Richelsdorfer Gebirge, Albungen]

OWerner, Carl - Dietrich (1961): Die Spatlagerstätten des Thüringer Waldes und ihre Stellung im Rahmen der saxonischen Metallprovinz Mitteleuropas. - Ber. Dt. Ges. geol. Wiss., Reihe B, 11 (1): 5 45, 3 Abb., 1 Tab.; Berlin

- $\square$ Ziehr, Heinz (1983): Zur Verbreitung von sedimentären Fluoritvorkommmen. - Der Aufschluss, $\underline{\text { 34: }}$ 69-80, 5 Abb.; Heidelberg

[darin: Unterwerra-Grauwackengebirge, Richelsdorfer Gebirge]

$\square$ Ziehr, H.; Matzke, K.; Ott, K. \& Sawary, E. (1978): Flußspat im Zechsteindolomit bei Eschwege/Hessen. - In: Koritnig, Sigmund [Schriftltg.]: Zur Mineralogie und Geologie der Umgebung von Göttingen - mit Westharz und Teilen des Nordhessischen Berglandes. - Sdbd. $\underline{28}$ : 248 - 259, 8 Abb., 1 Tab.; Heidelberg 1978

- $\square$ Ziehr, H.; Matzke, K. \& Vouttsidis, V. (1980): Ein stratiformes Fluoritvorkommen im Zechsteindolomit bei Eschwege und Sontra in Hessen. - Geol. Rundschau, 69: 325-348, 11 Abb., 3 Tab.; Stuttgart

\subsubsection{Steine und Erden}

$\square$ Anonym (1925): Zusätze um Großalmeroder Glashafenton für Spiegelglashafen verwenden zu können. - Sprechsaal, Z. d. keramischen, Glas- und verwandten Industrien, 58: 416-417; Coburg

OAuras, Michael; Katzschmann, Lutz \& Aselmeyer, Gunther (2007): Thüringer Natursteine im Überblick. - In: Siegesmund, S. \& Ehling, A. (eds.): Rohstoff Naturstein - Teil 2. - Natural Building Stone Ressources - Part 2. - Z. Dt. Ges. Geowiss., 158(4): 751-762, 11 Abb., 4 Tab.; Stuttgart [darin Lagerstätten West- und Nordwestthüringen]

$\square$ Borchard, Wanda (1924): Die Geschichte der Tonindustrie in Großalmerode. - Fachbücher d. Keramischen Rundschau, 13; 52 S.; (Verlag d. Keramischen Rundschau) Berlin - zgl. Diss. rer. pol. 
Univ. Göttingen

[Kurzinformation z. Lagerstättengeologie, Tonarten u. Verwendung]

-Brüning, Ulrich (1984): Die ziegeltechnische Eignung bestimmter Schichtglieder des Unteren Buntsandsteins in Süd-Niedersachsen. - Z. dt. geol. Ges., 135: 461-471, 8 Abb.; Hannover [technische Mineralogie]

- $\square$ - Burre, Otto \& Dienemann, Wilhelm (1931/1933): Vorkommen und Verbreitung technisch verwendbarer Gesteine, Tone und Sande in Deutschland. - Die Stein-Industrie (Der Steinbruch); Berlin

[Deutschlandweite Darstellung $m$. thematischen, großmassstäiben Übersichts-Karten, darin Abbaustellen in Hessen, WMK, Thüringen, Niedersachsen]

I. -- Einführung - $\underline{\mathbf{2 6}}(10):$ 141-142

II. -- 1. Tiefengesteine - $\underline{\mathbf{2 6}}(23): 318-319$, Kt. 1; -

III. -- 2. Ergußgesteine [H, WMK, TH, NIE] - 26 (24): 330-332, Kt. 2;

IV. -- 3. Vulkanische Tuffe [H (Habichtswald)]- $\underline{\mathbf{2 6}}(25): 339-340$, Kt. 3;

V. -- 4. Sandsteine, Grauwacken, Quarzite [H, WMK, TH, NIE]; - $\underline{\mathbf{2 6}}(26): 346-348$, Kt. 4; Berlin 1931

VI. -- 5. Kalksteine und Dolomite [H, WMK, TH, NIE]- 27(1/2): 6-8, Kt. 5.

VII. -- 6. Marmor und polierbare Kalksteine und Dolomite - 27(3/4): 19-20, Kt. 6 [Umgebung Mühlhausen]

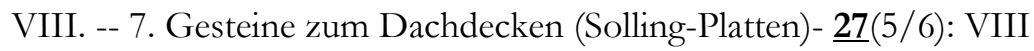

IX. -- 8. Farbige Gesteine - 27 (7/8): 53-54, Kt. 8

X. -- 9. Mühl-, Schleif- u. Wetzsteine [NIE, TH] - 27(15/16): 65-66, Kt. 9

XI. - 10. Gesteine für hochfeuerfeste Materialien [H, WMK, N] - 27(11/12): 85-86, Kt. 10

XII. - 11. Edelsande, Kristallquarz und Kieselgur - 27(13/14): 97-98, Kt. 11

XIII. -- 12. Kaolin. - 27(15/16): 113-114, Kt. 12

XIV. -- 13. Edeltone [WMIK, Großalmerode] - 27(21/22): 154-156, Kt. 13;

XV. -- 14. Gips und Anhydrit; 27(23/24): 172-173, Kt. 14; Berlin 1932

XVI. -- 15. Verteilung der technisch verwendbaren Gesteine, Tone und Sande auf die einzelnen deutschen Lande; 28(7/8): 53-55, Kt. 15; Berlin 1933

Referat in: N. Jb. Mineral. etc., Referate; 1933 (Bd. II): 1014-1015 (M. Henglein); Stuttgart

- $\square$ ODienemann, W. \& Burre, O. [Bearb.](1928): Die nutzbaren Gesteine Deutschlands und ihre Lagerstätten mit Ausnahme der Kohlen, Erze und Salze. - I. Bd.: Kaolin, Ton, Sand, Kies, Wiesenkalk, Kieselgur. - XII, 418 S., 58 Abb., 38 Tab.; (Enke) Stuttgart

Referat in: Zbl. Mineral. etc., Abt. B, 1929: 32; Stuttgart

[u.a. Ton-Abbau Großalmerode]

DODienemann, W. \& Burre, O. [Bearb.](1929): Die nutzbaren Gesteine Deutschlands und ihre Lagerstätten mit Ausnahme der Kohlen, Erze und Salze. - II. Bd.: Feste Gesteine - XIV, 485 S., 45 
Abb., 20 Tab; (Enke) Stuttgart

- $\square$ ODienemann, W. \& Burre, O. [Bearb.](1929): Die nutzbaren Gesteine Deutschlands und ihre Lagerstätten mit Ausnahme der Kohlen, Erze und Salze. - II. Bd.: Feste Gesteine - XIV, 485 S., 45 Abb., 20 Tab; (Enke) Stuttgart

- $\square$ Freyberg, Bruno v. (1926): Die Tertiärquarzite Mitteldeutschlands und ihre Bedeutung für die feuerfeste Industrie. - 242 S., 32, Abb., 15 Taf.; (Enke) Stuttgart

[Tertiär, Lagerstättenkunde; darin: Hann.-Münden, Dransfeld, Kaufunger Wald und Meißner, Habichtswald und Umgebung Kassel]

- $\square$ Gabert, C. (1922): Braunkohlenquarzite (Knollensteine) und ihre technische Verwendung. - Jb. Halleschen Verbandes etc., $\underline{\mathbf{3}}(2):$ 49-60; Leipzig

[darin: Habichtswald, Hirschberg, Meißner]

QGesang, H. (1962): Pleistozäne Lagerstätten der Steine und Erden im Thüringer Becken (Exkursion C 5). - In: Viete, Günter [Hrsg.]: „Das Pleistozän im sächsisch-thüringischen Raum“ -

Exkursionsführer zur Herbsttagung 1962 vom 19. bis 21. Oktober 1962 in Leipzig und Erfurt - und Kurzreferate der Vorträge anläßlich des 2. Treffens der Sektion Quartärgeologie am 18. Oktober 1962 in Leipzig. - [Exkursionsführer und Veröffentlichungen - Gesellschaft für Geologische

Wissenschaften der DDR, 12]; S. 219-224, 1 Abb., [2 Tab.]; Berlin 1962

[Darin Aufschlüsse: Großengottern, Langensalza, Burgtonna-Gräfentonna, Gotha]

QHopp, Heike (2007): Vorkommen, Eigenschaften und Konservierung von Sandsteinen des Unteren Keupers in Thüringen. - In: Siegesmund, S. \& Ehling, A. (eds.): Rohstoff Naturstein - Teil 2. Natural Building Stone Ressources - Part 2. - Z. Dt. Ges. Geowiss., 158(4): 773-784, 5 Abb., 1 Tab., 3 Taf.; Stuttgart [darin: Bausteinverwendung Schloß Friedenstein/Gotha; Tab. 1: Gesteinstechnische Kennwerte, darin Gestein d. Lagerstätten Kleinvargula, Gotha]

OHoppe, Walter (1963): Die Natursteinvorkommen der Deutschen Demokratischen Republik. - Z. angew. Geol., 9 (8): 393-400, 1 Kt.; Berlin

[darin: Westthüringen, Thüringer Wald]

-Lepper, Jochen \& Weber, Jutta (2001): Integratives Bewertungskonzept für eine siliziklastische Naturwerkstein-Lagerstätte im Roten Wesersandstein bei Bad Karlshafen. - Z. angew. Geol., 47(2): 79-86, 11 Abb., 1 Tab.; Berlin

-Simon, C. (1889): Entstehung von Quarziten der Braunkohlenformation. - Ber. Vereins Naturkde. z. Kassel, 34/35: 86-88; Kassel

[Trappquarzite Habichtswald]

QWagenbreth, Otfried (1968): Geologisch-gesteinskundliche und öknomische Gesichtspunkte für den Abbau und die Verwendung der Travertine Thüringens. - Z. angew. Geol., 14(3): 128-134, 7 Abb.; Berlin [darin: Langensalza, Mühlhausen, Ehringsdorf]

OWagenbreth, Otfried (1969): Lagerstätten der Werk- und Dekorationssteine in der DDR. - Z. angew. Geol., 15 (10): 536-547, 10 Abb.; Berlin [darin: Lagerstätten Westthüringen, Thüringer Wald, Südwestthüringen]

OWagenbreth, O. (1977): Die Rohstoffbasis unserer Werksteinindustrie aus der Sicht allgemeiner historischer Entwicklungslinien der Rohstoffnutzung. - Z. angew. Geol., 르(2): 75-78, 3 Abb., 1 Tab.; Berlin [darin Tab. Werksteinvorkommen; darin: Oberdorla, Langensalza, Kirchgandern] 


\subsubsection{Kupferschiefer}

-Amstutz, G. C. (1980): Kupferschiefer Metallogeny. - In: Janković, S. \& Sillitoe, R. H. (eds.):

European Copper Deposits - Proceedings of an International Symposium held at Bar, Yugoslawia, 18-22 September 1979. - Society f. Geology Applied to Mineral Deposits (SGA) - Spec. Publ., 1; 303 S.; hier S. 125-128, Fig. 71-75; Belgrade 1980

[darin Fig. 75: Diagramm Richelsdorfer Gebirge]

OAutorenkollektiv (1968): Lithologie, Paläogeographie und Metallführung des Kupferschiefers in der Deutschen Demokratischen Republik. - Geologie, 17(6/7): 776-791, 9 Abb.; Berlin

[Großregionale Betrachtung unter Einbeziehung von Westthüringen, Thüringer Becken, Umrandung des Thüringer Waldes]

- $\square$ Q $\bullet$ Beyschlag, Franz (1900): Beitrag zur Genesis des Kupferschiefers. - Z. prakt. Geologie, $\underline{8}:$ 115117; Berlin

Referat in: N. Jb. Mineral. etc., 1903 (Bd. I): 90 (E. Sommerfeldt); Stuttgart

[Großregionale Betrachtung]

-Cannon, Ralph (1986): Bergbau und Mineralien des Richelsdorfer Gebirges. - Rückblick, 2: 69-71; Hofgeismar

-Diedel, R. (1984): Mikrosondenuntersuchungen an Sulfiden des Kupferschiefers der Gebiete Spessart, Rhön und Richelsdorf. - Dipl.-Arb. [unveröff.] TU Aachen

QFreiesleben, Johann Carl (1807/1809/1815): Geognostischer Beytrag zur Kenntnis des

Kupferschiefergebirges mit besonderer Berücksichtigung auf einen Teil der Grafschaft Mannsfeld und Thüringens.

1 Teil; XIV, 202 S.; (Graz u. Gerlach) Freyberg 1807 - Teil 1 u. 2 i. e. Bd.

[darin: S. 49-50 Richelsdorfer Gebirge; S. 50-52 Thüringer Wald]

2. Teil; X, 242, 2 S., 1 Falt-Taf.; Freyberg 1809 - Teil 1 u. 2 i. e. Bd.

[darin: S. 22 Thüringer Wald, S. 103 Richelsdorfer Gebirge]

3. Teil; XXIV, 338 S., 1 Falt-Taf.; Freyberg 1815

[S. 229-234 Thüringer Wald; S. 235 Richelsdorfer Gebirge; Meißner-Vorland]

4. Teil; VIII, 459 S., 2 Falt-Taf.; Freyberg 1815

[S. 164-169 „Kohlenschiefer am Thüringer Walde“; S. 179-191 „Steinkohlen im Thüringer Walde“; S. 200-206 Rotliegend im Thüringer Wald]

Die Beschreibung des Geologie in Hessen beruht auf Wiedergabe von Beobachtungen von Jordan, G. (1803): Mineralogische Berg- und Hüttenmännische Reisebemerkungen vorzüglich in Hessen, Thüringen, am Rhein und in Seyn-Altenkirchner Gebiete gesammelt; XVIII, 288 S.; (Diederich) Göttingen

-OFreyberg, Bruno von (1924): Paläogeographische Karte des Kupferschieferbeckens. - Jb. Halleschen Verbandes etc., N.F., 4 (12): 266-278, 1 Abb., 1 Falt-Taf.; Halle (Saale)

[Großregionale Betrachtung, Bezug a. Hessen u. Thüringen]

-0•Gillitzer, G. (1936): Die Geologie der Erzanreicherungen im mitteldeutschen Kupferschiefer. - Jb. Hallesches Verbandes etc., N.F., 15: 9-27, 14 Abb.; Halle (Saale)

Referat in: N. Jb. Mineral. etc., Referate, 1939 (Bd. II): 268-270 (D. Hoenes), 1939 (Bd. III): 584-586 
(Walther Fischer); Stuttgart

[Paläogeogr. Kt. Kupferschiefer: Hessen, Thüringen, Niedersachsen]

-Großkurth, Gerhard Friedrich (1990): Einfluss der Halden des ehemaligen Kupferschiefer- und Schwerspat-Berbaues im Richelsdorfer Gebirge (Hessen) auf die Schwermetallführung des Gewässersystems. Geologische und geochemische Kartierung. - Dipl.- Arbeit [unveröff.] Univ. Göttingen; 160 S., 25 Abb., 53 Tab., 8 Anl.

-Hentschel, Gerhard (1979): Zur Kenntnis der Sekundärminerale im Richelsdorfer Gebirge (Hessen). Geol. Jb. Hessen, 107: 197-205; Wiesbaden

-Heppenheimer, Hermann (1995): Vergleichende geochemische und petrologische Untersuchungen am Kupferschiefer: ein Beitrag zur Klärung der Metallogenese. - Diss. Aachen 1995, 240 S., graph. Darst. Ill.

[Hessische Senke (Richelsdorfer Gebirge), Sangerhäuser Mulde, Niederrheinisches Zechsteinbecken]

-Jowett, E. C. (1987): Metal ratios in the Kupferschiefer as indicators of paleo-flow directions, Richelsdorf Hills, W. Germany [Posterbeitrag]. - In: Klare, Bernd \& Schröder, Bernd [eds.]: Zechstein 1987 - International Symposium Kassel/Hannover [28. April to 9. May, 1987] - Abstracts, Posters, Program; S. 125; [Subkommission Perm/Trias der Stratigraphischen Kommission der DUGW/IUGS] Bochum 1987

-Jowett, E. Craig (1991): Paleo-flow dircetions of basinal fluids determined from metal ratios, Richelsdorf Hills, F.R.G. - Zentralbl. Geol. Paläont. Teil1: 1991(4); S. 1017 - 1027, 10 fig., 1 tabl.; (Schweizerbart) Stuttgart

$\square$ Klein-Reesink, J.; Riegel, W. \& Schulz, K.-H. (1982): Tertiäre Braunkohlen und Kupferschiefer in Niederhessen. - Arbeitskreis f. Paläobotanik u. Palynologie. 11. - 13.3.1982 Dassel/Solling, Exkursion A. - Courier Forschungsinstitut Senckenberg, 56: 111-132, 12 Abb., 2 Tab.; Frankfurt [Hp. 3 Tagebau Paradiesfeld/Zeche Hirschberg, HP. 4 Frankershausen/Stbr. Schafhof]

- $\square$ Kulick, J.; Leifeld, D.; Meisl, St.; Pöschl, W.; Stellmacher, R.; Strecker, G.; Theuerjahr, A.-K. \& Wolf, M. (1984): Petrofazielle und chemische Erkundung des Kupferschiefers der Hessischen Senke und des Harz-Westrandes. - Geol. Jb., Reihe D., 68: 3-323, 37 Abb., 15 Tab.; 34 Taf.; Hannover [darin: Richelsdorfer Gebirge, Ringgau/Werra-Meißner-Kreis]

-Ludwig, Helga \& Rentzsch, Johannes (1967): Das Sanderzproblem - Ein Beitrag zur Genese des Kupferschiefers. - Ber. Dt. Ges. geol. Wiss., Reihe B, $\underline{\mathbf{1 2}}(1): 3-12,7$ Taf.; Berlin [darin: Richelsdorfer Gebirge]

-Messer, Ernst (1955): Kupferschiefer, Sanderz und Kobaltrücken im Richelsdorfer Gebirge. - Hess. Lagerstättenarchiv , $\underline{\mathbf{3}}$; 125 S., 39 Abb., 19 Tab., 29 Taf.; Wiesbaden - zgl. Diss. Bergakad. Clausthal 1954

- 0 Michael, R. (1900): Beitrag zur Genesis des Kupferschiefers < Referat zu F. Beyschlag: Ueber den Kupferschiefer und seine Entstehung - Vortrag in der Sitzung der deutschen geologischen Gesellschaft vom 7. März>. - Z. prakt. Geol., $\underline{8} .1900$ (4): 115-117; Berlin

[Darin: Thüringer Wald, Richelsdorfer Gebirge]

[•Paul, Josef (1982): Zur Rand- und Schwellenfazies des Kupferschiefers. - Z. dt. geol. Ges., 133: 571605, 11 Abb., 1 Tab. Hannover

[Südniedersachsen (Harzsüd- und Westrand), Thüringen, Polen]

-Paul, Josef (2006): Der Kupferschiefer: Lithologie, Stratigraphie, Fazies und Metallogenese eines Schwarzschiefers. - Z. dt. geol. Ges., 157(1): 57-76, 7 Abb., 1 Tab.; Hannover [darin: Richelsdorfer Gebirge, auch Paläontologie] 
-Püttmann, W.; Merz, C. \& Speczik, S. (1991): Oxidation of organic material in the Kupferschiefer and its relation to mineralization processes. - Zentralbl. Geol. Paläont. Teil1: 1991(4), S. 957-974, 9 fig., 3 tabl.; Stuttgart

[Richelsdorfer Gebirge/Spessart-Rhön]

-Putzer, Hanfrid (1972): Kupferschiefer in Zambia und Mitteleuropa, ein paläogeographischer Vergleich. - Geol. Jb., 90: 415-430, 3 Abb., 3 Tab.; Hannover [darin: Richelsdorfer Gebirge]

OReh, H. (1959): Zur Entwicklung des Kupferschiefers im Thüringer Becken. - Ber. Geol. Ges. DDR, 4(4),: 288-298, 7 Abb.; Berlin

[Großregionale Betrachtung u. Einbeziehung von Nordosthessen]

ORentzsch, Johannes (1964): Die feinstratigraphisch-lithologische Flözlagenparallelisierung im Kupferschiefer am Südrand des norddeutschen Zechsteinbeckens. - Z. angew. Geol., 11(1): 11-14, 4 Abb.; Berlin

[darin: Thüringisches Werragebiet]

-ORentzsch, Johannes (1964): Der Kenntnisstand über die Metall- und Erzverteilung im Kupferschiefer. - Z. angew. Geol., 10 (6); 281-288, 1 Abb.; Berlin [darin: Richelsdorfer Gebirge]

-Rentzsch, Johannes \& Thiergärtner, Hannes (1972): Vergleichende geologisch-mathematische Untersuchung der Buntmetallverteilung in Lagerstätten vom Typ Kupferschiefer. - Z. angew. Geol., $\underline{18}(12):$ 537-548, 14 Abb., 2 Tab.; Berlin

[Bezugnahme ausschl. a. Richelsdorfer Gebirge]

-Rentzsch, Johannes \& Franzke, Hans Joachim (1997): Regional tectonic control of the Kupferschiefer mineralization in Central Europe. - Z. geol. Wiss., 25(1/2): 121-139, 5 fig., 3 tabl.; Berlin [darin: Richelsdorfer Gebirge]

-Rentzsch, Johannes \& Franzke, Hans Joachim (1997): Die laterale Verbreitung der Erzmineralassoziationen im deutschen Kupferschiefer. - Z. geol. Wiss., 25(1/2): 141-149, 2 Abb., 2 Tab.; Berlin [darin: Richelsdorfer Gebirge]

- 0 Rentzsch, Johannes \& Friedrich, Günther (2003): Zur Herkunft der Metalle der Kupferschiefervererzung in Deutschland - Metallbilanz im Präzechstein und in der erzführenden Zone an der Zechsteinbasis. - Metal source of Kupferschiefer mineralization in Germany - Base metals in the Pre-Zechstein basement and in the ore bearing zone. - Hallesches Jb. Geowiss., Reihe B, 25: 1-20, 3 Abb., 4 Tab.; Halle (Saale)

[Bezugnahme a. Richelsdorfer Gebirge, Thüringer Wald]

$\square$ Ritzkowski, Siegfried (1987): Die Bildungstiefe des Kupferschiefers im Unterwerra-GrauwackenGebirge (Nördliches Hessen) [Posterbeitrag]. - In: Klare, Bernd \& Schröder, Bernd (eds.): Zechstein 1987 - International Symposium Kassel/Hannover [28. April to 9. May, 1987] - Abstracts, Posters, Program; S. 140; [Subkommission Perm/Trias der Stratigraphischen Kommission der DUGW/IUGS] Bochum 2002

QRösler, H. J. (1964): Eine Vererzung vom Kupferschiefertyp im Rotliegenden Thüringens. - Ber. geol. Ges. DDR, $\underline{\mathbf{9}}(2): 217-226,9$ Abb.; Berlin

-Schmidt, Franz-Peter (1985): Erzkontrolle im Kupferschiefer Osthessens, Bundesrepublik Deutschland. - Diss. Univ. Aachen 1985 [unveröff.]; 158 (48) S., Ill., graph. Darst.

[Richelsdorfer Gebirge]] 
-Schumacher, Claus (1985): Die Kupfervererzungen des basalen Zechsteins im Rahmen der sedimentären Entwicklung des Werra-Fulda-Beckens. - Diss. Fachber. Geowiss. FU Berlin; 142 S., 57 Abb., 6 Taf.; Tabellen

[darin: Richelsdorfer Gebirge]

oSpeczik, S.; Püttmann, W. \& Diedel, W. (1987): Origin of Kupferschiefer mineralization as suggested by vitrinite and liptinite rank measurements and organic geochemical studies [Vortragskurzfassung]. In: Klare, Bernd \& Schröder, Bernd [eds.]: Zechstein 1987 - International Symposium Kassel/Hannover - 28. April to 9. May, 1987 - Abstracts, Posters, Program; S. 104-105; [Subkommission Perm/Trias der Stratigraphischen Kommission der DUGW/IUGS] Bochum 1987 [darin: Richelsdorfer Gebirge]

-Theuerjahr, A.-K. (1987): Die Kupfersandsteine des Richelsdorfer Gebirges - ein Schlüssel zum Verständnis der Buntmetallmineralisation im Basalen Zechstein 1 der südlichen Hessischen Senke [Posterbeitrag]. - In: Klare, Bernd \& Schröder, Bernd [eds.]: Zechstein 1987 - International Symposium Kassel/Hannover [28. April to 9. May, 1987] - Abstracts, Posters, Program; S. 147; [Subkommission Perm/Trias der Stratigraphischen Kommission der DUGW/IUGS] Bochum 1987

-Theuerjahr, A.-K. (1987): Beitrag zur lithologisch-feinstratigraphischen Ausbildung und Mineralisation des Kupferschiefers in der Hessischen Senke, Bundesrepublik Deutschland [Vortragskurzfassung]. In: Klare, Bernd \& Schröder, Bernd [eds.]: Zechstein 1987 - International Symposium Kassel/Hannover - 28. April to 9. May, 1987 - Abstracts, Posters, Program; S. 108-109; [Subkommission Perm/Trias der Stratigraphischen Kommission der DUGW/IUGS] Bochum 1987 [Kupferschiefer - [Bohr] Programm]

-Tobschall, H. J.; Schmidt, F. P. \& Schumacher, C. (1986): Kupferschiefer und Kupfervererzungen im Richelsdorfer Gebirge, Hessen - Ihre Entstehung im Rahmen der sedimentären Entwicklung des basalen Zechsteins. - Fortschritte Mineral., 64, Beih. 2: 143-160, 5 Abb., 2 Tab.; Stuttgart

-Tonn, Harald (1990): A. Untersuchungen an Flüssigkeitseinschlüssen als Beitrag zur Genese der Kupferschiefermineralisation (Mikrothermometrie, Kathodenlumineszenz, REM-EDX

Mikroanalytik). - B. Geologische Kartierung im Bereich Cornberg-Nentershausen (Hessen) TK 4925 Sontra .; Dipl.-Arb. + Dipl.-Kart. Inst. [unveröff.]Univ. Göttingen; 60S., 40 S., 5 Taf., 3 Anl.; Göttingen

-Tonn, H.; Schmidt, F.-P.; Porada, H. \& Horn, E.-E. (1987): Fluid inclusion studies of high grade and structure bound Kupferschiefer mineralization of Richelsdorf and Spessart/Rhön [Posterbeitrag]. - In: Klare, Bernd \& Schröder, Bernd [Hrsg.]: Zechstein 1987 - International Symposium Kassel/Hannover [28. April to 9. May, 1987] - Abstracts, Posters, Program; S. 148; [Subkommission Perm/Trias der Stratigraphischen Kommission der DUGW/IUGS] Bochum 1987

- $\square$ Wedepohl, K. H. (1964): Untersuchungen am Kupferschiefer in Nordwestdeutschland. Ein Beitrag zur Deutung der Genese bituminöser Sedimente. - Geochimica Cosmochimica Acta, 28: 305-364, 18 Abb., 8 tab.; Oxford

[darin: WMK: Albungen-Fürstenstein, Schmelzhütte; Nentershausen]

$\square$ Wedepohl, K. H. (1965): Untersuchungen an Proben von Kupferschiefer aus Nordwestdeutschland und Diskussion seiner Bildungsbedingungen. - Freiberger Forschh., Reihe C, 193: 107-121, 3 Abb.; Leipzig [darin: Gelstertal]

-Wedepohl, K. H. (1980): The geochemistry of the Kupferschiefer bed in Central Europe. - In: Janković, S. \& Sillitoe, R. H. (eds.): European Copper Deposits - Proceedings of an International Symposium held at Bar, Yugoslawia, 18-22 September 1979. - Society f. Geology Applied to Mineral Deposits (SGA) - Spec. Publ., 1; 303 S.; hier S. 129 - 135, Fig. 76-78, tabl. 11-12; Belgrade 1980 [darin: Lagerstättenkarte m. Eintrag Richelsdorfer Gebirge, sonst kein Bezug zu Lokalitäten] 
-Wedepohl, K. H. (1987): Composition and genetic constraints of the Kupferschiefer bed [Vortragskurzfassung]. - In: Klare, Bernd \& Schröder, Bernd [eds.]: Zechstein 1987 International Symposium Kassel/Hannover - 28. April to 9. May, 1987 - Abstracts, Posters, Program; S. 116-118; [Subkommission Perm/Trias der Stratigraphischen Kommission der DUGW/IUGS] Bochum 1987

[Bezugnahme a. Richelsdorfer Gebirge]

$\square$ Wedepohl, K. H.; Delevaux, M.H. \& Doe, B.R. (1978): The potential source of lead in the Permian Kupferschiefer bed of Europe and some selected Paleozoic mineral deposits in the Federal Republic of Germany. - Contrib. Mineral. Petrol., 65: 273 - 281, 3 fig., 1 tabl.; Berlin-Heidelberg [darin: Gelstertal, Hundelshausen]

-Wedepohl, K. H. \& Rentzsch, J. (2006): The composition of brines in the early diagenetic mineralization of the Permian Kupferschiefer in Germany. - Contrib. Mineral. Petrol., 152: 323-333, 4 fig., 2 tabl.; Berlin-Heidelberg

[Großregionale Betrachtung - Richelsdorfer Gebirge erwähnt, sonst keine Lokalitäten]

\subsubsection{Magmatite}

\subsection{Paläozoische Magmatite}

QAndreas, D. (1988): Diskussionsbeitrag zu einer hydrothermal-postmagmatischen Genese der Vulkanitachate. - Z. angew. Geol., 34(3): 65-71, 13 Abb.; Berlin

[Georgenthal, Winterstein]

QBlankenburg, H.-J. \& Berger, H. (1981): Kristallgrößenuntersuchungen an Vulkanitachaten Examination of the crystalline size of volcanic agates. - Chemie der Erde, $\underline{40}(2): 139-145,3$ Abb., 2 Tab.; Jena [darin: Achate a.d. Thüringer Wald]

OBlankenburg, H.-J. \& Schrön, W. (1982): Zum Spurenelementchemismus der Vulkanitachate - The trace element content fo volcanic agates. - Chemie der Erde, $\underline{41}(2): 121-135,7$ Abb., 5 Tab.; Jena [darin: Achate a.d. Thüringer Wald]

@Blankenburg, H.-J.; Schrön, W. ; Starke, R. \& Klemm, W. (1983): Beziehungen zwischen Achat, Jaspis und der Gesteinsmatrix in sauren Vulkaniten. - Chemie der Erde, 42 (3): 157-172, 7 Abb., 7 Tab., Taf. I-II; Jena [darin: Achate a.d. Thüringer Wald]

OBlanckenburg, Hans-Joachim \& Eichler, Bernd (1986): Zum Spurenelementgehalt der eisenoxidreichen, erdigen Massen aus Rhyolith-Achatkugeln. - Some remarks to the trace element content of earthy masses rich in rion oxide won from Rhyolithic globe-shaped agates. - Chemie der Erde, 45(4): 295-299, 1 Abb., 3 Tab.; Jena [darin: Untersuchungen an Achaten a.d. Thüringer Wald]

QBräuer, H. (1967): Geochemische Gliederung granitischer Gesteine des Thüringer Waldes und Erzgebirges und ihre lagerstättengentische Bedeutung. - (Die Unterscheidung und Genese varistischer und postvaristischer magmatogener Lagerstätten Mitteleuropas) Freiberger Forschungshefte, Reihe C, 209: 153-168, 4 Abb., 7 Tab.; Leipzig [darin: Ruhler Kristallin (Ruhla, Brotterode); Suhler Granit] 
QBücking, H. (1888): Mittheilungen über die Eruptivgesteine der Section Schmalkalden (Thüringen). Jb. Preuß. Geol. Landesanst., $\underline{8}$ (f. 1887): 119-139, Taf. V; Berlin

Referat in: N. Jb. Mineral. etc., $\underline{\mathbf{1 8 8 9}}$ (Bd. II): 283-284 (E. Dathe); Stuttgart

QCotta, B. (1834): Porphyr im Thüringer Wald - N. Jb. Mineral. etc., 1833: 408-412 (Briefl. Mitt.); Stuttgart

口OCotta, B [ernhard] v. (1848): Bruchstücke [Nichtsagender Sammeltitel für petrographische

Beschreibung thüringischer (hessischer) Gesteinsvorkommen]. - N. Jb. Mineral. etc., 1848: 129-135; Stuttgart

[S. 131-132 II) Granit b. Bad Liebenstein; S. 132-133 III) Basalt der Stoffelskuppe bei Eisenach (und Blaue Kuppe b. Eschwege); S. 133-134 IV) Rotliegendes bei Friedrichroda mit Thierfährten; S. 134135 V) Dolomit-Breccie bei Neustedt/Werra; S. 135 VI) Thon-Gallen im Buntsandstein der WerraGegend

QCredner, Heinrich (1841): Melaphyr im Thüringer Wald. - N. Jb. Mineral. etc., 1841: 666 (Briefl. Mitt.); Stuttgart

QCredner, [Heinrich] (1848): Orthit im Granit des Thüringer Waldes, Vollborthit. - N. Jb. Mineral. etc., 1848: 199 - 200; Stuttgart

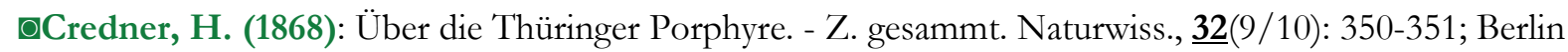

QFischer, Georg (1934): Die „Porphyrit“kuppe „Hühnerstein“ bei Möhrenbach in Thüringen.

[Vortragsreferat] - Z. dt. geol. Ges., $\underline{\mathbf{5}}$ (f. 1933): 781 - 787, 4 Abb.; Berlin

QFriedrich, Alexander (1878): Das Rotliegende und die basischen Eruptivgesteine der Umgebung des großen Inselsberges. - Z. f. gesammt. Naturwiss., $\underline{\mathbf{1 1}}$ [= 3. F., $\underline{\mathbf{3}}$ (1878): 719-770; Taf. 21, 22; Berlin zgl. Diss. Univ. Halle 1878

Referat in: N. Jb. Mineral. etc., 1880 (Bd. 2): 202-206 (Referat H. Bücking); Stuttgart

QFutterer, K. (1890): Die „Ganggranite“ von Grosssachsen und die Quarzporphyre von Thal im Thüringer Wald. - Mitt. Grhzgl. Bad. Geol. Landesanst., 2 2: 21-64, 1 Abb, 4 Taf.; Heidelberg - zgl. Diss. Univ. Heidelberg 1890

Referat in: N. Jb. Mineral. etc, 1891 (Bd. II): 280-281 (Chelius); Stuttgart

QGärtner, Hans Rudolf v. (1937): Bemerkungen zum Vulkanismus des Rotliegenden im südöstlichen Thüringer Walde. - Z. dt. geol. Ges., 오: 193-206, 8 Abb.; Berlin

[Umgebung Unterneubrunn]

QGoll, Martin (1996): Geochronometrie im Thüringer Wald - Quantifizierung der Entwicklung spätvariscischer Magmatite. - Diss. Univ. Heidelberg [unveröff.] 1997; VII, 173 S., Abb., Kt.; Heidelberg

QGoll, M.; Lippolt, H. J. \& Hess, J. C. (1995): Die zeitliche Quantifizierung der spätvariscischen vulkanischen Prozesse im Thüringer Wald. - Terra Nostra, 95(8): 99, 4 Abb., 1 Tab.; Bonn

OGoll, M.; Lippold, H.J. \& Hess, J. C. (1996): Geochronometrische Bilanz des permokarbonen Thüringer Wald - Magmatismus. - Terra nostra, 96(2): 83-88, 4 Abb.; Bonn

QGottesmann, Bärbel (1975): Granodiorite aus der Bohrung Ohrdruf 1/60 im mittleren Thüringer Wald. - Z. angew. Geol., 21 (10): 492-499, 12 Abb.; 2 Tab.; Berlin [Petrographie]

QGumprecht, F. E. (1842): Bedingungen des Entstehens und Zusammenvorkommens verschiedener Eruptivgesteine. - N. Jb. Mineral., 1842: 821-842; Stuttgart

[Melaphyr des Thüringer Waldes] 
QHaake, R. \& Holzhey, G. (1989): Achate in kugelförmigen Rhyolithen des Rotliegenden im sächsischthüringischen Raum. - Agates in spherule-shaped rhyolithes of the Rotliegendes in the Saxonianthuringian area. - Chemie der Erde, $\underline{49}$ (2): 173-183, 3 Abb., 1 Tab.; Taf. II-III; Jena

$\square$ Hagedorn, B. (1987): Geochemie und Petrographie der Diabase des Albunger Paläozoikums. - Dipl.Arb. [unveröff.] TU Braunschweig, $157 \mathrm{~S}$.

OHansch, Ralf \& Zeh, Armin (2000): Metabasites from the Ruhlaer Crystalline Complex: Evidence für distinct Variscan plate tectonic environments within the Mid-German Crystalline Rise / Metabasite des Ruhlaer Kristallins: Hinweise auf unterschiedliche prävariszische plattentektonische Bildungsräume in der Mitteldeutschen Kristallinzone. - Chemie der Erde, $\underline{\mathbf{6 0}}(1):$ 1-25, 9 fig., 4 tabl.; Jena

QHeide, F. (1922): Die gemischten Gänge im Thüringer Wald. - Steinbruch u. Sandgrube, 21 (5): 117123, Abb. 1-7, [3 Tab.]; 211(6): 145-148, Abb. 8-12, [2 Tab.]; Halle (Saale)

[Gangesteine im Trusetal-Granit/Ruhlaer Kristallin]

QHelmers, Johann Heinrich (1937): Die Differentiation der Eruptivgesteine der Blätter Ilmenau und Unterneubrunn. - Jb. Preuß. Geol. Landesanst., $\underline{\mathbf{5 7}}$ (f. 1936): 151-164, 2 Abb., 12 Tab.; Berlin

oHetzer, Wolfram \& Timmermann, Annedore (1993): Ein bisher unbekannter Syenit im Kleinen Thüringer Wald. - Z. geol. Wiss., 21(3/4): 383-388, 4 Abb.; Berlin

[Umgebung Gethles W'Schleusingen]

QHoffmann, Gerd (2007): Anatas in Quarzporphyren des Thüringer Waldes. - Der Aufschluss, $\underline{\mathbf{8}}$ (3): 171-180, 20 Abb.; Heidelberg

QHolzhey, Gerhard (1985): Über die Verbreitung von Achaten in permischen Vulkaniten des Thüringer Waldes. - Veröff. Naturkundemuseum Erfurt, Naturwiss. Rh., 4: 71-82, 11 Abb.; Erfurt

QHolzhey, Gerhard (1990): Porphyrkugeln des Thüringer Waldes aus der Sammlung von K.E.A. von HOFF. - Abh. Ber. Museums d. Natur Gotha, (16) 1990: 29-36, 5 Abb.; Gotha

OHolzhey, Gerhard (1993): Vorkommen und Genese der Achate und Parageneseminerale in Rhyolithkugeln aus Rotliegendvulkaniten des Thüringer Waldes. - Diss. TU Freiberg 1993; 187 Bl. [Hauptbd.], Tab.; 93 Bl. [Anl.-Bd.], 75 Abb., 73 Tab., 93 Taf.

[Unters. Vorkommen u.a. a. Bl. 5028 Eisenach-Ost, 5128 Ruhla, 5129 Waltershausen]

QHolzhey, Gerhard (1994): Zur Ausbildung der Randfazies rhyolithischer Rotliegendvulkanite des Thüringer Waldes. - Geowiss. Mitt. Thüringen, 22: 45-71, 14 Abb., 3 Tab.; Weimar

QHolzhey, Gerhard (1994): Zum Mikrogefüge von Achaten aus Rhyolithkugeln des Thüringer Waldes. Veröff. Naturkundemuseum Erfurt, Naturwiss. Rh., 13: 101-116, 14 Abb., 2 Tab.; Erfurt

OHolzhey, Gerhard (1995): Herkunft und Akkumulation des SiO2 in Rhyolithkugeln aus Rotliegendvulkaniten des Thüringer Waldes. - Geowiss. Mitt. Thüringen, $\underline{3}$ : 31-59, 10 Abb., 7 Tab.; Weimar

oHolzhey, Gerhard (1996): Zur Quarzmineralisation in Spärolithen innerhalb der Randfazies des Jüngeren Oberhöfer Quarzporphyrs bei Geraberg im Thüringer Wald. - Veröff. Naturkundemuseum Erfurt, Naturwiss. Rh., 15: 31-38, 16 Abb., 1 Tab.; Erfurt

OHolzhey, Gerhard (1999/2000): Mikrokristalline SiO2-Mineralisationen in rhyolithischen Rotliegendvulkaniten des Thüringer Waldes (Deutschland) und ihre Genese / Microcrystaline SiO2 mineralizations hosted in rhyolitic Rotliegend-volcanic rocks from the Thuringian Forest (Germany)

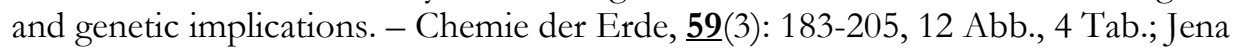


QHolzhey, Gerhard (2001): Contribution to petrochemical mineralogical characterization of alteration processes within the marginal facies of rhyolitic volcanics of Lower Permian age, Thuringian Forest, Germany / Beitrag zur petrochemisch-mineralogischen Charakterisierung von Alterationsprozessen in der Randfazies unterpermischr rhyolitischer Vulkanite des Thüringer Waldes, Deutschland. - Chemie der Erde, 61(3): 149-186, 28 fig., 10 tabl.; Jena

OHolzhey, Gerhard (2003): Mikrokristalline SiO2-Mineralisationen in rhyolithischen Rotliegendvulkaniten des Thüringer Waldes und ihre Genese. - Der Aufschluss, 또: 95-110, 12 Abb., 4 Tab.; Heidelberg

OHolzhey, Gerhard (2004): Rhyolithkugeln des Thüringer Waldes aus der Mineraliensammlung SEUGLING/Schmalkalden am Naturkundemuseum Erfurt. - Veröff. Naturkundemuseum Erfurt, Naturwiss. Rh., 23: 13-20, 8 Abb.; Erfurt

QHolzhey, Gerhard (2004): „Schneekopfkugeln“ aus den Unterrotliegend-Rhyolithen des Thüringer Waldes. - Abh. Ber. Museums d. Natur Gotha, (23) 2004: 121-132, 23 Abb.; Gotha

[John, Karl-Heinz (1970): Erarbeitung und Anwendung von Methoden zur Klärung einiger Probleme des Vulkanismus an ausgewählten Objekten im Bereich der Tambacher Mulde (Thüringer Wald). Diss. math.-nat. Humboldt-Univ. Berlin; 98 S., Anl.-Bd . 87 Abb.; Berlin

[Mineralogie, Geochemie Rotliegend-Vulkanite]

OJung, H. (1928): Die provinzielle Stellung der permischen Eruptivgesteine des Thüringer Waldes. Beitr. Geol. Thür., 22: 49-66, 13 Abb.; Jena

QKaemmel, Thomas (1954): Untersuchungen im Thüringer Hauptgranitmassiv, besonders bei Suhl. Dipl.-Arb. [unveröff.] Univ. Berlin 1954

Referat in: Geologie, 4 (2): 194; Berlin 1955

OKatzung, Gerhard \& Obst, Karsten (1996): Spätvariszischer basischer Magmatismus - der Höhenberg-Sill im Thüringer Wald. - Z. dt. geol. Ges., 147: 11-38, 16 Abb., 4 Tab.; Stuttgart

OKeil, Klaus \& Jacobi, B. (1961/62): Über einen granatführenden Quarzporphyr aus dem Thüringer Wald (Vorläufige Mitteilung). - Chemie der Erde, 21(1): 131-132, 1 Abb.; Jena [Fund Stbr. a.d. Waldschänke b. Friedrichroda]

OKopp, Jürgen; Bankwitz, Peter \& Naumann, Rudolf (2002): Magmenentwicklung im Wirkungsfeld einer transregionalen Scherzone: Geochemie und Geochronologie der Metamorphite der Bohrung Schleusingen 3/63 - Shear zone related magma evolution: geochemical and geochronological data of the metamorphic rocks of the Schleusingen 3/63 well. - Z. geol. Wiss., 30(4/5): 293-315, 16 Abb., 5 Tab.; Berlin

OLamprecht, J. (1958): Zur Petrographie des Ruhlaer Hauptgranites. - Fortschr. Mineral., 36(1): 58-59; Stuttgart

OLaufer, E. (1876): Die Quarz-Porphyre der Umgegend von Ilmenau. - Z. dt. geol. Ges., 28: 22-48; Berlin [Petrographie, Geochemie]

OLöffler, Hans Karl (1987): Petrographie und Petrochemie der Eruptivgesteine von Gehren-Ilmenau. Z. geol. Wiss., 15(5): 619-643, 26 Abb., 7 Tab.; Berlin

OLoretz, H. (1888): Ueber das Vorkommen von Kersantit und Glimmerporphyrit in derselben Gangspalte bei Unterneubrunn im Thüringer Walde. - Jb. Preuß. Geol. Landesanst., $\underline{8}$ (f. 1887): 100118, 1 Abb.; Berlin 
Referat in: N. Jb. Mineral. etc., 1891 (Bd. I): 65-67 (E. Dathe; zitierter Ort nicht korrekt); Stuttgart [Mineralogie und Geochemie]

GLoretz, H. (1893): Bemerkungen über den „Paramelaphyr“. - Jb. Preuß. Geol. Landesanst., $\underline{13}$ (f. 1892): 129-137; Berlin

[Ilmtal/Thüringer Wald]

OMädler, Jonas (1964): Petrographie, petrochemische Stellung und Metamorphose der

Granitporphyrgänge von Thal-Heiligenstein im nordwestlichen Thüringer Wald. - Ber. Dt. Ges. geol. Wiss., Reihe B, 14(4): 327-337, 2 Abb., 5 Taf.; Berlin

OMädler, Jonas \& Voigt, Heinz (1994): Aufbau, Petrographie und Genese eines Systems zusammengesetzter Gesteinsgänge am Südrand des Ruhlaer Kristallins westlich

Seeligenthal/Thüringer Wald (ehemaliger Gieselsberg-Schacht) - Geowiss. Mitt. Thüringen, 2: 1-28, 12 Abb., 4 Tab.; Weimar

[Paläozoische Magmatite]

QMeinel, Günter (1995): Magmatismus und Metamorphose [in Thüringen]. - In: Seidel, Gerd [Hrsg.]: Geologie von Thüringen. - 1. Aufl.; S. 180-187; Stuttgart 1995

OMeinel, Günter (2003): Magmatismus und Metamorphose [in Thüringen]. - In: Seidel, Gerd [Hrsg.]: Geologie von Thüringen. - 2., neu bearb. Aufl.; S. 207-214; Stuttgart 2003

OMeisel, Sören (2001): Die Vulkanitsequenz der Oberhof-Formation (Rotliegendes/Thüringer Wald) Upside down? <Vortragskurzfassung>. - In: Rauche, Henry [Hrsg.]: Regionale und angewandte Geologie der Grenzregion der Süddeutschen und der Mitteldeutschen Scholle. - Programm und Kurzfassungen der Vorträge. - 10. Jahrestagung Gesellschaft f. Geowissenschaften i. Schmalkalden, 19.-22. September 2001. - Exkursionsführer u. Veröff. Ges. f. Geowiss., 214; S. 169-170, 1 Abb.; Berlin 2001 [Petrographie]

$\square$ Mügge, O. (1921): Zur Kenntnis der Petrographie des älteren Palaeozoicums zwischen Albungen und Witzenhausen, besonders des Variolits. - Jb. Preuß. geol. Landesanst., $\underline{40}$ (f. 1919): 201-217; Berlin

QObst, K. (1993): Der Höhenberg-Dolerit. Geochemie, Magmencharkater und tektonomagmatische Stellung. - Dipl.-Arb. [unveröff.] Univ. Greifswald, 77 S.

[basischer Magmatit der Rotterode Vulkanit-Folge; nordwestlicher Thüringer Wald S’Friedrichroda]

DObst, Karsten (2001): Permosilesischer Gangmagmatismus im Kristallin des Thüringer Waldes - Neue Untersuchungen zur Geochemie und Genese <Vortragskurzfassung>. - In: Rauche, Henry [Hrsg.]: Regionale und angewandte Geologie der Grenzregion der Süddeutschen und der Mitteldeutschen Scholle. - Programm und Kurzfassungen der Vorträge. - 10. Jahrestagung Gesellschaft f. Geowissenschaften i. Schmalkalden, 19.-22. September 2001. - Exkursionsführer u. Veröff. Ges. f. Geowiss., 214; S. 187-188; Berlin 2001

DOrtmann, Renate (1958): Schwermineralanalytische Untersuchungen des Ruhlaer Granites. - Fortschr. Mineral., $\underline{\mathbf{3 6}}(1)$ : 58; Stuttgart

OPringsheim, Gustav (1880): Über einige Eruptivgesteine aus der Umgebung von Liebenstein in Thüringen. - Z. dt. geol. Ges., 32: 111-182, 7 Abb., Taf. X-XI; Berlin 1880 Referat in: N. Jb. Mineral. etc., 1881 (Bd. 2): 229- 231 (H. Rosenbusch); Stuttgart

QRichter, R. (1859): Zur Petrographie des Thüringerwaldes. - Z. gesammt. Naturwiss., 14: 352-353; Berlin [Magmatite, Fleckschiefer] 
ORöllig, Gerhard \& Schirmer, Bodo (1978): Zum Stoffbestand der subsequenten variszischen Vulkanite im Südteil der DDR. - Z. geol. Wiss., $\underline{\mathbf{6}}(9)$ : 1101-1118, 7 Abb.; Berlin [darin: Vulkanite des Thüringer Waldes]

OSchirmer, Bodo (1967): Erarbeitung und Anwendung von Methoden zur Klärung einiger Probleme der Sedimentation und des Vulkanismus an einem Einzelobjekt im Bereich der Westflanke der Tambacher Mulde, Thüringer Wald. - Diss. math.-nat. Humbold-Univ. Berlin 1967; 105 S., [12 S. Literaturverz.]; 29 Taf. (85 Abb.), 1 geol. Kt. u. weit. Anl.; Berlin [Petrographie Rotliegend]

OSchirmer, Bodo (1972): Beitrag zur Gliederung und Geochemie der permosilesischen Vulkanite des Thüringer Waldes. - Ber. Dt. Ges. geol. Wiss., Reihe A, 17 (6): 881 - 896, 6 Abb.; Berlin

oSchmid, E. E. (1881): Die quarzfreien Porphyre des centralen Thüringer-Waldgebirges und ihre Begleiter. - Denkschriften d. medicinisch-naturwiss. Ges. z. Jena, Bd. 2 [4. Heft]: 279-388, Taf. XVIXXI; Jena

Referat in: N. Jb. Mineral. etc., $\underline{1881}$ (Bd. 1): 71-82 (Referat H. Rosenbusch); Stuttgart

OSchneider Otto (1904): Das Gestein des Seebachfelsens bei Friedrichroda. - Jb. Preuß. Geol. Landesanst., $\underline{\mathbf{2 4}}$ (f. 1903): 503-553, 14 Abb., 2 Taf.; Berlin Referat in: N. Jb. Mineral. etc., 1906 (Bd. I): 208-209 (O. H. Erdmannsdörfer); Stuttgart [Problematikum: Einordnung eines Eruptivgesteins]

OSchwab, Max (1970): Die Beziehungen der subsequenten Vulkanite des Permosiles zum variszischen Orogen, dargestellt unter besonderer Berücksichtigung des Halleschen Vulkanitkomplexes. Geologie, 19(3): 249-280, 12 Abb., 3 Tab.; Berlin [darin: Thüringer Wald]

OSeyfarth, H.-H. (1962): Beobachtungen an pyroklastischen Gesteinen der Gehrener Schichten zwischen Ilmenau und Suhl/Thüringer Wald. - Dipl.-Arb. [unveröff.] Univ. Jena

OSeyfarth, Hans-Heinz (1964): Unterrotliegende Tuffe des südöstlichen Thüringer Waldes. - Geologie, 13(5): 556-569, 5 Abb., 4 Tab.; Berlin

OSiebel, Wolfgang (1998): Variszischer spät- bis postkollisionaler Plutonismus in Deutschland: Regionale Verbreitung, Stoffbestand und Altersstellung. - Z. geol. Wiss., 26(3/4): 329-358, 2 Abb., 1 Tab.; Berlin [darin: Pfalz, Schwarzwald, Thüringer Wald und Ruhlaer Kristallin, Ostbayern, Granulitgebirge, Lausitz]

QU1rich, E. (1915): Beiträge zur Kenntnis der Quarzporphyre in der Umgebung von Oberschönau i. Thür. - Zbl Mineral. etc., 1915: 577-589, 606-616; Stuttgart

QUtendörfer, A. (1915): Beiträge zur Petrographie des Hühnberggesteins zwischen Schmalkalden und Friedrichroda. - Zbl. Mineral., 1915: 623-633, 642-653, 2 Abb.; Stuttgart - zgl. Diss. Univ. Marburg 1915

OVoigt, Heinz (1972): Zur petrographischen Gliederung der intermediären Vulkanite des Thüringer Waldes. - Ber. Dt. Ges. geol. Wiss., Reihe A, 17 (6): 865 - 879, 5 Abb., 2 Tab.; Berlin

OVoland, Bernd (1965): Differentiationserscheinungen an einem olivinführenden Dolerit der Bohrung Schnellbach 1/62 (sog. „Metadiabas“ vom Hünberg/Thüringer Wald). - Dipl.-Arb. [unveröff.] Bergakademie Freiberg/Sa. 1965

Referat in: Geologie, 14(2): 220-221; Berlin 1965 
QWeiss, E. (1877): Porphyrvorkommen des nördlichen Thüringer Waldes. - Z. dt. geol. Ges., 29: 418423 (Verhdlgn.); Berlin

Referat in: N. Jb. Mineral. etc., 1878: 83-86 (Anonym); Stuttgart

OWeiss, E. (1881): Eruptivgesteine des nördlichen Thüringer Waldes. - Z. dt. geol. Ges., 33: 483-489, 2 Abb., 1 Tab.; Berlin

OWeiss, E. (1884): Petrographische Beiträge aus dem nördlichen Thüringer Walde. - Jb. Preuß. Geol. Landesanst., 4 (f. 1883): 213-237, 1 Taf.; Berlin

Referat in: N. Jb. Mineral. etc., 1885 (Bd. 1): 410-412 (Referat H. Bücking); Stuttgart [Rotliegend-Porphyre]

OWeiss, E. (1884): Über den Porphyr mit sogenannter Fluidalstructur von Thal im Thüringer Wald. - Z. dt. geol. Ges., 36: 858-868, 1 Abb.; Berlin

Referat in: N. Jb. Mineral. etc., $\underline{1878}$ (2. Bd.): 54-55 (Referat O. Mügge); Stuttgart

OWerner, Carl-Dietrich (1972): Zur Geochemie und Petrologie des Ruhlaer Granits (Thüringer Wald). Ber. Dt. Ges. f. geol. Wiss., Reihe B, 17(2): 219-262, 16 Abb., 19 Tab.; Berlin

QWolff, Fr. M. (1878): Untersuchungen von Melaphyren aus der Gegend von Kleinschmalkalden. - Z. gesammt. Naturwiss., $\underline{\mathbf{5 1}}$ (= 3. F., $\underline{3}):$ 245-272, 1 Abb., Taf. 8-10; Berlin - Diss. 1878

Referat in: N. Jb. Mineral. etc., 1879: 162 - 163; Stuttgart

OZeh, Armin \& Brätz, Helene (2000): Radiometrische und morphologische Untersuchungen an Zirkonen aus Granitporphyren, Rhyolithen und Granitgeröllen des nordwestlichen Thüringer Waldes. - Z. dt. geol. Ges., 151(1-2): 187-206, 4 Abb., 4 Tab.; Hannover

\subsection{Tertiäre Magmatite}

QAbratis, M.; Mädler,J.; Hautmann, S.; Leyk, H.-J.; Meyer, R.; Lippolt, H. J. \& Viereck-Götte, L. (2007): Two distinct Miocene age ranges of basaltic rocks from the Rhön and Heldburg areas (Germany) based on 40Ar / 39Ar step heating data. - Chemie der Erde / Geochemistry, 67(2): 133150, 6 fig., 5 tabl.; München [darin: Stoffelskuppe b. Eisenach, Pflasterkaute b. Marksuhl, Hörschel]

$\square$ Ackermann, Adam [Zusammstlg.](1995): 800 Jahre Mitterode: 1195 - 1995. - 172 S., zahl. Abb.; [Hrsg. Festausschuß Mitterode] Mitterode [darin S. 117: Der Alpstein [Basaltschlot]]

$\square$ Althaus (1842): Mesothype vom Alpstein; Späroidische Ausscheidungen im Muschelkalk. - N. Jb. Mineral. etc., 1842: 275-276 (Briefl. Mitt.); Stuttgart

$\square$ Anonym (1907): <Wiederausbruch erloschener Vulkane?]. - Eschweger Tageblatt, 1907; Nr. 91 v. 19.4.1907; Eschwege

[Bezugnahme a. Blaue Kuppe, Rosenbühl b. Niddawitzhausen, Meißner]

- $\square$ ○ीApel, Jürgen \& Rüppel, Heidi [Verfass. u. Hrsg.] (2005): Raus in die Natur - Tipps für den Sonntags-Ausflug im Dreiländereck Hessen - Niedersachsen - Thüringen. - 159 S., 111 Fotos, 34 Kt., 1 Zeit-Taf.; (LSRB-Verlag, Landschaftskundlicher-Studien-Reisebuch-Verlag) Witzenhausen [zahlreiche Ausflugstipps, auch zu tertiären Vulkangebilden]

-Apel, K. (1915): Die Basalte des Reinhardswaldes und seiner Umgebung. - N. Jb. Mineral. etc., Beil-Bd. 38: 525-586, 1 Abb., 1 Kt. (Taf. 21); Stuttgart

[u.a. Basalte $W^{\prime}$ Göttingen] 
$\square$ Aubuisson de Voisins, Jean François d' (1819) : Traité de géognosie. - Untertitel : Exposé des connaissances actuelles sur la constitution physique et minéralogie du globe terrestre. - $2 \mathrm{Bd}$. ; Bd. I, LXI, 496 S., 1 Taf. ; Bd. II, 2, 665 S., 1 gef. Bl., Ill.; (Levrault) Strasbourg/Paris [darin: Meissner: S. I,230 Geomorphologie; II, 445 Braunkohle; II, 556 Dolerit - erstmals in der Forschungsgeschichte wird die grobkörnige Varietät des Meissner-Basaltes als Dolerit bezeichnet]

-Bauer, M. (1900): Beiträge zur Kenntnis der niederhessischen Basalte. - Sitzber. Akad. Wiss. z. Berlin, $\underline{1900}$ (II. Halb-Bd.): 1023-1039; Berlin

Referat in: N. Jb. Mineral. etc, 1901 (Bd. II): 386 (E. Sommerfeldt); Stuttgart [Gebiet zw. Fulda und Schwalm]

-Bauer, M. (1903): Vorläufiger Bericht über weitere Untersuchungen im niederhessischen Basaltgebiet. Sitzber. Preuß. Akad. Wiss. z. Berlin, 1903 (2. Halbbd.): 992-996; Berlin

-Bauer, M. (1910): Vorläufige Mitteilung über die Eruptivgesteine am Westrande des niederhessischen Basaltgebiets nördlich der Eder. - Sitzber. Preuß. Akad. Wiss. z. Berlin, 1910 (2. Halbbd.): 990-995; Berlin

- $\square$ Becker, Arthur (1881): Ueber die Olivinknollen im Basalt. - Z. dt. geol. Ges., 33: 21-66; Berlin [darin: Hunrodsberg/Habichtswald, Bausberg b. Cassel, Alpstein b. Sontra]

$\square$ Belendorf, Klaus \& Gottschalk, Karl-Heinz (2005): Die Blaue Kuppe bei Eschwege in Hessen, ein weltberühmter Fundort. - Mineralien-Welt, 16 (4): 38 - 48, 27 Abb.; Haltern

- Bender, Friedrich (1911): Die Basalte des Stifts- und Kaufungerwaldes zwischen Werra und Fulda mit Einschluß der Hünenburg bei Eiterhagen. - Diss. Univ. Marburg 1911; 33 S., 1 Kt. Referat in: N. Jb. Mineral. etc., 1916 (Bd. I1): 54-59 (Arthur Schwandtke); Stuttgart [Gebiet der Söhre zw. Helsa und Eiterhagen]

- Berns, Arthur (1915): Beiträge zur Petrographie der Basalttuffe des Habichtswaldes. - Zbl. Mineral. etc., 1915: 483-500, 517-524; Stuttgart

-Beroldingen, Franz v. (1791): Die Vulkane älterer und neuer Zeiten - physikalisch und mineralogisch betrachtet. - 1. Theil; 293 S. [9 B1.]; 2. Theil; 406 S. [17 Bl.]; (Schwan u. Götz) Mannheim [darin 1. Theil S. 203-204, 209: Weißenstein/Habichtswald b. Kassel]

-Bischoff, Willi (1974): Eine Rarität vom Meenser Steinberg bei Göttingen. - Der Aufschluss, 25: 499501; Göttingen

@Blum, R. (1835): Über Marmolith im Dolerit von Eisenach. - N. Jb. Mineral. etc., 1835: 158-160; Stuttgart

ه $\square$ Blum, Reinhard (1860): Handbuch der Lithologie oder Gesteinslehre. - 356 S., 50 Abb.; (Enke) Erlangen

[darin: Basalte Meissner, Habichtswald]

-Bolter, Ernst (1961): Über Zersetzungsprodukte von Olivin-Feldspatbasalten. - Beitr. Mineral. Petrogr., $\underline{8}(2): 111$ - 140, 7 Abb., 14 Tab.; Berlin-Göttingen-Heidelberg

[darin: Basalte d.Umgebung v. Göttingen; Steinberg/Meensen, Hoher Hagen, Brackenberg, Bramburg]

Q■Bornemann [jun.], L. G. (1883): Bemerkungen über einige Basaltgesteine aus der Umgebung von Eisenach. - Jb. Preuß. Geol. Landesanst., $\underline{\mathbf{3}}$ (f. 1882): 149-157 (Abh. v. behördenfremden Pers.); Berlin 1883

Referat in: N. Jb. Mineral. etc., 1884 (Bd. 2): 366 (Referat H. Rosenbusch); Stuttgart 
[Mineralogie; darin: Stoffelskuppe b. Eisenach, Hörschel, Hütschhof; Bezugnahme a. Blaue Kuppe b. Eschwege]

OBornemann [jun.], L. G. (1888): Ueber einige neue Vorkommnisse basaltischer Gesteine auf dem Gebiet der Messtischblätter Gerstungen und Eisenach. - Jb. Preuß. Geol. Landesanst., $\underline{8}$ (f. 1887): 291-300, (Abh. v. Mitarb....) 4 Abb.; Berlin

Referat in: N. Jb. Mineral. etc., 1888 (Bd. I): 284-285 (E. Dathe); Stuttgart [darin: Stoffelskuppe]

$\square$ Boué, Ami (1829): Geognostisches Gemälde von Deutschland. - Herausgegeben von K.C. v. Leonhard. - XVI, 623 S., 8 Taf.; (Hermann) Frankfurt/M. [darin S. 523-547: Blaue Kuppe, Meißner; Vorlage nicht eingesehen, zitiert nach Oppitz (1991)]

-Buch, Leopold v. (1820): Über einige Berge der Trappformation in der Gegend von Grätz. Abhandlungen d. Königlichen Akademie der Wissenschaften in Berlin, 1818/1819: 111-118; (Reimer) Berlin [darin: Basalte der Umgebung v. Kassel - Ober-Vellmar („Ober-Wollmar`), Dörnberg, Weißenstein/Habichtswald]

-Buch, Leopold v. (1821): Ueber einige Berge der Trapp-Formazion bei Gräz. - Tb. Mineral., 15(2): 457472; Frankfurt/M. - Abdruck aus: Abhandlungen d. Königlichen Akademie der Wissenschaften in Berlin, 1818/19: 111-118; Berlin [darin: Basalte der Umgebung v. Kassel - Ober-Vellmar („Ober-Wollmar“), Dörnberg, Weißenstein/Habichtswald]

OBücking, H. (1881): Basaltische Gesteine aus der Gegend südwestlich vom Thüringer Walde und aus der Rhön. - Jb. Preuß. Geol. Landesanst., 1 (f. 1880): 140-189; Berlin [darin: Steinsburg b. Suhl]

- $\square$ Busse, Hentschel, Kutscher, Laemmlen, Pflanzl, Rösing \&Udluft (1959/60): Geologie der Umgebung von Eschwege und des Hohen Meißners - Bericht über die Exkursionen anläßlich der 110. Hauptversammlung [der Deutschen Geologischen Gesellschaft] vom 1.-9- September 1958 [in Kassel] - Exkursion F - Mesozoikum u. Tertiär der Hessischen Senke - Sonntag, den 7. September 1958 - Z. dt. geol. Ges., 111 (f. 1959/60): 288-301, 1 Abb.; Hannover

[Hp. 1-4: Buntsandstein i. d. Umgebung v. Eschwege; HP 5-10: Geologie des Hohen Meißners]

O■Cotta, B [ernhard] v. (1848): Bruchstücke [Nichtsagender Sammeltitel für petrographische Beschreibung thüringischer (hessischer) Gesteinsvorkommen]. - N. Jb. Mineral. etc., 1848: 129-135; Stuttgart

[S. 131-132 II) Granit b. Bad Liebenstein; S. 132-133 III) Basalt der Stoffelskuppe bei Eisenach (und Blaue Kuppe b. Eschwege); S. 133-134 IV) Rotliegendes bei Friedrichroda mit Thierfährten; S. 134135 V) Dolomit-Breccie bei Neustedt/Werra; S. 135 VI) Thon-Gallen im Buntsandstein der WerraGegend

-Carpenter, R.-L.; Edgar, A. D. \& Thibault, Y. (2002): Origin of spongy textures in clinopyroxen and spinel from mantle xenoliths, Hessian Depression, Germany. - Mineralogy Petrology, 74(2/4): 149162, 6 fig.; Wien

[Druseltal, Altenburg, Stopfling, kein Vorkommen i. WMK]

oCredner, [Heinrich] (1860): Über den Dolerit der Pflasterkaute bei Eisenach und die in demselben vorkommenden Mineralien. - N. Jb. Mineral. etc., 1860: 56-60; Stuttgart

$\square$ 일esse, M. A. (1857): Etudes sur le métamorphisme [I] - Metamorphose des Roches [Suite]. Annales des mines, memoires, (5ième sèr.) 12: 89-828 [1], 417-516 (Suite); Paris

[darin:

S. 278-279 Blaue Kuppe

S. 279-282 Stoffelskuppe 
S. 476 Warburg/Diemel, Säsebühl b. Dransfeld

S. 477-478 Pflasterkaute

S. 478 Stoffelskuppe

S. 478 - 480 Blaue Kuppe]

-Eitel, W. (1920): Über das Vorkommen von Zinkblende im Basalt des Bühls bei Cassel. Mit teilweiscer Benutzung orientierender mikroskopischer Studien von W. Irmer. - Zbl. Mineral. etc.., 1920: 273 285, 6 Abb.; Stuttgart

-Eitel, Wilhelm (1920): - Studien über die Genesis der Einschlüsse des Bühlbasaltes - Über Pseudomorphosen von Magnetkies nach Pyrit im Basalt des Bühls bei Kassel. - In: Eitel, W.; Irmer, W. \& Velde, L.: Das Vorkommen tellurischen Eisens im Basalte des Bühls bei Kassel, seine Begleitmineralien und Genesis. - Abh. Senckenberg. Naturforsch. Ges., 37(2): 139-142, 5 Abb.; Frankfurt a. M. 1920

-Eitel, Wilhelm (1920): - Studien über die Genesis der Einschlüsse des Bühlbasaltes - Über die Magneteisenerzeinschlüsse des Bühlbasalts und ihre Herkunft. - In: Eitel, W.; Irmer, W. \& Velde, L.: Das Vorkommen tellurischen Eisens im Basalte des Bühls bei Kassel, seine Begleitmineralien und Genesis. - Abh. Senckenberg. Naturforsch. Ges., 37(2): 143-147, 3 Abb.; Frankfurt a. M. 1920

-Eitel, Wilhelm (1920): - Studien über die Genesis der Einschlüsse des Bühlbasaltes - Vergleichende Betrachtungen über die Natur des Ovifak- und des Bühleisens. - In: Eitel, W.; Irmer, W. \& Velde, L.: Das Vorkommen tellurischen Eisens im Basalte des Bühls bei Kassel, seine Begleitmineralien und Genesis. - Abh. Senckenberg. Naturforsch. Ges., 37(2): 148-151, 5 Abb.; Frankfurt a. M. 1920

-Eitel, Wilhelm (1920): - Studien über die Genesis der Einschlüsse des Bühlbasaltes - Über die genetischen Beziehungen des gediegenen Eisens im Bühlbasalt zu den im demselben vorkommenden Einschlüssen von Magnetkies und Magnetit. - In: Eitel, W.; Irmer, W. \& Velde, L.: Das Vorkommen tellurischen Eisens im Basalte des Bühls bei Kassel, seine Begleitmineralien und Genesis. - Abh. Senckenberg. Naturforsch. Ges., 37(2): 152-156, 5 Abb.; Frankfurt a. M. 1920

-Eitel, Wilhelm (1920): - Studien über die Genesis der Einschlüsse des Bühlbasaltes -Über die petrographische Beschaffenheit der vom Bühlbasalt durchsetzten Schichten und ihre Beziehung zu den Einschlüssen dieses Vorkommens. - In: Eitel, W.; Irmer, W. \& Velde, L.: Das Vorkommen tellurischen Eisens im Basalte des Bühls bei Kassel, seine Begleitmineralien und Genesis. - Abh.

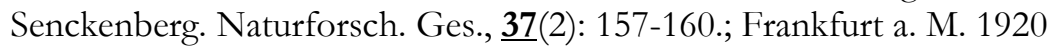

-Eitel, Wilhelm (1920): - Studien über die Genesis der Einschlüsse des Bühlbasaltes - Experimentelle Studien über die Bildung des Magnetkieses aus Pyrit bei höheren Temperaturen. - In: Eitel, W.; Irmer, W. \& Velde, L.: Das Vorkommen tellurischen Eisens im Basalte des Bühls bei Kassel, seine Begleitmineralien und Genesis. - Abh. Senckenberg. Naturforsch. Ges., 37(2): 161-165, 6 Abb.; Frankfurt a. M. 1920

[Bezugnahme a. d. Bühl-Basalt]

-Eitel, Wilhelm (1920): - Studien über die Genesis der Einschlüsse des Bühlbasaltes - Über die experimentelle Nachbildung des Bühleisens. - In: Eitel, W.; Irmer, W. \& Velde, L.: Das Vorkommen tellurischen Eisens im Basalte des Bühls bei Kassel, seine Begleitmineralien und Genesis. - Abh. Senckenberg. Naturforsch. Ges., 37(2): 166-168, 4 Abb.; Frankfurt a. M. 1920

-Eitel, Wilhelm (1920): - Studien über die Genesis der Einschlüsse des Bühlbasaltes - Über das Vorkommen eines Sillimanitgraphitgesteins mit Umwandlungs-Pseudomorphosen von Spinell, Rutil und Enstatit nach Granat als pyrometamorphe Einschlüsse des Bühlbasalts. - In: Eitel, W.; Irmer, W. \& Velde, L.: Das Vorkommen tellurischen Eisens im Basalte des Bühls bei Kassel, seine

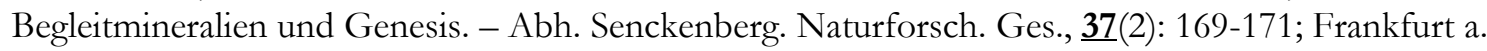
M. 1920 
-Eitel, Wilhelm (1920): - Studien über die Genesis der Einschlüsse des Bühlbasaltes - Die

Gasreaktionen im Bühlbasalt und ihre Rolle bei der Entstehung des gediegenen Eisens in dessen Einschlüssen. - In: Eitel, W.; Irmer, W. \& Velde, L.: Das Vorkommen tellurischen Eisens im Basalte des Bühls bei Kassel, seine Begleitmineralien und Genesis. - Abh. Senckenberg. Naturforsch. Ges., 37(2): 172-175, 1 Abb.; Frankfurt a. M. 1920

-Eitel, W.; Irmer, W. \& Velde, L. (1920): Das Vorkommen tellurischen Eisens im Basalte des Bühls bei Kassel, seine Begleitmineralien und Genesis. - Abh. Senckenberg. Naturforsch. Ges., 37(2); 175 S., 33 Abb., 12 Taf.; Frankfurt a. M.

Referat in: N. Jb. Mineral. etc., 1925 (Bd. I): 536-542 (Schlossmacher); Stuttgart

- •Ernst, T. (1935/1941): Olivinknollen der Basalte als Bruchstücke alter Olivinfelsen. - Nachr. Ges. Wiss. Göttingen, Math.-phys. Kl, Fachgr. IV, N.F., 1 (1934-1940): 147-154, 13 Abb.; Göttingen [Kristallgitterregelung von Olivin, u.a. Hirzstein/Habichtswald b. Kassel, Hoher Hagen b. Göttingen]

-Ernst, Theodor (1936): Der Melilith-Basalt des Westberges bei Hofgeismar, nördlich von Kassel, ein Assimilationsprodukt ultrabasischer Gesteine. - Chemie der Erde, 10: 631-666, 16 Abb., 13 Tab.; Jena

-Ernst, T. (1960): Probleme des Sonnenbrandes der basaltischen Gesteine. Z. dt. geol. Ges.., 112: 178162; Hannover

@Franke, H. (1974): Chemische Untersuchungen an den unter Tage im Grubengebiet „Ernst Thälmann II/III“ des VEB Kalikombinat Werra aufgeschlossenen gangförmigen Basalte. - Chemie der Erde, 33(2): 188-194, 2 Abb., 4 Tab.; Jena

$\square$ Faust, B. C. (1789): Nachricht von dem auf dem Meißner in Hessen über Steinkohlen und bituminösem Holze liegenden Basalte - Aus dem Augustmonate des 1784er Jahrgangs des Journals von und für Deutschland entlehnt, und mit einer Vorbemerkung, wie auch einigen erläuternden Anmerkungen versehen, von A. G. Werner. - Bergmännisches Journal, 1(1): 261-295; Freiberg/Sachsen

$\square$ Faujas de Saint-Fond, Barthélemy (1805/1809) : Essai de géologie, ou mémoires pour servir à l' histoire naturelle du Globe. - Tomé 1: Animaux et végétaux fossilere, [2] B1., 493 S., VII Bl., Ill.; (Levrault, Schoell) Paris 1805. - t. 2(p. 1): Minéraux, 400 S.; (Levrault, Schoell) Paris 1809. - T. 2(p. 2): Volcans, S. 402-731, Ill. ; (Levrault, Schoell) Paris - Taf.-Bd. XXIX pl.; (Levrault, Schoell) Paris 1809 [darin : Bd. 1, S. 450 Meißner ; Bd. 2(2), S. 417-418 Meißner]

-Frechen, Josef (1952): Die Herkunft der spätglazialen Bimstuffe in mittel- und süddeutschen Mooren. Geol. Jb., 67: 209 - 230, 9 Tab.; Hannover [Luttersee b. Seeburg i. Untereichsfeld; Erlenbruckmoor b. Hinterzarten/Schwarzwald]

-Fromm, Otto (1891): Petrographische Untersuchungen von Basalten aus der Umgebung von Kassel . Z. dt. geol. Ges., 43: 43-76, 9 Abb.; Stuttgart

Referat in: N. Jb. Mineral. etc., 1892 (Bd. I): 277-278 (O. Mügge); Stuttgart

Referat in: Z. f. Naturwiss., 64: 164-167; Halle

[Habichtswald, Kaufunger Wald, Bühl. B. Weimar, Dörnberg u.a.]

OFürste, Ria (1956): Untersuchungen über Zusammenhänge zwischen Basaltvorkommen und Vertaubungszonen auf dem Kaliwerk „Ernst Thälmann“ II/III. - Dipl.-Arb. [teilveröff.] Bergakademie Freiberg/Sa. 1956, 85 S. - Teilveröffentlichung in: Bergbautechnik, $\underline{7}$ (7/8); 1957 [Bibliographische Angaben nach: Auflistung von Diplomarbeiten BA Freiberg 1956 in: Geologie, $\underline{7}(1)$ : 102; Berlin 1958]

$\square$ Girard, A. (1841): Ueber Basalte und ihr Verhältnis zu den Doleriten. - Annalen d. Physik u. Chemie, $\underline{\mathbf{5 4}}$ (130 ges. Rh.)[2. Rh.](24): 557-565; Leipzig

[darin S. $561 \mathrm{ff}$ Dolerit Meißner] 
$\square$ Gross, V. (1973): Petrographisch-geochemische Untersuchungen der Differentiation und der Kontaktwirkung des Basaltes vom Hohen Meißner bei Eschwege. - Diss. Univ. Göttingen 1973; 85, XIX S.

QGrumbt, Eberhard \& Lützner, Harald (1966): Störungszonen im Deckgebirge des thüringischen Werra-Kaligebietes und ihre Beziehungen zum Basaltvulkanismus und zur Auslaugung Untersuchung der petrographischen, tektonischen und mineralischen Verhältnisse des Floßberggangzuges zwischen Ilmenau und Gehren als Beitrag zur Klärung der saxonischen Lagerstätten auf den Randspalten des Thüringer Waldes. - Geologie, $\underline{\mathbf{1 5}}$ (4/5): 531-544, 8 Abb.; Berlin

- $\square$ ○Grumbt, Eberhard \& Lützner, Harald (1983): Saxonische Tektonik und Basaltvulkanismus zwischen Thüringer Wald und Vorderrhön. - Z. geol. Wiss, 11 (8): 943-954, 2 Abb., 1 Tab., 1 Faltkt.; Berlin [großregionale Betrachtung unter Einbeziehung der nordhessischen Gräben; HE, WMK, THÜR, NIE]

- Grupe, O. \& Stremme, H. (1913): Die Basalte des Sollings und ihre Zersetzungsprodukte. - Jb. Preuß. Geol. Landesanst., $\underline{32}$ (f. 1911): 242-300, 3 Abb., Taf. 8-10; Berlin - Z. dt. geol. Ges., $\underline{62}$ (f. 1910): 174-191, 4 Tab. (Mber.); Berlin Referat in: N. Jb. Mineral. etc., 1913 (Bd. I): 422-426 (Milch), 427-428 (Hans Reck); Stuttgart [darin: Bramburg b. Adelebsen]

- $\square$ Gutberlet, W. K. J. (1855): Über Sphärosiderit und Bohnerz in basaltischen Gesteinen. - N. Jb. Mineral. etc., 1855: 166-169; Stuttgart [darin: Großalmerode/Ringenkuhl]

-Gutsche, A. \& Hermann, A. G. (1988): Wechselwirkungen zwischen fluiden Phasen und Evaporiten im Nahbereich von Basaltgängen. - Fortschr. Mineral., $\underline{\mathbf{6}}$, Beih. 1: 49; Stuttgart [Werk Hattorf, Philippsthal]

-Hartmann, Gerald (1986): Chemische Zusammensetzung und Mineralbestand von PeridotitXenolithen mit unterschiedlicher metasomatischer Überprägung aus Basalten der Hessischen Senke. Diss. Univ. Göttingen 1986; 99 S., 28 Abb., 10 Tab. + Anh. (Tab.)

[HE, darin: Hirzstein, Druseltal]

-Hartmann, G. \& Wedepohl, K. H. (1984): Ausgewählte Spurenelemente in Peridotit-Xenolithen mit unterschiedlicher metasomatischer Überprägung aus Basalten der Hessischen Senke. - Fortschr. Mineral., 62, Beih. 1: 82-84; Stuttgart [HE, ohne Lokalitätenbezug]

-Hartmann, G. \& Wedepoh1 K. H. (1986): Klinopyroxene in Mantel-Xenolithen mit unterschiedlicher metasomatischer Überprägung (Beispiele aus der Hessischen Senke). - Fortschr. Mineral., 64, Beih. 1: 64; Stuttgart

[HE, ohne Lokalitätenbezug]]

-Hartmann, Gerald \& Wedepohl K. Hans (1990): Metasomatically altered peridotite xenoliths from the Hessian Depressian (Northern Germany). - Geochimica Cosmochimica Acta, 54: 71-86, 7 fig., 4 tabl.;

[HE, darin: Hirzstein, Druseltal]

$\square$ Haüy, René-Just (1822): Traité de minéralogie. - 2. Auflage ; 4 Textbd. + Taf.Bd. m. 86 Taf.; Bd. 1: 592 S.; Bd. 2: 613 S.; Bd. 3593 S., Bd. 4604 S.; (Louis) Paris

[Haüy bezeichnet den grobkörnigen Basalt des Meissners als „Dolerit mit symplektitischem Gefüge“; offen läßt der Autor die Kardinalfrage der Plutonisten und Neptunisten: die vulkanische oder sedimentäre Entstehung des Basaltes; der Begriff Dolerit wurde erstmals in der Petrographie von Aubuisson 1819 verwandt und für die Beschreibung des grobkörnigen Meissnerbasaltes benutzt] 
- $\square \bullet$ Hausmann, [J. F. L.](1824): Uebersicht der jüngeren Flöz-Gebilde im Fluß-Gebiete der Weser. Tb. Mineral., 18 (3): 678-702; Frankfurt/M. - Auszug aus Hausmann: Uebersicht der jüngeren FlözGebilde. - Studien Göttingischen Vereins bergmänn. Freunde, 1: 381 - 567, Göttingen 1824 [Regionale Stratigraphie Trias-Tertiär Hessen, WMK, Niedersachsen; darin: Meißner, Hirschberg, Habichtswald]

- $\square$ Q $\bullet$ Hausmann, J.F.L. (1824, 1828): Übersicht der jüngeren Flötzgebilde im Flußgebiete der Weser, mit vergleichender Berücksichtigung ihrer Äquivalente in einigen anderen Gegenden von Deutschland und der Schweiz. - Studien Göttingischen Vereins bergmänn. Freunde, 1: 381 - 567, Göttingen 1824; 2: 215-482; Göttingen 1828

[Regionale Stratigraphie Trias-Tertiär Nordhessen, Südniedersachsen; Bd. 1, Stratigraphie Buntsandstein; S. 500-508 „Basaltische Massen im Sandstein“, darin: Blaue Kuppe bei Eschwege, Pflasterkaute bei Eisenach]

-Hausmann, J.F.L. (1849): Über den glasigen Feldspath im Basalte des Hohenhagens zwischen Göttingen und Münden. - Studien Göttingischen Vereins bergmänn. Freunde, $\underline{\mathbf{5}}$ : 83-90; Göttingen Auszug in: N. Jb. Mineral. etc., 1843: 350-351 (Auszüge); Stuttgart

[Aufsatzbesprechung von 1843; Aufsatz erscheint erst 1849!]

-Hausmann, J.F.L. (1849): Über den Tachylyt vom Säsebühl bei Dransfeld. - Studien Göttingischen Vereins bergmänn. Freunde, $\underline{\mathbf{5}}$ : 91-104; Göttingen

-Hausmann, J.F.L. (1849): Neuere Analyse des glasigen Feldspathes vom Hohenhagen bei Dransfeld Studien Göttingischen Vereins bergmänn. Freunde, $\underline{\mathbf{5}}$ : 348; Göttingen

- $\square \bullet$ Hausmann, J. F. L. (1858): Über das Vorkommen verschiedener Kieselgebilde in Begleitung des Basaltes. - Studien Göttinger Vereins bergmänn. Freunde, 7(2): 139 - 192; Göttingen [darin: Blaue Kuppe, Hirschberg, Habichtswald, Meißner, Steinberg b. Hann-Münden; S. 154-156: „Absatz von Kieselsinter in dem schlackigen Anthracite des Meißners; S. 165-172: „Durch Eindringung von kieselsäurehaltigem Wasser in die Schichten des vom Basalte durchbrochenen Muschelkalkes gebildeter Kieselkalk“ (Kontkatmetamorpher Marmor vom „Schieferberg b. Bransrode“/Hoher Meißner S” Weisenbach, heutiger Name „Heiligenberg“]

- $\square \bullet$ Hausmann, J. F. L. (1860): Ueber das Vorkommen von Quellengebilden in Begleitung des Basaltes der Werra- und Fulda-Gegenden. - Abh. Kgl. Ges. Wissenschaften z. Göttingen, $\underline{8}$ (f. 1858/59): 55102; (Dieterich) Göttingen [(Hydrothermale) Mineralisationen; Region Landkreis Göttingen zw. Göttingen u. Hann.-Münden, Werra-Meißner-Kreis, Nordosthessen; u.a. S. 68-79 Blaue Kuppe u. Kleine Kuppe; S, 76-77 Hirschberg b. Großalmerode, Heiligenberg S`Weißenbach]

-Hausmann, J.F.L. (1858): Chloropal vom Meenser Steinberg unfern Göttingen. - N. Jb. Mineral. etc., 1858: 569-572; Stuttgart

$\square$ Hausmann, J.F.L. (1849): Apophyllit von der blauen Kuppe bei Eschwege. - Studien Göttingischen Vereins bergmänn. Freunde, $\mathbf{5}$ : 346-347; Göttingen

-Heinrichs, Hartmut (1972): Mineralbestand und Chemismus der Alkali-Olivinbasalte aus der Umgebung von Homberg a. d. Efze (Hessen). - Notizbl. Hess. L.-A. Bodenforsch., 100: 164 - 176, 3 Abb., 4 Tab.; Wiesbaden

-Hentschel, Hans (1957): Typen tertiärer Basalttuffe im Raum des Habichtswaldes und ihre Lagebestimmungen. - Z. dt. geol. Ges., 108 (f. 1956): 268-269; Hannover [Vortragstext]

$\square$ Hentschel, H. (1968): Der Basalt des Meißner. - In: Kortitnig, Sigmund [Hrsg.](1968): Zur Mineralogie und Geologie der Umgebung von Göttingen mit Westharz und Teilen des nordhessischen Berglandes. - Der Aufschluss, Sdbd. 17: 151-165, 4 Abb., 1 Tab.; Heidelberg 
$\square$ Hentschel, H. (1978): Der Basalt des Meißner. - In: Koritnig, Sigmund [Schriftltg.]: Zur Mineralogie und Geologie der Umgebung von Göttingen - mit Westharz und Teilen des Nordhessischen Berglandes.- Der Aufschluss, Sdbd. 28: 208-228, 4 Abb., 2 Tab.; Heidelberg 1978

-Hentschel \& Rösing (1959/60): Habichtswald und Dörnberg bei Kassel - Bericht über die Exkursionen anläßlich der 110. Hauptversammlung [der Deutschen Geologischen Gesellschaft] vom 1.-9- September 1968 [in Kassel]. - Exkursion F - Mesozoikum u. Tertiär der Hessischen Senke Montag, den 9. September 1958 -Z. dt. geol. Ges., 111 (f. 1959/60): 305-310, 1 Tab.; Hannover

$\square$ Hentschel, H.; Kortinig, S.; Kutscher, F.; Rösing, F. (1962): Ganztagsexkursion zur Blauen Kuppe, am 25. Mai 1961. Geologischer Bericht. - (Übergeordn. Titel: Bericht über die Exkursionen während der Tagung des Naturhistorischen Vereins der Rheinlande und Westfalens vom 23. - 26. Mai 1961 in Kassel). - Decheniana - Verhdlgn. Naturhist. Vereins Rheinlande u. Westfalens, 114 (f. 1961): 195201, 2 Abb.; Bonn [darin: Blaue Kuppe, Stbr. a. Meinhard, Wienberg/Neuerode; Hoher Meißner: Haldenhaus, Kalbe, Seesteine, Kitzkammer)

-Herrmann, Albert Günter \& Wedepohl Karl Hans (1966): Die Verteilung des Yttriums und der Lanthaniden in einem Olivin-Alkali-Basalt mit Peridotit-Einschlüssen. - Beitr. Mineral. Petrogr., 13: 366-373, 2 Abb., 2 Tab.; Berlin-Heidelberg

[Basalt des Hirzsteins/Habichtswald]

- $\square$ Hessel, J. F. C. (1823): Einiges über Basaltberge und über die Lagerungsverhältnisse der Basaltsäulen an einem und demselben Basaltberge. - Schr. Ges. Beförd. Gesammt. Naturwiss. z. Marburg, 11: 153166; Marburg [Hinweis a. „Blaue Kuppe“ b. Eschwege]

$\square$ Hessel (1827): Mesothyp vom Alpstein bei Sontra. - Z. Mineral., 1827(9): 283-284; Frankfurt/M.

-Heykes, Klaas (1911): Die Basalte am Westrand der hessischen Senke zwischen Fritzlar und Wolfhagen. - N. Jb. Mineral., Beil.-Bd. 31: 269 - 302, 1 Taf. (Kt.); Stuttgart

-Heykes, Klaas (1928): Über niederhessische Basalte. - Sitzber. Preuß. Geol. Landesanst., $\underline{3}$ : 104 - 116, 3 Abb.; Berlin

-Heykes, Klaas (1930): Chemisch-petrographische Studien an Basalten Niederhessens und der Rhön. Sitzber. Preuß. Geol. Landesanst., $\underline{\mathbf{5}}$ : 75 - 85, 7 Abb.; Berlin

Referat in: N. Jb. Mineral. etc., Referate; 1932 (Bd. II): 345-346 (Chudoba); Stuttgart

-Heykes, Klaas (1931): Chemisch-petrographische Studien an Basalten Niederhessens und der Rhön. Jb. Preuß. Geol. Landesanst., $\underline{\mathbf{5 1}}$ (Teil 2)(f. 1930): 469-504, 7 Abb.; Berlin

-Hezel, Ludwig (1912): Die nördlichsten Ausläufer hessischer Eruptivgesteine westlich der Chaussee Trendelburg-Hofgeismar-Niedermeiser. - Diss. Univ. Marburg 1912; 62 S., 1 Kt.; (Schaaf) Marburg

- $\square$ OHoff, Karl Ernst Adolf von (1811): Beobachtungen über die Verhältnisse des Basaltes an einigen Bergen von Hessen und Thüringen. - Der Gesellschaft Naturforschender Freunde zu Berlin Magazin für die neuesten Entdeckungen in der gesammten Naturkunde, $\underline{5}$ : 347-362 u. Taf. VIII; Berlin [darin: Blaue Kuppe b. Eschwege, Pflasterkaute b. Marksuhl, Stoffelskuppe b. Eisenach, Habichtswald/Kassel, Hirschberg b. Großalmerode, Hoher Meissner]

口OHoff, K. E. A. von (1817): Quelques montagnes basaltiques de Hesse et de Thuringue (Extrait par M. de Bonnard). - Annales des mines, 1817(3): 361-368; Paris [darin S. 363-365: Blaue Kuppe b. Eschwege; auch Pflasterkaute, Stoffelskuppe, Steinsberg b. Suhl] 
QHoff, Karl Ernst Adolf v. (1821): Merkwürdiges Vorkommen des Basaltes in der Gegend von Eisenach. - Tb. Mineral., 15: 169-174; Frankfurt/M.

[Auszug aus: Magaz. Berliner Ges. Naturforsch. Freunde, 7, 309ff; Hörsel, Stoffelskuppe, Hütschhof, Pflasterkaute]

$\square$ Hoffmann, Friedrich (1823): Geognostische Bemerkungen über die Basalte der Gegend des Meißners und ihren vulkanischen Ursprung, (und Notiz von einigen barometrischen und electrometrischen Arbeiten). - Annalen d. Physik und der physikalischen Chemie, 15(3), zgl. Annalen der Physik, $\underline{\mathbf{7 5}}$ : 323-332; Leipzig [ [darin: Blaue Kuppe, Alpstein, Hoher Meißner, Hirschberg b. Großalmerode, Heiligenberg b. Weißenbach]

$\square$ Hoffmann, Friedrich (1838): Geschichte der Geognosie und Schilderung der vulkanischen Erscheinungen - Vorlesungen gehalten an der Universität zu Berlin in den Jahren 1834 und 1835. Friedrich Hoffmann - Hinterlassene Werke, Bd. ㄹ; VIII, 596 S.; (Nicolai) Berlin [darin S. 564: Mineralische Beschaffenheit der Laven: Dolerit vom Meissner]

-Hoppe, W. (1927/1928): Über die Erscheinung des Sonnenbrandes an Basalten. - Beitr. Geol. Thür., 1(6): 42-54; Jena

-Hornstein, F. F. (1907): Kurze Mitteilung über das Basaltvorkommen vom Bühl bei Weimar, nordwestlich von Cassel, und seine Einschlüsse, insbesondere die von gediegenem Eisen. - Ber. Versamml. Niederrhein. Geol. Vereins, 1902 [1. Jg.]: 54-56; Bonn

$\square$ Hotzler, Fritz (1996): Basalt - ein besonderes Gestein. - Das Werraland, $\underline{\text { 48}}(2)$ : 39, 1 Abb. (Blaue Kuppe); Eschwege

$\square$ [Humboldt, Alexander von](1790): Mineralogische Besonderheiten über einige Basalte am Rhein. Mit vorangeschickten, zerstreuten Bemerkungen über den Basalt der ältern und neuern Schriftsteller. - VIII, 126 S.; (Schulbuchhdlg.) Braunschweig

[darin: S. 16-17: Der Basalt des Meissners im Streit zwischen Neptunisten und Plutonisten]

$\square \mathrm{OHumboldt}$, Alexander von (1845): Kosmos - Entwurf einer physischen Weltbeschreibung. - Bd. 1; XVI, 493 S.; (Cotta) Stuttgart

[darin Bd. 1, S. 270: Kurze Erwähnung der Pflasterkaute b. Marksuhl und der Blauen Kuppe b. Eschwege]

-Irmer, Walter (1920): Der Basalt des Bühls bei Kassel und seine Einschlüsse von Magnetit, Magnetkies und gediegenem Eisen. In: Eitel, W.; Irmer, W. \& Velde, L.: Das Vorkommen tellurischen Eisens im Basalte des Bühls bei Kassel, seine Begleitmineralien und Genesis. - Abh. Senckenberg.

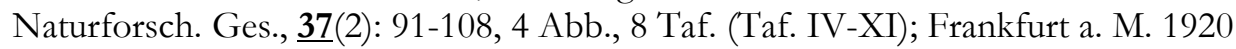

पJacobshagen, V.; Koritnig, S.; Ritzkowski, S.; Rösing, F., Wittig, R. \& Wycisk, P. (1977): Der Unterwerra-Sattel: sein Deckgebirge (Perm - Trias) und der gefaltete paläozoische Kern - (Exkursion C). - Unter Mitarbeit von G. Schalow und H. Schulze. - In: Geol.-Paläont. Inst. u. Museum der Universität [Hrsg.]: Exkursionsführer - Geotagung '77 Göttingen - Band II : Nordhessen und Südniedersachsen (Exkursionen C - D - J - K - L). - S. 1-34; 8 Abb.; (Selbstverlag GeologischPaläontologisches Institut) Göttingen 1977 [darin: Aufschluß 7 - „Blaue Kuppe“ S’ Eschwege]

口Jäger, Willy (1929): Spuren vulkanischer Tätigkeit bei Motzenrode. - Eschweger Tageblatt, 1929; Nr. 48 v. 26.2. 1929; Eschwege

[Basaltfund]

口Jäger, Willy (1930): Das neue Basaltvorkommen bei Motzenrode. - Eschweger Tageblatt, 1930; Nr. 2 v. 3.1.1930; Eschwege 
OJahne, Heinz \& Pader, Dietmar (1994): Untertageaufschluß eines Basaltschlotes durch den Bergbau im Werra-Kaligebiet. - Kali u. Steinsalz, 11(7): 218-224, 10 Bilder; Essen

[Hubenbergschlot, Thür. Werra-Kalirevier Unterbreizbach]

-Käding, Karl-Christian (1962): Geologische, magnetische und petrographische Untersuchungen tertärer Vulkanite und ihrer Begleiterscheinungen im Bereich des hessischen Werra-Kaligebietes. Diss. Freie Unversität Berlin 1962; 112 S., Abb., Anl.

QKästner, Hans (1974): Jungtertiärer Vulkanismus [in Thüringen]. - In: Hoppe, Walter \& Seidel, Gerd [Hrsg.]: Geologie von Thüringen [Bezirke Erfurt, Gera, Suhl]. - S. 782-789, Abb. 157-159, Tab. 107, Photo 92-97; (Haack) Gotha-Leipzig 1974

口Kästner, Hans \& Mädler, Jonas (1995): Jungtertiärer Vulkanismus [in Thüringen]. - In: Seidel, Gerd [Hrsg.]: Geologie von Thüringen. - 1. Aufl.; S. 412-418, 2 Abb.; Stuttgart 1995

○Kästner, Hans \& Mädler, Jonas (2003): Jungtertiärer Vulkanismus [in Thüringen]. - In: Seidel, Gerd [Hrsg.]: Geologie von Thüringen. - 2., neu bearb. Aufl.; S. 443-448, 2 Abb.; Stuttgart 2003

$\square$ Keferstein, Christian (1819): Beiträge zur Geschichte und Kenntnis des Basaltes, und der ihm verwandten Massen, in mehreren Abhandlungen. - 252 S., J. Ch. Hendel u. Sohn) Halle/Saale [darin: S. 214 - 216: Die „blaue Kuppe“ bei Eschwege u. Meißner]

- $10 \bullet$ Keferstein, Christian (1820): Geognostische Bemerkungen über die basaltischen Gebilde des westlichen Deutschlands, als Fortsetzung der Beyträge zur Geschichte und Kenntniß des Basaltes. VIII, 207 S., 1 Falt-Kt.; (J. Chr. Hendel u. Sohn) Halle/Saale

[darin S. 22 - 24: Habichtswald, Meißner, Hirschberg/Großalmerode, Erwähnung der „blauen Kuppe“, Basaltberge westl. Göttingen, Stoffelskuppe, Pflasterkaute bei Marksuhl]

- $\square$ OKeferstein, [Christian](1821): Die Entstehung der Basalte durch Feuer oder Wasser. - Tb. Mineral., 15(1): 153-169; Frankfurt/M. - Auszug aus: Keferstein, Christian: Beiträge zur Geschichte und

Kenntnis des Basaltes; Halle 1819

[Der Neptunisten-Plutonisten-Streit und ihre Vertreter; darin: „Blaue Kuppe b. Eschwege, Pflasterkaute b. Marksuhl]

-Keller, Rudolf (1950): Die Basalte des Kreises Hofgeismar. - Heimatjahrbuch f. d. Kreis Hofgeismar, 1951: 56-60, 3 Abb.; Kassel

-Klein, C. (1878): Über den Feldspat im Basalt vom Hohen Hagen und seine Beziehung zu dem Feldspat vom Monte Gibele auf der Insel Pantelleria. - Nachr. Kgl. Ges. Wiss. z. Göttingen, 14: 449-466; Göttingen - auch: N. Jb. Mineral., 1879: 86 - 87; Stuttgart

-Klüpfel, Walter (1953): „Basaltgeologie“ . Ein Beitrag zur Kenntnis der tertïren Basalte. - Z. dt. geol. Ges., 104: 326- 353, 20 Abb.; Hannover

[Tektonik und Gefüge von Basaltmassen; Abbaubeeinträchtigungen durch

Verwitterungserscheinungen, u.a. Sonnenbrand, Dauchbildung]

-Knipping, Bernhard (1987): Basaltintrusionen in Zechstein 1 - Evaporiten (Werra-Lagerstättenbezirk). - Diss. Univ. Göttingen 1987; 202 S.

[Geochemie]

$\square$ Köth, Wilhelm (1989): Die Blaue Kuppe, ein alter Vulkan. - Das Werraland, 41(4): 67-68; Eschwege

$\square$ Koritnig, Sigmund (1954): Die Vorgänge bei der Kontaktbildung im Buntsandstein der Blauen Kuppe und des Alpstein, Nordhessen. - Beitr. Mineral. Petrologie, 4: 89 - 98, 1 Abb.; Berlin-GöttingenHeidelberg 
$\square$ Koritnig, Sigmund (1955): Die Blaue Kuppe bei Eschwege mit ihren Kontakterscheinungen. - Beitr. Mineral. Petrologie, 4: 504 - 521, 11 Abb.; Berlin -Göttingen- Heidelberg

$\square$ Koritnig, Sigmund (1956): Die „Blaue Kuppe“ bei Eschwege. - Der Aufschluss, 7: 127 - 137, 3 Abb., 2 Tab.; Göttingen

-Koritnig, Sigmund (1964): Pseudodifferentiation eines basaltischen Magmas durch sekundäre Wasseraufnahme. - Beitr. Mineral. Petrogr., 10: 50 - 59, 3 Abb., 2 Tab.; Berlin-Göttingen-Heidelberg [Bramburg b. Adelebsen]

$\square$ Koritnig, Sigmund (1968): Die „Blaue Kuppe“ bei Eschwege. - Der Aufschluss, Sonderbd., 17: 173 182, 6 Abb.; Heidelberg

$\square$ Koritnig, Sigmund (1978): Die „Blaue Kuppe“ bei Eschwege. - In: Koritnig, Sigmund [Schriftltg.]: Zur Mineralogie und Geologie der Umgebung von Göttingen - mit Westharz und Teilen des Nordhessischen Berglandes. - Der Aufschluß, Sdbd. 28: 237 - 247, 7 Abb., 2 Tab.; Heidelberg 1978

-Koritnig, Sigmund (1968): Die sekundären Mineralbildungen im Basalt der Bramburg bei Adelebsen. Der Aufschluss, Sdbd. 17: 131-134, 4 Abb.; Heidelberg

- Koritnig, Sigmund (1972): Gyrolith, Okenit und Tacharanit als metasomatische Reaktionsprodukte aus dem Basaltvorkommen der Bramburg bei Göttingen, Deutschland. - Contr. Mineral. Petrol., 포: 293301, 4 Abb.; Berlin-Heidelberg

-Koritnig, Sigmund (1978): Die sekundäre Mineralbildung im Basalt der Bramburg bei Adelebsen. - In: Koritnig, Sigmund [Schriftltg.]: Zur Mineralogie und Geologie der Umgebung von Göttingen - mit Westharz und Teilen des Nordhessischen Berglandes. - Sdbd. 료; S. 168-176, 8 Abb.; Heidelberg 1978

- •Kreuzer, H.; Besang, C.; Harre, W.; Müller, P.; Ulrich, H.-J. \& Vinken, R. (1973): K/ArDatierungen an jungtertiären Basalten aus dem Vogelsberg und aus dem Raum zwischen Kassel und Göttingen. - Fortschr. Mineral., 吕, Beiheft 3: 10-11; Stuttgart

[Mehrer Vorkommen Lkr. Göttingen, Hessen (Westberg b. Hofgeismar; Druseltal/Habichtswald]

-Lang, Otto (1908): Zur Kenntnis der Verbreitung niederhessischer Basaltvarietäten. - Jb. Preuß. Geol. Landesanst., 26 (f. 1905): 272-352; Berlin

- 0 OLeonhard, Karl Caesar v. (1832): Die Basalt-Gebilde in ihren Beziehungen zu normalen und abnormalen Felsmassen. - Bd. 1, 498 S., sep. Taf.-Bd. m. 20 Taf.; Bd. 2, 536 S.; (Schweizerbart) Stuttgart

Bd. 2 beschreibt Intrusionsgefüge der Basalte und die Kontaktmetamorphose auf das Rahmengestein; Basalt/Ton: Meißner; Basalt/Buntsandstein: Blaue Kuppe/Eschwege; Pflasterkaute/Marksuhl; Basalt/Muschelkalk: Ahnetal/Kassel, Hörschel b. Eisenach]

- $\square$ Lepsius, Richard (1887 - 1892): Geologie von Deutschland und den angrenzenden Gebieten. Erster Teil: Das westliche und südliche Deutschland. - Reihe: Handbücher zur Deutschen Landes- und Volkskunde, Bd. 1; XIV, 800 S., 136 Abb., 5 Falt-Taf.; in 3 Lfgn.: 1.1887, 2.1889, 3.1892; (J.

Engelhorn) Stuttgart

[darin S. 402 Richelsdorfer Gebirge, S. 761 - 766 Kap.: „Basalte in nördlichen Teil des hessischen Waldgebirges“" [Knüll, Habichtswald, Reinhardswald, Kaufunger Wald und Meissner]; S. $761-766$ Petrographie und Geologie des Meißner-Basaltes)

- $\square$ Lippolt, Hans Joachim (1982): K/Ar Age Determinations and the Correlation of Tertiary Volcanic Activity in Central Europe. - Geol. Jb., Reihe D, 52: 113-135, 3 fig.; Hannover [darin: Niederhessen (ohne konkrete Lokalitäten)]

a $\square$ Lippolt, H. J. (1983): Distrubutions of volcanic activity in space and time. - In: Fuchs, K.; Gehlen, K. V.; Mälzer, H.; Murawski, H. \& Semmel, A. [eds.]: Plateau uplift: the Rhenish Shield - a case 
history. - p. 112 - 120, 3 fig.; (Springer) Berlin - Heidelberg - New York 1983

[darin: West- und Osteifel, Westerwald, Siebengebirge, Nördliche Hessische Senke]

-Loewer, E. (1896): Ueber die Basalttuffe vom Habichtswald und von Homberg, Reg.-Bez. Kassel. Abh. u. Ber. Vereins Naturkde. z. Kassel, 41 (1895/1896): 51-68, 1 Abb.; Kassel

-Lohmann, Ludwig (1964): Ein Beitrag zur Petrographie Melilith-führender Olivinnephelinite aus dem Gebiet Fritzlar-Naumburg (Nordhessen). - Beitr. Mineral. Petrogr., 9: 533-584, 18 Abb.; HeidelbergBerlin

- •Luc, Jean André de (1779): Lettres physiques et morales sur l’histoire de la terre et de l'homme, adressés à la Reine de la Grande Bretagne. - Tome III., 566 S.; Tome IV, [2] Bl., 640 S.; (V.

Duchesne) Paris - (De Tune) La Haye

darin:

Tome III: p. 497-504 - LETTRE LXXIX (Cassel, le 13. 7bre 1777)

Route de PYRMONT à CASSEL, par MUNDEN - Traces volcaniques sur la fin de cette route, et dans la Montagne de CASSEL. -

Tome IV : p. 442-476 - LETTRE CVII (Cassel, le 28e Juin 1778)

Volcans des environs de CASSEL, en partie recouvertes par des dépôts calcaires et sablonneux de la Mer. -

Tome IV: p. 477-486 - LETTRE CVIII (Gottingue, le 29. Juin 1778)

Route de CASSEl à GOTTINGUE - Traces volcaniques dans les Collines qui séparent ces deux Villes. -

Tome IV : p. 487-520 - LETTRE CIX (Gottingue, le 2e Juillet 1778)

Montagnes volcaniques de la Province de GOTTINGUE, recouvertes de pierre à chaux et celle-ci de pierre sableuse. -

Tome IV : p. 521-545 - LETTRE CX (Gottingue, le 3e Juillet 1778)

Autres Montagnes des environs de GOTTINGUE, dent le noyage est de pierre à chaux, et l'enveloppe de pierre sableuses ; suspectes de recevoir des Cônes volcaniques. -

$\square$ Ludwig, Otto (1954): Der Alpstein, ein erloschener Vulkan. Eine geologische Betrachtung aus dem Sontraer Land. - Werra-Rundschau, 1954; Nr. 21 v. 26.1.1954, S. 3; Eschwege

- •Lüc, Johann Andreas de [= Luc, Jean André de](1781/1782): Physikalische und moralische Briefe über die Geschichte der Erde und des Menschen an Ihro Majestät die Königin von Großbritannien. Bd. 1; [8 Bl.], 582 S: (Weidmann’s Erben u. Reich) Leipzig 1781 - Bd. 2, [6 Bl.] 612 S.; (Weidmann's Erben u. Reich) Leipzig 1782

Bd. 1/S. 558-562 - LXXIX. Brief [Cassel, den 13. Sept. 1777]: Reise von Pyrmont nach Cassel über Münden - Spuren von Vulkanen auf diesem Weg, und im Berge bey Cassel

Bd. 2/S. 177-191 - CVII. Brief [Cassel, den 28. Juni 1778]: Vulkane der Gegend um Kassel, die zum Teil mit kalkartigen und sandigen Bodensätzen des Meeres bedeckt sind.

Bd. 2/S. 191-195 - CVIII. Brief [Cassel, den 29. Juni 1778]: Reise von Cassel nach Göttingen Spuren von Vulkanen auf den Anhöhen zwischen den beyden Städten.

Bd. 2/S. 196-209 - CIX. Brief [Göttingen, den 2. Juli 1778]: Vulkane um Göttingen, die mit Kalkstein bedeckt sind, den wiederum der Sandstein bedeckt

Bd. 2/S. 210-217 - CX. Brief [Göttingen, den 3. Juli 1778]: Andere Berge um Göttingen, deren Kern von Kalkstein, der äußere Theil aber von Sandstein ist - Vermuthung, daß sie vulkanische Kegel bedecken. 
-Mengel, Kurt (1981): Petrographische und geochemische Untersuchungen an Tuffen des Habichtswaldes und seiner Umgebung und an deren Einschlüssen aus der tieferen Kruste und dem oberen Mantel. - Diss. Univ. Göttingen 1981; 104 S., graph. Darst.

-Mengel, Kurt (1983): Petrographie und Geochemie der Tuffe des Habichtswaldes und seiner Umgebung (Nördliche Hessische Senke). - N. Jb. Mineral., Abh., 147: 1-20, 4 Abb., 5 Tab.; Stuttgart

-Mengel, K. (1987): Petrologie und Geochemie von Unterkrusten-Xenolithen aus Tuffen des Habichtswaldes (nördliche Hessische Senke). - Fortschr. Mineral., 65, Beih. 1: 134; Stuttgart

-Mengel, K. (1990): Crustal xenoliths from Tertiary volcancis of the northern Hessian Depression Petrological and chemical evolution. - Contrib. Mineral. Petrology, 104(1): 8-26, 8 fig., 6 tabl.; BerlinHeidelberg

-Mengel, K. \& Wedepohl, K. H. (1983): Crustal xenoliths in Tertiary volcanics from the northern Hessian Depression. - In: Fuchs, K. et al. (eds.): Plateau Uplift - The Rhenish Massif - A Case History. - p. 332-335, 2 tabl.; (Springer-Verlag) Berlin-Heidelberg-New York 1983 [HE, Ohne Lokalitätenbezug]

- •Mengel, K.; Kramm, U.; Wedepohl, K. H.; \& Gohn, E. (1983): Sr-Isotope miozäner Basalte und Peridotiteinschlüsse der nördlichen Hessischen Senke. - Fortschr. Mineral., 61, Beih. 1: 147-149, Stuttgart [HE, NIE]

-Mengel, K.; Schneider, A. \& Wedepohl, K. H. (1983): Natürliche Schmelzen in Gesteinen des oberen Mantels. - Fortschr. Mineral., 61, Beih. 1: 149-150; Stuttgart [Nördliche Hessische Senke, ohne konkrete Lokalitäten]

-Mengel, K.; Sachs, P.; Stosch, H.-G.; Wörner, G. \& Loock, G. (1991): Crustal xenoliths from Cenozoic volcanic field of West Germany : Implications for structure and composition of the continental crust. - Tectonophysics, 195: 271-289, 4 fig., 4 tabl.; Amsterdam [HE; Eifel]

-Menzel, Herbert (2004): Betrachtungen zum tertiären Vulkanismus in der Eifel mit Beispielen weiterer Vulkan-Vorkommen im nördlichen Deutschland. - Der Aufschluss, 55(1): 25-34, 23 Abb.; Heidelberg [darin Erwähnung: Habichts- u. Reinhardswald]

-Möhl, Heinrich (1868): Der Bühl bei Weimar [Kassel/Ahnetal] in der Nähe von Kassel. Beitrag zur vulkanischen Entstehung basaltischer Gesteine. - Ber. Offenbacher Vereins Naturkde., 9: 61-80, 1 Abb.; Offenbach

- $\square \bullet$ Möhl, Heinrich (1871): Die Gesteine (Tachylit, Basalt und Dolerit) der Sababurg in Hessen ... nebst Vergleichung mit ähnlichen Gesteinen. - Bericht d. Vereins f. Naturkunde zu Cassel, 16/17/18; 32 S. (getr. Zählung), 2 Taf.; Kassel [darin: Dolerit Meißner, Säsebühl b. Dransfeld]

-Möhl, Heinrich (1872): Mikroskopische Untersuchung von Hauynbasalten in Hessen. - N. Jb. Mineral. etc., 1872: 77-80, 4 Abb.; Stuttgart [darin. Westl. Vorberge d. Habichtswaldes - Thurmberg bei Elberberg]

- $\square$ Möhl, H. (1873): Zusammenstellung, mikroskopische Untersuchung und Beschreibung einer Sammlung typischer Basalte. - N. Jb. Mineral. etc., 1874: 897 - 942, 1 Taf.; Stuttgart [darin: Meissner, Basalte Umgebung v. Kassel]

$\square$ Möhl, H. (1874): Durch Basalt veränderter Sandstein (Buchit) und Kalk (Marmor mit Chondrodit und Wollastonit) vom Weissholz bei Lütgeneder - (Mineralogische Mittheilungen, 13). - N. Jb. Mineral., 
1874: 799-804; Stuttgart

[darin S. 802: Buchit vom Rosenbühl b. Eschwege-Niddawitzhausen]

-Murawski, Hans (1952): Exkursionen zu den Basaltvorkommen westlich von Göttingen. - Fortschr. Mineral., 29/30 (f. 1950/51): 92-93; Stuttgart

QNaumann, Ernst (1914): Über einige vulkanische Erscheinungen im Werratale [Vortragstext]. - Jb. Preuß. Geol. Landesanst., $\underline{33}$ (Teil I)(f. 1912): 449-467, 1 Abb.; Berlin [Thüringer Werraland]

ONaumann, Ernst (1952): Über einige vulkanische Schlotbrekkzien, andere vulkanischer Erscheinungen und Auslaugungsbrekzien im Werragebiet und in der Rhön. - Geologie, 1: 59-63, 3 Abb.; Berlin

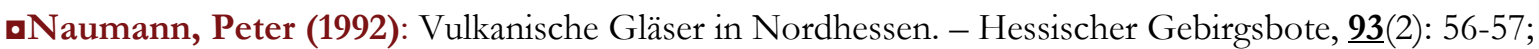
Melsungen

-Naumann, Peter (1992): Olivin - der „Edelstein“ der nordhessischen Basalte. - Hessischer

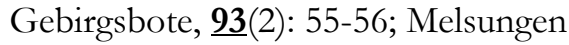

-Naumann, Peter (1993): Der Bühl bei Weimar. - Mitt. Geol. Interessengemeinschaft Nordhessen (GIN), 2; 21 S., 5 Abb., 1 Tab.; (Selbstverlag Peter Naumann) Hofgeismar 1993 [Basalt-Vorkommen mit Gediegen-Eisen-Einsprenglingen]

$\square$ Naumann, Peter (1994): Die „Blaue Kuppe“ bei Eschwege. - Hessischer Gebirgsbote, 95(2): 59; Melsungen

-Naumann, Peter (1996/1998): Basaltmineralien in Nordhessen. - Hessischer Gebirgsbote, 97(4): 164 , auch 99(4): 143; Melsungen

[Fundorte d. Umgebung von Kassel]

-Naumann, Peter (1993): Der Bühl bei Weimar. - Mitt. Geol. Interessengemeinschaft Nordhessen (GIN), 2; 21 S.; (Naumann) Hofgeismar

[Basalt-Vorkommen mit Gediegen-Eisen-Einsprenglingen, eine von etwa 10 weltweit bekannten Fundstellen]

$\square$ Nieuwenkamp, W. (1935): Zweidimensionale Cristobalitkristalle. - Z. Kristallogr., 90: 377 - 380, 7 Abb.; Leipzig

[Röntgenograph. Untersuchung v. Christobalit der „Blauen Kuppe“ bei Eschwege]

- $\square$ Nöggerath, Karl Jakob (1822-1826): Das Gebirge in Rheinland-Westfalen - nach mineralogischem und chemischen Bezuge. - 1. Bd., 370 S.: 7 Abb., (Eduard Weber) Bonn 1822. - 2. Bd.: 387 S., 7 Abb., (Eduard Weber) Bonn 1823. - 3. Bd.: 291 S., 6 Abb., (Eduard Weber) Bonn 1824. - 4 Bd.: 390 S., 2 Abb., (Eduard Weber) Bonn 1826

[darin Bd. III, S. 273 - 277: „Kurze Nachricht von einigen wenig bekannten Basalt-Gängen in Hessen (aus einem Briefe)"; Kontaktmetamorphose des Basaltes auf das Rahmengestein: Habichtswald, Ahnetal, Hirschberg; Schieferberg N’Meissner (heute: Heiligenberg S’ Weißenbach am Meißner)]

- $\square$ Nöggerath [Karl Jakob] (1825): Nachrichten über eine wenig bekannte Basaltgänge in Hessen. - Tb. Mineral., 19 (1): 263-264; Frankfurt/M. (Auszug aus: Nöggerath: Das Gebirge in Rheinland-Westfalen, Bd. III: 273-277; Bonn)

[darin: Umgebung Kassel, Heiligenberg S’ Weißenbach am Meißner]

-Oebbeke, K. (1889): Beiträge zur Kenntnis einiger hessischer Basalte. - Jb. Preuß. Geol. Landesanst., 9 (f. 1888): 390-416; Berlin Referat in: N. Jb. Mineral. etc, 1891 (Bd. II): 278-280 (K. Oebbeke); Stuttgart [Geochemie, Mineralogie Vorkommen Bl. Niederaula, Neukirchen] 
-Oehm, Josefa (1980): Untersuchungen zu Equilibrierungsbedingungen von Spinell-PeridotitEinschlüssen aus Basalten der Hessischen Senke. - Diss. Univ. Göttingen 1980; 78 S., graph. Darst.

- $\bullet$ Oehm J.; Schneider, A. \& Wedepohl, K. H. ( 1983): Upper mantle rocks from basalts of the northern Hessian depression (NW Germany). - TMPM - Tschermaks Mineralogische u.

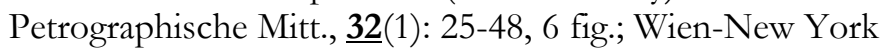
[Niedersachsen: Hoher Hagen; Hessische Senke, keine Vorkommen im WMK]

$\square$ Petersen, Theodor (1868): Ueber phosphorsauren Kalk. - Verh. K. k. geol. Reichsanstalt, 1868(14): 344-348; Wien [darin: Apatit im Dolerit des Meissners]

-Pickel, H.-J. (1969): Über ein Basalt- und Tuffvorkommen bei Burghasungen (Nordhessen). - Natur. u. Museum, 100(7): 333-338, Abb. 5; Frankfurt/M.

$\square$ Ramdohr, Paul (1920): Über die Basalte der Blauen Kuppe bei Eschwege und benachbarter Vorkommen und ihr Cristobalit (Vorläufige Mitteilung). - Zbl. Mineral., 1920: 33 - 36; Stuttgart [Blaue Kuppe b. Eschwege, Rosenbühl b. Niddawitzhausen, Alpstein b. Kirchhosbach]

$\square$ Ramdohr, Paul (1921): Über die Blaue Kuppe bei Eschwege und benachbarte Basaltvorkommen. - Jb. Preuß. Geol. Landesanst. , $\underline{40}$ (Teil I) (f. 1919): 284 - 355, 3 Abb., 1 Taf.; Berlin - zgl. Diss. Univ. Göttingen 1919

[Blaue Kuppe b. Eschwege, Rosenbühl b. Niddawitzhausen, Alpstein b. Kirchhosbach]

$\square$ Ramdohr, Paul (1921): Über die Blaue Kuppe bei Eschwege und benachbarte Basaltvorkommen. (Auszüge aus den Dissertationen der mathematisch-naturwissenschaftlichen Abteilung). - Jahrbuch Philosophischen Fakultät in Göttingen, 1921 (Erste Hälte: Januar-Juni) - II. Mathematisch-Naturwiss. Abteilung; S: 177-182; Göttingen [Blaue Kuppe, Alpstein b. Kirchhosbach, Rosenbühl b. Niddawitzhausen]

$\square$ Ramdohr, Paul (1922): Bericht über die Exkursion zur Blauen Kuppe bei Eschwege am 10.4.1921. Fortschr. Mineralogie, 1922: 36-37 (Teil Allgemeines); Jena

-Ramdohr, Paul (1953): Maldonit - Neue Beobachtungen am Bühl-Eisen. - Sitzber. Dt. Akad. Wiss. z. Berlin, Kl. Math. u. allgem. Naturwiss., 1952(5); 24 S., 8 Taf.; (Akademie-Verlag) Berlin

-Ramdohr, P. (1954): Klockmann’s Lehrbuch der Mineralogie. - 669 S., 687 Abb. u. Tab.; (Enke) Stuttgart

[Hinweis a. d. „Bühl bei Kassel“ als Fundort für tellurisches Eisen]

-Raspe, Rudolf Erich (1771): A letter ... containing a short account of some basalt hills in Hassia. Philosphical transactions of the Royal Society of London, 61(51-57): 580-583; London [Vorlage nicht eingesehen, zitiert nach Carozzi (1970)]

-Raspe, [Rudolf Erich] (1771): Nachricht von einigen niederhessischen Basalten, besonders aber einem Säulenbasaltstein Gebürge bei Felsberg und den Spuren eines verlöschten brennenden Berges am Habichtswalde über Weissenstein nahe bei Cassel. - Deutsche Schriften von der Königlichen Societät der Wissenschaften zu Göttingen, Bd. 1: 72-83; Tab. [ula] I; (Dieterich) Göttingen u. Gotha

-Raspe, Rudolf Erich (1774): Beytrag zur allerältesten und natürlichsten Historie von Hessen oder Beschreibung des Habichtswaldes und von verschiedner andern niederhessischen Vulcane in der Nachbarschaft von Cassel. - [5 Bl.] 76 S., 1 Falt-Taf.; (Cramer) Kassel [Regionale Geol. Kassel u. Umgebung; Habichtswald, Dörnberg, Kratzenberg, Frankenhausen, Katzenstein u. Hohlenstein zw. Harleshausen u. Dörnberg, Weidelsberg b. Wolfhagen, Schloßberg Felsberg, Schloßburg Aldenburg, Madenstein b. Gudensberg] 
-Raspe, Rudolf Erich (1776): An account of some German volcanos, and their productions. Wiith a new hypothesis of the prismatical basaltes. Established upon facts; being an essay of physical geography for philosophers and miners. Published as supplementary to Sir William Hamilton's observations on the Italian volcanos. - XIX, 140 p., 2 pl.; (Lockyer Davis) London [Regionale Geol. Kassel u. Umgebung; Habichtswald, Dörnberg, Kratzenberg, Frankenhausen, Katzenstein u. Hohlenstein zw. Harleshausen u. Dörnberg, Weidelsberg b. Wolfhagen, Schloßberg Felsberg, Schloßburg Aldenburg, Madenstein b. Gudensberg]

-Reuber, Otto (1904): Die Basalte südlich von Homberg a. d. Efze bis zum Knüllgebirge. - N. Jb. Mineral. etc., Beil.-Bd. 19: 503-555, 7 Abb., 3 Taf. (XXVII-XXIX); Stuttgart - zgl. Diss. Univ. Marburg 1904

-Rinne, Fritz (1889): Über Limburgit aus der Umgebung des Habichtswaldes. - Sitzber. Kgl. Preuß. Akad. Wiss. Berlin, 46: 1007-1026; Berlin

Referat in: N. Jb. Mineral. etc., $\underline{1890}$ (Bd. II): 245-246 (H. Traube); Stuttgart

- Rinne, Fritz (1890): Über Limburgit aus der Umgebung des Habichtswaldes. - N. Jb. Mineral. etc., $\underline{\mathbf{1 8 9 0}}$ (Teil II): 245 - 246 (Referat H. Traube); Stuttgart

- $\square \bullet$ Rinne, O. (1893): Über norddeutsche Basalte aus dem Gebiete der Weser und den angrenzenden Gebieten der Werra und Fulda - I. Untersuchungen im nördlichen, sowie einzelner Vorkommnisse im südlichen Teil des Gebietes. - Jb. Preuß. Geol. Landesanst., 13 (f. 1892): 1-95 (Abh. v. behördenfremden Personen), Taf. VI - IX; Berlin Referat in: N. Jb. Mineral. etc, $\underline{1894}$ (Bd. II): 56-59 (O. Mügge); Stuttgart [Vorkommen Lkr. Kassel, Lkr. Göttingen ; Habichtswald, Meißner, S. 16-18 Blaue Kuppe b. Eschwege u. Alpstein b. Kirchhosbach]

- $\square \bullet$ Rinne, O. (1898): Über norddeutsche Basalte aus dem Gebiete der Weser und den angrenzenden Gebieten der Werra und Fulda - II. Untersuchungen im südlichen Theile des Gebietes und Zusammenstellung von Beobachtungen im Gesamtgebiet. - Jb. Preuß. Geol. Landesanst., 18 (f. 1897): 3-102 (Abh. v. behördenfremden Personen), 29 Abb.; Berlin 1898

Referat in: N. Jb. Mineral. etc., 1898 (Bd. II): 433-435 (O. Mügge); Stuttgart [Lkr. Kassel, Schwalm-Eder-Kreis, Lkr. Göttingen, WMK; „Blaue Kuppe“ b. Eschwege m. Abb]

$\square$ Rose, H. \& Mügge, O. (1921): Einschlüsse kalkiger und kieseliger Gesteine im Basalt der Blauen Kuppe bei Eschwege. - Zbl. Mineral. etc., 1920: 97-102; Stuttgart

- Rosenbusch, Harry (1923): - Elemente der Gesteinslehre. Herausgeg. v. A. Osann. - 4., neu barb. Aufl.; 779 S., 115 Abb., zahlr. Tab.; (Schweizerbart) Stuttgart [darin: S. 429 Hyalitbasalt d. Sababurg, Säsebühl b. Dransfeld; S. 430 Chem. Analyse Plagioklasbasalt Bühl b. [Ahnatal] Weimar; S. 434 Chem. Analyse Basalt Bramburg b. Adelebsen; S. 600 Chem. Analyse Braunkohle Meißner]

-Rosenthal, L. (1921): Der Scharfenstein bei Gudensberg. - Hessischer Gebirgsbote, 29 (5/6): 28 - 29; Kassel [Basaltkuppe zw. Gudensberg und Dissen]

- $\square$ Rosenthal, L. (1921): Die „Feuerberge“ der Kasseler Gegend. - Hessischer Gebirgsbote, 29(11/12): 41 - 44; Kassel [darin: Hirschberg b. Großalmerode]

QRuhnke, A. (1986): Petrographische Charakterisierung von basischen Vulkaniten des Werra-Gebietes. Dipl.-Arb. [unveröff.] Univ. Greifswald

$\square$ Sandberger, F. (1873): Ueber Dolerit - 1. Die constituierenden Mineralien. - Sitzber. Kgl. Bayr. Akad. Wiss. München, Math.-phys. Kl., $\underline{\mathbf{3}}$ (1873): 140-154; München [darin: Ilmenit u. Apatit im Dolerit des Meißners] 
$\square$ Sandberger, F. (1874): Über Dolerit. - N. Jb. Mineral. etc., 1874: 88-93; Stuttgart [darin: Hoher Meißner]

OSartorius, B. G. (1804): Beschreibung einiger sehr interessanter Basaltstufen. - Magazin f.d. neuesten Zust. d. Naturkde. etc., $\underline{7}(2):$ 107-115, Taf. IV; Weimar

[Pflasterkaute, Kupfergrube]

OSartorius \& Görwitz (1802): Die Basalte in der Gegend von Eisenach. - 56 S.; (Wittekindt) Eisenach [darin: Stoffelskuppe, Pflasterkaute, Basaltvorkommen b. Stedtfeld]

$\square$ Sauer, Helmut (1950): Die Blaue Kuppe und ihre Pflanzenwelt. - Das Werraland, 1950 (April-Heft) [ = 1. Jg., H. 3]: 61-65, 3 Abb.; Eschwege [darin Erläuterungen zur Geologie der Blauen Kuppe]

$\square$ Schaub, J [ohannes] (1799): Nachrichten an Mineralogen und Geognosten besonders auch an die Besitzer meiner Beschreibung des Meissners. - Kaiserlich privilegirter Reichsanzeiger, 1799, Nr. 120 , Sp. 1397-1402;

[Argumente für die vulkanische Natur des (Meißner-) Basaltes im Neptunisten-Plutonisten-Streit]

$\square$ Schaumberg, Günther (1971): Die Aragonite der Blauen Kuppe bei Eschwege. - Der Aufschluss, 22 293-297, 6 Abb.; Heidelberg

$\square$ Schaumberg, Günther (1972): Die Aragonite der Blauen Kuppe. - Das Werraland, 24(3): 49-51, 4 Abb.; Eschwege

- $\square \bullet$ Scheffer, Reinhard (1973): Die derzeitigen Fundmöglichkeiten von Mineralien in den wichtigsten Basaltbrüchen von Nordhessen und Südniedersachsen.- Der Aufschluss, 24: 495-499; Göttingen

-Schlossmacher, K. (1911): Die Eruptivgesteine des Habichtswaldes und seiner Vorberge. - N. Jb. Mineral., Beil.-Bd. 31: 641 - 683, 1 Taf.; Stuttgart

- $\square$ Schneider, Alfred (1970): The sulfur isotope composition of basaltic rocks. - Contrib. Mineral. Petrol., 25: 95-124, 4 fig.l; Berlin-Heidelberg [darin: Bühl b. Weimar (Ahnetal b. Kassel); Hoher Meißner]

-Schnorrer, G.; Tetzer, G. \& Kronz, A. (2004): Der Basalt der Bramburg bei Adelebsen und seine Mineralparagenesen. - Der Aufschluss, 55: 337-368, 79 Abb., 2 Tab.; Heidelberg

$\square$ Schreyer, W.; Blümel, P. \& Maresch, W. (1986): Cordierit und Osumilith aus den Buchiten der Blauen Kuppe bei Eschwege. - Der Aufschluss, 37: 353-367, 12 Abb.; Heidelberg

-Schultz, Walter (1903): Beiträge zur Kenntnis der Basalte aus der Gegend von Homberg a. Efze. - N. Jb. Mineral. etc., Beil.-Bd. 16: 241-291, 3 Abb., Taf. IX-XII; Stuttgart

- $S$ chwandtke, Arthur (1907): Die neueren Untersuchungen der hessischen Basalte. - Ber. Versamml. Niederrhein. Geol. Vereins, 1907(2. Tl.) [1. Jg.]: 41-54; Bonn

Referat in: N. Jb. Mineral. etc., 1916 (Bd. I1): 54-59 (Arthur Schwandtke); Stuttgart [Forschungsstand, Bibliographie]

- SSchwandtke, Arthur (1921): Die Differenzierung der Hessischen Basalte und der Trachytdolerite. Sitzber. Ges. Beförderung d. ges. Naturwiss. z. Marburg, 4: 60-71; Marburg 1921 Referat in: N. Jb. Mineral. etc., 1924 (Bd. I): 57 (O. H. Erdmannsdörfer); Stuttgart [Vorlage nicht eingesehen, zitiert nach Angaben im genannten Referat]

- Schwarz, M. von (1937): Gefügeausbildung der terrestrischen Eiseneinschlüsse im Basalt vom Bühl bei Kassel. - Zbl. Mineral. etc., Abt. A, 1937: 74-91, 16 Abb.; Stuttgart 
- $\bullet$ Schwarzmann, Sigrid (1957): Über die Feldspat- und Feldspatgesteinsfremdlinge in den

Tertiärvulkaniten des Oberweser-Fulda-Gebietes. - Abh. Akad. Wiss. Göttingen, math-phys. Kl., 3. F., 25; 165 S., 6 Abb., 62 Tab., 4 Taf. (7 Abb.) Göttingen

[darin: Basalte d. Umgeb. v. Kassel; Lkr. Göttingen: Hoher Hagen/Dransfeld, Meensener Steinberg, Brunsberg]

-Seck, H. A. \& Wedepohl, K. H. (1983): Mantle xenoliths in the Rhenish Massif and the northern Hessian Depression. - In: K. Fuchs et al. (eds.): Plateau uplift in the Rhenish Massif - A Case History. - S. 343-351, 3 fig.; (Springer) Berlin-Heidelberg-New York 1983 [HE, Eifel]

- $\square$ Seck, Hans-Albert (1983): Eocene to recent volcanism within the Rhenish Massif and the northern Hessian Depression - summary. - In: Fuchs, K.; Gehlen, K. V.; Mälzer, H.; Murawski, H. \& Semmel, A. [eds.]: Plateau uplift: the Rhenish Shield - a case history. - p. 153 - 162, 1 fig., 5 tabl.; (Springer) Berlin - Heidelberg - New York 1983

- $\square$ OSenft, Ferdinand (1857): Classification und Beschreibung der Felsarten. - XXXII, 442 S., 12 Tab.; (Korn) Breslau

[darin: S. 273-277 („Eigentliche Basaltite, Lagerformen und Felsabsonderungen der basaltischen Gesteine") kurze Erwähnung Ahnatal b. Kassel, Blaue Kuppe b. Eschwege; detaililierter: Pflasterkaute b. Marksuhl, Stoffelskuppe b. Eisenach, Kupfergrube b. Hörschlitt/Eisenach; Chemische Analyse Dolerit vom Meissner, Steinsburg b. Suhl]

$\square$ Siuts, U. (1951) : Gesteinskundliche Lehrwanderung am 6. Juli 1951 nach der „Blauen Kuppe“ bei Eschwege und durch das „Höllental“ bei Albungen. 20 Blätter, zusammengeheftet [unveröff.], Hannoversch Münden [Standort: Bereichsbibl. Forstwissenschaften Uni. Göttingen Sign. Z 100/20]

OSoret (1825): Sur les Basaltes de Pflasterkaute. Extrait d'un lettre... - Nouveau bulletin des sciences/Soc. philomatique de Paris, $\underline{\mathbf{1 8 2 5}}$ (Août): 124-125; Paris

OSoret (1826): Basalte der Pflasterkaute bei Marksuhl. - Z. Mineral., 1826(5): 458-459; Frankf./M. Auszug aus: Bull. Soc. Phil., $\underline{\mathbf{1 8 2 5}}$ (Août): 124

[Flüssigkeitseinschlüsse in Drusenhohlräumen]

- Stelzner, Alfred (1883): Melilithführender Nephelinbasalt von Elbenberg in Hessen. - N. Jb. Mineral. etc., 1883(Bd. I): 205-207 (Briefl. Mitt.); Stuttgart

[Vorkommen SW' Kassel]

aStelzner, Alfred (1883): Über Melilith und Melilithbasalte. - N. Jb. Mineral. etc., Beil.-Bd. 22: 369 - 439; Stuttgart

[S. 432 Basalt des Habichtswaldes, Grebenstein b. Hofgeismar]

aStruve, [Heinrich] v. (1812): Über einen in der Gegend von Kassel aufgeführten Basaltgang. - Tb. Mineral., 6: 361-363; Frankf./M.

[“Teufelsmauer" am Hirzstein b. Kassel]

-Tadjerpsiheh, Nariman (1978): Petrographische Untersuchungen des Basaltgangs der Hünenburg über dem Auschnippetal und des Basalts vom Ossenberg bei Barterode nördlich Göttingens. - Dipl.-Arb. [unveröff.] Univ. Göttingen; 45 S., Abb., Tab.

-Tadjerpsiheh, Nariman (1978): Der Basaltgang der Hünenburg im Auschnippetal NW Göttingens. In: Koritnig, Sigmund [Schriftltg.]: Zur Mineralogie und Geologie der Umgebung von Göttingen mit Westharz und Teilen des Nordhessischen Berglandes. - Sdbd. 288: 177-181, 2 Abb., 2 Tab.; Heidelberg 1978 
-Techmer, Astrid (1989): Geochemische Untersuchungen an Xenolithen aus dem Habichtswald. Dipl.-Arb. [unveröff.] Univ. Göttingen 1989; 85 S.

-Velde, Luise (1920): Die silikatischen Einschlüsse im Basalt des Bühls bei Kassel. - In: Eitel, W.; Irmer, W. \& Velde, L.: Das Vorkommen tellurischen Eisens im Basalte des Bühls bei Kassel, seine Begleitmineralien und Genesis. - Abh. Senckenberg. Naturforsch. Ges., 37(2): 109-135, Taf. XII-XV (24 Abb.); Frankfurt a. M. 1920

-Vinx, R. \& Jung, D. (1977): Pargasitic-kaersutitic amphibole from a basanitic diatreme at the Rosenberg, North of Kassel (North Germany). - Contrib. Mineral. Petrology, 65: 135-142, 4 fig., 3 tabl.; Berlin-Heidelberg

-Voigt [Johann Carl Wilhelm] (1789): Beantwortung der Preisfrage. Was ist Basalt? Ist er vulkanisch oder ist er nicht vulkanisch? - Magazin für die Naturkunde Helvetiens, 4: 213-232 + [Anonym] Anhang zu den Preisfragen über den Basalt: 233-238; Zürich [darin: S. 221 Weißenstein/Habichtswald b. Kassel]

- $\square$ OVoigt, Joh. Carl Wilh. (1797): Practische Gebirgskunde. - 2., verm. Aufl.; XVI, 286 S. [1 Bl.]; (Industrie-Comptoir) Weimar [darin: S. 128 Rotliegend-Sandstein bei Eisenach; S. 159 Profilbeschr. Zechstein/Rotliegend Richelsdorfer Gebirge, S. 173, 174, 178,179,205 Meißner; S. 193 Vulcanische Brekkzie Weißenstein/Wilhelhmshöhe b. Kassel]

QVoigt, Johann Carl Wilhelm (1799): Von einigen Basalten im Eisenachischen < Abh. XVI des Bandes>. - In: Voigt, Johann Carl Wilhelm: Kleine mineralogische Schriften - Theil 1. - S. 181198; (bey den Gebrüdern Gaedicke) Weimar 1799

[Hütschhof, Stoffelskuppe, Pflasterkaue, Basaltgang in Hörschel]

doOVoigt, Johann Carl Wilhelm (1802): Mineralogische Reise nach den Braunkohlenbergwerken und Basalten Hessens, wie auch den Schieferkohlenwerken des Unterharzes. - VIII, 238 S.; Weimar [darin: Blaue Kuppe, Meißner, Hirschberg, Habichtswald]

[Erster Brief: Reise von Ilmenau über Gotha, Eisenach und Creutzburg nach der Blauen Kuppe bei Eschwege, in Hessen / Dritter Brief: Reise vom Meißner über Laudenbach, Aebteroda, die Ringkuhle, Wickenroda und Helse nach Cassel / - Fünfter Brief: Reise von Cassel über Helse, Witzenhausen, Heiligenstadt, Duderstadt bis Kloster Walkenried - Vorlage unvollständig: Titel des zweiten und vierten Briefes nicht ermittelbar]

-Waitz von Eschen, Friedrich Freiherr (1906): Die Basalte östlich der Linie Wabern - Gensungen. Diss. Univ. Marburg 1906, 35 S., 1 Falt-Bl.; Marburg Referat in: N. Jb. Mineral. etc., 1907 (Bd. II): 403 (R. Brauns); Stuttgart

$\square$ Walchner, F. A. (1839): Allgemeine Naturgeschichte für alle Stände, von Prof. Oken - Erster Band: Mineralogie und Geognosie. - XXIII, 860 S.; (Hoffmann'sche Verlagsbuchhdlg.) Stuttgart [darin: S. 807-808 Blaue Kuppe bei Eschwege, S. 819 Bühlchen bei Epterode]

$\square$ Walchner, Friedrich August (1846): Handbuch der Geognosie zum Gebrauche bei seinen Vorlesungen und zum Selbststudium, mit besonderer Berücksichtigung der mineralogischen Verhältnisse des Großherzogthums Baden. - 1120 S.; (Groos) Karlsruhe - 1. Auflage u. d. T.: Handbuch der gesammten Mineralogie in technischer Beziehung - zum Gebrauche bei seinen Vorlesungen und zum Selbststudium, mit besonderer Berücksichtigung der mineralogischen Verhältnisse des Großherzogthums Baden. - Teil 2: Geognosie - mit 11 Steintafeln. - 1104 S.; (Groos) Karlsruhe 1832 [Ausgabe v. 1846 - darin: S. 955 Blaue Kuppe bei Eschwege]

-Wedepohl, Karl Hans (1950): Der Feldspatbasalt des „Hohen Hagen“ bei Dransfeld. [W’ Göttingen] Heidelberger Beitr. Mineral. Petrogr., 2: 378-382, 2 Tab.; Berlin-Göttingen-Heidelberg 
-Wedepohl, Karl Hans (1954): Der trachydoleritische Basalt (Olivin-Andesin-Basalt) des Backenberges bei Güntersen, westl. Göttingen. - Heidelberger Beitr. Mineral. Petrogr., 4(1-2): 217-232, 1 Abb., 3 Tab.; Berlin-Göttingen-Heidelberg

- $\bullet$ Wedepohl, Karl Hans (1961): Geochemische und petrographische Untersuchungen an einigen jungen Eruptivgesteinen Nordwestdeutschlands. - Fortschr. Mineral., 39: 142-148, 2 Abb., 3 Tab.; Stuttgart [HE, NIE; Eifel]

- $\bullet$ Wedepohl, Karl Hans (1963): Die Nickel- und Chromgehalte von basaltischen Gesteinen und deren Olivin-führenden Einschlüssen. - N. Jb. Mineral., Mh., 1963: 237-242, 1 Abb.; Stuttgart [HE, NIE, Baunsberg]

- $\square \bullet$ Wedepohl, Karl Hans (1968): Die tertiären basaltischen Gesteine im nördlichen Hessen und südlichen Niedersachsen. - In: Koritnig, Sigmund [Zusstlg. u. red. Vorber.]: Zur Mineralogie und Geologie der Umgebung von Göttingen mit Westharz und Teilen des nordhessischen Berglandes Sonderheft zur Jahrestagung 1968 der VFMG in Göttingen. - Der Aufschluss, Sdh. 17; S. 112-120, 2 Tab., 1 Taf.; Heidelberg [darin: Hoher Meißner, Blaue Kuppe]

- $\square$ Wedepohl, Karl Hans (1978): Der tertiäre basaltische Vulkanismus der Hessischen Senke nördlich des Vogelsberges. - In: Koritnig, Sigmund [Schriftltg.]: Zur Mineralogie und Geologie der Umgebung von Göttingen - mit Westharz und Teilen des Nordhessischen Berglandes. - Sdbd. 288: 156-167; 4 Abb., 2 Tab.; Heidelberg 1978

[darin: Mikrosondenanalysen Basalte Hoher Meißner, Blaue Kuppe; auch radiometrische Alter der Basalte]

- $\square \bullet$ Wedepohl, Karl Hans (1982): K/Ar-Altersbestimmungen an basaltischen Vulkaniten der nördlichen Hessischen Senke und ihr Beitrag zur Diskussion der Magmengenese. - N. Jb. Mineral., Abh., 144: 172-196, 3 Abb., 2 Tab.; Stuttgart

- $\square \bullet$ Wedepohl, Karl Hans (1985): Origin of the Tertiary basaltic volcanism in the northern Hessian Depression. - Contrib. Mineral. Petrol., 89: 122-143, 4 fig., 7 tab.; Berlin-Heidelberg [HE, WMK, NIE]

- $\square \bullet$ Wedepohl, K. H. (1987): Kontinentaler Intraplatten-Vulkanismus am Beispiel der tertiären Basalte der Hessischen Senke. - Fortschr. Mineral., 65: 19-47, 10 Abb., 6 Tab.; Stuttgart [Übersichtsdarstellung; HE, WMK, NIE]

-Wedepohl, K. Hans (2000): The composition and formation of Miocene tholeiites in the Central European Cenozoic plume volcanism (CECV). - Contrib. Mineral. Petrol., 140: 180-189, 6 fig., 4 tabl.; Berlin-Heidelberg

[darin: Hessische Senke, ohne Bezug a. WMK]

- $\square \bullet$ Wedepohl, K. H. \& Hoefs, J. (1968): Strontium isotope studies on young volcanic rocks from Germany and Italy. - Contrib. Mineral. Petrol., 19: 328 - 338, 2 fig., 3 tabl.; Berlin-Heidelberg [HE, NIE, WMK; Habichtswald, Meißner]

- $\bullet$ Wedepohl, K. H. \& Muramatsu, Y. (1979): Chlorine in Tertiary basalts from the Hessian Depression in NW Germany. - Contrib. Mineral. Petrol., 무: 357 - 366, 4fig., 3 tabl.; Berlin-Heidelberg [HE, NIE; Hirzstein]

- $\square \bullet$ Wedepohl, Karl Hans \& Ritzkowski, S. (1980): [DMG-Tagung 1980] Exkursion E 1: Die nördliche Hessische Senke (Tertiär-Vulkanite, Kupferschiefer und variszischer Spilit). - Fortschr. Mineral., 58, Beih. 2 (Einführung zu den Exkursionen anläßlich der 58. Jahrestagung der Deutschen Mineralogischen Gesellschaft in Göttingen 1980): 3-33, 2 Abb., 3 Tab.; Stuttgart [darin Hp: Werra-Meissner-Kreis: Blaue Kuppe, Bilstein, Cornberg, Steinbruch Forsthaus Schmelzhütte, Hoher Meißner/Kalbe, Hoher Meissner/Kitzkammer; auch Hoher Hagen/Dransfeld, 
Westberg/Hofgeismar, Dörnberg/Zierenberg; Güntersberg b. Gudensberg, Isthaburg b. Istha, Steppling b. Homberg/Efze]

- •Wedepohl, K. H.; Mengel, K. \& Ritzkowski, S. (1983): The Tertiary basalts of the northern Hessian Depression and their mantle xenoliths. - DMG SFMC Joint Meeting 1983 - Excursion E 4. Fortschr. Mineral. 61, Beih. 2: 117 - 134, 2 fig., 3 tab.; Stuttgart

[HE, NIE; Habichtswald]

-Wedepohl, K. H.; Mengel, K.; Kramm, U. \& Gohn, E. (1984): Sr-isotopes in peridotite xenoliths and their basaltic host rocks from the northern Hessian Depression (NW Germany). - Contrib. Mineral. Petrol., 87: 369 - 375, 2 fig., 4 tabl.; Berlin-Heidelberg [HE, Hirzstein]

-Wedepohl, K. H.; Mengel, K. \& Oehm, J. (1984): Depleted mantle rocks and metasomatically altered peridotite inclusions in Tertiary basalts from the Hessian Depression (NW Germany). - In:

Kornprobst J. (ed.): Kimberlites II: The Mantle and Crust-Mantle Relationships. - Developments in Petrology 11 B (Proceedings of the "Third International Kimberlite Conference, Vol. II. - S. 191 201, 3 Fig., 2 Tabl.; (Elsevier) Amsterdam [darin: Habichtswald]

- •Wedepohl, K. H.; Harmon, R.S. \& Hoefs, J. (1987): Stable isotope (O, H, S) relationships in Tertiary basalts and their mantle xenoliths from the Northern Hessian Depression, W.-Germany. Contrib. Mineral. Petrol., 95: 350-369, 8 fig., 6 tabl.; Berlin-Heidelberg

[HE, NIE; Habichtswald]

-Wedepohl, Karl Hans \& Kramm, Ulrich (1990): Tertiary basalts and peridotite xenoliths form the Hessian Depression (NW Germany) reflecting mantle compositions low in radiogenic Nd and Sr. Contrib. Mineral. Petrol., 106: 1-8, 2 fig., 1 tabl.; Berlin-Heidelberg [HE, Hirzstein]

-Wedepohl, Karl Hans \& Baumann, Albrecht (1999): Central European Cenozoic plume volcanism with OlB characteristics and indications of a lower mantle source. -Contrib. Mineral. Petrol, 136: 225239, 6 fig., 4 tabl.; Berlin-Heidelberg

[HE, Habichtswald]

$\square$ Werner, A. G. (1789): Anmerkung zu Herrn Fausts Nachricht von dem auf dem Meißner in Hessen über Steinkohlen und bituminösen Holz liegenden Basalt. - Bergmännisches Journal, 22(1): 261-295; Freyberg

-Wiegel, Heinrich (1907): Petrographische Untersuchungen der Basalte des Schwälmerlandes bis an den Vogelsberg. - N. Jb. Mineral. etc., Beil.-Bd. 23: 345-405, 2 Abb., Taf. XI, XII; Stuttgart [darin: Umgebung Borken]

-Wildemann, Joh. Friedr. Wilhelm (1789): Beantwortung der Frage. Was ist Basalt? Ist er vulkanisch oder nicht vulkanisch? - Magagzin für die Naturkunde Helvetiens, 4: 135-212 + [Anonym] Anhang zu den Preisfragen über den Basalt: 233-238; Zürich

[darin: S. 191 Habichtswald/Kassel]

-Wunderlich, Hans Georg (1968): Der Hohe Hagen - ein Basaltschlot im südniedersächsischen Bruchschollengebirge. - In: Koritnig, Sigmund [Zusstlg. u. red. Vorber.]: Zur Mineralogie und Geologie der Umgebung von Göttingen mit Westharz und Teilen des nordhessischen Berglandes Sonderheft zur Jahrestagung 1968 der VFMG in Göttingen. - Der Aufschluss, Sdh. 17; S. 121-128, 3 Abb.; Göttingen 1968

$\square$ Zeuschner, Ludwig [= Zejsznera, Ludwika] (1829): Opuwstaniu i waylednym wieku formacy bazalttowje. - Warszawa 
[Bezugn. a. „Blaue Kuppe“ b. Eschwege, zitiert nach Beck (1956): Die Blaue Kuppe in der Wissenschaftsgeschichte]

- $\square$ OZirkel, Ferdinand (1866): Lehrbuch der Petrographie. - [In zwei Bänden]. - Zweiter Band; 635 S:; (Adolph Marcus) Bonn.

[darin S. 273-321: Gesteine der Basalt-Familie. - Bezugn. a. Basalte i. Hessen, WMK, Thüringen; Chemischer Analysen Meißner-Basalt, Pflasterkaute; Kontaktmetamorphose Basalt/Buntsandstein: Blaue Kuppe, Alpstein b. Sontra, Rosenbühl b. Eschwege-Niddawitzhausen; Pflasterkaute, Stoffelskuppe, Kupfergrube b. Hörschlitt; Intrusivverband m. Kalkstein: Ahnetal/Habichtswald, Basaltgang bei Hörschel(Thür.)]

- $\square$ OZirkel, Ferdinand (1870): Untersuchungen über die mikroskopische Zusammensetzung und Structur der Basaltgesteine. - 208 S.; 3 Taf. m. 79 Fig.; (Adolph Marcus) Bonn [darin: Basalte i. Hessen, Blaue Kuppe, Pflasterkaute b. Marksuhl, Stoffelskuppe]

- $\square$ Zirkel, Ferdinand (1873): Die mikroskopische Beschaffenheit der Mineralien und Gesteine. Mit 205 Holzschnitten. - 502 S.; (Wilhelm Engelmann) Leipzig

[darin Kap. Feldspatbasalt, Anamesit, Dolerit: Nennung von Lokalitäten in Hessen, WMK, Lkr. Göttingen: Stillberg i. Habichtswald, Meissner, Dransberg u. Säsebühl b. Dransfeld]

- $\bullet$ Zirkel, Ferdinand (1894): Lehrbuch der Petrographie. - [In drei Bänden]. - Zweite, gänzl. neu verfass. Aufl. - Zweiter Band; 941 S.; (Wilhelm Engelmann) Leipzig [darin S. 872-941: „Dolerit, Anamesit, Feldspathbasalt“ - Bezugnahme a. Basalte in Hessen, WMK, Niedersachsen; Chemische Analyse Grobkörniger Dolerit Meißner; Lagerungsformen Meißner-Basalt]

\subsubsection{Extraterrestrisches Material > Meteorite}

OBuchner, Otto (1863): Die Meteoriten in Sammlungen, ihre Geschichte, mineralogische und chemische Beschaffenheit. - XXVI, 202 S.; (Engelmann) Leipzig [darin: S. 189: Eisen-Meteoritenfall von Tabarz am 18. Oktober 1854]

Q Chladni, Ernst Florens Friedr. (1819): Ueber Feuer-Meteore, und über die mit denselben herabgefallenen Massen. - XXIV, 434 S., 10 Taf.; (Heubner) Wien [darin: S. 213-214 Meteoritenfall Schleusingen, S. 217-218 Nörten-Hardenberg]

ODe Serres, Marcel (1813): Observations - Sur la chute des Pierres, ou sur les Aerolithes. - Ann. d. Chimie, 85: 262-308; Paris

[darin S. 278 : Meteoritenfall von Schleusingen « en Bavière et aux portes de Munich » - Schleusingen verwechselt mit Münchener Ortsteil Schleißheim !)

EEberhardt, W[ilhelm](1855): Analyse eines Meteoreisens aus Thüringen. - Annalen d. Chemie u. Pharmacie, 96(3) [=N.F. 20(3)]: 286-289; Leipzig u. Heidelberg - Auszug aus: „Analysen einer Thüringer Mineralien“, Diss. Univ. Göttingen 1855; 32 S.; (Huth) Göttingen [Meteorit Tabarz]

OEberhardt, Wilhelm (1855): Analysen einiger Thüringer Mineralien [ u.a. Meteoreisen Tabarz]. - Diss. Univ. Göttingen 1855; 32 S.; (Huth) Göttingen

oHey, Max H. (1966): Catalogue of meteorites. With special reference to those represented in the collection of the British Museum (Natural History). - 3., revised a. enlarged ed.; 637 p.; London [darin S. 469: Meteorit von Tabarz] 
OKlein, C. (1879): Die Meteoritensammlung der Universität Göttingen am 2. Januar 1879. - Nachr. Kgl. Ges. Wiss. z. Göttingen, 1879(2): 84-100, 2 Tab.; Göttingen

Referat in: N. Jb. Mineral. etc., 1879: 408 [Autorreferat]; Stuttgart

[darin: Meteorit von Tabarz]

QLuedecke, P. (1900): Ueber Thüringer Meteoriten - Z. f. Naturwiss., $\underline{73}$ (3/4): 288-298; Leipzig

Referat in: Mitt. Geogr. Ges. (f. Thüringen), 19: 66 (E. Schütze); Jena 1900/1901

[darin: Meteorit v. Tabarz]

OPrior, George Th. \& Hey, Max H. (1953): Catalogue of meteorites. With special reference to those represented in the collection of the British Museum (Natural History). - 2., revised a. enlarged ed.; 432 p.; London

[darin S. 363-364: Meteorit von Tabarz]

OWappler, Gert \& Hoppe, Günter (1969): Katalog der Meteoriten aus dem Museum für Naturkunde an der Humboldt-Universität zu Berlin, Mineralogisches Museum. - Ber. Dt. Ges. f. geol. Wiss., Reihe B, 14(4): 359-381, 2 Tab.; Berlin

[darin S. 361-362, Tab. 1: Meteorit v. Tabarz (nicht in der Sammlung des Museums); S. 362, Tab. 2: Meteoritenfall v. Schleusingen]

OW[öhler] (1864): Die Meteoriten in der Universitäts-Sammlung zu Göttingen am 1. Januar 1864. Nachr. Kgl. Ges. Wiss. u. d. Georg-Augusts-Univ. z. Göttingen, 1864(Januar): 30-33; Göttingen [darin: Meteorit von Tabarz]

OWülfing, E. A. (1897): Die Meteoriten in Sammlungen und ihre Literatur - Nebst einem Versuch den Tauschwert der Meteoriten zu bestimmen. - XLVI, 460 S.; (Laupp) Tübingen [darin: Meteorit von Tabarz - Werk umfaßt eine alphabetische Auflistung von Meteoritenfundstücken der Welt mit erschienener Literatur und Verbleib der Bruchstücke (mit Gewichtsangaben)]

\subsection{Geochemie}

-Abo-Rady, Mustafa D. K. (1980): Schwermetalle in den Sedimenten der oberen Leine. - Dt. Gewässerkdl. Mitt.; 24(3): 93-100, 4 Abb., 10 Tab.; [Mineralogie, Geochemie; Stadtgebiet Göttingen]

@Anonym (1905): Kalisalze der Thüringer Gewerkschaft Großherzog von Sachsen. - Z. prakt. Geologie, 13: 191-192; Berlin

[Geochemie]

-Anonym (1980): Natürliche Schwermetallgehalte in hessischen Ackerböden. - Hessischer Gebirgsbote, 81(4): 124; Melsungen

$\square$ Bischof, Gustav (1863/1864/1866/1871): Lehrbuch der chemischen und physikalischen Geologie. - 2., neu bearb. Aufl.; 3 Bd. + Suppl. Bd. - Bd. 1: X, 865 S., 1 Faltkt., 1863; Bd. 2: 952 S., 1864; Bd. 3: XVI, 974 S., 1866; Suppl.-Bd. VIII, 214 S., 1871; (Adolph Marcus) Bonn

[Bischof setzt sich kritisch mit der Entstehung des Meißner-Basaltes auseinander und kommt - als vielleicht letzter Vertreter der neptunistischen Sichtweise zu der Ansicht, daß der Basalt nicht vulkanischen Ursprungs ist - Bd. 3: S. 178, 180, 377]

-Blanck, E. \& Zappf, L. (1926): Über Tiefenverwitterungserscheinungen im mittleren Buntsandsteine des Reinhardswaldes. - Chemie der Erde, 22: 446-480, 1 Abb., mehr. Tab.; Jena

Referat in: N. Jb. Mineral. etc., Referate, 1928 (Bd. II): 410 (Harrassowitz) 
-Blanck, E. [Verfass.]; Dörfeldt, W. \& Laves, F. [Mitwirkung] (1932): Verwitterungs- und Umwandlungserscheinungen an südhannvoerschen Basaltvorkommen. - Chemie der Erde, 7(4): 540552, 11 Tab.; Jena

Referat in: N. Jb. Mineral. etc., Referate, 1935 (Bd. II): 80-82 (Calsow); Stuttgart [Grefenburg, Bramburg]

$\square$ Blanck, E. \& Themlitz, R. (1938): Der rote See bei Witzenhausen, zugleich ein weiterer Beitrag zur rezenten und fossilen Verwitterung des Feldspatbasaltes. - Chemie der Erde, 11(3): 375 - 407, 3 Abb., zahlr. Tab.; Jena

[Geochemie]

-Böttcher, Gerd (1988): Der Stofftransport der Leine und ihrer Nebenflüsse in suspendierter Form zwischen der Grenze zur DDR und Northeim. - Dipl.-Arb. [unveröff.] Univ. Göttingen 1988; 75 S.

- 0 Born, Hans-Joachim (1936): Geochemische Zusammenhänge zw. Helium-, Blei- und Radiumvorkommen in deutschen Salzlagerstätten. - Kali, etc., 30(5): 41-45, 4 Tab.; Halle (Saale) Referat in: N. Jb. Mineral.etc., Referate; 1936 (Bd. II): 577-579, 3 Tab. (J. Leonhardt); Stuttgart

OBräuer, H. (1967): Geochemische Gliederung granitischer Gesteine des Thüringer Waldes und Erzgebirges und ihre lagerstättengentische Bedeutung. - (Die Unterscheidung und Genese varistischer und postvaristischer magmatogener Lagerstätten Mitteleuropas) Freiberger Forschungshefte, Reihe C, 209: 153-168, 4 Abb., 7 Tab.; Leipzig

[darin: Ruhler Kristallin (Ruhla, Brotterode); Suhler Granit]

QBräuer, Heinrich (1970): Spurenelementgehalte in granitischen Gesteinen des Thüringer Waldes und des Erzgebirges. - Übergeordneter Titel: Geochemie granitoider Gesteine im Erzgebirge und Thüringer Wald. - Freiberger Forschungshefte, Reihe C, 259: 83-139, 32 Abb., 31 Tab.; Leipzig

OD'Ans, J. \& Kühn, R. (1940): Über den Bromgehalt von Salzgesteinen der Kalisalzlagerstätten. - Kali, etc.,

$\underline{34}(4): 42-46$ (Teil I)

34(5): 59-64 (Teil II/III)

34(6): 77-83 (Teil IV/V), 6 Fig., 17 Tab.; Halle/Saale

[darin: Volkenroda, Thüringisches Werra-Kalirevier]

ODaut, G.; Henkel, K.; Ig1. M.; Mäusbächer, R. \& Schneider, H. (2002): Untersuchungen an Subrosionssenken des mittleren Werratales (Vortrag und Poster). - In: (Sediment 2002) Schriftenrh. Dt. Geol. Ges., 17: 48-49; Hannover

[Hptsächl. Gebiet zw. Immelborn und Schwallungen (Krs. Schmalkalden; Geomorphologie, Geochemie, Pollenanalyse]

-Diedel, R. (1984): Mikrosondenuntersuchungen an Sulfiden des Kupferschiefers der Gebiete Spessart, Rhön und Richelsdorf. - Dipl.-Arb. [unveröff.] TU Aachen

QDittrich, Erhard (1962): Zur Gliederung der Werra-Serie (Zechstein 1) im Werra-Kaligebiet. - Ber. Ges. geol. Wiss. DDR, $\underline{\mathbf{6}}$ (f. 1961)(2/3): 297-301, 3 Abb.; Berlin

[Stratigraphie, Geochemie]

QDöhner, Ch. (1976): Die Bromverteilung im Übergangsbereich Staßfurtflöz/Grauer Salzton des Südharz-Kalireviers. - Ein Beitrag zur Anwendung der Brommethode. - Z. angew. Geol., 22 (5): 201209, 3 Abb., 2 Tab.; Berlin

[Region Bischofferode, Volkenroda und Pöthen]

OEberhardt, W[ilhelm](1855): Analyse eines Meteoreisens aus Thüringen. - Annalen d. Chemie u. Pharmacie, 96(3)[=N.F. 20(3)]: 286-289; Leipzig u. Heidelberg - Auszug aus: „Analysen einer Thüringer Mineralien“, Diss. Univ. Göttingen 1855; 32 S.; (Huth) Göttingen 
OEberhardt, Wilhelm (1855): Analysen einiger Thüringer Mineralien. - Diss. Univ. Göttingen 1855; 32 S.; (Huth) Göttingen

$\square$ Ebhardt, H.; King, M.-T. \& Meyer, B. (1969): Mineralogisch-chemische Untersuchungen zum Prozeß der Rubefizierung in Kalkstein-Rotlehm und fossilem Laterit in Nordhessen. - Göttinger Bodenkdl. Ber., 9: 65-124, 6 Abb., 7 Tab.; Göttingen [Kammerbach b. Bad Sooden-Allendorf, Bl. 4725 Bad Sooden-Allendorf]

QErfurth, Alrun (1964): Geochemische Untersuchungen von Hartsalzen, die bei normaler Metamorphose oder am Salzhang entstanden sind. - Dipl.-Arb. [unveröff.] Bergakademie Freiberg/Sa. 1964

Referat in: Geologie, 15(2): 234-235; Berlin 1966

[Thür. Werra-Kalireviert, Schächte Alexandershall, Abterode]

QFandrich, Klaus (1962): Spurenmetalluntersuchungen im Unteren Kalilager der Grube Menzengraben (Werragebiet) und Betrachtungen zur Genese der dortigen Kalisalze $<$ Geochemie $>$. - Ber. geol. Ges. DDR, $\underline{\mathbf{6}}$ (f. 1961)(1): 125-151, 7 Abb., 3 Tab., 5 Taf.; Berlin

$\square$ Führes, Margit (1979): Untersuchungen zur Mineralführung und Geochemie an einem Bohrprofil im Braunkohlengebiet des Hohen Meißners. - Dipl.-Arb. [unveröff.] Univ. Gießen

-Giesecke, Bruno Th. (1858): Analysen des Bohnerzes von Mardorf und des daraus gewonnenen Roheisens. - Diss. phil. Univ. Göttingen 1858, 30 S.; (Giesecke \& Devrient) Leipzig [Geochemie]

QGobeau, Josef \& Birckenbach, Josef (1938): Untersuchung des Edelmetallgehaltes von Kalisalzlagerstätten. - Z. anorg. u. allgem. Chemie, 236: 37-44, 4 Tab.; Leipzig

Referat in: N. Jb. Mineral. etc., Referate, 1939 (Bd. I): 512 (Hans Himmel), 1942 (Bd. II): 100-102, 2 Tab. (J. Leonhardt); Stuttgart [Westthüringen, Thür. Werra-Kaligebiet]

-Goldberg, Gottfried; Lepper, Jochen; Röhling, Heinz-Gerd (1995): Geogene Arsengehalte in Gesteinen und Grundwässern des Buntsandsteins in Südniedersachsen. - Z. angew. Geol., 411(2): 118124, 5 Abb., 2 Tab.; Berlin [darin: Hardegsen]

$\square$ Graeger, N. (1839): Analysen einiger Basalte aus Kurhessen. - Archiv d. Pharmacie, (2. Rh.) 19 (1) (69, Ges. Rh.): 96-99; Hannover

[Meißner, Alpstein b. Sontra, „Rosenbühl“ b. Niddawitzhausen W’ Eschwege]

$\square$ Graeger (1847): Chemische Untersuchungen einiger Braunkohlen. - Ber. Vereins Naturkde. z. Kassel, 11: 15 -24; Kassel

[Meißner, Großalmerode-Hirschberg, Großalmerode-Faulbach];

- •Gramse, Malte (1970): Quantitative Untersuchungen mit der Elektronensonde an Pyroxenen aus Basalten und Peridotiteinschlüsssen. - Contrib. Mineral. Petrol., 299(1): 43-73, 25 Abb., 14 Tab.; Berlin-Heidelberg

- •Gramse, Malte (1971): Der Chemismus basaltischer Gläser - Untersuchungen mit der Elektronenmikrosonde. - Fortschr. Mineral., 49, Beih. 1: 97-98; Stuttgart [Nordhessen, Südniedersachsen, ohne konkrete Lokalitätsangaben]

OGreulich, Christa (1958): Über das Verhalten der Spurenelemente der Werra-Serie in der Schachtanlage „Marx-Engels“ Unterbreizbach/Rhön. - Dipl.-Arb. [unveröff.] Bergakademie Freiberg/Sa. 1958 Referat in: Geologie, $\underline{8}$ (8): 910; Berlin 1959 
$\square$ Gross, Volker (1973): Petroraphisch-geochemische Untersuchungen der Differentiation und Kontaktwirkung des Basaltes vom Hohen Meissner bei Eschwege. - Diss. Univ. Göttingen 1973; XIX, $85 \mathrm{~S}$.

-Großkurth, Gerhard Friedrich (1990): Einfluss der Halden des ehemaligen Kupferschiefer- und Schwerspat-Berbaues im Richelsdorfer Gebirge (Hessen) auf die Schwermetallführung des Gewässersystems. Geologische und geochemische Kartierung. - Dipl.- Arbeit [unveröff.] Univ. Göttingen; 160 S., 25 Abb., 53 Tab., 8 Anl.

OHaase, Karl Erich (1915): Die Gauverwandschaft der Ergußgesteine im Rotliegenden des nordwestlichen Thüringer Waldes. - Chemie der Erde 1: 171-218, 8 Abb., 1 Tab.; zgl. Diss. Univ. Jena 1915; Jena

Referat in: N. Jb. Mineral. etc., 1918: 45-47 (R. Nacken), 1921 (Bd. I): 38-44 (Georg Kalb); Stuttgart

$\square$ Hagedorn, B. (1987): Geochemie und Petrographie der Diabase des Albunger Paläozoikums. - Dipl.Arb. [unveröff.] TU Braunschweig, $157 \mathrm{~S}$.

OHansch, Ralf \& Zeh, Armin (2000): Metabasites from the Ruhlaer Crystalline Complex: Evidence für distinct Variscan plate tectonic environments within the Mid-German Crystalline Rise / Metabasite des Ruhlaer Kristallins: Hinweise auf unterschiedliche prävariszische plattentektonische Bildungsräume in der Mitteldeutschen Kristallinzone. - Chemie der Erde, $\underline{\mathbf{6 0}}(1): 1-25,9$ fig., 4 tabl.; Jena

-Hausmann, J.F.L. (1857): Klebschiefer im Basalt des Meenser Steinberges. - N. Jb. Mineral. etc., 1857: 834 [Auszüge]; Stuttgart [chem. Analyse]

-Heinrichs, Hartmut (1972): Mineralbestand und Chemismus der Alkali-Olivinbasalte aus der Umgebung von Homberg a. d. Efze (Hessen). - Notizbl. Hess. L.-A. Bodenforsch., 100: 164 - 176, 3 Abb., 4 Tab.; Wiesbaden

-Heppenheimer, Hermann (1995): Vergleichende geochemische und petrologische Untersuchungen am Kupferschiefer: ein Beitrag zur Klärung der Metallogenese. - Diss. Aachen 1995, 240 S., graph. Darst. Ill. [darin: Hessische Senke (Richelsdorfer Gebirge)]

QHerrmann, Albert Günter (1961): Über die Einwirkung Cu-, Sn-, Pb- und Mn-haltiger Erdölwässer auf die Staßfurt-Serie des Südharzbezirkes. - N. Jb. Mineral., Mh., 1961: 60-67, 1 Tab.; Stuttgart [Thüringen: Bischofferode, Sollstedt, Craya, Bhgn. Langensalza u. Kirchheiligen II]

口•Hermann, Albert Günter (1961): Über das Vorkommen einiger Spurenelemente in Salzlösungen aus dem deutschen Zechstein. - Kali u. Steinsalz, $\underline{\mathbf{3}}$ (7): 209-220, 2 Abb., 1 Zahlentaf.; Essen [Königshall-Hindenburg/Reyershausen; Südharz-Kalirevier, Volkenroda, Bhgn. Langensalza, Kirchheilingen]

Q•Herrmann, Albert Günter \& Hoffmann, Rainer Otto (1961): Zur Genese einiger Borate in den Salzablagerungen der Staßfurt-Serie des Südharzbezirkes einschließlich der Grube KönigshallHindenburg. - N. Jb. Mineral., Mh., 1961: 52-60, 1 Tab.; Stuttgart [Thüringen: Bischofferode, Sollstedt-Craya, Bhgn. Langensalza u. Kirchheiligen II]

OHerrmann, A. G.; Siewers, U.; Harazim, B. \& Usdowski, E. (2003): Kriterien zur Beurteilung von Salzlösungen in den Zechsteinevaporiten Mittel- und Norddeutschlands. - Kali u. Steinsalz, 2003(3): 24-35, 7 Tab.; Essen [Geochemie - darin: Merkers]

-Herrmann, A. G. (1987): Geochemische Aspekte der Zechsteinevaporite in Deutschland [Vortragskurzfassung]. - In: Klare, Bernd \& Schröder, Bernd [eds.]: Zechstein 1987 - International 
Symposium Kassel/Hannover - 28. April to 9. May, 1987 - Abstracts, Posters, Program; S. 40-41; [Subkommission Perm/Trias der Stratigraphischen Kommission der DUGW/IUGS] Bochum 1987

- Heykes, Klaas (1930): Chemisch-petrographische Studien an Basalten Niederhessens und der Rhön. Sitzber. Preuß. Geol. Landesanst., $\underline{\mathbf{5}}$ : 75 - 85, 7 Abb.; Berlin

Referat in: N. Jb. Mineral. etc., Referate; 1932 (Bd. II): 345-346 (Chudoba); Stuttgart

- $\square$ Hofmann, Richard \& Schürenberg, Horst (1979): Geochemische Untersuchungen gangförmiger Barytvorkommen in Deutschland. - Übergeordneter Titel: Zur Minerogenie des hydrothermalen Baryts in Deutschland. - Monograph Series on Mineral Deposits, 17; S. 1-80, 39 Abb.; (Bornträger) Berlin-Stuttgart [Kap. 6.3.1 Unterwerra-Grauwackengebirge, Richelsdorfer Gebirge]

OJohn, Karl-Heinz (1970): Erarbeitung und Anwendung von Methoden zur Klärung einiger Probleme des Vulkanismus an ausgewählten Objekten im Bereich der Tambacher Mulde (Thüringer Wald). Diss. math.-nat. Humboldt-Univ. Berlin; 98 S., Anl.-Bd . 87 Abb.; Berlin [Mineralogie, Geochemie Rotliegend-Vulkanite]

$\square$ Jordan, Johann Ludwig (1800): Mineralogische und chemische Beobachtungen und Erfahrungen. XXXVIII, 326 S., [1] Bl. Ill.; (Johann Christian Dieterich) Göttingen [darin S. 292-303, Kap. XIV: Aeußere Beschreibung und Zerlegung eines Kieselsinters aus dem Kohlenwerke des Meißners unweit Almerode $<$ Petrographie, Geochemie $>$ ]

-Jowett, E. C. (1987): Metal ratios in the Kupferschiefer as indicators of paleo-flow directions, Richelsdorf Hills, W. Germany [Posterbeitrag]. - In: Klare, Bernd \& Schröder, Bernd [eds.]: Zechstein 1987 - International Symposium Kassel/Hannover [28. April to 9. May, 1987] - Abstracts, Posters, Program; S. 125; [Subkommission Perm/Trias der Stratigraphischen Kommission der DUGW/IUGS] Bochum 1987

-Jowett, E. Graig (1991): Paleo-flow dircetions of basinal fluids determined from metal ratios, Richelsdorf Hills, F.R.G. - Zentralbl. Geol. Paläont. - Teil 1, 1991(4): 1017 - 1027, 10 fig., 1 tabl.; (Schweizerbart) Stuttgart

-Jung, H. (1918): Die chemischen und provinzialen Verhältnisse der jungen Eruptivgesteine Deutschlands und Nord-Böhmens. - Chemie der Erde, $\underline{\mathbf{3}}: 137$ - 340; Jena [darin: S. 245 - 257: Gesteine des Hessischen Berglandes, u. a. Blaue Kuppe]

OKaemmel, Th. (1972): Die praestefanische Verwitterungsrinde im Thüringer Wald im Rahmen der permosilesischen Verwitterungserscheinungen. - Jb. Geol., 4 (f. 1968): 81-96, 5 Abb., 2 Tab.; Berlin [Geochemie]

QKästner, Hans; Kühn, Wolfgang \& Langbein, Rolf (1966): Stratigraphische, petrographische und geochemische Untersuchungen im Unteren und Mittleren Buntsandstein des thüringischen WerraKaligebietes. - Geologie, 15(4/5): 461-483, 8 Abb., 1 Tab.; Berlin

QKieser, W. (1969): Geochemische Untersuchungen an Gesteinen und darauf entwickelten Böden des Raumes Thüringen. - Chemie der Erde, $\underline{\mathbf{2 8}}(3 / 4): 211-293,23$ Abb., 39 Tab.; Jena [darin: Westthüringen, Thüringer Wald]

-Klauer (1855): Krystalliner Speiskobalt von Riechelsdorf in Churhessen. - N. Jb. Mineral. etc., 1855: 71 [Auszüge]; Stuttgart [chem. Analyse]

-Knipping, B. (1986): 34S/32S Ratios of native sulphur in Zechstein 1 evaporites. Naturwissenschaften, 73: 614; Berlin-Heidelberg [Werra-Kali-Revier, Werk Hattorf/Philippsthal] 
-Knipping, Bernhard (1987): Basaltintrusionen in Zechstein 1 - Evaporiten (Werra-Lagerstättenbezirk). - Diss. Univ. Göttingen 1987; 202 S.

[Geochemie]

- Knipping, Bernhard (1991): Basaltische Gesteine in Zechsteinevaporiten. - Zentralbl. Geol. Paläont. Teil 1: 1991(4): S. 1149 - 1163, 7 Abb., 2 Tab.; (Schweizerbart) Stuttgart

[Modell Temperaturentwicklung; Isotopengeochemische Veränderungen in Zechstein 1 - Evaporiten des Werra-Fulda-Lagerstättenbezirkes, Kaliwerk Hattorf]

OKnipping, Bernhard \& Herrmann, Albert Günter (1985): Mineralreaktion und Stofftranspoert an einem Kontakt Basalt-Carnallitit im Kalisalzhorizont Thüringen der Werra-Serie des Zechsteins. Kali u. Steinsalz, 9(4): 111 - 124, 6 Abb., 6 Tab; Essen

- $\square \bullet$ Koritnig, S. (1951): Ein Beitrag zur Geochemie des Fluors. - Geochimica et cosmochimica acta, 1: 89-116, 1 Abb., 4 Tab.; London - zgl. Habil.-Schrift Univ. Göttingen 1951

[Fluor i. Vulkaniten u. Sedimenten]

-Krusch, P. (1919): Die Verteilung der Metallgehalte (Kupfer, Silber, Molybdän und Vanadin) im Richelsdorfer Gebirge. - Z. prakt. Geologie, 27: 76-84, 1 Abb., Berlin

- $\square$ Kulick, J.; Leifeld, D.; Meisl, St.; Pöschl, W.; Stellmacher, R.; Strecker, G.; Theuerjahr, A.-K. \& Wolf, M. (1984): Petrofazielle und chemische Erkundung des Kupferschiefers der Hessischen Senke und des Harz-Westrandes. - Geol. Jb., Reihe D., 68: 3-323, 37 Abb., 15 Tab.; 34 Taf.; Hannover [darin: Richelsdorfer Gebirge, Ringgau/Werra-Meißner-Kreis]

-Lange, Hans Peter (1982): Zur Geochemie des Kupferschiefers und der Sedimente des Hangenden und Liegenden im Richelsdorfer Gebirge/Hessen. - Diss. Univ. Mainz 1982; 426 S., graph. Darst., Kt.

$\square$ Lasaulx, A. v. (1870): Ueber die durch Basaltcontact veränderten Braunkohlen vom Meissner. Annalen d. Physik u. Chemie, 141: 141-149; Leipzig

OLeutwein, Friedrich \& Rösler, Hans Jürgen (1956): Geochemische Untersuchungen an paläozoischen und mesozoischen Kohlen Mittel- und Ostdeutschlands. - Freiberger Forschungshefte., Reihe C, 19: 1-196, 67 Bilder, 95 Tab.; Berlin

[darin S. 48-51, Abb. 14, Tab. 31-34: Gehalte an Spurenelementen - Kohle der Öhrenkammer bei Ruhla]

OLöffler, Hans Karl (1987): Petrographie und Petrochemie der Eruptivgesteine von Gehren-Ilmenau. Z. geol. Wiss., 15(5): 619-643, 26 Abb., 7 Tab.; Berlin

-Lüdecke, Carl (1892): Untersuchungen über Gesteine und Böden der Muschelkalkformation in der Gegend von Göttingen. - Z. f. Naturwiss., $6 \mathbf{5}$ [= 5. F., $\underline{\mathbf{3}}$ : 219-349, 11 Tab.; Leipzig - zgl. Diss. Univ. Leipzig

Referate in: N. Jb. Mineral. etc, 1894 (Bd. I): 480-483 (A. Leppla); Stuttgart - Z. prakt. Geologie, 1.1893 (5): 206-209 (Wahnschaffe)

[Mineralogie, Geochemie, Bodenkunde]

OLoretz, H. (1888): Ueber das Vorkommen von Kersantit und Glimmerporphyrit in derselben Gangspalte bei Unterneubrunn im Thüringer Walde. - Jb. Preuß. Geol. Landesanst., $\underline{8}$ (f. 1887): 100118, 1 Abb.; Berlin

Referat in: N. Jb. Mineral. etc., 1891 (Bd. I): 65-67 (E. Dathe; zitierter Ort nicht korrekt); Stuttgart [Mineralogie und Geochemie]

-Lüdecke, Carl (1892): Untersuchungen über Gesteine und Böden der Muschelkalkformation in der Gegend von Göttingen. - Z. f. Naturwiss., $\underline{\mathbf{5}}$ [= 5. F., $\underline{\mathbf{3}}$ ]: 219-349, 11 Tab.; Leipzig - zgl. Diss. Univ. Leipzig

Referate in: N. Jb. Mineral. etc, 1894 (Bd. I): 480-483 (A. Leppla); Stuttgart - Z. prakt. Geologie, 
1.1893 (5): 206-209 (Wahnschaffe)

[Mineralogie, Geochemie, Bodenkunde]

-Mengel, Kurt (1981): Petrographische und geochemische Untersuchungen an Tuffen des Habichtswaldes und seiner Umgebung und an deren Einschlüssen aus der tieferen Kruste und dem oberen Mantel. - Diss. Univ. Göttingen 1981; 104 S., graph. Darst.

-Mengel, Kurt (1983): Petrographie und Geochemie der Tuffe des Habichtswaldes und seiner Umgebung (Nördliche Hessische Senke). - N. Jb. Mineral., Abh., 147: 1-20, 4 Abb., 5 Tab.; Stuttgart

-Mengel, K. (1987): Petrologie und Geochemie von Unterkrusten-Xenolithen aus Tuffen des Habichtswaldes (nördliche Hessische Senke). - Fortschr. Mineral., 65, Beih. 1: 134; Stuttgart

-Mengel, K. (1990): Crustal xenoliths from Tertiary volcancis of the northern Hessian Depression Petrological and chemical evolution. - Contrib. Mineral. Petrol., 104(1): 8-26, 8 fig., 6 tabl.; BerlinHeidelberg

-Mengel, K. (1990): Chemical evolution of the lower crust beneath NW Germany, evidence from xenolithes of the Habichtswald area. - In: Crustal dynamics, pathways and records - Bochum, FRG, 21-24 February 1990. - Terra abstracts, $\underline{\mathbf{2}}$ (1992): 46-47; (Blackwell) Oxford

-Mengel, Kurt (1990): Der Beitrag von Xenolithen der nördlichen Hessischen Senke zu Problemen des Stoffbestandes und der Entwicklung der kontinentalen Unterkruste. - Habil.-Schr. [unveröff.] Univ. Göttingen 1990; 84 S, 32 S. Anh.

- $\square$ Mengel, Kurt \& Pourmoafi, Mohammad (1980): Alkali-, Erdalkali- und 3-d-Übergangselemente in Basalten der Nördlichen Hessischen Senke. - N. Jb. Mineral. , Mh., 1980: 66-74, 2 Abb., 2 Tab.; Stuttgart

- $\square$ Nielsen, H. \& Ricke, W. (1964): Schwefel-Isotopenverhältnisse von Evaporiten aus Deutschland. Ein Beitrag zur Kenntnis von $\delta^{34} \mathrm{~S}$ im Meerwasser-Sulfat. - Geochimica et cosmochimica acta, 28: 577-591, 3 Abb.; Oxford u.a [darin Probenahme Umgebung Bebra: Mönchhosbach, Cornberg, Heinebach; auch Hundelshausen b. Witzenhausen]

- $\square$ Nielsen, Heimo \& Rambow, Dietrich (1969): S-Isotopenuntersuchungen an Sulfaten hessischer Mineralwässer. - Notizbl. Hess. L.-A. Bodenforsch., 97: 352-366, 2 Abb., Taf. 14 u. 15; Wiesbaden [Hessen, WMK]

$\square$ Nölke, G. (1940/41): Über rezente und fossile Verwitterung des unteren Buntsandsteins im Gebiet des Harzes, der Hain- und Windleite sowie des Kaufunger Waldes. - In: Blanck, E. \& Melville, R.: Untersuchungen über die rezente und fossile Verwitterung der Gesteine, innerhalb Deutschlands, zugleich ein Beitrag zur Kenntnis der alten Landoberflächenbildungen der deutschen Mittelgebirgsländer - Teil I. - Chemie der Erde, 13(2): 99 - 191; hier: S. 135 - 169, 31 Tab.; Jena 1940/41

-Oebbeke, K. (1889): Beiträge zur Kenntnis einiger hessischer Basalte. - Jb. Preuß. Geol. Landesanst., 9 (f. 1888): 390-416; Berlin

Referat in: N. Jb. Mineral. etc, $\underline{1891}$ (Bd. II): 278-280 (K. Oebbeke); Stuttgart

[Geochemie, Mineralogie Vorkommen Bl. Niederaula, Neukirchen]

- $\square$ Oehlschlegel, H. G. (1964): Geochemische Untersuchungen an nordwestdeutschen und nordhessischen tertiären Braunkohlen. - N. Jb. Mineral. etc., Abh., 101(1): 67-96, 18 Abb., 9 Tab. i. T. u. a. Beil.; Stuttgart [u.a. Gahrenberg, Hirschberg, Hoher Meißner, Freudenthal/Oberkaufungen, Stellberg/Söhre, Marie Trost/Habichtswald] 
व•Oehm J.; Schneider, A. \& Wedepohl, K. H. ( 1983): Upper mantle rocks from basalts of the northern Hessian depression (NW Germany). - TMPM - Tschermaks Mineral. u. petrogr. Mitt., 32(1): 25-48, 6 fig.; Wien-New York

[Niedersachsen: Hoher Hagen; Hessische Senke, keine Vorkommen im WMK]

- $\square$ Osann, Alfred (1901): Versuch einer chemischen Klassifikation der Eruptivgesteine. II. Die Ergußgesteine. - Tschermaks Mineral. petrogr. Mitt., 20: 399 - 558; Wien [darin: Habichtswald; S. 446 Plagioklasbasalt Typ Meissner, Analyse Dolerit Hoher Meißner]

-Peters, Heide (1985): Die Verteilung von Blei, Kupfer und Zink im Kontaktbereich zwischen Basalten und Evaporitgesteinen der Werra-Serie des Zechsteins. - Dipl.-Arb. [unveröff.] Univ. Göttingen 1985; 118 S., Abb., Tab.

-Peters, Heide (1985): Vorkommen und Verteilung der Elemente Blei, Kupfer und Zink in einem Kontaktbereich Basalt - Carnallitit im Kaliflöz Thüringen. - Kali u. Steinsalz, 9 (6): 199 - 208, 3 Abb., 10 Tab.; Essen

OPhilippe, Sylvie \& Haack, Udo (1997): Rb-Sr Systematics in Carnallites and Carnalltic Rocks from the German Zechstein. - Geol. Jb., Reihe E, 57: 3-21, 6 fig., 6 tabl.; Hannover [darin: Pöthen b. Menteroda, Thüringen]

-Püttmann, W.; Merz, C. \& Speczik, S. (1991): Oxidation of organic material in the Kupferschiefer and its relation to mineralization processes. - Zentralbl. Geol. Paläont. - Teil 1: 1991(4), S. 957-974, 9 fig., 3 tabl.; Stuttgart

[Richelsdorfer Gebirge/Spessart-Rhön]

$\square$ Rammelsberg, C.F. (1849): Repertorium des chemischen Theils der Mineralogie - Viertes Heft. Nebentitel: Viertes Supplement zu dem Handwörterbuch der Mineralogie. - Nebentitel: - LVIII, 272 S.; (Lüderitz) Berlin [darin S. 53: Chemische Analyse - Dolerit vom Meißner]

$\square$ Rammelsberg, C. (1852): Mineralanalysen. - Ann. Physik u. Chemie, 모: 297-302; Leipzig [darin S. 298-299: Chemische Analyse des Dolerites vom Meißner]

$\square$ Rammelsberg, C.F. (1853): Repertorium des chemischen Theils der Mineralogie - Fünftes Heft. Nebentitel: Fünftes Supplement zu dem Handwörterbuch der Mineralogie. - X, 272 S.; (Lüderitz) Berlin [darin S. 99: Chemische Analyse - Dolerit vom Meißner]

$\square$ Rammelsberg, C. (1855): Dolerit vom Meissner. - N. Jb. Mineral. etc., 1855: 199 (Auszüge); Stuttgart [chem. Analyse; Auszug a. Annalen Physik, 85: 298-299]

$\square \oslash \bullet$ Röhling, Heinz-Gerd \& Wippermann, Thomas (2008): Untersuchungen zur geogenen Grundlast von Arsen im Buntsandstein von Südniedersachsen und angrenzenden Gebieten (Nordhessen, Nordwestthüringen). - In: Rosenberg, F. \& Röhling, H.-G. [Hrsg.]: Arsen in der Geosphäre. Schriftenrh. Dt. Geol. Ges., ㅁ: 81-92, 7 Abb., 1 Tab.; Hannover 2008 [darin: untersuchte Lokalitäten i. Lkr. Göttingen, thüring. Eichsfeld, WMK]

$\square$ Rose, H \& Mügge, O.: Einschlüsse kalkiger und kieseliger Gesteine im Basalt der Blauen Kuppe. Zbl. Mineral. etc., 1921: 97 - 102; Stuttgart

$\square$ Salzwedel, Ute (1992): Kalktuffvorkommen im Eschweger Raum. - Berliner Geogr. Abh., Beih.; 1; 85 S., 14 Abb., 20 Tab., 3 Taf., 3 Kt.; (Selbstverlag d. Instituts f. physische Geographie FU Berlin) Berlin [Travertinvorkommen Wanfried/Elfengrund, Grebendorf/Badstube]

$\square$ Sandberger, F. (1874): Über Dolerit. - N. Jb. Mineral. etc., 1874: 88-93; Stuttgart [darin: Hoher Meissner] 
$\square \bullet$ Savelli, Carlo \& Wedepohl, K. H. (1969): Geochemische Untersuchungen an Sinterkalken (Travertinen). - Contrib. Mineral. Petrol., 21: 238-256, 1 Abb., 7 Tab.; Berlin [Lkr. Göttingen: Lenglern, Rosdorf; Stadt Göttingen; Westerhof Lkr. Northeim; Flachsbachtal/Wendershausen WMK]

OSchirmer, Bodo (1972): Beitrag zur Gliederung und Geochemie der permosilesischen Vulkanite des Thüringer Waldes. - Ber. Dt. Ges. geol. Wiss., Reihe A, 17 (6): 881 - 896, 6 Abb.; Berlin

aSchmidt, Kai Herbert (1996): Die Entwicklung ungewöhnlicher Isotopensignaturen im lithosphärischen Erdmantel - eine kombinierte geochemische und experimentelle Untersuchung. XXVI, 58 S., Ill., graph. Darst.; zgl. Diss. Univ. Göttingen 1995; (Papierflieger) Clausthal-Zellerfeld [Untersuchungen an Fremdgesteins-Einschlüssen in Basalt-Tuffen des Habichtswaldes]

- Schneider, Alfred (1970): The sulfur isotope composition of basaltic rocks. - Contrib. Mineral. Petrol., 25: 95-124, 4 fig.l; Berlin-Heidelberg

[darin: Bühl b. Weimar (Ahnetal b. Kassel); Hoher Meißner]

OSchramm, H.; Pohl, A.; Wunderlich, J. \& Bischoff, R. (1977): Atlas der Schwermetallgehalte Thüringer Böden $1: 400.000$ - Hintergrundwerte für Schwermetalle und Arsen in Oberböden und bodenbildenden substratentypischen Bodengesellschaften. - 58 S., überwgd. Karten ua. Bodenübersichtskt. Thüringen 1:400.000 (BÜK 400), 46 x 64 cm; [Hrsg. Thür. Landesanst. f. Umwelt u. Geologie i. A. d. Thür. Ministeriums f. Landwirtsch., Natursch. u. Umwelt] Jena

- •Schulze-Dobrick, B. (1971): Die Verteilung des Vanadiums in basaltischen Gesteinen aus Nordhessen und Südniedersachsen. - Dipl.-Arb. [unveröff.] Geochem. Inst. Univ. Göttingen

OSöfner, Rudolf (1938): Zur Entstehung des Thüringer Buntsandsteins. - Chemie der Erde, $\underline{11}$ (3): 420 444, 8 Abb., Taf. III; Jena [Untersuch. a. Bohrkernmaterial d. Bhrg. [Bad] Langensalza 2 u. 3]

oSteinmann, Marc; Stille, Peter; Bernotat, Walter \& Knipping, Bernhard (1999): The corrosion in basaltic dykes in evaporites - Ar-Sr-Nd isotope and rare earth elements evidence. - Chemical geology, 153(1-4): 259-279, 19 fig., 8 tab.; Amsterdam

[Hessisches Werra-Kalirevier: Kaliwerk Hattorf]

- •Lepper, Jochen; Koch, Michale, Siewers, Ulrich \& Stephan, Hans-Georg (2002): EisenerzVorkommen im Solling, Reinhardswald und Bramwald (Südniedersachsen und Nordhessen) und deren geochemische Charkterisierung im Rahmen eines Archäometallurgie-Projekts. - Nachrichten a. Niedersachsens Urgeschichte, 72: 51-63, 3 Abb., 1 Tab.; Stuttgart

-Techmer, Astrid (1989): Geochemische Untersuchungen an Xenolithen aus dem Habichtswald. Dipl.-Arb. [unveröff.] Univ. Göttingen 1989; 85 S.

○'Thomson, Stuart N. (2001): Using apatite fission-track thermochronology to investigate late cretaceous inversion of the Variscan basement blocks of Central Germany (Harz and Thüringer Wald) $<$ Vortragskurzfassung > . - In: Rauche, Henry [Hrsg.]: Regionale und angewandte Geologie der Grenzregion der Süddeutschen und der Mitteldeutschen Scholle. - Programm und Kurzfassungen der Vorträge. - 10. Jahrestagung Gesellschaft f. Geowissenschaften i. Schmalkalden, 19.-22. September 2001. - Exkursionsführer u. Veröff. Ges. f. Geowiss., 214; S. 223-224; Berlin 2001

-Trenzen, Carl (1902): Beiträge zur Kenntnis einiger niederhesssischer Basalte. - N. Jb. Mineral. etc., $\underline{1902}$ (2. Bd.): 1-42; Stuttgart - zgl. Diss. Univ. Marburg 1901

[Geochemie]

-Usdowski, E. (2001): Stable sulfur isotopes as a possible tool for tracing the provencance of the raw material of gypsum mortars / Stabile Isotope des Schwefels als mögliches Werkzeug bei der 
Bestimmung der Herkunft des Rohmaterials von Gips-Mörteln. - Chemie der Erde, 61(2): 140-147, 2 fig., 3 tabl.; Jena

[Mörtel der Burg Plesse bei Eddigehausen N’ Göttingen]

OUsdowski, E. \& Herrmann, A. G. (2003): Eisen und Mangan in konzentrierten Evaporit-Lösungen. Kali u. Steinsalz, 2003(2): 6-11, 6 Abb., 3 Tab.; Essen

[darin: Kaliwerk Merkers]

OVoland, B. (1965): Differentiationserscheinungen am olivinführenden Dolerit der Höhen-Berge im Thüringer Wald (Bohrung Schnellbach 1/62). Teil I: Die petrographische Gliederung des Dolerits. Geologie, 14(9): 1077-1101, 13 Abb., 1 Tab.; Berlin

OWaskowiak, Rudolf (1969): Beitrag zur Geochemie des Bors im Kristallin von Ruhla-Brotterode. Geologie, 18 (4): 432-440, 1 Tab.; Berlin

-Wedepohl, Karl Hans (1950): Der Feldspatbasalt des „Hohen Hagen“ bei Dransfeld. [W’ Göttingen] Heidelberger Beitr. Mineral. Petrogr., 2: 378-382, 2 Tab.; Berlin-Göttingen-Heidelberg

-Wedepohl, Karl Hans (1954): Der trachydoleritische Basalt (Olivin-Andesin-Basalt) des Backenberges bei Güntersen, westl. Göttingen. - Beitr. Mineral. Petrogr., 4: 217-232, 1 Abb., 3 Tab.; BerlinGöttingen-Heidelberg

- $\bullet$ Wedepohl, Karl Hans (1961): Geochemische und petrographische Untersuchungen an einigen jungen Eruptivgesteinen Nordwestdeutschlands. - Fortschr. Mineral., $\underline{\text { 39: }} 142$ - 148, 2 Abb., 3 Tab.; Stuttgart [Untersuchgn. u.a. an Vulkaniten a. Nordhessen, Südniedersachsen]

- $\bullet$ Wedepohl, Karl Hans (1963): Die Nickel- und Chrom-Gehalte von basaltischen Gesteinen und deren Olivin-führenden Einschlüssen. - N. Jb. Mineral., Mh., 1963: 237 - 242, 2 Abb.; Stuttgart [Proben u.a. vom Westberg/Hofgeismar, Hirzstein, Baunsberg; Hoher Hagen/Dransfeld]

$\square$ Wedepohl, Karl Hans (1964): Untersuchungen am Kupferschiefer Nordwestdeutschlands: Ein Beitrag zur Deutung der Genese bituminöser Sedimente. - Geochimica et cosmochimica acta, 28: 305-364, 18 Abb., 8 Tab.; Oxford-London-New York-Paris

[Untersuchung an Proben: Forsthaus Schmelzhütte, 4725 Bad Sooden-Allendorf; Schacht Schnepfenbusch/Nentershausen Bl. 4925 Nentershausen]

- $\square$ Wedepohl, Karl Hans (1968): Die tertiären basaltischen Gesteine im nördlichen Hessen und südlichen Niedersachsen. - In: Koritnig, Sigmund [Zusstlg. u. red. Vorber.]: Zur Mineralogie und Geologie der Umgebung von Göttingen mit Westharz und Teilen des nordhessischen Berglandes Sonderheft zur Jahrestagung 1968 der VFMG in Göttingen. - Der Aufschluss, Sdh. 17; S. 112-120, 2 Tab., 1 Taf.; Heidelberg [darin: Hoher Meißner, Blaue Kuppe]

- $\square \bullet$ Wedepohl, [K.H.](1972): Basaltische Magmen in Nordhessen, Westfalen und Niedersachsen. - In: Kertz, W. [Hrsg.]: Das Unternehmen Erdmantel - Zwischenbilanz einer interdisziplinären Zusammenarbeit. - Reihe: Forschungsbericht/Deutsche Forschungsgemeinschaft. - 376 S., Ill., graph. Darst., Kt.; hier S. 253-255; (Steiner) Wiesbaden 1972

- $\square$ Wedepohl, Karl Hans (1978): Der tertiäre basaltische Vulkanismus der Hessischen Senke nördlich des Vogelsberges. - In: Koritnig, Sigmund [Schriftltg.]: Zur Mineralogie und Geologie der Umgebung von Göttingen - mit Westharz und Teilen des Nordhessischen Berglandes. - Sdbd. $\underline{28}$; S. 156-167; 4 Abb., 2 Tab.; Heidelberg [darin: Mikrosondenanalysen Basalte Hoher Meißner, Blaue Kuppe; auch radiometrische Alter der Basalte] 
- $\square \bullet$ Wedepohl, Karl Hans (1982): K/Ar-Altersbestimmungen an basaltischen Vulkaniten der nördlichen Hessischen Senke und ihr Beitrag zur Diskussion der Magmengenese. - N. Jb. Mineral., Abh., 144: 172-196, 3 Abb., 2 Tab.; Stuttgart

- $\square$ Wedepohl, Karl Hans (1983): Die chemische Zusammensetzung der basaltischen Gesteine der nördlichen Hessischen Senke und ihrer Umgebung. - Geol. Jb. Hessen, 111: 261-302, 3 Abb., 16 Tab.; Wiesbaden

[Untersuchungen u.a. an Proben: Hoher Meißner, Blaue Kuppe, Steinbergskopf/Kaufunger Wald]

-Wedepohl, Karl-Hans (1983): Tertiary volcanism in the northern Hessian Depression. - In: Fuchs, K. [ed.]: Plateau uplift: the Rhenish Shield - a case history; S. 134-138, 2 fig.; (Springer) Berlin Heidelberg - New York [Großregionale Betrachtung]

- $\square$ Wedepohl, K. H. (1985): Origin of the Tertiary basaltic volcanism in the northern Hessian Depression. - Contrib. Mineral. Petrol., 오: 122-143, 4 fig., 8 tab.; Heidelberg-Berlin [Hessen, WMK, Niedersachsen]

-Wedepohl, K. H. (1987): Composition and genetic constraints of the Kupferschiefer bed [Vortragskurzfassung]. - In: Klare, Bernd \& Schröder, Bernd [eds.]: Zechstein 1987 International Symposium Kassel/Hannover - 28. April to 9. May, 1987 - Abstracts, Posters, Program; S. 116-118; [Subkommission Perm/Trias der Stratigraphischen Kommission der DUGW/IUGS] Bochum 1987 [Bezugn. a. Richelsdorfer Gebirge]

OWerner, Carl-Dietrich (1970): Geochemie der Brotteröder Serie im Ruhlaer Kristallin. Übergeordneter Titel: Geochemie granitoider Gesteine im Erzgebirge und Thüringer Wald. Freiberger Forschungshefte, Reihe C, 259: 5-82, 9 Abb., 34 Tab.; Leipzig

OWerner, C.-D. (1972): Geochemische Untersuchungen an Gesteinen der alten Baustufe des Ruhlaer Kristallins (Thüringer Wald). - Ber. dt. Ges. geol. Wiss., Reihe B, 16 (f. 1971)(1): 41-91, 10 Abb., 31 Tab.; Berlin

OWerner, C.-D. (1972): Zur Geochemie der Ruhlaer Folge im Thüringer Wald. - Ber. dt. Ges. geol. Wiss., Reihe B, 17(2): 131-217, 18 Abb., 54 Tab.; Berlin

OWerner, Carl-Dietrich (1972): Geochemische Untersuchungen an Metamorphiten der Seimberg-Serie im Ruhlaer Kristallin (Thüringer Wald). - Ber. Dt. Ges. f. geol. Wiss., Reihe B, $\underline{\mathbf{1 6}}$ (f. 1971)(4): 491526, 5 Abb., 24 Tab.; Berlin

OWerner, Carl-Dietrich (1972): Zur Geochemie und Petrologie des Ruhlaer Granits (Thüringer Wald). Ber. Dt. Ges. f. geol. Wiss., Reihe B, 17(2): 219-262, 16 Abb., 19 Tab.; Berlin

-Wittstein, G. C. (1851): Chemische Untersuchung des Steinmarkes von Münden [Hannoversch Münden]. - N. Jb. Mineral. etc., 1851: 202 (Auszüge); Stuttgart [Vermutetes Verwitterungsprodukt des Buntsandsteins]

-Wolff, Hermann (1890): Beiträge zur chemischen Kenntnis der basaltischen Gesteine des Knüllgebiets (Kurhessen). - Diss. Univ. Erlangen 1890, 24 S., Abb.; München Referat in: N. Jb. Mineral. etc., 1891 (Bd. II): 278-280 (K. Oebbeke); Stuttgart

OZeh, A., Hansch, R., Brätz, H. \& Bombach, K. (2000): Herkunft und Verwitterung von Granitgeröllen in Rotliegendsedimenten des nordwestlichen Thüringer Waldes - Petrographische, geochemische und Zirkon-Untersuchungen. - N. Jb. Geol. Paläont., Abh., 218: 173-199, 5 Abb., 8 Tab.; Stuttgart 


\subsection{Braunkohle, Steinkohle (Stratigraphie, Petrographie, Lagerstättenkunde)}

-Anonym (1898): Neue Flötzfunde im Habichtswalde bei Cassel. - Z. prakt. Geologie, $\underline{6} .1898: 267$ (Notizen); Berlin

$\square$ Namenskürzel [H.J](1882): < Neues Kohlevorkommen am Hirschberg bei Großalmerode entdeckt]. Eschweger Kreisblatt, 1882; Nr. 3 v. 7.1.1882; Eschwege

$\square$ Anonym (1893): < Kohlenlagerstätte zwischen Velmeden und Lautenbach entdeckt> $>$ Eschweger Tageblatt u. Kreisblatt, 1893; Nr. 278 v. 27.11.1893; Eschwege

$\square$ Anoynm (1894): <Kohlenlagerstätte zwischen Frankenhain und Kammerbach entdeckt]. - Eschweger Tageblatt u. Kreisblatt, 1894; Nr. 19 v. 23.1.1894; Eschwege

$\square$ Anonym (1986):- Die Braunkohlenlagerstätte des Meißner. (Übertitel: Germerode und der Bergbau am Meißner) - In: Franz, D.; Großkurth, H.; Kovács, H. \& Schulze, E. [Hrsg.]: 800 Jahre Germerode - Eine Festschrift zur 800sten Wiederkehr der ersten urkundlichen Erwähnung von Germerode. - 202 S., zahlr. Abb. + Anzeigenteil; hier S. 127-129; Meißner-Germerode 1986

$\square$ Aubuisson de Voisins, Jean François d' (1819) : Traité de géognosie. - Untertitel : Exposé des connaissances actuelles sur la constitution physique et minéralogie du globe terrestre. $-2 \mathrm{Bd}$. ; Bd. I, LXI, 496 S., 1 Taf. ; Bd. II, 2, 665 S., 1 gef. Bl., Ill.; (Levrault) Strasbourg/Paris [darin: Meissner: S. I,230 Geomorphologie; II, 445 Braunkohle; II, 556 Dolerit - erstmals in der Forschungsgeschichte wird die grobkörnige Varietät des Meissner-Basaltes als Dolerit bezeichnet]

Sonntags-Ausflug im Dreiländereck Hessen - Niedersachsen - Thüringen. - 159 S., 111 Fotos, 34 Kt., 1 Zeit-Taf.; (LSRB-Verlag, Landschaftskundlicher-Studien-Reisebuch-Verlag) Witzenhausen [zahlreiche Ausflugstipps, auch zu Relikten von Braunkohlenlagerstätten - und BraunkohlenBergbauen: Ziel 41 (Steinberg b. Großalmerode)]

-Bender, Heike (1981): Geologische und lagerstättenkundliche Untersuchungen im Nordteil der Hessischen Senke, E. - T I: Die Geologie des Südrandes der Dransfelder Hochfläche östlich von Hann. Münden bei Wiershausen und Lippoldshausen. - Teil II: Palynologische und makropetrographische Untersuchungen der Flöze 2 und 3 der Braunkohle am Hirschberg bei Großalmerode (TK 25, Blatt Nr. 4724, Großalmerode). - Dipl.-Kart. u. Dipl.-Arb. [unveröff.] Univ. Göttingen; 173 S., 7 Abb., 9 Tab., 5 Beil.

[Lkr. Göttingen; Werra-Meißner-Kreis]

- $\square$ Beyschlag, Franz (1888): Ueber Aufnahmen in Hessen. - Jb. Preuß. Geol. Landesanst., $\underline{8}$ (f. 1887): LXI-LXIV; Berlin

[Bibliographisch bearbeitetes Gebiet von Hessen; darin: Kontaktmetamorphose Basalt/Braunkohle Stellberg/Söhre]

- Beyschlag, Franz (1915): Die Braunkohlenformationen in Niederhessen (Regierungsbezirk Kassel). In: Klein, Georg [Hrsg.]: Die deutsche Braunkohlenindustrie - Handbuch für den deutschen Braunkohlenbergbau. - 2. vollst. Neubearb. Aufl., Textbd.: 880 S., 606 Abb. , Taf.Bd. Taf. 1-29 + 1 Kt.-Beil.; hier: S. 122 - 127, Abb. 30-32; Halle/Saale 1915

$\square$ Braun, Erwin (1976): Die Braunkohlenlagerstätte des Meißner und die wirtschaftlichen Aspekte des Bergbaues. - Hessische Heimat, N.F., 26 (3) (Sonderheft: Braunkohlenbergbau und Landschaftspflege auf dem Hohen Meissner - Stand 1975): 85 - 88, 3 Abb.; Marburg/L. 
$\square$ Braun, Erwin (1986): Die Braunkohlenlagerstätte des Meißner und die wirtschaftlichen Aspekte des Bergbaues. (Übertitel: Germerode und der Bergbau am Meißner). - In: Franz, D.; Großkurth, H.; Kovács, H. \& Schulze, E. [Hrsg.]: 800 Jahre Germerode - Eine Festschrift zur 800sten Wiederkehr der ersten urkundlichen Erwähnung von Germerode. - 202 S., zahlr. Abb. + Anzeigenteil; hier S. 129-133, 2 Abb.; Germerode 1986

$\square$ Brosius, Marita (1952): Die Tertiärmulde von Glimmerode. - Hess. Lagerstättenarchiv, 4 ; 48 S., 17 Abb., 3 Tab., 5 Taf., 10 Anl.; Wiesbaden

$\square$ Brosius, Marita (1958): Tegelen-Braunkohle von Fürstenhagen bei Hessisch-Lichtenau. - Notizbl. Hess. L.-A. Bodenforsch., 뚜: 316 - 319, 2 Abb.; Wiesbaden

-Brosius, M. \& Gramann, F. (1959): Die stratigraphische Reichweite des Heskemer Pollenbildes in Borken (Tertiär, Niederhessen). - Z. dt. geol. Ges., 111: 182-197, 7 Abb., 3 Taf.; Hannover

- $\square$ OCBruhns, W. (1906): Die nutzbaren Mineralien und Gebirgsarten im Deutschen Reiche. - Neu bearb. u. Mitwirk. v. H. Bücking a. Grundlage d. gleichnam. Werkes v. Heinrich v. Dechen (1873); XIX, 859 S., 1 geol. Falt-Kt.; (Reimer) Berlin [darin: Braunkohlen - S. 279-281 „Ablagerungen am Knüll und Habichtswald“, S. 281-282 „Ablagerungen im Reinhardswalde“, „Ablagerungen auf der rechten Seite der Fulda und der Weser“ (Kaufungen, Meißner, Großalmerode, Kaufunger Wald, Lkr. Göttingen)]

- $\square 0 \bullet$ Dechen, Heinrich v. (1873): Die nutzbaren Mineralien und Gebirgsarten im Deutschen Reiche nebst einer physiographischen und geognostischen Übersicht des Gebietes. - XXIV, 806 S.; (Reimer) Berlin

[darin: S. 447 ff Braunkohlen: „Ablagerungen am Knüll und Habichtswalde“, „Ablagerungen im Reinhardswalde“, „Ablagerungen auf der rechten Seite der Fulda und der Weser“ (Kaufungen, Meißner, Großalmerode, Kaufunger Wald, Lkr. Göttingen)]

Referat in: Z. Berg-, Hütten- u. Salinenwesen, 21: 40-41 (Litteratur); Berlin 1873

$\square$ Finkenwirth, A. (1978): Die Braunkohle am Meißner. - In: Koritnig, Sigmund [Schriftltg.]: Zur Mineralogie und Geologie der Umgebung von Göttingen - mit Westharz und Teilen des Nordhessischen Berglandes. - Sdbd. 28; S. 229-236, 3 Abb.; Heidelberg

$\square$ Führes, Margit (1979): Untersuchungen zur Mineralführung und Geochemie an einem Bohrprofil im Braunkohlengebiet des Hohen Meißners. - Dipl.-Arb. [unveröff.] Univ. Gießen

$\square$ Führes, Margit (1982): Die basaltische Beeinflussung des Meissner-Flözes. - Giessener geologische Schriften, $\underline{\mathbf{3 6}}$; 106 S., 29 Abb.; Giessen - zgl. Diss. Univ. Giessen 1982

$\square$ Georgi, Klaus-Henning (1971-1986): Kreislauf der Gesteine - Eine Einführung in die Geologie. Reihe: rororo-Sachbuch. - 251 S., 265 Abb. u. graph. Darst.; (Rowohlt Taschenbuch Verlag) Reinbek b. Hamburg - mehrere unveränderte Nachdrucke der Erstauflage v. 1971, letzter 1986 [darin S. 177-180, 1 Abb., Kap. 11 - Druck und Hitze verwandeln Gesteine; Kontaktmetamorphose Basalt/Buntsandstein Blaue Kuppe (Foto) u. Basalt/Braunkohle Hoher Meißner]

-Gothan, Walter (1926): Die „Siegellackhölzer“ aus der Braunkohle von Volpriehausen bei Göttingen. Braunkohle - Z. f. Gewinnungen und Verwertung der Braunkohle, 24(46): 1002-1005, Abb. 331; Halle a.d. S.

Referat in: N. Jb. Mineral. etc., Abt. B, 1926 (Bd. II): 265 (Kräusel); Stuttgart

$\square$ Graeger (1847): Chemische Untersuchungen einiger Braunkohlen. - Ber. Vereins Naturkde. z. Kassel, 11: $15-24$; Kassel

[Meißner, Grloßalmerode-Hirschberg, Großalmerode-Faulbach] 
-Gregor, Hans-Joachim; Micklisch, N. [Beitr.]; Oschkinis, V.[Beitr.]; Thewalt, U. [Beitr.]; Vavra, N. [Beitr.] (2005): Pflanzen und Tiere aus den eozänen Braunkohlen des Untertagebaues Stolzenbach bei Kassel. - Philippia, 12(2): 147-181, 36 Abb., 2 Tab.; Kassel

-Gregor, Hans-Joachim \& Oschkinis, Viktor (2005): Die eozänen Braunkohlenschichten aus dem Untertagebau Stolzenbach bei Kassel (PreußenElektra, Niederhessen)- II. Die Blattabdrücke. Nebentitel: Untertagebau Stolzenbach der PreussenElektra Niederhessen: Geologie - Paläophytologie - Mineralogie (Festband VIKTOR OSCHKINIS). - Documena naturae, 156: 27-65, 1 Tab.., 14 Taf.; München

-Gregor, Hans-Joachim \& Oschkinis, Viktor (2005): Die eozänen Braunkohlenschichten aus dem Untertagebau Stolzenbach bei Kassel (PreußenElektra, Niederhessen)- III. Die Frucht- und Samenflora. - Nebentitel: Untertagebau Stolzenbach der PreussenElektra Niederhessen: Geologie Paläophytologie - Mineralogie (Festband VIKTOR OSCHKINIS). - Documena naturae, 156: 67-93, 1 Tab.., 9 Taf.; München

-Harnisch, W. (1954): Aufschluß und Wasserwirtschaft der Zeche Marie-Trost am Brasselsberg bei Kassel. - Bergbau i. Hessenland (Ausgabe Braunkohle), (4.Jg.) 1954 (2): 13, (3): 4, 1 Abb.; Kassel [Lagerstättengeologie, Hydrogeologie]

- $\square$ Harnisch, W. (1964): Geologie der Braunkohle in Nordhessen. - Bergbau im Hessenland, (14. Jg.) 1964(5): 14-16, 3 Abb.; Kassel

$\square$ Hausmann, Joh. Friedr. Ludw. (1847): Handbuch der Mineralogie. - Zweyter Teil: System und Geschichte der Mineralkörper - Bd. 2. - 2., gänzl. umgearb. Aufl.; VII, S. 897-1660, [1 Bl.]; (Vandenhoeck \& Rupprecht) Göttingen [darin S. 1520-1529: Steinkohlen/Anthracit; Bezugnahme auf Meißner, Hirschberg]

$\square$ Hegerfeld, L. (1978): Geologische Aufnahme des Lettenberges (Meißner) mit Untersuchung der unterirdischen Kohlenbrände. - Dipl.-Arb. [unveröff.] Univ. Gießen, 45 S.

$\square$ Hentschel, Hans \& Pfeffer, Paul (1957): Chemisch-petrographische Untersuchungen von Gesteinsveränderungen am Kontakt Kohle-Basalt im Bereich des Braunkohlenbergwerks Zeche Hirschberg bei Großalmerode in Hessen. - Notizbl. Hess. L.-A. Bodenforsch., 85: 297-333, 4 Abb., 9 Tab., Taf. 17; Wiesbaden

-Hoffmann, A. [Bearb.](1935): Die Braunkohlenvorräte des Deutschen Reiches. - Archiv f. Lagerstättenforschung, 61; 38 S., 1 Abb., 12 Taf.; [Preuß. Geol. Landesanst.] Berlin [Kurzinformationen Lagerstättengeologie u. Bergbau]

-Hummel, Karl (1930): Glanzkohlengänge in der Braunkohle des Habichtswaldes. - Z. dt. geol. Ges., $\underline{82}$ (1930): 489 - 497, 1 Abb., 1 Taf.; Berlin

Referat in: N. Jb. Mineral. etc., Referate; 1932 (Bd. II): 514-515 (E. Christa); Stuttgart

- $\square$ Jurasky, Karl A. (1936): Deutschlands Braunkohlen und ihre Entstehung. - Deutscher Boden, 2; VI, 165 S., 1 Titelbild, 67 Abb.; (Bornträger) Berlin

Referat in: N. Jb. Mineral. etc., Referate, 1936 (Bd. II): 755-756 (E. Hennig); 1937 (Bd. III): 403-404 (Kräusel); Stuttgart

[darin: Niederhessen, Revier Kassel; Grube Faulbach/Steinberg b. Großalmerode, Meißner]

- $\square$ Kämmerer, O. (1935): Niederhessischer Bezirk. - In: Hoffmann, A. [Bearb.]: Die

Braunkohlenvorräte des Deutschen Reiches. - Archiv f. Lagerstättenforschung, 61; 38 S., 1 Abb., 12

Taf.; hier: S. 17-18, 1 Abb., 1 Tab.; [Preuß. Geol. Landesanst.] Berlin 1935

[Kurzinformationen Lagerstättengeologie u. Bergbau] 
-Karakücükoglu, Mustafa (1989): Petrographische Untersuchungen im unteren Abschnitt des Hauptflözes der miozänen Braunkohle von Ostheim/Hessen. - Dipl.-Arb. Teil 2 [unveröff.] Univ. Göttingen 1989; 69 S.

- $\square$ Klein-Reesink, Josef (1980): Geologische und lagerstättenkundliche Untersuchungen im Nordteil der Hessischen Senke, A. - Teil I: Geologie des Berlepschgrabens. - Teil. II: Petrographische Untersuchung der Braunkohle von Borken (Bez. Kassel). - Dipl.-Kart. u. Dipl.-Arb. [unveröff.] Univ. Göttingen; 217 S., 15 Abb., 9 Tab., 6 Taf., 6 Beil.

[Teil I: Werra-Meißner-Kreis, Teil II: Schwalm-Eder-Kreis]

- $\square$ Klein-Reesink, Josef (1984): Stoffbestand und Genese der Niederhessischen Senke mit vergleichenden Untersuchungen an Braunkohlen der Oberpfalz und Ost-Westfalen. -133 S., 46 Abb., 14 Tab., 5 S. Anhang (Tab.) 5 Taf.; Diss. Univ. Göttingen 1984

[darin: Borken, Ostheim, Hirschberg-Großalmerode]

- $\square$ Klein-Reesink, Josef (1984): Stoffbestand und Genes der Niederhessischen Senke mit vergleichenden Untersuchungen an Braunkohlen der Oberpfalz und Ost-Westfalen. - Documentae naturae Forschungen aus der Naturwissenschaft, 17; 133 S., 46 Abb., 14 Tab., 5 S. Anhang (Tab.), 5 Taf. [darin: Borken, Ostheim, Hirschberg-Großalmerode]

$\square$ Klein-Reesink, J.; Riegel, W. \& Schulz, K.-H. (1982): Tertiäre Braunkohlen und Kupferschiefer in Niederhessen. - Arbeitskreis f. Paläobotanik u. Palynologie. 11. - 13.3.1982 Dassel/Solling, Exkursion A. - Courier Forschungsinstitut Senckenberg, 56: 111-132, 12 Abb., 2 Tab.; Frankfurt [Hp. 3 Tagebau Paradiesfeld/Zeche Hirschberg, HP. 4 Frankershausen/Stbr. Schafhof]

-Klein-Reesink, J.; Riegel, W. \& Schaub, K. (1982): Zur petrographischen Konstitution alt- und jungtertiärer Braunkohlen Niederhessens. - Z. dt. geol. Ges., 133: 309-337, 8 Abb., 3 Taf.; Hannover

$\square$ Koch, Friedhelm (2007): Die „Alte Zeche“ zwischen Velmeden und Lautenbach. Zur Erinnerung an eine fast vergessene Kohlenlagerstätte. - Hessischer Gebirgsbote, 108(2): 84-85, 4 Abb.; Melsungen

$\square$ Koch, Friedhelm (2007): Die „Alte Zeche“ zwischen Velmeden und Laudenbach. Ein Nachtrag. Hessischer Gebirgsbote, 108(3): ??; Melsungen

-Kremp, Gerhard (1950): Pollenanalytische Braunkohlenuntersuchungen im südlichen Niedersachsen, insbesondere im Solling. - Geol. Jb., 64 (f. 1943 - 1948): 489-517, 4 Abb.; Hannover-Celle [darin: Lkr. Göttingen: Brunsberg, Hoher Hagen b. Dransfeld - Kl. Steinberg b. Hann. Münden]

-Kröninger, Brigitte (1991): Palynologische Untersuchungen an der miozänen Braunkohle von Ostheim (Nordhessen). - Dipl.-Arb. Teil II [unveröff.] Univ. Göttingen 1991; 123 S.

- $\square$ Kühnert, Ernst (1841): Ueber den Werth einiger in der Umgebung von Cassel vorkommenden Braunkohlen. - Ann. Chemie Pharmacie, 37: 94-100; Heidelberg [darin: Meißner, Habichtswald, Hirschberg, Ringenkuhl, Stellberg/Söhrewald]

- $\square$ Landschütz, H. (1930): (Braunkohlen) - Der Niederhessische Braunkohlenbezirk (Revier Cassel). In: Hülsemann, P. [Hrsg.]: Die Bergwerke Deutschlands - Auf bergwirtschaftlicher und lagerstättenkundlicher Grundlage. - XI, 412 S., zahlr. Abb., Tab. 8 Kt.; hier: S. 71-77; (Enke) Stuttgart 1930

-Lang, H. D. (1959/60): Die Abhängigkeit der Braunkohlenbildung von der Gestalt und dem Untergrund der Niederhessischen Senke. - Z. dt. geol. Ges., 111: 247; Hannover

$\square[$ Lasaulx, A. von] (1871): <Untersuchungen] über die umgewandelten Kohlen des Meissners. Verhdlgn. Naturhist. Vereins d. Preuß. Rheinlande u. Westphalens, 228: 152 (Sitzber.) Bonn 
-Lengtat, Karl Heinz (1989): Paläobotanische Untersuchungen eines Blattlagenhorizontes in der Ostheimer Braunkohle (Nordhessen). - Dipl.-Arb. Teil II [unveröff.] Univ. Göttingen 1989; 52 S.

- $\square$ OLeonhard, Karl Caesar v. (1832): Die Basalt-Gebilde in ihren Beziehungen zu normalen und abnormalen Felsmassen. - Bd. 1, 498 S., sep. Taf.-Bd. 20 Taf.; Bd. 2, 536 S.; (Schweizerbart) Stuttgart Bd. 2 beschreibt Intrusionsgefüge der Basalte und die Kontaktmetamorphose auf das Rahmengestein an verschiedenen nordhessischen Lokalitäten; Kontaktmetamorphose Basalt/Ton: Meißner; Basalt/Braunkohle: Meissner/Hirschberg/Habichtswald; Basalt/Buntsandstein: Blaue Kuppe b. Eschwege; Pflasterkaute b. Marksuhl; Basalt/Muschelkalk: Ahnetal/Kassel, Hörschel b. Eisenach]

-Linstow, Otto v. (1915): Die Braunkohlenformation in Hannover, Braunschweig, Anhalt und im Reg.Bez. Magdeburg der Provinz Sachsen. - In: Klein, Georg [Hrsg.]: Die deutsche Braunkohlenindustrie - Handbuch für den deutschen Braunkohlenbergbau. - 2. vollst. Neubearb. Aufl., Textbd.: 880 S., 606 Abb. , Taf.Bd. Taf. 1-29 + 1 Kt.-Beil.; hier: S. 129-146, Abb. 33,34; Halle/Saale 1915

[darin: Hoher Hagen b. Dransfeld, Steinberg/Meensen, Teichberg b. Bühren, Steinberg b. Münden]

$\square$ Michael, Bernd (1993): Palynologische Untersuchungen am Flöz I der miozänen Braunkohle vom Hirschberg bei Großalmerode, Hessen. - Dipl.-Arb. [unveröff.] Univ. Göttingen ; 46 S., 3 Taf., 4 Anl.

-Minnigerode, Christian (1981): Geologische und lagerstättenkundliche Untersuchungen im Nordteil der Hessischen Senke - D. - Teil II: Makropetrographische und palynologische Untersuchungen der Braunkohle von Borken (Bez. Kassel). - Dipl.-Arb. [unveröff.] Univ. Göttingen; 201 S. 16 Abb., 5 Tab., 3 Taf., 3 Beil.

- Minnigerode, Christian \& Riegel, Walter (1981): Makropetrographische und palynologische Untersuchungen der Braunkohle von Borken (Bez. Kassel). - N. Jb. Geol. Paläont., Mh., 1983: 300320, 4 Abb., 4 Tab.; Stuttgart

- $\square$ Mohr (Med.-Rath)(1868): [Widerlegung der] Ansicht, dass man die stängelige Absonderung der Braunkohlen auf dem Meisner, Habichtswald und Hirschberg im Kurhessischen als einen Beweis der feurigen Einwirkung des Basaltes auf diese Brennstoffe ansehen dürfe. - Verhdlgn. d. Naturhist. Vereins d. Preuß. Rheinlande u. Westphalens, $\underline{\mathbf{2 5}}$ (= 3. F., $\underline{\mathbf{5}}$ ): 25 (Sitzber.); Bonn [Ein später Schlag gegen die magmatische Natur des Basaltes im Plutonisten-, Neptunisten-Streit]

-Mürriger, Friedrich \& Pflug, Hans (1951): Über die Alterstellung der Braunkohle von Burghasungen [Bl. 4621 Wolfhagen]. - Notizbl. Hess. L.-A. Bodenforsch., (VI Folge) 2: 87-97, 2 Taf.; Wiesbaden

- $\square$ Mürriger, Friedrich \& Pflanzl, Günther (1955): Pollenanalytische Datierungen einiger hessischer Braunkohlen. - Notizbl. Hess. L.-A. Bodenforsch., 83: 71-89, 1 Tab., 2 Taf; Wiesbaden [Darin: Hirschberg, Glimmerode, Oberkaufungen, Stellberg/Söhrewald, Zeche Marie/Habichtswald]

- $\square$ Namenskürzel [Ha](1954): Der niederhessische Braunkohlen-Bergbau - Geologische Übersicht und geschichtlicher Rückblick. - Bergbau i. Hessenland (Ausgabe Braunkohle), (4.Jg.) 1964(11): 3, 13-14, 3 Abb.; Kassel

$\square$ Naumann, Peter (1999): Retinit und Quarz in der Braunkohle von Großalmerode. - Hessischer Gebirgsbote, 100: 15; Melsungen

- $\square$ Oehlschlegel, H. G. (1964): Geochemische Untersuchungen an nordwestdeutschen und nordhessischen tertiären Braunkohlen. - N. Jb. Mineral. etc., Abh., 101(1): 67-96, 18 Abb., 9 Tab. i. T. u. a. Beil.; Stuttgart [u.a. Gahrenberg, Hirschberg, Hoher Meißner, Freudenthal/Oberkaufungen, Stellberg/Söhre, Marie Trost/Habichtswald] 
-Oschkinis, Viktor \& Gregor, Hans-Joachim (2005): Die eozänen Braunkohlenschichten aus dem Untertagebau Stolzenbach bei Kassel (PreußenElektra, Niederhessen)- I. Geologie und

Fundumstände - Nebentitel: Untertagebau Stolzenbach der PreussenElektra Niederhessen: Geologie - Paläophytologie - Mineralogie (Festband VIKTOR OSCHKINIS). - Documena naturae, 156: 1-25, 9 Abb., 5 Taf.; München

$\square$ Pflanzl, Günter (1956): Das Alter der Braunkohlen des Meißners, der Flöze 2 und 3 des Hirschberges und eines benachbarten Kohlenlagers bei Laudenbach. - Notizbl. Hess. L.-A. Bodenforsch., 며: 232244, 1 Tab., Taf. 16-17; Wiesbaden

-Pflug, Hans Dieter (1957): Zur Altersfolge und Faziesgliederung mitteleuropäischer (insbesondere hessischer) Braunkohlen. - Notizbl. Hess. L.-A. Bodenforsch., 85: 152-174, 5 Abb., 9 Tab., 3 Taf.; Wiesbaden [darin: Borken, Frielendorf]

- $\square$ Pietzsch, Kurt (1925): Handbuch der Geologie und Bodenschätze Deutschlands / Erich Krenkel [Hrsg.]. - Abt. 3: Die Bodenschätze Deutschlands - Bd. 1: Die Braunkohlen Deutschlands. - XII, 488 S., 105 Textabb., 20 Taf.; (Bornträger) Berlin [darin S. 205-225: Der Niederhessische Bezirk [Revier Cassel] (darin; Habichtswald, Stellberg, Hirschberg, Oberkaufungen, Glimmerode, Meißner)]

$\square$ Prauss, Michael (1980): Geologische und lagerstättenkundliche Untersuchungen im Nordteil der hessischen Senke - C. - Teil 2: Petrographische Untersuchungen der Flöze 2 und 3 der Braunkohle am Hirschberg bei Großalmerode. - Dipl.-Arb. [unveröff.] Univ. Göttingen; 179 S., 7 Taf., 6 Beil. [Die Vorlage enthält 2 Teile: Diplom-Kartierung und Diplom-Arbeit]

- $\square$ Prauss, Michael [Red.](1986): Die Braunkohlen der Niederhessischen Tertiärsenke. - 18 S., 5 Abb., 5 Tab.; [Stadt Kassel, Naturkundemuseum] Kassel [Borken, Großalmerode/Hirschberg]

$\square$ Regnault, V. (1837): Recherches sur les combustibles minéraux. - Annales des mines, (3ième sér.), 12: 161-240; Paris

[darin S. 220-221: «Lignite du mont Meisner; Braunkohle Meißner]

- $\square$ ORiess, Johann Philipp (1791): Mineralogische und bergmännische Beobachtungen über eine Hessische Gebirgsgegenden. - XIV, 102 S., 6 Taf.; (Rottmann) Berlin [darin: S. 28-54 Kupferschiefer- u. Kobalt-Bergbau Richelsdorfer Gebirge; S. 54-59 Kupferschiefer- u. Kobalt-Bergbau Glücksbrunn b. Bad Liebenstein; S. $69-84$ („Steinkohlen“-) Braunkohlenbergbau u. Tertiär-Stratigaphie am Meissner; S. 84-89 Alaun- und (,Steinkohlen“) Braunkohlen-Bergbau Oberkaufungen]

- Ritzkowski, Siegfried (1968): Die Tektonik der Braunkohlenlagerstätte von Borken (Tertiär, nördliches Hessen). - Notizbl. Hess. L.-A. Bodenforsch., 96: 273-280, 3 Abb., Taf. 9; Wiesbaden

- $\square$ Rosenthal, L. (1893): Die metamorphisierende Einwirkung der Basalte auf die Braunkohlenlager bei Cassel. - Z. prakt. Geol., 1.1893 (10): 378-381, 2 Fig.; Berlin [darin: Habichtswald, Hirschberg, Stellberg, Meißner]

- $\square$ Rosenthal, L. (1893): Die metamorphisierende Einwirkung der Basalte auf die Braunkohlenlager bei Cassel. - Z. prakt. Geol., 1.1893 (10): 378-381, 2 Fig.; Berlin [darin: Habichtswald, Hirschberg, Stellberg, Meißner]

- $\square$ Rosenthal, (Bergingenieur) (1895): Die tertiären Ablagerungen bei Kassel und ihre durch Basaltdurchbrüche veredelten Braunkohlenflöze. - Touristische Mitt. a. beiden Hessen, $\underline{\mathbf{3}}(12)$ : 149152; Kassel [Habichtswald, Stellberg, Großalmerode-Hirschberg, Hoher Meißner] 
- $\square$ Rosenthal, (Berg-Ingenieur) (1896): Die tertiären Ablagerungen bei Kasssel und ihre durch Basaltdurchbrüche veredelten Braunkohlenflöze. - Abh. u. Ber. Vereins Naturkde. z. Kassel, $\underline{41}$ (1995/1896): 106-117, 3 Abb. (Profile); Kassel

[darin: Habichtswald, Hirschberg, Stellberg, Meissner]

- $\square \bullet$ Rosenbusch, Harry (1923): - Elemente der Gesteinslehre. Herausgeg. v. A. Osann. - 4., neu barb. Aufl.; 779 S., 115 Abb., zahlr. Tab.; (Schweizerbart) Stuttgart

[darin: S. 429 Hyalitbasalt d. Sababurg, Säsebühl b. Dransfeld; S. 430 Chem. Analyse Plagioklasbasalt Bühl b. [Ahnatal] Weimar; S. 434 Chem. Analyse Basalt Bramburg b. Adelebsen; S. 600 Chem. Analyse Braunkohle Meißner]

- •Schaub, Klaus (1981): Geologische und lagerstättenkundliche Untersuchungen im Nordteil der Hessischen Senke - F. - Teil I: Die Geologie im Südteil der Dransfelder Muschelkalk-Hochfläche zwischen Meensen, Jühnde, Barlissen und Atzenhausen (TK 25 Jühnde, 4524). - Teil II:

Petrographische Untersuchungen an der Braunkohle von Ostheim (Bez. Kassel). - Dipl.-Kart. u. Dipl.-Arb. [unveröff.] Univ. Göttingen; 101 S., 4 Taf., 5 Beil.

[Lkr. Göttingen, Schwalm-Eder-Kreis]

$\square \bullet$ Prauss, Michael (1980): Geologische und lagerstättenkundliche Untersuchungen im Nordteil der hessischen Senke - Teil 1: Die Geologie am südöstlichen Ausläufer des Bramwaldes zwischen Schede und Werratal (Bl. Jühne). - Teil 2: Petrographische Untersuchungen der Flöze 2 und 3 der Braunkohle am Hirschberg bei Großalmerode. - Dipl.-Arb. [unveröff.] Univ. Göttingen 1980; Teil 1, 58 S.; Teil 2; $179 \mathrm{~S}$.

- Schenk, Erwin (1951): Ergebnisse geomagnetischer Untersuchungen im Braunkohlengebiet des Stellberges bei Kassel. - Notizbl. Hess. L.-A. Bodenforsch., [79] (6. F.) H. 2: 184 - 191, 2 Abb., 1 Taf.; Wiesbaden

هSchröck-Ergün, Doris (1992): Palynologische Untersuchungen zur Ökologie der Braunkohle von Ostheim, Bezirk Kassel. - Dipl.-Arb. [unveröff.] Univ. Göttingen 1992; 125 S., ca. 12 ungez. S. Anhang

$\square$ Schulz, Dirk-Olaf (1994): Petrographische Untersuchungen am Flöz 1 des Braunkohlevorkommens am Hirschberg. - Dipl.-Arb. [unveröff.] Univ. Göttingen; 68 S., Abb., Tab.

oSteckhan, Wilhelm (1988): Das Braunkohlevorkommen im Stellberg bei Kassel. - 96 S., Abb., Kt.; (Thiele \& Schwarz) Kassel

oStrippelmann (1827): Nachteilige und schädliche Wirkungen von Rauchgasen brennender sog. „gemeiner“ Braunkohle auf den menschlichen Organismus. - Z. Mineral., 1827(9): 287-293; Frankfurt/M.

[Kohlebrände Habichtswald]

-Strippelmann, F. E. (1833): Über den Brand in Braunkohlengruben mit vorzüglicher Rücksicht auf die Braunkohlenbergwerke am Habichtswald. - Studien Göttingischen Vereins bergmänn. Freunde, $\underline{3}:$ 99170; Göttingen

dStrippelmann, [F. E.] (1840): Vorkommen von Schwefel-Krystallen in den Braunkohlen-Ablagerungen bei Frielendorf unfern Kassel. - N. Jb. Mineral. etc., 1840: 485 (Auszug a.: Der Bergwerksfreund, 2: 299); Stuttgart

aStrippelmann, F. E. (1840): Flötz-artiger Basalt in Habichtswalder Braunkohle. - N. Jb. Mineral. etc., 1840: 369-370 (Auszug a. Bergwerks-Freund, 2: 297ff, Eisleben); Stuttgart

aStrippelmann, F. E. (1841): Über das Vorkommen einer flözartigen Einlagerung von basaltischen Massen in der Habichtsspieler Braunkohlenablagerung am Habichtswalde. - Studien Göttingischen Vereins bergmänn. Freunde, 4: 355-358; Göttingen 
aStrippelmann, [F.E.](1841): Vorkommen von Gyps und Schwefel in Braunkohlenablagerungen [von Frielendorf. - N. Jb. Mineral. etc., 1843: 809; Stuttgart - Auszug aus: Studien Göttingischen Vereins bergmänn. Freunde, 4: 358-359

[Lagerstätte von Frielendorf]

-Thewalt, Ulf \& Gregor, Hans-Joachim (2005): Die eozänen Braunkohlenschichten aus dem Untertagebau Stolzenbach bei Kassel (PreußenElektra, Niederhessen)- V. Die Minerale. - Nebentitel: Untertagebau Stolzenbach der PreussenElektra Niederhessen: Geologie - Paläophytologie Mineralogie (Festband VIKTOR OSCHKINIS). - Documena naturae, 156: 113-123, 5 Abb., 3 Taf.; München

-Udluft, Hans \& Lang, Hans Dietrich (1959): Die Niederhessischen Braunkohlen in ihrer Abhängigkeit von den faziellen Verhältnissen des tertiären Sedimentationsraumes. - Notizbl. Hess. L.-A. Bodenforsch., 87: 333-366, 14 Prof. u. Tab., Taf. 20; Wiesbaden

d $\square$ Uthemann, A. (1892): Die Braunkohlen-Lagerstätten am Meisner, am Hirschberg und am Stellberg mit besonderer Berücksichtigung der Durchbruchs- und Contacteinwirkungen, welche die Basalte auf die Braunkohlenflöze ausgeübt haben. - Abh. Kgl. Preuß. Geol. Landesanst., N.F., 17; 54 S., 10 Abb., 3 Falt-Taf.; Berlin

Referat in: N. Jb. Mineral. etc., $\underline{1893}$ (Bd. II): 164-165 (v. Koenen); Stuttgart

- Vavra, Norbert (2005): Die eozänen Braunkohlenschichten aus dem Untertagebau Stolzenbach bei Kassel (PreußenElektra, Niederhessen)- IV. Analyse des Bernsteins. - Nebentitel: Untertagebau Stolzenbach der PreussenElektra Niederhessen: Geologie - Paläophytologie - Mineralogie (Festband VIKTOR OSCHKINIS). - Documena naturae, 156: 95-111, 4 Abb., 1 Tab.., 3 Taf.; München

OVoigt, Johann Carl Wilhelm (1799): Von dem Bituminösen Holzlager, am Kirschofe, bey Niederndorf im Eisenachischen <Abh. IV des Bandes>. - In: Voigt, Johann Carl Wilhelm: Kleine mineralogische Schriften - Theil 1. - S. 66-72; (bey den Gebrüdern Gaedicke) Weimar 1799

OVoigt, Johann Carl Wilhelm (1799): Ueber die Steinkohlen am Schlierberge, bey Creutzburg, im Eisenachischen $<A b h$. X des Bandes $>$. - In: Voigt, Johann Carl Wilhelm: Kleine mineralogische Schriften - Theil 1. - S. 152-161; (bey den Gebrüdern Gaedicke) Weimar 1799

OVoigt, Johann Carl Wilhelm (1800): Ueber Stein- und Braunkohle < Abhandlung II des Bandes>. - In: Voigt, Johann Carl Wilhelm: Kleine mineralogische Schriften - Theil 2. - S. 54 - 106; (bey den Gebrüdern Gaedicke) Weimar 1800 [darin: Kohlen aus Thüringen, Meißner]

QVoigt, Johann Carl Wilhelm (1800): Einige Versuche mit Stein- und Braunkohlenarten, im Feuer $<$ Abhandlung XIII des Bandes>. - In: Voigt, Johann Carl Wilhelm: Kleine mineralogische Schriften - Theil 2. - S. 155 - 171; (bey den Gebrüdern Gaedicke) Weimar 1800 [Brennverhalten von Kohlen, darin: Kohlen aus Thüringen, Meißner]

口OVVoigt, Johann Carl Wilhelm (1802/1805): Versuch einer Geschichte der Steinkohlen, der Braunkohlen und des Torfes, nebst Anleitung, diese Fossilien kennen und unterscheiden zu lernen, sie aufzusuchen und nützlich anzuwenden. - 1. Bd., XXIII, 307, [5] S.; [Hoffmann'sche Hofbuchhdlg.] Weimar 1802 - 2. Bd., [IV], 197 S. [3], 2 Taf.; [Hoffmann'sche Hofbuchhdlg.] Weimar 1805 [darin Bd. 1: Torfabbau bei Creuzburg; Bd. 2: S. 61-90: „Der Manebacher Grund im Thüringer Wald“; S. 123-132 „Nachtrag zu des Verfassers mineralogischen Reise nach den Braunkohlenwerken und Basalten in Hessen etc.“ (Braunkohle und Basalt am/auf dem Hohen Meißner)]

$\square$ Waitz von Eschen, R. \& Strippelmann, F. E. (1828): Geognostische Betrachtung der am Hirschberge bei Großalmerode abgelagerten, tertiären Gebilde, nebst einigen Bemerkungen über den daselbst im Betriebe stehenden Bergbau. - Studien Göttingischen Vereins bergmänn. Freunde, 2: 121-168; 
(Dieterich) Göttingen

[Tertiärstratigraphie, Braunkohlenbergbau, Alaungewinnung]

$\square$ Waitz von Eschen (1880): Das Vorkommen und die Bildungsweise einer retinithaltigen Braunkohle [Vortragskurzfassung]. - Abh. Ber. Vereins f. Naturkunde z. Kassel, 26/27: 48; Kassel

[Faulbacher Mulde/Großalmerode]

$\square$ Werner, A. G. (1789): Anmerkung zu Herrn Fausts Nachricht von dem auf dem Meißner in Hessen über Steinkohlen und bituminösen Holz liegenden Basalt. - Bergmännisches Journal, 2 $(1)$ : 261-295; Freyberg

-Wollenhaupt, H. (1980): Geologische und lagerstättenkundliche Untersuchungen im Nordteil der Hessischen Senke - B. - Teil I: Die Geologie des Nordrandes des Leinholz-Gewölbes zwischen Berge und Mollenfelde (TK 4525 Reinhausen und TK 4625 Witzenhausen). - Teil II: Palynologische und petrographische Untersuchungen der Braunkohle von Schneppenhain (TK5021 Ziegenhain). - Dipl.Kart. u. Dipl.-Arb. [unveröff.] Univ. Göttingen, 151 S., Abb., 8 Taf., 7 Beil.

-Wunderlich, Hans Georg (1962): Umgrenzung von Basalt und Braunkohlen-Tertiär am Brunsberg und Hohen Hagen bei Dransfeld (Südhannover). - N. Jb. Geol. Paläont., Mh., 1962: 282 - 293, 2 Abb.; Stuttgart

a $\square$ Zinken, C. F. (1867): Die Braunkohle und ihre Verwendung. - Erster Theil: Die Physiographie der Braunkohle. - X, 818 S., Zchng., 3 Taf.; (Carl Rümpler) Hannover

[darin: umfassende Beschreibung der Vorkommen und Abbaue des nordhessischen

Braunkohlenreviers (Hessen-Cassel), ua. Hessische Senke, Reinhardswald, WMK; Lkr. Göttingen:

Steinberg b. Hann. Münden, Dransfeld]

[Ostheim/Habichtswald/Schimmberg u. Burgberg b.

Hoof/Stellberg/Möncheberg/Söhrewald/Lammsberg b.

Gudensberg/Meissner,/Hirschberg/Belgerskopf/Oberkaufungen/Steinberg N'Großalmerode, Rommerode, Epterode, Romeberg b. Homburg, Frielendorf/Heiligenberg b.

Gensungen/Reinhardswald(Immenhausen, Hohenkirchen, Holzhausen, Ahlberg/Gottsbüren]

o $\square$ Zinken, C. F. (1871): Die Braunkohle und ihre Verwendung. - [Zweiter Theil:] Ergänzungen zu der Physiographie der Braunkohle. - 257 S., 6 Taf.; (Buchhdlg. d. Waisenhauses) Halle

[darin: Habichtswald, Meißner, Steinberg b. Großalmerode]

\subsection{Süßwasserkalk (Travertin, Kalktuff)}

- $\square$ • Apel, Jürgen \& Rüppel, Heidi [Verfass. u. Hrsg.] (2005): Raus in die Natur - Tipps für den Sonntags-Ausflug im Dreiländereck Hessen - Niedersachsen - Thüringen. - 159 S., 111 Fotos, 34 Kt., 1 Zeit-Taf.; (LSRB-Verlag, Landschaftskundlicher-Studien-Reisebuch-Verlag) Witzenhausen [zahlreiche Ausflugstipps, auch zu Geotopen d. Quartärs: Ziel 16 (Moorbildung Kaufunger Wald), Ziel 23 (Schwemmschuttfächer Unterwerra), Ziel 52 (Travertinbildung), Ziel 73 (Kiesablagerung), Ziel 80 (Travertinbildung), Ziel 87 (Gletscherbildungen, Travertinbildungen i. Thüringen)]

@Bornemann [sen.], J. G. (1856): Über die Diluvial- und Alluvialbildungen der Umgegend von Mühlhausen im Gebiet des oberen Unstruttales. - Z. dt. geol. Ges., 요 89-116, 1 Tab.; Berlin [u.a. Travertinbildungen]

口Claus, H. (1973): Die geologisch-paläontologische Erforschung der Burgtonnaer Travertinlagerstätten. Abh. Ber. Museums d. Natur Gotha, [7] 1973: 1-8, 1 Abb.; Gotha 
QClaus, Hans (1978): Die geologisch-paläontologische Erforschung der Burgtonnaer Travertinlagerstätten. - Quartärpaläontologie, 3: 9-41, 1 Tab., Taf. 1-8; (Akademie-Verlag) Berlin

QFehler, Andreas (1998): Die Travertine von Bad Langensalza (Thüringen) - Landschafts- und Naturgeschichte zu Beginn einer neuen erdgeschichtlichen Epoche. - 170 S., 60 Abb.; (Rockstuhl) Bad Langensalza

OFritze, Eduard (2007): Der Eichsfelder Westerwald. - 1. Aufl., 240 S., zahlr. Abb., Tab.; (Rockstuhl) Bad Langensalza [darin Kap.: „Die Süßwasserablagerungen im Luttertal bei Großbartloff“]

QGesang, Heinrich (1978): Zur Geologie des Travertins von Burgtonna in Thüringen. Quartärpalontologie, 3: 43-49, 9 Abb.; (Akademie-Verlag)

OHiller, Achim \& Fuhrmann, Roland (1991): Radiocarbondatierungen an koexistenten Kohlenstoffträgern aus Binnenwasserkalkvorkommens Sachsens und Thüringens. - Z. geol. Wiss., 19(5): 569-584, 4 Abb., 2 Tab.; Berlin [darin: Mühlhausen, Bad Langensalza]

$\square$ Hotzler, Fritz (1996): Kalksinter - Ein Gestein, das noch heute entsteht. - Das Werraland, 48 (1): 10; Eschwege

@Kahlke, H.-D. [Hrsg.] (1978): Das Pleistozän von Burgtonna in Thüringen - Teil. 1. Die Travertine, Teil 2. Die Deckschichten der Travertine von Burgtonna in Thüringen. - Quartärpaläontologie Abh. Ber. Inst. Quartärpaläont., $\underline{\mathbf{3}}, 399$ S, 137 Abb., 56 Taf., 46 Tab.; (Akademie-Verlag) Berlin

QKahlke, Hans-Dietrich (1978): Zusammenfassender Überblick zur stratigraphischen Stellung der Travertine von Burgtonna in Thüringen. - Quartärpaläontologie, $\underline{\mathbf{3}}$ : 171-174, 2 Abb.; (AkademieVerlag) Berlin

OKamradt, Ivonne (2002): Beitrag zur kleinmaßstäblichen Fazies- und Architekturelement-Analyse der Süßwasserkalke von Burgtonna in Thüringen. - Beitr. Geol. Thüringen, 9: 247-271; Jena

OKohlstock, Karl (1926): Burgtonna: Kalktuffe; Gräfentonna: Gräberfund. - Entdeckungsreisen in der Heimat, 25; 2., vermehrte Aufl.; 16 S., Abb., Kt.; (Stollberg) Gotha

QKrause, Reinhard (1981): Der Wasserfall der Lutter bei Großbartloff. - Eichsfelder Heimathefte, [21 Jg.] 1981(3): 213-216, 1 Abb.; Worbis

OLindner, Andreas (1999): Diskussion der stratigraphischen Alter der Travertingerölle und der anstehenden Travertine im Gebiet der oberen Unstrut. - Geowiss. Mitt. Thüringen, 7: 99-126, 4 Abb., 1 Tab.; Jena

[Oberlauf bis Tonna]

QMallick, Ronzon (2000): Entwicklung der Mikrobeprobung zur Th-, U-Datierung und Anwendung an quartären Travertinen aus dem Thüringer Becken. - Diss. Univ. Heidelberg 2000; 162 S.

OMallick, Ronzon (2001): Präzise Th/U-Datierung archäologisch relevanter Travertinvorkommen Thüringens. - In: Wagner, G.[Hrsg.]: Frühe Menschen in Mitteleuropa - Chronologie, Kultur, Umwelt [Kolloquium 9.-11. März 2000 Heidelberg]. - Veröff. d. Vereins Homo Heidelbergensis von Mauer e.V. 1; 163 S., Abb., Kt.; hier: S. 77-89; (Shaker) Aachen 2001

OMallick, Ronzon \& Frank, Norbert (2002): A new technique for precise uranium-series dating of travertine micro-samples. - Geochimica et Cosmochimica Acta, $\underline{\mathbf{6 6}}$ (24): 4261 - 4272, 6 fig., 4 tab.; Amsterdam [Bad Langensalza, Bilzingsleben, Burgtonna, Weimar-Ehringsdorf] 
OMania, Dieter [Mitautor] (2003): Die Travertine in Thüringen und im Harzvorland - Travertines in Thuringia and the foothhills of the Harz. - Hallesches Jb. Geowiss., Reihe B, 17, 83 S., 53 Abb., Kt.; Halle/Saale

QRothe, H. W. (1954): Die Travertin-Fundstellen in Mühlhausen/Thür. - Der Aufschluss, $\underline{5}: 244-248,3$ Abb.; Rosdorf b. Darmstadt

$\square$ Salzwedel, Ute (1992): Kalktuffvorkommen im Eschweger Raum. - Berliner geogr. Abh., Beih.; 1; 85 S., 14 Abb., 20 Tab., 3 Taf., 3 Kt.; (Selbstverlag d. Instituts f. physische Geographie FU Berlin) Berlin [Travertinvorkommen Wanfried/Elfengrund, Grebendorf/Badstube]

$\square \bullet$ Savelli, Carlo \& Wedepohl, K. H. (1969): Geochemische Untersuchungen an Sinterkalken (Travertinen). - Contrib. Mineral. Petrol., 21: 238-256, 1 Abb., 7 Tab.; Berlin [Lkr. Göttingen: Lenglern, Rosdorf; Stadt Göttingen; Westerhof Lkr. Northeim; Flachsbachtal/Wendershausen WMK]

OSenft, F. (1861): Die Wanderungen und Wandlungen des kohlensauren Kalkes. - Z. dt. geol. Ges., 13: 263-346, 14 Abb.; Berlin [Reg. Bezug Thüringer Becken; sekundäre Kalklösung und -Fällung : Kalksinter, Tropfsteine, Travertin]

OSteiner, W. (1970): Stratigraphie und Sedimentationsgeschwindigkeit der Travertine von Burgtonna und Ehringsdorf. - Geologie, 19 (8): 931-993, 8 Abb.; Berlin

OSteiner, Waltner (1978): Zur Genese des Travertinlagers von Burgtonna in Thüringen. Quartärpaläontologie, $\underline{3}$ : 51-58, 6 Abb.; (Akademie-Verlag) Berlin

OWätzel, A. (1987): Zur Geomorphologie des Absatzraumes der holozänen Binnenwasserkalke im Mühlhäuser Becken. - Alt-Thüringen, 22/23: 7-28; Weimar

\subsection{Ingenieurgeologie, Geologie und Baukunst}

- $\square$ Aderhold, Gabriele (2005): Klassifikation von Erdfällen und Senkungsmulden in karstgefährdeten Gebieten Hessens, Empfehlungen zur Abschätzung des geotechnischen Risikos bei Baumaßnahmen. - Geol. Abh. Hessen, 115; 100 S., 46 Abb., 18 Tab., 2 Anl., 1 Kt.-Beil.; Wiesbaden

-Archner, Gundolf (1992): Ingenieurgeologische Kartierung der Stadt Göttingen- Blatt Groß Ellershausen Süd (TB Nord) mit Erläuterungen. - Dipl.-Arb. [unveröff.] Univ. Göttingen 1992; 32 S., ca. 110 ungez. S.

-Auras, Michael (1998): Der Habichtswald-Lapillituf als Naturwerkstein. - Denkmalpflege \& Kulturgeschichte, 2: 48-57; (Hess. Landesamt f. Denkmalpflege) Wiesbaden

-Bake, Rolf (1979): Ingenieurgeologische Kartierung der Altstadt Göttingen, Teilblatt Nord. - Dipl.-Arb. [unveröff.] Univ. Göttingen 1979; 137 S.

-Bartel, Gudrun (1990): Ingenieurgeologische Kartierung der Stadt Göttingen - Teilblatt Groß Ellershausen (Mitte). - Dipl.-Arb. [unveröff.] Univ. Göttingen 1990; 107 S.

-Bartholomä, Manuela (1987): Der Sand vom Hohen Hagen - Ingenieurgeologische Untersuchung eines Baustoffes. - Dipl.-Arb. [unveröff.] Univ. Göttingen 1987; 62 S. 
-Baucks, Volker (1993): Ingenieurgeologische Kartierung der Stadt Göttingen - Teilblatt Rosdorf (NENord). - Dipl.-Arb. [unveröff.] Univ. Göttingen 1993; 100 S.

OBiewald, Wolfgang (1993): Die Eisenbahnbrücke von Ilmenau-Roda und die Subrosion an der Randstörung des Thüringer Waldes. - Geowiss. Mitt. Thür., 11: 93-97, 4 Abb.

OBiewald, Wolfgang (1994): Das Zubruchgehen des alten Kupferschieferschachtes „Getreuer Friedrich“ im Revier Ilmenau/Roda und seine Folgen. - Beitr. Geol. Thür., N.F., 1: 85-94, 6 Abb.; Jena

QBiewald, Wolfgang (1996): Ingenieurgeologische Untersuchungen zu Setzungsschäden am Südturm der Stadtkirche St. Georg Schmalkalden (Thüringen). - Geowiss. Mitt. Thüringen, 4: 79-100, 7 Abb., 6 Fotos; Weimar

QBiewald, Wolfgang (2001): Baugrundschwächen in Thüringen? - Beispiele aus einem Aufgabenberiech der Ingenieurgeologen der TLUG < Vortragskurzfassung > - In: Rauche, Henry [Hrsg.]: Regionale und angewandte Geologie der Grenzregion der Süddeutschen und der Mitteldeutschen Scholle. Programm und Kurzfassungen der Vorträge. - 10. Jahrestagung Gesellschaft f. Geowissenschaften i. Schmalkalden, 19.-22. September 2001. - Exkursionsführer u. Veröff. Ges. f. Geowiss., 214; S. 79-82, 2 Abb.; Berlin 2001

[darin: Fallbeispiel Stadtkirche St. Georg, Schmalkalden]

-Birkefeld, Andreas (1997): Ingenieurgeologische Kartierung entlang der Bundesautobahn A 7 (km 264,38 - 268,35). - Dipl.-Kart. [unveröff.] Univ. Göttingen; 100 Bl.

- Breuer, Rolf (1990/91): Ingenieurgeologische Kartierung der Stadt Göttingen - Blatt Elliehausen (Teilblatt Nord). - Dipl.-Arb. [unveröff.] Univ. Göttingen 1990/91; 87 S., ca. 30 ungez. Bl.

-Bubenik, Rolf (1990): Ingenieurgeologische Kartierung der Stadt Göttingen - Blatt Groß Ellershausen - Teilblatt Süd. - Dipl.-Arb. [unveröff.] Univ. Göttingen 1990; 118 S.

-Burchard, Angelika (1995): Ingenieurgeologische Kartierung der Stadt Göttingen - Blatt Göttingen 4425/22 (DGK 5). - Dipl.-Kart. [unveröff.] Univ. Göttingen 1995; 28 S.

口Casper, H. (1942): Die Baumöglichkeiten für Talsperren im Einzugsgebiet der oberen Werra. - Die Weser, 21(3): 26-28; Bremen

[Stratigraphie und Baugrundgeologie]

-Daneshmand, Hayedeh (1991): Ingenieurgeologische Kartierung der Stadt Göttingen - Teilblatt Grone Nordost (Süd). - Dipl.-Arb. [unveröff.] Univ. Göttingen 1991; 70 S. u. ca. 85 ungez. Bl.

-Deichmann, Thomas (1979): Ingenieurgeologische Kartierung der Altstadt von Göttingen - Teilblatt Altstadt Süd. - Dipl.-Arb. [unveröff.] Univ. Göttingen 1979; 114 S.

ODeppe, Stefan \& Pippig, Matthias (2002): Erkundung und Maßnahmen zur Beherrschung der Salzlösungszuflüsse im Grubenfeld Merkers. - Kali u. Steinsalz, 2002(2): 40-49, 26 Abb.; Essen [Hydrogeologie, Ingenieurgeologie]

-Diesing, Hans-Jörg \& Ledendecker, Stefan (1986): Die Niederterrasse im Subrosionsbekcen von Pöhlde. Mit einem Kataster von grundwassergefährdenden Deponien. - Dipl.-Arb. [unveröff.] Univ. Göttingen 1986; 157 S.

-Dirks, Erwin (1993): Ingenieurgeologische Kartierung der Stadt Göttingen DGK 5 (Blatt Göttingen Nordwest) Nr. 4425/15. - Dipl.-Arb. Teil 1 [unveröff.] Univ. Göttingen 1993; 72 S.

-Edel, Beate von (1995): Ingenieurgeologisches Kartenwerk der Stadt Göttingen auf Basis der Deutschen Grundkarte (DGK 5), Blatt Geismar-West Nr. 4425/18 - Maßstab 1 : 5 000. - Dipl.-Kart. [unveröff.] Univ. Göttingen 1995; 1 Mappe m. Textbd. 18 Bl.; Anlagenbd. m. 7 Kt.) 
-Fahlbusch, Klaus (1977): Einige Basalt-Vorkommen, baugeologisch betrachtet. - Geol. Jb. Hessen, 105: 235-243; Wiesbaden

[darin: Vorkommen im Habichtswald]

-Feldmann, Reinhard (1983): Ingenieurgeologische Kartierung der Stadt Göttingen - Teilblatt Geismar-Süd; Dipl.-Arb. [unveröff.] Univ. Göttingen 1983; 170 S., 14 ungez. Bl.

-Finkenwirth, A. (1968): Böschungsrutschungen bei der Aufschlitzung des Braunhäuser Tunnels (Hauptstrecke Bebra-Göttingen) der Deutschen Bundesbahn. - Fortschr. Geol. Rheinlande u. Westfalen, 15: 441-462, 3 Abb., 2 Taf.; Krefeld

$\square$ Fleer, P. (1993): Geologie und Grundwasser in Eschwege im Hinblick auf die Baugrundverhältnisse im Stadtgebiet. - Dipl.-Arb. [unveröff.] Fachber. Geowiss. FU Berlin; 41 S.

- Gazawe, Camal (1990): Ingenieurgeologische Kartierung der Stadt Göttingen - Blatt Elliehausen Teilblatt Mitte. - Dipl.-Arb. [unveröff.] Univ. Göttingen 1990; 82 S.

- Geissler, Horst (1993): Geologische Aspekte bei Bau neuer Eisenbahntunnel in Niedersachsen. - In: Gross-Uffenorde, H.; Jahnke, H. \& Schindler, E. [Hrsg.]: O. H. Walliser Festschrift. - Göttinger Arb. Geol. Paläont., 58; S. 145-154, 7 Abb.; (Selbbstverlag d. Geol. Inst.) Göttingen 1993

- Gottschalk, Jürgen (1982): Ingenieurgeologische Kartierung der Stadt Göttingen, Teilblatt Treuenhagen. - Dipl.-Arb. [unveröff.] Univ. Göttingen, 98 S.

-Grossmann, Axel (1988): Ingenieurgeologische Kartierung der Stadt Göttingen - Teilblatt Grone Mitte. - Dipl.-Arb. [unveröff.] Univ. Göttingen 1988; 126 S.

-Gwinner, Manfred Peter (1956): Eine geologische Baugrundkarte der Stadt Göttingen. - Geol. u. Bauwesen, 22 (1): 49 - 53; Wien

- Heckert, Peter (1994): Ingenieurgeologische Kartierung der Stadt Göttingen - Blatt Elliehausen 4425/14 (DGK 5). - Dipl.-Kart. [unveröff.] Univ. Göttingen 1994; Textbd. 15 S., 8 Beil zus. i. Mappe

OHeyer (1924): Beispiele für den Einfluß der geologischen Lagerungsverhältnisse auf die Schießarbeit in dem oberen Lager der Gewerkschaft Alexandershall, Berka a.d. Werra. - Kali, etc., 18 (19): 287-288; Halle/Saale [Ingenieurgeologie]

$\square$ Hildebrand, Gerhard \& Prinz, Helmut (1973): Fallgewichstsseismische und ingenieurgeologische Untersuchungen für Straßenbauten über Zechstein-Sulfat. - In: Wolters, R. [beteiligt]: Symposium - Erdfälle und Bodensenkungen: Ingenieurgeologische Probeme löslicher Gesteine - Effondrements et affaissements: problèmes de géologie de l'ingénieur relatifs aux roches solubles - Sink-holes and subsidence: engineering geological problems related to soluble rocks. - Hannover 1973 - Proceedings. - Thema 3: Methoden der Abgrenzung von Erdfallbereichen und der Lokalisierung unterirdischer Hohlräume, S. T3/E1 - T3/E10, 7 Abb.; (Deutsche Gesellschaft f. Erd- und Grundbau) Essen 1973 [Straßenbau Umgebung Eschwege]

- Hooshyar, Farhad (1990): Ingenieurgeologische Kartierung der Stadt Göttingen - Blatt Grone, Teilblatt Nordost (Mitte). - Dipl.-Arb. [unveröff.] Univ. Göttingen 1990; 74 Bl.

OHopp, Heike (2007): Vorkommen, Eigenschaften und Konservierung von Sandsteinen des Unteren Keupers in Thüringen. - In: Siegesmund, S. \& Ehling, A. (eds.): Rohstoff Naturstein - Teil 2. Natural Building Stone Ressources - Part 2. - Z. Dt. Ges. Geowiss., 158(4): 773-784, 5 Abb., 1 Tab., 3 Taf.; Stuttgart

[darin: Bausteinverwendung Schloß Friedenstein/Gotha; Tab. 1: Gesteinstechnische Kennwerte, darin Gestein d. Lagerstätten Kleinvargula, Gotha] 
- $\square$ Hoppe, A. \& Fritsche, J. G. [Bearb.](1999): Tätigkeitsbericht des Hessischen Landesamtes für Bodenforschung 1996 bis 1999. - Geologie in Hessen, $\underline{\mathbf{5}} / 1999 ; 52$ S., 41 Abb.; [Hrsg. Hess.

Landesamt $\mathrm{f}$. Bodenforschung] Wiesbaden

[darin:

Kap.: Salzwasserversenkung und Grundwasserstypisierung in Osthessen - S. 27, Abb. 27-29;

Kap.: Geologische Beratung bei Planung und Bau der Bundesautobahn A 44, Kassel-Eisenach - S. 27 32, Abb. 40;

Kap.: Baugrund und Gründungsberatung für die staatliche Bauverwaltung am Beispiel des Schlosses Kassel-Wilhelmshöhe - S. 34-36, Abb. 34-36]

QHoppe, W. (1940): Die technische Untersuchung und Beurteilung der Sandsteine. - Z. prakt. Geol., $\underline{48}(3): 25-36$

$\underline{48}(4): 43-47$

48 (5): 49-59, 8 Abb.; Berlin

[darin: Rhät-Sandsteine Gr. Seeberg SE’ Gotha; Rotliegend-Sandsteine Tambach-Dietharz]

QKatzschmann, Lutz \& Seidel, Gerd (1993): Werksteine in den Städten des östlichen und südlichen Thüringer Beckens. - Z. angew. Geol., $\underline{\text { 39}(2): ~ 63-70, ~} 2$ Abb., 7 Tab.; Berlin

[Geologie und Baukunst, darin: Mühlhausen, Gotha, Ilmenau]

QKlaua, Dieter (1966): Beziehungen zwischen petrographischer Ausbildung und gesteinstechnischen Eigenschaften der Seeberg-Sandsteine (Rhät) bei Gotha in Thüringen. - Geologie, 15(7): 822-832, 3 Abb., 6 Tab.; Berlin

OKoch, Günter \& Gaitzsch, Hendrik (1989): Speicherraumausbildung in Salzlösungsvorkommen im Salinar des Werra-Kaligebietes und ihre Bedeutung für Abdichtungsinjektionen. - Z. angew. Geol., 35(6): 175-179, 10 Abb.; Berlin

[Ingenieurgeologie]

-Kracke, T.; Müller, Chr.; Krinninger, St.; Wedekind, W.; Rüdrich, J. \& Siegesmund, S. (2007): Buntsandsteine Göttingens: Verwendung, Verwitterung und Konsolidierung am Beispiel des Bartholomäus-Friedhofs. - In: Siegesmund, S. \& Ehling, A. (eds.): Rohstoff Naturstein - Teil 2. Natural Building Stone Ressources - Part 2. - Z. Dt. Ges. Geowiss., 158(4): 957-984, 19 Abb., 6 Tab.; Stuttgart

-Krakow, Lutz (1986): Ingenieurgeologische Kartierung der Stadt Göttingen - Teilblatt Grone Nord. Dipl.-Arb. [unveröff.] Univ. Göttingen 1986; 145 S.

QKirschstein, Mario (2001): Neubau BAB A 38 - Besonderheiten im Abschnitt des Rötausstriches am Südhang der Bleicheröder Berge und Möglichkeiten einer bautechnischen Berücksichtigung $<$ Vortragskurzfassung > . - In: Rauche, Henry [Hrsg.]: Regionale und angewandte Geologie der Grenzregion der Süddeutschen und der Mitteldeutschen Scholle. - Programm und Kurzfassungen der Vorträge. - 10. Jahrestagung Gesellschaft f. Geowissenschaften i. Schmalkalden, 19.-22. September 2001. - Exkursionsführer u. Veröff. Ges. f. Geowiss., 214; S. 145-146; Berlin 2001

[Stratigraphie, Geomorphologie, Ingenieurgeologie]

QKlaua, Dieter (1988): Dekorationssteine an romanischen Burgen Thüringens und ihre Herkunft. (Geologie und Denkmalpflege - Beiträge zur Verwendung, Verwitterung und Konservierung von Gesteinen in Architektur und Plastik der DDR) Abh. Staatl. Museums f. Mineralogie u. Geologie zu Dresden, 35: 15-20, 5 Bilder i. Tafelanh.; Leipzig [Runneburg/Weißensee, Wartburg b. Eisenach] 
-Kukis, Michael (1991): Ingenieurgeologische Kartierung der Stadt Göttingen - Teilblatt Grone Nordwest-Süd - mit ingenieurgeologischer Beschreibung der Lockergesteine. - Dipl.-Arb. [unveröff.] Univ. Göttingen 1991; 95 S., ca. 40 ungez. Bl.

-Lepper, Jochen (2007): Naturwerkstein - kein Baurohstoff wie all die anderen! - Z. Dt. Ges. Geowiss., 158(4): 685-693, 1 Abb., 3 Tab.; Stuttgart

[darin Tab. 3: Rohblockhöffigkeiten ausgewählter Naturwerksteine - u.a. Sandstein, Cornberg, Hessen]

-Loris, Peter (1990): Ingenieurgeologische Kartierung der Stadt Göttingen mit Beschreibung der Lockergesteine - Blatt Göttingen Nordwest (Teilblatt Nord). - Dipl.-Arb. [unveröff.] Univ. Göttingen 1990; 84 u. ca. 35 ungez. Bl.

-Manns, Michael (1991): Ingenieurgeologische Kartierung der Stadt Göttingen - Teilblatt Rosdorf (NW-Mitte). - Dipl.-Arb. [unveröff.] Univ. Göttingen 1991; 67 u. ca. 60 ungez. Bl.

-Meyer, Rolf (1985): Die Stabilität der Hänge an der Wellenkalk-Schichtstufe des Göttinger Waldes. Dipl.-Arb. [unveröff.] Univ. Göttingen 1985; 84 S.

-Möckel, Stefan (1991): Ingenieurgeologische Kartierung Blatt Rosdorf 4425/27-Mitte und bodenmechanische Beschreibung der Lockergesteine. - Dipl.-Arb. [unveröff.] Univ. Göttingen 1991; $84 \mathrm{~S}$.

QMolt, Emil \& Woite, Helmut (1938): Reichsautobahn Jena-Eisenach-Kassel-Warburg. Von Jena bis Gotha. Von Gotha bis Warburg. - Die Straße, $\underline{\mathbf{5}}(16): 502-507,4$ Abb.

Referat in: N. Jb. Mineral. etc., Referate, 1939 (Bd. II): 707 (Stützel); Stuttgart

[Baugrundgeologie, Naturstein-Fassadenverkleidung]

[Vorlage nicht eingesehen, zitiert nach Angaben im genannten Referat]

-Namenskürzel (-a)(1951): Hohlräume werden mit „,scharfem“ Sand verfüllt - Ein Jahr muß noch am Rothenberg gearbeitet werden. - HN, 1951; Nr. 140 v. 20.6.1951, 1 Abb.; Kassel

[Verfüllung v. Hohlräumen des ehemaligen Bergbaus i. Kassel, Marburger Straße]

$\square$ Namenskürzel (B) (1962): < Baugrundschäden durch Subrosion> In Weißenbach ist es unheimlich. Der Untergrund bricht ein / Baugebiet gesperrt / Risse in der Kirche. - Werra-Rundschau, 1962; Nr. 6 v. 8.1.1962, [S. 5], 1 Abb.; Eschwege

$\square$ Namenskürzel (Na) (1966): < Hohlraumerkundung a. d. B 27 bei Eschwege-West $>$ Bodenmessungen mit Hammerschlag - Seismik. „Lockerzonen“ unterhalb der B 27 festgestellt. Geologische Landesämter Wiesbaden und Hannover führen die Untersuchungen durch. - Werra-Rundschau, 1966; Nr. 91 v. 20.4.1966, S. 3, 1 Abb.; Eschwege

- $\square$ Namenskürzel (rff)(1981): „Störzone“ verhindert Bau einer Aufbereitungsanlage - 50-100 km breiter Streifen in Nordhessen ungeeignet. - HA, 1981; Nr. 119 v. 25.5.1981; Kassel [Untergrund-Geologie und Wiederaufbereitungsanlage für Kernbrennstoffe]

-Namenskürzel (m.s.)(1984): Straße/Einsturzgefahr - Suche nach alten Stollen. - HNA, 1984; Nr. 52 v. 1.3.1984, 2 Abb.; Kassel [Bergbaurelikte im Habichtswald/Kassel]

-Pohl, Andreas (1995): Ingenieurgeologische Kartierung Blatt Holtensen West (Teilblatt Süd) - DGK 4425/8 mit Erläuterungen. - Dipl.-Arb. u. Dipl.-Kart. [unveröff.] Univ. Göttingen 1995

$\square$ Prinz, H. (1973): [Fallstudie Straßenbau bei Eschwege] Diskussion Thema 4 (Fallstudien und konstruktive Maßnahmen beim Bauen in Erdfallgebieten). - In: Wolters, R. [beteiligt]: Symposium Erdfälle und Bodensenkungen: Ingenieurgeologische Probeme löslicher Gesteine - Effondrements et affaissements: problèmes de géologie de l'ingénieur relatifs aux roches solubles - Sink-holes and 
subsidence: engineering geological problems related to soluble rocks. - Hannover 1973 - Proceedings. - Thema 4: Fallstudien und konstruktive Maßnahmen beim Bauen in Erdfallgebieten, S. D4/1 D4/19, Abb. u. Tab.; hier S. 13, 2 Abb.(Deutsche Gesellschaft f. Erd- und Grundbau) Essen 1973 [Straßenbau bei Eschwege]

$\square$ Prinz, Helmut (1973): Gründung eines Bauwerkes in einer Korrosionssenke im Zechsteinsulfat. - In: Wolters, R. [beteiligt]: Symposium - Erdfälle und Bodensenkungen: Ingenieurgeologische Probeme löslicher Gesteine - Effondrements et affaissements: problèmes de géologie de l'ingénieur relatifs aux roches solubles - Sink-holes and subsidence: engineering geological problems related to soluble rocks. - Hannover 1973 - Proceedings. - Thema 4: Fallstudien und konstruktive Maßnahmen beim Bauen in Erdfallgebieten, S. T4/C1-C4, 2 Abb.; (Deutsche Gesellschaft f. Erd- und Grundbau) Essen 1973 [Straßenbau Umgebung Eschwege]

ORöhling, H.-G. (2003): Woher kommen die Baustein der Martinskirche in Heiligenstadt. - In: Müller, Th. T. [Hrsg.]: Die St. Martinskirche zu Heiligenstadt - 17 Beiträge zu ihrer Geschichte. Heiligenstädter Schriften, 2; S. 151-172, 14 Abb., 4 Tab., 3 Taf.; (Cordier) Heiligenstadt [Vorlage nicht eingesehen]

QRöhling, Heinz-Gerd (2004): Der Heidkopftunnel - der Tunnel der deutschen Einheit. - Eichsfelder Heimatzeitschrift, 48 (5)/2004(Mai): 169-170, 1 Abb.; Duderstadt

QRöhling, Heinz-Gerd (2008): Au(f)s diesem Fels müßt ihr bauen! - Zur geologischen Einordnung der Burg Hanstein. - In: Hanstein, Hans-Dieter von [Hrsg.]: Burg Hanstein - Zur 700jährigen Geschichte einer eichsfeldischen Grenzfeste. - Herausgegeben im Auftrag des Familienverbandes der von Hanstein von.. - 296 S., zahlr. Abb.; hier S. 67-80, 12 Abb., 1 Tab.; (Mecke Druck u. Verlag) Duderstadt 2008

[Regionalgeologie, Erdgeschichte der Buntsandstein-Zeit, Solling-Sandstein als Baustein]

$\square$ Sauer (1961): < Instabilität des Kalbefelsens/Hoher Meißner> Naturschutzschutzbeauftragter Dr. Sauer stellt fest: Die Ursache liegt beim Bergbau. Sofortmaßnahmen zur Rettung der Kalbe gefordert. Höchste Eile notwendig. - Werra-Rundschau, 1961; Nr. 139 v. 20.6.1961, S. 3; Eschwege

-Schmidt, Hermann (1962): Göttinger Bausteine, geologisch gesehen. - Göttinger Jb., 1962: 11 - 18; Göttingen

-Schulten, Annette (1992): Ingenieurgeologische Grundlagen für die Stadtentwicklungsplanung mit der ingenieurgeologischen Kartierung des Teilblattes Holtensen Ost (Südteil). - Dipl.-Arb. [unveröff.] Univ. Göttingen 1992; 71 Bl., ca. 80 ungez. Bl.

OSchulze, Silvia (2001): Neue Erkenntnisse zur Ausbildung und subrosiven Beeinflussung der Röt-Folge am Südhang der Bleicheröder Berge <Vortragskurzfassung>. - In: Rauche, Henry [Hrsg.]:

Regionale und angewandte Geologie der Grenzregion der Süddeutschen und der Mitteldeutschen Scholle. - Programm und Kurzfassungen der Vorträge. - 10. Jahrestagung Gesellschaft f. Geowissenschaften i. Schmalkalden, 19.-22. September 2001. - Exkursionsführer u. Veröff. Ges. f. Geowiss. e.V., 214; S. 215-216; Berlin 2001

[Stratigraphie, Geomorphologie, Ingenieurgeologie]

-Schwanitz, Max (1987): Ingenieurgeologische Kartierung der Stadt Göttingen - Teilblatt Grone-Süd; Dipl.-Arb. [unveröff.] Univ. Göttingen 1987; 136 S.

aSeib, Gerhard (2007): Noch einmal zu Richelsdorfer Kupferschlackensteinen. - Rund um den Alheimer, 28: 23; Rotenburg/Fulda

[Verwendung als Baustein]

-Senft, Birgit (1994): Ingenieurgeologie der Groner Senke. - Dipl.-Arb. [unveröff.] Univ. Göttingen 1994; VII, 83 S. 
-Shojaei-Kawan, Houshang (1989): Ingenieurgeologische Kartierung von Teilblatt Groß Ellershausen Nord 4425/20 und bodenmechanische Beschreibung der Lockergesteine. - Dipl.-Arb. [unveröff.] Univ. Göttingen 1989; 90 S.

-Stautmeister, Holger (1995): Ingenieurgeologische Kartierung der Stadt Göttingen - Blatt Groß Ellershausen-Süd, 4425/26 (DGK 5). - [Dipl.-Arb.] [unveröff.] Univ. Göttingen 1995; Textbd. 19 S. u. 1 Kt., zus. i. Kassette

-Steging, Mathias (1983): Ingenieurgeologische Kartierung der Stadt Göttingen - Teilblatt GeismarNord. - Dipl.-Arb. [unveröff.] Univ. Göttingen 1983; III, 101 S.

-Tatter, Uwe-Christian (1993): Ingenieurgeologische Kartierung der Stadt Göttingen - DGK 5 Groß Ellershausen-Süd 4425/26 (Süd). - Dipl.-Arb. [unveröff.] Univ. Göttingen 1993; 79 S.

-Usdowski, E. (2001): Stable sulfur isotopes as a possible tool for tracing the provencance of the raw material of gypsum mortars / Stabile Isotope des Schwefels als mögliches Werkzeug bei der Bestimmung der Herkunft des Rohmaterials von Gips-Mörteln. - Chemie der Erde, 61(2): 140-147, 2 fig., 3 tabl.; Jena

[Mörtel der Burg Plesse bei Eddigehausen N’ Göttingen]

OWiefel, Josepha (1964): Die ingenieurgeologische Detailkarte der Stadt Ilmenau im Maßstab $1: 5000$. Z. angew. Geol., 10 (1): 37-42, 3 Abb.; Berlin

-Wilczewski, Norbert; Schulten, Annette \& Hering, Gerd (1993): Geologie und Stadtentwicklungsplanung. - In: Gross-Uffenorde, H.; Jahnke, H. \& Schindler, E. [Hrsg.]: O. H. Walliser Festschrift. - Göttinger Arb. Geol. Paläont., 58; S. 155-159, 2 Abb.; Göttingen 1993

-Wischnow, Dirk (1994): Ingenieurgeologische Kartierung der Stadt Göttingen: Blatt Grone - 4425/21 (DGK 5). - Dipl.-Kart. [unveröff.] Univ. Göttingen 1994; 6 S., 2 aufgez. Kt.

- $\square$ Wittke, W. (1973): Fallstudien und konstruktive Maßnahmen beim Bauen in Erdfallgebieten. - In: Wolters, R. [beteiligt]: Symposium - Erdfälle und Bodensenkungen: Ingenieurgeologische Probeme löslicher Gesteine - Effondrements et affaissements: problèmes de géologie de l'ingénieur relatifs aux roches solubles - Sink-holes and subsidence: engineering geological problems related to soluble rocks. - Hannover 1973 - Proceedings. - Thema 4: Fallstudien und konstruktive Maßnahmen beim Bauen in Erdfallgebieten,, S. G4/1 - G4/9; (Deutsche Gesellschaft f. Erd- und Grundbau) Essen 1973 [darin: Kassel, Eschwege]

- $\square \bullet$ Wolters, R. [beteiligt](1973): Symposium - Erdfälle und Bodensenkungen: Ingenieurgeologische Probeme löslicher Gesteine - Effondrements et affaissements: problèmes de géologie de l'ingénieur relatifs aux roches solubles - Sink-holes and subsidence: engineering geological problems related to soluble rocks. - Proceedings; ca. 300 S. (keine durchgehende Zählung); (Deutsche Gesellschaft f. Erdund Grundbau) Essen

QWunderlich, Jürgen (2001): Die Tunnelbauwerke der BAB A 71, Kammquerungsstrecke Thüringer Wald - Einige Bemerkungen zum Realitätsgehalt der geologischen Tunnelprognosen $<$ Vortragskurzfassung > . - In: Rauche, Henry [Hrsg.]: Regionale und angewandte Geologie der Grenzregion der Süddeutschen und der Mitteldeutschen Scholle. - Programm und Kurzfassungen der Vorträge. - 10. Jahrestagung Gesellschaft f. Geowissenschaften i. Schmalkalden, 19.-22. September 2001. - Exkursionsführer u. Veröff. Ges. f. Geowiss., 214; S. 233-239, 3 Tab.; Berlin

\subsection{Salzlösungszuflüsse und deren Bekämpfung}


ODeppe, Stefan \& Pippig, Matthias (2002): Erkundung und Maßnahmen zur Beherrschung der Salzlösungszuflüsse im Grubenfeld Merkers. - Kali u. Steinsalz, 2002(2): 40-49, 26 Abb.; Essen

OKoch, Günter \& Oettel, Siegfried (1982): Zu einigen hydrogeologischen Ergebnissen bei der Untersuchung von Salzlösungszuflüssen in den Gruben des VEG Kalibetrieb „Werra“ und daraus abzuleitende Schlußfolgerungen für die Methodik der Bekämpfungsarbeiten. - Z. geol. Wiss., 10 $\underline{10}$ (1): 133-140, 7 Abb.; Berlin

QKoch, Günter \& Gaitzsch, Hendrik (1989): Speicherraumausbildung in Salzlösungsvorkommen im Salinar des Werra-Kaligebietes und ihre Bedeutung für Abdichtungsinjektionen. - Z. angew. Geol., 35(6): 175-179, 10 Abb.; Berlin

OSchwandt, Arnold (1972): Beziehungen zwischen Salzlösungszuflüssen und Tektonik im Kalibergbau der DDR. - Ber. Dt. Ges. geol. Wiss., Reihe A, 17(2): 177-190, 9 Abb.; Berlin [darin: Merkers/Werra-Kalirevier]

-OSchwerter, Reinhard (1992): Die Bekämpfung von Salzlösungszuflüssen. - Kali u. Steinsalz, 11(1/2): 32-43, 9 Bilder, 2 Tab.; Essen

[Südharz-Kalirevier, Werra-Kalirevier]

\subsection{Geophysik}

-Ackermann, K. (1884): Bestimmung der erdmagnetischen Inklination von Kassel. - Abh. u. Ber. Vereins Naturkde. z. Kassel, $\underline{\mathbf{3 1}}$ (f. 1882/1883), 12 S. (getr. Zählg.); Kassel

OAhorner, Ludwig (1989): Seismologische Untersuchung des Gebirgsschlages am 13. März 1989 bei Völkershausen (DDR) im Kalibergbaugebiet an der Werra. - Kali u. Steinsalz, 10 (4/5): 110-116, 11 Bilder; Essen

OAhorner, Ludwig (1998): Entstehung und Ablauf des Gebirgschlages von Völkershausen am 13. März 1989 im Kalibergbaugebiet des Werratales, Thüringen, aus seismologischer Sicht. - In: Leydecker, Günter [Koordinator]: Der Gebirgschlag vom 13. März 1989 bei Völkershausen in Thüringen im Kalibergbaugebiet des Werratals. - Geol. Jb., Reihe E, 525; S. 25 - 46, 15 Abb.; Hannover 1998

-Angenheister, Gustav \& Consbuch, Claus v. (1961): Pulsationen des erdmagnetischen Feldes in Göttingen von 1953-1958. - Z. Geophysikk, 27(1): 3-12, 27(2): 103-111, insges. 5 Abb.; Würzburg

- $\square$ Q Anonym (1903): <Der Direktor des Geophysikalischen Instituts Göttingen, Prof. Wiechert, zu den Erderschütterungen vom Montag abend, 14.12.1903>. - Eschweger Tageblatt, 1903; Nr. 297 v. 19.12.1903; Eschwege

व $\square$ OAnonym (1903): < Ueber die erdbebenartige Erscheinung in Mitteldeutschland am Montag, den 13. Dezember...> - Eschweger Tageblatt, 1903; Nr. 300 v. 23.12.1903; Eschwege

- $\square$ ○ीAnonym (1911): Eine Erdbebenacht <Beben vom 16./17. November, Epizentrum Schwäbische Alb>. - Eschweger Tageblatt, 1911; Nr. 271 v. 17.11.1911; Eschwege

व $\square$ QAnonym (1911): Die Ursache des Bebens <Beben vom 16./17. November, Epizentrum Schwäbische Alb>. - Eschweger Tageblatt, 1911; Nr. 272 v. 18.11.1911; Eschwege

$\square$ Anonym (1903): < Erderschütterungen auch im Werratal und am östlichen Meißner spürbar> Eschweger Tageblatt, 1903; Nr. 294 v. 16.12.1903; Eschwege 
-Björnsson, Axel (1969): Aufzeichnung und Auswertung erdmagnetischer Pulsationen in Island und Göttingen. - Z. f. Geophysik, 포: 419-429, 8 Abb.; Würzburg

$\square$ Blum, Rainer (1993): Die magnetische Totalintensität am Meißner. - Geol. Jb. Hessen, 121: 191-205, 8 Abb.; Wiesbaden

-Blum, R.; Horn, M. \& Koschyk, K. (1984): Seismische Untersuchungen in der nördlichen Hessischen Senke. - Geol. Jb. Hessen, 112: 219 - 233, 7 Abb.; Wiesbaden

-Blum, R.; Diez, P. \& Etz, R. (2004): Die „Horn’sche Anomalie“ bei Warburg - Eine magnetische Neuvermessung. - Geol Jb. Hessen, 131 (f. 2003): 53 - 59, 5 Abb.; Wiesbaden [Bl. 4521 Liebenau]

$\square$ Breuer, Barbara; Dies, Maren \& Senf, Nicole (2001): Untersuchung des Salzeintrags aus der Werra in ein Flussauengebiet durch den Einsatz von geoelektrischen Messungen. - Z. angew. Geol., 47(3/4): 176-181, 5 Abb., 6 Tab.; Hannover [Werraaue bei Witzenhausen/Wenderhausen]

QBrieden, H.-J. (1967): Untertägige Slingrammessungen im Werra-Kalirevier zur Festlegung laugengefährdeter Grubenbaue. - (Geophysik im Bergbau, Teil II) Freiberger Forschungshefte., Reihe C, 226: 137-148, 9 Abb.; Leipzig

-Cornelius, Carl-Detlef (1954): Wie breiten sich Erdbebenwellen im Boden aus? - Das Einsturzbeben

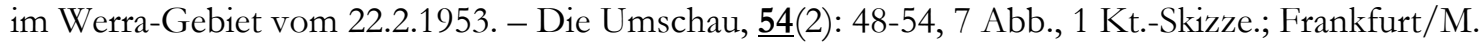
[Region Widdershausen, Kreis Hersfeld-Rotenburg]

DODachroth, Wolfgang (1988): Gesteinsmagnetischer Vergleich permischer Schichtfolgen im Mitteleuropa. - Z. geol. Wiss., 16(10): 959-968, 9 Abb.; Berlin [darin: Richelsdorfer Gebirge]

OEllenberg, Jürgen (1993): Rezente vertikale Erdkrustenbewegungen in Thüringen. - In: Mäusbacher, Roland \& Sedlacek, Peter [Hrsg.]: Freistaat Thüringen - Beiträge zur Landesforschung und Landesentwicklung. - Jenaer Geographische Schriften, 1; 199 S., zahlr. Abb. u. Tab.; hier: 7-22, 10 Abb.; Jena 1993

[darin: Westliches Thüringen]

- • Fromm, Kurt (1989): Paläomagnetische Datierung hochgelegener Sand-Kies-Terrassen der Weser. Eiszeitalter u. Gegenwart, 39: 57-61, 4 Abb.; Stuttgart

[Gewissenruh, Fürstenberg, Warmbeck]

OGabriel, Gerald; Jahr, Thomas \& Weber, Ute (2001): The gravity field south of the Harz Mountains - Predominated by granitic material? - Das Schwerefeld südlich des Harzes - Durch granitisches Material dominiert? - Z. geol. Wiss., 29(3): 249-266, 11 Abb., 2 Tab.; Berlin [darin: Nordwestthüringen]

-Gauss, K. F. [ermittelt](1834): Vorläufiger Bericht über verschiedene, in Göttingen ausgestellte magnetische Beobachtungen. - Göttinger gelehrte Anzeigen, 1834 (Nr. 128): 1265-1274; Göttingen

$\square$ Grubbe, K. (1976): Seismic c-refraction measurements along two crossing profiles in Northern profiles in Northern Germany and their interpretaion by a ray-tracing method. - In: Giese, Pl; Prodehl, C. \& Stein, A.: Explosion seismology in Central Europe - data and results. - Crustal and upper mantle structure in Europe, 1; XV, 429 S., 284 fig., 3 maps; hier: S. 268-282, 9 fig; (Springer) BerlinHeidelberg-New York [Hoher Meißner, Lkr. Göttingen, Solling - Gegend W'Nienburg]

-Hempfling, Rüdiger (1977): Beobachtung und Auswertung tagesperiodischer Variationen des erdelektrischen Feldes in der Umgebung von Göttingen. - Diss. Univ. Göttingen 1977; 83 S., Abb., 
13 Tab.

[Meßstationen i. Bramwald und Leinetal]

$\square \bullet$ Hinz, E.; Kaminski, W. \& Stein, A. (1976): Results of Seismic Refraction Profils from the Hoher Meißner to the North German Plain. - In: Giese, P1; Prodehl, C. \& Stein, A. (eds.): Explosion seismology in Central Europe - data and results. - Crustal and upper mantle structure in Europe, 1; XV, 429 S., 284 fig., 3 maps; hier: S. 257-267, 7 fig; (Springer) Berlin-Heidelberg-New York 1976 [Hoher Meißner, Lkr. Göttingen, Solling - Region Nienburg]

OHurtig, E.; Grosser, H.; Knoll, P. \& Neunhöfer, H. (1982): Seismologische und geomechanische Untersuchungen des seismischen Ereignisses vom 23.6.1975 im Werragebiet bei Sünna (DDR). Gerlands Beitr. Geophysik, 91(1): 45-61, 12 Abb.; Leipzig

-Jaeschke, Rudolf (1963): Registrierung von Pulsationen im südlichen Niedersachsen als Beitrag zur erdmagnetischen Tiefensondierung. - Mitt. Max-Planck-Inst. Aeronomie, 12 (1963); 38 S., 33 Abb., 3 Tab.; Berlin - auch als Diss. Univ. Göttingen 1963, 60 gez. Bl., Ab. [darin: Göttingen]

OJahr, Thomas; Kaiser, Diethelm \& Kroner, Corinna (2008): Die geophysikalische Erkundung von Erdfällen in Ernstroda (Thüringen). - The geophysical survey of earth subsidence in Ernstroda

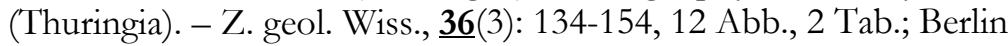

-Käding, Karl-Christian (1962): Geologische, magnetische und petrographische Untersuchungen tertärer Vulkanite und ihrer Begleiterscheinungen im Bereich des hessischen Werra-Kaligebietes. Diss. FU Berlin Fachber. Geowiss. 1962; 112 S., Abb., Anl.

QKauter, Kurt (1963): Beitrag zur Klärung der Geologie des tieferen Untergrunds im nordwestlichen Thüringer Becken. - Z. angew. Geol., 9 (4): 198-204, 8 Abb.; Berlin [Strukturgeologie, Geophysikalische Messungen]

OKlaus, Dieter \& Schröder, Norbert (1967): Erfahrungen beim Einsatz geophysikalischer Meßverfahren in der Flußspat- und Schwerspaterkundung. - Z. angew. Geol., 13(11/12): 610-618, 11 Abb.; Berlin [darin: Bohrungen bei Ruhla]

QKnoll, Peter (1990): The fluid-induced tectonic rockburst of March 13, 1989 in the „Werra“ potash mining district of the GDR (first results). - Gerlands Beiträge z. Geophysik, 99 (3): 239-245, 4 fig.; Leipzig

-Koenen, A. v. (1895): Ueber die Auswahl der Punkte bei Göttingen, an welchen bei Probependelmessungen Differenzen in der Intensität der Schwere zu erwarten waren. - Nachr. Ges. Wiss. z. Göttingen, 1895: 242-247; Göttingen - Aufsatz zusammen mit W. Schur: Ueber die Ergebnisse der ersten Pendelmessungen.

-Kohlrausch, F. (1869): Die erdmagnetischen Elemente für Göttingen 1867 Juli 9 nebst Säcularvariationen. - Annalen d. Physik u. Chemie, 138(1)[zgl. 5. Reihe, Bd. 18]: 173; Leipzig

-Korb, H. G. (1961): Über die Analyse der Schwankungen des Grundwasserspiegels in dem überfluteten Bergwerk Sontra. - Z. Geophysik, 27 (2): 75-88, 6 Abb.; Würzburg

-Krahmann, Rudolf (1926): Magnetische Untersuchung im Habichtswald bei Kassel als Ergänzung der geologischen Kartierung. - Z. prakt. Geol., 34.1926 (1): 11-14, 2 Abb.; Berlin

- $\bullet$ Kremser, Gert (1962): Ergebnisse erdmagnetischer Tiefensondierung in der Umgebung von Göttingen. - Z. f. Geophysik, 208(1): 1-10, 9 Abb.; Würzburg [u.a. Profil Pöhlde-Hann. Münden - Oelshsn./Hess.; Wildeck/Kr. Hersfeld-Rotenburg] 
QKunze, Alfred (1972): Bericht über die Auswirkungen des Erdbebens vom 22.1.1970 in der Schwäbischen Alb auf den Südwestteil der DDR. - Geologie, 21 (3): 270-287, 2 Abb., 1 Tab.; Berlin [darin: Eisenach, Gotha, Bezirk Suhl]

- $\square$ OKutscher, Fritz (1953): Angewandte Erdmagnetische Messungen in Hessen: 1. Zusammenstellung der bisherigen speziellen erdmagnetischen Messungen in Hessen. - Notizbl. Hess. L.-A.

Bodenforsch., [6. Folge, H. 4] 81: 350-367, 9 Abb.; Wiesbaden

[darin: „Erdmagnetische Messungen auf Basalte“: a) Habichtswald b) Solling c) Umgebung Kassel, d) Stellberg/Söhrewald e) Meißner (Kitzkammer, Plateau zw. Altarstein u. Bransrod) f) Basalt i. thür. Kaligebiet]

$\square$ Kutscher, Fritz (1965): Angewandte erdmagnetische Messungen in Hessen - 6. Erdmagnetische $\Delta Z$ Messungen im Gebiet der Blauen Kuppe südlich Eschwege. - Notizbl. Hess. L.-A. Bodenforsch., 93: 351-354, 1 Abb.; Wiesbaden

-Kutscher, Fritz (1966): Angewandte Erdmagnetische Messungen in Hessen: 7. Erdmagnetische Messungen an den Wolkenbrüchen bei Trendelburg (Bl. 4422 Trendelburg, Hessen). - Notizbl. Hess. L.-A. Bodenforsch., 94: 394 - 397, 1 Abb.; Wiesbaden

OLeydecker, Günter [Koordinator] (1998): Der Gebirgschlag vom 13. März 1989 bei Völkershausen in Thüringen im Kalibergbaugebiet des Werratals. - Geol. Jb., Reihe E, 포; 98 S., 40 Abb., 10 Tab., 3 Taf.; Hannover 1998

OLeydecker, Günter \& Aichele, Helmut (1998): The Seismogeographical Regionalisation of Germany. The Prime Example für Third-Level Regionalisation. - In: Leydecker, Günter [Koordinator] Der Gebirgschlag vom 13. März 1989 bei Völkershausen in Thüringen im Kalibergbaugebiet des Werratals. - Geol. Jb., Reihe E, 55; 98 S., Abb., Kt.; Hannover; hier: S. 85 - 98, 6 Abb., 1 Tab.; Hannover 1998

OLeydecker, G.; Grünthal, G. \& Ahorner, L. (1998): Der Gebirgsschlag vom 13. März 1989 bei Völkershausen in Thüringen im Kalibergbaugebiet des Werratals. - Makrosseismische Beobachtungen und Analysen. - In: Leydecker, Günter [Koordinator]: Der Gebirgschlag vom 13. März 1989 bei Völkershausen in Thüringen im Kalibergbaugebiet des Werratals. - Geol. Jb., Reihe E, 포; S. 5 - 24, 4 Abb., 5 Tab.; Hannover 1998

-Lötzsch, Katharina (2005): Ein Vibrator steht im Walde - K+S AG geht mit riesiger Rüttelplatte auf Salzsuche im Werra-Fulda-Kalirevier. - Werra-Rundschau, 2005; Nr. 113 v. 18.3.2005, 3 Abb.; Eschwege [Vibro-Seis; Seismische Lagerstättenerkundung]

QLux, K.-N. \& Tita, J. (1985): Ein Katalog geologisch-geophysikalischer Normalprofile ausgewählter stratigraphischer und regionaler Einheiten in der DDR. - Z. angew. Geol., 31(3): 68-71, 1 Abb.; Berlin [darin: Profile Westthüringen]

-Meitzner, Wolfgang (1962): Magnetische Untersuchungen am Backenberg bei Güntersen. - Z. f. Geophysik, 28 (3): 137-154, 11 Abb., [2 Tab.]; Würzburg

OMeincke, Wilhelm (1966): Geothermische Verhältnisse im Zechstein und Buntsandstein des Thüringer Beckens und ihre Beziehungen zu den Strukturen des variszischen Untergrundes. - Ber. dt. Ges. geol. Wiss., Reihe A, 11 (1/2): 209-216, 6 Abb., 1 Tab.; Berlin

OMenning, M. ; Katzung, G. \& Lützner, Harald (1988): Magnetostratigraphic investigations in the Rotliegendes (300-252 Ma) of Central Europe. - Z. geol. Wiss., 16 (11/12): 1045-1063, 7 fig.; Berlin [darin: Thüringer Wald]

$\square$ Namenskürzel (Na) (1966): < Hohlraumerkundung a. d. B 27 bei Eschwege-West $>$ Bodenmessungen mit Hammerschlag - Seismik. „Lockerzonen“ unterhalb der B 27 festgestellt. Geologische 
Landesämter Wiesbaden und Hannover führen die Untersuchungen durch. - Werra-Rundschau, 1966; Nr. 91 v. 20.4.1966, S. 3, 1 Abb.; Eschwege

口ONamenskürzel (dpa) (1975): Gebirgsschlag löste Beben aus - DDR-Bergwerk eingestürzt. - HA, $\underline{\mathbf{1 9 7 5}}$; Nr. 150 v. 3.7.1975; Kassel

ONamenskürzel (nh) (1989): Gebirgsschlag in DDR-Kalibergwerk - Risiko eines Bebens bewußt eingegangen. - Die Weser, $\underline{\mathbf{6 3}}(3)$ : 76-77, 1 Abb.; Bremen

[Kalibergwerk Werra-Revier]]

- OONamenskürzel (dpa/red)(1989): Auch Teile des Bundesgebietes erschüttert: Sprengung in DDR löste Erdbeben aus. - HNA, 1989; Nr. 62 v. 14.3.1989; Kassel

[Hessisch-thüringisches Werra-Kalirevier]

- 0 Namenskürzel (AP) (1989): DDR gibt Bundesrepublik Schuld an Gebirgsschlag - Forderung: Einpressen von Kali-Abwässern einstellen. - HNA, 1989; Nr. 62 v. 14.3.1989; Kassel [Hessisch-thüringisches Werra-Kalirevier]

- OONamenskürzel (dpa/AP/red)(1989): Erdbeben nach Sprengung im Kalibergbau - Bonn weist Vorwürfe aus DDR zurück. - HNA, 1989; Nr. 63 v. 15.3.1989; Kassel

-ONamenskürzel (dpa)(1989): Gebirgsschlag im Werra-Kalibergbaugebiet - Bebenexperte: Tausende Stützpfeiler eingeknickt. - HNA, 1989; Nr. 70 v. 23.3.1989; Kassel

QNaunhöfer, Horst \& Grünthal, Gottfried (1995): Das Erdbeben vom 7. April 1847 im Thüringer Wald. - Z. geol. Wiss., 23 (3): 277-286, 3 Abb.; Berlin

-Nyblad, Iris (1996): Die Geologie des südlichen Endes des Oberaulaer Grabens und seiner Tiefenfortsetzung nach gravimetrischer Modellierung. - Dipl.-Arb. [unveröff.] Univ. Göttingen 1996; 82, 54 S. - Die Vorlage enthält zwei Werke

-Patriciu, Valeriu (1930): Geologische und geophysikalische (radioaktive) Untersuchungen am Westrande des Göttinger Leinetalgrabens. - Abh. Pr. Geol. Landesanst., N.F., 116: 163-194, 2 Abb., Taf. 11 u. 12; Berlin

- Patzke, Werner (1936): Untersuchungen über die Genauigkeit von Pendelmessungen an fester Station (Reichsvermessung 1935, Basisstation Göttingen). - Z. f. Geophysik, 12(5/6). 253-268, 16 Abb., 6 Tab., 1 Taf.; Braunschweig - zgl. Diss. rer. nat. Univ. Göttingen 1936

-0•Peter, Christof (1995): Elektrische Leitfähigkeitsmodelle in Südhannover, Nordhessen und im westlichen Thüringen, abgeleitet aus der elektromagnetischen Induktion durch natürliche Felder. - II, 130 S., Abb.; (Cuillier) Götttigen; zgl. Diss. Univ. Göttingen 1994

[Untersuchungen zw. Hannover, Herborn/Hessen und Erfurt]

-Plaumann, Siegfried \& Lepper, Jochen (1980): Gravimetrische Untersuchungen an Erdfällen im Reinhardswald und Solling. - Geol. Jb. Hessen, 107: 251-259, 6 Abb.; Wiesbaden [Untersuchungen u.a.: (Kleiner) "Trockener" und (Großer) "Nasser Wolkenbruch" E' Trendelburg]

$\square$ Plein, Eberhard (1954): Erdmagnetische Messungen an dem Basaltvorkommen des Hirschbergs bei Großalmerode (Niederhessen). - Notizbl. Hess. L.-A. Bodenforsch., $\underline{\mathbf{8 2}}$ (= 6. F., H. 5): 334 - 340, 3 Abb.; Wiesbaden

$\bullet \square$ Pockels, F. (1897): Ueber den Gesteinsmagnetismus und seine wahrscheinlichen Ursachen. - N. Jb. Mineral. etc., 1897(Bd. I): 66-73 (Briefl. Mitt.); Stuttgart [Bezugnahme a. Meissner, Bilstein i. Kaufunger Wald; Brackenberg b. Göttingen, Hoher Hagen b. Dransfeld, Hengelsberg] 
-Prechtl, Daniel (1994): I. Geologische Kartierung des Ottrauer Grabens in Hessen (TK 25: 5122 Neukirchen) - II. Geologie des Ottrauer Grabens und seine Tiefenfortsetzugn nach gravimetrischer Modellierung. - Dipl.-Kart. u. Dipl.-Arb. 1994; 73 S., ca. 20 ungez. S. Anhang

QRische, H. (1960): Über die Möglichkeien der reflexionsseismischen Erkundung im Thüringer Becken. - Ber. geol. Ges. DDR, $\underline{\mathbf{5}}(1 / 2)$ : 78-84, 4 Abb., 1 Tab.; Berlin [Erdöl-, Erdgasgebiet Mühlhäusen-Bad Langensalza]

ORoesing, G.; Behrens, H.-J.; Kuhnt, W. \& Fleischer, W. (1987): Application of simple source models for description of the mechanism of small seismic events in mining regions. - Gerlands Beiträge z. Geophysik, $\underline{\mathbf{9 6}}$ (2): 162-170, 7 fig., 1 tabl.; Leipzig [Thür. Werra-Kalirevier, Lokalitäten anonymisiert]

-Schenk, Erwin (1951): Ergebnisse geomagnetischer Untersuchungen im Braunkohlengebiet des Stellberges bei Kassel. - Notizbl. Hess. L.-A. Bodenforsch., [79] (6. F.) H. 2: 184 - 191, 2 Abb., 1 Taf.; Wiesbaden

-Schmucker, Ulrich (1957): Gesteinsmagnetische Untersuchungen und Experimente am Basalt des Steinberges bei Barlissen. - Abh. Akad. Wiss. Göttingen, Math.-phys. Klasse, $\underline{\mathbf{3}}$, Nr. 26; 100 S., 63 Abb., 5 Tab.; Göttingen

-Schult, Axel (1963): Über die Magnetisierung der Basaltvorkommen in der Umgebung von Göttingen. Z. Geophysik, 29(1): 1-20, 13 Abb., 3 Tab.; Würzburg

-Schur, W. (1895): Ueber die Ergebnisse der ersten Pendelmessungen. - Nachr. Ges. Wiss. z. Göttingen, 1895: 242-247; Göttingen - Aufsatz zusammen mit A. v. Koenen: Ueber die Auswahl der Punkte bei Göttingen, an welchen bei Probependelmessungen Differenzen in der Intensität der Schwere zu erwarten waren.

OSchwarz, Jochen \& Goldbach (1998): Ergebnisse einer Ingenieuranalyse des Gebirgsschlages in Völkershausen vom 13. März 1989. - In: Leydecker, Günter [Koordinator]: Der Gebirgschlag vom 13. März 1989 bei Völkershausen in Thüringen im Kalibergbaugebiet des Werratals. - Geol. Jb., Reihe E, 55; S. 47 - 67, 4 Abb., 3 Tab, 3 Taf.; Hannover 1998

Q๑口Seebach, Karl v. (1873): Das Mitteldeutsche Erdbeben vom 6. März 1872 - Ein Beitrag zu der Lehre von den Erdbeben. - IV, 192 S., 3 Taf., 2 Falt-Kt.; (Haessel) Leipzig [Berichte von der Wirkung des Bebens in alphabetisch aufgelisteten Orten von Hessen, Thüringen u. Südniedersachsen]

OSieberg, A. (1927/28): Thüringens Erdbeben und ihre Erforschung. - Beitr. Geol. Thür. 12(2): 38 - 44, 1 Kt.; Jena

[darin: Beben v. Friedrichroda am 30. November 1919]

- DSiemens, Günter (1971): Magnetische $\Delta T$-Messungen im Werra-Kaligebiet zur Erkundung von Basaltgängen. - Kali u. Steinsalz, $\underline{\mathbf{5}}(11):$ 385-390, 4 Bilder; Essen

OSonntag, Klaus (1964): Erdmagnetische Messungen zur Basalterkundung in der Vorderrhön. - Z. angew. Geol., 10 (10): 549-565, 3 Abb.; Berlin

[Südwestthüringen]

- $\square$ Stein, A.; Thümmel, E. \& Vees, R. (1982): Tiefenseismische Untersuchungen auf einem Profil zwischen Ardennen und Meißner. - Jahrestagung Dt. Geophysikalische Ges e.V. (in Hannover, 30.3. - 02.04,1982), 42: 95, 1 Abb.; Hannover

$\square$ Vogt, A. (1992): Zur Geologie des Gebietes östlich von Hundelshausen (Werra-Grauwackengebirge, Nord-Osthessen) - Teil. I: Kartierbericht - Teil II: Gefährdungsabschätzung im Sulfatkarst östlich 
von Hundelshausen (Kartierung, Hydrogeologie, Petrographie und Geophysik). - Dipl.-Arb. [unveröff.] Univ. Marburg; 71 S., 50 Abb., 6 Tab., 7 Beil.

-Wendler, Ralph (1968): Die magnetischen Strukturen im östlichen Hessen. - Notizbl. Hess. L.-A. Bodenforsch., 96: 290-299, 2 Abb., Taf. 10-11; Wiesbaden

-Wiechert, E. (1899): Seismometrische Beobachtungen im Göttinger Geophysikalischen Institut. Nachr. Kgl. Ges. Wiss. z. Göttingen, Math-Phys. Kl., 1899: 195-208, 8 Abb.; Göttingen Referat in: N. Jb. Mineral. etc, 1901 (Bd. I): 386 (E. Sommerfeldt); Stuttgart

OWüstner, L. (1964): Salzauslaugung und Tektonik im Zechstein des Werra-Kaligebietes nach Ergebnissen seismischer Messungen. - Z. angew. Geol., 10 (4): 172 - 179, 6 Abb., Berlin

OZwerger, R. v. (1934): Tektonik, Anomalien des Erdmagnetismus und Erdölhöffigkeit in Mitteldeutschland. - Kali, etc.,

29(5): $62-65$

$\underline{29}(6): 72-75$

$\underline{\mathbf{2 9}}(7): 86-88$

29(8): $98-100$

29(9): 112-114, 5 Fig.; Halle/Saale

[darin: Westthüringen, Isoanomalienkarte der Vertikalintensität]

\subsection{Hydrogeologie}

\subsubsection{Allgemein}

-Ackermann, E. (1977): Große Karstquellen am Leinetalgraben - (Exkursion D). - Exkursionsführer Geotagung '77, Bd. II, S. 35-40, 2 Abb.; (Selbstverlag Geol.-paläont. Inst. Univ. Göttingen) Göttingen

OAdam, C; Körner, W. \& Richter, D. (1974): Möglichkeiten des Versenkens flüssiger radioaktiver Abfälle in Gesteinsschichten des tieferen Untergrunds auf dem Territorium der DDR. - Z. geol. Wiss., 2 (9): 1017-1031, 4 Abb., 3 Tab.; Berlin

[Bezugnahme a. Versenkung Kaliabwässer im thüringischen Werra-Kalirevier]

-Anonym (1787): Nachricht von dem Gesundbrunnen bei dem Dorfe Geismar in Hessen unweit dem Meisebugschen Städtgen Züschen. - Hessische Beiträge z. Gelehrsamkeit u. Kunst, 2 (4): 725-730;

Frankfurt/M.

[Hydrochemie]

$\square$ Anonym (1898): < Interessante Sonderlinge bei Quellen und Bächen: Ein Mühlbach bei Röhrda - Der intermittierdende Karlsbrunnen in Eichenberg - Die Bachschwinde im „Höllengraben“ bei Eichenberg> - Eschweger Tageblatt u. Kreisblatt, 1898; Nr. 195 v. 22.08.1898; Eschwege

-Anonym (1899): < Ein Quellen-Sonderling: Die Rhumequelle bei dem Dorf Rhumspringe im Kreise Heiligenstadt [!]> - Eschweger Tageblatt u. Kreisblatt, 1899; Nr. 88 v. 15.04 .1899 (Erstes Blatt); Eschwege

-Anonym (1908): <Thermalquelle in Kassel-Wilhelmshöhe erbohrt]. - Eschweger Tageblatt, 1912; Nr. 221 v. 19.9.1908; Eschwege

$\square$ Anonym (1919): < Gatterbach versickert oberhalb Wanfried bei der Mittelmühle]. - Eschweger Tageblatt, 1919; Nr. 183 v. 8.8.1919; Eschwege 
$\square$ Anonym (1926): <Mineralquelle bei Waldkappel erbohrt?] - Eschweger Tageblatt, 1926; Nr. 174 v. 28.7.1926; Eschwege

$\square$ Anonym (1927): < Salzhaltige Quelle im „Bruch“ bei Niederhone entdeckt]. - Eschweger Tageblatt, 1927; Nr. 139 v. 17.6.1927; Eschwege

$\square$ Anonym (1928): < Gemeinde Eltmannshausen erbohrt starke Quelle für Trinkwasserversorgung]. Eschweger Tageblatt, 1928; Nr. 134 v. 9.6. 1928; Eschwege

$\square$ Anonym (1929): < Gatterbach versickert oberhalb Wanfried bei der Kratzmühle> - Eschweger Tageblatt, 1929; Nr. 161 v. 12.7.1929; Eschwege

$\square$ Anonym (1929): < Gatterbach versickert oberhalb Wanfried zwischen Kratzmühle und Mittelmühle> Eschweger Tageblatt, 1929; Nr. 297 v. 19.12.1929; Eschwege

$\square$ Anonym [1995]: Bodenarten, Quellen und Flurnamen der Gemarkung [Wolfterode]. - In: Festausschuß [Hrsg.]: 800 Jahre Wolterode 1195-1995. - 174 S., Abb.; hier: S. 7-8; Meißner-Wolfterode

- $\square$ ○Apel, Jürgen \& Rüppel, Heidi [Verfass. u. Hrsg.] (2005): Raus in die Natur - Tipps für den Sonntags-Ausflug im Dreiländereck Hessen - Niedersachsen - Thüringen. - 159 S., 111 Fotos, 34 Kt., 1 Zeit-Taf.; (LSRB-Verlag, Landschaftskundlicher-Studien-Reisebuch-Verlag) Witzenhausen [zahlreiche Ausflugstipps, auch zu Quellen: Ziel 85 (Melchiorbrunnen b. Oberdorla), Ziel 87 (Erdfallquellen b. Bad Langensalza)]

OAurada, Klaus D. (1996): Entwicklungslinien salzwassereinleitender Bergbaureviere im Saale- und Werragebiet und ihre regionalen Auswirkungen. - In: Thomae, M. (Ed.): Bergbaufolgelandschaften und Bergschäden des Kalibergbaues. - Exkursionsfhr. u. Veröff. GGW - Ges. f. Geowiss. e.V.; 198: 1-154, 51 Abb., 25 Tab.; hier S. 91-107, 4 Abb., 6 Tab.; Berlin [Hydrogeologie]

-Beer, Wolfgang \& Kluge, Simone (1999): Grundwasserspiegelmessungen zur Überwachung der Salzwasserversenkungen im Werra-Kaligebiet. - Kali u. Steinsalz, 12(11): 75-84, 8 Bilder - zgo. Glückauf, 135(12): 823-827, 8 Bilder; Essen

QBernhardi, R. (1847): Über die Ergebnisse zweier Bohr-Versuche auf Steinsalz bei Salzungen (Bericht über die 4. Versamml. d. naturwiss. Vereins f. Thüringen im Mai 1845, S. 8)

Referat in: N. Jb. Mineral. etc., 1847: 364-365; Stuttgart

[Zechsteinstratigraphie, Hydrogeologie, Salinenwesen]

- $\square$ Bodem, Martina (1991): Auswirkungen saurer Depositionen auf das Grundwasser und Stoffbilanz im Buntsandstein Nordhessens. - Hessische Forstliche Versuchsanstalt, Forschungsberichte, 14; 126 S., graph. Darst.; zgl. Diss. TU Darmstadt; (Hess. Forstliche Versuchsanstalt Hannoversch-Münden) Hannoversch-Münden

QBöhme, Hermann (1926): Über eine schwimmende Insel im Hautsee bei Eisenach. - Z. prakt. Geol.,

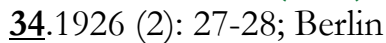

-Böhme, Hermann (1928): Über den Seeburger See und seine Insel. Zugleich ein Beitrag zur Entstehung plötzlich auftauchender Inseln. - Unser Eichsfeld, 23 (8): 168-174, 2 Abb.; Duderstadt

-Böttcher, M.E. ; Klein, S.; Rienäcker, J. \& Schwecke, H. (2008): A hydrochemical model for subterrestrial mixing of the Rhume Spring karst waters - Results form high water events und long term investigations. - In: Sauter, M.; Ptak, Th.; Kaufmann-Knoke, R.; Lodemann, M.; Van den Kerckhof, A. (Hg.): Grundwasserressourcen - Kurzfassung der Vorträge und Poster. - Tagung der Fachsektion Hydrogeologie in der DGG (FH-DGG) - Göttingen, 21 bis. 25. Mai 2008. - Schriftenrh. Dt. Ges. Geowiss., 57: 44; Berlin-Hannover 2008 
QBorn, Hans-Joachim (1936): Geochemische Zusammenhänge zwischen Helium-, Blei- und Radiumvorkommen in deutschen Salzlagerstätten. - Kali, etc., $\underline{\mathbf{3 0}}$ (5): 41-45, 3 Tab.; Halle/Saale [darin Tab. 3: Hydrochemie Radiumgehalte deutscher Tiefenwässer; u.a. Sollstedt, Volkenroda]

$\square$ Breuer, Barbara; Dies, Maren \& Senf, Nicole (2001): Untersuchung des Salzeintrags aus der Werra in ein Flussauengebiet durch den Einsatz von geolelektrischen Messungen. - Z. angew. Geol., 47(3/4): 176-181, 5 Abb., 6 Tab.; Hannover [Werraaue bei Witzenhausen/Wenderhausen]

$\square$ Brühl, Hans-Karl \& Theurer, G. (1986): Untersuchungen zur Wechselwirkung zwischen der Werra und dem Grundwasser in der Talaue im Bereich der Trinkwasserbrunnen bei Aue. - In: Stäblein, Gerhard [Hrsg.]: Geo- und biowissenschaftliche Forschungen der Freien Universität Berlin im Werra-Meißner-Kreis (Nordhessen). - Berliner Geogr. Abh., 41; zgl. Beiträge zur Werra-MeißnerForschung, İ; S. 41 - 51, (Selbstverl. Inst. Phys. Geogr. FU Berlin) Berlin 1986

$\square$ Brühl, Hanskarl \& Theurer, Gabriele (1986): Untersuchungen zur Wechselwirkung zwischen der Werra und dem Trinkwasserbrunnen bei Aue. - In: Brachmann, Richard [Red. u.

Gesamtgestaltung]: Zwischen Entwicklung und Bewahrung - Der ländliche Raum im Jahr 2000. ASG Frühjahrstagung 1986. Herausgegeben aus Anlaß der Frühjahrstagung 1986 der Agrarsozialen Gesellschaft in Eschwege, Werra-Meißner-Kreis. 108 S:, zahlr. Abb. u. Kt.; hier S. 68-72, 4 Abb.; [Hrsg. Hess. Minister f. Landwirtschaft u. Forsten] Wiesbaden 1986

$\square$ Brühl, Hanskarl \& Heger, Bernd (1989): Zur Hydrogeologie des Hohen Meissners. - In: Jacobshagen, Volker \& Kuhnert, Christian [Hrsg.]: Der Hohe Meißner in Hessen - Ergebnisse geologischer und geomorphologischer Forschungen. - Berliner geowiss. Abh., Reihe A, 114; S. 77-90, 8 Abb.; (Selbstverlag Fachber. Geowiss. FU Berlin) Berlin 1989

$\square$ Brühl, Hanskarl; Schlösser, Inga; Wurl, Jobst \& Heger, Bernd (1989): Der Hohe Meißner und sein Vorland als Grundwassereinzugsgebiet. Ein Beitrag zur Wasserversorgung in Nordhessen. - Teil I : Zur Hydrogeologie des Hohen Meißners. - Teil II: Die hydrogeologischen Verhältnisse im östlichen Vorland des Hohen Meißners. - Dt. gewässerkundl. Mitt., (Teil I) $\underline{33}$ : 1-9, 8 Abb.; (Teil II) $\underline{33}$ : 64-70, 7 Abb., 1 Tab.;

$\square$ Brühl, Hanskarl; Schlösser, Inga \& Wurl, Jobst (1989): Die hydrogeologischen Verhältnisse im östlichen Meißnervorland des Hohen Meißners. - In: Jacobshagen, Volker \& Kuhnert, Christian [Hrsg.]: Der Hohe Meißner in Hessen - Ergebnisse geologischer und geomorphologischer Forschungen. - Berliner geowiss. Abh., Reihe A, 114; S. 91-102, 7 Abb., 1 Tab.; (Selbstverlag Fachber. Geowiss. FU Berlin) Berlin 1989

-Burmeister, Helmut [Hrsg.](1989): Beschreibung der Gesundbrunnen und Bäder bey Hofgeismar. Unveränd. reprogr. Nachdruck der Ausgabe von 1772, mit einem Vorwort versehen von Helmut Burmeister; XV, 150 S., 7 Taf. i. Anh.; Hofgeismar

- 0 Cerny, R. (1993): Rechtliche Rahmenbedinungen für die Salzabwasserbeseitigung der Kaliwerke im Werragebiet. - In: (Salz in Werra und Weser - Ursachen, Folgen und Abhilfe. - Ergebnisse einer Fachtagung der ARGE Weser am 22. März 1993 in Kassel) DVWK-Mitteilungen, 24; S. 169 - 182; [Dt. Verband Wasserwirtschaft u. Kulturbau e.V.] Bonn

$\square$ Cyffka, Bernd; Hummel, Keith-Helge \& Pörtge, Karl-Heinz (1989): Untersuchungen zum Abflußverhalten und zum Gewässerchemismus im Gewässerkundlichen Forschungsgebiet Ziegenhagen. - Die Erde, 120: 181-188, 8 Abb., 3 Tab.; Berlin [Kaufunger Wald, Hessen]

$\square$ Cyffka, Bernd (1990): Das Abflußverhalten in kleinen Buntsandstein-Einzugsgebieten Untersuchungen im gewässerkundlichen Forschungsgebiet Ziegenhagen (Kaufunger Wald, Nordhessen). - Göttinger. Geogr. Abh., 923; VII, 180 S., 57 Abb., 35 Tab.; Göttingen - zgl. Diss. Univ. Göttingen 1990 
$\square$ Cyffka, Bernd; Gerold, Gerhard \& Pörtge, Karl-Heinz (1991): Gebietsdifferenzierter Wasser- und Stoffhaushalt im Gewässerkundlichen Forschungsgebiet Ziegenhagen (Kaufunger Wald). Gesellschaft für Ökologie - Verhandlungen, 20 (2) (f. 1990): 629-634; graph. Darst.; Freising [Kaufunger Wald, Hessen]

$\square$ Dannenberg, Friedrich Karl (1980): Hydrogeologische und hydrologische Bearbeitung des Netratales (südlich von Eschwege, Nordhessen). - Dipl.-Arb. [unveröff.] TU Berlin, 73 S.

ODeppe, Stefan \& Pippig, Matthias (2002): Erkundung und Maßnahmen zur Beherrschung der Salzlösungszuflüsse im Grubenfeld Merkers. - Kali u. Steinsalz, 2002(2): 40-49, 26 Abb.; Essen [Hydrogeologie, Ingenieurgeologie]

QDeubel, F. (1940): Grundwassergewinnung aus Bohrungen im thüringischen Buntsandstein. - Beitr. Geol. Thür., 6(1): 25-30; Jena

Referat in: N. Jb. Mineral. etc., Referate, 1941 (Bd. II): 480 (Koehne); Stuttgart [darin: Nordrand Thür. Wald b. Eisenach, Werratal obehalb Gerstungen]

- $\square$ Diederich, Gisbert; Finkenwirth, Alfred; Hölting, Bernward; Kaufmann, Eberhard; Rambow, Dietrich; Scharpff, Hans-Jürgen; Stengel-Rutkowski, Witigo \& Wiegand, Klaus (1985): Erläuterungen zu den Übersichtskarten 1:300.000 der Grundwasserergiebigkeit, der Grundwasserbeschaffenheit und der Verschmutzungsempfindlichkeit des Grundwassers von Hessen. - Geol. Abh. Hessen, 87; 51 S., 2 Tab., 3 Tab., 3 Kt. 1 : 300.000 i. sep. Tasche; Wiesbaden darin enthalten Karten (gleicher Blattschnitt wie GÜK Hessen)

Karte 1: Übersichtskarte der mittleren Grundwasserergiebigkeit - Maßstab $1: 300.000$

Karte 2: Übersichtskarte der Grundwasserbeschaffenheit - Maßstab $1: 300.000$

Karte 3: Übersichtskarte der Verschmutzungsempfindlichkeit - Maßstab $1: 300.000$

-Diestel, Walter (1931): Von der Rhume und ihrer Quelle. - Die Weser, 10 (11): 297; Bremen

QDietrich, P. G. (1975): Zur Hydrogeologie des Mittleren Muschelkalks im Thüringer Becken - Beispiel einer regionalen hydrodynamischen Rayonisierung. - Z. angew. Geol., 21 (8): 384-391, 4 Abb., 9 Tab.; Berlin [darin: Westthüringen; Tab. 6. Mühlhausen-Langensalzaer Keupermulde]

-Dürrbaum, H.-J.; Matthess, G. \& Rambow, D. (1969): Untersuchungen der Gesteinsdurchlässigkeit des Buntsandsteins in Nordhessen. - Notizbl. Hess. L.-A. Bodenforsch., 97: 258 - 274, 10 Abb., 4 Tab.; Wiesbaden

-Fey, A. (1895): Von dem Gesundbrunnen bei Nordshausen, einer verschollenen Wunderquelle. Hessenland, 9(17): 226-227; Kassel

- 0 Finkenwirth, Alfred (1967): Deep well disposal of waste brine in the Werra Potash Region. Mémoires/International Association Hydrogeologists, (Congress of Hannover 1965) 7: 123-129, 4 fig., 2 tabl.; Hannover

[Kalilaugenversenkung im Plattendolomit, Werra-Kalirevier Hessen u. Thüringen]

- $\square$ Finkenwirth, Alfred (1970): Hydrogeologische Neuerkenntnisse in Nordhessen. - Notizbl. Hess. L.A. Bodenforsch., 요: 212 - 233, 1 Abb., 8 Tab., 2 Taf.; Wiesbaden [Werra-Meißner-Kreis, Kr. Hersfeld-Rotenburg]

- $\bigcirc$ Finkenwirth, A. \& Fritsche, H.G. (1993): Hydrogeologische Möglichkeiten und Grenzen der Versenkung < von Kaliabwässern des Hessisch-Thüringischen Werra-Kalireviers>. - In: (Salz in Werra 
und Weser - Ursachen, Folgen und Abhilfe. - Ergebnisse einer Fachtagung der ARGE Weser am 22. März 1993 in Kassel) DVWK-Mitteilungen, 24; S. 40-65, Bild 11-16, 1 Kt. S. 68; [Dt. Verband Wasserwirtschaft u. Kulturbau e.V.] Bonn

-Fleck, Alexander (1990): Hydrogeologie des Göttinger Waldes - Hydrogeologische Kartierung und Jahresbilanz. - Dipl.-Arb. [unveröff.] Univ. Göttingen 1990; 222 Bl.

$\square$ Fleer, P. (1993): Geologie und Grundwasser in Eschwege im Hinblick auf die Baugrundverhältnisse im Stadtgebiet. - Dipl.-Arb. [unveröff.] FU Berlin; 41 S.

-Frank, Werner Hartmut (1987): Die Bewirtschaftung und Beschaffenheit von Grundwasservorkommen im nordwestlichen Eichsfeld (Südniedersachsen). - Z. dt. geol. Ges., 138: 477 - 490, 5 Abb., 2 Tab.; Hannover

$\square$ Frick, Friedrich \& Pickel, Hans Jürgen (1971): Ein Färbeversuch im mittleren Muschelkalk bei Retterode (Nordhessen). - bbr - Bohrtechnik, Brunnenbau, Rohrleitungsbau, 22 (12): 435-438, 4 Abb., 1 Tab.; Köln

[Hydrogeologie von Karstgesteinen]

-Fritsche, H. - G.; Hemfler, M.; Kämmerer, D.; Leßmann, B.; Mittelbach, G.; Peters, A.; Pöschl, Rumohr, S. \& Schlosser-Kluger, J. (2003): Beschreibung der hydrogeologischen Teilräume von Hessen gemäß EU-Wasserrahmenrichtlinie (EU-WRRL). - Geol Jb. Hessen, 130: 5 - 19, 1 Abb.; Wiesbaden

$\square$ Führer, Hans (1943): Wie Grandenborn seine Wasserarmut beseitigte. - Eschweger Tageblatt, 1942; Nr. 19 v. 23.724.01.1943

$\square$ Geyh, Mebus \& Rambow, Dietrich (1997): Isotopenhydrologische Untersuchungen an Grundwässern aus dem Buntsandstein Nordhessens. - Geol. Jb. Hessen: 125: 43-62, 6 Abb., 1 Taf.; Wiesbaden [Untersuchungen u.a. an Brunnen auf Bl. 4724 Hessisch Lichtenau: Br. Walburg, Querenberg; Hirschhagen]

-Gottlieb, Joseph (2004): Eine Beschreibung der Rhumequelle vor 80 Jahren - Europas größte Quelle. Eichsfelder Heimatzeitschrift, 48(4)/2004(April): 125-127, 1 Abb.; Duderstadt

-Grimm, Arnulf (1969): Die Grundwasserverhältnisse im Raum Kassel (Nordhessen) unter besonderer Berücksichtigung der Hydrochemie. - Göttinger Arb. Geol. Paläont., 2 ; 50, 93, 10 S., 21 Beil.; (Selbstverl. Geol. Inst.) Göttingen

OGrimm, Helmut (1992): Die Treffurter Normannstein-Quelle. - Das Werraland, 44(1): 58, 1 Abb.; Eschwege

$\square$ Hampel, H. \& Pekdeger, A. (1993): Die hydrogeologischen Verhältnisse im Eschweger Becken. - In: Jacobshagen, V.; Möller, K. \& Jäkel, D. [Hrsg.]: Hoher Meißner und Eschweger Becken Geowissenschaftliche und vegetationskundliche Charakteristik einer nordhessischen Landschaft. Berliner geogr. Abh., 56 ; zgl. Beiträge zur Werra-Meißner-Forschung, III; XII, 288 S., 95 Abb., 23 Tab., 5 Kt.-Beil.; hier: S. 59-77, 6 Abb., 1 Tab., 1 Kt.; (Selbstverlag Geomorphologisches Laboratorium FU Berlin) Berlin 1993

-Hanisch, Tobias (2003): Untersuchung zur Wasser- und Stoffbilanz im Einzugsgebiet der Rhumequelle (Südwestharz). - Bachelor-Arbeit [unveröff.] Univ. Göttingen 2003; 39 S.

QHecht, Günter (1964): Über das Vorkommen natriumhydrogenkarbonathaltiger Wässer in Thüringen. Z. angew. Geol., 10 (5): 250-255, 2 Abb., 2 Tab.; Berlin [darin: Bhrg 2/1960 Katharinenberg; Bhg. Bad Salzungen 1937; Bhg. Finsterbergen 1962] 
QHecht, Günter (1974): Bodenschätze [in Thüringen] - Wässer. - In: Hoppe, Walter \& Seidel, Gerd [Hrsg.]: Geologie von Thüringen [Bezirke Erfurt, Gera, Suhl]. - S. 940-964, Abb. 192-193, Tab. $117-$ 124; (Haack) Gotha-Leipzig 1974

QHecht, Günter (1994): Die Mineralwasserbohrungen Bad Liebenstein 1/1979 und 2/1980 . - Geowiss. Mitt. Thüringen, 2: 149-215, 7 Abb., 8 Tab., Anl. 2 u. 3; Weimar

[Hydrogeologie, Schichtenverzeichnis]

OHecht, Günter (1995): Die Solebohrungen von Bad Salzungen. - Geowiss. Mitt. Thüringen, 3: 135-172, 2 Abb., 10 Tab., Beil. 5-9; Weimar [Hydrogeologie, Reg. Geol. - Schichtenverzeichnis)]

QHecht, Günter (1995): Bodenschätze [in Thüringen] - Grundwässer. - In: Seidel, Gerd [Hrsg.]: Geologie von Thüringen. - 1. Aufl.; S. 455-494, 9 Tab.; Stuttgart 1995

QHecht, Günter (2000): Zur Entwicklung der Salzwasserversenkung im Werra-Kaligebiet. - Geowiss. Mitt. Thüringen, Beih. 9: 125-138, 3 Abb., 1 Beil.; Weimar

OHecht, Günter (2003): Bodenschätze [in Thüringen] - Grundwässer. - In: Seidel, Gerd [Hrsg.]: Geologie von Thüringen. - 2., neu bearb. Aufl.; S. 487-529, 8 Tab.; Stuttgart 2003

QHecht, G.; Ellenberg, J. \& Beer, W. (2001): Exkursion C 2 - Subrosion und Hydrogeologie im WerraKaligebiet. - In: Jockel, Andreas [Hrsg.]: Regionale und angewandte Geologie der Grenzregion der Süddeutschen und der Mitteldeutschen Scholle. - Exkursionsführer zur 10. Jahrestagung der Gesellschaft für Geowissenschaften e.V. in Schmalkalden - 19.-22. September 2001. Exkursionsführer u. Veröff. d. Ges. f. Geowiss., 213; S. C2-1 bis C2-16, 6 Abb.; Berlin 2001

$\square$ Heinrich, Arno (1980): Die Wasserversorgung des Werra-Meißner-Kreises. - Das Werraland, 32(2): 1820; Eschwege [u.a Hydrogeologie]

-Hellrung, Carl Ludwig (1844): Die goldene Mark Duderstadt - Wahrheit und Dichtung. - 288, 16 S., 1 Abb..; (Wagner) Duderstadt [darin S. 65-144: „Der Rhumesprung“ - S. 65-113, 1 Abb.: „I. Sein Dasein“; S. 113-132: „II. Die Götter der alten Sassen“; S. 132-144: „III. Die Sage vom Ruhmesprung“]

-Herrmann, Axel (1969): Die geologische und hydrogeologische Situation der Rhumequelle am Südharz. - Abh. z. Karst- und Höhlenkunde, Reihe B - Hydrologie - H. 1; 8 S., 2 Abb.; [Hrsg. Verbd. Dt. Höhlen- u. Karstforscher e.V., München] München - auch : Jh. f. Karst- und Höhlenkunde, 9 (f. 1968/69) (Der Südharz - seine Geologie, seine Höhlen- und Karsterscheinungen): 107 - 112, 2 Abb.; München

- $\square$ Hessische Landesanstalt für Umwelt [Hrsg.] (1998): Wasserbilanz für den Regierungsbezirk Kassel - Planungsregion Nordhessen. - Umweltplanung, Arbeits- und Umweltschutz, 257; Teil 2 Anhang: Daten aus dem Bereich der Wasserversorgung und der Hydrogeologie; 185 S., graph. Darst. [Hess. Landesanstalt Umwelt] Wiesbaden

oHessler, Carl (1906): Bewässerung [Hydrogeographie]- In: Hessler, Carl [Hrsg.]: Hessische Landesund Volkskunde - Das ehemalige Kurhessen und das Hinterland. Bd. I: Hessische Landeskunde. Erste Hälfte. - 531 S., zahlr. Abb.; hier: S. 119-143, Abb.; (Elwert) Marburg 1906

OHessmann, Wolf (1982): Tektonische Beanspruchung und Verformung, strukturelle Position und Dislokationsintensität - Kriterien zur Einschätzung hydrogeologischer Verhältnisse des Gebirges. Z. geol. Wiss., 10 (1): 31-52, 5 Abb.; Berlin [Südwestthüringen] 
- $\square$ Hölting, Bernward (1969): Die Ionenverhältnisse in den Mineralwässern Hessens. - Notizbl. Hess. L.-A. f. Bodenforschung, 97: 333-351, 12 Abb.; Wiesbaden

[Hessenweite Verteilungskarten]

-Hölting, Bernward \& Laemmlen, Manfred (1974): Geologische und hydrogeologische Ergebnisse von Brunnenbohrungen am Süd- und Südwesthang des Knüllgebirges (Hessen). - Notizbl. Hess. L.A. Bodenforsch., 102: 270-295, 3 Abb., 2 Tab.; Wiesbaden

- $\square$ Hölting, Bernward; Kanz, Werner \& Schulz, Horst-D. (1982): Geohydrochemie im Buntsandstein der Bundesrepublik Deutschland - Statistische Auswertung von Grundwasseranalysen. - DVWKSchriften, 54: 85-193, 33 Abb., 31 Taf.; (Parey) Hamburg [darin einbezogen: Hessen]

OHoffmann, Johann Carl (1754): Historisch-physicalische Nachricht von einem Stahl- oder martial. Trink- und Badebrunnen... bey der Stadt Salzungen, der Grundhöfer Sauerbrunn genannt, worinn dessen...Entdeckung, Einfassung, mineral. Gehalt...gründlich beschrieben wird. - XIV, 99 S.; (Grieszbach) Eisenach

$\square$ Holthusen, Henning (1977): Hydrogeologische und hydrochemische Untersuchungen in Sedimenten der Trias südöstlich Eschwege (Nordhessen). - Dipl.-Arb. [unveröff.] Fachber. Geowiss. FU Berlin; $54 \mathrm{~S}$.

OHoppe, Walter (1943): Die hydrogeologischen Grundlagen der Wasserversorgung in Thüringen. Mit einer hydrogeologischen Karte i. M. 1: 500000 und 18 geologischen Profilen. - 120 S., 18 Abb., 1 Falt-Kt., 22 Tab.; (Fischer) Jena

OHoppe, W. (1954): Die Grundwasserführung der Gesteine Thüringens. - Geologie, $\underline{\mathbf{3}}(6 / 7):$ 876-890, 1 Falt-Bl. (Hydrogeol.-Kt.); Berlin

QHoppe, Walter (1962): Die Bedeutung der herzynischen Störungszonen für die Grundwasserführung des Thüringer Beckens. - Geologie, 11 (6): 679 - 699, 1 Abb., 10 Tab.; Berlin [darin: Eichenberg-Gotha-Saalfelder Störungszone u. a. bekannte Störungszonen]

QHoppe, Walter (1962): Grundlagen, Auswirkungen und Aussichten der Kaliabwasserversenkung im Werra-Kaligebiet. - Geologie, 11(9): 1059 - 1086, 8 abb., 8 Tab.; Berlin

QHoppe, Walter (1972): Die Mineral- und Heilwässer Thüringens (Geologie, Chemie, Geschichte, Nutzung). - Geologie, Beih. 75: 1-183, 19 Abb., 75 Tab. (einschl. 37 Diagr.); Berlin [darin: Bad Langensalza, Bad Liebenstein, Bad Salzungen, Buchenau b. Eisenach, Creuzburg, Grundhof b. Bad Salzungen, Ruhla Schmalkalden, Suhl]

- $\square$ Hoppe, A. \& Fritsche, J. G. [Bearb.](1999): Tätigkeitsbericht des Hessischen Landesamtes für Bodenforschung 1996 bis 1999. - Geologie in Hessen, ్/1999; 52 S., 41 Abb.; [Hrsg. Hess. Landesamt f. Bodenforschung] Wiesbaden [darin:

Kap.: Salzwasserversenkung und Grundwasserstypisierung in Osthessen - S. 27, Abb. 27-29;

Kap.: Geologische Beratung bei Planung und Bau der Bundesautobahn A 44, Kassel-Eisenach - S. 2732, Abb. 40;

Kap.: Baugrund und Gründungsberatung für die staatliche Bauverwaltung am Beispiel des Schlosses Kassel-Wilhelmshöhe - S. 34-36, Abb. 34-36]

$\square$ Hosseinini-Arab, Ali (1993): Hydrogeologie der Werratalaue nördlich von Eschwege. - Dipl.-Arb. [unveröff.] Fachber. Geowiss. FU Berlin; 50, XXXV S., 25 Abb., 1 Beil. 
QHüls, Matthias; Schlegelmilch, Volker \& Tita, Jost (1996): Gefährungsabschätzung eines Tanklagers - Traceruntersuchungen im Oberen Muschelkalk am Kindel/Thüringen. - Z. angew. Geol., 42(1): 2732, 4 Abb., 3 Tab.; Berlin

[Hydrogeologie, Geochemie, Geoelektrische Messungen ]

-Issendorf, Volker (1993): Hydrogeologie des Einzugsgebietes des Brunnen Lenglern, Gemeinde Bovenden. Mit hydrogeologischer Kartierung 1: 10 000. - Dipl.-Arb. [unveröff.] Univ. Göttingen 1993; $109 \mathrm{~S}$.

OJeschke, Christina (2008): Salinität der Oberflächengewässer in den Bleicheröder Bergen und das Vorkommen von salzspezifischen Bakterien. - In: Wunderlich, J. [Red.]: Exkursionsführer Geologie des Eichsfeldes - zur 18. Jahreshauptversammlung (Vortrags- und Exkursionsveranstaltung) vom 16. bis 18. Mai 2008 in Heilbad Heiligenstadt. - Führung: H. Heiland, L. Nolte, H.-G. Röhling \& G. Seidel. - S. 39; [Hrsg.: Thüringer Geologischer Verein e.V.] Jena 2008

OKäbel, Herbert (1982): Zur Hydrodynamik der Grundwasserstockwerke in salinaren Becken der DDR. - Z. geol. Wiss., 10 10): 53-60, 1 Abb., 1 Tab.; Berlin

[darin: Werra-Kalirevier]

QKäbel, Herbert (2001): Zur Grundwasserbewegung im Subsalinar und im Plattendolomit des thüringischen Werra-Kaligebietes <Vortragskurzfassung>. - In: Rauche, Henry [Hrsg.]: Regionale und angewandte Geologie der Grenzregion der Süddeutschen und der Mitteldeutschen Scholle. Programm und Kurzfassungen der Vorträge. - 10. Jahrestagung Gesellschaft f. Geowissenschaften i. Schmalkalden, 19.-22. September 2001. - Exkursionsführer u. Veröff. Ges. f. Geowiss., 214; S. 141 142; Berlin 2001

- $\square$ OKahlert, Margit \& Wolff, Peter (1993): Die Entwicklung der Werraversalzung. - Das Werraland, 45(2): 33-35, 1 Abb.; Eschwege

OKaiser, Erich (1905): Die hydrologischen Verhältnisse am Nordostabhang des Hainich im nordwestlichen Thüringen. - Jb. Preuß. Geol. Landesanst., 23 (f. 1902): 323-341, 5 Tab., Taf. 18; Berlin Referat in: N. Jb. Mineral. etc., 1905 (Bd.II): 448-449 (Wüst); Stuttgart

$\square$ Kaufmann, Eberhard \& Leßmann, Bernd (2006): Zur Hydrogeologie der Solequellen von Bad Sooden-Allendorf. - Geol. Jb. Hessen, $13 \mathbf{3}$ (f. 2005): 5-17, 5 Abb.; Wiesbaden

$\square$ Keilhack, Konrad (1912/1917/1935): Lehrbuch der Grundwasser- und Quellenkunde - Für Geologen, Hydrologen, Bohrunternehmer, Brunnenbauer, Bergleute, Bauingenieure und Hygieniker. - [1. Aufl.]; XI, 545 S., 249 Abb., 1 Taf.; (Bornträger) Berlin 1912 - Zweite, neu bearb. u. vermehrte Aufl.; XII, 640 S., 267 Abb., 1 Taf.; (Bornträger) Berlin 1917 - 3., völlig neu bearb. u. vermehrte Aufl.; XI, 575 S., 308 Abb., 1 Taf.; (Bornträger) Berlin 1935 [darin: Quellen des Meißners und deren Hydrochemie]

-Keindorf, Gudrun (1998): Wo die Rhumequelle rauscht... Altes und Neues von der Rhumequelle. Eichsfeld - Monatszeitschrift des Eichsfeldes, 41(1)[1998(Jan.)]: 415-417; Duderstadt

-Keindorf, Gudrun (2000): 750 Jahre Rhumspringe - Die Geschichte eines Dorfes im Untereichsfeld. 367 S:, 135 Abb., 1 Kt.-Beil.; [Hrsg. Gemeinde Rhumspringe] (Mecke) Duderstadt

[darin S. 17-30, Abb. 1-6: „Eine Landschaft entwickelt sich“, S. 31-71, Abb. 7-17: „Die Rhumequelle und die Geschichte ihrer Erforschung]

-Keller, Rudolf (1938): Vom Ursprung der Solquellen des Kreises Hofgeismar. - Heimatkalender f.d. Landkreis Hofgeismar, 1939: 36 - 39; Hofgeismar

ØKnothe, Emil (1858): Ueber die Soolen Salzungens. - Diss. phil. Univ. Göttingen 1858; 32 S., [1] Bl.; (Dieterich) Göttingen 
[Hydrochemie]

QKoch, Günter \& Oettel, Siegfried (1982): Zu einigen hydrogeologischen Ergebnissen bei den Untersuchungen von Salzlösungszuflüssen in den Gruben des VEB Kalibetrieb „Werra“ und daraus abzuleitende Schlußfolgerungen für die Methodik der Bekämpfungsarbeiten. - Z. geol. Wiss., 10 (1): 133-140, 7 Abb.; Berlin

-Kühn, V. \& Neumann, Klaus (1989): Die Quellwässer des Kaufunger Waldes. Hydrochemie und geologischer Untergrund. - Dipl.-Arb. [unveröff.] Univ. Göttingen; 143 S., 4 Beil.

$\square$ Künzel, Artur (1983): Die Wirkung des Werrasalzes auf Grundwasser und Flora. - Das Werraland, 35(3): 50-51; Eschwege

$\square$ Lähne, R. (2003): Hydrodynamik des Talraumes bei Eschwege (Nordhessen). - Dipl.-Arb. [unveröff.] Univ. Halle-Wittenberg

$\square$ Lähne, R.; Gossel, W. \& Wycisk, P. (2006): Das Geologische Modell als Grundlage für die Hydrogeologische Modellierung des Talraums Eschwege (Werra). - In: Voigt, H.-J.; KaufmannKnoche, R. ; Jahnke, Ch. \& Herd, R. [Hrsg.]: Indikatoren im Grundwasser - Kurzfassungen der Vorträge und Poster - Tagung der Fachsektion Hydrogeologie in der DGG - 24. bis 28. Mai 2006 in Cottbus. - Schriftenrh. Dt. Geol. Ges., 43: 148; Hannover 2006

$\square$ Laußat, Petra (1995): Grundwasserbewegung in der Stadt Eschwege (Nordhessen). - Dipl.-Arb. [unveröff.] Fachber. Geowiss. FU Berlin; 45 S, 14 Abb., 1 Kt.

-Leßmann, Bernd (1993): Hydrogeologische Untersuchungen im Pöhlder Becken. - Dipl.-Arb. [unveröff.] Univ. Göttingen; 87 S.

-Leßmann, Bernd (1993): Geologische Kartierung und Hydrogeologie des Rheinhäuser Forstes und seiner Umgebung. - Dipl.-Kart.. [unveröff.] Univ. Göttingen 1993; 70 S.

-Linstow, O. v. (1929): Salzlager, Solquellen und Erdfälle in dem Gebiet zwischen Kassel und Karlshafen. - Kali, etc.,

$\underline{\mathbf{2 3}}(4): 54-56$

$\underline{23}(5): 71-74$

23(6): 86-88, mehr. Fig.; Halle/Saale

Referat in: N. Jb. Mineral. etc., Referate, 1931 (Bd. III): 135 (A. Bentz); Stuttgart

[darin: Wolkenbrüche b. Trendelburg; Solquelle Kassel-Wilhelmshöhe]

-Loewer, E. (1895): Geologische Erläuterungen zur Anlage der neuen städtischen Wasserwerke nach Besichtigung am 5. Mai 1894. - Abh. u. Ber. Vereins Naturkde. z. Kassel, 40 (f. 1894/1895), 12 S. (getr. Zählg.); Kassel

[Hydrogeologie]

- $\square \bullet L u ̈ t t i g$, Gerd \& Fricke, Wolfgang (1965): Hydrogeologische Aspekte der Einleitung von KaliEndlaugen in Flußsysteme, erläutert am Beispiel Werra - Weser. - Mémoires/International Association Hydrogeologists, (Congress of Hannover 1965) 7: 111-120, 11 Abb.; Hannover [Hessen, Werra-Meißner-Kreis, Niedersachsen]

OMeincke, Wilhelm (1967): Hydrodynamik im Solling-Sandstein (Mittlerer Buntsandstein) des Thüringer Beckens. - Z. angew. Geol., 13: 399-405, 6 Abb.; Berlin

OMeincke, Wilhelm (1967): Hydrodynamik im Staßfurtkarbonat des Thüringer Beckens. - Z. angew. Geol., 13: 462-465, 2 Abb., 2 Tab.; Berlin

-Meischner, D. (2008): Trinkwasser-Prospektion in salinartektonisch verstelltem Gebirge - das Beispiel Göttingen. - In: Sauter, M.; Ptak, Th.; Kaufmann-Knoke, R.; Lodemann, M.; Van den 
Kerckhof, A. (Hg.): Grundwasserressourcen - Kurzfassung der Vorträge und Poster. - Tagung der Fachsektion Hydrogeologie in der DGG (FH-DGG) - Göttingen, 21 bis. 25. Mai 2008. - Schriftenrh. Dt. Ges. Geowiss., 57: 40; Berlin-Hannover 2008

oMempel, Gerhard (1939): Die hydrologischen Verhältnisse von Nordwestthüringen. - Jb. Preuß. Geol. Landesanst., $\underline{\mathbf{5 9}}$ (Teil A) (f. 1938): 587-646, 1 Abb., Taf. 30-38; Berlin Referat in: N. Jb. Mineral. etc., Referate, 1940 (Bd. III): 583-584 (Hesemann)); Stuttgart [Region d. Unstrut-Hainich-Kreises als Untersuchungsgebiet]

-Mestwerdt, A. (1913): Die Quellen von Germete bei Warburg und von Calldorf in Lippe. - Jb. Pr. Geol. Landesanst., $\underline{32}$ Teil 1 (f. 1911): 145-161, 1 Abb., Taf. 5-6; Berlin

OMerz, Georg (1987): Zur Petrographie, Stratigraphie, Paläogeographie und Hydrogeologie des Muschelkalks (Trias) im Thüringer Becken. - Z. geol. Wiss, 15: 457-473, 9 Abb.; Berlin

OMerz, Georg (1989): Der Mühlberger Spring. - Veröff. Naturkundemuseum Erfurt, Naturwiss. Rh., $\underline{8}$ : 38-40; Erfurt

口Merz, Georg (1991): Zur geologischen Situation der Wachsenburg unter besonderer Berücksichtigung des Burgbrunnens. - Veröff. Naturkundemuseum Erfurt, Naturwiss. Rh., 10: 80-87, 1 Abb.; Erfurt [Hydrogeologie, Geol. Überblick]

OMeyer, M.; Dietrich, H. \& Bittner, U. (1994): Modellvorstellungen zur Paläohydrodynamik im WerraAnhydrit des nördlichen Thüringer Beckens/Modelling concepts on the paleohydrodynamics in the Werra Anhydrite of the northern Thuringian Basin. - Zbl. Geol. Paläont. - Teil 1, 1994 (1/2): 217226, 6 Abb.; Stuttgart

-Michaelis, Jochen (1987): Hydrochemische Modellbetrachtungen zur Kalkauflösung und Entwicklung karbonatischer Grundwässer im Göttinger Wald unter spezieller Berücksichtigung der stabilen Isotope des Kohlenstoffs und des Schwefels. - Diss. Univ. Göttingen 1987, 116 S., Abb., Kt.

$\square$ Möller, Klaus (1988): Das Eschweger Becken und seine Randgebiete - Ergebnisse geomorphographischer und hydrochemischer Analysen. - In: Liedtke, Herbert [Hrsg.]: Untersuchungen zur Geomorphologie der Bundesrepublik Deutschland - Neue Ergebnisse der Geomorphologische Kartierung - Beiträge zum GMK-Schwerpunktprogramm VIII - Berliner Geogr. Abh., 47: 77-92, 8 Abb., 1 Tab.; Berlin 1988

-Möller, Lotte (1949): Naturräumliche Gliederung Niedersachsens auf Grund der chemischen Beschaffenheit der Grund- und Oberflächenwässer. - Neues Archiv f. Niedersachsen, 1949(14): 787802, 9 Abb. (8 Abb. u. 1 Falt-Kt.); Bremen-Horn

$\square$ Mötzing, K. (1970): Das Dorf Eichenberg - Seine Umgebung und sein „Carlsbrunnen“. - Das Werraland, 22(3): 40-43, 4 Abb.; Eschwege

[Eichenberg mit Ortsteilen, darin: Hydrogeologie des Karlsbrunnens]

OMüller, E. Peter (1968): Zur Geochemie der Tiefenwässer und der organischen Substanz im Nordteil der DDR. - Z. angew. Geol., 15(3): 113-124, 13 Abb., 5 Tab.; Berlin [darin: Hydrochemisches Profil Thüringer Becken mit Profilpunkten a. Westthüringen (u.a. Langensalza - Fahner Höhe - Gotha]

OMüller, Erich Peter \& Papendiek, Günther (1975): Zur Verteilung, Genese und Dynamik von Tiefenwässern unter besonderer Berücksichtigung des Zechsteins. - Z. geol. Wiss., $\underline{\mathbf{3}}(2):$ 167-196, 14 Abb., 4 Tab.; Berlin [darin: Thüringer Becken]

-Müller, H. (1938): Die Wasserverhältnisse im Einzugsgebiet der Garte bei Göttingen. - IV, 84 S., 4 Bl., 42 Abb.; [Hrsg. Wirtschafswiss. Ges. Studium Niedersachsens] (Stalling) Oldenburg i. O. 
-Namenskürzel (Jg.) (1926): Die „Neujahrsquelle“ in Königswald. - Eschweger Tageblatt, 1926; Nr. 4 v. 6.01.1926; Eschwege

[Neue Quelle im Karstgebiet des Sontraer Berglandes?]

$\square$ Namenskürzel (mk) (1949): „Der Meißner“ - ein Heimatbuch von Prof. Ulrich [Buchbesprechung]. Werra-Rundschau, 1949; Nr. 126 v. 1.6.1949, S. 5; Eschwege

[S. 9-25, 2 Abb.: „Der Meißner landschaftlich und geologisch“; S. 25-29: „Quellen“ [auch Hydrogeologie]; S. 29-45, 1 Abb.: „Das Braunkohlenwerk“]

$\square$ Namenskürzel (Werra-Rundschau) (1956): Meißnerquelle mit 0 Grad Wassertemperatur. - WerraRundschau, 1956; Nr. 167 v. 20.7.1956, S. 3; Eschwege

$\square$ Namenskürzel (kk) (1959): <Wasserbohrung im Friedatal> Weiches Wasser für Eschwege - Bohrversuche im Friedatal lassen hoffen/... - Werra-Rundschau, $\underline{1959}$; Nr. 265 v. 14.11.1959, S. 3, 2 Abb.; Eschwege

$\square$ Namenskürzel (Werra-Rundschau) (1960): < Friedrichsstollen, Hoher Meißner $>$ Erdrutsch geräumt $100 \mathrm{cbm}$ Wasser. Friedrichstollen-Quelle wiedergefunden - Sorgen um die Wasserversorgung. Werra-Rundschau, 1960; Nr. 173 v. 28.7.1960, S. 3, 2 Abb.; Eschwege

$\square$ Namenskürzel (pn) (1963): <Wasserbohrungen in Bad Sooden-Allendorf $>$ - Neues Wasser frühestens in einem Jahr - Badeanstalt will Wasserversorgung auf 40-50 Jahre sicherstellen. - Werra-Rundschau, $\underline{\mathbf{1 9 6 3}}$; Nr. 203 v. 3.09.1963; Eschwege

$\square$ Namenskürzel [v](1965): Weitere Versuchsbohrung beschlossen. - HA - Werra-Nachrichten, 1965; Nr. 86 v. 12.4.1965; Witzenhausen [Wasserbohrung a. „Heyersköpfchen“/Bad Sooden-Allendorf]

-Namenskürzel (red) (1997): Herbstausstellung: Wünschelrute - ein Wunschtraum? - Am Stand der „Vereinigung deutscher Rutengänger“" haben Besucher der Herbstausstellung in Kassel Gelegenheit, sich über die Arbeit mit der umstrittenen Wünschelrute zu informieren. - Werra-Rundschau, 1997; Nr. 219 v. 20.9.1997, S. 5; Eschwege

-Neumann, Jörg; Fleck, Gerd \& Wycisk, Peter (2001): Flächendifferenzierte Bewertung und Interpretation der hydrogeologischen Situation am südöstlichen Stadtrand von Kassel. - Geol Jb. Hessen, 128: 97 - 106, 8 Abb., 1 Tab.; Wiesbaden

QOestreich, Wolfgang (1963): Hydrochemische Untersuchungen im Thüringer Wald südlich Ilmenau. Z. angew. Geol., 9(3): 113-121, 8 Abb., 7 Tab.; Berlin

-Otto, Bernhard (1966): Altes und Neues von der Rhumequelle. - Die Goldene Mark, 17 (3): 42-47, 1 Abb.; Duderstadt [Bezugnahme a. Hydrogeologie; Geschichte, Mystik]

$\square$ Otter, Bettina (1994): Die hydrogeologischen Verhältnisse der Gemarkung Eschwege (Nordhessen). Dipl.-Arb. [unveröff] Fachber. Geowiss. FU Berlin; 63 S., 26 Abb.

$\square$ Otto, Roland (1986): HYDAT I : Ein Kleinrechnerprogramm zur Auswertung von Abflußmessungen sowie Darstellung von Abfluß- bzw. Niederschlagszeitreihen. - In: Stäblein, Gerhard [Hrsg.]: Geound biowissenschaftliche Forschungen der Freien Universität Berlin im Werra-Meißner-Kreis

(Nordhessen). - Berliner Geogr. Abh., 41; zgl. Beiträge zur Werra-Meißner-Forschung, İ; S. 53 - 57, 4 Abb.; (Selbstverl. Inst. Phys. Geogr. FU Berlin) Berlin 1986

$\square$ Peter, Matthias (1997): Evaluierung eines Sanierungskonzeptes zur Verringerung der Nitratbelastung in einem Trinkwasserschutzgebiet in Nordhessen. - Boden und Landschaft, 16; XI, 247 S., graph. Darst., Kt.; [Justus Liebig-Universität] Gießen - zgl. Diss. Univ. Gießen 1997 
-Pfaff, F. (1908): Der Kressenbrunnen bei Grebenstein. - Hessenland, 22 (17): 239-241; (18): 254-256, 1 Abb.; Kassel

-Pickel, Hans-Jürgen (1969): Notiz über eine Strukturkarte des zentralen Stadtgebietes der Stadt Kassel vor der ersten Besiedlung. - Notizbl. Hess. L.-A. Bodenforsch., 97: 331 - 332, 1 Abb.; Wiesbaden

-Pickel, H.-J. \& Schubath, H. (1978): Zur Hydrochemie neuer Tiefenwaservorkommen in Nordhessen. - Geol. Jb. Hessen, 106: 403 - 441, 1 Abb., 3 Tab.; Wiesbaden [Bhrgn. Emstal, Edertal]

-Pickel, H.-J. \& Schubotz, K.-W. (1986): Methodik und Ergebnisse eines Soleinleitungsversuchs im Niestetal (Nordhessen). - Geol. Jb. Hessen, 114: 277 - 286, 3 Abb., 1 Tab.; Wiesbaden

-Quadflieg, Arnold (1990): Die Auswirkungen saurer Depositionen auf das Grundwasser in Kluftgrundwasserleitern des nord- und osthessischen Buntsandsteingebietes. - Z. dt. geol. Ges., 141: (Hydrogeologische Beiträge, 12): 456-467, 11 Abb., 2 Tab.; Hannover

- $\square$ Quadflieg, Arnold (1990): Zur Geohydrochemie der Kluftgrundwasserleiter des nord- und osthessischen Buntsandsteingebietes und deren Beeinflussung durch saure Depositionen. - Geol. Abh. Hessen, 90; 110 S., 26 Abb., 24 Tab., 8 Beil., Wiesbaden [darin: WMK: Umgebung Hessisch Lichtenau, östl. Begrenzung Linie Rommerode-Walburg]

$\square$ Rahbar, Yasaman, (1998): Modellierung der Grundwasserversalzung in der Werratalaue bei Eschwege (Nordhessen). - Diss. FU Berlin; 148 S., Anh., Ill., graph. Darst.

- Rambow; Dietrich (1972): Hydrogeologie und Trinkwassererschließung im Kreis Melsungen. - Hdb. d. Kreises Melsungen, 1973 (42. Jg.): 107 - 110; Melsungen

- Rambow, Dietrich (1977): Grenzen der Grundwassernutzung in Nordhessen. - Z. dt. geol. Ges., $\underline{\mathbf{1 2 8}}$ : 297-304, 2 Abb.; Hannover [Umgebung Kassel]

-Rambow, D. (1984): Zur Geologie und Hydrogeologie der Gemeinde Söhrewald. - In: Heß, G.; Peter, D.; Scholz, Th. H.D. \& Werner, H.-U.[Red.-Ausschuss]: Söhrewald 1984 - ein Beitrag zur Heimatkunde. - 365 S. + Anzeitenteil (S. 366-391), Abb.; hier S. 334-339, 2 Abb.; [Hrsg. Arbeitskreis Söhrewaldbuch] Söhrewald 1984

-Rambow, Dietrich (2002): Grundwasser - wichtige Lebensgrundlage, Hydrogeologie, Wassererschließung. - In: Rapp, Hermann-Josef [Hrsg.]: Reinhardswald - Eine Kulturgeschichte. - 240 S., 73 Abb.; hier S. 138-151, Abb. 41-43; (Euregio) Kassel 2002

OReh, Herbert (1954): Die Mineralquellen des Bades Liebenstein. - Geologie, $\underline{\mathbf{3}}(6 / 7):$ 891-916, 8 Abb.; Berlin [Hydrogeologie, Regionale Geologie/Bohrprofil]

oReichardt, Eduard (1859): Chemische Untersuchung der Mineralquelle zu Liebenstein im Herzogthum Sachsen-Meiningen. - Nebst einem Vorworte v. H. Doebner. - 51 S.; (Hahn) Hannover

ORemus, Walter \& Zieschang, Johannes (1975): Zur regionalen Einschätzung der Nutzungsmöglichkeiten von Mineralwässern für balneologische Zwecke. - Z. angew. Geol., 21(9): 423-427, 1 Abb.; Berlin [darin: „Mineralwasserprovinz V (Thüringer Becken-Provinz), Mineralwasserprovinz VI (WerraProvinz)]

- 0 Riek, Wolfgang (2008): Hilft Holland aus der Klemme? - Testlauf für Verwertung von K+S Abwässern - Hessens Behörden wollen Versenkung „kritisch prüfen“. - Werra-Rundschau, 2008; Nr. 
220 v. 19.09.2008, 1 Kt.; Eschwege

[Hydrogeologie, Interessenkonflikt Bergbau-Naturschutz]

- 0 Riek, Wolfgang (2008): Die Kalilauge kommt wieder zurück - Umweltministerium: 30\% der seit den 1920ern versenkten Abwässer in Buntsandsteinschichten aufgestiegen. - Werra-Rundschau, 2008; Nr. 253 v. 29.10.2008, 1 Foto, 1 Diagr.; Eschwege

$\square$ Ritzkowski, Siegfried (1986): Geologie und Hydrogeologie des Werra-Meißner-Gebietes - Geschichte, Bedeutung, Zukunftsperspektiven. - In: Brachmann, Richard [Red. u. Gesamtgestaltung]: Zwischen Entwicklung und Bewahrung - Der ländliche Raum im Jahr 2000. ASG Frühjahrstagung 1986. Herausgegeben aus Anlaß der Frühjahrstagung 1986 der Agrarsozialen Gesellschaft in Eschwege, Werra-Meißner-Kreis. 108 S:, zahlr. Abb. u. Kt.; hier S. 64-67, 2 Abb.; [Hrsg. Hess. Minister f. Landwirtschaft u. Forsten] Wiesbaden 1986

- $\bigcirc$ Rödel, R. (2002): Analyse und Modellierung hydrogeologischer Konsequenzen der Salzwasserversenkung im Werra-Kalirevier. - In: Schafmeister, Maria-Theresia \& Meyer, Tammo [Hrsg.]: Grundwasserresourcen im Spannungsfeld zwischen Erschließung und Naturschutz. Fachtagung der Fachsektion Hydrogeologie in der Deutschen Geologischen Gesellschaft Greifswald, 9.-11. Mai 2002 -Kurzfassung der Vorträge und Poster. - Schriftenrh. Dt. Geol. Ges., 19: 126; Hannover 2002

-Röhling, Heinz-Gerd (2003): Die Rhumequelle im Eichsfeld - eine der größten Karstquellen in Mitteleuropa. - Eichsfeld-Jahrbuch, 11: 329-357, 9 Abb., 4 Tab.; Duderstadt

@Röhling, Heinz-Gerd \& Nolte, Leander (2002): Die Bohrung „Heiligenstädter Martinsbrunnen“ Geologie des Deckgebirges und hydrogeologische Ergebnisse. - Eichsfeld-Jahrbuch, 10 (2002): $257-$ 282, 8 Abb., 6 Tab.; Duderstadt

ORöhling, H.-G. \& Nolte, L. (2008): Die Solebohrung „Heiligenstädter Martinsbrunnen“ - Geologie und Hydrogeologie <Vortragskurzfassung > . - In: Wunderlich, J. [Red.]: Exkursionsführer Geologie des Eichsfeldes - zur 18. Jahreshauptversammlung (Vortrags- und Exkursionsveranstaltung) vom 16. bis 18. Mai 2008 in Heilbad Heiligenstadt. - Führung: H. Heiland, L. Nolte, H.-G. Röhling \& G. Seidel. - S. 49-50, 1 Abb.; [Hrsg.: Thüringer Geologischer Verein e.V.] Jena 2008

ORöhling, H.-G. \& Nolte, L. (2004): Die Solebohrung „Heiligenstädter Martinsbrunnen“ Geologische und hydrogeologische Ergebnisse. - Beitr. Geol. Thüringen, N. F., 19: 17-36, 6 Abb., 6 Tab., 2 Beil.; Jena [Vorlage nicht eingesehen]

- Röhring, Matthias (1989): Die geologischen Ursachen des Mineralwasservorkommens am Gesundbrunnen bei Hofgeismar. - In: Burmeister, Helmut \& Röhring, Micha [Hrsg.]: Brunnen, Bürger, Bäder - Ein Erinnerungsband zur 350-jährigen Geschichte des Gesundbrunnens bei Hofgeismar.- Reihe: Die Geschichte unserer Heimat, $\underline{\mathbf{3}}$; 84 S., 42 Abb.; hier S. 8-10; [Hrsg. Verein f. hess. Gesch. u. Ldskde. e.V. - Kassel 1834; Zweigverein Hofgeismar] Hofgeismar 1989

OSchlegelmilch, Volker (1986): Schwefelbad Gräfentonna?. - Veröff. Naturkundemuseum Erfurt, Naturwiss. Rh., 5: 48-50, 1 Abb.; Erfurt

- Schlie, Peter (1989): Hydrogeologie des Grundwasserwerkes Stegemühle in Göttingen. - Göttinger Arb. Geol. Paläont., 43; IV, 143 S.; zgl. Diss. Univ. Göttingen 1987 (Selbstverl. Geol. Inst.) Götttingen

$\square$ Schlösser, Inga (1989): Hydrogeologische und hydrochemische Untersuchungen im südöstlichen Vorland des Hohen Meißners. - Dipl.-Arb. [unveröff.] Fachber. Geowiss. FU Berlin, 89 S.

-Schmidt, Hermann (1952): Quellen und Grundwasser im Landkreis Göttingen. - Göttinger Jb., 1952: 18 - 24, 3 Abb.; Göttingen 
oSchwandt, Arnold (1991): Zur Hydrogeologie der Zechstein-Sedimente in den Kali- und Steinsalzabbbaugebieten Mitteldeutschlands/On the hydrogeology of Zechstein Sediments from potassium und rock salt mining - districts of Central Germany. - Zbl. Geol. Paläont., Teil 1, 1991(4): 1263-1273, 9 Abb.; Stuttgart

-Schraft, Adalbert \& Rambow, Dietrich (1984): Vergleichende Untersuchungen zur Gebirgsdurchlässigkeit im Buntsandstein Osthessens. - Geol. Jb. Hessen, 112: 235 - 261, 18 Abb., 3 Tab.; Wiesbaden

- $\square$ Schraft, A.; Fritsche, J.-G.; Hempfler, M.; Mittelbach, G.; Rambow, D. \& Tangermann, H. (2001): Die hydrogeologischen Einheiten Nordhessens, ihre Grundwasserneubildung und ihr nutzbares Grundwasserdargebot (Ldkrs. Waldeck-Frankenberg, Kassel, Schwalm-Eder, WerraMeißner, Hersfeld-Rotenburg, Fulda und Stadt Kassel). - Geol Jb. Hessen, 129: 27 - 53, 9 Tab., 1 Anl.; Wiesbaden

OSchwandt, Arnold (1972): Beziehungen zwischen Salzlösungszuflüssen und Tektonik im Kalibergbau der DDR. - Ber. Dt. Ges. geol. Wiss., Reihe A, 17(2): 177-190, 9 Abb.; Berlin [darin: Merkers/Werra-Kalirevier]

OSchwartz, v. (1901): Die Quellen und Wässer des Seebergs bei Gotha. _ In: Naturwissenschaftliches und Geschichtliches vom Seeberg. - S. 58-68.; [Hrsg. Naturwiss. Verein z. Gotha) (Thienemann) Gotha 1901

$\square$ Schwarzenberg (Bergrath) (1838): Ueber den unterirdischen Lauf der Grubenwasser vom Meisner. Jber. Thätigkeit Vereins f. Naturkunde in Cassel. - ㄹ: 12 - 13; Kassel

OSeidel, Gerd (1964): Zur Endlaugenversenkung im Südharzkalirevier. - Z. angew. Geol., 10 (6): 290 295, 3 Abb., 1 Tab.; Berlin

[Hydrogeolgoie, auch Zechstein-Stratigraphie]

OSinn, Wolfgang \& Weigel, Heinrich (1994): Der Hautsee mit der schwimmenden Insel. - Das Werraland, $\underline{\mathbf{4 6}}$ (4): 81-84, 3 Abb.; Eschwege

[Landkr. Wartburg-Eisenach; auch Geologie und Archäologie, Märchen, Sagen]

- $\square$ OSkowronek, Frank; Fritsche, Johann-Gerhard; Aragon, Ute \& Rambow, Dietrich (1999): Die Versenkung und Ausbreitung von Salzabwasser im Untergrund des Werra-Kaligebietes. - Geol. Abh. Hessen, 105; 83 S., 23 Abb., 12 Tab.; Wiesbaden [Untersuchgn. auch auf Bl. 4925 Sontra, 4926 Herleshausen, 4927 Creuzburg]

OSobotha, Ernst (1936): Die Quellen am Rusteberg (Beiträge zur Geologie des Rusteberggebietes, II). Unser Eichsfeld, 31(1): 6-7; Duderstadt

OSommer, Th. \& Hesse, G. (2002): Hydrogeologie einer anthropogen überprägten Flußlandschaft - das Unstruttal zwischen Quelle und Sömmerda (Thüringer Becken) (Exkursion K am 5. April 2002) Jahresversammlung 2002 Oberrheinischer Geologischer Verein, Jena]. - Jber. Mitt. Oberrhein. Geol. Verein, N.F., 4: 241-256, 11 Abb., 1 Tab.; Stuttgart

- $\square$ Spichalsky, Bernd (1998): Wasserbilanz für den Regierungsbezirk Kassel - Planungsregion Nordhessen. - Umweltplanung, Arbeits- und Umweltschutz, 25; Teil 2 Anhang: Daten aus dem Bereich der Wasserversorgung und der Hydrogeologie. - 185 S., graph. Darst.; [Hess. Landesanstalt Umwelt] Wiesbaden

OSobotha, Ernst (1937): Zur Kenntnis der Quellen in der Umgebung von Herrenbreitungen (Werra). Z. dt. geol. Ges., 89: 207 - 210, 2 Abb.; Berlin Referat in: N. Jb. Mineral. etc., Referate, 1938 (Bd. II): 41 (Koehne); Stuttgart 
- Sobotha, Ernst (1980): Grundwasser im Eichsfeld - Landschaft und Grundwasserbereiche in einem Beispielraum Südniedersachsens. - Schriftenrh. Arbeitsgem. Südniedersächs. Heimatfrde. - Historisch naturwiss. Vereinigung, 4 - 50 S., 5 Blockbilder, 13 Kt.; (Zander) Herzberg-Pöhlde

$\square$ Taute, Thomas (1992): Die hydrogeologischen Verhältnisse auf der Gemarkung Meinhard (Nordhessen). - Dipl.-Arb. [unveröff.] Fachber. Geowiss. FU Berlin, 100 S.

$\square$ Thom, S.; Hentschel, B., Pekdeger, A.; Rahbar, J.; Taute, T. \& Ratei, H. (1993): Die Grundwasserversalzung in der Werratalaue bei Eschwege (Nordhessen). - In: Jacobshagen, V.; Möller, K. \& Jäkel, D. [Hrsg.]: Hoher Meißner und Eschweger Becken - Geowissenschaftliche und vegetationskundliche Charakteristik einer nordhessischen Landschaft. - Berliner geogr. Abh., $\underline{\mathbf{5}}$; zgl. Beiträge zur Werra-Meißner-Forschung, III; S. 79-116, 24 Abb., 2 Tab.; (Selbstverlag Geomorphologisches Laboratorium FU Berlin) Berlin 1993

$\square$ Thom, S.; Hentschel, B.; Sommer von Jarmerstedt, Chr. \& Pekdeger, A. (1995): Die Grundwasserversalzung in der Werra-Talaue durch Uferfiltration. - Z. dt. geol. Ges., 146: 114-1121, 5 Abb., 2 Tab.; Stuttgart

[Werraaue im WMK zwischen Jestädt und Frieda]

Q'Thüringer Landesanstalt f. Gewasserkunde [Hrsg.](1928): Die Grundwasserbewegung im Werratale von Obermaßfeld bis Leimbach (Salzungen) in den Abflußjahren 1925, 1926 und 1927. Jahresbericht Thüringer Landesanst. f. Gewässerkde., f. 1927?: 1 Taf., 1 Kt.; Weimar Referat in: N. Jb. Mineral. etc., Referate, $\underline{\mathbf{1 9 2 8}}$ (II): 626 (J. Denner); Stuttgart [Vorlage nicht eingesehen, zitiert nach Angaben im genannten Referat]

-Thürnau, Karl (1913): Der Zusammenhang der Rhumequelle mit der Oder und Sieber. - Jb. f. d. Gewässerkunde Norddeutschlands - Besondere Mitteilungen, 2,6; VI, 25 S., 9 Taf.; (Mittler) Berlin zgl. Diss. Techn. Hochschule Hannover 1912

$\square$ Toussaint, Benedikt (1979): Der Ringgau, ein natürliches Groß-Lysimeter. - Dargestellt am Wasserhaushalt der Breitauer Kressenteichquelle unter besonderer Berücksichtigung der Karsthydrogeologie. - Geol Jb., Reihe C, 21: 99-135, 10 Abb., 11 Tab.; Hannover

- $\square$ Toussaint, Benedikt (1981): Ermittlung des Leerlaufkoeffizienten nach MAILLET und des effektiv nutzbaren Gesteinshohlraumes in hessischen Flußgebieten durch Auswertung der Abflüsse im Trockenjahr 1976. - Dt. gewässerkundl. Mitt., 25: 70 - 84, 6 Abb., 1 Tab.; Koblenz [darin: Werra, Wehre, Fulda]

$\square$ Toussaint, Benedikt (1985): Die Karsthydrogeologie des nordosthessischen Ringgaues. - In: Verband der Deutschen Höhlen- und Karstforscher e.V. [Hrsg.]: Karst und Höhle 1984/1985. Beiträge zur Karst- und Höhlenforschung in Hessen. - S. 71 - 98, 18 Abb., 6 Tab.; (Selbstverlag d. Verbandes) München 1985

$\square$ Toussaint, Benedikt (2005): Analyse der Schüttungen ausgewählter Quellen im nordhessischen Ringgau. - Jber. HLUG, f. 2004; S. 9-21, 11 Abb.; Wiesbaden

口Ulrich [Wilhelm] (1949): Der Meißner. - 116 S., 5 Abb.; (Werraland-Verlag) Eschwege Referat in: Das Werraland, 1: 17-18 (Perst) [S. 9-25, 2 Abb.: „Der Meißner landschaftlich und geologisch“; S. 25-29: „Quellen“ [auch Hydrogeologie]; S. 29-45, 1 Abb.: „Das Braunkohlenwerk“]

OVölker, Reinhard (1983): Die großen Erdfallquellen von Mühlhausen. - Mühlh. Beitr., ㅁ: 84-96, 8 Abb.; Mühlhausen

$\square$ Vogt, A. (1992): Zur Geologie des Gebietes östlich von Hundelshausen (Werra-Grauwackengebirge, Nord-Osthessen) - Teil. I: Kartierbericht - Teil II: Gefährdungsabschätzung im Sulfatkarst östlich 
von Hundelshausen (Kartierung, Hydrogeologie, Petrographie und Geophysik). - Dipl.-Arb. [unveröff.] Univ. Marburg; 71 S., 50 Abb., 6 Tab., 7 Beil.

OWackenroder, Heinrich (1832): Chemische Untersuchung der Mineralquelle zu Liebenstein im Herzogthume Sachsen-Meiningen. - N. Jb. d. Chemie u. Physik, $\underline{\mathbf{5}}(9)$; 47 S.; Halle

-Wieting, Joachim [Red.] (1990): Mögliche Auswirkungen sauerer Depositionen auf das Grundwasser in Kluftgrundwasserleitern des Buntsandsteins Nord- und Osthessens - Die regionale Ausdehnung der immissionsbedingten Grundwasserversauerung im südlichen Taunus und in Nord- und Osthessen. - Umweltbundesamt - Texte, 90-34; 57 S., graph. Darst., 12 Kt.-Beil.; [Umweltbundesamt, Hess. Landesamt Bodenforschung]Berlin 1990

[Untersuchungen i. Nordhessen auf TK 25 B1. 4722 Niederzwehren, 4723 Oberkaufungen, 4823

Melsungen, 4923 Altmorschen, 5023 Ludwigseck, 5123 Niederaula, 5223 Queck, 5323 Schlitz, 5324

Hünfeld]

$\square$ Will, Norbert (1995): Gewässerkundliche Untersuchungen von Quellwässern im Bereich des Rüstungsaltstandortes Hirschhagen. - Dipl.-Arb. [unveröff.] Geogr. Inst. Universität Göttingen; IV, 79 S., graph. Darst, Kt. + 10 Kt.-Beil.

$\square$ Will, N.; Cyffka, B. \& Wolf, M. (1998): Nitrotoluolbelastung von Quell- und Grundwässern als Folge einer Rüstungsaltlast. - Geoökodynamik, 19: 103-118; Bensheim

[Untersuchung im Industriegebiet Rüstungsfabrik Hessisch Lichtenau/Hirschhagen]

OWolf, Hans Joachim (1951): Beitrag zur Geologie und Hydrogeologie der Oberrotliegendmulde von Tambach in Thüringen. - Dipl.-Arb. Univ. Berlin 1951, 31 S.

Referat in: Geologie, 1: 400; Berlin 1952

OWolff, Hans Joachim (1953): Beitrag zur Hydrogeologie der Oberrotliegendmulde von Tambach in Thüringen. - Abh. d. meteorologischen u. hydrologischen Dienstes der Deutschen Demokratischen Republik, 22 (Bd. III); 23 S., 6 Taf. (I-VI); (Akademie-Verlag) Berlin

$\square$ Wolff, P. (1982): Der Salzgehalt des Salzbaches und die Entstehung von Erdfällen und Landsenkungen in der Gemarkung Witzenhausen-Wendershausen. - Arb. u. Ber. GHS Kassel, Fachbereich 11: Int. Agrarwirtsch., Fachgeb. Kulturtechik u. Wasserwirtsch., 2; 9 S., [3 Bl.], Kt.; [Ghs Kassel, Fachber. Int. Agrarwirtschaft] Witzenhausen

$\square$ Wolff, Peter \& Hermann, Ulrike (1985): Zum Einfluß der Werraversalzung auf die Ökologie des

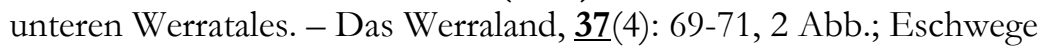
[darin: hydrogeologische Aspekte]

$\square$ Wolf, Peter \& Hermann, Ulrike (1987): Zur Salzbelastung der Kiesteiche und Baggerseen im Werratal.

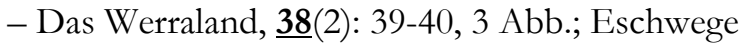

$\square$ Wurl, Jobst (1988): Hydrogeologische und hydrochemische Untersuchungen im östlichen Vorland des Hohen Meißners und am Unterwerra-Sattel (Bl. 4725 Bad Sooden-Allendorf). - Dipl.-Arb. [unveröff.] Fachber. Geowiss. FU Berlin, 102 S.

$\square$ Wycisk, P.; Meissner, B. \& Eisinger, M. (1993): Geowissenschaftliche Naturraumpotentialkarten als Arbeitsmittel der Umweltplanung - Grundwassernutzung Hoher Meißner. - In: Jacobshagen, V.; Möller, K. \& Jäkel, D. [Hrsg.]: Hoher Meißner und Eschweger Becken - Geowissenschaftliche und vegetationskundliche Charakteristik einer nordhessischen Landschaft. - Berliner geogr. Abh., $\underline{\mathbf{5}}$; zgl. Beiträge zur Werra-Meißner-Forschung, III; XII, S. 51 - 58, 1 Abb., 1 Kt.; (Selbstverlag Geomorphologisches Laboratorium FU Berlin) Berlin 1993

$\square$ Yasaman, Rahbar (1998): Modellierung der Grundwasserversalzung in der Werratalaue bei Eschwege (Nordhessen). - Diss. FU Berlin; 140 S., Anh., Ill., graph. Darst. 


\subsubsection{Karlsbrunnen bei Eichenberg, Werra-Meißner-Kreis}

$\square$ Anonym (1898): <Interessante Sonderlinge bei Quellen und Bächen: Ein Mühlbach bei Röhrda - Der intermittierdende Karlsbrunnen in Eichenberg - Die Bachschwinde im „Höllengraben“ bei Eichenberg> - Eschweger Tageblatt u. Kreisblatt, 1898; Nr. 195 v. 22.08.1898; Eschwege

$\square \bullet$ Böhme, Hermann (1932): Merkwürdige Quellen im Hannoverlande. - Die Weser, 11(6): 71-72; Bremen [Mariaspring u. Gronespring b. Göttingen, Karlsbrunnen Eichenberg, Rhumespring]

$\square$ Brauns, Eduard (1974): Der Karlsbrunnen in Eichenberg. - Hessischer Gebirgsbote, 75(3): 60-61, 1 Abb.; Melsungen [auch Geologie u. Märchen]

$\square$ Maurer, Jacob (1978): Das traurige Schicksal eines Naturdenkmals - Der Karlsbrunnen bei Eichenberg droht zu versiegen. - Das Werraland, $\underline{\mathbf{3 0}}(2): 19,1$ Abb.; Eschwege

$\square$ Mötzing, K.. (1970): Das Dorf Eichenberg - Seine Umgebung und sein „Carlsbrunnen“. - Das Werraland, 22 (3): 40-43, 4 Abb.; Eschwege [darin Kap. „Der Karlsbrunnen“; Hydrogeologie des Karlsbrunnens]

$\square$ Wenzel, Ernst (1912): Der Karlsbrunnen in Eichenberg. - Hessenland, 26 (13): 200-201; Marburg

$\square$ Wenzel, Ernst (1926): Der Karlsbrunnen zu Eichenberg. - Das Werratal, $\underline{\mathbf{3}}(10):$ 147-148, 2 Abb.; Eschwege

\subsection{3 „Rote Seen“}

-Althaus (1840): Der Landsee von Dens. - N. Jb. Mineral. etc., 1840: $84-85$ (Briefl. Mitt.); Stuttgart

-Anonym (1944): Ein „Blutsee“ in Hessen <Denser See i. Dens, Kreis Hersfeld-Rotenburg>. Eschweger Tageblatt, 1944; Nr. 3 v. 5.01.1944

-Anonym (1995): Der See [von Dens] - seine Entstehung und Bedeutung früher und heute. - In: Tense - Dens: 800 Jahre: 1195 - 1995 - Festschrift zum Jubiläum von 6. bis 9. Juli 1995. - 74 S., zahlr. Abb.; hier: S. 27-34, 3 Abb.; [Hrsg. Festausschuß 800-Jahrfeier] Dens 1995

- $\square$ ○ीApel, Jürgen \& Rüppel, Heidi [Verfass. u. Hrsg.] (2005): Raus in die Natur - Tipps für den Sonntags-Ausflug im Dreiländereck Hessen - Niedersachsen - Thüringen. - 159 S., 111 Fotos, 34 Kt., 1 Zeit-Taf.; (LSRB-Verlag, Landschaftskundlicher-Studien-Reisebuch-Verlag) Witzenhausen [zahlreiche Ausflugstipps, auch zum „Roten See“ i. Kaufunger Wald (Ziel 40)]

$\square$ Blanck, E. \& Themlitz, R. (1938): Der rote See bei Witzenhausen, zugleich ein weiterer Beitrag zur rezenten und fossilen Verwitterung des Feldspatbasaltes. - Chemie der Erde, 11(3): 375 - 407, 3 Abb., zahlr. Tab.; Jena

[Geochemie]

- Böhme, Hermann (1926): Der rote See bei Dens (Kreis Rotenburg). - Mein Heimatland, 7 (16): 124 127; Bad Hersfeld

-Böhme, Hermann (1926): Der rote See bei Dens (Kreis Rotenburg). - Heimat-Schollen, 1926 (11): 84 - 86, 1 Abb.; Melsungen 
- $\square$ Böhme, Hermann (1927): Das Rätsel Roter Seen im Hessenland. - Das Werratal, 4(3): 33-36;

Eschwege 1927

[Denser See b. Sontra, Hesselbühl(Roter See) Kaufunger Wald b. Großalmerode]

- $\square$ Böhme, Hermann (1935): Das Rätsel Roter Seen im Hessenland. - Hessischer Gebirgsbote, 41(4): 29-

31, 1 Abb.; Melsungen

[Dens, Hesselbühl(Roter See) Kaufunger Wald b. Großalmerode]

-Brauns, Eduard (1974): Der „rote“ See in Dens. - Hessischer Gebirgsbote, 75(2): 36-37, 1 Abb.;

Melsungen

[auch Geologie u. Märchen]

- $\square$ Fischer, Karl Rudolf (1932): Das Rätsel der hessischen „Blutseen“. - Volk u. Scholle, 10 (2): 42 - 43; Darmstadt

$\square$ Häger, Adolf (1925): Eine Wanderung zum Roten See bei Witzenhausen. - Heimat-Schollen, 1925 (15): 116 - 118, 4 Abb.; Melsungen

- $\square$ Heynemann, Rudolf (1928): Hessen, das Land der hundert Bergwunder. Märchenberge und Zauberseen. - Die Weser, 7(4): 111-122, 1 Abb. [Roter See/Kaufunger Wald]; Bremen

[Mystik und etwas Geologie]

aSchellhase, Karl W. (1935/36): Der rote See bei Dens und die Geschichte des Dorfes Dens. - Das Werratal, 12[1935](7): 51-54; 13 [1936](1): 4-6; Eschwege

$\square$ Wedekind, E. (1925): Der rote See im Kaufunger Wald bei Witzenhausen. - Abh. u. Bericht Vereins f. Naturkunde. z. Kassel, 무: 163 - 169; Kassel

$\square$ Wedekind, E. (1936): Zur Kenntnis des Kolloidsees bie Witzenhausen an der Werra. - Kolloid-Z., 70: 39; Darmstadt

Referat in: N. Jb. Mineral. etc., Referate, 1936 (Bd. II): 44 (F. Neumeier); Stuttgart

$\square$ Wedekind, E. \& Straube, A. (1922): Der Kolloidsee bei Witzenhausen an der Werra. - Zeitschrift f. angewandte Chemie, $\underline{\mathbf{3 5}}$ (43): 253; Leipzig

[Hydrochemie/Kolloidchemie „Roter See“/Hesselbühl i. Kaufunger Wald]

OZieschang, Johannes (1968): Zur Verbreitung der Mineralwässer in der Deutschen Demokratischen Republik. - Z. angew. Geol., 14(9): 493-497, 1 Abb.; Berlin

[darin: „Mineralwasserprovinz V (Thüringer-Becken-Provinz), VI (Werra-Provinz)“]

$\square$ Zippel, Hans (1937): Allerlei Naturmerkwürdigkeiten in Deutschland. - Die Weser, $\underline{\mathbf{1 6}}(10):$ 154-156, 1 Abb. („Blaue Kuppe“); Bremen

[darin: Roter See/Kaufunger Wald; „Blaue Kuppe“ nur als Abbildung]

\subsection{Geomorphologie, Naturräumliche Gliederung}

-Ackermann, Ernst (1953): Der aktive Bergrutsch südlich der Mackenröder Spitze in geologischer Sicht. - Nachr. Akad. Wiss. Göttingen; Math-phys. Kl., Math. - Phys. - Chem. Abt., 1953: 67 - 83, 7 Abb.; Göttingen

-Ackermann, Ernst (1954): Ein Tertiärvorkommen auf dem Göttinger Muschelkalk und seine Bedeutung für die Datierung der Oberfläche. - N. Jb. Geol. Paläont, 98: 70-79; Stuttgart 
$\square \bullet A c k e r m a n n$, Ernst (1958): Bergstürze und Schuttströme an der Wellenkalkschichtstufe Mitteldeutschlands in Gegenwart und Vergangenheit. - Natur u. Volk, $\underline{88}(4)$ : 123 - 132, 17 Abb.; Frankfurt/M.

[darin: Schickeberg/Ringgau; Kielforst b. Herleshausen, Mackenröder Spitze E' Göttingen]

$\square$ Ackermann, Ernst (1959): Die Sturzfließung am Schickeberg südlich Eschwege. - Notizbl. Hess. L.-A. Bodenforsch., 87: 172 - 187, 5 Abb., 2 Taf.; Wiesbaden

$\square$ Ackermann, Ernst (1959): Der Abtragungsmechanismus an der Wellenkalkschichtstufe. I. Bewegungsarten der Massenverlagerungen und morphologische Formen. - Z. Geomorph., N.F., 3: 193 - 226, 15 Abb.; II Massenverlagerungen im Wechsel der klimatischen Veränderungen. - Z. Geomorph., N.F., 3: 283 - 304, 8 Abb.; Berlin

II darin: Kielforst b. Herleshausen, Mackenröder Spitze E` Göttingen; II - darin: Schickeberg/Ringgau]

$\square \bullet A c k e r m a n n$, Ernst (1977): Zeitliche und räumliche Gliederung der Rutschfließungen an der Wellenkalk-Schichtstufe - (Exkursion L). - In: Geol.-Paläont. Inst. u. Museum der Universität [Hrsg.]: Exkursionsführer - Geotagung '77 Göttingen - Band II : Nordhessen und Südniedersachsen (Exkursionen C - D - J - K - L). - S. 113-120, 4 Abb.; Göttingen

[Schickeberg/Ringau Lkr. Eschwege; Mackenröder Spitze Lkr. Göttingen]

- $\square$ Aderhold, Gabriele (2005): Klassifikation von Erdfällen und Senkungsmulden in karstgefährdeten Gebieten Hessens, Empfehlungen zur Abschätzung des geotechnischen Risikos bei Baumaßnahmen. - Geol. Abh. Hessen, 115; 100 S., 46 Abb., 18 Tab., 2 Anl., 1 Kt.-Beil.; Wiesbaden

-Althaus (1840): Der Landsee von Dens. - N. Jb. Mineral. etc., 1840: 84-85 (Briefl. Mitt.); Stuttgart

- $\square \bullet$ Amthauer, Helmut (1972): Untersuchungen zur Talgeschichte der Oberweser. - Göttinger geogr. Abh., 59; 99 S., 3 Abb., 3 Kt.-Beil.; (Goltze) Göttingen

Untersuchungen u.a. an der Werra: Bad Sooden-Allendorf, Ermschwerd, Hedemünden; Oberweser v. Hann.-Münden bis Lauenförde]

$\square$ Angerhöfer, Horst (1987): Das Werraland - Kurze geographische Landeskunde. - Schriftenreihe Kreissparkasse Eschwege, $\underline{\mathbf{5}}$; 91 S., 9 Kt., Anh. m. 4 Diagr., 4 Kt.; Eschwege [Kap. z. Regionalgeologie, regionalen Geomorphologie]

$\square$ Angerhöfer, Horst (2002): Geologische und sozialgeographische Verhältnisse um und in Grebendorf. In: Bachmann, H.; Menthe, H., Schönberg, D.; Schönberg, S.; Strieb, A.; Strieb, G. \& Stück, H. (2002): 740 Jahre Grebendorf - Geschichte und Geschichten eines Dorfes. - 211 S., zahlr. Abb.; hier: S. 20-32, 1 Tab.; [Hrsg.: Arbeitskreis „Geschichte Grebendorf“] Eschwege 2002

$\square$ Angersbach, A. L. (1896): Der Felssturz im Königenthale bei Rambach. - Abh. u. Ber. Vereins Naturkde. z. Kassel, $\underline{40}$ (1894/1895): 40-48; Kassel

[Rambach, Gem. Weißenborn]

$\square$ Anonym (1882): <Erdfall bei Gut Mönchehof/Weidenhausen]. - Eschweger Kreisblatt, $\underline{1882} ; \mathrm{Nr} .54$ v. 9.5.1882; Eschwege

$\square$ Anonym (1883): <Bergrutsch bei Albungen verschüttet Bahnstrecke]. - Eschweger Kreisblatt, $\underline{\mathbf{1 8 8 3}}$; Nr. 9 v. 20.1.1883; Nr. 10 v. 23.1.1883; 13 v. 30.1.1883; Eschwege

$\square$ Anonym (1894): <Neuer Erdfall in den „Krippen“ (Kripplöchern) bei Frankershausen]. - Eschweger Tageblatt u. Kreisblatt, 1894; Nr. 74 v. 30.3.1894; Eschwege

$\square$ Anonym (1914): <Neuer Erdfall nahe der Oberdorfer Mühle bei Frankershausen> - Eschweger Tageblatt, 1914; Nr. 110 v. 12.5.1914; Eschwege 
$\square$ Anonym (1922): < Felsbewegungen am „Stinkloch“ (Stinksteinwand) Meißner]. - Eschweger Tageblatt, 1922; Nr. Nr. 249 v. 24.10.1922; Eschwege

$\square$ Anonym (1938): <Erdfall von 10 Breite und $17 \mathrm{~m}$ Tiefe in der Feldmark von Jestädt> - Eschweger Tageblatt, 1938; Nr. 164 v. 16./17.07.1938; Eschwege

-Anonym (1995): Der See [von Dens] - seine Entstehung und Bedeutung früher und heute. - In: Tense - Dens: 800 Jahre: 1195 - 1995 - Festschrift zum Jubiläum von 6. bis 9. Juli 1995. - 74 S., zahlr. Abb.; hier: S. 27-34, 3 Abb.; [Hrsg. Festausschuß 800-Jahrfeier] Dens 1995

- $\square$ O Apel, Jürgen \& Rüppel, Heidi [Verfass. u. Hrsg.] (2005): Raus in die Natur - Tipps für den Sonntags-Ausflug im Dreiländereck Hessen - Niedersachsen - Thüringen. - 159 S., 111 Fotos, 34 Kt., 1 Zeit-Taf.; (LSRB-Verlag, Landschaftskundlicher-Studien-Reisebuch-Verlag) Witzenhausen [zahlreiche Ausflugstipps, auch zu Geotopen der Geomorphologie; Ziel 36 (Bachschwinde Witzenhausen/Roßbach), Ziel 15 (Flußlauf Fulda b. Kassel), Ziel 56 (Werralauf b. Werleshausen), Ziel 64 (Karst östl. Meißnervorland), Ziel 75 (Zeugenbergbildung/Eschwege), Ziel 90 (Erosion Thüringer Wald/Eisenach ]

OArand, Siegfried \& Kaaden, Heiko (1986): Geologische und geomorphologische Betrachtung der Landschaft um Uder (Eichsfeld). - Eichsfelder Heimathefte, (26. Jg.) 1986(1): 22-36, 3 Abb.; Worbis

$\square$ Barsch, Dietrich \& Stäblein, Gerhard (1982): Erträge und Fortschritte der geomorphologischen

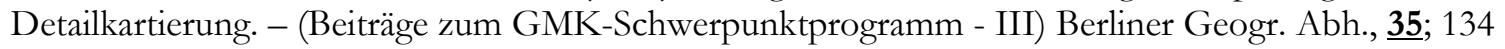
S., zahlr. Abb. u. Kt.; (Selbstverl. Geogr. Inst. FU Berlin) Berlin

QBartholomäus, K. (1957): Bodensenkungen im Gefolge des Solverfahrens im Rötsalz von Buchenau. Dipl.-Arb. [unveröff.] Bergakademie Freiberg 1957

$\square$ Beck, Hanno (1956): Echte Eiszeitspuren auf dem Meißner. Überraschende Ergebnisse neuerer geographischer Forschungen. - Werra-Rundschau, 1956, Nr. 9 v. 7.12.1956, S. 4; Eschwege

-Benda, L; Gaertner, H. R. v.; Herrmann, R.; Lüttig, G.; Streif, H.; Vinken, R. \& Wunderlich, H. G. (1968): Känozoische Sedimente in tektogenetischen Fallen und Subrosionssenken in SüdNiedersachsen. - Z. dt. geol. Ges., $\underline{117}$ (f. 1965): 713 - 726, 1 Abb., 1 Tab.; Hannover [darin: Bramburg, Hoher Hagen, Bilshausen, Seeburger See]

-Bernhard, Horst (1973): Fossile Einbruchschlote im Muschelkalk Nordhessens. - In: Wolters, R. [beteiligt]: Symposium - Erdfälle und Bodensenkungen: Ingenieurgeologische Probeme löslicher Gesteine - Effondrements et affaissements: problèmes de géologie de l'ingénieur relatifs aux roches solubles - Sink-holes and subsidence: engineering geological problems related to soluble rocks. Hannover 1973 - Proceedings. - Thema 2: Mechanismen von Erdfällen und natürlichen Bodensenkungen, S. T2/H1 - T2/H5, 1 Abb.; (Deutsche Gesellschaft f. Erd- und Grundbau) Essen 1973

[Bundesautobahn Dortmund-Kassel bei Kassel]

-Bock, W. (1925): Der große Wolkenbruch bei Trendelburg. - Der Naturforscher, 2: 415-416; BerlinLichterfelde [Nicht in der Vorlage eingesehen, zitiert nach Herrmann (1972)]

ØBöhme, Hermann (1926): Der Hautsee mit der schwimmenden Insel bei Dönges (Kreis Eisenach). Ein Naturwunder unserer engen Heimat. - Das Werratal, $\underline{\mathbf{3}}(4)$ : 53-56, 1 Abb., (5): 74-76; Eschwege [Subrosionsstruktur]

-Bork, Hans-Rudolf (1981): Die holozäne Relief- und Bodenentwicklung im Unteren Rhume- und Sösetal. - Göttinger Jb., 1981: 7 - 22, 4 Abb.; Göttingen 
-Bork, Hans-Rudolf (1982): Die holozäne Relief- und Bodenentwicklung im Untereichsfeld und im südwestlichen Harzvorland. - Diss. TU Braunschweig; IV, 187 S.; Abb., Beil.

-Bork, H. (1983): Die holozäne Relief- und Bodenentwicklung in Lössgebieten - Beispiele aus dem südöstlichen Niedersachsen. - In: Bork, H. R. \& Ricken, W. [Hrsg.]: Bodenerosion, holozäne und pleistozäne Bodenentwicklung. - Catena, Suppl., 푸 138 S.; hier S. 1-93, 12 Abb., 2 Tab.; (CatenaVerlag) Cremlingen-Destedt 1983

[Unter-Eichsfeld] - Die Vorlage enthält zwei Werke: Bork, H. R. (s. o.) und Ricken, W.: Mittel- und jungpleistozäne Lössdecken im südwestlichen Harzvorland. - S. 95-138, 12 Abb., 2 Tab.

-Bork, Hans Rudolf (1985): Untersuchungen zur nacheiszeitlichen Relief- und Bodenentwicklung im Bereich der Wüstung Drudevenshusen bei Landolfshausen, Ldkr. Göttingen. - Nachr. a. Niedersachsens Urgeschichte, 54: 59-75, 3 Abb., 3 Tab.; Hildesheim

-Bork, Hans Rudolf (1988): Mittelalterliche Relief-, Sediment- und Bodenentwicklung im Bereich der Wüstung Drudewenshausen. - Archäol. Korrespondenzbl., 18: 89-95, 2 Abb., 1 Tab.; Mainz

-Bork, H.-R.; Bork, H.; Dalchow, C.; Faust, B.; Piorr, H.-P. \& Schatz, T. (1998): Landschaftsentwicklung in Mitteleuropa - Wirkungen des Menschen auf Landschaften. - 328 S., 68 Abb., 36 Tab.; (Klett-Perthes) Gotha/Stuttgart [darin Fallstudien Untereichsfeld: S. 53-57,,Geköpfte und auf den Kopf gestellte Böden im Tiefen Tal“; S: 57-65 „Rasche und vollständige Bodenabtragung bei Drudenvenshausen“; S: 93-102 „Wölbächer bei Rüdershausen: Flurstrukturen lenken Bodenerosion“; S. 126-127 „Das Dorf Drudevenshausen und die Folgen der Bodenerosion“; S: 144 - 145 „Pedimentation bei Desingerode“; S. 145-151 „Die nacheiszeitliche Entwicklung der Rhumeaue bei Katlenburg“]

-Brauns, Eduard (1983): Ein Streifzug durch die nordhessische Bergwelt. - Hessischer Gebirgsbote, 84(2): 63 - 66; Melsungen

- Bremer, Hanna (1959): Flußerosion an der oberen Weser. Ein Beitrag zu den Problemen des Erosionsvorganges, der Mäander und der Gefällskurve. - Göttinger Geogr. Abh., 22; 192 S., 16 Abb., 6 Tab., 7 Textfig. u. 6 Fig. als Beil..; Göttingen - Referate in: Ber. Dt. Landeskde., 26: 116-117 (Hans Poser); Bad-Godesberg 1960/61 - Z. Geomorph., N.F., 4(3/4): 303-306 (H. Graul); Berlin 1960

-Brinkmann, R. (1932): Morphogenie und jüngste Tektonik im Leinetalgrabengebiet. - Abh. Preuß. Geol. Landesanst., N.F., 139: 102-135, 10 Abb.; Berlin

-Brinkmann, Roland (1933): Landschaftsformung und junge Krustenbewegungen im Leinegebiet. - Die Naturwissenschaften, 21: 7 - 11, 5 Abb.; Berlin

[Bezug a. Göttinger Leinetalgraben]

- $\square \bullet$ Brosche, Karl-Ulrich (1984): Zur jungpleistozänen und holozänen Talentwicklung des Werratales zwischen Hannoversch-Münden und Phillipstal (östl. Bad Hersfeld). - Eiszeitalter u. Gegenwart, 34: 105 - 129, 10 Abb., 3 Tab.; Hannover [darin: Profile im Werratal b. Eschwege]

$\square$ Brosche, Karl Ulrich \& Schultz, Hans Dietrich (1972): Probleme der Schichtstufenlandschaft Schmitthenners Theorie im Lichte neuerer Forschungen, insbesondere in Norddeutschland. - Geogr. Z., 60: 241-269, 2 Fig., 7 Abb. (Photos); Wiesbaden

[Werra-Meißner-Kreis: Goburg/Gobert, Ringgau, Schlierbachswald]

- •Brüning, Herbert (1966): Vorkommen und Entwicklungsrhythmus oberpleistozäner PeriglazialErscheinungen und ihr Wert für pleistozäne Hangformung - dargestellt an Beispielen aus dem Bereich der nördlichen Lößgrenze, aus dem Leinetal und den Leinetalrandgebieten. - Forsch. Dt. Landeskde., 156; 97 S., 52 Abb.; Bad Godesberg

[Unters. u.a. Umgebung v. Göttingen (Friedland, Krebeck, Settmarshsn.) Kassel-Niedervellmar] 
-Brunotte, Ernst (1987): Strukturformen im Altrelief der Dransfelder Hochfläche. - Z. Geomorphologie, N.F., Suppl.-Bd. 6ㅜ 37 - 47, 3 Abb.; Berlin - Stuttgart

-Brunotte, Ernst \& Garleff, Karsten (1979): Geomorphologische Gefügemuster des Niedersächsischen Berglandes in Abhängigkeit von Tektonik und Halokinese, Resistenzverhältnissen und Abflußsystemen. - In: Hagedorn, J.; Hövermann, J. \& Nitz, H. J. [Hrsg.]: Festschrift Dt. Geogr.Tag Göttingen 1979, 42, S. 21 - 42, 3 Abb.; Göttingen 1979 [darin: Göttinger Leinetalgraben, Dransfelder Hochfläche]

-Brunotte, E.; Garleff, K. \& Wahle, H. (1980): Neue morphographische und geomorphologische Karten aus dem südniedersächsischen Bergland. - 6 Kartenproben im [Maßstab] 1:50 000 und 1: 100 000. - Neues Archiv f. Niedersachsen, 29 (1): 85 - 96, 7 Abb.; Göttingen

-Brunottte, E.; Garleff, K. \& Jordan, H. (1985): Die Geomorphologische Übersichtskarte 1 : $50000 \mathrm{zu}$ Blatt 4325 Nörten-Hardenberg der Geol. Karte von Niedersachsen $1: 25$ 000. - Z. dt. geol. Ges., 136: 277 - 285, 1 Abb., 1 Kt.; Hannover

-Brunotte, E.; Hagedorn, J. \& Pörtge, K.-H. (1986): Exkursion B: Südlicher Leinetalgraben Reinhäuser Wald - westliches Untereichsfeld: Quartäre Fußflächen- und Talentwicklung im Leinetalgraben, Subrosionserscheinungen, Felsformen, Tal- und Flächenbildung im Bausandstein, historische und aktuelle Bodenerosion. - In: Dt. Arbeitskreis f. Geomorphologie - Jahrestagung 1986, 8. - 10. Oktober 1986 in Göttingen; Exkursionsführer; 37 S.; hier: S. 13 - 15, 12 Abb.; (Geogr. Inst.) Göttingen

-Brunotte, Ernst \& Garleff, Karsten (1989): Structural landforms and planation surfaces in southern Lower Saxony. - In: Ahnert, Frank [ed.]: Landforms und Landform evolution in West Germany] Catena Supplement, 15: 151 - 164, 6 Abb.; Braunschweig 1989 [darin: Dransfelder Hochfläche]

- Bubenzer, Olaf (1999): Sedimentfallen als Zeugen der spät- und postglazialen Hang- und Talbodenentwicklung im Einzugsgebiet der Schwülme (Südniedersachsen). - Kölner Geogr. Arb., 72; 132 S., 52 Abb., 16 Tab.; (Selbstverl. Geogr. Inst. Univ. Köln)

[ Raum Dransfeld - Adelebsen]

$\square \bullet C l a a s e n$, Karlheinz (1941): Die Flußterrassen des Werratals zwischen Bad Sooden-Allendorf und Hann. Münden. - Archiv f. Landes- u. Volkskunde v. Niedersachsen - Veröff., 1941(7) (= Bd. 1 125-166, 5 Abb., 10 Profile, 1 Tab., 1 Kt.; Oldenburg i. O.

$\square \bullet$ Claasen, Karlheinz (1944): Flußterrassen und Landschaft an der unteren Werra (zwischen Bad Sooden-Allendorf und Hannoversch-Münden. - Archiv f. Landes- u. Volkskunde v. Niedersachsen Veröff., 1944(20) (= Bd. $\underline{\mathbf{5}}(20))$ : 120-140, 14 Abb., 4 Profile, 2 Ktn.; Oldenburg i. O.

QCredner, H. (1851): Über den vormaligen Lauf der Gewässer auf der Nordseite des Thüringer Waldes. - Z. dt. geol. Ges., 3: 380-382 (Mber.); Berlin

-Damm, Bodo (2002): Die „Altmündener Wand“ am Rabanenkopf - 120 Jahre Hangrutschungen, Sanierungskonzepte, Hang- und Verkehrssicherung in Südniedersachsen. - Göttinger Jb., 무: 7 - 20, 7 Abb., 1 Tab.; (Goltze) Göttingen

ODaut, G.; Henkel, K.; Ig1. M.; Mäusbächer, R. \& Schneider, H. (2002): Untersuchungen an Subrosionssenken des mittleren Werratales (Vortrag und Poster). - (Sediment 2002) Schriftenrh. Dt. Geol. Ges., 17: 48-49; Hannover [Hptsächl. Gebiet zw. Immelborn und Schwallungen (Krs. Schmalkalden; Geomorphologie, Geochemie, Pollenanalyse] 
-Diestel, Walter (1930): Nachmittagswanderung im Diemeltal. - Die Weser, $\underline{9}$ (7): 207-208, 1 Abb.; Bremen [darin: „Wolkenbrüche“ bei Trendelburg]

OEbert, Artur (1922): Beiträge zur Kenntnis der prätertiären Landoberfläche im Thüringer Wald und Frankenwald. - Jb. Preuß. Geol. Landesanst., $\underline{41}$ (Teil I)(f. 1920): 392-470, 17 Abb., Taf. 19-22; Berlin

OEllenberg, Jürgen (1968): Die geologisch-geomorphologische Entwicklung des südwest-thürinigschen Werragebietes im Pliozän und Quartär. - Diss. Univ. Jena 1969; V, 188 Bl, Anh., 3 Anl.

OEllenberg, Jürgen (1968): Beziehungen zwischen Auslaugung und quartärer Sedimentation im thüringischen Werra-Kali-Gebiet. - Z. dt. geol. Ges., 117 (f. 1965): 670-679, 6 Abb., 1 Tab.; Hannover

QEllenberg, Jürgen (1969): Die Auslaugungssenke Hörschlitt im thüringischen Werra-Kali-Gebiet. Geologie, 18 (4): 488-490, 2 Abb., 1 Tab.; Berlin

QEllenberg, Jürgen (1972): Auslaugung und Sedimentation im Gebiet von Gerstungen. - Geologie, 21(3): 295-304, 3 Abb.; Berlin

QEllenberg, Jürgen (1976): Die zeitliche Fixierung der Subrosionsprozesse im thüringischen WerraKaligebiet. - Wiss. Z. E.-M.-Arndt-Univ. Greifswald, Mathem.-naturwiss. Rh., 27(1/2): 25-28, 3 Abb.; Greifswald

OEllenberg, Jürgen (1982): Die Subrosion im Werra-Kaligebiet der DDR, quartärgeologische, geomorphologische und tektonische Aspekte. - Z. geol. Wiss., 10 (1): 61-71, 6 Abb.; Berlin

QEllenberg, Jürgen (1986): Zur zeitlichen Fixierung von Subrosionsprozessen im Quartär. - Z. geol. Wiss., 14(2): 193-198, 3 Abb.; Berlin

[Mittlere Werra]

OEllenberg, Jürgen (2002): Bad Salzungen - Salzauslaugungen. - In: Sedlacek, Peter [Hrsg.]: (Spuren suchen - Landschaften entdecken) Thüringen - Geographische Exkursionen. - 325 S., 105 Abb.; hier: S. 57 - 59, Abb. 23 u. 24; (Justus Perthes) Gotha 2002

@Ellenberg, Jürgen (2002): Breitungen - Salzwiesen in der Werra. - In: Sedlacek, Peter [Hrsg.]: (Spuren suchen - Landschaften entdecken) Thüringen - Geographische Exkursionen. - 325 S., 105 Abb.; hier: S. 64-65, Abb. 27; (Justus Perthes) Gotha 2002

व $\square$ OElsheimer, Ernst (1907): Volksdichte und Besiedelungen im Meißnerlande. - Diss. phil. Univ. Marburg 1907; 116 S., 1 Falt-Kt.; (Lüdtke \& Martens) Kiel

[WMK, Hessen, Thüringen; darin S. 6-10: Regionalgeologie, S. 10-13: Geomorphologie, S. 13-17: Hydrographie]

-Erasmus, Wilhelm (1965): Landschaftskundliche Untersuchungen an Kalksteinhängen in der Umgebung Göttingens. - Diss. math.- nat. [unveröff.] Univ. Göttingen 1965; 121 S., 8 Abb. a. T., 4 graph. Darst., 9 Kt.-Beil.; Göttingen

- $\square$ Ernst, Eugen \& Klingsporn, Hermann (1969): Hessen in Karte und Luftbild - Topographischer Atlas - Teil I; 182 S., zahlr. Abb. u. Kt.; [Hrsg. Hess. Landesvermessungsamt](Wachholtz) Neumünster 1969

[darin: 18. Der Meißner - 22. Der Ringgau - ein Ausläufer des Thüringer Stufenlandes - 26. Die Kragenhöfer Schleife der Fulda nördlich Kassel]

OErnst, Werner (1992): „Panta rhei* - auch bei der Werra“ ( *“alles fließt“ - Zitat von Heraklit (540 bis 480 v. Chr.)). - Das Werraland, 44(2): 35-37, 2 Abb., 1 strat. Tab.; Eschwege

[Fluviatile Geomorphologie, Quartärgeologie]] 
QEyser, Margret (1924): Versuch einer Entwicklungsgeschichte des Hörselsystems. (Beiträge zur Morphologie von Thüringen). - Mitt. Geogr. Ges. f. Thür., 37: 11-20, 4 Abb.; Jena - Auszug aus Diss. Univ. Jena 1918

-Finkenwirth, Alfred \& Holtz, Siegfried (1974): Entstehung und Alter des Erdfalls „Seeloch“ bei Bad Hersfeld (Nordhessen). - Notizbl. Hess. L.-A. f. Bodenforsch., 102: 207-214, 1 Abb.; Wiesbaden

OFlaskamp, Franz (1931): Der Erdbruch und Erdrutsch bei Winzigerode im Eichsfeldischen Ohmgebirge am 5. und 6. März 1798. - Unser Eichsfeld, 26(12): 270-282; Duderstadt

QFörtsch (1895): Die Bodensenkungen in Gräfentonna und Burgtonna. - Z. f. Naturwiss., $\underline{\mathbf{6 8}}(5 / 6)$ : 445447; Leipzig

Referat in: Mitt. Geogr. Ges. (f. Thüringen), 17: 99 (Alfred Berg); Jena 1898

$\square$ Freund, J. (1928): Die Erdfälle bei Hermannrode. - Das Werratal, $\underline{\mathbf{5}}(8)$ : 126; Eschwege

QFreyberg, Bruno von (1923): Die tertiären Landoberflächen in Thüringen. - Fortschr. Geol., Paläont., (Bd. 2) H. ㅁ; 77 S., 19 Abb., 6 Tab., 1 Taf. (2 Abb.); (Bornträger) Berlin

QFreyberg, Bruno von (1937): Thüringen - Geologische Geschichte und Landschaftsbild. - Schriften Dt. Naturkde.-Vereins, N.F., $\underline{\mathbf{5}}$; 160 S., 252 Abb.; (Hohenlohe'sche Buchhandlung Ferdinand Rau) Öhringen

$\square$ Friedrich, Ludwig (1985): Karsterscheinungen in Weißenbach am Meißner - ein Dorf wird verlegt. In: Verband der Deutschen Höhlen- und Karstforscher e.V. [Hrsg.]: Karst und Höhle 1984/1985. Beiträge zur Karst- und Höhlenforschung in Hessen. - S. 167-170, 1 Abb.; (Selbstverlag d. Verbandes) München 1985

- $\bullet$ Fuchs, Gerhard (1966): Die Bedeutung des Klimas für die Ausformung des Wesertales. - Die Weser, 40(9): 150-152; Bremen

$\square$ Garleff, Karsten (1966): Beitrag zur Deutung der Terrassen im unteren Werratal. - Eiszeitalter u. Gegenwart, 17: 118 - 124, 3 Abb.; Öhringen

[Werratal zwischen Wendershausen und Unterrieden]

- $\square \bullet$ Garleff, Karsten (1985): Erläuterungen zur Geomorphologischen Karte der Bundesrepublik Deutschland. - Blatt 2: C 4722 Kassel; 74 S., Abb.; Berlin

- $\square$ Garleff, K. \& Brosche, U. (1986): Exkursion A - Kasseler Becken - Hoher Meißner - Werratal: Skulptur- und Strukturformengenese seit dem Mitteltertiär, plio-/pleistozäne Fußflächen, Morphogenese des Meissners, Talentwicklung an Werra- und Fulda. - In: Dt. Arbeitskreis f. Geomorphologie - Jahrestagung 1986, 8. - 10. Oktober 1986 in Göttingen; Exkursionsführer; 37 S.; hier: S. 1 - 12, 9 Abb.; (Geogr. Inst.) Göttingen

- $\square \bullet$ Garleff, Karsten; Brunotte, Ernst \& Sting1, Helmut (1988): Fußflächen im zentralen Teil der Hessischen Senke. - In: Liedtke, Herbert [Hrsg.]: Untersuchungen zur Geomorphologie der Bundesrepublik Deutschland - Neue Ergebnisse der Geomorphologische Kartierung - Beiträge zum GMK-Schwerpunktprogramm VIII. - Berliner geogr. Abh., 47: 63-76, 8 Abb.; Berlin 1988

[Nordhessen, Werra-Meißner-Kreis, Südniedersachsen]

$\square$ Gehlsdorf, Herbert (1926): Landschaft und Besiedlung im Ringgaugebiet - Eine siedlungsgeographische Untersuchung. - Reihe: Landeskundliche Arbeiten des Geographischen Seminars der Universität Göttingen, o. Zhlg.; 154 S., 5 Kt.-Beil., 12 Abb. i. Text, 36 Abb. a. Taf.; (Johs. Braun) Eschwege - zgl. Diss. Univ. Göttingen 1926

[Überblick Geologie, Geomorphologie einzelner Landschaftsteile] 
OGeiger, Walter (1974): Ein Haifischzahnfund im Sachsental bei Kaltenohmfeld - Eine geomorphologsch-geologische Betrachtung des Ohmgebirges. - Eichsfelde Heimathefte, (14. Jg.) 1974(4): 340-354, 12 Abb.; Worbis

-Gerold, Gerhard \& Pörtge, Karl-Heinz (1989): Einfluss von Relief- und Substratvarianz auf Abfluss und Stoffaustrag in Teileinzugsgebieten der oberen Leine, Südniedersachsen. - (Grunert, Jörg \& Höllermann, Peter [Hrsg.]: Geomorphologie und Landschaftsökologie) Bonner Geogr. Abh., 85: 100113, 9 Abb., 2 Tab.; Bonn

[Bergland S' Göttingen, Einzugsgebiet Dramme, Garte und Wendebach]

- Gerold, Gerhard \& Molde, Peter (1989): Einfluß der Pedo-hydrologischen Einzugsgebietsvarianz auf Oberflächenabfluß und Stoffaustrag im Einzugsgebiet des Wendebaches. - Göttinger geogr. Abh. (Pörtge, K.-H. \& Hagedorn, J. [Hrsg.]: Beiträge zur aktuellen fluviatilen Morphodynamik), $\underline{86}$ : 81-93, 7 Abb., 1 Tab.; Göttingen

- $\square$ • Gerstenhauer, Armin (1969): Die Karstlandschaften Deutschlands - mit einer zweifarbigen Karte. - Abh. Karst- u. Höhlenkunde, Reihe A, $\underline{\mathbf{5}}$; - 8 S., 1 Falt-Kt.; München [alle Regionen]

-Gerwien, E. (1914): Der Lauf der Oberweser im Buntsandsteingewölbe. - Diss. Humboldt-Univ. Berlin, 70 S., 1 Taf; Berlin

QGeyer, Roland (1994): Die Geologischen Naturdenkmale im Kreis Eisenach [Wartburgkreis]: 2. Die Erdfälle bei Frauensee. - Knüllgebirgsbote, 1994(3): 3, 1 Abb.; Bad Hersfeld

-Göbel, Peter (1976): Beobachtungen zur Schichtstufenentwicklung im Fulda-Werra-Bergland. - Z. Geomorph., N.F., Suppl.-Bd., 24: 33 - 41, 4 Abb.; Berlin-Stuttgart [Untersuchungen a. Bl. 5125 Friedewald]

-Göbel, Peter (1978): Vorschläge zur Aufnahme und Gestaltung geomorphologischer Karten - erläutert am Beispiel der Geomorphologischen Karte 1 . 25 000, Bl. 5125 Friedewald. - Geol. Jb. Hessen, 106: 303 - 317; Wiesbaden

QGrahmann, Bernhard (1924): Das Flußgebiet der Schleuse (Beiträge zur Morphologie von Thüringen). - Mitt. Geogr. Ges. f. Thür., 37: 21-28; Jena - Auszug aus Diss. Univ. Jena 1918

هGreiling, Reinhard (1977): Über die Subrosionssenke „der See“ bei Kleinensee (Osthessen, TK 25 Bl. 5025 Hönebach). - Geol. Jb. Hessen, 105: 169 - 175, 3 Abb.; Wiesbaden

OGresky, Wolfgang (1974): Der Bodensteiner Erdrutsch von 1798 und und G. Chr. Lichtenberg. - Die Goldene Mark, 25(3/4): 72-77; Duderstadt

[Bodenstein b. Wintzigerode; das Ereignis in briefl. Mitteilung von Joh. Friedr. Benzenburg an Georg Christoph Lichtenberg]

- •Grimm, Arnulf \& Lepper, Jochen (1973): Schlotförmige Erdfälle im Sollinggewölbe und deren Beziehung zu Salzwasservorkommen. - In: Wolters, R. [beteiligt]: Symposium - Erdfälle und Bodensenkungen: Ingenieurgeologische Probeme löslicher Gesteine - Effondrements et affaissements: problèmes de géologie de l'ingénieur relatifs aux roches solubles - Sink-holes and subsidence: engineering geological problems related to soluble rocks. - Hannover 1973 - Proceedings. - Thema 2: Mechanismen von Erdfällen und natürlichen Bodensenkungen, S. T2/E1 - T2/E7, 3 Abb., 2 Tab., 1 Taf.; (Deutsche Gesellschaft f. Erd- und Grundbau) Essen 1973 [Erdfälle Bl. 4323 Uslar und 4322 Bad Karlshafen]

QGrumbt, Eberhard \& Lützner, Harald (1966): Störungszonen im Deckgebirge des thüringischen Werra-Kaligebietes und ihre Beziehungen zum Basaltvulkanismus und zur Auslaugung Untersuchung der petrographischen, tektonischen und mineralischen Verhältnisse des 
Floßberggangzuges zwischen Ilmenau und Gehren als Beitrag zur Klärung der saxonischen Lagerstätten auf den Randspalten des Thüringer Waldes. - Geologie, $\underline{\mathbf{1 5}}$ (4/5): 531-544, 8 Abb.; Berlin

OGrupe, O. (1926): Tal- und Terrassenbildung im Gebiete der Werra-Fulda-Weser und Soergels „Gliederung und absolute Zeitrechnung des Eiszeitalters“. - Geol. Rundschau, 17: 161 - 196, 9 Abb.; Berlin

Referat in: N. Jb. Mineral. etc., Referate, 1928 (Bd. II): 535; Stuttgart [darin: Altenbreitungen/Thüringen]

$\square \bullet$ Gruppe, O [skar] (1927): Zur Talentwicklung des Wesersystems. Entgegnung an Herrn Soergel. Geol. Rundschau, 18: 456 - 461; Berlin

QHändel, Fritz (1924): Das Granitgebiet vom Suhl und Mehlis (Beiträge zur Morphologie von Thüringen). - Mitt. Geogr. Ges. f. Thür., 37: 34-36; Jena - Auszug a. Diss. Univ. Jena 1920 [Flußgebiet von Hasel und Schwarza b. Kloster Rohr]

- $\square \bullet$ Hagedorn, Jürgen [Hrsg.] (1986): Deutscher Arbeitskreis f. Geomorphologie - Jahrestagung 1986, 8. - 10. Oktober 1986 in Göttingen; Exkursionsführer; 37 S., 35 Abb., 1 Tab.; (Selbstverlag Geogr. Inst.) Göttingen

-Hagedorn, J. ; Brunotte, E. \& Schröder, E. (1972): Kuppenrelief und Felsformen im Bausandstein des Göttinger Waldes (südöstlich Göttingen). - (Hans Poser-Festschrift z. 65 Geburtstag) Göttinger geogr. Abh. 65: 203 - 219, 11 Abb., 1 Tab.; Göttingen

-Hagedorn, Jürgen; Hong, Seong Jo \& Pretzsch, Kurt (1997): Die geomorphologische Bedeutung von Schwermetallgehalten holozäner Auensedimente. Beispiele aus Mitteleuropa. - In: Güßefeld, Jörg \& Spönemann, Jürgen [Hrsg.]: Geographie in der Grundlagenforschung und als Angewandte Wissenschaft) Göttinger Geogr. Abh., 100: 23-41, 11 Abb.; Göttingen 1997 [darin: N-Hang Kaufunger Wald zw. Hedemünden und Kleinalmerode]

-Hannemann, M. (1936): Morphologische Untersuchungen im Hessischen Bergland. - Festschr. 100 Jahrfeier Vereins f. Geogr. Statist. z. Frankfurt a. M., S. 241 - 275; Frankfurt/M.

$\square 0 \bullet$ Hartung, Wilhelm (1969): Die Werra - Laufrichtung und Talformen in geologischer Sicht. - Das Werraland, 21 (2): 27-28; Eschwege

[WMK, Thüringen, Niedersachsen]

QHecht, G.; Ellenberg, J. \& Beer, W. (2001): Exkursion C 2 - Subrosion und Hydrogeologie im WerraKaligebiet. - In: Jockel, Andreas [Hrsg.]: Regionale und angewandte Geologie der Grenzregion der Süddeutschen und der Mitteldeutschen Scholle. - Exkursionsführer zur 10. Jahrestagung der Gesellschaft für Geowissenschaften e.V. in Schmalkalden - 19.-22. September 2001. Exkursionsführer u. Veröff. Ges. f. Geowiss., 213; S. C2-1 bis C2-16, 6 Abb.; Berlin 2001

- $\square$ Heck, Herbert Lothar (1929): Beiträge zur Talgeschichte der oberen Leine. - Jb. Preuß. Geol. Landesanst., 49 (Teil I) (f. 1928)): 427 - 453, 5 Abb., 6 Taf. (28-33); Berlin [darin: Profil von Berge zw. Eichenberg u. Hebenshausen]

- Hempel, Lena (geb. Tecklenburg) (1953): Das morphologische Landschaftsbild des UnterEichsfeldes unter besonderer Berücksichtigung der Bodenerosion und ihrer Kleinformen. - Forsch. Dt. Landeskde., 요; 55 S., 6 Abb., 6 Kt.; Remagen - auch als Diss. Univ. Göttingen 1953 [Untersuch. i. Gebiet zw. Gieboldehausen u. Duderstadt]

- Hempel, Ludwig (1951): Struktur- und Skulpturformen im Raum zwischen Harz und Leine. Göttinger Geogr. Abh., 7; 66 S., 17 Abb., 1 Falt-Kt.; Göttingen [darin: Göttinger Wald u. Hünstollen, Triaslandschaft um Reiffenhausen] 
-Hempel, Ludwig (1954): Beispiele von Bodenerosions-Karten im niedersächsichen Bergland sowie Bemerkungen über Berücksichtigung der Erosionsschäden bei der Bodenschätzung. - Neues Archiv f. Niedersachsen, 7: 140-143, 3 Kt.; Bremen-Horn [darin: Bl. 4425 Göttingen]

- Hempel, Ludwig (1955): Studien über Verwitterung und Formenbildung im Muschelkalkgestein. Ein Beispiel zur klimatischen Morphologie. - Göttinger geographische Abhandlungen, 18; 112 S., 13 Abb., Profile, 2 Kt., 4 Taf. (13 Abb., 3 Kt.-Beil.; zgl. Habil.-Schr. Univ. Göttingen; (Selbstverl. Geogr. Inst.) Göttingen

[Untersuch. u. a. Meißner, Göttinger Wald und Hünstollen, Dransfelder Hochfläche, Fläche von Neuenrode]

- $\bullet$ Hempel, Ludwig (1955): Rumpfflächenlandschaft oder Schichtstufenlandschaft? - Neue Beobachtungen zur Verzahnung beider Großformen. - Nachr. Akad. Wiss. Göttingen, Math.-phys. Kl., Math.-Phys.-Chem. Abt., 1955: 223 - 238, 9 Abb.; Göttingen [darin: Dransfelder Hochfläche, Umgebung Hofgeismar und Grebenstein/Nordhessen]

-Hempel, Ludwig (1955): Frostbodenbildung und Lößanwehung in der Würmeiszeit auf Muschelkalk und Buntsandstein bei Göttingen. - Akad. Wiss. u. Lit. Z. Mainz - Abh. Math.-Natwiss. Kl., 1955, H. 2; 42 S., 8 Abb.; Wiesbaden

- •Hempel, Ludwig (1957): Gesteinsstruktur und klimatisch bedingte Formungstendenzen - Ihre Bedeutung für das Aussehen von Muschelkalklandschaften. - Verhdlgn. Dt. Geographentag, $\underline{30}$ : 331337, 2 Taf. (8 Abb.), 2 Profile; Wiesbaden [darin: Umgebung Göttingen, Lkr. Kassel]

-Hempel, Ludwig (1957): Flächenformen und Flächenbildung in der Stufenlandschaft. Beobachtungen aus Deutschland und Großbritannien. - Petermanns geogr. Mitt., 101(3): 178-184, 6 Abb. i. Text u. a. Taf. 22/23; Gotha

[darin: Göttinger Wald]

- Hempel, Ludwig (1958): Möglichkeiten und Grenzen der Auswertung amtlicher Karten für die Geomorphologie. - Verhdlgn. Dt. Geographentag (Würzburg, 29. Juli - 5. August 1957), 31: 272-279, 10 Abb., 2 Tab.; Wiesbaden

[darin: Lkr. Göttingen]

- $\bullet$ Hempel, Ludwig (1958): Studien in nordeutschen Buntsandsteinlandschaften. - Forsch. Dt. Landeskde., 112; 116 S., 41 Abb., 1 Kt.; Remagen

[darin: Untereichsfeld u. Randgebiete bis Göttingen (Reinhäuser Wald), Bramwald, Werratal, Kaufunger Wald, Region Bad Hersfeld]

- •Hempel, Ludwig (1958): Eiszeitklima und Gesteinsstruktur - ihre Bedeutung für die asymmetrischen Talformen im Buntsandstein. - Eiszeitalter u. Gegenwart, 9: 49 - 60, 6 Abb.; Öhringen [darin: Harzvorland, Solling, Reinhäuser Wald, Kaufunger Wald]

- Hempel, Ludwig (1963): Bodenerosion in Nordwestdeutschland. Erläuterungen zu Karten von Schleswig-Holstein, Hamburg, Niedersachsen, Bremen und Nordrhein-Westfalen. - Forsch. dt. Landeskde., 144; 16 S., 9 Kt. (1-4 als Beil.); (Selbstverlag Bundesanst. f. Landeskde. u. Raumforsch.) Bad Godesberg

[darin: Karte 2: Bodenerosion in Nordwestdeutschland (südlicher Teil); Karte 4: Bodenerosion Kartierungsblatt 4425 Göttingen]

- Hempel, Ludwig (1966): Bodenerosion in landeskundlicher Sicht. Gedanken zu Karten der Bodenerosion von Niedersachsen. - Neues Archiv f. Niedersachsen, 15(4): 292-296, 3 Photos; Göttingen [darin: Unter-Eichsfeld] 
-Hermann, Rudolf (1972): Über Erdfälle äußerst tiefen Ursprungs (Die „Wolkenbrüche“ bei Trendelburg und die „Meere“ bei Bad Pyrmont). - Notizbl. Hess. Landesamtes f. Bodenforsch., 100: 177-193, 5 Abb., 1 Taf.; Wiesbaden

-Herrmann, Rudolf (1972): Wie die „Wolkenbrüche“ bei Trendelburg entstanden sind. Heimatjahrbuch. f. d. Landkreis Hofgeismar, 1973: 76 - 79, 1 Abb.; Hofgeismar

-Herrmann, Rudolf (1972): Wie die „Wolkenbrüche“ bei Trendelburg entstanden sind. - Jb. Lkr. Kassel, 1973: (77 Bildseite +) 77-79, 1 Abb., Foto Bildseite 104; Wolfhagen

-Hessler, Carl (1906): Bodengestalt [Geomorphologie]- In: Hessler, Carl [Hrsg.]: Hessische Landesund Volkskunde - Das ehemalige Kurhessen und das Hinterland. Bd. I: Hessische Landeskunde. Erste Hälfte. - 531 S., zahlr. Abb.; hier: S. 1-18, Abb.; (Elwert) Marburg 1906

$\square$ Hieke, Werner \& Ritzkowski, Siegfried (1969): Die altquartäre Subrosionssenke von Fürstenhagen bei Hess. Lichtenau (Nördliches Hessen). - Geol. Rundschau, 묘: 190-196, 2 Abb., 1 Tab. Stuttgart

QHildebrandt, Hans (1932): Gemorphologische Untersuchungen über das Tambacher Becken und seine Umrandung. - Diss. Univ. Jena, 40 S.

•Hövermann, Jürgen (1953): Die Oberflächenformen um Göttingen. - Göttinger Jb., 1953: 63-74, 1 Kt.; Göttingen

-Hövermann, Jürgen (1953): Studien über die Genesis der Formen im Talgrund südhannoverscher Flüsse. - Nachr. Akad. Wiss. Göttingen, Math.-Nat. Kl. (Biol., Physiol., Chem. Abt.), 1953: 1 - 14; Göttingen [darin: Leineaue, 2 Profile Rosdorf b. Göttingen]

OHoff, [K. E. A.] (1830): Das Nadelöhr im Thale der Werra und Einiges über Thalbildungen. - Jb. Mineral., 1(4): 421-441, Taf. V; Heidelberg [darin S. 438: Flußlauf der Werra zw. Eisenach u. Münden]

QHoff, [K. E. A.] (1834): Erdfall bei Gotha im Muschelkalk. - N. Jb. Mineral. etc., 1834(3): 327-329 (Briefl. Mitt.); Stuttgart [Erdfälle S-Hang Krahnberg/Gotha]

-Hofmann, Walter [Hrsg.] (1969): Landformen im Kartenbild: Topographisch-geomorphologische Kartenproben $1: 25.000$. Gruppe IV - Mittelgebirge: an Vulkanismus gebundene Formen. Kartenprobe 2: Vulkanstiele im Tertiärhügelland, Gudensberg bei Kassel. - 11 S., Abb., 7 Kt.-Beil.; (Westermann) Braunschweig

-Hofmann, Walter [Hrsg.](1974): Landformen im Kartenbild: Topographisch-geomorphologische Kartenproben $1: 25.000$. Gruppe III : Mittelgebirge - Schichttafeln, Schichtstufen, Schichtkämme. Kartenprobe 3: Schichtstufe mit Zeugenbergen im Muschelkalk bei Waake, östlich Göttingen. - 12 S., Abb., 8 Kt.-Beil.; (Westermann) Braunschweig

$\square$ Hong, Seong Jo (1995): Holozäne und aktuelle Tal- und Flußentwicklung auf der Nordostabdachung des Kaufunger Waldes, Nordhessen. - 152 S., 51 Abb., 9 Tab., 4 Fototaf. (8 Abb.), 2 Beil. (1 morph. Kt., 1 strat. Taf.); zgl. Diss. Univ. Göttingen; [Cuvillier]Göttingen

[Untersuchungsgebiet zwischen Ermschwerd und Oberode]

- 0 Hoppe, Walter (1944): Die Auslaugungserscheinungen im Werra-Kaligebiet, ihre Bedeutung für die Lagerstätte und die Landschaftsform. - Jb. Reichsanst. Bodenforschung, $\underline{\mathbf{6 2}}$ (f. 1941): 248-271, 3 Abb., Taf. 12; Berlin

$\square$ Hotzler, Fritz (1994): Über die Entstehung der Hie- und Kripplöcher. - Das Werraland, $\underline{46}(2): 42-43,5$ Abb.; Eschwege 
-Huckriede, Reinhold \& Urban, Brigitte (1998): Ein landschafts- und flußgeschichtlich wichtiges Pannon- bis Altquartär-Profil bei Fritzlar/Hessen. - Z. dt. geol. Ges., 149: 105 - 126, 3 Abb., 6 Taf.; Stuttgart

OIg1, Monika (2000): Untersuchungen zur spät- und postglazialen Fluß- und Landschaftsgenese im mittleren Werratal unter besonderer Berücksichtigung von Subrosionssenken. - Diss. Univ. Jena [unveröff.] 2000; VI, 227 S., Ill., graph. Darst.,Kt.

$\square$ Jacobshagen, Volker (1997): Fossile und rezente Subrosion von Zechstein-Evaporiten der Region Eschwege - Hoher Meißner (Nordhessen). - Z. geol. Wiss., 25(3/4): 253-261, 5 Abb.; Berlin

- $\square$ Jacoby, Karl (1934): Die Landschaftsformen in Niederhessen. - Hessischer Gebirgsbote, 40(4): 29 31, 3 Abb.; Melsungen

[Abb. Heldrastein, Gudensberg]

口Jäger, Willy (1925): Über die Entstehung der Leuchtberge bei Eschwege. - Das Werratal, 20(4): 57-59; Eschwege

- $\square$ Jäschke, Max (1888): Das Meissnerland. Erster Theil: Physiographie. - Forsch. Dt. Landes- u. Volkskde., $\underline{\mathbf{3}}$ - zgl. Diss. Univ. Marburg 1888

Referat in: N. Jb. Mineral. etc, $\underline{\mathbf{1 8 8 9}}$ (Bd. II): 71-72 (Franz Beyschlag); Stuttgart [Geomorphologie]

OJohnsen, G. (1981): Bewegungsmessungen im Bereich von Blockrutschungen an der Röt/WellenkalkSchichtstufe Thüringens. - Z. angew. Geol., 27(8): 386-392, 10 Abb., 2 Tab.; Berlin [Nordrand Bleicheröder Berge]

QJülich, Eberhard (2002): Subrosionserscheinungen im Röt (Oberer Buntsandstein) im Bereich des Ohmgebirges (NW-Thüringen, Eichsfeld) - Herbstexkursion des Thüringer Geologischen Vereins am 19.10.2002. - Mittbl. Thür. Geol. Verein, 16: 34-36; Jena

- $\square$ ○|Keller, H. [Hrsg.] (1901): Weser und Ems, ihre Stromgebiete und ihre wichtigsten Nebenflüsse. Eine hydrographische, wasserwirtschaftliche und wasserrechtliche Darstellung. - Bd. I: Stromgebiete und Gewässer. - XVIII, 168 S., (Reimer) Berlin 1901 - Bd. II: Quell- und Nebenflüsse der Weser (ohne Aller). - [4], 603 S.; (Reimer) Berlin [darin: Werra, Fulda, Eder, Diemel, Oberweser]

[Bd. I - darin: 3. Kapitel: „Oberflächengestalt und geologische Verhältnisse“]

[Bd. II: „1. Abtheilung: Gebietsbeschreibung (Bodengestalt, Bodenbeschaffenheit, Gewässernetz, ....; 2. Abtheilung: Flußbeschreibung"]

-Kelletat, Dieter (1969): Erdbülten als Frühjahrsformen im Raum um Göttingen. - Eiszeitalter u. Gegenwart, 20: 131 - 137, 5 Abb., 3 Tab.; Öhringen

$\square$ Kessler, Karl-Heinz (2007): Geschichten aus Breitau und Umgebung, das Schulgebäude, das Gruppenwasserwerk und die Naturkatastrophe am Schickeberg <Werra-Meißner-Kreis>. - Rund um den Alheimer, 28: 16-23, 6 Abb.; Rotenburg/Fulda

[Bergrutsch an der Steilkante des Unteren Muschelkalkes am Schickeberg bei Breitau]

-Kimpel, W. (1954): Die geographischen Gegebenheiten in der Entwicklung der Stadt Kassel. Hessische Heimat, N.F., $\underline{4}(2):$ 6-9, Abb. 6; Marburg/L.

[darin: „Die Auswirkungen der geomorphologischen Gegebenheiten“]

$\square$ Kirbis (geb. Müller-Harbeck), Gudrun (1950): Beiträge zur Morphologie der Goburg. - Göttinger Geogr. Abh., $\underline{\mathbf{5}}$; 42 S., 7 Abb., 2 Skizz., 2 Tab., 2 Kt.; Göttingen

Referat in: Das Werraland, 4: 30-31 (Beck); Eschwege - auch als Diss. Univ. Göttingen 1947 
OKirschstein, Mario (2001): Neubau BAB A 38 - Besonderheiten im Abschnitt des Rötausstriches am Südhang der Bleicheröder Berge und Möglichkeiten einer bautechnischen Berücksichtigung $<$ Vortragskurzfassung $>$. - In: Rauche, Henry [Hrsg.]: Regionale und angewandte Geologie der Grenzregion der Süddeutschen und der Mitteldeutschen Scholle. - Programm und Kurzfassungen der Vorträge. - 10. Jahrestagung Gesellschaft f. Geowissenschaften i. Schmalkalden, 19.-22. September 2001. - Exkursionsführer u. Veröff. Ges. f. Geowiss., 214; S. 145-146; Berlin 2001 [Stratigraphie, Geomorphologie, Ingenieurgeologie]

- $\square$ OCKlink, Hans-Jürgen (1969): Die naturräumlichen Einheiten auf Bl. 112 Kassel [TK Maßstab 1 : 200.000]. - Reihe: Geographische Landesaufnahme 1 : 200.000, Naturräumliche Gliederung Deutschlands. - 108 S., 1 Kt., 1 Beil.-Kt. 1 : 200.000; (Bundesforschungsanstalt f. Landeskunde u. Raumordnung) Bonn-Bad Godesberg

[HE, WMK, THÜ, NIE]

-Klode, Wilfried [1996]: Die Erdfälle in Ellenbach - (Übertitel: Geologie und Flora in Ellenbach). - In: Klode, W.; Ludwig, H. \& Sandrock, H. [Verantwortl.]: 850 Jahre Ellenbach - Eine Chronik. - 410 S., zahlr. Abb.; hier: S. 31-41, 5 Abb.; [Hrsg. Heimatverein Ellenbach 1995 eV.] Alheim-Ellenbach

-Klüpfel, Walther (1930): Die Bedeutung der Reliefgenerationen für die Vulkangebiete (Westerwald, Vogelsberg, Habichtswald, Hegau, Böhmisches Mittelgebirge). - Geol. Rundschau, 21: 151 - 162, 1 Abb.; Berlin

-Klug, Stefan (1995): Rutschungen an der Grenze Buntsandsein/Muschelkalk. - Dipl.-Arb. [unveröff.] Univ. Göttingen, $107 \mathrm{~S}$.

[Göttinger Wald, Plesse, Eddigehausen]

OKrähann, G. (1964): Die Großformen des Thüringer Waldes. - Geogr. Ber., 9: 107 - 112, 1 Kt.; Gotha

OKrause, Reinhard (1981): Der Wasserfall der Lutter bei Großbartloff. - Eichsfelder Heimathefte, [21] 1981(3): 213-216, 1 Abb.; Worbis

$\square$ Krönert, Sibylle (1986): Bodenerosion im Raum Eschwege. - In: Möller, Klaus \& Stäblein, Gerhard [Hrsg.]: Verhandlungen des Geowissenschaftlichen Symposiums „Naturraumpotential und Umweltschutz“ - Ansätze und Ergebnisse physiogeographischer-geoökologischer Untersuchungen in Nordhessen. - FU Berlin, FB Geowissenschaften, Inst. f. physische Geographie,

Geomorphologisches Laboratorium. - S. 57-59, 1 Abb.; (Selbstverlag Inst. Phys. Geogr.) Berlin 1986

OKrümmling, H.; Tornack, E.; Wiefel, J. \& Wucher, K. (1975): Massenverlagerungen an der RötMuschelkalk-Schichtstufe Nordwest-Thüringens. - Z. angew. Geol., 21(11): 552-558, 2 Abb., 2 Tab.; Berlin [Umgebung Obergebra b. Bleicherode]

-Lang, Otto (1907): Die Schlingenbildung des Fuldatales bei Guxhagen. - Jb. Preuß. Geol. Landesanst., $\underline{25}$ (f. 1904): 477-487, 1 Abb.; Berlin

-Lange, Wilhelm (1911): Der Bergrutsch im Ahnatal. - Tourist. Mitt. a. bd. Hessen, 19 (2): 13 - 15, (6): $61-62,1$ Abb.; Kassel

-Linstow, Otto v. (1910): Der Seeburger See in Sage und Geschichte. - Hannoverland, (Bd. 4) 1910: 131 134; Hannover [darin: temporäre Inseln im Seeburger See]

-Linstow, O. v. (1929): Salzlager, Solquellen und Erdfälle in dem Gebiet zwischen Kassel und Karlshafen. - Kali, etc.,

$\underline{23}(4): 54-56$

23 $(5): 71-74$

23(6): 86-88, mehr. Fig.; Halle/Saale 
Referat in: N. Jb. Mineral. etc., Referate, 1931 (Bd. III): 135 (A. Bentz); Stuttgart [darin: Wolkenbrüche b. Trendelburg; Solquelle Kassel-Wilhelmshöhe]

-Linstow, Otto v. (1930): Jugendliche Bodenbewegungen im Bereich der Weser am Fuß des Sollings. Z. dt. geol. Ges., $\underline{\mathbf{8 1}}$ (f. 1929): 66 - 70, 1 Abb.; Berlin

[Wesertal zw. Oedelsheim und Karlshafen]

-Lohmann, Hans Heinrich (1962): Zur Formentwicklung von Salzauslaugungstrichtern. - Notizbl. Hess. L.-A. Bodenforsch., 90: 319-326, 2 Abb., Taf. 31; Wiesbaden [darin: „Wolkenbrüche“ (Nördlicher Reinhardswald)]

-Ludwig, Willi (1993): Plötzlich tat sich die Erde auf - Gipsauswaschungen haben oft ungewöhnliche Folgen. - Kreis Hersfeld-Rotenburg - Heimatkalender 1993 und Wegweiser ( 37. Jg. ): 49 - 53, 4 Abb.; Bad Hersfeld

- $\square$ Lüttig, Gerd (1974): Geological history of the river Weser (Northwest Germany). - In: Macar, P. [coord.]: Centenaire de la Societé géologique de Belgique - L'évolution quaternaire des bassins fluviaux de la mer du Nord merdionale. - 318 S.; hier: S. 21-34, 1 Abb., 1 Tab.; [ed. Soc. géol. d. Belgique] Liège 1974

OLützner, Harald (2002): Tambach-Dietharz - Morphogenese und Geologie des Thüringer Waldes. In: Sedlacek, Peter [Hrsg.]: (Spuren suchen - Landschaften entdecken) Thüringen - Geographische Exkursionen. - 325 S., 105 Abb.; hier: S. 252-255, Abb. 97; (Justus Perthes) Gotha 2002

$\square$ Maier, Barbara geb. Sippell (1952): Zur Morphologie des Soodener Berglandes. - Göttinger Geogr. Abh., 11; 39 S., 7 Abb., 1 Tab., 1 mehrf. Falt-Kt.; Göttingen 1952 - auch als Diss. Univ. Göttingen 1947 u. d. Namen Sippell, Barbara

-Meiburg, Peter (1980): Subrosionsstockwerke im Nordhessischen Bergland. - Der Aufschluss, 31: 265 - 287, 8 Abb.; Heidelberg

OMeinecke, F. (1913): Über die Entwicklungsgeschichte des Werratales. - Mitt. Sächs. Thür. Vereins Erdkde. z. Halle, 37: 77 - 110, 1 Tab.; Halle/Saale

-Mensching, Horst (1950): Schotterfluren und Talauen im Niedersächsischen Bergland. - Göttinger geogr. Abh., 4 ; 54 S., 8 Abb. (2 Taf.), 3 Prof., 5 Kt.; Göttingen [u.a. Leine, Weser]

$\square$ Mensching, H. (1953): Die periglaziale Formung der Landschaft des unteren Werratales. - Göttinger geogr. Abh., 14: 80 - 126, 16 Abb., 1 Taf; Göttingen

-Meyer, Rolf (1985): Die Stabilität der Hänge an der Wellenkalk-Schichtstufe des Göttinger Waldes. Dipl.-Arb. [unveröff.] Univ. Göttingen 1985; 84 S.

-Meyer, Rolf Heinrich (1986): Die Stabilität der Hänge an der Wellenkalk-Schichtstufe des Göttinger Waldes. - Plesse-Archiv, 21(1985): 237-288, 19 Abb., 5 Beil.; Göttingen

Bd. 1 (1953-1962); I-IX, S. 1-608; Bd. II (1959-1962), S. 609-1399; in Lieferungen ausgegeben; BonnBad Godesberg [darin: Naturräume des gesamten bibliographisch erfassten Gebietes: Bd. I: 35 Osthessisches Bergland, 36 Oberes Weserbergland, 39 Thüringisch-Fränkisches Mittelgebirge - Bd. II 47/48 Thüringer Becken und Randplatten; Ausführliche Beschreibung von Teilräumen unter diesen Übertiteln] 
व $\square$ Michel, H. (1939): Das Gesicht der niederhessischen Landschaft (Die physische Landschaft). Hessischer Gebirgsbote, $\underline{\mathbf{4 5}}(2): 22$ - 26, 12 Abb.; Melsungen

[Fotos: Todstein b. Abterode, Sandsteinbruch Cornberg, Weinberg/Kassel u.a.]

$\square$ Möller, Klaus (1979): Detailaufnahme, Darstellung und Interpretation der Geomorphologie des Gebietes der unteren Berka. - Hausarbeit [zur. 1. Staatsprüfung Wiss. Lehramt a. Gymnasien]; [FU Berlin, Fachber. Geowissenschaften] 1979; 99 S., 35 Abb, 6 Falt-Kt.;

$\square$ Möller, Klaus (1982): Geomorphologische Detailaufnahme und Interpretation des Meißners und seines östlichen Vorlandes. - Dipl.-Arb. [unveröff.] Fachber. Geowissenschaften FU Berlin; 104 S.

$\square$ Möller, K. (1986): Erkenntnisse und Konsequenzen für die Landnutzung im östlichen Meißnervorland - Ergebnisse geomorphologischer Untersuchungen. - In: Möller, Klaus \& Stäblein, Gerhard [Hrsg.]: Verhandlungen des Geowissenschaftlichen Symposiums „Naturraumpotential und Umweltschutz“ - Ansätze und Ergebnisse physiogeographischer-geoökologischer Untersuchungen in Nordhessen. - FU Berlin, FB Geowissenschaften, Inst. f. physische Geographie,

Geomorphologisches Laboratorium. - S. 10-16, 3 Abb.; (Selbstverlag Inst. Phys. Geogr.) Berlin 1986

$\square$ Möller, Klaus (1986): Die Rutschungen im Innenkippenbereich des Tagebaus Kalbe (Hoher Meißner/Nordhessen). -In: Stäblein, Gerhard [Hrsg.]: Geo- und biowissenschaftliche Forschungen der Freien Universität Berlin im Werra-Meißner-Kreis (Nordhessen). - Berliner Geogr. Abh., 41; zgl. Beiträge zur Werra-Meißner-Forschung, I; S. 217 - 225, 10 Abb.; (Selbstverl. Inst. Phys. Geogr. FU Berlin) Berlin 1986

$\square$ Möller, Klaus (1987): Darstellung von Subrosionsphänomenen am Beispiel Nordhessen [Vortragszusammenfassung]. - In: Hütteroth, W.-D. \& Becker, H. [Hrsg.]: Tagungsberichte und wiss. Abhandlungen 45. Dt. Geographentag Berlin - 30. September - 5. Oktober 1985; 551 S.; hier S. 521; (Steiner) Stuttgart 1987

[Zechsteinmantel Unterwerra-Grauwackengebirge]

$\square$ Möller, Klaus (1987): Geomorphologisch-Geologischer Wanderführer durch das Werra-MeißnerGebiet. Teil 1: Das östliche Meißnervorland. - 83 S., 34 Abb., 2 Tab.; (Keitz \& Fischer) Eschwege [Teil 1: Alles Erschienene!]

$\square$ Möller, Klaus (1988): Das Eschweger Becken und seine Randgebiete - Ergebnisse geomorphographischer und hydrochemischer Analysen. - In: Liedtke, Herbert [Hrsg.]: Untersuchungen zur Geomorphologie der Bundesrepublik Deutschland - Neue Ergebnisse der Geomorphologische Kartierung - Beiträge zum GMK-Schwerpunktprogramm VIII. - Berliner Geogr. Abh., 47: 77-92, 8 Abb., 1 Tab.; Berlin 1988

$\square$ Möller, Klaus (1988): Reliefentwicklung und Auslaugung in der Umgebung des Unterwerra-Sattels (Nordhessen). - Berliner Geogr. Abh., 48; zgl. Beitr. Werra-Meißner-Forsch., II; 187 S., 55 Abb., 20 Tab., 2 Kt.-Beil.; Berlin - zgl. Diss. FU Berlin

$\square$ Möller, Klaus (1989): Die geomorphologischen Verhältnisse am Hohen Meissner und ihre Interpretation. - In: Jacobshagen, Volker \& Kuhnert, Christian [Hrsg.]: Der Hohe Meißner in Hessen - Ergebnisse geologischer und geomorphologischer Forschungen. - Berliner geowiss. Abh., Reihe A, 114; S. 103-114, 3 Abb., 3 Beil.; (Selbstverlag Fachber. Geowiss. FU Berlin) Berlin 1989

$\square$ Möller, Klaus \& Stäblein, Gerhard (1982): Struktur- und Prozeßbereiche der GMK 25 am Beispiel des Meißners (Nordhessen). - In: Barsch, Dietrich \& Stäblein, Gerhard: Erträge und Fortschritte der geomorphologischen Detailkartierung. -Berliner Geogr. Abh., 포; 134 S., hier S. 73-85, 4 Abb., 1 Tab., 2 Beil.; (Selbstverl. Geogr. Inst. FU Berlin) Berlin 1982

$\square$ Möller, Klaus \& Stäblein, Gerhard [Hrsg.](1986): Verhandlungen des Geowissenschaftlichen Symposiums „Naturraumpotential und Umweltschutz“ - Ansätze und Ergebnisse physiogeographischergeoökologischer Untersuchungen in Nordhessen. - FU Berlin, FB Geowissenschaften, Inst. f. 
physische Geographie, Geomorphologisches Laboratorium. - 59 S., Abb., Diagr., Falt-Kt., 1 Beil. (Geomorphol. Kt. 1 : 25000 d. Bundesrepublik Deutschland, Bl. 17 (Bl. 4725 Bad Sooden-Allendorf); (Selbstverlag Inst. Phys. Geogr.) Berlin

$\square$ Möller, Klaus \& Stäblein, Gerhard (1986): Die geomorphologische Karte $1: 25.000$ Blatt 17, 4725 Bad Sooden-Allendorf - Erkenntnisse und Anwendungen. - In: Stäblein, Gerhard [Hrsg.]: Geound biowissenschaftliche Forschungen der Freien Universität Berlin im Werra-Meißner-Kreis (Nordhessen). - Berliner Geogr. Abh., 41; zgl. Beiträge zur Werra-Meißner-Forschung, I; S. 227 255, 15 Abb., 1 Tab., 1 Kt.-Beil.; (Selbstverl. Inst. Phys. Geogr. FU Berlin) Berlin 1986

$\square$ Möller, Klaus \& Jäkel, Dieter (1993): Die geomorphologischen und bodenkundlichen Verhältnisse in der Umgebung von Eschwege in Nordhessen sowie ihre Bedeutung für planungsrelevante Sachverhalte. - In: Jacobshagen, V.; Möller, K. \& Jäkel, D. [Hrsg.]: Hoher Meißner und Eschweger Becken - Geowissenschaftliche und vegetationskundliche Charakteristik einer nordhessischen Landschaft. - Berliner geogr. Abh., $\underline{\mathbf{5 6}}$; zgl. Beiträge zur Werra-Meißner-Forschung, III.; S. 199-288, 29 Abb., 5 Tab., 1 Kt.; (Selbstverlag Geomorphologisches Laboratorium FU Berlin) Berlin 1993

○Möller, L. (1863): Der Erdfall bei Dachrieden unweit Mühlhausen. - Z. gesammt. Naturwiss., 21: 450452; Berlin

- $\square$ Mötzing, Kurt (1975): Die Entstehung der basaltischen Felsenmeere unserer Heimat. - Hessischer Gebirgsbote, $\underline{\mathbf{7 6}}(4): 112$ - 113, 3 Abb.; Melsungen] [darin: Hoher Meißner]

- Molde, Peter (1991): Aktuelle und jungholotäne fluviatile Geomorphodynamik im Einzugsgebiet des Wendebaches (Südniedersachsen). - Göttinger geogr. Abh., 94; 107 S., 54 Abb., 11 Tab., 19 Photos; (Goltze) Göttingen

QMorgenroth, Volker (1994): Subrosion einer Anhydritlinse im Trusetaler Bergbaurevier. - Veröff. Naturkundemuseum Erfurt, Naturwiss. Rh., 13: 72-78, 4 Abb.; Erfurt

-Mortensen, Hans (1949): Rumpffläche - Stufenlandschaft - Alternierende Abtragung. - Petermanns geogr. Mitt., 93: 1 - 14, 9 Abb.; Gotha [darin: Dransfelder Hochfläche]

-Mortensen, Hans \& Hövermann, Jürgen (1956): Der Bergsturz an der Mackenröder Spitze bei Göttingen. - Rapp. Commité p. l'étude des Versants, preparé pour le 18ieme Congrès international de Géographie, Rio de Janeiro 1956 ; S. 149 - 155, 1 Abb., 1 Kt.; Amsterdam

-Mortensen, Hans (1960): Neues über den Bergrutsch südlich der Mackenröder Spitze und über die holozäne Hangformung an Schichtstufen im mitteleuropäischen Klimabereich. - (Internationale Beiträge z. Hang- und Wandformung) Z. Geomorph., Suppl.-Bd. 1: 114 - 123, 5 Abb., 1 Taf.; Berlin

-Mortensen, Hans (1963): Hangformung in der näheren und weiteren Umgebung von Göttingen. Bericht über die Geländeexkursionen am 29.8.1962 und am 30.8.1962. - Nachr. Akad. Wiss. Göttingen, math.-nat. Kl., 1963: 279 - 287, 5 Abb.; Göttingen [darin: Mackenröder Spitze, Unter-Eichsfeld]

-Nagel, Ulrich \& Seedorf, Hans Heinrich (1965): Das Bergrutschgelände südlich der Mackenröder Spitze bei Göttingen. A.: Zur isometrisch-paralellperspektischen Blockbild-Darstellung (U. Nagel). B. Geologisch-morphologische Erläuterungen (H. Seedorf) - Neues Archiv f. Niedersachsen, 14 (3): 225 - 231, 5 Abb., 1 Falt-Kt.; Göttingen

-Nagel, Ulrich \& Schunke, Ekkehard (1979): Geomorphologische Erläuterungen zum Orohydrographischen Blockbild der Umgebung von Göttingen von Ulrich Nagel. - Neues Archiv f. Niedersachsen, 28 (2): 200-222; Göttingen 
$\square$ Namenskürzel [K.J.](1881): <Erdfall am Burgberg bei Ulfen]. - Eschweger Kreisblatt, 1881; Nr. 134 v. 12.11.1881; Eschwege

$\square$ Namenskürzel (Ldg) (1951): Tiefe Erdspalte auf der Boyneburg entdeckt. - Werra-Rundschau, 1951; Nr. 132 v. 11.6.1951, S. 3; Eschwege

$\square$ Namenskürzel (HG) (1958): < Kühe in unterirdischen Hohlraum an den Kripplöchern eingebrochen> Plötzlich stürzten die Kühe in eine Erdspalte ab. - Werra-Rundschau, 1958, Nr. 149 v. 2.7.1958, S. 3; Eschwege [Das Aufsehen erregende Ereignis im Karstgebiet NSG „Kripplöcher“ bei Frankershausen ist bis heute unvergessen]

$\square$ Namenskürzel (lh) (1958): <Einbruch im Karstgebiet Kripplöcher b. Frankershausen>Landesgeologe wird Kripplöcher untersuchen. - Werra-Rundschau, 1958; Nr. 153 v. 7.7.1958, S. 3; Eschwege [Bei dem Ereignis waren zwei Kühe in einen unterirdischen Hohlraum eingebrochen]

$\square$ Namenskürzel (FH) (1958): Einbruchstellen an den Kripplöchern untersucht - Kommission des Geologischen Landesamtes weilte in Frankershausen. - Werra-Rundschau, 1958; Nr. 154 v. 8.7.1958, S. 3; Eschwege

$\square$ Namenskürzel (Werra-Rundschau) (1958): < Untersuchung der Erdfälle im NSG Kripplöcher> Bergrat Eckert: „Wir werden das Geheimnis der Höhle erforschen!“. In einiger Zeit: Per Strickleiter in die Kripplöcher bei Frankershausen/Vorläufig keine Sprengung. - Werra-Rundschau, 1958; Nr. 173 v. 30.7.1958, S. 3, 1 Abb.; Eschwege [Karsthohlräume im NSG „Kripplöcher“ als mögliche Objekte für Höhlentourismus?]

$\square$ Namenskürzel (Werra-Rundschau) (1959): Kripplöcher-Geheimnis bleibt ungelöst. Kein Weg in die Frankershäuser Unglückshöhle/Fremdenverkehrs-Hoffnung war vergebens. Werra-Rundschau, 1959; Nr. 296 v. 22.12.1959, S. 4; Eschwege

$\square$ Namenskürzel (Werra-Rundschau) (1960): < Friedrichsstollen, Hoher Meißner $>$ Erdrutsch geräumt $100 \mathrm{cbm}$ Wasser. Friedrichstollen-Quelle wiedergefunden - Sorgen um die Wasserversorgung. Werra-Rundschau, 1960; Nr. 173 v. 28.7.1960, S. 3, 2 Abb.; Eschwege

$\square$ Namenskürzel (B) (1962): < Baugrundschäden durch Subrosion> In Weißenbach ist es unheimlich. Der Untergrund bricht ein / Baugebiet gesperrt / Risse in der Kirche. - Werra-Rundschau, 1962; Nr. 6 v. 8.1.1962, [S. 5], 1 Abb.; Eschwege

$\square$ Namenskürzel (aja) (1976): Erdreich brach nachts ein - 17 Meter tiefes Loch entstand bei Witzenhausen. - HA, 1976; Nr. 83 v. 7.4.1976; Kassel [Erdfall b. Witzenhausen/Wendershausen, Werra-Meißner-Kreis]

$\square$ Namenskürzel (H. S.) (1978): Neuer Riß an der Kalbe. - Das Werraland, 30(3): 44-45, 1 Abb.; Eschwege

ONaumann, Ernst (1952): Über einige vulkanische Schlotbrekkzien, andere vulkanischer Erscheinungen und Auslaugungsbrekzien im Werragebiet und in der Rhön. - Geologie, 1: 59-63, 3 Abb.; Berlin

- Naumann, Peter (1994): Der „Große Wolkenbruch“ bei Trendelburg. - Mitt. Geol. Interessengemeinschaft Nordhessen (GIN), $\underline{\mathbf{5}} ; 34$ S., 3 Abb., 1 Tab.; (Selbstverlag Peter Naumann) Hofgeismar

ONeureuther, Franz (1919): Zur eichsfeldischen Heimatkunde - 8. Die Oberflächengestalt der eichsfeldischen Landschaft. - Unser Eichsfeld, 14(1/2): 1-14; Heiligenstadt 
ONeureuter, Franz (1925): Die Arbeit des fließenden Wassers. - Ein Kapitel aus der Geologie der Heimat. - Unser Eichsfeld, 20: 228-234; Duderstadt

[Erosion, Geomorphologie, Bezugn. a. Eichsfeld]

OPatzelt, Gerald (2002): Zum Verlauf der Küllstedter Störungszone, zur Erdfallbildung und Erdfallgefahr bei Mühlhausen und Oberdorla. - Mühlhäuser Beitr., 25: 7-14, 2 Abb.; Mühlhausen

$\square$ Penndorf, Hans (1925): Die geomorphologischen Verhältnisse der Umgegend von Witzenhausen. Das Werratal, 2(8): 122-127, 4 Abb.; Eschwege

- $\square$ OPerst, Otto [Hrsg.] (1960): Das Werraland in der Beschreibung Niederhessens von Landgraf Hermann zu Hessen-Rotenburg. - Eingeleitet und herausgegeben von... - Reihe: Aus dem Werraland, 7; Separatdruck aus der Zeitschrift „Das Werraland, 12. Jahrgang. 1960, Vierteljahresschrift des Werratalverins e.V., Eschwege. - 35 S.; (Rossbach) Eschwege - auch in: Das Werraland, 12(3): 38-43, 12(4): 57-61; Eschwege

[darin erwähnt: Erdfälle b. Frauensee, Erdfälle im Amt Sontra, besonders bei Berneburg; der Rote See in Dens; das Kohlenbergwerk auf dem Meissner; die Stinksteinwand; das Salzwerk in Allendorf in den Soden]

$\square$ Perst, Otto (1961): „Die Kalbe rutscht!“ - Das Werraland, 13 (3/4): 35-41, 4 Abb.; Eschwege

$\square$ Perst, Otto (1962): Zum Bergsturz an der Plesse 1640. - Das Werraland, 14(1): 6-7, 1 Abb.; Eschwege

OPhilippi, E. (1911): Über die präoligocäne Landoberfläche in Thüringen. - Z. dt. geol. Ges., $\underline{\mathbf{6 2}}$ (f. 1910): 305-404 (Abh.), 23 Abb., Taf.. IV; Berlin

Referat in: Mitt. Geogr. Ges. (f. Thür.): 30: 228-235; Jena 1912

[Geomorphologie, Tektonik, u.a. der Thüringer Störungszonen]

-Pörtge, Karl-Heinz \& Molde, Peter (1989): Feststoff- und Lösungsabtrag im Einzugsgebiet des Wendebaches. - In: Pörtge, K.-H. \& Hagedorn, J. [Hrsg.]: Beiträge zur aktuellen fluviatilen Morphodynamik - Göttinger Geogr. Abh., 무: 115-121, 4 Abb., 1 Tab.; Göttingen 1989

-Pörtge, Karl-Heinz \& Schäbitz, Frank (1992): Interglaziale Ablagerungen in einer Subrosionssenke bei Wöllmarshausen, Südniedersachsen. - In: Grunert, Jörg \& Höllermann, Peter [Hrsg.]: Geomorphologie und Landschaftsökologie. - Bonner Geogr. Abh., 85: 209-222, 4 Abb.; Bonn 1992 [Quartär, Vegatationsgeschichte/Pollenanalyse Gartetal E’ Göttingen]

OPorzig, Matthias (1986): Historische Bodenerosion im Untereichsfeld. - Eichsfelder Heimatstimmen, 30/1986: 264-266, 1 Abb.; Duderstadt

[Lkr. Göttingen]

$\square$ Poser, Hans (1933): Morphologische Studien aus dem Meißner-Gebiet. Oberflächengestaltung des Meißnergebietes. - Jb. geogr. Ges. Hannover, f. 1932/33: 121-178, 5 Abb., 3 Taf.; Hannover - in erweiterter Form als Diss. Univ. Göttingen 1930

[Hitzeröder Plateau, Wellingeröder Plateau, Gebiet um Frankershausen, Meißner]

$\square$ Poser, H. \& Brochu, M. (1954): Zur Frage des Vorkommens pleistozäner Glazialformen am Meißner. - Abh. Braunschweiger wiss. Ges., ㅁ: 113 - 115, 4 Abb.; Braunschweig

-Poser, H. \& Schunke, E. (1974): Geomorphologische Beschreibung. - In: Hofmann, Walter

[Hrsg.]: Landformen im Kartenbild: Topographisch-geomorphologische Kartenproben 1 : 25.000. Gruppe III : Mittelgebirge - Schichttafeln, Schichtstufen, Schichtkämme. - Kartenprobe 3: Schichtstufe mit Zeugenbergen im Muschelkalk bei Waake, östlich Göttingen. - 12 S., Abb., 8 Kt.Beil.; hier: S. 5-12, 2 Abb.; (Westermann) Braunschweig 1974 
-Priesnitz, Kuno (1970): Karstmorphologische Untersuchungen im Niedersächsischen Bergland. - Diss. math. - nat. [unveröff.] Univ. Göttingen; 188 S., 6 Abb., 4 Tab., 10 Beil.; Göttingen [darin: Göttinger Wald]

- Rambow, Dietrich \& Lemmer, Frank (2002): Zur Genese der Tertiärsenken südöstlich von Kassel : Tektonik oder Subrosion? - Geol. Jb. Hessen, 130: 73-89, 10 Abb., 1 Tab.; Wiesbaden

-Redemann, Emil (1957): Der große Wolkenbruch. - Heimatjahrbuch. f. d. Landkreis Hofgeismar, 1958: 66 - 68, 1 Abb.; Hofgeismar

[Erdfälle Großer und Kleiner Wolkenbruch bei Trendelburg]

ORichter, Hans (2002): - Thüringer Becken (Die deutsche Mittelgebirgsschwelle) - In: Liedtke, Herberg \& Marcinek, Joachim [Hrsg.]: Physische Geographie Deutschlands. - 3. überarb. u. erw. Aufl.; S. 508 - 513, Abb. 9.31/9.32, Tab. 9.1; (Klett-Perthes) Gotha 2002

@Richter, Hans (2002): - Thüringisch-fränkisch-vogtländische Mittelgebirge (Die deutsche Mittelgebirgsschwelle) - In: Liedtke, Herberg \& Marcinek, Joachim [Hrsg.]: Physische Geographie Deutschlands. - 3. überarb. u. erw. Aufl.; S. 513 - 520; (Klett-Perthes) Gotha 2002 [darin: Thüringer Wald]

-Ricken, W. \& Meyer, B. (1982): Lößbürtige Böden des Jung-Quartärs zwischen Harz und Leine Beziehungen zur Quartär-Chronostratigraphie; Relief-Geschichte der Landschaft, fluviatilen Sedimentation, Paläoklimakunde und Variation der holozänen Prozesse der Bodenbildung. - Bericht über die Exkursion des Arbeitskreises „Paläoböden“ der Deutschen Bodenkundlichen Gesellschaft am 16. und 17.10.1982. - Mitt. Dt. bodenkdl. Ges., 34: 249-268, 6 Abb.; Göttingen [darin: Tongrube zw. Göttingen u. Rosdorf; Kiesgrube b. Reinshof S’ Göttingen]

ORiese, A. (1993): Naturräumliche Gliederung Thüringens. - Erfurter geographische Studien, 1: 3-15, Abb. 1; Erfurt

[Bezugn. a. Regionale Geologie u. Geomorphologie]

-Rösing, Franz (1956/1957): Das prätuffische Relief des Habichtswaldes und seiner Umgebung. - Z. dt. geol. Ges., 108 (f. 1956): 267-268; Hannover

[Vortragstext]

-Rösing, Franz (1966): Über Buntsandsteinschutt. - Z. dt. geol. Ges., 108: 990-994; Hannover [Vortragstext; Abh. ü. d. Höhenzug der Söhre E’ Kassel, Bl. 4723 Oberkaufungen, Bl. 4722 Niederzwehren]]

-Rösing, Franz (1969): Geologisch-morphologische Erläuterung. - In: Hofmann, Walter [Hrsg.]: Landformen im Kartenbild: Topographisch-geomorphologische Kartenproben $1: 25.000$. Gruppe 4 Mittelgebirge: an Vulkanismus gebundene Formen. Kartenprobe 2: Vulkanstiele im Tertiärhügelland, Gudensberg bei Kassel. - 11 S., Abb., 7 Kt.-Beil.; hier: S. 10-11; (Westermann) Braunschweig 1969

$\square$ Rösing, Franz \& Wenzel, Bernward (1989): Der Bergrutsch am Nordhang der Hörne bei Bad Sooden-Allendorf (Nordhessen) am 21.7.1985. - Geol. Jb. Hessen, 117: 237 - 250, 7 Abb.; Wiesbaden

-Rohdenburg, Heinrich (1965): Untersuchungen zur pleistozänen Formung am Beispiel der Westabdachung des Göttinger Waldes. - Gießener geogr. Schr., 1; 76 S., Abb., Kt., 1 Beil.; (Schmitz) Gießen

-Rohdenburg, Heinrich (1965): Die Muschelkalk-Schichtstufe am Ostrand des Sollings und des Bramwaldes. Eine morphologische Untersuchung unter besonderer Berücksichtigung der jungquartären Hangformung. - Göttinger geogr. Abh., $\underline{\text { 33; }} 91$ S., 24 Abb., 4 Kt.; Göttingen

- $\square$ Rohdenburg, H. (1968): Jungpleistozäne Hangformung in Mitteleuropa - Beiträge zur Kenntnis, Deutung und Bedeutung ihrer räumlichen und zeitlichen Differenzierung. - Göttinger bodenkdl. Ber., 
ㅁ: 3-107, 39 Abb.; Göttingen

[darin: Bischhausen u. Witzenhausen (Werra-Meißner-Kreis); Kirchberg u. Felsberg/Schwalm-EderKreis]

-Rohdenburg, H.; Meyer, B.; Willerding, U. \& Jankuhn, H. (1962): Quartärgeomorphologische, bodenkundliche, paläobotanische und archäologische Untersuchungen an einer Löß-SchwarzwerdeInsel mit einer wahrscheinlich spätneolithischen Siedlung im Bereich der Göttinger Leineaue. Göttinger Jb., 1962: 36 - 56, 6 Abb., 2 Tab., 1 Foto; Göttingen

$\square$ Rother, Klaus (1971): Die eiszeitliche Vergletscherung der Mittelgebirge Mitteleuropas. - Geogr. Rdschau, 23: 260-266; Braunschweig [darin S. 262: Meißner, unvergletschert]

OSchilder, C. \& Schwandt, A. (1983): Zur Tektonik und Auslaugung in Kali- und Steinsalzabbaugebieten. - Z. geol. Wiss., 11(8): 1023 - 1033, 8 Abb.; Berlin [Werra-Kalirevier; Südharz-Kalirevier]

口OSchmidt, Karl-Heinz (1988): Die Wellenkalk-Schichtstufe in Nordhessen. - Ber. Dt. Landeskde., 62: 337-355, 5 Abb., 3 Tab.; Trier

[Graburg, Gobert, Auflistung mit Bezug auf Thüringen]

- $\square$ Schmitt, Gerhard E. (1990): Naturkundliche Wanderungen in Hessen. - 158 S., 62 Abb., Kt.; (Hitzeroth) Marburg [Darin: Werra-Meißner-Kreis; Blaue Kuppe, Erdfalltrichter „Wolkenbrüche“ bei Trendelburg]

OSchneider, H.; Ig1, M.; Mäusbacher, R. \& Ellenberg, J. (2001): Untersuchungen zur spät- und postglazialen Landschaftsgenese des mittleren Werratales. [Vortrags-Kurzfassung]. - In: Gaupp, R. \& Van der Klauw, S. [Hrsg.]: Sediment 2001, Jena, 6.6. - 8.6.2001 - Programm, Kurzfassungen, Exkursionsführer. - Schriftenrh. Dt. Geol. Ges, 13: 86; Hannover 2001 [Südwestthüringen; Geomorphologie, Palynologie]

- 0 Schott, Carl (1931): Die Blockmeere in den deutschen Mittelgebirgen. - Forsch. Dt. Landes- u. Volkskde., 299(1); 78 S., 2 Abb.; 16 Taf.; Stuttgart

Referat in: N. Jb. Mineral. etc., Referate; 1932 (Bd. II): 507 (Georg Wagner); Stuttgart [darin: Thüringer Wald, Knüll]

QSchramm, Herbert (1964): Untersuchungen zur altpleistozänen Flußgeschichte des Apfelstädt/HörselSystems - Ein Beitrag zur Stratigraphie und Paläogeographie des Altpleistozäns in Thüringen. - Diss. Univ. Jena 1964; II, 134 S., Anh., Ill., Anl.

$\square$ Schütt, Horst (1961): Starke Regenfälle im Frühjahr 1961 und ihre Auswirkungen. Über einige Formen der Erosion und Solifluktion bei Bad Sooden-Allendorf. - Das Werraland, 13(3/4): 53-55; Eschwege

OSchulze, Silvia (2001): Neue Erkenntnisse zur Ausbildung und subrosiven Beeinflussung der Röt-Folge am Südhang der Bleicheröder Berge <Vortragskurzfassung>. - In: Rauche, Henry [Hrsg.]:

Regionale und angewandte Geologie der Grenzregion der Süddeutschen und der Mitteldeutschen Scholle. - Programm und Kurzfassungen der Vorträge. - 10. Jahrestagung Gesellschaft f. Geowissenschaften i. Schmalkalden, 19.-22. September 2001. - Exkursionsführer u. Veröff. Ges. f. Geowiss., 214; S. 215-216; Berlin 2001

[Stratigraphie, Geomorphologie, Ingenieurgeologie]

-Schunke, Ekkehard (1968): Die Schichtstufenhänge im Leine-Weser-Bergland in Abhängigkeit vom geologischen Bau und Klima. - Göttinger geogr. Abh., 43, 219 S., Abb.; Göttingen. - zgl. Diss. Univ. Göttingen u.d.T.: Die Schichtstufenhänge des Leine-Weser-Berglandes in Abhängigkeit von Gestein und Klima.; Göttingen

[Untersuchungen u. a. Lkr. Göttingen; Göttinger Wald, Dransfelder Hochfläche] 
- $S$ chwarz, Friedrich (1943): Pliozän und junge Hebung im Unterlauf der Fulda. - Z. Geomorph., 11 (f. 1939 - 1943): 231 - 236; Berlin

aSeib, Gerhard (2001): 1867 tat sich bei Nentershausen plötzlich die Erde auf. - Hersfeld-Rotenburg Heimatkalender für den Kreis Hersfeld-Rotenburg, 40: 198-199; Bad Hersfeld

QSeidel, Gerd (1970): Zur Auslagung im Gebiet des Leinefelder Sattels. - Jb. f. Geol.., $\underline{3}$ (f. 1967): 205215, 4 Abb.; Berlin

aSemmel, Arno (1973): Geomorphologische Fragen im Kasseler Raum. - In: Born, Martin [Hrsg.]: Beiträge zur Landeskunde von Nordhessen. Festschrift zum 39. Deutschen Geographentag vom 11.16. Juni 1973 in Kassel. - Marburger geographische Schriften, 60; 416 S.; hier S. 23-36, 5 Abb.; Marburg 1973

- $\square$ ○्Semmel, Arno (1996): Geomorphologie der Bundesrepublik Deutschland - Grundzüge, Forschungsstand, aktuelle Fragen, erörtert an ausgewählten Landschaften. - 5. überarb. u. reg. erweit. Aufl.; Reihe: Erdkundliches Wissen, 30; 199 S., 61 Abb.; (Franz Steiner) Stuttgart [darin: „Thüringer Wald“, „Thüringer Becken“, „Hessisch-Niedersächsisches Bergland“; [Hoher] Meißner"]

- $\square$ Semmel, Arno (1968): Studien über den Verlauf jungpleistozäner Formung in Hessen. - Frankfurter Geogr. Hefte, 45: 133 S., 35 Abb.; Frankfurt/M.

[auch nordhessisches Bergland: Lohne b. Kirchberg, Vollmarshausen, Lehmgruben Oetmannshausen u. Albungen]

-Semmel, Arno (1971): Untersuchungen zur jungpleistozänen Talentwicklung in deutschen Mittelgebirgen. - Z. Geomorph. N.F., Suppl.-Bd., 14: 105 - 112, 3 Abb.; Berlin/Stuttgart [darin: Profil Wölfersheim a. d. Werra b. Heringen]

-Semmel, Arno (1976): Die Beziehungen zwischen Relief, Gestein und Böden in hessischen Buntsandsteinlandschaften. - Z. Geomorph., N.F., Suppl.-Bd., 24: 23 - 32, 4 Abb.; Berlin-Stuttgart

-Semmel, A. (1987): Historisch-genetische Morphologie in der praktischen Anwendung. - Verhdlgn. Dt. Geographentag (Berlin, 30. Sept. - 5. Oktober 1985), 45: 102-110, 5 Abb.; Wiesbaden [darein: S. 107-110 Fallbeispiel: „Reliefentwicklung und forstliche Standortqualität am Beispiel des Fulda-Werra-Berglandes]

-Semme1, Arno (1991): Neotectonics and geomorphology in the Rhenish Massif and the Hessian Basin. - Tectonophysics, 195: 291 - 297, 1 Abb.; Amsterdam [darin: Fuldatal]

- Semmel, Arno (2002): Hessisches Bergland - (Die deutsche Mittelgebirgsschwelle). - In: Liedtke, Herberg \& Marcinek, Joachim [Hrsg.]: Physische Geographie Deutschlands. - 3. überarb. u. erw. Aufl.; S. 481 - 494, Abb. 9.12 - 9.22; (Klett-Perthes) Gotha 2002 [darin: Dreienberg b. Friedewald, Kasseler Becken, Werratal)

-Semmel, Arno (2002): Niedersächsiches Bergland - (Die deutsche Mittelgebirgsschwelle). - In: Liedtke, Herberg \& Marcinek, Joachim [Hrsg.]: Physische Geographie Deutschlands. -3. überarb. u. erw. Aufl.; S. 494 - 503, Abb. 9.23 - 9.28; (Klett-Perthes) Gotha 2002

-Siegert, L. (1913): Über die Entwicklung des Wesertales. - Z. dt. geol. Ges., 64 (f. 1912), Abh. (1/2): 233 - 264, 4 Abb.; Berlin [auch Werratal]

-Siegert, L. (1921): Beiträge zur Kenntnis des Pliozäns und der diluvialen Terrassen im Flußgebiet der Weser. - Abh. Preuß. Geol. Landesanst., N.F., 90; 132 S., 17 Taf.; Berlin 
$\square$ Sippell, Barbara (1947): Zur Morphologie des Soodener Berglandes; Diss. Univ. Göttingen 1947; 70 S. [maschinenschriftl.], 1 Kt.-Beil. - auch unter dem Titel: Barbara Maier, geb. Sippell : Zur Morphologie des Soodener Berglandes. - Göttinger Geogr. Abh., 11; Göttingen 1952

oSinn, Wolfgang \& Weigel, Heinrich (1994): Der Hautsee mit der schwimmenden Insel. - Das Werraland, 46: 81-84, 3 Abb.; Eschwege

[Landkr. Wartburg-Eisenach]

-Sobotha, Ernst (1923): Versuch einer Entwicklungsgeschichte und Charkterisierung der Landschaften des Untereichsfelder Beckens nebst seinen westlichen und südlichen Randgebieten. - Diss. Univ. Göttingen, 1923, 46 S., 13 Taf. (Abb., Kt.)

-Sobotha, Ernst (1932): Salzauslaugung auf dem Untereichsfeld. - Unser Eichsfeld, 27: 79 - 82, 6 Abb.; (Aloys Mecke) Duderstadt

- -Sobotha, Ernst (1932): Über Salzauslaugung, Tektonik und Oberflächenformen zwischen Westharz und Vogelsberg. - Z. dt. geol. Ges., 4: 725 - 732, 3 Abb.; Berlin

-Sobotha, Ernst (1933): Eine morphologische Karte des nordwestlichen Eichsfeldes. - Z. Geomorph., 7 (f. 1932/33): 295 - 298, 1 Abb.; Leipzig

-Sobotha, Ernst (1933): Drei Blockdiagramme zur Talgeschichte der Aue (Nordwestliches Eichsfeld). Geographischer Anzeiger, 34 (1933). 61 - 62, 6 Abb.; Gotha

OSobotha, Ernst (1933): Salzhang und Oberflächenformen im östlichen Vorland des Ohmgebirges (Südharz). - Zbl. Mineral. etc., Abt. B, 1933: 412 - 418, 2 Abb.; Stuttgart

D-Sobotha, Ernst (1934): Zur Tektonik und Beckenbildung im nordwestlichen Eichsfeld. - Z. dt. geol. Ges., $8 \mathbf{5}$ (f. 1933): 788 - 791, 1 Abb.; Berlin

[Östl. Lkr. Göttingen, Umgebung Heiligenstadt]

- -Sobotha, Ernst (1970): Geomorphologie und Grundwasser. - Verhdlgn. Dt. Geographentag, (Kiel, 21. - 26. Juli 1969), 37: 167-173, 2 Abb.; Wiesbaden

[darin: Subrosion Umgebung Bad Hersfeld]

$\square$ •Soergel, W. (1927): Zur Talentwicklung von Werra-Weser und des Ilm-Saalesystems. - Geol. Rundschau, 18: 103 - 120; Berlin

$\square$ Stäblein, Gerhard (1986): Zechstein leaching and karst landforms in the Werra-MeißnerArea/Northern Hesse. On the base of the detailed Geomorphological Map 1 : 25000 (GMK 25) Sheet Bad Sooden-Allendorf. - Z. Geomorph., N.F., Suppl.-Bd., 59: 49-65, 1 Tab., 1 Kt.-Beil.; BerlinStuttgart

$\square$ Stäblein, Gerhard (1986): Geomorphologische Gliederung des Werra-Meißner-Landes. - In: Stäblein, Gerhard [Hrsg.]: Geo- und biowissenschaftliche Forschungen der Freien Universität Berlin im Werra-Meißner-Kreis (Nordhessen). - Berliner Geogr. Abh., 41; zgl. Beiträge zur Werra-MeißnerForschung, I; S. 257 - 265, 1 Kt.-Beil.; (Selbstverl. Inst. Phys. Geogr. FU Berlin) Berlin 1986

$\square$ Stäblein, Gerhard (1987): Bodenerosion und geomorphologische Kartierung - Probleme und Ansätze einer geomorphologischen Kartierung (Nordhessen). - Münstersche Geographische Arbeiten, (Ludwig-Hempel - Festschrift) 27: 29-41, 4 Abb., 5 Tab.; [Schöningh] Paderborn [Bezug a GMK 25 Blatt Bad Sooden-Allendorf]

$\square$ Stäblein, Gerhard \& Möller, Klaus (1986): Subrosionsformen im Bereich des Meißners in Nordhessen. - Geol. Jb. Hessen, 114: 295 - 310, 4 Abb., 1 Tab., 1 Kt.; Wiesbaden 
-Stein, Christoph (1975): Studien zur quartären Talbildung in Kalk- und Sandgesteinen des LeineWeser-Berglandes. - Göttinger geogr. Abh., 64; 131 Sl, 61 Abb.., 3 Beil.; zgl. Diss. Univ. Göttingen 1975; (Goltze) Göttingen

[Untersuch. u.a.: Göttinger Wald, Dransfelder Hochfläche, Buntsandsteingebiet SE’ Göttingen]

OSteinmüller, A. (1965): Zusammenhänge zwischen Auslaugung, Lagerungs- und Oberflächenformen im thüringischen Eichsfeld. - Z. angew. Geol., 11: 90-95, 3 Abb.; Berlin

[Buntsandstein- u. Muschelkalkgebiete, u.a. Kalteneber, Travertin Großbartloff, Röhrig]

OSteinmülller, Arno (1995): Geomorphologischer Überblick [über Thüringen]. - In: Seidel, Gerd [Hrsg.]: Geologie von Thüringen. - 1. Aufl.; S. 6-12; Stuttgart 1995

OSteinmüller, Arno (2003): Geomorphologischer Überblick [über Thüringen]. - In: Seidel, Gerd [Hrsg.]: Geologie von Thüringen. - 2., neu bearb. Aufl.; S. 6-13; Stuttgart 2003

-Thomas, Jürgen (1991): Talaue und Schwemmfächer als Indikatoren der holozänen fluviatilen Geomorphodynamik an der oberen Weser. - In: Mäckel, R. \& Röhrig, A. [Hrsg.]: Forschungen zur Fluss- und Hangdynamik. - Freiburger Geogr. H., 33; S. 67 - 77, 5 Abb.; Freiburg i. Br. 1991

-Thomas, Jürgen (1993): Untersuchungen zur holozänen fluvialen Geomorphodynamik an der oberen Weser. - Göttinger geogr. Abh., 98; 111 S., 67 Abb., 9 Tab., 1 Beil.; zgl. Diss. Univ. Göttingen 1993; (Goltze) Göttingen

[Untersuch. im Wesertal zw. Hann. Münden u. Gieselwerder, Reinhardswald und Bramwald]

$\square$ Tolle-Krieger, Ingeborg (1941): Eschwege und seine Landschaft. - 87 S. (Braun) Eschwege - zgl. Diss. Univ. Heidelberg 1938 u. d. T. Tolle, Ingeborg: „Das Becken von Eschwege“; 88 S.

[darin: Kap. „Die Naturlandschaft des Eschweger Beckens“ (u.a. Regionalgeologie, regionale Geomorphologie)]

OVölker, C. \& Völkel, R. [Red.](2002): Exkursionsführer Subrosionserscheinungen im Röt (Oberer Buntsandstein) im Bereich des Ohmgebirges (NW-Thüringen, Eichsfeld). - 35 Bl., Abb., Tab., Kt.; [Hrsg.: Thür. Geol. Verein] Jena

-Völksen, Gerd (1973): Die Bodenerosion als bewirtschaftungstechnisches Kriterium. Mit Bildbeispielen aus dem Raum Duderstadt. - Neues Archiv f. Niedersachsen, 22: 341-355, 10 Abb., Göttingen [Bodenkunde, Geomorphologie]

OWätzel, A. (1987): Zur Geomorphologie des Absatzraumes der holozänen Binnenwasserkalke im Mühlhäuser Becken. - Alt-Thüringen, 22/23: 7-28; Weimar

OWeber, Hans (1924): Beiträge zur Geologie und Morphologie des Thüringerwaldrandes zwischen Frankenhain und Georgenthal. - Z. dt. geol. Ges., 76: 250 - 264, 1 Abb.; Berlin

OWeber, Hans (1926): Die Oberflächenformen der Tambacher Schichten bei Eisenach. - Forsch. z. dt. Landes- u. Volkskde., 24(2): 70-124, 11 Abb., 2 Taf.; (Engelhorn) Stuttgart

口OWeber, Hans (1929): Geomorphologische Studien in Westthüringen. - Forsch. Dt. Landes- u. Volkskde., 27 (3): 267-474, 15 Abb., 1 Kt.; Stuttgart [darin: Ringgau, Hainich]

OWeber, Hans (1930): Der Erdfall 1926 bei Creuzburg an der Werra. - Beitr. Geol. Thür., 22: 109-112, 2 Abb.; Jena

OWeber, Hans (1933): Geomorphologische Probleme des Thüringer Landes. - Z. Geomorph., $\underline{7}$ (1932/33): 177 - 205, 1 Abb.; Leipzig 
OWeber, Hans (1941): Untergrund und Oberflächengestalt im Thüringerwalde. Ein Beitrag zur Morphologie und Morphogenese des deutschen Mittelgebirgslandes. - Monogr. Geol. Paläont., Serie II, H. $\underline{8} ; 183$ S., 34 Abb., 12 Tab.; (Bornträger) Berlin Referat in: N. Jb. Mineral. etc., Referate, 1942 (Bd. III): 172-174 (E. Hennig)); Stuttgart

OWeber, Hans (1942): Die Silbacher Scholle als Beispiel einer Strukturlandschaft des Thüringer Waldes. - Beitr. Geol. Thür., $\underline{6}$ : 115-123, 2 Abb.; Jena [Region NE' Schleusingen]

OWeber, Hans (1942): Die kinematsiche Komponente im Formenschatz des Thüringer Waldes. - Beitr. Geol. Thür., ㅁ: 198-204, 2 Abb.; Jena

OWeber, Hans (1944): Zur Morphogenese des Thüringer Waldes. - Beitr. Geol. Thür., 7: 49-53; Jena

- $\square$ OWeber, Hans (1952): Pliozän und Auslaugung im Gebiet der oberen Werra. - Geologica, $\underline{8}$; 136 S., 17 Abb., 4 Taf.; (Akademie-Verlag) Berlin

Referat in: Geologie, $\underline{\mathbf{3}}(1)$ : 86-87 (F. Stock); Berlin

[darin: Untersuchungen Blätter Berka, Creuzburg, Herleshausen u. Hönebach; die Auslaugungssenke a. d. Werra zwischen Berka und Gerstungen; der Zechstein von Wommen; Tekt. Karte m. Anteilen Werra-Meissner-Kreis]

OWeber, Hans (1952): Fragen der Oberflächengestaltung in der thüringischen Zechstein- und Triaslandschaft. - Hallesches Jb. Mitteldt. Erdgeschichte, $\underline{1}$ (Lfg. 4): 259 - 276, 1 Abb.; Halle

OWeber, Hans (1955): Der Kleine Thüringer Wald als Strukturlandschaft. - Beitr. Geol. Thür. , ㅁ: 2-30, 7 Abb., 2 Taf.; Frankfurt/M.

[Tektonik, Geomorphologie]

OWeber, Hans (1955): Zur Formenentwicklung der thüringischen Erdfälle. - Hall. Jb. f. Mitteldt. Erdgeschichte, $\underline{\mathbf{2}}(2):$ 100-107, 8 Abb. i. Text, 11 Fig. a. Taf. III-IV; Halle [darin: Der Erdfall 1937 bei Frauensee - Der Erdfall 1924 bei Zimmern]

OWeber, Hans (1956): Formenkundliche Probleme im Thüringer Gebirge. - Hallesches Jb. Mitteldt. Erdgeschichte, 2 2 (3): 142-165, 8 Abb.; (Halle) Saale [Geomorphologie]

OWeber, Hans (1963): Struktur- und Auslaugungsmorphologie der Drei Gleichen bei Arnstadt in Thüringen. - Hallesches Jb. mitteldt. Erdgeschichte, 5 : 47-60, 2 Abb., Taf. VII-XIII (15 Bilder); Leipzig

口OWege (1926): Von der Entstehung des Werratales bei Herleshausen. - Das Werratal, $\underline{\mathbf{3}}(2): 24-26,3$ Abb.; Eschwege

- $\square \bullet$ Weiland, F. (1938): Morphologie des Kaufunger Waldes. - Jb. Niedersächs. Geol. Vereins, 29: 1 89, 13 Abb., 7 Taf (11 Fotos); Hannover - zgl. Diss. Univ. Göttingen 1937

$\square$ Wenzel, Bernward (1994): Zur Lithostratigraphie und Sedimentologie des Röt und zu den Massenverlagerungen an der Röt/Muschelkalkgrenze in Nordhessen.- Gießener geol. Schriften, $\underline{\mathbf{3}}$; VIII, 248 S., Ill., graph. Darst., Kt.; Teil A: Zur Lithostratigraphie und Sedimentologie des Röt in Nordosthessen, S. 1-141, 23 Abb., i. Text, Taf., Tab. i. Anhang; Teil. B.: Zu den Massenverlagerungen an der Röt-/Muschelkalkgrenze in Nordosthessen. S. 141-248, 21 Abb. i. Text; Kt., fProfile, Taf., Tab. i. Anhang; zgl. Diss. Univ. Gießen 1994; (Lenz) Gießen [Untersuchungsgebiet Röt/Muschelkalkgrenze im Werra-Meißner-Kreis; Hörne, Plesse, Rabenklippe, Schiefergrundskopf, Schickeberg, Kielfors u.a.]

-Wenzel, Hermann (1931): Morphologie und Talgeschichte des Niederhessischen Berglandes. - I. Die diluvialen Terrassen der Eder. - Z. Geomorphologie, $\underline{\mathbf{6}}(4 / 5)$ : 129-173, 1 Abb., Taf. IV - VI; Berlin 
$\square$ Wenzens, Gerd (1969): Morphologie des Sontraer Beckens. - Rhein-Mainische Forschungen, $\underline{\mathbf{6 8}} ; 100$ S., 20 Abb., 6 Tab.; 2 Kt.; Würzburg - zgl. Diss. Univ. Frankfurt/M. 1969

-Wenzens, G. (1969): Gipskarstformen im Sontraer Zechsteingebiet. - 5. Internationaler Kongreß f. Speläologie, Bd. 1: Morphologie des Karstes; Proceedings Int. Congress of Speleology, ‥1: S. M 2.1 M.2.11, Ill.; München

-Wenzens, Gerd (1985): Der Einfluß der Gips- und Salzauslaugung auf die Oberflächenformung im Sontraer Zechsteinbecken. - In: Verband der Deutschen Höhlen- und Karstforscher e.V.

[Hrsg.]: Karst und Höhle 1984/1985. Beiträge zur Karst- und Höhlenforschung in Hessen. - S. 155165, 5 Abb., 2 Tab.; (Selbstverlag d. Verbandes) München 1985

[Umgebung Richelsdorfer Gebirge]

OWietze, Charlotte (1924): Zur Morphologie des Gebirgsrandes zwischen Georgenthal und Schmerbach (Beiträge zur Morphologie von Thüringen) - Mitt. Geogr. Ges. f. Thür., 37: 37-38; Jena - Auszug a. unveröff. Manuskript)

-Wilczewski, Norbert (2003): Rutschungen an der Grenze Buntsandstein/Muschelkalk. - In: Van den Kerkhof, A. M. van den [Hrsg.]: Festschrift zum 70. Geburtstag von Professor Dr. Hans-Jürgen Behr. - Göttinger Arb. Geol. Paläont., Sonderheft ㅁ; [1], 123 S., Abb. u. Tab.; (Selbstverlag d. Geol. Inst.) Göttingen 2003

[Göttinger Wald, Plesse]

-Wildhagen, Holger (1972): Holozäne Bodenentwicklung, Sedimentbildung und Geomorphogenese im Flussauen-Bereich des Göttinger Leinetalgrabens. - Diss. Univ. Göttingen 1972, 158 S.;

s.a. Wildhagen, Holger \& Meyer, Brunk (1972): Holozäne Boden-Entwicklung, Sedimentbildung und Geomorphogenese im Flussauen-Bereich des Göttinger Leinetalgrabens - 1. Spätglazial und Holozän bis zum Beginn der eisenzeitlichen Auenlehm-Ablagerung. - (Übergeordn. Titel: Ergebnisse neuerer Auenforschungen im Leinegraben-Gebiet). - Göttinger bodenkdl. Ber., 21: 1-75, 9 Abb., 5 Tab., 1 Falt-Taf. (3 Kt. 1-3); Göttingen

s.a. Wildhagen, Holger \& Meyer, Brunk (1972): Holozäne Boden-Entwicklung, Sedimentbildung und Geomorphogenese im Flussauen-Bereich des Göttinger Leinetalgrabens - 2. Die Auenlehmdecken des Subatlantikums. - (Übergeordn. Titel: Ergebnisse neuerer Auenforschungen im LeinegrabenGebiet).- Göttinger bodenkdl. Ber., 21: 77-158, 6 Abb., 3 Tab., 2 Falt-Taf. (Kt. 4-9 Kt.); Göttingen -

-Wildhagen, Holger \& Meyer, Brunk (1972): Holozäne Boden-Entwicklung, Sedimentbildung und Geomorphogenese im Flussauen-Bereich des Göttinger Leinetalgrabens - 1. Spätglazial und Holozän bis zum Beginn der eisenzeitlichen Auenlehm-Ablagerung. - (Übergeordn. Titel: Ergebnisse neuerer Auenforschungen im Leinegraben-Gebiet). - Göttinger bodenkdl. Ber., 21: 1-75, 9 Abb., 5 Tab., 1 Falt-Taf. (3 Kt. 1-3); Göttingen - s. a. Wildhagen, Holger (1972): Holozäne Bodenentwicklung, Sedimentbildung und Geomorphogenese im Flussauen-Bereich des Göttinger Leinetalgrabens. Diss. Univ. Göttingen 1972

-Wildhagen, Holger \& Meyer, Brunk (1972): Holozäne Boden-Entwicklung, Sedimentbildung und Geomorphogenese im Flussauen-Bereich des Göttinger Leinetalgrabens - 2. Die Auenlehmdecken des Subatlantikums. - (Übergeordn. Titel: Ergebnisse neuerer Auenforschungen im LeinegrabenGebiet).- Göttinger bodenkdl. Ber., 21: 77-158, 6 Abb., 3 Tab., 2 Falt-Taf. (Kt. 4-9 Kt.); Göttingen s. a. Wildhagen, Holger (1972): Holozäne Bodenentwicklung, Sedimentbildung und Geomorphogenese im Flussauen-Bereich des Göttinger Leinetalgrabens. - Diss. Univ. Göttingen 1972

-Wilhelm, Otto (1937): Morphologische Untersuchungen am Nordrand der Niederhessischen Senke. Jb. Geogr. Ges. Hannover, 1936/1937: 77 - 165, 8 Taf. (5 Abb., 3 Falt-Kt.; Hannover [Umgebung v. Hofgeismar, Habichtswald u. a. Geb.] - zgl. Diss. Univ. Göttingen 1937 
$\square$ Winterhoff, Wulfard \& Höllermann, Peter (1968): Morphologie, Flora und Vegetation des Bergsturzes am Schickeberg [Nordhess]. - Nachr. d. Akad. Wiss. Göttingen, II. math.-nat. Klasse; 1968, H. 7; VI, 62 S., 9 Abb., 8 Tab., 1 Beil.-Kt.; (Vandenhoeck \& Ruprecht) Göttingen [darin: Überblick Geologie, Geomorphologie; Erwähnung d. Bergstürze a. Plesse b. Wanfried, Manrod/Ringgau-Rambach, Kielforst b. Herleshausen]

$\square$ Wölker, Thomas (1991): Auf den Spuren der Vergangenheit - Ein historisch-geographischer Führer durch den Ammicheroder Kessel bei Bad Sooden-Allendorf. - 40 S., 8 Kt.; [Hrsg. i. Auftrag d. Vereins f. Heimatkde e.V.; Bad Sooden-Allendorf)(Selbstverlag d. Vereins) Bad Sooden-Allendorf [darin Informationen zur Geologie, Geomorphologie]

$\square$ Wolff, P. (1982): Der Salzgehalt des Salzbaches und die Entstehung von Erdfällen und Landsenkungen in der Gemarkung Witzenhausen-Wendershausen. - Arb. u. Ber. GHS Kassel, Fb. Int. Agrarwirtschaft, Fachgebiet Kulturtechik u. Wasserwirtschaft, 2; 9 S., [3 Bl.], Kt.; [Ghs Kassel, Fachber. Int. Agrarwirtschaft] Witzenhausen

-Wolpers, Georg (1969): Inseln im Seeburger See. Ein Bericht aus dem Jahre 1911. - Die Goldene Mark, $\underline{\mathbf{2 0}}(2)[=1969(2)]:$ 17-20; Duderstadt

[darin: temporäre Insel im Seeburger See]

-Wolpers, Georg (1980): Das war etwas Neues vom Seeburger See. - Die Goldene Mark, $\underline{31}(1)[=1980(1)]: 17-20$; Duderstadt

[darin: temporäre Insel im Seeburger See]

- $\square \bullet$ Wolters, R. [beteiligt](1973): Symposium - Erdfälle und Bodensenkungen: Ingenieurgeologische Probeme löslicher Gesteine - Effondrements et affaissements: problèmes de géologie de l'ingénieur relatifs aux roches solubles - Sink-holes and subsidence: engineering geological problems related to soluble rocks. - Proceedings; ca. 300 S. (keine durchgehende Zählung); (Deutsche Gesellschaft f. Erdund Grundbau) Essen

-Worthmann, Heinrich (1937): Die Terrassen der Diemel zwischen Sauerland und Weser. - Jb. Preuß. Geol. Landesanst., $\underline{57}$ (H. 1) (f. 1936): 359-413, 6 Abb., Taf. 15-17; Berlin

OWüstner, L. (1964): Salzauslaugung und Tektonik im Zechstein des Werra-Kaligebietes nach Ergebnissen seismischer Messungen. -Z. angew. Geol., 10 (4): 172 - 179, 6 Abb., Berlin

- $\square$ Zeiller, Martin (1655): Martin Zeillers Topographia Hassiae, Et Regionum Vicinarum - Das ist, Beschreibung und eygentliche Abbildung der vornehmsten Stätte und Plätze in Hessen und denen benachbarten Landschafften, als Buchen, Wetterau, Westerwald, Löhngau, Nassau, Solms/ Hanau, Wigenstein und andern. - In dieser andern Edition mit sondern Fleiß durchgesehen/ von vorigen Fehlern corrigirt, gebessert und vermehret. - [1] Bl., 151, [9] S. mit 62 Kupferstichen und einem Titelkupfer [des Kupferstechers Matthaeus Merian < des Älteren>]; (Zum Truck verlegt von denen Merianischen Erben) Franckfurt am Mayn

[Es existiert eine weiter Auflage von 1655, die im Karlsruher Virtuellen Katalog als 2. Auflage des Jahres bezeichnet wird]

darin in beiden Ausgaben: Historischer Bergsturz an der Plesse bei Wanfried am 24. Januar 1640]

\subsection{Höhlenkunde}

$\square$ Anonym (1900): < Höhle im Gipsbruch am Schloßberg bei Sontra entdeckt]. - Eschweger Tageblatt u. Kreisblatt, 1900; Nr. 177 v. 31.7.1900; Eschwege 
$\square \bullet$ Namenskürzel (ns)(1957): Höhlen in Hessen und Waldeck - Wer kennt den Hohlstein, das Klingelloch, den Klugstein, die Hollenkammer. - Kasseler Post - 1957, Nr. 15 v. 18.1.1957, Beilage „Deutsches Vaterland“; Kassel

[Klingelloch bei Hann.-Münden/Laubach, Hohlstein b. Hilgershausen/Werra-Meißner-Kreis]

- $\square$ ○ीApel, Jürgen \& Rüppel, Heidi [Verfass. u. Hrsg.] (2005): Raus in die Natur - Tipps für den Sonntags-Ausflug im Dreiländereck Hessen - Niedersachsen - Thüringen. - 159 S., 111 Fotos, 34 Kt., 1 Zeit-Taf.; (LSRB-Verlag, Landschaftskundlicher-Studien-Reisebuch-Verlag) Witzenhausen [zahlreiche Ausflugstipps, auch zu Höhlen: Ziel 63 (Hohlstein b. Hilgershausen)]

- $\square$ Böhm, Ronald; Pflug, Eberhard; Stein, Gerhard \& Zaenker, Stefan (1985): Karst und Höhlen in der Hessischen Senke, der Diemelplatte und dem Fulda-Werra-Bergland. - In: Verband der Deutschen Höhlen- und Karstforscher e.V. [Hrsg.]: Karst und Höhle 1984/1985. Beiträge zur Karst- und Höhlenforschung in Hessen. - S. 187-190; (Selbstverlag d. Verbandes) München 1985 [darin: Höhlen Landkreis Kassel, Werra-Meißner-Kreis: Umgebung Heldrastein, Graburg, Friedewald, Kr. Hersfeld-Rotenburg]

-Brust, Michael K. [Mitautor] (2002): Die Schauhöhle Altenstein in Schweina - Natur- und Kulturgeschichte eines Geotops. - Schriftenrh. TLUG, 푸; 162 S., zahlr. Abb., Faltkt.; Jena [Aufsätze z. Geologie, Flora, Botanik u.a.]

$\square$ Deichmann, L. (1892): Der Hohlstein bei Hilgershausen. - Tourist. Mitth. Hessen-Nassau u. Waldeck, $\underline{1}(2): 15$ - 19; Kassel

[,Hilgershäuser Höhle"]

-Dewald, Wulfhart (1985): Der Landecker Berg und seine Höhlen. - In: Verband der Deutschen Höhlen- und Karstforscher e.V. [Hrsg.]: Karst und Höhle 1984/1985. Beiträge zur Karst- und Höhlenforschung in Hessen. - S. 191-198, 3 Abb., 4 Taf.; (Selbstverlag d. Verbandes) München 1985 [darin: Höhlen Landkreis Kassel, Werra-Meißner-Kreis: Umgebung Heldrastein, Graburg, Friedewald, Kr. Hersfeld-Rotenburg]

ㅁFritze, Franz] (1854): Der Nordwesten des Thüringer Waldes oder zehn Tage in Ruhla - Gemälde aus dem Badeort Ruhla und seiner Umgebung - Eisenach, Wilhelmsthal, Altenstein, Liebenstein, Inselsberg und Reinhardsbrunn - Ein Reisehandbuch und Wegweiser (nebst einer Reiseroute durch die übrigen Theile des Waldes). - XIV, 230 S., 1 Kt.; (Veit) Berlin

[darin S. 41-42 Alabastersteinbruch bei Kittelsthal; S. 48-51 Geologischer Überblick Thüringer Wald; S. 108-112 Die Höhle von Altenstein; S. 164-165 Marienhöhle < Marienglashöhle b. Tabarz>]

QHess von Wichdorff, H. (1911): Die Tropfsteinhöhle im Zechstein-Bryozoenriff bei Thal in Thüringen und ihre genetischen Beziehungen zu den dortigen Schwerspatgängen. - Jb. Preuß. Geol. Landesanst., $\underline{\mathbf{3 0}}$ (Teil I) (f. 1909): 567-575, 5 Abb.; Berlin

QHess von Wichdorff, H. (1921): Über den Nachweis von Spuren alter Flußläufe in Höhlen im westlichen Thüringer Wald. - Z. Dt. Geol. Ges., 72 (f. 1920): $42-46$ (Sitzber.), o. Abb.; Stuttgart

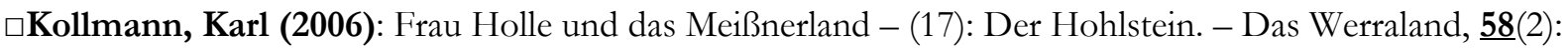
39-42, 6 Abb.; Bad Sooden-Allendorf

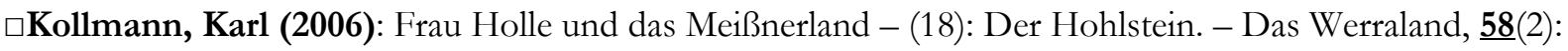
57-60, 5 Abb.; Bad Sooden-Allendorf

$\square$ Landau, G. (1833): Der Hohlstein in Niederhessen. - Archiv für die Geschichte und Alterthumskunde Westphalens, $\underline{\mathbf{6}}(2 / 3)$ : 315-318; Lemgo

[Höhlenkunde, Geologie u. Sagenwelt]

QLuedecke (1900): Eine neue Höhle im Zechstein Thüringens. - Z. f. Naturwiss., 72(4/5) (= 5. F., 10]: 357-358; Stuttgart 
Referat in: Mitt. Geogr. Ges. (f. Thüringen), 19: 61 (Anonym); Jena 1900/1901 [Thal b. Ruhla]

$\square$ Mötzing, Kurt (1968): Sandsteinhöhlen unter dem Heldrastein. - Das Werraland, 20 (4): 62-64, 1 Abb.; Eschwege

$\square$ Namenskürzel (B) (1962): Kammerbacher Höhle wird ausgebaut - See erhält Unterwasserbeleuchtung./Bauarbeiten werden einige Monate dauern. - Werra-Rundschau , 1962; Nr. 1 v. 2.1.1962, [S. 6], 2 Abb.; Eschwege

QNebel, Brigitte \& Nebel, Jürgen (1969): Mineralogische und geochemische Untersuchungen an Höhleneinlagerungen. - Geologie, 18(10): 1214-1230, 10 Abb., 3 Tab.; Berlin [Einlagerungen: Höhlenlehm, Tropfstein-Kalksinter; darin: Altensteiner Höhle]

$\square$ Pflug, Eberhard (1985): Karst und Höhlen im Werra-Fulda-Bergland - Mit Beiträgen v. D. Kraus und Gerhard Stein. - In: Verband der Deutschen Höhlen- und Karstforscher e.V. [Hrsg.]: Karst und Höhle 1984/1985. Beiträge zur Karst- und Höhlenforschung in Hessen. - S. 145-154, 2 Abb.; (Selbstverlag d. Verbandes) München 1985 [Werra-Meißner-Kreis, Sontraer Bergland]

OPustal, Ina [Red.](2005): Thüringen Untertage - Ein Exkurs zu Schauhöhlen, Besucherbergwerken und GeoMuseen. - 317 S., Ill. Graph. Darst., Kt.; [Hrsg. Thür. Landesanst. f. Umwelt u. Geologie, i. Zus.Arbeit m. Bergmannsverein „Otto Ludwig Krug v. Nidda“ e.V. u. Thür. Höhlenverein e.V.] Jena

$\square$ Reinboth, Friedrich (1985): Aus der Geschichte der Kammerbacher Höhle. - In: Verband der Deutschen Höhlen- und Karstforscher e.V. [Hrsg.]: Karst und Höhle 1984/1985. Beiträge zur Karst- und Höhlenforschung in Hessen. - S. 171-175, 2 Abb.; (Selbstverlag d. Verbandes) München 1985

$\square$ Reinboth, Friedrich (1988): Aus der Geschichte der Kammerbacher Höhle. Die Kammerbacher Höhle - die älteste urkundlich genannte Höhle Deutschlands. - Das Werraland, $\underline{40}$ (2): 19-21, 4 Abb.; Eschwege - Nachdruck aus: Karst und Höhle, 1984/85: 171-175, München 1985)

$\square$ Rupprecht, G. (1927): Die Sandsteinhöhlen unter dem Heldrastein. - Das Werratal, $\underline{4}(4): 55-56$; Eschwege

$\square$ Sippel, Klaus (1997): Der Hohlstein bei Hilgershausen, Stadt Bad Sooden-Allendorf. Führungsblatt zu der Höhle zwischen Hilgershausen und Kammerbach. - Archäologische Denkmäler in Hessen, 138; 11 S.; (Landesamt für Denkmalpflege) Wiesbaden

- $\square$ Stein, Gerhard (1985): Der hessische Höhlenkataster. - In: Verband der Deutschen Höhlen- und Karstforscher e.V. [Hrsg.]: Karst und Höhle 1984/1985. Beiträge zur Karst- und Höhlenforschung in Hessen. - S. 29-34, 6 Abb., 2 Tab., 2 Taf.; (Selbstverlag d. Verbandes) München 1985

$\square$ Stein, Karl \&Pflug, Eberhard (1985): Höhlen im Sandstein. - In: Verband der Deutschen Höhlenund Karstforscher e.V. [Hrsg.]: Karst und Höhle 1984/1985. Beiträge zur Karst- und Höhlenforschung in Hessen. - S. 227-229; (Selbstverlag d. Verbandes) München 1985 [darin: Höhlen i. östl. Werra-Meißner-Kreis]

$\square$ Stein, Karl \&Pflug, Eberhard (1985): Höhlen im Basalt. - In: Verband der Deutschen Höhlen- und Karstforscher e.V. [Hrsg.]: Karst und Höhle 1984/1985. Beiträge zur Karst- und Höhlenforschung in Hessen. - S. 235-239, 1 Taf.; (Selbstverlag d. Verbandes) München 1985 [darin: Kitzkammer/Hoher Meißner]

$\square$ Stieß, Ludwig (1943): Der Hohlstein bei Kammerbach-Hilgershausen. - Hessischer Gebirgsbote, 499(3): 30-31, 2 Abb.; Melsungen [darin Foto: Kripplöcher bei Frankershausen am Meißner] 
OStrauß, Reinhold (1925): Die Menschengrube bei Lengenfeld unterm Stein. - Eschweger Tageblatt, 1925; Nr. 197 v. 22.08.1925; Eschwege

[Eine Höhle im Muschelkalk und ihre Geschichte]

- $\square$ Verband der Deutschen Höhlen- und Karstforscher e.V. [Hrsg.](1985): Karst und Höhle 1984/1985. Beiträge zur Karst- und Höhlenforschung in Hessen. - 311 S., 85 Abb., 12 Tab., 91 Taf.; 1 Kt.; (Selbstverlag d. Verbandes)

OWagenbreth, Otfried (1970): Die Marienhöhle bei Friedrichroda und ihre Wiederherstellung als

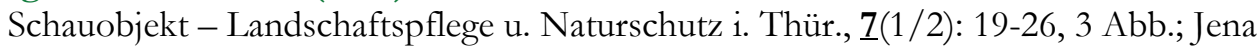

$\square$ Weber, Alfred (1925): Der Hohlstein oder die Kammerbacher bzw. Hilgershäuser Höhle. - Das Werratal, 2 2 (1): 10-12, 3 Abb.; Eschwege [auch Geologie u. Sagen, Märchen, Mystik]

\subsection{Bodenkunde}

-Ahl, Christian \& Meyer, Brun (1989): Sedimentschichten aus Laacher Bims und Flugsand unter geschützten Felsdächern (Abris) im südniedersächsischen Bergland bei Göttingen. - Mitt. Dt. Bodenkdl. Ges., 59: 825-830, 8 Tab.; Oldenburg i. O.

-Andres, E.; Becker, K. W. \& Meyer, B. (1986): CO2-Konzentrationen in einem aufgelockerten Kalksteinverband und deren Bedeutung für die Carbonatabfuhr mit dem Sickerwasser. - Mitt. Dt. Bodenkdl. Ges., 43: 951-956, 3 Abb., 2 Tab.; Göttingen [Göttinger Wald]

-Anonym (1980): Natürliche Schwermetallgehalte in hessischen Ackerböden. - Hessischer Gebirgsbote, 81(4): 124; Melsungen

Q Ausborn (1936): Die Hauptbodenarten des Eichsfeldes. - Unser Eichsfeld, 31: 243-247; Duderstadt

-Bachmann, Stefan; Stolz, Wolfgang; Kantor, Wilfried \& Kuhnt, Gerald (1994): Begleitstudie zur bundesweiten Bodenzustandserhebung in Walde. - Umweltbundesamt - Texte, 6/94; 340 S., hier: S. 259-264; (Umweltbundesamt) Berlin 1994

[Bodenprrofil Bl. 4624 Hedemünden, Lkr. Gö; Profilbeschreibung, bodenphysikalische und bodenchemische Kennwerte]

-Bailly, Friedrich (2006): Die Molkenböden des Reinhardswaldes. - Jb. Lkr. Kassel, 2007: 31-41, 5 Abb.; Kassel

$\square$ Balazs, Arpad (1989): Säurebilanz eines Fichtenbestandes im hessischen Forstamt Witzenhausen. - In: Brechtel, Horst-Michael [Hrsg.]: Beitr. Hess. Forstl. Versuchsanst. z. wiss. Tagung Dt. Verbandes f. Wasserwirtsch., Kulturbau e.V.. „Immissionsbelastung des Waldes und seiner Böden - Gefahr für die Gewässer - Fulda 28.- 30. November 1988;.; Hess. Forst. Versuchsanstalt , Forschber., ㅁ: 65-82, 8 Bilder; Hann.-Münden 1989 - auch: DVWK-Mitteilungen, 17: 167-173, graph. Darst.; Bonn 1989

- $\square$ Balázs, Árpád (1989): Räumliche und zeitliche Variation der Niederschlagsinhaltsstoffe in Freiland und unter Fichtenaltbeständen in Hessen. - In: Brechtel, Horst-Michael, [Hrsg.]: Beitr. Hess. Forstl. Versuchsanst. z. wiss. Tagung Dt. Verbandes f. Wasserwirtsch., Kulturbau e.V.. „Immissionsbelastung des Waldes und seiner Böden - Gefahr für die Gewässer - Fulda 28.- 30. November 1988. - Hessische ForstlicheVersuchsanstalt, Forschungsberichte, ㅁ: 53-64, 3 Bilder; 
Hann.-Münden 1989 - auch: DVWK-Mitteilungen, 17: 65-73, graph. Darst., Bonn 1989 [darin: Meßstationen Witzenhausen, Reinhardswald]

- $\square$ Balázs, Árpád (1991): Niederschlagsdeposition in Waldgebieten des Landes Hessen - Ergebnisse von den hessischen Stationen der „Waldökosystemstudie Hessen“. - Hessische Forstliche Versuchsanstalt, Forschungsberichte, 11; 168 S., 81 Tab.; Hann. - Münden [darin: Meßgebiete Reinhardswald, Witzenhausen]

- $\square$ Balázs, Árpád (1998): 14 Jahre Niederschlagsdeposition in Hessischen Waldgebieten - Ergebnisse von den Meßstationen der Waldökosystemstudie Hessen. - Hessische Landesanstalt f. Forsteinrichtung, Waldforschung und Waldökologie, Forschungsberichte, 25, 129 S., 33 Abb., 16 Tab.; Anhang (31 Tab.); [Hrsg.: Hessischer Minister d. Innern, f. Landwirtschaft, Forsten, Naturschutz] (Hess. Landesanstalt f. Forsteinrichtung, Waldforschung u. Waldökologie) Hann.Münden [darin: Meßstationen Witzenhausen, Reinhardswald]

$\square$ Balázs, Árpád \& Brechtel, Horst-Michael (1989): Mangan-, Aluminium- und Nitratkonzentrationen im Sickerwasser unter Fichtenaltbeständen in Hessen. - In: Brechtel, Horst-Michael [Hrsg.]: Beitr. Hess. Forstl. Versuchsanst. z. wiss. Tagung Dt. Verbandes f. Wasserwirtsch., Kulturbau e.V. (DVWK) „Immissionsbelastung des Waldes und seiner Böden - Gefahr für die Gewässer - Fulda 28.- 30. November 1988; Beitr.. - Hessische Forstliche Versuchsanstalt, Forschungsberichte, $\underline{8}: 83$ 92, 1 Bild, 1 Tafel; Hann.-Münden 1989 - auch: DVWK-Mitteilungen, 17: 175-182, graph. Darst., Bonn 1989 [darin: Meßstation Witzenhausen]

- $\square$ Balázs, A., Brechtel, H.-M. \& Elrod, J. (1989): Beurteilung der Pufferkapazität bewaldeter Einzugsgebiete in Nordhessen aufgrund der Bachwasserqualität. - In: Brechtel, Horst-Michael, [Hrsg.]: Beitr. Hess. Forstl. Versuchsanst. z. wiss. Tagung Dt. Verbandes f. Wasserwirtsch., Kulturbau e.V. (DVWK) „Immissionsbelastung des Waldes und seiner Böden - Gefahr für die Gewässer - Fulda 28.- 30. November 1988; Beitr. 3.5. - Hessische Forstliche Versuchsanstalt, Forschungsbericht, $\underline{8}$ : 111-140, 35 Bilder, Hann.-Münden 1989 - auch: DVWK-Mitteilungen, 17: 227238, graph. Darst., Bonn 1989

[Nordhess. Bergland, Reinhardswald, Kaufunger Wald - Einzugsgebiet Elbe, Losse, Nieste, Gelster]

-Bargon, Egon \& Rambow, Dietrich (1966): Ein lößbedecktes Lateritprofil in Nordhessen. - Z. dt. geol. Ges, $\underline{116}$ (f. 1964): 1014 - 1019, 2 Abb.; Hannover

[Bl. 4822 Gudensberg; Hessische Senke]

OBarthel, F.; Borsdorf, K. H.; Malinowski, D. \& Thoste, V. (1995): Die Verteilung von Radionukliden in den oberflächennahen Böden in Sachsen und Thüringen.- Z. geol. Wiss., $\underline{23}(5 / 6)$ : 527-545, 9 Abb., 2 Tab.; Berlin [darin: Gesamt-Thüringen]

$\square$ Becker, K.-W. (2003): Bodenbearbeitung ohne Pflug - Auswirkungen auf die Dichte des Bodens und die Speicherung von Humus. - Vortragszusammenfassung - Tagung Dt. Bodenkdl. Ges. 30. August 07. September 2003 in Frankfurt/Oder. - Mitt. dt. bodenkdl. Ges., 102(2): 617 -618; [Untersuchungsgebiet Raum Witzenhausen]

$\square$ Blanck, E.; Oldershausen, E. v. \& Maurmann, G. (1932): Über Roterdebildungen im und auf Zechsteinkalk im mittleren Deutschland. - Chemie der Erde, 7(4): 620-640, Tab.; Jena

Referat in: N. Jb. Mineral. etc., Referate, 1935 (Bd. II): 83-84 (Calsow); Stuttgart [Vorkommen an der Landstraße zwischen Bad Sooden-Allendorf und Kammerbach]

$\square$ Blanck, E. \& Melville, R. (1941/42): 8. Über Roterdebildung auf Zechsteinkalk und devonischem Massenkalk im Gebiet Westdeutschlands. - Enthalten in: E. Blanck \& R. Mellville: Untersuchungen über die rezente und fossile Verwitterung der Gesteine, innerhalb Deutschlands, zugleich ein Beitrag zur Kenntnis der alten Landoberflächenbildungen der deutschen Mittelgebirgsländer - Teil V. - 
Chemie der Erde, 14(3): 253-311; hier S. 272-291, zahlr. Tab.; Jena 1941/42 [darin: Untersuchungen Lokalitäten Kammerbach, (Bad) Sooden]

$\square$ Bodem, M.; Balazs, A.; Brechtel, H.-M. \& Ritter, R. (1989): Chemische Qualität des

Bodensickerwassers von Waldstandorten bei Düngungsversuchen im Zusammenhang mit Bodenversauerung - Vergleich von Ergebnissen aus Hessen und Baden-Württemberg. - In: Brechtel, Horst-Michael [Hrsg.]: Beitr. Hess. Forstl. Versuchsanst. z. wiss. Tagung Dt. Verbandes f. Wasserwirtsch., Kulturbau e.V. (DVWK) „Immissionsbelastung des Waldes und seiner Böden Gefahr für die Gewässer - Fulda 28.- 30. November 1988; Hess. Forst. Versuchsanstalt , Forschber., 8: 141-171, 13 Bilder; Hann.-Münden 1989 - auch DVWK-Mitteilungen, 17: 465-482, graph. Darst., Bonn 1989 [darin: Meßstelle Witzenhausen]

-Bork, Hans Rudolf (1979): Bodenerosion im Unteren Eichsfeld und Randgebieten - Beobachtungen zur Schneeschmelze im März 1979. - Eichsfelder Heimatstimmen, 23: 258-263, 8 Abb.; Lingen/Ems

-Bork, Hans Rudolf (1982): Die holozäne Relief- und Bodenentwicklung im Untereichsfeld und im südwestlichen Harzvorland. - Diss. TU Braunschweig; IV, 187 S.; Abb., Beil.

-Bork, H. (1983): Die holozäne Relief- und Bodenentwicklung in Lössgebieten - Beispiele aus dem südöstlichen Niedersachsen. - In: Bork, H. R. \& Ricken, W. [Hrsg.]: Bodenerosion, holozäne und pleistozäne Bodenentwicklung. - Catena, Suppl., 3; 138 S.; hier S. 1-93, 12 Abb., 2 Tab.; (CatenaVerlag) Cremlingen-Destedt 1983

[Unter-Eichsfeld] - Die Vorlage enthält zwei Werke: Bork, H. R. (s. o.) und Ricken, W.: Mittel- und jungpleistozäne Lössdecken im südwestlichen Harzvorland. - S. 95-138, 12 Abb., 2 Tab.

-Bork, Hans Rudolf (1985): Untersuchungen zur nacheiszeitlichen Relief- und Bodenentwicklung im Bereich der Wüstung Drudevenshusen bei Landolfshausen, Ldkr. Göttingen. - Nachr. a. Niedersachsens Urgeschichte, 4: 59-75, 3 Abb., 3 Tab.; Stuttgart

-Bork, Hans Rudolf (1988): Bodenerosion und Umwelt. Verlauf, Ursachen und Folgen der mittelalterlichen und neuzeitlichen Bodenerosion.- Bodenerosionsprozesse, Modelle und Simulationen. - Landschaftsgenese und Landschaftsökologie, 13; zgl. Habilschr. TU Braunschweig; IV, 249 S.; Braunschweig

-Bork, Hans Rudolf (1988): Mittelalterliche Relief-, Sediment- und Bodenentwicklung im Bereich der Wüstung Drudewenshausen. - Archäol. Korrespondenzbl., 18: 89-95, 2 Abb., 1 Tab.; Mainz

-Bork, Hans-R.udolf \& Rohdenburg, Heinrich (1979): Beispiele für jungpleistozäne Bodenerosion und Bodenbildung im Untereichsfeld und Randgebieten. - Landschaftsgenese und Landschaftsökologie, $\underline{3}$ : 115-134, 5 Abb.; Braunschweig [Landkreise Northeim und Göttingen: Elvershausen, Thiershausen, Rüdershausen, Lindau]

-Bork, H.-R.; Bork, H.; Dalchow, C.; Faust, B.; Piorr, H.-P. \& Schatz, T. (1998): Landschaftsentwicklung in Mitteleuropa - Wirkungen des Menschen auf Landschaften. - 328 S., 68 Abb., 36 Tab.; (Klett-Perthes) Gotha/Stuttgart [darin Fallstudien Untereichsfeld: S. 53-57,,Geköpfte und auf den Kopf gestellte Böden im Tiefen Tal“; S: 57-65 „Rasche und vollständige Bodenabtragung bei Drudenvenshausen“; S: 93-102 „Wölbächer bei Rüdershausen: Flurstrukturen lenken Bodenerosion“; S. 126-127 „Das Dorf Drudevenshausen und die Folgen der Bodenerosion“; S: 144 - 145 „Pedimentation bei Desingerode“; S. 145-151 „Die nacheiszeitliche Entwicklung der Rhumeaue bei Katlenburg“]

-Brandt, Michael (2001): Bodenprofile der hessischen Staatsdomäne Frankenhausen. - Arbeitsbericht /Universität/Gesamthochschule Kassel, Fachbereich 11: Landwirtschaft, Internationale Agrarentwicklung u. ökologische Umweltsicherung - Fachgebiet Bodenkund, 4; 72 [Bl.], 3 [Bl.] Anhang, 3 Abb. sowie zahlr. Abb. u. Tab i. d. Profilbeschreibungen; Witzenhausen 
-Brandt, Michael; Wildhagen, Holger \& Heß, Jürgen (2001): Bodenmonitoring auf der Hessischen Staatsdomäne Frankenhausen - Kartier- und Analysenergebnisse. - Arbeitsbericht /Universität/Gesamthochschule Kassel, Fachbereich 11: Landwirtschaft, Internationale Agrarentwicklung u. ökologische Umweltsicherung - Fachgebiet Bodenkund, ; 109 [Bl.]m 23 Abb., zahlr. Tab.; Witzenhausen

QBrandtner, Wolfgang \& Hinrichs, Ute (1996): Bodendauerbeobachtungsflächen als Teil des Umweltmonitorings in Thüringen. - Veröff. Naturkundemuseum Erfurt, Naturwiss. Rh., 15: 25-30, 1 Abb., 1Kt.; Erfurt

$\square$ Brechtel, Horst-Michael [Hrsg.]: Beitr. Hess. Forstl. Versuchsanst. z. wiss. Tagung Dt. Verbandes f. Wasserwirtsch., Kulturbau e.V. (DVWK) „Immissionsbelastung des Waldes und seiner Böden Gefahr für die Gewässer - Fulda 28.- 30. November 1988. - Hessische Forstliche Versuchsanstalt, Forschungsberichte, $\underline{\mathbf{8}} ; 198$ S.; (Hess. Forstl. Versuchsanstalt) Hannoversch Münden 1989 - auch DVWK-Mitteilungen, 17, 548 S., graph. Darst.; Bonn 1989

$\square$ Ebhardt, H.; King, M.-T. \& Meyer, B. (1969): Mineralogisch-chemische Untersuchungen zum Prozeß der Rubefizierung in Kalkstein-Rotlehm und fossilem Laterit in Nordhessen. - Göttinger Bodenkdl. Ber., 9: 65-124, 6 Abb., 7 Tab.; Göttingen [Untersuchg. in Kammerbach b. Bad Sooden-Allendorf, Bl. 4725 Bad Sooden-Allendorf]

- $\square$ Emmerich, Karl-Heinz [Bearb.]; Kaiser, Brigitte [Mitarb.] (1998): Böden im Wandel Dauerbeobachtung von Böden in Hessen. - Geologie in Hessen, 2; 27 S., 13 Abb., Tab.; [Hrsg. Hess. Landesamt f. Bodenforschung] Wiesbaden

[darin. Tab. 1: Lokalitäten im WMK: Witzenhausen, Hess. Lichtenau, Wanfried]

$\square$ Feiertag, Alexander \& Wilke, Sabine (1995): Der Hohe Meißner - Geologische Entwicklung und Bodenvergesellschaftung. - 37 S.; BPSII - Arbeit Fachber. 13 (Feiertag); Hausarbeit Fachber. 19 (Wilke); Ghs/Univ. Kassel

- $\square$ Fickel, W.; Schrader, L. ; Semmel, A. \& Zakosek, H. (1982): Paläoböden in Hessen. - Geol. Jb., Reihe F, 14: 101 - 128, 1 Abb.; (Übergeordneter Titel: Mückenhausen, Eduard: Inventür der Paläböden in der Bundesrepublik Deutschland) Hannover

[Bodenprofile a. Bl. 4622 Kassel-West, 5024 Rotenburg/F., 5124 Bad Hersfeld, 4724 Witzenhausen, 4722 Kassel]

QFritzsche, Bernd (1987): Die Bedeutung der Triasgesteine für die Bodenbildung im Thüringer Becken. - Z. geol. Wiss., 15(4): 485-494, 8 Abb., Berlin

$\square \bullet$ Gebhardt, H.; Hugenroth, P. \& Meyer, B. (1969): Pedochemische Verwitterung und Mineralumwandlung im Trachyt-Bims, Trachyt-Tuff und in den Tuff-Mischsedimenten der Laacher Eruptionsphase. - Göttinger Bodenkdl. Ber., 11: 1-83, 14 Abb., 7 Tab.; Göttingen [darin: Hünstollen (b. Göttingen), Leine (b. Northeim), Lutteranger (Unter-Eichsfeld), Hoher Meißner (Bischhausen)]

-Grupe, Heinrich (1962): Die ältesten Ackerböden des Kreises Hofgeismar. - Heimatjahrbuch. f. d. Landkreis Hofgeismar, 1963: 53 - 58, 1 Kt.; Hofgeismar [Lößablagerungen der Region als frühgeschichtliche Ackerbau-Standorte]

$\square$ Grupe, Marianne \& Kunz, Herbert (1993): Bodenuntersuchungen im Bereich des UBA-Meßnetzes als Bestandsaufnahme zur Beweissicherung von Umweltveränderungen. - Texte, Umweltbundesamt, 9360; 319 S., hier: S. 172-199; (Umweltbundesamt) Berlin 1993

[Kap. 3.10 Probenahmestelle Herleshausen; alle Bodenprofile auf Bl. 4926 Herleshausen]

- •Grupe, O. (1923): Zur Entstehung des Molkenbodens. - Internationale Mitteilungen f. Bodenkunde, 13(3-4): 99-106; Berlin

[Diskussion über Genese der Molkenböden im Solling, Reinhardswald, Bramwald] 
-Hase, D [ietrich] \& Meyer, B[runk] (1969): Feuchte-Jahresgang, Wasser-Bewegungen u. -Bilanzen in dicken Würmlöß-Decken und ihren holzänen Böden (Parabraunerde, Griserde, Feuchtschwarzerde) bei unterschiedlichen Grundwasserständen im Raum Niedersachsen. - Göttinger Bodenkdl. Ber., 11: 85-183, 7 Abb., 7 Tab.; Göttingen

[Umgebung Einbeck, Hollenstedt b. Northeim, Rosdorf b. Göttingen]

-Haubenthal, Christof (1978): Über Schwarzerden in der Niederhessischen Senke. - Geol Jb. Hessen, 106: 319-366, 20 Abb., 17 Tab., Taf. 25; Wiesbaden - auch als Diss. Univ. Bonn 1977

[Untersuchungen im Dreieck Fritzlar - Wichdorf - Kirchbauna]

- $\square$ Hocke, Richard (1995): Waldbodenzustand in Hessen. - Hess. Landesanstalt f. Forstwissenschaft, Waldforschung, Waldökologie. - Wald in Hessen, Forschungsbericht, 19, 136 S., 87 Abb., 39 Kt., 13 Tab., 18 Überischten; [Hrsg. Hess. Ministerium d. Innern, f. Landwirtsch., Forsten, Naturschutz, Wiesbaden ] (Hess. Landesanstalt f. Forstwiss. ...) Hann.-Münden

[HE, WMK - Bodenzustandserhebung u.a. im Werra-Meißner-Kreis, Forstamtsbezirke Witzenhausen, Bad Sooden-Allendorf, Hessisch Lichtenau, Reichensachsen]

QHofmann, W. \& Fiedler, H. J. (1986): Charakterisierung von Zersatzzonen und Schuttdecken in mitteleuropäischen Gebirgsböden. - Characterization of decomposition zones and detrital layers in Central-European mountains soils. - Chemie der Erde, 4ㅍ(1/2): 23-37, 9 Tab.; Jena [darin: Lokalitäten Thüringer Wald]

QHofmann, W. \& Fiedler, H. J. (1987): Zur bodentypologischen Charakterisierung mitteleuropäischer Gebirgsböden. - Soil-typlogical characterization of Central European mountainous soils. - Chemie der Erde, $\underline{\mathbf{4 6}}(1 / 2): 55-72,8$ Tab.; Jena [darin: Profil Oberhof 1/Thüringer Wald]

OHoppe, Walter (1943): Erläuterungen zur Übersichtskarte der Bodenarten Thüringens auf geologischer Grundlage. - 43 S., 2 Tab.; (Justus Perthes) Gotha

$\square$ Hornberger (1908): Ein Beitrag zur Kenntnis der Zusammensetzung von Buntsandsteinböden. - Z. f. Forst- und Jagdwesen, 40: 94-102; Berlin

[Bodenchemie 2 Podsolböden Kaufunger Wald, Revier Kattenbühl]

-Hoyningen-Huene, Paul Friedrich v. (1939): Die niedersächsischen Böden. Erläuterungen zum Bodenkundlichen Atlas von Niedresachsen. - Gesamttitel: Geßner, Ludwig [Hrsg.] \& Brüning, Kurt [Ltg.](1940): Bodenkundlicher Atlas von Niedersachsen - Grundlagen für Raumplanung und Landesplanung. - Teil 2: Textband. - Veröff. Wirtschaftswiss. Ges. z. Studium Niedersachsens, Reihe B (Forschungen), 17; 158 S., 7 Taf.; (Stalling) Oldenburg i. O.

-Hufmann, H. (1954): Mineralogische Untersuchungen an fünf Bodenprofilen über Basalt, Muschelkalk und Buntsandstein. - Beitr. Mineral. Petrogr., 4: 67-88, 3 Abb.; Berlin-Göttingen-Heidelberg [Untersuchte Profile i. Lkr. Göttingen; Brunsberg, Bramburg, Steinberg, Bremke, Sauenberg]

-Hugenroth, P. (1985): Exkursions-Führer zur Jahrestagung 1985 in Göttingen - Mitt. Dt. Bodenkdl. Ges., 42; 453 S., zahlr. Abb., Tab.; Göttingen [darin: Exkursionen Göttinger Wald, Holzerode, Reinshof, Drakenberg, Lößböden, Muschelkalkböden]

-Jörgensen, R. G.; Wolters, V.; Meyer, B. (1990): Einfluß des Mineralkörpers auf den mikrobiellen Kohlenstoffumsatz in unterschiedlich versauerten Böden eines Buchenwaldes. - Mitt. Dt. Bodenkdl. Ges., 62: 117-120, 3 Tab.; Göttingen [Göttinger Wald]

-Jung, Gernot (1968): Die Teillandschaften des Leinetales und seiner Randgebiete von Friedland bis Alfeld. - Diss. Univ. Göttingen 1968, 271 S. + sep. Kt.-Bd.; Göttingen 
[Landschaftsökologische Differenzierung nach „Ökotopen“(Bodenausgangsgestein und Bodentyp, Exposition, Bodenchemie, Bodenphysik); im Lkr. Göttingen [weiter unterteilte] Teillandschaften Kennbuchstaben D. Leine-Ilme-Senke, F Dransfelder Hochfläche, G. Northeim-Göttinger Wald]

-Jungmann, Walter Wilhelm (1980): Die Bodenkarte des Landes Hessen (1:25 000) mit Erläuterungen als zentraler Teil landschaftsökologischer Vorerkundung - dargestellt am Beispiel der topographischen Blätter 4921 Borken/Hessen und 4821 Fritzlar. - Diss. Univ. Marburg 1980, 168 S., graph. Darst., Kt., 10 Beil.

-Keller, Rudolf (1933): Unser Lößboden. - Heimatkalender Landkreis Hofgeismar, 1934: 40 - 43; Hofgeismar [Bezug auf Landkreis Hofgeismar]

OKieser, W. (1969): Geochemische Untersuchungen an Gesteinen und darauf entwickelten Böden des Raumes Thüringen. - Chemie der Erde, 묘(3/4): 211-293, 23 Abb., 39 Tab.; Jena [darin: Westthüringen, Thüringer Wald]

$\square$ Klinge, H.; Puffe, D.; Scheffer, Fr. \& Welte, E. (1962): Die Rendsinen der mitteldeutschen Berg- und Hügellandschaften (Leine-Weser-Bergland). - 3. Mitteilung: Humus und Stickstoff in den Rendsinen unter verschiedenen Standortsbedingungen. - Z. f. Pflanzenernährung, Düngung, Bodenkunde., 96(17): 46-62, 2 Abb., 10 Tab.; Weinheim

[darin: Meißner als einzigem regional konkretierten Untersuchungsgebiet]

-Klink, Hans-Jürgen (1964): Landschaftsökologische Studien im südniedersächsischen Bergland. Erdkunde, 18(4): 267-284, 7 Abb., 2 Photos, 1 Luftbild, 1 Kt.-Beil.; Bonn [darin: Bodenentwicklung Göttinger Wald]

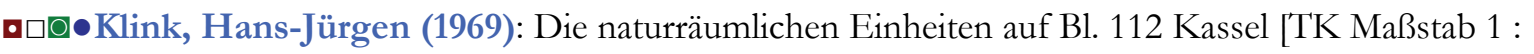
200.000]. - Reihe: Geographische Landesaufnahme 1 : 200.000, Naturräumliche Gliederung Deutschlands. - 108 S., 1 Kt., 1 Beil.-Kt. 1 : 200.000; (Bundesforschungsanstalt f. Landeskunde u. Raumordnung) Bonn-Bad Godesberg [HE, WMK, THÜ, NIE - darin Bodengeographie]

$\square$ Künzel, Artur (1970): Bodenkundliche und klimatische Verhältnisse im Gebiet von Witzenhausen und ihre Auswirkung auf den Obstanbau. - Das Werraland, 22(2): 25-26; Eschwege

-Ließ, Siegfried (1988): Charakterisierung des bodenchemischen Zustandes von Waldböden auf Basalt und Kalk mit unterschiedlichen Lößlehmablagerungen im Habichtswald. - Dipl.-Arb. [unveröff.] FB 13 Gesamthochsch. Kassel; 97 S., graph. Darst., Kt.; Kassel

-Linstow, Otto v. (1922): Zur Herkunft des Molkenbodens. - Int. Mitt. f. Bodenkde., 12: 173-179, [3] Tab.; Berlin-Wien [Molkenböden Reinhardswald; Genetische Interpretation]

-Lüdecke, Carl (1892): Untersuchungen über Gesteine und Böden der Muschelkalkformation in der Gegend von Göttingen. - Z. f. Naturwiss., $\underline{\mathbf{5}}$ [= 5. F., 주: 219-349, 11 Tab.; Leipzig - zgl. Diss. Univ. Leipzig Referat in: N. Jb. Mineral. etc, 1894 (Bd. I): 480-483 (A. Leppla); Stuttgart [Mineralogie, Geochemie, Bodenkunde]

$\square \bullet$ Maurmann, Grete (1931): Über roterdeähnliche Böden auf Kalkgesteinen Mitteldeutschlands. Chemie der Erde, $\underline{\mathbf{6}}$ : 77-116, 5 Tab.; Jena

Referat in: N. Jb. Mineral. etc., Referate; 1932 (Bd. II): 258 (Harrassowitz); Stuttgart [Unterer Muschelkalk - Plesseforst b. Göttingen; Zechsteinkarbonate b. [Bad]Sooden[-Allendorf]]

OMeng, Armin (1931): Die Beziehung der landwirtschaftlichen Bodennutzung in Thüringen zu den natürlichen Verhältnissen. - Mitt. Geogr. Ges. (f. Thür.), 38: 5-94, 4 Falt-Kt.; Jena 
[darin Kap.: „, Der Einfluß der orographischen Verhältnisse“, „Der Einfluß der geologischen Verhältnisse"]

- Meyer, Brunk (1955): Grundlagen und Ergebnisse einer Untersuchung der bodenkundlichen Verhältnisse in Südniedersachsen. - Diss. Univ. Göttingen 1955, 148 S., 19 gez. Bl., Abb. [Bodenprofile Umgebung Rosdorf b. Göttingen]

$\square$ Möller, Klaus \& Jäkel, Dieter (1993): Die geomorphologischen und bodenkundlichen Verhältnisse in der Umgebung von Eschwege in Nordhessen sowie ihre Bedeutung für planungsrelevante Sachverhalte. - In: Jacobshagen, V.; Möller, K. \& Jäkel, D. [Hrsg.]: Hoher Meißner und Eschweger Becken - Geowissenschaftliche und vegetationskundliche Charakteristik einer nordhessischen Landschaft. - Berliner geogr. Abh., 56; zgl. Beiträge zur Werra-Meißner-Forschung, III.; S. 199-288, 29 Abb., 5 Tab., 1 Kt.; (Selbstverlag Geomorphologisches Laboratorium FU Berlin) Berlin 1993

-Oelkers, Karl-Heinz (1970): Die Böden des Leinetals. Ihre Eigenschaften, Verbreitung, Entstehung und Gliederung - ein Beispiel für die Talböden im Mittelgebirge und dessen Vorland. - Geol. Jb., Beih., 99 (3. Beitr.): 71-152, 16 Abb., 5 Tab., Falt-Taf. 5-7, Fototaf. 8 u. 9; Hannover [darin: „Böden zwischen Göttingen und Friedland“] - zgl. Diss. Bonn 1968

-Oelkers, K. H. (1971): Die Erarbeitung von Gesetzmäßigkeiten der Bodenverbreitung Südniedersachsens, unter Verwendung der Bodenschätzung sowie geologischer und morphologischer Karten. - Z. dt. geol. Ges., 122: 1-10, 5 Abb.; Hannover [darin: Ideal-Profil Unter-Eichsfeld]

OPaul, Josef (2005): Permo-carboniferous palaeosols in Central Germany (Permokarbone Paläoböden in Mitteldeutschland). - Festschrift für Gerhard H. Bachmann, Teil II. - Hallesches Jb. Geowiss., Reihe B, Beihefte, 19, 214 S., zahlr. Abb.; hier S. 25-35, 11 Abb.; Halle [darin Profil Epichnellen/Bahnhof Förtha]

-Peinemann, N. \& Brunotte, G. (1982): Nährstoffgehalte von Lößboden-Toposequenzen in Südniedersachsen und Franken unter dem Einfluß der Bodenerosion. - Catena Supplement, 9: 307 318, 5 Abb.; Braunschweig-Cremlingen [Untersuchter Standorte: u.a. Rosdorf b. Göttingen]

$\square$ Preis, W.; Sauer, S.; Peter, M. \& Harrach, Th. (2001): Bodenkundliche Aussagekraft von Bodenwertzahlen der Bodenschätzung. [Vortragszusammenfassung] - Mit. Dt. Bodenkdl. Ges., 96(2): 545-546;

[Untersuchungen in hessischen Wasserschutzgebieten, u.a. Bad Soden-Allendorf]

$\square$ Puffe, Dieter \& Zerr, Walter (1989): Untersuchungen an Böden unter Grünland im Gebiet des Hohen Meißners. - Eichhofberichte, Reihe A, 13; 32 Bl., graph. Darst., Kt.; [Hess. Landwirtschaftl. Lehr- u. Forschungsanstalt] Bad Hersfeld

QRau, D. (1962): Rezente und fossile Lößböden im Thüringer Becken und in dessen Randgebieten (Exkursion B 4). - In: Viete, Günter [Hrsg.]: „Das Pleistozän im sächsisch-thüringischen Raum“ Exkursionsführer zur Herbsttagung 1962 vom 19. bis 21. Oktober 1962 in Leipzig und Erfurt - und Kurzreferate der Vorträge anläßlich des 2. Treffens der Sektion Quartärgeologie am 18. Oktober 1962 in Leipzig. - Exkursionsführer u. Veröff. Ges. geol. Wiss. DDR, 12; S. 145-153, 1 Abb.; Berlin 1962 [darin: Aufschlüsse Burgtonna, Gotha, Körner, Mühlhausen]

QRau, Dietrich (1965): Untersuchungen zur Morphologie und Genese der Lößböden im Thüringer Becken. - Abh. Zentral. Geol. Instituts, 4: 1-71, 12 Abb., 14 Tab.; Berlin - zgl. Diss. Univ. Jena

ORau, Dietrich (1969): Untersuchungen an rezenten und fossilen Lößböden in Thüringen. - Geologie, 18(6): 691-699, 2 Abb., 1 Tab.; Berlin

[darin: Körner] 
QRau, Dietrich (1974): Böden [in Thüringen]. - In: Hoppe, Walter \& Seidel, Gerd [Hrsg.]: Geologie von Thüringen [Bezirke Erfurt, Gera, Suhl]. - S. 965-895, Abb. 194-200; (Haack) Gotha-Leipzig 1974

QRau, Dietrich \& Heide, Klaus (1966): Über Tonmineraluntersuchungen an thüringischen LößBodentypen. - Geologie, 15(7): 833 - 840, 4 Abb., 1 Tab.; Berlin [darin: Bodenprofil Lokalität Körner/Unstrut-Hainich-Kreis]

-Ricken, W. \& Meyer, B. (1982): Lößbürtige Böden des Jung-Quartärs zwischen Harz und Leine Beziehungen zur Quartär-Chronostratigraphie; Relief-Geschichte der Landschaft, fluviatilen Sedimentation, Paläoklimakunde und Variation der holozänen Prozesse der Bodenbildung. - Bericht über die Exkursion des Arbeitskreises „Paläoböden“ der Deutschen Bodenkundlichen Gesellschaft am 16. und 17.10.1982. - Mitt. Dt. Bodenkdl. Ges., 34: 249-268, 6 abb.; Göttingen [darin: Tongrube zw. Göttingen u. Rosdorf; Kiesgrube b. Reinshof S' Göttingen]

$\square$ Rissiek, Rolf (1985): Feuchtstandorte am Hohen Meißner. Konstituierende und charakterisierende Parameter. - Dipl.-Arb. [unveröff.] FB Geowissenschaften FU Berlin. - 102 S., 31 Abb., 6 Tab.

-Ritzkowski, Siegfried (1973): Böden des Tertiärs im nördlichen Hessen - Bodenkundliche Exkursionen. - Mitt. Dt. Bodenkdl. Ges., 17: 119 -122, 2 Abb.; Giessen [2 Aufschlüsse b. Vollmarshausen Bl. 47234 Oberkaufungen]

- Rohdenburg, H.; Meyer, B.; Willerding, U. \& Jankuhn, H. (1962): Quartärgeomorphologische, bodenkundliche, paläobotanische und archäologische Untersuchungen an einer Löß-SchwarzwerdeInsel mit einer wahrscheinlich spätneoltihischen Siedlung im Bereich der Göttinger Leineaue. Göttinger Jb., 1962: 36 - 56, 6 Abb., 2 Tab., 1 Foto; Göttingen

-Rohdenburg, Heinrich \& Meyer, Brunk (1963): Rezente Mikroformung in Kalkgebieten durch inneren Abtrag und die Rolle der periglazialen Gesteinsverwitterungen. Eine geomorphologische Auswertung von Bilanzanalysen an Bodenprofilen. - Z. Geomorph., N.F., 7: 130 - 146, 5 Abb.; Berlin [Boden-Catena Göttinger Wald]

- •Rohdenburg, Heinrich \& Meyer, Brunk (1968): Zur Feinstratigraphie und Paläopedologie des Jungpleistozäns nach Untersuchungen an südniedersächsischen und nordhessischen Lößprofilen. (Löß-Forschungen in Südniedersachsen und Nordhessen). - Göttinger bodenkdl. Ber., 2: 1-135, 25 Abb., 12 Tab.; Göttingen - auch: Landschaftsgenese und Landschaftsökologie, $\underline{\mathbf{3}}$ : 1-89; Braunschweig 1979

[Südniedersachsen, Raum Kassel]

- $\square \bullet$ Rohdenburg, H. \& Meyer, B. (1968): Zur Datierung und Bodengeschichte mitteleuropäischer Oberflächenformen (Schwarzerde, Parabraunerde, Kalksteinbraunlehm): Spätglazial oder Holozän?. Gött. Bodenkdl. Ber., ㅁ: 127-212, 12 Abb.; Göttingen

[darin: Baunatal-) Großenritte b. Kassel, Bischhausen/WMK, Luttertal b. Göttingen]

-Rühl, Arthur (1973): Waldvegetationsgeographie des Weser-Leineberglandes. - Veröff.

Niedersächsischen Instituts f. Landeskunde u. Landesentwicklung a.d. Univ. Göttingen - Reihe A:

Forschungen z. Landes- u. Volkskde. - zgl. Schr. Wirtschaftswiss. Gesellschaft z. Studium

Niedersachsens e.V., N.F., 101. - VIII, 95 S., 3 Kt.-Beil.; (Wurm) Göttingen

[Bodenausgangsgestein, Bodentyp und Vegetation]

-Scheffer, Friedrich \& Meyer, Brunk (1958): Bodenkundliche Untersuchungen an neolithischen Siedlungsprofilen des Göttinger Leinetalgrabens. - Göttinger Jb., 1958: 3 - 39, 3 Abb.; Göttingen

- •Scheffer, F.; Meyer, B. \& Kalk, E. (1958): Mineraluntersuchungen an Würm-Löß südniedersächsischer Lößfluren als Voraussetzung für die Mineralanalyse verschiedener 
Lößbodentypen. - Chemie der Erde, 19(4): 338-360, 6 Abb., 3 Tab.; Jena

[Raum Hildesheim - Leinetalgraben (Göttingen) - Kassel; ohne konkrete Lokalitäten]

-Scheffer, Friedrich \& Meyer, Brunk (1959): Ein bodenkundlicher Beitrag zur Grabung im Muschelkalkgebiet des Hünstollens bei Göttingen. - Göttinger Jb., 1959: 3 - 8, 3 Abb., 1 Tab.; Göttingen

-Scheffer, F.; Welte, E. \& Meyer, B. (1960): Die Rendsinen der mitteldeutschen Berg- und Hügellandschaften (Leine-Weser-Bergland). - 1. Mitteilung: Genese und Verbreitunsbedingungen der Rendsinen. - Z. f. Pflanzenernährung, 90(1/2): 18-36, 5 Abb., 4 Tab.; Weinheim [darin: Göttinger Wald]

-Scheffer, F.; Welte, E. \& Meyer, B. (1962): Die Rendsinen der mitteldeutschen Berg- und Hügellandschaften (Leine-Weser-Bergland). - 2. Mitteilung: Fraktur, Nichtkarbonatgehalt und spezifische Auflösungsgeschwindigkeit des Kalkgesteins als bestimmende Größen der Bodenentwicklungsgeschwindigkeit. - Z. f. Pflanzenernährung, 98(1): 1-17, 3 Abb., 2 Tab.; Weinheim [darin: Göttinger Wald]

- $\square$ Schönhals, Ernst (1954): Die Böden Hessens und ihre Nutzung - mit einer bodenkundlichen Übersichtskarte 1 : 300 000. - Abh. Hess. L.-A. Bodenforsch., 2; 288 S., 25 Abb., 60 Tab., 15 Taf.; Wiesbaden

aSchrader, Ludolf (1983): Schwarzerdevorkommen in Hessen. - Geol. Jb. Hessen, 111: 315 - 323, 1 Abb.; Wiesbaden [darin: Vorkommen a. Bl. 4622 Kassel-West, 4722 Niederzwehren, 4821 Fritzlar]

OSchramm, Herbert A. (1995): Böden [in Thüringen]. - In: Seidel, Gerd [Hrsg.]: Geologie von Thüringen. - 1. Aufl.; S. 495-512, 1 Abb.; Stuttgart 1995

OSchramm, Herbert A. (2003): Böden [in Thüringen]. - In: Seidel, Gerd [Hrsg.]: Geologie von Thüringen. - 2., neu bearb. Aufl.; S. 531-547, 1 Abb.; Stuttgart 2003

OSchramm, H.; Pohl, A.; Wunderlich, J. \& Bischoff, R. (1977): Atlas der Schwermetallgehalte Thüringer Böden $1: 400.000$ - Hintergrundwerte für Schwermetalle und Arsen in Oberböden und bodenbildenden substratentypischen Bodengesellschaften. - 58 S., überwgd. Karten ua. Bodenübersichtskt. Thüringen 1:400.000 (BÜK 400), 46 x 64 cm; [Hrsg. Thür. Landesanst. f. Umwelt u. Geologie i. A. d. Thür. Ministeriums f. Landwirtsch., Natursch. u. Umwelt] Jena

OSee, K. v. (1921): Beobachtungen an Verwitterungsböden auf Kalksteinen, ein Beitrag zur Frage der Rendzinaböden. - Internationale Mitteilungen f. Bodenkunde, 11: 85-104, [2] Tab.; Berlin [Untersuchte Standorte: I. Wippertal b. Kirchworbis; Ohmgebirge: II. Trippelberg; III, IV. Kälberberg; V., VI. Langenberg]

-Semmel, Arno (1976): Die Beziehungen zwischen Relief, Gestein und Böden in hessischen Buntsandsteinlandschaften. - Z. Geomorph., N.F., Suppl.-Bd. 24: 23 - 32, 4 Abb.; Berlin-Stuttgart

-Siebner, Clemens Stephan (2000): Wasserbewegung und Stofftransport in Pelosolen am Beispiel des Südniedersächsischen Röts (Oberer Buntsandstein). - Göttinger Bodenkundl. Ber., o. Z.; X, 115 S., 2; 20 Abb., 13 Tab i. Text; Anh. m. Tab.; zgl. Diss. Univ. Göttingen 2000

[Untersuchg. a. Bl. 4525 Reinhausen [Friedland], 4526 Gelliehausen [Gleichen]]]

-Thöle, Rolf \& Meyer, Brunk (1979): Bodengenetische und -ökologische Analyse eines RepräsentativAreals der Göttinger Muschelkalk-Scholle als landschaftsökologische Planungsgrundlage. - Göttinger bodenkundliche Berichte: 59: 1-230, 15 Abb., 17 Tab., Tab.-Anhang m. Abb. (17 Bodenprofile); Göttingen - zgl. Diss. Univ. Göttingen [Göttinger Wald, 17 Bodenprofile] 
- •Vogel von Falckenstein, K. (1914): Die Molkenböden des Bram- und Reinhardswaldes im Buntsandsteingebiet der Oberweser. - Int. Mitt. f. Bodenkde., 4: 105-137, 4 Abb., 6 Tab.; Berlin-Wien [Stagnogley-Bodenbildung auf Buntsandstein-Ausgangsgestein; 4 Lokalitäten Bramwald, 6 Lokalitäten Reinhardswald]

OWätzel, Alfred (1995): Ein Geotop des Jungquartärs im Unstrut-Hainich-Kreis - die ehemalige Ziegeleigrube Körner. - Beitr. Geol. Thüringen, N.F., 2: 141-151, 3 Abb., 1 Tab., 2 Taf.; Weimar [Referenzprofil Löß- und Bodenstratigraphie von Thüringen]

- $\square$ Wagner, Julius (1961): Hessen. - Reihe: Harms Landeskunde, Bd. İ; 441 S.; 89 Abb. u. Kt.-Skizz. sowie Diagr., 16 Farb-Taf.; (List) München [darin: „Die physisch-geographischen Verhältnisse“: S. 14-29, Abb. 1-5 „Geologie und Morphologie“; S. 37-39 „Die Böden“; S. 40-45, Abb. 6 „Gewässer und Talbildung“]

-Walter, Michael \& Brosche, Karl-Ulrich (1982): Zur Bedeutung der Lößstratigraphie für die Rekonstruktion des jungpleistozänen Klimas im nördlichen Mitteleuropa am Beispiel norddeutscher Lößprofile. - Ber. Naturhist. Ges. Hannover, 125: 97-159, 15 Abb., 8 Tab.; Hannover [Bezug u.a. 2 Profile im Werra-Meißner-Kreis: Eschwege, Frauenborn]

-Wildhagen, Holger (1972): Holozäne Bodenentwicklung, Sedimentbildung und Geomorphogenese im Flussauen-Bereich des Göttinger Leinetalgrabens. - Diss. Univ. Göttingen 1972, 158 S.; s.a. Wildhagen, Holger \& Meyer, Brunk (1972): Holozäne Boden-Entwicklung, Sedimentbildung und Geomorphogenese im Flussauen-Bereich des Göttinger Leinetalgrabens - 1. Spätglazial und Holozän bis zum Beginn der eisenzeitlichen Auenlehm-Ablagerung. - (Übergeordn. Titel: Ergebnisse neuerer Auenforschungen im Leinegraben-Gebiet). - Göttinger bodenkdl. Ber., 21: 1-75, 9 Abb., 5 Tab., 1 Falt-Taf. (3 Kt. 1-3); Göttingen s.a. Wildhagen, Holger \& Meyer, Brunk (1972): Holozäne Boden-Entwicklung, Sedimentbildung und Geomorphogenese im Flussauen-Bereich des Göttinger Leinetalgrabens - 2. Die

Auenlehmdecken des Subatlantikums. - (Übergeordn. Titel: Ergebnisse neuerer Auenforschungen im Leinegraben-Gebiet).- Göttinger bodenkdl. Ber., 21: 77-158, 6 Abb., 3 Tab., 2 Falt-Taf. (Kt. 4-9 Kt.); Göttingen -

$\square$ Wildhagen, Holger (1998): Bodenkundliche Standortbeschreibungen der Versuchsflächen des Fachbereichs. - Univ./Ghs. Kassel, Fachbereich 11, Fachgebiet Bodenkunde, Arbeitsberichte, 1; 35 Bl., graph. Darst., Kt.; Witzenhausen

[Versuchsflächen a. Bl. 4625 Witzenhausen; Lage zwischen Hebenshausen und Eichenberg sowie Umgebung der Bahnüberführung B27 N’Arnstein]

-Wildhagen, Holger \& Meyer, Brunk (1972): Holozäne Boden-Entwicklung, Sedimentbildung und Geomorphogenese im Flussauen-Bereich des Göttinger Leinetalgrabens - 1. Spätglazial und Holozän bis zum Beginn der eisenzeitlichen Auenlehm-Ablagerung. - (Übergeordn. Titel: Ergebnisse neuerer Auenforschungen im Leinegraben-Gebiet). - Göttinger bodenkdl. Ber., 21: 1-75, 9 Abb., 5 Tab., 1 Falt-Taf. (3 Kt. 1-3); Göttingen - s. a. Wildhagen, Holger (1972): Holozäne Bodenentwicklung, Sedimentbildung und Geomorphogenese im Flussauen-Bereich des Göttinger Leinetalgrabens. Diss. Univ. Göttingen 1972

-Wildhagen, Holger \& Meyer, Brunk (1972): Holozäne Boden-Entwicklung, Sedimentbildung und Geomorphogenese im Flussauen-Bereich des Göttinger Leinetalgrabens - 2. Die Auenlehmdecken des Subatlantikums. - (Übergeordn. Titel: Ergebnisse neuerer Auenforschungen im LeinegrabenGebiet).- Göttinger bodenkdl. Ber., 21: 77-158, 6 Abb., 3 Tab., 2 Falt-Taf. (Kt. 4-9 Kt.); Göttingen s. a.: Wildhagen, Holger (1972): Holozäne Bodenentwicklung, Sedimentbildung und Geomorphogenese im Flussauen-Bereich des Göttinger Leinetalgrabens. - Diss. Univ. Göttingen 1972

-Wildhagen, Holger \& Brandt, Michael (2000): Zwei Boden-Dauerbeobachtungsflächen auf der Domäne Frankenhausen (Kreis Kassel). - Arbeitsbericht /Universität/Gesamthochschule Kassel, 
Fachbereich 11: Landwirtschaft, Internationale Agrarentwicklung u. ökologische Umweltsicherung Fachgebiet Bodenkunde, $\underline{\mathbf{3}}$; 36 Bl., 6 Abb.; Witzenhausen

\subsection{Geotourismus (Besucherbergwerke, Museen, Ausstellungen, Sammlungen, Schauhöhlen $u$.}

\section{a.)}

$\square \bullet$ Anonym (1942): Geologie in einem Turm < Basalt vom Meißner und vom Hohen Hagen in einer Gesteinsammlung sämtlicher Gesteine Deutschlands>. - Eschweger Tageblatt, 1942; Nr. 154 v. 4./5.06.1942; Eschwege

-Anonym (1960): Bergbaumuseum auf Burg Tannenberg? Sontraer Schülder trägt alte Geräte aus dem Kupferbergbau zusammen. - Bergbau im Hessenland, $\underline{\mathbf{1 0}}$ (10): 8-9, 5 Abb.

$\square$ Anonym (1989): Überregionale Medien am „Geologischen Wanderpfad“ des WTV Witzenhausen interessiert. - Das Werraland, 41(3): 43-44; Eschwege

-Anonym (1993): ... schon dagewesen? Auf den Spuren des Kalibergbaus - Das Kali-Bergbaumuseum Volpriehausen. - Die Weser, 67(1): 24, 1 Abb.; Bremen

-Anonym (2004): Bergbaurelikte bei Oberellenbach und noch viel mehr. - Knüllgebirgsbote, 2004(1): 6, 2 Abb.; Bad Hersfeld

[Lehrpfad Bergbaugeschichte „Baumbacher Hoch“; Lkr. Hersfeld-Rotenburg]

$\square$ Anonym (2008): <Eschwege> Ausstellung im Hochzeitshaus: Petrographie - Stein-Zeit in der Kunst. Maler Dieter Schönberg präsentiert vom 2. bis. 28. November auf einmalige Weise die Verschmelung von Natur, Wissenschaft und Kunst. - Werra-Rundschau, 2008; Nr. 253 v. 29.10.2008, 1 Abb.; Eschwege

-Anonym (o. J.): Auf den Spuren des Kalibergbaus in Südniedersachsen - Kali-Bergbaumuseum Volpriehausen. - 12 S., Abb.; ohne Ort

- $\square$ •Apel, Jürgen \& Rüppel, Heidi [Verfass. u. Hrsg.] (2005): Raus in die Natur - Tipps für den Sonntags-Ausflug im Dreiländereck Hessen - Niedersachsen - Thüringen. - 159 S., 111 Fotos, 34 Kt., 1 Zeit-Taf.; (LSRB-Verlag, Landschaftskundlicher-Studien-Reisebuch-Verlag) Witzenhausen [zahlreiche Ausflugstipps, auch zu Geotopen]

- $\square$ • Apel, Jürgen \& Rüppel, Heidi [Verfass. u. Hrsg.] (2005): Raus in die Natur - Tipps für den Sonntags-Ausflug im Dreiländereck Hessen - Niedersachsen - Thüringen. - 159 S., 111 Fotos, 34 Kt., 1 strat. Tab.; (LSRB-Verlag, Landschaftskundlicher-Studien-Reisebuch-Verlag) Witzenhausen [zahlreiche Ausflugstipps, auch Bergwerkrelikten, Ziel 66: Kupferschiefer/Schwerspatgrube Grube Gustav]

-Bös, Wolfgang \& Kunz, Reiner (1997): Geologische Sehenswürdigkeiten im Wolfhager Land. - 1 Faltplan [ m. zahlr. Abb., Routenplänen f. geol. Exkursionen, Abriß der Erdgeschichte]. - (Landkreis Kassel/Untere Naturschutzbehörde) Kassel

-Farrenkopf, Michael (1995): Weitere Teileröffnung des Werra-Kalibergbau-Museums in Heringen. Der Anschnitt, 47(6): 209-210, 1 Abb.; Bochum

@Göbel, Ulrich; Pippig, Matthias \&Ruck, Hartmut (2002): Erlebnis-Bergwerk Merkers. - 2. vollst. überarb. u. erw. Aufl.; 49 S., Ill.; (K+S Aktiengesellschaft) [Philippsthal] 
-Hamm, F. (1936): Die erdgeschichtliche Sammlung im Heimatmuseum zu Duderstadt. - Unser Eichsfeld, 31(12): 265-275, 4 Taf.; Duderstadt

-Hein, Christian \& Riek, Wolfgang (1981): Wo einst Pferde Kohle förderten: Kaufunger Göpelwerk „Ein Kulturdenkmal ersten Ranges“. - HA, 1981; Nr. 45 v. 23.2.1981; Kassel

$\square$ Hellmund, Wolfgang (1993): Geologen und Mineralogen zu Gast beim WTV Witzenhausen. - Das Werraland, $\underline{43}(4)$ : 86; Eschwege

[Geotourismus]

-Herbst, Detlef (1986): Das Kali-Bergbaumuseum in Volpriehausen. - Der Anschnitt, 38(3-4): 153-154, 1 Abb.; Bochum

- $\square$ Hessischer Fremdenverkehrsverband (1995): Glück auf in Hessens Unterwelt - alle Bergwerke und Schauhöhlen auf einen Blick. - 1 Faltblatt, zahlr. Ill, Kt., [Hess. Fremdenverkehrsverband e.V.] Wiesbaden

$\square$ Hotzler, Fritz (1987): Besucherbergwerk Grube Gustav im Höllental. - Das Werraland, 39(2): 30-31, 3 Abb.; Eschwege

0Jahn, Gerhard (1996): Vom Salz der Erde - Ein Erlebnisbericht vom Besuch der Kaligrube Merkers in Thüringen im März 1992. - Der Aufschluss, 45: 99-109, 12 Abb.; Heidelberg

•Jahnke, Hans (ca. 2000): Geopark Göttingen. - [28 S.], Ill.; (Selbstverlag Inst. u. Mus. Geol. Paläont. Univ. Göttingen) Göttingen

Q•Jansen, Ulrich; Köngishoff, Peter \& Steininger, Fritz F. [Hrsg.] (2004): Zeugen der Erdgeschichte - Ein Reiseführer zu den schönsten Fossilien in deutschen Naturkundemuseen. - 2., überarb. u. erweit. Aufl., 127 S., 251 Abb.; (Schweizerbart) Stuttgart [darin: Exponate a. d. Geowissenschaftlichen Zentrum der Universität Göttingen; Museum am Lindelbühl/Mühlhausen]

OKauter, Kurt \& Oschmann, Martin (1970): Zur Bedeutung der Bestände im Bezirksnaturkundemuseum Gotha. - Geologie, 19(6): 686-695, 7 Abb.; Berlin

-Kautzsch, Angelika (ca. 1992): Nordhessisches Braunkohle-Bergbaumuseum Borken Museumsführer. - 15 S., zahlr. Abb.; [Hrsg. Magistrat d. Stadt Borken] Borken (Hessen)

$\square$ Kirchmeier (1940): Ferienheim Friedrichstollen am Meißner. - Hessischer Gebirgsbote, $\underline{46}(1): 5$ - 6, 3 Abb.; Melsungen [darin Fotos: „Krippenlöcher“ bei Frankershausen am Meißner, Höllental am Meißner]

$\square$ Klepsch, Hugo (1980): Das Salzmuseum in Bad Sooden-Allendorf. - Das Werraland, 32(2): 27, 1 Abb.; Eschwege

$\square$ Kollmann, Karl [Red.](1989): Die Grube Gustav im Bilsteiner Bergbaurevier. - 1. Aufl.; 87 S., + 2 Kt., zahlr. Abb.; [Hrsg. Förderverein Besucherbergwerk „Grube Gustav“] Meißner-Abterode [Kupferschiefer-, Schwerspatbergbau]

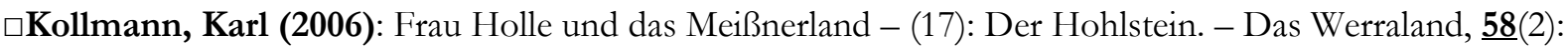
39-42, 6 Abb.; Bad Sooden-Allendorf

$\square$ Kollmann, Karl (2006): Frau Holle und das Meißnerland - (18): Der Hohlstein. - Das Werraland, $\underline{\mathbf{5 8}}(2)$ : 57-60, 5 Abb.; Bad Sooden-Allendorf 
$\square$ Künzel, Artur (1987): Geologischer Wanderweg eingeweiht . - Das Werraland, 39(4): 86; Eschwege [Umgebung Witzenhausen]

-Kunz, R.; Halfar, W.; Hoffmann, R. \& Schröder, A. (1992): Geologie des Wolfhagener Landes. (Führer durch Raum 10 und die Landschaft Geologie des Wolfhagener Landes). - Schr. Vereins Regionalmuseum Wolfhagen, Reihe Museumsführer, Bd. 10; 100 S., 56 Abb., 8 Taf.; (Verein Regionalmuseum) Wolfhagen

OLangenhan, A[1win] (1908): Sammler und Sammlungen - Sammlung A. Langenhan, Friedrichroda. Z. Mineral., Geol., Paläont.; 1908(6); Berlin

-Lüers, Tina (2003): Urzeitliche Strukturen aus zermahlenem Stein - Kunstausstellung der „Erdmalgruppe“ im Geowissenschaftlichen Zentrum der Universität. - Göttinger Tageblatt, 2003; Nr. 192 v. 19.08.2003; S. 13, 1 Abb.; Göttingen

-Meiburg, Peter (1992): Geschützte und schutzwürdige geologische Naturdenkmäler in Hessen. - In: Wiedenbein, Friedrich \& Grube, Alf [Hrsg.]: Geotopschutz und geowissenschaftlicher Naturschutz. Workshop Geotopschutz und Geowissenschaftlicher Naturschutz 05.03 .92 - 06.03.92. S. 30-31; Erlangen 1992

-Mende, Bruno (1991): Wanderführer Nordhessen und angrenzende Gebiete. - 669 S., zahlr. Abb.; (Bernecker) Melsungen [Überblick Regionalgeologie]

OMey, Eberhard (2004): Über die Entwicklung fürstlicher Naturalienkabinette in Thüringen. Gesamttitel: Kap. 9 - Von der fürstlichen Sammmlung zum Museum - Naturkundliches Sammeln und Naturwissenschaft - Geologie, Mineralogie, Paläontologie. - In: Scheumann, Konrad \& Jördis, Frank [Hrsg.]: Neu entdeckt: Thüringen $-<$ Land der Residenzen $<1485-1918><2$. Thüringer Landesausstellung Schloss Sondershausen, 15. Mai - 3. Oktober 2004>. - Katalog 2. - S. 178-193, zahlr. Abb.; Mainz 2004

OMistereck, Richard (2004): „Was Gott beschert, bleibt unverwehrt“ - Wandern auf dem Stedtfelder Bergbaulehrpfad. - Knüllgebirgsbote, 2004(1): 8; Bad Hersfeld

[Lehrpfad Geschichte d. Kupferschieferbergbaus am Nordrand d. Thüringer Waldes; Stedtfeld b. Eisenach]

OMöller, L. (1861): Naturhistorische Sammlungen in Mühlhausen und Umgebung. - Z. gesammt. Naturwiss., 17: 57-58; Berlin

[auch geowiss. Sammlungen]

-Mühlhausen, Fritz (1962): Kasseler Naturkundemuseum erwarb Cornberger Fährtenplatten. Hessischer Gebirgsbote, 63(3): 35-36, 2 Abb.; Melsungen [Chirotherienfährten a. d. Cornberger Sandstein]

OMüller, Johannes (1938): Naturschutz auf dem Eichsfelde. - Unser Eichsfeld, 33(3): 54-61, 3 Abb.; Duderstadt [darin: Zechstein-Dolomitfelsen am Hasenwinkel b. Fretterode]

$\square$ Namenskürzel (B) (1962): Kammerbacher Höhle wird ausgebaut - See erhält Unterwasserbeleuchtung./Bauarbeiten werden einige Monate dauern. - Werra-Rundschau , 1962; Nr. 1 v. 2.1.1962, [S. 6], 2 Abb.; Eschwege

- $\square$ Namenskürzel (HC) (1963): Sontra pflegt seine Bergbautradition - Barbarastollen als Erinnerungsstätte geweiht /Historischer Festzug zum Siedlerjubiläum. - Werra-Rundschau, 1963; Nr. 129 v. 6.06.1963, S. 3, 2 Abb.; Eschwege [Erinnerung an den Schwerspat- und Kupferschieferbergbau im Richelsdorfer Gebirge] 
-Namenskürzel (d)(1975): .../Alte Braunkohlenzeche wird Museum - Kreis Kassel richtet den historisch wertvollen Roßgang in Kaufungen her. - HA, 1975; Nr. 116 v. 22.5.1975; Kassel

$\square$ Namenskürzel (cc) (1978): Badestadt erhält die berühmte „Salzbibel“ - 3bändiges Werk als Reproduktion fürs Salzmuseum. - Werra-Rundschau, 1978; Nr. 88 v. 15./16.04.1978, S. 5, 1 Abb.

-Namenskürzel (rmy)(1985): Einzigartiges Museum für Bundesrepublik: Zeugnis des Kalibergbaus. HNA - Northeimer Neueste Nachrichten, 1985; Nr. 221 v. 24.9.1985; Kassel [Kalibergbaumuseum Volpriehausen, Lkr. Northeim]

$\square$ Namenskürzel (k)(1987): Spezial-Wanderpfad ist fertig - Ausflug in die Geologie. - HNA, 1987; Nr. 169 v. 24.7.1987; Kassel

[Geologie-Wanderpfad Gelstertal-Witzenhausen]

-Namenskürzel (hro)(1992): Braunkohle-Bergbaumuseum [Borken]: Einblick in die Welt unter Tage. HNA, 1992; Nr. 242 v. 16.10.1992; Kassel

$\square$ Namenskürzel [S.F.](1998): Neuer Weg durch das Naturschutzgebiet „Hielöcher“. - Das Werraland, 50(4): 90, 1 Abb.; Eschwege [Geotourismus]

-Namenskürzel (mic) (2005): Geologiepfad am Hohen Hagen eröffnet - Investitionsvolumen von 60.000 Euro / Konzept stammt von Geographin. - Göttinger Tageblatt, 2005; Nr. 91 v. 20.04.2005; S. 13, 1 Abb.; Göttingen

$\square$ Naumann, Peter (1991): Besucherbergwerk „Grube Gustav“. - Hessischer Gebirgsbote, 92(3): 89; Melsungen

-Naumann, Peter (1995): Das Sandsteinmuseum Kloster Cornberg. - Hessischer Gebirgsbote, 96 (4): 169; Melsungen

$\square$ Pujiula, Franzisco (2008): Bilder von leuchtenden Gesteinen - Dieter Schönberg stellt im Hochzeitshaus 40 Werke aus, die eine verborgene Welt zeigen <Ausstellung Petrographie>. - WerraRundschau, 2008; Nr. 257 v. 3.11.2008, 2 Abb.; Eschwege

OPustal, Ina [Red.](2005): Thüringen Untertage - Ein Exkurs zu Schauhöhlen, Besucherbergwerken und GeoMuseen. - 317 S., Ill. Graph. Darst., Kt.; [Hrsg. Thür. Landesanst. f. Umwelt u. Geologie, i. Zus.Arbeit m. Bergmannsverein „Otto Ludwig Krug v. Nidda“ e.V. u. Thür. Höhlenverein e.V.] Jena

-Rimbach, M.; Schönhut, Horst \& Schröder, Hans (1998): 100 Jahre Braunkohle Borken - der Borkener Braunkohle-Rundweg. Wegweiser mit Kurzbeschreibung des Borkener Braunkohlereviers. 120 S., zahlr. Abb.; [Hrsg. Magistrat d. Stadt Borken u. Geschichtsverein Borken] Borken (Hessen)

$\square$ Rüppel, H. \& J. Apel (2001): Naturpark Meißner und Kaufunger Wald - Geologische Wanderkarte 1 : 100000 - Mit Erläuterungen zu den Natursehenswürdigkeiten entlang der Rad- u. Wanderwege auf beiden Seiten der Faltkarte. - (Landschaftskundlicher-Studien-Reisebuch-Verlag) Witzenhausen

$\square$ Rüppel, Heidi \& Apel, Jürgen (2002): Rad- und Wander-Führer - Auf Entdeckungstour im WerraBergland rund um Meißner und Kaufunger Wald. - Bd. 1 Hannoversch Münden, Witzenhausen, Bad Sooden-Allendorf. - 152 S., 33 Abb., 15 graph. Darst., 19 Kt.; (Landschaftskundlicher StudienReisebuch-Verlag) Witzenhausen 2002

- $S$ Schaake, Manfred (1994): Kali- und Bergbaumuseum: Vom „harten Brot“ der Kumpel. - HNA, 1994; Nr. 127 v. 6.6.1994; Kassel

Kali- und Bergbaumuseum Heringen; Hessisches Kalirevier] 
QSchäfer, Daniela (2000): Geologische Route durch den Naturpark „Eichsfeld-Hainich-Werratal“ - ein Beitrag zum Geotourismus und Geotopschutz in Thüringen. - Geowiss. Mitt. Thüringen, Beih. 10 163-166, 3 Abb.; Weimar

$\square$ Schlingloff, Wilhelm (1982): Geweih- und Knochengeräte im Eschweger Heimatmuseum. - Das Werraland, 34(2): 21-22, 3 Abb.; Eschwege

$\square$ Schmidt, Hans Heinrich (1989): Beschreibung des Besucherbergwerks [Grube Gustav]. - In: Kollmann, Karl [Red.]: Die Grube Gustav im Bilsteiner Bergbaurevier. - 1. Aufl.; 68-74, 7 Abb., [1 Tab.]; [Hrsg. Förderverein Besucherbergwerk „Grube Gustav“] Meißner-Abterode 1989

OSchmidt, Helmut (1992): In der Unterwelt des Werratales - Erlebnisbergwerk Merkers hautnah! - Das Werraland, 44(3): 70-71, 2 Abb.; Eschwege - Geotourismus

- $\square$ Schmitt, Gerhard E. (1990): Naturkundliche Wanderungen in Hessen. - 158 S., 62 Abb., Kt.; (Hitzeroth) Marburg

[Darin: Werra-Meißner-Kreis; Blaue Kuppe, Erdfalltrichter bei Trendelburg]

- Schmidt, Hans-Heinrich (1994): Hessische Besucherbergwerke, Schauhöhlen und Bergbaumuseen. In: Mitteilungen des Nassauischen Vereins für Naturkunde, 33: 9-14; [Nassauischer Verein für Naturkunde] Wiesbaden

-Schröder, Hans \& Wächtler, Eberhard (1993): Das Nordhessische Braunkohle-Bergbaumuseum Borken - ein Spiegel der regionalen Montangeschichte. - Der Anschnitt, 45(1): 33-36, 1 Abb.; Bochum

$\square$ Seib, Gerhard (1986): Ein neues Besucherbergwerk in Hessen [Grube Gustav b. Abterode, WerraMeißner-Kreis]. - Hessische Heimat, $\underline{\mathbf{3 6}}$ (4): 153-154, Abb. 46-47; Marburg/L.

- Sindermann, Sabine (2004): Kreisheimatmuseum Rotenburg an der Fulda - Der Erdgeschichte auf der

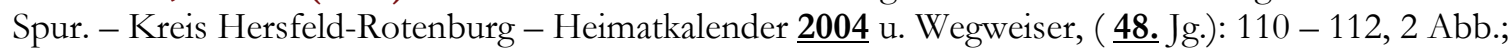
Bad Hersfeld

OSlotta, Rainer (1992): Denkmäler des Bergbaus, Bergbaumuseen und Besucherbergwerke in Deutschland - Ein Sachstandsbericht. - Der Anschnitt, 44(4): 123-132, 7 Abb., 1 Kt.; Bochum [in der Karte verzeichnet: Kalibergwerk Bleicherode; Kittelsthal, Schwerspatgrube Wolfsberg, Kalibergwerk Merkers, Schmalkalden-Asbach (Eisenerzgrube Finsterthal), Friedrichroda (Gipsbergbau, Marienglashöhle), Meißner-Abterode (Schwerspat-Grube Gustav)]

OSpecht, Gerhard (2005): „Steinreiche Werra“ - Im Gerstunger Heimatmuseum. - Das Werraland, 푸(3): 62, 1 Abb.; Eschwege

[Ausstellung]

-Steinert, Arne (1996): Industriemuseum Saline Luisenhall - Konzeption und Perspektive. - In: Just, Rüdiger \& Meißner, Uwe [Hrsg.]: Das Leben in der Saline - Arbeiter und Unternehmer. Internationale Salzgeschichtetagung. - Schriften u. Quellen z. Kulturgeschichte d. Salzes, $\underline{\mathbf{3}}$. - 356 S., Ill., graph. Darst.; hier S. 330-338; (Halle) Saale

[Aufsatzsammlung, Internationale Salzgeschichtetagung: Technisches Halloren- und Salinemuseum, Halle (Saale)]

-Steinert, Arne (1997): Konzepte der Musealisierung von Technik und Arbeit: Museale Erschließung Perspektive für das Industriedenkmal Saline Luisenhall [Göttingen]. - Studien zur Technik-, Wirtschafts- und Sozialgeschichte, 10; 397 S., 74 Abb.; (Lang) Frankfurt/M. u.a. - zgl. Diss. Univ. Göttingen 1996 Referat (Mende) in: Der Anschnitt, $\underline{\mathbf{5 1}}(2-3):$ 126-127; Bochum 1999 
ه'Thonicke, Frank (1991): Besucherbergwerk: Salzkristalle funkeln wie Diamanten. - HNA, 1991; Nr. 181 v. 7.8.1991; Kassel [Besucherbergwerk Merkers, Thüringer Werra-Kalirevier]

dTrott, Karl (1992): Steine.... Die bekanntesten Gesteinsblöcke an Wanderwegen im heimatlichen Bereich. - Knüllgebirgsbote, 1992(2): 38-39, 4 Abb.; Bad Hersfeld

-Trzciok, Isabel (2005): Arbeiten zwischen Menschen und Steinen. - Dr. Mike Reich ist Kustos der Sammlungen der Fakultät für Geowissenschaften <Universität Göttingen>. - Göttinger Tageblatt, 2005; Nr. 176 v. 30.07.2005; S. 32, 1 Abb.; Göttingen

OWagenbreth, Otfried (1970): Die Marienhöhle bei Friedrichroda und ihre Wiederherstellung als Schauobjekt - Landschaftspflege u. Naturschutz i. Thür., $\underline{7}(1 / 2):$ 19-26, 3 Abb.; Jena

OWerneburg, Ralf \& Kroniger, Martin (1994): Höhepunkte der Schleusinger Sonderausstellung „THÜRINGER SAURIER“ (Triassic Park). - Veröff./ Naturhist. Museum Schleusingen, 9: 125-131, 12 Abb.; Schleusingen

OWerneburg, Ralf \& Kroniger, Martin (1997): Höhepunkte der Schleusinger Sonderausstellung „DINOSAURIER - Knochen, Bilder und Plastiken“. - Veröff./ Naturhist. Museum Schleusingen, 12: 73-76, 9 Abb.; Schleusingen

-Wollemann, Ewa Janina (2002): Der Geologie- und Bergbau-Pfad am Hohen Hagen (Südniedersachsen) - Konzeption, Rahmenbedingungen und Realisierung. - Dipl.-Arb. [unveröff.] Geogr. Inst. Univ. Göttingen; IV, 89 S., Ill., graph. Darst., Anh.Geologie und Archäologie, Märchen und Sagen

\subsection{Geologie und Archäologie, Märchen und Sagen}

口[O•Apel, Jürgen \& Rüppel, Heidi [Verfass. u. Hrsg.] (2005): Raus in die Natur - Tipps für den Sonntags-Ausflug im Dreiländereck Hessen - Niedersachsen - Thüringen. - 159 S., 111 Fotos, 34 Kt., 1 strat. Tab.; (LSRB-Verlag, Landschaftskundlicher-Studien-Reisebuch-Verlag) Witzenhausen [zahlreiche Ausflugstipps, auch zu archäologisch-geologischen Sehenswürdigkeiten: Ziel 11 (Quarzit v. Großenritte) - Ziel 21 (Vossküppel/Naturpark Münden)]

OBehm-Blancke, Günter (1961): Das Paläolithikum in Thüringen. - Geologie, 10 (4/5): 551-569, 3 Abb.; Berlin [darin: Seebach-Höngeda, Burgtonna]

-Bernhard, Horst (1991): Geologisch bedingte Schäden an historischen Bauwerken aus Naturstein (Basalt-Tuff) im Staatspark Kassel-Wilhelmshöhe und deren Sanierung (Exkursion I am 6. April 1990) [112. Tagung des Oberrheinischen Geologischen Vereins in Bad Wildungen 1990].- Jber. Mitt. Oberrhein. Geol. Vereins, 푸 177-186, 3 Abb.; Stuttgart

-Brauns, Eduard (1969): Der Scharfenstein bei Dissen. - Hessischer Gebirgsbote, 70(1): 13, 1 Abb.; Melsungen

[Basaltfelsen S’ Gudensberg; Geologie, Vorgeschichte, Märchen/Sagen]

-Brauns, Eduard (1970): Der Blumenstein (Wichtelkirche) am Dörnberg. - Hessischer Gebirgsbote, 71(4): 74, 1 Abb.; Melsungen

[Basaltfelsen auf dem Dörnberg-Plateau; Geschichte der Befestigungsanlage, Märchen-Sagen] 
-Brauns, Eduard (1971): Von den Riesensteinen (Menhiren) in Nordhessen. - Hessischer Gebirgsbote, 72 (1): 5 - 7, 4 Abb.; Melsungen

$\square$ Brauns, Eduard (1974): Der Karlsbrunnen in Eichenberg. - Hessischer Gebirgsbote, 725(3): 60-61, 1

Abb.; Melsungen

[auch Geologie u. Märchen]

-Brauns, Eduard (1974): Der „rote“ See in Dens. - Hessischer Gebirgsbote, 75(2): 36-37, 1 Abb.; Melsungen

[auch Geologie u. Märchen]

-Bunsen, R. \& Hausmann, J.F.L: (1854): Über das Vorkommen menschlicher Kunstprodukte in den Kalktufflagern der Gegend von Göttingen. - Studien Göttingischen Vereins bergmänn. Freunde, $\underline{\mathbf{6}}$ 96-102; Göttingen

-Follmann, Fritz (1970): Die Sage von der Teufelsmauer - Hessischer Gebirgsbote, 71(4): 82; Melsungen [,Teufelsmauer“ - Basaltgang im vulkanischen Tuff des Habichtswaldes]

-Grote, K.; Freese, H.-D. (Mitarbeit) (1982): Die Felsschutzdächer (Abris) im südniedersächsischen Bergland - Ihre archäologischen Funde und Befunde. - Nachrichten aus Niedersachsens Urgeschichte, 51: 17-40, 27 Abb., 2 Tab.; Hildesheim

[Archäologie; darin: Abris im Mittleren Buntsandstein des Lkr. Göttingen, mit Auflistung]

-Hausmann, J.F.L. (1856): Über das Vorkommen altdeutscher Kunstprodukte im Kalktuff von Rauschenwasser. - Studien Göttingischen Vereins bergmänn. Freunde, 7(1): 102-110; Göttingen

-Hellrung, Carl Ludwig (1844): Die goldene Mark Duderstadt - Wahrheit und Dichtung. - 288, 16 S., 1 Abb..; (Wagner) Duderstadt [darin S. 65-144: „Der Rhumesprung“ - S. 65-113, 1 Abb.: „I. Sein Dasein“; S. 113-132: „II. Die Götter der alten Sassen“; S. 132-144: „III. Die Sage vom Ruhmesprung“]

$\square$ Heynemann, Rudolf (1928): Hessen, das Land der hundert Bergwunder. Märchenberge und Zauberseen. - Die Weser, 7(4): 111-122, 1 Abb. [Roter See/Kaufunger Wald]; Bremen [Mystik und etwas Geologie]

QHotzler, Fritz (1991): Der Große Hörselberg - ein Wahrzeichen Westthüringens. - Das Werraland, 43 (3): 52-53, 1 Abb.; Eschwege

[Geologie und Sagenwelt]

$\square$ Kollmann, Karl (2002): Frau Holle und das Meißnerland - (2): Der Frauhollenteich [Teil 1]. - Das Werraland, $\underline{\mathbf{5 4}}(1)$ : 1-4, 6 Abb.; Bad Sooden-Allendorf

$\square$ Kollmann, Karl (2002): Frau Holle und das Meißnerland - (3): Der Frauhollenteich [Teil 2]. - Das Werraland, 54(2): 33-36, 3 Abb.; Bad Sooden-Allendorf

$\square$ Kollmann, Karl (2002): Frau Holle und das Meißnerland - (4): Der Frauhollenteich [Teil 3]. - Das Werraland, 54(4): 83-84, 3 Abb.; Bad Sooden-Allendorf

$\square$ Kollmann, Karl (2004): Frau Holle und das Meißnerland - (9): Die Kitzkammer. - Das Werraland; 56(1): 10-13, 5 Abb.; Eschwege

[Geologie, Sagen um die Kitzkammer; Säulenbasaltfelsen am Westhang des Meißner]

$\square$ Kollmann, Karl (2005): Frau Holle und das Meißnerland - (12): Der Altarstein und seine Umgebung. -

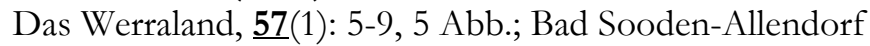

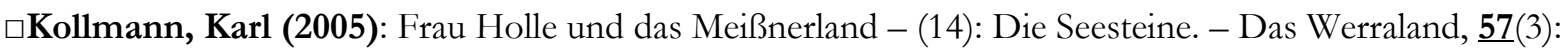
52-54, 4 Abb.; Bad Sooden-Allendorf 
$\square$ Kollmann, Karl (2005): Frau Holle und das Meißnerland - (15): Der Bär oder Todstein bei Abterode. Das Werraland, 57(4): 83-84, 3 Abb.; Bad Sooden-Allendorf

$\square$ Kollmann, Karl (2006): Frau Holle und das Meißnerland - (16): Die Hollsteine. - Das Werraland, $\underline{\mathbf{5 8}}(1)$ : 13-15, 5 Abb.; Bad Sooden-Allendorf

$\square$ Kollmann, Karl (2006): Frau Holle und das Meißnerland - (17): Der Hohlstein. - Das Werraland, $\underline{\mathbf{5 8}}(2)$ : 39-42, 6 Abb.; Bad Sooden-Allendorf

$\square$ Kollmann, Karl (2006): Frau Holle und das Meißnerland - (18): Der Hohlstein. - Das Werraland, $\underline{\mathbf{5 8}}(3)$ : 57-60, 5 Abb.; Bad Sooden-Allendorf

$\square$ Kollmann, Karl (2006): Frau Holle und das Meißnerland - (19): Der Mühlstein bei Wolftterode. - Das Werraland, 58 (4): 80-81, 2 Abb.; Bad Sooden-Allendorf

$\square$ Kollmann, Karl (2007): Frau Holle und das Meißnerland (20): Die Blaue Kuppe bei Eschwege. - Das Werraland, $\underline{\mathbf{5 9}}(1):$ 13-15, 2 Abb.; Bad Sooden-Allendorf

$\square$ Kollmann, Karl (2005): Frau Holle und das Meißnerland - Einem Mythos auf der Spur. - 167 S., zahlr. Abb.; [Hrsg. Hist. Ges. d. Werralandes u. Werratalverein] Eschwege [u.a. Sagen, Mythen, Märchen bezogen a. geol. Naturdenkmale]

$\square$ Landau, G. (1833): Der Hohlstein in Niederhessen. - Archiv für die Geschichte und Alterthumskunde Westphalens, $\underline{\mathbf{6}}(2 / 3):$ 315-318; Lemgo

[Höhlenkunde, Geologie u. Sagenwelt]

-Lange, W. (1925): Über Steine und Felsen im hessischen Volksglauben. - Hessischer Gebirgsbote, $\underline{\mathbf{3 1}}$ (3): $19-20$; Kassel

- Lepper, Jochen; Koch, Michale, Siewers, Ulrich \& Stephan, Hans-Georg (2002): EisenerzVorkommen im Solling, Reinhardswald und Bramwald (Südniedersachsen und Nordhessen) und deren geochemische Charkterisierung im Rahmen eines Archäometallurgie-Projekts. - Nachr. a. Niedersachsens Urgeschichte, 2: 51-63, 3 Abb., 1 Tab.; Stuttgart

-Linstow, Otto v. (1910): Der Seeburger See in Sage und Geschichte. - Hannoverland, [Bd. 4] 1910: 131134; Hannover

[darin: temporäre Inseln im Seeburger See]

-Loewer (Generalarzt I. Classe a. D.) (1893): Waffen und Geräthe der Steinzeit in Hessen in geologischer Beziehung. - Ber. Vereins Naturkde. z. Kassel, $\underline{\mathbf{3 8}}$ (1892/1893): 16-28; Kassel

OMallick, Ronzon (2001): Präzise Th/U-Datierung archäologisch relevanter Travertinvorkommen Thüringens. - In: WAGNER, G.[Hrsg.]: Frühe Menschen in Mitteleuropa - Chronologie, Kultur, Umwelt [Kolloquium 9.-11. März 2000 Heidelberg]. - Veröff. d. Vereins Homo Heidelbergensis von Mauer e.V. 1; 163 S., Abb., Kt.; hier: S. 77-89; (Shaker) Aachen 2001;

OMüller, Johannes (1940): Die Bedeutung der Bodenfunde in den Mergelgruben bei Heiligenstadt. Unser Eichsfeld, $\underline{\mathbf{3 5}}$ (7/8): 101-106, 1 Tab..; Duderstadt

-Mötzing, Kurt (1978): Quarzitdenkmäler in der Umgebung Kassels im Besonderen im Reinhardswald und Grenzsteine aus Quarzit. - Hessischer Gebirgsbote, 79 (1): 7 - 10, 4 Abb.; Melsungen [Tertiärquarzite der nördlichen Hessischen Senke]

-Mötzing, Kurt (1978): Verschiedene Auffassungen der Wissenschaft über Oberflächengebilde an und auf Steinen. - Hessischer Gebirgsbote, $\underline{79}$ (4): 136 - 138, 2 Abb.; Melsungen

[Nordhessische Tertiärquarzite als steinzeitliche Kulturdenkmäler] 
-Mötzing, Kurt (1979): Die Quarzitmenhire in Hessen. - Hessischer Gebirgsbote, $\underline{80}$ (1): 13 - 18, 3 Abb.; Melsungen

[Nordhessische Tertiärquarzite als steinzeitliche Kulturdenkmäler]

-Mötzing, Kurt (1977): Der Quarzit - Entstehung, Vorkommen, vielseitige Verwendung und volkskundliche Bedeutung. - Hessischer Gebirgsbote, 78(3): 84 - 86, 2 Abb.; Melsungen [Tertiärquarzite d. Kasseler Umgebung]

-Mötzing, Kurt (1978): Quarzite von volkskundlicher Bedeutung - Sagenbehaftete Nagelsteine, Näpfchensteine (Weckmichschüsseln, Vogtstein, Wiershäuser Stein) - Hessischer Gebirgsbote, $\underline{79}$ (3): 98 - 99, 2 Abb.; Melsungen

[Tertiärquarzite der nördlichen Hessischen Senke]

Q Müller, Johannes (1935): Ein Spiel der Natur, keine vorgeschichtliche Werkzeuge. - Unser Eichsfeld, 30: 97-98, 1 Abb.; Duderstadt

[Gesteine mit ,artefaktischem“, von Menschenhand geformten Aussehen]

$\square$ Namenskürzel (Werra-Rundschau) (1960): Sage und Geschichte um den Altarstein $<$ Hoher Meißner>. - Werra-Rundschau, 1960; Nr. 230 v. 28.9.1960, S. 3, 1 Abb.; Eschwege

-Otto, Bernhard (1966): Altes und Neues von der Rhumequelle. - Die Goldene Mark, 17 (3): 42-47, 1 Abb.; Duderstadt

[Bezugnahme a. Hydrogeologie; Geschichte, Mystik]

ORhode (1933): Die Funde in den Heiligenstädter Mergelgruben nach der naturwissenschaftlichen und prähistorischen Bedeutung. - Unser Eichsfeld, 28: 167-186, 3 Abb.; Duderstadt

-Rohdenburg, H.; Meyer, B.; Willerding, U. \& Jankuhn, H. (1962): Quartärgeomorphologische, bodenkundliche, paläobotanische und archäologische Untersuchungen an einer Löß-SchwarzwerdeInsel mit einer wahrscheinlich spätneoltihischen Siedlung im Bereich der Göttinger Leineaue. Göttinger Jb., 1962: 36 - 56, 6 Abb., 2 Tab., 1 Foto; Göttingen

- $\square$ Schneider, Peter (1985): Höhlensagen aus Hessen. - In: Verband der Deutschen Höhlen- und Karstforscher e.V. [Hrsg.]: Karst und Höhle 1984/1985. Beiträge zur Karst- und Höhlenforschung in Hessen. - S. 35-44; (Selbstverlag d. Verbandes) München 1985 [darin: Frau Hollenstein, Frau Holle-Teich a. d. Hohen Meißner]

$\square$ Schulze, Alfred (1969): Der Wolfstisch bei Hitzelrode - Zur Vor- und Frühgeschichte im Werraland. Das Werraland, 21(3): 37-40, 4 Abb.; Eschwege

$\square$ Seib, Gerhard (1989): Der Bergknappe zu Abterode. - In: Kollmann, Karl [Red.]: Die Grube Gustav im Bilsteiner Bergbaurevier. - 1. Aufl.; S. 75-77; [Hrsg. Förderverein Besucherbergwerk „Grube Gustav“] Meißner-Abterode 1989

OSinn, Wolfgang \& Weigel, Heinrich (1994): Der Hautsee mit der schwimmenden Insel. - Das Werraland, 46: 81-84, 3 Abb.; Eschwege [Landkr. Wartburg-Eisenach; auch Geologie und Archäologie, Märchen, Sagen]

- Sippel, Klaus (1993): Wandern und Kultur: Wanderweg zu archäologischen Denkmälern am Eisenberg. - Knüllgebirgsbote, 1993(4): 110-112, 3 Abb.; Bad Hersfeld [u.a. Bergbaurelikte, Eisenerz-, Alaungewinnung]

口Sippel, Klaus (1993): Hügelgräber, Bergwerksrelikte und die Wüstung Holnstein im östlichen Knüllvorland - Begleitheft zum archäologischen Wanderwerg am Eisenberg in der Gemeinde Neuenstein, Kreis Hersfeld-Rotenburg. - Archäologische Denkmäler in Hessen, 110; 15 S.; Abb., Kt.; (Abt. Archäol. u. paläontolog. Denkmalpflege i. Landesamt f. Denkmalpflege Hessen) Wiesbaden 
- $\square$ Sippel, Klaus (1999): Zur Archäologie und Geschichte des mittelalterlichen Kupferbergbaus bei Sontra. - In: Kollmann, Karl [Schriftltg.]: 500 Jahre Bergwerksordnung zu Sontra - 1499-1999. Beiträge z. Geschichte d. Stadt Sontra, 10: 51-66, 6 Abb.; [Hrsg. Magistrat Stadt Sontra] Sontra 1999

-Sippel, Klaus (2000): Ausgrabung eines spätmittelalterlichen Bergwerkstollens bei Sontra - ein archäologisches Denkmal des frühen Kupferschieferbergbaus in Osthessen. - Denkmalpflege \& Kulturgeschichte, 1: 57-61; Ill., graph. Darst.; Wiesbaden

aSippel, Klaus (2002): Bauteile von einer Förderhaspel aus einem spätmittelalterlichen Kupferschieferbergwerk im Richelsdorfer Gebirge/Bebra-Solz (Landkreis Hersfeld-Rotenburg). Hessen-Archäologie, 2001: 162-164; Ill; Stuttgart

-Sippel, Klaus (2005): Wirtschaftsarchäologische Geländeforschungen zum neutzeitlichen Bergbau und Hüttenwesen in Nordhessen - Ein Überblick über den Stand der Forschung zu Herstellungs- und Gewinnungsarten von Glas, Kupfer, Eisen, Alaun, Sand und Teer. - ZAM - Z. f. Archäologie d. Mittelalters, 33/2005: 103-122, 6 Abb.; Köln/Bonn

G'Toepfer, Volker (1978): Die paläolithischen Funde im Travertin von Burgtonna in Thüringen. Quartärpaläontologie, $\underline{3}: 175$ - 178, 2 Abb. ; (Akademie-Verlag) Berlin

$\square$ Wittmann, H. (1929): Der Wolfstisch bei Hitzelrode. - Das Werratal, $\underline{6}$ (1): 3-4, 1 Abb.; Eschwege [Naturdenkmal, Geologie u. Sagen, Märchen, Mystik; auch Bezugnahme a. „Pferdeloch“]

\subsection{Geologie und Poesie, Scherze, Humor}

$\square$ Anonym [„Der Werraschorsche“](1924): Das Leben ist jetzt recht gefährlich...<Gedicht $>$. - Das Werratal, 16): [96]; Eschwege

[Poetische Schilderung eines vermeindlichen Wieder-Ausbruchs des Vulkans der „Blauen Kuppe“ b. Eschwege]

$\square$ Anonym (1929): < Hoheneiche - Prähistorischer Fund bei Bauarbeiten an der Wegstrecke Hoheneiche - Netra: Fossile Knochen eines Fischsauriers (Ichthyosaurus) <Aprilscherz>. - Eschweger Tageblatt, 1929; Nr. 75 v. 30.03 .1929

$\square$ Anonym (1930): < Drohender Felssturz an der Plesse bei Wanfried $><$ Aprilscherz $>$. - Eschweger Tageblatt, 1930; Nr. 76 v. 31.3.1930; Eschwege

$\square$ Anonym (1930): < Heilquelle am Wichtelbrunnen nahe Reichensachsen erbohrt $><$ Aprilscherz $>$. Eschweger Tageblatt, 1930; Nr. 76 v. 31..3.1930; Eschwege

$\square$ Anonym (1931): <Wahrscheinlich Erdölquelle bei Schwebda entdeckt $><$ Aprilscherz $>$. - Eschweger Tageblatt, 1931; Nr. 76 v. 31.3.1931; Eschwege

$\square$ Anonym (1931): < Drohender Felssturz und neu entdeckte Thermalquelle an der „Blauen Kuppe" $^{\text {" }}><$ Aprilscherz $>$ - Eschweger Tageblatt, 1931; Nr. 76 v. 31.3.1931; Eschwege

¿Cloos, Hans (1947): Gespräch mit der Erde - Geologische Welt- und Lebensfahrt. - 407 S., 71 Taf.; (Piper) München

[Der Klassiker der poetischen Geologie! - darin S. 236-247 das Kap.: „Steine unter dem Kopfkissen“ - behandelt Thüringer Wald, Profil von Epichnellen [Bahnhof Förtha]] 
口Jäger, Willy (1923): Im Briefwechsel mit der „Blauen Kuppe“. - Eschweger Tageblatt, 1923; 26.6.1923; Eschwege

[Fiktiver Briefwechsel über Interessenkonflikt Steinbruchbetrieb/Naturschutz]

口Jäger, Willy (1923): Geologische Träumereien im Höllental. - Eschweger Tageblatt, 1923; Nr. 190 v. 16.8.1923; Eschwege

[Poetische Erdgeschichte des Albunger Paläozoikums]

口Jäger, Willy (1924): An den Ruinen der „mitteldeutschen Alpen“ bei Albungen. - Eschweger Tageblatt, 1924; Nr. 43 v. 20.2.1924; Eschwege

[Poetische Erdgeschichte des Unterwerra-Grauwackengebirges bei Albungen]

口Jäger, Willy (1924): Eschweger Pflaster. - WT, 1⑺: 104; Eschwege

[Petrographie eines Basalt-Dünnschliffes, angefertigt aus einem Eschweger Pflasterstein; poetische Beschreibung]

口Jäger, Willy (1925): Im Schatten des hessischen Bergkönigs. - Eschweger Tageblatt, 1925; Nr. 180 v. 3.8.1925; Eschwege

[Poetische Regionalgeologie des Werralandes]

口Jäger, Willy (1926): Wenn Berg und Tal der Heimat reden könnten... Erdgeschichtliche Plaudereien von.... - Eschweger Tageblatt, 1926; Nr. 58 v. 10.03.1926; Eschwege

[Poetische Erdgeschichte des Werra-Meißner-Region]

$\square$ Namenskürzel (Kh) (1956): Uransucher stiegen in den Fürstenstein-Stollen - Mit dem Scintillometer wurden Strahlen festgestellt - Suche in Sontra ohne Ergebnis <Aprilscherz! > . Werra-Rundschau, 1956; Nr. 77 v. 31.03.1956; S. 3, 1 Abb.; Eschwege

[Berichtigung der Scherzmeldung: Nr. 78 v. 3.04.1956; S. 4]

$\square$ Wiechmann, Karl (1966): Charles de Gaulle in der Blauen Kuppe entdeckt. - Werra-Rundschau, 1966; Nr. 48 v. 26.02.1966; S. 5, 1 Abb.; Eschwege

[Französische Besucher erkennen in der Form einer Felsnase das morphologisch markante

Riechorgan des französischen Staatspräsidenten wieder - Künstlerlaune der Natur oder Formgebung durch Abbau ?]

\subsection{Exkursionsführer u. - berichte - Geotope}

\subsubsection{Exkursionsführer - Exkursionsberichte}

-Ackermann, E. (1977): Große Karstquellen am Leinetalgraben - (Exkursion D). - Exkursionsführer Geotagung '77, Bd. II, S. 35-40, 2 Abb.; (Selbstverlag Geol.-paläont. Inst. Univ. Göttingen) Göttingen

-Anonym (1895): < Ausflug des Werrathal-Zweigvereins Boyneburg - Besichtigung der Bergbauanlagen im Richelsdorfer Gebirge> - Eschweger Tageblatt u. Kreisblatt, 1895; Nr. 146 v. 25.06.1895; Eschwege

$\square$ Anonym (1900): < Geologische Exkursion des Landwirthschaftlichen Kreisvereins im Höllental und im östlichen Meißnervorland>- Eschweger Tageblatt u. Kreisblatt, 1900; Nr. 135 v. 12.6.1900; Eschwege

- $\square$ Anonym (1902): <Deutsche Geologische Gesellschaft führt Exkursionen in Nordhessen durch]. Eschweger Tageblatt u. Kreisblatt, 1902; Nr. 6.8.1902; Eschwege

[Meißner-Gebiet, Habichtswald] 
$\square$ Anonym (1902): < Exkursion der Deutschen Geologischen Gesellschaft: Höllenthal, Zechstein-Vorland des Meißners und Meißner]. - Eschweger Tageblatt u. Kreisblatt, 1902; Nr. v. 12.8.1902; Eschwege

$\square$ Anonym (1913): < Geologisch-Botanische Exkursion im Gelstertal] Wissenschaftliche Ausflüge im Sommer 1910 - 4. Sontag, 8. Mai, Tagestour: Witzenhausen - Hundelshausen - Grossalmerode. Abh. Ber. Naturkdl. Vereins Kassel, 53: 208-211; Kassel

QAnonym (1931): < Besichtigung des Kalibergwerks Bleicherode durch die Landwirtschaftsschule Eschwege > - Eschweger Tageblatt, 1931; Nr. 48 v. 26.02.1931

@Anonym (1932): Profile und Schichtfolgen zu den Geologischen Exkursionen in Thüringen. - Der Deutschen Geologischen Gesellschaft zu ihrer Hauptversammlung in Jena 3. - 8. August 1932 überreicht vom Thüringischen Geologischen Verein. - 28 S., 49 Profile u. Schichtfolgenverzeichn.; (Thüringischer Geologischer Verein) Jena [darin: Exk. C 1: Rotliegendes des Thüringer Waldes bei Oberhof und Ilmenau]

-Arp, G.; Hoffmann, V.-E.; Seppelt, S. \& Riegel, W. (2004): Exkursion 6: Trias und Jura von Göttingen und Umgebung. - In: Reitner, Joachim; Reich, Mike \& Schmidt, G. [Hrsg.]: Geobiologie - Exkursionen und Workshops : excursions and workshops. [ 74. Jahrestagung der Paläontologischen Gesellschaft; Göttingen, 2.-8. Oktober 2004]. - 256 S., zahlr. Abb., Tab.; hier: S. 147 - 192, 18 Abb.; (Universitätsverlag) Göttingen 2004

-Baatz, H. (1959/1960): Gelber Berg Niederkaufungen [Tertiär von Niederkaufungen] - Bericht über die Exkursionen anläßlich der 110. Haupfversammlung [der Deutschen Geologischen Gesellschaft] vom 1.-9- September 1968 [in Kassel]. - Exkursion F - Mesozoikum u. Tertiär der Hessischen Senke Montag, den 8. September 1958, nachmittags - Fortsetzung des Kasseler Grabens und Tertiär von Ober- und Niederkaufungen - Z. dt. geol. Ges., 111 (f. 1959/60): 303-305; Hannover

- $\square$ •Bachmann, G. H.; Beutler, G. \& Lerche, J. [eds.] (1998): Excursions on the International Symposium on the Epicontental Triassic - Halle (Saale) - September 1998. - Institut für Geologische Wissenschaften und Geiseltalmuseum Martin-Luther-Universität Halle-Wittenberg. - Hallesches Jb. Geowiss., Reihe B, Beih., $\underline{\mathbf{6}}$; 250 S., zahlr. Ill., graph. Darst., Tab., Kt.; Halle (Saale) [darin: Excursion F, G, H - HE, WMK, THÜ, NIE]

- obBachmann, Gerhard H. \& Beutler, Gerhard (1998): Excursion G - The Classic Germanic Triassic in the Southeastern Part of the Germanic Basin: Stratigraphy, Sedimentary Environments, Cyclic and Sequence Stratigraphy. - In: Bachmann, G. H.; Beutler, G. \& Lerche, J. [eds.] (1998): Excursions on the International Symposium on the Epicontental Triassic - Halle (Saale) - September 1998. Institut f. Geologische Wissenschaften und Geiseltalmuseum Martin-Luther-Universität HalleWittenberg. - Hallesches Jb. Geowiss., Reihe B, Beih., ㅁ: 153-194, 30 Fig.; Halle (Saale) [darin Exkursionsziele: Burg Gleichen, Wartha-Hörschel, Gerstungen, Friedewald]

QBeutler, Gerhard (1998): Excursion F - Stratigraphy, Sedimentary Environtments and Cyclic Deposition of the Keuper in the Southeastern of the Germanic Basin (Thuringia) - (With contributions by Werner Ernst, Axel Kellner \& Joachim Schubert). - In: Bachmann, G. H.; Beutler, G. \& Lerche, J. [eds.] (1998): Excursions on the International Symposium on the Epicontental Triassic - Halle (Saale) - September 1998. - Institut f. Geologische Wissenschaften und Geiseltalmuseum Martin-Luther-Universität Halle-Wittenberg. - Hallesches Jb. Geowiss., Reihe B, Beih., 6: 141-152, 8 Fig.; Halle (Saale)

[darin: Seeberg b. Gotha]

$\square \bullet$ Blanckenhorn \& Beyschlag (1902): Bericht über die in Verbindung mit der allgemeinen Versammlung in Cassel ausgeführten Exkursionen. - Z. dt. geol. Ges., 54: 149-151; Berlin [darin: „Grabenknoten“ b. Eichenberg, Meissner, Hirschberg b. Großalmerode] 
-Boigk, H. \& Murawski, H. (1958): Stratigraphie Unterer Muschelkalk, Mittlerer Buntsandstein; saxonische Tektonik am Leinetalgrabenrand und im Solling; Tertiär- und Basaltvorkommen der Dransfelder Hochfläche. [Exkursion Hauptversammlung Hannover 1956) - Z. dt. geol. Ges., 109 (f. 1957): 282 - 285; Hannover

-Brunotte, E.; Hagedorn, J. \& Pörtge, K.-H. (1986): Exkursion B: Südlicher Leinetalgraben Reinhäuser Wald - westliches Untereichsfeld: Quartäre Fußflächen- und Talentwicklung im Leinetalgraben, Subrosionserscheinungen, Felsformen, Tal- und Flächenbildung im Bausandstein, historische und aktuelle Bodenerosion. - In: Dt. Arbeitskreis f. Geomorphologie - Jahrestagung 1986 , 8. - 10. Oktober 1986 in Göttingen; Exkursionsführer; 37 S.; hier: S. 13 - 15, 12 Abb.; (Geogr. Inst.) Göttingen

- $\square$ Busse, Hentschel, Kutscher, Laemmlen, Pflanzl, Rösing \&Udluft (1959/60): Geologie der Umgebung von Eschwege und des Hohen Meißners - Bericht über die Exkursionen anläßlich der 110. Hauptversammlung [der Deutschen Geologischen Gesellschaft] vom 1.-9- September 1958 [in Kassel] - Exkursion F - Mesozoikum u. Tertiär der Hessischen Senke - Sonntag, den 7. September 1958 - Z. dt. geol. Ges., 111 (f. 1959/60): 288-301, 1 Abb.; Hannover

[Hp. 1-4: Buntsandstein i. d. Umgebung v. Eschwege; HP 5-10: Geologie des Hohen Meißners]

- $\square$ Dahlgrün,F.; Grupe, O.; Martini, H. J.; Paeckelmann, W. \& Schröder, E. (1937): Lehrausflüge anläßlich der Hauptversammlung [der Deutschen Geologischen Gesellschaft] in Kassel im August 1936. - Z. dt. geol. Ges., $\underline{88}$ (f. 1936): 591 - 619, 19 Abb.; Berlin

[S. 605 - 614: ,Saxonische Tektonik westlich und östlich von Kassel - Grabenzonen westlich des Habichtswaldes, Niederhessisches Bergland“)

- $\square$ Dersch-Hansmann, Michaela [Mitautorin] (1999): Geotope in Hessen. - In: Hoppe, Andreas \& Steininger, Fritz [Hrsg.]: Exkursionen zu Geotopen in Hessen und Rheinland-Pfalz sowie zur naturwissenschaftlichen Beobachtungspunkten Johann Wolfgang von Goethes in Böhmen. Schriftenreihe Dt. Geol. Ges., $\underline{\mathbf{8}}$ (Kleine Senckenberg Reihe, 31); 252 S., zahlr. Abb. S. 69-126, 43 Abb.; (Deutsche Geologische Gesellschaft) Hannover 1999 [darin: Haltepunkt 7 Blaue Kuppe, Hp. Höllental/Schmelzhütte, Hp. 9 Frankershausen/Stbr. Schafhof, Hp. 10 Hoher Meißner/Kalbe, Hp. 11 Kitzkammer, Hp. Cornberg]

ODeubel, F. (1930): Halbtagsexkursion in das Keuper- und Juragebiet nordwestlich von Eisenach. Beitr. Geol. Thür., 1 (6): 84-86; Jena

ODeubel (1956): Besuch der erdgasführenden Strukturen im Raum Mühlhausen - Langensalza Exkursion C am 17. Oktober 1955. - Bericht über die Mitgliederversammlung und Exkursionstagung der Geologischen Gesellschaft der Deutschen Demokratischen Republik vom 16. bis. 18. Oktober 1955 in Eisenach. - Ber. geol. Ges. DDR, 2(1): 60; Berlin

-Ehrenberg, K.-H.; Kulick, H. \& Hottenrott, M. (1991): Basalt, Pliozän und Pleistozän bei Fritzlar (Exkursion B am 2. April 1991) [112. Jahresversamml. d. Oberrhein. geol. Vereins, 2. - 6. April 1991 in Bad Wildungen/Nordhessen]. - Jber. Mitt. Oberrhein. geol. Vereins, N.F., 73: 49 - 56, 1 Tab.; Stuttgart

OEllenberg, J. \& Kuhn, G. (1969): Das Quartär und seine nutzbaren Gesteine im Werragebiet (Exkursion A). - In: Steinmüller, Arno [Hrsg.]: Exkusrionsführer zum Treffen der Sektion Quartärgeologie vom 19. - bis 21. Septemberg 1969 in Erfurt - „Ergebnisse quartärgeologischer Untersuchungen in Thüringen. - Exkursionsführer u. Veröff. Ges. geol. Wiss. DDR, 33; 82 S., zahlr. Abb.; hier S. 5-23, 7 Abb.; [Herausgeg. i. Auftrag d. Dt. Ges. f. geol. Wiss.] Berlin 1969 [Oberes Werratal zw. Frauensee u. Breitungen, Niederschmalkalden]

@Ellenberg, J.; Kahlke, R.-D. \& Maul, L. (1997): Litho- und Biostratigraphie der thüringischen Quartär-Abfolge. Exkursion A 2. - In: Lützner, H. \& Seidel, G. (eds): Regionale Geologie von Europa - Exkursionsführer. - 149. Hauptversammlung - Deutsche Geologische Gesellschaft und Jahreshauptversammlung Fachsektion Geoinformatik. - Jena, 27.9 bis 3.10.1997 - Schriftenrh. Dt. 
Geol. Ges., 3: 35-37, 8 Abb.; Hannover 1997

[darin: Travertinbruch Burgtonna, Kiesgrube Oberzella/Werra; Werra bei Breitungen, Untermaßfeld]

OEllenberg, J.; Schröder, B.; Peterek, A. \& Morgenroth, V. (2001): Exkursion A 1 - Geologie und Landschaftsgeschichte im Dreiländereck Hessen, Bayern und Thüringen. - In: Jockel, Andreas [Hrsg.]: Regionale und angewandte Geologie der Grenzregion der Süddeutschen und der Mitteldeutschen Scholle. - Exkursionsführer zur 10. Jahrestagung der Gesellschaft für Geowissenschaften e.V. in Schmalkalden - 19.-22. September 2001. - Exkursionsführer u. Veröff. Ges. f. Geowiss., 213; S. A1-1 bis A1-46, 16 Abb.; Berlin 2001

OErnst, W. \& Beutler, G. (1977): Exkursionsführer Trias-Kolloquium von 17. - bis 19. Mai 1977 in Eisenach - Gesellschaft f. Geologische Wissenschaften der DDR (GGW). - Exkursion: Trias nördlich des Thüringer Waldes bei Eisenach. - Exkursionsführer u. Veröff. Ges. geol. Wiss., 146; 25 S., 4 Abb., 1 Beil.; Berlin

-Franke, W.; Paul, J. \& Schröder, H.-G. (1977): Stratigraphie, Fazies und Tektonik im Gebiet des Leinetalgrabens (Trias, Tertiär) - (Exkursion I). - In: Geol.-Paläont. Inst. u. Museum der Universität [Hrsg.]: Exkursionsführer - Geotagung '77 Göttingen - Band II : Nordhessen und Südniedersachsen (Exkursionen C - D - J - K - L). - S. 41-62, 8 Abb.; Göttingen 1977 [darin: Stbr. Marzhausen]

QFranzke, H. J.; Morgenroth, V. \& Rauche, Henry (2001): Exkursion C 1 - Ganglagerstätten im westlichen Thüringer Wald. - In: Jockel, Andreas [Hrsg.]: Regionale und angewandte Geologie der Grenzregion der Süddeutschen und der Mitteldeutschen Scholle. - Exkursionsführer zur 10. Jahrestagung der Gesellschaft für Geowissenschaften e.V. in Schmalkalden - 19.-22. September 2001. - Exkursionsführer u. Veröff. Ges. f. Geowiss., 213; S. C1-1 bis C1-24, 13 Abb.; Berlin 2001

- $\square$ Garleff, K. \& Brosche, U. (1986): Exkursion A - Kasseler Becken - Hoher Meißner - Werratal: Skulptur- und Strukturformengenese seit dem Mitteltertiär, plio-/pleistozäne Fußflächen, Morphogenese des Meissners, Talentwicklung an Werra- und Fulda. - In: Dt. Arbeitskreis f. Geomorphologie - Jahrestagung 1986, 8. - 10. Oktober 1986 in Göttingen; Exkursionsführer; 37 S.; hier: S. 1 - 12, 9 Abb.; (Geogr. Inst.) Göttingen

-Gaupp, R. \& von der Klauw, S. [Hrsg.](2001): Sediment 2001, Jena, 6.6. - 8.6.2001 - Programm, Kurzfassungen, Exkursionsführer; Schriftenreihe Dt. Geol. Ges, 13; 171 S.; Hannover

- $\square \bullet$ Geol.-Paläont. Inst. u. Museum der Universität [Hrsg.] (1977): Exkursionsführer - Geotagung '77 Göttingen - Band II : Nordhessen und Südniedersachsen (Exkursionen C - D - J - K - L). Zusatz Umschlagtitel: 25.9.-3.10.1977 - Deutsche Geologische Gesellschaft - Paläontologische Gesellschaft. - 120 S., zahlr. Abb.; (Selbstverlag Geol. Paläont. Inst. u. Museum Univ. Göttingen) Göttingen

口Gesang, H. (1962): Pleistozäne Lagerstätten der Steine und Erden im Thüringer Becken (Exkursion C 5). - In: Viete, Günter [Hrsg.] : „Das Pleistozän im sächsisch-thüringischen Raum“ -

Exkursionsführer zur Herbsttagung 1962 vom 19. bis 21. Oktober 1962 in Leipzig und Erfurt - und Kurzreferate der Vorträge anläßlich des 2. Treffens der Sektion Quartärgeologie am 18. Oktober 1962 in Leipzig. - Exkursionsführer u. Veröff. - Ges. geol Wiss DDR, 12; S. 219-224, 1 Abb., [2 Tab.]; Berlin 1962

[Darin Aufschlüsse: Großengottern, Langensalza, Burgtonna-Gräfentonna, Gotha]

OGeyer, Roland (1995): Exkursionen zu Geologischen Naturdenkmalen bei Eisenach/Thüringen. - Der Aufschluss, 46: 249-261, 18 Abb.; Heidelberg

QGeyer, R.; Patzelt, G. \& Schäfer, D. (o.J.): Naturpark Eichsfeld-Hainich-Werratal - Geologie erleben Geologische Route durch den Naturpark - 24 S.; [Hrsg. Verein der Freunde des Naturparks Eichsfeld-Hainich-Werratal und des Nationalparks Hainich e.V.]; Heiligenstadt/Thüringen 
QGrumbt, Eberhard [Hrsg.](1971): Die Entwicklung des tieferen Tafeldeckgebirges und dessen Beziehung zum Unterbau (Thüringer Wald und südwestthüringisches Triasgebie). - Kurzreferate und Exkursionsführer - Tagung vom 25. bis 28. Oktober 1971 in Suhl - Deutsche Gesellschaft für Geologische Wissenschaften. - Exkursionsführer u. Veröff. Ges. Geol. Wiss. (GGW), 48; 143 S., Abb. u. Tab.; Berlin

[darin: „Exkursionsreihe A - Ruhlaer Kristallin“ - „Exkursionsreihe B - Übersicht über Stefan und Rotliegendes (Thüringer Wald)“ - „Exkursionsreihe C - Spezielle Probleme des Stefan und Rotliegenden (Thüringer Wald)“ - „Exkursion D - Der Zechstein am Nord- und Südrand des Thüringer Waldes"]

OHaase, G. (1968): Exkursionsbefahrung der Schachtanlage „Ernst Thälmann“ in Merkers, WerraKalirevier - 48. Treffen des Fachverbandes Mineralogie und der Sektion Kali - „Geochemischlagerstättenkundliche Probleme im salinaren Bereich“. - Ber. Dt. Ges. f. geol. Wiss., Reihe B, 13(5): 623-624; Berlin

[Sehr kurz]

- $\square \bullet$ Hagedorn, Jürgen [Hrsg.] (1986): Dt. Arbeitskreis f. Geomorphologie - Jahrestagung 1986, 8. 10. Oktober 1986 in Göttingen; Exkursionsführer; 37 S., 35 Abb., 1 Tab.; (Selbstverlag Geogr. Inst.) Göttingen

OHaubold, H. [Hrsg.](1983): Exkursionsführer und Kurzreferate - Fortschritt der Paläontologie und Stratigraphie des Rotliegenden - Tagung der Ges. Geol. Wiss. DDR (GGW) vom 13.-15. April 1983 Erfurt. - Exkursionsfüher u Veröff. Ges. geol. Wiss. DDR, 115; 36 S., Abb., 2 Beil.; (AkademieVerlag) Berlin

QHecht, G.; Ellenberg, J. \& Beer, W. (2001): Exkursion C 2 - Subrosion und Hydrogeologie im WerraKaligebiet. - In: Jockel, Andreas [Hrsg.]: Regionale und angewandte Geologie der Grenzregion der Süddeutschen und der Mitteldeutschen Scholle. - Exkursionsführer zur 10. Jahrestagung der Gesellschaft für Geowissenschaften e.V. in Schmalkalden - 19.-22. September 2001. Exkursionsführer u. Veröff. Ges. f. Geowiss., 213; S. C2-1 bis C2-16, 6 Abb.; Berlin 2001

OHeiland, H.; Nolte, L.; Röhling, H.-G. \& Seidel, G. (2008): Geologisch-historische Stadtführung in Heilbad Heiligenstadt. - In: Wunderlich, J. [Red.]: Exkursionsführer - Geologie des Eichsfeldes zur 18. Jahreshauptversammlung (Vortrags- und Exkursionsveranstaltung) vom 16. bis 18. Mai 2008 in Heilbad Heiligenstadt. - Führung: H. Heiland, L. Nolte, H.-G. Röhling \& G. Seidel. - S. 26-32, 5 Abb., 2 Tab.; [Hrsg.: Thüringer Geologischer Verein e.V.] Jena 2008

-Hentschel \& Rösing (1959/60): Habichtswald und Dörnberg bei Kassel - Bericht über die Exkursionen anläßlich der 110. Hauptversammlung [der Deutschen Geologischen Gesellschaft] vom 1.-9- September 1968 [in Kassel]. - Exkursion F - Mesozoikum u. Tertiär der Hessischen Senke Montag, den 9. September 1958 - Z. dt. geol. Ges., 111 (f. 1959/60): 305-310, 1 Tab.; Hannover

-Hentschel, Hans \& Rösing, Franz (1962): Geologische Halbtagsexkursion in das Dörnberggebiet, am 23. Mai 1961. Geologischer Bericht. - (Übergeordn. Titel: Bericht über die Exkursionen während der Tagung des Naturhistorischen Vereins der Rheinlande und Westfalens vom 23. - 26. Mai 1961 in Kassel). - Decheniana - Verhdlgn. Naturhist. Vereins Rheinlande u. Westfalens, 114 (f. 1961): 187190; Bonn

$\square$ Hentschel, H.; Kortinig, S.; Kutscher, F.; Rösing, F. (1962): Ganztagsexkursion zur Blauen Kuppe, am 25. Mai 1961. Geologischer Bericht. - Bericht über die Exkursionen während der Tagung des Naturhistorischen Vereins der Rheinlande und Westfalens vom 23. - 26. Mai 1961 in Kassel. Decheniana - Verhdlgn. Naturhist. Vereins Rheinlande u. Westfalens, 114 (f. 1961): 195-201, 2 Abb.; Bonn [darin: Blaue Kuppe, Stbr. a. Meinhard, Wienberg/Neuerode; Hoher Meißner: Haldenhaus, Kalbe, Seesteine, Kitzkammer) 
QHoppe (1956): Befahrung des Kaliwerkes „Ernst Thälmann“ bei Merkers (Rhön) - Exkursion A am 17. Oktober 1955. - Bericht über die Mitgliederversammlung und Exkursionstagung der Geologischen Gesellschaft der Deutschen Demokratischen Republik vom 16. bis. 18. Oktober 1955 in Eisenach. Ber. geol. Ges. DDR, 2 (1): 58-59; Berlin

OHoppe (1956): Südwestrand des Thüringer Waldes zwischen Eisenach und Bad Liebenstein. Exkursion D am 18. Oktober 1955. - Bericht über die Mitgliederversammlung und Exkursionstagung der Geologischen Gesellschaft der Deutschen Demokratischen Republik vom 16. bis. 18. Oktober 1955 in Eisenach. - Ber. geol. Ges. DDR, 2 (1): 60-61; Berlin

OHoppe, Walter [Hrsg.](1959): Exkursionsführer Thüringer Becken - Jahrestagung der Geologischen Gesellschaft in der Deutschen Demokratischen Republik vom 23. bis 26. April 1959 in Weimar. - 134 S., zahlr. Abb. auf Faltbl.; (Akademie-Verlag) Berlin

-Hoppe, Andreas \& Steininger, Fritz (1999): Exkursionen zu Geotopen in Hessen und RheinlandPfalz sowie zur naturwissenschaftlichen Beobachtungspunkten Johann Wolfgang von Goethes in Böhmen. - Schriftenreihe Dt. Geol. Ges., $\underline{8}$ (Kleine Senckenberg Reihe, 1ㅜ); 252 S.; Ill., graph. Darst., Kt.; (Deutsche Geologische Gesellschaft) Hannover

QHuckriede, Hermann (2003): Aufschluss am Bahnhof Förtha: Basisschichten (Zechsteinkonglomerat bis Zechsteinkalk) der Werra-Folge des Zechsteins / Exkursionspunkt 3

- In: Exkursionsführer - Die Geologie rund um die Wartburg. - S. 21-23; [Thür. Geol. Verein] Jena 2003

QHuckriede, Hermann (2003): Ringberg bei Ruhla: Gesteinsverband der Gömigenstein-Formation des nordwestlichen Ruhlaer Kristallins / Exkursionspunkt 5. - In: Exkursionsführer - Die Geologie rund um die Wartburg. - S. 25-27; [Thür. Geol. Verein] Jena 2003

OHuckriede, Hermann (2003): Ehemaliger Gipssteinbruch Kittelsthal: Zechstein-Abfolge WerraAnhydrit bis Leine-Karbonat/Exkursionspunkt 6 - In: Exkursionsführer - Die Geologie rund um die Wartburg. - S. 27-29; [Thür. Geol. Verein] Jena 2003

-Hugenroth, P. (1985): Exkursions-Führer zur Jahrestagung 1985 in Göttingen - Mitt. Dt. Bodenkdl. Ges., $\underline{42}$; 453 S., zahlr. Abb., Tab.; Göttingen

[darin: Exkursionen Göttinger Wald, Holzerode, Reinshof, Drakenberg, Lößböden, Muschelkalkböden]

$\square$ Jacobshagen, V.; Koritnig, S.; Ritzkowski, S.; Rösing, F., Wittig, R. \& Wycisk, P. (1977): Der Unterwerra-Sattel: sein Deckgebirge (Perm - Trias) und der gefaltete paläozoische Kern - (Exkursion C). - Unter Mitarbeit von G. Schalow und H. Schulze. - In: Geol.-Paläont. Inst. u. Museum der Universität [Hrsg.]: Exkursionsführer - Geotagung '77 Göttingen - Band II : Nordhessen und Südniedersachsen (Exkursionen C - D - J - K - L). - S. 1-34; 8 Abb.; (Selbstverlag GeologischPaläontologisches Institut) Göttingen 1977

口Jäger, Willy (1927): Mit Prof. Dr. Ramdohr in der „Blauen Kuppe“. - Eschweger Tageblatt, 1927; Nr. 130 v. 7.6.1927; Eschwege [Exkursionsbericht]

OJockel, Andreas [Hrsg.](2001): Regionale und angewandte Geologie der Grenzregion der Süddeutschen und der Mitteldeutschen Scholle. - Exkursionsführer zur 10. Jahrestagung der Gesellschaft für Geowissenschaften e.V. in Schmalkalden - 19.-22. September 2001. Exkursionsführer u. Veröff. Ges. f. Geowiss., 213; 169 S., 61 Abb., 16 Tab.; Berlin

QJülich, Eberhard (2002): Subrosionserscheinungen im Röt (Oberer Buntsandstein) im Bereich des Ohmgebirges (NW-Thüringen, Eichsfeld) - Herbstexkursion des Thüringer Geologischen Vereins am 19.10.2002. - Mittbl. Thür. Geol. Verein, 16: 34-36; Jena 
QKahlke, Hans-Dietrich \& Maul, Lutz Chr. (2002): Pleistozäne Fossillagerstätten in Thüringen (Exkursionen H am 5. April 2002). - Jber. Mitt. Oberrhein. geol. Vereins, N.F., 84: 225 - 239, 6 Abb.; Stuttgart

[Weimar-Ehringsdorf, Burgtonna]

$\square$ Klein-Reesink, Josef; Riegel, Walter \& Schulz, Karl-Heinz (1982): Tertiäre Braunkohlen und Kupferschiefer in Niederhessen. - Arbeitskreis f. Paläobotanik u. Palynologie. 11. - 13.3.1982 Dassel/Solling, Exkursion A. - Courier Forschungsinstitut Senckenberg, 무: 111-132, 12 Abb., 2 Tab.; Frankfurt [Hp. 3 Tagebau Paradiesfeld/Zeche Hirschberg, HP. 4 Frankershausen/Stbr. Schafhof]

-Koenen, Adolf v. (1910): Exkursion nach dem Hainberg bei Göttingen am 2. April 1910. - Jber. Niedersächs. Geol. Vereins Hannover, 3 : XVIII; enthalten in: Jber Naturhistorischen Ges. z. Hannover, $\underline{\mathbf{3}}$; Hannover

Referat in: N. Jb. Mineral. etc., 1912 (Bd. I): 475 (Schöndorf); Stuttgart [Lias]

- $\square$ Koritnig, Sigmund (1952): Exkursion im Richelsdorfer Gebirge und zur Blauen Kuppe bei Eschwege. - Fortschr. Mineral., 29/30 (f. 1950/51): 94-100; Stuttgart

OKrähann, G.; Rosenkranz, E. \& Hönsch, J. [Hrsg.](1989): Thüringer Wald und nördliches Vorland - Kleiner Exkursionsführer. - Reihe: Geograph. Bausteine, N. Rh., 35; 160 S., 23 Abb., 18 Foto-Taf., 1 Kt.-Beil.; (Haack) Gotha

[darin S. 9-26, Abb. 1-5: „Physisch-geographischer Überblick“ - Weitere Informationen zur Regionalgeologie in den Exkursionsbeschreibungen]

OKrause, Torsten (2002): Kleintektonische Vielfalt und Bedeutung der Eichenberg-Saalfelder Störungszone im Strukturbild der Thüringer Mulde - vorgestellt am Beispiel des Rät-Lias-Grabens am Wanderslebener Röhnberg (Gotha) und der Zechsteinaufpressung bei Hütscheroda (Eisenach). Exkursionsführer Die Geologie von Nordwest-Thüringen - 12. Jahreshauptversamml. [Thüringer Geologischen Vereins] (Vortrags- und Exkursionstagung) vom 25. bis 26. Mai 2002 in Mühlhausen; S. 8-10; Jena

OKreisverwaltung Sangerhausen [Hrsg.] (1996): Führer Karstwanderweg Teil 1 - Landkreis Sangerhausen - 64. S., ; Sangerhausen

-Kühn, Robert (1952): Nachexkursion im Kaliwerk Hattorf, Philippsthal - als Beitrag zur Kenntnis der Petrographie des Werra-Kaligebietes. - Fortschr. Mineral., 29/30 (f. 1950/51): 101-114, 9 Abb. (i. Text u. Taf. 7-10); Stuttgart

[Salzpetrographie, Basaltgänge u. Kontaktmetamorphose]

- $\square$ Kulick, J. \& Paul, J. [Hrsg.](1987): Internationales Symposium Zechstein 1987 - Kassel/Hannover. Exkursionsführer, Bd. II - Exkursionen D, E, F, L, M: Zechsteinaufschlüsse in der Hessischen Senke und am westlichen Harzrand; 309 S., zahlr. Abb., Tab.; [Hess. Landesamt f. Bodenforschung] Wiesbaden 1987

- $\square$ Kulick, J. \& Richter-Bernburg, G. (1987): Der über Tage anstehende Zechstein in Hessen [Exkursionen D, M] - 2. Tag: Zechstein im Richelsdorfer Gebirge und an der Fulda [Stopp D10-D17, S. 83-113, Abb. 39-60] - 3. Tag: Zechstein im Werra-Grauwackengebirge [Stopp D18-D28] S. 115140, Abb. 61-81; In: Kulick, J. \& Paul, J. [Hrsg.]: Internationales Symposium Zechstein 1987 Kassel/Hannover. Exkursionsführer, Bd. II - Exkursionen D, E, F, L, M; S. 19-140, 81 Abb., 1 Tab.; [Hess. Landesamt f. Bodenforschung] Wiesbaden 1987

[Stop D9: Naturkundemuseum Ottoneum/Kassel: Fährten des Cornberger Sandsteins (S. 72-79); D10 Schwerspatgrube Münden/Nentershausen, D11 Stbr. Cornberg, D18-D28 (Zechstein im WerraGrauwackengebirge): Albungen, Jestädt, Reichensachsen/Weinberg, Oberhone, Höllental/Schmelzhütte, Frankershausen/Schafhof, Hundelshausen, Witzenhausen-Papierfabrik] 
OLandratsamt Nordhausen [Hrsg.](1997): Führer Karstwanderweg Teil 2 - Landkreis Nordhausen 72 S.; Nordhausen

- $\square$ Ql Lepper, J.; Röhling, H.-G.; Stollhofen, H. \& Tietze, K.-W. (1998): Excursion H - The Buntsandstein of the Hessian Depression: Contrasting Styles of Basinal and Marginal Depostition. (With contributions... ). - In: Bachmann, G. H.; Beutler, G. \& Lerche, J. [eds.] (1998):

Excursions on the International Symposium on the Epicontental Triassic - Halle (Saale) - September 1998. - Institut f. Geologische Wissenschaften und Geiseltalmuseum Martin-Luther-Universität Halle-Wittenberg. - Hallesches Jb. Geowiss., Reihe B, Beih., ㅁ: 195-227, 20 Fig.; Halle (Saale) [HE, WMK, THÜ, NIE]

OLützner, Harald (1986): Exkursionsführer und Kurzreferate - Lithologie und Vulkanotektonik im Rotliegenden des Thüringer Waldes - Vortrags- und Exkursionstagung für junge Geologen vom 2. bis. 4. Oktober in Eisenach - Gesellschaft f. geol Wiss. d. DDR (GGW); 40 S., 9 Abb.; Berlin

OLützner, H. (compilation) (1987): Sedimentary and volcanic Rotliegendes of the Saale Depression. Excursion guide book- Symposium on Rotliegendes in Central Europe, Erfurt, May 24-30, 1987; 197 S.; (Zentralinstitut f. Physik d. Erde) Potsdam [darin: Rotliegendes of the Thuringian Forest (Thüringer Wald); Upper Carboniferous and Rotliegendes of the Mansfeld-Halle district]

OLützer, Harald (2003): Die Eisenach-Formation (Rotliegendes) - Verbreitung und Faziesinterpretation. - In: Exkursionsführer Die Geologie rund um die Wartburg. S. 8-10; [Hrsg. Thür. Geol. Verein] Jena 2003

OLützner, H., Van der Klauw, S., Rauche, H. \& Zeh, A. (1997): Ruhlaer Kristallin, Tambacher und Eisenacher Rotliegendbecken - Exkursion A 1. - In: Lützner, H. \& Seidel, G. (eds):

Hauptversammlung der Deutschen Geologischen Gesellschaft - Jena, 27.9 bis 3.10.1997 - Regionale Geologie von Europa, Exkursionsführer. - Schriftenrh. Dt. Geol. Ges., 3: 1-34, 9 Abb.; Hannover 1997

OMartens, Thomas (2003): Thüringer Wald. - Serientitel: Sammlung geologischer Führer, Bd. 95; X, 252 S., 68 Abb., 17 Tab., 12 Farbfotos, zahlr. Kt.; (Bornträger) Berlin-Stuttgart

-Martini, Hans Joachim (1958): Exkursion [am 4. Oktober 1956] Göttingen - Leinetalgraben zwischen Göttingen und Echte - Jurascholle des Kahleberges bei Echte - Ostende der Leinetalachse, Weißjuraschollen von Dannhausen - Salzsubrosionssenke von Seesen mit dem Teritär von Bornhausen [Hauptversamml. Hannover 1956]. - Z. dt. geol. Ges., 109 (f. 1957): 286 - 288, 1 Abb.; Hannover

$\square$ Maurer, Jacob (1978): Geologische Wanderung in das Erdmittelalter - Werratalverein Witzenhausen verfolgt erdgeschichtliche Spuren im heimatlichen Raum. - Das Werraland, 30(2): 17-19; Eschwege

$\square$ Maurer, Jacob (1987): Geologische Wanderung im Werra-Schiefer-Gebirge bei Witzenhausen. - 47 S., 11 Abb., 2 strat. Tab.; (Selbstverlag Werrratalverein Witzenhausen e.V.) Witzenhausen [Exkursionsführer m. 17 Stationen]

$\square$ Möller, Klaus (1987): Geomorphologisch-Geologischer Wanderführer durch das Werra-MeißnerGebiet. Teil 1: Das östliche Meißnervorland. - 83 S., 34 Abb., 2 Tab.; (Keitz \& Fischer) Eschwege Teil 1: Alles Erschienene!]

QMorgenroth, V. (1989): Exkursionsführer - Trias und Tertiär in der Vorderrhön - vom 3. - bis 6. Oktober in Bad Salzungen - Gesellschaft f. geologische Wissenschaften d. DDR (GGW). Exkursionsführer u. Veröff. Ges. f. Geol. Wiss., 170; 30 S., 5 Abb.; Berlin

-Murawski, Hans (1952): Exkursion in die Ziegeleigrube der Fa. Levin in Göttingen und in die Basaltsteinbrüche der Bramburg bei Adelebsen. - Z. dt. geol. Ges., 103: 423-426, 2 Abb.; Hannover 
-Murawski, Hans (1952): Exkursionen zu den Basaltvorkommen westlich von Göttingen. - Fortschr. Mineral., 29/30 (f. 1950/51): 92-93; Stuttgart

-Namenskürzel (Jg.) (1926): <Wissenschaftliche Vereinigung Eschwege - Studienfahrt nach Göttingen. - Besichtigung des Instituts für Luft- und Wasserströmung, der Erdbebenwarte und des Botanischen Gartens>. - Eschweger Tageblatt, 1926; Nr 124 v. 31.05 .1926

-Namenskürzel (h) (1970): Zwischen Habichtswald und Lindenberg - Stadtausflug mit Geologenkarte - Kasseler Bürger blickten in versunkene Erdzeitalter. - HA, 1970; Nr. 97 v. 24.4.1970; Kassel

ONaumann, Ernst (1927/1928): Halbtagesexkursion von Eisenach nach Creuzburg, Buchenau und der Spindelskoppe am 10. Juni 1927. (Bericht über die Exkursionen des Thüringischen Geologischen Vereins währe-nd der dritten Hauptversammlung in Eisenach am 10. und 11. Juni 1927) - Beitr. Geol. Thür., 1(6): 83-84; Jena

ONaumann, E. (1932): Rotliegendes des mittleren Thüringer Waldes (Exkursionsbericht - Lehrausflüge vor u. nach d. Hauptversamml. d. Dt. Geol. Ges. in Jena vom 3.-8. August 1932). - Z. dt. geol. Ges., 84: 753-755, 1 Abb.; Berlin

ONitz, Bernhard \& Kleßen, Reinhard [Hrsg.](1998): Exkursionsführer zur Hauptexkursion 1997: Harz, Thüringer Wald, Odenwald, Schwäbische Alb - Zur Frage der Geologie und Geomorphologie ausgewählter deutscher Mittelgebirge. - Beiträge der Teilnehmer an der Hauptexkursion 1997. Arbeitsberichte Geogr. Inst. Humboldt-Univ. z. Berlin; 31; 67 S., Abb.; [Selbstverlag Geogr. Inst. Humboldt-Univ. Berlin] Berlin

OPatzelt, Gerd (1988): Die Trias von Nordwestthüringen - Kurzreferate und Exkursionsführer, Tagung vom 12. - 14. Okt. 1988 in Mühlhausen. - 32 S., 2 Beil.;

OPatzelt, Gerald (1994): Streifzüge durch die Erdgeschichte Nordwestthüringens - geologischer Abriß und Exkursionsführer. - 96 S., 53 Abb., 6 Tab.; (Perthes) Gotha

OPatzelt, G. (2002): Einschnitt der ehemaligen Bahntrasse zwischen Heyerode und Diedorf - Unterer Muschelkalk (Jena-Formation), Trochitenkalk und untere Ceratitenschichten (Meißner-Formation) Exkursionsführer Die Geologie von Nordwest-Thüringen - 12. Jahreshauptversamml. [Thüringer Geologischen Vereins] (Vortrags- und Exkursionstagung) vom 25. bis 26. Mai 2002 in Mühlhausen; S. 35-38; Jena

- $\square$ Penndorf, Wilhelm (1926): Geologische Wanderungen im Niederhessischen Bergland. - 345 S.

(Heimatschollen-Verlag Bernecker) Melsungen

[Umfassender Exkursionsführer ohne Illustrationen]

OPippig, Matthias \& Beer, Wolfgang (2001): Exkursion B 1 - Stratigraphie, Petrologie und Tektonik der Grube Merkers. - In: Jockel, Andreas [Hrsg.]: Regionale und angewandte Geologie der Grenzregion der Süddeutschen und der Mitteldeutschen Scholle. - Exkursionsführer zur 10. Jahrestagung der Gesellschaft für Geowissenschaften e.V. in Schmalkalden - 19.-22. September 2001. - Exkursionsführer u. Veröff. Ges. f. Geowiss., 213; S. B1-1 bis B1-8, 6 Abb.; Berlin 2001

$\square$ Q Pompeckj, J.F. (1910): Exkursion nach Eichenberg-Witzenhausen-Hanstein am 3. April.1910. Jber. Niedersächsischen Geol. Vereins, $\underline{\mathbf{3}}$ : XVIII - XXV, 2 Abb.; Hannover Referat in: N. Jb. Mineral. etc., 1912 (Bd. I): 475-476 (Schöndorf); Stuttgart [Regionalgeologie]

$\square$ Ramdohr, Paul (1922): Bericht über die Exkursion zur Blauen Kuppe bei Eschwege am 10.4.1921. Fortschr. Mineralogie, 1922: 36-37 (Teil Allgemeines); Jena 
ORau, D. (1962): Rezente und fossile Lößböden im Thüringer Becken und in dessen Randgebieten (Exkursion B 4). - In: Viete, Günter [Hrsg.]: „Das Pleistozän im sächsisch-thüringischen Raum“ Exkursionsführer zur Herbsttagung 1962 vom 19. bis 21. Oktober 1962 in Leipzig und Erfurt - und Kurzreferate der Vorträge anläßlich des 2. Treffens der Sektion Quartärgeologie am 18. Oktober 1962 in Leipzig. - Exkursionsführer u. Veröff. Ges. geol. Wiss. d. DDR, 12; S. 145-153, 1 Abb.; Berlin 1962 [darin: Aufschlüsse Burgtonna, Gotha, Körner, Mühlhausen]

-Reitner, Joachim; Reich, Mike \& Schmidt, G. [Hrsg.] (2004): Geobiologie - Exkursionen und Workshops : excursions and workshops. [ 74. Jahrestagung der Paläontologischen Gesellschaft; Göttingen, 2.-8. Oktober 2004]. - Reihe: Göttinger Universitätsdrucke. - 256 S., zahlr. Abb., Tab.; (Universitätsverlag) Göttingen

[ Exkursion 6: Trias und Jura von Göttingen und Umgebung]

- $\square$ Richter-Bernburg, Gerhard (1955): Der Zechstein zwischen Harz und Rheinischem Schiefergebirge - Bericht über eine Exkursion zu den Zechsteinaufschlüssen dieses Gebietes anläßlich der Frühjahrstagung der Deutschen Geologischen Gesellschaft in Goslar 1953. - Z. dt. geol. Ges., 105 (f. 1953): 876 - 899, 8 Abb.; Hannover

[Harzsüdrand - Werra-Meissner-Kreis, Umgebung Rotenburg/Fulda, Rand d. Rhein. Schiefergeb. b. Waldeck-Korbach-Marsberg]

- $\square$ Ritzkowski, S. (1969): Nördliches Hessen [Oligozän-Aufschlüsse]. - In: Anderson, Hans Joachim [Hrsg.]: Führer zur Oligocän-Exkursion 1969 - Köln, Münster, Hannover, Göttingen, Mainz - 20.27. April 1969. - Internationale Union f. Geologischen Wissenschaften [nternational Union of Geological Sciences]/Landesausschuß der Bundesrepublik Deutschland. - 112 S., 33 Abb., Tab.; hier S. $57-83,17$ Abb. Tab.; Marburg 1969

[Borken, Niederkaufungen, Glimmerode]

- $\square$ Ritzkowski, S. \& Rösing, F. (1977): Tertiär Nordhessens - (Exkursion K). - In: Geol.-Paläont.

Inst. u. Museum der Universität [Hrsg.]: Exkursionsführer - Geotagung '77 Göttingen - Band II : Nordhessen und Südniedersachsen (Exkursionen C - D - J - K - L). - S. 63-111, 16 Abb., 1 stratigr. Tab.; (Selbstverlag GPI Uni. Göttingen) Göttingen 1977

[darin: Borken, Verna, Obervorschütz, Knickhagen, Bühl b. Ahnatal/Weimar; Breitenbach, Hoof, Vollmarshausen, Glimmerode, Hoher Meissner]

$\square \oslash \bullet$ Röhling, H.-G.; Stollhofen, H. \& Tietze, K.-W. (2002): Trias Exkursion I: Buntsandstein zwischen Hannover und Würzburg. - In: Niebuhr, Birgit [Hrsg.]: GEO 2002 - Planet Erde: Vergangenheit, Entwicklung, Zukunft - 1.-5. Oktober 2002 in Würzburg. - Exkursionsführer Excursion guide. - Schriftenrh. Dt. Geol. Ges., 22: 5-28, 13 Abb., 3 Tab.; Hannover 2002 [darin Aufschlüsse WMK, Thür. Eichsfeld, Niedersachsen]

ORöhling, Heinz-Gerd \& Heiland, Helmut (2008): Trias im Eichsfeld - Exkursion 18. Mai 2008. - In: Wunderlich, J. [Red.]: Exkursionsführer - Geologie des Eichsfeldes - zur 18. Jahreshauptversammlung (Vortrags- und Exkursionsveranstaltung) vom 16. bis 18. Mai 2008 in Heilbad Heiligenstadt. - Führung: H. Heiland, L. Nolte, H.-G. Röhling \& G. Seidel. - S. 51-70, 14 Abb.; [Hrsg.: Thüringer Geologischer Verein e.V.] Jena 2008

$\square$ Rösing, Franz (1959): Bericht über die Exkursionen anläßlich der 110. Hauptversammlung in Marburg a. d. Lahn vom 1. - 9. September - Alter Steinbruch unmittelbar südlich Neuerode und Steinbruch Wienberg bei Neuerode. - Z. dt. geol. Ges., 111: 289-291; Hannover

-Rösing, Franz (1962): Geologische Halbtagsexkurison durch den Habichtswald un den Kasseler Graben am 24. Mai. 1961. - (Übergeordn. Titel: Bericht über die Exkursionen während der Tagung des Naturhistorischen Vereins der Rheinlande und Westfalens vom 23. - 26. Mai 1961 in Kassel). Decheniana - Verhdlgn. Naturhist. Vereins Rheinlande u. Westfalens, 114 (f. 1961): 190-194, 1 Profilberschr.; Bonn 
-Roth, Harry (1958): Befahrung des Kalisalzbergwerkes „Wintershall“ der Gewerkschaft Wintershall in Heringen/Werra..- Fortschr. Mineralogie, 프; Beih. 1: 82-88, 1 Abb.; 1 Tab.; Stuttgart [Mineralogie, Petrographie Zechstein-Salzlagerstätte]

- Roth, Harry (1962): Die Werra-Kailsalzlagerstätte (Exkursionsbericht). -- (Übergeordn. Titel: Bericht über die Exkursionen während der Tagung des Naturhistorischen Vereins der Rheinlande und Westfalens vom 23. - 26. Mai 1961 in Kassel). - Decheniana - Verhdlgn. Naturhist. Vereins Rheinlande u. Westfalens, 114 (f. 1961): 203-205, 1 Profilberschr.; Bonn

$\square$ Rüppel, Heidi \& Apel, Jürgen (2002): Rad- und Wander-Führer - Auf Entdeckungstour im WerraBergland rund um Meißner und Kaufunger Wald. - Bd. 1 Hannoversch Münden, Witzenhausen, Bad Sooden-Allendorf. - 152 S., 33 Abb., 15 graph. Darst., 19 Kt.; (Landschaftskundlicher StudienReisebuch-Verlag) Witzenhausen 2002

-Schmidt, Hermann (1928): Exkursion nach Diemarden und Bremke (Muschelkalk und Buntsandstein). [Tagung der Paläontologischen Gesellschaft in Göttingen - 29. September bis 4. Oktober 1926]. Paläont. Z., 9: 2-4, 2 Abb.; Berlin

aSchmidt, Hermann (1962): Gemeinsame Ganztagsexkursion nach Rotenburg/Fulda und in das Richelsdorfer Gebirge am 26. Mia 1961 (Geologischer Bericht). - (Übergeordn. Titel: Bericht über die Exkursionen während der Tagung des Naturhistorischen Vereins der Rheinlande und Westfalens vom 23. - 26. Mai 1961 in Kassel). - Decheniana - Verhdlgn. Naturhist. Vereins Rheinlande u. Westfalens, $\underline{114}$ (f. 1961): 202; Bonn

OSeidel, Gerd (1972): Das Thüringer Becken - Geologische Exkursionen. - Reihe: Geographische Baustein, N.F., 11; 96 S., 13 Abb., (VEB Hermann Haack) Gotha/Leipzig

OSeidel, Gerd (1992): Das Thüringer Becken. - Sammlung Geologischer Führer, Bd. 85; I, 204 S., 70 Abb., 17 Tab.; (Bornträger) Berlin-Stuttgart

$\square$ Siuts, U. (1951): Gesteinskundliche Lehrwanderung am 6. Juli 1951 nach der „Blauen Kuppe“ bei Eschwege und durch das „Höllental“ bei Albungen. 20 Blätter, zusammengeheftet [unveröff.], Hannoversch Münden [Standort: Bereichsbibl. Forstwissenschaften Universität Göttingen Sign. Z 100/20]

OSommer, Th. \& Hesse, G. (2002): Hydrogeologie einer anthropogen überprägten Flußlandschaft - das Unstruttal zwischen Quelle und Sömmerda (Thüringer Becken) (Exkursion K am 5. April 2002) Jahresversammlung 2002 Oberrheinischer Geologischer Verein, Jena]. - Jber. Mitt. Oberrhein. Geol. Verein, N.F., 84: 241-256, 11 Abb., 1 Tab.; Stuttgart

OUhlig, Lotar \& Langer, Helmut (1964): Exkursion B4: Der nordwestliche Thüringer Wald und sein Vorland. - In: Exkursionsführer VII. Wiss. Hauptversammlung d. Geogr. Ges. d. DDR - Leipzig 1964; S. 187-200, 1 Falt-Taf. (1Kt.-Skizz., 1 Langsprofil, 1 strat. Profil)

QUnger, K. P. \& Schramm, H. (1962): Altpleistozäne Schichtenfolgen und deren Gliederung im nördlichen Vorland des Thüringer Waldes (Exkursion C 1). - In: Viete, Günter [Hrsg.]: „Das Pleistozän im sächsisch-thüringischen Raum“ - Exkursionsführer zur Herbsttagung 1962 vom 19. bis 21. Oktober 1962 in Leipzig und Erfurt - und Kurzreferate der Vorträge anläßlich des 2. Treffens der Sektion Quartärgeologie am 18. Oktober 1962 in Leipzig. - Exkursionsführer u. Veröff. Ges. geol Wiss. d. DDR, 12; S. 171-180, 5 Abb.; Berlin 1962

[Darin Aufschlüsse: Gräfentonna, Westhausen, Gotha; Alsberg W'Gotha]

OViete, Günter [Hrsg.] (1962): „Das Pleistozän im sächsisch-thüringischen Raum“ - Exkursionsführer zur Herbsttagung 1962 vom 19. bis 21. Oktober 1962 in Leipzig und Erfurt - und Kurzreferate der Vorträge anläßlich des 2. Treffens der Sektion Quartärgeologie am 18. Oktober 1962 in Leipzig. Exkursionsführer u. Veröff. Ges. geol Wiss. d. DDR, 12; 224 S., zahlr. Abb., Tab.; Berlin 
OVölker, C. \& Völkel, R. [Red.](2002): Exkursionsführer Subrosionserscheinungen im Röt (Oberer Buntsandstein) im Bereich des Ohmgebirges (NW-Thüringen, Eichsfeld). - 35 Bl., Abb., Tab., Kt.; [Hrsg.: Thür. Geol. Verein] Jena

OWeber, Hans (1927/1928): Halbtagesexkursion in die Tambacher Schichten des Georgentals und nach dem Basaltdurchbruch der Stoffelskuppe. - (Bericht über die Exkursionen des Thüringischen Geologischen Vereins währe-nd der dritten Hauptversammlung in Eisenach am 10. und 11. Juni 1927) - Beitr. Geol. Thür., 1(6): 73-83, 3 Abb., 2 Tab.; Jena

OWeber, Hans (1965): Exkursionsvorschläge für die Drei Gleichen bei Arnstadt in Thüringen. Hallesches Jb. mitteldt. Erdgeschichte, $\underline{\mathbf{6}}$ (f. 1964): 67-70, Taf. XI (2 Bilder); Leipzig

- $\bullet$ Wedepohl, Karl Hans \& Ritzkowski, S. (1980): [DMG-Tagung 1980] Exkursion E 1: Die nördliche Hessische Senke (Tertiär-Vulkanite, Kupferschiefer und variszischer Spilit). - Fortschr. Mineral., $\underline{\mathbf{5 8}}$, Beih. 2 (Einführung zu den Exkursionen anläßlich der 58. Jahrestagung der Deutschen Mineralogischen Gesellschaft in Göttingen 1980): 3-33, 2 Abb., 3 Tab.; Stuttgart [darin Hp: Werra-Meissner-Kreis: Blaue Kuppe, Bilstein, Cornberg, Forsths. Schmelzhütte, Hoher Meissner/Kalbe, Hoher Meissner/Kitzkammer; auch Hoher Hagen/Dransfeld, Westberg/Hofgeismar, Dörnberg/Zierenberg; Güntersberg b. Gudensberg, Isthaburg b. Istha, Steppling b. Homberg/Efze]

OWunderlich, Jürgen (1991): Exkursionsführer - Der Kristallinkomplex von Ruhla-Brotterode. - 89 S., 25 Abb.; (Thür. Geol. Verein) Jena

OWunderlich, J. [Red.] (2008): Exkursionsführer - Geologie des Eichsfeldes - zur 18.

Jahreshauptversammlung (Vortrags- und Exkursionsveranstaltung) vom 16. bis 18. Mai 2008 in Heilbad Heiligenstadt. - Führung: H. Heiland, L. Nolte, H.-G. Röhling \& G. Seidel. - 73 S., 33 Abb., 7 Tab.; [Hrsg.: Thüringer Geologischer Verein e.V.] Jena

QZimmermann, E. (1927/1928): Tagesexkursion in das Randgebiet des Thüringer Waldes zwischen Eisenach und Bad Thal.. - (Bericht über die Exkursionen des Thüringischen Geologischen Vereins währe-nd der dritten Hauptversammlung in Eisenach am 10. und 11. Juni 1927) - Beitr. Geol. Thür., 1(6): 86-93; Jena

\subsubsection{Geotop-Führer und -Verzeichnisse}

@Geyer, Roland (о. J.): Naturschönheiten im Landkreis Eisenach - 1. Teil: Geologische Naturdenkmale. - 32 S. zahlr. Abb. (Fotos, Profile, Kt., strat. Tab.); [Hrsg.: Umweltamt des Landrates Eisenach Untere Naturschutzbehörde] Eisenach [darin: Profil von Epichnellen/Bhf. Förtha; Kristallinaufschluß Busbahnhof Ruhla; Stoffelskuppe u. Pflasterkaute; Granitporphyr von Thal/Heiligenstein; Basaltgang Bhf. Hörschel]

OGeyer, R.; Jahne, H. \& Storch, S. (1999): Geologische Sehenswürdigkeiten des Wartburgkreises und der kreisfreien Stadt Eisenach - Schriftenreihe Naturschutz im Wartburgkreis, H. $\underline{8}$; 188 S., 162 Abb., 1 Übersichtskarte 1 : 100.000; [Hrsg. Thür. Landesamt f. Geologie, Wartburgkreis, Stadt Eisenach]; Eisenach

OKrause, Reinhard (2006): Geologische Naturdenkmale und ausgewählte Geotope. - Schriftenreihe Naturschutz i. Landkreis Gotha, H. ․ - 1. Aufl.; 114 S., Ill., graph. Darst., Kt.; [Hrsg.: Landratsamt Gotha, Fachdienst Naturschutz u. Landschaftspflege] Gotha 
$\square$ Sauer, Helmut (1983): Die Naturlandschaft des Werralandes. - In: Hildebrand, Erich

[Gesamtkonzeption, Red.]: Land an Werra und Meißner - Ein Heimatbuch. - [1. Auflage], 384 S., zahlr. Abb.; hier: S. 189-194, 2 Abb., 1 strat. Tab.; darin enthalten: „Geologisch bemerkenswerte Punkt“; [Hrsg. Hist. Ges. Werralandes](Bing) Korbach 1983

$\square$ Sauer, Helmut u.a. (1990): Geologisch bemerkenswerte Punkte. - (Autor: Helmut Sauer, ergänzt durch Wolfram Brauneis u. Klaus Möller). - In: Hildebrand, Erich [Gesamtkonzeption, Red.]: Land an Werra und Meißner - Ein Heimatbuch. - 3., überarb. Auflage; 384 S., zahlr. Abb.; hier: S. 193-196, 1 Abb., 1 strat. Tab.; (Bing) Korbach 1990

\subsection{An den Grenzen der Geologie}

-Namenskürzel (red) (1997): Herbstausstellung: Wünschelrute - ein Wunschtraum? - Am Stand der „Vereinigung deutscher Rutengänger" haben Besucher der Herbstausstellung in Kassel Gelegenheit, sich über die Arbeit mit der umstrittenen Wünschelrute zu informieren. - Werra-Rundschau, 1997; Nr. 219 v. 20.9.1997; S. 5; Eschwege

\subsection{Hochschulschriften}

\subsubsection{Diplom-Arbeiten, Diplom-Kartierungen u. a. Examensarbeiten}

Diese Liste wurde anhand von Literaturlisten verschiedener Veröffentlichungen sowie Zettelkatalogen von Bibliotheken erstellt, ohne Überprüfung der Angaben in der Vorlage. Die Einsichtnahme in DiplomArbeiten, Diplom-Kartierungen des Geowissenschaftlichen Zentrums der Universität Göttingen ist genehmigungspflichtig (Stand 2006).

\subsubsection{Hessen - ohne Werra-Meißner-Kreis}

-Baatz, H. (1959): Das Kaufunger Tertiär östlich von Kassel. - Dipl.-Arb. [unveröff.] Univ. Marburg/L.

- $\square$ Bühmann, Dieter (1970): Tonmineralogische Untersuchungen an tertiären Sedimenten aus dem nördlichen Hessen. - Dipl.-Arb. [unveröff.] Univ. Göttingen, 40 S.

ه $\square$ Bühmann, Dieter (1970): Tonmineralogische Untersuchungen an tertiären Sedimenten aus dem nördlichen Hessen. - Dipl.-Arb. [unveröff.] Univ. Göttingen, 40 S.

-Diersche, Volker (1969): Zur Geologie der Warburger Störungszone süd-westliche Liebenau (N.Hessen) (Messtischblatt Liebenau 4521). - Dipl.-Arb. Univ. Hamburg, Fachber. Geowiss., 1969; 340, 38 S.; Hamburg

-Findeisen, H.-K. (1952): Geologische Beschreibung des Stadtgebietes von Kassel und seiner näheren Umgebung. - Dipl.-Arb. [unveröff.] Univ. Heidelberg 1952, 134 S. 
-Großkurth, Gerhard Friedrich (1990): Einfluss der Halden des ehemaligen Kupferschiefer- und Schwerspat-Berbaues im Richelsdorfer Gebirge (Hessen) auf die Schwermetallführung des Gewässersystems. Geologische und geochemische Kartierung. - Diplom- Arbeit [unveröff.] Univ. Göttingen; 160 S.

-Hieke, W. (1965): Stratigraphie und Tektonik am Remsfelder Grabenknoten (Niederhessen). - Dipl.Arb. [unveröff.] Univ. Marburg 1965

- dütte, H. (1985): Revisionskartierung des Keupers im Ostteil des Netra-Grabens. - Dipl.-Arb. [Dipl.Kart.?] [unveröff.] Ruhr-Univ. Bochum; 36 S.

-Karakücükoglu, Mustafa (1989): Geologische Teilkartierung der Blätter Homberg a. d. Efze und Altmorschen. - Dipl.- Arb. Teil 1 [unveröff.] Univ. Göttingen; 41 S.

-Karakücükoglu, Mustafa (1989): Petrographische Untersuchungen im unteren Abschnitt des Hauptflözes der miozänen Braunkohle von Ostheim/Hessen. - Dipl.-Arb. Teil 2 [unveröff.] Univ. Göttingen 1989; 69 S.

- $\square$ Klein-Reesink, Josef (1980): Geologische und lagerstättenkundliche Untersuchungen im Nordteil der Hessischen Senke, A. - Teil I: Geologie des Berlepschgrabens. - Teil. II: Petrographische Untersuchung der Braunkohle von Borken (Bez. Kassel). - Dipl.-Kart. u. Dipl.-Arb. [unveröff.] Univ. Göttingen; 217 S.

-Kray, Markus (1994): [I.] Die paläogenen und neogenen Sedimente am Stellberg bei Kassel. - Dipl.Arb. [unveröff.] Univ. Göttingen. - 52 S., 40 ungez. Bl. [die Vorlage enthält zwei Arbeiten: Dipl.-Arb. u. Dipl.-Kart. ]

-Kröninger, Brigitte (1991): Geologische Teilkartierung des Blattes Nr. 4922 Homberg/Efze. - Dipl.Arb. Teil I [unveröff.] Univ. Göttingen 1991; 59 S.

- $\square$ Kühn, V. \& Neumann, Klaus (1989): Die Quellwässer des Kaufunger Waldes. Hydrochemie und geologischer Untergrund. - Dipl.-Arb. [unveröff.] Univ. Göttingen; 143 S.

-Lengtat, Karl Heinz (1989): Geologische Teilkartierung des Blattes 4922 Homberg/Efze. - Dipl.-Arb. Teil I [unveröff.] Univ. Göttingen 1989; 108 S.

-Lengtat, Karl Heinz (1989): Paläobotanische Untersuchungen eines Blattlagenhorizontes in der Ostheimer Braunkohle (Nordhessen). - Dipl.-Arb. Teil II [unveröff.] Univ. Göttingen 1989; 52 S.

-Ließ, Siegfried (1988): Charakterisierung des bodenchemischen Zustandes von Waldböden auf Basalt und Kalk mit unterschiedlichen Lößlehmablagerungen im Habichtswald. - Diplom-Arbeit (unveröffentlicht) Fachber. 13 Univ./Gesamthochschule Kassel; 97 S.

-Lukas, Volker (1986): Feinstratigraphische, sedimentologisches und tektonische Untersuchungen im Hersfelder Graben. - Dipl.-Arb. [unveröff.] Univ. Gießen, 139 S.

-Nyblad, Iris (1996): Die Geologie des südlichen Endes des Oberaulaer Grabens und seiner Tiefenfortsetzung nach gravimetrischer Modellierung. - Dipl.-Arb. [unveröff.] Univ. Göttingen 1996; 82, 54 S. - Die Vorlage enthält zwei Werke

-Nyblad, Iris (1996): Geologische Kartierung des südlichen Endes des Oberaulaer Grabens im Maßstab 1 : 10000 - Kartengrundlage: TK 25 Nr. 5122 Neukirchen. - Dipl. - Kart. [unveröff.] Univ. Göttingen 1996; 82, 54 S. - Die Vorlage enthält zwei Werke

-Oppermann, S. A. (1970): Das Rotliegende des Richelsdorfer Gebirges. - Dipl.-Arb. [unveröff.] Univ. Mainz 1970; 63 S. 
-Peters, Heide (1985): Die Verteilung von Blei, Kupfer und Zink im Kontaktbereich zwischen Basalten und Evaporitgesteinen der Werra-Serie des Zechsteins. - Dipl.-Arb. [unveröff.] Univ. Göttingen 1985; $118 \mathrm{~S}$.

-Precht1, Daniel (1994): I. Geologische Kartierung des Ottrauer Grabens in Hessen (TK 25: 5122 Neukirchen) - II. Geologie des Ottrauer Grabens und seine Tiefenfortsetzugn nach gravimetrischer Modellierung. - Dipl.-Kart. u. Dipl.-Arb. 1994; 73 S., ca. 20 ungez. S. Anhang

-Schröck-Ergün, Doris (1992): Geologische Teilkartierung im SE-Teil des Blattes Homberg, TK 4922. - Dipl.-Kart. [unveröff.] Univ. Göttingen 1992; 52, 5 ungez. S. Anhang

هSchröck-Ergün, Doris (1992): Palynologische Untersuchungen zur Ökologie der Braunkohle von Ostheim, Bezirk Kassel. - Dipl.-Arb. [unveröff.] Univ. Göttingen 1992; 125 S., ca. 12 ungez. S. Anhang

aStier, G, (1974): Das Perm des westlichen Richelsdorfer Gebirges und geologische Kartierung im Nordwestteil der TK 25 Hönebach. - Dipl-Arb. [unveröff.] Univ. Frankfurt; 245 S.

-Techmer, Astrid (1989): Geochemische Untersuchungen an Xenolithen aus dem Habichtswald. Dipl.-Arb. [unveröff.] Univ. Göttingen 1989; 85 S.

-Tonn, Harald (1990): A. Untersuchungen an Flüssigkeitseinschlüssen als Beitrag zur Genese der Kupferschiefermineralisation (Mikrothermometrie, Kathodenlumineszenz, REM-EDX Mikroanalytik). - B. Geologische Kartierung im Bereich Cornberg-Nentershausen (Hessen) TK 4925 Sontra .; Dipl.-Arb. + Dipl.-Kart. Univ. Göttingen [unveröff.]; 60 S.

- $\square$ Wollenhaupt, Hartmut (1980): Geologische und lagerstättenkundliche Untersuchungen im Nordteil der Hessischen Senke - B. - Teil I: Die Geologie des Nordrandes des Leinholz-Gewölbes zwischen Berge und Mollenfelde (TK 4525 Reinhausen und TK 4625 Witzenhausen). - Teil II: Palynologische und petrographische Untersuchungen der Braunkohle von Schneppenhain (TK5021 Ziegenhain). Dipl.-Kart. u. Dipl.-Arb. [unveröff.] Univ. Göttingen, 151 S.

\subsubsection{Werra-Meißner-Kreis}

$\square$ Abhari, Fereshteh (1982): Geologie des Gebietes zwischen Waldkappel und Germerode (TK 4825 Waldkappel, Niederhessen). - Dipl.-Arb. [unveröff.] Fachber. Geowiss. FU Berlin, 51 S.

$\square$ Ahmadian, F. (1982): Geologische Untersuchung des Gebietes zwischen Wommen und Hohenhaus (TK 4926 Herleshausen, Niederhessen) - Maßstab 1 : 10.000. - Dipl.-Arb. [unveröff.] Fachber. Geowiss. FU Berlin, 44 S.

$\square$ Amiri, Golam Hossain (1976): Geologie des Unterwerra-Sattels bei Eschwege. - Dipl.-Arb. [unveröff.] Fachber. Geowiss. FU Berlin, 53 S.

$\square$ Aramesh, J. (1993): Geologie des Gebietes östlich Albungen (Nordhessen) unter besonderer Berücksichtigung der Terebratelzone (Unterer Muschelkalk). - Dipl.-Arb. [unveröff.] Fachber. Geowiss. FU Berlin, 67 S.

$\square$ Baldzahn-Straka, Heike (1987): Geologische Untersuchung des nordwestlichen Meißnergebietes. Bearbeitung des NW-Quadranten der geologischen Meißnerkarte. - Dipl.-Arb. [unveröff.] Fachber. Geowiss. FU Berlin, 124 S.

$\square \bullet$ Bender, Heike (1981): Geologische und lagerstättenkundliche Untersuchungen im Nordteil der Hessischen Senke, E. - T I: Die Geologie des Südrandes der Dransfelder Hochfläche östlich von 
Hann. Münden bei Wiershausen und Lippoldshausen. - Teil II: Palynologische und makropetrographische Untersuchungen der Flöze 2 und 3 der Braunkohle am Hirschberg bei Großalmerode (TK 25, Blatt Nr. 4724, Großalmerode). - Dipl.-Kart. u. Dipl.-Arb. [unveröff.] Univ. Göttingen; 173 S.

[Lkr. Göttingen, Werra-Meißner-Kreis]

$\square$ Bogenschneider, Hans-Heiko (1993): Geologische Untersuchung des Gebietes südöstlich von Waldkappel (Nordhessen). - Dipl.-Kart. [unveröff.] Fachber. Geowiss. FU Berlin; 53 S.

$\square$ Bogenschneider, Hans-Heiko (1994): Untersuchung der Terebratel-Zone zwischem dem Ringgau und Sontra (Nordhessen). - Dipl.-Arb. [unveröff.] Fachber. Geowiss. FU Berlin; 55 S.

$\square$ Brandt, Karl-Heinz ((1974): Die Geologie der Unterwerra-Mulde zwischen Witzenhausen und Hedemünden. - Dipl.-Arb. [unveröff.] Univ. Göttingen, 45 S.

$\square$ Brehm, Ulrike (1985): Dynamik von Hangbewegungen an der Wellenkalkschichtstufe des Ringgaus und deren Ursachen. - Dipl.-Arb. [unveröff.] Univ. Göttingen, 92 S.

$\square$ Bröcker, Zoya (1994): Geologie des Gebietes südlich des Wehretales zwischen Waldkappel und Bischhausen (Nordhessen). - Dipl.-Arb. u. Dipl.-Kart. [unveröff.] Fachber. Geowiss. FU Berlin; 64 S.

$\square$ Buchstein, Hella (1984): Zur Lithostratigraphie der Salmünster-Folge bei Eschwege (Nordhessen). Dipl.-Arb. [unveröff.] Fachber. Geowiss. FU Berlin, 130 S.

$\square$ Buchstein, Hella (1984): Geologische Kartierung am Osthand des Wehretals zwischen Wichmannshausen und Reichensachsen (TK 25, Blatt 4825 Waldkappel). - Dipl.-Kart. [unveröff.] Fachber. Geowiss. FU Berlin, 35 S.

- $\square$ Bühmann, Dieter (1970): Tonmineralogische Untersuchungen an tertiären Sedimenten aus dem nördlichen Hessen. - Dipl.-Arb. [unveröff.] Univ. Göttingen, 40 S.

$\square$ Chawki, Nidal (1975): Geologische Untersuchungen beiderseits des unteren Vierbachtals südwestöocj von Eschwege (Bl. 4825) Waldkappel (Nordhessen). - Dipl.-Arb. [unveröff.] Fachber. Geowiss. FU Berlin, $52 \mathrm{~S}$.

$\square$ Clasen, Frauke \& Gehrke, Bettina (1990): Isolierte Muschelkalkschollen auf Röt im Werratal (TK 25: 4624 Hedemünden u. 4625 Witzenhausen). - Dipl.-Arb. Teil II (Dipl.-Kart.) [unveröff.] Univ. Göttingen, 32 S.

$\square$ Dannenberg, Friedrich Karl (1980): Hydrogeologische und hydrologische Bearbeitung des Netratales (südlich von Eschwege, Nordhessen). - Dipl.-Arb. [unveröff.] TU Berlin, 73 S.

$\square$ Dehnavi, Nemati Nematolah (1991): Geologische Kartierung zwischen Asbach und Rothestein (TK 4726 Grebendorf, N-Hessen). - Dipl.-Kart. [unveröff.] Fachber. Geowiss. FU Berlin; 27 S.

$\square$ Ehwald, Siegfried (1991): Geologische Kartierung zwischen Aue und Völkershausen (TK 25, Blatt 4826 Eschwege, Nordhessen), - Dipl.-Kart. [unveröff.] Fachber. Geowiss. FU Berlin; 31 S.

$\square$ E1 Noman, J. (1982): Geologische Kartierung des Gebietes zwischen Blankenbach und Unhausen (Mtbl. Herleshausen 4926), Niederhessen. - Dipl.-Arb. [unveröff.]Fachber. Geowiss. FU Berlin; 48 S.

$\square$ Faupel, Jürgen (1971): Geologische Untersuchungen im NW-Teil des Unterwerra-Sattels. - Dipl.-Arb. [unveröff.] Univ. Göttingen; 110 S. 
$\square$ Feiertag, Alexander \& Wilke, Sabine (1995): Der Hohe Meißner - Geologische Entwicklung und Bodenvergesellschaftung. - 37 S.; BPSII - Arbeit Fachber. 13 (Feiertag); Hausarbeit Fachber. 19 (Wilke); Ghs/Univ. Kassel

$\square$ Felbinger, Dieter (1971): Geologische Untersuchungen auf Blatt 4926 (Herleshausen) unter besonderer Berücksichtigung des Muschelkalks und des Quartärs. - Dipl.-Arb. [unveröff.] Univ. Frankfurt/M., $149 \mathrm{~S}$.

$\square$ Fleer, Petra (1993): Geologie und Grundwasser in Eschwege im Hinblick auf die Baugrundverhältnisse im Stadtgebiet. - Dipl.-Arb. [unveröff.] Fachber. Geowiss. FU Berlin; 41 S.

$\square$ Fleer, P. (1993): Geologische Kartierung der Stadt Eschwege, Nordhessen. - Dipl.-Kart. [unveröff.] Fachber. Geowiss. FU Berlin; 43 S.

$\square$ Führes, Margit (1979): Untersuchungen zur Mineralführung und Geochemie an einem Bohrprofil im Baunkohlengebiet des Hohen Meißners. - Dipl.-Arb. [unveröff.] Univ. Gießen

$\square$ Gangel, Lorant (1970): Geologische Untersuchungen auf Bl. 4826 Eschwege (NE) und auf Bl. 4726 Grebendorf (SE) mit besonderer Berücksichtigung des mittleren und oberen Buntsandsteins und des Quartärs. - Dipl.-Arb. [unveröff.] Univ. Frankfurt/M.; 175 S.

$\square$ Gilani, Farhad D. S. (1993): Korngrößenverteilung, Petrographie und Kornformbestimmung von Mittelterrassenschottern der Werra bei Grebendorf (Hessen). - Dipl.-Arb. [unveröff.] Fachber. Geowiss. FU Berlin; 39 S.

$\square$ Ghamadan, Mohammad Naser (1992): Korngrößenverteilung, Petrographie und Kornformbestimmung von Niederterrassenschottern der Werra (Eschwege, Deutschland). - Dipl.Arb. [unveröff.] Fachber. Geowiss. FU Berlin

$\square$ Grabner, J. S. (1970): Geologische Untersuchungen in der Umgebung von Wanfried. - Dipl.-Arb. [unveröff.] Univ. Frankfurt, 150 S.

$\square$ Haan, Karin (1985): Geologische Kartierungen auf Blatt Eschwege (TK 4826) und Blatt Treffurt (TK 4827) (Leuchtberge, Lotzenkopf, Heldra). - Dipl.-Kart. [unveröff.] Fachber. Geowiss. FU Berlin, 30 S.

$\square$ Haan, Karin (1985): Zur Lithostratigraphie des Unteren Buntsandsteins bei Eschwege in Niederhessen. - Dipl.-Arb. [unveröff.] FU Berlin; 137 S.; Berlin

$\square$ Hachula, Johannes (1983): Struktur und geologische Entwicklung des Sontragrabens in seinem Nordwestteil (Niederhessen). - Dipl.-Arb. [unveröff.] Fachber. Geowiss. FU Berlin, 37 S.

$\square$ Haffer, Jürgen (1956): Zur Stratigraphie und Tektonik des Mittleren Buntsandsteins bei Witzenhausen/Werra. - Dipl.-Arb. [unveröff.] Univ. Göttingen

$\square$ Hagedorn, B. (1987): Geochemie und Petrographie der Diabase des Albunger Paläozoikums. - Dipl.Arb. [unveröff.] TU Braunschweig, $157 \mathrm{~S}$.

$\square$ Hampel, Matthias (1994): Hydrogeologische und hydrochemische Bestandsaufnahme im Eschweger Becken (Nordhessen). - Dipl.-Arb. [unveröff.] Fachber. Geowiss. FU Berlin; 68 S.

$\square$ Hampel, Matthias (1994): Geologische Kartierung bei Niederdünzebach, Aue, Alter Kirche. - Dipl.Kart. [unveröff.] Fachber. Geowiss. FU Berlin; 38 S.

$\square$ Hangebrook, B. (1985): Revisionskartierung des Keupers im Westteil des Netra-Grabens. - Dipl.-Kart. [unveröff.] Ruhr-Univ. Bochum, $47 \mathrm{~S}$. 
$\square$ Hanko-Assfalg, Renate (1985): Geologie des hessischen Anteils auf Blatt Creuzburg (Werra-MeißnerKreis). - 84 S., Dipl.-Arb. [unveröff.] Fachber. Geowiss. FU Berlin

$\square$ Harling, Johannes (1986): Geologische Untersuchung des südöstlichen Meißner-Gebietes. - Dipl.-Arb. [unveröff.] Fachber. Geowiss. FU Berlin; 83 S.

$\square$ Hegerfeld, L. (1978): Geologische Aufnahme des Lettenberges (Meißner) mit Untersuchung der unterirdischen Kohlenbrände. - Dipl.-Arb. [unveröff.] Univ. Gießen, 45 S.

$\square$ Heinecker, Carsten (1989): Hydrogeologische Bestandsaufnahme des TrinkwasserErschließungsgebietes der Stadt Witzenhausen (Hessen). - Dipl.-Arb. [unveröff.] Univ. Göttingen; 79 S.

$\square$ Heldmaier, Wolfram (1992): Zur Geologie am Nordende des Werra-Grauwacken-Sattels, S’Witzenhausen/Nordhessen. - Diplom-Arbeit Teil A (Diplom-Kartierung) [unveröff.] Fachber. Geowiss. Univ. Marburg 1992; 31 S.

$\square$ Heldmaier, Wolfram (1992): Mikrofazies des Zechsteinkalkes (Ca1) auf der Nordhessischen Zechsteinplattform (Buchenauer Schwelle). - Diplom-Arbeit Teil B (Diplom-Arbeit) [unveröff.] Fachber. Geowiss. Univ. Marburg 1992; 94 S.

$\square$ Herrmann, Regina (1986): Geologische Untersuchungen des nordöstlichen Meißnergebietes. - Dipl.Arb. [unveröff.] Fachber. Geowiss. FU Berlin, 94 S.

$\square$ Hintenberg, Anrita (1994): Geologische Untersuchung des Gebietes südöstlich Bischhausen (Nordhessen) unter besonderer Berücksichtigung der Terebratelzone. - Dipl.-Arb. [unveröff.] Fachber. Geowiss. FU Berlin; 108 S.

$\square$ Hofmann, Rudolf (1986): Geologische Kartierung von Nesselröden (TK 25, Blatt 4726 Herleshausen, Nordhessen). - Dipl.-Arb. [unveröff.] Fachber. Geowiss. FU Berlin, 65 S.

$\square$ Holthusen, Henning (1977): Hydrogeologische und hydrochemische Untersuchungen in Sedimenten der Trias südöstlich Eschwege (Nordhessen). - Dipl.-Arb. [unveröff.] Fachber. Geowiss. FU Berlin; $54 \mathrm{~S}$.

$\square$ Holthusen, Henning (1977): Die Geologie des Ringgaus südlich Grandenborn in Nordhessen (TK 4926 Herleshausen). - Dipl.-Kart. [unveröff.] Fachber. Geowiss. FU Berlin; 21 S.

$\square$ Hosseinini-Arab, Ali (1993): Hydrogeologie der Werratalaue nördlich von Eschwege. Dipl.-Arb. [unveröff.] Fachber. Geowiss. FU Berlin, 50, XXXV S..

$\square$ Hosseiini-Arab, Ali (1993): Geologische Kartierung zwischen Langenhain und Weissenborn (Bl. 4826 Eschwege, Nordhessen). - Dipl.-Kart. [unveröff.] Fachber. Geowiss. FU Berlin; 35 S.

$\square \bullet$ Huttel, Peter (1984): Der Westrand des Leinetalgrabens bei Marzhausen (GK25 Reinhausen 4525). Dipl.-Arb. (unveröff.) Univ. Göttingen; 196 S.

$\square$ Karimi, M. (1980): Geologie des Netra-Grabens zwischen Datterode und Netra (TK 4826 Eschwege und 4926 Herleshausen). - Dipl.-Arb. [unveröff.] Fachber. Geowiss. FU Berlin, 79 S.

$\square$ Kersten, Gundula (1986): Geologische Kartierung des südwestlichen Meißner-Gebietes und Bearbeitung der Lagerungsverhältnisse am Hohen Meißner. - Dipl.-Arb. [unveröff.] Fachber. Geowiss. FU Berlin; 118 S.

- $\square$ Klein-Reesink, Josef (1980): Geologische und lagerstättenkundliche Untersuchungen im Nordteil der Hessischen Senke, A. - Teil I: Geologie des Berlepschgrabens. - Teil. II: Petrographische 
Untersuchung der Braunkohle von Borken (Bez. Kassel). - Dipl.-Kart. u. Dipl.-Arb. [unveröff.] Univ. Göttingen; 217 S.

$\square$ Knoche, Götz (1969): Die Trias des östlichen Netratales in Nordhessen. -Dipl.-Arb. [unveröff.] Fachber. Geowiss. FU Berlin,74 S.

$\square$ Koltze, Eberhard (1975): Geologische Untersuchungen am Unterwerra-Sattel zwischen Bad SoodenAllendorf, Hilgershausen und Oberrieden. - Dipl.-Arb. [unveröff.] Univ. Göttingen, 163 S.

$\square$ Kreysing, Klaus (1956): Der Buntsandstein am abtauchenden Werra-Sattel. - Dipl.- Arb [unveröff.] Univ. Göttingen

$\square$ Kross, Günther (1969): Geologische Kartierung des westlichen Netratales unter besonderer Berücksichtigung der Stratigraphie des Mittleren Buntsandsteins. -.Dipl.-Arb. [unveröff.] Fachber. Geowiss. FU Berlin; $80 \mathrm{~S}$

口๑ロKühn, V. \& Neumann, Klaus (1989): Die Quellwässer des Kaufunger Waldes. Hydrochemie und geologischer Untergrund. - Dipl.-Arb. [unveröff.] Univ. Göttingen; 143 S.

$\square$ Kunz, Heinrich (1962): Geologische Untersuchungen auf Blatt 4726 Grebendorf (Niederhessen). Dipl.-Arb. [unveröff.] Univ. Frankfurt, 193 S.

$\square$ Lähne, R. (2003): Hydrodynamik des Talraumes bei Eschwege (Nordhessen). - Dipl.-Arb. [unveröff.] Univ. Halle-Wittenberg

$\square$ Laussat, Petra (1995): Grundwasserbewegung in der Stadt Eschwege (Nordhessen). - Dipl.-Arb. [unveröff.] Fachber. Geowiss. FU Berlin; 45 S.

口Laussat, Petra (1995): Geologische Kartierung der Umgebung der „Blauen Kuppe“ südlich von Eschwege/Nordhessen. - Dipl.-Kart. [unveröff.] Fachber. Geowiss. FU Berlin; 30 S.

$\square$ Liebmann, C. C. (1973): Flächen im Fulda-, Werra-Bergland zwischen Waldkappel und Rotenburg/Fulda, unter besonderer Berücksichtigung der Flächen im Buntsandstein. - Dipl.-Arb. [unveröff.] Fachber. Geowiss. FU Berlin, 118 S.

$\square$ Martin, Wolfgang (1965): Geologie der Umgebung von Weißenborn auf Bl. 4826 Eschwege (Nordhessen). - Dipl.-Arb. [unveröff.] Univ. Frankfurt/M., 89 S.

$\square$ Meier, R. (1991): Geologische Kartierung südlich des Schlierbachs zwischen Völkershausen und Weißenborn bei Eschwege, Nordhessen. - Dipl.-Kart. [unveröff.] Fachber. Geowiss. FU Berlin, 32 S.

$\square$ Natge-Efoughe, Claudia (1997): Geologische Teilkartierung des Blattes Nr. 4624 Ermschwerd (Hedemünden). - Dipl.-Kart. [unveröff.] Univ. Göttingen; 67 S.

$\square$ Nemati-Dehnavi, Nematolah (1991): Geologische Kartierung zwischen Asbach und Rothestein (TK 4726 Grebendorf, Nord-Hessen). - Dipl.-Kart. [unveröff.] Fachber. Geowiss. FU Berlin; 35 S., 4 Abb., 3 Kt.

$\square$ Nieberding, Franz (1972): Geologische Untersuchungen am Südende des Leinetalgrabens (Top. Karte 4625 Witzenhausen). - Dipl.-Arb. [unveröff.] Univ. Göttingen; 67 S.

$\square$ Nöll, Tilo (1973): Die Geologie im Bereich des nördlichen Teils des Altmorschener-Lichtenauer Grabens bei Trubenhausen. - Dipl.-Arb. [unveröff.] Univ. Göttingen; 76 S.

$\square$ Otter, Bettina (1994): Die hydrogeologischen Verhältnisse der Gemarkung Eschwege (Nordhessen). Dipl.-Arb. [unveröff] Fachber. Geowiss. FU Berlin; 63 S. 
$\square$ Otter, Bettina (1994): Geologische Kartierung des westlichen Stadtgebietes von Eschwege (Nordhessen). - Dipl.-Arb. [unveröff] Fachber. Geowiss. FU Berlin; 31 S.

$\square$ Plein, Eberhard (1952): Geologische Untersuchungen im Gebiet von Großalmerode. - Dipl.-Arb. [unveröff.] Univ. Göttingen, 68 S.

$\square \bullet$ Prauss, Michael (1980): Geologische und lagerstättenkundliche Untersuchungen im Nordteil der hessischen Senke - Teil 1: Die Geologie am südöstlichen Ausläufer des Bramwaldes zwischen Schede und Werratal (Bl. Jühne). - Teil 2: Petrographische Untersuchungen der Flöze 2 und 3 der Braunkohle am Hirschberg bei Großalmerode. - Dipl.-Arb. [unveröff.] Univ. Göttingen 1980; Teil 1, 58 S.; Teil 2; $179 \mathrm{~S}$.

$\square$ Rastgoo, Y. (1990): Geologische und mikrofazielle Untersuchungen im Gebiet nordwestlich von Neuerode (Blatt 4726 Grebendorf, Werra-Meißner-Kreis, Nordhessen). - Dipl.-Arb. [unveröff.] Fachber. Geowiss. FU Berlin, 72 S.

$\square$ Ratei, Hans Joachim (1990): Geologische Kartierung auf dem Blatt Eschwege (TK 4826) und auf dem Blatt Grebendorf (TK 4726), 1 : 25000. - Dipl.-Kart. [unveröff.] Fachber. Geowiss. FU Berlin, 33 S.

$\square$ Ratei, Hans-Joachim (1992): Boden- und Grundwasserversalzung der Werratalaue bei Eschwege (Nordhessen). - Dipl.-Arb. [unveröff.] Fachber. Geowiss. FU Berlin; 101 S., LXIII S. Anhang

$\square$ Reza, Vashmeh Hamid (1993): Geologische und mikrofazielle Untersuchungen im Gebiet von Bad Sooden-Allendorf (Blatt 4625 Witzenhausen, Nordhessen). - Dipl.-Arb. [unveröff.] Fachber. Geowiss. FU Berlin; 36 S.

$\square$ Rissiek, Rolf (1985): Feuchtstandorte am Hohen Meißner. Konstituierende und charakterisierende Parameter. - Dipl.-Arb. [unveröff.] FB Geowissenschaften FU Berlin. - 102 S., 31 Abb., 6 Tab. [Bodenkunde]

$\square$ Röhling, Heinz-Gerd (1982): Zur Geologie auf Blatt 4824 (Hessisch Lichtenau). - Dipl.-Arb. [unveröff.] Univ. Gießen

$\square$ Rothstein, Antje (1991): Geologie des Sontraer Grabens zwischen Sontra und Stadthosbach, Nordhessen (TK 25: 4925 Sontra) mit geologischer Kartierung 1:10.000. - Dipl.-Arb. [unveröff.] Univ. Göttingen; 105 S.

$\square$ Samai, Abbas (1979): Geolgische Kartierung des Ringgaus zwischen Breitau und Grandenborn (TK 25 Nr. 4926 Herleshausen Niederhessen). - Dipl.-Arb. [unveröff.] Fachber. Geowiss. FU Berlin, 20 S.

$\square$ Schalow, Günter (1978): Geologie des Gebietes zwischen Hilgershausen und Frankershausen auf der Südwestflanke des Unterwerra-Sattels (TK 25 Bl. Nr. 4725 Bad Sooden-Allendorf, Nordhessen]. Dipl.-Arb. [unveröff.] Univ. Göttingen; 192 S.

$\square$ Schlösser, Inga (1989): Hydrogeologische und hydrochemische Untersuchungen im südöstlichen Vorland des Hohen Meißners. - Dipl.-Arb. [unveröff.] Fachber. Geowiss. FU Berlin, 89 S.

$\square$ Schulz, Dirk-Olaf (1993): Petrographische Untersuchungen am Flöz 1 des Braunkohlevorkommens am Hirschberg. - Dipl.-Arb. [unveröff.] Univ. Göttingen; 68 S.

$\square$ Schulz, Dirk-Olaf (1994): Geologische Teilkartierung des Blattes 4724 Großalmerode; Dipl.-Kart. [unveröff.] Univ. Göttingen; 57 S.

$\square$ Schulz, Klaus-Hasse (1981): Die Geologie des südöstlichen Teils des Blattes Nr. 4725 Bad SoodenAllendorf (nördliches Hessen, Unterwerra-Sattel) und eine mikrofazielle Analyse des Zechsteinkalks (Ca1). - Dipl.-Arb. [unveröff.] Univ. Göttingen, 156 S. 
$\square$ Schulze, Hartmut (1977): Geologische Untersuchungen im Zentrum des Unterwerra-Sattels unter besonderer Berücksichtigung der Tektonik und der Petrographie der Werra-Grauwacke. - Dipl.-Arb. [unveröff.] Univ. Göttingen, $116 \mathrm{~S}$.

$\square$ Schuster, Joachim (1986): Geologie des Sontraer Grabnes zwischen Sontra und Weißenborn (Nordhessen) (GK 25: 4925 Sontra). - Dipl.-Arb. (unveröff.) Univ. Göttingen, 190 S.

$\square$ Spierling, Paul (1985): Hydrogeologische und hydrochemische Untersuchungen zum Grundwasserhaushalt in einem Buntsandsteingebiet des südlichen Meißner-Vorlandes (Nordhessen). Dipl.-Arb. [unveröff.] Fachber. Geowiss. FU Berlin, 97 S.

$\square$ Spierling, P. (1985): Geologische Kartierung des Trimberges und des östlichen Vierbachtales südwestlich von Eschwege (Nordhessen). - Dipl.-Kart. [unveröff.] Fachber. Geowiss. FU Berlin, 32 S.

$\square$ Stützer, Andrea (1986): Geomorphologische Aufnahme, Kartierung und Geomorphotopengefüge im Mittelgebirge zwischen Eschwege und Herleshausen. - Dipl.-Arb. [unveröff.] Fachber. Geowiss. FU Berlin

$\square$ Taute, Thomas (1992): Die hydrogeologischen Verhältnisse auf der Gemarkung Meinhard (Nordhessen). - Dipl.-Arb. [unveröff.] Fachber. Geowiss. FU Berlin, 100 S.

$\square$ Taute, Thomas (1992): Geologische Kartierung zwischen Kellaer Bach und Frieda nordöstlich von Eschwege (Nordhessen). - Dipl.-Kart. [unveröff.] Fachber. Geowiss. FU Berlin, 34 S.

$\square$ Theurer, Gabriele (1983): Ursachen zunehmender Gesamtmineralisation in Wässern aus einzelnen Trinkwasserfassungsanlagen der Stadtwerke Eschwege. - Dipl.-Arb. [unveröff.] Fachber. Geowiss. FU Berlin; XIII, 132 S.

$\square$ Theurer, Gabriele (1983): Geologische Kartierung im Sontragraben bei Ulfen (TK 4926) Maßstab 1: 10.000. - Dipl.-Kart. [unveröff.] Fachber. Geowiss. FU Berlin, 24 S.

$\square$ Things, Wolfgang (1992): Geologische Kartierung zwischen Weißenborn und Großburschla (Bl. 4826 Eschwege, Nordhessen). - Dipl.-Kart. [unveröff.] Fachber. Geowiss. FU Berlin; 40 S.

$\square$ Thom, Sabine (1991): Geologische Kartierung bei Grebendorf und Schwebda nördlich von Eschwege. - Dipl.-Kart. [unveröff.] Fachber. Geowiss. FU Berlin, 51 S.

$\square$ Thom, Sabine (1992): Grundwasserversalzung in der Werratalaue bei Eschwege (Nordhessen). Eine hydrochemische und hydrogeologische Untersuchung. - Dipl.-Arb. [unveröff.] Fachber. Geowiss. FU Berlin; 154 S.

$\square$ Toofani Milani, Hossein (1987): Geologie des Südteils des Hohen Meißners (TK 4825, Waldkappel, Nordhessen). - Dipl.-Arb. [unveröff.] Fachber. Geowiss. FU Berlin, 78 S.

口Ullmann, W. (1985): Geologische Kartierung in der Umgebung von Unhausen, Werra-Meißner-Kreis (TK 25, 4926 Herleshausen). - Dipl.-Arb.[unveröff.] Fachber. Geowiss. FU Berlin, 42 S.

$\square$ Vogt, A. (1992): Zur Geologie des Gebietes östlich von Hundelshausen (Werra-Grauwackengebirge, Nord-Osthessen) - Teil. I: Kartierbericht - Teil II: Gefährdungsabschätzung im Sulfatkarst östlich von Hundelshausen (Kartierung, Hydrogeologie, Petrographie und Geophysik). - Dipl.-Arb. [unveröff.] Univ. Marburg; 71 S.

$\square$ Walther, Manfred (1978): Geologie des nördlichen Hohen Meißners (Nördliches Hessen, GK 25 Bad Sooden-Allendorf 4725). - Dipl.-Arb. [unveröff.] Univ. Göttingen; 151 S. 
口Weik, S. (1989): Geologie des nördlichen Meißner-Vorlandes. - Dipl.-Arb. [unveröff.] Fachber. Geowiss. FU Berlin; 47 S.

$\square$ Wenzel, Bernward (1983): Geologische Untersuchungen auf Blatt 4824 Hessisch Lichtenau NW-Teil. Dipl.-Arb. [unveröff.] Univ. Gießen

$\square$ Wolf, Daniel (2002): Sedimentation und pedogene Bildungen der Solling-Folge bei Eschwege/NEHessen. - Dipl.-Arb./Dipl.-Kart. [unveröff.] Univ Göttingen; 26, 27 S.

- $\square$ Wollenhaupt, Hartmut (1980): Geologische und lagerstättenkundliche Untersuchungen im Nordteil der Hessischen Senke - B. - Teil I: Die Geologie des Nordrandes des Leinholz-Gewölbes zwischen Berge und Mollenfelde (TK 4525 Reinhausen und TK 4625 Witzenhausen). - Teil II: Palynologische und petrographische Untersuchungen der Braunkohle von Schneppenhain (TK5021 Ziegenhain). Dipl.-Kart. u. Dipl.-Arb. [unveröff.] Univ. Göttingen, 151 S.

$\square$ Woyzechowski, Sonja (1984): Biofazies des Trochitenkalkes im Bereich des Netragrabens und des Ringgaues (Nordhessen). - Dipl.- Arb. [unveröff.] Fachber. Geowiss. FU Berlin 1984

$\square$ Wurl, Jobst (1988): Hydrogeologische und hydrochemische Untersuchungen im östlichen Vorland des Hohen Meißners und am Unterwerra-Sattel (Bl. 4725 Bad Sooden-Allendorf). - Dipl.-Arb. [unveröff.] Fachber. Geowiss. FU Berlin, 102 S.

$\square$ Yaghoobi, Behroos (1972): Geologische Kartierung im Suntergraben auf Blatt 4825 Waldkappel (Nordhessen). - Dipl.-Arb. [unveröff.] Fachber. Geowiss. FU Berlin, 63 S.

$\square$ Youssefi, Mahmoud (1977): Geologie des Wellingeröder Plateaus bei Eschwege. Topographische Karte 1 : 250004725 Bad Sooden-Allendorf und 4825 Waldkappel (Nordhessen). - Dipl.-Arb. [unveröff.] Fachber. Geowiss. FU Berlin, 48 S.

\subsubsection{Thüringen}

OBartholomäus, K. (1957): Bodensenkungen im Gefolge des Solverfahrens im Rötsalz von Buchenau. Dipl.-Arb. [unveröff.] Bergakademie Freiberg 1957

QBehrendt, L. (1961): Beitrag zur Kenntnis des Blattes Tambach-Dietharz. - Dipl.-Arb. [unveröff.] [Humboldt-Univ.?] Berlin 1961

QBlum, H. (1959): Feinstratigraphische Untersuchungen des Unteren Muschelkalkes im Bereich der Hörselberge und im Raum Creuzburg-Treffurt. - Dipl.-Arb. [unveröff.] Univ. Halle

QDittrich, E. (1954): Zur Kenntnis der Struktur von Langensalza. - Dipl.-Arb. [unveröff.] Univ. Jena

QEngel, J. C. (1999): Geologische Kartierung im Raum Ferna. - Dipl.-Kart. [unveröff.] Univ. Hannover 1999

OEyrich, A. (1964): Der Tambacher Sandstein. - Dipl.-Arb. [unveröff.] [Humboldt-Univ.?] Berlin 1964; $71 \mathrm{~S}$.

OFahlbusch, Klaus (1953): Die Saalfeld-Gotha-Eichenberger-Störungszone im Gebiet von Arnstadt. Dipl.-Arb. [unveröff.] Univ. Berlin 1953

Referat in: Geologie, 4 (2): 200; Berlin 1955 
QFarshad, Farhad (1995): Geologische Kartierung der Trias im Osten des Eichenberger Grabenknotens zwischen Arenshausen und Gerbershausen in Thüringen (TK 25 Blatt 4625 Witzenhausen). - Dipl.Kart. [unveröff.] Univ. Göttingen; 50 S.

GGilani, Farhad D. S. (1992): Geologische Kartierung des Gebietes nördlich von Ifta - Blatt TK 4927. Dipl.-Kart. [unveröff.] Fachber. Geowiss. FU Berlin; 25 S.

ØGlässer, H. (1961): Beitrag zur Kenntnis des Blattes Tambach-Dietharz. - Dipl.-Arb. [unveröff.] [Humboldt-Univ.?] Berlin 1961; 100 S.

GGötz, Annette E. (1992): Feinstratigraphie und Tektonik am Südwestrand des Creuzburger Grabens. Dipl.-Arb. [unveröff.] TH Darmstadt; Darmstadt [Unterer Muschelkalk]

QGreulich, Christa (1958): Über das Verhalten der Spurenelemente der Werra-Serie in der Schachtanlage „Marx-Engels“ Unterbreizbach/Rhön. - Dipl.-Arb. [unveröff.] Bergakademie Freiberg/Sa. 1958 Referat in: Geologie, $\underline{8}$ (8): 910; Berlin 1959

QHenke, Bernd (1997): Geologische Kartierung im nordöstlichen Teil des Eichenberg-Gothaer-Grabens in Thüringen (TK 25, Blatt 4625 Witzenhausen, Blatt 4626 Heiligenstadt). - Dipl.-Kart. [unveröff.] Univ. Göttingen; 99 Bl.

OJacobi, K. (1993): Geologische Kartierung der Trias am Südwestrand des Eichenberg-Gothaer-Grabens in Thüringen (TK 25 Blatt 4625 Witzenhausen). - Dipl.-Kart. (unveröff.) Univ. Göttingen; 66, 93 S. [die Vorlage enthält 2 Werke: Dipl.-Arb. u. Dipl.-Kart)

OJanson, Johann (1957): Die Mächtigkeit des Buntsandsteins und des Muschelkalkes im Nordwestteil des Thüringer Beckens auf Grund von Tiefbohrungen, Tagesaufschlüssen und Schachtprofilen. Dipl.-Arb. [unveröff.] Bergakademie Freiberg/Sa. 1957; 47 S.

Referat in: Geologie, $\underline{8}(2): 213$; Berlin 1959

OJohn, K. H. (1964): Beitrag zur Revisionskartierung des Blattes Waltershausen-Friedrichroda. - Dipl.Arb. [unveröff.] [Humboldt-Univ.?] Berlin 1964; 77 S.

QKaemmel, Thomas (1954): Untersuchungen im Thüringer Hauptgranitmassiv, besonders bei Suhl. Dipl.-Arb. [unveröff.] Univ. Berlin 1954

Referat in: Geologie, 4 (2): 194; Berlin 1955

OKirchhoff, Torsten (1999): Geologische Kartierung der Muschelkalkhochfläche des Röhringberges im Bereich Birkenfeld, Röhrig, Thalwenden in Westthüringen (TK 25 Blatt 4626 Heiligenstadt). - Dipl.Kart. [unveröff.] Univ. Göttingen 1999; 40 Bl., Anhang + 2 Kt.-Beil.

QKray, Markus (1994): [II.] Geologische Kartierung der Trias am Südwestrand des Eichenberg-GothaerGrabens bei Fretterode in Thüringen ( TK 25; Blatt 4625 Witzenhausen, 4626 Heiligenstadt, 4725 Bad Sooden-Allendorf, 4726 Grebendorf) - Dipl.- Kart. [unveröff.] Univ. Göttingen. - 44 S.

ONeumann, W. (1951): Kristalline Schiefer bei Ruhla. - Dipl.-Arb. [unveröff.] Univ. Berlin 1951, 44 S. Referat in: Geologie, 1: 400; Berlin

OPetri, Rüdiger (2004): Fluviatile Architektur der Solling-Folge bei Marth, Eichsfeld-Kreis (Thüringen). - Bachelor-Examensarbeit [unveröff.] Univ. Göttingen, 30 Bl.

OPorstmann, E. (1961): Die Manebacher Schichten im Gebiet nordöstlich Goldlauter-Heinebach (Blatt Suhl). - Dipl.-Arb. [unveröff.] Univ. Jena, 76 S.

OPratzka, G. (1956): Lagerstättengeologische Bearbeitung der Flußspat-Schwerspatlagerstätten in der Umgebung von Trusetal/Thür. - Dipl-Arb. [unveröff.] Bergakademie Freiberg/Sa. 1956 
ORekabsaz, Mohammed Taghi (1993): Geologische Untersuchungen an der Hessisch-Thüringischen Grenze zwischen Klein Töpfer und Hildebrandshausen. - Dipl.-Arb. [unveröff.] Fachber. Geowiss. FU Berlin; $89 \mathrm{~S}$.

ORentzsch, Johannes (1956): Untersuchungen der Flußspatvorkommen des Thüringer Waldes. - Dipl.Arb. [unveröff.] Bergakademie Freiberg i. S.

Referat in: Geologie, ㅁ: 454; Berlin 1957

[darin: Floßberggang - Steinbach, Mommel, Hühn i.d. Region Steinbach - Schmalkalden]

ORietschel, Manfred (1957): Der Einfluß der Tektonik auf die Ausbildung des unteren und oberen Kalilagers im Bereich der Schachtanlage Dietlas I. - Dipl.-Arb. [unveröff.] Bergakademie Freiberg/Sa., $48 \mathrm{~S}$.

Referat in: Geologie, $\underline{\mathbf{8}}(2):$ 216-217; Berlin 1959

ORost, Ursula (1957): Erdöl- und Erdgasvorkommen in den Kaliwerken des Werragebietes und des nordöstlichen Teiles des Thüringer Beckens. - Dipl.-Arb. [unveröff.] Bergakademie Freiberg/Sa. 1957, $60 \mathrm{~S}$.

Referat in: Geologie, $\underline{\mathbf{8}}(2): 217$; Berlin 1959

ORuhnke, A. (1986): Petrographische Charakterisierung von basischen Vulkaniten des Werra-Gebietes. Dipl.-Arb. [unveröff.] Univ. Greifswald

OSchneider, C. (1999): Geologische Kartierung im Raum Ferna. - Dipl.-Kart [unveröff.] Univ. Hannover 1999

OSlotta, J. (1966): Beitrag zur Revisionskartierung der Blätter 1. Waltershausen-Friedrichroda (Nr. 5129) (Zechstein und Buntsandstein) - 2. Tambach-Dietharz (Nr. 5229) (Buntsandstein). - Dipl.-Arb. [unveröff.] [Humboldt-Univ.?] Berlin 1966

OSpecht, Heiner (1994): [Teil 2] - Geologische Kartierung des Höhebergzuges zwischen GothaEichenberg-Graben und Werra (westliches Thüringen, TK 25, 4625) im Maßstab 1 : 10000. - Dipl.Kart. [unveröff.] Univ. Göttingen, 63 S.

[Die Vorlage enthält 2 Werke: Dipl.-Arb. und Dipl.-Kart]

OStammeyer, P. (1965): Feinstratigraphische Untersuchungen im Unteren Muschelkalk von NWThüringen (Eichsfeld, Hainich und westlicher Dün). - Dipl.-Arb. [unveröff.] Humboldt-Univ. Berlin

OStrienitz, Rolf (1962): Paragenetisches und geochemische Untersuchungen verschiedener Salzgesteine der Flöze Thüringen und Hessen. - Dipl.-Arb. [unveröff.] Bergakademie Freiberg/Sa. 1962 Referat in: Geologie, 12(9): 1113-1114; Berlin 1963

[Thür. Werra-Kalirevier]

@Thalheimer, H. (1965): Die Tambacher Schichten. - Dipl.-Arb. [unveröff.] [Humboldt-Univ.?] Berlin 1965

○Tremel, Heike (2000): Die Geologie am Südostrand des Leinetalgrabens bei Arenshausen, Westhüringen (TK 25: 4625 Witzenhausen). - Dipl.-Kart. [unveröff.] Univ. Göttingen; 44 Bl.

OU1rich, Horst (1956): Untersuchung des Eisenmanganerz-Schwerspatvorkommens von Schmalkalden /Thür. - Dipl.-Arb. [unveröff.] Bergakademie Freiberg i. S. 1956 Referat in: Geologie, ㅁ: 456; Berlin 1957

OVoland, Bernd (1965): Differentiationserscheinungen an einem olivinführenden Dolerit der Bohrung Schnellbach 1/62 (sog. „Metadiabas“ vom Hünberg/Thüringer Wald). - Dipl.-Arb. [unveröff.] Bergakademie Freiberg/Sa. 1965

Referat in: Geologie, 14(2): 220-221; Berlin 1965 
oWolf, Hans Joachim (1951): Beitrag zur Geologie und Hydrogeologie der Oberrotliegendmulde von Tambach in Thüringen. - Dipl.-Arb. Univ. Berlin 1951, 31 S.

Referat in: Geologie, 1: 400; Berlin 1952

@Zeibig, S. (1983): Strukturelle und substanzmäßige Gesetzmäßigkeiten des Kaliflözes Thüringen im Werra-Kaligebiet. - Dipl.-Arb. [unveröff.] Bergakademie Freiberg/Sa. 1983

\subsubsection{Niedersachsen}

-Alexa, Christian (1988): Geologische Teilkartierung auf Blatt Dransfeld 4424, östlich Ossenfeld. Dipl.-Arb. [unveröff.] Univ. Göttingen 1988; 41 S.

-Adeyemi, Adekunle (1978): Muschelkalk und Keuper am Ostrand des Leinetalgrabens nordöstlich Göttingen TK 25: 4425 Göttingen; Dipl.-Arb. [unveröff.] Geol.-Paläont. Inst. Univ. Göttingen, 142 S.

-Anders, Carsten (1998): Oberer Muschelkalk und Unterer Keuper in der Bohrung 10 Deiderode (Trias, südliches Niedersachsen). - Die Geologie beiderseits der Arenshäuser Verwerfung, südlicher Leinegraben, nördlich Kirchgandern und Arenshausen, West-Thüringen, Süd-Niedersachsen (TK 25: 4625 Blatt Witzenhausen). - Dipl.-Arb. /Dipl.-Kart. (unveröff.) Univ. Göttingen, 65,33 Bl.

-Archner, Gundolf (1992): Ingenieurgeologische Kartierung der Stadt Göttingen- Blatt Groß Ellershausen Süd (TB Nord) mit Erläuterungen. - Dipl.-Arb. [unveröff.] Univ. Göttingen 1992; 32 S., ca. 110 ungez. S.

-Bake, Rolf (1979): Ingenieurgeologische Kartierung der Altstadt Göttingen, Teilblatt Nord. - Dipl.-Arb. [unveröff.] Univ. Göttingen 1979; 137 S.

-Bartel, Gudrun (1990): Ingenieurgeologische Kartierung der Stadt Göttingen - Teilblatt Groß Ellershausen (Mitte). - Dipl.-Arb. [unveröff.] Univ. Göttingen 1990; 107 S.

-Bartholomä, Manuela (1987): Der Sand vom Hohen Hagen - Ingenieurgeologische Untersuchung eines Baustoffes. - Dipl.-Arb. [unveröff.] Univ. Göttingen 1987; 62 S.

-Bartholomä, Manuela (1987): Geologische Kartierung im Maßstab 1 : 10000 mit Erläuterungen des Teilblattes Bühren-Nord auf der topographischen Karte TK 25: 4524 Scheden. - Dipl.-Arb. [Dipl.Kart.] Unvi. Göttingen 1987; 26 S.

-Baucks, Volker (1993): Ingenieurgeologische Kartierung der Stadt Göttingen - Teilblatt Rosdorf (NENord). - Dipl.-Arb. [unveröff.] Univ. Göttingen 1993; 100 S.

-Beer, Wolfgang (1977): Röt und Unterer Muschelkalk am Ostrand des Göttinger Waldes zwischen Södderich und Billingshausen (TK 25: 4425 Götttingen, 4426 Waake, 4326 Lindau). - Dipl.-Arb. [unveröff.] Univ. Göttingen, $176 \mathrm{~S}$.

- $\square$ Bender, Heike (1981): Geologische und lagerstättenkundliche Untersuchungen im Nordteil der Hessischen Senke, E. - T I: Die Geologie des Südrandes der Dransfelder Hochfläche östlich von Hann. Münden bei Wiershausen und Lippoldshausen. - Teil II: Palynologische und makropetrographische Untersuchungen der Flöze 2 und 3 der Braunkohle am Hirschberg bei Großalmerode (TK 25, Blatt Nr. 4724, Großalmerode). - Dipl.-Kart. u. Dipl.-Arb. [unveröff.] Univ. Göttingen; 173 S. 


\section{[Lkr. Göttingen, Werra-Meißner-Kreis]}

-Bindseil, Tatjana (2001): Der Rand des Leinetalgrabens zwischen Reiffenhausen und Kirchgandern (TK 32-D-d-2 Arenshausen und TK 25: 4525 Friedland). - Dipl.-Kart. [unveröff.] Univ. Göttingen; 41 $\mathrm{Bl}$.

- Birkefeld, Andreas (1997): Ingenieurgeologische Kartierung entlang der Bundesautobahn A 7 (km 264,38 - 268,35). - Dipl.-Kart. [unveröff.] Univ. Göttingen; 100 Bl.

-Böhme, Thomas (1984): Geologie des westlichen Leinetal-Grabenrandes zwischen Mariengarten, Elkershausen und Dahlenrode (GK25: 4925 Reinhausen). - Dipl.-Arb. [unveröff.] Univ. Göttingen; $127 \mathrm{~S}$.

-Böttcher, Gerd (1988): Der Stofftransport der Leine und ihrer Nebenflüsse in suspendierter Form zwischen der Grenze zur DDR und Northeim. - Dipl.-Arb. [unveröff.] Univ. Göttingen 1988; 75 S.

-Breuer, Rolf (1990/91): Ingenieurgeologische Kartierung der Stadt Göttingen - Blatt Elliehausen (Teilblatt Nord). - Dipl.-Arb. [unveröff.] Univ. Göttingen 1990/91; 87 S., ca. 30 ungez. Bl.

-Brocke, Reiner (1987): Palynologische Untersuchungen im Oberen Muschelkalk und seinem Grenzbereich westlich Göttingen. - Geologische Teilkartierung auf Blatt 4425 Dransfeld zwischen Barterode und Imbsen. - Dipl.-Arb. [unveröff.] Univ. Göttingen 1987; II, 75,83 S.

-Brüggemann, Karl (1959): Stratigraphie und Tektonik des Mittleren Buntsandsteins im Raume Hannoversch-Münden. - Dipl.-Arb. [unveröff.] Univ. Göttingen 1959; 42 S.

-Bubenik, Rolf (1990): Ingenieurgeologische Kartierung der Stadt Göttingen - Blatt Groß Ellershausen - Teilblatt Süd. - Dipl.-Arb. [unveröff.] Univ. Göttingen 1990; 118 S.

-Burchard, Angelika (1995): Ingenieurgeologische Kartierung der Stadt Göttingen - Blatt Göttingen 4425/22 (DGK 5). - Dipl.-Kart. [unveröff.] Univ. Göttingen 1995; 28 S.

-Daneshmand, Hayedeh (1991): Ingenieurgeologische Kartierung der Stadt Göttingen - Teilblatt Grone Nordost (Süd). - Dipl.-Arb. [unveröff.] Univ. Göttingen 1991; 70 S. u. ca. 85 ungez. Bl.

-Deichmann, Thomas (1979): Ingenieurgeologische Kartierung der Altstadt von Göttingen - Teilblatt Altstadt Süd. - Dipl.-Arb. [unveröff.] Univ. Göttingen 1979; 114 S.

-Diesing, Hans-Jörg \& Ledendecker, Stefan (1986): Die Niederterrasse im Subrosionsbecken von Pöhlde. Mit einem Kataster von grundwassergefährdenden Deponien. - Dipl.-Arb. [unveröff.] Univ. Göttingen 1986; 157 S.

-Dirks, Erwin (1993): Ingenieurgeologische Kartierung der Stadt Göttingen DGK 5 (Blatt Göttingen Nordwest) Nr. 4425/15. - Dipl.-Arb. Teil 1 [unveröff.] Univ. Göttingen 1993; 72 S.

-Dubrall, André (1990): Der Westrand des Leinetal-Grabens zwischen Lenglern und Harste (TK 25: 4324, 4325, 4424, 4425]. - Dipl.-Arb. [unveröff.] Univ. Göttingen 1990; 38,45 Bl.

-Dünkel, Helmut (1987): Geologie der Dransfelder Hochfläche östlich Jühnde, südliches Niedersachsen - [Übergeordneter Titel]

Teil 1: Sedimentologische Untersuchungen im Bereich der Schaumkalkbände [Dipl.-Arb. ]

Teil 2: Kartierung der südlichen Dransfelder Hochfläche, östlich Jühnde (Dipl.-Kart. ]

Dipl.-Arb. u. Dipl.-Kart. [unveröff.] Univ. Göttingen, 238 S.

-Edel, Beate von (1995): Ingenieurgeologisches Kartenwerk der Stadt Göttingen auf Basis der Deutschen Grundkarte (DGK 5), Blatt Geismar-West Nr. 4425/18 - Maßstab 1 : 5 000. - Dipl.-Kart. [unveröff.] Univ. Göttingen 1995; 1 Mappe m. Textbd. 18 Bl.; Anlagenbd. m. 7 Kt.) 
-Feldmann, Reinhard (1983): Ingenieurgeologische Kartierung der Stadt Göttingen - Teilblatt Geismar-Süd; Dipl.-Arb. [unveröff.] Univ. Göttingen 1983; 170 S., 14 ungez. Bl.

-Fleck, Alexander (1990): Hydrogeologie des Göttinger Waldes - Hydrogeologische Kartierung und Jahresbilanz. - Dipl.-Arb. [unveröff.] Univ. Göttingen 1990; 222 Bl.

- Fleitmann, Dominik (1997): Kartierung einer salinartektonischen Struktur bei Wibbecke, GK 25: 4424 Dransfeld. - Dipl.-Kart. [unveröff.] Univ. Göttingen; 68 S.

- Friese, Bernd (1980): Unterer Muschelkalk und Buntsandstein am Südostrand des Göttinger Waldes und am Hengstberg (TK 25: 4426 Ebergötzen). - Dipl.-Arb. [unveröff.] Univ. Göttingen 1980; 146 S.

- Gazawe, Camal (1990): Ingenieurgeologische Kartierung der Stadt Göttingen - Blatt Elliehausen Teilblatt Mitte. - Dipl.-Arb. [unveröff.] Univ. Göttingen 1990; 82 S.

-Gischler, Eberhard (1988): Der Westrand des Leinetal-Grabens zwischen Elliehausen und Lenglern (TK25: 4425 Göttingen). - Dipl.-Arb. [unveröff.] Univ. Göttingen; 177 S.

- Gottschalk, Jürgen (1982): Ingenieurgeologische Kartierung der Stadt Göttingen, Teilblatt Treuenhagen. - Dipl.-Arb. [unveröff.] Univ. Göttingen, 98 S.

- Grossmann, Axel (1988): Ingenieurgeologische Kartierung der Stadt Göttingen - Teilblatt Grone Mitte. - Dipl.-Arb. [unveröff.] Univ. Göttingen 1988; 126 S.

- Heckert, Peter (1994): Ingenieurgeologische Kartierung der Stadt Göttingen - Blatt Elliehausen 4425/14 (DGK 5). - Dipl.-Kart. [unveröff.] Univ. Göttingen 1994; Textbd. 15 S., 8 Beil zus. i. Mappe

-Heinrich, Hartmut (1977): Oberer Buntsandstein und Unterer Muschelkalk am Nordrand des Göttinger Waldes zwischen Leinetal-Graben und Billingshausen (TK 25: 4325 Nörten-Hardenberg, 4326 Lindau, 4425 Waake). - Dipl.-Arb. [unveröff.] Inst. Univ. Göttingen, 143 S.

-Hoffmann, Veit Enno R. K. (2004): Sedimentologie und Paläontologie des Rhätkeupers der Tongrube Hottenrode (Ober-Trias, Landkreis Göttingen) an der Grenze zu Nordhessen. - Bachelor-Arbeit Univ. Göttingen 2004; 42 S.

-Hooshyar, Farhad (1990): Ingenieurgeologische Kartierung der Stadt Göttingen - Blatt Grone, Teilblatt Nordost (Mitte). - Dipl.-Arb. [unveröff.] Univ. Göttingen 1990; 74 Bl.

-Horn, Manfred (1958): Zur Stratigraphie und Tektonik des Mittleren Buntsandsteins zwischen Harz und Solling. - Dipl.-Arbeit [unveröff.] Univ. Göttingen 1958; 37 S.

$\square \bullet$ Huttel, Peter (1984): Der Westrand des Leinetalgrabens bei Marzhausen (GK25 Reinhausen 4525). Dipl.-Arb. (unveröff.) Univ. Göttingen; 196 S.

-Igers, Ludwig (1984): Der Muschelkalk des Göttinger Waldes zwischen Westerberg und Hollandsgrund (TK 4425 Göttingen, 4426 Ebergötzen, 4525 Friedland, 4526 Gleichen). - Dipl.-Arb. [unveröff.] Univ. Göttingen; 222 S.

-Issendorf, Volker (1993): Hydrogeologie des Einzugsgebietes des Brunnen Lenglern, Gemeinde Bovenden. Mit hydrogeologischer Kartierung 1: 10 000. - Dipl.-Arb. [unveröff.] Univ. Göttingen 1993; 109 S.

-Jahanseir, Darjoush (1990): Der Westrand des Leinetal-Grabens zwischen Erbsen und Lödingsen im Süden, Fehrlingsen-Asche und Hettensen im Norden - TK 25 Blättter 4424 Dransfeld, 4324 Hardegsen. - Dipl.-Arb. [unveröff.] Univ. Göttingen; 115 Bl.. 
-Khanaqa, Polla A. A. (1989): Geologische Teilkartierung auf Blatt Dransfeld Nr. 4424 zwischen Barterode und Ossenfeld. - Dipl.-Arb. [Teil 1] [unveröff.] Univ. Göttingen; 70 S.

-Kleefeldt, Matthias (1977): Geologie der Umgebung von Adelebsen. - Dipl.-Arb. [unveröff.] Univ. Göttingen 1977; 138 S.

-Klug, Stefan (1995): Rutschungen an der Grenze Buntsandsein/Muschelkalk. - Dipl.-Arb. [unveröff.] Univ. Göttingen, 107 S.

[Göttinger Wald, Plesse, Eddigehausen]

-Krakow, Lutz (1986): Ingenieurgeologische Kartierung der Stadt Göttingen - Teilblatt Grone Nord. Dipl.-Arb. [unveröff.] Univ. Göttingen 1986; 145 S.

-Kröninger, Brigitte (1991): Palynologische Untersuchungen an der miozänen Braunkohle von Ostheim (Nordhessen). - Dipl.-Arb. Teil II [unveröff.] Univ. Göttingen 1991; 123 S.

-Kropp, Jürgen (1988): Geologie des Westteils der Dransfelder Hochfläche, westlich Göttingen. - Teil I: Geologische Kartierung des Westteils der Dransfelder Hochlfäche zwischen Varlosen, Scheden und Dransfeld. - Teil II: Stratigraphischer Vergleich tertiärzeitlicher Sande und ihre fazielle Interpretation - Bühren/Dransfelder Stadtwald. - Dipl.-Arb. Teil I u. Teil II [unveröff.] Univ. Göttingen 1988; Teil I: 58 S.; Teil II: $50 \mathrm{~S}$.

-Kukis, Michael (1991): Ingenieurgeologische Kartierung der Stadt Göttingen - Teilblatt Grone Nordwest-Süd - mit ingenieurgeologischer Beschreibung der Lockergesteine. - Dipl.-Arb. [unveröff.] Univ. Göttingen 1991; 95 S., ca. 40 ungez. Bl.

- Lavahuhn, Cordelia (1981): Unterer Muschelkalk und Oberer Buntsandstein am Ostrand des Göttinger Waldes zwischen Herberhausen und Mackenrode (TK 4426 Ebergötzen). - Dipl.-Arb. [unveröff.] Univ. Göttingen; $125 \mathrm{~S}$.

-Leßmann, Bernd (1993): Hydrogeologische Untersuchungen im Pöhlder Becken. - Dipl.-Arb. [unveröff.] Univ. Göttingen; 87 S.

-Leßmann, Bernd (1993): Geologische Kartierung und Hydrogeologie des Rheinhäuser Forstes und seiner Umgebung. - Dipl.-Kart.. [unveröff.] Univ. Göttingen 1993; 70 S.

-Loris, Peter (1990): Ingenieurgeologische Kartierung der Stadt Göttingen mit Beschreibung der Lockergesteine - Blatt Göttingen Nordwest (Teilblatt Nord). - Dipl.-Arb. [unveröff.] Univ. Göttingen 1990; 84 u. ca. 35 ungez. Bl.

-Manns, Michael (1991): Ingenieurgeologische Kartierung der Stadt Göttingen - Teilblatt Rosdorf (NW-Mitte). - Dipl.-Arb. [unveröff.] Univ. Göttingen 1991; 67 u. ca. 60 ungez. Bl.

-Matzke, Stefani (1988): Geologie der südlichen Dransfelder Hochfläche. - Teil 1: Die tertiären Sande des Steinberges bei Meensen. - Teil 2: Geologie des Steinberges bei Meensen. - Dipl.-Arb. [Teil $1 \mathrm{u}$. Teil 2] [unveröff.] Univ. Göttingen 1988; 179 S.

- Meyer, Rolf (1985): Die Stabilität der Hänge an der Wellenkalk-Schichtstufe des Göttinger Waldes. Dipl.-Arb. [unveröff.] Univ. Göttingen 1985; 84 S.

-Möckel, Stefan (1991): Ingenieurgeologische Kartierung Blatt Rosdorf 4425/27-Mitte und bodenmechanische Beschreibung der Lockergesteine. - Dipl.-Arb. [unveröff.] Univ. Göttingen 1991; $84 \mathrm{~S}$.

-Moeller, Heiko (1980): Der Ostrand des Leinetal-Grabens zwischen Groß-Schneen, Ludolfshausen und Reiffenhausen (TK 25: 4525 Reinhausen). - Dipl.-Arb. [unveröff.] Univ. Göttingen; 216 S. 
-Müller, Horst (1957): Stratigraphische und tektonische Untersuchungen im Mittleren Buntsandstein des Bramwaldes. - Dipl.-Arb. Univ. Göttingen 1957

- Peine, Karin (1992): Mikrofazielle Analyse der Grenzbank $\gamma-\partial$ (Jura/Lias) in Göttingen. - Dipl.-Arb. Teil 1 [unveröff.] Univ. Göttingen 1992; 137 S.

-Peine, Karin (1992): Kartierung der südlichen Dransfelder Hochfläche nördlich Atzenhausen. - Dipl.Arb. Teil 2 [unveröff.] Univ. Göttingen; 48 S.

-Pöhlig, Charlotte (1981): Sedimentationsgeschichte des Lutterangers im Unter-Eichsfeld (TK: 4426 Ebergötzen und 4427 Duderstadt). - Dipl.-Arb. [unveröff.] Univ. Göttingen; 135 S.

- Pohl, Andreas (1995): Ingenieurgeologische Kartierung Blatt Holtensen West (Teilblatt Süd) - DGK 4425/8 mit Erläuterungen. - Dipl.-Arb. u. Dipl.-Kart. [unveröff.] Univ. Göttingen 1995

$\square \bullet$ Prauss, Michael (1980): Geologische und lagerstättenkundliche Untersuchungen im Nordteil der hessischen Senke - Teil 1: Die Geologie am südöstlichen Ausläufer des Bramwaldes zwischen Schede und Werratal (Bl. Jühne). - Teil 2: Petrographische Untersuchungen der Flöze 2 und 3 der Braunkohle am Hirschberg bei Großalmerode. - Dipl.-Arb. [unveröff.] Univ. Göttingen 1980; Teil 1, 58 S.; Teil 2; $179 \mathrm{~S}$.

-Rahnema, Assadulla (1979): Die Geologie des Göttinger Waldes zwischen Herberhausen und Waake (TK 25 Göttingen 4425 und Waake 4426). - Dipl.-Arb. [unveröff.] Univ. Göttingen 1979; 89 S.

- Rebers, Hartmut (1987): Oberer Muschelkalk und Unterer Keuper im Einschnitt der DBNeubaustrecke Hannover-Würzburg ( $\mathrm{km} \mathrm{105,600} \mathrm{-} \mathrm{108,420)} \mathrm{südlich} \mathrm{Olenhusen} \mathrm{bei} \mathrm{Göttingen} \mathrm{(Trias,}$ südliches Niedersachsen). - Dipl.-Arb. Teil 1 [unveröff.] Univ. Göttingen 1987; 86 S.

- Rebers, Hartmut (1987): Geologie der Muschelkalkfläche zwischen Settmarshausen und Mengershausen bei Göttingen (Muschelkalk, Keuper, südliches Niedersachsen). - Dipl.-Arb. Teil 2 [unveröff.] Univ. Göttingen 1987; 58 S.

-Rettberg, Herbert (1991): Die Foraminiferen-Fauna der Wasserbohrung Milchhof Göttingen aus dem Lias. - Dipl.-Arb. [unveröff.] Univ. Göttingen; 111 S.

-Rettberg, Herbert (1991): Kartierung des Keupers und Lias im Neubaugebiet von Weende Nord bei Göttingen (TK 25: 4425 Göttingen). - Dipl.- Kart. [unveröff.] Univ. Göttingen; 72,29 S.

-Rexhäuser, H. (1958): Zur Stratigraphie und Tektonik des Mittleren Buntsandsteins zwischen Gelliehausen und Holzerode. - Dipl.-Arb. [unveröff.] Univ. Göttingen 1958; 41 S.

-Schaub, Klaus (1981): Geologische und lagerstättenkundliche Untersuchungen im Nordteil der Hessischen Senke - F. - Teil I: Die Geologie im Südteil der Dransfelder Muschelkalk-Hochfläche zwischen Meensen, Jühnde, Barlissen und Atzenhausen (TK 25 Jühnde, 4524). - Teil II: Petrographische Untersuchungen an der Braunkohle von Ostheim (Bez. Kassel). - Dipl.-Kart. u. Dipl.-Arb. [unveröff.] Univ. Göttingen; 101 S.

-Schlüter, Petra (1992): Palynologie des Rhät-Lias-Grenzbereichs im Neubaugebiet von Weende-Nord bei Göttingen. - Dipl.-Arb. [unveröff.] Univ. Göttingen 1992; 105 S.

-Schmucker, Ulrich (1956): Magnetische Untersuchungen am Basaltkörper des Steinberges/Barlissen. Dipl.-Arb. [unveröff.] Univ. Göttingen; 93 S.

-Schneider, Albert (1957): Zum Mittleren Buntsandstein im Gebiet des Bremker Waldes. - Dipl.- Arb. [unveröff.] Univ. Göttingen 
-Schröder, Heinz Gerd (1977): Geologie und Tektonik am Leinetal-Grabenrand zwischen Bovenden und Nörten-Hardenberg (TK 25 Nörten-Hardenberg/TK 25 Göttingen). - Dipl.-Arb. [unveröff.] Univ. Göttingen; III, 134 S.

-Schröder, Lothar (1960): Der Mittlere Buntsandstein im Raume Suterode, SE’ Northeim. - Dipl.-Arb. [unveröff.] Univ. Göttingen; 67 S.

-Schulten, Annette (1992): Ingenieurgeologische Grundlagen für die Stadtentwicklungsplanung mit der ingenieurgeologischen Kartierung des Teilblattes Holtensen Ost (Südteil). - Dipl.-Arb. [unveröff.] Univ. Göttingen 1992; 71 Bl., ca. 80 ungez. Bl.

-Schüssler, Peter (1989): Geologie des Ostteils der Dransfelder Hochfläche westlich Göttingen. - Teil 1: Geologische Kartierung des Ostteils der Dransfelder Hochfläche zwischen Dransfeld, Varmissen, Jühnde und Meensen. - Teil 2: Die tertiärzeitlichen Sedimente im Ostteil des Dransfelder Stadtwaldes. - Dipl.-Arb. Teil 1 u. Teil 2 [unveröff.] Univ. Göttingen 1989; Teil 1: 73 S., Teil 2: 70 S.

-Schwanitz, Max (1987): Ingenieurgeologische Kartierung der Stadt Göttingen - Teilblatt Grone-Süd; Dipl.-Arb. [unveröff.] Univ. Göttingen 1987; 136 S.

-Schwedhelm, Edgar (1980): Entwicklungsgeschichte einer Subrosionssenke im Untereichsfeld - der Seeanger bei Seeburg (TK 25: Blatt 4426 Ebergötzen). - Dipl.-Arb. [unveröff.] Univ. Göttingen; 134 S.

-Senft, Birgit (1994): Ingenieurgeologie der Groner Senke. - Dipl.-Arb. [unveröff.] Univ. Göttingen 1994; VII, $83 \mathrm{~S}$.

-Shojaei-Kawan, Houshang (1989): Ingenieurgeologische Kartierung von Teilblatt Groß Ellershausen Nord 4425/20 und bodenmechanische Beschreibung der Lockergesteine. - Dipl.-Arb. [unveröff.] Univ. Göttingen 1989; 90 S.

- Stautmeister, Holger (1995): Ingenieurgeologische Kartierung der Stadt Göttingen - Blatt Groß Ellershausen-Süd, 4425/26 (DGK 5). - [Dipl.-Arb.] [unveröff.] Univ. Göttingen 1995; Textbd. 19 S. u. 1 Kt., zus. i. Kassette

-Steging, Mathias (1983): Ingenieurgeologische Kartierung der Stadt Göttingen - Teilblatt GeismarNord. - Dipl.-Arb. [unveröff.] Univ. Göttingen 1983; III, 101 S.

-Stein, Volker (1966): Der Untere Muschelkalk zwischen dem Göttinger Wald und dem Elfass. - Wiss. Arbeit f. d. 2. Staatsprüfung f. Geologen - Niedersächsisches Landesamt für Bodenforschung, Hannover; 74 S., 2 Beil.

- Tatter, Uwe-Christian (1993): Ingenieurgeologische Kartierung der Stadt Göttingen - DGK 5 Groß Ellershausen-Süd 4425/26 (Süd). - Dipl.-Arb. [unveröff.] Univ. Göttingen 1993; 79 S.

-Thiede, Peter (1981): Die Geologie des Südrandes der Dransfelder Muschelkalkhochfläche nordöstlich Hedemünden und die Tektonik der nördlichen Randstrukturen zwischen Berge und Wiershausen. Dipl.-Arb. [unveröff.] Univ. Göttingen; IV, 243 S.

-Vath, Ulrich (1988): Stratigraphie und Fauna der Wasserbohrung Rosdorf bei Göttingen (Oberer Keuper, Lias). - Dipl.-Arb. Teil 1 [unveröff.] Univ. Göttingen 1988; 63 S.

-Vath, Ulrich (1988): Geologie des Ostrandes der Dransfelder Hochfläche zwischen Leinshausen und Deiderode, südwestlich Göttingen. - Dipl.-Arb. Teil 2 [unveröff.] Univ. Göttingen 1988; 92 S.

-Welsch, Michael (1980): Muschelkalk und Keuper am Ostrand des Leinetalgrabens zwischen Groß Schneen, Reiffenhausen und Reckershausen (TK 25: 4425 Reinhausen). - Dipl.-Arb. [unveröff.] Univ. Göttingen,; 157 S. 
-Wischnow, Dirk (1994): Ingenieurgeologische Kartierung der Stadt Göttingen: Blatt Grone - 4425/21 (DGK 5). - Dipl.-Kart. [unveröff.] Univ. Göttingen 1994; 6 S., 2 aufgez. Kt.

-Worf, Hans (1959): Der Mittlere Buntsandstein im Raume Nörten-Hardenberg - Reyershausen Sudershausen. - Dipl. - Arb. [unveröff.] Univ. Göttingen; 47 S.

-Wüstemann, Peter (1991): (I) Geologische Kartierung am Westrand des Leinetalgrabens im Bereich des Eichenberger Graben-Knotens (TK 25: 4625 Witzenhausen). - (II) Die Schichtenfolge des Unteren Lias (Hettangium) der Ziegeleitongruben am Aschenberg bei Göttingen. - Dipl.-Kart. + Dipl.-Arb. [unveröff.] Univ. Göttingen; 204 S.

\subsubsection{Dissertationen}

- $\square$ Altenburger, Uwe (1987): Zur Sedimentologie des Unteren und Mittleren Buntsandsteins Nordosthessens (BRD). - Diss. Univ. Mainz 1987; 276 S. (92); Ill., graph. Darst.

-Baatz, Henning (1960): Stratigraphische und paläogeographische Untersuchungen im Kasseler Tertiär. - Diss. Univ. Marburg 1960; 90 Bl., Taf., Anh.

- $\square$ Bindig, Michael (1991): Räumliche und zeitliche Entwicklung der fluviatilen Environments der Solling-Formation (Buntsandstein, Germanische Trias). - Diss. TH Darmstadt 1991; 218 (162) S.

OBismarck, Wolfram (1942): Diluviale Beckenablagerungen im nordwestlichen Eichsfeld. - Diss. Univ. Jena, 87 Bl., Abb.

-Bork, Hans Rudolf (1982): Die holozäne Relief- und Bodenentwicklung im Untereichsfeld und im südwestlichen Harzvorland. - Diss. TU Braunschweig; IV, 187 S.; Abb., Beil.

-Bornemann [sen.], J. G. (1854): Über die Liasformation in der Umgebung von Göttingen und ihre organischen Einschlüsse. Diss. Univ. Göttingen 1854; 77 S., 4 Taf.; (Bornemann) Berlin

$\square$ Brosius, Marita (1957): Der Grabenknoten von Hessisch-Lichtenau und die Glimmeröder Tertiärmulde. - Diss. Univ. Marburg, 171 gez. Bl., Abb., Tab.

- $\square$ Bühmann, Dieter (1974): Die Tonmineralzusammensetzung in den Sedimenten der Niederhessischen Senke als Indikator festländischer Verwitterung und brackisch-mariner Tonmineralneubildung. - Diss. Univ. Göttingen, 81 S., 20 Abb., Tab. i. Anhang

[Unters. v. Sedimenten d. Tertiärs. Trias; u.a. Region Kassel - Fritzlar, Beberbeck, Glimmerode Großalmerode, Stellberg]

QDittrich, Eberhard (1964): Beiträge zur Kenntnis des Zechsteins im nordöstlichen Werra-Fulda-Becken und seinen Randgebieten. - Diss. Univ. Jena 1964; Teil 1 - Textband, 242, 12 Bl., Anhang; Teil 2 Anlagenband.: 60 Anl.

- $0 \bullet$ Dünkel, Helmut (1992): Stratigraphie, Petrographie und Fazies des mittleren Muschelkalks in Südostniedersachsen im Vergleich mit angrenzenden Gebieten (Nordhessen, Nordrhein-Westfalen und Thüringen). - 147 S., 22 Abb. i. Text; 13 gez. Abb. i. Anh., 11 Tab., 13 Foto-Taf.; (Cuvillier) Göttingen - zgl. Diss. Univ. Göttingen 1992 [darin: Untersuchungen. Lkr. Göttingen (Dransfelder Hochfläche); Hess. Diemelgebiet, Bhrg. Küllstedt/Thür.] 
-Ebert; Theodor (1882): Die tertiären Ablagerungen der Umgebung von Cassel. - Diss. Univ. Göttingen 1881; $28 \mathrm{~S}$.

-Echle, Wolfram (1960): Mineralogische Untersuchungen an Sedimenten des Steinmergelkeupers und der Roten Wand aus der Umgebung von Göttingen. - Diss. Univ. Göttingen 1960; 76 gez. Bl., Abb.

QEllenberg, Jürgen (1968): Die geologisch-geomorphologische Entwicklung des südwest-thürinigschen Werragebietes im Pliozän und Quartär. - Diss. Univ. Jena 1969; V, 188 Bl, Anh., 3 Anl.

QEnderlein, F. (1974): Zur Stratigraphie der Quarzporphyre der Oberhöfer Porphyrplatte. - Diss. Hochschule f. Architektur, Bauwesen Weimar 1974; 150 S.

OEngels, Christian (1963): Beiträge zur geologischen Stellung des Dolerites der Höhenberge im Rotliegenden der Tambacher Mulde. - Diss. Univ. Jena 1963; Teil 1: 140 Bl., Teil 2: 51 Bl. (Abb. 1 98);

-Erasmus, Wilhelm (1965): Landschaftskundliche Untersuchungen an Kalksteinhängen in der Umgebung Göttingens. - Diss. math.- nat. Univ. Göttingen 1965; 121 S., 8 Abb. a. T., 4 graph. Darst., 9 Kt.-Beil.; Göttingen

-Findeisen, Hans-Kurt (1952): Pleistozäne und tertiäre Flußablagerungen in der Umgebung von Kassel. - Diss. Univ. Heidelberg 1952, 144 S., 16 Taf., 1 Tab.

- $\square$ Frick, Friedrich (1969): Feinstratigraphie und mikrofazielle Untersuchungen im Plattendolomit (Ca 3 Leine-Serie) des nordosthessischen Zechsteins. - Diss. TH Aachen 1969; 106 S.

[Zechsteinmantel Unterwerra-Grauwackengebirge, Baumbacher Hoch W’Rotenburg/Fulda; Richelsdorfer Gebirge]

QFürste, Ria (1956): Untersuchungen über Zusammenhänge zwischen Basaltvorkommen und Vertaubungszonen auf dem Kaliwerk „Ernst Thälmann“ II/III. - Dipl.-Arb. [teilveröff.] Bergakademie Freiberg/Sa. 1956, 85 S. - Teilveröffentlichung in: Bergbautechnik, $\mathbf{7}$ (7/8); 1957 [Bibliographische Angaben nach: Auflistung von Diplomarbeiten BA Freiberg 1956 in: Geologie, 7(1): 102; Berlin 1958]

-Gerwien, E. (1914): Der Lauf der Oberweser im Buntsandsteingewölbe. - Diss. Humboldt-Univ. Berlin, 70 S., 1 Taf; Berlin

$\square$ Götz, Annette (1995): Feinstratigraphie und Mikrofazies der Oolithbänke (Unterer Muschelkalk, Trias) Mitteldeutschlands und angrenzender Gebiete. - Diss. TH Darmstadt 1995; II, 115 S., Ill., graph. Darst.; Darmstadt

QGoll, Martin (1996): Geochronometrie im Thüringer Wald - Quantifizierung der Entwicklung spätvariscischer Magmatite. - Diss. Univ. Heidelberg 1997; VII, 173 S., Abb., Kt.

$\square$ Gross, Volker (1973): Petroraphisch-geochemische Untersuchungen der Differentiation und Kontaktwirkung des Basaltes vom Hohen Meissner bei Eschwege. - Diss. Univ. Göttingen 1973; XIX, $85 \mathrm{~S}$.

QHeinrich, Wolf Dieter (1979): Paläökologische und biotstratigraphische Untersuchungan an Mikromammalierfaunen aus dem Pleistozän von Ehringsdorf, Taubach und Burgtonna in Thüringen. - Diss. Humboldt-Universität Berlin; Berlin

-Hezel, Ludwig (1912): Die nördlichsten Ausläufer hessischer Eruptivgesteine westlich der Chaussee Trendelburg-Hofgeismar-Niedermeiser. - Diss. Univ. Marburg 1912; 62 S., 1 Kt.; (Schaaf) Marburg

QHildebrandt, Hans (1932): Gemorphologische Untersuchungen über das Tambacher Becken und seine Umrandung. - Diss. Univ. Jena, $40 \mathrm{~S}$. 
$\square$ Holzapfel, Martin (1998): Die allochthonen Triasschollen bei Hundelshausen, Nordhessen geologische Kartierung, Beschreibung und Deutung. - Diss. Univ. Würzburg; XL, 79 S. (18), Ill., graph. Darst., Kt.

QHolzhey, Gerhard (1993): Vorkommen und Genese der Achate und Parageneseminerale in Rhyolithkugeln aus Rotliegendvulkaniten des Thüringer Waldes. - Diss. TU Freiberg 1993; 187 Bl. [Hauptbd.], Tab.; 93 Bl. [Anl.-Bd.], 75 Abb., 73 Tab., 93 Taf. [Untersuchte Vorkommen u.a. a. Bl. 5028 Eisenach-Ost, 5128 Ruhla, 5129 Waltershausen]

$\square$ Hong, Seong Jo (1995): Holozäne und aktuelle Tal- und Flußentwicklung auf der Nordostabdachung des Kaufunger Waldes, Nordhessen. - 152 S., 51 Abb., 9 Tab., 4 Fototaf. (8 Abb.), 2 Beil. (1 morph. Kt., 1 strat. Taf.); zgl. Diss. Univ. Göttingen; [Cuvillier] Göttingen [Untersuchungsgebiet zwischen Ermschwerd und Oberode]

OJahn, Reinhold (1930): Pollenanalytische Untersuchungen an Hochmooren des Thüringer Waldes. Diss. Univ. Jena 1930, 25 S., 6 Abb., 5 Tab.; Jena [Großes Moor am Beerberg, Teufelskreis, Saukopfmoor NW' Oberhof, Schwarzwassergrund b. Schmiedefeld]

OJuderselben, Georg (1969): Zur Petrologie des sedimentären Rotliegenden im Thüringer Wald und seinem Vorland. - Diss. Hochsch. Architektur u. Bauw. Weimar; 163 Bl., Abb., Anl.

QKästner, Hans (1966): Beitrag zur Geologie der Kalisalz- und Kohlensäurelagerstätten im südlichen Werra-Kaligebiet. - Diss. Hochschule f. Architektur u. Bauwesen Weimar 1966; VII, 129 S.; 8 Bl., 36 Beil. (Text- u. Anlagenbd.)

$\square$ Kahlert, Margit (1992): Auswirkungen der Werra-Versalzung auf die ökologischen Verhältnisse der Auenlandschaft des Werratals. - Diss. Univ./Ghs Kassel; 167 S., Ill., graph. Darst., Kt.

OKlaua, Dieter (1964): Sedimentpetrographische Untersuchungen der Rhätsandsteine Thüringens. Diss. Hochschule f. Architektur, Bauwesen Weimar 1964

- Knipping, Bernhard (1987): Basaltintrusionen in Zechstein 1 - Evaporiten (Werra-Lagerstättenbezirk). - Diss. Univ. Göttingen 1987; 202 S.

[Geochemie]

QKnoth, Wolfram (1969): Beiträge zur Kenntnis des Stephan und Rotliegenden des nordwestlichen Thüringer Waldes. - Diss. Univ. Halle 1969; VI, 165 gez. Bl., Abb., Taf.; Halle

- $\square \bullet$ Kunz, Heinrich (1964): Stratigraphisch-fazielle Untersuchungen im höheren Buntsandstein Osthessens. - Diss. Univ. Frankfurt/M. 1964; 232 S., 13 Abb., 4 Tab., 20 Taf.

$\square$ Lenz, Hans Gerhard (1981): Johann Thoelde - ein Paracelsist und „Chymicus“ und seine Beziehung zu Landgraf Moritz von Hessen-Kassel. - Diss. Univ. Marburg/Lahn 1982; 268 S.

- $\square$ Lippmann, Friedrich (1952): Mineralogische Untersuchungen an einigen nordhessischen Tertiärtonen. - Diss. Univ. Göttingen 1952; 73, IV gez. Bl.

[Großalmerode, Oberkaufungen]

OLützner, Harald (1974): Sedimentation des Rotliegenden im Thüringer Wald. - B-Dissertation [= Habilschrift der DDR-Universitäten] Univ. Greifswald 1974; Teil 1: S. 1 - 161, Abb., Kt.; Teil 2: S. 161 - 384, Abb., Kt.; Teil 3: S. 385-533, Abb., Kt., 5 Beil.

-Meiburg, Peter (1969): Die Warburger Störungszone - Ein Beitrag zur Geologie des Warme-DiemelGebietes (Nordhessen/Ost-Westfalen). - Diss. Univ. Münster 1971; 394 B., Ill., graph. Darst., Kt., Anl. 
- Meyer, Brunk (1955): Grundlagen und Ergebnisse einer Untersuchung der bodenkundlichen Verhältnisse in Südniedersachsen. - Diss. Univ. Göttingen 1955, 148 S., 19 gez. Bl., Abb. [Bodenprofile Umgebung Rosdorf b. Göttingen]

- Michaelis, Jochen (1987): Hydrochemische Modellbetrachtungen zur Kalkauflösung und Entwicklung karbonatischer Grundwässer im Göttinger Wald unter spezieller Berücksichtigung der stabilen Isotope des Kohlenstoffs und des Schwefels. - Diss. Univ. Göttingen 1987, 116 S., Abb., Kt.

QMühlenberg, A. (1908): Das Konglomerat des Gottlob bei Friedrichroda, ein Rhyakkumulat. Typus einer neuen Gesteinsart. - Diss. Univ. Halle 1908, 55 S.; (Karras) Halle

$\square$ Munk, Carsten (1983): Vergleichende Gefügeuntersuchungen für den Tunnelbau im Buntsandstein. Diss. Univ. Marburg/Lahn 1983; 146 S., 48 Abb., 21 Tab., 12 Taf. (Anlage)

[Schürzeberg b. Oberrieden/Werra-Meißner-Kreis]

QNaumann van Padang, Maur (1924): Tektonische Studien im nordwestlichen Teil des Gothaer Grabens. - Diss. Friedrich-Wilhelms-Univ. Berlin; 80 S., Abb.

- $\square$ Ochmann, Mario (1984): Untersuchung des Geröllbestandes und von Quarzkörnern der SollingFolge (mittlerer Buntsandstein) im Gebiet der Hessischen Senke und ihre paläogeographische Ausdeutung. - Diss. Univ. Hannover 1984; 277 S., 33 Abb., 7 Tab., Taf. 1-3. Taf. 4-44 (Fototafeln) [Untersuchungsgebiet Teilgebiete A, B, C: HE, WMK]

$\square$ Pflanzl, Günter (1953): Die Geologie des Meissners in Hessen. - Diss. Univ. Marburg 1953; 301 S., 49 Abb., 6 Anl.; Marburg

$\square$ Plein, Eberhard (1952): Der Bau des niederhessischen Berglandes im Raum von Großalmerode. - Diss. Univ. Göttingen 1952; 93 gez. Bl., Abb., Taf.; Göttingen

-Priesnitz, Kuno (1970): Karstmorphologische Untersuchungen im Niedersächsischen Bergland. - Diss. math. - nat. Univ. Göttingen; 188 S., 6 Abb., 4 Tab., 10 Beil.; Göttingen [darin: Göttinger Wald]

$\square$ Rahbar, Yasaman, (1998): Modellierung der Grundwasserversalzung in der Werratalaue bei Eschwege (Nordhessen). - Diss. FB Geowissenschaften FU Berlin; 148 S., Anh., Ill., graph. Darst.

$\square 0 \bullet$ Rettig, Ben (1996): Die Solling-Folge (Mittlerer Buntsandstein) im Grenzgebiet NiedersachsenThüringen-Hessen. - Mitt. a. d. Geol. Inst. Univ. Hannover, 35; 107 S., 41 Abb., 5 Tab., Taf. 1-3 (i. Tasche); zgl. Diss. Univ. Hannover 1996; Hannover [Unterrsuchungsgebiet: Südniedersachsen, Thüringer Eichsfeld nördl. Leine, auch Gebiet des WerraMeißner-Kreises; Aufschlüsse auf Bl. 4625 Witzenhauesen, 4724 Großalmerode, 4725 Bad SoodenAllendorf, 4726 Grebendorf, 4727 Küllstedt, 4827 Treffurt]

- $\square$ Ritzkowski, Siegfried (1965): Das marine Oligozän im nördlichen Hessen - Stratigraphie und Paläogeographie. - Diss. Univ. Marburg/L. 1965; 194 S., 28 Abb., 4 Tab.

$\square$ Schmid, Martin (1991): Der variszische Stockwerkbau des Unterwerra-Grundgebirges: das tektonische Bindeglied zwischen Harz und Rheinischem Schiefergebirge. - Braunschweiger geologischpaläontologische Dissertationen, 12, 82S.; Braunschweig - zgl. Diss. Naturwiss. F. TU Braunschweig

OSchramm, Herbert (1964): Untersuchungen zur altpleistozänen Flußgeschichte des Apfelstädt/HörselSystems - Ein Beitrag zur Stratigraphie und Paläogeographie des Altpleistozäns in Thüringen. - Diss. Univ. Jena 1964; II, 134 S., Anh., Ill., Anl. 
- Schröder, Lothar (1963): Zur Sedimentologie des Mittleren Buntsandsteins. - Diss. Univ. Göttingen $1963,76 \mathrm{~S}$.

[Südniedersachsen, Nordhessen]

-Schumacher, C. (1985): Die Kupfervererzungen des basalen Zechsteins im Rahmen der sedimentären Entwicklung des Werra-Fulda-Beckens. - Diss. Fachber. Geowissenschaften FU Berlin; 142 S., 57 Abb., 6 Taf.

-Sobotha, Ernst (1923): Versuch einer Entwicklungsgeschichte und Charkterisierung der Landschaften des Untereichsfelder Beckens nebst seinen westlichen und südlichen Randgebieten. - Diss. Univ. Göttingen, 1923, 46 S., 13 Taf. (Abb., Kt.)

$\square$ Stark, Hans (1950): Altersstellung und Tektonik des Paläozoikums bei Albungen. - Diss. Univ. Göttingen 1950; 56 S., 11 Abb., 6 Kt.

oStier, Alfred (1922): Wirtschaftsgeschichte von Friedrichroda vom 17. - 19. Jahrhundert. - Diss. Univ. Jena 1922; $149 \mathrm{~S}$.

[darin: Kap. 3: Bergbau"]

-Stremme, Eduard (1888): Beitrag zur Kenntnis der tertiären Ablagerungen zwischen Cassel und Detmold, nebst einer Besprechung der norddeutschen Pecten-Arben. - Diss. Univ. Göttingen 1888; 46 S., 1 Bl.; (Starcke) Berlin

-Tornquist, Alexander J. H. (1892): Der Gypskeuper in der Umgebung von Göttingen. - Diss. Univ. Göttingen 1892; 38 S.; (Hofer) Göttingen

Referat in: N. Jb. Mineral. etc, $\underline{1893}$ (Bd. II): 134 (A. Leppla); Stuttgart

-Waitz von Eschen, Friedrich Freiherr (1906): Die Basalte östlich der Linie Wabern - Gensungen. Diss. Univ. Marburg 1906, 35 S., 1 Falt-Bl.; Marburg

Referat in: N. Jb. Mineral. etc., 1907 (Bd. II): 403 (R. Brauns); Stuttgart

- $\square$ Q Wirth, Uwe (1983): Zur Vorgeschichte und Gründung einer staatlichen geologischen Institution in der 2. Hälfte des 19. Jahrhunderts in Preußen, dargestellt am Beispiel der Preußischen Geologischen Landesanstalt in Berlin. - Diss. Univ. Rostock 1983; II, 155, 8 S. 


\section{Bergbaugeschichte}

\subsection{Braunkohle, Steinkohle}

$\square$ Anonym (1882): < Zeche Marie am Hirschberg bei Großalmerode in Betrieb gegangen> $>$ Eschweger Kreisblatt, 1882; Nr. 53 v. 6.5.1882; Eschwege

- $\square$ Anonym (1884): Der Bergwerksbetrieb im Preussischen Staate während des Jahres 1883. - Z. Berg-, Hütten- u. Salinenwesen, 32: 78-154 (Statistischer Theil); Berlin

[darin: S. 111-126: II. Braunkohlenbergbau: darin S. 125: Braunkohlengruben im Regierungsbezirk Cassel - HE, WMK]

Jahresberichte erscheinen für alle Jahrgangsbände im gesonderten statitistischen Teil mit eigener Seitenzählung]

$\square$ Anonym (1885): <Braunkohlenförderung bei Großalmerode und Abtransport der Kohle> - Eschweger Kreisblatt, 1885; Nr. 208 v. 4.9.1885; Eschwege

$\square$ Anonym (1888): <Braunkohlenbergbau Meißner: Stollen am Schwalbenthal geschlossen> - Eschweger Kreisblatt, 1888; Nr. 161 v. 11.7.1888; Eschwege

$\square$ Anonym (1893): < Kohlenlagerstätte bei Laudenbach entdeckt> - Eschweger Tageblatt u. Kreisblatt, $\underline{\mathbf{1 8 9 3}}$; Nr. 213 v. 11.9.1893; Eschwege

[Bergbaugeschichte]

-Namenskürzel (L.) (1893): Neue Braunkohlenfelder im niederhessischen Tertiärgebiet. - Z. prakt. Geol., [1] $\underline{1893}$ (10): 408-409; Berlin

[Großenritte, $12 \mathrm{~km}$ südwestl. Cassel]

- $\square$ Anonym (1897): <Wirtschaftsbericht über die Braunkohlenwerke Meißner und Habichtswald sowie die Saline Sooden a. W.> - Eschweger Tageblatt u. Kreisblatt, 1897; Nr. 10 v. 13.01.1897; Eschwege

-Anonym (1898): Neue Flötzfunde im Habichtswalde bei Cassel. - Z. prakt. Geologie, [6. Jg.] 1898: 267 (Notizen); Berlin

-Anonym (1903): <Der Brand des fiskalischen Kohlenbergwerkes im Habichtswald $>$ - Eschweger Tageblatt, 1903; Nr. 46 v. 24.02.1903; Eschwege

$\square$ Anonym (1913): Wassereinbruch auf einem Meißnerschacht - Ein Bergmann als Leiche geborgen. Eschweger Tageblatt, 1913; Nr. 91 v. 19.4.1913; Eschwege

[Braunkohlen-Zeche Marie, Hirschberg b. Großalmerode]

$\square$ Anonym (1918): < Braunkohlenbergwerk in Bransrode am Meißner erhöht Produktion> - Eschweger Tageblatt, 1918; Nr. 219 v. 18.9.1918; Eschwege

$\square$ Anonym (1920): < Neues Leben im Braunkohlenbergwerk Bransrode am Meißner> - Eschweger Tageblatt, 1920; Nr. 283 v. 4.12.1920; Eschwege

$\square$ Anonym (1921): < Die Braunkohlenzechen Glimmerode und Bransrode/Meißner> - Eschweger Tageblatt, 1921; Nr. 260 v. 5.11.1921; Eschwege

$\square$ Anonym (1922): < Giftige Gase im Braunkohlenbergwerk Bransrode am Meißner> - Eschweger Tageblatt, 1922; Nr. 84 v. 8.4.1922; Eschwege 
$\square$ Anonym (1922): <Ausbau der Braunkohlenzechen Glimmerode und Bransrode/Meißner]. - Eschweger Tageblatt, 1922; Nr. 177 v. 1.8.1922; Eschwege

$\square$ Anonym (1922): <Braunkohlenzeche Bransrode am Meißner: Wilhelmstollen eingestürzt]. - Eschweger Tageblatt, 1922; Nr. 217 v. 16.9.1922; Eschwege

$\square$ Anonym (1929): <Braunkohlenwerk Bransrode soll wegen Sicherheitsproblemen stillgelegt werden> Eschweger Tageblatt, 1929; Nr. 121 v. 27.5.1929; Eschwege

-Anonym (1934): <Inbetriebname der Braunkohlenzeche „Heiligenberg“ am Heiligenberg b. Gensungen> - Eschweger Tageblatt, 1934; Nr. 149 v. 29.06.1934; Eschwege

- $\square$ Anonym (1941): Unsere Braunkohle als Wirtschaftsreserve - Im Kasseler Revier schon 1571 erwähnt. - Eschweger Tageblatt, 1941; Nr. 13 v. 18./19.01.1941; Eschwege

-Anonym (1946): Kassels Bergwerk. - HN, 1946; Nr. 61 v. 19.6.1946; Kassel [Braunkohlen-Zeche Herkules, Habichtswald/Kassel]

- $\square$ Anonym (1946): Wo unsere Kohle herkommt. - HN, 1946; Nr. 23 v. 20.3.1946, 2 Abb.; Kassel [Portrait Nordhessisches Braunkohlenrevier]

$\square$ Anonym (1946): Kohlenbergbau am Meißner. - HN, 1946; Nr. 87 v. 20.8.1946; Kassel

- $\square$ Anonym (1947): Der Schlüssel zum Wiederaufbau - Unerschlossene Kohlevorkommen in Kassels Umgebung. - HN, 1947; Nr. 11 v. 25.1.1947; Kassel

$\square$ Anonym (1952): Schüler erleben Braunkohlen-Tiefbau-Zeche Glimmerode. - Bergbau i. Hessenland (Ausgabe Braunkohle), (2. Jg.) 1952(19): 4, 14; 2 (21): 13-14; Kassel

$\square$ Anonym (1953): Kampf um den Meißner-Bergbau. - Bergbau i. Hessenland (Ausgabe Braunkohle), (3. Jg.) $\underline{1953}(10):$, (10): 14, (11): 14; Kassel

-Anonym (1953): „Kaufungen liegt auf Kohle“. - Bergbau i. Hessenland (Ausgabe Braunkohle), (3. Jg.) $\underline{1953}(18):$ 3, 1 Abb.; Kassel

$\square$ Anonym (1954): Bei den Kumpels im Hirschberg. - Bergbau i. Hessenland (Ausgabe Braunkohle), (4.Jg.) 1954(17): 3-4, 4 Abb.; Kassel

- $\square$ Anonym (1955): Wo bleibt unsere Braunkohle? - Bergbau i. Hessenland (Ausgabe Braunkohle), (5. Jg.) 1955 (12): 3, 1 Abb.; Kassel [darin: Meißner]

$\square$ Anonym (1957): Braunkohle - das Gold Kurhessens - Abbau seit 1578 - Neun Generationen Waitz von Eschen. - Kasseler Post, 1957, Nr. 166 v. 22. Juli 1957, 3 Abb.; Kassel

$\square$ Anonym (1958): Aus der Geschichte des hessischen Braunkohlenbergbaus. - Bergbau i. Hessenland, (8. Jg.) $\underline{1958}(1): 8-9,4$ Abb.; Kassel

[Meißner, Hirschberg]

-Anonym (1959): Die Entwicklung der BUBIAG [Braunkohlen- und Brikettindustrie Aktiengesellschaft]. - Bergbau im Hessenland, (9. Jg.) 1959(4): 6-7; Kassel

[Wirtschaftliche Informationen und Geschichte der Gesellschaft; Bezugn. a. Betriebssteile Frielendorf und Meißner]

-Anonym (1959): Zeche Gahrenberg. - Bergbau im Hessenland, (9. Jg.) 1959(12): 4, 3 Abb.; Kassel [Foto S. 5 - ohne Bezug zum Aufsatz -: Zeche Stellberg-Wiesenschacht i. d. Söhre bei Wattenbach] 
-Anonym (1960): G. E. Habich's Söhne 175 Jahre - Der werkseigene Braunkohlenbergbau <Zeche Gahrenberg>. - Bergbau im Hessenland, (10. Jg.) 1960(8): 4-8, 4 Abb.; Kassel

$\square$ Anonym (1960): Auf dem Meißner. - Die Weser, $\underline{\mathbf{3 4}}(5)$ : 87-89, 3 Abb.; Bremen [darin: Braunkohlebergbau auf dem Meißner]

-Anonym (1962): Tagebau Singlis [Revier Borken] im Aufschluß. - Bergbau im Hessenland, (12. Jg.) 1962(8): 16-17, 4 Abb.; Kassel

-Anonym (1963): Umstellung auf Stellberg-Wiesenschacht - Tagebaugewinnung statt Tiefenschacht. Bergbau im Hessenland, (13. Jg.) 1963(1): 5, 1 Abb.; Kassel

-Anonym (1964): Jetzt Tagebau-Kohle am Stellberg - Bohrungen lassen weitere Vorräte erkennen. Bergbau im Hessenland, (14. Jg.) 1964(2): 4-5, 4 Abb.; Kassel

$\square$ Anonym (1964): Innenkippe am Fuß der Kalbe [Tagebau Hoher Meißner]. - Bergbau im Hessenland, (14. Jg.) 1964(3): 4-5, 7 Abb.; Kassel

[überwiegend Fotos vom Tagebau]

$\square$ Anonym (1964): Zeche Glimmerode erweitert den Kohlenbunker. - Bergbau im Hessenland, (14. Jg.) 1964(4): 4-5, 6 Abb.; Kassel

[überwiegend Fotos vom Tagebau]

$\square$ Beck, Hanno (1965): Natur- und Kulturgeschichte des Meißners (Serie: Eschweger Literatur, 27). Werra-Rundschau, 1965; Nr. 241 v. 16.10.1965, S. 7; Eschwege

[Erforschungsgeschichte, Bergbaugeschichte]

$\square$ Betz, Wolfgang; Bornscheuer, Uwe [beteiligt]: Spurensicherung Werra und Meißner - der Fluß und der Berg. - Jugendliche untersuchen ein Stück ihrer Region. - 115 S., zahlr. Abb.; [Bund Deutscher Pfadfinder (BDP) - Region Nordhessen; Kreisjugendpflege Werra-Meißner-Kreis, u.a.] o. O. [darin: Kiesbaggerei a.d. Werra/Kohlebergbau a.d. Meißner, Hydrogeographie; Mühlen, Fischerei, Lohgerberei]

-Anonym (1966): 400 Jahre alter Bergbau im Habichtswald. - Bergbau im Hessenland, 16(2): 4; Kassel [Erster Stollenvortrieb auf Braunkohle am Ziegenkopf i. d. Jahren 1570 u. 1580]

-Anonym (1966): Tagespresse informierte die Öffentlichkeit über die Probebohrungen der HBZ im Habichtswald. - Bergbau im Hessenland, 16(2): 4-6, 3 Abb.; Kassel

- $\square$ Anonym [1966]: Die bergbaulichen Vorkommen in Nordhessen: Der nordhesssische Braunkohlenbergbau. - In: Harnisch, W.; Hasemann, H. \& Hoffmann, E. [Bearb.]: Geschichte des bergbaulichen Vereins Kassel. - 176 S., Abb., statist. Tab.; hier: S. 59-73, 3 Abb.; [Hrsg. Bergbauverein Hessen e.V.] Kassel 1966 [Bergbau-Geschichte, Lagerstättengeologie, Wirtschaftliche Bedeutung]

$\square$ Becker, G. (1967): Tiefbau auf dem Meißner wird eingestellt. - Werra-Rundschau, 1967; Nr. 215 v. 16.09.1967; S. 3, 2 Abb.; Eschwege

[Tiefbau „Am Grebestein“]

- $\square$ Anonym (1967): Nordhessens Braunkohlenbergbau. - Bergbau im Hessenland, 17(2): 10-14, 4 Abb.; Kassel

-Anonym (1968): Strukturwandel bei der BUBIAG, Betriebsabteilung Frielendorf. - Bergbau im Hessenland, 18(1)[damit Erscheinen eingestellt]: 6-9, 11 Abb; Kassel

-Anonym (1968): Steigerung der Kohleförderung bei der Abteilung Borken der Preußenelektra. Bergbau im Hessenland, 18(1)[damit Erscheinen eingestellt]: 12-15, 8 Abb.; Kassel 
$\square$ Anonym (1974): Anno 1767 - Ein schweres Bergwerksunglück am Hirschberg [Großalmerode, Braunkohlen-Bergwerk]. - In: Wollenhaupt, Gustav [Hrsg.]: Geschichte der Stadt Großalmerode und familienkundliche Nachrichten. - Teil 1; 117 S., Abb.; hier S. 107-108; (Im Selbstverlag) Großalmerode 1974

- $\square$ • Apel, Jürgen \& Rüppel, Heidi [Verfass. u. Hrsg.] (2005): Raus in die Natur - Tipps für den Sonntags-Ausflug im Dreiländereck Hessen - Niedersachsen - Thüringen. - 159 S., 111 Fotos, 34 Kt., 1 Zeit-Taf.; (LSRB-Verlag, Landschaftskundlicher-Studien-Reisebuch-Verlag) Witzenhausen [zahlreiche Ausflugsziele, auch zu Relikten von Braunkohlenlagerstätten - und BraunkohlenBergbauen: Ziel 41 (Steinberg b. Großalmerode)]

$\square$ Arend, Edmund (1971): Plauderei über die ehemalige Gewerkschaft Steinberg bei Großalmerode. Hessischer Gebirgsbote, 72(3): 47; Melsungen

-Baas, Friedrich-Karl (1973): Der Ahlberg - ein interessantes Wanderziel im Reinhardswald. Hessischer Gebirgsbote, 74(4): 85-87, 2 Abb.; Melsungen [darin: Erdgeschichte, Braunkohle-Bergbau]

-Bambey, Hartwig (1990): Die Zeche Frielendorf: Der nordhessische Braunkohlenbergbau - ein kurzer Überblick. - In: Bambey, Hartwig: Frielendorf: Bilder-Lese-Buch. - Zur Geschichte des Marktfleckens an der Ohe. - 400 S., zahlr. Abb.; hier S. 211-213, 1 Abb. (Übers.-Kt.); [Verlag d. Gemeindevorstandes d. Gemde. Frielendorf] Frielendorf 1990

-Bambey, Hartwig (1990): Die Zeche Frielendorf: Geschichte des Frielendorfer Braunkohlenbergbaus. - In: Bambey, Hartwig: Frielendorf: Bilder-Lese-Buch. - Zur Geschichte des Marktfleckens an der Ohe. - 400 S., zahlr. Abb.; hier S. 213-300, zahlr. Abb.; [Verlag d. Gemeindevorstandes d. Gemde. Frielendorf] Frielendorf 1990

- $\square$ Baron (1978): 400 Jahre Kasseler Braunkohlenbergbau - Ältestes Revier Deutschlands Jubiläumsfeier 1928 - Rege Förderung durch den Schlüsselstollen. - HA, 1978; Nr. 161 v. 15.7.1978

- $\square$ Bartholmai, H. (1936): Die technisch-wirtschaftliche Entwicklung des Braunkohlenbergbaus im Bergrevier Kassel. - XVI, 121 S., 1 Kt.; (Robert Noske) Borna-Leipzig

$\square$ Bauer, G.; Jahn, G. \& Nink, W. (1991): Braunkohlenabbau bei Großalmerode. - In: Jahn, Gert [Hrsg.]: Hessen - Unser Land in Karte, Bild und Wort. - 64 S., zahlr. Abb. u. Kt., hier S. 52-53, 6 Abb.; (List-Schrödel) München 1991

[Schulgeographie]

- $\square$ Bechtolsheimer, Karl (1952): Sontra - Westdeutsches Kupfervorkommen. - Volk u. Scholle, 24(1/2): 15; Darmstadt [Bergbaugeschichte]

ه $\square \bullet$ Bergbaulicher Verein Kassel e.V. [Hrsg.](1928): Der Kasseler Braunkohlenbergbau - Anläßlich des 350jährigen Bestehens des Kasseler Braunkohlenbergbaus herausgegeben vom Bergbaulichen Verein Kassel e.V.; 108 S., 2; 1 Kt., 18 Fototaf. i. Text; 2 S., 5 Taf. i. Anh.; [Hrsg. Bergbaulicher Verein] Kassel

[Bergbau i. Lkr./ Stadtgebiet Kassel; Schwalm-Ederkreis; Werra-Meißner-Kreis, Lkr. Göttingen (Steinberg, Kaufunger Wald)]

$\square$ Bergler (1963): Tagebau Höllkopf [Zeche Glimmerode/Hess. Lichtenau]. - Bergbau im Hessenland, 13(5): 16-17, 7 Abb.; Kassel

- $\square$ Berthold, Günter (2001): Die Anfänge des Braunkohlenbergbaus in Nordhessen. - In: Wächtler, Eberhard [Red.]: 4. Montanhistorisches Kolloquium: Zur Geschichte des Braunkohlenbergbaus. Mensch - Natur - Technik. - 186 S., zahlr. Abb. u. Tab.; hier S. 25-32; [Hrsg. Magistrat der Stadt 
Borken] Borken (Hessen) 2001

-Best, Ingeborg (2004): Die Zeche Frielendorf als Arbeitgeber vieler Siebertshäuser Bürger. In: Gemeinde Frielendorf [Hrsg.]: 750 Jahre Siebertshausen - ein kleines Geschichtsbuch einer kleinen Gemeinde. - 114 S.; zahlr. Abb.; hier S. 19-22, 5 Abb.; Frielendorf 2004

OBeyschlag, F. (1882): Geognostische Skizze der Umgebung von Crock. - Z. f. Naturwiss., $\underline{\mathbf{5 5}}$ (4 F., H. 1) (1878): 571-647; Anhang S. 646-647: Das Crocker Steinkohlenbergwerk; Berlin

口OBeyschlag, Franz (1886): Erläuterungen zur Geologischen Specialkarte von Preussen und den Thüringischen Staaten. - Lieferung 23 - Blatt Allendorf - Gradabth. 55, Bl. 46; [ heute: 4725 Bad Sooden-Allendorf ]. - Geol. Aufn.: Friedrich Moesta, Verf.: ... - 66 S., 2 Taf.; (i. Comm. Simon Schropp'sche Hof-Landkartenhdlg. (J. H. Neumann)) Berlin 1886

Hrsg.: Königlich Preußische Geologische Landesanstalt und Bergakademie; Berlin Dazugehörige Karte herausgegeben 1878

[darin S. 53 - 63: Anhang: „Die bergbaulichen Verhältnisse des Blattes Allendorf“; überwiegend Darstellung des Braunkohlenbergbaus am Meißner)

-Beyschlag, F. (1915): Die Braunkohlenformationen in Niederhessen (Regierungsbezirk Kassel). - In: Klein, Georg [Hrsg.]: Die deutsche Braunkohlenindustrie - Handbuch für den deutschen Braunkohlenbergbau. - 2., vollst. neu bearb. Aufl., Textbd.: 880 S., 606 Abb. , Taf.Bd. Taf. 1-29 + 1 Kt.-Beil.; hier: S. 122 - 127, Abb. 30-32; Halle/Saale 1915

-Bickel, Hans \& Schönhut, Horst (2002): Nordhessischer Braunkohlenbergbau: Die Grube Altenburg in Borken (Hessen). - 367 S:, 211 Abb.; [Hrsg. Magistrat Stadt Borken/Hessen] (Bernecker) Melsungen Referat (Wächtler) in: Der Anschnitt, 52 (2): 120-121; Bochum 2003

-Bonnemann, Alfred (1984): Der Reinhardswald. - XI, 451 S.; 21 Abb., 90 Tab.; (Verlag d. Weserbuchhdlg) Hann.-Münden [darin S. 3 - 39: „Die geologischen Zeitalter“ (Erdgeschichte der Region), Abb. 1-7, 10 Tab.; S. 3345375: „Der Braunkohlenbergbau und seine Betriebe“]

-Bonnemann, Alfred (1993): Kohle und Holz im Gahrenberg. - In: Hess. Forstamt Gahrenberg [Hrsg.]: 125 Jahre Forstamt Gahrenberg 1868-1993. - 66 S., zahlr. Abb.; hier: S. 57-60, 3 Abb.; Hann.-Münden 1993

$\square$ Braun, Erwin (1976): Die Braunkohlenlagerstätte des Meißner und die wirtschaftlichen Aspekte des Bergbaues. - Hessische Heimat, N.F., 26(3) (Sonderheft: Braunkohlenbergbau und Landschaftspflege auf dem Hohen Meissner - Stand 1975): 85 - 88, 3 Abb.; Marburg/L.

-Braun, Erwin (1985): Kohle aus Kaufungen. - In: Wroz, Wilfried u. a. [Bearb.]: 975 Jahre Kaufungen - 1011-1986 - Beiträge zur Heimatkunde. - 383 S., zahlr. Abb.; hier: S. 181-193, 10 Abb.; [Hrsg. Gemeindevorstand d. Gemeinde Kaufungen] Kaufungen 1985

$\square$ Braun, Erwin (1986): Die Braunkohlenlagerstätte des Meißner und die wirtschaftlichen Aspekte des Bergbaues. (Übertitel: Germerode und der Bergbau am Meißner). - In: Franz, D.; Großkurth, H.; Kovács, H. \& Schulze, E. [Hrsg.]: 800 Jahre Germerode - Eine Festschrift zur 800sten Wiederkehr der ersten urkundlichen Erwähnung von Germerode. - 202 S., zahlr. Abb. + Anzeigenteil; hier S. 129-133, 2 Abb.; Germerode 11986

- $\square$ Braun, Erwin (1999): Zur Geschchichte des Braunkohlenbergbaus in Hessen - A history of lignite mining in Hesse. - In: Wächtler, Eberhardt [Red.]: Zur Geschichte des Braunkohlenbergbaus in Deutschland und Tschechien - 3. Montanhistorisches Kolloquim; 389 S.; hier: S. 245-255, 2 Kt.; [Magistrat der Stadt Borken] Borken (Hessen) 1999 
$\square$ Brehm, Helene (1992): Vom Wissener und Höllental. - In: Gier, Karl [Hrsg.]: Helene Brehm Geschichten und Gedichte. - Gesammelt und zusammengestellt von Karl Gier. - Nebentitel: Heimatklänge aus dem Meißnerland. - 250 S.; hier S. 30-35; (Eigenverlag Karl Gier) MeißnerAlberode 1992

[Geologie, Bergbau, Flora]

$\square$ Busse, Mark-Christian von (2003): Vor 15 Jahren: Grubenunglück in Borken: Der Wecker tickt noch immer - Wilfried Dönch wurde 65 Stunden nach dem Grubenunglück in Borken gerettet. - WerraRundschau-Sonntagszeit, 2003; Nr. 22 . 1.6.2003, 2 Abb.; Eschwege

- $\square$ Cancrinus, Franz Ludwig (1767): Beschreibung der vorzüglichsten Bergwerke in Hessen, in dem Waldeckischen, an dem Haarz, in dem Mansfeldischen, in Chursachsen, und in dem Saalfeldischen. [8] Bl., 429, [1] S.; 1 Abb., 11 Falt-Taf.; (Andreä) Frankfurt/M.

[darin: Eisenbergwerk Hohenkirchen b. Kassel, Hüttenwerke Veckerhagen, Karlshafener Blaufarbenwerke, Eisenbergwerk b. Homberg, „Von dem riegelsdorfer Schieferwerk in Hessen“ (Richelsdorfer Kupferschiefer-Bergbau); „Von dem Steinkohlenbergwerk an den Weissener in Hessen“ (Braunkohlen-Bergbau am Hohen Meißner)]

- $\square$ Christopher, Andreas (1993): Der hessische Braunkohlenbergbau und seine Bahnen. - Reihe: Bergbau und Bahnen, 2; 2. Aufl., 176 S., 189 Abb., Tab.; (Verlag im Biebertal) Biebertal [Information über alle Braunkohlen-Bergwerke der ganzen bibliographisch erfassten Region]

-Dreyer, Klaus [Red.](1988): Bergbau in Ihringshausen/Zeche Möncheberg. - „Heimaterzählungen“, 2 ; 62 S., 11 Abb.; Heimaterzählungen/Heimat- u. Verkehrsverein Fulda e.V.; [Hrsg. Heimat- u. Verkehrsverein Fuldatal] Fuldatal [Braunkohlenbergbau]

$\square$ Ebel, Willi (1969): Jubiläums-Festschrift zur 860-Jahrfeier der Gemeinde Rommerode vom 20. Juni bis 23. Juni 1969. - 50 S., zahlr. Abb. + Anzeigenteil; [Hrsg. Gemeindevorstand Rommerode] Rommerode [darin S. 12-27, 7 Abb.: „Das Leben in Rommerode im Laufe der Jahrhunderte. - 1. Wie die Bewohner ihren Lebensunterhalt verdienten“ - (Glasherstellung, Alaunherstellung, BraunkohlenBergbau, Tonverarbeitende Industrie)]

-Eckert, O. (1967): 100 Jahre Bergamt Kassel. - Bergbau im Hessenland, 17(4): 15-17, 3 Abb.; Kassel

OErnst, Werner (2000): Steinkohle bei Tambach-Dietharz. - Abh. Ber. Museums d. Natur Gotha, (21) 2000: 99-102, 2 Abb.; Gotha

[Bergbaugeschichte]

$\square$ Erxleben, J. C. P.(1765): Nachricht von einer Reise nach dem Weißner, in Absicht auf die natürliche Geschicht dieses Berges und der um ihn liegenden Gegend. - Hannoverisches Magazin, $1765=3$. Jg.)(63): Sp. 993-1007, (64): Sp. 1009-1014; [Auszug in Tourist. Mitt. Hessen, ㅁ: 8-11; Kassel 1899] [Saline Sooden, Braunkohlenbergbau a. d. Meißner, ausführlich: Alaunherstellung in Großalmerode, Strahlkies v.on Großalmerode; Botanik]

QFiala, Claudia (2000): Zur Geschichte des Steinkohlenbergbaus. - In: Meyer, Monika [Red.]: Manebach im Thüringer Wald und seine Geschichte - Bergbau, Fossilien, Glas, Masken. - 2., verbess. Aufl.; 160 S., mehr. Abb. i. T., 12 Abb. i. Anhg.; hier S. 59-69, 3 Abb. i. T., Abb. 13 a. S. 108-109; (Escher) Gehren 2000

$\square$ Finkenwirth, A. (1978): Die Braunkohle am Meißner. - In: Koritnig, Sigmund [Schriftltg.]: Zur Mineralogie und Geologie der Umgebung von Göttingen - mit Westharz und Teilen des Nordhessischen Berglandes. - Der Aufschluss, Sdbd. 료: 229-236, 3 Abb.; Heidelberg 1978

d $\square$ Follmann, Fritz (1968): Braunkohlen-Abbau beendet - was nun? - Hessischer Gebirgsbote, $\underline{\mathbf{6 9}}$ (2): 30 -31 ; Melsungen 
[darin: Habichtswald, Stellberg/Söhrewald, Gahrenberg, Höllkopf/Glimmerode, Kalbe/Hoher Meißner]

-Follmann, Fritz (1971): <Zeche Gahrenberg - letzte Schicht im Oktober 1970 gefahren> (Wissenswertes aus der Heimat in Kürze). - Hessischer Gebirgsbote, 72(1): 3; Melsungen

$\square$ Frank, Johann (1989): Das braune Gold - Bergbau im Lichtenauer Raum. - In: Koch, Georg; Heyner, Georg; Frank, Johann; Mühlhausen, Walter; Bauer, Günter: 700 Jahre Hessisch Lichtenau 1289 - 1989. Beiträge zur Heimatkunde. - 343 S., 100 Abb., 11 Kt.; hier S. 111-116, 2 Abb., 1 Tab.; [Hrsg. Magistrat der Stadt Hessisch Lichtenau] Hessisch Lichtenau 1989 Referat in: Z. Vereins hess. Gesch. u. Landeskde., 94: 427-429 (Reyer) [Braunkohlenbergbau Zeche Glimmerode u.a. Orte]

$\square$ Franz, Dieter u.a [Hrsg.](1986): 800 Jahre Germerode - Eine Festschrift zur 800sten Wiederkehr der ersten urkundlichen Erwähnung von Germerode. - 202 S. + Werbeteil, zahlr. Abb.; [Herausgegeben im Auftrag des Festausschusses] Germerode [darin Kap.: Germerode und der Bergbau am Meißner - Die Braunkohlenlagerstätten des Meißner; Erwin Braun: Die Braunkohlenlagerstätte des Meißner und die wirtschaftlichen Aspekte des Bergbaus]

-Gerland, Walter (1952): Habichs Farbenfabrik in Veckerhagen. - Heimatjahrbuch. f. d. Landkreis Hofgeismar, f. 1953: 85 - 87, 2 Abb.; Hofgeismar [Herstellung der Malfarbe „Kasseler Braun“ aus erdiger Weichbraunkohle des Gahrenberges]

-Gerstein, Hellmut (1992): Der Braunkohlenbergbau im Habichtswald. - Jb. Lkr. Kassel, 1993: 59 - 62, 2 Abb.; Kassel

$\square$ Gunkel, Otto (1989): Hessische Braunkohle - 400 Jahre Bergbau auf dem Meißner (750 m) in Nordhessen. - Das Werraland, 41(4): 58-59; Eschwege

$\square$ Gunkel, Otto (1998): Erster Braunkohlenabbau in Deutschland - wo? - Das Werraland: $\underline{\mathbf{5 0}}$ (1): 17-18; Eschwege [Kölner Bucht? - Hoher Meißner?]

-Habich, Friedrich (1929): Habich's Fabrik in Veckerhagen und das Braunkohlenwerk am Gahrenberg. - Heimatjahrbuch f.d. Lkr. Hofgeismar, $\underline{1930}$ : 88; Hofgeismar

-Harnisch, W. (1954): Aufschluß und Wasserwirtschaft der Zeche Marie-Trost am Brasselsberg bei Kassel. - Bergbau i. Hessenland (Ausgabe Braunkohle), (4. Jg.) 1954(2): 13, (3): 4, 1 Abb.; Kassel [Lagerstättengeologie, Hydrogeologie]

- Hartung, Wilhelm (1966): Der Bergbau am Kleinen Steinberg (Kaufunger Wald). - Werraland, 18(4): 59-60; Eschwege [Niedersächsischer Teil des Kaufunger Waldes]

OHerbst, G. (1848): Bericht über einen Bohrversuch nach Steinkohle bei Tambach im Herzogthum Gotha. - Berg- u. hüttenmännische Zeitung., 7 [N.F. 2] (2): 25-27, (3): 40-44; Freiberg/Sa.

- $\square 0 \bullet$ Héron de Villefosse, Antoine Marie (1810): De la richesse minérale. Considérations sur les mines, usines et salines des différens états, et particulièrement du royaume de Westphalie, pris pour terme de comparaison. - Tome premier - Division économique. - XXVII, 593 p.; (Levrault) Paris - [Insgesamt drei Bände u. Atlas-Band in Folio-Format]

[darin : S. 151-169 «Sur les mines et usines de la Hesse (u.a. Richelsdorfer Gebirge, Karlshafen, Meissner, Habichtswald ; S. 178-183 Eisenerzbergbau Schmalkaldener Revier ; S. 140-141

Braunkohlebergbau Steinberg b. Münden] 
$\square$ Hinze, Günter (1999): 400 Jahre Braunkohlebergbau am Hirschberg in Großalmerode - 400 years of lignite mining at Hirschberg near Großalmerode. - In: Wächtler, Eberhardt [Red.]: Zur Geschichte des Braunkohlenbergbaus in Deutschland und Tschechien - 3. Montanhistorisches Kolloquim; 358 S.; [; hier S. 257-280; 12 Abb., 1 Tab.; Magistrat der Stadt Borken] Borken 1999

$\square$ Hinze, Günter (2001): 400 Jahre Braunkohlenbergbau am Hirschberg in Großalmerode. - 31 S., 13 Abb.; (Zeche Hirschberg) Großalmerode

$\square$ Hinze, Günter (2008): 400 Jahre Braunkohlenbergbau am Hirschberg. - 323 S., Ill., graph. Darst., Kt..; (Hrsg./Verleger: Zeche Hirschberg GmbH) Kassel

-Hoffmann, A. [Bearb.](1935): Die Braunkohlenvorräte des Deutschen Reiches. - Archiv f. Lagerstättenforschung, 61; 38 S., 1 Abb., 12 Taf.; [Preuß. Geol. Landesanst.] Berlin [Kurzinformationen Lagerstättengeologie u. Bergbau]

-Hoffmann, Erich (1964): Schienenstoß und Rechen 130 Jahre alt - Interessante Funde im nordhessischen Tiefbau. - Bergbau im Hessenland, 14(6): 16-17, 7 Abb.; Kassel [Funde Ostheim, Ihringshausen-West, Stellberg/Söhre]

$\square$ Hofsommer, Erich (2007): Braunkohlenbergbau in und bei Epterode. - In: Nobel, Hermann: Chronik Epterode - Von Euerharderot zu Epterode - 825 Jahre Epterode. Mit Beiträgen von Stefan Bauer, Erich Hofsommer, Dr. Friedhelm Koch, Dr. Karl Kollmann \& Werner Sippel. Herausgegeben vom Magistrat der Stadt Großalmerode anläßlich der 825-Jahr-Feier. - 453 S., zahlr. Abb. u. Tab.; hier S. 345-364, 27 Abb.; (Magistrat d. Stadt Großalmerode) Großalmerode 2007

$\square$ Hotzler, Fritz (1988): Aus der Geschichte des Kohlenabbaues auf dem Meißner. - Das Werraland, 40 (2): 25-27, 1 Abb.; Eschwege

$\square$ Hotzler, Fritz (1988): Aus der Vergangenheit des Gasthauses Schwalbenthal auf dem Meißner. - Das Werraland, 40 (3): 40-41, 1 Abb.; Eschwege

$\square$ Gresky, Wolfgang (1978): Eine Wanderung über den Meißner im Jahre 1785. - Das Werraland, $\underline{\mathbf{3 0}}(4)$ : 55-56, 2 Abb.; Eschwege

[Reiseschilderung u.a. Bergbau]

$\square$ Gunkel, Otto (1989): Hessische Braunkohle - 400 Jahre Bergbau auf dem Meißner (750 m) in Nordhessen. - Das Werraland, $\underline{41}(4)$ : 58-59; Eschwege

$\square$ Henschel (1841): Über einen Schwelbrand im Bransröder Stollen auf dem Meißner. - Notizenblatt Göttingischen Vereins bergmänn. Freunde, 34: 3-4; Göttingen

[Vorlage nicht eingesehen, zitiert nach Oppitz (1991)]

-Huber, K. H. (1952): Wenn ein Dorf auf Kohle gebaut hat. Wo heute die Häuser von Großenglis stehen, wird bald in rastloser Arbeit die Braunkohle abgebaut. - HN, 1952; Nr. 257 v. ??.11.1952, 6 Abb.; Kassel

-Hucke, Georg (1996): Zeche Frielendorf. - In: Gemeindevorstand der Gemeinde Frielendorf [Hrsg.]: Geschichte und Geschichten einer ehemaligen Bergarbeitersiedlung [Frielendorf OT Welcherod]. - 319 S., zahlr. Abb.; hier S. 177-212, 28 Abb.; (Plag) Schwalmstadt 1996 [Bezugn. a. Zeche Frielendorf, Tiefbau Stolzenbach, Tagebau Dillich]

$\square$ Jacobshagen, V.; Kuhnert, Christian \& Wycisk, Peter (1989): Geologie des Hohen Meißners in Nordhessen. - In: Jacobshagen, Volker \& Kuhnert, Christian [Hrsg.]: Der Hohe Meißner in Hessen - Ergebnisse geologischer und geomorphologischer Forschungen. - Berliner geowiss. Abh., Reihe A, 114; S. 9-76, 8 Abb., 5 Tab., 2 Beil.; (Selbstverlag Fachber. Geowiss. FU Berlin) Berlin 1989 [darin Kap.: „Geschichte des Bergbaus und der geologischen Erforschung“] 
$\square$ Johannes, M. (1925): Ein Besuch im Bransröder Stollen. - Heimat-Schollen, 1925 (5): 36 - 38, 1 Abb.; Melsungen

-Jünemann, Ingrid (1983): Ehemaliger Bergmann erinnert sich: Die „dunkle“ Vergangenheit der alten Kaufunger Kumpel. - HA, 1983; Nr. 174 v. 30.7.1983; Kassel

-Junker, Georg (1992): Die heimatliche Landschaft: Die Veränderung der Landschaft durch den Braunkohlenabbau. - In: Junker, Georg \& Mai, Gerhard: Chronik Allendorf - Texte und Bilder zur Geschichte eines Dorfes in der „Schmalzgrube“. - 216 S., zahlr. Abb.; hier S. 15-20, 4 Abb.; [Hrsg. Gemeindevorstand d. Gemeinde Frielendorf] Frielendorf-Allendorf 1992 [Tagebau Frielendorf]

-Kämmerer, O. (1935): Niederhesssischer Bezirk. - In: Hoffmann, A. [Bearb.]: Die Braunkohlenvorräte des Deutschen Reiches. - Archiv f. Lagerstättenforschung, 61; 38 S., 1 Abb., 12 Taf.; hier: S. 17-18, 1 Abb., 1 Tab.; [Preuß. Geol. Landesanst.] Berlin 1935 [Kurzinformationen Lagerstättengeologie u. Bergbau]

-Kajdan (1963): Wassereinbruch im Tiefbau Altenburg 4 [Borkener Revier] der Preußenelektra. Bergbau im Hessenland, 13 (3): 4-5, 2 Abb.; Kassel

-Kirchvogel, Paul Adolf (1940): Der Roßgang in Oberkaufungen. - Hessische Heimat, 1939/40(1): 15 16, Abb. 23; Marburg/L.

[Roßgang = Pferdegöpel i. Braunkohlenbergbau Oberkaufungen]

-Kirchvogel, Paul Adolf (1940): Historisch-technische Kulturpflege [Roßgang in Oberkaufungen]. Hessische Heimat, 1939/40(1): 16-19, Abb. 24-26; Marburg/L. [Roßgang $=$ Pferdegöpel i. Braunkohlenbergbau Oberkaufungen]

-Knauf, Wilhelm (1953): Gefährlich sind die nachdrängenden Sandmassen. - Ein Gang durch die Braunkohlenwerke in Holzhausen. - Heimatjahrbuch. f. d. Landkreis Hofgeismar, f. 1954: 37 - 40, 2 Abb.; Hofgeismar

-Knauf, Wilhelm (1988): Gefährlich sind die nachdrängenden Sandmasssen. Ein Gang durch die Braunkohlenwerke in Holzhausen. - In: Arend, Stefan [Zusammstlg. u. Bearb.]: Zwischen Gahrenberg und Sudholz - Ein Sammelband zur Geschichte von Holzhausen/Rhw.; Reihe: Arbeitskreis f. Heimatgeschichte d. Stadt Immenhausen, H. 11; 96 S., Abb.; hier S. 16-20; (Eigenverlag d. Stadt Immenhausen) Immenhausen 1988

$\square$ Koch, Friedhelm (2004): Ein Bergwerksunglück in Großalmerode im Jahr 1767. Dargestellt in zwei historischen Quellen. - Hessischer Gebirgsbote, 105(3): 109-111, 1 Abb.; Melsungen

$\square$ Koch, Friedhelm (2005): Ein tragisches Bergwerksunglück in Großalmerode im Jahr 1767. Dargestellt auf der Grundlage zweier historischer Quellen. - Dortmunder Beitr. z. Landeskde., Naturwiss. Mitt., 39: 31-38, 3 Abb.; Dortmund

$\square$ Koch, Friedhelm (2008): ,,Wilhelm Heinrich“ in Laudenbach - Einst eine Zeche zwischen Meißner und Hirschberg. - Das Werraland, $\underline{\mathbf{6 0}}$ (3): 57-59, 5 Abb.; Bad Sooden-Allendorf [Braunkohle-Bergbau]

$\square$ Koch, Friedhelm (2009): Nachtrag zu „,Wilhelm Heinrich“. - Das Werraland, 61(1): 18-19; Bad Sooden-Allendorf [Braunkohle-Bergbau Laudenbach/Gelstertal]

-Kolms, Günter (1990): Schlußakt der Braunkohletradition: Tagebau Ostheim ging zu Ende. - HNA (FHA), 1990; Nr. 47 v. 24.2.1990; Kassel 
-Kreßmann, H. (1929): Die Bedeutung der niederhessischen Braunkohlen für das Wirtschaftsgebiet Hessen-Nassau. - Heimatkalender f. d. Landkreis Hofgeismar, f. 1930: 82 - 85, 1 Kt.; Hofgeismar

-Krischmann, Helmut (1993): Bergbaugeschichte: Gras gewachsen über die Kohle]. - HNA, 1993; Nr. 47 v. 25.2.1993; Kassel [Steinertfeld/Kaufungen]

- $\square$ Landschütz, H. (1930): Braunkohlen - Der Niederhessische Braunkohlenbezirk (Revier Cassel). - In: Hülsemann, P. [Hrsg.]: Die Bergwerke Deutschlands - Auf bergwirtschaftlicher und lagerstättenkundlicher Grundlage. - XI, 412 S., zahlr. Abb., Tab. 8 Kt.; hier: S. 71-77; (Enke) Stuttgart 1930

- $\square$ Lange, Erich (1955): Steinkohlen- und Braunkohlenkleinbetriebe $<$ in der Bundesrepublik Deutschland >. - Z. angew. Geol., 1 (1): 39-40; Berlin [darin: Frielendorf, Großalmerode(Steinsberg/Boolsgraben)]

-Langrock, Heinrich (1980): Die Zeche Marie am Bilstein im Habichtswald. - In.: Heimatverein Dorothea Viehmann - Heimatbrief 24(4): 156-159; Kassel

-Linstow, Otto v. (1915): Die Braunkohlenformation in Hannover, Braunschweig, Anhalt und im Reg.Bez. Magdeburg der Provinz Sachsen. - In: Klein, Georg [Hrsg.]: Die deutsche Braunkohlenindustrie - Handbuch für den deutschen Braunkohlenbergbau. - 2. vollst. Neubearb. Aufl., Textbd.: 880 S., 606 Abb. , Taf.Bd. Taf. 1-29 + 1 Kt.-Beil.; hier: S. 129-146, Abb. 33,34; Halle/Saale 1915

[darin: Hoher Hagen b. Dransfeld, Steinberg/Meensen, Teichberg b. Bühren, Steinberg b. Münden]

-Lohmann, Hans (1928) [1966]: Der Kasseler Braunkohlenbergbau und die einheimische Wirtschaft [Vortragstext]. - In: Harnisch, W.; Hasemann, H. \& Hoffmann, E. [Bearb.]: Geschichte des bergbaulichen Vereins Kassel. - 176 S., Abb., statist. Tab.; hier: S. 155-166; [Hrsg. Bergbauverein Hessen e.V.] Kassel [1966] - Erstveröffentlichung in: Braunkohle - Z. f. Gewinnung u. Verwertung d. Braunkohle, $\underline{\text { 33; }}$; Halle/Saale 1928

-Lotze, Siegfried (1997): Vom Bergamt Veckerhagen, der Zeche Gahrenberg und den Bergleuten. - In: Lotze, Siegfried [Hrsg.]: Veckerhagen in sieben Jahrhunderten - Beiträge zur Sozial-, Wirtschaftsund Kunstgeschichte eines Oberweserdorfes. - Reihe: Die Geschichte unserer Heimat, 266; 364 S., zahlr. Abb.; hier S. 133-135, 2 Abb.; Veckerhagen 1997

-Lungershausen, Kurt (1962): 400 Jahre Alaun- und Kohlenbergbau in Kaufungen. - Bergbau im Hessenland, 12(1): 4-10, 4 Abb.; Kassel

- $\square$ Meyer, Werner (1927): Die geschichtliche Entwicklung und Bedeutung des hessischen Braunkohlebergbaus. - In: Adler, Arthur [Hrsg.]: Heimat-Kalender des Kreises Eschwege für das Jahr 1928 (1. Jg.). Ein Nachschlagebuch und Ratgeber für die Familie in Stadt und Land. - 92 S., Abb.; hier S. 30-34, 1 Abb.; (Johs. Braun) Eschwege 1927

$\square$ Müller, Alfred (1979): Geschichtliches vom Meißner-Bergbau - Zusammengestellt aus alten Jahrbüchern... - Werra-Rundschau, 1979; Nr. 299 v. 24.12.1979, S. 7; Eschwege

$\square$ Namenskürzel (B)(1946): Der Bergbau am Meißner. - HN, 1946; Nr. 151 v. 14.12.1946; Kassel [Braunkohle]

-Namenskürzel (m)(1947): Zeche Herkules in diesem Jahr erschöpft - Noch 100 t Tageslieferung. Kasseler Zeitung, 1947; Nr. 30 v. 5.2.1947, 1 Abb.; Kassel [Zeche Herkules, Habichtswald/Kassel]

$\square$ Namenskürzel (Hkr) (1948): <Großalmerode $>$ Eine Stadt lebt von Ton und Kohle. - WerraRundschau, 1948; Nr. 4. v. 24.1.1948; Eschwege 
$\square$ Namenskürzel (mk) (1949): „Der Meißner“ - ein Heimatbuch von Prof. Ulrich [Buchbesprechung]. Werra-Rundschau, 1949; Nr. 126 v. 1.6.1949, S. 5; Eschwege

[S. 9-25, 2 Abb.: „Der Meißner landschaftlich und geologisch“; S. 25-29: „Quellen“ [auch Hydrogeologie]; S. 29-45, 1 Abb.: „Das Braunkohlenwerk"]

-Namenskürzel (bf)(1951): Neue Förderanlage am Ronneberg - Braunkohlenzeche wird erweitert. HN, 1951; Nr. 94 v. 23.4.1951; Kassel

[Knüllgebiet/Rinnetal]

-Namenskürzel (rb)(1951): Kraftwerk Borken beginnt heute mit Bohrungen nach Braunkohle im Wiesengelände der Schwalm. - HN, 1951; Nr. 138 v. 18.6.1951; Kassel

$\square$ Namenskürzel (o)(1952): Auf 1200 Stufen zum Braunkohlen-Abbau. - Die breiten Flöze in Glimmerode sind nur erst an ihren Rändern ,angekratzt“" - HN (WN), 1952; Nr. 97 v. 26.4.1952; Kassel

-Namenskürzel [B1.](1952): Ein neues Braunkohlenwerk entsteht. - Zeche „Möncheberg“ KasselIhringshausen. - Bergbau i. Hessenland (Ausgabe Braunkohle), (2. Jg.) 1952(7): 4, 5 Abb.; Kassel

-Namenskürzel [L.U.](1952): Die Kaufunger „Alte Hütte“. - Bergbau i. Hessenland (Ausgabe Braunkohle), (2.Jg.) 1952(6): 4, 13, 1 Abb.; Kassel

-Namenskürzel (ski)(1952): Mit dem Mikrophon vor Ort: In der Zeche Marie wird ein neues Flöz erschlossen, das etwa 500000 Tonnen Kohle und Arbeit für zwei Jahre verspricht. - HA, 1952; Nr. 111 v. 14.5.1952, 2 Abb.; Kassel

-Namenskürzel (b)(1952): Zeche „Heiligenberg“ von der Stillegung bedroht - Kohlevorhaben in drei Monaten erschöpft - 40000 DM zur Erschließung neuer Abbaufelder benötigt. - HN (EB), 1952; Nr. 239 v. 16.10.1952, 2 Abb.; Kassel

[Zeche Heiligenberg b. Melsungen]

-Namenskürzel [ULE] (1953): Eine Million Tonnen Braunkohle - Neues Vorkommen im Habichtswald wird erschlossen. - Bergbau i. Hessenland (Ausgabe Braunkohle), (3.Jg.) 1953(11): 4, 3 Abb.; Kassel [Zeche Marie]

-Namenskürzel (ju)(1953): Detonationen dröhnten durch die Zeche „Marie“ - Neues Braunkohlevorkommen im Habichtswald erschlossen - Eine Million Tonnen für Abbau reif gemacht. - Kasseler Post, 1953; Nr. 129 v. 8.6.1953; Kassel

-Namenskürzel (kx)(1953): Generalangriff auf 1 Million Tonnen Kohle - Ein unerschlossenes Braunkohlenvorkommen unter dem Habichtswald lockt - aber das Grundwasser vereitelte schon viermal alle schönen Pläne. - HN, 1953; Nr. 131 v. 10.6.1953, 2 Abb.; Kassel

- $\square$ Namenskürzel (H.H.) (1953): Braunkohle und ihre Bedeutung für die Wirtschaft von Kurhessen. HN, 1953; Nr. 146 v. 27.7.1953, 3 Abb.; Kassel

-Namenskürzel (b)(1953): Der Heiligenberg - Stollen liegt tot - Das Ostfeld kann aber abgebaut werden - Kumpfel schöpfen neue Hoffnung - Zur Erschließung fehlen rund 100000 D-Mark - Das dritte Bohrloch entscheidet. - HN, 1953; Nr. 187 v. 14.8.1953, 2 Abb.; Kassel [Braunkohlebergbau Heiligenberg b. Melsungen]

-Namenskürzel (on)(1953): Braunkohlenzeche Osterberg fördert wieder - Am Osterberg bei Holzhausen wurde bereits 1592 nach Kohle gegraben. - HN (NHS)[vermutlich Ausgabe Nordhessischer Spiegel], 1953; Nr. 254 v. 31.10.1953; Kassel 
- $\square$ Namenskürzel [F.B.](1954): Bismarcks Base und die Zeche Gahrenberg. - Bergbau i. Hessenland (Ausgabe Braunkohle), (4. Jg.) 1954(7): 3-4, 1 Abb.; Kassel

- $\square$ Namenskürzel [H.-n.](1954): Braunkohle an der Hasenhecke. - Bergbau i. Hessenland (Ausgabe Braunkohle), (4. Jg.) 1954(7): 13, 3 Abb.; Kassel

[Braunkohle-Exploration Kassel-Wolfsanger]

- $\square$ Namenskürzel [Ha](1954): Der niederhessische Braunkohlen-Bergbau - Geologische Übersicht und geschichtlicher Rückblick. - Bergbau i. Hessenland (Ausgabe Braunkohle), (4. Jg.) 1954(11): 3, 13-14, 3 Abb.; Kassel

-Namenskürzel (BF)(1954): 120 Jahre Zeche Gahrenberg - Den größen Wassereinbruch erlebte die Grube im April 1948. - HA (NHS)[vermutlich Ausgabe Nordhessischer Spiegel], 1954; Nr. 79 v. 3.4.1954, 1 Abb.; Kassel

$\square$ Namenskürzel [FHS](1955): Schwieriger Abbau auf Zeche Glimmerode. - Bergbau i. Hessenland (Ausgabe Braunkohle), (5. Jg.) 1955(9): 3-4, 2 Abb.; Kassel

[Lagerstättengeologie, Bergbaugeschichte]

- $\square$ Namenskürzel [FHS](1955): Berg- und Hüttenwerke in der Landgrafenzeit. - Bergbau i. Hessenland (Ausgabe Braunkohle), (5. Jg.) 1955 (12): 4; Kassel

[Eisenerzbergwerke; Braunkohle u.a. Meißner)]

-Namenskürzel [R](1955): Bergbau am Kaufunger Roßschacht. - Bergbau i. Hessenland (Ausgabe Braunkohle), (5.Jg.) 1955(13): 3-4, 5 Abb.; Kassel

$\square$ Namenskürzel (o)(1955): Erstmals seit 400 Jahren - Braunkohlentagebau am Hirschberg - Zeche Hirschberg kann 100000 t Braunkohlen über Tage abbauen. - HN (FB)[vermutlich Ausgabe Fuldabote], 1955; Nr. 191 v. 19.8.1955, 2 Abb.; Kassel

-Namenskürzel (al)(1955): Seit 56 Jahren: Braunkohlenrevier Borken - Das erste Kohlenbergwerk befand sich in der Nähe von Gombeth. - HN (HE) [vermutlich Ausgabe Heimat-Echo], 1955; Nr. 228 v. 1.10.1955; Kassel

$\square$ Namenskürzel (wn)(1957): Naturschutz oder Arbeitslosigkeit? - Betriebsrat der Zeche Meißner nahm Stellung zum Meißnerproblem. - HN (WN)[vermutlich Ausgabe Witzenhäuser-Nachichten], 1957; Nr. 45 v. 22.2.1957; Kassel

-Namenskürzel (b)(1957): .../Neues Braunkohlen-Vorkommen im Raum Ostheim soll abgebaut werden - Direktor Hoffmann: Arbeiten beginnen mit großer Wahrscheinlichkeit im Frühjahr 1958 Bau einer Autobahn-Auffahrt für den Abtransport. - HN (HE)[vermutlich Ausgabe Heimat-Echo], 1957; Nr. 11 v. 14.1.1957; Kassel

$\square$ Namenskürzel (HG) (1957): Verstärkte Kohleförderung auf dem Meißner geplant. Neu eingeführter gleisloser Abbau soll Erschließung in südöstlicher Richtung beschleunigen. - Werra-Rundschau, 1957; Nr. 96 v. 25.4.1957, S. 3, 2 Abb.; Eschwege

$\square$ Namenskürzel (1h)(1957): Kohle am Meißner soll total abgebaut werden. Bergbau bracht sich an keine Begrenzung mehr zu halten -Nur die Kalbe bleibt ausgenommen. - Werra-Rundschau, 1957; Nr. 294 v. 19.12.1957, S. 4; Eschwege

$\square$ Namenskürzel (KK) (1960): < Geschichte des Hauses Schwalbenthal, Hoher Meißner>. - WerraRundschau, 1960; Nr. 90 v. 16.4.1960, S. 6, 1 Abb.; Eschwege

$\square$ Namenskürzel (Werra-Rundschau) (1960): Kohlestückchen in der Quelle - 400 Jahre Bergbau auf dem Meißner. - 1560 unternahmen Eschweger und Kasseler ersten Versuch / Ersatz für gelichtete Sodwälder. - Werra-Rundschau, 1960; Nr. 181 v. 6.8.1960, S. 5, 1 Abb.; Eschwege 


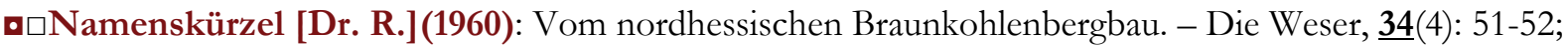
Bremen

-Namenskürzel (1h) (1963): Grubenbrand nach drei Tagen unter Kontrolle - 10000 Tonnen Braunkohle erfaßt / Ursache: Selbstentzündung. - Werra-Rundschau, 1963; Nr. 44 v. 21.2.1963, S. 4; Eschwege

[Zeche „Neue Hoffnung“ am Osterberg b. Holzhausen / Lkr. Hofgeismar, heute Lkr. Kassel]

-Namenskürzel [Bu](1963): Neuzeitlicher Bergbau im historischen Oberkaufungen. - Bergbau im Hessenland, $\underline{\mathbf{1 3}}(2)$ : 6-7, 7 Abb.; Kassel

-Namenskürzel (d)(1966): Am Stellberg in der Söhre wird gebohrt - Neue Kohlenflöze gesucht Tagebau zieht Mitte 1967 um - Alte Grube nicht mehr ergiebig. - HA, 1966; Nr. 277 v. 29.11.1966, 3 Abb.; Kassel

-Namenskürzel [Kj](1967): Zur Lage des Braunkohlenbergbaus in Borken. - Bergbau i. Hessenland, (17) 1967(2): 4-6, 2 Abb.; Kassel

[Wirtschaftliche Situation]

- $\square$ Namenskürzel [St.](1967): Hessische Braunkohlenwerke (HBZ) GmbH müssen ihre Tiefbaubetriebe stillegen. - Bergbau i. Hessenland, (17) 1967(1): 4-5, 2 Abb.; Kassel

[Zeche Glimmerode, Zeche Marie/Habichtswald]

- $\square$ Namenskürzel (o)(1967): Zwei Braunkohlengruben werden stillgelegt: 240 Entlassungen - Tiefbau der Zeche Glimmerode und Stellberg betroffen/... - HA, 1967; Nr. 31 v. 6.2.1967; Kassel

- $\square$ Namenskürzel (t)(1967): Bergamt Kassel feiert Jubiläum - Ein Jahrhundert „vor Ort“ - Schon in alten Zeiten wurde in Nordhessen nach Kohle gebohrt. - HA, 1967; Nr. 227 v. 30.9.1967; Kassel

$\square$ Namenskürzel (o)(1967): Zeche Hirschberg stellt Braunkohlen-Tiefbau ein - Ab 1968 nur Tagebau 120 Bergleute werden entlassen. - HA, 1967; Nr. 243 v. 19.10.1967; Kassel

-Namenskürzel [Lr](1968): Tiefbau Altenburg IV [Revier Borken] beendet. - Bergbau i. Hessenland, (18) $\underline{1968}(1)$ [damit Erscheinen eingestellt]: 2-3, 4 Abb.; Kassel

- $\square$ Namenskürzel (0)(1968): HBZ stellt die gesamte Braunkohlenförderung ein - Auf dem Zechengelände am Stellberg und Glimmerode sollen Erholungszentren mit Teichen entstehen. - HA, 1968; Nr. 93 v. 20.4.1968; Kassel

-Namenskürzel (d)(1969): Nach 100 Jahren... Traum von schwarzen Diamanten - Geschichte des Braunkohlenbergbaus begann am Möncheberg. - HA, 1969; Nr. 302 v. 31.12.1969, 1 Abb.; Kassel

-Namenskürzel (j)(1970): Nach 128 Jahren in Veckerhagen - Zeche Gahrenberg fährt letzte Schicht/... - HA, 1970; Nr. 252 v. 30.10.1970; Kassel

-Namenskürzel (d)(1971): Braunkohlengrube hat ausgedient - Tagebaubetrieb der Zeche Freudenthal wegen Absatzmangels stillgelegt. - HA, 1971; Nr. 103 v. 5.5.1971; Kassel

-Namenskürzel (yv)(1971): Der Braunkohlenbergbau bei Sipperhausen [Gemeinde Malsfeld, SchwalmEder-Kreis] - Seit mehr als 100 Jahren wird in diesem Gebiet das „schwarze Gold“ gewonnen. - HA (FHA)[vermutlich Ausgabe Fritzlar-Homberg], 1971; Nr. 106 v. 8.5.1971; Kassel

-Namenskürzel (yg)(1973): In Ostheim: Abbau der Braunkohle hat begonnen - Tiefenbohrung fündig. - HA (MA)[vermutlich Ausgabe Melsungen] 1973; Nr. 120 v. 24.5.1973; Kassel 
- $\square$ Namenskürzel (d)(1973): Bei langfristigen Abnahmegarantien: Braunkohle für 20-25 Jahre Förderung im Großraum Kassel ließe sich verdreifachen. - HA, 1973; Nr. 286 v. 8.1.2.1973; Kassel

$\square$ Namenskürzel (t)(1974): Nordhessens reichster Energievorrat: Braunkohle hat wieder Chancen. Neue Analyse: Weniger Schwefel. - HA, 1974; Nr. 258 v. 6.11.1974; Kassel

[Braunkohlenabbau am Hirschberg b. Großalmerode]

-Namenskürzel (zef)(1975): Eine halbe Million Tonnen Braunkohle noch abbaulohnend: PREAG erschließt Tagebau - „Haarhausen II“ - Ab Frühjahr Abraumförderung. - HA (Ausgabe FritzlarHomberg), 1975; Nr. 36 v. 12..2.1975; Kassel

[Borkener Revier]

-Namenskürzel (zef)(1975): Im Revier der Grube Altenburg, Borken: Letzte Kohle aus dem Tagebau IV - Neun Millionen Tonnen gefördert - Künftig 130 ha große Wasserfläche. - HA (Ausgabe Fritzlar-Homberg) $\underline{\mathbf{1 9 7 5}}$; Nr. 107 v. 10.5.1975; Kassel

$\square$ Namenskürzel (k)(1978): Wieder Braunkohlen-Abbau bei Glimmerode. - HA (E-Ederbote), 1978; Nr. 53 v. 3.3.1978; Kassel

[ehemalige Zeche Glimmerode bei Hessisch-Lichtenau/Retterode]

-Namenskürzel (rff)(1978): 400 Jahre Kasseler Braunkohlenbergbau - Ältestes Revier Deutschlands Jubiläumsfeier 1928 - Rege Förderung durch den Schlüsselstollen. - HA, 1978; Nr. 167 v. 22.7.1978; Kassel

$\square$ Namenskürzel (k)(1979): Auf „toten Böden“ grünt es wieder: GhK und Bergamt stellen Rekultivierungsprojekt bei Lichtenau vor. - HA, 1979; Nr. 209 v. 8.9.1979; Kassel [Ehemalige Zeche Glimmerode bei Hessisch-Lichtenau/Retterode]

-Namenskürzel (wfr)(1982): Preag will bei Frielendorf wieder Braunkohle abbauen - Ein Million Tonnen im Tagebau für Kraftwerk in Borken. - HA, 1982; Nr. 255 v. 3.11.1982; Kassel

- $\square$ Namenskürzel (m.s.)(1984): Braunkohle aus Nordhessen: Bleibt die Energie bald vor der Tür? HNA, 1984; Nr. 284 v. 5.12.1984; Kassel

[Mögliches Verbot des Hausbrandes mit nordhessischer Braunkohle wegen hoher Umweltbelastung]

$\square$ Namenskürzel (t)(1985): Zeche Hirschberg/Vorwurf an Behörden: Ein Ofen-Rohrkrepierer. - HNA, $\underline{1985}$; Nr. 8 v. 10.1.1985; Kassel

[Mögliches Verbot der Hausbrandes mit nordhessischer Braunkohle wegen hoher Umweltbelastung]

-Namenskürzel (mdm)(1986): 83jähriger Karl Kiel arbeitete als Schmied unter Tage - Erdrutsch läßt Erinnerungen an früheren Bergbau aufleben. - HNA*, 1986; Nr. 82 v. 9.4.1986; Kassel [Bergbaugeschichte Zeche Möncheberg]

-Namenskürzel (zol)(1987): Bergbau in der Söhre - Viele Spuren sind heute schon verwischt. - HNA, 1987; Nr. 193 v. 21.8.1987, 1 Abb.; Kassel

[Kohlebergbau, Basalt]

-Namenskürzel (g)(1988): Nach Katastrophe im Juni - 150 Mitarbeiter betroffen - Grube Stolzenbach wird nicht wieder in Betrieb genommen. - HNA, 1988; Nr. 245 v. 20.10.1988; Kassel [Grubenunglück am 1. Juni 1988 i. Braunkohlentiefbau Stolzenbach mit 51 Toten; Borkener Braunkohlenrevier]

- $\square$ Namenskürzel (g)(1988): Kreis-DGB macht Rechnung auf: Braunkohle reicht über 2000 hinaus. HNA (MA) [vermutlich Melsunger Ausgabe], 1988; Nr. 62 v. 14.3.1988; Kassel 
- $\square$ Namenskürzel (hos)(1988): Braunkohlenrevier: Abbau seit 1578. - HNA, 1988; Nr. 127 v. 2.6.1988; Kassel [Nordhessischer Braunkohlenbergbau]

-Namenskürzel (beb)(1988): Neues Heft beschreibt die Geschichte der früheren Zeche Möncheberg Ein Bildhauer fand Kohle statt Ton. - HNA, 1988; Nr. 128 v. 4.6.1988; Kassel

-Namenskürzel (fs)(1988): Zechen Heiligenberg, Obermelsungen und Heßlar - Kohlenabbau schon anno dazumal. - HNA (MA) [vermutlich Melsunger Ausgabe], 1988; Nr. 216 v. 16.9.1988; Kassel

$\square$ Namenskürzel (stu)(1991): Zeche Hirschberg: Braunkohle - Energie mit Zukunft? - HNA, 1991; Nr. 168 v. 23.7.1991; Kassel

[Zeche Hirschberg, Großalmerode]

-Namenskürzel (VBS) (2003): Vor 15 Jahren: Grubenunglück in Borken - Gewaltige Explosion setzte giftige Gase frei. - Werra-Rundschau-Sonntagszeit, 2003; Nr. 22 v. 1.6.2003, 2 Abb.; Eschwege

-Naumann, Peter (1983): Der Braunkohlenbergbau des Reinhardswaldes. - Rückblick - Z. d. Geol. Interessengemeinschaft Nordessen (GIN), 2: 6-8; o.O. [Hofgeismar]

d $\square$ OPerst, Otto [Hrsg.] (1960): Das Werraland in der Beschreibung Niederhessens von Landgraf Hermann zu Hessen-Rotenburg. - Eingeleitet und herausgegeben von... - Reihe: Aus dem Werraland, 7; Separatdruck aus der Zeitschrift „Das Werraland, 12. Jahrgang. 1960, Vierteljahresschrift des Werratalverins e.V., Eschwege. - 35 S.; (Rossbach) Eschwege - auch in: Das Werraland, 12(3): 38-43, 12(4): 57-61; Eschwege

[darin erwähnt: Erdfälle b. Frauensee, Erdfälle im Amt Sontra, besonders bei Berneburg; der Rote See in Dens; das Kohlenbergwerk auf dem Meissner; die Stinksteinwand; das Salzwerk in Allendorf in den Soden]

-Peter, Dietmar (1984): Der Bergbau am Stellberg. - In: Heß, G.; Peter, D.; Scholz, Th. H.D. \& Werner, H.-U. [Red.-Ausschuss]: Söhrewald 1984 - ein Beitrag zur Heimatkunde. - 365 S. + Anzeitenteil (S. 366-391), Abb.; hier S. 11-19, 10 Abb.; [Hrsg. Arbeitskreis Söhrewaldbuch] Söhrewald 1984

[Braunkohlenbergbau i. d. Söhre]

-Peter, Dietmar (1984): Zwischen Liegendem und Hangendem (Erinnerungen ehemaliger Bergleute). In: Heß, G.; Peter, D.; Scholz, Th. H.D. \& Werner, H.-U. [Red.-Ausschuss]: Söhrewald 1984 ein Beitrag zur Heimatkunde. - 365 S. + Anzeitenteil (S. 366-391), Abb.; hiers S. 21-25, 6 Abb.; [Hrsg. Arbeitskreis Söhrewaldbuch] Söhrewald 1984

-Peter, Dietmar (2001): Bergbau in der Söhre. - In: Scholz, Th. Hans-Dieter [Vorsitz d. Red. „Ausschuss Festschrift“]: 650 Jahre Wellerode 1351-2001. - 312 S. + Anzeigenteil, Abb.; hier: S. 160; [Hrsg. Gemeinde Söhrewald] Söhrewald 2001

-Pötter, Willy (2001): Die Familie Henschel und ihre Bedeutung für Ihringshausen. - Hessischer Gebirgsbote, 102(2): 61 - 63, 6 Abb.; Melsungen

[Kassel-Ihringshausen; Braunkohlenbergbau Ihringshausen, Ziegeleigrube Möncheberg]

$\square$ Preßler, Georg (1997): Bergbau in der Region um Laudenbach. - In: Kollmann, Karl [Red.]: 700 Jahre Laudenbach - Ein Dorf im Wandel der Zeiten. - 279 S., zahlr. Abb.; hier: S. 213-218, 6 Abb.; [Hrsg. Stadt Großalmerode, Ortsbeirat Laudenbach u. Kulturausschuß Laudenbach] GroßalmerodeLaudenbach 1997

[Braunkohle-Bergbau am Meißner]

-Quest, Thorsten (1989): Das Braunkohlenwerk an der Wahlsburg zwischen Lippoldsberg und Vernawahlhausen. - Jb. Lkr. Kassel, 1990: 106 - 108; Kassel 
- $\square$ ORiess, Johann Philipp (1791): Mineralogische und bergmännische Beobachtungen über eine Hessische Gebirgsgegenden. - XIV, 102 S., 6 Taf.; (Rottmann) Berlin [darin: S. 28-54 Kupferschiefer- u. Kobalt-Bergbau Richelsdorfer Gebirge; S. 54-59 Kupferschiefer- u. Kobalt-Bergbau Glücksbrunn b. Bad Liebenstein; S. $69-84$ („,Steinkohlen“-) Braunkohlenbergbau u. Tertiär-Stratigaphie am Meissner; S. 84-89 Alaun- und („Steinkohlen“) Braunkohlen-Bergbau Oberkaufungen]

-Röhler, W. (1962): Aus der Entwicklung von Handwerk und Industrie: Der Braunkohlenbergbau bei Oberkaufungen - In: Meyer, Fritz: Oberkaufungen im Wandel der Zeiten. - 504 S., Abb., Tab.; hier: S. 210-215, 1 Abb.; [Hrsg. Gemeinde Kaufungen] (Bernecker) Melsungen 1962

-Röhler, Willi (1974): Der Roßgang und der frühe Bergbau zu Kaufungen. - Jb. Lkr. Kassel, 1975: 78 80, 2 Abb. (Taf.); Kassel

- Röhler, Willy (2007): Beitrag zur Geschichte über die Entwicklung des Braunkohlebergbaues um Oberkaufungen. - Herausgegeben von Jürgen Röhler und Johannes Schwidurski. - 85 S., zahlr. Abb., 1 Falt-Kt.; (Selbstverlag d. Herausgeber) Köln - Kaufungen.

$\square$ Röhler, Willy (2007): Beiträge zur Geschichte des Braunkohlenbergbaues am Hirschberg bei Großalmerode (Hessen) - Die Zeche Hirschberg. - Herausgegeben von Jürgen Röhler und Johannes Schwidurski. - 195 S., Abb.; (Selbstverlag d. Herausgeber) Köln - Kaufungen

$\square$ Rosenberg, G. (1957): Gleisloser Abraum auf dem Meißner. - Bergbau i. Hessenland (Ausgabe Braunkohle), (7. Jg.) 1957(11): 4-5, 7 Abb.; Kassel

[Bilder vom Tagebau Kalbe/Meißner]

OSchemm, Ch[rista] v. ([1997]: Der Bergbau um Cabarz und Tabarz. - In: Gemeindeverwaltung Tabarz [Hrsg.]: Tabarz im Thüringer Wald. Festschrift: 600 Jahre Cabarz - 725 Jahre Mönchehof. 130 S., zahlr. Abb.; hier S. 99-102, 1 tab. Übers., 1 Abb.; (Löhr) Ruhla [1997]

OSchmidt, Artur (1927): Beitrag zur Geschichte des Thüringer Lettenkohlenbergbaues. - Jb. Halleschen Verbandes., N.F., ㅁ: 82-86, 1 Abb.; Halle (Saale)

[Thüringer Becken, Rand d. Thüringer Waldes]

aSchmidt, Georg (1995): Der Braunkohlenbergbau im Raum Holzhausen und Umgebung. - In: Festausschuß „975 Jahre Holzhausen/Reihardswald“ [Hrsg.]]: 975 Jahre Holzhausen (Reinhardswald) 1020-1995. - ohne Seitenzählung; hier 2 S.; Holzhausen/Reinharswald 1995

- -Schneider, L. (1931): Das Braunkohlenbergwerk Frielendorf - (Aus Hessens Industrie, Handel und Gewerbe). - Hessenland, 42(1): 23-26, 1 Abb.; Marburg

aSchönhut, Horst (2002): Die Grube Altenburg in Borken (Hessen) - Geschichte des Borkener Braunkohlenabbaus. - Reihe: Nordhessischer Braunkohlenbergbau, o. Zählg.; 367 S., 209 Abb.; [Hrsg. Magistrat d. Stadt Borken] Borken (Hessen)

[Die Vorlage enthält zwei Werke: 1.) Schönhut, Horst: Die Grube Altenburg, S. 1-255 und 2.) Bickell, Hans: Die Übertage-Geräte der Grube Altenburg - die Bagger, Lokomotiven und Hilfsgeräte im Übertage-Betrieb der Grube Altenburg, S. 257-365]

-Schönhut, Horst (ca. 1998): Die Gewerkschaft Frielendorf - Geschichte der Frielendorfer Braunkohlenzeche. - Reihe: Nordhessischer Braunkohlenbergbau, o. Zhlg.; 288 S., 132 Abb.; [Hrsg. Geschichtsverein Borken e.V.] Borken

oSchreiber (1966): Zeche Stellberg. - Bergbau i. Hessenland, (16) 1966(6): 7, 1 Abb.; Kassel

- $\square$ Schreiber (1967): Glückauf zur letzten Schicht der Tiefbaue Glimmerode und Stellberg. - Bergbau i. Hessenland, (17) 1967(3): 4-7, 9 Abb.; Kassel 
-Schröder, E. (1996): Der Braunkohlenbergbau am Brunsberg bei Dransfeld im 19. Jahrhundert. Göttinger Jb., 44: 133-137, 2 Abb.; Göttingen

$\square$ Schwarzkopf, Eduard (1927): Zum 300jährigen Jubiläum des Kohlebergbaues auf'm Meißner in zierlichen Reimen. - In: Adler, Arthur [Hrsg.]: Heimat-Kalender des Kreises Eschwege für das Jahr 1928(1. Jg.). Ein Nachschlagebuch und Ratgeber für die Familie in Stadt und Land. - 92 S., Abb.; hier S. 34-35; (Johs. Braun) Eschwege 1927

- $\square[$ Seebohm] (1928): Der Kasseler Braunkohlenbergbau. - Hessenland, $\underline{40}$ (7): 203-210, 2 Kt.; Kassel [darin: Bergbau auf dem Meißner]

- Seib, Gerhard (1961): Blende, Frosch und Kreisel-Geleucht im Richelsdorfer Bergbau. - Bergbau i. Hessenland, (11 Jg.) 1961(7): 8-9, 10 Abb.; Kassel

- Seib, Gerhard (1974): Studien zur Geschichte der Industriearchitektur in Hessen (II) - Der Roßgang $<$ Pferdegöpel> bei Kaufungen. - HH, N.F. 24(1): 53-56, Abb. 36-42; Marburg [OBZ]

$\square$ Seib, Gerhard (1975): Technische Denkmäler in der Bundesrepublik Deutschland. - Denkmäler des Braunkohlenbergbaus - 19. Meissner. - In: Slotta, Rainer [Hrsg.]: Technische Denkmäler in der Bundesrepublik Deutschland. - Veröff. a. d. Dt. Bergbaumuseum Bochum, 7; S. 44-45, 2 Abb.; [Hrsg. Dt. Bergbaumuseum Bochum] Bochum 1975

-Seib, Gerhard (1975): Technische Denkmäler in der Bundesrepublik Deutschland. - 25. Kaufungen „Roßgang" - In: Slotta, Rainer [Hrsg.]: Technische Denkmäler in der Bundesrepublik Deutschland. - Veröff. a. d. Dt. Bergbaumuseum Bochum, 7; S. 57, 1 Abb.; [Hrsg. Dt. Bergbaumuseum Bochum] Bochum 1975

هSeib, Gerhard (1974): Der letzte bergmännische Pferdegöpel Westeuropas. Rettung eines technischen Kulturdenkmals in Hessen. - Der Anschnitt, 26(6): 26-29, 6 Abb.; Eschwege [Technisches Denkmal Braunkohlebergbau - Oberkaufungen Lkr. Kassel]

$\square$ Simon, Helmut (2006): Hausen - Höchstgelegener Ort Kurhessens - Die Geschichte eines niederhessischen Dorfes am Meißner in der Zeit von 1364 bis 2005. - 592 S:, zahlr. Abb.; [Hrsg. Helmut Simon, Kirchenvorstand Ev. Kirchengemeinde Hausen; Ortsbeirat Hausen] Hausen [darin S. 11-18, 8 Abb.: „Zum Naturraum von Hausen“; S. 29-46, zahlr. Abb. „Die Geschichte des Bergbaues am Hohen Meißner (Braunkohle, Alaun, Wascherde)]

- $\square$ Steckhan, Wilhelm (1952): Der Braunkohlenbergbau in Nordhessen. - Hessisches Lagerstättenarchiv, 1; S. S. 1-212, Abb. 1-38 (insges. 45); [Hrsg.: Hess. Landesamt f. Bodenforschung] Wiesbaden - zgl. Diss. Bergakademie Clausthal 1952 - fakisimilierter Nachdruck 1998

-Steckhan, Wilhelm (1988): Der Braunkohlenbergbau und seine geschichtliche Entwicklung in fünf Jahrhunderten im Habichtswald bei Kassel. - 132 S., Abb.; (Thiele \& Schwarz) Kassel

oSteckhan, Wilhelm (1988): Das Braunkohlevorkommen im Stellberg bei Kassel. - 96 S., Abb., Kt.; (Thiele \& Schwarz) Kassel

-Strippelmann, F. E. (1824): Bemerkungen über das Braunkohlenwerk und den darauf aufgeführten Bergbau am Habichtswalde. - Studien Göttingischen Vereins bergmänn. Freunde, 1: 233-286, 5 Tab.; Göttingen

oStrippelmann, F. E. (1833): Über den Brand in Braunkohlengruben mit vorzüglicher Rücksicht auf die Braunkohlenbergwerke am Habichtswald. - Studien Göttingischen Vereins bergmänn. Freunde, $\mathbf{3}$ : 99170; Göttingen 
-Strippelmann, F. E. (1833): Werthbestimmung des gewerkschaftlichen Möncheberger BraunkohlenWerkes unweit Kassel. - Studien Göttingischen Vereins bergmänn. Freunde, ㅁ: 171-190; Göttingen

-Strippelmann, F. E. (1833): Werthbestimmung des gewerkschaftlichen Braunkohlenwerks am Stillberg unweit Wollrode im Kreise Melsungen. - Studien Göttingischen Vereins bergmänn. Freunde, $\underline{\mathbf{3}}$ : 191206; Göttingen

$\square$ Strippelmann, F. E. (1837): Bergbau am Hirschberg bei Großalmerode. - Notizenblatt Göttingischen Vereins bergmänn. Freunde, $\underline{\mathbf{3}}$ : 1-2; Göttingen

[Nicht in der Vorlage eingesehen, Zitat nach Oppitz (1991)]

-Strippelmann, Berginspector (1843): (Staatswirthschaftliche und gewerbliche Statistik) Übersicht der Braunkohlen- und Torfförderungen in den Jahren 1837 bis einschließlich 1841 in Kurhessen, mit einigen daran geknüpften Bemerkungen. - Landwirthschaftliche Zeitung f. Kurhessen, 1843(1) (21. Jg.): 71-73; Kassel

-Strippelmann, Berginspector (1844): (Staatswirthschaftliche und gewerbliche Statistik) Übersicht der Braunkohlen- und Torfförderung in Kurhessen im Jahre 1842. - Landwirthschaftliche Ztg f. Kurhessen, (22. Jg.) 1844(2): $164+3$ S. Anl.; Kassel

-Strippelmann, Berginspector (1845-1847): (Staatswirthschaftliche und gewerbliche Statistik) Tabellarische Übersicht der Braunkohlenförderung in Kurhessen [in den Jahren 1843-1846]. Landwirthschaftliche Zeitung f. Kurhessen, (23. Jg.) 1845(2): 151 [Statistik für 1843]; (24. Jg.) 1846(3): 247-249 [Statistik für 1844]; (25. Jg.) 1847(2): 143-145 [Statistik für 1845]; (25. Jg.) 1847(4): 315-318 [Statistik für 1846]; Kassel

$\square$ Stumpf, Kerstin (1991): Bergbau: jenseits des Sonnenlichts. - HNA, 1991; Nr. 168 v. 23.7.1991; Kassel [Braunkohleabbau Hirschberg b. Großalmerode]

-Thonicke, Frank (1988): Schweres Unglück in der nordhessischen Braunkohlengrube BorkenStolzenbach - Explosion: 16 Kumpel tot, 41 vermißt/... - HNA, 1988; Nr. 127 v. 2.6.1988; Kassel [Grubenunglück v. 1. Juni 1988 mit 51 Toten]

- Thonicke, Frank (1988): Tränen, Trauer, Hoffnung: Der Tag nach der Katastrophe von Borken - „Da hab ich nur noch geheult“. - HNA, 1988; Nr. 127 v. 2.6.1988; Kassel [Grubenunglück v. 1. Juni 1988 mit 51 Toten]

$\square$ Thonicke, Frank (2002): Tradtition des Braunkohleabbaus in Nordhessen geht zu Ende. - „Glückauf, ihr Männer“ - Am 31. Dezember wird die letzte Braunkohle in der Zeche Hirschberg <Großalmerode> abgebaut. - Werra-Rundschau, 2002; Nr. 283 v. 4.12.2002, 4 Abb.; Eschwege

$\square$ Thonicke, Frank (2002): Tradtition des Braunkohleabbaus in Nordhessen geht zu Ende. - Statt Kohle Kanäle in Belgien - Die Geschichte des Bergbaus in Nordhessen hat auch Kurioses parat. - WerraRundschau, 2002; Nr. 283 v. 4.12.2002; Eschwege

-Thonicke, Frank (2008): Keiner verhinderte Katastrophe. - HR-Film zeigt: Das Unglück von Stolzenbach musste nicht passieren. - Werra-Rundschau, 2008; Nr. 215 v. 13./14.09.2008, 1 Foto, 1 Kt.; Eschwege [Bergwerksunglück Braunkohlen-Grube Stolzenbach b. Borken, Schwalm-Eder-Kreis, 1988]

$\square$ Träger, Harry \& Marzela, Clemens (2006): Der Braunkohlenbergbau am Meißner - 1558-1974. Ein historischer Rückblick und Begleitbroschüre für montanhistorische Wanderungen auf dem Meißner. 160 S., 122 Abb., 1 Kt.-Beil.; (Geiger) Horb [darin: S. 56-59, 2 Abb.: „Geologie“ [des Meißners]]

$\square$ Ulrich [Wilhelm] (1949): Der Meißner. - 116 S., 5 Abb.; (Werraland-Verlag) Eschwege Referat in: Das Werraland, 1: 17-18 (Perst) 
[S. 9-25, 2 Abb.: „Der Meißner landschaftlich und geologisch“; S. 25-29: „Quellen“ [auch Hydrogeologie]; S. 29-45, 1 Abb.: „Das Braunkohlenwerk“]

-Vogt, Egon E. (1966): Kumpel der Zeche Marie sagten dem Bergbau ade - Zum letztenmal im Habichtswald vor Ort. - HA, 1966; Nr. 174 v. 30.7.1966, 1 Abb.; Kassel

$\square$ Vogt, Egon E. (1977): Eine Million Tonnen „braunes Gold“ - Hirschberg: Wieder unter Tage. - HA, 1977; Nr. 303 v. 30.12.1977; 2 Abb.; Kassel

[Wiederaufnahme Tiefbau Zeche Hirschberg b. Großalmerode]

- $\square$ Vogt, Egon E. (1981): Noch erhebliche Vorräte an Braunkohle - Studie des Bergamtes Kassel: Kraftwerk Borken über Jahrzehnte gesichert. - HA, 1981; Nr. 151 v. 4.7.1981; Kassel [Rohstoffversorgung durch Nordhessischer Braunkohlenbergbau]

- $\square$ Vogt, Egon E. (1986): Lagerstätten in Nordhessen werden untersucht - Erste Erkenntnis: Braunkohlenvorräte reichen noch weit über das Jahr 2000 hinaus. - HNA, 1986; Nr. 286 v. 10.12.1986; Kassel

- $\square$ Voigt, Johann Carl Wilhelm (1802): Mineralogische Reise nach den Braunkohlenbergwerken und Basalten Hessens, wie auch den Schieferkohlenwerken des Unterharzes. - VIII, 238 S.; Weimar [darin: Blaue Kuppe, Meißner, Hirschberg, Habichtswald] [Erster Brief: Reise von Ilmenau über Gotha, Eisenach und Creutzburg nach der Blauen Kuppe bei Eschwege, in Hessen / Dritter Brief: Reise vom Meißner über Laudenbach, Aebteroda, die Ringkuhle, Wickenroda und Helse nach Cassel / - Fünfter Brief: Reise von Cassel über Helse, Witzenhausen, Heiligenstadt, Duderstadt bis Kloster Walkenried]

-Wächtler, Eberhard [Red.] (1999): Zur Geschichte des Braunkohlenbergbaus in Deutschland und Tschechien - 3. Montanhistorisches Kolloquium - Braunkohlebergbau, Tradition und Zukunft Borken, Kassel 1999. - 358 S., Abb., Kt.; [Hrsg. Magistrat der Stadt Borken] Borken/Hessen

- $\square$ Waitz von Eschen, Friedrich Frhr. (2005): Der nordhessische Braunkohlenbergbau 1578 - 2003. Z. Vereins hess. Gesch. u. Landeskde., 110: 113-128, 3 Abb., 1 Kt., 1 Tab., 2 graph. Darst.; Kassel

$\square$ Waitz von Eschen, R. \& Strippelmann, F. E. (1828): Geognostische Betrachtung der am Hirschberge bei Großalmerode abgelagerten, tertiären Gebilde, nebst einigen Bemerkungen über den daselbst im Betriebe stehenden Bergbau. - Studien Göttingischen Vereins bergmänn. Freunde, 22: 121168; (Dieterich) Göttingen

[Tertiärstratigraphie, Braunkohlenbergbau, Alaungewinnung]

-Wenzel, Waldemar (1999): Die ehemalige Zeche Gahrenberg. - Das Werraland, 51(1): 10, 1 Abb.; Eschwege

[Braunkohlen-Zeche Gahrenberg im Reinhardswald N’ Hann. Münden]

-Wenzel, Waldemar (1999): Die ehemalige Zeche Gahrenberg. - Hessischer Gebirgsbote, 100(1): 14 15, 2 Abb.; Melsungen

- $\square$ Zinken, C. F. (1867): Die Braunkohle und ihre Verwendung. - Erster Theil: Die Physiographie der Braunkohle. - X, 818 S., Zchng., 3 Taf.; (Carl Rümpler) Hannover

[darin: umfassende Beschreibung der Vorkommen und Abbaue des nordhessischen

Braunkohlenreviers (Hessen-Cassel), u. a. Hessische Senke, Reinhardswald, WMK; Lkr. Göttingen:

Steinberg b. Hann. Münden, Dransfeld]

[Ostheim/Habichtswald/Schimmberg u. Burgberg b.

Hoof/Stellberg/Möncheberg/Söhrewald/Lammsberg b.

Gudensberg/Meissner,/Hirschberg/Belgerskopf/Oberkaufungen/Steinberg N'Großalmerode, Rommerode, Epterode, Romeberg b. Homburg, Frielendorf/Heiligenberg b.

Gensungen/Reinhardswald(Immenhausen, Hohenkirchen, Holzhausen, Ahlberg/Gottsbüren] 


\subsection{Kupferschiefer, Schwerspat- und Kobalt}

$\square$ Anonym (1890): < Nachgrabungen nach Kupferschiefer und Silbererz am Kupferberg bei Wellingerode - Zwei Schurfstollen zur Lagerstättenerkundung geplant> - Eschweger Tageblatt u. Kreisblatt, 1890; Nr. 73 v. 27.03.1890; Eschwege

-Anonym (1894): < Grubenunglück in der Schwer-Spatgrube Münden bei Nentershausen. - Ein verschütteter Bergmann gerettet> - Eschweger Tageblatt u. Kreisblatt, 1894;

Nr. 227 v. 27.09 .1894

Nr. 228 v. 28.09 .1894

-Anonym (1895): < Ausflug des Werrathal-Zweigvereins Boyneburg - Besichtigung der Bergbauanlagen im Richelsdorfer Gebirge> - Eschweger Tageblatt u. Kreisblatt, 1895; Nr. 146 v. 25.06.1895; Eschwege

$\square$ Anonym (1900): < Tiefbohrungen bei Wellingerode nach Kupferschiefer und Kalisalz]. - Eschweger Tageblatt u. Kreisblatt, 1900; Nr. 270 v. 16.11.1900; Eschwege

$\square$ Anonym (1957): <Bergwerksunglück in der Schwerspat-Grube Gustav>. - Werra-Rundschau, 1957; Nr. 265 v. 14.11.1957, S. 1+3; Eschwege

$\square$ Anonym (1957): <Bergwerksunglück in der Schwerspat-Grube Gustav>. - Werra-Rundschau, 1957; Nr. 266 v. 15.11.1957, S. 1+3, 3 Abb.; Eschwege

$\square$ Anonym (1957): <Bergwerksunglück in der Schwerspat-Grube Gustav>. - Werra-Rundschau, 1957; Nr. 267 v. 16.11.1957, S. 5, 1 Abb.; Eschwege

$\square$ Anonym (1957): <Bergwerksunglück in der Schwerspat-Grube Gustav>. - Werra-Rundschau, 1957; Nr. 268 v. 18.11.1957, S. 1+3, 6 Abb.; Eschwege

$\square$ Anonym (1957): <Bergwerksunglück in der Schwerspat-Grube Gustav>. - Werra-Rundschau, 1957; Nr. 269 v. 19.11.1957, S. 3, 1 Abb.; Eschwege

-Anonym (1969): Die Friedrichshütte im Ibatal. - Hessischer Gebirgsbote, $\underline{70}(2): 42$ - 43, 1 Abb.; Melsungen

[Verarbeitung v. Kupferschiefer / Richelsdorfer Gebirge]

-Anonym [1978]: Die Richelsdorfer Hütte und ihre Geschichte. - In.: Festausschuß 700 Jahre

Richelsdorf [Hrsg.]: Richeolvisitorf - Richelsdorf. 700 Jahre Richelsdorf: 1277-1977. - 120 S., Abb.; hier: S. 89-92, 3 Abb.; Richelsdorf [1978]

-Anonym (1983): Nentershausen und der Bergbau. - Hersfeld-Rotenburg: Heimatkalender des Landkreises Hersfeld-Rotenburg für 1983 ... (27 Jg.): 220-224; 2 Abb., 1 Kt.; Bad Hersfeld

-Anonym (1995): Der Bergbau [bei Dens]. - In: Festausschuß 800-Jahrfeier [Hrsg.]: Tense - Dens: 800 Jahre: 1195 - 1995 - Festschrift zum Jubiläum von 6. bis 9. Juli 1995. - 74 S., zahlr. Abb.; hier: S. 58-61, 2 Abb.; Dens 1995

[Kupferschiefer-Bergbau Reichenbergschacht]

$\square$ Anonym (1997): Der Bergbau um Hornel. - In: Festausschuß 700 Jahre Hornel [Hrsg.]: 700 Jahre Hornel - Chronik von 1297 bis 1997 - Ein kleines Dorf zwischen Fulda und Meißner. - 192 S., zahlr. Abb.; hier: S. 131-145, 12 Abb.; (Gajewski) Ringgau 1997 
-Anonym (2004): Bergbaurelikte bei Oberellenbach und noch viel mehr. - Knüllgebirgsbote, 2004(1): 6, 2 Abb.; Bad Hersfeld

[Lehrpfad Bergbau-Geschichte „Baumbacher Hoch“; Lkr. Hersfeld-Rotenburg]

$\square$ Anonym (2007): Rettung in der Bombe - Helfer bergen im November 1957 zwei eingeschlossene Bergleute aus der Grube Gustav <Werra-Meißner-Kreis>. - Werra-Rundschau, 2007; Nr. 278 v. 29.11.2007, 2 Abb.; Eschwege

- $\square$ ○ीApel, Jürgen \& Rüppel, Heidi [Verfass. u. Hrsg.] (2005): Raus in die Natur - Tipps für den Sonntags-Ausflug im Dreiländereck Hessen - Niedersachsen - Thüringen. - 159 S., 111 Fotos, 34 Kt., 1 Zeit-Taf.; (LSRB-Verlag, Landschaftskundlicher-Studien-Reisebuch-Verlag) Witzenhausen [zahlreiche Ausflugsziele, auch zur alten Kupferschiefer- und Schwerspat-Bergbau-Relikten - Ziel 48 (Gelstertal), Ziel 66: (Grube Gustav/WMK), Ziel 94 (Richelsdorfer Gebirge)]

- $\square$ Bärtling, Richard (1911): Die Schwerspatlagerstätten Deutschlands in geologischer, lagerstättenkundlicher und bergwirtschaftlicher Hinsicht. - 188 S., 19 Abb.; (Enke) Stuttgart [darin: Grube Chattenberg b. Bad Sooden-Allendorf; Grube Münden/Nentershausen, Richelsdorfer Gebirge und Heinebach/Rotenburg F., Grube Mannel bei Herges-Vogtei i. Thür.)

$\square$ Bielenstein, Erika (2000): Die „Bilsteine“ als Einrichtungen des früh- und hochmittelalterlichen Bergbaus - ein Versuch. - Der Anschnitt, $\underline{\mathbf{5 2}}(2-3)$ : 106-109; Bochum [Bilsteine deutschlandweit: Nr. 14: Bilstein im Höllental/WMK]

$\square$ Bierwirth, H. (1925): Das Höllental. - Eschweger Tageblatt, 1925; Nr. 161 v. 11.7.1925; Eschwege [darin: Bergbaugeschichte des Höllentals, Geschichte der Burgen und Wallanlagen]

$\square$ Bierwirth, Heinrich (1927): Heimatklänge aus dem Werratale. - 2., vermehrte Aufl.; 195 S., Abb.; (A. Roßbach) Eschwege [darin Kap.: Das Höllental; S. 95-101, 1 Abb.; Heimatkunde, Bilsteinsage, Kupferschieferbergbau]

-Braune, Hermann (1999): Bergbau im Richelsdorfer Gebirge. - Knüllgebirgsbote, 1999(3): 3-4; Ill.; Homberg

- $\square$ Cancrinus, Franz Ludwig (1767): Beschreibung der vorzüglichsten Bergwerke in Hessen, in dem Waldeckischen, an dem Haarz, in dem Mansfeldischen, in Chursachsen, und in dem Saalfeldischen. [8] Bl., 429, [1] S.; 1 Abb., 11 Falt-Taf.; (Andreä) Frankfurt/M.

[darin: Eisenbergwerk Hohenkirchen b. Kassel, Hüttenwerke Veckerhagen, Karlshafener Blaufarbenwerke, Eisenbergwerk b. Homberg, „Von dem riegelsdorfer Schieferwerk in Hessen“ (Richelsdorfer Kupferschiefer-Bergbau); „Von dem Steinkohlenbergwerk an den Weissener in Hessen“ (Braunkohlen-Bergbau am Hohen Meißner)]

- $\square$ Cornelius, Detlef (1948): 500 Jahre Kupferbergbau bei Sontra. - Aus der Geschichte des Kreises Rotenburg. - Werra-Rundschau, 1948; Nr. 90 v. 5.10.1948, S. 3; Eschwege

-Credé, Heinrich (1955): 100 Jahre Schwerspatabbau im Richelsdorfer Gebirge. - Das Werraland, $\underline{7}(1)$ : 10-11, 2 Abb.; Eschwege

ه $\square$ Credé, Heinrich (1966): 75 Jahre Schwerspatmahlwerk in Sontra. - Hessische Heimat, N.F., 16(3/4): 96-98; Marburg/l.

-Deisenroth, Otto (1950): In einem heimatlichen Berwerk (1950). - 8 S.; o.O. [Kupferschiefer-Bergbau Richelsdorfer Gebirge] [Nachgewiesener Standort: Stadtarchiv Eschwege]

-Deisenroth, Otto (1979): Kinderarbeit vor 100 Jahren [Bergbau, Richelsdorfer Gebirge]. - In: HersfeldRotenburg: Heimatkalender des Landreises Hersfeld-Rotenburg, 23, S. 52-53; o.O. [Bad Hersfeld?] 
-Deist, Adam (1939): Der Bergbau im Richelsdorfer Gebirge und seine geographischen Wirkungen. Geographischer Anzeiger, 40(14): 316-323, 342-344, 1 Abb. i. T., 10 Abb. a. Taf. 37, 38; Gotha

Q[Eckardt, Johann Ludwig v.] (1783): Nachricht von dem ehmaligen Bergbau bey Ilmenau in der Grafschaft Henneberg und Vorschläge ihn durch eine neue Gewerkschaft wieder in Aufnahme zu bringen. - 36 S.; Weimar

-Ey d. Aelt, C. (1843): Bergmännische Bemerkungen über den Richelsdorfer Kupferschieferbergbau. Archiv. f. Mineralogie, Geognosie, Bergbau u. Hüttenkde., 17(2): 750-775; Berlin

$\square$ Fabig, Reinhard (1988): Der Gang unter Wommen. - Das Werraland, 40 (3): 45, 1 Abb.; Eschwege [Hohlraum als Relikt ehemaligen Kupferschiefer-Bergbaus?]

- $\square$ Görlich, Paul (1975): Freie und Hänselstadt Sontra. - Mein Heimatland, 26(14): 52; Bad Hersfeld [darin: Sontra als Stadt des Kupfer-Bergbaus]

- Grassmann (1886): Das Richelsdorfer Kupfer- und Kobaltwerk in Hessen. - Hierzu die Texttafel p. Z. Berg-, Hütten- u. Salinenwesen, 34: 195-207 (Abb.); Berlin

Referat in: N. Jb. Mineral. etc, $\underline{1888}$ (Bd. I): 245 (G. Greim); Stuttgart

[Regionalgeologie, Lagerstättengeologie, Bergbaugeschichte, Förderstatistik]

-Haarberg, Rudolf (1993): Wassereinbruch im Reichenbergschacht. - Knüllgebirgsbote, 1993(2): 42-43, 2 Abb.; Bad Hersfeld

[Kupferschieferbergbau Richelsdorfer Gebirge]

- 0 Hausbrand, O. (1938): Der ehemalige Kobaltbergbau auf den sogenannten Zechsteinrücken. - Z. Berg-, Hütten- u. Salinenwesen, 우: 127-152, 5 Abb.; Berlin

Referat in: N. Jb. Mineral. etc., Referate, 1939 (Bd. II): 240 (H. v. Philipsborn); Stuttgart [darin: Richelsdorfer Gebirge, Gräfenhain-Nauendorf u. Catterfeld zw. Friedrichroda und Georgenthal, Kühberg-Asbach b. Schmalkalden, Glücksbrunn b. Schweina, Stedtfeld b. Eisenach, Kupfersuhl, Ekardtshausen b. Eisenach]

- $\square$ Henn, Ernst (1968): Der Bergbau in der Gemarkung Sontra. - Beiträge zur Geschichte der Stadt Sontra, 1: 19-23; Sontra 1968

- $\square 0 \bullet$ Héron de Villefosse, Antoine Marie (1810): De la richesse minérale. Considérations sur les mines, usines et salines des différens états, et particulièrement du royaume de Westphalie, pris pour terme de comparaison. - Tome premier - Division économique. - XXVII, 593 p.; (Levrault) Paris - IInsgesamt drei Bände u. Atlas-Band in Folio-Format]

[darin : S. 151-169 «Sur les mines et usines de la Hesse (u.a. Richelsdorfer Gebirge, Karlshafen, Meissner, Habichtswald ; S. 178-183 Eisenerzbergbau Schmalkaldener Revier ; S. 140-141

Braunkohlebergbau Steinberg b. Münden]

-Héron de Villefosse, Antoine Marie (1819): De la richesse minérale. Considérations sur les mines, usines et salines des différens états, présentées comparativement. - Avec un Atlas in-folio de 65 planches. - Tome troisième: Division technique (IIIe et IV.e parties). - XX, 538 p.; (Imprimerie royale) Paris [Insgesamt drei Bände u. Atlas-Band in Großfolio-Format mit 65 Tafeln] [darin S. 353-356 : Usines à cuivre de la Hesse, darin: Richelsdorf]

$\square$ Hotzler, Fritz (1995): Schönheit und Vielseitigkeit des Höllentales. - Das Werraland, 47(3): 62, 1 Abb.; Eschwege - [Regionalgeologie, Kupferschiefer-Bergbau]

- $\square$ Kessler, Karl-Heinz (2003): Das ehemalige Barytwerk in Sontra. - Rund um den Alheimer, 24: 34 45, 4 Abb.; Rotenburg/Fulda 
- $\square$ OJordan, Johann Ludwig (1803): Mineralogische, berg- und hüttenmännische Reisebemerkungen vorzüglich in Hessen, Thüringen, am Rheine und im Seyn-Altenkirchner Gebiethe. - 288 S., 4 FaltTaf.; (Dieterich) Göttingen

[darin: I Unterwerra-Grauwackengebirge u. Zechsteinmantel; II Bergbau i. Richelsdorfer Gebirge; IIIIII-XVI Regional-Geologie, Bergbau Umgebung Bad Liebenstein - Schmalkalden]

$\square$ Kollmann, Karl [Red.](1989): Die Grube Gustav im Bilsteiner Bergbaurevier. - 86 S., Ill. Kt.; [Förderverein Besucherbergwerk „Grube Gustav“] Meissner-Abterode [Kupferschiefer, Schwerspat]

$\square$ Kollmann, Karl (1989): Geschichte des Kupferbergbaus. - In: Kollmann, Karl [Red.]: Die Grube Gustav im Bilsteiner Bergbaurevier. - 1. Aufl.; S. 26-46, 4 Abb.; [Hrsg. Förderverein Besucherbergwerk „Grube Gustav“] Meißner-Abterode 1989

$\square$ Kollmann, Karl (1989): Geschichte des Schwerspatbergbaus. - In: Kollmann, Karl [Red.]: Die Grube Gustav im Bilsteiner Bergbaurevier. - 1. Aufl.; S. 47-67, 23 Abb.; [Hrsg. Förderverein Besucherbergwerk „Grube Gustav“] Meißner-Abterode 1989

- $\square$ Kollmann, Karl [Schriftltg.] (1999): 500 Jahre Bergwerksordnung zu Sontra - 1499-1999. - Beiträge zur Geschichte der Stadt Sontra, 10; 88 S., Abb.; [Hrsg. Magistrat Stadt Sontra] Sontra [Beiträge einzelner Autoren zur regionalen Bergbaugeschichte]

$\square$ Kollmann, Karl (o. J.): Bergbau. - In: Kollmann, Karl [Red.]: Die Geschichte des Dorfes Hitzerode im Meißnervorland. - S. 199-205, 1 Grubenskizze; [Hrsg. Hist. Ges. d. Werralandes] Hitzerode, o. J. [Kupferschieferbergbau östl. Meißnervorland zw. Orferode u. Hitzerode, Kurzübersicht Schwerspatbergbau benachbarte Gemarkung]

$\square$ Lerch (1959): Zu Gast in Frau Holles zauberhaftem Märchen- und Sagenreich. - Ferienparadies wurde zum Grenzland - Wachttürme und Zehnmeterstreifen zerteilen die Landschaft ... - WerraRundschau, 1959; Nr. 78 v. 4.4.1959, S. 5, 1 Abb.; Eschwege [Meißner, Wolfterode, Höllental, Bergbau i. Höllental]

-Ludwig, Willi (1983): Vom Schmelzwerk zum Nahausflugsziel Friedrichshütte. - Kreis HersfeldRotenburg - Heimatkalender 1983 und Wegweiser (27. Jg. ): 97 - 98, 2 Abb.; Bad Hersfeld

OMistereck, Richard (2004): „Was Gott beschert, bleibt unverwehrt“ - Wandern auf dem Stedtfelder Bergbaulehrpfad. - Knüllgebirgsbote, 2004(1): 8; Bad Hersfeld [Lehrpfad Geschichte d. Kupferschieferbergbaus am Nordrand d. Thüringer Waldes; Stedtfeld b. Eisenach]

-Möller, Hanskarl (1988): Bergbau im Richelsdorfer Gebirge. -1. Aufl., 72 S., zahlr. Abb. [Bildband]; (Geiger) Horb a. Neckar

-Möller, Hans-Karl (1993): Auf den Spuren des Bergbaus in und um Cornberg. - In: HersfeldRotenburg - Heimatkalender des Landkreises Hersfeld-Rotenburg 1993 und Wegweiser ( 37 Jg.): 162 166; Bad Hersfeld

- $\square$ Namenskürzel (dt) (1949): Sontraer Kupferschiefer[bergbau] heute. Eindrücke von einer Besichtigungsfahrt. - Werra-Rundschau, 1949; Nr. 20 v. 25.1.1949, S. 3; Eschwege

$\square$ Namenskürzel (eb) (1963): „Wir beteten jeden Tag für die Eingeschlossenen“ - Vor sechs Jahren erlitten Richard Kayl und Anton Plichal das gleiche Schicksal im Höllental. - Werra-Rundschau, 1963; Nr. 261 v. 9.11 .1963 , S. 3, 3 Abb.; Eschwege [Anläßlich des Grubenunglücks bei Lengede: Erinnerung an das Grubenunglück in der Schwerspatgrube Gustav b. Abterode im November 1957] 
- $\square$ Namenskürzel (HC) (1963): Sontra pflegt seine Bergbautradition - Barbarastollen als Erinnerungsstätte geweiht /Historischer Festzug zum Siedlerjubiläum. - Werra-Rundschau, 1963; Nr. 129 v. 6.06.1963, S. 3, 2 Abb.; Eschwege

[Erinnerung an den Schwerspat- und Kupferschieferbergbau im Richelsdorfer Gebirge]

- $\square$ Namenskürzel (HC) (1965): 75 Jahre Schwerspatmahlwerk in Sontra / .. - Werra-Rundschau, 1965; Nr. 112 v. 15.5.1965, S. 7, 1 Abb.; Eschwege

[Bergbaugeschichte Schwerspatgewinnung]

- $\square$ Namenskürzel (eb) (1967): Enttäuschung und Empörung im Sontraer Land - Eine 500jährige Bergbautradition fand ihr Ende. - Werra-Rundschau, 1967; Nr. 77 v. 3.04.1967; S. 4; Eschwege [Schließung der Schwerspatgruben Franziska, Dachsberg und „Lange Hecke"]

QNamenskürzel (dpa, th)(1992): Spat Bergbau: Abgebaut wird jetzt der Arbeitsplatz. - HNA, 1992; Nr. 47 v. 25.2.1993; Kassel

[Trusetal b. Schmalkalden]

- $\square$ Naumann, Peter (1989): Kupferbergbau und Schmelzhütten in Nordhessen. - Rückblick, $\underline{\mathbf{5}}(1989) ; 4$

S. (ohne Seitenzählung); Hofgeismar

[Nordhessen, WMK]

-Neumann, H. (1932): Friedrichshütte bei Bebra - Zu ihrer 200-Jahrfeier. - Heimat-Schollen, 12 (8): 60 - 63, 2 Abb.; Melsungen

-Neumann, Hans (2004): Das Bergwerk. - In: Ludwig Büff: Zur Geschichte von Nenterhausen - mit Ergänzungen des Arbeitskreises Geschichte und von Hans Neumann. - 239 S:, zahlr. Abb.; hier: S. 157-175, 5 Abb., 2 Tab.; (Blücher) Merzhausen [b. Freiburg i. Br.] 2004

[Kupferschieferbergbau Grube Schnepfenbusch]

QRein, W. (1862): Alte Bergwerke und Salzquellen. - Z. Vereins f. Thür. Geschichte, $\underline{\mathbf{5}}$ : 411; Jena [Urkundliche Erwähnung Saline Wilhelmsglücksbrunn b. Creuzburg a. d. J. 1452,

Kupferschieferbergwerke nordwestl. Thüringer Wald]

- $\square$ ORiess, Johann Philipp (1791): Mineralogische und bergmännische Beobachtungen über eine Hessische Gebirgsgegenden. - XIV, 102 S., 6 Taf.; (Rottmann) Berlin

[darin: S. 28-54 Kupferschiefer- u. Kobalt-Bergbau Richelsdorfer Gebirge; S. 54-59 Kupferschiefer- u. Kobalt-Bergbau Glücksbrunn b. Bad Liebenstein; S. 69-84 (,Steinkohlen“-) Braunkohlenbergbau u. Tertiär-Stratigaphie am Meissner; S. 84-89 Alaun- und („Steinkohlen“) Braunkohlen-Bergbau Oberkaufungen]

-Röhring, Micha (1998): Bergbau im Richelsdorfer Gebirge im 20. Jahrhundert - Die Gewinnung von Kupferschiefer und Schwerspat bei Sontra in Hessen. - Hessische Forschungen zur geschichtlichen Landes- und Volkskunde, $\underline{\mathbf{3}}$; 356 S., zahlr. Abb., Tab.; zgl. Diss. Univ. Würzburg [Hrsg. Verein hess. Geschichte u. Landeskunde] Kassel

$\square$ Schmidt, Hans Heinrich (1989): Bergbau - Allgemeines [Bergbautechnik]. - In: Kollmann, Karl [Red.]: Die Grube Gustav im Bilsteiner Bergbaurevier. - 1. Aufl.; S. 14-25, 11 Abb. u. Skizz.; [Hrsg. Förderverein Besucherbergwerk „Grube Gustav“] Meißner-Abterode 1989 [Kupferschiefer-, Schwerspatbergbau]

aSchneider, Konrad (2003): Kupfermünzen für Richelsdorf. Eine Berg- und Hüttenverwaltung versorgt sich selbst mit Lohngeldern. - Z. Vereins hess. Gesch. u. Landeskde., 108: 95-106, 4 Abb.; Kassel [Bergbau- und Münzgeschichte]

aSeib, Gerhard (1960): 500 Jahre Bergbau im Richelsdorfer Gebirge 1460 - 1960. - 75 S.; Nentershausen 
-Seib, Gerhard (1975): Technische Denkmäler in der Bundesrepublik Deutschland. - 24. Richelsdorf Nentershausen - Zechenhaus auf dem „Triesch“ und „Richelsdorfer Hütte“. - In: Slotta, Rainer: Technische Denkmäler in der Bundesrepublik Deutschland. - Veröff. a. d. Dt. Bergbaumuseum Bochum, 7; S. 55-56, 1 Abb.; [Hrsg. Dt. Bergbaumuseum Bochum] Bochum 1975 [Lkr. Hersfeld-Rotenburg]

-Seib, Gerhard (1983): Technische Denkmäler in der Bundesrepublik Deutschland. - III Hessen - Die Gruben in Richelsdorf. - In: Slotta, Rainer: Technische Denkmäler in der Bundesrepublik Deutschland. - Bd. 4: Der Metallerzbergbau. - Veröff. a. d. Bergbaumuseum Bochum, $\underline{\mathbf{2 6}},-$ Teil I: S. 270-320, 23 Abb., 2 Tab.; Bochum 1983

[Kreis Hersfeld-Rotenburg]

- Seib, Gerhard (1990): Der Bergbau auf Kupferschiefer im Richelsdorfer Gebirge. - In: Armbrecht, Friedrich [Hrsg.]: Der Schlag, der in den Ohren schallt. Zur Geschichte der Kupfergewinnung und Kupferverarbeitung. - Austellung des Westfälischen Freilichtmuseums Hagen, Landesmuseum für Handwerk u. Technik 27. Mai - 31. Oktober 1990. - Ausstellungskatalog, S. 119-130, Ill.; Hagen/W. 1990

-Seib, Gerhard (1997): Friedrichshütte im Ibatal - An der Wirkungsstätte des Großvaters. - Kreis Hersfeld-Rotenburg - Heimatkalender 1997 und Wegweiser (1․ Jg. ): 67 - 69, 3 Abb.; Bad Hersfeld] [Ein Familienmitglied des ehemaligen Hüttenbesitzers besucht die ehemalige Kupferschmelze]

- Seib, Gerhard (1999): Schlackensteine (Formschlacken)-Spuren des Richelsdorfer Bergbaus im Ortsbild. - Rund um den Alheimer, 20: 28 - 39, 19 Abb.; Rotenburg/Fulda

- $\square$ Seib, Gerhard (1999): Sontra und sein Bergbau. - In: Kollmann, Karl [Schriftltg.]: 500 Jahre Bergwerksordnung zu Sontra - 1499-1999. - Beiträge z.Geschichte d. Stadt Sontra, 10: 67-87, [12] Abb.; [Hrsg. Magistrat Stadt Sontra] Sontra 1999

[Kupferschiefer-, Schwerspatbergbau]

- Seib, Gerhard (2005): „Statistische Notizen über die Richelsdorfer Kupferschiefer- und Kobaltbergwerke (1867). - Rund um den Alheimer, 26: 34-36, 4 Abb.; Rotenburg/Fulda

-Seib, Gerhard (2006): „Arbeit von Kindern und Jugendlichen im Richelsdorfer Bergbau - Quellen des 18. und 19. Jahrhunderts. - Rund um den Alheimer, 27: 39-48, 6 Abb.; Rotenburg/Fulda

- $\square$ Sippel, Klaus (1999): Zur Archäologie und Geschichte des mittelalterlichen Kupferbergbaus bei Sontra. - In: Kollmann, Karl [Schriftltg.]: 500 Jahre Bergwerksordnung zu Sontra - 1499-1999. Beiträge z. Geschichte d. Stadt Sontra, 10: 51-66, 6 Abb.; [Hrsg. Magistrat Stadt Sontra] Sontra 1999

- DSippel, Klaus (1999): Der Kupferschieferbergbau im Richelsdorfer Gebirge - Führungsblatt zu spätmittalterlichen und neuzeitlichen Relikten bei Iba und Nentershausen, Kr. Hersfeld-Rotenburg. Archäologische Denkmäler in Hessen, 134; 20 S., Abb., Kt.; [Hrsg. Abt. Archäologische u.

Paläontologische Denkmalpflege i. Landesamt f. Denkmalpflege Hessen, Archäologische Gesellschaft i. Hessen e.V.] Wiesbaden

-Sippel, Klaus (2000): Ausgrabung eines spätmittelalterlichen Bergwerkstollens bei Sontra - ein archäologisches Denkmal des frühen Kupferschieferbergbaus in Osthessen. - Denkmalpflege \& Kulturgeschichte, 1: 57-61; Ill., graph. Darst.; Wiesbaden

هSippel, Klaus (2002): Bauteile von einer Förderhaspel aus einem spätmittelalterlichen Kupferschieferbergwerk im Richelsdorfer Gebirge/Bebra-Solz (Landkreis Hersfeld-Rotenburg). Hessen-Archäologie, 2001: 162-164; Ill; Stuttgart

OSteenbuck, Kurt (1984): Goethes Wirken für das Bergwerk in Ilmenau. Die Zeit der Vorbereitung von 1776 - 1784. - Der Anschnitt, 36(5-6): 187-202, 11 Abb.; Bochum 
OSteenbuck, Kurt (1995): Silber und Kupfer aus Ilmenau - Ein Bergwerk unter Goethes Leitung. Hintergründe, Erwartungen, Enttäuschungen. - Schriften d. Goethe-Gesellschaft, 무; 358 S., Ill., graph. Darst., 2 Kt.; (Böhlau's Nachfolger) Weimar

Referat in: Der Anschnitt, 47(6): 215 (Brosin); Bochum 1995

- $\square$ Stoppel, Dieter \& Gundlach, Heinrich (1978): Zur Geologie und Bergbaugeschichte der Schwerspat- und Kobalterzvorkommen im Unterwerra-Grauwackengebirge und Richelsdorfer Gebirge. - In: Koritnig, Sigmund [Schriftltg.]: Zur Mineralogie und Geologie der Umgebung von Göttingen - mit Westharz und Teilen des Nordhessischen Berglandes. - Der Aufschluss, Sdbd. $\underline{28}$ : 261 - 285, 23 Abb.; Heidelberg 1978

-Straube, Heinz (1991): Bernsdorfer Hütte - Alte Hütte - Richelsdorfer Hütte 1460 - 1700. - Kreis Hersfeld-Rotenburg - Heimatkalender 1991 und Wegweiser, (35. Jg. ): 64 - 66, 3 Abb.; Bad Hersfeld

aStraube, Heinz (1997): Friedrichshütte im Ibatal - Schmelzwerk, Kobaltlieferant, Erholungsort. - Kreis Hersfeld-Rotenburg - Heimatkalender 1997 und Wegweiser (⒈ Jg. ): 70 - 71, 2 Abb.; Bad Hersfeld

- $\square$ Strube, Hans (1956): Der Richelsdorfer Kupferbergbau. Ein Beitrag zur Geschichte eines für den Kreis Rotenburg [an der Fulda] schicksalhaften Industriezweigs. - Hessische Heimat, N.F., $\underline{\mathbf{5}}$ (f. 1955/56)(4): 30-31; Marburg/L.

[2. Hälfte 15. Jhds.; darin auch Sontra]

- $\square$ Strube, Hans (1974): Kupferschmelzhütten im Sontraer Raum - Von den Anfängen bis zum Ausbruch des Dreißigjährigen Krieges. - Hessische Heimat, N.F., 24(4): 199-208, Abb. 28-31; Marburg/L.

- $\square$ Strube, Hans (1976): Die Bergstadt Sontra. - Hessische Heimat, N.F., 26 (2): 52-55; Marburg/L. [darin: Kupferschmelzbetriebe Umgebung Sontra, Richelsdorfer Gebirge]

- $\square$ Strube, Hans (1980): Der Kupferbergbau im Niederfürstentum Hessen. - Z. Vereins hess. Gesch. u. Landeskde., 87 (f. 1978/79): 35-204, o. Abb.; Kassel

[Bergbaugeschichte; Raum Sontra-Richelsdorf, Gericht Bilstein (Abterode), Witzenhausen, Oberellenbach]

- $\square$ Triller, Harald (2005): Schwarzer Freitag für die Knappen - Am 27. Oktober 1955 das Aus für Kupferschiefer-Bergbau / 1700 Menschen vor ungewisser Zukunft. - Werra-Rundschau, 2005; Nr. 250 v. 27.10.2005, 2 Abb.; Eschwege

[Kupferschieferbergbau Richelsdorfer Gebirge]

OVoigt, Johann Carl Wilhelm (1821): Geschichte des Ilmenauischen Bergbaues nebst einer geognostischen Darstellung der dasigen Gegend und einem Plane, wie das Werk mit Vortheil wieder anzugreifen - nebst dem Portrait des Verfassers, einer petrographischen Karte und 3 Steindrucken.XIV, 111 S., Ill., (1 Kt.; 3 Taf., 2 Widmungsbrife); (Voigt) Sondershausen-Nordhausen

$\square$ Vorwachs, Rudolf (1982): 650 Jahre Blankenbach - Jubiläumsfeier vom 23. Juli - 25. Juli 1982. - 158 S., zahrl. Abb.; [Hrsg. Der Festausschuß - 650 Jahre Blankenbach] [Sontra-] Blankenbach [darin S. 81-84, 1 Abb.; „Bergbau um Blankenbach“ (Kupferschiefer)]

OWagenbreth, Ottfried (1983): Goethe und der Ilmenauer Bergbau. - 96 S., 31 Abb., 15 Tab.; (Nationale Forschungs- u. Gedenkstätten d. klassischen deutschen Literatur) Weimar

OWagenbreth, Otfried (2006): Goethe und der Ilmenauer Bergbau. - 2., erw. Aufl.; 140 S., Ill., graph. Darst., Kt.; (TU Bergakademie Freiberg) Freiberg/Sa.

$\square$ Weiße, Johanna (1976): Das Wirtschaftsleben im Meißnervorland. - In: Festausschuß...[Hrsg.]: 900 Jahre Abterode-Meißner 1076-1976. - S. 163-168; Abterode 1976 [darin S. 167-168 Kupferbergbau, S. 168 Barytgruben] 
- $\square$ Westermann (1959): Stillegung des Kupferschieferbergbaus in Sontra - Überführung der Arbeitskräfte in andere Industrien - Maßnahmen für das Sontra-Gebiet. - Bulletin d. Presse- u. Informationsamtes der Bundesregierung, 1959, Nr. 17; S. 158-159; Bonn

- $\square$ OWWitter, Wilhelm (1938): Die Ausbeutung der mitteldeutschen Erzlagerstätten in der frühen Metallzeit. - Reihe: Die älteste Erzgewinnung im nordisch-germanischen Lebenskreis, Bd. $\underline{\mathbf{I}} ; 275$ S., 40 Abb., 9 Tab., 1 Einschalttaf., 8 Taf.; (Rabitzsch) Leipzig

[S. 84-91: „Die Kupfererzlagerstätten des Frankenwaldes und des Thüringer Waldes“, darin: Eisenacher Revier, Altensteiner Revier, Ilmenauer Reviert; S. 91-94: „Die Kupfererzlagerstätten in Hessen": darin: Werra-Meißner-Kreis, Richelsdorfer Gebirge]

OWünscher, Siegfried (1932): Geschichte des Kupferschieferbergbaues und seines Hüttenwesens im Fürstentum Eisenach. - Diss. phil. Univ. Jena 1932; VII, 159 S.; (Kühner) Eisenach

\subsection{Kalisalze}

QAnonym (1896): Kalisalze in Thüringen. - Z. prakt. Geologie,[4. Jg.] 1896: 81-82 (Notizen); Berlin [Explorationsgeschichte]

$\square$ Anonym (1900): < Tiefbohrungen bei Wellingerode nach Kupferschiefer und Kalisalz]. - Eschweger Tageblatt u. Kreisblatt, 1900; Nr. 270 v. 16.11.1900; Eschwege

QAnonym (1907): <Bohrversuche auf Kalisalz bei Buchenau erfolglos]. - Eschweger Tageblatt, 1907; Nr. 133 v. 10.6.1907; Eschwege

-Anonym (1938): Kino, Radio, Eisenbahn - 660 Meter unter dem Werratal. - Der zuständige Berggeist protestierte zunächst, wurde dann aber friedlich $<$ Kaliwerk Hattorf, Hessisch-Thüringisches WerraKalirevier). - Eschweger Tageblatt, 1938; Nr. 287 v. 8.12.1938; Eschwege

-Anonym (1951): Fester, zäher Arbeitswille an der Zonengrenze. - Hessischer Volkskalender Illustrierter Familienkalender für das Jahr 1952 - ㅇ‥ Jg.; S. 11, 1 Abb.; (Thiele \& Schwarz) Kassel [darin: Kalibergbau im hessischen Werra-Kalirevier]

-Anonym (1957): Die Kaliindustrie im Kreise Hersfeld. - Heimatkalender des Kreises Hersfeld, 1957: 42 - 45, 1 Abb.; Bad Hersfeld

- DAnonym (1993): Fusion in Sachen Salz - Deutsche Kali-Industrie auf dem Weg in die Gewinnzone. Die Weser, 67(1): 8-10, 1 Abb.; Bremen [darin: Werra-Kalireviert Hessen, Thüringen]

QBaar, A. (1953): Über Zusammenhänge zwischen Tektonik, Landschaftsform und Kalilagerstätte am Südharz. - Freiberger Forschungshefte, Reihe C, 5: 5-10, 1 Bild; Berlin [darin: Bezugnahme auf Südharz-Kalirevier, Werra-Kalirevier]

-Bauer, G; Jahn, G. \& Nink, W. (1991): Kalibergbau in Osthessen. - In: Jahn, Gert [Hrsg.]: Hessen Unser Land in Karte, Bild und Wort. - 64 S., zahlr. Abb. u. Kt., hier S. 40-41, 8 Abb., 1 Profil; (ListSchrödel) München 1991

[Schulgeographie]

- $\mathrm{OB}$ Baumert, B. (1932): Entwicklung und bergbauliche Bedeutung des Werra-Fulda-Kalibezirks. - Kali, etc., $\underline{26}(17): 208-214$ 
$\underline{\mathbf{2 6}}(18): 223-226$

$\underline{26}(19): 235-239$

$\underline{26}(20): 249-252$

26 (21): 260-265; insges. 36 Abb.; Halle/Saale

OBarthel, Rolf (1979): Aus der Geschichte der Kaliindustrie im Kreis Worbis. - Eichsfelder Heimathefte, (19. Jg.) 1979(2): 106-109; Worbis

-Burghardt, Gustav-Adolf \& Kokorsch, Rudolf (1990): Der Verbund der Grubenbetriebe Hattorf und Wintershall. - Kali u. Steinsalz, 10(7/8): 233-240, 16 Bilder; Essen [darin: die Werra-Kalilagerstätte]

@Behmann, Christiane \& Heinrich, Ralf Rüdiger (1990): VEB Kali-Kombinat: Aufbruch oder Abbruch. - Die Weser, 64(1): 49-52, 5 Abb.; Bremen

- 0 Blasig, W. (1993): Der Kalibergbau an der Werra. - In: (Salz in Werra und Weser - Ursachen, Folgen und Abhilfe. - Ergebnisse einer Fachtagung der ARGE Weser am 22. März 1993 in Kassel) DVWKMitteilungen, 24; S. 11-19, 1 Kt. S. 10, Bild 1-3; [Dt. Verband Wasserwirtschaft u. Kulturbau e.V.] Bonn

OBrehme, U1rich (1993): Kali und Salz: Von den Emotionen überrascht - Die Kali und Salz AG versteht die Welt nicht mehr: Da hat man sich breitschlagen lassen, bei der Sanierung im Osten zu helfen, und jetzt wird man als raffgieriger Kapitalist verunglimpft? - Ein Gespräch mit dem Vorstand. - HNA, 1993; Nr. 164 v. 17.7.1993; Kassel

口oBrückner, Lothar; Büxel, Eckart \& Hohmann, Hermann-Josef (1998): Die ersten Jahrzehnte Der Aufstieg des Werra-Fulda-Reviers zwischen 1893 und 1933. - In: Eisenbach, Ulrich \& Paulinyi, Akos [Hrsg.]: Die Kaliindustrie an Werra und Fulda - Geschichte eines landschaftsprägenden Industriezweigs. - Schriften z. hessischen Wirtschafts- und Unternehmensgeschichte, $\underline{3}$; S. 49-78, Abb. 10-23, Tab. 4-5, Grafik 3; (Hessisches Wirtschaftsarchiv) Darmstadt 1998

-Burghardt, Gustav-Adolf \& Kokorsch, Rudolf (1990): Der Verbund der Grubenbetriebe Hattorf und Wintershall. - Kali u. Steinsalz, 10 (7/8): 233-240, 16 Bilder; Essen [darin: die Werra-Kalilagerstätte]

ODeutsches Bergbaumuseum Bochum [Hrsg.](2003): Kali im Südharz-Unstrut-Revier. - Bd. 1: 444 S., Ill. Graph. Darst., Kt.; Veröff. a. d. Dt. Bergbau-Mus. Bochum, 116(Bd. 1); Bochum - Bd. 2: S. 459-908, Ill. Graph. Darst., Kt.; Veröff. a. d. Dt. Bergbau-Mus. Bochum, $\underline{\mathbf{1 1 6}(B d . ~ 2) ; ~ B o c h u m ~-~ B d . ~ 3: ~}$ Döring, Günter (2005): Entwicklung der Kali-Verarbeitungstechnologie - Verfahren und Ausrüstungen. - 304 S., Ill., graph. Darst., Kt.; Veröff. a. d. Dt. Bergbau-Mus. Bochum, 132; Bochum

QDietz, C. (1929): Überblick über die Salzlagerstätte des Werra-Kalireviers und die Beschreibung der Schächte „Sachsen-Weimar“ und „Hattorf“" - Z. dt. geol. Ges., $\underline{\mathbf{8 0}}$ (f. 1928): 68 - 93 (Briefl. Mitt.), 4 Abb.; Berlin-Stuttgart

QDuchrov, Günther (1996): Kalibergbau im Südharz-Unstrut-Revier - die ersten und die vorerst letzten Aktivitäten. - Der Anschnitt, 48 (5-6): 178-194, 9 Abb.; Bochum [darin: Bischofferode, Menteroda]

QDuchrov, Günther (1997): Der 100-jährige „Rhönmarsch“ in die Kohlensäurefelder des südthüringischen Kalibergbaus. - Der Anschnitt, 499(4): 123-147; [12] Abb., 2 Tab.; Bochum [Kohlensäure, Kalibergbau thüringisches Werra-Kalirevier]

ODuncker (Bergassessor) (1929): Die Entwicklung der Kaliindustrie im Südharz- und Unstrutgebiet. Kali, etc., $\underline{\mathbf{2 3}}$ (4): 49 - 53, 4 Abb.; 
$\underline{\mathbf{2 3}}(5): 65$ - 70, 9 Abb.;

$\underline{\mathbf{2 3}}(6): 81-86,8$ Abb.;

23 (7): 97- 101, 3 Abb.;Halle/Saale

- 0 Eisenbach, Ulrich \& Paulinyi, Akos [Hrsg.] (1998): Die Kaliindustrie an Werra und Fulda Geschichte eines landschaftsprägenden Industriezweigs. - Schriften z. hessischen Wirtschafts- und Unternehmensgeschichte, $\underline{\mathbf{3}}$; 280 S., 112 Abb., 8 Grafiken, 17 Tab.; (Hessisches Wirtschaftsarchiv) Darmstadt [Aufsatzsammlung - darin: Hessisch-thüringisches Werra-Kalirevier]

- 0 Fulda, Ernst (1925): Überblick über die Salzlagerstätten Deutschlands. - Kali, etc., 19(2): 17 - 24, 2 Kt.; Halle/Saale

@Fulda, Ernst (1941): Die Entdeckung des Kalisalzvorkommens südlich vom Harz durch Hermann Pinno. - Kali, etc., $\underline{\mathbf{3 5}}(9)$ : 147-151, 2 Abb.; Halle/Saale

Referat in: N. Jb. Mineral. etc., Referate, 1942 (Bd. II): 173 (J. Leonhard); Stuttgart

QFulda, Ernst (1943): Die Erschließung der nordwestthüringischen Kalisalzlagerstätten. - Beiträge Geol. Thür., 7: 213 - 226, 3 Abb.; Jena

-Göbel, Ulrich (2000): Ein Jahrhundert Kalibergbau an der Werra: Die Welt unter unseren Füßen. Kreis Hersfeld-Rotenburg - Heimatkalender $\underline{2000}$ und Wegweiser (4․ Jg.): 41 - 44, 3 Abb.; Bad Hersfeld

OHempel, D.; Fisch, W.; Hoffmann, R. \& Rauer, H. (1991): Schlagwetterexplosion mit Brandereignis als Folge eines Gebirgsschlags im Kaliwerk Bleicherode/Südharz <1982>. - Kali u. Steinsalz, 10 (12): 428-431, 1 Zahlentaf.; Essen

-Herrmann, A.-G.; Käding, K. Ch. \& Struensee, G. v. (1980): [DMG-Tagung 1980] Exkursionen E2 und E5 - Kalisalzlagerstätten des Sulfat-Typs - Hatttorf (Werra-Fulda-Bezirk) und Salzdetfurth (Bezirk Südhannover). Entstehung, Umbildung, Bergbau. Von wirtschaftlicher Nutzung von Salzlagerstätten. - Fortschr. Mineral., $\underline{\mathbf{5 8}}$, Beih. 2 (Einführung zu den Exkursionen anläßlich der 58. Jahrestagung der Deutschen Mineralogischen Gesellschaft in Göttingen 1980): 33-53, 4 Abb., 6 Tab.; Stuttgart

-OHohmann, Hermann-Josef (1992): Im Zeichen des „Weißen Goldes“: Eine Exkursion in das hessisch-thüringische Kalirevier an der Werra. - Hessische Blätter f. Volkskunde- u. Kulturforschung, (Hessen u. Thüringen - Kulturwissenschaftliche Bilanz und Perspektive) 228: 77-93, 11 Abb.; (JonasVerlag) Marburg

-Hohmann, H.-J. \& Mehnert, D. [Bearb.](2003): Werra, Wald und weißer Berg - Streifzüge durch Heringen in Vergangenheit und Gegenwart. - 192 S., zahlr. Abb., Kt.; [Hrsg. Magistrat der Stadt Heringen] Heringen/Werra

-Hohmann, Hermann-Josef [Hrsg.] (2004): Bunte Salze, weiße Berge - Wachstum und Wandel der Kaliindustrie zwischen Thüringer Wald, Rhön und Vogelsberg. - 191 S., zahlr. Abb., Kt.; (Ulmenstein) Hünfeld

- 0 Hornung (Fabrikdirektor) (1932/1933): Geschichte der Kalifabriken an der Werra. - Kali, etc., $\underline{26}(22): 275-277$

$\underline{\mathbf{2 6}}(23): 287-292$

$\underline{26}(24): 301-305$;

$\underline{27}(1): 1-4$

$\underline{27}(2): 20-21$

27(3): 34-36, insges. 34 Abb.; Halle/Saale 
OHuhn, Karl-Hermann (1990): Was wird aus Werra-Kali? - HNA (Sonntagszeit), 1990, Nr. 51 v. 23.12.1990; Kassel

[Thüringer Werra-Kalirevier]

OHuhn, Karl-Hermann (1993): Kalikumpel in Bischofferode: „Wir gehen bis zum Äußersten“. - HNA, 1993; Nr. 164 v. 17.7.1993; Kassel

[Protestaktionen/Hungerstreik der Kalikumpel]

-Käding, Karl-Christian (2001): Die Werra-Fulda-Kalilagerstätte - 100 Jahre Förderung. - Glückauf, 137(7/8): 433 - 438 - zgl. Kali u. Steinsalz, 14(16): 23-28, 8 Bilder; Essen

OKalibergwerk Volkenroda [Hrsg.](1966): 50 Jahre Kalibergwerk Vokenroda - 1906-1956; Chronik. 88 S. Ill., graph. Darst.; Volkenroda

QKaliwerk Südharz, Werk Volkenroda [Hrsg.](1981): 75 Jahre Kalibergbau in Volkenroda (Nebentitel) - Von der Grubengründung bis zum sozialistischen Großbetrieb - Fakten, Ereignisse und Betrachtungen aus Vergangenheit und Gegenwart in Wort und Bild; zusammengestellt anläßlich des Jubiläums im Jahre 1981 - Text: Autorenkolletiv u. K.W. Schönau. - 84 S., Ill., graph. Darst., 1 Kt.; Volkenroda

dOKatzenberger, Christoph (1995): Vertrag über Kalibergbau abgesegnet - Das Thüringer Kabinett hat einem Abkommen mit der hessischen Kali- und Salz GmbH zum grenzüberschreitenden Kaliabbau in Unterbreizbach zugestimmt. - HNA (T = Thüringen?), 1995; Nr. 201 v. 30.8.1995; Kassel

OKeller, Werner (1990): 750 Kumpels werden entlassen - Hoffen auf Folgenutzung - „Aus“ für den Kaliabbau kommt nach 81 Jahren [Kaliwerk Menteroda]. - HNA (W-Th), 1990; Nr. 145 v. 26.6.1990

-Kokorsch, Rudolf (1998): Die Kaliindustrie in Hessen 1945 bis 1989. - In: Eisenbach, Ulrich \& Paulinyi, Akos [Hrsg.]: Die Kaliindustrie an Werra und Fulda - Geschichte eines landschaftsprägenden Industriezweigs. - Schriften z. hessischen Wirtschafts- und Unternehmensgeschichte, $\underline{\mathbf{3}}$; S. 95-122, Abb. 32-39, Tab. 7-11; (Hessisches Wirtschaftsarchiv) Darmstadt 1998

-OKunze, Dietmar \& Stahl, Ingo (1997): The Werra Production Center of the newly formed Kali and Salz GmbH - Complex Raw Ore and Diversified Product Lines. - Kali u. Steinsalz, 12(4): 135-140, 15 Fig.; Essen

[HE, THÜ, darin: Lagerstättengeologie]

-Landeck, W. u. A. \& Göbel, Manfred (1995): 90 Jahre Kaliwerk Hattorf. - Mein Heimatland, 36(9): 181-184, 4 Abb.; Bad Hersfeld

-Licht, Heinrich (1988): Neunzig Jahre Kali-Industrie im Werratal. - Mein Heimatland, 33(9): 33-35, 3 Abb.; Bad Hersfeld

-oLohmann \& Seglitz (1931): Die Kali-Industrie an der Werra. - Die Weser, 10(8): 226-230, 6 Abb; Bremen

[Werra-Kalirevier Hessen u. Thüringen]

-OLohrbach, Reinhard (1930): Der Kalibergbau im oberen Werragebiet. - Eschweger Tageblatt, 1930; Nr. 141 v. 19.09 .1930

-Mehnert, Dagmar (2002): Konkurrenz, Konzepte, Kieserit - die Kaliindustrie im Werratal 1918 1928. - Hess. Forsch. geschichtl. Landeskde. u. Volkskde., 39; VI, 352 S., Abb., Kt.; [Verein Hess. Gesch. u. Ldskde.] Kassel; zgl. Diss. Univ. Göttingen 2000

Referat (Kokorsch) in: Der Anschnitt, 52 (2): 117-119; Bochum 2003 
-Messer, Ernst (1978): Die nordhessischen Kaligruben. - Kali u. Steinsalz, $\mathbf{7}$ (7): 306-318, 11 Abb., 6 Tab.; Essen

[Zechstein-Stratigraphie, Lagerstättengeologie, Bergbau; Hattorf, Wintershall, Neuhof-Ellers]

-oMocarzski, Norbert (1998): Kalibergbau in der NS-Zeit 1033 - 1945. - In: Eisenbach, U1rich \& Paulinyi, Akos [Hrsg.]: Die Kaliindustrie an Werra und Fulda - Geschichte eines landschaftsprägenden Industriezweigs. - Schriften z. hessischen Wirtschafts- und Unternehmensgeschichte, $\underline{\mathbf{3}}$; S. 79-94, Abb. 24-31, Tab. 6; (Hessisches Wirtschaftsarchiv) Darmstadt 1998

- 0 Müller von der Grün, Claus Peter (1998): Unter einem Dach: Die wiedervereinigte Kaliindustrie im geeinten Deutschland. - In: Eisenbach, Ulrich \& Paulinyi, Akos [Hrsg.]: Die Kaliindustrie an Werra und Fulda - Geschichte eines landschaftsprägenden Industriezweigs. - Schriften z. hessischen Wirtschafts- und Unternehmensgeschichte, $\underline{\mathbf{3}}$; S. 223-241, 10 Abb., Tab. 17; (Hessisches Wirtschaftsarchiv) Darmstadt 1998

-Namenskürzel (c) (1950): Der Kalibergbau vor entscheidender Erweiterung. - Hessische Nachrichten, 1950; Nr. 185 v. 14.8. u. Nr. 190 v. 19.8.1950; Kassel [Kaliwerk Hattorf, Philippsthal]

-Namenskürzel (dm)(1951): Fördertürme und Halden im Werratal - Der Kalibergbau verwandelte eine Landschaft - Bereits die Germanen erkannten Bedeutung der Salzquellen. - Hessische Nachrichten, 1951; Nr. 173 v. 28.7.1951; Kassel

-Namenskürzel (ax)(1953): Besuch in einer unterirdischen Stadt - 2,6 Millionen Tonnen Rohsalz wurden 1952 im Kali-Bergwerk Hattorf bei Philippsthal gefördert und zu 200000 Tonnen Kali verarbeitet. - Hessische Nachrichten, 1953; Nr. 197 v. 26.8.1953; Kassel

-Namenskürzel (el/bf)(1955): 50 Jahre Kaliwerk Hattorf - Kurze Feier vor der Frühschicht Bundesflagge wehte vom Förderturm - Am 1. September 1905 wurde offiziell mit den Abteufarbeiten begonnen. - Hessische Nachrichten (Fuldabote), 1955; Nr. 203 v. 2.9.1955; Kassel

-Namenskürzel (c) (1960): Neue Förderanlage in Ransbach - Rationalisierung im Kalibergwerk Hattorf - Förderkörbe für 104 Kumpel. - HA, 1960; Nr. 84 v. 8.4.1960; Kassel

-Namenskürzel (ix) (1960): Umstellung am 17. November: Verbesserungen im Kaliwerk Hattorf Ransbach wird neuer Zentralpunkt - Sechzig Meter hoher Förderturm und Kaue errichtet. - HA, $\underline{1960}$; Nr. 265 v. 12.11.1960; Kassel

-Namenskürzel (by) (1960): Reger Betrieb 700 Meter unter der Erdoberfläche - Ein Besuch während der Arbeitszeit im Kalischacht. - HA, , 1961; Nr. 271 v. 21.11.1961; Kassel

[Kaliwerk Hattorf, Philippsthal]

-Namenskürzel (s) (1968): Von der Kipplore zum Förderband - Rationalisierung im Kaliwerk Hattorf bei Philippsthal jetzt vollkommen. - HA, 1968; Nr. 71 v. 23.3.1968; Kassel

-Namenskürzel (H.L/lh) (1975): 1977 Stopp für Absenkung von Kalilauge in den Untergrund. Beeinträchtigung des Grundwassers befürchtet. - HA (FA), 1975; Nr. 122 v. 30.5.1975; Kassel

QNamenskürzel (k)(1990): Historie: Werk prägt die Region [Kaliwerk Menteroda]. - HNA (W-Th), 1990; Nr. 145 v. 26.6.1990; Kassel

ONamenskürzel (1th)(1990): Kali-Grube: Letzte Schicht in Volkenroda [Menteroda]. - HNA (Th), 1990; Nr. 171 v. 26.7.1990; Kassel 
- 0 Namenskürzel (dpa)(1993): Fusionsplan: Eiszeit im deutschen Kalibergbau - Zu Zeiten der Grenze arbeiteten die Kumpel in Thüringen und Hessen noch friedlich nebeneinander - Heute herrscht eisige Kälte: Der Fusionsplan entzweit sie. - HNA (MA), 1993; Nr. 39 v. 16.2.1993; Kassel

ONamenskürzel (dpa/cmk)(1993): Kaliwerk Bischofferode: Waigel besiegelt Schließung/ . . - HNA (MA), 1993; Nr. 155 v. 7.7.1993; Kassel

ONamenskürzel (dpa) (1993): Bischofferode: Schlechte Karten erwischt - Im Konzept der gesamtdeutschen Kali-Industrie ist für den Standort Bischofferode in Thüringen kein Platz - Die Chancen scheinen schlecht zu stehen für die kämpfenden Kumpel. - HNA, 1993; Nr. 162 v. 15.7.1993; Kassel

[Protestaktionen/Hungerstreik der Kalikumpel]

ONamenskürzel (dpa/th)(1993): Kaliregion Merkers: Ex-Bergleute räumen jetzt auf - In Merkers beginnt, was die Kumpel in Bischofferode mit allen Mitteln verhindern wollen: Ehemalige KaliBergleute richten den Grubenstandort für neue Gewerbeansiedlungen her. - HNA (T), 1993; Nr. 179 v. 4.8.1993; Kassel

QNamenskürzel (dpa)(1993): Kali-Fusion: Die Rechnung von K+S ging nicht auf: Seit drei Jahren kämpfen die Nordthüringer Kali-Kumpel um den Erhalt ihrer Arbeitsplätze - Das Grubensterben begann zunächst unbemerkt - 20000 Kumpels verloren bereits ihren Job. - HNA, 1993; Nr. 184 v. 10.8.1993; Kassel

OParnieske-Pasterkamp, Jutta (2003): Zur Haldenstruktur und Salzlösungsgenese von Rückstandshalden der Kaliindustrie in Nordthüringen - The structure and salt solution genesis of residual heaps of potash industries in Northern Thuringia. - Z. geol. Wiss., 31(1): 45-91, 12 Abb., 25 Tab., 2 Taf.; Berlin [Rückstandshalden Bischofferode, Menteroda]

- 0 Pörtge, Karl-Heinz (1999): Der Kalibergbau und seine Folgen in Thüringen und Hessen. Petermanns Geographische Mitteilungen, 143(1): 59-71, 28 Abb.; Gotha [Bergbau u. Interessenkonflikte, Naturschutz]

ORademacher, Edgar (1982): Zur Geschichte der ehemaligen Kaliwerke in Hüpstedt. - Eichsfelder Heimathefte, (22. Jg.) 1982(2): 107-119, 5 Abb., 1 Tab., 2 geol. Profile; Worbis

ORademacher, Edgar (1999): Neues Fördergerüst auf Felsenfest. - Eichsfeld - Monatszeitschrift des Eichsfeldes, $\underline{43}$ (11)/1999(Nov.): 420-421, 2 Abb.; Duderstadt

[ Aufgel. Kalibergwerk Hüpstedt b. Leinefelde]

ORauch, Bernhard (2002): Bischofferode - Einzigartiges Sterben eines Kalistandortes. - In: Sedlacek, Peter [Hrsg.]: (Spuren suchen - Landschaften entdecken) Thüringen - Geographische Exkursionen. - 325 S., 105 Abb.; hier: S. 60-63, Abb. 25 u. 26; (Justus Perthes) Gotha

-Rausch, Dietrich; Böning, Karl-Heinz \& Busche, Heinz (1972): Zusammenlegung der Grubenbetriebe Wintershall und Herfa-Neurode des Kaliwerkes Wintershall. - Kali u. Steinsalz, $\underline{\mathbf{6}}(3)$ : 77-88, 7 Bilder, 2 Zahlentafeln; Essen

- $\bigcirc$ Riek, Wolfgang (2008): Beben wie nach Bomben - Vor fast 20 Jahren erschütterte der weltweit heftigste Gebirgsschlag unsere Region. - Werra-Rundschau, 2008; Nr. 48 v. 26.02.2008, 1 Kt.; Eschwege $<$ Gebirgsschlag im Kaliwerk Ernst Thälmann/Thüinger Werra-Kalirevier v. 13.03.1989>

-Roos, Achim v. (1963): „Schneelandschaft“ in 430 Meter Tiefe - Ganz Kassel hat im Stollensystem der Kaligrube Heringen Platz - Ein „Edersee“ unter der Erde. - HA, 1963; Nr. 298 v. 24.12.1963; Kassel 
-Roth, Harry \& Messer, Ernst (1981): Die Nutzung lagerstättenkundlicher Erkenntnisse für Planung

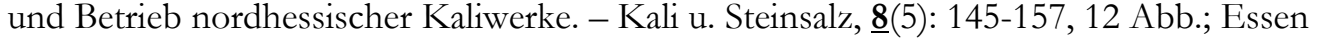

ORothe, Simone (1990): Will die Treuhand Kali-Industrie stillegen? Verzweifelte Kumpel blieben unter Tage. - HNA (Th), 1990; Nr. 179 v. 4.8.1990; Kassel

[Südharz Kalirevier; darin Bleicherode]

@Ruck, Hartmut (1990): Bad Salzungen - Chronik einer thüringischen Stadt. - Mein Heimatland, $\underline{\text { 34}}(2)$ : 21-24, 3 Abb.; 34(4b): 25-26, 2 Abb.; Bad Hersfeld [darin: Saline, Kali-Bergbau]

-Ruck, Hartmut (1992): Erlebnisbergwerk Merkers. - Kreis Hersfeld-Rotenburg - Heimatkalender 1992 und Wegweiser (36. Jg. ): 97 - 98, 1 Abb.; Bad Hersfeld

ORuck, Hartmut (1998): Die Kaliindustrie in Thüringen 1945-1989. - In: Eisenbach, Ulrich \& Paulinyi, Akos [Hrsg.]: Die Kaliindustrie an Werra und Fulda - Geschichte eines landschaftsprägenden Industriezweigs. - Schriften z. hessischen Wirtschafts- und Unternehmensgeschichte, $\underline{3}$; S. 123-136, Abb. 40-48; (Hessisches Wirtschaftsarchiv) Darmstadt 1998

OSaar, Horst (2003): Bittersalz - der Untergang der Thüringer Kali-Industrie. - Urbs et regio, 푸; 197 S., zahlr. Abb.; (University Press) Kassel

OSchäfer, Aloys (1925): Der Kalischacht Hüppstedt. - Unser Eichsfeld, 20: 33-38, 2 Abb.; Duderstadt

OSchiller, Thomas (1990): Dem Südharz droht das wirtschaftliche Aus: Von den Kali-Fördertürmen wehen jetzt schwarze Fahnen. - HNA (Th), 1990; Nr. 180 v. 6.9.1990; Kassel [Kleinbodungen, Bleicherode]

- DSchmelz, Gustav (1960): Kali, ein Handelsgut der Weltwirtschaft. - Die Weser, 34(5): 72-75, 5 Abb.; Bremen [Bezugnahme a. Werra-Kali-Revier Hessen]

-Scholl, Ludwig (1932): Der Kalibergbau im Kreise Uslar. - Die Weser, 11(1): 4-6, 2 Abb.; Bremen [Kaliwerk „Wittekind“ Volpriehausen]

-Schroth, Hermann E. (1977): Die Errichtung einer Großhalde unter umweltschützenden Bedingungen. - Kali u. Steinsalz, 7[1976-1979](4): 147-154, 15 Abb.; Essen [Werk Wintershall/Heringen]

- $S$ Slotta, Rainer (1980): Technische Denkmäler in der Bundesrepublik Deutschland. - Bd. 3 : Die Kaliund Steinsalzindustrie. - Veröff. a. d. Dt. Bergbaumuseum Bochum, 17; 780 S., zahlr. Abb.; [Hrsg. Dt. Bergbaumuseum Bochum] Bochum

- SSlotta, Rainer (1980): Technische Denkmäler in der Bundesrepublik Deutschland - Kaliwerk Wintershall (1) mit den Schachtanlagen Grünberg, Heringen, Herfa-Neurode. - In: Slotta, Rainer: Technische Denkmäler in der Bundesrepublik Deutschland. - Bd. $\underline{3}$ : Die Kali- und Steinsalzindustrie. - Veröff. a. d. Dt. Bergbaumuseum Bochum, 17; S. 60-83, 11 Abb.; [Hrsg. Dt. Bergbaumuseum Bochum] Bochum 1980 [Kreis Hersfeld-Rotenburg]

-Slotta, Rainer (1980): Technische Denkmäler in der Bundesrepublik Deutschland - Stillgelegtes Kaliwerk Oberhof - Reinhardsbrunn (30) mit den Schachtanlagen Oberhof und Reinhardsbrunn. In: Slotta, Rainer: Technische Denkmäler in der Bundesrepublik Deutschland. - Bd. $\underline{3}$ : Die Kali- und Steinsalzindustrie. - Veröff. a. d. Dt. Bergbaumuseum Bochum, 17; S. 479-484, 3 Abb.; [Hrsg. Dt. Bergbaumuseum Bochum] Bochum [Sudheim-Levershausen N'Göttingen, Lkr. Northeim] 
-Slotta, Rainer (1980): Technische Denkmäler in der Bundesrepublik Deutschland - Stillgelegtes Kaliwerk Königshall-Hindenburg (31) mit den Schachtanlagen Königshall und Hindenburg (Napoleon). - In: Slotta, Rainer: Technische Denkmäler in der Bundesrepublik Deutschland. - Bd. 3: Die Kali- und Steinsalzindustrie. - Veröff. a. d. Dt. Bergbaumuseum Bochum, 17; S. 484-496, 3 Abb.; [Hrsg. Dt. Bergbaumuseum Bochum] Bochum [Reyershausen N'Göttingen, Lkr. Northeim]

-Slotta, Rainer (1980): Technische Denkmäler in der Bundesrepublik Deutschland - Stillgelegtes Kaliwerk Hildasglück (24) mit den Schachtanlagen Wittekind (Justus) und Hildasglück - 3417 Volpriehausen (Solling). - In: Slotta, Rainer: Technische Denkmäler in der Bundesrepublik Deutschland. - Bd. $\underline{3}$ : Die Kali- und Steinsalzindustrie. - Veröff. a. d. Dt. Bergbaumuseum Bochum, 17; S. 390-401, 6 Abb.; [Hrsg. Dt. Bergbaumuseum Bochum] Bochum [Volpriehausen/Solling]

OSlotta, Rainer (1991): Das Kaliwerk Bleicherode als zentrales Denkmal der deutschen Kaliindustrie eine Chance. - Der Anschnitt, 43(5-6): 146-157, 10 Abb.; Bochum

OSlotta, Rainer (2000): Technische Denkmale der deutschen Kaliindustrie. - Der Anschnitt, $\underline{\mathbf{5 2}}(2-3)$ : 96105, [9] Abb.; Bochum [darin: Bleicherode, Abteroda, Merkers]

Q๑Spier, Hans-Harm \& Ruck, Hartmut (1997): Verwahrung von Salzbergwerken - Ergebnisse und Konzepte. - Kali u. Steinsalz, 12(5): 169-179, 9 Bilder, 2 Tab.; Essen [darin: Königshall-Hindenburg/Reyershausen, Wittekind-Hildasglück/Volpriehausen; Merkers, Buggingen]

-Storck, Ulrich (1952): Das Wiederherstellen der Förderfähigkeit des ersoffenen Kalibergwerks Königshall - Hindenburg. - Kali u. Steinsalz, 1 (1): 3 - 24, 15 Abb.; Essen [Reyershausen b. Göttingen]

ØThonicke, Frank (1991): 6000 Kumpels verlieren ihren Job: Kali und Salz AG schließt nun Gruben. HNA (Th), 1991; Nr. 49 v. 27.2.1991; Kassel

QThonicke, Frank (1991): Die Schließung der Kali-Gruben und ihre Folgen für die Menschen - Das Beispiel Menteroda in Thüringen - „Verkohlt sind wir, hier ist es zappenduster“. - HNA, 1991; Nr. 58 v. 9.3.1991; Kassel

- $\square$ Thonicke, Frank (1993): Die Kali-Kumpel sitzen nicht in einem Boot. In Bischofferode kämpfen die Kali-Kumpel verzweifelt um ihre Grube. Anderswo werden durch den Fusionsvertrag 7500 Arbeitsplätze erhalten - Wie denken Kumpel, deren Job gerettet ist, über Bischofferode? - HNA, $\underline{\text { 1993; }}$ Nr. 32 (Sonntagszeit) v. 15.8.1993; Kassel

Ø'Thonicke, Frank (1993): Kali-Kumpel: „Wir kommen nur im Sarg hier raus“/ .. - HNA, 1993; Nr. 155 v. 7.7.1993; Kassel [Kampf der Kumpel gegen die Betriebsschließung des Kaliwerks Bischofferode]

- $\bigcirc$ Thonicke, Frank (1996): Fusion: Hessen baut Kali aus Thüringen ab - Stollen frei für grenzüberschreitende Kaligewinnung - In 500 Metern Tiefe begannen gestern die Kumpel, sich nach Thüringen vorzubohren. - HNA, 1996, v. 4.7.1996; Kassel

口Thonicke, Frank (1999): Kalibergwerk Bischofferode - Statt 1000 nur 200 neue Arbeitsplätze. Werra-Rundschau, 1999; Nr. 162 v. 15.7.1999, S. 5, 3 Abb.; Eschwege

-Vogt, Egon E. (1980): Seit 75 Jahren: Kali aus Hattorf für die Welt - Jetzt jährlich 1,3 Millionen Tonnen. - HA, 1980; Nr. 200 v. 29.8.1980; Kassel 
- 0 Vogt, Egon E. (1984): Lose Vereinbarung soll durch Gesetz bekräftigt werden:

Grenzüberschreitender Kaliabbau kommt heute vor das Kabinett. - HA, 1984; Nr. 126 v. 30.5.1984;

Kassel

[Hessisch-thüringisches Kalirevier]

-Vollmershausen, Myriam (1993): Kali - eine Industrie an der Werra. - Begleitbd z. Fotoausst.v. M.

Vollmershausen i. Zusarbeit. m. Werra-Kalibergbau-Museum Heringen. - 95 S., zahlr. Abb.; (Ott) Bad Hersfeld

[Fotoband]

-Wagenhoff, Albrecht (1982): Geschichte des Kalibergwerkes Königshall-Hindenburg in Reyershausen. - Plesse-Archiv, 18: 165 - 189, 10 Abb,; (Goltze) Göttingen

[Reyershausen b. Göttingen]

Do•Walterspiel, Otto (1980): 75 Jahre Kaliverein. - Kali u. Steinsalz, $\underline{8}(3):$ 71-75; Essen

-Weger, Ernst (1960): Fernsehtechnik im Kalibergbau - Moderne Steueranlage verbilligt Förderung Autos fahren auf Salzstraßen. - HA, 1960; Nr. 281 v. 2.12.1960; Kassel

-OZapp, Johannes \& Lindloff, Uwe (2003): Verbesserung der Konkurrenzfähigkeit des Werkes Werra. Projekt zur Gewinnung und Verarbeitung von Sylvinit. - Kali u. Steinsalz, 2003(1): 34-41, 7 Abb.; Essen

[Verbundwerk „Werra“ der Kali u. Salz AG: Hess.-thür. Kaliwerke Wintershall, Hattorf, Unterbreizbach]

\subsection{Erdöl- und Erdgas}

@Albrecht, Helmuth (1932): Die Löschung eines Ölsondenbrandes unter Tage auf Volkenroda. - Kali, etc., 26 (7): 77-86, o Abb.; Halle

QAnonym (1934): Bohrungen nach Erdöl im Stadtgebiet von Mühlhausen. - Unser Eichsfeld, 29: 101; Duderstadt

@Karinin, W.-D.; Merkel, D.; Piske, J. \& Schrekenmayr, St. (1998): Historie und gemeinsames Explorationskonzept EEG/BEB nach 1990. - In: Karinin, W.-D.; Merkel, D. \& Piske, J.: Geowissenschaftliche Ergebnisse der Kohlenwasserstoff-Exploration im Land Brandenburg und im Thüringer Becken in den Jahren 1991-1196 (Zechstein und Rotliegendes). [Beiträge von zahlreichen Autoren]- Geol. Jb., Reihe A., 149, 320 S., zahlr. Abb., Tab., Kt.; Hannover - hier: S. 7 - 23, 11 Abb., 2 Tab.; Hannover 1998 [darin: statist. Angaben über Lagerstätten in Westthüringen: Volkenroda, Mühlhausen, Langensalza]

ONamenskürzel (Dr. H.R.) (1959): Erdgasausbruch bei Mühlhausen- Riesige Feuersäule schießt Tag und Nacht empor. - Werra-Rundschau, 1959; Nr. 187 v. 15.8.1959, S. 5; Eschwege

\subsection{Steine und Erden}

$\square$ Anonym (1892): < Gipsabbau am Krösselberg zwischen Abterode und Wolfterode geplant - Gipsmühle zur Aufbereitung an der Berka unterhalb Forsthaus Schmelzhütte> - Eschweger Tageblatt u.

Kreisblatt, 1892; Nr. 292 v. 12.12.1892; Eschwege 
$\square$ Anonym (1900): <Tiefbohrungen bei Wellingerode nach Kupferschiefer und Kalisalz]. - Eschweger Tageblatt u. Kreisblatt, 1900; Nr. 270 v. 16.11.1900; Eschwege

$\square$ Anonym (1925): <Weitere Basaltbrüche auf der Westseite des Meißners bei Hausen geplant]. Eschweger Tageblatt, 1925; Nr. 241 v. 13.10.1925; Eschwege

OAnonym (1925): <Ortschaft Falken an der Werra - Sandgruben im wirtschaftlichen Aufwind > Eschweger Tageblatt, 1925; Nr. 195 v. 20.08.1925; Eschwege

$\square$ Anonym (1929): < Betriebseröffnung Basaltwerk Georg Köhler GmbH, Bransrode am Meißner> Eschweger Tageblatt, 1929; Nr. 222 v. 21.9.1929; Eschwege

$\square$ Anonym (1931): < Basaltwerk Köhler, Bransrode am Meißner, nimmt nach kurzer Pause Betrieb wieder auf $>$-Eschweger Tageblatt, 1931; Nr. 65 v. 18.3.1931; Eschwege

$\square$ Anonym (1931): <Basaltwerk Köhler, Bransrode am Meißner, stillgelegt> -Eschweger Tageblatt, 1931; Nr. 290 v. 11.12.1931; Eschwege

$\square$ Anonym (1932): < Basaltwerk Bransrode am Meißner vor Weiterführung des Betriebs].- Eschweger Tageblatt, 1932; 8.2.1932; Eschwege

$\square$ Anonym (1932): Auseinandersetzung des Kreises mit dem Basaltwerk Bransrode/Meißner. - Eschweger Tageblatt, 1932; Nr. 119 v. 24.5.1932; Eschwege

$\square \bullet$ Anonym (1938): < Kammersprengung im Steinbruch Bransrode mit 64 Zentnern Sprengstoff Seismische Erschütterung in der Erdbebenwarte Göttingen aufgezeichnet $<$ Basaltsteinbruch Bransrode/Meißner>. - Eschweger Tageblatt, 1938; Nr. 102 v. 3.05.1938; Eschwege

- $\square$ ○ीApel, Jürgen \& Rüppel, Heidi [Verfass. u. Hrsg.] (2005): Raus in die Natur - Tipps für den Sonntags-Ausflug im Dreiländereck Hessen - Niedersachsen - Thüringen. - 159 S., 111 Fotos, 34 Kt., 1 Zeittaf.; (LSRB-Verlag, Landschaftskundlicher-Studien-Reisebuch-Verlag) Witzenhausen [zahlreiche Ausflugsziele, auch zu Bergbaurelikten - Ziel 14 (Alaungewinnung Oberkaufungen) - Ziel 18 (Steinberg b. Hann. - Münden]

$\square$ Bachmann, Gustav (1961): Die Schmelztiegelmacher von Großalmerode. - Z. Vereins hess. Gesch. u. Landeskde., 72: 190-195; Kassel [darin: Bergbau Steine und Erden]

$\square$ Bauer, Stefan (1999): Der Großalmeroder Tonbergbau von 1887-1998. - (Magistrat der Stadt Großalmerode) Großalmerode

$\square$ Bauer, Stefan (2007): Tonabbau in der Gemarkung Epterode. - In: Nobel, Hermann: Chronik Epterode - Von Euerharderot zu Epterode - 825 Jahre Epterode. Mit Beiträgen von Stefan Bauer, Erich Hofsommer, Dr. Friedhelm Koch, Dr. Karl Kollmann \& Werner Sippel. - Herausgegeben vom Magistrat der Stadt Großalmerode anläßlich der 825-Jahr-Feier. - 453 S., zahlr. Abb. u. Tab.; hier S. 365-378, 11 Abb.; (Magistrat d. Stadt Großalmerode) Großalmerode 2007 [weiterer Artikel: Nobel, Hermann: Tonverarbeitendes Gewerbe. - S. 379-388, 10 Abb.]

$\square$ Betz, Wolfgang; Bornscheuer, Uwe [beteiligt]: Spurensicherung Werra und Meißner - der Fluß und der Berg. - Jugendliche untersuchen ein Stück ihrer Region. - 115 S., zahlr. Abb.; [Bund Deutscher Pfadfinder (BDP) - Region Nordhessen; Kreisjugendpflege Werra-Meißner-Kreis, u.a.] o. O. [darin: Kiesbaggerei a.d. Werra/Kohlebergbau a.d. Meißner, Hydrogeographie; Mühlen, Fischerei, Lohgerberei]

-Bodenbrenner, Kurt (1991): Die Gewinnung von Düngegips aus der Sicht der kurhessischen OberBerg- und Salzwerks-Direktion. - Hessische Heimat, N.F., 411(1): 3-11, 11 Abb.; Marburg/L. 
[darin: Erwähnung der Gips-Vorkommens von Konnefeld („Baumbacher Hoch“) Lkr. Hersfeld/Rotenburg; ansonsten Haubern b. Frankenberg]

-Bölling-Pitzschke, Erich (1996): Sandgruben. - In: Pitzschke, Angela [Bearb.](1996): Drei Dörfer ein Ort: Lohfelden - Geschichte und Geschichten. -351 S., zahlr. Abb.; hier S. 3 - 6, [Hrsg. Gemeindevorstand der Gemeinde Lohfelden] Lohfelden [,Sandgruben in Lohfelden“ - „Sandgruben in Vollmarshausen“]

$\square$ Borchard, Wanda (1924): Die Geschichte der Tonindustrie in Großalmerode. - Fachbücher d. Keramischen Rundschau, 13; 52 S.; (Verlag d. Keramischen Rundschau) Berlin - zgl. Diss. rer. pol. Univ. Göttingen [Kurzinformation z. Lagerstättengeologie, Tonarten u. Verwendung]

QBurre, Otto (1926): Die wichtigsten an Berliner Bauten in der Außenarchitektur vewandten natürlichen Gesteine nach Art und Herkunft. - Jb. Preuß. Geol. Landesanst., 47 (f. 1926): 116-159, Taf. 6; Berlin [darin: Rhät-Sandstein v. Seeberg b. Gotha]

- $\square$ ○•Burre, Otto \& Dienemann, Wilhelm (1932/1933): Vorkommen und Verbreitung technisch verwendbarer Gesteine, Tone und Sande in Deutschland. - Die Stein-Industrie (Der Steinbruch), 27 (1932): 154, 172; $\underline{\mathbf{2 8}}(3 / 4)$ [1933]: 53-55, 1 Kt. ( $\underline{\mathbf{2 8}}(3 / 4)$ : 15. Verteilung der technisch verwendbaren Gesteine, Tone und Sande auf die einzelnen Landschaften); Berlin Referat in: N. Jb. Mineral. etc., Referate; 1933 (Bd. II): 1014-1015 (M. Henglein); Stuttgart [Abbaustellen i. Hessen, Niedersachsen, Thüringen] [Vorlage nicht eingesehen, zitiert nach angegebenem Referat]

QCebulla, R.; Kuhn, G. \& Sippel, U. (2001): Gewinnungsstellen von Steine- und Erden-Rohstoffen in Thüringen - eine Übersicht. - Geowiss. Mitt. Thüringen, 9: 21-28, 1 Abb.; Jena

-Credé, Heinrich (1959): Der Cornberger Sandstein. - Das Werraland, 11(4): 58-59, 3 Abb.; Eschwege

a•Diestel, Walter (1954): Sollinger Platten. - Die Weser, 28(3): 32-33, 3 Abb.; Bremen [Natur-Werksteingewinnung im Raum Karlshafen-Würgassen und die Verwendung]

$\square$ Ebel, Willi (1969): Jubiläums-Festschrift zur 860-Jahrfeier der Gemeinde Rommerode vom 20. Juni bis 23. Juni 1969. - 50 S., zahlr. Abb. + Anzeigenteil; [Hrsg. Gemeindevorstand Rommerode] Rommerode [darin S. 12-27, 7 Abb.: „Das Leben in Rommerode im Laufe der Jahrhunderte. - 1. Wie die Bewohner ihren Lebensunterhalt verdienten“ - (Glasherstellung, Alaunherstellung, BraunkohlenBergbau, Tonverarbeitende Industrie)]

$\square$ Erxleben, J. C. P.(1765): Nachricht von einer Reise nach dem Weißner, in Absicht auf die natürliche Geschicht dieses Berges und der um ihn liegenden Gegend. - Hannoverisches Magazin, $1765=3$. Jg.)(63): Sp. 993-1007, (64): Sp. 1009-1014; [Auszug in Tourist. Mitt. Hessen, ㅁ: 8-11; Kassel 1899] [Saline Sooden, Braunkohlenbergbau a. d. Meißner, ausführlich: Alaunherstellung in Großalmerode, Strahlkies v.on Großalmerode; Botanik]

$\square$ Festausschuß [Hrsg.](1982): Epterode 1182 - 1982 und Einweihung des Dorfgemeinschaftshauses vom Freitag, den 20. bis Montag, den 23. August 1982. - Ohne Seitenzählung, zahlr. Abb.; Epterode [darin Kap: Das Bühlchen bei Epterode; Der Ton, die Töpfer, die Epteroder Tiegelmacher und die Goebels]

-Fritsche, Ernst (1931): Die Hartstein-Industrie im Kreise Uslar. - Die Weser, 10(12): 309-311, 3 Abb.; Bremen [Bramburg b. Adelebsen, Grefenburg b. Barterode] 
$\square$ Gresky, Wolfgang (1977): Technologische Exkursion Göttinger Studenten nach Großalmerode 1785. Kaufunger Wald, H. : 9-12, 1 Kt.; Kaufungen

[Tonverarbeitendes Handwerk]

-Habich, Friedrich (1929): Habich's Fabrik in Veckerhagen und das Braunkohlenwerk am Gahrenberg. - Heimatjb. Lkr. Hofgeismar, 1930 : 88; Hofgeismar [Farberde „Kasseler Braun“]

-Habich, Hermann [Red.][ca.1985]: 200 Jahre G. E. Habich's Soehne, Veckerhagen - Farbenfabrik auf dem Weg durch 2 Jahrhunderte. - o. Seitenzählg., Abb.; [Selbstverlag G. E. Habich’s Soehne] Reinhardshagen-Veckerhagen

[Farberde „Kasseler Braun“ - Braunkohlenbergwerk Gahrenberg]

-Hamm, F. (1957): Fernhandel früherer Zeiten mit niedersächsischen Gesteinen. - Beiträge Naturkunde Niedersachsens, $\underline{\mathbf{1 0}}(2):$ 27-32; Hannover [darin: Basalte Landkreis Göttingen, Northeim; Mühlsteinquarzit Kattenbühl b. Hann. Münden]

-Hartung, Wilhelm (1966): Der Bergbau am Kleinen Steinberg. - Das Werraland, 18(4): 59-60; Eschwege [Tonbergbau und Keramische Industrie am Steinberg im Kaufunger Wald, Lkr. Göttingen]

$\square$ Höck, Alfred (1971): Großalmeröder Ton und Töpferware - Notizen aus den Jahren 1839 und 1846. Das Werraland, 23 (1): 4-6, 6 Abb.; Eschwege

-Höck, Alfred (1972): Torf im Amt Borken 1787. - Z. Vereins hess. Gesch. u. Landeskde., 무: 137-142; Kassel [Bergbaugeschichte Steine und Erden]

OHoppe, Vinzenz (1980): Die frühere Hausteinindustrie am Hainich und Landgraben. - Eichsfelder Heimathefte. - (20 Jg.) $\underline{\mathbf{1 9 8 0}}(2)$ : 158-163, 3 Abb.; Worbis

OHoppe, W. (1933): Uebersicht über die im Straßenbau verwendbaren Gesteine Thüringens. - Die SteinIndustrie (Der Steinbruch), 28 (15): 126-127, 140-141, 1 Kt.; Berlin [darin: Thüringer Wald]

OHoppe, W. (1939): Überblick über die thüringischen Werk- und Dekorationssteine und ihre wichtigsten Abbaugebiete. - Steinindustrie u. Straßenbau, 34(7): 120-122; Berlin

Referat in: N. Jb. Mineral. etc., Referate, 1939 (Bd. II): 555-557 (M. Henglein); 1940 (Bd. III): 182

(Walther Fischer); Stuttgart

[darin:Thüringer Wald, westl. Thüringer Becken]

OHoppe (1939): Zusammenstellung der Werk- und Dekorationssteine Thüringens nach ihrem

Verwendungszweck. - Stein-Industrie u. -Straßenbau, 34(8): 148-150;

Referat in: N. Jb. Mineral. etc., Referate, 1940 (Bd. III): 183 (Walther Fischer); Stuttgart

[darin: Abbaustellen Thüringer Wald, Thüringer Becken]

OHoppe (1939): Vorkommen und Beschaffenheit der Werk- und Dekorationssteine in Thüringen. - 28 Abb., 1 Taf., 1 Kt.; (Union) Berlin

[Vorlage nicht eingesehen, Relevanz vermutet]

OHundt, Rudolf (1936): Thüringer Granit und Thüringer Travertine. - Steinbruch u. Sandgrube, $\underline{\mathbf{3 5}}(24)$ : 333-334;

Referat in: N. Jb. Mineral. etc., Referate, 1937 (Bd. II): 478 (Stützel); Stuttgart

[Abbaustellen Thüringer Wald, westl. Thüringer Becken]

OHundt, Rudolf (1937): Thüringer Marmor und Thüringer Kalke. - Steinbruch u. Sandgrube, $\underline{36}(2):$ 1920; 
Referat in: N. Jb. Mineral. etc., Referate, 1937 (Bd. II): (Stützel); Stuttgart [Bezugnahme a. Abbaustellen Oberdorla, Treffurt]

-Kirchvogel, Paul Adolf (1960): 175 Jahre G. E. Habich's Söhne Veckerhagen. Aus der Geschichte einer deutschen Farbenfabrik. - Nach Akten u. Dokumenten aus dem Familien- u. Firmenarchiv u. d. Hess. Staatsarchiv Marburg bearbeitet. - 145 S, Abb..; [Eigenverlag G. E. Habich’s Söhne] Veckerhagen [Braunkohlenbergwerk Gahrenberg, Farberde „Kasseler Braun“]

-Kirchvogel, Paul Adolf (1960): 175 Jahre G.E. Habich's Söhne, Veckerhagen. - Heimatjahrbuch f.d. Kreis Hofgeismar, 1961: 74-75; Kassel - Auszug aus der Festschrift:: Kirchvogel, Paul Adolf: 175 Jahre G. E. Habich's Söhne Veckerhagen. Aus der Geschichte einer deutschen Farbenfabrik. - Nach Akten u. Dokumenten aus dem Familien- u. Firmenarchiv u. d. Hess. Staatsarchiv Marburg bearbeitet. - 145 S, Abb..; [Eigenverlag G. E. Habich's Söhne] Veckerhagen 1960

[Braunkohlenbergwerk Gahrenberg, Farberde „Kasseler Braun“]

-Kirchvogel, Paul Adolf (1978): Die Farbenfabrik G. E. Habich’s Söhne Veckerhagen. - In: Bluemel, Wolfgang [Red.]: Reinhardshagen: 1100 Jahre Vaake - 700 Jahre Veckerhagen. Festschrift zum Heimatfest 1978. - 87 S., zahlr. Abb.; S. 59-65; (Selbstverlag) Reinhardshagen 1978 [Braunkohlenbergwerk Gahrenberg, Farberde „Kasseler Braun“]

$\square$ Koch, Friedhelm (2005): Die „Alte Alaun Hütte“ am Meißner. Ein Beitrag zur Geschichte des Bergbaues in Niederhessen. - Das Werraland, 57(2): 23-26, 5 Abb.; Bad Sooden-Allendorf

$\square$ Koch, Friedhelm (2006): Der Hohe Meißner in Nordhessen. Vergessene Kapitel der Bergbaugeschichte. - Teil 1: Alaunabbau. - Dortmunder Beitr. z. Landeskde., Naturwiss. Mitt., 40: 47-58, 5 Abb.; Dortmund

$\square$ Koch, Friedhelm (2008): Alaun- und Wascherde- Zwei längst vergessene Abbauprodukte des Hohen Meißners - Teil 1. - Hessischer Gebirgsbote, 109(4): 184-186, 3 Abb.; Melsungen

$\square$ Koch, Friedhelm \& Siemon, Helmut (2006): Wascherdegewinnung am Meißner. Eine kurze bergbauliche Periode im 19. Jahrhundert. - Das Werraland, $\underline{\mathbf{5 8}}(1)$ : 4-5, 1 Abb.; Bad Sooden-Allendorf

QKöllner, Otto (1901): Das Vorkommen und die technische Verwendung der nutzbaren Schichten des Seebergs. In: Naturwissenschaftliches und Geschichtliches vom Seeberg. - S. 55-57.; [Hrsg. Naturwiss. Verein z. Gotha) (Thienemann) Gotha 1901

$\square$ Landau, G. (1843): Die Thongruben zu Großalmerode. - Z. Vereins hess. Gesch u. Landeskde., 3: 353363; Kassel

$\square$ Landau, G. (1843): Geschichte der Glashütten in Hessen und der Tongruben bei Großalmerode. Zwei Abhandlungen; 88 S.; (Döll u. Schäfer) Kassel - 1. faksimilierter Nachdruck, Hrsg. V. Dieter Carl; (Verlag Hist. Edition Dieter Carl) Vellmar - Der faksimilierte Nachdruck enthält drei Werke von Landau: Geschchichte der Glashütten..., Geschichte der Alaunbergwerke, Geschichte der Fischerei in Deutschland

- $\square$ Landau, G. (1854): Gesichte der hessischen Alaunbergwerke in Nordhessen. - Z. Vereins hess. Gesch. u. Landeskde., 6: 184-215; Kassel [darin: Bergwerke b. Oberkaufungen, Großalmerode/Hirschberg, Epterode, Faulbach, Gahrenberg, Meißner, Fürstenhagen, Kaufunger Wald]

-Landau, G. (1854): Geschichte der hessischen Alaunwerke. - Z. Vereins Hess. Gesch. u. Landeskde., ㅁ: 184-215; Kassel - 1. faksimilierter Nachdruck, Hrsg. v. Dieter Carl; (Verlag Hist. Edition Dieter Carl) Vellmar - Der faksimilierte Nachdruck enthält drei Werke von Landau: Geschchichte der Glashütten..., Geschichte der Alaunbergwerke..., Geschichte der Fischerei in Deutschland. 
- $\square$ Lange (1897): Zur Geschichte einzelner Industrien: Industrie der Steine und Erden. - Übertitel: Gewerbliche Betriebe der Stadt Cassel und des nördlichen Hessens. - In: Lange, Wilhelm Chr. [Red.]: Festschrift zur 38. Hauptversammlung d. Vereins Deutscher Ingenieure - Gewidmet vom Hessischen Bezirksverein; 176 S:, Abb.; hier S. 105-113; (Weber \& Weidemeyer) Kassel 1897 [darin: Tonbergbau Großalmerode]

- $\square$ Lange (1897): Der heutige Stand der einzelnen Industrien: Steine und Erden. - Übertitel: Gewerbliche Betriebe der Stadt Cassel und des nördlichen Hessens. - In: Lange, Wilhelm Chr. [Red.]:

Festschrift zur 38. Hauptversammlung d. Vereins Deutscher Ingenieure - Gewidmet vom Hessischen Bezirksverein; 176 S:, Abb.; hier S. 123-134; (Weber \& Weidemeyer) Kassel 1897 [darin S. 123-126: „Die Thonindustrie von Großalmerode]

OLange, Peter (1983): Die Nutzung des thüringischen Buntsandsteins in Vergangenheit und Gegenwart. -Z. geol. Wiss., 11 (3): 267-282, 8 Tab.; Berlin

[Erwähnung von Steinbrüchen im thüringischen Eichsfeld]

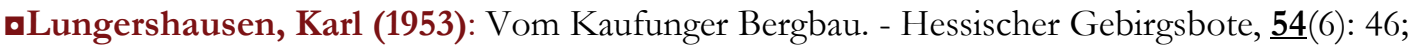
Melsungen

-Lungershausen, Karl (1961): Die Bielsteinkirche [und „Roßgang“ in Oberkaufungen]. - Hessischer Gebirgsbote, $\underline{\mathbf{6 2}}$ (3): 27 - 28, 1 Abb.; Melsungen [Bilsteinkirche: Basaltsäulen-Felsgruppe Im Söhrewald b. Kassel; Roßgang: Pferdegöpelwerk des Braunkohlen- Bergbaus in Oberkaufungen b. Kassel]

-Lungershausen, Kurt (1962): 400 Jahre Alaun- und Kohlenbergbau in Kaufungen. - Bergbau i. Hessenland, (12. Jg.) 1962(1): 4-10, 4 Abb.; Kassel

$\square$ Lungershausen, Karl (1976): Bergbau im Hessenland. - Hessischer Gebirgsbote, $\underline{77}$ (2): 52 - 53; Melsungen

[Johannes Rhenanus und die Soodener Saline]

-Lungershausen, Karl (1988): Mühlsteine vom Kattenbühl - Über Ursprung und Handel von Mühlsteinen im Weserraum. - Kaufunger Woche, H. 며: 2, 1 Abb.; Kaufungen

-Möller, Hans-Karl (1993): Auf den Spuren des Bergbaus in und um Cornberg. - In: Hersfeld-

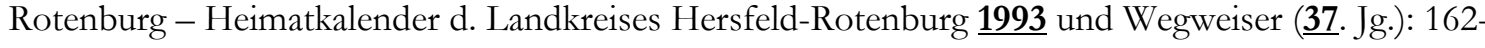
166; Bad Hersfeld

-Mötzing, Kurt (1977): Verwendung des Quarzits in wirtschaftlicher Hinsicht sowie als Zier- und Gedenkstein. - Hessischer Gebirgsbote, $\underline{78}$ (4): 114 - 115, 2 Abb.; Melsungen [Tertiärquarzite d. Kasseler Umgebung]

- $\square$ Mötzing, Kurt (1970): Der Alaunbergbau im alten Hessen. - Hessischer Gebirgsbote, $\underline{71}$ (4): 78; Melsungen

[Gahrenberg, Oberkaufungen, Großalmerode]

$\square$ Namenskürzel (Hkr) (1948): <Großalmerode> Eine Stadt lebt von Ton und Kohle. - WerraRundschau, 1948; Nr. 4. v. 24.1.1948; Eschwege

$\square$ Namenskürzel (HG) (1950): Sandhasen - nicht nur ein Symbol. - Putz- und Mauersand aus den Grebendörfer Bergen sehr gefragt. - Werra-Rundschau, 1950; Nr. 256 v. 2.11.1950, S: 4, 1 Abb.; Eschwege

-Namenskürzel (t)(1951): Dumpf hallen die Detonationen über den Berg - Täglich werden bis zu 175 Tonnen Oberellenbacher Gips auf dem Bahnhof Heinebach verladen. - HN, 1951; Nr. 128 v. 6.6.1951, 1 Abb.; Kassel 
$\square$ Namenskürzel (pl) (1957): Kirchhosbachs „Alpen“: Lukrativer Basaltsteinbruch. Hochgebirge en miniature - Wird auch die Bundeswehr am Alpstein sprengen? - Werra-Rundschau, 1957; Nr. 10 v. 12.1.1957, S. 3, 1 Abb.; Eschwege

[Angedachte Basaltgewinnung am Alpstein bei Kirchhosbach]

-Namenskürzel [Lu](1960): Alaun - In Oberkaufungen wurde dieses wichtige Mineral abgebaut. Bergbau i. Hessenland, (10. Jg.) 1960(5): 4-5, 2 Abb.; Kassel

$\square \bullet$ Namenskürzel (-t)(1960): Hundert Jahre Kiesbetrieb an Werra und Oberweser. - Die Weser, $\underline{34}$ (7): 110-111, 2 Abb.; Bremen

$\square$ Namenskürzel (-e./FVV) (1973): Die Stadt des guten Tons - Großalmerode hat es ,in sich“. Hessischer Gebirgsbote, 74(3): 62; Melsungen

[Bergwirtschaft, Tonindustrie]

-Namenskürzel [hei](1990): <Wiedereröffnung Basalttuff-Steinbruch im Druseltal/Kassel]. - HNA (Kasseler Zeitung) 1990; Nr. 217 v. 18.9.1990; Kassel

-Naumann, Peter (1990): Sandstein im Weserbergland - Baustein durch Jahrhunderte. - Hessischer Gebirgsbote, $\underline{91}$ (3): 97; Melsungen

[Buntsandstein Landkreis Kassel]

-Naumann, Peter (1993): Rupelton und Kasseler Meeressand - Tertiärsande und ihre Verwendung im Reinhardswald und Solling. - Hessischer Gebirgsbote, $\underline{94}$ (1): 17-18; Melsungen

-Naumann, Peter (1993): Basalteisen-Vorkommen wurden nur teilweise genutzt. - Hessischer Gebirgsbote, 94 (2): 68; Melsungen

[Nordhessische Bergbaugeschichte, Gewinnung von Brauneisenstein aus Basaltverwitterung]

-Naumann, Peter (1993): Basalttuff für die Restaurierung historischer Bauten in Kassel. - Hessischer Gebirgsbote, 94 (3): 114; Melsungen

$\square$ Naumann, Peter (1994): Seit 800 Jahren wird in Großalmerode Ton abgebaut. - Hessischer Gebirgsbote, $\underline{95}$ (1): 16; Melsungen

-Naumann, Peter (1995): „Kasseler Braun“ und die Farbenfabrik Habich in Veckerhagen. - Geol.mineral. Mitt. a. Nordhessen, $\underline{\mathbf{5}}$; 21 S.; (Naumann) Hofgeismar

-Naumann, Peter (1998): Das Blaufarbenwerk zu Karlshafen. - Hessischer Gebirgsbote, 99 (1): 8 - 9; Melsungen

$\square$ Nobel, Hermann (2007): Alaun-Werk am Bühlchen. - In: Nobel, Hermann: Chronik Epterode Von Euerharderot zu Epterode - 825 Jahre Epterode. Mit Beiträgen von Stefan Bauer, Erich Hofsommer, Dr. Friedhelm Koch, Dr. Karl Kollmann \& Werner Sippel. - Herausgegeben vom Magistrat der Stadt Großalmerode anläßlich der 825-Jahr-Feier. - 453 S., zahlr. Abb. u. Tab.; hier S339-344, 10 Abb.; (Magistrat d. Stadt Großalmerode) Großalmerode 2007

OOtto, Jörg (2000): Seeberger Sandstein - geschätztes Baumaterial und gefährlicher Arbeitsstoff. Veröff. Naturkundemuseum Erfurt, Naturwiss. Rh., 19: 31-34, 6 Abb.; Erfurt [Rhät-Sandstein]

$\square$ Pagenkopf (1898): Der Mergel und seine Verwendung in der Landwirtschaft $<$ Bezugnahme auf neu entdecktes Mergellager bei Netra u. Landwirtschaft der Region>. - Eschweger Tageblatt u. Kreisblatt, $\underline{\mathbf{1 8 9 8}}$; Nr. 30 v. 5.02.1898; Eschwege

OPatzelt, Gerald (1989): Das Material historischer Bauten in Nordwest-Thüringen. - 1. Teil. Mühlhäuser Beitr., 12: 83-90, 1 Abb.; Mühlhausen 
OPatzelt, Gerald (1990): Das Material historischer Bauten in Nordwest-Thüringen. - 2. Teil. Mühlhäuser Beitr., 13: 27-35; Mühlhausen

-Pötter, Willy (2001): Die Familie Henschel und ihre Bedeutung für Ihringshausen. - Hessischer Gebirgsbote, $\underline{102}$ (2): 61 - 63, 6 Abb.; Melsungen

[Kassel-Ihringshausen; Braunkohlenbergbau Ihringshausen, Ziegeleigrube Möncheberg]

$\square$ Rupprecht, G. (1927): Die Sandsteinhöhlen unter dem Heldrastein. - Das Werratal, 4 (4): 55-56; Eschwege

-Schmidt, Hermann (1962): Göttinger Bausteine, geologisch gesehen. - Göttinger Jb., 1962: 11 - 18 ; Göttingen

$\square$ Schulin, Wolfgang (1998): Kiesabbau im Werratal - eine Landschaft wird verändert. - Schriften d. Werratalvereins Witzenhausen, 35; 84 S., zahlr. Abb.; (Werratalverein Witzenhausen e.V.) Witzenhausen

[Kies-Gewinnung - Renaturierung]

$\square$ Seib, Gerhard (1975): Technische Denkmäler in der Bundesrepublik Deutschland. - 20. Rinkenkuhl/Ehem. Zechenhaus und Fabrikschloß“. - In: Slotta, Rainer: Technische Denkmäler in der Bundesrepublik Deutschland. - Veröff. a. d. Dt. Bergbaumuseum Bochum, 7; S. 46-47, 2 Abb.; [Hrsg. Dt. Bergbaumuseum Bochum] Bochum 1975

$\square$ Simon, Helmut (2006): Hausen - Höchstgelegener Ort Kurhessens - Die Geschichte eines niederhessischen Dorfes am Meißner in der Zeit von 1364 bis 2005. - 592 S:, zahlr. Abb.; [Hrsg. Helmut Simon, Kirchenvorstand Ev. Kirchengemeinde Hausen; Ortsbeirat Hausen] Hausen [darin S. 11-18, 8 Abb.: „Zum Naturraum von Hausen“; S. 29-46, zahlr. Abb. „Die Geschichte des Bergbaues am Hohen Meißner (Braunkohle, Alaun, Wascherde)]

$\square$ Stephan, Hans-Georg (1986): Großalmerode - Ein Zentrum der Herstellung von technischer Keramik, Steinzeug und Irdenware in Hessen. - Die Geschichte der keramischen Gewerbe in Großalmerode und die Entwicklung ihrer Produktion vom 12. bis zum 19. Jahrhundert - Teil I. Mit Zeichnungen von Hans Riecheling. - 229 S., 185 Abb.; [Hrsg. Glas- u. Keramikmusueum Großalmerode] Großalmerode [darin S. 48-54, Abb. 3, 28: Der Tonabbau]

$\square$ Stephan, Hans Georg (1995): Großalmerode - Zentrum der Herstellung von technischer Keramik, Steinzeug und Irdenware in Hessen. - Bd. II: Technische und Baukeramik, Tonpfeifen, Knicker, Steingut, Porzellan, Aspekte von Handel, früher chemischer Industrie, Bergbau und Gewerbegeschichte. - 248 S., Abb.; [Hrsg. Geschichtsverein Großalmerode als Träger d. Glas- u. Keramikmuseums Großalmerode] Großalmerode

$\square$ Stück, Tobias (2008): <Gemeinde Meißner, OT Vockerode> Dolomitgestein ist überlebenswichtig. Köhler-Kalk hat sich Nische im Kampf gegen übermächtige Konkurrenz gesichert, die jetzt zur Neige geht. - Werra-Rundschau, 2008; Nr. 268 v. 13.11.2008; 6 Abb.; Eschwege

oWachwitz, Karl (1935): Mühlsteine aus deutschem Naturgestein. - Steinbruch u. Sandgrube, 34(12): 150-151; Halle (Saale)

[Thüringer Mühlstein-Industrie]

$\square$ Waitz von Eschen, R. \& Strippelmann, F. E. (1828): Geognostische Betrachtung der am Hirschberge bei Großalmerode abgelagerten, tertiären Gebilde, nebst einigen Bemerkungen über den daselbst im Betriebe stehenden Bergbau. - Studien Göttingischen Vereins bergmänn. Freunde, 2: 121-168; (Dieterich) Göttingen

[Tertiärstratigraphie, Braunkohlenbergbau, Alaungewinnung] 
- $\square$ Walter, Hans-Henning (1989): Die Alaunproduktion in Deutschland vom Mittelalter bis zum 19. Jahrhundert. - Übersicht und Anregung zu regionalhistorischer Forschung. - Der Anschnitt, $\underline{41}$ (1): 218, 13 Abb., 1 Tab.; Bochum [in der tabellarischen Auflistung: Großalmerode, Oberkaufungen]

OWeber, Hans (1952): Saxonische Tektonik des Thüringerwaldrandes bei Ohrdruf. - Geologie, 1 (4): 243256, 3 Abb.; Berlin

$\square$ Wiggert (1887): Die Thongewinnung und Thonwaaren-Industrie bei Großalmerode in der Provinz Hessen. - Hierzu die Texttafel c. - Z. Berg-, Hütten- und Salinenwesen, 35: 336-351 (Abh.), 1 Kt.; Berlin

-Wroz, Winfried [Konzeption]; Lerche, Silvia [Mitarbeit] (2004): Philipp von Hessen und die Montanindustrie in der Region Söhre-Kaufunger Wald. - Begleitpublikation zur Ausstellung im Regionalmuseum Kaufungen 2004; 64 S., zahlr. Abb.; [Hrsg.: Gemeinde Kaufungen, Regionalmuseum] [darin S. 33-37, 3 Abb., Kap. VIII: „Hitze und fauliger Urin - Die Alaun-Herstellung“]

\subsection{Metallische Rohstoffe (ohne Kupferschiefer)}

$\square$ Anonym (1890): < Nachgrabungen nach Kupferschiefer und Silbererz am Kupferberg bei Wellingerode - Zwei Schurfstollen zur Lagerstättenerkundung geplant> - Eschweger Tageblatt u. Kreisblatt, 1890; Nr. 73 v. 27.03.1890; Eschwege

QAnonym (1898): Kupfer- und Silberbergbau in Ohrdruf. - Z. prakt. Geologie, [6. Jg.] 1898: 338 (Notizen); Berlin

-Anonym (1955): Aus alten hessischen Berg- und Hüttenwerken. - Bergbau i. Hessenland (Ausgabe Braunkohle), (5. Jg.) 1955(7): 3; Kassel

[Eisenerzbergbau Umgebung Homberg (Holzhausen, Mardorf)]

-Anonym (1969): Der „Eisenhammer“ in Lippoldsberg. - Hessischer Gebirgsbote, $\underline{70}$ (3): 58 - 59; Melsungen

- $\square$ Cancrinus, Franz Ludwig (1767): Beschreibung der vorzüglichsten Bergwerke in Hessen, in dem Waldeckischen, an dem Haarz, in dem Mansfeldischen, in Chursachsen, und in dem Saalfeldischen. [8] Bl., 429, [1] S.; 1 Abb., 11 Falt-Taf.; (Andreä) Frankfurt/M.

[darin: Eisenbergwerk Hohenkirchen b. Kassel, Hüttenwerke Veckerhagen, Karlshafener Blaufarbenwerke, Eisenbergwerk b. Homberg, „Von dem riegelsdorfer Schieferwerk in Hessen“ (Richelsdorfer Kupferschiefer-Bergbau); „Von dem Steinkohlenbergwerk an den Weissener in Hessen“ (Braunkohlen-Bergbau am Hohen Meißner)]

ODeubel, F. (1936): Neuaufschluß- und Erweiterungsarbeiten im thüringischen Erzbergbau. - Metall u. Erz, 33 (1): 23-25; Halle/Saale

Referat in: N. Jb. Mineral. etc., Referate, 1936 (Bd. II): 720 (Cissarz); Stuttgart [darin: Eisenerze des Schmalkaldener Reviers]

QGötze, Otto (1940): Eisengruben und Eisenhütten im vormaligen Herzogthum Gotha nach dem 30jährigen Krieg bis zur Mitte des 19. Jahrhunderts. - Beitr. Geol. Thür., ㅁ: 132 - 174, mehr. Tab.; Jena

-Grassmann (1886): Das Richelsdorfer Kupfer- und Kobaltwerk in Hessen. - Hierzu die Texttafel p. Z. Berg-, Hütten- u. Salinenwesen, 34: 195-207 (Abb.); Berlin 
Referat in: N. Jb. Mineral. etc, $\underline{1888}$ (Bd. I): 245 (G. Greim); Stuttgart

[Regionalgeologie, Lagerstättengeologie, Bergbaugeschichte, Förderstatistik]

- $\square 0 \bullet$ Héron de Villefosse, Antoine Marie (1810): De la richesse minérale. Considérations sur les mines, usines et salines des différens états, et particulièrement du royaume de Westphalie, pris pour terme de comparaison. - Tome premier - Division économique. - XXVII, 593 p.; (Levrault) Paris - Insgesamt drei Bände u. Atlas-Band in Folio-Format]

[darin : S. 151-169 «Sur les mines et usines de la Hesse (u.a. Richelsdorfer Gebirge, Karlshafen, Meissner, Habichtswald); S. 178-183 Eisenerzbergbau Schmalkaldener Revier ; S. 140-141

Braunkohlebergbau Steinberg b. Münden]

OIsert, F. (1930): Eisen- und Manganerze - Thüringisch-Sächsischer Bezirk. - In: Hülsemann, P.

[Hrsg.](1930): Die Bergwerke Deutschlands - Auf bergwirtschaftlicher und lagerstättenkundlicher Grundlage. - XI, 412 S., zahlr. Abb., Tab. 8 Kt.; hier: S. 194-197; (Enke) Stuttgart

- $\square$ OJordan, Johann Ludwig (1803): Mineralogische, berg- und hüttenmännische Reisebemerkungen vorzüglich in Hessen, Thüringen, am Rheine und im Seyn-Altenkirchner Gebiethe. - 288 S., 4 FaltTaf.; (Dieterich) Göttingen [darin: I Unterwerra-Grauwackengebirge u. Zechsteinmantel; II Bergbau i. Richelsdorfer Gebirge; IIIIII-XVI Regional-Geologie, Bergbau Umgebung Bad Liebenstein - Schmalkalden]

-Lotze, Siegfried (1989): 400 Jahre Eisenerzbergbau am Rande des Reinhardswaldes. - Jahrbuch Lkr. Kassel , 1990: 109 - 116, 5 Abb., 2 Abb. a. Taf.; Kassel

QMeinhold, R. (1980): Steinkohlenbergbau in Thüringen 1946-1949. - Z. geol. Wiss., $\underline{8}(10):$ 1321-1333, 4 Abb.; Berlin [darin: Crock, Ilfeld, Manebach, Ruhla, Tabarz]

-Mötzing, Kurt (1970): Der Alaunbergbau im alten Hessen. - Hessischer Gebirgsbote, 11(4): 78; Melsungen

-Mötzing, Kurt (1975): Die Alaunbergbau-Halde bei Epterode. - Hessischer Gebirgsbote, $\underline{76}(2): 44$ - 45; Melsungen

- $\square$ Namenskürzel [FHS](1955): Berg- und Hüttenwerke in der Landgrafenzeit. - Bergbau i. Hessenland (Ausgabe Braunkohle), (5. Jg.) 1955(12): 4; Kassel [Eisenerzbergwerke; Braunkohle u.a. Meißner)]

-Naumann, Peter (1995): „Kasseler Braun“ und die Farbenfabrik Habich in Veckerhagen. - Geol.mineral. Mitt. a. Nordhessen, $\underline{\mathbf{5}}$; 21 S.; (Selbstverlag Naumann) Hofgeismar

-Naumann, Peter (1997): Ein Schürfversuch auf Galmei bei Breuna/Nordhessen. - Hessischer Gebirgsbote, 98(1): 17; Melsungen

-Naumann, Peter (1997): Der historische Eisenerzbergbau bei Immenhausen. - Hessischer Gebirgsbote, 孚(3): 108 - 109, 1 Abb.; Melsungen

-Rabe (1925): Das Eisenbergwerk bei Gombeth <Schwalm-Eder-Kreis>. - Hessenland, 37(5): 149-151; Kassel

ORußwurm, P. (1914): Der Suhler Eisenerzbergbau. Gründe für seinen Niedergang und Möglichkeiten einer Wiederbelebung. - Z. prakt. Geologie, 22: 273-277, 1 Fig.; Berlin

- QSchäfer, Frank (2004): Eine geologische Betrachtung des spätmittelalterlichen Eisenerzabbaus im nördlichen Habichtswald bei Kassel. - Philippia, 11(3): 167-182, 2 Abb., 3 Tab.; Kassel 
OSchmidt, Ralf (1996): Beitrag zur Geschichte des Kobaltbergbaus von Glücksbrunn bei Schweina/Thür. - Veröff./ Naturhist. Museum Schleusingen, 11: 77-95, 18 Abb.; Schleusingen

OSchmidt, Ralf \& Schulze, Michael u. Sabine (2002): Zur Geschichte des Uranerzbergbaus zwischen Suhl und Schleusingen. - Veröff./ Naturhist. Museum Schleusingen, 17: 3-16, 18 Abb.; Schleusingen

aSeib, Gerhard (1975): Technische Denkmäler in der Bundesrepublik Deutschland. - 24. Richelsdorf Nentershausen - Zechenhaus auf dem „Triesch“ und „Richelsdorfer Hütte“. - In: Slotta, Rainer: Technische Denkmäler in der Bundesrepublik Deutschland. - Veröff. a. d. Dt. Bergbaumuseum Bochum, 7; S. 55-56, 1 Abb.; [Hrsg. Dt. Bergbaumuseum Bochum] Bochum

- Slotta, Rainer (1983): Technische Denkmäler in der Bundesrepublik Deutschland. - Bd. 4: Der Metallerzbergbau. - Veröff. a. d. Bergbaumuseum Bochum, 26; Teil I: XX, 852 S., zahlr. Abb.; Teil II: VII, S. 853-1520, zahlr. Abb.; Bochum

OSteenbuck, Kurt (1995): Silber und Kupfer aus Ilmenau - Ein Bergwerk unter Goethes Leitung. Hintergründe, Erwartungen, Enttäuschungen. - Schriften d. Goethe-Gesellschaft, 65; 358 S-, Ill., graph. Darst., 2 Kt.; (Böhlau) Weimar

- Stüssel, K. (1931): Die Eisenbergwerke bei Hohenkirchen. - Heimatkalender f. d. Kreis Hofgeismar, 1932: 66-67; Kassel

OWagenbreth, Otfried (1991): Geologie, Bergbau, Denkmalpflege. - Z. geol. Wiss., 19 (1): 65-71, 10 Abb.; Berlin

[darin: Relikte Eisenbergbau Schmalkalden]

OZerrenner, Carl (1861): Der Braunstein- oder Manganerz-Bergbau in Deutschland, Frankreich und Spanien. - Ein mongraphischer Versuch für Geologen, Bergleute, Glashüttenbesitzer, Leiter von Chemikalien-Fabriken usw. - IX, 186 S., 2 Falt-Taf.; (J.G. Engelhardt) Freiberg [darin S. 108-169: „Die Braunstein-Bergbaue des Thüringer Waldes“ (Region Schmalkalden, Herzogthum Sachsen-Gotha, Region Gehren]

\subsection{Salinenwesen}

$\square$ Anonym (1874): Der Salinenbetrieb im Preuss. Staate im Jahre 1873. - Z. Berg-, Hütten- u. Salinenwesen, 22: 173-178 (Statistischer Teil); Berlin [darin: „Saline Sooden bei Allendorf im Regierungsbezirk Cassel“]

$\square$ Anonym (1897): <Wirtschaftsbericht über die Braunkohlenwerke Meißner und Habichtswald sowie die Saline Sooden a. W.> - Eschweger Tageblatt u. Kreisblatt, 1897; Nr. 10 v. 13.01.1897; Eschwege

$\square$ Anonym (1940): Straße des Salzes [I-II]. - Eschweger Tageblatt, 1940;

Nr. 271 v. $16 . / 17.11 .1940$

Nr. 277 v. 23./24.11.1940; Eschwege

[Salinengeschichte Saline Sooden/Werra, Geschichte des Salzhandels]

$\square$ Anonym (1941): Lob der Quelle - Gedanken zum Brunnenfest in Bad Sooden-Allendorf. - Eschweger Tageblatt, 1941; Nr. 126 v. 31.05./01.06.1941; Eschwege

[Salinengeschichte Saline Sooden/Werra]

OAnonym (1988): Die Creuzburger Saline. - Das Werraland, 40(4): 60, 1 Abb.; Eschwege

[Nachdruck aus „Wartburgland, Mitteilungen des Heimatkreises Eisenach der

Bundeslandsmannschaften e.V.“, IXX, 1988] 
- $\square$ ○ीApel, Jürgen \& Rüppel, Heidi [Verfass. u. Hrsg.] (2005): Raus in die Natur - Tipps für den Sonntags-Ausflug im Dreiländereck Hessen - Niedersachsen - Thüringen. - 159 S., 111 Fotos, 34 Kt., 1 Zeit-Taf.; (LSRB-Verlag, Landschaftskundlicher-Studien-Reisebuch-Verlag) Witzenhausen [zahlreiche Ausflugsziele, auch zu ehemaligen Salinen - Ziel 60 (Saline Sooden), Ziel 84 (Saline Creuzburg)]

OBernhardi, R. (1847): Über die Ergebnisse zweier Bohr-Versuche auf Steinsalz bei Salzungen (Bericht über die 4. Versamml. d. naturwiss. Vereins f. Thüringen im Mai 1845, S. 8)

Referat in: N. Jb. Mineral. etc., 1847: 364-365; Stuttgart

[Zechsteinstratigraphie, Hydrogeologie, Salinenwesen]

-Borufka, Marc (2006): <Saline Luisenhall, Göttingen> Gewinn in der Nische - Salinenbetreiber Jörg Bethmann ist mit der letzten Pfannensaline Europas profitabel. - Werra-Rundschau, 2006; Nr. 116 v. 19.5.2006, 1 Abb.; Eschwege

$\square$ Brandt, Albert Wilhelm (1961): Die Pfännerschaft Allendorf heute. - Das Werraland, 13(1): 11-12; Eschwege

$\square$ Cramer, H. (1879): M. Johannes Rhenanus, der Pfarrherr und Salzgräfe zu Allendorf a. d. W. - Ein Beitrag zur Bergwerksgeschichte Pommerns aus dem 16. Jahrhunderts. - VI, 41 S.; (Buchhdlg. d. Waisenhauses) Halle (Saale) [darin: Saline Sooden]

$\square$ Eckhardt, Wilhelm A. (2007): Landgraf Philipp von Hessen und das Salzwerk Sooden. - Z. Vereins hess. Gesch. u. Landeskde., 112: 85-112, 2 Abb.; Eschwege

口OEmons, Hans-Heinz \& Walter, Hans-Henning (1986): Die Siedesalzproduktion in Deutschland

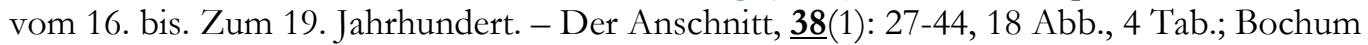
[darin: Salinen Allendorf, Creuzburg, Salzungen]

- $\square$ - Emons, Hans-Heinz \& Walter, Hans-Henning (1988): Alte Salinen in Mitteleuropa - Zur Geschichte der Siedesalzgewinnung vom Mittelalter bis zur Gegenwart. - 1. Aufl.; 279 S., 208 Abb., 6 Kt.; (Dt. Verlag Grundstoffindustrie) Leipzig [darin Hessen: Karlshafen; WMK: Sooden-Allendorf; Thüringen: Salinen Creuzburg, Salzungen, Schmalkalden; Niedersachsen: Göttingen]

$\square$ Engels, Ernst (1880?): Rechtsgeschichte der Saline Sooden bei Allendorf an der Werra. - Z. f. Bergrecht, 21: 179-220; Bonn

OErnst, Werner (1993): Soda aus Buchenau - Das Werraland, 45(1): 32-33, 1 Abb.; Eschwege

$\square$ Erxleben, J. C. P.(1765): Nachricht von einer Reise nach dem Weißner, in Absicht auf die natürliche Geschicht dieses Berges und der um ihn liegenden Gegend. - Hannoverisches Magazin, $1765 \quad(=3$. Jg.)(63): Sp. 993-1007, (64): Sp. 1009-1014; [Auszug in Tourist. Mitt. a. bd. Hessen, $\underline{8}$ : 8-11; Kassel 1899]

[Saline Sooden, Braunkohlenbergbau a. d. Meißner, ausführlich: Alaunherstellung in Großalmerode, Strahlkies v.on Großalmerode; Botanik]

$\square$ Franz, Eckhart G. (1968): Vom Salzwerk zum Solbad - 150 Jahre Solbadeanstalt Sooden-Allendorf. Das Werraland, 20(2): 17-23, 3 Abb.; Eschwege

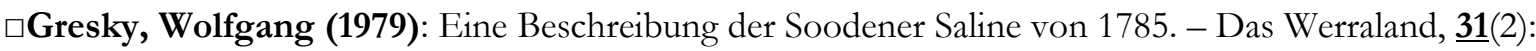
21-22, 1 Abb.; Eschwege

$\square$ Gunkel, Otto (1991): Die Saline Sooden an der Werra in westfälischer Zeit (1806-1813). - Das Werraland, $\underline{43}$ (4): 69-70; Eschwege. 
$\square$ Gunkel, Otto (1992): Die Saline Sooden an der Werra in westfälischer Zeit (1806-1813). - Hessischer Gebirgsbote, $\underline{\text { 93}}(2)$ : 86-87; Melsungen

$\square$ Gunkel, Otto (1998): Obersalzgrebe Jakob Sigismund Reichsfreiherr Waitz von Eschen (1698-1776). Das Werraland, 50 (4): 94; Eschwege

$\square$ Gunkel, Otto (2002): Siedeöfen und -pfannen in der mittelalterlichen Saline Allendorf. - Das Werraland, $\underline{\mathbf{5 3}}$ (3): 68-69; Eschwege

$\square$ Hartung, Silke (1992): Beiträge zur Geschichte der Saline Sooden unter besonderer Berücksichtiung ihrer forstlichen Bedeutung. - Dipl.-Arb. [unveröff.] Univ. Göttingen; 117 S., 3 Abb., 1 Kt., 19 Tab., 2 Graphiken; 11 S. Anh. (Abb., Tab., Kt.)

$\square$ Henkel, Adolf (1908): Die Saline Sooden a. d. Werra unter dem Landgrafen Philipp dem Großmütigen und Wilhelm IV. - Z. hess. Gesch. u. Landeskde., 41: 1-67; Kassel auch als Diss. Marburg 1907; 67 S.

OHornung, V. (1935/1936): Salinen und Solquellen des Werratales im Wandel der Geschichte. - Kali, etc.,

29.1935 (22): 226-228

29.1935(23): 233-238, Abb. 1

29.1935(24): 246-249, Abb. 2,3

30.1936(1): 5-7, Abb. 4-7; Halle (Saale)

[ausschließlich Saline Bad Salzungen]

-Hornung, V. (1944): Reiseberichte des M. Johannes Rhenaus, des Pfarrherrn und Salzgräfen zu Sodden, aus dem 16. Jahrhundert über Salinen und Solquellen damaliger Zeit. - Kali, etc., $\underline{\mathbf{3 8}}$ (7): 127 -130; Halle/Saale

$\square$ Jakob, Bruno (1934): Salzquellen und Salzsud in Hessen. - Hessischer Volkskalender 1935 - $\underline{\mathbf{5 2}}$. Jg. - S. 58-61; (Thiele \& Schwarz) Kassel

[Geschichte der hessischen Salinen - darin ausführlich: Geschichte der Saline Sooden (BSA)]

$\square$ Klepsch, Hugo (1982): Das Salzmuseum in Bad Sooden-Allendorf. - Der Anschnitt, 34(5-6): 240-241; Bochum

[Wenige Sätze zum Museum, ausführliche Salinengeschichte]

$\square$ Klepsch, Hugo (1984): Bad Sooden-Allendorf . Die Entwicklung vom Salinenstädtchen zum SoleHeilbad. - Hesssische Heimat, N.F., 34(2/3): 94-98, Abb. 67-72; Marburg/L.

$\square$ Klepsch, Hugo (2001): 14 Gradierwerke machten Sole stark. Die Bedeutung der Gradierwerke für die ehemalige Saline Sooden und das heutige Bad Sooden-Allendorf. - Das Werraland, 53(4): 83-85, 3 Abb.; Eschwege

$\square$ Klepsch, Hugo (2005): Salz prägte Leben und Arbeit - Ergänzungen zur 600 Jahren alten Söder Marienglocke. - Das Werraland, 57(4): 85-86, 1 Abb.; Bad Sooden-Allendorf [Salinenwesen, Wirtschaftsgeschichte]

$\square$ Koch, Wolfgang (1988): Der „Salzpfarrer“ und Bergmeister Johannes Rhenanus (1528-1589) - ein Gottesmann mit Blick nach vorn. - Der Aufschluss, 39: 39-47, 1 Abb.; Heidelberg

$\square$ Koch, Wolfgang (1988): Nachtrag zum „Salzpfarrer“ Johannes Rhenanus (1528-1589) - ein Gottesmann mit Blick nach vorn. - Der Aufschluss, 29: 186; Heidelberg

$\square$ König, York Egbert \& Kollmann, Karl (1976): Salzsieden wie zu alten Zeiten - Erinnerung an die vor 70 Jahren stillgelegte Saline Sooden. - Das Werraland, 28 (3): 42, 1 Abb.; Eschwege [Brunnenfest Bad Sooden-Allendorf] 
$\square$ Kopp, Ulrich Friedrich (1788): Beytrag zur Geschichte des Salzwerkes in den Soden bey Allendorf an der Werra. - [4] Bl., 152 S.; (Akad. Buchhdlg.) Marburg

OLandeck, Werner u. Anneliese (1999): Creuzburg an der Werra - eine Stadt im hessisch-thüringischen Grenzraum.. - Mein Heimatland, $\underline{\mathbf{3 8}}$ (17): 93-96, 2 Abb. (Teil I); $\underline{\mathbf{3 8}}$ (18): 97 - 98, 2 Abb. (Teil II); Bad Hersfeld

[Teil 2: darin: Kap. „Die Salzgewinnung in Creuzburg“]

-Mozer, Ubbo (1968): Salzgewinnung bei Hersfeld im 15. Jahrhundert.. Salz- und Mineralquellen bestimmen das Bild des Kreises Hersfeld. - Mein Heimatland, 23 (9): 36; Bad Hersfeld

$\square$ Namenskürzel [Lu](1963): Der Rheinlandt aus Milsungen genannt Rhenanus - Meißnerkohle für die Siedepfannen. - Bergbau im Hessenland, 13(4): 12-13, 3 Abb.; Kassel

QNamenskürzel [He](1988): Vom Bergbau im Eichsfeld. - Eichsfelder Heimatstimmen, $\underline{32} .1988$ (4): 156-158, 2 Abb.; Duderstadt [Salinenwesen i. Thür.]

$\square$ Nebe, Kurt (1932): Die Verfassung der Saline Sooden a. d. Werra seit der sog. ewigen Lokation vom 3. Mai 1586 bis zu ihrem 1866 erfolgten Übergang an Preußen. - VI, 150 S. - (Bernecker) Melungen 1932 - Diss. Univ. Göttingen 1933

$\square$ Nietmann, Wilhelm (1950/1951): Die Salzgewinnung in der Königlich Preußischen Saline zu Sooden an der Werra um 1900. - Das Werraland, [= $\underline{\mathbf{2}}(2)]$ Dezember 1950: 22-23; Eschwege 1950; $\underline{\mathbf{3}}$ (1): 9-10; Eschwege 1951

- $\square$ OPerst, Otto [Hrsg.] (1960): Das Werraland in der Beschreibung Niederhessens von Landgraf Hermann zu Hessen-Rotenburg. - Eingeleitet und herausgegeben von... - Reihe: Aus dem Werraland, 7; Separatdruck aus der Zeitschrift „Das Werraland, 12. Jahrgang. 1960, Vierteljahresschrift des Werratalverins e.V., Eschwege. - 35 S.; (Rossbach) Eschwege - auch in: Das Werraland, 12 (3): 38-43, 12(4): 57-61; Eschwege

[darin erwähnt: Erdfälle b. Frauensee, Erdfälle im Amt Sontra, besonders bei Berneburg; der Rote See in Dens; das Kohlenbergwerk auf dem Meissner; die Stinksteinwand; das Salzwerk in Allendorf in den Soden]

-Pflughaupt, Alvin (1863): Analysen der Salzsolen von Lüneburg und Göttingen. - 43 S., Diss. Univ. Göttingen 1863; (Huth) Göttingen

$\square$ Piasecki, Peter (1989): Innovationen im deutschen Salinenwesen im 16. Jahrhundert. - In: Lamschus, Christian [Hrsg.]: Salz- Arbeit und Technik. - Produktion und Distribution in Mittelalter und Früher Neuzeit. - Schriftenrh.: „De Sulte“, 3. - 330 S., zahlr. Abb. u. Tab.; hier S. 163-177, o. Abb.; (Deutsches Salzmuseum) Lünburg 1989

[darin: Kohlefeuerung Saline Sooden b. Allendorf]

ORach, Alfred (1935): Geschichte der Salzunger Saline von ihren Anfängen bis 1934. - 96 S., Ill., 16 Taf.; (Scheermessers) Bad Salzungen

$\square$ Rädlein, Martin Otto Johannes (1931): Von der Saline zum Solbad. - Das Werratal, $\underline{8}(5):$ 66-69, 2 Abb.; Eschwege

$\square$ Reccius, Adolf (1954): Die „Ewige Lokation“ des Salzwerkes zu Sooden. - Das Werraland, $\underline{\mathbf{6}}(1):$ 8-9, 1 Abb.; Eschwege

$\square$ Reccius, Adolf (2004): Vor 50 Jahren. Die „ewige Lokation“ des Salzwerkes zu Sooden. - Ein Aufsatz aus einem alten Werraland Heft [6(1), 1954]. - Das Werraland, $\underline{\mathbf{5 6}}(1)$ : 16-17; Eschwege 
$\square$ Reccius, Adolf (1930): Geschichte der Stadt Allendorf in den Soden. - Beitr. z. Gesch. d. Werralandschaft, $\underline{\mathbf{3}}$; 152 S., Abb., 1 Falt-Plan; (Selbstverlag d. Stadt Bad Sooden-Allendorf, i. Komm. Elwert) Marburg/L. [darin: S. 40-51 Kap.: „Die mittelalterliche Stadt: Pfännerschaft“; S: 90-99 Kap.: „Die neuzeitliche Stadt: Salzwerk und Bad"]

$\square$ Reccius, Adolf \& Schütt, Horst (2000): Geschichte der Stadt Allendorf in den Soden. - Schriftenrh. a. d. Stadtarchiv Bad Sooden-Allendorf, $\underline{\mathbf{5}}$; 2. überarb. u. ergänzte Aufl.; 216 S.; (Kartogr. Kommunale Verlagsges.) 2000 [darin S. 84-91, 3 Abb.: „Salzwerk und Bad“]

○Rein, W. (1862): Alte Bergwerke und Salzquellen. - Z. Vereins f. thür. Geschichte, $\underline{\mathbf{5}}$ : 411; Jena [Urkundliche Erwähnung Saline Wilhelmsglücksbrunn b. Creuzburg a. d. J. 1452, Kupferschieferbergwerke nordwestl. Thüringer Wald]

ORein, W. (1865): Salzquellen. - Z. Vereins f. thür. Geschichte, ㅁ: 375; Jena [Urkundliche Erwähnung der Saline Wilhelmsglücksbrunn b. Creuzburg a. d. J. 1426]

ORuck, Hartmut (1990): Bad Salzungen - Chronik einer thüringischen Stadt. - Mein Heimatland, $\underline{\text { 34}(2): ~}$ 21-24, 3 Abb.; 34(4b): 25-26, 2 Abb.; Bad Hersfeld [darin: Saline, Kali-Bergbau]

OSchmidt, Horst \& Walter, Hans-Henning (1988): Geschichte des Creuzburger Salzwerks. Eisenacher Schriften z. Heimatkunde, 푸; 71 S., 26 Abb.; Eisenach

OSchmidt, H. (1993): Das Creuzburger Salzwerk - Saline Wilhelmsglücksbrunn. - Das Werraland, 45(1): 1-4, 4 Abb.; Eschwege

$\square$ Schütt, Horst (1994): Die Auflösung der Pfännerschaft in Sooden 1905. - Das Werraland, $\underline{46}(2):$ 41; Eschwege

$\square$ Schütt, Horst (1999): Zur Geschichte der Gradierwerke in der Saline Sooden an der Werra. Schriftenreihe a. d. Stadtarchiv Bad Sooden-Allendorf, 1; 19 S., Ill; [Magistrat d. Stadt Bad SoodenAllendorf] 1999

- -Sieburg, Armin (1988): 150 Jahre Solbad Karlshafen. - Die Weser 62(5): 116-117, 2 Abb.; Bremen [darin: Saline Karlshafen]

-Steinert, Arne (1997): Konzepte der Musealisierung von Technik und Arbeit: Museale Erschließung Perspektive für das Industriedenkmal Saline Luisenhall [Göttingen]. - Studien zur Technik-, Wirtschafts- und Sozialgeschichte, 10; 397 S., 74 Abb.; (Lang) Frankfurt/M. u.a. - zgl. Diss. Univ. Göttingen 1996

Referat (Mende) in: Der Anschnitt, 51(2-3): 126-127; Bochum 1999

$\square$ Thölde, Johann (1612): Haliographica - Das ist: gründliche und eigendliche Beschreibung aller Saltzmineralien - Beneben einer historischen Beschreibung aller Saltzwerke. - Reprint der Erstausgabe Leipzig (Apel) von 1612; 336 S., 15 S. Register, 2 Beil. - Mit einem Nachwort von Hans-Henning Walter, 26 S., 4 Abb.; 1 Tab.; (Reprint-Verlag) Leipzig 1992 [darin S. 129-141 „Aldendorff in Hessen“(Bad Sooden-Allendorf), S. 141-145 „Saltzungen“ (Bad Salzungen, S. 176 „Creutzburgk an der Werra“ (Creuzburg)]

$\square$ Wagner, G. (1865): Geschichte der Stadt Allendorf a. d. Werra und der Saline Sooden. - VIII, 171 S.; (Akad. Buchhdlg.) Marburg

OWalch, Ernst Julius \& Hertel, L. (1897/1898/1907): Das Salzunger Salzwerk. - Schriften d. Vereins f. Sachsen-Meiningsche Geschichte u. Landeskunde, $\underline{\mathbf{2 7}}(1897): 16-45 ; \underline{\mathbf{2 8}}(1897): 23-40 ; \underline{\mathbf{2 9}}$ (1898): 71 98; $\underline{\mathbf{5 6}}(1907):$ 1-35; Hildburghausen 
oWalter, Hans-Henning (1986): Geschichte der Salzproduktion in Südthüringen - alte Salinen in Salzungen, Schmalkalden und Lindenau. - Veröff./ Naturhist. Museum Schleusingen, 1: 3-14, 8 Abb., 2 Tab.; Schleusingen

Q $\square$ Walter, Hans-Henning (1988): Siedesalzproduktion aus natürlichen Soolen im 19. Jahrhundert. - Z. geol. Wiss., 16 (1): 77-81, 1 Abb., 3 Tab.; Berlin [darin: [Sooden] Allendorf, Salzungen, Schmalkalden]

$\square$ Walter, Hans Henning (1997): Der Allendorfer Salinist Johannes Rhenanus und seine Salinenreise in Mitteldeutschland im Jahre 1568. - Der Anschnitt, 49 (1-2): 16-22, [9] Abb.; Bochum

$\square$ Weber, Kristin (2006): Der vergessene Alchimist: Johann Thölde de Grevendorv. - Das Werraland, $\underline{\mathbf{5 8}}(1): 1-3,4$ Abb.; Eschwege

$\square$ Weiß, Otto (1851): Die Kurhessische Saline Sooden bei Allendorf an der Werra. - Archiv f. Mineralogie, Geognosie., Bergbau u. Hüttenkunde, 24(2): 332-371; Berlin Referat in: N. Jb. Mineral. etc., 1853: 70; Stuttgart

$\square$ Zeeden, Reinhard (1927): Bad Sooden-Allendorf - Bad Sooden-Werra und Allendorf. Ein Blick in die Entwicklung beider Orte. - Das Werratal, 4(7): 101-103, 1 Abb.; Eschwege [darin: Salinengeschichte]

\subsection{Regionaler Bergbau}

- $\square$ Anonym (1953): Hessens Bodenschätze und Bergleute weithin bekannt. - Bergbau i. Hessenland (Ausgabe Braunkohle), (3. Jg.) 1953(10): 3-4, 1 Abb.; Kassel [darin: Kupferschiefer, Schwerspat Richelsdorfer Gebirge, Unterwerrra; Wilhelm Ludwig von Eschwege]

- $\square$ Anonym (1953): Mineralgewinnung im Hessenland. - Bergbau i. Hessenland (Ausgabe Braunkohle), (3. Jg.) $\underline{1953}(16):$ 4, 4 Abb.; Kassel

- $\square$ Anonym [1966]: Die bergbaulichen Vorkommen in Nordhessen: Der sonstige Bergbau. - In: Harnisch, W.; Hasemann, H. \& Hoffmann, E. [Bearb.]: Geschichte des bergbaulichen Vereins Kassel. - 176 S., Abb., statist. Tab.; hier: S. 75-82, 2 Abb.; [Hrsg. Bergbauverein Hessen e.V.] Kassel [1966] [Kali, Salz, Ton, Schwerspat, Quarzit, Schiefer]

D $\square$ Anonym [1966]: Einzelangaben über den Bergbau in Nordhessen und seine Bergwerke. - In: Harnisch, W.; Hasemann, H. \& Hoffmann, E. [Bearb.]: Geschichte des bergbaulichen Vereins Kassel. - 176 S., Abb., statist. Tab.; hier: S. 85-113, graph. Darst., statist. Tab.; [Hrsg. Bergbauverein Hessen e.V.] Kassel [1966]

OAnonym (1999): Glück auf in Thüringen - Bergbau und Bergleute im Thüringer Wald. - 118 S., Abb.; (Thon) Schwerin

$\square$ Baier, Hans-Rudolf (1968): Der Bergbau im Gebiet des Meißners. - Bad Sooden-Allendorf, handschriftl. Jahresarbeit d. Gymnasiums Bad Sooden-Allendorf 1968; 86 S., 20 Abb.; Eschwege [Vorlage nicht eingesehen, zitiert nach OPPITZ 1991]

OBauer, Eberhard (2000): Bergbautradition im Wandel der gesellschaftlichen Sphäre. - Ihre Pflege aus der Sicht der Thüringer Bergmannsvereine. - Der Anschnitt, $\underline{\mathbf{2}}$ (2-3): 90-95, 5 Abb.; Bochum [darin Bergmannsvereine aus Westthüringen] 
OBemmann, Rudolf (1911): Der Bergbau im Mühlhäuser Gebiete. - Mühlhäuser Geschichtsblätter - Z. d. Altertumsvereins f. Mühlhausen i. Thür. u. Umgegend, 12 (f. 1911-1912): 45-46; Mühlhausen [Geschichte des Bergbaus in Schriften u. Urkunden]

- $\square$ Bergmann, Waltari; Schad, Ernst \& Tunger, Horst (1969): Hessen - unser Heimatland. - 6., durchges. Auflage, zahlr. Abb.; (Verlag Moritz Diesterweg) Frankfurt a. M. u.a.

[Schulbuch für den Heimatkunde-Unterricht 4. Klasse;

darin S. 13-16 Thema: „Bodenfunde und Gesteine unserer Heimat“ (u.a. „Von Spangensteinen, Fischaugen und Bonifatiuspfenningen“ - „Mammut und Wollnashorn am Schmisssing bei Altmorschen“"

darin S. 101-116: „Reich ist das Land an Bodenschätzen“ (Lagerstätten, Bergbau]

-Brandt, Herbert [1993]: Glashütten - und Bergarbeiterdorf Wickenrode bis zum Ende des 19. Jahrhunderts. - 289 S., Abb.; [Hrsg. Gemeinde Helsa] [darin S. 172-182, 2 Abb.: „Alaun-, Kohle- und Silberbergwerk“ - S. 201-202: „Eisenhutüten, Lehmgruben, Steinbrüche"]

- $\square$ Q Braun (1934): Die Wirtschaft an der Oberweser, Werra und Fulda und ihre Bedeutung und Aufgaben im Dritten Reich. - Die Weser, 13 (12): 162-164, 3 Abb.; Bremen [u.a. Bergwirtschaft]

- $\square$ Braun (Berg-Direktor) (1978): Der Bergbau in Nordhessen einst und jetzt. - Hessischer Gebirgsbote, 79(4): 135, 2 Abb.; Melsungen

$\square$ Brehm, Helene (1992): Vom Wissener und Höllental. - In: Gier, Karl [Hrsg.]: Helene Brehm Geschichten und Gedichte. - Gesammelt und zusammengestellt von Karl Gier. - Nebentitel: Heimatklänge aus dem Meißnerland. - 250 S.; hier S. 30-35; (Eigenverlag Karl Gier) MeißnerAlberode 1992

[Geologie, Bergbau, Flora]

- $\square$ Cancrinus, Franz Ludwig (1767): Beschreibung der vorzüglichsten Bergwerke in Hessen, in dem Waldeckischen, an dem Haarz, in dem Mansfeldischen, in Chursachsen, und in dem Saalfeldischen. [8] Bl., 429, [1] S.; 1 Abb., 11 Falt-Taf.; (Andreä) Frankfurt/M.

[darin: Eisenbergwerk Hohenkirchen b. Kassel, Hüttenwerke Veckerhagen, Karlshafener Blaufarbenwerke, Eisenbergwerk b. Homberg, „Von dem riegelsdorfer Schieferwerk in Hessen“ (Richelsdorfer Kupferschiefer-Bergbau); „Von dem Steinkohlenbergwerk an den Weissener in Hessen“ (Braunkohlen-Bergbau am Hohen Meißner)]

-Cannon, Ralph (1986): Bergbau und Mineralien des Richelsdorfer Gebirges. - Rückblick, 2.1986: 6971; Hofgeismar

QCrome, August F. W. (1827): Geographische-statistische Darstellung der Staatskräfte, von den sämtliche, zum deutschen Staatenbunde gehörigen, Ländern..... - III. Theil, 270 S.; (Fleischer) Leipzig

darin S. 52-94: Großherzogthum Sachsen-Weimar-Eisenach; S. 67 Kurzdarstellung der Bergwirtschaft]

OCrome, August F. W. (1827): Geographische-statistische Darstellung der Staatskräfte, von den sämtliche, zum deutschen Staatenbunde gehörigen, Ländern..... - IV. u. letzter Theil; (Fleischer) Leipzig

[darin S. 28-55 Gotha, S. 39-40 Bergwirtschaft; S. 73-146 Sachsen-Meiningen, S. 91-94 Bergwirtschaft, Mineralquellen, Solequellen]

-ODeubel, F. (1938): Neuaufschlüsse im thüringischen Bergbau. - Beitr. Geol. Thür., ㅁ: 57-62; Berlin Referat in: N. Jb. Mineral. etc., Referate, 1940 (Bd. III): 14-15 (Walther Fischer); Stuttgart 
[Westthüringen, Richelsdorfer Gebirge]

-Deist, Adam (1939): Der Bergbau im Richelsdorfer Gebirge und seine geographischen Wirkungen. Geographischer Anzeiger, 40 (14): 316-323, 342-344, 1 Abb. i. T., 10 Abb. a. Taf. 37, 38; Gotha

- $\square$ ODienemann, W. \& Burre, O. [Bearb.](1928): Die nutzbaren Gesteine Deutschlands und ihre Lagerstätten mit Ausnahme der Kohlen, Erze und Salze. - I. Bd.: Kaolin, Ton, Sand, Kies, Wiesenkalk, Kieselgur. - XII, 418 S., 58 Abb., 38 Tab.; (Enke) Stuttgart

Referat in: Zbl. Mineral. etc., Abt. B, 1929: 32; Stuttgart

[u.a. Ton-Abbau Großalmerode]

- $\square$ ODienemann, W. \& Burre, O. [Bearb.](1929): Die nutzbaren Gesteine Deutschlands und ihre Lagerstätten mit Ausnahme der Kohlen, Erze und Salze. - II. Bd.: Feste Gesteine - XIV, 485 S., 45 Abb., 20 Tab; (Enke) Stuttgart

$\square$ Ebel, Willi (1969): Jubiläums-Festschrift zur 860-Jahrfeier der Gemeinde Rommerode vom 20. Juni bis 23. Juni 1969. - 50 S., zahlr. Abb. + Anzeigenteil; [Hrsg. Gemeindevorstand Rommerode] Rommerode [darin S. 12-27, 7 Abb.: „Das Leben in Rommerode im Laufe der Jahrhunderte. - 1. Wie die Bewohner ihren Lebensunterhalt verdienten“ - (Glasherstellung, Alaunherstellung, BraunkohlenBergbau, Tonverarbeitende Industrie)]

- $\square$ Einecke, E.-J. [Red.] (1995): Bergbehörden und Bergbau in Hessen. - 129 S., Abb., Kt.; [Hrsg.Oberbergamt Hessen] (Länderdienst-Verlag) München

QFreyberg, Bruno von (1923): Erz- und Minerallagerstätten des Thüringer Waldes. - 198 S., Abb., Kt.; (Bornträger) Berlin

OFulda, R. (1881): Ueber den Schmalkalder Bergbau. [Vortragstext] - Ber. d. Vereins f. Naturkunde z. Cassel, 28: 113 - 126. 3 Taf.; Kassel

QGläser, Friedrich Gottlob (1775): Versuch einer mineralogischen Beschreibung der gefürsteten Grafschaft Henneberg chursächsischen Anteils - nebst einer kurzen Geschichte des ehemaligen und ietzigen Bergbaues derselben. - 106 S.; (Crusius) Leipzig

- $\square$ Grotefend, W. (1897): Die hessischen Landgrafen und die Berg- und Hüttenwerke. - Hessenland - Z. f. hess. Geschichte u. Literatur, 11(1): 3-5, (2): 18-19; (3): 30-31; Kassel

- $\square$ Harnisch, W. (1964): Geschichte des nordhessischen Bergbaus. - Bergbau im Hessenland, 14(4): 1011, 2 Abb.; Kassel

-Harnisch, W.; Hasemann, H. \& Hoffmann, E. (1966): Geschichte des Bergbaulichen Vereins Kassel. - 175 S., Abb.; (Bergbauverein Hessen e.V.) Kassel

- $\square$ Henn, Ernst (1968): Der Bergbau in der Gemarkung Sontra. - Beiträge zur Geschichte der Stadt Sontra, 1: 19-23; Sontra

OHepke (1906): Bergbau auf dem Eichsfelde. - Unser Eichsfeld, 11(10): 176; Heiligenstadt

- $\square$ • Héron de Villefosse, Antoine Marie (1810): De la richesse minérale. Considérations sur les mines, usines et salines des différens états, et particulièrement du royaume de Westphalie, pris pour terme de comparaison. - Tome premier - Division économique. - XXVII, 593 p.; (Levrault) Paris - [Insgesamt drei Bände u. Atlas-Band in Folio-Format]

[darin : S. 151-169 «Sur les mines et usines de la Hesse (u.a. Richelsdorfer Gebirge, Karlshafen, Meissner, Habichtswald ; S. 178-183 Eisenerzbergbau Schmalkaldener Revier ; S. 140-141

Braunkohlebergbau Steinberg b. Münden] 
-Hülsemann, P. [Hrsg.](1930): Die Bergwerke Deutschlands - Auf bergwirtschaftlicher und lagerstättenkundlicher Grundlage. - XI, 412 S., zahlr. Abb., Tab. 8 Kt.; (Enke) Stuttgart

- $\square$ Illner (Bergmeister)(1897): Der Bergbau in Hessen. - In: Lange, Wilhelm Chr. [Red.]: Festschrift zur 38. Hauptversammlung d. Vereins Deutscher Ingenieure - Gewidmet vom Hessischen Bezirksverein; 176 S:, Abb.; hier S. 87-103; (Weber \& Weidemeyer) Kassel 1897 [Gesamtdarstellung Bergbau Regierungsbezirk Kassel]

$\square$ Jacobshagen, V.; Kuhnert, Christian \& Wycisk, Peter (1989): Geologie des Hohen Meißners in Nordhessen. - In: Jacobshagen, Volker \& Kuhnert, Christian [Hrsg.]: Der Hohe Meißner in Hessen - Ergebnisse geologischer und geomorphologischer Forschungen. - Berliner geowiss. Abh., Reihe A, 114; S. 9-76, 8 Abb., 5 Tab., 2 Beil.; (Selbstverlag Fachber. Geowiss. FU Berlin) Berlin 1989 [darin Kap.: „Geschichte des Bergbaus und der geologischen Erforschung“]

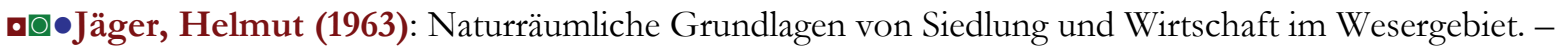

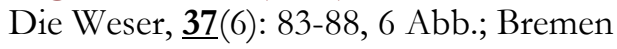
[Geographie, Regionale Geologie, Bergwirtschaft Hessen, Thüringen, Niedersachsen]

- $\square$ OJordan, Johann Ludwig (1803): Mineralogische, berg- und hüttenmännische Reisebemerkungen vorzüglich in Hessen, Thüringen, am Rheine und im Seyn-Altenkirchner Gebiethe. - 288 S., 1 Tab., 3 Falt-Taf.; (Dieterich) Göttingen [Regionalgeologie östl. Meißnervorland, „Riegelsdorfer“ [Richelsdorfer] Gebirge, Region um Schmalkalden]

- $\square$ Kaerger, Günther (1980): Die Steinberge bei Münden. - Kaufunger Wald, H. 11: 3; Kaufungen [Bergbau: Sand, Ton, Braunkohle, Basalt]

$\square$ Krück, Karl (1983): Großalmerode - Vom Zunftort der Waldgläsner zur Stadt des Tons und der Kohle. - In: Hildebrand, Erich [Gesamtkonzeption, Red.]: Land an Werra und Meißner - Ein Heimatbuch.. - [1. Auflage]; S. 277-283, 6 Abb..; [Hrsg.: Hist. Ges. Werralandes](Bing) Korbach [darin: Glasherstellung, Feuerfestindustrie, regionaler Bergbau (Braunkohle, Basalt, Ton)]

$\square$ Krück, Karl (1990): Großalmerode - Vom Zunftort der Waldgläsner zur Stadt des Tons und der Kohle. $\square$ Hildebrand, Erich [Gesamtkonzeption, Red.]): Land an Werra und Meißner - Ein Heimatbuch.. - 3., überarb. Auflage; S. 288-294, 6 Abb.; (Bing) Korbach 1990

-Landau, Georg (1867): Beschreibung des Kurfürstenthums Hessen. - 2. Aufl.; X, 649 S., 2; (J. Georg Luckhardt) Kassel

[darin: Überblick über die Regionalgeologie, Bodenschätze]

OMartens, Thomas (1990): Verborgene Schätze. - In: Zimmermann, Wolfgang [Hrsg.]: Thüringer Wald - Kleiner Naturführer. - Abh. u. Ber. Museums Natur Gotha, (9) 2000; 5., erw. Nachaufl., 94,2 S.; 35 Abb., 1 Kt.; hier: S. 14-19, Abb. 4, [1 Tab.]; Gotha 1990 [Bodenschätze, Bergbau (-Geschichte)]

-Möller, Hans-Karl (1993): Auf den Spuren des Bergbaus in und um Cornberg. - In: Hersfeld-

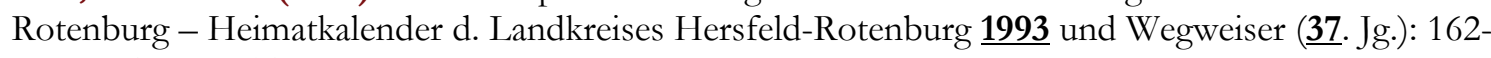
166; Bad Hersfeld

QMüller, Gerhard \& Römer, Gunter (2002): Alter Bergbau und Hüttenwesen im Eichsfeld - Die historische Bedeutung der Harzer Montanindustrie für die wirtschaftliche Entwicklung des Eichsfeldes. - Eichsfeld-Jahrbuch, 10 : 61-88, 18 Abb.; Duderstadt

$\square$ Namenskürzel (-e./FVV) (1973): Die Stadt des guten Tons - Großalmerode hat es „,in sich“. Hessischer Gebirgsbote, 74(3): 62; Melsungen [Bergwirtschaft, Tonindustrie] 
$\square$ Namenskürzel (Hkr) (1948): <Großalmerode> Eine Stadt lebt von Ton und Kohle. - WerraRundschau, 1948; Nr. 4. v. 24.1.1948; Eschwege

$\square$ Nobel, Hermann (2007): Chronik Epterode - Von Euerharderot zu Epterode - 825 Jahre Epterode. Mit Beiträgen von Stefan Bauer, Erich Hofsommer, Dr. Friedhelm Koch, Dr. Karl Kollmann \& Werner Sippel. - Herausgegeben vom Magistrat der Stadt Großalmerode anläßlich der 825-Jahr-Feier. - 453 S., zahlr. Abb. u. Tab.; (Magistrat d. Stadt Großalmerode) Großalmerode [darin: Bergwirtschaft, Geologie u. Paläontologie der Gemarkung, Geologie u. Mineralogie d. Bühlchens]

$\square$ Peitz, Christina (2008): < Hessisch Lichtenau - Firmenportrait Bohrfirma Anger's und Söhne> 6000 Meter unter die Erde - Traditionsunternehmen H. Anger's Söhne ist auf Tiefbohrungen spezialisiert. - Werra-Rundschau, 2008; Nr. 138 v. 16.06.2008; 1 Abb.; Eschwege

ORegel, Fritz (1896): Thüringen - Ein geographisches Handbuch. Dritter Teil: Kulturgeographie. - 1. Die Bodenbenutzung 2. Die Förderung der nutzbaren Mineralien und Gesteine 3. Gewerbe und Industrie 4. Handel und Verkehr 5. Bevölkerungsverteilung und Siedlungsverhältnisse 6. Geistige Kultur und staatliche Einrichtungen. . - XVI, 490 S.; (Gustav Fischer) Jena

[S. 97-145 „Zweiter Abschnitt: Die Förderung der nutzbaren Gesteine und Mineralien]

-ORiess, Johann Philipp (1791): Mineralogische und bergmännische Beobachtungen über eine Hessische Gebirgsgegenden. - XIV, 102 S., 6 Taf.; (Rottmann) Berlin [darin: S. 28-54 Kupferschiefer- u. Kobalt-Bergbau Richelsdorfer Gebirge; S. 54-59 Kupferschiefer- u. Kobalt-Bergbau Glücksbrunn b. Bad Liebenstein; S. 69-84 („Steinkohlen“-) Braunkohlenbergbau u. Tertiär-Stratigaphie am Meissner; S. 84-89 Alaun- und (,Steinkohlen“) Braunkohlen-Bergbau Oberkaufungen]

$\square$ Schuchardt, J. (1927): Die Industrie von Großalmerode. - Hessischer Gebirgsbote, $\underline{\mathbf{3 3}}(6): 51$ - 52; Kassel [darin: Montanindustrie, Bergbau]

OSchumacher, Ralf (1991): Der historische Bergbau um Ruhla - Geologie, Bergbaugeschichte und Fossilien. - Der Aufschluss, 42: 225-229, 3 Abb.; Heidelberg

-Slotta, Rainer (1975): Technische Denkmäler in der Bundesrepublik Deutschland. - Veröff. a. d. Dt. Bergbaumuseum Bochum, 푸 648 S., zahlr. Abb.; [Hrsg. Dt. Bergbaumuseum Bochum] Bochum

OStier, Alfred (1922): Wirtschaftsgeschichte von Friedrichroda vom 17. - 19. Jahrhundert. - Diss. Univ. Jena 1922; 149 S.

[darin: Kap. 3: Bergbau"]

-Straube, Heinz (1971): Vom Bergbau im Richelsdorfer Gebirge. - In: Herzog, Friedrich [Red.]: Der Kreis Rotenburg in Nordhessen. - 243 S., zahlr. Abb.; hier: S. 127-134, Abb. 62-65; [Hrsg. Landrat Otto-Ulrich Bährens u. Dr. Konrad Theiss] (Theiss) Stuttgart-Aalen 1971 [Kupferschiefer, Schwerspat, Kobalt]

$\square$ Strippelmann, F. E. (1837): Bergbau am Hirschberg bei Großalmerode. - Notizenblatt Göttingischen Vereins bergmännischer Freunde, $\underline{3}$ : 1-2; Göttingen [Vorlage nicht eingesehen, zitiert nach Oppitz (1991)]

$\square$ Weiss, Otto (1864): Ueber die geognostischen Verhältnissse sowie die nutzbaren Mineralien und Gesteine in der Umgebung der Saline Soden bei Allendorf an der Werra. - Ber. Vereins Naturkde. z. Cassel, $\underline{14}$ (1862/1863, 1863/1864): 45-62; Kassel

- $\square$ Wigand (Bergrat)(1908): Meine Ausbildung als kurhessischer Bergwerksbeflissener in 1846/47. Hessenland, 22(21): 301-303, 22(22): 319-321; Kassel 
[Darin: Bergreviere Richelsdorfer Gebirge u. Meißner, Hirschberg b. Großalmerode, Faulbach, Saline Sooden a.d. Werra]

- $\square$ Wigand (1909): Kurhessens Bergbau zur Zeit der Einverleibung in das Königreiche Preußen. Hessenland, 23 (21): 303-305; Kassel

- $\square$ Wigand, Karl (1956): Chronik des hessischen Bergbaus. - 146 S., graph. Darst., Kt.; (Bergbaulicher Verein) Kassel

[u.a. Geschichte u. Jahreschronik Bergbau auf Braunkohle, Ton, Kupferschiefer, Schwerspat im Werra-Meißner-Kreis]

- $\square$ Wittich, E. (1905): Das Bergwesen in Hessen unter der Regierung Phillips des Großmütigen. Z. Berg-

, Hütten- u. Salinenwesen, 53: 556-559; Berlin

[Gesamtdarstellung, Urkunden zum Bergrechte der Zeit (Bergordnungen)]

- $\square$ Zeiller, Martin (1655): Martin Zeillers Topographia Hassiae, Et Regionum Vicinarum - Das ist, Beschreibung und eygentliche Abbildung der vornehmsten Stätte und Plätze in Hessen und denen benachbarten Landschafften, als Buchen, Wetterau, Westerwald, Löhngau, Nassau, Solms/ Hanau, Wigenstein und andern. - In dieser andern Edition mit sondern Fleiß durchgesehen/ von vorigen Fehlern corrigirt, gebessert und vermehret. - [1] Bl., 151, [9] S. mit 62 Kupferstichen und einem Titelkupfer [des Kupferstechers Matthaeus Merian < des Älteren>]; (Zum Truck verlegt von denen Merianischen Erben) Franckfurt am Mayn

[Es existiert eine weiter Auflage von 1655, die im Karlsruher Virtuellen Katalog als 2. Auflage des Jahres bezeichnet wird]

[darin werden in beiden Ausgaben erwähnt: Salinenbetrieb bei Allendorf; der unterirdische Braunkohlenbrand auf dem Meißner (,Stinksteinwand“); Kupferbergbau im Werra-Meißnr-Kreis: Grube Gustav/Höllental u. Sontra; Historischer Bergsturz an der Plesse bei Wanfried am 24. Januar 1640; „Steinkohlen“-Bergbau Habichtswald/Kassel, Alaun- u. „Steinkohlen“-Bergbau am Hirschberg b. Großalmerode]

\subsection{Bergaufsicht - Bergrecht - Salinenrechte}

\section{Bergaufsicht}

- $\square$ Anonym (1852): Kurfürstlich Hessischer Bergwerks-Staat. - Berg- u. hüttenmännische Ztg., 1 (36): Sp. 699-701; Nordhausen-Leipzig

[Organisation der kurhessischen Bergbehörden]

- $\square$ (• Anonym (1891): Die Begrenzung der einzelnen Bergreviere des Preussischen Staates. - Z. Berg-, Hütten- u. Salinenwesen, $\underline{\text { 39: }}$ 85-93 (Abh.); Berlin

[darin: Oberbergamtsbezirk Clausthal mit den Bergrevieren Hannover, Schmalkalden, Cassel]

- 0 Q $\bullet$ Fürer, Gotthard (1983): Das Amtshaus zu Clausthal - Baugeschichte und Entwicklung des Oberbergamtes in Clausthal-Zellerfeld. - Der Anschnitt, 35(1): 22-36, 18 Abb.; Bochum

[Das Oberbergamt als Oberbehörde der Bergämter Kassel, Schmalkalden, Goslar]

\section{Bergrecht}

- $\square$ Strube, Hans (1976): Die Berggerichtsbarkeit in der Landgrafschaft Hessen von den Anfängen bis zur Bergordnung Landgraf Moritz 1616. - Z. Vereins hess. Gesch. u. Landeskde., $\underline{85}$ (f. 1975): 125-133; 
Kassel

[darin: Revier Bilstein, Nentershausen]

- $\square$ Gromes, Ilse (1968): Bergwerksordnung 1499 [Sontra]. - Beiträge zur Geschichte der Stadt Sontra, $\underline{1}$ : 1-18; [Hrsg. Magistrat Stadt Sontra] Sontra 1968

- $\square$ Gunkel, Otto (1990): Hessisches Bergrecht in sechs Jahrhunderten. - Das Werraland, 42 (2): 31-32; auch: Hessischer Gebirgsbote, 91(3): 95; Melsungen

- $\square$ Henn, Ernst (1999): Bergwerksordnung zu Sontra - Umsetzung in heutigen Sprachgebrauch. - In: Kollmann, Karl [Schriftltg.]: 500 Jahre Bergwerksordnung zu Sontra - 1499-1999. - Beiträge zur Geschichte der Stadt Sontra, 10: 41-50; [Hrsg. Magistrat der Stadt Sontra] Sontra 1999

- $\square$ Hess. Landesverband des Bundes Deutscher Hütten- u. Knappenvereine e.V. [Hrsg.]: Bergwerksordnung zu Sontra 1499 - Bergkwergksordenunge zcu Sonntra 1499. - 39 S., Abb.; o.O., o.J

\section{$\underline{\text { Rechtsgeschichte der Salinen }}$}

$\underline{\text { Saline Sooden }}$

$\square$ Engels, Ernst (1880?): Rechtsgeschichte der Saline Sooden bei Allendorf an der Werra. - Z. f. Bergrecht, 21: 179-220; Bonn

$\square$ Nebe, Kurt (1932/33): Die Verfassung der Saline Sooden a. d. Werra seit der sog. ewigen Lokation vom 3. Mai 1586 bis zu ihrem 1866 erfolgten Übergang an Preußen. - VI, 150 S. - (Bernecker) Melungen 1932 - Diss. Univ. Göttingen 1933

$\square$ Reccius, Adolf (1954): Die „Ewige Lokation“ des Salzwerkes zu Sooden. - Das Werraland, $\underline{\mathbf{6}}(1):$ 8-9, 1 Abb.; Eschwege

$\square$ Reccius, Adolf (2004): Vor 50 Jahren. Die „ewige Lokation“ des Salzwerkes zu Sooden. - Ein Aufsatz aus einem alten Werraland Heft [Heft 6(1), 1954]. - Das Werraland, $\underline{\mathbf{6}}$ (1): 16-17; Eschwege

$\square$ Schütt, Horst (1994): Die Auflösung der Pfännerschaft in Sooden 1905. - Das Werraland, 466(2): 41; Eschwege

$\underline{\text { Wilhelmsglücksbrunn }}$

ORein, W. (1862): Alte Bergwerke und Salzquellen. - Z. Vereins f. Thür. Geschichte, ㅁ: 411; Jena [Urkundliche Erwähnung Saline Wilhelmsglücksbrunn b. Creuzburg a. d. J. 1452, Kupferschieferbergwerke nordwestl. Thüringer Wald]

QRein, W. (1865): Salzquellen. - Z. Vereins f. Thür. Geschichte, ㅁ: 375; Jena

[Urkundliche Erwähnung der Saline Wilhelmsglücksbrunn b. Creuzburg a. d. J. 1426] 


\section{Geologie, Bergbau und Interessenkonflikte, Renaturierung, Naturschutz}

\subsection{Bergbau im Habichtswald (Stadt, Lkr. Kassel)}

\section{$\underline{\text { Braunkohle }}$}

-Namenskürzel (dpa) (1965): Gegen Braunkohlenabbau im Habichtswald - Untersuchungsbohrungen beantragt / Einspruch des Kasseler Magistrats. - Werra-Rundschau, 1965; Nr. 154 v. 7.7.1965, S. 4; Eschwege

-Namenskürzel (red)(1965): Erholung wichtiger als Kohle, darum: „Hände weg vom Habichtswald“. Braunkohlenvorräte am Herkules sind für die Volkswirtschaft unerheblich. - HA, 1965; Nr. 157 v. 10.7.1965, 3 Abb.; Kassel

-Namenskürzel (t)(1965): Habichtswald muss Erholungsgebiet bleiben: Stadt wehrt sich gegen Braunkohlen-Abbau/... - HA, 1965; Nr. 153 v. 6.7.1965, 1 Abb.; Kassel

-Namenskürzel (o)(1965): Braunkohlenwerke: Wir wollen keinen Ärger - Enstscheidung über Tageoder Tiefbau noch nicht gefallen - Abgrenzung der Interessen möglich. - HA, 1965; Nr. 155 v. 8.7.1965; Kassel

[Braunkohle im Habichtswald]

-Namenskürzel (1)(1966): Dem Habichtswald droht neue Gefahr: Kohleflöze sollen freigelegt werden Hessische Braukohlenwerke haben Schürfgenehmigung beantragt. - HA, 1966; Nr. 24 v. 29.1.1966; Kassel

هNamenskürzel (ml)(1966): Kassel kämpft um seinen Habichtswald - Regierungspräsident: Zu energischen Schritten entschlossen. - HA, 1966; Nr. 30 v. 5.2.2.1966; Kassel

[Lagerstättenuntersuchungen Braunkohle im Habichtswald]

-Namenskürzel (eg)(1966): Wiesbaden bleibt dabei: Kein Tagebau im Habichtswald - Aber Probebohrungen gehen trotzdem weiter. - HA, 1966; Nr. 35 v. 11.2.1966; Kassel [Lagerstättenuntersuchungen Braunkohle im Habichtswald]

-Namenskürzel (o)(1966): Rettung für den Habichtswald in Sicht - HBZ will die Entscheidung der hessischen Landesregierung respektieren - Nordhessens Braunkohlenzechen und Kasseler Kraftwerke nicht in Gefahr. - HA, 1966; Nr. 36 v. 12.2.1966; Kassel

[Geplanter Braunkohlenabbau Habichtswald/Kassel]

-Namenskürzel (ml)(1966): .../Im Habichtswald wird es keinen Tagebau geben - HBZ: Antrag auf Zulassung aussichtslos. - HA, 1966; Nr. 112 v. 14.5.1966, 1 Abb.; Kassel

[Geplanter Braunkohlen-Tagebau im Habichtswald/Kassel]

-Namenskürzel (t/th)(1971): Kein Bergbau im Habichtswald - Braunkohlenwerke und Land Hessen schlossen Vergleich. - HA, 1971; Nr. 105 v. 7.5.1971; Kassel 


\section{$\underline{\text { Basalt }}$}

-Huhn, Karl-Hermann (1988): Wald soll Basaltbruch weichen. - HNA, 1988; Nr. 45 v. 6.11.1988; Kassel

[Basaltabbau Habichtswald]

-Huhn, Karl-Hermann (1988): Breiter Protest gegen Pläne des Steinbruch-Unternehmen: Wald soll Basaltbruch weichen. - HNA (Sontagszeit), 1988; Nr. 45 v. 6.11.1988, 1 Abb.; Kassel [Basaltabbau Habichtswald]

-Namenskürzel (s)(1975): Am Brandkopf im Habichtswald: Basaltabbau geht weiter - Freigegebene Fläche reicht noch für sechs Jahre. - HA, 1975; Nr. 84 v. 11.4.1975; Kassel

-Namenskürzel (h)(1977): Unweit vom Silbersee: Neuer Basaltbruch im Habichtswald? - Mit vier Probebohrungen begonnen. - HA, 1977; Nr. 81 v. 6.4.1977, 3 Abb.; Kassel

-Namenskürzel (m.s.)(1978): Weiteren Basaltabau stoppen! - Im Habichtswald - Strikte Ablehnung der Kasseler Naturschutzstelle. - HA, 1978; Nr. 135 v. 14.6.1978

-Namenskürzel (h)(1979): Naturschützer stoppen weiteren Basalt-Abbau - Über 10 Hektar Naturpark gefährdet. - HA, 1979; Nr. 17 v. 20.1.1979; Kassel

[,Silbersee“ i. Habichtswald/Kassel]

-Namenskürzel (h)(1979): Gegen Abbaupläne im Habichtswald und am Meißner - MdL Schmidt: Erholungsraum sichern. - HA, 1979; Nr. 30 v. 5.2.1979; Kassel

[Basalt im Habichtswald, Braunkohle auf dem Hohen Meißner]

-Namenskürzel (f)(1979): Ja zum Basaltabbau innerhalb der Habichtswalder Gemarkung/.... - HA, $\underline{1979}$; Nr. 53 v. 3.3.1979; Kassel

-Namenskürzel (h/m.s.)(1979): Minister will Basaltabbau noch einmal überdenken - Pro und Kontra bei Ortstermin. - HA, 1979; Nr. 75 v. 29.3.1979, 3 Abb.; Kassel

[,Silbersee“" Habichtswald/Kassel]

-Namenskürzel (d)(1979): Kabinett soll über Basaltabbau entscheiden - Kreisausschuß schaltet wegen Entwicklung am Silbersee Ministerpräsident Börner ein. - HA, 1979; Nr. 87 v. 12.4.1979; Kassel [,Silbersee“ Habichtswald/Kassel]

-Namenskürzel (h/d)(1979): Basaltabbau: Nun soll Ministerpräsident ran - Kreis zieht gegen GörlachErlaß zu Felde. - HA, 1979; Nr. 88 v. 14.4.1979; Kassel

[,Silbersee“" Habichtswald/Kassel]

-Namenskürzel (h)(1980): Schutzgemeinschaft ist besorgt - Gegen Fortsetzung des Basaltabbaus im Habichtswald. - HA, 1980; Nr. 22 v. 26.1.1980; Kassel

-Namenskürzel (h)(1980): Scharfer Protest gegen Ausdehnung des Basaltbruchs - Schutzgemeinschaft: Ein Spiel hinter den Kulissen. - HA, 1980; Nr. 23 v. 28.1.1980; Kassel [Basaltabbau Habichtswald]

-Namenskürzel (h)(1980): Basaltbruch Menke weiter im Streit der Meinungen - CDU-Vorstoß im Landtag - Protest der Naturfreunde. - HA, 1980; Nr. 27 v. 1.2.1980; Kassel [Basaltabbau Habichtswald]

-Namenskürzel (h)(1980): „Eindeutig gegen gültiges Recht““ - Neuer Protest gegen Basaltabbau im Habichtswald. - HA, 1980; Nr. 57 v. 7.3.1980; Kassel 
-Namenskürzel (h)(1988): Basalt-Bruch am Druseltal plant Erweiterung: „Ausverkauf der Landschaft“. - HNA, 1988; Nr. 30 v. 5.2.1988, 1 Abb.; Kassel

-Namenskürzel (h)(1988): Zweckverband - Protest gegen Basaltabbau. - HNA, 1988; Nr. 44 v. 22.2.1988; Kassel

[Geplante Erweiterung Basaltabbau Steinbruch Druseltal/Habichtswald]

-Namenskürzel (W.R.)(1988): Basaltsteinbruch im Druseltal - Wurbs: Magistrat gegen Erweiterung. HNA, 1988; Nr. 59 v. 10.3.1988; Kassel

-Namenskürzel (b)(1994): Basaltabbau - Deutliche Mehrheit für die Natur. - HNA, 1994; Nr. 94 v. 23.4.1994, 1 Abb.; Kassel

[Geplante Erweiterung Basaltabau Habichtswald]

-Namenskürzel (tos)(1996): Druseltal - Steinbruch bedroht Arbeitsplätze. - HNA, 1996; v. 5.12.1996; Kassel

[Basaltabbau Habichtswald/Kassel]

-Namenskürzel (tos)(1996): Druseltal - Basaltabbau bis zum Jahr 2031? - HNA, 1996; v. 6.12.1996; Kassel

\subsection{Bergbau in der Söhre (Landkreis Kassel)}

\section{Braunkohle}

- $\square$ Namenskürzel (0)(1968): HBZ stellt die gesamte Braunkohlenförderung ein - Auf dem Zechengelände am Stellberg und Glimmerode sollen Erholungszentren mit Teichen entstehen. - HA, $\underline{1968}$; Nr. 93 v. 20.4.1968; Kassel

-Namenskürzel (aim)(1988): Kohleabbau in der Söhre: Gemeinden fordern Gutachten - Versiegen die Quellen? - HNA, 1988; Nr. 136 v. 14.6.1988; Kassel

[Kohleabbau und mögliche hydrogeologische Auswirkungen]

- Ritz, Achim (1988): Bergrecht im Verhältnis zur Wasserversorgung - Beispiel Söhre: Schürfen nach Kohle hat Gewicht. - HNA, 1988; Nr. 172 v. 27.7.1988; Kassel

-Ritz, Achim \& Krischmann, Helmut (1988): Heftiger Protest gegen geplanten Kohleabbau in Nordhessen - Ein neues Mutlangen in der Söhre? - HNA, Sontagszeit, 1988; Nr. 49 v. 4.12.1988; Kassel [Geplanter Braunkohlenabbau in der Söhre bei Helsa]

-Namenskürzel (kri)(1989): Söhrekohle: Dr. Möller weist Vorwürfe zurück - Weitergabe von Daten erst nach Auswertung im Dezember. - HNA, 1989; Nr. 266 v. 14.11.1989; Kassel [Geplanter Braunkohlenabbau in der Söhre bei Helsa; Untersuchung zur ökologischen Auswirkung des Kohlenabbaus]

-Namenskürzel (man)(1989): Kohleabbau in der Söhre: Experte legt Zwischenbericht vor - Sorge um Wasser wächst. - HNA, 1989; Nr. 283 v. 5.12.1989; Kassel [Geplanter Braunkohlenabbau in der Söhre bei Helsa; Untersuchung zur ökologischen Auswirkung des Kohlenabbaus]

-Keller, Werner (1989): Grube Hirschberg: Heimische Braunkohle hat Chancen - Zeche pocht auf Söhre-Abbau. - HNA (Witzenhäuser Allgemeine), 1989; Nr. 219 v. 20.9.1989; Kassel 
[Geplanter Braunkohlenabbau in der Söhre bei Helsa]

-Namenskürzel (kri)(1990): Söhrekohle-Studie: Abbau gefährdet Wasser. - HNA, 1990; Nr. 207 v. 6.9.1990; Kassel

[Geplanter Braunkohlenabbau in der Söhre bei Helsa; Untersuchung zur ökologischen Auswirkung des Kohlenabbaus]

-Namenskürzel (kri)(1991): Kohleabbau: Genehmigungen für Bohrungen stehen bevor. - HNA, 1991; Nr. 233 v. 8.10.1991; Kassel

[Geplanter Braunkohleabbau i. d. Söhre bei Helsa; Probebohrungen]

-Namenskürzel (kri)(1991): Söhrekohle/Raumordnungsverfahren - Waitz: Liefern Unterlagen `91. HNA, 1991; Nr. 133 v. 12.6.1991; Kassel

[Geplanter Braunkohleabbau Söhrewald Lkr. Kassel]

-Krischmann, Helmut (1992): Grünes Licht für Bohrungen. - HNA (MA = Melsunger Ausgabe), 1992; Nr. 36 v. 12.2.1992; Kassel

[Geplanter Braunkohleabbau i. d. Söhre bei Helsa; Probebohrungen]

øKrischmann, Helmut (1992): Söhrekohle - Grünes Licht für Bohrungen. - HNA, 1992; Nr. 30 v. 5.2.1992; Kassel

[Geplanter Braunkohleabbau Söhrewald Lkr. Kassel]

\section{$\underline{\text { Basalt }}$}

-Namenskürzel (kri)(1988): Basaltabbau - Gemeindevorstand: Massiver Eingriff in die Natur. - HNA, $\underline{1988}$; Nr. 179 v. 4.8.1988; Kassel

[Söhre Lkr. Kassel]

-Namenskürzel (kri)(1988): Geplanter Basaltabbau - Bergamt: Umweltverträglichkeit wird geprüft Naturschützer: Biotope in Gefahr. - Hessisch-Niedersächsische Allgemeine, 1988; Nr. 190 v. 17.8.1988; Kassel

[Söhre Lkr. Kassel]

\subsection{Bergbau im „Tiefenbach“ b. Helsa-Wickenrode (Landkreis Kassel)}

-Namenskürzel (hkl) (1976): Auflagen gefordert für Kohleabbau bei Helsa/.../ Generelle Ablehung könnte rechtliche Folgen haben - Kreisausschuß teilt Helsaer Bedenken. - HA, 1976; Nr. 193 v. 20.8.1976; Kassel

[Geplanter Abbau im Tiefenbach bei Helsa-Wickenrode]

-Namenskürzel (kri)(1987): Im Tiefenbach in Wickenrode/Transporte über B451? - Zeche will Kohleabbau erweitern. - HNA, 1987; Nr. 35 v. 11.2.1987; Kassel [Geplanter Braunkohlenabbau bei Helsa-Wickenrode]

-Namenskürzel (clx)(1987): Zeche Hirschberg will bei Helsa fördern: Lärmwelle durch Kohlenlaster? Hessisch Niedersächsische Allgemeine, 1987; Nr. 250 v. 27.10.1987; Kassel [Geplanter Braunkohlen- u. Tonbabbau im „Tiefenbach“ bei Helsa-Wickenrode] 
-Namenskürzel (kri)(1991): Kohleabbau: Droht Gefahr fürs Trinkwasser? - HNA, 1991; Nr. 201 v. 30.8.1991; Kassel

[Tagebau „Paradiesfeld“ am Hirschberg b. Großalmerode]

-Krischmann, Helmut (1994): Braunkohle und Ton: Gefährdet Abbau Quellen? - HNA, 1994; Nr. 302 v. 30.12.1994; Kassel

[Geplanter Braunkohlen- und Tontagebau Tiefenbach b. Helsa-Wickenrode]

-Namenskürzel (els)(1995): Tagebau: Parlament legt Veto ein. - HNA, 1995; Nr. 72 v. 25.3.1995;

Kassel

[Geplanter Braunkohlen- und Tontagebau Tiefenbach b. Helsa-Wickenrode]

-Namenskürzel (bea)(1996): Naturschutzgebiet Tiefenbach - Grünes Licht für Braunkohleabbau. HNA, 1996; v. 8.11.1996; Kassel

-Namenskürzel (bea)(1996): Braunkohleabbau: Helsa legt Widerspruch ein - Die Gemeinde Helsa hat gegen die Genehmigung des Braunkohle- und Tontagebaus „Tiefenbach“ in Wickenrode ihr Veto eingelegt. - HNA, 1996; v. 6.12.1996; Kassel

\title{
4.4 Bergbau auf dem Hohen Meißner (Werra- Meißner-Kreis)
}

\author{
Braunkohle-Bergbau 1947 - 1974
}

$\square$ Anonym (1952): Wie steht der Kampf um die Kalbe? - Das Werraland, 4(3): 44-45; Eschwege [Braunkohlenabbau contra Naturschutz]

$\square$ Namenskürzel (wu)(1952): Dr. Hoch verspricht seine Hilfe zur Wahrung der Meißner-Landschaft. $\mathrm{HN}(\mathrm{WN}), \underline{1952}$; Nr. 79 v. 3.4.1952; Kassel

$\square$ Namenskürzel (wu)(1952): Protest gegen Beseitung der Meißner-Wahrzeichen - Abtragung der Kalbe und Zuschüttung des Frau-Hollenteiches vorbereitet - Untertage-Abbau der Braunkohle gefordert. HN, 1952; Nr. 73 v. 27.3.1952; Kassel

$\square$ Anonym (1953): Kampf um den Meißner-Bergbau. - Bergbau i. Hessenland (Ausgabe Braunkohle), (3.Jg.) 1953(10): 4, (10): 14, (11): 14; Kassel

$\square$ Sauer, Helmut (1957): Der Kampf um den Meißner ist von neuem entbrannt. - Das Werraland, $\underline{\mathbf{9}}(1)$ : 12; Eschwege

[Braunkohle-Bergbau contra Naturschutz]

$\square$ Namenskürzel (Werra-Rundschau) (1957): <Braunkohlebergbau Hoher Meißner> Alarmnachricht vom Meißner - Kreistag beschloß sofortige Schritte gegen eine weitere Ausdehnung des Braunkohleabbaues. - Werra-Rundschau, 1957; Nr. 11 v. 14.1.1957, S. 4; Eschwege

$\square$ Sauer (1957): Meißner-Bergbau kann nicht unbeschränkt vorgehen. - Werra-Rundschau, 1957; Nr. 85 v. 10.4.1957, S. 4; Eschwege

[Braunkohlenbergbau contra Naturschutz]

$\square$ Namenskürzel (Werra-Rundschau) (1958): Staatsbegräbnis 1. Klasse für den Meißner!/... - WerraRundschau, 1958; Nr. 17 v. 21.1.1958, S. 3; Eschwege

[Diskussion: Braunkohlenbergbau contra Naturschutz] 
$\square$ Namenskürzel (Werra-Rundschau) (1958): TV „Die Naturfreunde“ fordern Erhaltung des Meißners. Erneuter dringender Apell an die hessische Landesregierung. - Werra-Rundschau, 1958; Nr. 224 v. 27.9.1958, S. 4; Eschwege

$\square$ Perst, Otto (1958): Totale Verwüstung des Meißners? - Das Werraland, 10(1): 2-4; Eschwege [Braunkohlenabbau contra Naturschutz]

$\square$ Perst, Otto (1958): Immer wieder der Meißner. - Das Werraland, $\underline{10}$ (2): 17-18; Eschwege [Braunkohlenabbau contra Naturschutz]

$\square$ Namenskürzel (Werra-Rundschau) (1958): <Braunkohlenbergbau am Meißner geht weiter> Regierung traf Meißner-Entscheidung nach sorgfältiger Prüfung. Innenminister Schneider beantwortete Eingabe der Bundesleitung der „Naturfreunde“. - Werra-Rundschau, 1958; Nr. 292 v. 17.12.1958, S. 3; Eschwege

$\square$ Finck, Luwig (1959): ... zu den Verwüstungen auf dem Meißner. - Das Werraland, 11(3): 33-34; Eschwege [Bergbau contra Naturschutz]

$\square$ Johannes, Martin Otto (1959): Trauriges Wiedersehn mit der Kalbe. - Das Werraland, 11(1): 1; Eschwege

$\square$ Namenskürzel (Werra-Rundschau) (1959): Kohleabbau am Meißner wird fortgesetzt - Entwicklung kann nicht mehr gestoppt werden. - Werra-Rundschau, 1959; Nr. 132 v. 11.6.1959, S. 4; Eschwege

$\square$ Beck, Hanno (1961): Erhaltet den Meißner und nicht den Bergbau. - Der König der hessischen Berge ist ein Symbol wie Kyffhäuser und Brocken. - Werra-Rundschau, 1961; Nr. 251 v. 28.10.1961, [S. 4]; Eschwege

$\square$ Anonym (1961): „Die Kalbe rutscht!“ - Das Werraland, 13 (3/4): 35-41, 4 Abb.; Eschwege [Bergbaufolgeschäden im Bereich der Kalbe/Meißner]

$\square$ Sauer (1961): <Instabilität des Kalbefelsens/Hoher Meißner> Naturschutzschutzbeauftragter Dr. Sauer stellt fest: Die Ursache liegt beim Bergbau. Sofortmaßnahmen zur Rettung der Kalbe gefordert. Höchste Eile notwendig. - Werra-Rundschau, 1961; Nr. 139 v. 20.6.1961, S. 3; Eschwege

$\square$ Namenskürzel (Werra-Rundschau) (1961): < Diskussion um Braunkohlebergbau auf dem Hohen Meißner> Die „Rache des Naturschutzes“: Kletterpartie in Geröllhalden. Eine neue Runde im Kampf um den Meißner / Landtagsausschüsse besichtigen Kalbe. - Werra-Rundschau , 1961; Nr. 256 v. 3.11.1961, [S. 4] 1 Abb.; Eschwege

$\square$ Anonym (1962): Die Landesregierung und der Meißner. - Das Werraland, 14(1): 8-11; Eschwege [Wiedergabe der Rede des Ministers Franke zum Naturschutz und Bergbau auf dem Meißner]

$\square$ Anonym (1964): Neue Gefahren für den Meißner? - Das Werraland, 16(1): 9; Eschwege [Bergbau contra Naturschutz]

$\square$ Namenskürzel (h)(1965): Entsteht in 20 Jahren ein Meißner-Bergsee? - Neue Überlegungen zum Thema „Bergbau-Folgen“. - HA (WN) [vermutlich Ausgabe Werra-Nachrichten, 1965; Nr. 181 v. 7.8.1965, 1 Abb.; Kassel

$\square$ Heintze, Gottfried (1966): Rekultivierung der Kippen auf dem Meißner. - Das Werraland, 18(2): 19-21; Eschwege 
$\square$ Huhn, Karl-Hermann (1966): Bisher einmaliges Experiment - Grüner Schleier über schwarze Vergangenheit - Geröllhalden auf dem Meißner werden aufgeforstet. - HA, 1966; Nr. 112 v. 14.5.1966, 1 Abb.; Kassel

$\square$ Sauer, Helmut (1968): Der Meißner - Kernstück eines Naturparks. - Geogr. Rdschau, 20: 181-187, 1 Abb.; Braunschweig [Geomorphologie, Geologie, Naturschutz]

$\square$ Anonym (1969): Um die Zukunft des Meißners - Wie wird nach Beendigung des Braunkohlenabbaues das Gelände um die Kalbe aussehen? - Das Werraland, 21(2): 21-22; Eschwege

$\square$ Namenskürzel (WL) (1969): Um die Zukunft des Meißners - Wie wird nach Beendigung des Braunkohlenabbaues das Gelände um die Kalbe aussehen? - Das Werraland, 21(2): 21-22; Eschwege

$\square$ Anonym (1972): Fragen zu den Problemen auf dem Meißner. - Das Werraland, 24(2): 23-24; Eschwege [Basaltabbau, Naturschutz, Rekultivierung]

d $\square$ Follmann, Fritz (1972): Der Meißner - Bergkönig oder Ausbeutungsobjekt? - Hessischer Gebirgsbote, $\underline{\mathbf{7 3}}(10): 10$ - 11, 1 Abb.; Melsungen

$\square$ Wentzel, Karl Friedrich (1976): Holz, Kohle, Basalt, Naturschutz und Erholung - Der Meißner im Konflikt. - Hessische Heimat, N.F., 26(3) (Sonderheft: Braunkohlenbergbau und Landschaftspflege auf dem Hohen Meissner - Stand 1975): 79 - 82, 2 Abb.; Marburg/L.

$\square$ Schade, Hartmut (1976): Vorzeitiges Ende der Kohlegewinnung am Meißner - was wird aus der Bergbaulandschaft? - - Hessische Heimat, N.F., 26(3) (Sonderheft: Braunkohlenbergbau und Landschaftspflege auf dem Hohen Meissner - Stand 1975): 99 - 106, 4 Abb.; Marburg/L.

$\square$ Trott zu Solz, Friedrich von (1976): Erfolge und Mißerfolge in der Praxis der Rekultivierung auf dem Hohen Meißner. - Hessische Heimat, N.F., 26 (3) (Sonderheft: Braunkohlenbergbau und Landschaftspflege auf dem Hohen Meissner - Stand 1975): 106 - 110, 4 Abb.; Marburg/L.

$\square$ Schmeisky, Helge (1990): Rekultivierungs- und Ausgleichsmaßnahmen im Braunkohletagebau. - In: Wiemer, Klaus [Hrsg.]: Abfallwirtschaft und Deponietechnik '90, S. 381-394, graph. Darst.; 1990

$\square$ Anonym (2002): Vor 50 Jahren: Was steht am Meißner auf dem Spiel? - Das Werraland, 54(1): 17-18; Eschwege

[Abdruck des Gutachtens des Kreisbeauftragen für Naturschutz und Landschaftspflege Dr. Helmut Sauer zum Themenkreis: Bergbaulichen Nutzung des Meißners, Auswirkung auf Natur und Erholungswert, Naturschutz]

$\square$ Möller, Dieter (2003): <Schwelbrand im Bereich der Stinksteinwand > Gemeingefahr auf dem Meißner - Flächenbrand ruft Gemeinde auf den Plan - Forderungen nach Abhilfe gestellt. - WerraRundschau, 2003; Nr. 97 v. 26.4.2003, 2 Abb.; Eschwege

$\square$ Möller, Dieter (2006): <Schwelbrand im Bereich der Stinksteinwand > Phänomen ist stinkendes Ärgernis - Vockerode: Schwelbrand auf dem Meißner bekommt Kommune ohne Hilfe nicht in Griff. - Werra-Rundschau, 2006; NR. 66 v. 18./19.3.2006, 1 Abb.; Eschwege

\section{Geplante Wiederaufnahme des Braunkohlenbergbaus ab 1976}

$\square$ Namenskürzel (h)(1976): Gegen neuen Meißner-Abbau - Versuchsbohrungen - Naturschutzring protestiert. - HA, 1976; Nr. 190 v. 17.8.1976; Kassel

[Erneuter Abbau der Meißner-Braunkohle] 
$\square$ Namenskürzel (aja) (1976): Meißner: Braunkohlenflöze sind bis zu 22 Meter stark - Abbau innerhalb 15 Jahren - Bisher acht Bohrungen. - HA, 1976; Nr. 198 v. 26.8.1976; Kassel

$\square$ Sauer, Helmut (1976): Weitere Zerstörung muß vom Meißner ferngehalten werden. - Das Werraland, $\underline{28}(3):$ 39-40; Eschwege

[Geplante Wiederaufnahme Braunkohleabbau contra Naturschutz]

$\square$ Sauer, Helmut (1976): Die Meißnerlandschaft - Hessische Heimat, N.F., 26 (3) (Sonderheft:

Braunkohlenbergbau und Landschaftspflege auf dem Hohen Meissner - Stand 1975): 82 - 84, 2 Abb.; Marburg/L.

$\square$ Namenskürzel (i)(1977): IG Bergbau, PREAG-Betriebsrat und Gewerkschaftsausschuss: Kompromiß finden für Abbau der Meißnerkohle und Landschaftsschutz/... - HA (Fritzlar-Homberger Ausgabe), 1977; Nr. 37 v. 14.2.1977; Kassel

$\square$ Namenskürzel (t)(1977): Börner auf dem Hohen Meißner: Schrecklicher Eingriff in die Natur. Ministerpräsident informiert sich über Konflikt um Kohleabbau. - HA, 1977; Nr. 46 v. 24.2.1977; Kassel

$\square$ Namenskürzel (hum) (1977): MdL Meister fragt Minister Karry nach Meißner-Braunkohlenabbau: Laufzeit bis 1990 errechnet. 125 neue [Arbeits-] Plätze. - HA (Witzenhäuser Nachrichten), 1977; Nr. 115 v. 18.5.1977; Kassel

$\square$ Namenskürzel (H.L.)(1977): Umstrittener Braunkohlenabbau auf dem Meißner - Karry: Keine Patentlösung - „Alle Belange abwägen“/... - HA, 1977; Nr. 149 v. 1.7.1977; Kassel

$\square$ Anonym (1977): Neuer Braunkohletagebau auf dem Meißner? - Antwort der Preußenelektra zu den Fraben des Werratalvereins. - Das Werraland, 29(1): 1-3, 2 Abb.; Eschwege

$\square$ Anonym (1977): Meißner-Braunkohlenabbau. - Das Werraland, 29 (3): 46; Eschwege

$\square$ Sauer, Helmut (1977): Raumordnungsverfahren „Geplanter Braunkohlenabbau auf dem Meißner“. Das Werraland, 29(4): 51-52; Eschwege

$\square$ Sauer, Helmut (1978): Die Entstehungsgeschichte der Meißner-Misere. - Das Werraland, $\underline{\text { 30}}(3)$ : 33-38, 4 Abb; Eschwege

[Braunkohlebergbau contra Naturschutz]

$\square$ Sauer, Helmut (1978): Neuer Riß auf der Kalbe [Hoher Meißner]. - Das Werraland, 30(3): 44, 1 Abb.; Eschwege [Bergbau-Folgeschäden?]

$\square$ Anonym (1978): Naturschutz und Bergbau [Hoher Meißner] im Widerstreit der Interessen. - Das Werraland, 30(3): 41-42; Eschwege

$\square$ Bevern, Otto (1978): Warum nicht Steinkohle an Stelle von Braunkohle? - Das Werraland, $\underline{\text { 30}}$ (3): 38-39; Eschwege [geplanter Braunkohleabbau Hoher Meißner contra Naturschutz]

$\square$ Gießmann, Rainer (1978): Gegen Kohleabbau auf dem Hohen Meißner: Kinder hauen auf die Pauke „Ein Märchenland und Eure Heimat“. - HA, 1978; Nr. 114 v. 19.5.1978; Kassel

$\square$ Leonhard, Joachim (1978): Meißner '78 - eine Region zwischen Hoffen und Bangen. - Das Werraland, 30(3): 39-41, 2 Abb.; Eschwege 
$\square$ Leonhard, Joachim (1978): Anmerkungen zu den Informationen der Preag. - Das Werraland, $\underline{\text { 30}(3): ~}$ 42-44, 2 Abb.; Eschwege

[Meißner, Braunkohle-Bergbau contra Naturschutz]

$\square$ Leonhardt, Joachim (1978): Meißner '78 - eine Region zwischen Hoffen und Bangen. - Das Werraland, $\underline{\mathbf{3 0}}$ (3): 39-41, 2 Abb.; Eschwege

[Bergbau contra Naturschutz]

$\square$ Moog, Karl-Ernst (1978): Naturschutz und Bergbau im Widerstreit der Interessen. - Das Werraland, 30(3): 41-42; Eschwege

$\square$ Kreisstelle für Naturschutz und Landschaftspflege [Hrsg.](1979): Resolution der Kreisstelle ... $<$ Zum geplanten Braunkohlenabbau auf dem Meißner>. - Das Werraland, 31(1): 2; Eschwege

$\square$ Namenskürzel (W. H.) (1979): Meißner - Probeschurf am Weiberhemdmoor? - Genaue Prüfung der von der Preag geplanten Gesamtmaßnahme dringender denn je? - Das Werraland, 31(3): 33-34; Eschwege

$\square$ Maurer, Jacob (1978): Naturschutz im Werra-Meißner-Kreis. - Das Werraland, $\underline{\mathbf{3 5}}$ (3): 45-47; Eschwege [darin: Bergbau Hoher Meißner, Hesselbühl („Roter See“) Kaufunger Wald b. Großalmerode, Bilstein/Kaufunger Wald]

$\square$ Namenskürzel (eg)(1978): 22000 Bürger gegen Abbau von Braunkohle. - HA, 1978; Nr. 79 v. 5.4.1978; Kassel

$\square$ Namenskürzel (t)(1978): Braunkohlenflöz am Lettenberg wird untersucht. - HA, 1978; Nr. 124 v. 1.6.1978; Kassel [Geplanter Braunkohlenabbau auf dem Hohen Meißner; Lettenberg nahe der „Kalbe“]

$\square$ Namenskürzel (jrx)(1978): Kohleförderung angelaufen - Lettenberg: Stollen vorbereitet. - HA, 1978; Nr. 148 v. 30.6.1978; Kassel

[Geplanter Braunkohlenabbau auf dem Hohen Meißner; Lettenberg nahe der „Kalbe“]

$\square$ Namenskürzel (led)(1978): Am Meißner wird zur Probe Kohle im Tiefbau gewonnen - „So zügig und so landschaftsschonend wie möglich“". - HA, 1978; Nr. 155 v. 8.7.1978; Kassel

$\square$ Anonym (1979): Resolution der Kreisstelle für Naturschutz und Landschaftspflege. - Das Werraland, 31(1): 2, 1 Abb.; Eschwege

[Naturschutz contra Braunkohle-Abbau auf dem Meißner]

$\square$ Eder, Lothar (1979): [Ministerpräsident] Börner will nicht ran ans „Weiberhemd“ - Der geplante Kohleabbau am Meißner treibt nicht nur Genossen ins gegensätzliche Lager. - HA, 1979; Nr. 60 v. 12.3.1979; Kassel

[,Weiberhemd“: Moorgebiet auf der Meißner-Hochfläche]

$\square$ Namenskürzel (H. L.) (1979): Raumordnungsverfahren geht weiter - „Weiberhemd“ wird geschont Probeschurf am Meißner um 140 Meter verschoben. - HA, 1979; Nr. 59 v. 10.3.1979; Kassel [Probeschurf für geplanten Braunkohlenabbau am Meißner; „Weiberhemd“: Moorgebiet auf der Meißner-Hochfläche]

$\square$ Namenskürzel (h)(1979): Kohle aus dem Meißner oder nicht: Landesregierung am Zug. - HA, 1979; Nr. 130 v. 7.6.1979; Kassel

$\square$ Namenskürzel (t)(1979): Ministerpräsident hatte auf den Meissner eingeladen - „Berg wird nicht zerstört" - Fronten zwischen Befürwortern und Gegnern verhärtet. - HA, 1979; Nr. 139 v. 16.6.1979; Kassel 
- $\square$ Namenskürzel (h)(1979): Gegen Abbaupläne im Habichtswald und am Meißner - MdL Schmidt: Erholungsraum sichern. - HA, 1979; Nr. 30 v. 5.2.1979; Kassel

[Basalt im Habichtswald, Braunkohle auf dem Hohen Meißner]

$\square$ Leonhardt, Joachim (1980): Rettet den Meißner - Ein Berg soll verheizt werden. - In: Keller, Will [Hrsg.]: Werraland. - MERIAN - das Monatsheft der Städte und Landschaften - Sonderheft Juli 1980; S. 51-55; 3 Abb.; (Hoffmann und Kampe) Hamburg 1980

$\square$ Namenskürzel (ter)(1980): 3000 junge Leute demonstrierten gegen Kohleabbau auf dem Meißner. HA (E = Ederbote), 1980; Nr. 126 v. 2.6.1980; Kassel

$\square$ Namenskürzel (t)(1980): Probeschurf ständig überwacht - Braunkohlenflöz auf dem Meißner kommt erst im Herbst zum Vorschein. - HA, 1980; Nr. 141 v. 21.6.1980; Kassel

$\square$ Namenskürzel (stx)(1980): Preag will 4,5 Millionen Tonnen Meißnerkohle abbauen. - Antrag beim Bergamt gestellt - 15 Jahre Abbauzeit. - HA, 1980; Nr. 287 v. 10.12.1980; Kassel

$\square$ Sauer, Helmut (1980): Naturschutz und Braunkohletagebau. - Das Werraland, $\underline{\mathbf{3 2}}(2): 17-18$; Eschwege [Meißner]

$\square$ Keller, Werner (1981): Epteröder Zeche fürchtet um ihre Existenz - Wenn am Meißner nicht abgebaut wird. - HA, 1981; Nr. 7 v. 9.1.1981; Kassel

$\square$ BUND Landesverband Hessen e.V.[Hrsg.](1981): Der Meißner soll nicht verheizt werden. - BUND Hessen gegen Wiederaufnahme des Braunkohletagebaus auf dem Meißner [Presseerklärung]. - Das Werraland, $\underline{\text { 33 }}(3)$ : 40; Eschwege

$\square$ Zick, Jürgen (1982): „Nein“ des Ministers zum Kohleabbau auf dem Meißner!: Nicht mit den Belangen der Landesplanung vereinbar. - Das Werraland, 34(3): 33; Eschwege

$\square$ Roth, Peter (1983): Frau Holles Reich ist bedroht: Hoher Meißner - Naturzerstörung zugunsten einer Dreckschleuder. - In: Bölsche, Jochen [Hrsg.]: Die deutsche Landschaft stirbt - zerschnitten, zersiedelt, zerstört. - Reihe: Spiegel-Buch, 37; 333 S.; hier S. 205-208; (Rowohlt) Reinbek

$\square$ Siebert, Horst (1993): Der Meißner - seine Bedeutung und Anforderungen der Gesellschaft heute. Vortrag anlässlich der 110-Jahr-Feier des Werratalvereins auf dem Meißner am 20. Juni 1993. - Das Werraland, 45 (3): 53-56, 4 Abb.; Eschwege [darin: Braunkohlen-Bergbau am Meißner]

\section{$\underline{\text { Basalt }}$}

$\square$ Anonym (1972): Neue Gefahren für den Meißner? [Basaltabbau Bransrod]. - Das Werraland, 24(1): 19, 2 Abb.; Eschwege

$\square$ Anonym (1972): Fragen zu den Problemen auf dem Meißner. - Das Werraland, 24(2): 23-24; Eschwege [Basaltabbau, Naturschutz, Rekultivierung]

$\square$ Namenskürzel (h)(1965): Neue Gefahren am Meissner? - Basaltverwertungspläne noch nicht aufgegeben - Bubiag machte in Wiesbaden neue Vorschläge. - HA (WN) [vermutlich Ausgabe WerraNachrichten], 1965; Nr. 175 v. 31.7.1965, 3 Abb.; HA, 1965; Nr. 184 v. 11.8.1965, 3 Abb.; Kassel 
-Namenskürzel (lh) (1975): Absenkung von Kalilauge noch höchstens fünf Jahre - Regierungssprecher berichtigt Angaben vom Mittwoch. - HA (FA), 1975; Nr. 123 v. 31.5.1975; Kassel

-Vogt, Egon E. (1978): „Doch kein Brett vor dem Kopf“ - Salz: Arbeit und Ärger - Hohenroda: In Tuchfühlung zur Grenze. - HA, 1978; Nr. 14 v. 17.1.1978; Kassel

[Kalilaugenversenkung, Trinkwasserqualität, Aufhaltung der verfestigten Produktionsrückstände und ein Gedanke: Kalilauge durch Pipeline zur Nordsee transportieren und dort einleiten]

-Zundel, Rolf (1982): Die Begrünung der Kalihalde in Reyershausen. - Plesse-Archiv, 18: 189 - 204, 9 Abb., 3 Kt., graph. Darst.; Göttingen

- 0 Riek, Wolfgang (1994): Kalilaugen-Versenkung: Der Salzsee tief unten ist vielen nicht geheuer. HNA, 1994; Nr. 49 (Sonntagszeit) v. 4.12.1994; Kassel

[Hessisch-Thüringisches Werra-Kalirevier]

OSchmeisky, Helge (1998): Zur Begrünung von Rückstandshalden der Kaliindustrie - Ergebnisse einer 25jährigen Forschungsarbeit. - Glückauf, 134(3): 501 - 515, 16 Abb.; Essen

[darin: Bleicherode]

口OPörtge, Karl-Heinz (1999): Der Kalibergbau und seine Folgen in Thüringen und Hessen. Petermanns Geographische Mitteilungen, 143(1): 59-71, 28 Abb.; Gotha

[Bergbau u. Interessenkonflikte, Naturschutz]

-Fritsche, Johann-Gerhard (2002): Die Erweiterung der Rückstandshalden der Kaliindustrie im WerraFulda-Kaligebiet. Maßnahmen zum Grundwasserschutz. - Jber. HLUG, f. 2001, S. 127-131, 3 Abb.; Wiesbaden

\subsection{Bergbau im Hessisch-Thüringischen Kali- Bergbaurevier - Werra-Versalzung}

- $\square$ • Anonym (1912): Ein Erfolg der Proteste gegen die Verunreinigung der Werra - Einleitung von Kaliabwässern behördlich untersagt $<$ Kurzmeldung > . - Eschweger Tageblatt, 1912; Nr. 157 v. 6.07.1912; Eschwege

- $\square$-Anonym (1913): Stellungnahme der Stadt Eschwege gegen die Versalzung der Werra $<$ Kurzmeldung >. - Eschweger Tageblatt, 1913; Nr. 134 v. 11.06.1913; Eschwege

-Reimer, C. L. (1918): Der Chlorgehalt der Werra bei Münden im II. Halbjahr 1917. - Kali, etc., 12 (5): 72-73, Tab.; Halle/Saale

- $\square$ Q0 Anonym (1956): Die Belastung der Weser durch Kaliabwässer. - Die Weser, $\underline{\mathbf{3 0}}$ (1): 4-5, 1 Übersichts-Kt.; Bremen

[Das Werra-Kalirevier und die Versalzung von Werra und Weser]

- $\square \bullet L u ̈ s s e n s, ~ H e i n r i c h ~(1962): ~ D i e ~ F l u ß u ̈ b e r w a c h u n g ~ i m ~ E i n z u g s g e b i e t ~ d e r ~ W e s e r . ~-~ D i e ~ W e s e r, ~ \underline{36}(6)$ : 96-99, 3 Abb., 1 Übersichts-Kt.; Bremen [Schriftliche Fassung eines Vortrages, gehalten auf dem Wesertag 1962] [Kaliabwässerüberwachung; darin Überwachungsstellen Heldra, Jestädt]

- $\square$-Henne, Hans (1964): Die Beseitigung der Kaliabwässer. - Die Weser, $\underline{\text { 38}(2): ~ 19-20, ~} 1$ Abb.; Bremen

[Versalzung der Werra durch Kaliabwässer des Werra-Kalireviers] 
-Schroth, Hermann E. (1973): Die Beseitigung der Abfallstoffe in der BRD. - Kali u. Steinsalz, $\underline{\mathbf{6}}(5)$ : 158-164, 9 Bilder; Essen

[darin: Hess. Werra-Kalirevier]

oSchroth, Hermann E. (1977): Die Errichtung einer Großhalde unter umweltschützenden Bedingungen. - Kali u. Steinsalz, 7(4): 147-154, 14 Bilder; Essen

[Wintershall/Heringen]

- $\square$ (Deijering, Meertinus (1978): Die Werraversalzung - ein derzeit unlösbares ökologisches Problem. - Beitr. z. Naturkunde Osthessens, 13/14: 207-208; Fulda

[Vorlage nicht eingesehen]

- $\square$ ○ीAnonym (1979): Ein Beitrag zur Diskussion: Das Projekt einer Salzwasserpipeline Werra/Weser. Die Weser, $\underline{\mathbf{5 3}}(6)$ : 131-135, 1 Abb.; Bremen

- $\square$ O०Menk, Horst (1980): Die Werra-Versalzung - ein Umweltskandal. - Hessischer Gebirgsbote, $\underline{\mathbf{8 1}}$ (4): 118 - 122, 7 Abb., 2 Tab.; Melsungen

- $\square$ (0) Ostermeyer, Jürgen (1980): Ein sterbender Fluß? Der andere Staat vergiftet die Werra. - In: Keller, Will [Hrsg.]: Werraland. - MERIAN - das Monatsheft der Städte und Landschaften; Sonderheft Juli 1980; S. 56-61, 10 Abb.; (Hoffmann und Kampe) Hamburg 1980

- $\square 0 \bullet$ Singewald, Arno (1980): Umweltfreundliche Aufbereitung von Kalium- und Magnesiumsalzen. Kali u. Steinsalz, $\underline{8}(1): 2-8,11$ Bilder, 1 Zahlentaf.; Essen [darin: Werraversalzung durch Kalilaugen (Salzgehalt, Chlorideinleitung)]

- $\square$ Q0 Anonym (1982): Flüsse - Im Koma. - Deutsch-deutsche Experten beraten über eine Reduzierung des Schadstoff-Transports von Ost nach West. - DER SPIEGEl, 1982; Nr. 22 v. 31.05.1982, S. 4852, 3 Abb.; Hamburg

[Versalzung der Werra durch Kaliabwässer des hessisch-thüringischen Werra-Kalireviers]

- $\square$-Wroz, Winfried (1982): Die Salzbelastung von Werra, Weser und Rhein - ein Umweltproblem. Betreuender Hrsg.: Hartmut Beck. - Umweltschutz im Unterricht, $\underline{8} ; 76$ S., Ill., graph. Darst.; (AulisDeubner-Verlag) Köln; (Bund Naturschutz in Bayern) Münschen

- $\square$ Q $\bullet$ Wroz, Winfried (1983): Die Werra - ein toter Fluß?. - In: Hildebrand, Erich

[Gesamtkonzeption, Red.]: Land an Werra und Meißner - Ein Heimatbuch.. - [1. Auflage]; S. 205 - 207, 1 Abb.; [Hrsg.: Hist. Ges. Werralandes](Bing) Korbach 1983

- •Lenz, Otto (1983): Stand der Untersuchungen zur Begrünung von Rückstandshalden der Kaliindustrie. - Kali u. Steinsalz, $\underline{8}(12): 406-410,1 \mathrm{Kt}$.; Essen [darin: Königshall-Hindenburg/Reyershausen, Wintershall/Heringen, Hattorf/Philippstahl]

- $\square$ • Anonym (1988): Signale zum Erfolge - 14 Millionen Tonnen Salze in Werra und Weser Fortschritte in deutsch-deutschen Verhandlungen. - Die Weser, $\underline{\mathbf{6 2}}$ (1): 7-8, 1 Abb.; Bremen

- $\square$-Anonym (1989): Abwasser - Geist von gestern. - Millionen Kubikmeter Abwasser werden in der Bundesrepublik jährlich über Schluckbrunnen tief in die Erde versenkt - Ursache für das jüngste Erdbeben in Thüringen? - DER SPIEGEL, 1989/16; 17.04.1989; Hamburg [darin: Bergschlag in Völkershausen/Thüringen im März 1989; Kalilaugen-Verpressung im hessischthüringischen Werra-Kalirevier]

- $\square$ Q $\bullet$ Anonym (1990): Zehn Jahre Verhandlungen und keine Ergebnisse - eine Chronik. - Die Weser, 64(1): 4-5, 1 Abb., 1 Kt.; Bremen

[deutsch-deutsche Verhandlungen zur Reduzierung der Salzeinleitungen im Hessisch-Thüringischen Werra-Kalirevier] 


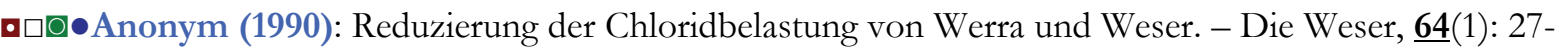
33, 3 Abb.; Bremen

- DoAnonym (1990): Gemeinsame Sicherheits- und Ökologiestrategie der Kalibetriebe an der Werra. - Die Weser, 64(1): 52-53, 1 Abb.; Bremen

- $\square$ (Ononym (1990): Weitere Fortschritte für Werra und Weser. - Die Weser, 64(4): 120-121; Bremen [Deutsch-Deutsche Zusammenarbeit zur Reduzierung der Kaliabwässer-Einleitung im hessischthüringischen Werra-Kalirevier]

- $\square$ Oण Jantzen, Karl-Heinz (1990): Vernichtung des Lebensraumes in Werra und Weser durch unzulässige Salzeinleitungen - 10 Jahre Verhandlungen und keine Ergebnisse. - Die Weser, 64(1): 4-5, 1 Abb., 1 Kt.; Bremen

[deutsch-deutsche Verhandlungen zur Reduzierung der Salzeinleitungen im Hessisch-Thüringischen Werra-Kalirevier]

- $\square$ •Hofacker, Hendrik (1990): Gesamtdeutsche Initiative für die Werra - DDR Umweltschützer machen mobil. - Die Weser, 64(5): 173-174; Bremen

[nitiatiative gegen die Werra-Versalzung durch Kali-Abwässer des hessisch-thüringischen WerraKalireviers]

- $\square$-Namenskürzel (rrh) (1990): Salzfracht von Werra und Weser wird verringert. - Erster Teilerfolg erzielt - weitere Maßnahmen erforderlich. - Die Weser, 64(5): 156-163, 3 Abb., 1 Tab.; Bremen

- $\square$ Q $T$ Töpfer, Klaus (1990): Von der Oberliegermentalität zur Partnerschaft. - Die Weser, 64(2/3): 6973; Bremen

[Deutsch-Deutsche Zusammenarbeit zur Reduzierung der Kaliabwässer-Einleitung im hessischthüringischen Werra-Kalirevier]

- $\square$ Q $\bullet$ Wroz, Winfried (1990): Die Werra - ein toter Fluß?. - In: Hildebrand, Erich

[Gesamtkonzeption, Red.]: Land an Werra und Meißner - Ein Heimatbuch. - 3., überarb. Auflage; S. 207 - 210, 1 Abb.; [Hrsg.: Hist. Ges. Werralandes](Bing) Korbach 1990

- $\square$ ○•Heinrich, Ralf Rüdiger (1992): Die unendliche Geschichte der Versalzung von Werra und Weser. - Die Weser, $\underline{\mathbf{6 6}}(2):$ 37-40, 1 Abb.; Bremen

[Schriftliche Fassung eines Vortrages, gehalten auf dem Wesertag 192 in Hameln]

- $\square$ - Cerny, R. (1993): Rechtliche Rahmenbedinungen für die Salzabwasserbeseitigung der Kaliwerke im Werragebiet. - In: (Salz in Werra und Weser - Ursachen, Folgen und Abhilfe. - Ergebnisse einer Fachtagung der ARGE Weser am 22. März 1993 in Kassel) DVWK-Mitteilungen, 24; S. 169 - 182; [Dt. Verband Wasserwirtschaft u. Kulturbau e.V.] Bonn

- $\square$ •Hühn, R. (1993): Die Betroffenheit der Bürger an der Werra. - In: Salz in Werra und Weser Ursachen, Folgen, Abhilfe. Ergebnisse einer Fachtagung der ARGE Weser am 22. März 1993 in Kassel; S. 104-111; Bonn

- $\square$-Kahlert, Margit \& Wolff, Peter (1993): Die Entwicklung der Werraversalzung. - Das Werraland, 45(2): 33-35, 1 Abb.; Eschwege

- $\square 0 \bullet L i e r s c h$, K.-M (1993): Die Entwicklung der Salzfrachten in Werra und Weser. - In: Salz in Werra und Weser - Ursachen, Folgen, Abhilfe. - Ergebnisse einer Fachtagung der ARGE Weser am 22. März 1993 in Kassel - Deutscher Verband für Wasserwirtschaft und Kulturbau. - Mitteilungen Dt. Verbandes f. Wasserwirtschaft u. Kulturbau e.V., 24; XVIII, 187 S., Ill., graph. Darst., Kt.; hierS. S. 69-82; graph. Darst., Kt.; (Dt Verb. Wasserwirtschaft u. Kulturbau; Bonn 
- 0 Schmeisky, Helge; Kunick, Manfred \& Lenz, Otto (1993): Zur Begrünung von Rückstandshalden der Kaliindustrie. - Kali u. Steinsalz, 11(5/6): 132-152, 38 Bilder, 2 Tab.; Hessen [darin: Rückstandshalde III, Werk Wintershall/Heringen; Pilotprojekt Bleicherode]

DoEisenbach, Ulrich (1998): Kaliindustrie und Umwelt. - In: Eisenbach, Ulrich \& Paulinyi, Akos [Hrsg.]: Die Kaliindustrie an Werra und Fulda - Geschichte eines landschaftsprägenden Industriezweigs. - Schriften z. hessischen Wirtschafts- und Unternehmensgeschichte, $\underline{\mathbf{3}}$; S. 194-222, Abb. 94-106, Tab. 14-16; (Hessisches Wirtschaftsarchiv) Darmstadt 1998

[darin: Kaliendlaugenversenkung und Abwässereinleitung in die Werra]

-0•Schmeisky, Helge (1998): Zur Begrünung von Rückstandshalden der Kaliindustrie - Ergebnisse einer 25jährigen Forschungsarbeit. - Kali u. Steinsalz, - enthalten in: Glückauf, 134(9): 501 - 515, Bilder, 4 Tab.; Essen

[darin: Königshall-Hindenburg, Wintershall III, Heitersheim [Bugggingen, Südbaden], Bleicherode, Bischofferode]

- $\square 0 \bullet$ Strube, Manfred (2000): Salzlast in der Werra - Vergleichmäßigung und Steuerung. - Kali u. Steinsalz, 13(14): 81-85, Bilder - zgl. Glückauf, $\underline{136}$ (12): 755-759, 5 Bilder; Essen

- 0 Baethge, Hans-Georg (2002): Wasserwirtschaft in der deutschen Kaliindustrie. - Kali u. Steinsalz, 2002(1): 24 - 31, 11 Abb.; Essen

[darin: Kalilaugeneinleitung in die Werra]

-Hofmann, Hubertus (2004): Untersuchungen zur Begrünung und zur Sukzession auf einer anhydritisch geprägten Rückstandshalde der Kaliindustrie im Werragebiet. - Ökologie u.

Umweltsicherung, 24. - 212 S., Ill. Graph. Darst, Kt.; (Univ. Kassel, Fachgebiet Landschaftsökologie u. Naturschutz, Fachbereich 11, Ökologische Agrarwissenschaften) Witzenhausen - zgl. Diss. Univ. Kassel 2003

[Halde Werk Wintershall b. Heringen]

- $\square$ • Gruß, Joachim (2006): Nein zu 700 Jahre mehr Salzmüll in der Werra! - Dem Hauptnaturschutzwart hat es die Stimmung verschlagen. - Das Werraland, $\underline{\mathbf{8}}(4)$ : 94-95; Bad SoodenAllendorf

- $\square 0 \bullet$ Sagawe, Harald (2006): Salzpipeline zur Werra - Kali und Salz will 700.000 Kubikmeter Chloridlauge in den Fluss einleiten. - Werra-Rundschau, 2006; Nr. 239 v. 14.10./15.10.2006, 2 Abb.; Eschwege s. dazu Kommentar: „Am Salzwasser-Kanal“ (Dieter Preuß)

$\square$ OStück, Tobias (2007): Salzlauge sorgt für Gefahr - Kali \& Salz weiß nicht, wohin mit Abfall / Trinkwasser könnte bald betroffen sein. - Werra-Rundschau, 2007; Nr. 177 v. 2.8.2007; Eschwege [Möglicher Einfluß der Kalilaugenverpressung im Plattendolomit auf die Trinkwasserqualität der Gemeinde Herleshausen]

- $\square$ Q0 Anonym (2007): < Kalilaugen-Einleitung in die Werra> Geplante Einleitungen führen zu ökologischen Schäden - Wanfried: Heiß diskutiertes Thema bei Jahreshauptversammlung des Angelsportvereins ... - Werra-Rundschau, 2007; Nr. 63 v. 15.03.2007, 1 Abb.; Eschwege

- $\square$-Klebe, Peter (2007): Bergbaufirma K + S droht mit Kurzarbeit. - Streit um Salzlaugen-Entsorung eskaliert.... - Werra-Rundschau, 2007; Nr. 237 v. 12.10.2007; Eschwege

[Widerstand gegen Kalilaugen-Verpressung im Untergrund der „Gerstunger Mulde“ und mögliche Auswirkungen auf das Grundwasser und die Firmenpolitik des Kaliproduzenten]

- $\square 0 \bullet$ Klebe, Peter (2007): Harte Front bei Salzlauge. - Gerstungen will Verpressung nicht länger hinnehmen - K + S: Kurzarbeit möglich. - Werra-Rundschau, 2007; Nr. 237 v. 12.10.2007; Eschwege [Widerstand gegen Kalilaugen-Verpressung im Untergrund der „Gerstunger Mulde“ und mögliche Auswirkungen auf das Grundwasser und die Firmenpolitik des Kaliproduzenten] 
- 0 ○/Klebe, Peter (2007): Keine Kompromisse bei Grenzwerten - Roland Koch (CDU) im Redaktionsgespräche: Salzbelastung der Werra langfristig durch bessere Technik senken. - WerraRundschau, 2007; Nr. 248 v. 25.10.2007, 1 Portrait; Eschwege

- $\square 0 \bullet$ Klebe, Peter (2007): K+S plant mit schärferen Werten - Unternehmen rechnet mit geringerer Einleitungsmenge von Salzlauge ab 2012 - Weserbund will Masterplan. - Werra-Rundschau, 2007; Nr. v. 24./25.11.2007, 1 Abb., 1 Kt.; Eschwege

[Geplante Einleitung von Kalilauge aus Werk Neuhof in die Werra bei Philippsthal]

- $\square$ Q $\bullet$ Namenskürzel (Werra-Rundschau) (2007): CDU macht Druck auf Kali + Salz. - Genehmigung, aber nur mit Auflagen. - Werra-Rundschau, 2007, Nr. 130 v. 7.06.2007; Eschwege

[Einleitung von Kalilauge in die Werra durch eine Salzpipeline]

- $\square$ (Mayer, Helmut (2006): „Ökologische Opferstrecke“ - Die Werra hat immer noch ein ungesundes Übermaß an Salzgehalt vorzuweisen. - Werra-Rundschau, 2006; Nr. 241 v. 20.10.2006, 1 Abb.; Eschwege

- $\square$ Q $\bullet$ Riek, Wolfgang (2007): Tiefe Gräben an der Werra - Streit um die Kali-Versenkung - Pumpen gestoppt - Erfurt wirft K + S ,grobe Zumutung“"vor. - Werra-Rundschau, 2007; Nr. 247 v. 24.10.2007, 1 Foto, 1 Übersicht-Kt.; Eschwege - dazu Kommentar: Druck von allen Seiten Wolfgang Riek über den Streit um die Kali-Abwässer

[Kali-Laugenverpressung in den Untergrund bei Gerstungen]

- $\square$ ○्Namenskürzel (kle) (2007): Klage gegen Salzeinleitung eingereicht $<$ Geplante Einleitung von Kaliabwässern in die Werra in Hessisch-thüringischen Werra-Kalirevier>. - Werra-Rundschau, 2007; Nr. 296 v. 21.12.2007; Eschwege

- $\square$-Thonicke, Frank (2008): Strafanzeige gegen Kasseler K+S Manager. - Vorwurf: Unerlaubte Gewässerverunreinigung <Widerstand gegen Einleitung von Kaliabwässer des HessischThüringischen Kalireviers in die Werra>. - Werra-Rundschau, 2008; Nr. 33 v. 8.02.2008; Eschwege

- $\square$ ○ीThonicke, Frank (2008): Kampf gegen Salz wird härter. - Witzenhausen stellt Strafanzeige gegen $\mathrm{K}+\mathrm{S}$ Manager - Werra-Anreiner schließen sich zusammen. <Widerstand gegen Einleitung von Kaliabwässer des Hessisch-Thüringischen Kalireviers in die Werra >. - Werra-Rundschau, 2008; Nr. 33 v. 8.02.2008, 2 Abb., 1 Kt.; Eschwege

- $\square$ ○•Riek, Wolfgang (2008): Auch K+S denkt nun an die Nordsee-Pipeline. - Werra-Rundschau, 2008; Nr. 39 v. 15.02.2008; Eschwege

[Geplante Einleitung von Kaliabwässern des Werkes Neuhof-Ellers in die Werra]

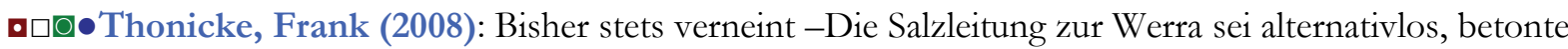
K+S bislang. - Werra-Rundschau, 2008; Nr. 39 v. 15.02.2008; Eschwege

[Geplante Einleitung von Kaliabwässern des Werkes Neuhof-Ellers in die Werra]

- $\square$ Q Thonicke, Frank (2008): Runder Tisch ringt um den Kompromiss. - Am Dienstag erste Gespräche in Kassel um Werra-Belastung und Kali-Produktion - Serienteil 1: Die Geschichte der Kontraverse. - Werra-Rundschau, 2008; Nr. 64 v. 15.03.2008, 1 Foto, 1 Kt.; Eschwege [Geplante Einleitung von Kaliabwässern des Werkes Neuhof-Ellers in die Werra]

- $\square$ - Riek, Wolfgang (2008): 1000 Jahre auf Halde. - Auftürmen, versenken oder in die Werra kippen: Kali-Entsorgung unter Druck. - Werra-Rundschau, 2008; Nr. 66 v. 18.03.2008, 1 Abb.; Eschwege [Geplante Einleitung von Kaliabwässern des Werkes Neuhof-Ellers in die Werra]

- $\square$ Qी Thonicke, Frank (2008): Werra - früher so salzig wie die Nordsee. - Im Fluss ist neben Waser und Salz noch allerhand drin - Das große Problem aber bleibt die Salzbelastung. - Werra-Rundschau, 2008; Nr. 67 v. 19.03.2008; Eschwege 
- $\square$ Qठ Riek, Wolfgang (2008): Nebel über Kalihalden. - Patentanwalt stellt neues Entsorgungskonzept vor - K+S will keine „faulen Geschäfte“. - Werra-Rundschau, 2008; Nr. 98 v. 26./27.04.2008, 1 Abb.; Eschwege

[Neues Entsorgungskonzept für Kaliendlaugen Hessisch-thüringisches Werra-Kalirevier]

- $\square$-Salzmann, Dieter (2008): Kali + Salz lenkt ein. - Unternehmen: Laugen-Transport zur Nordsee auch per Bahn möglich. - Werra-Rundschau, 2008; Nr. 108 v. 9.05.2008, 1 Abb.; Eschwege [Kaliwerk Neuhof-Ellers bei Fulda, Alternative zur Kaliabwässer-Entsorgung in die Werra]

- 0 Riek, Wolfgang (2008): Hilft Holland aus der Klemme? - Testlauf für Verwertung von K+S Abwässern - Hessens Behörden wollen Versenkung „,kritisch prüfen“. - Werra-Rundschau, 2008; Nr. 220 v. 19.09.2008, 1 Kt.; Eschwege

[Hydrogeologie, Interessenkonflikt Bergbau-Naturschutz]

- $\square$ ○ीKlebe, Peter (2008): Absage an Leitung zur Weser. - Weserbund kündigt entschiedenen Widerstand gegen Alternativplan zur Entsorgung von Salzlauge durch K + S an. - Werra-Rundschau, 2008; Nr. 244 v. 18./19.10.2008; 1 Abb.; Eschwege

- $\square$ OӨRiek, Wolfgang (2008): K + S: 360 Mio. Euro sollen Werra entsalzen - Düngerkonzern plant Investitionspaket für Kalirevier Hessen/Thüringen. - Werra-Rundschau, 2008; Nr. 253 v. 29.10.2008; Eschwege

- $\square$ - Riek, Wolfgang (2008): K + S Pakte gegen Umweltprobleme der Kaliindustrie. - Abwasserhahn kleiner gedreht - 360-Mio.-Euro-Plan: Besserung für die salzige Werra und Ausweg aus der Versenkungs-Sackgasse. - Werra-Rundschau, 2008; Nr. 253 v. 29.10.2008, 1 Abb., 1 Kt.; Eschwege

- $\bigcirc$ Riek, Wolfgang (2008): Die Kalilauge kommt wieder zurück - Umweltministerium: 30\% der seit den 1920ern versenkten Abwässer in Buntsandsteinschichten aufgestiegen. - Werra-Rundschau, 2008; Nr. 253 v. 29.10.2008, 1 Foto, 1 Diagr.; Eschwege

ORiek, Wolfgang (2008): Thüringen zieht die Notbremse - Bergamt bestätigt Kalilaugen-Aufstieg Ministerium: Keine Versenkung mehr. - Werra-Rundschau, 2008; Nr. 265 v. 12.11.2008; 2 Fotos, 1 Kt., 1 Zchng.; Eschwege

-Namenskürzel (2008): Versenkung im Boden vor dem Aus. - Werra-Rundschau, 2008; Nr. 267 v. 14.11.2008; Eschwege [Versenkung von Kali-Abwässern des hessischen Werra-Kalireviers in den Plattendolomit]

- $\square$ - Keller, Werner (2009): Der am stärksten belastete Fluss Deutschlands. - Werra-Weser-Anrainer bezweifeln K+S Gutachten zur Wasserqualität der Werra. - WR, 2009; Nr. 17 v. 21.01.2009; Eschwege

- $\square 0 \bullet$ Riek, Wolfgang (2009): Werra: Erst schlechter, bevor es besser wird. - Brinckmann: Ende der Salzwasser-Versenkung verdoppelt Probleme. - WR, 2009; Nr. 18 v. 22.01.2009; Eschwege [Nebenartikel: Zum Tage - Im Fluss und darunter - Wolfgang Riek über die Werraversalzung]

- $\square$ Q Riek, Wolfgang (2009): Versalzene Werra, verdoppeltes Problem - Interview mit Hans Brinckmann, Leiter des runden Tisches: „Mit drastischen, schnellen Rückgängen ist nicht zu rechnen“. WR, 2009; Nr. 18 v. 22.01.2009; 2 Abb.; Eschwege

- $\square$ O०Riek, Wolfgang (2009): < Interessenkonflikt Kaliabwässerentsorgung Hessisch-Thüringisches Werra-Kalirevier> Ein Papier, zig Meinungen - Kalivertrag ist umstritten: Lob, Tadel und Anwälte, die Gegenwähr prüfen. - WR, 2009; Nr. 31 v. 6.02.2009; 1 Abb.; Eschwege

- $\square$ ○्Stück, Tobias (2009): < Konflikt Entsorgung von Kaliabwässern und Salzabfällen im HessichThüringischen Werra-Kalirevier> Am Ende herrscht Zufriedenheit - Nach anfänglichen 
Schwierigkeiten kann runder Tisch Forderungen in Vertrag einbringen. - WR, 2009; Nr. 32 v. 7.02.2009; 1 Abb.; Eschwege

[Themenseite: mit weiteren Artikeln: (wrk) „Reuß-Vorschlag: Laugenzüge rollen nicht“; „Der

Untergrund ist schon voll - Wolfram Brauneis erklärt im WR-Interview die Zukunft der Salzabfälle“]

- $\square$ OKlebe, Peter (2009): Studie: Salz lässt Arten sterben. - Gutachten: Oberhalb der Einleitungspunkte in die Werra tummeln sich deutlich mehr Kleinlebewesen. - WR, 2009; Nr. 91 v. 20.04.2009; 1 Abb.; Eschwege

[Einleitung von Kaliabwässern in die Werra]

- $\square$ Qण Pinto, José (2009): K+S dämpft Erwartungen - Düngemittel - und Salzproduzent rechnet für 2009 mit weniger Umsatz und Gewinn. - WR, 2009; Nr. 111 v. 14.05.2009; 3 Fotos, 1 Diagr.; Eschwege

[Wirtschaftsbericht über den Kasseler Kaliproduzenten; darin: Umweltproblematik der Kalilabwässerversenkung, bzw. Einleitung von Kaliabwässern des in die Werra]

\subsection{Gipsabbau Oberhone (WMK)}

$\square$ Namenskürzel (wl) (1974): Bürgermeister Willi Pfister: Gipswerk erhielt keine Abbaugenehmigung $<$ Widerstand gegen geplanten Gipsaabau bei Oberhone>. - WR, 1974; Nr. 3 v. 4.1.1974, S. 3; Eschwege

$\square$ Namenskürzel (eh) (1974): Auch Oberhone wehrt sich gegen Gipswerk <Widerstand gegen geplanten Gipsabbau bei Oberhone>. - WR, 1974; Nr. 16 v. 19.1.1974, S. 3; Eschwege

$\square$ Namenskürzel (eh) (1974): Versammlung der Bürgerinitiative Heuberg <Widerstand gegen geplanten Gipsabbau bei Oberhone>. - WR, 1974; Nr. 20 v. 24.1.1974; S. 3; Eschwege

$\square$ Namenskürzel (wl) (1974): ... / Für Gipsabbau-Gebiet besteht Landschaftsschutz / . . <Widerstand gegen geplanten Gipsabbau bei Oberhone>. - WR, 1974; Nr. 31 v. 6.2.1974, S. 3; Eschwege

$\square$ Namenskürzel (Na) (1979): Eine Nachricht, die bei vielen wie eine Bombe einschlagen dürfte: Antrag auf Gipsabbau gestellt - Im Bereich Oberhone - Niederhone - Heuberg / ... - WR, 1979; Nr. 297 v. 21.12.1979, S. 3, 1 Abb.; Eschwege

$\square$ Namenskürzel (Na) (1979): < Geplanter Gisbbau bei Oberhone> Alle Fraktionen gegen Gipsabbau / ... - WR, 1979; Nr. 298 v. 22./23.12.1979, S. 3; Eschwege

$\square$ Namenskürzel (wl) (1980): < Geplanter Gipsabbau bei Oberhone> Klagt Stadt gegen Gipsabbau? Bürgermeister Rudolph: Bohrgenehmigung im Jahr 1971 erteilt. - WR, 1980; Nr. 7 v. 9.1.1980, S. 3, 2 Abb.; Eschwege

$\square$ Namenskürzel (Na) (1980): < Geplanter Gipsabbau bei Oberhone> „Gipsabbau unbedingt verhindern“ / ... - WR, 1980; Nr. 9 v. 11.1.1989, S. 3, 1 Abb.; Eschwege

$\square$ Namenskürzel (Na) (1980): < Geplanter Gipsabbau bei Oberhone> Anwohner sollen , nicht belästigt werden“. Eigene Straße für Gipstransporte geplant. - Firma Knauf möchte so bald wie möglich mit der Förderung des begehrten Rohstoffes beginnen. - WR, 1980; Nr. 33 v. 8.2.1980, S. 3, 2 Abb., Eschwege

$\square$ Namenskürzel (wl) (1980): <Geplanter Gipsabbau bei Oberhone> Gipsabbau: Klares „Nein“ Fraktionen v. SPD, CDU und FDP einig / Rudolph: Pläne unvollständig. - WR, 1980; Nr. 52 v. 1./2.3.1980, S. 6; Eschwege 
$\square$ Namenskürzel (mö) (1982): Nach Erdabsenkung in Oberhone: Massive Proteste gegen GipsProbeschurf - Interessengemeinschaft der vom Gipsabbau betroffenen Bürger fordert sofortige Einstellung. - WR, 1983; Nr. 88 v. 16./17.4.1983, S. 3, 4 Abb.; Eschwege

$\square$ Namenskürzel (Na) (1984): <Gipsabbau Oberhone, Sprengung> In Oberhone flogen die Brocken: Sprengungen im Gipsabbaugebiet: Einwohner sind empört / Bergamt ermittelt an Ort und Stelle. WR, 1984; Nr. 51 v. 29.2.1984; S. 3, 4 Abb.; Eschwege

$\square$ Namenskürzel (mö) (1984): Zauberwelt der Bergkristalle - Glitzernde und funkelnde Kostbarkeiten auf Schloß Wolfsbrunnen / Ständige Ausstellung. - WR, 1984; Nr. 75 v. 28.3.1984; S. 6, 2 Abb.; Eschwege

$\square$ Namenskürzel (mö) (1984): < Gipsabbau Oberhone> 15-Punkte-Katalog als Basis für Interessenwahrung von Stadt und Bürgern. - WR, 1984; Nr. 116 v. 18.5.1984, S. 3; Eschwege

$\square$ Namenskürzel (cc) (1996): < Gipsabbau Oberhone> Bei Ausweitung des Gipsabbaus über zweite Sohle müßten größere Flächen abgetragen werden - Auch auf Oberhoner Seite ein „,kleinerer Tagebau“?. - WR, 1996; Nr. 21 v. 25.1.1996, S. 7, 2 Abb.; Eschwege

$\square$ Namenskürzel (hm) (1996): <Gipsabbau Oberhone> Initiativen gegen Gipsabbau formieren sich Berg und Bürger wehren sich. - WR, 1996; Nr. 75 v. 28.3.1996, S. 13, 1 Abb.; Eschwege

$\square$ Namenskürzel (cc) (1996): < Geplante Ausweitung Gipsabbau Oberhone> Knauf-Antrag in Kürze erwartet / Bergamt warnt vor ,verkapptem Tagebau“ - Gipsabbau: Stadt empfiehlt Niederhone auszuklammern. - WR, 1996; Nr. 120 v. 24.5.1996, S. 9; Eschwege

$\square$ Namenskürzel (kk) (1996): <Gipsabbau Oberhone> Ausweitung Gipsabbau / Bau- und Planungsausschuß - Klares Nein zum Tagebau. - WR, 1996; Nr. 208 v. 6.11.1996, S. 10, 1 Abb.; Eschwege

$\square$ Namenskürzel (kk) (1996): <Gipsabbau Oberhone; Sitzung Bauausschuß und Ortsbeirat Oberhone> Gemeinsame Sitzung: Gipsabbau in Oberhone - Alles dreht sich um das „Loch“. - WR, 1996; Nr. 255 v. 1.11.1996, S. 9; Eschwege

$\square$ Namenskürzel (kk) (1996): <Gipsabbau Oberhone> Erweiterung Gipsabbau / Stellungnahme liegt vor - Stadt <Eschwege $>$ hat jede Menge Bedenken. - WR, 1996; Nr. 285 v. 6.12.1996, S. 10; Eschwege

- $\square$ Huhn, Karl-Hermann (1996): Gips-Abbau: Das Bergrecht bezwingt den Bürgerwillen. - HNA, 1996; Nr. 15 v. 14.4.1996; Kassel

[Oberhone u. Berneburg im Werra-Meißner-Kreis, Morschen im Schwalm-Eder-Kreis]

$\square$ Namenskürzel (Werra-Rundschau/kk)(1997): Verein gegründet: Kräfte gebündelt gegen Ausweitung des Gipsabbaues. - Werra-Rundschau, 1997; v. 28.2.1997; Eschwege [Gipsabbau Eschwege-Oberhone]

$\square$ Namenskürzel (dk) (1997): Gipsabbau am Steinröllchen in Oberhone: Erde auf Viehweide eingebrochen - Feuerwehr rettet Reh aus Doline. - WR, 1997; Nr. 138 v. 18.6.1997, S. 13, 3 Abb.; Eschwege

$\square$ Namenskürzel (sj) (1998): Gipsabbau in Oberhone / Grünes Licht für Bau einer Verladestation. Genehmigung quasi erteilt - mit „erheblichen Auflagen“. - WR, 1998; Nr. 138 v. 18.6.1998, S. 9; Eschwege 
$\square$ Namenskürzel (WR/hm) (1998): Erweiterter Gipsabbau in Grube Alfons < Oberhone> Bürgerinitiative sieht Ungereimtheiten beim Genehmigungsverfahren. - WR, 1998; Nr. 201 v. 31.8.1998, S. 10, 2 Abb; Eschwege

$\square$ Namenskürzel (cc) (1998): Gipsabbau in Oberhone / Zulassungsbescheid - Zweifel an Rechtmäßigkeit. - WR, 1998; Nr. 235 v. 9.10.1998, S. 12; Eschwege

$\square$ Namenskürzel (WR) (2000): < Gipsabbau Oberhone> Bürgerinitiative Gips warnt vor Gefahren der Dolinen: Absperrmaßnahmen reichten nicht aus. - WR, 2000; Nr. 159 v. 12.7.2000, S. 9, 2 Abb.; Eschwege

$\square$ Anonym (2001): <Gipsabbau Oberhone> Bürgerinitiative Gips erhält Einblick in Grube Alfons Schon einige Probleme gelöst. - WR, 2001; Nr. 249 v. 26.10.2001, S. 11, 1 Abb.; Eschwege

$\square$ Namenskürzel (WR) (2003): Erdpyramiden am Steinröllchen <zwischen Oberhone und Heuberg> Bürgerinitiative Gips beklagt neue Gefährdungsstellen. - WR, 2003; Nr. 97 v. 26.4.2003, 1 Abb.; Eschwege

$\square$ Namenskürzel (WR) (2004): < Gipsabbau Oberhone> Mit kleinen Schritten zum Erfolg - Seit 30 Jahren beobachtet eine Bürgerinitiative kritisch den Gipsabbau. - WR-Sonntagszeit, 2004; Nr. 39 v. 3.10.2004, 1 Abb.; Eschwege

$\square$ Namenskürzel (WR/HM) (2004): < Ausweitung Gipsabbau Oberhone> Angst vor Gipsabbau über Tage - Firma Knauf strebt ihn erneut im Stadtgebiet an bis zu 200 Meter an Wohnhäuser heran. WR, 2004; Nr. 264 v. 10.11.2004, 1 Abb.; Eschwege

\subsection{Gipsabbau Krösselberg/Meißnervorland}

$\square$ Namenskürzel (mö) (1997): Gemeindevertretung Meißner: Neuaufstellung des Regionalplanes für die Region Nordhessen - Gipsabbau am „Krösselberg“ in der Debatte. - WR, 1997; Nr. 171 v. 26.7.1997, S. 12, 2 Abb.; Eschwege

$\square$ Möller, Dieter (1997): Gemeinden Meißner/Berkatal: Gipsabbau am „Krösselberg“ ins Auge gefaßt Mandatsträger informierten sich vor Ort in Morschen. - WR, 1997; Nr. 253 v. 31.10.1997, S. 11, 3 Abb.; Eschwege

$\square$ Namenskürzel (hs) (1998): Gipsabbau am Krösselberg - Bürger kündigen Widerstand an. - WR, 1998; Nr. 116 v. 20.5.1998, S. 15; Eschwege

$\square$ Namenskürzel (cc) (1999): Interessengemeinschaft Krösselberg führte Landtagsabgeordneten die Problematik vor Augen - Widerstand gegen Gipsabbau wächst. - WR, 1999; Nr. 90 v. 19.4.1999, S. 7, 1 Abb.; Eschwege

$\square$ Namenskürzel (sj) (1999): Gipsabbau am Krösselberg - „Aus Naturschutzsicht zu begrüßen“ - WR, 1999; Nr. 153 v. 5.7.1999, S. 7, 1 Abb.; Eschwege

$\square$ Namenskürzel (WR) (1999): Gipsabbbau am Krösselberg - „Aus Artenschutzsicht keine schwerwiegenden Bedenken“. - WR, 1999; Nr. 164 v. 17.7.1999, S. 11; Eschwege

$\square$ Namenskürzel (mö) (2000): Gemeinde Meissner: Abgrenzungsvorschläge für Flora - Fauna - HabitatKrosselberg bleibt für Gipsabbau offen. - WR, 2000; Nr. 23 v. 28.1.2000, S. 11, 1 Abb.; Eschwege 
$\square$ Möller, Dieter (2001): Geplanter Gipsabbau <am Krösselberg>: Bürgerentscheid am 28. Oktober SPD: „Den BI-Antrag ablehnen“. - WR, 2001; Nr. 201 v. 30.8.2001, S. 13, 1 Abb.; Eschwege

$\square$ Möller, Dieter (2001): Geplanter Gipsabbau am Krösselberg - „Große Chance für Meißner“. - WR, 2001; Nr. 244 v. 20.10.2001, S. 14, 1 Abb.; Eschwege

$\square$ Möller, Dieter (2001): <Fa. Knauf zum geplanten Gipsabau am Krösselberg> Gipsabbau am am Krösselberg: Interview mit Werksleitung der Gebr. Knauf - „Behauptungen längst unhaltbar“. - WR, 2001; Nr. 279 v. 30.11.2001, S. 14, 1 Abb.; Eschwege

$\square$ Möller, Dieter (2001): Geplanter Gipsabbau am Krösselberg - BI-Sprecher Rolf Sennhenn sieht: Wenig Demokratieverständnis. - WR, 2001; Nr. 291 v. 14.12.2001, S. 14, 1 Abb.; Eschwege

\subsection{Weiterer Bergbau an anderen Lokalitäten}

\section{Basalt und Braunkohle}

$\square$ Anonym (1919): <Die „Blaue Kuppe“ als Naturdenkmal erhalten]. - Eschweger Tageblatt, 1919; Nr. 196 v. 23.8.1918; Eschwege

$\square$ Anonym (1920): < Einschränkung des Basaltabbaus an der „Blauen Kuppe“ nach Initiative des Werratalvereins]. - Eschweger Tageblatt, 1920; Nr. 42 v. 19.2.1920; Eschwege

口Jäger, Willy (1923): Im Briefwechsel mit der „Blauen Kuppe“. - Eschweger Tageblatt, 1923; 26.6.1923; Eschwege

[Fiktiver Briefwechsel über Interessenkonflikt Steinbruchbetrieb/Naturschutz]

-Anonym (1962): Der Gaußturm am Rande des Abgrundes - Ein heftiger Streit im Süden Niedersachsens. - Die Weser, $\underline{\mathbf{3 6}}(7):$ 117-120, 2 Abb.; Bremen

[Basaltabbau am Hohen Hagen b. Göttingen und entstehende Beeinträchtigungen]

-Beuermann (1962): Die Tragödie vom Gaußturm auf dem Hohen Hagen. - Das Werraland, 14(2): 2223, 1 Abb.; Eschwege

[Bergbau contra Erhalt des alten Gaußturmes]

$\square$ Namenskürzel (H.) (1972): Neue Gefahren für den Meißner? - Das Werraland, 24(1): 19, 2 Abb.; Eschwege [Basaltabbau contra Naturschutz]

$\square$ Namenskürzel (aja)(1976): PREAG plant Tagebau bei Retterode: Wasservorkommen durch Kohleabbau gefährdet?/... - HA (WN), 1976; Nr. 238 v. 12.10.1976; Witzenhausen [Kohleabbau Randbereich ehemalige Zeche Glimmerode]

-Krischmann, Helmut (1994): Braunkohle und Ton - Gefährdet Abbau Quellen? - HNA, 1994; Nr. 302 v. 30.12.1994, 1 Abb.; Kassel [Geplanter Abbau b. Wickenrode (Hirschberg)]

$\square$ Namenskürzel (kri)(1991): Kohleabbau - Droht Gefahr fürs Trinkwasser. - HNA, 1991; Nr. 201 v. 30.8. 1991, 1 Abb.; Kassel [Hirschberg b. Großalmerode] 


\section{$\underline{\text { Abbau anderer Steine und Erden-Vorkommen }}$}

QAnonym (1930): Creuzburg - Der Abbau der Nordmannsköpfe < Kalksteingewinnung contra Naturschutz>. - Eschweger Tageblatt, 1930; Nr. 199 v. 26.08.1930

- $\square$ Huhn, Karl-Hermann (1996): Gips-Abbau: Das Bergrecht bezwingt den Bürgerwillen. - HNA, 1996; Nr. 15 v. 14.4.1996; Kassel

[Oberhone u. Berneburg im Werra-Meißner-Kreis, Morschen im Schwalm-Eder-Kreis]

-Koch, Imke (1996): Gipsbruch: Die Gegner geben nicht auf - Das Gelände für einen potentiellen Gipsbruch am Konnefelder Rotenberg ist zum Abbaugebiet deklariert worden - Jetzt geht das Genehmigungsverfahren in die zweite Runde - Doch die Gegner des Gipsbruches geben nicht auf. HNA (Ro), 1996; v. 8.11.1996; Kassel

$\square$ Namenskürzel (Mö) (2006): < Geplanter Kiesabbau zw. Niederhone und Jestädt> Kiesabbau sorgt für Diskussionen - Gefährdung des Hochwasserschutzes, Förderlärm und erhöhte Verkehrsbelastung befürchtet. - Werra-Rundschau, 2006; Nr. 134 v. 12.6.2006, 1 Abb; Eschwege

$\square$ Möller, Dieter (2007): Tiefe Enttäuschung in Jestädt - Regierungspräsidium genehmigt Bau einer Kiesaufbereitungsanlage in Niederhone. - Werra-Rundschau, 2007; Nr. 59 v. 10./11.3.2007, 1 Abb.; Eschwege

-Namenskürzel (ach)(1987): Die Grünen schlagen Alarm: Kiesgrube in der Fuldaaue? - Ehemaliger Hafen. - HNA, 1987; Nr. 14 v. 17.1.1987; Kassel

-Namenskürzel (sgr)(1987): Pläne für die Fuldaaue - Nach Kiesabbau neue Lebensräume? - HNA, $\underline{1987}$; Nr. 23 v. 28.1.1987; Kassel

-Namenskürzel (mdm)(1987): Firma stellt Kiesabbau wieder ein - Noch fehlt Rekultivierungsplan. HNA, 1987; Nr. 247 v. 23.10.1987; Kassel

[Kiesabbau in der Fuldaaue/Kassel]

-Namenskürzel (ach)(1988): Diplomarbeit zum Kiesabbau in der Fuldaaue - Anstoß zum Überdenken. - HNA, 1988; Nr. 67 v. 19.3.1988; Kassel

-Namenskürzel (hro)(1993): Niederhessische Senke: 400 Millionen Tonnen Kies lagern noch in der Erde [Borkener Senke, Schwalm-Eder-Kreis]. - HNA, 1993; Nr. 204 v. 2.9.1993; Kassel

-Namenskürzel (awe)(1996): Hafen - Helleberg [Kassel]: Kiesabbau soll im Herbst beginnen. Ab Herbst soll in Hafennähe mit großflächigem Kiesabbau begonnen werden. Nach Abschluß der jahrelangen Arbeiten entsteht eine Wasserfläche, die als Landschaftsschutzgebiet ausgewiesen wird. HNA, 1996; v. 10.2.1996; Kassel

$\square$ Richert, Wilfried (1988): Die Wendershäuser Aue. Landschaftszerstörung als geplante Veränderung der Landschaftsstruktur durch Kiesabbau und Werrapark. - In: Groeneveld, Sigmar [Hrsg.]: Grün kaputt - warum? - Textsammlung, Gesamthochschule/Unversität Kassel; Fachbereich 21 Internatiionale Agrarwirtschaft - Witzenhausen; 278 S., Abb., hier S. 269-275; Witzenhausen 1988

- $\square$ Saemann, Ulrich (1970): Neue Seen entstehen - Auf ödem Land grünt es wieder - Technik heilt Wunden, die der Bergbau schlug. - HA, 1970; Nr. 169 v. 25.7.1970, 2 Abb.; Kassel [Hessen, WMK]

-Thaetner, Inge (1995): Werratal: Widerstand gegen Kiesabbau wächst. Werra-Gemeinden wollen sich nicht die Landschaft durch wachsenden Kiesabbau verschandeln lassen, dessen Genehmigung sich zudem außerhalb ihrer Zuständigkeit vollzieht [Wartburgkreis]. - HNA (Ausgabe Thüringen), 1995; Nr. 153 v. 5.7.1995; Kassel 


\subsection{Rekultivieren - Begrünen - Verwahren}

$\square$ Anonym (1968): Rekultivierung des Betriebsgeländes der Zeche Glimmerode. - Bergbau im Hessenland, 18 (1)[damit Erscheinen eingestellt]: 10-11, 5 Abb.; Kassel

d $\square$ Follmann, Fritz (1968): Braunkohlen-Abbau beendet - was nun? - Hessischer Gebirgsbote, 69(2): 30 -31 ; Melsungen [darin: Habichtswald, Stellberg/Söhrewald, Gahrenberg, Höllkopf/Glimmerode, Kalbe/Hoher Meißner]

-Fritsche, Johann-Gerhard (2002): Die Erweiterung der Rückstandshalden der Kaliindustrie im WerraFulda-Kaligebiet. Maßnahmen zum Grundwasserschutz. - Jber. HLUG, f. 2001, S. 127-131, 3 Abb.; Wiesbaden

- Heintel, Hans (1956): Bergbaugebiet wird wieder Ackerland - „PREAG“ Borken gibt jährlich etwa 400000 DM für „Rekultivierungsarbeiten“ aus. - HN, 1956; Nr. 214 v. 11.9.1956; Kassel

$\square$ Heintze, Gottfried (1961): Landschaftspflegerische Planung am Meißner. - Das Werraland, 13(1): 8-11, 3 Abb.; Eschwege

[Bergbau u. Renaturierung]

$\square$ Heintze, Gottfried (1976): Landschaftsplanung und Landschaftspflege am Meißner 1950 - 1970. Hessische Heimat, N.F., 26 (3) (Sonderheft: Braunkohlenbergbau und Landschaftspflege auf dem Hohen Meissner - Stand 1975): 88 - 98, 11 Abb.; Marburg/L.

-Hofmann, Hubertus (2004): Untersuchungen zur Begrünung und zur Sukzession auf einer anhydritisch geprägten Rückstandshalde der Kaliindustrie im Werragebiet. - Ökologie u. Umweltsicherung, 24. - 212 S., Ill. Graph. Darst, Kt.; (Univ. Kassel, Fachgebiet Landschaftsökologie u. Naturschutz, Fachbereich 11, Ökologische Agrarwissenschaften) Witzenhausen - zgl. Diss. Univ. Kassel 2003

[Halde Werk Wintershall b. Heringen]

- •Lenz, Otto (1983): Stand der Untersuchungen zur Begrünung von Rückstandshalden der Kaliindustrie. - Kali u. Steinsalz, $\underline{\mathbf{8}}(12):$ 406-410, 1 Kt.; Essen

[darin: Königshall-Hindenburg/Reyershausen, Wintershall/Heringen, Hattorf/Philippstahl]

-Meyer, Hans-Karl (1957): Der Landschaftswandel in den Braunkohlengebieten von Borken und Frielendorf unter besonderer Berücksichtigung der Rekultivierung. - Marburger geographische Schriften, $\underline{\mathbf{5}}$; 104 S., Abb., Kt., Taf.; (Selbstverl. Geogr. Inst. Univ. Marburg) Marburg - zgl. Diss. Univ. Marburg 1957

- $\square$ Namenskürzel (0)(1968): HBZ stellt die gesamte Braunkohlenförderung ein - Auf dem Zechengelände am Stellberg und Glimmerode sollen Erholungszentren mit Teichen entstehen. - HA, $\underline{1968}$; Nr. 93 v. 20.4.1968; Kassel

-Namenskürzel (zef)(1975): Im Revier der Grube Altenburg, Borken: Letzte Kohle aus dem Tagebau IV - Neun Millionen Tonnen gefördert - Künftig 130 ha große Wasserfläche. - HA (FHA) $\underline{\mathbf{1 9 7 5}}$; Nr. 107 v. 10.5.1975; Kassel

-Namenskürzel (t)(1977): Aus Trichtern eine Seenplatte: Landschaft nach „Großalmeroder Art“ Nach Braunkohlenabbau über Tage entsteht ein neues Naherholungsgebiet. - HA, 1977; Nr. 155 v. 8.7.1977; Kassel [Umgebung Großalmerode] 
$\square$ Namenskürzel (t)(1981): Tagebaufelder der Natur zurückgegeben - bei Großalmerode „Renaturalisierung“. - HA, 1981; Nr. 235 v. 10.10.1981; Kassel [Braunkohlenbergbau am Hirschberg b. Großalmerode]

- $\square$ Namenskürzel (t)(1984): Auf Abraumkippen grünt es wieder: Erfolge bei Rekultivierung. - HNA, 1984; Nr. 195 v. 22.8.1984; Kassel

[darin: Hirschberg b. Großalmerode, ehem. Zeche Glimmerode b. Hessisch-Lichtenau/Retterode]

OParnieske-Pasterkamp, Jutta (2003): Zur Haldenstruktur und Salzlösungsgenese von Rückstandshalden der Kaliindustrie in Nordthüringen - The structure and salt solution genesis of residual heaps of potash industries in Northern Thuringia. - Z. geol. Wiss., 31(1): 45-91, 12 Abb., 25 Tab., 2 Taf.; Berlin [Rückstandshalden Bischofferode, Menteroda]

$\square$ Schade, Hartmut (1976): Vorzeitiges Ende der Kohlegewinnung am Meißner - was wird aus der Bergbaulandschaft? - - Hessische Heimat, N.F., 26(3) (Sonderheft: Braunkohlenbergbau und Landschaftspflege auf dem Hohen Meissner - Stand 1975): 99 - 106, 4 Abb.; Marburg/L.

-Schmeisky, H. (1990): Rekultivierungs- und Ausgleichsmaßnahmen im Braunkohletagebau. - In: Wiemer, K. [Hrsg.]: Abfallwirtschaft und Deponietechnik '90. - Abfall-Wirtschaft, $\underline{\mathbf{5}} ; 737$ S., Ill., graph. Darst.; hier: S. 381-394, Abb. 1a-c, 2, 4 Diagr.; (Fachgebiet Abfallwirtschaft und Recycling, Universität Kassel) Kassel 1990

[Borkener Braunkohlerevier]

口0•Schmeisky, Helge (1998): Zur Begrünung von Rückstandshalden der Kaliindustrie - Ergebnisse einer 25jährigen Forschungsarbeit. - Kali u. Steinsalz, - enthalten in: Glückauf, 134(9): 501 - 515, Bilder, 4 Tab.; Essen [darin: Königshall-Hindenburg, Wintershall III, Heitersheim [Bugggingen, Südbaden], Bleicherode, Bischofferode]

- $\bigcirc$ Schmeisky, Helge; Kunick, Manfred \& Lenz, Otto (1993): Zur Begrünung von Rückstandshalden der Kaliindustrie. - Kali u. Steinsalz, 11(5/6): 132-152, 38 Bilder, 2 Tab.; Hessen [darin: Rückstandshalde III, Werk Wintershall/Heringen; Pilotprojekt Bleicherode]

Q•Spier, Hans-Harm \& Ruck, Hartmut (1997): Verwahrung von Salzbergwerken - Ergebnisse und Konzepte. - Kali u. Steinsalz, 12(5): 169-179, 9 Bilder, 2 Tab.; Essen [darin: Königshall-Hindenburg/Reyershausen, Wittekind-Hildasglück/Volpriehausen; Merkers, Buggingen]

- $\square$ Vogt, Egon E. (1978): Eine Wiedergutmachung an der Natur - Nach Kohleabbau: Lebensraum wird neu gestaltet. - HA, 1978; Nr. 156 v. 10.7.1978; Kassel

[Rekultivierung Borken, Hirschberg b. Großalmerode; Exberg b. Epterode;]

-Zundel, Rolf (1982): Die Begrünung der Kalihalde in Reyershausen. - Plesse-Archiv, 18: 189-204, 9 Abb., 3 Kt., graph. Darst.; Göttingen

\subsection{Geologie und Naturschutz}

$\square$ Angerhöfer, Horst (1990): Der Altarstein - Verwirrungen um ein Naturdenkmal. - Das Werraland, 42(3): 47-49, 1 Abb., 1 Kt.-Skizz.; Eschwege 
$\square$ Anonym (1920): < Blaue Kuppe - Schutzmaßnahmen zum Erhalt des geologischen Naturdenkmals bei Eschwege - Aus einem Brief des Regierungspräsidenten zu Cassel an den Werratalverein>. Eschweger Tageblatt, 1920; Nr. 42 v. 19.02.1920; Eschwege

- $\square$ Anonym (1924): < Schutzmaßnahmen für Basaltvorkommen in Nordhessen]. - Eschweger Tageblatt, 1924; Nr. Nr. 176 v. 29.7.1924; Eschwege

[darin: Blaue Kuppe b. Eschwege; Bilsteinkirche b. Eschenstruth; Bühl b. Ahnatal/Weimar, Helfensteine am Dörnberg]

$\square$ Anonym (1924): <Zechstein-Felsen bei Albungen unter Schutz gestellt]. - Eschweger Tageblatt, 1924; Nr. 233 v. 3.10.1924; Eschwege

$\square$ Anonym (1942): Sicherung naturgeschichtlicher Bodenaltertümer im Kreis Eschwege. - Eschweger Tageblatt, 1942; NR. 214 v. 12./13.09.1942; Eschwege

QAnonym (1993): Naturdenkmal bleibt sichtbar: Ein Stück Heimatkunde. - Hessischer Gebirgsbote, 94(2): 64; Melsungen

[Bahnhof Hörschel/Werra; Basaltgang im Unteren Muschelkalk]

- Friese, H. (1980): Geologische Naturdenkmäler von Niedersachsen - Sonderausstellung 1974/75: Niedersächsisches Landesmuseum Hannover/Naturkunde-Abteilung; 3. Aufl., 35 S., [17] Abb.; Hannover [darin: Rhumequelle/Rhumspringe; Basalt Hoher Hagen/Dransfeld]

-Ganßauge, Gottfried (1959): Alte Bäume und markante Steine - Naturdenkmale um Kassel. Hessische Heimat, N.F., $\underline{8}(4)$ : 12-14, Abb. 11-16; Marburg

-Germeroth, Rüdiger; Koenies, Horst \& Kunz, Reiner (2005): Natürliches Kulturgut Vergangenheit und Zukunft der Naturdenkmale im Landkreis Kassel. - 1. Aufl., 192 S., zahlr. Abb., Kt., Kt.-Skizz., graph. Darst.; [Hrsg. Kreisausschuss Landkreis Kassel, Untere Naturschutzbehörde] (Cognitio) Wolfhaben

[darin S. 13 - 45, Abb., Kt.-Skizz., graph. Darst.: „Geologische Naturdenkmale“ mit Abriß der regionalen Erdgeschichte]

QGeyer, Roland (1994): Die Geologischen Naturdenkmale im Kreis Eisenach [Wartburgkreis]: 1. Das Zechsteinprofil am Bahnhof Förtha. - Knüllgebirgsbote, 1994(2): 6, 1 Abb.; Bad Hersfeld

OGeyer, Roland (1994): Die Geologischen Naturdenkmale im Kreis Eisenach [Wartburgkreis]: 2. Die Erdfälle bei Frauensee. - Knüllgebirgsbote, 1994(3): 3, 1 Abb.; Bad Hersfeld

QGeyer, Roland (1994): Die Geologischen Naturdenkmale im Kreis Eisenach (Wartburgkreis): 3. Der Basaltgang am Bahnhof Hörschel. - Knüllgebirgsbote, 1994(4): 9-10, 1 Abb.; Bad Hersfeld

QGeyer, Roland (1995): Die Geologischen Naturdenkmale im Kreis Eisenach (Wartburgkreis): 4. Geolog. Naturdenkmale bei Neuenhof. - Knüllgebirgsbote, 1995(1): 12, 1 Abb.; Bad Hersfeld [Rotliedendes, Zechstein]

OGeyer, Roland (1994): Die Geologischen Naturdenkmale im Wartburgkreis: 5. Felsformationen südlich von Eisenach. - Knüllgebirgsbote, 1995(4): 6; Bad Hersfeld [Rotliegendes]

OGeyer, Roland (2001): Geotopschutz und Öffentlichkeitsarbeit im Wartburgkreis $<$ Vortragskurzfassung > . - In: Rauche, Henry [Hrsg.]: Regionale und angewandte Geologie der Grenzregion der Süddeutschen und der Mitteldeutschen Scholle. - Programm und Kurzfassungen der Vorträge. - 10. Jahrestagung Gesellschaft f. Geowissenschaften i. Schmalkalden, 19.-22. September 2001. - Exkursionsführer u. Veröff. Ges. f. Geowiss., 214; S. 111-113; Berlin 2001 
QGeyer, Roland (o. J.): Naturschönheiten im Landkreis Eisenach - 1. Teil: Geologische Naturdenkmale. - 32 S. zahlr. Abb. (Fotos, Profile, Kt., strat. Tab.); [Hrsg.: Umweltamt des Landrates Eisenach Untere Naturschutzbehörde] Eisenach [darin: Profil von Epichnellen/Bhf. Förtha; Kristallinaufschluß Busbahnhof Ruhla; Stoffelskuppe u. Pflasterkaute; Granitporphyr von Thal/Heiligenstein; Basaltgang Bhf. Hörschel]

$\square$ Hotzler, Fritz (1999): Naturdenkmäler im Meißnervorland. - Das Werraland, 51(1): 13, 1 Abb.; Eschwege [Felsbildungen im Zechstein-Hauptdolomit]

OHuneck, M.; Irmer, R. \& Lange, H. (1987): Natur- und Bodendenkmale im Kreis Ilmenau. - 35 S., Ill., graph. Darst., 1 Kt.-Beil.; [Kreisleitung Ilmenau - Kulturbund d. DDR] Ilmenau

OKrause, Reinhard (1981): Der Wasserfall der Lutter bei Großbartloff. - Eichsfelder Heimathefte, [21] 1981(3): 213-216, 1 Abb.; Worbis

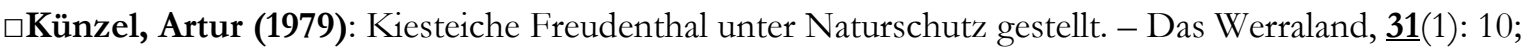
Eschwege

$\square$ Lätsch, Götz (1978): Die Kiesteiche bei Ermschwerd sollten Naturschutzgebiet werden. - Das Werraland, $\underline{\mathbf{3 0}}(1)$ : 7; Eschwege

$\square$ Maurer, Jacob (1978): Das traurige Schicksal eines Naturdenkmals - Der Karlsbrunnen bei Eichenberg droht zu versiegen. - Das Werraland, $\underline{\mathbf{3 0}}(2):$ 19, 1 Abb.; Eschwege

$\square$ Maurer, Jacob (1978): Naturschutz im Werra-Meißner-Kreis. - Das Werraland, $\underline{\mathbf{3 5}}$ (3): 45-47; Eschwege [darin: Bergbau Hoher Meißner, Hesselbühl („Roter See“) Kaufunger Wald b. Großalmerode, Bilstein/Kaufunger Wald]

$\square$ Maurer, Jacob (1981): Neues Naturschutzgebiet Liebenberg - Hasenkanzel. Beschreibung und

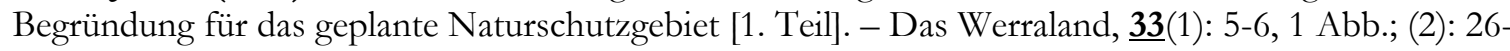
28; Eschwege [darin: S. 6, Abb.: „Geologie“]

$\square$ Möller, Klaus (1990): Der Hohe Meissner - wertvoller Naturraum konkurriert mit unterschiedlichen Nutzungsansprüchen. - Fliegende Blätter: ornitholog. Mitt. u. Naturschutz-Informationen a.d. WerraMeissner-Kreis, $\underline{4}(4), 1989 / 1990: 21-28$

OMorgenroth, Volker (2000): Geschütze und schützenswerte geologische Objekte im Kreis Schmalkalden - Meiningen, 1. Fortsetzung. - Veröff./ Naturhist. Museum Schleusingen, 15: 61-79, 59 Abb., 1 Übers.-Kt.;

OMorgenroth, Volker (2001): Geschütze und schützenswerte geologische Objekte im Kreis Schmalkalden - Meiningen, 2. Fortsetzung. - Veröff./ Naturhist. Museum Schleusingen, 16: 1-14, Abb. 60-74; Schleusingen

$\square$ Namenskürzel [ds](2006): Geologische Sehenswürdigkeit bei Eschwege (Hessen) wieder freigelegt. GMIT - Geowissenschaftliche Mitteilungen, $\underline{26}$ (Dezember 2006): 18-19; Bonn [Zechsteinprofil Fürstenstein b. Albungen, Blaue Kuppe b. Eschwege]

-Naumann, Peter (1986): Geologische Denkmäler - Geologie und Naturschutz im Landkreis Kassel. Hessischer Gebirgsbote, $\underline{\mathbf{8 7}}(4)$; Melsungen

-Naumann, Peter (1987): Das Diemeltal bei Liebenau: Mineralisation und Dioxindeponie (Lamerden) Muschelkalkfossilien und Bauschuttdeponie (Haueda). - Hessischer Gebirgsbote, $\underline{\mathbf{8 8}}(2)$ : 55 - 58; Melsungen 
ONeureuter, Franz (1925): Das erste eichsfeldische Naturschutzgebiet. - Der Hasenwinkel bei Fretterode. - Unser Eichsfeld, 20: 132-135; Duderstadt [auch Regionalgeologie; Einrichtung des Naturschutzgebietes 1920]

-Nielbock, Ralf \& Röhling, Heinz-Gerd (2005): Einhornhöhle und Rhumequelle - herausragende Geotope im südniedersächsischen Zechstein-Karst. - Eichsfelder Heimatzeitschrift, 49 (5)/2005(Mai): 161-164, 2 Abb.; Duderstadt

$\square$ Nöldechen, W. (1975): Naturzerstörung am Ludwigstein durch Straßenausbau. - Das Werraland, 27(2): 27; Eschwege

[Instabile Sandsteinfelsen a. d. B27 unterhalb Ludwigstein]

OPeter, Heinz (1978): Schutzgebiete und Naturdenkmäler im Kreis Worbis. - Eichsfelder Heimathefte, (18. Jg.) $\underline{\mathbf{1 9 7 8}}(1):$ 83; Worbis

[darin: [geol.] Flächendenkmäler: Wasserfall der Lutter bei Großbartloff, geologischer Aufschluß bei Großbartloff]

OPustal, I.; Putschkus, F. \& Hauste, Karl-Hermann (1995): Geotopschutz in Thüringen. - Geowiss. Mitt. Thüringen, $\underline{\mathbf{3}}$ : 173-181; Weimar

OPustal, Ina (2000): Stand und Perspektiven des Geotopschutzes im Freistaat Thüringen. - Geowiss. Mitt. Thüringen, Beih. 10: 237-244, 2 Abb., 1 Tab.; Weimar

$\square$ Reinhardt, Hugo (1965): Eine Landschaft verändert ihr Gesicht - Die Rückwirkung auf Wild und Vogelwelt. - Das Werraland, 17(2): 23-24; Eschwege

[Kiesabbau im Werratal bei Eschwege]

QRöhling, Heinz-Gerd (2005): Der Hasenwinkel bei Fretterode - ältestes Naturschutzgebiet im Eichsfeld und bedeutender Geotop. - Eichsfelder Heimatzeitschrift, 49(7/8)/2005(Juli/August): 249251, 3 Abb.; Duderstadt

- Schaefer, Bernhard (1926): Der Hirzstein im Habichtswald als Naturschutzgebiet. - Hessenland, $\underline{\text { 38}}(8)$ : 163-167, 8 Abb.; Kassel

[Botanik, Geologie]

- $\square$ OSchäfer, B. (1932): Bodengestaltung und Naturschutz des Regierungsbezirks Kassel. - Das Werratal, 9(2): 18-23, 4 Abb.; Eschwege

OSchneider, Roland (1987): Geologische Naturdenkmale im Bezirk Suhl. Übersicht und Diskussion. Veröff./ Naturhist. Museum Schleusingen, 2: 77-95, 7 Abb., 2 Tab.; Schleusingen

$\square$ Schönnamsgruber, Helmut (1979): Meißner - Kernstück eines der schönsten Naturparke Deutschlands. - Das Werraland, $\underline{\mathbf{3 1}}(1)$ : 1-2; Eschwege

- $\square$ Schulze, H. (1939): Naturschutz im Regierungsbezirk Kassel. - Hessischer Gebirgsbote, $\underline{45}(2): 27$ 29, 3 Abb.; Melsungen

[Fotos: Bühl b. Ahnatal/Weimar, Kitzkammer/Hoher Meissner]

oSitte, J. (1983): Limburgitgang in der Wellenkalk-Folge - ein geologisches Naturdenkmal des Kreises Eisenach. - Landsch.Pflege u. Naturschutz. Thüringen, 20(1): 23-25; Jena

$\square$ Ullrich, Prof. (1939): Wie deutsche Kulturlandschaft wurde. Eine kulturgeschichtliche Wanderung im Werratal. - Hessischer Gebirgsbote, $\underline{\mathbf{4 5}}(1): 2$ - 8, 7 Abb.; Melsungen [darin: Waldschäden durch übermäßigen Holzeinschlag für die Saline Sooden b. Allendorf; Fotos: Heldrastein, Hesselbühl/Kaufunger Wald, Roter See, Blaue Kuppe] 
OWätzel, Alfred (1995): Ein Geotop des Jungquartärs im Unstrut-Hainich-Kreis - die ehemalige Ziegeleigrube Körner. - Beitr. Geol. Thüringen, N.F., 2: 141-151, 3 Abb., 1 Tab., 2 Taf.; Weimar [Referenzprofil Löß- und Bodenstratigraphie von Thüringen]

OWagenbreth, Otfried (1970): Entwurf eines Systems geologischer Naturdenkmale in Thüringen. Landschaftspflege u. Naturschutz i. Thür., $\underline{\mathbf{7}}(1 / 2):$ 5-19, 8 Abb.; Jena [darin: Naturdenkmale (Geotope) in Westthüringen]

OWildner, Helmut (1960): Naturdenkmäler um Tabarz. - „Der Friedenstein“, 1960(April-Heft): 86-89; [Deutscher Kulturbund Gotha] Gotha [auch geologische Naturdenkmäler]

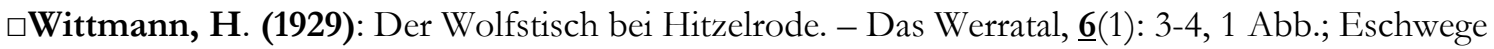
[Naturdenkmal, auch Geologie u. Sagen, Märchen, Mystik; auch Bezugnahme a. „Pferdeloch“] 


\section{Geowissenschaftliche Karten und Kartenerläuterungen}

\subsection{Geologische Karte 1 : 25.000 (Regelblattschnitt)}

Die Kartenwerke wurden/werden stets mit einer mehrfarbigen geologischen Karte herausgegeben, die nicht gesondert aufgelistet wurden. Der überwiegende Teil der Karten stammt noch aus der Zeit des wilhelminischen Kaiserreichs und wurde von der (Kgl.) Preussischen Geologischen Landesanstalt (und Bergakademie) Berlin herausgeben. Die Höhenangaben dieser „preußischen“ Kartenwerke beziehen sich noch auf den Meridian von Ferro (alter Name der kanarischen Insel „Hiero“), die Höhenangabe erfolgte in preußischen Decifuß.

Die aufgeführten Blätter der amtlichen Geologischen Karte im Maßstab $1: 25000$ im Regelblattschnitt bieten annähernd flächendeckend geologische Basisinformationen über das bibliographisch erfaßte Gebiet. Ein Großteil der aufgeführten Kartenerläuterungen (Erläuterungen zu Karten der Könglich Preußischen Geologischen Landesanstalt) sind jedoch älteren Datums und stammen noch aus „Kaiser's Zeiten“. Sie sind vom Umfang her meist recht kurz gehalten. Neubearbeitungen durch die Geologischen Dienste der Bundesländer bieten dagegen umfangreiche Informationen zur regionalen Geologie aus verschiedenen Fachdisziplinen. Die Königlich Preussische Geologische Landesanstalt zu Berlin wurde am 1.1.1873 gegründet. Einige Kartenerläuterungen tragen aber ein Erscheinensdatum, das vor dieses Termin liegt (1-3. Lieferung). Diese Lieferungen werden in späteren Verzeichnissen der Preußischen Geologischen Landesanstalt als Ausgaben der Anstalt geführt. Aus diesem Grunde werden bei den bibliographischen Daten auch diese Karten und Kartenerläuterungen als Ausgaben der Königlich Preußischen Geologischen Landesanstalt geführt.

-Keilhack, K. \& Zimmermann, E. (1897): Verzeichnis von auf Deutschland bezüglichen geologischen Schriften- und Kartenverzeichnissen. - Abh. Preuß. Geol. Landesanst., N.F., 26; IX, 108 S.; Berlin Referat in: N. Jb. Mineral. etc, $\underline{1898}$ (Bd. I): 463-464 (Th. Liebisch) Stuttgart

-Schamp, Heinz (1961): Ein Jahrhundert amtliche geologische Karten - Verzeichnis der amtlichen geologischen Karten von Deutschland und Nachweis ihrer Standorte in Bibliotheken und Instituten. Ber. dt. Landeskde., Sdh. 4; 536 S., 2 Kt.-Beil..; [Bundesanst. f. Landeskde. u. Raumforschung] Bad Godesberg

-Fachbereich Bodenkunde und Geologie, Niedersächsiches Landesamt f. Bodenforschung [Hrsg.](2000): Ausgabeformen der Flächendatenbank des Niedersächsischen Bodeninformationssystems NIBIS. - Arbeitshefte Boden, 2000/1: 3-107, 9 Abb., 4 Tab., 27 Karten; Hannover darin: Geologische Karte von Niedersachsen $1: 25000$ (GK 25). - S. 23-29, Abb. 5, Karte 4 u. 5

-Fachbereich Bodenkunde und Geologie, Niedersächsiches Landesamt f. Bodenforschung [Hrsg.](2000): Ausgabeformen der Flächendatenbank des Niedersächsischen Bodeninformationssystems NIBIS. - Arbeitshefte Boden, 2000/1: 3-107, 9 Abb., 4 Tab., 27 Karten; Hannover darin: Petrographische Karte. - S. 29 
Die regionale Zugehörigkeit der Kartenerläuterungen, bzw Karten wird durch die schon im Autorenverzeichnis vergebenen Symbole gekennzeichnet.

Q Karte/Kartenerläuterung/Karte zu Thüringischen Gebiet

- Karte/Kartererläuterungen/Karte zu Niedersächsischem Gebiet

- Karte/Kartenerläuterung/Karte zu Hessischem Gebiet (Stadt/Landkreis Kassel, Schwalm-Eder-Kreis, Kreis Hersfeld-Rotenburg) oder überregional von Hessen

$\square$ Karte/Kartenerläuterung/Karte zum Gebiet des Werra-Meißner-Kreises

Kartenerläuterungen, bzw. Karten, die mehrere der genannten Kriterien erfüllen, tragen entsprechende Symbolkombinationen

Die Erläuterungen der Geologischen (Special-) Karte von Preußen ohne Verlagsangabe (ab 1904) wurden von der (Königlich) Preußischen Geologischen Landesanstalt direkt vertrieben

Die doppelten Linien trennen Karten mit gleicher Breitengradbegrenzung ab.

- 4322 Bad Karlshafen

Geologische Karte von Nordrhein-Westfalen 1 : 25000; Erläuterungen zu Blatt 4322 Karlshafen.

Verf.: Jochen Lepper mit zahlr. Beitr. and. Fachautoren. - 190 S., 14 Abb., 11 Tab., 6 Taf.;

Geologisches Landesamt Nordrhein-Westfalen, Krefeld 1976

••4323 Uslar

Geologische Karte von Niedersachsen 1 : 25000; Erläuterungen zu Blatt Uslar Nr. 4323. Verf.: Jochen Lepper mit zahlr. Beitr. anderer Fachautoren. - 129 S., 14 Abb., 13 Tab., 10 Taf., 7 Kt.; Hrsg.: Niedersächsisches Landesamt für Bodenforschung; Hannover 1977

\section{-4422 Trendelburg}

Erläuterungen zur Geologischen Karte von Preußen und benachbarten deutschen Ländern Lieferung 278 - Blatt Trendelburg - Nr. 2517 - Gradabth. 55, Nr. 25; [heute: 4422 Trendelburg]. Verf.: Otto v. Linstow. - 36 S.; Berlin 1928

Hrsg.: Preußische Geologische Landesanstalt, Berlin

\section{- 4423 Oedelsheim}

Erläuterungen zur Geologischen Karte von Preußen und benachbarten deutschen Ländern Lieferung 278 - Blatt Ödelsheim - Nr. 2518 - Gradabth. 55, Nr. 26; [heute: 4423 Oedelsheim]. Verf.: Otto v. Linstow. - 31 S.; Berlin 1928

Hrsg.: Preußische Geologische Landesanstalt, Berlin

\section{- 4424 Dransfeld}

Erläuterungen zur Geologischen Specialkarte von Preussen und den Thüringischen Staaten. Lieferung 91 - Blatt Dransfeld - Gradabth. 55, Nr. 27; [heute: 4424 Dransfeld]. - Verf.: A. v. Koenen. - 15 S.; (Simon Schropp'sche Hof-Landkartenhdlg. (J.H. Neumann)) Berlin 1900 Hrsg.: Königlich Preußische Geologische Landesanstalt und Bergakademie; Berlin

\section{-4425 Göttingen}

Erläuterungen zur Geologischen Specialkarte von Preussen und den Thüringischen Staaten. - LXII Lfg. [=62. Lieferung] - Blatt Göttingen - Gradabth. 55, No. 28; [heute: 4425 Göttingen]. - Verfass.: A. v. Koenen. - 58 S.; (Simon Schropp'sche Hof-Landkartenhdlg. J. H. Neumann); Berlin 1894 Ohne Hrsg.: In später erschienenen Verzeichnissen der Kgl. Preuß. Geol. Landesanstalt wird diese Kartenerläuterung unter den Veröffentlichungen der Landesanstalt geführt 
Dazugehörige Karte herausgegeben 1893, geognostisch bearbeitet durch A. v. Koenen 1882-1888.

Referat: Geologische Specialkarte von Preussen und den Thüringischen Staaten. - [Koenen, A. v. \& Ebert, Th.]: LXII. Lieferung: Blatt Göttingen, Reinhausen, Waake, Gelliehausen; 1894 1+2: A. v. Koenen; 3: A. v. Koenen \& Th. Ebert; 4: Th. Ebert - in: N. Jb. Mineral. etc, 1896 (Bd. I): 273-275 (Kayser); Stuttgart

Erläuterungen zur Geologischen Specialkarte von Preussen und benachbarten Bundesstaaten. - 72. Lieferung [Fehlangabe $=62$. Lieferung] - Blatt Göttingen - Gradabth. 55, Bl. 28; [heute: 4425 Göttingen]. - 2. Auflage. - Verfass.: A. v. Koenen. - 57 S.; Berlin 1908

Hrsg.: Königlich Preußische Geologische Landesanstalt; Berlin

Dazugehörige Karte herausgegeben 1893 (II. Ausgabe), geognostisch bearbeitet durch A. v. Koenen 1882-1888.

Geologischen Karte von Preußen und benachbarten deutschen Ländern - Lieferung 62 Erläuterungen zu Blatt Göttingen Nr. 2520; [heute: 4425 Göttingen]. - 3., neu bearb. Aufl. - Verf.: H. Stille. - 40 S., 3 Abb.; Berlin 1932

Hrsg.: Preußische Geologische Landesanstalt, Berlin

Geologische Specialkarte von Preußen - Lieferung 30 [d.i. Lieferung 62!] - Blatt Göttingen Nr. 28 [d.i. Nr. 2520]; [heute: 4425 Göttingen]. - Verf.: Hans Stille. - 40 S., 3 Abb.; Berlin 1932 Hrsg.: Preußische Geologische Landesanstalt, Berlin [Fehldruck? - falsche Lieferungsnummer falsche Blattnr. ]

\section{-4426 Ebergötzen [ehemals: Waake]}

Erläuterungen zur Geologischen Specialkarte von Preussen und den Thüringischen Staaten. - 62. Lieferung - Blatt Waake - Gradabth. 55, Nr. 29; [heute: 4426 Ebergötzen]. - Verf.: A. v. Koenen, Th. Ebert. - 22 S.; (Simon Schropp'sche Hof-Landkartenhdlg. (J. H. Neumann)) Berlin 1894 Hrsg.: Königlich Preußische Geologische Landesanstalt und Bergakademie; Berlin

Referat: Geologische Specialkarte von Preussen und den Thüringischen Staaten. - [Koenen, A. v. \& Ebert, Th.]: LXII. Lieferung: Blatt Göttingen, Reinhausen, Waake, Gelliehausen; 1894 1+2: A. v. Koenen; 3: A. v. Koenen \& Th. Ebert; 4: Th. Ebert - in: N. Jb. Mineral. etc, 1896 (Bd. I): 273-275 (Kayser); Stuttgart

\section{-4427 Duderstadt}

Erläuterungen zur Geologischen Specialkarte von Preussen und den Thüringischen Staaten. - [Ohne Lieferungsangabe, d.i. Lfg. 27] - Blatt Duderstadt - Gradabth. 55, Nr. 30; [heute: 4427 Duderstadt]. Verf.: O. Speyer. - 6 S.; (i. Comm. Simon Schropp'sche Hof-Landkartenhdlg.) Berlin 1894

Hrsg.: Königlich Preußische Geologische Landesanstalt und Bergakademie; Berlin Dazugehörige Karte herausgegeben 1879

¿• 4428 Weißenborn-Lüderode

Erläuterungen zur Geologischen Specialkarte von Preussen und den Thüringischen Staaten. - [Ohne Lieferungsangabe, d. i. Lfg. 27] - Blatt Gerode - Gradabth. 56, No. 25; [heute: 4428 WeißenbornLüderode]. - Verfass. K. Seebach \& O. Speyer. - 15 S., 1 Abb.; (I. Comm. Simon Schropp'sche HofLandkartenhdlg. (J. H. Neumann)); Berlin 1884

Ohne Hrsg.: In später erschienenen Verzeichnissen der Kgl. Preuß. Geol. Landesanstalt wird diese Kartenerläuterung unter den Veröffentlichungen der Landesanstalt geführt Geologische Karte geognostisch aufgenommen durch K. v. Seebach und O. Speyer 1879 


\section{-4521 Liebenau}

Erläuterungen zur Geologischen Karte von Hessen 1 : 25000 Blatt Nr. 4521 Liebenau: Verf.: Peter Meiburg mit Beträgen anderer Fachautoren. - 175 S., 27 Abb., 13 Tab., 2 Beibl.;

Hrsg.: Hessisches Landesamt für Bodenforschung, Wiesbaden 1983

\section{-4522 Hofgeismar}

Erläuterungen zur Geologischen Karte von Preußen und benachbarten deutschen Ländern. -

Lieferung 278 - Blatt Hofgeismar - Nr. 2590 - Gradabth. 55, Nr. 31; [heute: 4522 Hofgeismar]. -

Verf.: Otto v. Linstow u. Hans Bredin. - 38 S.; Berlin 1928

Hrsg.: Preußische Geologische Landesanstalt, Berlin

\section{-•4523 Hannoversch Münden}

Erläuterungen zur Geologischen Karte von Preußen und benachbarten deutschen Ländern. -

Lieferung 278 - Blatt Hann. Münden - Nr. 2591 - Gradabth. 55, Nr. 32; [heute: 4523 Hannoversch

Münden]. - Verf.: Otto v. Linstow. - 45 S.; Berlin 1928

Hrsg.: Preußische Geologische Landesanstalt, Berlin

$\square \bullet 4524$ Scheden [ehemals: Jühnde]

Erläuterungen zur Geologischen Specialkarte von Preussen und den Thüringischen Staaten. -

Lieferung 91 - Blatt Jünde - Grababth. 55, Nr. 27; [heute: 4524 Scheden]. - Verf.: A. v. Koenen. - 19

S.; (Simon Schropp'sche Hof-Landkartenhdlg. (J. H. Neumann)) Berlin 1900

Hrsg.: Königlich Preußische Geologische Landesanstalt und Bergakademie; Berlin

\section{$\square \bullet 4525$ Friedland [ehemals: Reinhausen]}

Erläuterungen zur Geologischen Specialkarte von Preussen und den Thüringischen Staaten. - LXII. [62.] Lieferung - Blatt Reinhausen - Gradabth. 55, Nr. 34; [heute: 4525 Friedland]. - Verf.: A. v. Koenen. - 21 S.; (Simon Schropp'sche Hof-Landkartenhdlg. (J. H. Neumann)) Berlin 1894 Hrsg.: Königlich Preußische Geologische Landesanstalt und Bergakademie; Berlin

Referat: Geologische Specialkarte von Preussen und den Thüringischen Staaten. - [Koenen, A. v. \& Ebert, Th.] (1894): LXII. Lieferung: Blatt Göttingen, Reinhausen, Waake, Gelliehausen; 1894 1+2: A. v. Koenen; 3: A. v. Koenen \& Th. Ebert; 4: Th. Ebert - in: N. Jb. Mineral. etc, 1896 (Bd. I): 273275 (Kayser); Stuttgart

\section{4526 Gleichen [ehemals: Gelliehausen]}

Erläuterungen zur Geologischen Specialkarte von Preussen und den Thüringischen Staaten. - LXII. [62.] Lieferung - Blatt Gelliehausen - Gradabth. 55, Nr. 35; [heute: 4526 Gleichen]. - Verf.: Th. Ebert. - 14 S., 3 Abb.; (Simon Schropp'sche Hof-Landkartenhdlg. (J. H. Neumann)) Berlin 1894 Hrsg.: Königlich Preußische Geologische Landesanstalt und Bergakademie; Berlin

Referat: Geologische Specialkarte von Preussen und den Thüringischen Staaten. - [Koenen, A. v. \& Ebert, Th.] (1894): LXII. Lieferung: Blatt Göttingen, Reinhausen, Waake, Gelliehausen; 1894 1+2: A. v. Koenen; 3: A. v. Koenen \& Th. Ebert; 4: Th. Ebert - in: N. Jb. Mineral. etc., 1896 (Bd. I): 273275 (Kayser); Stuttgart

\section{0-4527 Berlingerode}

Erläuterungen zur Geologischen Karte von Preußen und benachbarten Bundesstaaten. - Lieferung 112 - Blatt Berlingerode - Gradabth. 55, Nr. 36; [ heute: 4527 Berlingerode ]. - Verf.: O. Zeise. - 8 S.; Berlin 1904

Hrsg.: Königlich Preußische Geologische Landesanstalt und Bergakademie; Berlin Dazugehörige Karte herausgegeben 1902 
Referat: Erläuterungen zur Geologischen Karte von Preußen und benachbarten Bundesstaaten. Lfg. 112: Berlingerode, Heiligenstadt, Dingelstädt, Kella, Lengenfeld... Lfg. 128: Langensalza, Langula, Henningsleben (Großenbehringen). - N. Jb. Mineral. etc., 1906 (Bd. II): 229-232 (Karl Walter); Stuttgart

\section{Worbis}

Erläuterungen zur Geologischen Specialkarte von Preussen und den Thüringischen Staaten. - [Ohne Lieferungsangabe, d.i. Lfg. 3] - No. 274 - Blatt Worbis - Gradabth. 52 $/ 51^{\circ}$ der Breite, $28^{\circ} / 29^{\circ}$ der Länge, Bande V, Blatt 2 [d. i. Gradabth. 56; Nr. 31]; [heute: 4528 Worbis]; Verf.: K. von Seebach. 16 S.; (Verlag v. J. H. Neumann) Berlin 1872

Ohne Hrsg.: In später erschienenen Verzeichnissen der Kgl. Preuß. Geol. Landesanstalt wird diese Kartenerläuterung unter den Veröffentlichungen der Landesanstalt geführt

\section{O4529 Bleicherode}

Erläuterungen zur Geologischen Specialkarte von Preussen und den Thüringischen Staaten. - [Ohne Lieferungsangabe, d.i. Lfg. 3] No. 275 - Blatt Bleicherode - Gradabth. $52^{\circ} / 51^{\circ}$ der Breite, $28^{\circ} / 29^{\circ}$ der Länge, Bande V, Nr. 2 [d.i. Gradabth. 56, Nr. 32]; [heute: 4529 Bleicherode]. - Verf.: H. Eck. 12 S.; (Verlag von J. H. Neumann) Berlin 1872

Ohne Hrsg.: In später erschienenen Verzeichnissen der Kgl. Preuß. Geol. Landesanstalt wird diese Kartenerläuterung unter den Veröffentlichungen der Landesanstalt geführt

\section{-4621 Wolfhagen}

Erläuterungen zur Geologischen Karte von Hessen 1 : 25000 Blatt Nr. 4621 Wolfhagen; Verf. Franz Rösing mit Beiträgen and. Fachautoren. - 246 S., 13 Abb., 8 Tab., 2 Diagr.;

Hrsg.: Hessisches Landesamt für Bodenforschung, Wiesbaden 1966

\section{-4622 Kassel West [ehemals: Wilhelmshöhe]}

Erläuterungen zur Geologischen Karte von Preußen und benachbarten Bundesstaaten. - Lieferung 92 - Blatt Wilhelmshöhe - Gradabth. 55, Nr. 37; [ heute: 4622 Kassel West]. - Verf.: F. Beyschlag. 63 S., Abb., 1 Kt. 2 Taf. [Foto]; Berlin 1908

Hrsg.: Königlich Preußische Geologische Landesanstalt; Berlin

Erläuterungen zur Geologischen Karte von Hessen 1 : 25000 - Blatt 4622 Kassel West. - 2., neu bearb. Aufl.; Verf.: F. Rösing mit Beitr. and. Autoren. - 205 S., 9 Abb., 4 Tab.; Wiesbaden 1958 Hrsg.: Hessisches Landesamt für Bodenforschung

Erläuterungen zur Geologischen Karte von Hessen 1 : 25000 - Blatt 4622 Kassel West. - 3., unveränd. Aufl.; Verf.: F. Rösing mit Beitr. and. Autoren. - 205 S., 9 Abb., 4 Tab.; Wiesbaden 1969 Hrsg.: Hessisches Landesamt für Bodenforschung

\section{- 4623 Kassel Ost [ehemals: Cassel]}

Erläuterungen zur Geologischen Karte von Preußen und benachbarten Bundessstaaten. - Lieferung 92 - Blatt Cassel - Gradabth. 55, Nr. 38; [heute: 4623 Kassel Ost]. - Verf.: F. Beyschlag. - 34 S.; Berlin 1906

Hrsg.: Königlich Preußische Geologische Landesanstalt; Berlin

\section{$\square \bullet 4624$ Hedemünden [ehemals: Ermschwerd]}

Erläuterungen zur Geologischen Specialkarte von Preussen und den Thüringischen Staaten. - XXIII. [23.] Lieferung - Blatt Ermschwerd - Gradabth. 55, Nr. 39; [heute: 4624 Hedemünden ]. - Geol. Aufn.: Friedrich Moesta; Verf.: Franz Beyschlag. - 17 S.; (i. Comm. Simon Schropp’sche Hof- 
Landkartenhdlg. (J. H. Neumann)) Berlin 1886

Ohne Hrsg.: d.i.: Königlich Preußische Geologische Landesanstalt und Bergakademie; Berlin

\section{$\square 04625$ Witzenhausen}

Erläuterungen zur Geologischen Specialkarte von Preussen und den Thüringischen Staaten. - XXIII. [23.] Lieferung - Blatt Witzenhausen - Gradabth. 55, Nr. 40; [heute: 4625 Witzenhausen]. - Geol. Aufn.; Friedrich Moesta; Verf.: Franz Beyschlag. - 37 S.; (i. Comm. Simon Schropp'sche HofLandkartenhdlg. (J. H. Neumann)) Berlin 1886

Ohne Hrsg.: d.i. Königlich Preußische Geologische Landesanstalt und Bergakademie; Berlin Dazugehörige Karte herausgegeben 1878

04626 Heilbad Heiligenstadt [ehemals: Heiligenstadt]

Erläuterungen zur Geologischen Karte von Preußen und benachbarten Bundesstaaten. - Lieferung 112 - Blatt Heiligenstadt - Gradabth. 55, Nr. 41; [ heute: 4626 Heiligenstadt ]. - Verf.: O. Zeise. - 13 S.; Berlin 1904

Hrsg.: Königlich Preußische Geologische Landesanstalt und Bergakademie; Berlin Dazugehörige Karte herausgegeben 1902

Referat: Erläuterungen zur Geologischen Karte von Preußen und benachbarten Bundesstaaten. Lfg. 112: Berlingerode, Heiligenstadt, Dingelstädt, Kella, Lengenfeld... Lfg. 128: Langensalza, Langula, Henningsleben (Großenbehringen). - N. Jb. Mineral. etc., 1906 (Bd. II): 229-232 (Karl Walter); Stuttgart

04627 Leinefelde [ehemals: Dingelstädt]

Erläuterungen zur Geologischen Karte von Preußen und benachbarten Bundesstaaten. - Lieferung 112 - Blatt Dingelstädt - Gradabth. 55, Nr. 42; [ heute: 4627 Leinefelde ]. - Verf.: E. Naumann; 47 S.; Berlin 1904

Hrsg.: Königlich Preußische Geologische Landesanstalt und Bergakademie; Berlin Dazugehörige Karte herausgegeben 1902

Referat: Erläuterungen zur Geologischen Karte von Preußen und benachbarten Bundesstaaten. Lfg. 112: Berlingerode, Heiligenstadt, Dingelstädt, Kella, Lengenfeld - Lfg. 128: Langensalza, Langula, Henningsleben (Großenbehringen). - N. Jb. Mineral. etc., 1906 (Bd. II): 229-232 (Karl Walter); Stuttgart

04628 Leinefelde Ost [ehemals: Nieder-Orschla]

Erläuterungen zur Geologischen Specialkarte von Preussen und den Thüringischen Staaten. - [Ohne Lieferungsangabe, d.i. Lfg. 3] No. 295 - Blatt Nieder-Orschla - Gradabth. 52\% $/ 51^{\circ}$ der Breite, $28^{\circ} / 29^{\circ}$ der Länge, Bande 4, Nr. 1 [d. i. Gradabth. 56, Nr. 49; [heute: 4628 Leinefelde-Ost]. - Verf.: K. von Seebach. - 12 S.; (Verlag von J. H. Neumann) Berlin 1872

Ohne Hrsg.: In später erschienenen Verzeichnissen der Kgl. Preuß. Geol. Landesanstalt wird diese Kartenerläuterung unter den Veröffentlichungen der Landesanstalt geführt

04629 Menteroda [ehemals: Gross-Keula]

Erläuterungen zur Geologischen Specialkarte von Preussen und den Thüringischen Staaten - [Ohne Lieferungsangabe, d.i. Lfg. 3] - No. 296 - Blatt Gross-Keula - Gradabth. 52 $/ 51^{\circ}$ der Breite, $28^{\circ} / 29^{\circ}$ der Länge, Bande 4, Nr. 2 [d.i. Gradabth. 56, Nr. 50]; [heute: 4629 Menteroda]. - Verf.: K. Giebelhausen. - 11 S.; (Verlag von J. H. Neumann) Berlin 1872 Ohne Hrsg.: In später erschienenen Verzeichnissen der Kgl. Preuß. Geol. Landesanstalt wird diese Kartenerläuterung unter den Veröffentlichungen der Landesanstalt geführt 
Erläuterungen zur Geologischen Karte 1 : 25000 von Thüringen - Blatt Menteroda Nr. 4629 - 2., neu bearb. Aufl.; Verf.: Harald Lützner \& Hans Kästner m. Beitr. and. Autoren. - 216 S., 25 Abb., 26 Tab., [12] Beil.; Weimar 1996

Hrsg. : Thüringer Landesanstalt für Geologie, Weimar

\section{-4721 Naumburg}

Erläuterungen zur Geologischen Karte von Hessen 1 : 25000 - Blatt Nr. 4721 Naumburg. - Bearb. u. Verf. Manfred Horn mit Beiträgen and. Fachautoren. - 285 S., 29 Abb., 10 Tab., 1 Taf., 1 Beibl.; Hrs. Hessisches Landesamt für Bodenforschung, Wiesbaden 1971

\section{-4722 Niederzwehren [ehemals: Besse]}

Erläuterungen zur Geologischen Karte von Preußen und benachbarten Bundesstaaten. - Lieferung 92 - Blatt Besse - Gradabth. 55, No. 43; [heute: 4722 Niederzwehren]. -- Verfass.: Franz Beyschlag; 29 S; Berlin 1909

Hrsg.: Königlich Preußische Geologische Landesanstalt.

Dazugehörige Karte herausgegeben 1901 - Geognostisch bearbeitet durch Franz Beyschlag und Oskar Zeise 1896-1898.

\section{-4723 Oberkaufungen}

Erläuterungen zur Geologischen Karte von Preußen und benachbarten Bundessstaaten. - Lieferung 92 - Blatt Oberkaufungen - Gradabth. 55, Nr. 44; [heute: 4723 Oberkaufungen]. - Verf. F.

Beyschlag. - 45 S.; 1 Abb. (Kt.); Berlin

Hrsg.: Königlich Preußische Geologische Landesanstalt; Berlin 1908

Geologischen Karte von Hessen 1 : 25000 - Erläuterungen 4723 Oberkaufungen. - 2., neu bearb. Aufl. - Verf.: Hans Günter Kupfahl. - 212 S., 15 Abb., 3 Taf., 17 Tab.; 1 Beil.; Wiesbaden 1981 Hrsg.: Hessisches Landesamt f. Bodenforschung; Wiesbaden

\section{- 4724 Großalmerode}

Erläuterungen zur Geologischen Specialkarte von Preussen und den Thüringischen Staaten- XXIII [23.] Lieferung Blatt Grossalmerode - Gradabth. 55, Nr. 45; [4724 Großalmerode]. - Geol. Aufn.: Friedrich Moesta; Verf.: Fr. Beyschlag. - 55 S., 2. Falttaf. (2 Prof., 1 geol. K.); (i. Comm. Simon Schropp'sche Hof-Landkartenhdlg. (J. H. Neumann)) Berlin 1886

Ohne Hrsg.: d.i.: Königlich Preußische Geologische Landesanstalt und Bergakademie; Berlin

\section{$\square 04725$ Bad Sooden-Allendorf [ehemals: Allendorf]}

Erläuterungen zur Geologischen Specialkarte von Preussen und den Thüringischen Staaten. Lieferung 23 - Blatt Allendorf - Gradabth. 55, Nr. 46; [ heute: 4725 Bad Sooden-Allendorf ]. Geol. Aufn.: Friedrich Moesta, Verf.: Fr. Beyschlag. - 66 S., 2 Taf.; (i. Comm. Simon Schropp'sche Hof-Landkartenhdlg. (J. H. Neumann)) Berlin 1886

Hrsg.: Königlich Preußische Geologische Landesanstalt und Bergakademie; Berlin Dazugehörige Karte herausgegeben 1878

04726 Grebendorf [ehemals: Kella]

Erläuterungen zur Geologischen Karte von Preußen und benachbarten Bundesstaaten. - Lieferung 112 - Blatt Kella - Gradabth. 55, Nr. 47; [heute: 4726 Grebendorf]. - Geol. Aufn.: H. Bücking (1885), H. Pröscholdt (1894), O. Zeise (1899, 1900) - Verf.: Oskar Zeise. - 21 S.; Berlin 1904

Hrsg.: Königlich Preußische Geologische Landesanstalt und Bergakademie; Berlin Dazugehörige Karte herausgegeben 1902

Referat: Erläuterungen zur Geologischen Karte von Preußen und benachbarten Bundesstaaten. Lfg. 
112: Berlingerode, Heiligenstadt, Dingelstädt, Kella, Lengenfeld... Lfg. 128: Langensalza, Langula, Henningsleben (Großenbehringen). - N. Jb. Mineral. etc., 1906 (Bd. II): 229-232 (Karl Walter); Stuttgart

Q4727 Küllstedt [ehemals: Lengenfeld]

Erläuterungen zur Geologischen Karte von Preußen und benachbarten Bundessstaaten. - Lieferung 112 - Blatt Lengenfeld - Gradabth. 55, Nr. 48; [heute: 4727 Küllstedt]. - Verf.: Erich Kaiser. - 42 S.; Berlin 1904

Hrsg.: Königlich Preußische Geologische Landesanstalt und Bergakademie; Berlin Dazugehörige Karte herausgegeben 1902

Referat: Erläuterungen zur Geologischen Karte von Preußen und benachbarten Bundesstaaten. Lfg. 112: Berlingerode, Heiligenstadt, Dingelstädt, Kella, Lengenfeld... Lfg. 128: Langensalza, Langula, Henningsleben (Großenbehringen). - N. Jb. Mineral. etc., 1906 (Bd. II): 229-232 (Karl Walter); Stuttgart

\section{Mühlhausen (Thüringen)}

Erläuterungen zur Geologischen Specialkarte von Preussen und den Thüringischen Staaten. - [Ohne Lieferungsangabe, d.i. Lfg. 25 ] - Blatt Mühlhausen - Gradabth. 56, Nr. 43; [heute: 4728

Mühlhausen]. - Verf.: K. von Seebach. - 20 S.; (Simon Schropp'sche Hof-Landkartenhdlg. J. H. Neumann)) Berlin 1883

Ohne Hrsg.: d.i. Königlich Preußische Geologische Landesanstalt und Bergakademie; Berlin

\section{Schlotheim [ehemals: Körner]}

Erläuterungen zur Geologischen Specialkarte von Preussen und den Thüringischen Staaten. - [Ohne Lieferungsangabe, d.i. 25. ] - Blatt Körner - Gradabth. 56, Nr. 44; [heute: 4729 Schlotheim]. - Verf.: Max Bauer. - 9 S.; (Simon Schropp'sche Hof-Landkartenhdlg. (J. H. Neumann)) Berlin 1883

Ohne Hrsg.: d.i.: Königlich Preußische Geologische Landesanstalt und Bergakademie; Berlin

Erläuterungen zur Geologischen Karte $1: 25000$ von Thüringen Blatt Schlotheim Nr. 4729 - Blatt Ebeleben, Nr. 4730. - 2., neu bearb. Aufl.; Verf.: Eberhard Grumbt (verst.), Hans Kästner \& Harald Lützner. - 262 S., 25 Abb., 33 Tab., 9(17) Beil.; Weimar 1997

Hrsg. : Thüringer Landesanstalt für Geologie, Weimar

\section{-4822 Gudensberg}

Erläuterungen zur Geologischen Karte von Preußen und benachbarten Bundesstaaten. - Lieferung 198 - Blatt Gudensberg - Gradabth. 55, Nr. 49; [heute: 4822 Gudensberg]. - Bearb.: Otto Lang u. Max Blanckenhorn, Verf.: Max Blanckenhorn u. Verwend. e. ält. Entwurfs v. O. Lang. - 104 S., 2 Abb., mit e. Anhang „Zur Vorgeschichte von Gudensberg. v. Eisentraut; Berlin 1919

Hrsg.: Preußische Geologische Landesanstalt; Berlin

\section{-4823 Melsungen}

Erläuterungen zur Geologischen Specialkarte von Preussen und den Thüringischen Staaten. - XLV. [45.] Lieferung - Blatt Melsungen - Gradabth. 55, Nr. 50; [heute: 4823 Melsungen]. - Verf.: Franz Beyschlag. - 20 S.; (Simon Schropp'sche Hof-Landkartenhdlg. (J. H. Neumann)) Berlin 1891 Ohne Hrsg.: d.i.: Königlich Preußische Geologische Landesanstalt und Bergakademie; Berlin

Erläuterungen zur Geologischen Karte von Hessen 1 : 25000 - Blatt 4823 Melsungen. 2. Aufl. Verf.: Hans- Günther Kupfahl Kupfahl. - 195 S., 27 Abb., 22 Tab., 1 Taf., 1 Beibl.; Wiesbaden 1975 Hrsg.: Hessisches Landesamt f. Bodenforschung; Wiesbaden 


\section{- $\square$ 4824 Hessisch Lichtenau [ehemals: Lichtenau]}

Erläuterungen zur Geologischen Specialkarte von Preussen und den Thüringischen Staaten. - XLV. [45.] Lieferung - Blatt Lichtenau - Gradabth. 54, Nr. 51; [heute: 4824 Hessisch Lichtenau]. - Geol. Aufn..: Friedrich Moesta - 23 S.; (Simon Schropp'sche Hof-Landkartenhdlg. (J. H. Neumann)) Berlin 1891

\section{$\square 4825$ Waldkappel}

Erläuterungen zur Geologischen Specialkarte von Preussen und den Thüringischen Staaten. - [Ohne Lieferungsangabe, d. i. Lieferung 8] - Blatt Waldkappel - Gradabth. 55, Nr. 52; [heute: 4825 Waldkappel]. - Verf.: Friedrich Moesta. - 24 S.; (Verlag der Neumann'schen Kartenhdlg.) Berlin 1876 Ohne Hrsg.: d.i.: Königlich Preußische Geologische Landesanstalt und Bergakademie; Berlin

\section{$\square 4826$ Eschwege}

Erläuterungen zur Geologischen Specialkarte von Preussen und den Thüringischen Staaten. - [Ohne Lieferungsangabe, di. i. Lieferung 8] Blatt Eschwege - Gradabth. 55, Nr. 53; [heute: 4826 Eschwege]. - Verf.: Friedrich Moesta - 17 S., 2 Profile.; (Verlag der Neumann'schen Kartenhdlg.) Berlin 1876 Ohne Hrsg.: d.i.: Königlich Preußische Geologische Landesanstalt und Bergakademie; Berlin Dazugehörige Karte herausgegeben 1872

\section{Treffurt}

Erläuterungen zur Geologischen Karte von Preußen und benachbarten Bundessstaaten. - Lieferung 129 - Blatt Treffurt - Gradabth. 55, Nr. 54; [heute: 4827 Treffurt]. - Verf.: E. Naumann \& W.

Frantzen. - 64 S.; Berlin 1907

Hrsg.: Königlich Preußische Geologische Landesanstalt; Berlin

Referat: Erläuterungen zur Geologischen Karte von Preußen und benachbarten Bundesstaaten. Lfg. 129: Creuzburg, Treffurt i. Th., Mihla (Berka v. d. Hainich), Schmalkalden. - N. Jb. Mineral. etc., $\underline{1908}$ (Bd. I): 87-91, (Karl Walter); Stuttgart

\section{Q4828 Mühlhausen (Thüringen) Süd [ehemals: Langula]}

Erläuterungen zur Geologischen Karte von Preußen und benachbarten Bundessstaaten. - Lieferung 128 - Blatt Langula - Gradabth. 56, Nr. 49; [heute: 4828 Mühlhausen (Thüringen) Süd]. - Verf.: E. Kaiser. - 58 S.; Berlin 1905

Hrsg.: Königlich Preußische Geologische Landesanstalt und Bergakademie; Berlin

Referat: Erläuterungen zur Geologischen Karte von Preußen und benachbarten Bundesstaaten. Lfg. 112: Berlingerode, Heiligenstadt, Dingelstädt, Kella, Lengenfeld... Lfg. 128: Langensalza, Langula, Henningsleben (Großenbehringen). - N. Jb. Mineral. etc., 1906 (Bd. II): 229-232 (Karl Walter); Stuttgart

04829 Bad Langensalza [ehemals: Langensalza]

Erläuterungen zur Geologischen Karte von Preußen und benachbarten Bundessstaaten - Lieferung 128 - Blatt Langensalza - Gradabth. 56, Nr. 50; [heute: 4829 Bad Langensalza]. - Verf. Erich Kaiser \& Ernst Naumann. - 72 S., 6 Abb.; Berlin 1905

Hrsg.: Königlich Preußische Geologische Landesanstalt und Bergakademie; Berlin

Referat: Erläuterungen zur Geologischen Karte von Preußen und benachbarten Bundesstaaten. Lfg. 112: Berlingerode, Heiligenstadt, Dingelstädt, Kella, Lengenfeld... Lfg. 128: Langensalza, Langula, Henningsleben (Großenbehringen). - N. Jb. Mineral. etc., 1906 (Bd. II): 229-232 (Karl Walter); Stuttgart 


\section{-4921 Borken (Hessen)}

Erläuterungen zur Geologischen Karte von Preußen und benachbarten deutschen Ländern. -

Lieferung 261 - Blatt Borken - Gradabth. 54, Nr. 60; [heute: 4921 Borken (Hessen)]. - Bearb. u.

Verfass.: M. Blanckenhorn. - 71 S.; Berlin 1926

Hrsg.: Preußische Geologische Landesanstalt, Berlin

Referat: Geologische Karte von Preußen und benachbarten Ländern 1 : 25000. - Lfg. 261 [....]

Herausgeg. V. d. Preuß. Geol. Landesanstalt 1926 [...] - Blatt Borken [heute 4921 Borken], Blatt

Ziegenhain, Blatt Schrecksbach. - N. Jb. Mineral. etc., Abt B, 1927 (Bd. II): 48-49 ( o.

Verfasserangabe); Stuttgart

\section{-4922 Homberg/Efze}

Erläuterungen zur Geologischen Karte von Preußen und benachbarten Bundesstaaten. - Lieferung 198 - Blatt Homberg a. d. Efze Gradabth. 55, Nr. 55; [heute: 4922 Homberg/Efze]. - Bearb.: Otto Lang u. Max Blanckenhorn, Verf.: Max Blanckenhorn. - 125 S., 2 Abb., 3 Taf.; Berlin 1920

Hrsg.: Preußische Geologische Landesanstalt; Berlin

\section{-4923 Altmorschen}

Erläuterungen zur Geologischen Karte von Preußen und benachbarten Bundesstaaten. - XLV. [45.] Lieferung - Blatt Altmorschen - Gradabth. 55, Nr. 56; [heute: 4923 Altmorschen ]. - Verf.: Franz Beyschlag. - 24 S.; (Simon Schropp'sche Hof-Landkartenhdlg. (J. H. Neumann)) Berlin 1891

O. Hrsg.: d. i. Königlich Preußische Geologische Landesanstalt und Bergakademie; Berlin

Geologische Karte von Hessen $1: 25000$ - Erläuterungen Blatt 4923 Altmorschen. - 2. neubearb. Aufl. - Verf.: Roland Ernst Becker \& Jens Kulick, mit. Beitr. and. Autoren. - 394 S., 66 Abb., 34 Tab., 1 Beibl., 1 Beil.; Wiesbaden 1999

Hrsg.: Hessisches Landesamt für Bodenforschung, Wiesbaden

\section{-4924 Seifertshausen}

Erläuterungen zur Geologischen Specialkarte von Preussen und den Thüringischen Staaten. - XIV. [45.] Lieferung - Blatt Seifertshausen - Gradabth. 55, Nr. 57; [heute: 4924 Seifertshausen]; Verf.: Franz Beyschlag. - 14 S.; (Simon Schropp’sche Hof-Landkartenhdlg. (J. H. Neumann)) Berlin 1891 Ohne Hrsg.: d.i. Königlich Preußische Geologische Landesanstalt und Bergakademie; Berlin

\section{- $\square 4925$ Sontra}

Erläuterungen zur Geologischen Specialkarte von Preussen und den Thüringischen Staaten. - [Ohne Lieferungsangabe, d. i. Lieferung 8] - Blatt Sontra - Gradabth. 55, Nr. 58; [heute: 4925 Sontra]. Verf.: Franz Beyrich \& Friedrich Moesta. - 25 S., 2 geol. Profile a. Taf.; (Verlag der Neumann'schen Landkartenhdlg.) Berlin 1876

Ohne Hrsg.: d. i. Königlich Preußische Geologische Landesanstalt und Bergakademie; Berlin

Erläuterungen zur Geologischen Karte von Hessen $1: 25$ 0000, 2. Auflage. - Verf. Renate MotzkaNöhring. - 296 S., 91 Abb., 14 Tab., 6 Taf., 1 Beil.; Wiesbaden 1987

Hrsg.: Hessisches Landesamt f. Bodenforschung; Wiesbaden

\section{$\square 04926$ Herleshausen [ehemals: Netra]}

Erläuterungen zur Geologischen Specialkarte von Preussen und den Thüringischen Staaten. - [Ohne Lieferungsangabe, d. i. Lieferung 8] - Blatt Netra - Gradabth. 55, Nr. 59; [heute: 4926 Herleshausen]. - Verf.: Friedrich Moesta. - 28 S., 2 Taf.; (Verlag der Neumann'schen Landkartenhdlg.) Berlin 1876

Ohne Hrsg.: d.i.: Königlich Preußische Geologische Landesanstalt und Bergakademie; Berlin Dazugehörige Karte herausgegeben 1872 
04927 Creuzburg

Erläuterungen zur Geologischen Karte von Preußen und benachbarten Bundessstaaten - Lieferung 129 - Blatt Creuzburg - Gradabth. 55, Nr. 60 [heute: 4927 Creuzburg]. - Verf.: Ernst Naumann \& W. Frantzen. - 87 S., 5 Abb., 1 Taf.; Berlin 1907

Hrsg.: Königlich Preußische Geologische Landesanstalt; Berlin

Referat: Erläuterungen zur Geologischen Karte von Preußen und benachbarten Bundesstaaten. Lfg. 129: Creuzburg, Treffurt i. Th., Mihla (Berka v. d. Hainich), Schmalkalden. - N. Jb. Mineral. etc., 1908 (Bd. I): 87-91, (Karl Walter); Stuttgart

\section{O4928 Mihla}

Erläuterungen zur Geologischen Karte von Preußen und benachbarten Bundesstaaten. - Lieferung 129 - Blatt Mihla - Gradabth. 56, Nr. 55; [heute: 4928 Mihla ]. - Verf.: Ernst Naumann. - 58 S., 4 Abb. (Profile); Berlin 1907

Hrsg.: Königlich Preußische Geologische Landesanstalt; Berlin

Referat: Erläuterungen zur Geologischen Karte von Preußen und benachbarten Bundesstaaten. Lfg. 129: Creuzburg, Treffurt i. Th., Mihla (Berka v. d. Hainich), Schmalkalden. - N. Jb. Mineral. etc., 1908 (Bd. I): 87-91, (Karl Walter); Stuttgart

\section{O4929 Behringen [ehemals: Henningsleben (Großenbehringen)]}

Erläuterungen zur Geologischen Karte von Preußen und benachbarten Bundesstaaten. - Lieferung 128 - Blatt Henningsleben (Großenbehringen) - Gradabth. 56, Nr. 56; [ heute: 4929 Behringen ]. Verf.: Ernst Naumann. - 55 S.; 3 Abb.; Berlin 1905

Hrsg.: Königlich Preußische Geologische Landesanstalt und Bergakademie; Berlin

Referat: Erläuterungen zur Geologischen Karte von Preußen und benachbarten Bundesstaaten. Lfg. 112: Berlingerode, Heiligenstadt, Dingelstädt, Kella, Lengenfeld... Lfg. 128: Langensalza, Langula, Henningsleben (Großenbehringen). - N. Jb. Mineral. etc., 1906 (Bd. II): 229-232 (Karl Walter); Stuttgart

04930 Gräfentonna

Erläuterungen zur Geologischen Specialkarte von Preussen und den Thüringischen Staaten. - [Ohne Lieferungsangabe, d.i. Lfg. 23] - Blatt Gräfen-Tonna - Gradabth. 56, Nr. 57; heute: 4930

Gräfentonna]. - Verf.: O. Speyer; 14 S.; (Simon Schropp'sche Hof-Landkartenhdlg. (J. H. Neumann)) Berlin 1883

Ohne Hrsg.: d.i. Königlich Preußische Geologische Landesanstalt und Bergakademie; Berlin

\section{-5022 Schwarzenborn}

Erläuterungen zur Geologischen Karte von Preußen und benachbarten Bundesstaaten. - Lieferung 198 - Blatt Schwarzenborn - Gradabth. 69, Nr. 1; [heute: 5022 Schwarzenborn]. - Aufn.: O. Lang u. M. Blanckenhorn; Erl.: M. Blanckenhorn. - 136 S., 1 Abb., 1 Falt-Taf. (Profile); Berlin 1919 Hrsg. Preußische Geologische Landesanstalt; Berlin

Dazugehörige Karte herausgegeben 1918

\section{-5023 Ludwigseck}

Erläuterungen zur Geologischen Specialkarte von Preussen und den Thüringischen Staaten - XLV. [45.] Lieferung - Blatt Ludwigseck - Gradabth. 69, Nr. 2; [heute: 5023 Ludwigseck]. - Geol. Aufn.: Fr. Moesta u. Fr. Beyschlag; Verf.: F. Beyschlag. - 18 S.; (Simon Schropp'sche Hof-Landkartenhdlg. (J. H. Neumann)) Berlin 1891 
Ohne Hrsg.: d.i. Königlich Preußische Geologische Landesanstalt und Bergakademie; Berlin Dazugehörige Karte herausgegeben 1889

Geologischen Karte von Hessen 1 : 25000 - Erläuterungen 5023 Ludwigseck - 2., neu bearb. Aufl. Verf.: Roland Ernst Becker, m. Beitr. and. Autoren; 237 S., 40 Abb., 21 Tab., 2 Taf., 1 Beil; Wiesbaden 1989

Hrsg.: Hessisches Landesamt f. Bodenforschung; Wiesbaden

\section{-5024 Rotenburg a. d. Fulda [ehemals: Rotenburg]}

Erläuterungen zur Geologischen Specialkarte von Preussen und den Thüringischen Staaten. - XLV. [45.] Lieferung - Blatt Rotenburg - Gradabth. 69, Nr. 3; [heute: 5024 Rotenburg a.d. Fulda]. - Verf.: Friedrich Moesta.. - 10 S.; (Simon Schropp'sche Hof-Landkartenhdlg. (J. H. Neumann)) Berlin 1891 Ohne Hrsg.: d.i. Königlich Preußische Geologische Landesanstalt und Bergakademie; Berlin

Erläuterungen zur Geologischen Karte von Hessen 1 : 25000 - Blatt Nr. 5024 Rotenburg a. d. Fulda. 2. Aufl. - Verf.: Renate Motzka; 186 S., 19 Abb., 20 Tab., 1 Beibl.; Wiesbaden 1974

Hrsg.: Hessisches Landesamt f. Bodenforschung; Wiesbaden

\section{-05025 Hönebach}

Erläuterungen zur Geologischen Specialkarte von Preussen und den Thüringischen Staaten. - [Ohne Lieferungsangabe, d.i. Lfg. 8] - Blatt Hönebach - Gradabth. 69, Nr. 4; [ heute: 5025 Hönebach]. Verf.: Friedrich Moesta. - 23 S., Anh. (Profile); (Verlag der Neumann’schen Kartenhandlung) Berlin 1876

Ohne Hrsg.: d.i. Königlich Preußische Geologische Landesanstalt und Bergakademie; Berlin Dazugehörige Karte herausgegeben 1872

-05026 Berka /Werra [ehemals: Gerstungen]

Erläuterungen zur Geologischen Specialkarte von Preussen und den Thüringischen Staaten. - [Ohne Lieferungsangabe, d.i. Lieferung 8] - Blatt Gerstungen Gradabth. 69, No. 5; [heute: 5026

Berka/Werra]. -- Verfass.: Friedrich Moesta. - 14 S.; (Verlag der Neumann'schen Kartenhandlung)

Berlin 1876

Ohne Hrsg.: In später erschienenen Verzeichnissen der Kgl. Preuß. Geol. Landesanstalt wird diese

Kartenerläuterung unter den Veröffentlichungen der Landesanstalt geführt

Dazugehörige Karte geognostisch aufgenommen 1871 durch ...

Erläuterungen zur Geologischen Karte von Preußen und benachbarten deutschen Ländern. - [Ohne Lieferungsangabe, d.i. Lfg. 8] - Blatt Berka (Bl. Gerstungen der 1. Auflage) - Nr. 2927 - Gradabth. 69, Nr. 5; [heute: 5026 Berka/Werra]. - 2. neu bearb. Auflage; Verf.: H. Bücking, m.e. Beitr. v. E. Fulda. - 24 S., 2 Abb.; Berlin 1925

Hrsg.: Preußische Geologische Landesanstalt, Berlin

Geologische Karte von Thüringen Bl. 5026 Berka (Werra). - 3., neu bearb. Aufl.; Wiss. Bearb. E. Grumbt, J. Ellenberg, H. Lützner, S. Redlich; [Hrsg. Thüringer Landesanstalt f. Umwelt u. Geologie, Jena/Weimar] Weimar 2001

\section{O5027 Eisenach}

Erläuterungen zur Geologischen Karte von Preußen und benachbarten Bundessstaaten. - Lieferung 113 - Blatt Eisenach - Gradabth. 69, Nr. 6; [heute: 5027 Eisenach]. - Verf.: Ernst Naumann. - 74 S., 5 Abb., 3 (Foto) Taf.; Berlin 1913

Hrsg.: Königlich Preußische Geologische Landesanstalt; Berlin

Dazugehörige Karte herausgegeben 1912

Referat: Geologische Spezialkarte von Preussen und benachbarten Bundesstaaten. - Bl. Eisenach, 
Wutha, Fröttstedt und Salzungen [heute: 5027 Eisenach, 5028 Eisenach-Ost, 5029 Waltershausen-N, 5127 Bad Salzungen] - N. Jb. Mineral. etc., 1916 (Bd. I): $81-82$ (Geol. Landesanstalt); Stuttgart

05028 Eisenach Ost [ehemals: Wutha]

Erläuterungen zur Geologischen Karte von Preußen und benachbarten Bundessstaaten. - Lieferung

113 - Blatt Wutha - Gradabth. 70, Nr. 1; [heute: 5028 Eisenach Ost]. - Verf.: E. Zimmermann. - 110

S., 1 Profil a. Faltkt.; Berlin 1913

Hrsg.: Königlich Preußische Geologische Landesanstalt; Berlin

Dazugehörige Karte herausgegeben 1904

Referat: Geologische Spezialkarte von Preussen und benachbarten Bundesstaaten. - Bl. Eisenach, Wutha, Fröttstedt und Salzungen [heute: 5027 Eisenach, 5028 Eisenach-Ost, 5029 Waltershausen-N, 5127 Bad Salzungen] - N. Jb. Mineral. etc., 1916 (Bd. I): $81-82$ (Geol. Landesanstalt); Stuttgart

\section{Waltershausen Nord [ehemals: Fröttstedt]}

Erläuterungen zur Geologischen Karte von Preußen und benachbarten Bundessstaaten. - Lieferung

113 - Blatt Fröttstedt - Gradabth. 70, Nr. 8; [heute: 5029 Waltershausen N]. - Verf.: L. G.

Bornemann \& E. Zimmermann. - 37 S.; Berlin 1912

Hrsg.: Königlich Preußische Geologische Landesanstalt; Berlin

Referat: Geologische Spezialkarte von Preussen und benachbarten Bundesstaaten. - Bl. Eisenach, Wutha, Fröttstedt und Salzungen [heute: 5027 Eisenach, 5028 Eisenach-Ost, 5029 Waltershausen-N, 5127 Bad Salzungen] - N. Jb. Mineral. etc., 1916 (Bd. I): $81-82$ (Geol. Landesanstalt); Stuttgart

\section{Gotha}

Erläuterungen zur Geologischen Specialkarte von Preussen und den Thüringischen Staaten. XXXIX. [39.] Lieferung - Blatt Gotha - Gradabth. 70, No. 3; [heute: 5030 Gotha]. - Verfass.: Max Bauer. - 21 S.; (I. Comm. Simon Schropp'sche Hof-Landkartenhdlg. (J. H. Neumann)); Berlin 1889 Ohne Hrsg.: In später erschienenen Verzeichnissen der Kgl. Preuß. Geol. Landesanstalt wird diese Kartenerläuterung unter den Veröffentlichungen der Landesanstalt geführt

Dazugehörige Karte geognostisch bearbeitet in den Jarhen 1878-1880 durch...

Erläuterungen zur Geologischen Karte 1: 25000 von Thüringen, Blatt Gotha, Nr. 5030 - 2. Aufl. Verf.: Kurt P. Unger, mit Beiträgen anderer Autoren. - 172 S., 25 Abb., 23 Tab., 6 Beil.; Weimar 1994 Dazugehörige Karte herausgegen als: Geologische Karte der Detuschen Demokratischen Republik, Gotha - 5030; 2. Auflage; [Hrsg. Zentrales Geologische Institut, Berlin] Berlin ca. 1976

\section{-5122 Neukirchen}

Erläuterungen zur Geologischen Karte von Preußen und benachbarten Bundesstaaten. - Lieferung 198 - Blatt Neukirchen - Gradabth. 69, Nr. 7; [heute: 5122 Neukirchen]. - Aufn.: K. Oebbeke u. M. Blanckenhorn; Erl.: M. Blanckenhorn (u. Benutzg. e. ält. Entwurfs v. K. Oebbeke). - 71 S., 3 Abb.; Berlin 1919

Hrsg. Preußische Geologische Landesanstalt; Berlin

Dazugehörige Karte herausgegen 1918

\section{-5123 Niederaula}

Erläuterungen zur Geologischen Karte von Preußen und benachbarten Bundesstaaten. - Lieferung 198 - Blatt Niederaula - Gradabth. 69, Nr. 8; [heute: 5123 Niederaula]. - Aufn.: K. Oebbeke u. M. Blanckenhorn; Erl.: M. Blanckenhorn (u. Benutzg. e. ält. Entwurfs v. K. Oebbeke). - 47 S., 2 Abb.; Berlin Hrsg.: Preußische Geologische Landesanstalt; Berlin 1920

Dazugehörige Karte herausgegeben 1918 
-5124 Bad Hersfeld [ehemals: Hersfeld]

Erläuterungen zur Geologischen Specialkarte von Preussen und den Thüringischen Staaten. - 36.

Lieferung - Blatt Hersfeld - Gradabth. 69, Nr. 9; [heute: 5124 Bad Hersfeld]. - Verf.: A. v. Koenen. 15 S.; (i. Comm. Simon Schropp'sche Hof-Landkartenhdlg. (J. H. Neumann)) Berlin 1888

O. Hrsg. d. i. Königlich Preußische Geologische Landesanstalt und Bergakademie; Berlin

Erläuterungen zur Geologische Karte von Hessen 1 : 25000 Blatt Nr. 5124 Bad Hersfeld. - 2. neu bearbeitete Auflage - Verf.: Laemmlen, Manfred. - 280 S., 16 Abb., 7 Diagr., 10 Tab., 31 Textprofile, 4 Taf., 1 Beibl.; Wiesbaden 1967

Hrsg.: Hessisches Landesamt für Bodenforschung; Wiesbaden

\section{-05125 Friedewald}

Erläuterungen zur Geologischen Specialkarte von Preussen und den Thüringischen Staaten. - 36.

Lieferung - Blatt Friedewald - Gradabth. 69, Nr. 10; [heute: 5125 Friedewald]. - Verf.: A. v. Koenen.

- 16 S.; (i. Comm. Simon Schropp’sche Hof-Landkartenhdlg. (J. H. Neumann)) Berlin 1888

O. Hrsg.; d. i. Königlich Preußische Geologische Landesanstalt und Bergakademie; Berlin

Erläuterungen zur Geologischen Karte von Preußen und benachbarten deutschen Ländern - Blatt Friedewald (Lieferung 36 der ersten Auflage) [heute: 5125 Friedewald] - 2. neu bearb. Aufl., Verf.: H. Bücking, m. e. bergbaul. Teil v. C. Dietz. - 42 S., 7 Abb.; Berlin 1927

Hrsg.: Preußische Geologische Landesanstalt, Berlin

\section{-05126 Vacha}

Erläuterungen zur Geologischen Specialkarte von Preussen und den Thüringischen Staaten - 36.

Lieferung - Blatt Vacha - Gradabth. 69, Nr. 11; [heute: 5126 Vacha]. - 1. Auflage; Verf.: A. v.

Koenen. - 19 S.; (i. Comm. Simon Schropp'sche Hof-Landkartenhdlg. (J. H. Neumann)) Berlin 1888

Hrsg.: Königlich Preußische Geologische Landesanstalt und Bergakademie; Berlin

Erläuterungen zur Geologischen Karte von Preußen und benachbarten deutschen Ländern -

Lieferung 36 - Blatt Vacha - Nr. 2990; [heute: 5126 Vacha]. - 2. neu barb. Aufl. - Verf.: H. Bücking

m.e. bergbaul. Beitr. v. E. Fulda. - 35 S.; Berlin 1925

Hrsg.: Preußische Geologische Landesanstalt, Berlin

Geologische Karte von Thüringen Bl. 5126 Vacha - 3., neu bearb. Aufl.; Wiss. Bearb. H. Lützner, E. Grumbt, J. Ellenberg, S. Redlich. - [Hrsg. Thüringer Landesanst. f. Bodenforschung, Weimar] Weimar 2000

\section{Q5127 Bad Salzungen [ehemals: Salzungen]}

Erläuterungen zur Geologischen Karte von Preußen und benachbarten Bundessstaaten. - Lieferung 113 - Blatt Salzungen - Gradabth. 69, Nr. 12; [heute: 5127 Bad Salzungen]. - Verf.: Ernst Naumann. - 104 S.; Berlin 1914

Hrsg.: Königlich Preußische Geologische Landesanstalt; Berlin

Referat: Geologische Spezialkarte von Preussen und benachbarten Bundesstaaten. - Bl. Eisenach, Wutha, Fröttstedt und Salzungen [heute: 5027 Eisenach, 5028 Eisenach-Ost, 5029 Waltershausen-N, 5127 Bad Salzungen] - N. Jb. Mineral. etc., 1916 (Bd. I): $81-82$ (Geol. Landesanstalt); Stuttgart

Geologische Karte von Thüringen - B1. 5127 Bad Salzungen. - 2., neu bearb. Aufl.; [Hrsg. Thüringer Landesanstalt f. Umwelt u. Geologie, Jena/Weimar] Weimar 2002 
05128 Ruhla [ehemals: Brotterode]

Erläuterungen zur Geologischen Karte von Preußen und benachbarten deutschen Ländern.

Lieferung 183 - Blatt Brotterode - Nr. 2992 - Gradabth. 70, Nr. 7; [heute: 5128 Ruhla]. - Verf.: E.

Zimmermann. - 136 S., 3 Abb.; Berlin 1930

Hrsg.: Preußische Geologische Landesanstalt, Berlin

Dazugehörige Karte herausgegeben 1920

05129 Waltershausen [ehemals: Waltershausen-Friedrichroda]

Erläuterungen zur Geologischen Karte von Preußen und benachbarten Bundessstaaten. - Lieferung

183 - Blatt Waltershausen-Friedrichroda - Gradabth. 70, Nr. 8; [heute: 5129 Waltershausen]. - Verf.:

E. Zimmermann, u. Benutzung v. Vorarb. von R. Scheibe. - 82 S., 1 Tab.; Berlin 1924

Ohne Hrsg.: d.i. Preußische Geologische Landesanstalt; Berlin

Dazugehörige Karte herausgegeben 1914

\section{o5130 Ohrdruf}

Erläuterungen zur geologischen Specialkarte von Preussen und den Thüringischen Staaten. - 39. Lfg.

- Blatt Ohrdruf - Gradabth. 70, Nr. 9; [heute: 5130 Ohrdruf]. - Geogn. bearb. v. M. Bauer, E.

Weiss \& R. Scheibe. - 19 S.; (i. Comm. Simon Schropp'sche Hof-Landkartenhdlg. (J. H. Neumann))

Berlin 1889

Ohne Hrsg.: d. i. Königlich Preußische Geologische Landesanstalt u. Bergakademie; Berlin

Herausgegeben mit einer mehrfarbigen Karte

\section{Arnstadt}

Erläuterungen zur geologischen Specialkarte von Preussen und den Thüringischen Staaten. - 39. Lfg. - Blatt Arnstadt - Gradabth. 70, Nr. 10; [heute: 5131 Arnstadt]. - Geogn. bearb. v. E.E. Schmid. - 29 S., 1 Abb.; (i. Comm. Simon Schropp'sche Hof-Landkartenhdlg. (J. H. Neumann)); Berlin 1889

Ohne Hrsg.: d. i. Königlich Preußische Geologische Landesanstalt u. Bergakademie; Berlin

Erläuterungen zur Geologischen Karte von Preußen und benachbarten Bundessstaaten - Lfg. 39 Blatt Arnstadt - Gradabt. 70, Nr. 10; [heute: 5131 Arnstadt] - 2. Auflage. - Für die zweite Aufl. neu begangen u. erläutert durch E. Zimmermann I. - 50 S., 1 Bl.; Berlin 1924

O. Hrsg., d. i. Preußische Geologische Landesanstalt; Berlin

Dazugehörige Karte herausgegeben 1920

\section{Bad Salzungen Süd [ehemals: Altenbreitungen]}

Erläuterungen zur geologischen Spezialkarte von Preußen und den Thüringischen Staaten. -

XXXVII. Lieferung [Lieferung 37] - Blatt Altenbreitungen - Gradabth. 69, Nr. 18; [heute: 5227 Bad Salzungen S]. - Geol. Aufn.: H. Emrich u. H. Bücking., Verf.: H. Bücking. - 21 S.; (i. Comm. Simon Schropp'sche Hof-Landkartenhdlg. (J. H. Neumann)) Berlin 1889

Hrsg.: Königlich Preußische Geologische Landesanstalt u. Bergakadamie; Berlin

Dazugehörige Karte herausgegeben 1879

\section{Schmalkalden}

Erläuterungen zur Geologischen Karte von Preußen und benachbarten Bundesstaaten. - Lieferung 129 - Blatt Schmalkalden - Gradabth. 70, Nr. 13; [heute: 5228 Schmalkalden]. - Geol. Aufn. U. Verf.: H. Bücking. - 71 S., 4 Abb.; Berlin 1906

O. Hrsg: d.i. Königlich Preußische Geologische Landesanstalt; Berlin

Dazugehörige Karte herausgegeben 1907

Referat: Erläuterungen zur Geologischen Karte von Preußen und benachbarten Bundesstaaten. Lfg. 129: Creuzburg, Treffurt i. Th., Mihla (Berka v. d. Hainich), Schmalkalden. - N. Jb. Mineral. etc., 1908 (Bd. I): 87-91, (Karl Walter); Stuttgart 
05229 Tambach-Dietharz [ehemals: Tambach]

Erläuterungen zur Geologischen Karte von Preußen und benachbarten Bundesstaaten. - Lieferung 183 - Blatt Tambach - Gradabth. 70, Nr. 14; [heute: 5229 Tambach-Dietharz]. - Geol. Aufn. H.

Bücking u. R. Scheibe; Verf. B. Kühn. - 62 S., 3 Abb., 1 Taf.; Berlin 1920

Hrsg: Preußische Geologische Landesanstalt; Berlin

Dazugehörige Karte herausgegeben 1912

05230 Oberhof (Gräfenroda) [ehemals: Crawinkel-Gräfenroda = Crawinkel-Oberhof)

Erläuterungen zur Geologischen Karte von Preußen und benachbarten Bundesstaaten. - Lieferung 64

- Blatt Crawinkel-Gräfenroda (= Crawinkel-Oberhof) - Gradabth. 70, Nr. 15; [heute: 5230 Oberhof

(Gräfenroda)]. - Geol. Aufn. u. Verfass. E. Zimmermann. - 128 S., 4 B1.; Berlin 1908

Hrsg. Königlich Preußische Geologische Landesanstalt.; Berlin

Dazugehörige Karte herausgegeben 1898 (1. Auflage); 1975 (2. Auflage)

Erläuterungen zur Geologischen Karte 1 : 25.000 von Thüringen - Blatt Oberhof (Gräfenroda), Nr. 5320. - 2. [neu bearb.] Aufl.; Verfass.: D. Andreas, mit zahlr. Beitr. weiterer Fachautoren. - 370 S., 37 Abb., 38 Tab.; 15 Beil.; Weimar 1998

Hrsg. Thüringer Landesamt f. Geologie, Weimar

Herausgegeben mit einer mehrfarbigen Geologischen Karte

05329 Suhl - West [ehemals: Mehlis]

Erläuterungen zur Geologischen Karte von Preußen und benachbarten Bundesstaaten - Lieferung 183 - Blatt Mehlis; [heute: 5329 Suhl-West] - Gradabth. 70, Nr. 20. - Geol. Aufn.: R. Scheibe; Verf.: B. Kühn. - 60 S., 1 Falt-Taf.; Berlin 1920

Hrsg.: Preußische Geologische Landesanstalt, Berlin

Dazugehörige Karte herausgegeben 1915

\section{O5330 Suhl}

Erläuterungen zur Geologischen Karte von Preußen und den Thüringischen Staaten. - Lieferung 64 - Blatt Suhl - Gradabth. 70, Nr. 21; [heute: 5330 Suhl]. - Geol. Aufnahme: F. Beyschlag, K. v.

Fritsch, R. Scheibe, E. Zimmermann; Verf.: E. Zimmermann, R. Scheibe. - 158 S., 4 Bl., 1 Falt-Taf. (Profile); Berlin 1908

Hrsg.: Königlich Preußische Geologische Landesanstalt, Berlin

Dazugehörige Karte herausgegeben 1898

\section{O5331 Ilmenau}

Erläuterungen zur Geologischen Karte von Preußen und den Thüringischen Staaten. - Lieferung 64 Blatt Ilmenau - Gradabth. 70, Nr. 22; [heute: 5331 Ilmenau]. - Geol. Aufn. u. Verfass.: H. Loretz, R. Scheibe, E. Zimmermann. - 185 S., 4 Bl.; 1 Falt-Taf. (Profile); Berlin 1908

Hrsg.: Königlich Preußische Geologische Landesanstalt, Berlin

Dazugehörige Karte herausgegeben 1898

\section{Suhl Süd [ehemals: Schleusingen]}

Erläuterungen zur Geologischen Karte von Preußen und den Thüringischen Staaten. - Lieferung 64

- Blatt Schleusingen - Gradabtheilung 70, Nr. 27; [heute: 5430 Suhl Süd]. - Geogn. bearb. d. F.

Beyschlag, K. v. Fritsch, R. Scheibe und E. Zimmermann. - 136, [4] S., 2 Falt-Taf.; Berlin 1908

Hrsg.: Königlich Preußische Geologische Landesanstalt, Berlin

Dazugehörige Karte herausgegeben 1898 


\subsection{Geowissenschaftliche Karten - verschiedene Maßstäbe und Themen}

\subsubsection{Geologische Übersichtskarten}

\subsubsection{Länderübergreifende Kartenwerke}

\section{$\underline{\text { Geologische Übersichtskarte }-1: 200.000 \text { [Bundesrepublik Deutschland] }}$}

-Geologische Übersichtskarte - 1 : 200.000 - CC 4718 Kassel. - Wiss. Bearb. H. Waldeck; [Hrsg. Bundesanstalt f. Geowiss. u. Rohstoffe i. Zusarb. m. d. Geol. Landesämtern d. Bundesrepublik Deutschland] Hannover 1998

-Geologische Übersichtskarte - 1 : 200.000 - CC 4726 Goslar. - Wiss. Bearb.; [Hrsg. Bundesanstalt f. Geowiss. u. Rohstoffe i. Zusarb. m. d. Geol. Landesämtern d. Bundesrepublik Deutschland] Hannover 1986

-Geologische Übersichtskarte - 1 : 200.000 - CC 5518 Fulda. - Wiss. Bearb.; [Hrsg. Bundesanstalt f. Geowiss. u. Rohstoffe i. Zusarb. m. d. Geol. Landesämtern d. Bundesrepublik Deutschland] Hannover 1988

○Geologische Übersichtskarte - 1 : 200.000 - CC 5526 Erfurt. - Wiss. Bearb. G. Seidel, H. Kästner, H. Wefel; [Hrsg. Bundesanstalt f. Geowiss. u. Rohstoffe i. Zusarb. m. d. Geol. Landesämtern d. Bundesrepublik Deutschland] Hannover 1998

Geologische Übersichtskarte von Deutschland - Maßstab $1: 200000$

[Hrsg. Preußische Geologische Landesanstalt, Berlin]

Titeldaten n. Verzeichn. Veröff. Preuß. Geol. Landesanstalt, $\underline{33}$ (Stand Dezember 1930)

Göttingen (99)

Kassel (112)

Fulda (126)

Geologische Karte der Deutschen Demokratischen Republik - Maßstab 1:100 000

oGeologische Karte der Deutschen Demokratischen Republik - Blatt Gotha. - Maßstab 1 : 100 000. - [Bearb. u. Hrsg.: Staatl. Geol. Kommission d. DDR]; Berlin 1954

○ Geologische Karte der Deutschen Demokratischen Republik - Blatt Mühlhausen. - Maßstab 1 : 100 000. - [Bearb. u. Hrsg.: Staatl. Geol. Kommission d. DDR]; Berlin 1956 - in russischer Sprache abgefaßt 


\subsubsection{Länderbezogene Kartenwerke}

\subsection{Hessen}

\section{$\underline{1: 1.000 .000}$}

Hessisches Landesamt f. Bodenforschung [Bearb. u. Hrsg.](1952): Geologische Übersichtskarte von Hessen. - Maßstab 1 : 1000 000. - 1 mehrfarb. Kt., 41,5 x 59 cm; [Hess. Landesamt f. Bodenforschung] Wiesbaden

Matheis, J. [Bearb.][1964]: Geschichtlicher Atlas von Hessen - 2.: Geologische Übersichtskarte von Hessen. - Maßstab 1 : 1000 000; 1 Blatt; [Hrsg. Landesamt f. Geschichtliche Landeskunde] [Marburg/L.]

Matheis, J. [Bearb.](1974): Geologische Übersichtskarte von Hessen. - Maßstab 1 : 1000 000. - 2. Aufl.; 1 mehrfarb. Kt., 43 x 52 cm; (Hess. Landesamt f. Bodenforschung) Wiesbaden

\section{$1: 400.000-1: 300.000$}

- Schwarzenberg, Adolph \& Reuße, Heinrich (1853): Geognostische Karte von Kurhessen und den angrenzenden Ländern zwischen Taunus-Harz u. Weser-Gebirge. - Ohne Maßstabsangabe [ca. 1 : 400.000]; о. O

-Mitarb. Hess. Landesamt f. Bodenforschung [Wiss. Bearb.](1989): Geologische Übersichtskarte 1 : 300000 von Hessen [GÜK 300 Hessen] - 4., neu barb. Aufl. ; [Hrsg. Hess. Landesamt Bodenforschung] Wiesbaden 1989

-Rösing, Franz [Bearb.](1976/1973/1960): Geologische Übersichtskarte von Hessen - 1 : 300000 [GÜK 300 Hessen]. - 3. Aufl., 1976. - 2., überarb. Aufl. 1973, 1 . Aufl. 1960; 1 mehrfarb. Kt., 64 x $85 \mathrm{~cm}$

-Thews, Joe-Dietrich (1996): Erläuterungen zur Geologischen Übersichtskarte von Hessen 1 : 300.000 (GÜK 300 Hessen) Teil 1: Kristallin, Ordovizium, Silur, Devon, Karbon.- Geol. Abh. Hessen, 96; 237 S., 39 Abb., 17 Tab., 7 Taf.; [Hrsg. Hess. Landesamt Bodenforschung] Wiesbaden [ darin: Unterwerra-Grauwackengebirge zwischen Witzenhausen und Albungen, Stratigraphie Devon]

\section{$\underline{1: 100.000}$}

- Schwarzenberg, A. (1825): Petrographische Karte vom Kreise Cassel. - Entworfen und gezeichnet von A. Schwarzenberg. Lithographie v. J. C. Arnold. - 1 mehrfarb. Kt., 42 x 35 cm; Inselkarte o. Kartenrahmen; Maßstab i. graph. Darstellung (Stunden) [ca. 1 : 100.000]; Kassel Vermutlich Kartenbeilage zu nachfolgendem Zeitrschriftenaufsatz: Schwarzenberg, BergKommissar (1825): Beschreibung der im Kreise Cassel vorkommenden Gebirgs- und Erd-Arten, besonders in Beziehung auf Oekonomie und Technologie. - Landwirthschaftliche Zeitung für Kurhessen, $\underline{\mathbf{3}}$ (1825)(Januarheft): 10 - 22; (Februarheft): 40 - 47; (Märzheft): 53 - 59; (Laupe) Kassel

-Schwarzenberg, A. (1827): Petrographische Karte des Kreises Wolfhagen. - Entworfen und gezeichnet von A. Schwarzenberg. Lithographie v. J. C. Arnold. - 1 mehrfarb. Kt., 25 x 38 cm; Inselkarte o. Kartenrahmen; Maßstab i. graph. Darstellung (Stunden)[ca. 1 : 100.000]; (Bohné) Kassel Vermutlich Kartenbeilage zu nachfolgendem Zeitrschriftenaufsatz: Schwarzenberg, Adolf (1827): 
Beschreibung der im Kreise Wolfhagen vorkommenden Gebirgs- und Erd-Arten, besonders in Beziehung auf Technologie und Oekonomie, nebst einer dazu gehörigen petrographischen Karte. Landwirthschaftliche Zeitung f. Kurhessen, $\underline{\mathbf{5}}(20)(1827):$ 274-295; $\underline{\mathbf{5}}(21)(1827): 306-327$; $\underline{\mathbf{5}}(21)(1827)$ : 338-363; Kassel

-Schwarzenberg, A. (1830): Petrographische Karte des Kreises Hofgeismar. - Entworfen und gezeichnet von A. Schwarzenberg. Lithographie v. J. C. Arnold. - 1 mehrfarb. Kt., 41 x 29 cm; Inselkarte o. Kartenrahmen; Maßstab i. graph. Darstellung (Stunden)[ca. 1 : 100.000]; (Bohné) Kassel Vermutlich Kartenbeilage zu nachfolgendem Zeitrschriftenaufsatz: Schwarzenberg , A. (1830): Beschreibung der im Kreise Hofgeismar vorkommenden Gebirgs- und Erdarten usw., nebst einer petrographischen Karte dieses Kreises Kurhessens. - Landwirthschaftliche Zeitung für Kurhessen, $\underline{\mathbf{8}}(1830)$; Kassel

[Vorlage nicht eingesehen, zitiert nach Krauß 1913]

$\square$ Rüppel, H. \& J. Apel (2001): Naturpark Meißner und Kaufunger Wald - Geologische Wanderkarte 1 : 100000 - Mit Erläuterungen zu den Natursehenswürdigkeiten entlang der Rad- u. Wanderwege auf beiden Seiten der Faltkarte. - (Landschaftskundlicher-Studien-Reisebuch-Verlag) Witzenhausen

\section{$\underline{1: 50.000}$}

-Backhaus, E. u. a. [Bearb.](1980): Geologische Karte des Reinhardswaldes - 1 : 50 000. - Bearb. ...; mit Erläuterungsheft: 32 S., Abb.; [Hrsg.: Hess. Landesamt für Bodenforschung] Wiesbaden 1980

$\square$ Jacobshagen, V.; Brede, R.; Hampel, M. \& Kuhnert, C. [Bearb.](1993): [Geologische Karte] Hoher Meißner und Eschweger Becken - Beilage Geologie. - Maßstab 1 : 50 000; Bearb. V. Jacobshagen, R. Brede; M. Hampel, C. Kuhnert. - Beilage in: Jacobshagen, V.; Möller, K. \& Jäkel, D. (1993): Hoher Meißner und Eschweger Becken - Geowissenschaftliche und vegetationskundliche Charakteristik einer nordhessischen Landschaft. - Berliner geogr. Abh., $\underline{\mathbf{5 6}}$; zgl. Beiträge zur WerraMeißner-Forschung, III; XII, 288 S., 95 Abb., 23 Tab., 5 Kt.-Beil.; (Selbstverlag Geomorphologisches Laboratorium FU Berlin) Berlin

- $\square$ Anonym (ca. 1852): [Geologische] Karte des Kurfürstenthums Hessen. - Maßstab 1 : 50000 Farbige Flächen handkoloriert. - Erschienen: „Mitte 19. Jahrhundert“, auch 1852; Anzahl nachgewiesen: drei Blätter: 7 Witzenhausen, 8 Asbach, 12 Sontra; Bestand nachgewiesen: Staatsarchiv Marburg KW 45; Bibliothek/Geozentrum Hannover (Bundesanstalt f. Geowissenschaften u. Rohstoffe u.a.), Hannover [Topographische Grundlage: „Karte vom Kurfürstenthum Hessen“ - Maßstab 1 : 50 000. Herstellung: Kurfürstlich Hessischer Generalstab, 39 Blätter als einfarbige Drucke, 1 Titelblatt mit Zeichenerklärung und Blattübersicht; erschienen 1840-1858]

$\square$ Weiss, Otto u.a.(1851): Geognostische Karte der Umgegend der kurfürstlich Hessischen Saline Sooden bei Allendorf a. d. Werra. - entworfen u. gezeichnet v. Otto Weiss, Herwig.... - Archiv f. Mineralogie, Geognosie, Bergbau u. Hüttenkunde, 24; 1 mehrfarb. Kt., Maßstab 1 : 50 000; 38 x 30 $\mathrm{cm}$; (Reimer) Berlin

\section{$\underline{1: 25.000}$}

$\square$ Kupfahl, H.-G.; Laemmlen, M. \& Pflanzl, G. (1979): Geologische Karte des Meißner - 1 : 25 000. Bearb. H.-G. Kupfahl, M. Laemmlen, G. Pflanzl; [Hrsg. Hess. Landesamt f. Bodenforschung] Wiesbaden 1979

$\square$ Schmidt, Bernd (1991): Stratigraphie und Tektonik der Umgebung von Hessisch LichtenauHirschhagen (Nordhessen) Blatt Nr. 4724 Großalmerode. - Geol. Abh. Hessen, 94, 61 S., 6 
Abb., 1 Taf., 1 Kt.; Wiesbaden. - Kartenbeilage 1:25000 [Buntsandsteinmassiv des Hirschhagener Waldes und des Rohrberges, Gelbe Strut]

$\square$ Hofmann, R. (1988): Geologische Karte der Gemarkung Eschwege. - FU Berlin; 38 S., 1 Kt. 1 : 25000 (unveröff.)

[Nachgewiesen: Geowissenschaftliche Bibliothek der FU Berlin]

\subsection{Thüringen}

$\underline{1: 500.000-1: 400.000}$

○ Deubel, F. \& Martini, H. J. (1942): Geologische Karte von Thüringen 1 : 500 000; (Perthes) Gotha 1942

ㅁ Hoppe, [W.] \& Seidel, G. [Hrsg.](1969): Geologische Karte von Thüringen 1 : 500 000. - Hrsg.: [W.] Hoppe \& G. Seidel; Geol. Bearb.: P. Puff; Neubearb. D. Geol. Karte v. Thüringen v. 1942 - (Haack) Gotha-Leipzig 1969

○Thüringer Landesanstalt f. Bodenforschung [Hrsg.](1994): Thüringen - Geologische Übersicht 1 : $400000-71,5$ x 33,5 cm; „Kurze Erläuterungen zur Karte“ a. d. Rückseite; [Hrsg.: Thüringer Landesanstalt für Bodenforschung, Weimar]; (Justus Perthes Verlag) Gotha 1994

\section{$\underline{1: 200.000}$}

QCredner, Heinrich (1855): Geognostische Karte des Thüringer Waldes [Maßstab 1 : 200 000]. - 2. Aufl.; Bearb. Credner, Heinrich; 1 Kt. m. 27 Profile a. 4 Bl.; (Perthes) 1855; dazugehörig: Credner, Heinrich (1855): Versuch einer Bildungsgeschichte der geognostischen Verhältnisse des Thüringer Waldes - zur Erläuterung der geognostischen Karte des Thüringer Waldes; 82 S.; (Perthes) Gotha

OSeidel, G. u.a. [Bearb.](2002): Geologische Übersichtskarte von Thüringen 1 : 200000 . - Geol. Bearb.: G. Seidel, H. Kästner, H. Wiefel, T. Heuse, H. Huckriede, L. Katschmann, K. Wucher; Geol. Red.: T. Heuse, H. Huckriede, L. Katschmann. - ca. 103 x 83 cm, mit Legende auf separatem Beiblatt ca. 91 x 62 cm; [Hrsg.: Thüringer Landesanstalt für Umwelt und Geologie] Jena 2002

oCotta, Bernhard v. (1844-1847): Geognostische Karte von Thüringen - als Fortsetzung der von der Königlich Sächsischen Regierung herausgegebenen geognostischen Karte von Sachsen .... - Blatt Rudolstadt 1844 [erschienen 1847] - Blatt Meiningen [1847] - Blatt Weimar-Gotha 1846 [erschienen 1847] - Blatt Mühlhausen 1847; (Arnoldische Buchhdlg.) Dresden-Leipzig

Referat in: Archiv f. Mineralogie, Bergbau u. Hüttenwesen, 22(1): 300-305 (v. Dechen); Berlin

oThüringer Landesanstalt f. Umwelt u. Geologie (2003): Geologie \& Hydrogeologie im Überblick Daten zur Geologischen und Hydrogeologischen Übersichtskarte von Thüringen. Generiert für den Maßstab $1: 200$ 000. - Elektronische Ressource: 1 CD-ROM; [Hrsg.: Thüringer Landesanstalt für Umwelt und Geologie] Jena 2003

\section{$\underline{1: 100.000}$}

OBeyschlag, Franz [1898]: Geognostische Übersichtskarte des Thüringer Waldes. - Maßstab 1: 100 000 - [Nach den Aufnahmen der Kgl. Preuß. Geol. Landesanstalt zusammengestellt] Bearb.: Franz Beyschlag; 57 x 84 cm; Hrsg. Kgl. Preuß. Geol. Landesanstalt u. Bergakad.; (Schropp) Berlin Referat in: N. Jb. Mineral. etc., $\underline{1898}$ (Bd. II): 80-81 (Dames); Stuttgart

Referat in: Mitt. Geogr. Ges. (f. Thür.), 16: 91; Jena 1898 
OKästner, H. [Red.](1996): Geologische Karte Thüringer Wald 1 : 100000 - 1. Aufl.; Red. H. Kästner; Verf.: D. Andreas; H. Kästner; G. Seidel; H. Wiefel \& J. Wunderlich; 103 x 83 cm, 1 Nebenk.; 2 geol Schnitte, 1 Profil , textl. Erläuterungen a.d. Rückseite; [Hrsg.: Thüringer Landesanstalt für Geologie, Weimar] Weimar 1996

\subsection{Niedersachsen}

\section{$1: 500.000$}

-Hinze, C. \& Waldeck, H. [Zusammstlg.](1985): Geologische Übersichtskarte von Niedersachsen. Maßstab 1 : 500000 - Zusstellg.: C. Hinze, H. Waldeck.; 70 x 64 cm.; [Hrsg. Niedersächsisches Landesamt f. Bodenforschung] Hannover 1985

-Bradel, E.; Hinze, C. \& Look, E.-R. [Zusammstlg.](1988): Geologische Übersichtskarte von Niedersachsen 1 : 500000 - Mit Blattschnitt der geologischen Kartenwerke 1 : 200000 und 1 : 25 000. - Zusammenstellung E. Bradel; C. Hinze, E.-R. Look.; a. d. Rückseite mit Texten zu verschiedenen Themen, u.a. „Geowissenschaftliche Dienste“ [in Niedersachsen ansässig], „Rohstoffindustrie in Niedersachsen“ (m. 2. Übersichtskarten u. Diagr.), „Schematisches Profil der Schichtfolge in Niedersachsen“ [Devon-Quartär, mit Neben-Profil Quartär] ; Nebenkarte (Maßstab 1 : 1000 000) „Die Salzstrukturen in Niedersachsen - The Salt Structures in Lower Saxony (FRG)“; (Niedersächsische Akademie d. Geowissenschaften) Hannover 1988

[T]

\section{$\underline{1: 100.000}$}

-Stille, Hans \& Lotze, Franz [Bearb.] (1953): Geologische Übersichtskarte der Umgebung von

Göttingen 1 : 100000 - mit Erläuterungsheft. - Bearb.: Stille, Hans \& Lotze, Franz; m.

Erläuterungsheft, 67 S., 14 Abb., 1 Geol.-Kt.; Göttingen/Berlin 1933

\subsubsection{Stratigraphische Karten}

QLithofazieskarte Quartär 1 : $\mathbf{5 0 . 0 0 0}$ - LKQ 50

[Keine weiteren Titeldaten gefunden]

Kartenset aus drei Teilblättern:

Karte 1 - Weichsel bis Holozän (W-H)

Karte 2 - Präweichsel [Q1-iE]

Karte 3 - Darstellung der Quartärbasis

Kartenblätter mit Regionalbezug:

2561 Mühlhausen - 1977

W-H [Weichsel bis Holozän]

Q1-iE

2661 Eisenach-Nord - 1976

Weichsel bis Holozän

Präweichsel

Darstellung der Quartärbasis 
2662 Bad Langensalza - 1972

Weichsel bis Holozän

Präweichsel

Darstellung der Quartärbasis

2761 Eisenach-Süd - 1975

W-Ho

Q1-iE

Darstellung der Quartärbasis

2762 Gotha - 1973

Weichsel-Holozän

Präweichsel

Darstellung der Quartärbasis

-Wortmann, Heinrich (1942): Bemerkungen zu einer Karte der Lößverbreitung in Niedersachsen. Archiv. f. Landes- u. Volkskde v. Niedersachsen. - [3. Jg.] 1942(12): 192-202, 1 Abb., 1 Farb-Kt. (Kt. d. Lößverbreitung i. Niedersachsen) $1: 700000$ [1:800 000 ! lt. Kt.-Legende]; (Stalling) Oldenburg i. O.

\subsubsection{Rohstoff- und Lagerstättenkarten}

\subsubsection{Länderübergreifende Kartenwerke}

\section{$\underline{\text { Karte der oberflächennahen Rohstoffe der Bundesrepublik Deutschland 1: } 200000}$}

-Karte der oberflächennahen Rohstoffe der Bundesrepublik Deutschland 1:200 000 - CC 4718 Kassel - Bearb.: W. Barth - [Hrsg. Bundesanst. f. Geowiss. Rohstoffe u.d. staatl. Geol. Diensten d. Bundesrepublik Deutschland]

; Hannover 1996

-Karte der oberflächennahen Rohstoffe der Bundesrepublik Deutschland 1: 200000 - [CC 4726 Goslar - Bearb.: V. Stein; [Hrsg. Bundesanst. f. Geowiss. u. Rohstoffe u.d. staatl. Geol. Diensten d. Bundesrepublik Deutschland] Hannover 1988

-Karte der oberflächennahen Rohstoffe der Bundesrepublik Deutschland 1 : 200000 - CC 5518 Fulda - Bearb.: W. Barth; [Hrsg. Bundesanst. f. Geowiss. U. Rohstoffe u.d. staatl. Geol. Diensten d. Bundesrepublik Deutschland] Hannover 1999

\section{$\underline{\text { Karte der nutzbaren Lagerstätten Deutschlands - 1:200.000 }}$}

- Karte der nutzbaren Lagerstätten Deutschlands - $1: 200.000$ - [2] Gruppe Preußen und benachbarte Bundesstaaten: Lf. III, [Bl. 99] - Blatt Göttingen. - [Hrsg. Kgl. Preuß. Geol. Landesanst.] Berlin 1910

- Karte der nutzbaren Lagerstätten Deutschlands - 1 : 200.000 - [2] Gruppe Preußen und benachbarte Bundesstaaten: Lf. XII, Bl. 112 - Blatt Kassel. - [Hrsg. Preuß. Geol. Landesanst.] Berlin 1921

Q Karte der nutzbaren Lagerstätten Deutschlands - $1: 200.000$ - [2] Gruppe Preußen und benachbarte Bundesstaaten: Lf. XII, [Bl. 127]- Blatt Gotha. - [Hrsg. Preuß. Geol. Landesanst.] Berlin 1922 


\subsubsection{Länderbezogene Kartenwerke}

\subsection{Hessen}

- $\square$ Übersichtskarte der oberflächennahen Rohstoffe in Hessen (KOR 300). - Bearb.: W. Barth et al.; 1 mehrfarb. Kt., 60 x 85 cm, Maßstab 1 : 300.000; [Hrsg. Hess. Landesamt f. Bodenforschung] Wiesbaden 1995

-Standortkarte der Kies/Sand-Industrie in Hessen - 1 : 250000 ; (Stein-Verlag) Wiesbaden 1980 $(124 \times 88 \mathrm{~cm})$

-OGeologische Übersichtskarte der Kalisalzvorkommen im Werragebiet

Nach den Aufnahmen der Kgl. Preuß. Geologischen Landesanstalt entworfen von F. BeyschlagMaßstab 1 : 100000 - 1 Kt., mehrfarbig, 34 x 31 cm; o. J. [auch „ca. 1910“]

-Standortkarte von Hessen - Rohstoffkarte [Maßstab 1:50 000]; Hrsg.: Hess. Ministerium d. Innern, Landwirtschaft, Forsten, Naturschutz - Abt. Ländl. Raum; auch Hess. Ministerium f. Landesentwicklung, Wohnen, Landwirtschaft, Forsten und Naturschutz; Bearb.: Hessisches Landesamt für Bodenforschung; Wiesbaden 1997 - 1999

Mit Kurzbeschreibung des geologisches Profils im Abbaubetrieb (Steinbruch, Kiesgrube, Lehmgrube u.a). Abbaubetriebe farblich grau hervorgehoben.

Kartenblätter mit Regionalbezug:

L 4520 Warburg (1999)

L 4522 Hann. Münden (1999)

L 4720 Wolfhagen (1999)

L 4722 Kassel (1999)

L 4724 Witzenhausen (1999)

L 4920 Fritzlar (1999)

L 4922 Melsungen (1999)

L 4924 Sontra (1999)

L 4926 Eschwege (1999)

L 5124 Bad Hersfeld (1997)

\subsection{Thüringen}

○Übersichtskarte der in Abbau stehenden Steine und Lagerstätten von Thüringen - $1: 400.000$ (KAL 400) - [Hrsg. Thüringer Landesanstalt f. Geologie] Weimar 2000

○Übersichtskarte der in Abbau stehenden Steine und Lagerstätten von Thüringen - Arbeitskarte. - 1 : 200.000 - Ausgabe 2000 (Stand: 31.12.1999) -[KAL 200]. - Übergeordneter Titel: Atlas des Geopotentials von Thüringen 1 : 200.000 Bl. 1.5. - Titel der Erläuterugnen: Verzeichnis der Gewinnungsstellen. - [Hrsg. Thüringer Landesanstalt f. Geologie] Weimar 2000

@Geologische Übersichtskarte der Kalisalzvorkommen am Südharz

Bearb. F. Beyschlag; [Hrsg. Preußische Geologische Landesanstalt, Berlin] Titeldaten n. Verzeichn. Veröff. Preuß. Geol. Landesanstalt, $\underline{33}$ (Stand Dezember 1930) 
- $\mathrm{OGeologische} \mathrm{Übersichtskarte} \mathrm{der} \mathrm{Kalisalzvorkommen} \mathrm{im} \mathrm{Werragebiet}$

Nach den Aufnahmen der Kgl. Preuß. Geologischen Landesanstalt entworfen von F. BeyschlagMaßstab 1 : 100000 - 1 Kt., mehrfarbig, 34 x 31 cm; o. J. [auch „ca. 1910“]

\subsection{Niedersachsen}

\section{Geowissenschaftliche Karte des Naturraumpotentials von Niedersachsen und Bremen}

- Geowissenschaftliche Karte des Naturraumpotentials von Niedersachsen und Bremen -

1 : 200.000 - CC 4726 Goslar. - [Hrsg. Niedersächs. Landesamt f. Bodenforsch.] - Hannover 1982 [Nur niedersächsische Flächenanteile]

Kartenset bestehend aus den Karten

Oberflächennahe Rohstoffe - Lagerstätten und Vorkommen

Oberflächennahe Rohstoffe - Rohstoffsicherungsgebiete -

Tiefliegende Rohstoffe - Erze, Steinkohle, Industrieminerale

Tiefliegende Rohstoffe - Salz

Schutzwürdige geowissenschaftliche Objekte [Stammdaten auf der Rückseite]

- Geowissenschaftliche Karte des Naturraumpotentials von Niedersachsen und Bremen -

1 : 200.000 - CC 4718 Kassel. - [Hrsg. Niedersächs. Landesamt f. Bodenforsch.] - Hannover 1982 -

[Nur niedersächsische Flächenanteile]

Kartenset bestehend aus den Karten

Oberflächennahe Rohstoffe - Lagerstätten und Vorkommen

Oberflächennahe Rohstoffe - Rohstoffsicherungsgebiete

Tiefliegende Rohstoffe - Salz [Niedersächische Flächenanteile u. Karlshafen/Hessen]

Baugrund

Schutzwürdige geowissenschaftliche Objekte [Stammdaten a. d. Rückseite]

\subsubsection{Hydrogeologische Karten}

\subsubsection{Hessen einschließlich Werra-Meißner-Kreis}

- $\square$ Diederich, Gisbert; Finkenwirth, Alfred; Hölting, Bernward; Kaufmann, Eberhard; Rambow, Dietrich; Scharpff, Hans-Jürgen; Stengel-Rutkowski, Witigo \& Wiegand, Klaus (1985):

Erläuterungen zu den Übersichtskarten 1 : 300.000 der Grundwasserergiebigkeit, der

Grundwasserbeschaffenheit und der Verschmutzungsempfindlichkeit des Grundwassers von Hessen.

- Geol. Abh. Hessen, 87; 51 S., 2 Tab., 3 Tab., 3 Kt. 1 : 300.000 i. sep. Tasche; Wiesbaden

darin enthalten Karten (gleicher Blattschnitt wie GÜK Hessen)

Karte 1: Übersichtskarte der mittleren Grundwasserergiebigkeit - Maßstab 1 : 300.000

Karte 2: Übersichtskarte der Grundwasserbeschaffenheit - Maßstab 1 : 300.000

Karte 3: Übersichtskarte der Verschmutzungsempfindlichkeit - Maßstab 1 : 300.000 
-Diederich, Gisbert [Mitautor](1991): Hydrogeologisches Kartenwerk Hessen Maßstab 1 : 300 000. Geol. Abh. Hessen, 95; 83 S., 4 Tab. + 5 Kt.-Beil.; [Hess. Landesamt Bodenforschung] Wiesbaden

- Übersichtskarte der hydrogeologischen Einheiten grundwasserleitender Gesteine in Hessen 1 : 300 000; Bearb.: Diederich, Gisbert; 91 x 64 cm; [Hess. Landesamt Bodenforschung] Wiesbaden 1991 Kt.-Beil. Zu:

-Mineral- und Heilwasservorkommen in Hessen $1: 300000$ - Bearbeiter: B. Hölting; mit Erläuterungen; [Hrsg. Hess. Landesamt Bodenforschung] Wiesbaden 1985

-Trinkwasserschutzgebiete [in Hessen] 1 : 200.000 - Stand 1979; Verzeichnis der Trinkwasser- und Heilquellenschutzgebiete in Hessen. Mit Kartenerläuterung, 66 Bl., 1 Kt.-Beil.; [Hess. Landesanst. Umwelt] Wiesbaden

-Trinkwasser- und Heilquellenschutzgebiete in Hessen - Übersichtskarte $1: 200000$ 6. Auflage. Stand 30.9.1992 - KartenerläuterungUmweltplanung, Arbeits- und Umweltschutz, 145; 274 S., graph. Darst, Kt.-Beil; [Hess. Landesanst. Umwelt] Wiesbaden 1993

-Trinkwasser- und Heilquellenschutzgebiete in Hessen - Übersichtskarte $1: 200$ 000; 7. Aufl., Stand: 30.11.1996. Kartenbeilage zu: [Hess. Landesanst. Umweltschutz] (1997): Trinkwasser- und Heilquellenschutzgebiete in Hessen .- Kartenerläuterung. - Umweltplanung, Arbeits- und Umweltschutz, 219; 289 S., graph. Darst. + Kt.-Beil.; [Hess. Landesanst. Umweltschutz] Wiesbaden

-Trinkwasser- und Heilquellenschutzgebiete in Hessen .- Kartenerläuterung Übersichtskarte $1: 200$ 000; 7. Aufl., Stand: 30.11.1996. - Umweltplanung, Arbeits- und Umweltschutz, 219; 289 S., graph. Darst. + Kt.-Beil.; [Hrsg. Hess. Landesanst. Umweltschutz] Wiesbaden 1997

$\square$ Gelöste Karbonate, Sulfate und Chloride in Oberflächen- und wasserwirtschaftlich erfaßten Wässern. - Maßstab 1 : 75000 - Kartenbeilage in: Möller, Klaus (1988): Reliefentwicklung und Auslaugung in der Umgebung des Unterwerra-Sattels (Nordhessen). - Berliner Geogr. Abh., 48; zgl. Beiträge zur Werra-Meißner-Forschung, II; 187 S., 55 Abb., 20 Tab., 2 Kt.-Beil.; Berlin - zgl. Diss. FU Berlin [Werra-Meißner-Kreis nördlich der Wehre und nördlich der Netra, ohne Hessisch-Lichtenauer Bergland]

$\square$ Hoher Meißner und Eschweger Becken - Beilage Hydrogeologie - Maßstab 1:50 000. - Bearb. M. Hampel, A. Pekdeger (1993). - Kartenbeilage in: Jacobshagen, V.; Möller, K. \& Jäkel, D. (1993): Hoher Meißner und Eschweger Becken - Geowissenschaftliche und vegetationskundliche Charakteristik einer nordhessischen Landschaft. - Berliner Geogr. Abh., $\underline{\mathbf{5 6}}$; zgl. Beiträge zur WerraMeißner-Forschung, III.; XII, 288 S., 95 Abb., 23 Tab., 5 Kt.-Beil.; (Selbstverlag Geomorphologisches Laboratorium FU Berlin) Berlin

- $\square$ Standortkarte von Hessen - Hydrogeologische Karte [ Maßstab 1:50 000]; Hrsg.: Hessisches Ministerium des Innern, Landwirstschaft, Forsten, Naturschutz - Abt. Ländl. Raum; Bearb.: Hessisches Landesamt für Bodenforschung; Wiesbaden 1988 - 1997

Kartenblätter mit Regionalbezug (Erscheinungsjahr):

L 4520 Warburg (1995)

L 4522 Hann. Münden (1996)

L 4720 Wolfhagen (1996)

L 4722 Kassel (1995)

L 4724 Witzenhausen (1995)

L 4920 Fritzlar (1997)

L 4922 Melsungen (1995)

L 4924 Sontra (1995) 
L 4926 Eschwege (1995)

L 5124 Bad Hersfeld (1988)

$\square$ Geowissenschaftliches Naturraumpotential Hoher Meißner - Grundwassernutzung. - Maßstab 1 : 15 000. - Wiss. Konzept: B. Meissner; P. Wyciszk unter Mitarb. v. K. Möller. Kartographische Bearb. u. Herstellung: Maria Eisinger. - Kartenbeilage zu: Wycisk, P.; Meissner, B. \& Eisinger, M. (1993): Geowissenschaftliche Naturraumpotentialkarten als Arbeitsmittel der Umweltplanung Grundwassernutzung Hoher Meißner. - In: Jacobshagen, V.; Möller, K. \& Jäkel, D. [Hrsg.]: Hoher Meißner und Eschweger Becken - Geowissenschaftliche und vegetationskundliche Charakteristik einer nordhessischen Landschaft. - Berliner geogr. Abh., $\underline{\mathbf{6}}$; zgl. Beiträge zur WerraMeißner-Forschung, III; S. 51 - 58, 1 Abb., 1 Kt.; (Selbstverlag Geomorphologisches Laboratorium FU Berlin) Berlin 1993

\subsubsection{Thüringen}

○Hydrogeologische Übersichtskarte der Deutschen Demokratischen Republik - $1: 200.000$ - M 32-XI Gotha. - Hydrogeol. Bearb. S. Jungwirth; [Hrsg. Zentrales Geologisches Institut, i. A. d. Staatsekretariats f. Geologie]; Berlin 1971

Kartenset bestehend aus den Karten

Hydrogeologische Grundkarte

Hydrochemische Karte Gesamthärte

Hydrochemische Karte Chloride

@Geologie \& Hydrogeologie im Überblick - Daten zur Geologischen und Hydrogeologischen Übersichtskarte von Thüringen. Generiert für den Maßstab 1 : 200 000. - Elektronische Ressource: 1 CD-ROM; Hrsg.: Thüringer Landesanstalt für Umwelt und Geologie; Jena 2003

○Hydrogeologisches Kartenwerk der Deutschen Demokratischen Republik - $1: 50000$ - [HK 50] Hrsg. Zentrales Geologisches Institut, Berlin

Kartenset bestehend aus

Nutzerrichtlinie für die hydrogeologische Grundkarte - Karte 1

Nutzerrichtlinie für die hydrogeologischen Kennwerte - Karte 2.1

Nutzerrichtlinie für die Karte der Hydroisohypsen - Karte 2.2

Keine Titeldaten gefunden - Karte 3

Nutzerrichtlinie für die Karte der Grundwassergefährung - Karte 4

Nutzerrichtlinie für die hydrogeologische Grundkarte - tertiäre Grundwasserleiter - Karte 5

Blätter

1102-3/4 - Heiligenstadt/Worbis - 1984

1103-3/4 - Bleicherode/Nordhausen-Süd 1984

1202-1/2 - Ershausen/Mühlhausen - 1984

1202-3/4 - Creuzburg/Mihla 
1203-3/4 - Bad Langensalza/Erfurt NW - 1984

1302-1/2 - Berka/Eisenach - 1984

1303-1/2 - Gotha/Erfurt W - 1984

1302-3/4 - Bad Salzungen/Schmalkalden - 1984

1403-1/2 - Suhl/Schmiedefeld - 1985

\subsubsection{Bodenkarten}

\subsubsection{Länderübergreifende Kartenwerke}

\section{Bodenübersichtskarte 1:200 000 - [Bundesrepublik Deutschland]}

Hrsg. Bundesanst. f. Geowiss. u. Rohstoffe i. Zusarb. m. staatl. Geol. Diensten d. Länder der

Bundesrepublik Deutschland, Ad-hoc Arbeitsgruppe Boden; Hannover

- $\square$ ○ Bodenübersichtskarte - $1: 200000$ - [BÜK 200] - [Bundesrepublik Deutschland] CC 4718

Kassel. - Bodenkdl. Bearb. M. Irle u.a.; 50 x 45 cm; [Hrsg. Bundesanst. f. Geowiss. u. Rohstoffe i.

Zusarb. m. staatl. Geol. Diensten d. Länder der Bundesrepublik Deutschland, Ad-hoc Arbeitsgruppe

Boden] Hannover 2001

- $\square$ Bodenübersichtskarte - 1:200 000 - [BÜK 200] - [Bundesrepublik Deutschland] CC 5518 Fulda.

- Bodenkdl. Bearb. M. Irle, W. Rosenberger; 50 x 45 cm; [Hrsg. Bundesanst. f. Geowiss. u. Rohstoffe

i. Zusarb. m. staatl. Geol. Diensten d. Länder der Bundesrepublik Deutschland, Ad-hoc

Arbeitsgruppe Boden] Hannover 2004

Q $\square$ Bodenübersichtskarte - 1:200 000 - [BÜK 200] - [Bundesrepublik Deutschland] CC 5526 Erfurt. -50 x $45 \mathrm{~cm}$; [Hrsg. Bundesanst. f. Geowiss. u. Rohstoffe i. Zusarb. m. staatl. Geol. Diensten d. Länder der Bundesrepublik Deutschland, Ad-hoc Arbeitsgruppe Boden] Hannover 2005

\subsubsection{Länderbezogene Kartenwerke}

\subsection{Hessen}

-Bodenkarte von Hessen [1 : 600 000]. - Bearb.: W. Schottler. - In: Notizbl. Vereins f. Erdkunde u. d. Hess. Geol. Landesanst. z. Darmstadt, 1929; Darmstadt

aSchottler, W. (1930): Erläuterungen zur Bodenkarte von Hessen im Maßstab 1 : 600 000. - 50 S.; Notizbl. Vereins f. Erdkunde u.d. Hess. Geol. Landesanst. z. Darmstadt, 1929; Darmstadt

-Bodenübersichtskarte von Hessen 1 : 500000 [BÜK 500] Bearb.: E. Schönhals, K.-J. Schnabel; [Hrsg. Hess. Landesamt Bodenforschung] Wiesbaden 1989

\section{Standortkarte von Hessen}

- Standortkarte von Hessen - Karte der natürlichen Standorteignung für landbauliche Nutzung [Maßstab 1:50 000]; Hrsg.: Hess. Min. Landesentwicklung, Umwelt, Landwirtsch., Forsten - Abt. Ländlicher Raum; Bearb.: Hessisches Landesamt für Bodenforschung; Wiesbaden 1979

Kartenblätter mit Regionalbezug: 
L 4520 Warburg (1979)

L 4522 Hann. Münden (1979)

L 4720 Wolfhagen (1979

L 4722 Kassel (1979)

L 4724 Witzenhausen (1979)

L 4920 Fritzlar (1979)

L 4922 Melsungen (1979)

L 4924 Sontra (1979)

L 4926 Eschwege (1979)

L 5124 Bad Hersfeld (1979)

oStandortkarte von Hessen - Gefahrenstufenkarte Bodenerosion durch Wasser [Maßstab 1:50 000]; Hrsg.: Hess. Min. Landesentwicklung., Wohnen, Landwirtsch., Forsten u. Naturschutz - Abt.

Ländlicher Raum; Bearb.: Hessisches Landesamt für Bodenforschung; Wiesbaden 1991 - 1993

Kartenblätter mit Regionalbezug

L 4520 Warburg (1993)

L 4522 Hann. Münden (1991)

L 4720 Wolfhagen (1993)

L 4722 Kassel (1991)

L 4724 Witzenhausen (1993)

L 4920 Fritzlar (1993)

L 4922 Melsungen (1993)

L 4924 Sontra (1991)

L 4926 Eschwege (1993)

L 5124 Bad Hersfeld (1993)

\section{Bodenkarte von Hessen - 1:25000}

\section{$\underline{4523 \text { Münden }}$}

-•Bodenkarte von Hessen - 1 : 25000 - 4523 Münden. - Bodenkdl. bearb. v. C.-P. Ziehlke; (Hrsg. Hess. Landesamt f. Bodenforschung) Wiesbaden 1997 - Dazu erschienen:

- •Emmerich, Karl-Heinz (1997): Erläuterungen zur Bodenkarte von Hessen 1 : 25000 - 4523 Münden. - 113 S., graph. Darst., Kt.; (Hrsg. Hess. Landesamt f. Bodenforschung) Wiesbaden

\section{$\underline{4821 \text { Fritzlar }}$}

Bodenkarte von Hessen - 1: 25000 - 4821 Fritzlar. - Bodenkdl. bearb. v. C. Haupenthal (Hrsg. Hess. Landesamt f. Bodenforschung) Wiesbaden 1976 - Dazu erschienen

-Haupenthal, Christoph (1976): Erläuterungen zur Bodenkarte von Hessen - 1 : 25000 - 4821 Fritzlar. - 90 S., graph. Darst.; (Hrsg. Hess. Landesamt f. Bodenforschung) Wiesbaden 


\subsection{Thüringen}

øÜbersichtskarte der Bodenarten Thüringens auf geologischer Grundlage. - Bearb. W. Hoppe. (Perthes) Gotha 1942 - Dazu erschienen:

øHoppe, Walter (1943): Erläuterungen zur Übersichtskarte der Bodenarten Thüringens auf geologischer Grundlage. - 43 S., 2 Tab.; (Justus Perthes) Gotha

OBodenübersichtskarte von Thüringen - 1: 400.000 [BÜK 400] - Bearb. H. Schramm. - M. Text u. Nebenkt.; [Hrsg. Thür. Landesanstalt f. Geologie] Weimar 1997

@Bodengeologische Übersichtskarte der Deutschen Demokratischen Republik - 1 : 100.000 Hrsg. Zentrales Geologisches Institut, Berlin

Kartenblätter mit Regionalbezug:

Bezirk Erfurt - 1973

Bezirk Suhl - 1974

○Mittelmaßstäbige Landwirtschaftliche Standortkartierung - $1: 100.000$

[Keine weiteren Titeldaten gefunden]

Kartenblätter mit Regionalbezug:

40 Heiligenstadt

47 Eisenach

@Digitale Bodengeologische Konzeptkarte - 1 : 50.000

[Keine weiteren Titeldaten gefunden]

Kartenblätter mit Regionalbezug:

L 4726 Heilbad Heiligenstadt - 1996

L 4728 Mühlhausen - 1996

L 4926 Eschwege - 1996

L 4928 Bad Langensalza - 1996

L 5126 Eisenach - 1996

L 5328 Schmalkalden - 1996

L 5330 Suhl - 1996

\subsection{Niedersachsen}

\section{Bodenübersichtskarte von Niedersachsen Maßstab 1:500 000 (BÜK500)}

[Hrsg. Niedersächs. Landesamt f. Bodenforschung, bzw. Nachfolgeinstitution Landesamt f. Bergbau, Energie und Geologie] Hannover 
-Gehrt, Ernst \& Sbresny, Jan (1999): Erläuterungen zur Ableitung und den Inhalten der Bodenübersichtskarten $1: 200000$ (BÜK 200) und 1 : 500000 (BÜK 500) von Niedersachsen. Arbeitshefte Boden, 1999/1: 3-60, 11 Abb., 15 Tab.; Hannover

-Fachbereich Bodenkunde und Geologie, Niedersächsiches Landesamt f. Bodenforschung [Hrsg.](2000): Ausgabeformen der Flächendatenbank des Niedersächsischen Bodeninformationssystems NIBIS. - Arbeitshefte Boden, 2000/1: 3-107, 9 Abb., 4 Tab., 27 Karten; Hannover darin: Karte der Bodenlandschaften von Niedersachsen 1:500 000 und Bodenübersichtskarte von Niedersachsen 1: 500 000. - S. 79-80, Karte 21

\section{Karte der Bodenlandschaften von Niedersachsen 1:500 000 (BL500)}

[Hrsg. Niedersächs. Landesamt f. Bodenforschung, bzw. Nachfolgeinstitution Landesamt f. Bergbau, Energie und Geologie] Hannover

-Fachbereich Bodenkunde und Geologie, Niedersächsiches Landesamt f. Bodenforschung [Hrsg.](2000): Ausgabeformen der Flächendatenbank des Niedersächsischen Bodeninformationssystems NIBIS. - Arbeitshefte Boden, 2000/1: 3-107, 9 Abb., 4 Tab., 27 Karten; Hannover darin: Karte der Bodenlandschaften von Niedersachsen 1:500 000 und Bodenübersichtskarte von Niedersachsen $1: 500$ 000. - S. 79-80, Karte 21

\section{Karte der Bodengroßlandschaften von Niedersachsen 1:500 000 (BGL500)}

[Hrsg. Niedersächs. Landesamt f. Bodenforschung, bzw. Nachfolgeinstitution Landesamt f. Bergbau, Energie und Geologie] Hannover

-Fachbereich Bodenkunde und Geologie, Niedersächsiches Landesamt f. Bodenforschung [Hrsg.](2000): Ausgabeformen der Flächendatenbank des Niedersächsischen Bodeninformationssystems NIBIS. - Arbeitshefte Boden, 2000/1: 3-107, 9 Abb., 4 Tab., 27 Karten; Hannover darin: Karte der Bodengroßlandschaften von Niedersachsen 1: 500 000. - S. 57-58, Karte 16

\section{Bodenübersichtskarte von Niedersachsen $1: 200000$}

[Hrsg. Niedersächs. Landesamt f. Bodenforschung, bzw. Nachfolgeinstitution Landesamt f. Bergbau, Energie und Geologie] Hannover

- Gehrt, Ernst \& Sbresny, Jan (1999): Erläuterungen zur Ableitung und den Inhalten der Bodenübersichtskarten 1: 200000 (BÜK 200) und 1 : 500000 (BÜK 500) von Niedersachsen. Arbeitshefte Boden, 1999/1: 3-60, 11 Abb., 15 Tab.; Hannover

- Fachbereich Bodenkunde und Geologie, Niedersächsiches Landesamt f. Bodenforschung [Hrsg.](2000): Ausgabeformen der Flächendatenbank des Niedersächsischen Bodeninformationssystems NIBIS. - Arbeitshefte Boden, 2000/1: 3-107, 9 Abb., 4 Tab., 27 Karten; Hannover darin: Bodenübersichtskarte von Niedersachsen 1 : 200000 (BÜK 200). - S. 75-76; Karte 20

\section{Bodenübersichtskarte von Niedersachsen 1 : 50000 (BÜK 50)}

[Hrsg. Niedersächs. Landesamt f. Bodenforschung, bzw. Nachfolgeinstitution Landesamt f. Bergbau, Energie und Geologie] Hannover 
-Fachbereich Bodenkunde und Geologie, Niedersächsiches Landesamt f. Bodenforschung [Hrsg.](2000): Ausgabeformen der Flächendatenbank des Niedersächsischen

Bodeninformationssystems NIBIS. - Arbeitshefte Boden, 2000/1: 3-107, 9 Abb., 4 Tab., 27 Karten; Hannover darin: Bodenübersichtskarte von Niedersachsen 1: 50000 (BÜK 50). - S. 71, Karte 19

-Boess, Jürgen; Müller, Udo \& Sbresny, Jan (1999): Erläuterungen zur digitalen Bodenkundlichen Übersichtskarte 1:50 000 (BÜK 50) von Niedersachsen. - Arbeitshefte Boden, 1991/1: 61-98, 4 Abb., 12 Tab.; Hannover

-Boess, J.; Müller, U.; Ostmann, U.; Sbresny, J. \& Steininger, A. (2004): Erläuterungsheft zur digitalen nutzungsdifferenzierten Bodenkundlichen Übersichtskarte 1:50 000 (BÜK 50n) von Niedersachsen. - Arbeitshefte Boden, 2004/3; 61 S., 10 Abb., 35 Tab.; Hannover

\section{Bodengrundlagenkarte von Niedersachsen $1: 25000$ (BK 25)}

-Fachbereich Bodenkunde und Geologie, Niedersächsiches Landesamt f. Bodenforschung [Hrsg.](2000): Ausgabeformen der Flächendatenbank des Niedersächsischen

Bodeninformationssystems NIBIS. - Arbeitshefte Boden, 2000/1: 3-107, 9 Abb., 4 Tab., 27 Karten; Hannover

darin: Bodengrundlagenkarte von Niedersachsen $1: 25000$ (BK 25). - S. 67-68, Karte 18

- Fachbereich Bodenkunde und Geologie, Niedersächsiches Landesamt f. Bodenforschung [Hrsg.](2000): Ausgabeformen der Flächendatenbank des Niedersächsischen

Bodeninformationssystems NIBIS. - Arbeitshefte Boden, 2000/1: 3-107, 9 Abb., 4 Tab., 27 Karten; Hannover darin: Forstliche Standortkarte. - S. 19-20, Karte 3

- Fachbereich Bodenkunde und Geologie, Niedersächsiches Landesamt f. Bodenforschung [Hrsg.](2000): Ausgabeformen der Flächendatenbank des Niedersächsischen

Bodeninformationssystems NIBIS. - Arbeitshefte Boden, 2000/1: 3-107, 9 Abb., 4 Tab., 27 Karten; Hannover

darin: Bodenschätzungskarten. - S. 13-14, Karte 1 u. 2

- Bodenkarte von Niedersachsen - 4426 Ebergötzen. - Grundkarte. - Maßstab 1: 25000 - Bearb. E. Gehrt; (Niedersächsisches Landesamt f. Bodenforschung) Hannover 1996

- Bodenkarte von Niedersachsen - $\mathbf{4 5 2 6}$ Gleichen. - Grundkarte - Maßstab 1 : 25000 - Bearb. I. Benne; (Niedersächsisches Landesamt f. Bodenforschung) Hannover 1985

\section{Einzelveröffentlichungen}

-Geßner, Ludwig [Hrsg.] \& Brüning, Kurt [Ltg.](1940): Bodenkundlicher Atlas von Niedersachsen Grundlagen für Raumplanung und Landesplanung. - Teil 1: Kartenbände - Abt. A.: Bodenkarten; Veröff. Wirtschaftswiss. Ges. z. Studium Niedersachsens, Reihe C (Kartenwerke) 16 ; 67 Bl. Karten [Maßstab $1: 100$ 000]; (Stalling) Oldenburg i. O. - Dazu erschienen: 
- Hempel, Ludwig (1954): Beispiele von Bodenerosions-Karten im niedersächsichen Bergland sowie Bemerkungen über Berücksichtigung der Erosionsschäden bei der Bodenschätzung. - Neues Archiv f. Niedersachsen, 7: 140-143, 3 Kt.; Bremen-Horn [darin: Bl. 4425 Göttingen]

-Hoyningen-Huene, Paul Friedrich v. (1939): Die niedersächsischen Böden. Erläuterungen zum Bodenkundlichen Atlas von Niedresachsen. - Gesamttitel: Geßner, Ludwig [Hrsg.] \& Brüning, Kurt [Ltg.](1940): Bodenkundlicher Atlas von Niedersachsen - Grundlagen für Raumplanung und Landesplanung. - Teil 2: Textband; Veröff. Wirtschaftswiss. Ges. z. Studium Niedersachsens, Reihe B (Forschungen) 17; 158 S., 7 Taf.; (Stalling) Oldenburg i. O.

-Niedersächsiches Landesamt f. Bodenforschung [Hrsg.](1997): Böden in Niedersachsen - digitale Bodenkarte 1:50 000 und Bodenübersichten - Datenbank repräsentativer Profile inklusive Abfragemöglichkeiten - Online-Texte zu den wichtigsten Böden und Bodenlandschaften. Elektronische Ressource: 1 CD-Rom mit Textbeilage; (Hrsg. Niedersächsiches Landesamt f. Bodenforschung) Hannover

-Selke, Max (1935): Die Böden Süd-Niedersachsens. - Textband. - Veröff. Wirtschaftswiss. Ges. z. Studium Niedersachsens e.V., Reihe. B. (Forschungen), 12; 231 S., Abb. u. Tab. (o. Zählg.), 12 Taf., 2 Falt-Kt. (Niedersachsen - Bodenkarte $1: 800$ 000; Niedersachsen - Entwässerungsbedürftige Böden 1 : 800 000); (Stalling) Oldenburg i. O. - dazu sep. Atlas-Bd. (Folio-Format) mit drei Falt-Kt. $1: 200$ 000; (Stalling) Oldenburg i. O.

-Selke, Max (1934): Die Böden Süd-Niedersachsens. - Teil II: Bodenkarten Niedersachsens. - Veröff. Wirtschaftswiss. Ges. z. Studium Niedersachsens e.V., Reihe C (Kartenwerke), $\underline{\mathbf{3}} ; 3$ Karten Maßstab 1 : 200000 in jeweils 2 Teilblättern; (Stalling) Oldenburg i. O.

[I. Bodenarten und -schichtung - II. Bodenentstehungstypen - III. Bodenklassen]

\subsubsection{Sonstige Karten (Tektonik, Geophysik, Geochemie, Ingenieurgeologie u.a.)}

\section{$\underline{\text { Tektonik }}$}

- $\square$ Übersichtskarte der saxonischen Gebirgsbildung zwischen Vogelsberg - Rhön und der Norddeutschen Tiefebene $1: 250$ 000. - Bearb.: Hans Stille - 1 mehrfarb, Kt.; [Hrsg. Preuß. Geol. Landesanstalt] Berlin 1922

\section{Geophysik}

oStörungen der erdmagnetischen Totalintensität $\Delta \mathbf{Z}$ in Hessen - $1: 300.000$. - Bearb. R. Blum u.a.; [Hrsg. Hess. Landesamt f. Bodenforschung] 1986

- Karte der Bouguer-Schwere in Hessen - 1 : 300.000. - Bearb. R. Blum \& R. Wendler. - [Hess. Landesamt $\mathrm{f}$. Bodenforschung] Wiesbaden 1984

\section{Ingenieurgeologie}

OIngenieurgeologische Karte der Deutschen Demokratischen Republik -

Auslaugungserscheinungen - Maßstab 1 : 100.000 - mit Erläuterungen - Staatl. Geolog. Kommission d. Deutschen Demokratischen Republik - Zentrales Geologisches Institut; Hrsg. Zentrales Geologisches Institut, Berlin 1964 - 
Blatt Gotha M-32-46

○Übersichtskarte der Bodenarten Thüringens auf geologischer Grundlage - 1 : 500 000. - Bearb. Walter Hoppe; 40 x 34 cm; (Perthes) Gotha 1942

\section{$\underline{\text { Umwelt u. Geochemie }}$}

OSchramm, H.; Pohl, A.; Wunderlich, J. \& Bischoff, R. (1977): Atlas der Schwermetallgehalte Thüringer Böden 1 : 400.000 - Hintergrundwerte für Schwermetalle und Arsen in Oberböden und bodenbildenden substratentypischen Bodengesellschaften. - 58 S., überwgd. Karten ua.

Bodenübersichtskt. Thüringen 1:400.000 (BÜK 400), 46 x 64 cm; [Hrsg. Thür. Landesanst. f. Umwelt u. Geologie i. A. d. Thür. Ministeriums f. Landwirtsch., Natursch. u. Umwelt] Jena

ه Gewässerstrukturgüte in Hessen 1999 - Erläuterungsbericht. 52 S., Ill., graph. Darst., Kt.Beil. (Hessische Gewässerstruktur-Gütekarte Stand 1999); [Hess. Ministerium Umwelt, Landwirtsch., Forsten] Wiesbaden 2000

- $\square$ Hintergrundgehalte umweltrelevanter Schwermetalle in Gesteinen und oberflächennahem Untergrund Hessens - Übersichtskarte. - Bearb. F. Rosenberg \& K. J. Sabel. - 1 mehrfarb. Kt, 57 x 85 cm, mit Texten, Maßstab 1 : 300.000; [Hrsg. Hess. Landesamt f. Bodenforschung] Wiesbaden 1996

OKontaminationsanalyse - Geologie. - Kartenwerk 1 : 50.000 (KK 50)

[Keine weiteren Titeldaten gefunden]

Kartenset bestehend aus:

Karte der Flächennutzung

Karte der Kontaminationsherde

Karte der anthropogenen und geogenen Umweltbeeinflussung

Kartenblätter mit Regionalbezug:

2462 Bischofferode (1980)

2560 Birkenfeld (1980)

2561 Mühlhausen

2661 Eisenach-Nord

2662 Bad Langensalza

2761 Eisenach-Süd

2762 Gotha

2862 Suhl

\section{Geomorphologie}

- $\square$ • Geomorphologische Gliederung des Werra-Meißner-Landes. - Maßstab ca. 1 : 250 000. Kartenbeilage zu: Stäblein, Gerhard (1986): Geomorphologische Gliederung des Werra-MeißnerLandes. - In: Stäblein, Gerhard [Hrsg.]: Geo- und biowissenschaftliche Forschungen der Freien Universität Berlin im Werra-Meißner-Kreis (Nordhessen). - Berliner Geogr. Abh., 41; zgl. Beiträge zur Werra-Meißner-Forschung, 五; S. 257 - 265, 1 Kt.-Beil.; (Selbstverl. Inst. Phys. Geogr. FU Berlin) Berlin 1986

$\square$ Auslaugungsformen in der Umgebung des Unterwerra-Sattels - Maßstab 1 : 75000 Kartenbeilage in: Möller, Klaus (1988): Reliefentwicklung und Auslaugung in der Umgebung des Unterwerra-Sattels (Nordhessen). - Berliner Geogr. Abh., 또; zgl. Beiträge zur Werra-MeißnerForschung, II; 187 S., 55 Abb., 20 Tab., 2 Kt.-Beil.; Berlin - zgl. Diss. FU Berlin 
[Werra-Meißner-Kreis nördlich der Wehre und nördlich der Netra, ohne Hessisch-Lichtenauer Bergland]

$\square$ Hoher Meißner und Eschweger Becken - Beilage: Geomorphologie - Maßstab 1 : 50 000. - Bearb. K. Möller, D. Jäkel. - Kartenbeilage in: Jacobshagen, V.; Möller, K. \& Jäkel, D. [Hrsg.]: Hoher Meißner und Eschweger Becken - Geowissenschaftliche und vegetationskundliche Charakteristik einer nordhessischen Landschaft. - Berliner Geogr. Abh., 56 ; zgl. Beiträge zur Werra-MeißnerForschung, III; XII, 288 S., 95 Abb., 23 Tab., 5 Kt.-Beil.; (Selbstverlag Geomorphologisches Laboratorium FU Berlin) Berlin 1993

$\square$ Geomorphologische Karte der Bundesrepublik Deutschland 1: 25000 - GMK 25 Blatt 17 - 4725 Bad Sooden-Allendorf. - Hrsg. D. Barsch; O. Fränzle; H. Leser; H. Liedtke u. G. Stäblein als Mitglieder Koordinierungskommission GMK Schwerpunktprogramm d. Dt.

Forschungsgemeinschaft; Aufnahme K. Möller \& G. Stäblein 1979-1982; Berlin 1984

\section{Ende}


Die Region - mit den markanten Erhebungen des Hohen Meißners und des Thüringer Waldes - stellt geologisch und bergbaugeschichtlich einen Teil der deutschen Mittelgebirge dar, der Fachleute sowie Amateure und Naturfreunde gleichermaßen fasziniert. Die vorliegende Bibliographie versucht erstmals länderübergreifend die umfangreiche Fachliteratur der Dreiländer-Region zu erschließen. Dabei wurden sowohl fachwissenschaftliche als auch heimatkundliche Publikationen und unveröffentlichtes Material berücksichtigt. 